\title{
2021 Annual Meeting
}

\author{
Seismological Society of America \\ Technical Sessions \\ 19-23 April
}

\section{PROGRAM COMMITTEE}

The Co-Chairs of the 2021 SSA Annual Meeting are Rich Briggs of the U.S. Geological Survey, Diego Melgar of the University of Oregon and Jenny Nakai of the University of New Mexico.

\section{Meeting Contact}

program@seismosoc.org

\section{TECHNICAL PROGRAM}

The 2021 SSA Technical Program comprises oral and poster presentations presented over five days, 19-23 April. The session descriptions, detailed program schedule and all abstracts appear in the following pages.

\section{PLENARY SESSIONS}

\section{Opening Keynote: What Have We Learned About the Earth's Interior from Seismology in the Last 40 Years?}

Monday, 19 April, 8:30-9:30 AM Pacific

Barbara Romanowicz, University of California, Berkeley. Session moderated by SSA President John Townend

A special welcome from SSA President John Townend, Victoria University of Wellington will open the meeting, followed by a presentation by Barbara Romanowicz, University of California, Berkeley on the advances in understanding the Earth's internal structure. Jeroen Ritsema, University of Michigan and editor-at-large of The Seismic Record will kick off a Q\&A session.

What Have We Learned About the Earth's Interior from Seismology in the Last 40 Years?

Building upon theoretical foundations laid in the 1970s and owing to the large quantity of high quality digital seismological data accumulating since the early 1980s, our understanding of the earth's internal structure, as constrained by seismological observations, has rapidly evolved in the last 40 years. From a static view of a planet organized in concentric spheri-

Volume 92 • Number 2B • April 2021 • www.srl-online.org cal shells, to the present three dimensional models that reflect its dynamic nature from the upper mantle to the center of the inner core, we now have a clearer picture, among others, about the fate of tectonic slabs or the complex nature of the boundary layer (D") at the base of the mantle. The formation history of continents, as recorded in the lithosphere of old cratons, is emerging, and evidence for the existence of deeply rooted mantle plumes is mounting. There are live debates about the earth's inner core dynamics. Combined with insights from geodynamics, mineral physics, geochemistry and other geoscience subfields, we are poised to reconstruct the evolution of our planet through time and the nature of the present-day coupling between the deep interior and plate tectonics. I will review some of the most significant seismological contributions to our knowledge in this field over the last few decades.

\section{Joyner Lecture: Are Small Earthquakes a Big Deal?}

Monday, 19 April, 12:30-1:30 PM Pacific

Julian J. Bommer, Imperial College London. Introduced by SSA President John Townend, Victoria University of Wellington

Earthquake engineering has traditionally focused on protecting society against the effects of large-magnitude earthquakes but in recent years there has been increasing interest regarding the impact of smaller earthquakes. This has been driven partly by the occurrence of some low-magnitude earthquakes that have caused unexpected levels of damage and particularly by the heightened concern regarding earthquakes of anthropogenic origin. A number of case histories of small magnitude events reported to have caused damage are then reviewed, highlighting in each case the specific factors contributing to the impact-and in some cases arguing that the physical impact may have been exaggerated.

The lecture re-visits the often misunderstood rationale behind the exclusion of smaller magnitude earthquakes from probabilistic seismic hazard analysis as being related to the risk posed by such events. This is followed by a global analysis of small-to-moderate magnitude earthquakes to ascertain the likelihood of these resulting in damage and/or injury, also considering the generally shallower depths of induced events. Consideration is also given to the question of the smallest 
magnitudes of relevance to hazards other than ground shaking, including liquefaction and surface rupture. The lecture concludes with some insights regarding if and when smaller earthquakes should be a concern as well as discussing the challenges associated with modeling the resulting hazard and risk that such events can pose.

\section{Machine Learning in Seismology: A Fireside Chat Where Are We Now and Where Are We Going?}

Tuesday, 20 April, 8:30-9:30 AM

Karianne Bergen, Brown University; Daniel Trugman, University of Texas at Austin and Qingkai Kong, University of California, Berkeley. Introduced and moderated by William R. Walter, Lawrence Livermore National Laboratory.

A moderated conversation with three early-career researchers discussing the following topics at the intersection of machine learning and earthquake science:

- The current state of the field: what's working so far and what have been the greatest successes?

- Reasons for skepticism: what are the major limitations and sticking points?

- Frontiers: what are the major growth areas for machine learning in earthquake science over the next few years?

- Geo-data science education: how can we integrate machine learning into Earth science curricula?

- Career paths: what are the new and emerging career paths at the intersection of data science and machine learning?

\section{Can We Talk? Film and Discussion}

Tuesday, 20 April, 12:30-2:15 PM Pacific

Kendall Moore, University of Rhode Island

SSA will screen the film Can We Talk?, which explores the issue of 'social belonging' in the context of STEM (Science, Technology, Engineering, Math) and the effect it has on the lives of underrepresented people of color (UR-POC) who are pursuing an education or career in STEM; or, have decided to leave because of an overwhelming feeling of not belonging. Following the film, Kendall Moore will lead a live discussion with SSA 2021 attendees.

\section{Effective Earthquake Communication to Three Different Players}

Wednesday, 21 April, 8:30-9:30 Am Pacific

Xyoli Pérez-Campos, Instituto de Geofísica, Universidad Nacional Autónoma de México. Session introduced and moderated by Sergio E. Barrientos, University of Chile

A growing concern across countries is how scientific knowledge is disregarded by those making official policy as well as the general public. Therefore, effective science communication is needed to reach all levels.

In many of our countries, we lack a liaison office between scientists and legislators. Our results stay on shelves and scientific meetings but are not being translated into policy that could prevent disasters from occurring. In contrast, there are good examples in countries where science advisors are close and changes are happening; learning from their experience, successes and errors might lead to a change. In Mexico, a new initiative has emerged to install a liaison office inside the Congress with trained scientists that can identify and translate the science needed for policy making.

Also, in some countries, the number of stakeholders when an earthquake occurs is way more than two, and the structure for decision making is quite complicated. Coordination between them is key to a fast and optimal response. With this complex system, knowledge, precision and effective communication are critical for quick and informed decision-making. However, many helpful products end up in web portals with no use from decision-makers since we have overseen communication and training. One problem is the high rotation in office personnel, so training should be continuously done and in good coordination with the various governmental agencies responsible for quick decision-making.

Another critical element is the public. There are many outreach efforts by various agencies through blogs and social networks. However, sometimes, especially when a big earthquake happens, it requires extra efforts to fight against popular pseudo-scientists or fake news. Identifying the usual questions and public concerns can help in designing target publications and communications. Also, right after a big earthquake, media handling through press conferences and one-on-one interviews can diffuse part of the confusion and concern first generated by the event. It also helps having a strong trustable figure as the spoke-person, whom the public and media will look to and listen to.

\section{Innovation Showcase}

Wednesday, 21 April, 12:30-1:30 PM Pacific

New tools and systems are key to advancing seismology! SSA is hosting a special hour for exhibitors to showcase their technologies and advancements. Find out what's new and ask your questions. (These presentations are paid advertisements.)

\section{The Future of Space Geodesy in Earth Science and Hazards}

Thursday, 22 April, 8:30-9:30 AM Pacific

Dara E. Goldberg, U.S. Geological Survey; David Schmidt, University of Washington; Manoochehr Shirzaei, Virginia Tech. Discussion led by Diego Melgar, University of Oregon

Exciting new advances in space geodesy continue to make it a fundamental discipline for understanding tectonics, earthquakes and hazards. For example, new constellations of InSAR satellites have revolutionized the quality and frequency with which observations can be made of the changes of the Earth's surface. Tectonic geodesy has taken to the seafloor by combining acoustic ranging from autonomous platforms with traditional GNSS techniques. Meanwhile, real-time science and 
hazards characterization from GNSS observables are becoming widespread across the globe. These advances are not without challenges. In this session, we will explore what the future holds for the intimate relationship between geodesy and seismology.

\section{Rules and Outliers in Seismology-Implications for Hazard Mitigation Strategy}

Thursday, 22 April, 12:30-1:30 PM Pacific

Hiroo Kanamori, Caltech

Session introduced and moderated by James Mori, Kyoto University.

To deal with complex and unpredictable earthquake behavior, seismologists strive for finding rules and outliers in seismology. The difficulty in performing in situ experiments in seismology necessitates detailed studies of individual earthquakes to find general rules and outliers. For a long time, such studies required painstaking efforts to analyze seismograms and bulletins as demonstrated, for example, by Gutenberg and Richter's $(1941,1954)$ Seismicity of the Earth. The recent advances in theory, data acquisition system, and analysis methods have facilitated detailed studies of individual earthquakes, enabling us to find various rules as well as outliers, which together help us understand the basic physics of earthquakes. Outliers are damaging because our preparedness is based on regular rules. Thus, good understanding of outliers is important for minimizing the unexpected impact of earthquakes. A classic example of scaling relations is the relationship between the aftershock area and the magnitude (Utsu and Seki, 1954). With a subsequent better physical understanding of the magnitude, frictional processes and energy budget, we now have many relationships for diverse groups of earthquakes, from silent, slow, to regular earthquakes. Many causes are responsible for outliers. For example, interactions between slip patches can cause complex events with long duration and large magnitude. Near-surface site response can cause unexpectedly damaging ground motions. Oblique plate convergence can cause unexpected source mechanisms. I will summarize the recent progress in understanding the diversity of earthquakes in terms of energy budget and some examples of outliers and will discuss the implications of rules and outliers for hazard mitigation strategy using scenario earthquakes and real-time technology.

\section{Monitoring COVID-19 Lockdown with Seismology}

Friday, 23 April, 8:30-9:30 Aм Pacific

Thomas Lecocq, Royal Observatory of Belgium; Eric Larose, Université Grenoble Alpes; Meghan S. Miller, Australian National University; Shiba Subedi, Universite de Lausanne. Discussion led by Zhigang Peng, Georgia Institute of Technology.

In recent years, seismological tools have been increasingly used to monitor human activities around the world. In this plenary session, we highlight several recent studies on how anthropogenic noises have changed due to different lockdown measures, and whether the reduction of human noises may lead to detections of more natural seismic events. In addition, the fusion between COVID lockdown and seismic noises provide an excellent opportunity for education and outreach. In this session, we include presentations on this topic followed by a panel discussion on how to use these opportunities to better engage the public and next generation in seismology and earthquake sciences.

\section{Seismology Career Panel: Pathways to National Laboratories, Data Science, the Oil and Gas Industry and Consulting/Risk Analysis}

Friday, 23 April, 12:30-1:30 PM Pacific

Yanet Cuddus, Schlumberger; Ivan Wong, Lettis Consultants International, Inc.; Jiayi Xie, Xaxis; Brian Young, Sandia National Laboratories. Discussion led by Jenny Nakai, University of New Mexico.

This session is aimed towards early-career scientists, students and those wishing to explore opportunities in, or know more about, exciting industries which have employed larger proportions of seismologists than academia. Speakers from diverse fields and careers within seismology discuss their career path, the work they do and new areas of research.

The speakers will be given 12-minutes each to address these questions, which will be followed by a general audience Q\&A. The speakers may be available after the session for smaller breakout room chats to address additional questions or provide guidance for interested participants.

This program reflects the planned SSA Annual Meeting as of 1 March 2021.

\section{SSA Meetings Code of Conduct}

SSA is committed to fostering the exchange of scientific ideas by providing a safe, productive and welcoming environment for all SSA sponsored meeting participants, including attendees, staff, volunteers and vendors. We value the participation of every member of the community and want all participants to have an enjoyable and fulfilling experience.

All participants at SSA meetings are expected to be considerate and collaborative, communicating openly with respect for others and critiquing ideas rather than individuals. Behavior that is acceptable to one person may not be acceptable to another, so use discretion to be sure that respect is communicated.

\section{Unacceptable Behavior}

Examples of unacceptable behavior include, but are not limited to:

- Physical or verbal abuse of any kind.

- Threatening or stalking any participant. 
- Making inappropriate comments whether verbal or digital related to gender, gender identity and expression, age, sexual orientation, disability, physical appearance, body size, race, ethnicity, religion (or lack thereof), national origin, or other legally protected group status or characteristics.

- Inappropriate use of nudity and/or sexual images or language in public spaces or in presentations.

- Harassment intended in a joking manner still constitutes unacceptable behavior.

- Retaliation for reporting harassment is also a violation of this Code of Conduct, as is reporting an incident in bad faith.

\section{Reporting Unacceptable Behavior}

Any participant experiencing or witnessing behavior that at any time in their judgment constitutes an immediate or serious threat to public safety is advised to contact emergency services immediately.
If you are the subject of unacceptable behavior or have witnessed any such behavior, you are encouraged to notify SSA by writing to the Executive Director Nan Broadbent at nbroadbent@seismosoc.org. Writing down the details of the incident is also recommended. Requests for confidentiality will be honored to the extent possible.

\section{Consequences}

SSA staff (or their designee) or security may take any action deemed necessary and appropriate for any unacceptable behavior, including but not limited to that described above. Possible actions include removal of a participant from the meeting, without refund. Suspension or termination of membership in SSA, denial to participate in future SSA events or meetings, or other action(s) may be taken in SSA's sole discretion, depending on the severity of the unacceptable behavior.

SSA is committed to handling all situations to the best of its ability. However, this Code of Conduct is informational and is not a contract. 


\section{Technical Sessions}

\section{The 2020 Simeonof Island, Alaska, Earthquake: Observations, Modeling and Tectonic Insights}

In July 2020, a Mw 7.8 earthquake struck along the Alaskan subduction zone at the edge of the Shumagin Gap, a region with poorly coupled megathrust that has been devoid of large earthquakes for the last century. The relation of the Simeonof Island earthquake and its associated afterslip to plate coupling in the region is important to determine the future tsunamigenic potential of the subduction interface, of interest to both local and Pacific basin wide communities. Moreover, understanding why seismic and aseismic slip occurs in poorly coupled subduction zones is relevant to characterizing hazards globally. Past events along the edges of the Shumagin gap, most notably in 1936 and 1948, showed that shallow megathrust slip is possible. Here we invite submissions that describe the entire earthquake cycle within the Shumagin Gap, including but not limited to: historical seismicity, preseismic deformation and coupling, earthquake rupture modeling, aftershock monitoring and forecasts, field observations, postseismic deformation, tsunami observations and hazards implications.

Conveners: Brendan W. Crowell, University of Washington (crowellb@uw.edu); Natalia A. Ruppert, University of Alaska Fairbanks (naruppert@alaska.edu)

\section{The 7 January 2020 South of Indios (M6.4) Earthquake in Puerto Rico, Response and Lessons}

The Puerto Rico archipelago is located in the active plate boundary between the North American and the Caribbean plates. Large magnitude earthquakes and destructive tsunamis are part of its geologic history, including events in the last 500 years, i.e. 1670, 1787, 1867 and 1918. The most recent event occurred on 7 January 2020 (M6.4), causing significant damages and destruction to the main island.

Although the southwestern region of Puerto Rico is identified as one of the most active regions in the area, it was not until 28 December 2019 that the southwestern region of the island experienced a major significant event since 1918. The activity consisted of an ongoing seismic sequence with the largest earthquake, magnitude 6.4, occurring on 7 January 2020 located South of Indios neighborhood of Guayanilla, Puerto Rico. In the aftermath of the event, the Island was declared in an official state of emergency at local and federal levels.

One person was killed and four were injured during the event. The main shock caused a power outage across the island, as well as structural damage to roads and bridges, especially in the southwestern region. Public offices, churches and schools were closed. Hospitals mostly in the southwestern region were evacuated for safety reasons. Residents were terrified to go into their homes for fear that another quake will bring the structures down.

In this session we will discuss the response carried out at all levels from the event detection, alert notifications, research and field work to the emergency response and public preparedness. Lessons learned will be a topic of discussion as well.

Conveners: Victor A. Huerfano, Puerto Rico Seismic Network (victor@prsnmail.uprm.edu); Lorna G. JaramilloNieves, Universidad de Puerto Rico, Recinto de Río Piedras (lorna.jaramillo@upr.edu); Gisela Báez-Sánchez, Puerto Rico Seismic Network (gisela.baez1@upr.edu); Wildaomaris Gonzalez, Bureau of Emergency Management and Disaster Administration, Puerto Rico (wgonzalez@premapr.onmicrosoft.com)

\section{Advances in Real-Time Geophysical Network Operations and Data Analytics}

The ongoing upgrade of existing GNSS network infrastructure to real-time capability combined with advances in data management has made the possibility of hemispherical-scale low-latency, high-rate GNSS monitoring systems an actuality. Real-time GNSS streams are already being incorporated into earthquake and tsunami early warning systems, space weather monitoring and meteorological forecasting.

To become an integral part of monitoring systems the networks must have redundant data flow paths and low latencies both in data retrieval and analysis. This, and the interest in integrating GNSS, seismic and meteorological networks combined with the push of data processing to the network edge has created an opportunity to rethink traditional data flow paths and the implementation of real-time data analysis for geophysical monitoring.

This session provides an opportunity for network operators, researchers and infrastructure groups to discuss these ideas. We encourage presentations on the upgrade of existing geophysical networks to real-time capability, the integration of GNSS and seismic networks, the use of cloud technology and containerized systems to manage data flow and the development of real-time analytics to monitor the state of health of the networks, the data quality of the incoming streams and real-time data processing. 
Conveners: Kathleen Hodgkinson, UNAVCO (hodgkinson@unavco.org); David J. Mencin, UNAVCO (dmencin@ unavco.org)

\section{Advances in Seismic Interferometry: Theory, Computation and Applications}

Seismic interferometry extracts information from the ambient seismic field and enables imaging in the absence of earthquakes or artificial sources. Recent developments in seismic interferometry have benefited from continuous records of ambient seismic noise from traditional broadband instruments and emerging new acquisition technologies, such as large-N nodal arrays and distributed acoustic sensing systems. These have opened up the possibility of performing high-resolution tomographic imaging anywhere dense networks are available. In addition, the temporal variation in continuous seismic records provides the possibility of monitoring the transient changes of subsurface properties for various geological targets, such as glaciers, volcanoes, groundwater, reservoirs, active faults, infrastructure and even other planetary bodies. We welcome contributions of recent advances in and applications of seismic interferometry on a broad range of topics, including (but not limited to) theoretical developments in amplitude measurements and structural inversion, utilization of higher-order cross-correlations, new analyzing techniques and computer programs and novel applications across disciplines.

Conveners: Doyeon Kim, University of Maryland, College Park (dk696@cornell.edu); Ross Maguire, University of New Mexico (rmaguire@unm.edu); Tieyuan Zhu, Penn State University (tuz47@psu.edu); Nori Nakata, Massachusetts Institute of Technology (nnakata@mit.edu); Ved Lekic, University of Maryland (ved@umd.edu); Marine Denolle, Harvard University (mdenolle@fas.harvard.edu)

\section{Advances in the Science and Observation of Tsunamis}

The catastrophic tsunami events originated after the 26 December 2004 Sumatra and 112011 Tohoku earthquakes reshaped the technology of the tsunami warning and the global strategy for the tsunami hazard mitigation. Tsunami warning services now cover most of the vulnerable coastlines around the World. New tsunami-specific real-time observation systems have been deployed for operations and the network of real-time data sources is continuously expanding. New data and methods are available for real-time seismic sources assessments of tsunamis. The accuracy, reliability and coverage of the warning services have increased.

However, significant challenges still exist as large tsunamis of the last decade have shown. Over 30 significant events that occurred since the 2011 Tohoku revealed many new gaps in the tsunami warning and hazard mitigation strategies. The death toll of over 5000 from just two tsunamis in Indonesia in 2018 demonstrated that much more needs to be done to make the tsunami warning systems robust and effective. The science of tsunamigenity of the seismic sources in particular requires more research, as was demonstrated by the two recent strikeslip earthquakes of the 28 September 2018 in Sulawesi and the 19 October 2020 in Alaska that generated unexpectedly strong tsunamis.

The original research on all areas of tsunami science are invited for the session, including seismic tsunami sources studies; tsunami generation, propagation and coastal impacts; research on tsunami hazard mitigation and tsunami warning strategies and other relevant topics.

Conveners: Vasily V. Titov, National Oceanic and Atmospheric Administration (vasily.titov@noaa.gov); Bruce Jaffe, U.S. Geological Survey (bjaffe@usgs.gov)

\section{Advances in Understanding Near-Field Ground Motions: Observation, Prediction and Application}

The characterization of near-field ground motions is critical for expanding our understanding of earthquake hazard as well as improving rapid response and earthquake early warning efforts. Recent earthquakes like the 2019 Ridgecrest Sequence have provided observations of near-field ground motions in unprecedented detail, while increased computational capabilities have enabled significant advances in ground-motion simulations. With these developments come new opportunities to improve our understanding of near-field seismic ground motions, including, for example, how ground-motion characteristics translate into perceived shaking intensities as well as characterization of path and site effects. In turn, these improvements in near-field ground-motion models can lead to increased accuracy in applications such as early warning alerts, rapid response loss estimates and structural response to shaking. We invite submissions related to this broad area of near-field ground motion. Possible topics include: near-field observations; advances in near-field ground-motion modeling; and applications such as seismic hazard modeling, structural response modeling, rapid response products and earthquake early warning.

Conveners: Jessie K. Saunders, U.S. Geological Survey (jksaunders@usgs.gov); Dara E. Goldberg, U.S. Geological Survey (degoldberg@usgs.gov); Tara Nye, University of Oregon (tnye@uoregon.edu); Valerie Sahakian, University of Oregon (vjs@uoregon.edu)

\section{Advances in Upper Crustal Geophysical Characterization}

The upper crust plays a critical societal role, from access to clean water to the production of energy to the impact of geo- 
logic hazards. It is also our window into the layers below; geophysical variability in the near surface can map into deeper structure if not properly considered. With respect to seismic hazards and earthquake ground motions, variability in near surface geophysical properties can lead to an overall amplification or deamplification of strong ground motions, large lateral variability in site response, as well as resonance at specific ground shaking frequencies. With respect to groundwater, characterizing soil porosity, regolith development and fracture permeability all lead to better estimates of storage potential and groundwater flow rates. Geophysical characterization of the near surface is therefore critical to being able to address these issues. A vast number of methods exists with which to characterize the subsurface from direct methods that measure rock density and seismic velocity in-situ to indirect methods where seismic wave travel times, gravity, resistivity and other parameters are measured at the Earth's surface, and subsurface properties are inferred. We seek contributions that include direct and indirect field observations, laboratory experiments and geophysical theory that links observation and expectation to studies that explore the impact of competing assumptions.

Conveners: Oliver S. Boyd, U.S. Geological Survey (olboyd@usgs.gov); William J. Stephenson, U.S. Geological Survey (wstephens@usgs.gov); Lee Liberty, Boise State University (lliberty@boisestate.edu)

\section{Amphibious Seismic Studies of Plate Boundary Structure and Processes}

Recent years have seen a rapid increase in the number of shorecrossing seismic experiments aimed at characterizing seismicity, deformation and structure at continental margins. Many studies use controlled source imaging in conjunction with continuous recordings of natural seismic sources. Examples of data integration include using ocean-bottom seismometer data in both disciplines and combining results from shallower, high-resolution imaging with deeper, lithospheric-scale studies to understand structures that influence seismicity and plate boundary processes. We invite contributions from the community of seismologists studying plate boundary processes at the transition from onshore to offshore (ocean or lake) environments, including subduction zones, active or relict rifted margins and transform faults.

Conveners: Jenny S. Nakai, University of New Mexico (jenakai@unm.edu); Lindsay Lowe-Worthington, University of New Mexico (lworthington@unm.edu); Anne M. Trehu, Oregon State University (anne.trehu@oregonstate.edu)

\section{Analyses and Implications of the 4 August 2020 Beirut Explosion Series}

On 4 August 2020 at 15:07 UTC, a fire at the port of Beirut in Lebanon $(33.54 \mathrm{o}, 33.51 \mathrm{o})$ detonated a purported $\sim 2.8 \mathrm{kT}$ mix- ture of ammonium nitrate and fuel that resulted in a sequence of explosion phenomena. These video-captured events triggered a shock wave and visible Wilson cloud, destroyed buildings and shattered glass several kilometers from the explosion(s) hypocenter. Mechanical waveform sensors that include seismic, infrasonic and hydroacoustic receivers recorded waveforms from the event out to regional distances and provide data on explosion size and timing. Assessment of this event therefore has multiple implications beyond seismology that include the interface between science and society, forensics, emergency response and hazard mitigation. This session welcomes submissions on the analysis of this event that include, but are not limited to (1) hydroacoustic and seismo-acoustic detection and association of the blast waveforms; (2) study of energy coupling mechanisms at the ground-water-air interface; (3) analyses of aseismic geophysical signatures, such as cratering; (4) multi-signature data fusion of both traditional and non-traditional data sources; (5) methods to quantify uncertainties of parameter estimates of the source or propagation path (exploitation of ground truth) and (6) broader implications of rapid response and societal consequences. We encourage both poster and talk submissions.

Conveners: Joshua D. Carmichael, Los Alamos National Laboratory (joshuac@lanl.gov); Fransiska K. Dannemann Dugick, Sandia National Laboratories (fdannemanndugick@ gmail.com); Seung-Hoon Yoo, Applied Research Associates (syoo@ara.com); Stephen J. Arrowsmith, Southern Methodist University (sarrowsmith@mail.smu.edu)

\section{Application of Remote Sensing and Space-Based Earth Observations Data in Earthquake Research}

Earthquakes are one of the most unexpected and most destructive natural disasters. Spatial and temporal patterns and features of the multi-physical parameters, such as subsurface stress field, fluid flows, crustal deformation and other surface processes before and after large earthquakes are essential clues about the evolution of the earthquake cycle. Detection and identification of these processes in multiple Spatio-temporal scales much depend on observational techniques.

Recently, Remote Sensing and Space-Based Earth Observations are used in earthquake monitoring and forecast research. These include the observations of ionosphere disturbances before and during large earthquakes, as well as gravity changes due to large earthquakes detected in GRACE satellite missions. Several satellite missions such as the CSES-01 and FORMOSAT-7/COSMIC-2 are launched to detect possible atmospheric/ionospheric anomalies associated with earthquakes and other natural hazards. The development of these powerful remote sensing tools and finely tuned detection algorithms provide an exciting opportunity to image, assess and quantify physical processes that occur before, during and after large earthquakes. 
This session focuses on the latest advances in remote sensing technology in earthquake research. This session expands the discussions of geohazards' predictability by presenting the latest results from cross-disciplinary observations from both space and ground measurements associated with earthquakes. These presentations will include but are not limited to: observations, modeling and analyses, geochemical, seismic, electromagnetic, thermodynamic processes, crustal deformation and case studies related to stress changes in the lithosphere along with their statistical and physical validation. Using such an interdisciplinary approach, we hope to advance current earthquake research studies and gain a better understanding of the lithosphere-atmosphere-ionosphere coupling processes.

\section{Joint SSC-SSA Session}

Conveners: Xuhui Shen, National Institute of Natural Hazards, MEMC (shenxh@seis.ac.cn); Dimitar Ouzounov, Chapman University (dimitar.p.ouzounov@nasa.gov); Zhima Zeren, National Institute of Natural Hazards, MEMC (zerenzhima@qq.com); Ramesh P. Singh, Chapman University (rsingh@chapman.edu); Angelo D. Santis, Istituto Nazionale di Geofisica e Vulcanologia (angelo.desantis@ingv.it); ShunRong Zhang, Massachusetts Institute of Technology (shunrong@mit.edu); Jing Cui, National Institute of Natural Hazards, MEMC (jingcui_86@yahoo.com)

\section{Applications and Technologies in Large-Scale Seismic Analysis}

The growth and maturation of technologies that make it easier to analyze large volumes of data has enabled new areas of research in seismology. Computational frameworks like Apache Spark and Dask augment existing tools like MPI. New programming languages like Julia and the emergence of new scalable analysis capabilities in languages like Java and Python supplement traditional languages like $\mathrm{C}$ and Fortran. Finally, new platforms like the commercial cloud offer alternatives to existing high performance computing platforms. Technologies like these increase accessibility to a new scale of inquiry, making large-scale research in seismology more tractable than ever before. In this session, we invite researchers and data providers to share work in data-hungry applications, approaches to large data collection, storage and access and experiences with processing platforms and architectures.

Conveners: Jonathan K. MacCarthy, Los Alamos National Laboratory (jkmacc@lanl.gov); Chad Trabant, Incorporated Research Institutions for Seismology (chad@iris.washington. edu)

\section{Back to the Future: Innovative New Research with Legacy Seismic Data}

There has been much discussion in recent years about Big Data and, within the seismological community, how to cope with its ever-expanding volume of digital data. But there exists a source of yet Bigger Data: historical seismic records. With more than a century of seismic waveform data, there is opportunity to resolve intimate details of, and potentially revolutionize, our understanding of Earth dynamics, including phenomena associated with tectonic and geologic processes, seismic sources, climate change and seismic hazard. The challenge: much of the waveform data is tucked away on analog media such as paper, tape or film, or archaic and arcane digital media in holdings that are at risk of being lost forever. These data sets are not only more difficult to physically access and read than their digital counterparts, but often demand innovative approaches to perform any type of modern seismic analysis.

We invite presentations that highlight the discovery, preservation and/or use of seismic datasets spanning multiple decades. Such presentations would include those that address the problems of restoration, digitization and storage of the vast archives of legacy data. We encourage contributions that illustrate the on-going value of legacy data in the general fields of study for which seismographic data have been used and the value of legacy seismographic data in other geophysical disciplines. A few examples include studies of regional or local seismicity, earthquake recurrence and prediction, seismic hazard, climate signatures, inner core rotation and growth and $4 \mathrm{D}$ seismic tomography. We also seek contributions that feature efforts in standardizing metadata and image data formats, improving accessibility through rapid scanning, advances in vectorization software and tuned data compression algorithms, efforts in compiling calibrations of seismometers and application of machine learning techniques to directly extract geophysical information from the legacy data.

Conveners: Garrett G. Euler, Los Alamos National Laboratory (ggeuler@lanl.gov); Brian Young, Sandia National Laboratories (byoung@sandia.gov); Ana C. Aguiar Moya, Lawrence Livermore National Laboratory (aguiarmoya1@llnl. gov); Thomas Lee, Harvard University (thomasandrewlee@g. harvard.edu); Qi Ou, University of Oxford (qi.ou@earth. ox.ac.uk); Richard Lewis, Defense Threat Reduction Agency (richard.d.lewis1.civ@mail.mil); James Dewey, U.S. Geological Survey (jdewey@usgs.gov)

\section{Beyond Poisson: Seismic Hazards and Risk Assessment for the Real Earth}

Traditional probabilistic seismic hazard assessments (PSHA) assume that it is adequate to model earthquakes as temporally random, independent events modeled as a Poisson process. This approach removes the obvious clustering due to aftershocks and swarms; averages or carves out rate variations on short time scales due to natural processes such as volcanoes, as well as short-lived induced seismicity in order to focus on long-term so-called tectonic rates; and may not even use timedependent mainshock probability variations due to elastic 
rebound. This may be adequate for long-term (e.g. 50-year) models aimed at low probabilities of exceedance for engineering purposes. The risk industry, typically managing risk transfer contracts from 1 to 5 years, is interested in assessing risk due to processes that act at or affect shorter time scales, from induced seismicity to aftershocks to fault interaction and elastic rebound. Over shorter timescales, when considering the impacts of multiple events and/or at higher probabilities of exceedance, non-Poissonian behavior becomes more important. Recently our ability to describe non-Poissonian behavior has been improved through short-term aftershock and swarm models, models of fluid injection and long-term physicsbased simulators. As a result, some national hazard models have incorporated these processes. Many challenges remain. For instance, understanding the impact of incomplete data and non-stationarity on long-term empirical rate estimates is a particularly difficult issue in regions with low seismicity rates and is critical even for traditional PSHA. We encourage contributions that explore how we can better model the broad range of real Earth behavior in different time scales that goes beyond the Poisson process; how we can test those models and include them in hazard and risk assessments; and the societal utility of doing so for a range of users including engineers, the insurance industry, emergency planning and mitigation.

Conveners: Andrew Michael, U.S. Geological Survey (ajmichael@usgs.gov); Edward H. Field, U.S. Geological Survey (field@usgs.gov); Delphine D. Fitzenz, Risk Management Solutions (delphine.fitzenz@rms.com); Matthew C. Gerstenberger, GNS Science (m.gerstenberger@gns.cri.nz); Andrea L. Llenos, U.S. Geological Survey (allenos@usgs.gov); Warner Marzocchi, University of Naples Federico (warner. marzocchi@unina.it); Margarita Segou, British Geological Survey (msegou@bgs.ac.uk); Tina Wang, University of Otago (twang@maths.otago.ac.nz)

\section{Constructing and Testing Regional and Global Earthquake Forecasts}

Regional and global earthquake rate and rupture forecasts underpin seismic hazard and risk assessments. They can also serve to test critical hypotheses about seismogenesis, including earthquake nucleation, rupture, interaction and variations of their characteristics with tectonic setting. Global models offer greater testability than regional models because of the larger and more frequent earthquakes. Initiatives to construct and test global models have been led by the Global Earthquake Model (GEM) Foundation, the Southern California Earthquake Center (SCEC), the European H2020 project RISE, re/insurance interests and others. Regional models, on the other hand, benefit from more available and higher resolution datasets, from dense geological records to waveform-similarity enhanced catalogs and long historical catalogs that can be exploited to express bespoke hypotheses, such as spatio-temporal b-value variations, foreshock patterns, Coulomb stress transfer, geodetically detected aseismic slip or fault-based rupture forecasts. Regional and national models are more commonly constructed and can underpin national seismic hazard models and require testing at lower magnitudes to increase test data. We welcome contributions that construct and test probabilistic earthquake forecast models and algorithms from regional via national to global scales. Submissions may include hypothesis-generating research about what controls earthquake potential but should also develop plans for testing prospectively. We also seek submissions that build on vetted earthquake forecasts to construct seismic hazard and risk models, particularly at global scales.

Conveners: Maximilian Werner, University of Bristol (max.werner@bristol.ac.uk); David D. Jackson, University of California, Los Angeles (djackson@g.ucla.edu); Danijel Schorlemmer, GFZ German Research Centre for Geosciences (ds@gfz-potsdam.de)

\section{Critical Zone, Environmental and Cryospheric Seismology}

Environmental seismology is the study of seismic signals generated at and near the surface created by environmental forces in the atmosphere, hydrosphere or solid Earth, and as such covers a broad range of subjects. Contributions to this session are welcome on a wide variety of topics including-but not limited to-seismically focused scenarios associated with the microseism, landslides, rock falls, debris flows, lahars, snow avalanches, cliff or pinnacle resonance, river bedload transport, flood events, fluid flow in open and confined channels, water gravity waves or infragravity waves, tides, sea ice variability, subglacial hydrology, hurricanes, tornadoes or anthropogenic sources. Explorations of the seismic behavior of cryospheric media, including permafrost, ice sheet/ shelves modeling, snow and firn dynamics, glacier stick-slip, icequakes, iceberg calving and crevassing and temporal monitoring are also encouraged. Studies focusing on critical zone and engineering applications are additionally welcome and may include studies of groundwater and remediation, site characterization for geologic and seismic hazard applications, monitoring of critical infrastructure and geotechnical applications. Contributions that seek to conduct monitoring, create physical or statistical models of source processes or systems, detect events, characterize a wave propagation environment or interact with other branches of the Earth or social sciences are additionally encouraged. Submissions running the gamut from site-specific case studies to ongoing methodological advances are warmly welcomed.

Conveners: Julien Chaput, University of Texas at El Paso (jchaput82@gmail.com); Tieyuan Zhu, Pennsylvania State University (tyzhu@psu.edu); Richard Aster, Colorado State University (rick.aster@colostate.edu); Wei Wang, Pennsylvania 
State University (wpw5162@psu.edu); Lucia Gonzalez, University of Texas at El Paso (lgonzalez5@miners.utep.edu); Jonathan Ajo-Franklin, Rice University (ja62@rice.edu); Paul Winberry, Central Washington University (paul.winberry@ gmail.com); Grace Barcheck, Cornell University (grace.barcheck@cornell.edu); James St Clair, Pacific Northwest National Laboratory (james.stclair@pnnl.gov)

\section{Crustal Stress and Strain and Implications for Fault Interaction and Slip}

During earthquake cycles, crustal deformation includes multiple components such as inelastic strain increments associated with earthquakes, elastic strain accumulated in the interseismic period, aseismic slip on some fault sections and viscoelastic strain near and below the brittle-ductile transition depth. Resolving stress and strain distributions in the crust, specifically near fault zones, is essential for a better understanding of deformation processes, fault interactions and providing constraints on fault zone geometry and rheology.

This session focuses on (1) the estimation of the state of stress/strain in different phases of earthquake cycle and (2) the analysis of stress/strain distributions at different spatial and temporal scales by soliciting works based on theory, observations, modeling and laboratory experiments. Contributions are encouraged but not limited to address the following questions: 1) What can we extract from geodetic, geologic, borehole and seismic data regarding the state of stress and strain at regional and local scales?; 2) How are stress and strain distributed in laboratory experiments and nature and how can we bridge the two?; 3) What are the insights from numerical simulations on the state of stress and to what extent can models help in interpreting observations such as earthquakes or slow slip events?; 4) How will spatial stress/strain variations from long-term data compilations improve our knowledge of the motion partitioning across complex fault zone areas, aseismic slip, fault zone structure and earthquake cycles?; 5) How can information on the state of stress/strain be used to improve long-term earthquake forecasting and seismic hazard assessments?

Conveners: Niloufar Abolfathian, Jet Propulsion Laboratory, Caltech (niloufar.abolfathian@jpl.nasa.gov); Thomas Goebel, University of Memphis (thgoebel@memphis. edu); Mong-Han Huang, University of Maryland (mhhuang@ umd.edu)

\section{Cryptic Faults: Assessing Seismic Hazard on Slow Slipping, Blind or Distributed Fault Systems}

Characterization of active faults for seismic hazard often relies on the analysis of geomorphic records preserved within the landscape that indicate fault movement. In certain environ- ments, particularly those that are slow $(<5 \mathrm{~mm} / \mathrm{yr})$ slip rate, blind and distributed fault systems, tectonic activity leaves subtle tectonic signals within the landscape, challenging the conventional methods of identification and characterization of these fault systems. In recent years, advances in remote sensing, including high-resolution topographic data from lidar and unmanned aerial vehicles, have revolutionized the identification of fault-related features at the earth's surface and led to increasing confidence in the characterization (fault length, slip rate, recurrence interval) of faults. Recent numerical and experimental models further provide analogues for surficial fault rupture patterns and fault-related features to locate potential faults. In addition, advances in Quaternary geochronology and Bayesian modeling have refined ages of geomorphic and stratigraphic surfaces, resulting in better constraints on the activity of faults. Thus, the recognition of active and potentially active fault traces is expanding, ultimately leading to improved seismic hazard models.

This session will include studies that focus on new data and how methods have been applied to the characterization of cryptic faults. In particular, we welcome presentations on the application of remote sensing, geophysical, modeling and field work techniques, as well as geomorphic or paleoseismic case studies on cryptic slow slip rate, blind or distributed fault systems in any tectonic setting.

Conveners: Jessica A. T. Jobe, U.S. Bureau of Reclamation (jessietjobe@gmail.com); Stephen J. Angster, U.S. Geological Survey (sangster@usgs.gov)

\section{Data Fusion and Uncertainty Quantification in Shallow Crust Characterization and Modeling}

Non-invasive methods for sub-surface seismic site characterizations have clear advantages relating to cost and effort over their invasive counterparts. However, these methods rely on several constituents that can lead to poor estimations of sub-surface properties, which significantly affect earthquake hazard assessment at the regional scale. The limiting factors include the ill-posedness of inverse problems, the shallow crust's inherent complexity and measurement and modeling uncertainties. Recent studies have shown that joint inversion of complementary datasets and statistical inference techniques can improve the estimated properties and quantify uncertainties. We here invite contributions describing the development and implementation of state-of-the-art methods in inverse problems, data assimilation and uncertainty quantification to improve constraints on shallow crust properties. We also invite contributions to the development of three-dimensional shallow crust velocity models using the methodologies mentioned above, as well as other novel approaches.

Conveners: Elnaz Seylabi, University of Nevada, Reno (elnaze@unr.edu); Domniki Asimaki, Caltech (domniki@ 
caltech.edu); Alan Yong, U.S. Geological Survey (yong@usgs. gov); Nori Nakata, Massachusetts Institute of Technology (nnakata@mit.edu)

\section{Earthquake Early Warning Live in California! Current Status and Challenges}

In October 2019, Earthquake Early Warning (EEW) alerts were made publicly available throughout California for the first time ever. This milestone followed closely on the heels of the 2019 Ridgecrest sequence, which included both the largest main shock and the most energetic aftershock sequence encountered by the US ShakeAlert EEW system (with public alerts only available in Los Angeles at that time). These events contributed to the already rapidly advancing realm of EEW research, which spans a wide range of fields including computer science, earthquake physics, seismic network design, social science and more. EEW systems are also being developed and coming online elsewhere in the world, with each system facing its own unique set of obstacles.

Many challenges remain to maximize the potential of these systems and prevent harm from system errors and malfunctions (e.g. false alerts). Unanswered questions range from the scientific (e.g., real-time magnitude estimates of large earthquakes and rupture predictability) to the practical (e.g., how to distribute alerts to the public most efficiently, minimizing data transmission delays).

In this session we welcome abstracts related to all aspects of EEW including, but not limited to, algorithm development, system performance, improved trigger detection/discrimination techniques, network build-out, alerting methods and technology and EEW education and outreach.

Conveners: Angela I. Chung, University of California, Berkeley (aichung@berkeley.edu); Men-Andrin Meier, Caltech (mmeier@caltech.edu)

\section{Earthquake Early Warning System in the Americas: The On-Going Effort and the State of the Art}

Latin America and the Caribbean constitute one of the most earthquake-prone regions of our planet, where an exponentially growing population undergoing rapid urbanization and living in mostly vulnerable structures is frequently exposed to extremely high ground accelerations from shallow large-continental and offshore-megathrust and tsunami earthquakes. In the last 20 years, a total of 143 earthquakes with magnitudes larger than 6.5 have struck the region. From these, 29\% have occurred with moment magnitudes between 7 and 8 , whereas $\sim 4 \%$ are great earthquakes, with magnitudes larger than 8 , generating in most cases, a negative socio-economic impact in the developing economies.
The urgent necessity for better assessment of earthquake hazards and mitigation of some of the consequences of these damaging events has led to the development of Earthquake Early Warning Systems (EEWs) across the Americas and the Caribbean. International collaborations for building capacities and sharing experiences are on-going, these efforts are accompanied by a continuous increase in data quality and accessibility, modern technology (low latency broadband and strong motion instruments, GNSS, cheap sensors including smartphones and social network data) and improved EEW methodologies.

The aim of this session is to provide the state-of-the-art overview of earthquake early warning and rapid response systems in the Americas. We expect to generate a space to share experiences, new techniques and opportunities, but also to identify challenges, pinpoint components requiring improvement and to establish new international collaborations. We welcome contributions on Earthquake Early Warning and rapid response development, that span an end-to-end EEW system, from development of EEW-ready networks and the application of EEW algorithms to tools for public alert dissemination and social science considerations.

Conveners: Esteban J. Chaves, Volcanological and Seismological Observatory of Costa Rica, Universidad Nacional (esteban.j.chaves@una.cr); Marino Protti, Volcanological and Seismological Observatory of Costa Rica, Universidad Nacional (marino.protti.quesada@una.cr); Edmundo Norabuena, Instituto Geofísico del Perú (enorabuena@igp.gob.pe); Gerardo Suarez, Universidad Nacional Autónoma de México (gersua@ yahoo.com)

\section{Earthquake Science, Hazards and Policy in Cascadia}

The Cascadia Subduction Zone (CSZ) is the most densely populated subduction zone in the United States that is capable of producing megathrust earthquakes of approximately magnitude 9 (M9), yet its historical seismic quiescence contributes to its status as an "end-member" global subduction zone with respect to seismic activity. Recent years have brought a rapid increase in fundamental earthquake scientific knowledge about the region, through both observational studies such as the Cascadia Initiative, shoreline-crossing work, seafloor geodetic advancements and geophysical network buildout, as well as extensive geophysical modeling work. Recent projects such as the National Science Foundation-funded "M9 Project" have inspired integration of earthquake ground motion simulations with tsunami, ground failure and structural engineering studies, as well as social and behavioral sciences, planning and policy. Beyond these recent advances, Cascadia is home to large stakeholder companies involved in technological development and cloud computing infrastructure. 
This session will highlight advances across earthquake hazards studies related to Cascadia earthquakes and their cascading hazards. We welcome submissions that fall within or across any of these categories, including both onshore and offshore observational and modeling work; geologic and geophysical earthquake studies in the CSZ; hazards-focused work including developments in earthquake recurrence, source physics, ground motion estimation, seismic hazard analyses, ground failure and tsunami studies; as well as social and behavioral sciences and planning studies related to the interpretation and application of recent scientific developments to quantify and reduce risk in the region.

Conveners: Valerie Sahakian, University of Oregon (vjs@uoregon.edu); Erin A. Wirth, U.S. Geological Survey, Earthquake Science Center (emoriarty@usgs.gov); Janet Watt, U.S. Geological Survey, Pacific Coastal and Marine Science Center (jwatt@usgs.gov); Carlos Molina-Hutt, University of British Columbia (carlos.molinahutt@civil.ubc.ca); Grace Parker, U.S. Geological Survey, Earthquake Science Center (gparker@usgs.gov); Ann Bostrom, University of Washington (abostrom@uw.edu)

\section{Effects and Uses of Aseismic Deformation and Fault Creep in Seismic Hazard and Warning}

While earthquake hazard increases with fault area and slip, the hazard can relate to the extent of aseismic deformation. For instance the down-dip extent of intermediate and large earthquakes is limited by ductile deformation. The rate strengthening rheology provides a dynamic barrier to propagation during the earthquake and a static barrier by relaxing down-dip stress during the interseismic period. The along strike extent of rupture can also be limited by fault rheology and by longterm aseismic deformation producing a relaxed region, e.g., the creeping section of the San Andreas.

Aseismic deformation and fault creep can also correlate in time and space with seismic slip, such as in regions of low seismic coupling. Volcanoes, regions of induced seismicity and subduction zones often have low coupling coefficients yet host significant seismicity. For example, small scale seismicity can be generated by larger scale aseismic fault creep, allowing the seismicity to be used as a proxy for slip. In instances of accelerating aseismic deformation, such seismicity may have value for warning. At larger scale, the subduction zone foreshocks and transient creep events that preceded the great Tohoku earthquake, were perhaps related to megathrust earthquake initiation and may also be useful for warning. Underlying all of these observations are poorly known physics dictated by the rheology. The strongest rheological constraints may come from the observations themselves, but the physics are most easily determined in experiments or in models.
We invite a broad range of contributions that illustrate the value of including aseismic deformation and fault creep in earthquake hazard and warning. While context is provided by the above examples, these are not comprehensive. Contributions are expected from earthquake science disciplines that provide observations, constraints or implications, e.g., seismology, geodesy, fault mechanics, numerical modeling, experimental rock mechanics.

Conveners: Nicholas Beeler, U.S. Geological Survey (nbeeler@usgs.gov); Amanda M. Thomas, University of Oregon (amt.seismo@gmail.com); Manoochehr Shirzaei, Virginia Tech (shirzaei@vt.edu)

\section{Exploring Rupture Dynamics and Seismic Wave Propagation Along Complex Fault Systems}

Investigations related to how complexities in fault parameters and geometry could potentially impact the behavior of earthquake rupture and affect seismic hazard are areas of active and challenging research. This session will highlight recent advances in rupture dynamics on complex fault systems. We are open to a wide range of studies related to numerical, experimental and observational fault rupture dynamic studies with heterogeneities such as fault geometry, fault roughness, frictional parameters, topography, creeping mechanisms, stress asperities, off-fault material properties, bi-material interfaces and wedge structures along subduction zones. We also encourage contributions on research that explores links between earthquake source physics, tsunami generation/propagation and ground motion variability.

Conveners: Kenny Ryan, Air Force Research Laboratory (0k.ryan0@gmail.com); Roby Douilly, University of California, Riverside (roby.douilly@ucr.edu); Christos Kyriakopoulos, University of Memphis (christos.k@memphis.edu); Eric L. Geist, U.S. Geological Survey (egeist@usgs.gov); Ruth Harris, U.S. Geological Survey (harris@usgs.gov); David D. Oglesby, University of California, Riverside (david.oglesby@ucr.edu)

\section{Explosion Seismology Applications and Advances}

Explosion sources are an important component of seismology. They can be tools to characterize the sub-surface for a variety of applications using established networks as well as inexpensive and easy to deploy arrays/networks of sensors. As a result, the wavefield produced by explosions is being studied with unprecedented detail. In regions of low natural background seismicity, mine blasting can dominate monitoring catalogs and identifying and separating these sources from tectonic earthquakes is important for hazard assessment. The seismo-acoustic signals from accidental explosions can be used in their forensic analysis and to study propagation 
issues. Recordings of surface explosions can illuminate geologic structures in regions where there is a lack of seismicity to better characterize the velocity structure. Recent work using template matching, waveform modeling for moment tensors and combining seismo-acoustic data has shown great success in characterizing explosions and discriminating them from earthquakes and other sources. We welcome abstracts in explosion source physics, wave propagation, Large-N network design, distributed acoustic sensing (DAS), new sensor technologies, multi-physics data fusion and advanced processing techniques applied to explosion sources.

Conveners: Catherine M. Snelson, Los Alamos National Laboratory (snelsonc@lanl.gov); William R. Walter, Lawrence Livermore National Laboratory (walter5@llnl.gov); Rigobert Tibi, Sandia National Laboratories (rtibi@sandia.gov); Cleat P. Zeiler, Nevada National Security Site (zeilercp@nv.doe.gov)

\section{Fault Displacement Hazard: New Data and Modeling Advances}

Coseismic fault displacements resulting from earthquakes can cause significant damage to the built world. Fault displacement hazard quantification presents an especially important challenge for distributed infrastructures that span long distances, such as railways, or that densely cover wide areas, such as gas distribution systems. For these types of infrastructure, fault crossings can not always be avoided and present a threat that is often difficult to mitigate. In spite of the risks it poses, fault displacement hazard is poorly constrained, partly due to the scarcity of detailed fault-displacement observations. In this session, we welcome presentations on topics that support the development of the next generation probabilistic fault displacement hazard analysis (PFDHA) models. PFDHA requires the integration of the best available information and science from fault rupture physics and rheology while accounting for region-specific geology, seismicity and tectonic setting of the study area. Topics of interest for this session include: (i) new fault displacement datasets; (ii) recent advances in surface deformation imaging that facilitate the gathering and interpretation of detailed fault displacement data; (iii) emergent techniques for dynamic rupture modeling that support a better physical understanding of this complex natural phenomenon; and (iv) new engineering modeling approaches that integrate information from several disciplines and take into account variability and uncertainty quantification.

Conveners: Yousef Bozorgnia, University of California, Los Angeles (yousefbozorgnia@ucla.edu); Christine A. Goulet, Southern California Earthquake Center (cgoulet@usc. edu); Yongfei Wang, Southern California Earthquake Center (yongfeiw@usc.edu)

\section{Fiber-Optic Seismology}

Recent advancement in the field of photonics has led to novel sensing methods based on optical interferometry. For example, Distributed Acoustic Sensing (DAS) is rapidly becoming a popular tool among seismological research groups worldwide. DAS enables Large- $\mathrm{N}$ array seismology in novel and unique spaces such as in boreholes, mines, underneath streets in urban areas and offshore. The main advantages of DAS for seismology include, but are not limited to, dense recording, long spatial and temporal deployment of sensors, time-lapse repeatability and the unique opportunity to leverage existing fiber infrastructure such as telecommunication cables.

Because data acquired with DAS instruments contain information on the displacement gradient of a seismic wavefield along the direction of the fiber (i.e., strain), there is a need to develop a fundamental theoretical framework to cope with this new data type. The high spatial resolution and broadband nature of DAS furthermore allows for new data analysis methods or the adaptation of existing Large-N methods to this new data type.

This session will span a wide range of topics related to fiber-optic sensing methods in seismology and geophysics, including but not limited to: advancements in optical engineering; developments in theoretical and methodological aspects of fiber-optic sensing; case studies from ongoing fiberoptic sensing experiments worldwide; comparisons between non-inertial and inertial instruments; and insights gained from fiber-optic sensing measurements in the context of other types of seismological/geophysical datasets.

We invite contributions from research related to all aspects of fiber-based sensing.

Conveners: Patrick Paitz, ETH Zürich (patrick.paitz@ erdw.ethz.ch); Verónica Rodríguez Tribaldos, Lawrence Berkeley National Laboratory (vrodrigueztribaldos@lbl.gov); Ariel Lellouch, Stanford University (ariellel@stanford.edu)

\section{How Should Low-Probability Earthquakes be Considered in Hazard Assessments?}

Large, shallow, crustal earthquakes can have very long recurrence intervals, on the order of tens of thousands of years. However, their occurrence near urban centers represents one of the most significant and enigmatic seismic risks facing our society today. For example, the 2011 Christchurch earthquake resulted in losses of 3-4\% of New Zealand's Gross Domestic Product [Parker \& Steenkamp, 2012], despite occurring on a previously unknown, shallow fault within the city limits. This highlights the need for seismic hazard assessment that in some way considers the impact of low probability earthquakes.

There have been great strides in characterizing some of the faults capable of this type of rupture, largely from the disci- 
plines of satellite geodesy and paleoseismology. These studies are often expensive and spatially limited, however, leading to fault catalogs which are heterogeneous in content and demonstrably incomplete. For this reason, fault databases are inconsistently incorporated in seismic hazard maps even when there is some information available about a potentially damaging earthquake source. To bridge this gap will require participation from scientists, engineers and government agencies to (1) establish how much can be known about faults, (2) evaluate impacts to society and consider their sensitivity to unknowns and (3) consider the implications for policy. This session invites presentations which highlight recent advances in characterizing low probability faults, including their geometry, mechanism, magnitude-recurrence interval, maximum magnitude or other properties. We then welcome studies which quantitatively assess the resulting seismic hazards or consider the effect of such faults on seismic hazard mapping programs. The goal of this session is to facilitate a vibrant discussion concerning the future of seismic assessment which can fully incorporate the latest research in earthquake physics, geodesy, geomorphology and tectonics.

Conveners: Tiegan E. Hobbs, Natural Resources Canada (tiegan.hobbs@canada.ca); Chris Rollins, University of Leeds (j.c.rollins@leeds.ac.uk); Kristin Morell, University of California, Santa Barbara (kmorell@geol.ucsb.edu)

\section{How Well Can We Assess Site Effects So Far?}

In seismic hazard and risk analyses, the effects of near-surface geology on ground shaking need to be quantified as precisely as possible. Ergodic amplification equations in ground motion models (GMM) can only give an average estimate of amplification, and bias is expected in a posterior application at a specific site. Various approaches are currently available to quantify site-specific amplification. If ground-motion records are available at or near a target site, ergodic models can be calibrated to derive site-specific amplification function. Otherwise, ground response analyses (GRA) are carried out to characterize site response. In addition, the horizontal-to-vertical spectral ratio (HVSR) of either earthquake or ambient noise recordings has been proven to be a cost-effective approach in site-effects studies.

In this session, we invite studies dealing with different approaches to quantify site effects. Studies on how to improve our current practice in ground response estimation are particularly welcome, e.g., the search of optimal site characterization proxy (alternative or complementary to the time-averaged $30 \mathrm{~m}$ shear-wave velocity and/or the fundamental resonant frequency) to improve ergodic site response models; novel approaches to evaluate the attenuation of wave propagation; ground response analysis and its associated uncertainty; soil nonlinearity, numerical or empirical studies on $2 \mathrm{D} / 3 \mathrm{D}$ site effects; and innovative application of the horizontal-to-vertical spectral ratio (HVSR) technique; and integration of site effects into seismic hazard analysis.

Conveners: Chuanbin Zhu, GFZ German Research Centre for Geosciences (chuanbin.zhu@gfz-potsdam.de); Marco Pilz, GFZ German Research Centre for Geosciences (pilz@gfzpotsdam.de); Yefei Ren, Institute of Engineering Mechanics, China Earthquake Administration (renyefei@iem.net.cn); Fumiaki Nagashima, Disaster Prevention Research Institute, Kyoto University (nagashima.fumiaki.6v@kyoto-u.ac.jp)

\section{Imaging Incipient and Fossil Subduction Zones}

Subduction is a fundamental Earth process - it is integral for plate tectonics and the recycling of the planet's surface, plays a significant role in long term climate regulation and is the principal source of volcanic and seismic hazard around the globe. We are at a critical juncture where large-scale multidisciplinary efforts are being launched to better understand the descent of oceanic slabs. But how can new trenches be generated? And what happens when the descent of the down-going slab ceases? Causes of subduction initiation and consequences of its termination are two aspects of the subduction cycle that have received little attention. Thus, they remain enigmatic, controversial and models are typically not well supported by observations. 3D high-resolution seismic images are central to the understanding of the subduction cycle and are crucial in the investigation of the mechanisms that drive likely modes of subduction initiation and termination. The goal of this session is to motivate discussion on the current state of subduction-zone imaging with a special focus on incipient and fossil subductions, new seismic network deployments, advanced seismic imaging methods (e.g., ambient noise tomography, migration imaging and full waveform inversion) that can explore and fully utilize big seismic datasets to better image subduction past, present and future.

Conveners: Simone Pilia, University of Cambridge (sp895@cam.ac.uk); Min Chen, Michigan State University (chenmi22@msu.edu); Caroline Eakin, Australian National University (caroline.eakin@anu.edu.au)

\section{Infrasound and the Seismo-Acoustic Wavefield}

Infrasound monitoring is used to detect and study a variety of natural and anthropogenic sources, as well as to probe temporal and spatial variations in the atmosphere. Many infrasound sources occurring above and within the solid earth or hydrosphere also generate seismic waves. This session focuses on coupled seismo-acoustic propagation through the Earthocean-atmosphere system. Consideration of the seismoacoustic wavefield has the potential to both better constrain 
directionality and location for a variety of geophysical sources such as volcanoes, earthquakes and chemical or nuclear explosions and elucidate a wider variety of propagation phenomena than seismology or infrasound alone. To take full advantage of a seismo-acoustic wavefield over multiple distance scales, new sensor technologies and data fusion schemes are necessary.

We invite submissions detailing recent science results and research advances in infrasound, seismo-acoustics and similar multi-phenomenological research. Presentations that explore observations and/or interpretations of seismo-acoustic phenomena, existing and emerging source and propagation models, advances in instrumentation, inversion methods and signal analysis techniques are welcome.

Conveners: Jordan W. Bishop, University of Alaska Fairbanks (jwbishop2@alaska.edu); Fransiska Dannemann Dugick, Sandia National Laboratories, Southern Methodist University (fdannemann@mail.smu.edu); Gil Averbuch, Southern Methodist University (gil.averbuch@gmail.com); Jeffrey B. Johnson, Boise State University (jeffreybjohnson@ boisestate.edu)

\section{Insight Seismology on Mars: Results From the First Martian Year of Data and Prospects for the Future}

The InSight mission landed on Mars on 26 November 2018 and was the first to place an ultra-sensitive broadband seismometer on the surface of another planet. It will provide key information on the composition and structure of an Earth-like planet that has gone through most of the evolutionary stages of the Earth up to, but not including, plate tectonics. Using seismology, geodesy and heat flow measurement, InSight aims to determine the thickness and structure of the Martian crust and mantle, the size and state of the core, the planet's thermal state and the level of tectonic activity and rate of meteorite impacts.

The two-year (one Mars year) InSight primary mission (with extension possible as the spacecraft continues to function on Mars) ushers in a new era in planetary seismology. In the coming years and decades NASA may launch missions to explore the interiors of our Moon, Venus and the "Ocean Worlds" of the Solar System (e.g., Europa, Enceladus and Titan). Other Space agencies might also launch additional missions with seismometers. While the focus of these mission concepts vary from fundamental geophysics to detection of life and conditions for life, seismological exploration of planetary bodies' interiors is likely to play a key role in understanding planetary state and evolution by helping to determine their thermal and chemical make-up.

We invite contributions that take advantage of the seismic data from the first year on Mars, as well as modeling that looks forward to upcoming data from Mars or other planetary bodies. With data being made available through the IRIS Data Management Center, results from both within and outside the mission science team are welcome.

Conveners: Mark P. Panning, Jet Propulsion Laboratory, Caltech (mark.p.panning@jpl.nasa.gov); Sharon Kedar, Jet Propulsion Laboratory, Caltech (sharon.kedar@jpl.nasa. gov); Bruce Banerdt, Jet Propulsion Laboratory, Caltech (william.b.banerdt@jpl.nasa.gov)

\section{Inspiring a New Generation of Seismology Leaders}

Racial and ethnic diversity in geosciences has not improved in nearly half a century. Furthermore, a changing political climate and recent events have sparked a nation-wide increased awareness of social justice issues. These events are prompting numerous diversity initiatives within the academic realm, which are being communicated widely through webinars, conferences and various social media platforms. In the geoscience community, these initiatives include newly-formed organizations (e.g. the SSA Diversity, Equity and Inclusion Task Force) that aim to dismantle systems of oppression for people with marginalized identities. Student and early-career seismologists are often advised to keep their distance from these discussions because of the common notion that diversity initiatives are undertaken at the expense of science. This either/or approach of research and diversity is unnecessary and harmful to our community. As seismologists, we work with various communities globally, which requires awareness of the diverse perspectives and identities that we interact with. Consequently, equity and diversity are necessary for scientific progress. The work of budding leaders in seismology, at the forefront of making change, should be acknowledged and heard.

This session aims to establish a community of seismologists interested in making our field more just, equitable, diverse and inclusive. We seek abstracts that highlight diversity initiatives by and/or for seismologists. We also solicit abstracts that outline strategies for integrating diversity and inclusion initiatives in academic, government and industry programs. These presentations can include personal experiences, experiences with outreach or in the field, visions for the future of seismology and/or equitable applications of our science. Note, these abstracts must be constructive for an effective conversation to take place. We encourage and will prioritize abstracts from students and early-career scientists.

Conveners: Monique M. Holt, University of Utah (mholt@ seis.utah.edu); Kevin B. Kwong, University of Washington (kbkwong@uw.edu); Barrett N. Johnson, University of Washington (bnjo@uw.edu) 


\section{Intermountain West Earthquakes in the Spring of 2020}

The Intermountain West region of the United States experienced several moderate-to-strong earthquakes in the spring of 2020. The most significant of these were the 18 March 2020 Mw 5.7 earthquake north of Magna, Utah (a suburb of Salt Lake City), the 31 March 2020 Mw 6.5 earthquake northwest of Stanley, Idaho and the 15 May 2020 Mw 6.5 Monte Cristo Range earthquake, northwest of Tonopah, Nevada. This session seeks contributions on all aspects of these earthquake sequences including geologic, geodetic and seismological studies on topics such as earthquake source properties, near-field ground motions, surface rupture, damage assessments, aftershock forecasting, seismic hazard implications and seismotectonics.

Conveners: Jayne Bormann, University of Nevada, Reno (jbormann@unr.edu); Ryan D. Gold, U.S. Geological Survey (rgold@usgs.gov); Keith Koper, University of Utah (koper@ seis.utah.edu)

\section{Mechanisms of Induced Seismicity: Pressure Diffusion, Elastic Stressing and Aseismic Slip}

The rise of man-made earthquakes has generated interest from a broad range of scientists and stakeholders. The interest stems from both practical and scientific standpoints, whereby induced seismicity poses a hazard that can potentially be mitigated and also presents an opportunity to learn about earthquakes in an environment where driving mechanisms may be better constrained. Recent advances in seismic and geodetic monitoring has allowed for more detailed observations of anthropogenically induced and triggered seismicity. These observations have revealed more complex interactions beyond effective stress reduction, including aseismic processes and elastic stress effects. A better understanding of the contributions from these processes (as a function of distance and time, as well as flow and elastic parameters) has significant implications for the expected seismic hazard. In addition, seismic hazard assessment is tied to improved characterizations of the primary controlling factors on induced earthquakes (e.g. injection volumes and rates, change in reservoir pressure, induced stressing rates).

We solicit studies on any types of induced seismicity around the world, including geothermal, hydrocarbon production, waste-water disposal, $\mathrm{CO} 2$ sequestration and gas storage. Case studies from the laboratory to large- $\mathrm{N}$ array deployments to field-scales are welcomed. We also seek studies from a wide variety of disciplines that aim to monitor, observe and model injection-induced seismicity. The aim of this session is to bring together numerical, observational and experimental studies on both aseismic and seismic processes associated with induced earthquakes.
Conveners: Ruijia Wang, University of New Mexico (ruijia@unm.edu); Matthew Weingarten, San Diego State University (mweingarten@sdsu.edu); Thomas Goebel, University of Memphis (thgoebel@memphis.edu); Heather DeShon, Southern Methodist University (hdeshon@mail. smu.edu); Kyung Won Chang, Sandia National Laboratories (kchang@sandia.gov)

\section{Modern Geodesy for Observation and Its Modeling of Earthquake Deformation}

In this session, we would like to explore and discuss the crustal deformation features of intraplatel earthquake cycles based on all modernly available geodetic methods, including GNSS, InSAR and other techniques. The applications of these geodetic observations and techniques have significantly improved our understanding of earthquakes. This session intends to cover all of the fields of research that use geodetic applications for earthquake studies. The focus is to discuss how accurate geodetic observations help to update and challenge our current understanding of earthquakes, particularly with respect to the lithosphere's rheologic structure, hazard analysis and varying fault behaviors during seismic cycles. We would like to call for submissions involving new applications of geodetic techniques on earthquake cycle deformation studies as well as reviews on geodetic developments for earthquake application. This is a session to review and promote the revolutionary contribution of geodetic observations to seismological research.

Joint SSC-SSA Session

Conveners: Xinjian Shan, China Earthquake Administration (xjshan@163.com); Benchun Duan, Texas A\&M University (bduan@geos.tamu.edu); Jiankun He, Chinese Academy of Sciences (jkhe@itpcas.ac.cn); Mingsheng Liao, Wuhan University (liao@whu.edu.cn); Guohong Zhang, China Earthquake Administration (274990177@qq.com)

\section{Network Seismology: Keeping the Network Running While Integrating New Technologies}

This session highlights the unique observations, opportunities, challenges and future directions of seismic operation centers. Seismic operation centers play a crucial role in collecting seismic data, generating earthquake products, including catalogs, warnings and maps of ground shaking and responding to many stakeholders, including government agencies and the public. The purpose of the session is to foster collaboration between network operators, inform the wider seismological community of the interesting and challenging problems within network seismology and look to the future on how to improve monitoring capabilities. We encourage submissions related to challenges faced by networks from crises like the 
COVID shutdown, fires and other natural disasters. We also encourage submissions describing new techniques that would benefit network operations for detecting and locating earthquakes, particularly in a near real-time environment. We are especially interested in algorithms and machine learning (ML) applications, especially comparisons between ML and tried and true human-design algorithms and examples of where ML has been implemented into network operations.

Conveners: William L. Yeck, U.S. Geological Survey (wyeck@usgs.gov); Kris L. Pankow, University of Utah Seismograph Stations (pankowseis2@gmail.com); Renate Hartog, Pacific Northwest Seismic Network (jrhartog@ uw.edu)

\section{New Insights Into the Preparatory Phase of Earthquakes From Tectonic, Field and Lab Experiments}

Earthquake prediction and forecasting has been a great scientific challenge for many decades. When reviewing the historical developments around the world, we find that advances in our understanding of the predictability of earthquakes emerge from detailed analyses of new datasets and types of significant earthquakes as well as statistical research, model developments, lab and field experiments. Recently, new constraints have been placed on the earthquake preparation and nucleation phase from detailed observations of foreshocks, aseismic slip before subduction zone earthquakes, seismic slip nucleation in the lab and from statistical analyses of seismicity. Particularly strong constraints can emerge from experiments to catch large earthquakes in the act, such as the Parkfield, California, Earthquake Prediction Site of the U.S. Geological Survey and more recently the China Seismic Experimental Site (CSES) of the China Earthquake Administration. By using the seismically active Sichuan-Yunnan region as a natural observatory, CSES plans to foster an international and interdisciplinary cooperation on fundamental research in continental earthquakes.

In this session, we welcome contributions that illuminate or constrain the earthquake preparation phase from across the scales, from lab and field scales to global studies and across the disciplines, including seismology, geodesy, geophysics and numerical modelling to experimental rock mechanics. We seek presentations that either develop new hypotheses (in exploratory research) or aim to test existing hypotheses (in confirmatory research). We also welcome contributions that leverage data science, including artificial intelligence, big data or cloud computing, to advance earthquake predictability research.

Joint SSC-SSA Session

Conveners: Zhigang Peng, Georgia Institute of Technology (zpeng@gatech.edu); Yongxian Zhang, China Earthquake Administration (yxzhseis@sina.com); Maximilian Werner, University of Bristol (max.werner@bristol.ac.uk); Vladimir
Kossobokov, Russian Academy of Sciences (volodya@mitp. ru); John Ebel, Boston College (john.ebel.1@bc.edu); Weijun Wang, China Earthquake Administration (wjwang@cea-ies. ac.cn)

\section{Numerical Modeling of Earthquake Motion, Rupture Dynamics, Seismic Noise, Wave Propagation and Inverse Problems}

Continuous development of numerical modeling methodology in seismology is driven by emerging requirements in the observational seismology, advances in the mathematical sciences, evolution of computer architectures and programming models, adaptation of methods originating in other scientific fields, as well as by practical applications including site-specific seismic hazard assessment.

This session is a forum for presenting advances in numerical methodology, whether the principal context is observational, mathematical/numerical, computational or application. We invite contributions focused on development, verification and validation of numerical-modeling methods and methodologically important applications especially to earthquake ground motion, seismic noise and rupture dynamics, including applications from field of induced seismicity with particular focus on multi-physics aspects, for example, combining fluid migration and stress transfer in porous media with rupture dynamics and wave propagation in poro-elastic media and full seismic cycle simulations. We encourage contributions on the analysis of methods, fast algorithms, high-performance implementations, large-scale simulations, non-linear behavior, multi-scale problems and confrontation of methods with data, such as inverse problems.

Conveners: Peter Moczo, Comenius University Bratislava (moczo@fmph.uniba.sk); Wei Zhang, Southern University of Science and Technology (zhangwei@sustech.edu.cn); Jozef Kristek, Comenius University Bratislava (kristek@fmph. uniba.sk); Martin Galis, Comenius University Bratislava (martin.galis@uniba.sk); Chanseok Jeong, Central Michigan University (jeong1c@cmich.edu); Elnaz Seylabi, University of Nevada, Reno (elnaze@unr.edu)

\section{Overdue?}

Are California and other regions overdue for large earthquakes? Comparison of instrumental seismic data with longer term geological and paleoseismic data suggest that such regions have experienced fewer large earthquakes in the last century than the long term average. A commonly accepted implication is that such regions might be overdue and should expect an accelerated rate. Is the current rate actually anomalous? Just due to expected random variations? A low point between supercycles? A result of different observational tech- 
niques between the instrumental and pre-instrumental periods? We welcome presentations that will clarify the options, suggest testable hypotheses and enrich the conversation.

Conveners: David D. Jackson, University of California, Los Angeles (djackson@g.ucla.edu); Danijel Schorlemmer, GFZ German Research Centre for Geosciences (ds@gfz-potsdam.de)

\section{Physics-Based Earthquake Rupture Modeling and Strong Motion Simulations}

Advancements in high-performance computing, improved understanding of physical processes during earthquake rupture and an increased number of observations of seismic events have contributed to the development of high-resolution seismic velocity models and numerical techniques for simulating earthquake ground motion for engineering applications. The integration of this multidisciplinary knowledge into fault-tostructure simulation techniques requires interaction between earth scientists and earthquake engineers. This session will focus on state-of-the-art research on kinematic and dynamic rupture modeling, computational aspects of ground motion modeling and verification of simulation techniques in building response analysis. We welcome studies focused on all aspects of physics-based earthquake rupture modeling and 3D wave propagation modeling, including: simulations incorporating free-surface topography, small-scale heterogeneity superimposed on deterministic velocity models, linear and non-linear constitutive material models, representation of near-surface geotechnical soil properties in site response, large-scale ground motion simulation on HPC platforms as well as simulations of ground motion variability and building response. Additionally, we encourage submissions related to implementing information from ground motion simulation research into targets for engineering constraints and their application in seismic hazard assessment, as well as theoretical and numerical modeling approaches addressing recordings with emerging sensor technologies such as DAS and rotational sensors.

Conveners: Arben Pitarka, Lawrence Livermore National Laboratory (pitarka1@llnl.gov); Alice-Agnes Gabriel, University of California (gabriel@geophysik.uni-muenchen. de); Kyle B. Withers, Geologic Hazards Science Center, U.S. Geological Survey (kwithers@usgs.gov); František Gallovič, Charles University (gallovic@karel.troja.mff.cuni.cz); Arthur Rodgers, Lawrence Livermore National laboratory (rodgers7@llnl.gov)

\section{Probabilistic Seismic Hazard Assessment: Where Do We Go from Here?}

A half century after its introduction (Cornell, 1968), probabilistic seismic hazard assessment (PSHA) has been adopted widely by governmental agencies and industry as the standard approach to assess hazards from future earthquakes. PSHA maps are used for myriad reasons, including building code development. Over time, extensive research has been done to develop methodology and refine key inputs -- earthquake rupture forecast $(\mathrm{ERF})$ models and ground motion prediction equations (GMPEs). Increasingly, PSHA maps are based on input ERFs and GMPEs that are constrained by best-available science, subject to certain assumptions.

However, due to the long time horizons of long-term PSHA maps relative to paleoseismic, historical and instrumental observation periods, evaluation of maps remains challenging. In this session we welcome contributions focused on the question, where does PSHA go from here?

For this session we welcome contributions focused on this question, including but not limited to: evaluation and/or testing of PSHA maps, novel approaches to improve PSHA and/ or its inputs, investigations of the sensitivity of PSHA maps to inputs and/or assumptions and alternative approaches to PSHA.

Conveners: Susan E. Hough, U.S. Geological Survey (hough@usgs.gov); Seth Stein, Northwestern University (s-stein@northwestern.edu)

\section{Recent Development in Ultra-Dense Seismic Arrays with Nodes and Distributed Acoustic Sensing}

Recently, ultra-dense seismic deployments, typically consisting of hundreds to thousands of short-period nodal instruments or distributed acoustic sensing (DAS) systems with fiber optic cables, have been widely used in seismological studies. These dense arrays have very close station spacings ranging from several meters to hundreds of meters to record well-sampled and unaliased wavefields in local or regional settings. Data acquired by such dense systems promote the development of new arraybased analysis methods to mine seismic wavefields and greatly improve our understanding of fine-scale subsurface properties, microseismic activities and earthquake rupture processes. In this session, we invite contributions from areas that are broadly related to ultra-dense arrays. Example topics include, but are not limited to, novel instrument development, new field experiments with nodal or DAS arrays, high-resolution imaging of subsurface structure, environmental seismology, microseismic detection/relocation, source characterization and related big data processing techniques.

Joint SSC-SSA Session 
Conveners: Marianne S. Karplus, University of Texas at El Paso (mkarplus@utep.edu); Nori Nakata, Massachusetts Institute of Technology (nnakata@mit.edu); Xiangfang Zeng, Chinese Academy of Sciences (zengxf@whigg.ac.cn); Xiaobo Tian, Institute of Geology and Geophysics (txb@mail.iggcas. ac.cn)

\section{Recent Engineering Uses of National Seismic Hazard Models}

The U.S. Geological Survey (USGS), Natural Resources Canada (NRCan) and agencies of several other countries have recently updated their National Seismic Hazard Models (NSHMs) and/or are in the process of doing so-e.g., GNS Science of New Zealand. Earthquake engineers are using these NSHMs and/or providing input on their development. For example, the 2018 USGS NSHM has been used for the "2020 NEHRP Recommended Seismic Provisions for New Buildings and Other Structures," developed by the Building Seismic Safety Council (BSSC) for adoption into building codes throughout the United States. Through prior dialogue between the BSSC and USGS, the BSSC "Project 17" committee requested an expanded set of spectral acceleration periods and site conditions (i.e., 30-meter shear-wave velocities) for the 2018 NSHM. This BSSC request influenced the ground motion models and sedimentary basin depths incorporated by the USGS. Furthermore, BSSC review of preliminary results from the 2018 NSHM led to improvements to the modeling of basin effects. Similarly, the sixth generation of the NRCan NSHM is being used for the 2020 National Building Code of Canada (NBCC) and includes an expanded set of site conditions tailored to their use in the NBCC. GNS Science is updating its New Zealand NSHM and is including engineering users throughout their process. Concurrently, the New Zealand government is running a process to re-evaluate how NSHM results are used to meet building code goals. This session invites presentations on other recent engineering uses of and/or input on NSHMs, not only for construction codes but also seismic risk assessments and other engineering applications. In particular, we welcome contributions from international earthquake engineers and scientists who can more readily participate in the online-only format of this year's SSA Annual Meeting.

Conveners: Nicolas Luco, U.S. Geological Survey (nluco@ usgs.gov); Michal Kolaj, Natural Resources Canada (michal. kolaj@canada.ca); Sanaz Rezaeian, U.S. Geological Survey (srezaeian@usgs.gov); Peter M. Powers, U.S. Geological Survey (pmpowers@usgs.gov); Matthew C. Gerstenberger, GNS Science (m.gerstenberger@gns.cri.nz); Ken Elwood, University of Auckland (k.elwood@auckland.ac.nz)

\section{Seismic Hazard Analysis for Critical Infrastructure}

The term critical infrastructure refers to the facilities and systems that provide vital services to a nation. Examples of critical infrastructure include nuclear power plants and nuclear waste repositories, dams and infrastructure that supports the emergency services sector, energy sector and water systems, among others. Potential damage or destruction to any of these facilities or systems would likely have a detrimental effect on public health, safety and security. Regulatory guidance defines appropriate procedures to perform planning, siting, data collection and analysis needed to ensure the physical elements of critical infrastructure are located and constructed to sufficiently withstand seismic loads and avoid earthquake-related effects of permanent ground displacement such as surface faulting and liquefaction. These types of studies involve rigorous data collection and site-specific analysis that considers seismogenic sources over a wide area. The results of these studies can be of great benefit to neighboring and regional communities because the level of detail and areal extent is often much greater than conventional studies for non-critical infrastructure. When critical infrastructure is impacted by an earthquake, post-event assessments are performed to document the resulting deformation and to determine the extent and nature of the impact on critical structures for the purpose of improving engineering practices in the future. In this session, we welcome submissions that cover a wide-range of seismic hazard-related studies and analysis that have been performed to ensure the resiliency of critical infrastructure. We have a particular interest in submissions that discuss key insights from recent seismic events that discuss ground shaking and building damage, triggered ground failure in proximity to infrastructure and complexities related to surface fault deformation and pipelines.

Conveners: Mark Zellman, BGC Engineering, Inc. (mzellman@bgcengineering.com); Joanna R. Redwine, U.S. Bureau of Reclamation (jredwine@usbr.gov); Laurel M. Bauer, U.S. Nuclear Regulatory Commission (laurel.bauer@nrc.gov)

\section{Sensors, Seismicity and Imaging}

We bring together contributions encompassing testing and characterization of new seismic instrumentation, a comparison between catalogs of moment tensors, an updated seismicity catalog, and imaging in the Middle East, Asia and the Central US from the crust to the core.

Conveners: Rich Briggs, U.S. Geological Survey (rbriggs@ usgs.gov); Diego Melgar, University of Oregon (dmelgarm@ uoregon.edu); Jenny Nakai, University of New Mexico (jenakai@unm.edu) 


\section{Strategies and Actions for Fostering a Diverse Seismology Community}

The goal of this session is to share ideas, efforts and programs that the community is currently using to increase diversity in seismology and related fields. In spite of efforts to increase diversity for several decades, the demographic makeup of the geosciences remains imbalanced in proportion to that of the U.S. population (Bernard and Cooperdock, 2018, Dutt, 2019), even though the work of demographically underrepresented groups is scientifically novel and highly innovative (Hofstra et al. 2020).

New strategies to address these disparities will be highlighted in this session. We encourage submissions on topics such as: providing education on implicit biases; developing equitable selection processes; ensuring an inclusive and welcoming work environment; creating safe fieldwork spaces (Demery and Pipkin, 2020); acknowledging mental health issues related to experiences of identity; and fostering retention. We welcome examples in seismology such as successful broader impacts activities, policy changes, efforts in Diversity, Equity and Inclusion (DEI) education and recruitment and retention of underrepresented students/employees, postdoctoral researchers, staff and faculty.

We welcome submissions from principal investigators, educators, scientists in national laboratories, the USGS and BOR, non-profits and industry seismologists who have incorporated elements of outreach and diversity into their research and leadership efforts, as well as specialists in DEI and education efforts. The emphasis is on finding out how leaders are currently promoting and addressing diversity, education and inclusion efforts and actions we can take to make progress on those efforts.

Conveners: Valerie Sloan, National Center for Atmospheric Research (vsloan@ucar.edu); Aradhna Tripati, University of California, Los Angeles (atripati@g.ucla.edu); Aubreya Adams, Colgate University (aadams@colgate. edu); Wendy Bohon, Incorporated Research Institutions for Seismology (wendy.bohon@iris.edu)

\section{Strong-Motion Data Processing and Dissemination: State-of-the-Art and Outlook}

Strong-motion waveforms and associated metadata are key input to a broad range of studies spanning the domains of engineering seismology, soil dynamics, earthquake engineering, seismic hazard and risk and computational near-source seismology. The deployment of dense accelerometer networks with modern broadband high-dynamic-range instruments has progressively blurred the traditional boundary between weakmotion and strong-motion seismology. Some strong-motion data banks started to also include on-scale data recorded by velocity sensors especially for low-magnitude events and the discussion is open on whether this should become standard practice. Geophysical characterization of the recording sites has become a standard, and open databases have been created to host both basic and advanced station metadata crucial to the scientific interpretation of earthquake recordings. The dramatic increase in the amount of available data prompts for new dissemination strategies centered on web services, standardized and optimized data formats and the development of automatic processing techniques, which in turn require strict quality checks prior to data dissemination. Machine learning methods promise to provide an automated solution to quality checks that have traditionally been performed by visual inspection. In this session we welcome contributions on strong-motion data processing (manual and automatic) and dissemination strategies (data formats, databases, web services) as implemented by seismological agencies worldwide. We aim at collecting input from the global community to optimize and harmonize best practices in strong-motion data management.

Conveners: Carlo Cauzzi, ORFEUS, ETH Zürich (carlo. cauzzi@sed.ethz.ch); Hamid Haddadi, California Geological Survey, California Department of Conservation, COSMOS (hamid.haddadi@conservation.ca.gov); Giovanni Lanzano, Istituto Nazionale di Geofisica e Vulcanologia (giovanni.lanzano@ingv.it); Eric M. Thompson, U.S. Geological Survey (emthompson@usgs.gov)

\section{Subduction Processes Along Latin America Subduction Zones}

Subduction zones along Latin America, including those in Mexico, Central America, Caribe and South America, present a dynamic and complex diversity of Earth processes that have important effects on permanent and elastic deformation. Both in the strike and dip directions there is a marked segmentation with a wide variety of seismic and aseismic slip behavior at the plate interface and different deformation styles in the down-going and overriding plates. In addition to megathrust earthquakes, intermediate depth earthquakes and shallow backarc earthquakes are often very damaging and less well studied. Furthermore, recent years have seen an increase in onshore/offshore experiments tackling issues such as fluid content and interaction between seismic and aseismic slip. Likewise, improvements in seismic imaging and earthquake sources studies have led to a wealth of new knowledge related to convergent margin processes including both flat and normal slab subduction.

In this session, we invite contributions studying the variety of subduction processes that take place in these subduction zones and their effects on permanent and elastic deformation along the margin. We welcome both theoretical, observational and modeling studies, including studies using passive and active seismology and geodesy.

Joint LACSC-SSA Session 
Conveners: Hans Agurto-Detzel, Géoazur, IRD (agurto@ geoazur.unice.fr); Susan L. Beck, University of Arizona (slbeck@arizona.edu); Isabella Gama, Brown University (isabella_gama_dantas@brown.edu); Rafael Almeida, Yachay Tech University (ralmeida@yachaytech.edu.ec)

\section{Tectonics and Seismicity of Stable Continental Interiors}

Perhaps the least understood seismicity and tectonic deformation is that in stable continental interiors far removed from active plate boundaries. Areas of interest include central and eastern North America, northern Europe, Australia and parts of Asia. New understandings of intraplate tectonic activity and corresponding seismicity are being achieved through a variety of approaches, including increased completeness of earthquake catalogs from local or national-scale monitoring efforts like USARRAY, new methods of identifying smaller earthquakes from existing data, through analyses of data sets that image subsurface faults, through studies that constrain historical slip on such faults, from examinations of geodetic, geomorphologic and elevation changes and through improved measurements of local stresses. Complementing these approaches are studies that show that the lower attenuation of ground motions and strong site responses in continental interior regions result in earthquakes having greater impacts than those at plate boundaries.

This session seeks diverse contributions related to intraplate earthquake hazards with goals of describing seismicity, characterizing active faults and/or deformation in stable continental interiors, learning the long-term earthquake histories, assessing potential ground motion impacts, applying lessons learned from induced earthquakes and understanding the mechanisms that cause enigmatic intraplate earthquakes. Contributions regarding 2020 earthquakes such as those in Sparta, North Carolina are especially welcome.

Conveners: Anjana K. Shah, U.S. Geological Survey (ashah@usgs.gov); Christine A. Powell, CERI, University of Memphis (capowell@memphis.edu); Will Levandowski, Tetra Tech (will.levandowski@tetratech.com)

\section{Tectonics, Seismicity and Recent Significant Events in the Caribbean}

Greater and Lesser Antilles are located at the active plate boundary between the North American and the Caribbean plates. Large magnitude earthquakes and destructive tsunamis are mostly caused by the convergence and interactions of these plates. In the 20th century, there have been several large magnitude and destructive earthquakes such as the 1918 M7.4 earthquake, the 1943 M7.6 earthquake, the 1946 M8.0 earthquake and the 2010 M7.0 Haiti earthquake (Puerto Rico and
Hispaniola). The most recent 2020 M6.4 earthquake caused significant damages and destruction in Puerto Rico.

In addition to earthquakes, other tsunamigenic events, including submarine/subaerial landslides, submarine volcanoes and subaerial pyroclastic flows have occurred in the Caribbean. Large tsunamis have hit the islands killing many people. The exposure and associated risk have increased because of the high population density and extensive development near the coast, including tourism and recreation infrastructure. All the northeastern Caribbean has a significant exposure to earthquakes and tsunamis and that is the goal of this session to have a forum to present the actuality of research, activity, forecasting, etc. in this very sensitive part of the world.

Joint LACSC-SSA Session

Conveners: Victor A. Huerfano, Puerto Rico Seismic Network (victor@prsnmail.uprm.edu); Guoqing Lin, University of Miami (glin@rsmas.miami.edu); Eugenio Polanco, Universidad Autonoma de Santo Domingo (eugenio. fisico@gmail.com); Joan Latchman, University of the West Indies Seismic Research Centre (j_latchman@uwiseismic. com); Wenyuan Fan, University of California, San Diego (wenyuanfan@ucsd.edu)

\section{Towards an Integrated View of Earthquake Gates From Geologic Observations and Numerical Models}

Fault complexities, such as bends, stepovers and branches, may inhibit earthquake rupture propagation. Numerical modeling, Quaternary slip rate analyses and paleoseismic studies have demonstrated that these structural complexities can act as earthquake gates that exhibit a time-dependent probability of throughgoing rupture. Earthquake gate breaching is sensitive to a variety of parameters, including stress heterogeneities due to prior rupture history, rupture directivity and velocity, rheological properties and fault geometry. Observational records of global earthquake gates remain sparse, and numerical models remain relatively simple compared to real-world fault systems. However, in concert both approaches have advanced our understanding of earthquake gate timing and mechanical behavior considerably.

In this session, we seek to bring together geoscientists from a diverse disciplinary range interested in rupture behavior and timing through fault complexities. We welcome studies using geologic observations, observational seismology and numerical modeling to advance our understanding of earthquake gate behavior. We are particularly interested in studies that synthesize observations from multiple disciplines.

Conveners: Veronica B. Prush, McGill University (vbprush@ucdavis.edu); Alba M. Rodriguez Padilla, University of California, Davis (arodriguezpadilla@ucdavis. edu); Julian C. Lozos, California State University, Northridge 
(julian.lozos@csun.edu); Michele L. Cooke, University of Massachusetts, Amherst (cooke@umass.edu)

\section{Tsunami Warning System in Latin America and the Caribbean: COVID-19 Challenges}

The SARS-Cov-2, was first identified in December 2019 in Wuhan, China and rapidly became a Public Health Emergency worldwide in early 2020. As of 1 October 2020, over 39.0 million cases and more than 1.0 million deaths have been reported.

In the Latin American and Caribbean region, the COVID19 pandemic represents a major challenge in all fronts, but particularly in the ongoing Tsunami Warning System, that involves the TSP (Tsunami Service Provider), the communication protocol of national agencies and the public in the hazard zones. Associated research, academic initiatives and preparedness activities in the region have been affected as well.

This session provides a broad opportunity to present how our Tsunami Warning System is impacted, responding and planning in the face of this and future health emergencies. It will provide a forum to identify inter- and transdisciplinary strategies to sustain the system and adjustments needed under this new reality. Topics will include from the monitoring and detection; hazard and risk assessments, forecast and warnings, mitigation, education, preparedness, response and recovery strategies. As is broadly known, over the past centuries several tsunamigenic earthquakes devastated our region and the associated sea waves destroyed our coastlines causing tragedies i.e. Peru (1687), Ecuador (1906), Dominican Republic (1946), Chile (1960, 2010), etc. Recent tsunami events have demonstrated that the risk and vulnerability from tsunami hazards continues to grow with expanding coastal populations and infrastructure. While the understanding and warning capabilities have significantly increased over the last decades, it is mandatory to adapt our programs to include the public health recommendations.

Joint LACSC-SSA Session

Conveners: Victor A. Huerfano, Puerto Rico Seismic Network (victor@prsnmail.uprm.edu); Christa von Hillebrandt-Andrade, National Oceanic and Atmospheric Administration (christa.vonh@noaa.gov); Silvia ChaconBarrantes, Universidad Nacional de Costa Rica (silviach@una. ac.cr); Sergio E. Barrientos, University of Chile (sbarrien@dgf. uchile.cl)

\section{UN Decade of Ocean Science for Sustainable Development and Seismology}

The UN Decade of Ocean Science for Sustainable Development will take place 2021-2030. It seeks to transform the ocean, the understanding of the ocean and address future challenges that face the ocean and thus humankind. The Implementation Plan proposes seven outcomes, two of which are related and would benefit from an advancement of seismology in the ocean: A safe ocean where life and livelihoods are protected from ocean-related hazards, including submarine earthquakes and tsunamis and an accessible ocean with open and equitable access to data, information and technology and innovation. Likewise, two of the Decade challenges are relevant to the seismological community: enhanced multi-hazard early warning services and a sustainable ocean observing system across all ocean basins that delivers accessible, timely and actionable data and information to all users. Additionally, there are seismological observations and methods that could contribute to other areas of Ocean Science.

This session will seek to discuss the transformational and innovative technologies that may be developed and deployed to address the gap in telemetered, near real time, permanent, continuous and high quality seismic and geophysical data that permit the quick characterization of hazards and complement the higher density land stations. Despite notable advances in the global tsunami warning system, including land based instrumentation, significant detection, measurement and forecast uncertainties remain to meet emergency response and community needs. A new generation of ocean sensing capabilities presents an opportunity to address several of these uncertainties. The conveners invite talks on technologies, methods and applications, including but not limited to long term sea floor seismographs, ocean observatories, submarine communication cables, (SMART) and ocean geodesy. Proposals on strategic partnerships between the academic, research, government and industry are also welcome.

Conveners: Christa Von Hillebrandt-Andrade, National Oceanic and Atmospheric Administration (christa.vonh@ noaa.gov); Monica Kohler, Caltech (kohler@caltech.edu)

\section{Updating the US National Seismic Hazard Models}

The U.S. Geological Survey (USGS) National Seismic Hazard Models (NSHMs) are a bridge between best-available earthquake science and public policy. Over the next few years, the National Seismic Hazard Model Project (NSHMP) will publish updates to three model regions: Hawaii, the conterminous U.S. (CONUS) and Alaska. This effort will bring NSHMs for all 50 states in line with current data and modeling approaches. Although the CONUS NSHM was updated in 2018, the Alaska seismic hazard model was last updated in 2007 and Hawaii in 1998. Over the next few years, the NSHMP will evaluate the new NGA-Subduction GMMs for use in the Cascadia and Aleutian arc subduction zones. It will also consider deep basin effects in other locations with high population density as it did for Los Angeles, San Francisco, Seattle and Salt Lake City in the 2018 CONUS update. New ground motion modeling 
approaches (e.g. simulation-based, non-ergodic) also require attention.

For this session, we invite contributions on current and future NSHM components. Example topics include: Atlantic and Gulf Coast and other alternative site amplification models, new fault data and models, fault-system modeling (e.g. UCERF3), NGA-Subduction GMMs, physics-based (3D simulation) ground motion model validation and implementation, non-ergodic aleatory uncertainty, basin models, new geodetic data and inversions, $\mathrm{M}$-area scaling relations, the Alaska megathrust geometry and recurrence and novel approaches to modeling and computing hazard and associated uncertainties. Although the session is largely focused on updates to U.S. models, much of what goes into modeling earthquake hazard has global applicability. We therefore also welcome submissions on the development and details of other NSHMs worldwide.

Conveners: Peter M. Powers, U.S. Geological Survey (pmpowers@usgs.gov); Allison M. Shumway, U.S. Geological Survey (ashumway@usgs.gov); Mark D. Petersen, U.S. Geological Survey (mpetersen@usgs.gov); Sanaz Rezaeian, U.S. Geological Survey (srezaeian@usgs.gov)

\section{Utilizing Earthscope and Aacse Datasets in Alaska and Canada to Unravel Earth Science Mysteries}

As part of the National Science Foundation (NSF) funded EarthScope project, the USArray Transportable Array (TA) in Alaska and western Canada deployed and operated near 200 telemetered broadband seismic and infrasound stations. This systematic coverage of continental Alaska and northwest Canada has provided an unprecedented dataset for the seismological community. This large-scale scientific experiment also inspired another simultaneous effort, the Alaska Amphibious Community Seismic Experiment (AACSE), and is complemented by numerous seismic and nonseismic field efforts in the Aleutians through the NSF GeoPRISMS program. This session invites results from studies utilizing all or part of this community datasets to investigate crustal and mantle structures, active tectonics, volcanism, local and regional earthquakes or other elastic wave sources and seismic wave propagation.

Conveners: Natalia A. Ruppert, University of Alaska Fairbanks (naruppert@alaska.edu); Meghan S. Miller, Australian National University (meghan.miller@anu.edu.au)

\section{Waveform Cross-Correlation-Based Methods in Observational Seismology}

Recent development in observational seismology relies heavily on the mining of increasingly large datasets through waveform cross-correlation-based techniques to improve signal to noise ratios and extract useful information from continuous seismograms. These include obtaining accurate differential arrival times with waveform correlation analysis for accurate earthquake relocation and 3D seismic tomography, detecting low-magnitude events using array-based waveform matching, extracting empirical Green's functions (e.g., surface and body waves) from cross-correlation of continuous ambient noise waveforms and creating virtual sources or receivers from cross-correlating earthquake coda waveforms. In this session, we welcome both methodologically- and observationally-focused contributions that utilize correlation-based methods to detect repeating earthquakes near creeping faults and volcanoes, relocate microearthquakes and low-frequency earthquakes around seismically active regions and image subsurface structures and monitor their temporal changes with ambient noise and earthquake coda correlation techniques. We hope to provide a platform for discussing how to efficiently apply correlation-based methods to ultra-dense arrays and long-duration continuous waveforms to better extract useful seismic events and image subsurface structures.

Conveners: Esteban J. Chaves, Volcanological and Seismological Observatory of Costa Rica, Universidad Nacional (esteban.j.chaves@una.cr); Zhigang Peng, Georgia Institute of Technology (zpeng@gatech.edu); Marine Denolle, Harvard University (mdenolle@g.harvard.edu); William Frank, Massachusetts Institute of Technology (wfrank@mit. edu); Taka’aki Taira, University of California, Berkeley (taira@ berkeley.edu); Haijiang Zhang, University of Science and Technology of China (zhang11@ustc.edu.cn)

\section{What Can We Infer About the Earthquake Source Through Analyses of Strong Ground Motion?}

Because the earthquake source cannot be directly observed, we rely on multiple analyses to infer knowledge of the parameters used to describe an earthquake. In this session we would invite presentations that describe methods and results for inferring the properties of the earthquake source, such as, rupture velocity, fracture energy, stress drop (stress parameter), slip-rate functions, critical slip weakening distance, friction, scaling laws, duration, moment rate, spatial heterogeneity, directivity, etc. We encourage presentations that discuss uncertainties in the inferred parameters. We look forward to presentations that link earthquake simulations, both kinematic and dynamic, to generation of near-source ground motions. In particular, analysis of near-source data sets using inversion, arrays or other novel methods are most welcome.

Conveners: Ralph J. Archuleta, University of California, Santa Barbara (ralph.archuleta@ucsb.edu); Joe Fletcher, U.S. Geological Survey (jfletcher@usgs.gov); Greg Beroza, Stanford University (beroza@stanford.edu) 


\section{When Seismology Meets Machine Learning, Data Science, HPC, Cloud Computing and Beyond}

Seismology is a data rich and data-driven science. As seismologists, we are lucky to be in an age where new tools and techniques are emerging to facilitate extracting insights from huge amounts of data. Over the past few years, there has been a new surge of interests in the applications of machine learning and data science techniques to seismological problems, as well as exploring the use of HPC and cloud computing to address computation-intensive tasks, and this new sub-field is rapidly evolving. Recent examples of seismological tasks in which machine learning applications have been shown to be promising include earthquake signal detection, seismic phase picking, phase association, first polarity determination, magnitude estimation, source location determination, event discrimination, seismic image pre-processing and interpretation, signal denoising, subsurface characterization, ground motion prediction and simulation, lab earthquake and aftershock prediction and exploratory data analyses. Though the progress on these tasks is not even, there is huge potential and more room for improvement in the near future. In this session, we invite contributions discussing the application of machine learning, data science, high performance computing, cloud computing and other recent data driven related efforts in all seismological problems. We welcome contributors to discuss successes, challenges and lessons learned in the application of these developing technologies.

Conveners: Qingkai Kong, Berkeley Seismology Lab, University of California, Berkeley (kongqk@berkeley.edu); S. Mostafa Mousavi, Stanford University (mmousavi@stanford. edu); Jiun-Ting Lin, University of Oregon (jiunting@uoregon. edu) $\mathbf{\Sigma}$ 


\section{Overview of Technical Program}

\begin{tabular}{|c|c|c|c|c|}
\hline Monday & Tuesday & Wednesday & Thursday & Friday \\
\hline 8:30-9:30 Am Pacific & 8:30-9:30 am Pacific & 8:30-9:30 am Pacific & 8:30-9:30 am Pacific & 8:30-9:30 am Pacific \\
\hline What Have We Learned & Machine Learning. K. & Effective Earthquake & The Future of Geodesy. & COVID-19 Lockdown \\
\hline About the Earth's & Bergen; D. Trugman; Q. & Communication. Xyoli & D. Goldberg; D. Melgar; & and Seismology. T. \\
\hline Interior from Seismology & Kong; W. R. Walter & Pérez-Campos & D. Schmidt; M. Shirzaei & Lecocq; E. Larose; M. \\
\hline in the Last 40 Years?: & & & & Miller; S. Subedi; Z \\
\hline Barbara Romanowicz & & & & Peng \\
\hline 9:45-11:00 Aм Pacific & 9:45-11:00 Aм Pacific & 9:45-11:00 Aм Pacific & 9:45-11:00 am Pacific & 9:45-11:00 Am Pacific \\
\hline Oral Session & Oral Session & Oral Session & Oral Session & Oral Session \\
\hline 11:00-11:30 am Pacific & 11:00-11:30 am Pacific & 11:00-11:30 am Pacific & 11:00-11:30 am Pacific & 11:00-11:30 am Pacific \\
\hline Oral Session Discussion & Oral Session Discussion & Oral Session Discussion & Oral Session Discussion & Oral Session Discussion \\
\hline 11:30 AM-12:30 PM Pacific & 11:30 AM-12:30 PM Pacific & 11:30 AM-12:30 PM Pacific & 11:30 AM-12:30 PM Pacific & 11:30 AM-12:30 PM Pacific \\
\hline Poster Session & Poster Session & Poster Session & Poster Session & Poster Session \\
\hline 12:30-1:30 pm Pacific & 12:30-2:15 PM Pacific & 12:30-1:30 PM Pacific & 12:30-1:30 pm Pacific & 12:30-1:30 pm Pacific \\
\hline Joyner Lecture: Are & Can We Talk? A Film & Innovation Showcase & Rules and Outliers & Seismology Career \\
\hline Small Earthquakes a Big & and Live Discussion led & & in Seismology. Hiroo & Panel: Yanet Cuddus, \\
\hline Deal?: Julian J. Bommer & by Kendall Moore & & Kanamori & $\begin{array}{l}\text { Ivan Wong, Jiayi Xie, } \\
\text { Brian Young }\end{array}$ \\
\hline 1:30-2:00 pM Pacific & & 1:30-2:00 pm Pacific & 1:30-2:00 pm Pacific & 1:30-2:00 pM Pacific \\
\hline$\underline{B r e a k}$ & & Break & Break & Break \\
\hline 2:00-3:15 pM Pacific & & 2:00-3:15 pM Pacific & 2:00-3:15 pm Pacific & 2:00-3:15 pm Pacific \\
\hline \multirow[t]{3}{*}{ Oral Session } & 2:15-2:30 pm Pacific & Oral Session & Oral Session & Oral Session \\
\hline & Break & & & \\
\hline & 2:30-3:45 pM Pacific & & & \\
\hline 3:15-3:45 PM Pacific & Oral Session & 3:15-3:45 PM Pacific & 3:15-3:45 pM Pacific & 3:15-3:45 pm Pacific \\
\hline Oral Session Discussion & & Oral Session Discussion & Oral Session Discussion & Oral Session Discussion \\
\hline 3:45-4:45 pM Pacific & 3:45-4:15 PM Pacific & 3:45-4:45 PM Pacific & 3:45-4:45 pM Pacific & 3:45-4:45 pM Pacific \\
\hline \multirow[t]{2}{*}{ Poster Session } & Oral Session Discussion & Poster Session & Poster Session & Poster Session \\
\hline & 4:15-5:15 pM Pacific & & & \\
\hline \multicolumn{5}{|l|}{ 4:30-4:45 pM Pacific } \\
\hline \multirow{2}{*}{\multicolumn{5}{|c|}{$\begin{array}{l}\text { President's Address, } \\
\text { William R. Walter }\end{array}$}} \\
\hline & & & & \\
\hline 5-6:15 PM Pacific & & 5-6:15 PM Pacific & 5-6:15 PM Pacific & \\
\hline \multirow[t]{2}{*}{ Oral Session } & & Oral Session & Oral Session & \\
\hline & 5:30-6:45 pM Pacific & & & \\
\hline 6:15-6:45 PM Pacific & Oral Session & 6:15-6:45 pM Pacific & 6:15-6:45 pM Pacific & \\
\hline Oral Session Discussion & & Oral Session Discussion & Oral Session Discussion & \\
\hline
\end{tabular}

6:45-7:15 PM Pacific

Oral Session Discussion 


\section{Monday, 19 April}

\section{Morning Oral Session}

9:45-11:30 Am Pacific

- Exploring Rupture Dynamics and Seismic Wave Propagation Along Complex Fault Systems I

- Explosion Seismology Applications and Advances I

- New Insights Into the Preparatory Phase of Earthquakes From Tectonic, Field and Lab Experiments I

- Seismic Hazard Analysis for Critical Infrastructure

- Subduction Processes Along Latin America Subduction Zones I

- The UN Decade of Ocean Science for Sustainable Development and Seismology

- When Seismology Meets Machine Learning, Data Science, HPC, Cloud Computing and Beyond I

\section{Morning Poster Session}

11:30 AM-12:30 PM Pacific

- Back to the Future: Innovative New Research with Legacy Seismic Data

- Beyond Poisson: Seismic Hazards and Risk Assessment for the Real Earth

- Explosion Seismology Applications and Advances

- Subduction Processes Along Latin America Subduction Zones

- The UN Decade of Ocean Science for Sustainable Development and Seismology

\section{Early Afternoon Oral Session}

2:00-3:45 PM Pacific

- Beyond Poisson: Seismic Hazards and Risk Assessment for the Real Earth

- Explosion Seismology Applications and Advances II

- Mechanisms of Induced Seismicity: Pressure Diffusion, Elastic Stressing and Aseismic Slip I

- New Insights Into the Preparatory Phase of Earthquakes From Tectonic, Field and Lab Experiments II

- Subduction Processes Along Latin America Subduction Zones II

- When Seismology Meets Machine Learning, Data Science, HPC, Cloud Computing and Beyond II

\section{Afternoon Poster Session}

\section{3:45-4:45 Pм Pacific}

- Exploring Rupture Dynamics and Seismic Wave Propagation Along Complex Fault Systems

- Modern Geodesy for Observation and Its Modeling of Earthquake Deformation

- New Insights Into the Preparatory Phase of Earthquakes From Tectonic, Field and Lab Experiments

- Seismic Hazard Analysis for Critical Infrastructure

- When Seismology Meets Machine Learning, Data Science, HPC, Cloud Computing and Beyond

\section{Late Afternoon Oral Session}

5:00-6:45 Pм Pacific

- Back to the Future: Innovative New Research with Legacy Seismic Data

- Data Fusion and Uncertainty Quantification in Shallow Crust Characterization and Modeling

- Earthquake Early Warning System in the Americas: The On-Going Effort and the State of the Art I

- Mechanisms of Induced Seismicity: Pressure Diffusion, Elastic Stressing and Aseismic Slip II

- Modern Geodesy for Observation and Its Modeling of Earthquake Deformation

- New Insights Into the Preparatory Phase of Earthquakes From Tectonic, Field and Lab Experiments III

- When Seismology Meets Machine Learning, Data Science, HPC, Cloud Computing and Beyond III 


\section{Tuesday, 20 April}

\section{Morning Oral Session}

9:45-11:30 am Pacific

- Amphibious Seismic Studies of Plate Boundary Structure and Processes

- Constructing and Testing Regional and Global Earthquake Forecasts I

- Earthquake Early Warning System in the Americas: The On-Going Effort and the State of the Art II

- Exploring Rupture Dynamics and Seismic Wave Propagation Along Complex Fault Systems II

- How Well Can We Assess Site Effects So Far? I

- Infrasound and the Seismo-Acoustic Wavefield I

- Probabilistic Seismic Hazard Assessment: Where Do We Go from Here? I

- Tectonics, Seismicity and Recent Significant Events in the Caribbean

\section{Morning Poster Session}

11:30 AM-12:30 Рм Pacific

- Constructing and Testing Regional and Global Earthquake Forecasts

- Earthquake Early Warning System in the Americas: The On-Going Effort and the State of the Art

- Earthquake Science, Hazards and Policy in Cascadia

- Intermountain West Earthquakes in the Spring of 2020

- Probabilistic Seismic Hazard Assessment: Where Do We Go from Here?

- Tectonics, Seismicity and Recent Significant Events in the Caribbean

\section{Early Afternoon Oral Session}

2:30-4:15 PM Pacific

- Earthquake Science, Hazards and Policy in Cascadia I

- How Well Can We Assess Site Effects So Far? II

- Intermountain West Earthquakes in the Spring of 2020 I

- Mechanisms of Induced Seismicity: Pressure Diffusion, Elastic Stressing and Aseismic Slip III

- Probabilistic Seismic Hazard Assessment: Where Do We Go from Here? II

- Utilizing Earthscope and AACSE Datasets in Alaska and Canada to Unravel Earth Science Mysteries

\section{Afternoon Poster Session}

\section{4:15-5:15 PM Pacific}

- Amphibious Seismic Studies of Plate Boundary Structure and Processes

- Effects and Uses of Aseismic Deformation and Fault Creep in Seismic Hazard and Warning

- Infrasound and the Seismo-Acoustic Wavefield

- Mechanisms of Induced Seismicity: Pressure Diffusion, Elastic Stressing and Aseismic Slip

- Recent Development in Ultra-Dense Seismic Arrays with Nodes and Distributed Acoustic Sensing

- Utilizing Earthscope and AACSE Datasets in Alaska and Canada to Unravel Earth Science Mysteries

\section{Late Afternoon Oral Session}

\section{5:30-7:15 Pм Pacific}

- Earthquake Science, Hazards and Policy in Cascadia II

- Effects and Uses of Aseismic Deformation and Fault Creep in Seismic Hazard and Warning

- Intermountain West Earthquakes in the Spring of 2020 II

- Mechanisms of Induced Seismicity: Pressure Diffusion, Elastic Stressing and Aseismic Slip IV

- Recent Development in Ultra-Dense Seismic Arrays with Nodes and Distributed Acoustic Sensing 


\section{Wednesday, 21 April}

\section{Morning Oral Session}

9:45-11:30 Aм Pacific

- Advances in Upper Crustal Geophysical Characterization I

- Constructing and Testing Regional and Global Earthquake Forecasts II

- Cryptic Faults: Assessing Seismic Hazard on Slow Slipping, Blind or Distributed Fault Systems I

- Infrasound and the Seismo-Acoustic Wavefield II

- Inspiring a New Generation of Seismology Leaders

- Overdue?

- Updating the US National Seismic Hazard Models I

- What Can We Infer About the Earthquake Source Through Analyses of Strong Ground Motion? I

\section{Morning Poster Session}

11:30 AM-12:30 PM Pacific

- The 2020 Simeonof Island, Alaska, Earthquake: Observations, Modeling and Tectonic Insights

- Advances in Upper Crustal Geophysical Characterization

- Application of Remote Sensing and Space-Based Earth Observations Data in Earthquake Research

- Cryptic Faults: Assessing Seismic Hazard on Slow Slipping, Blind or Distributed Fault Systems

- Sensors, Seismicity and Imaging

- Updating the US National Seismic Hazard Models

\section{Early Afternoon Oral Session}

2:00-3:45 PM Pacific

- Advances in Upper Crustal Geophysical Characterization II

- Cryptic Faults: Assessing Seismic Hazard on Slow Slipping, Blind or Distributed Fault Systems II

- How Well Can We Assess Site Effects So Far? III

- Strategies and Actions for Fostering a Diverse Seismology Community

- Tsunami Warning System in Latin America and the Caribbean: COVID-19 Challenges

- Updating the US National Seismic Hazard Models II

- Waveform Cross-Correlation-Based Methods in Observational Seismology I

- What Can We Infer About the Earthquake Source Through Analyses of Strong Ground Motion? II

\section{Afternoon Poster Session}

3:45-4:45 Pм Pacific

- How Well Can We Assess Site Effects So Far?

- Waveform Cross-Correlation-Based Methods in Observational Seismology

- What Can We Infer About the Earthquake Source Through Analyses of Strong Ground Motion?

\section{Late Afternoon Oral Session}

5:00-6:45 PM Pacific

- The 2020 Simeonof Island, Alaska, Earthquake: Observations, Modeling and Tectonic Insights

- Application of Remote Sensing and Space-Based Earth Observations Data in Earthquake Research I

- How Well Can We Assess Site Effects So Far? IV

- Sensors, Seismicity and Imaging

- Updating the US National Seismic Hazard Models III

- Waveform Cross-Correlation-Based Methods in Observational Seismology II 


\section{Thursday, 22 April}

\section{Morning Oral Session}

9:45-11:30 Aм Pacific

- Advances in the Science and Observation of Tsunamis

- Advances in Understanding Near-Field Ground Motions: Observation, Prediction and Application I

- Constructing and Testing Regional and Global Earthquake Forecasts III

- Crustal Stress and Strain and Implications for Fault Interaction and Slip I

- Fault Displacement Hazard: New Data and Modeling Advances I

- Imaging Incipient and Fossil Subduction Zones

- Infrasound and the Seismo-Acoustic Wavefield III

- Network Seismology: Keeping the Network Running While Integrating New Technologies I

\section{Morning Poster Session}

11:30 AM-12:30 PM Pacific

- The 7 January 2020 South of Indios (M6.4) Earthquake in Puerto Rico, Response and Lessons

- Advances in Seismic Interferometry: Theory, Computation and Applications

- Advances in Understanding Near-Field Ground Motions: Observation, Prediction and Application

- Crustal Stress and Strain and Implications for Fault Interaction and Slip

- Network Seismology: Keeping the Network Running While Integrating New Technologies

- Recent Engineering Uses of National Seismic Hazard Models

\section{Early Afternoon Oral Session}

2:00-3:45 PM Pacific

- The 7 January 2020 South of Indios (M6.4) Earthquake in Puerto Rico, Response and Lessons

- Advances in Understanding Near-Field Ground Motions: Observation, Prediction and Application II

- Analyses and Implications of the 4 August 2020 Beirut Explosion Series I

- Crustal Stress and Strain and Implications for Fault Interaction and Slip II

- Network Seismology: Keeping the Network Running While Integrating New Technologies II

- Physics-Based Earthquake Rupture Modeling and Strong Motion Simulations I

- Recent Engineering Uses of National Seismic Hazard Models I

\section{Afternoon Poster Session}

3:45-4:45 PM Pacific

- Advances in the Science and Observation of Tsunamis

- Critical Zone, Environmental and Cryospheric Seismology

- Fault Displacement Hazard: New Data and Modeling Advances

- Imaging Incipient and Fossil Subduction Zones

- Physics-Based Earthquake Rupture Modeling and Strong Motion Simulations

\section{Late Afternoon Oral Session}

5:00-6:45 PM Pacific

- Advances in Real-Time Geophysical Network Operations and Data Analytics

- Advances in Seismic Interferometry: Theory, Computation and Applications

- Application of Remote Sensing and Space-Based Earth Observations Data in Earthquake Research II

- Critical Zone, Environmental and Cryospheric Seismology

- Recent Engineering Uses of National Seismic Hazard Models II 


\section{Friday, 23 April}

\section{Morning Oral Session}

9:45-11:30 Aм Pacific

- Analyses and Implications of the 4 August 2020 Beirut Explosion Series II

- Earthquake Early Warning Live in California! Current Status and Challenges I

- Fault Displacement Hazard: New Data and Modeling Advances II

- Fiber-Optic Seismology I

- How Should Low-Probability Earthquakes be Considered in Hazard Assessments?

- Numerical Modeling of Earthquake Motion, Rupture Dynamics, Seismic Noise, Wave Propagation and Inverse Problems I

- Strong-Motion Data Processing and Dissemination: State-of-the-Art and Outlook

- Tectonics and Seismicity of Stable Continental Interiors I

\section{Morning Poster Session}

11:30 AM-12:30 PM Pacific

- Analyses and Implications of the 4 August 2020 Beirut Explosion Series

- Earthquake Early Warning Live in California! Current Status and Challenges

- Fiber-Optic Seismology I

- Insight Seismology on Mars: Results From the First Martian Year of Data and Prospects for the Future

- Strong-Motion Data Processing and Dissemination: State-of-the-Art and Outlook

- Tectonics and Seismicity of Stable Continental Interiors I

- Towards an Integrated View of Earthquake Gates From Geologic Observations and Numerical Models

\section{Early Afternoon Oral Session}

2:00-3:45 рм Pacific

- Applications and Technologies in Large-Scale Seismic Analysis

- Earthquake Early Warning Live in California! Current Status and Challenges II

- Fiber-Optic Seismology II

- Insight Seismology on Mars: Results From the First Martian Year of Data and Prospects for the Future

- Numerical Modeling of Earthquake Motion, Rupture Dynamics, Seismic Noise, Wave Propagation and Inverse Problems II

- Physics-Based Earthquake Rupture Modeling and Strong Motion Simulations II

- Tectonics and Seismicity of Stable Continental Interiors II

- Towards an Integrated View of Earthquake Gates From Geologic Observations and Numerical Models

\section{Afternoon Poster Session}

3:45-4:45 PM Pacific

- Advances in Real-Time Geophysical Network Operations and Data Analytics

- Fiber-Optic Seismology II

- Numerical Modeling of Earthquake Motion, Rupture Dynamics, Seismic Noise, Wave Propagation and Inverse Problems

- Tectonics and Seismicity of Stable Continental Interiors II 


\section{Program for 2021 SSA Annual Meeting}

Presenting author is indicated in bold.

\section{Monday, 19 April 2021-Morning Oral Session}

\begin{tabular}{|c|c|c|c|c|}
\hline \multirow[t]{2}{*}{$\begin{array}{l}\text { 8:30-9:30 } \\
\text { AM Pacific }\end{array}$} & \multicolumn{4}{|c|}{$\begin{array}{c}\text { Opening Keynote: What Have We Learned About the Earth's Interior from Seismology in the Last } 40 \text { Years? } \\
\text { Barbara Romanowicz, University of California, Berkeley }\end{array}$} \\
\hline & $\begin{array}{l}\text { When Seismology Meets } \\
\text { Machine Learning, Data } \\
\text { Science, HPC, Cloud } \\
\text { Computing and Beyond I } \\
\text { (see page 1467) }\end{array}$ & $\begin{array}{l}\text { New Insights Into the } \\
\text { Preparatory Phase of } \\
\text { Earthquakes From } \\
\text { Tectonic, Field and Lab } \\
\text { Experiments I (see page } \\
1403 \text { ) }\end{array}$ & $\begin{array}{l}\text { The UN Decade of Ocean } \\
\text { Science for Sustainable } \\
\text { Development and } \\
\text { Seismology (see page } \\
1449 \text { ) }\end{array}$ & $\begin{array}{l}\text { Subduction Processes } \\
\text { Along Latin America } \\
\text { Subduction Zones I (see } \\
\text { page 1434) }\end{array}$ \\
\hline $\begin{array}{l}45 \mathrm{AM} \\
\text { acific }\end{array}$ & $\begin{array}{l}\text { Latent Crustal Fluid } \\
\text { Injection Transients in } \\
\text { Southern California } \\
\text { Viewed Through Long- } \\
\text { Duration Earthquake } \\
\text { Swarms. Ross, Z. E., } \\
\text { Cochran, E. S. }\end{array}$ & $\begin{array}{l}\text { STUDENT: Investigating } \\
\text { Earthquake Nucleation: } \\
\text { What Do Foreshocks, } \\
\text { Aftershocks and Sequences } \\
\text { Tell Us? Colquhoun, R. L., } \\
\text { Hawthorne, J. }\end{array}$ & $\begin{array}{l}\text { UN Decade of Ocean } \\
\text { Science for Sustainable } \\
\text { Development (2021- } \\
\text { 2030): An Opportunity } \\
\text { for the Transformation } \\
\text { of Seismology. Von } \\
\text { Hillebrandt-Andrade, C. }\end{array}$ & $\begin{array}{l}\text { INVITED: Synchronous } \\
\text { Seismic Sequences and } \\
\text { Slow Slip Events Along the } \\
\text { South America Subduction } \\
\text { Zone. Nocquet, J., Vaca, } \\
\text { S., Villegas-Lanza, J., Klein, } \\
\text { E., Vallee, M., et al. }\end{array}$ \\
\hline $\begin{array}{l}\text { 10:00 AM } \\
\text { Pacific }\end{array}$ & $\begin{array}{l}\text { STUDENT: Machine- } \\
\text { Learning-Facilitated } \\
\text { Earthquake Detection and } \\
\text { Characterization Near the } \\
\text { Weiyuan Shale Gas Blocks, } \\
\text { Sichuan, China. Zhou, P., } \\
\text { Ellsworth, W. L., Yang, H., } \\
\text { Tan, Y., Beroza, G. C., et al. }\end{array}$ & $\begin{array}{l}\text { Reassessing Foreshock } \\
\text { Activity in Southern } \\
\text { California. Marsan, D., } \\
\text { Moutote, L., Lengliné, O., } \\
\text { Duputel, Z. }\end{array}$ & $\begin{array}{l}\text { Science Monitoring } \\
\text { and Reliable } \\
\text { Telecommunications } \\
\text { (SMART) Subsea Cables } \\
\text { for Climate Monitoring } \\
\text { and Disaster Risk } \\
\text { Reduction: A Contribution } \\
\text { to the UN Decade } \\
\text { for Ocean Science for } \\
\text { Sustainable Development. } \\
\text { Howe, B., Barnes, C. R. }\end{array}$ & $\begin{array}{l}\text { STUDENT: Repeating } \\
\text { Earthquakes Cluster at the } \\
\text { Edge of the Afterslip in the } \\
\text { Aftermath of the } 16 \text { April } \\
2016 \text { M7.8 Pedernales } \\
\text { Earthquake in Ecuador. } \\
\text { Chalumeau, C., Agurto- } \\
\text { Detzel, H., De Barros, L., } \\
\text { Charvis, P., Galve, A., et al. }\end{array}$ \\
\hline $\begin{array}{l}\text { 10:15 AM } \\
\text { Pacific }\end{array}$ & $\begin{array}{l}\text { STUDENT: Earthquake } \\
\text { Phase Association Using a } \\
\text { Gaussian Mixture Model. } \\
\text { Zhu, W., McBrearty, I. W., } \\
\text { Mousavi, S., Ellsworth, W. } \\
\text { L., Beroza, G. C. }\end{array}$ & $\begin{array}{l}\text { STUDENT: Tracking a } \\
\text { Precursory Phase: The } \\
\text { Case of the Mw } 6.32009 \\
\text { Laquila Earthquake. } \\
\text { Cabrera, L., Poli, P., Frank, } \\
\text { W. B. }\end{array}$ & $\begin{array}{l}\text { Successfully Proven } \\
\text { Advancements in } \\
\text { Autonomous Ocean } \\
\text { Bottom Seismometers: } \\
\text { Güralp Aquarius. Reis, } \\
\text { W., Lindsey, J., Hill, P., } \\
\text { Watkiss, N. }\end{array}$ & $\begin{array}{l}\text { Small Patches of the Cocos } \\
\text { Megathrust in Mexico } \\
\text { Ruptured by the June } 2020 \\
\text { Mw 7.4 La Crucecita, } \\
\text { March } 2012 \text { Mw } 7.4 \\
\text { Ometepec and February } \\
2018 \text { Mw 7.2 Pinotepa } \\
\text { Earthquakes. Fielding, E. } \\
\text { J., Jolivet, R., Gombert, } \\
\text { B., González-Ortega, A. J., } \\
\text { Duputel, Z., et al. }\end{array}$ \\
\hline
\end{tabular}




\begin{tabular}{|c|c|c|c|}
\hline \multirow[t]{2}{*}{$\begin{array}{l}8: 30-9: 30 \\
\text { AM Pacific }\end{array}$} & \multicolumn{3}{|c|}{$\begin{array}{l}\text { Opening Keynote: What Have We Learned About the Earth's Interior from Seismology in the Last } 40 \text { Years? } \\
\text { Barbara Romanowicz, University of California, Berkeley }\end{array}$} \\
\hline & $\begin{array}{l}\text { Seismic Hazard Analysis for } \\
\text { Critical Infrastructure (see page } \\
1427 \text { ) }\end{array}$ & $\begin{array}{l}\text { Explosion Seismology Applications } \\
\text { and Advances I (see page 1355) }\end{array}$ & $\begin{array}{l}\text { Exploring Rupture Dynamics and } \\
\text { Seismic Wave Propagation Along } \\
\text { Complex Fault Systems I (see page } \\
1352 \text { ) }\end{array}$ \\
\hline $\begin{array}{l}\text { 9:45 AM } \\
\text { Pacific }\end{array}$ & $\begin{array}{l}\text { Sigma-2: Improving the Reliability } \\
\text { of Seismic Hazard Assessment for } \\
\text { Critical Facilities. Daniel, G. }\end{array}$ & $\begin{array}{l}\text { Comparing Higher-Dimensional } \\
\text { Velocity Models for Seismic } \\
\text { Location Accuracy Using a } \\
\text { Consistent Travel Time Framework. } \\
\text { Begnaud, M. L., Ballard, S., Conley, } \\
\text { A., Hammond, P., Young, C. J. }\end{array}$ & $\begin{array}{l}\text { Geometrical Fault Complexity } \\
\text { and the Rupture Dynamics of the } \\
2019 \text { M6.4 and M7.1 Ridgecrest, } \\
\text { California Earthquakes. Lozos, J., } \\
\text { Harris, R. }\end{array}$ \\
\hline $\begin{array}{l}\text { 10:00 AM } \\
\text { Pacific }\end{array}$ & $\begin{array}{l}\text { Analysis of Watts Bar Nuclear Power } \\
\text { Plant Strong-Motion Records of the } \\
\text { M } 4.412 \text { December } 2018 \text { Decatur } \\
\text { Tennessee Earthquake. Graizer, V., } \\
\text { Seber, D., Stovall, S. }\end{array}$ & $\begin{array}{l}\text { Using Empirical Source Templates as } \\
\text { Mother Wavelets in the Continuous } \\
\text { Wavelet Transform. Langston, C. A. }\end{array}$ & $\begin{array}{l}\text { INVITED: Observationally } \\
\text { Constrained Multi-Scale } \\
\text { Dynamic Rupture Modeling of } \\
\text { the } 2019 \text { Ridgecrest Earthquakes. } \\
\text { Taufiqurrahman, T., Gabriel, A., Li, } \\
\text { D., Ulrich, T., Wirp, S. A., et al. }\end{array}$ \\
\hline $\begin{array}{l}10: 15 \text { AM } \\
\text { Pacific }\end{array}$ & $\begin{array}{l}\text { Sensitivity to Optimization for } \\
\text { Scenario Maps for Performance } \\
\text { Evaluation of Distributed } \\
\text { Infrastructure. Walling, M., Kuehn, } \\
\text { N., Gregor, N., Al Atik, L., Kottke, A. }\end{array}$ & $\begin{array}{l}\text { The Finite-Interval Spectral } \\
\text { Power-A Tool for Identification of } \\
\text { Underground Cavities. Kristekova, } \\
\text { M., Kristek, J., Moczo, P., Labak, P. }\end{array}$ & $\begin{array}{l}\text { STUDENT: Frequency-Difference } \\
\text { Backprojection of Earthquakes. Neo, } \\
\text { J., Fan, W., Huang, Y., Dowling, D. } \\
\text { R. }\end{array}$ \\
\hline
\end{tabular}


Monday, 19 April (continued)

\begin{tabular}{|c|c|c|c|c|}
\hline & $\begin{array}{l}\text { When Seismology Meets } \\
\text { Machine Learning... }\end{array}$ & $\begin{array}{l}\text { New Insights Into the } \\
\text { Preparatory Phase... }\end{array}$ & $\begin{array}{l}\text { The UN Decade of Ocean } \\
\text { Science... }\end{array}$ & $\begin{array}{l}\text { Subduction Processes } \\
\text { Along Latin America... }\end{array}$ \\
\hline $\begin{array}{l}\text { 10:30 AM } \\
\text { Pacific }\end{array}$ & $\begin{array}{l}\text { Scalable Machine- } \\
\text { Learning Driven Model for } \\
\text { Declustering Earthquake } \\
\text { Catalogs. Aden-Antoniow, } \\
\text { F., Frank, W. B., Seydoux, } \\
\text { L. }\end{array}$ & $\begin{array}{l}\text { Event Detection } \\
\text { and Foreshock } \\
\text { Characterization Using the } \\
\text { Ridgecrest and San Jacinto } \\
\text { Dense Nodal Array Data. } \\
\text { Meng, H., Shearer, P. M., } \\
\text { Fan, W. }\end{array}$ & $\begin{array}{l}\text { Cabling a Tectonic Plate-A } \\
\text { Decade of Geophysical } \\
\text { Monitoring Enabled } \\
\text { Through Ocean Networks } \\
\text { Canada's Neptune } \\
\text { Observatory. Heesemann, } \\
\text { M., Diederichs, A., } \\
\text { Kukovica, J., Schlesinger, A., } \\
\text { Davis, E., et al. }\end{array}$ & $\begin{array}{l}\text { Application of ISC-PPSM } \\
\text { to Subduction Zone } \\
\text { Seismicity in South and } \\
\text { Central America. Garth, } \\
\text { T. I. M., Sigloch, K., } \\
\text { Storchak, D. A. }\end{array}$ \\
\hline $\begin{array}{l}\text { 10:45 AM } \\
\text { Pacific }\end{array}$ & $\begin{array}{l}\text { HypoSVI: Hypocenter } \\
\text { Inversion with Stein } \\
\text { Variational Inference } \\
\text { and Physics Informed } \\
\text { Neural Networks. } \\
\text { Daniel, J. D., Ross, Z. E., } \\
\text { Azizzadenesheli, K., Muir, } \\
\text { J. }\end{array}$ & $\begin{array}{l}\text { STUDENT: Geometrical } \\
\text { Implications for } \\
\text { Calibrating Acoustic } \\
\text { Sensors for Lab-Generated } \\
\text { Earthquake Sources. } \\
\text { Brotherson, L. O., } \\
\text { Faulkner, D. R., Edwards, } \\
\text { B. }\end{array}$ & $\begin{array}{l}\text { Earthscope-Oceans: } \\
\text { Closing the Oceanic } \\
\text { Coverage Gap for } \\
\text { Seismology and } \\
\text { Environmental Sensing. } \\
\text { Simons, F. J., Chen, } \\
\text { Y. J., Simon, J. D., } \\
\text { Pipatprathanporn, S., } \\
\text { Bonnieux, S., et al. }\end{array}$ & $\begin{array}{l}\text { STUDENT: Using Physics- } \\
\text { Based Models to Explore } \\
\text { Physical Controls on } \\
\text { Tsunami Earthquake } \\
\text { Generation. Meng, Q., } \\
\text { Duan, B., Luo, B. }\end{array}$ \\
\hline $\begin{array}{l}\text { 11:00-11:30 } \\
\text { AM Pacific }\end{array}$ & \multicolumn{4}{|c|}{ Oral Session Discussion } \\
\hline $\begin{array}{l}\text { 12:30 PM } \\
\text { Pacific }\end{array}$ & \multicolumn{4}{|c|}{ Morning Poster Session (see page 1252) } \\
\hline
\end{tabular}

\section{Early Afternoon Oral Session}

\begin{tabular}{|c|c|c|c|}
\hline \multirow{3}{*}{$\begin{array}{l}\text { 12:30- } \\
1: 30 \mathrm{PM} \\
\text { Pacific } \\
1: 30- \\
2: 00 \mathrm{PM} \\
\text { Pacific }\end{array}$} & \multicolumn{3}{|c|}{$\begin{array}{l}\text { Joyner Lecture: Are Small Earthquakes a Big Deal? } \\
\text { Julian J. Bommer, Imperial College London }\end{array}$} \\
\hline & \multicolumn{3}{|c|}{ Break } \\
\hline & $\begin{array}{l}\text { When Seismology Meets Machine } \\
\text { Learning, Data Science, HPC, } \\
\text { Cloud Computing and Beyond II } \\
\text { (see page 1467) }\end{array}$ & $\begin{array}{l}\text { New Insights Into the Preparatory } \\
\text { Phase of Earthquakes From } \\
\text { Tectonic, Field and Lab } \\
\text { Experiments II (see page 1403) }\end{array}$ & $\begin{array}{l}\text { Beyond Poisson: Seismic Hazards } \\
\text { and Risk Assessment for the Real } \\
\text { Earth (see page 1322) }\end{array}$ \\
\hline $\begin{array}{l}\text { 2:00 PM } \\
\text { Pacific }\end{array}$ & $\begin{array}{l}\text { STUDENT: Nature of Deep } \\
\text { Earthquakes in Pacific Plate From } \\
\text { Unsupervised Machine Learning. } \\
\text { Mao, G. L., Ferrand, T. P., Zhu, B., } \\
\text { Xi, Z., Chen, M. }\end{array}$ & $\begin{array}{l}\text { Localization of Seismicity Prior to } \\
\text { Large Earthquakes. Zaliapin, I., } \\
\text { Ben-Zion, Y. }\end{array}$ & $\begin{array}{l}\text { STUDENT: Embracing Data } \\
\text { Incompleteness for Better } \\
\text { Earthquake Forecasting. Mizrahi, } \\
\text { L., Nandan, S., Wiemer, S. }\end{array}$ \\
\hline $\begin{array}{l}2: 15 \text { PM } \\
\text { Pacific }\end{array}$ & $\begin{array}{l}\text { Identification of Repeating } \\
\text { Seismic Events Using Non-Linear } \\
\text { Dimensionality Reduction. } \\
\text { Bregman, Y., Niv, I., Ben Horin, Y., } \\
\text { Rabin, N. }\end{array}$ & $\begin{array}{l}\text { Investigating Potential Earthquake } \\
\text { Preparatory Phase From Short- } \\
\text { Term and Long-Term Seismic } \\
\text { Observations. Yao, D., Huang, Y., } \\
\text { Peng, Z., Xue, L., Fu, Y., et al. }\end{array}$ & $\begin{array}{l}\text { MMPP Models of Background } \\
\text { Seismicity: A Comparative } \\
\text { Analysis for Different Declustering } \\
\text { Algorithms. Varini, E., Peresan, A., } \\
\text { Benali, A. }\end{array}$ \\
\hline
\end{tabular}


10:30 AM

Pacific

10:45 AM

Pacific

11:00-11:30

AM Pacific

11:30 AM-

12:30 PM

Pacific
Seismic Hazard Analysis for

Critical Infrastructure...

InviTeD: Fault Displacement Hazard

Evaluation for a Gas Transmission

Pipeline: Holocene Rupture and

Paleoslip Measurements Along

Reverse Fault Splays Formed by a

Restraining Bend in the Calaveras

Fault. Givler, R. W., Madugo, C.,

Page, W., Bloszies, C., Clahan, K., et al.

How to Present and Interpret

Probabilistic Fault Displacement

Hazard Analysis (PFDHA) Results

to Improve Engineering Decision-

Making. Thompson, S. C., Zandieh,

A., Givler, R. W.
Explosion Seismology Applications and Advances I...

Examining the Complex

Relationship Between Seismic

Moment and Explosive Yield.

Pasyanos, M. E., Chiang, A., Gök,

R.

Regional-Scale Crustal and Mantle

Structure of the Western United

States From Adjoint Waveform

Tomography for Improved Source

Characterization. Rodgers, A. J.,

Krischer, L., Afanasiev, M., Boehm,

C., Chiang, A., et al.
Exploring Rupture Dynamics and Seismic Wave Propagation...

Structural Control of $2015 \mathrm{Mw}$

7.8 Gorkha Rupture. Ghosh, A.,

Mendoza, M., Douilly, R., Zhou, Y.,

Li, B.

INVITED: Geometric Controls on

Pulse-Like Rupture in a Dynamic

Model of the 2015 Gorkha

Earthquake. Wang, Y., Day, S. M.,

Denolle, $\mathrm{M}$.
Morning Poster Session (see page 1252)

Oral Session Discussion
$12: 30-$

$1: 30 \mathrm{PM}$

Pacific

$1: 30-$

2:00 PM

Pacific

2:15 PM

Pacific

\begin{tabular}{|c|c|c|}
\hline \multicolumn{3}{|c|}{$\begin{array}{l}\text { Joyner Lecture: Are Small Earthquakes a Big Deal? } \\
\text { Julian J. Bommer, Imperial College London }\end{array}$} \\
\hline \multicolumn{3}{|c|}{ Break } \\
\hline $\begin{array}{l}\text { Subduction Processes Along Latin } \\
\text { America Subduction Zones II (see } \\
\text { page 1434) }\end{array}$ & $\begin{array}{l}\text { Mechanisms of Induced } \\
\text { Seismicity: Pressure Diffusion, } \\
\text { Elastic Stressing and Aseismic Slip } \\
\text { I (see page } 1390 \text { ) }\end{array}$ & $\begin{array}{l}\text { Explosion Seismology Applications } \\
\text { and Advances II (see page 1355) }\end{array}$ \\
\hline $\begin{array}{l}\text { Cocos Tear Beneath Central- } \\
\text { Southern Mexico. Álvarez-Ruedas, } \\
\text { H. R., Pérez-Campos, X. }\end{array}$ & $\begin{array}{l}\text { INVITED: STUDENT: Constraining } \\
\text { the Stability of a Rate-and-State } \\
\text { Fault Subjected to Fluid Injection. } \\
\text { Larochelle, S., Lapusta, N., } \\
\text { Ampuero, J., Cappa, F. }\end{array}$ & $\begin{array}{l}\text { STUDENT: Developing a Joint } \\
\text { Regional Waveform-Insar Moment } \\
\text { Tensor Inversion: Application to 6th } \\
\text { North Korean Nuclear Test. Chi- } \\
\text { Duran, R., Dreger, D. S., Rodgers, } \\
\text { A. J. }\end{array}$ \\
\hline $\begin{array}{l}\text { STUDENT: Adjoint Tomography of } \\
\text { South America and Geometry of the } \\
\text { Nazca Slab. Ciardelli, C., Bozdağ, } \\
\text { E., Assumpção, M., van der Lee, S. }\end{array}$ & $\begin{array}{l}\text { STUDENT: Simulation of Sequence } \\
\text { of Induced Earthquakes and } \\
\text { Aseismic Slip Due to Injection Into } \\
\text { a Hydrologically Isolated Rate and } \\
\text { State Fault. Mia, M., Abdelmeguid, } \\
\text { M., Elbanna, A. }\end{array}$ & $\begin{array}{l}\text { Insights From the Source Physics } \\
\text { Experiment on Seismic Waves } \\
\text { Generated by Explosions. Walter, W. } \\
\text { R., Ford, S. R., Pitarka, A., Pyle, M. } \\
\text { L., Pasyanos, M. E., et al. }\end{array}$ \\
\hline
\end{tabular}




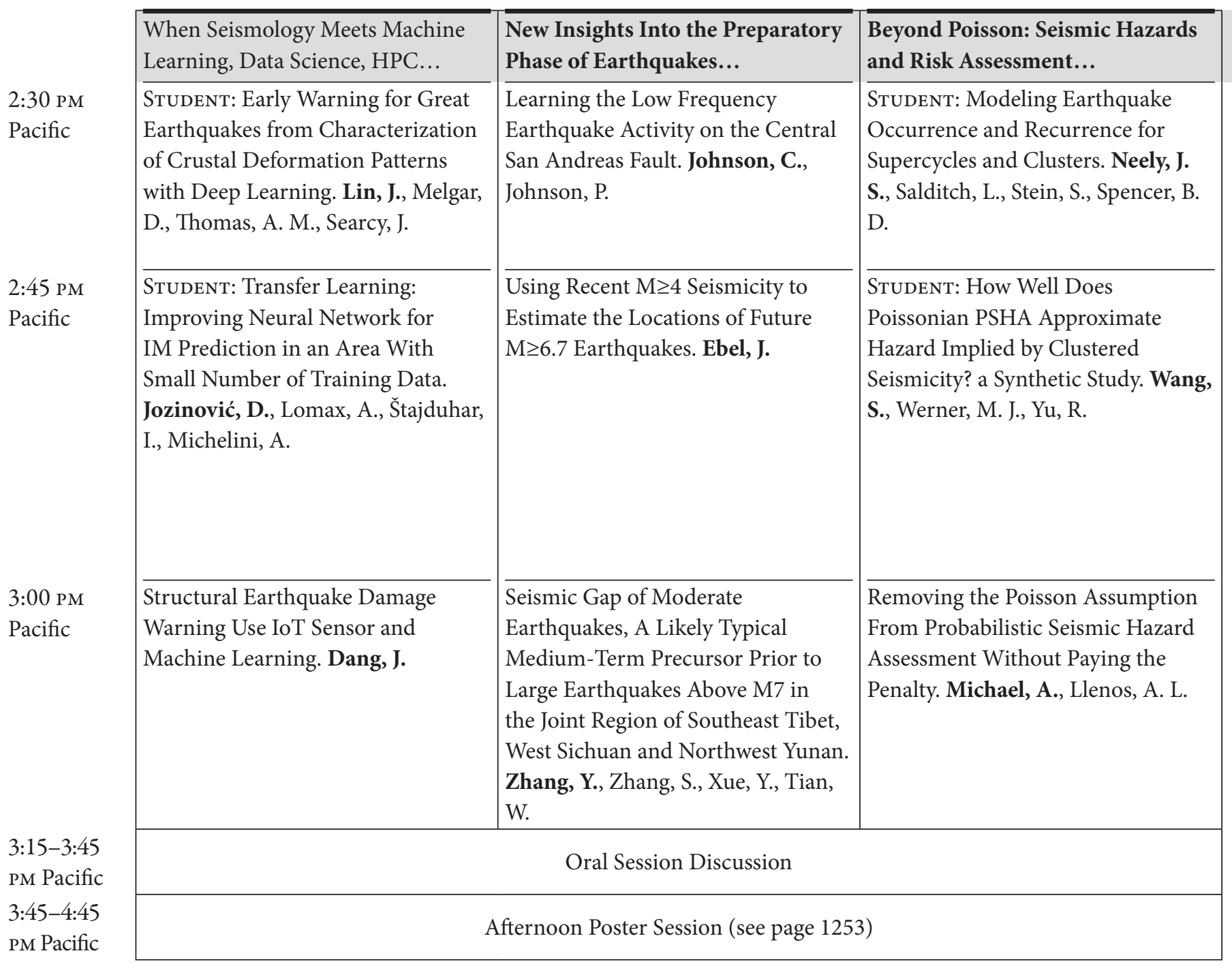

\section{Late Afternoon Oral Session}

5:00 PM Nowcasting Earthquakes:

Pacific

When Seismology Meets
Machine Learning, Data
Science, HPC, Cloud
Computing and Beyond
III (see page 1467).
Nowcasting Earthquakes:
Imaging the Earthquake
Cycle in California With
Machine Learning.
Rundle, J. B., Donnellan,
A.

A.
New Insights Into the

Preparatory Phase of

Earthquakes From

Tectonic, Field and Lab

Experiments III (see page 1403)

STUdEnT: The Accelerated

Slip Deficit Rate of the

Longmenshan Fault Plane

Before the 2008 M8.0

Wenchuan Earthquake.

Zhao, J., Yuan, Z., Yue, C.
Modern Geodesy for Observation and Its Modeling of Earthquake Deformation (see page 1396)

STUdEnT: Viscoelastic Relaxation and Afterslip Inferred From a Decade of Geodetic Measurements After the 2001 Mw7.8 Kokoxili, China Earthquake. Zhao, D., Qu, C., Shan, X., Zhang, G.
Earthquake Early Warning System in the Americas: The On-Going Effort and the State of the Art I (see page 1346)

Towards Earthquake Early Warning Across Central America. Massin, F., Böse, M., Suárez Bonilla, F., Burgoa Rosso, B., Chaves, E. J., et al. 
2:30 PM

Pacific

2:45 PM

Pacific

3:00 PM

Pacific

3:15-3:45

PM Pacific

3:45-4:45

PM Pacific
Subduction Processes Along Latin America Subduction Zones II...

Mantle Flow Pattern Through the Patagonian Slab Window and Around the South America From Shear Wave Splitting Analysis.

Ben Mansour, W., Wiens, D. A., Magnani, M., Shore, P.

Student: Caribbean Slab Dynamics Beneath Northwest South America From SKS and Local S Splitting. Cornthwaite, J., Niu, F., Levander, A., Schmitz, M., Prieto, G., et al.

\section{Student: Ongoing Deformation} and Earthquake Potential in Northwestern Colombia Due to the Slow Subduction of the Caribbean Plate Revealed by GPS Data.

Lizarazo, S. C., Sagiya, T., MoraPaez, H.
Mechanisms of Induced Seismicity...

STUDENT: Rapid Fluid Injection Into a Low Permeability Laboratory Fault Promotes Seismic Swarms. Cebry, S. B. L., McLaskey, G. C.

Student: The Combination

of Long- and Short-Period

"Deformation" Signals in Meter-

Scale Hydraulic Fractures Provides

New Insights Into the Cause of

Induced Seismicity. Niemz, P.,

Dahm, T., Milkereit, C., Cesca, S.,

Petersen, G. M., et al.

Understanding Controls on

Maximum Induced Earthquake

Magnitudes. Kroll, K., Cochran, E. S.
Explosion Seismology Applications and Advances II...

Effects of Multi-Scale Structure

on Shear Wave Generation and

Propagation Using Source Physics

Experiment Data. Chen, T., Larmat, C., Alfaro-Diaz, R. A., Rowe, C. A., Abrams, J. R., et al.

Simulation of Underground

Chemical Explosions in Soft

Alluvium, Hard Granite and Brittle

Tuff Using Anisotropic Near-

Field Hydrodynamic Generated

Source Coupled to Far-Field Linear

Anisotropic Wave Propagation.

Ezzedine, S. M., Vorobiev, O. Y., Pitarka, A., Walter, W. R., Antoun, T. $\mathrm{H}$.

Modeling Source Physics Explosions Recorded on a Distributed Fiber Optic Sensor. Mellors, R., Abbott, R. E., Steedman, D., Pitarka, A.

Oral Session Discussion

Afternoon Poster Session (see page 1253)

5:00 PM

Pacific

\begin{tabular}{l}
\hline Mechanisms of Induced \\
Seismicity: Pressure Diffusion, \\
Elastic Stressing and Aseismic Slip \\
II (see page 1390). \\
\\
\hline STUDENT: Investigating the \\
Influence of Site Effects and Spatial \\
Stacking on Source Parameter \\
Estimation for Induced Earthquakes \\
Using a Large-N Array. Chang, H., \\
Abercrombie, R. E., Nakata, N., \\
Pennington, C. N., Kemna, K. B., et \\
al.
\end{tabular}

Data Fusion and Uncertainty Quantification in Shallow Crust Characterization and Modeling (see page 1338)

Urban Seismic Site Characterization With Fiber-Optic Seismology. Beroza, G. C., Spica, Z., Perton, M., Martin, E., Biondi, B.
Back to the Future: Innovative New Research with Legacy Seismic Data (see page 1320)

Invited: Securing Seismic Legacy

Data. Hwang, L. J., Ahern, T., Ebinger, C., Ellsworth, W. L., Euler, G. G., et al. 
Monday, 19 April (continued)

\begin{tabular}{|c|c|c|c|c|}
\hline & $\begin{array}{l}\text { When Seismology Meets } \\
\text { Machine Learning... }\end{array}$ & $\begin{array}{l}\text { New Insights Into the } \\
\text { Preparatory Phase... }\end{array}$ & $\begin{array}{l}\text { Modern Geodesy for } \\
\text { Observation... }\end{array}$ & $\begin{array}{l}\text { Earthquake Early } \\
\text { Warning System... }\end{array}$ \\
\hline $\begin{array}{l}5: 15 \mathrm{PM} \\
\text { Pacific }\end{array}$ & $\begin{array}{l}\text { STUDENT: Semi-Supervised } \\
\text { Surface Wave Tomography } \\
\text { Using Wasserstein } \\
\text { Cycle-Consistent GANs: } \\
\text { Application to Southern } \\
\text { California Plate Boundary } \\
\text { Region. Cai, A., Qiu, H., } \\
\text { Niu, F. }\end{array}$ & $\begin{array}{l}\text { Migrating Foreshocks } \\
\text { Before the } 2014 \text { M6.5 } \\
\text { Ludian, Yunnan } \\
\text { Earthquake. Deng, S., } \\
\text { Jiang, H., Ma, Y., Song, J., } \\
\text { An, Y., et al. }\end{array}$ & $\begin{array}{l}\text { STUDENT: An Improved } \\
\text { Quadtree Sampling } \\
\text { Method for InSAR Seismic } \\
\text { Deformation Inversion. } \\
\text { Gao, H., Liao, M., Feng, G. }\end{array}$ & $\begin{array}{l}\text { Extending the National } \\
\text { Seismic Network in } \\
\text { Guatemala. Alvarado } \\
\text { Sosa, R., Yani Quiyuch, } \\
\text { R., Castro, D., Massin, F., } \\
\text { Clinton, J. }\end{array}$ \\
\hline $\begin{array}{l}\text { 5:30 PM } \\
\text { Pacific }\end{array}$ & $\begin{array}{l}\text { Slab Morphology at the } \\
\text { Source Region of the } 2015 \\
\text { Mw } 7.9 \text { Bonin Earthquake } \\
\text { Imaged by Full Waveform } \\
\text { Inversion. Chen, M., Xi, } \\
\text { Z., Kiser, E., Kehoe, H. }\end{array}$ & $\begin{array}{l}\text { Phenomenology and } \\
\text { Physics of Potential } \\
\text { Precursors of Earthquakes: } \\
\text { Lessons Learnt from } \\
\text { the China Seismic } \\
\text { Experimental Site (CSES). } \\
\text { Wu, Z., Zhang, Y., Zhang, } \\
\text { X., Shao, Z., Liu, J. }\end{array}$ & $\begin{array}{l}\text { INVITED: Mapping } \\
\text { Tectonic Strain in the } \\
\text { Central Alpine-Himalayan } \\
\text { Belt With Sentinel-1 Insar } \\
\text { and GNSS Observations. } \\
\text { Rollins, C. }\end{array}$ & $\begin{array}{l}\text { Developing EEW } \\
\text { Capabilities at the } \\
\text { OVSICORI Seismic } \\
\text { Processing Center. Chaves, } \\
\text { E. J., Garita, C., Protti, M., } \\
\text { Massin, F., Burgoa Rosso, } \\
\text { B., et al. }\end{array}$ \\
\hline $\begin{array}{l}5: 45 \text { PM } \\
\text { Pacific }\end{array}$ & $\begin{array}{l}\text { An EPIC Machine } \\
\text { Learning Implementation. } \\
\text { Chung, A. I., Meier, M., } \\
\text { Henson, I. }\end{array}$ & $\begin{array}{l}\text { Relocation of the } 2019 \\
\text { Changning Ms6.0 } \\
\text { Earthquake Sequence and } \\
\text { Apparent Stress Analysis. } \\
\text { Wang, Y., Ma, Y., Xie, M. }\end{array}$ & $\begin{array}{l}\text { STUDENT: A Study of } \\
\text { Faulting Near Dushanbe } \\
\text { (Tajikistan) from Time } \\
\text { Series InSAR and } \\
\text { Tectonic Geomorphology. } \\
\text { Wilkinson, R., Daout, S., } \\
\text { Ischuk, A., Johnson, B., } \\
\text { Parsons, B., et al. } \\
\end{array}$ & $\begin{array}{l}\text { Cooperation With } \\
\text { Stakeholders of the } \\
\text { Future Earthquake Early } \\
\text { Warning System (EEW) } \\
\text { in Nicaragua. Strauch, W., } \\
\text { Talavera, E. }\end{array}$ \\
\hline $\begin{array}{l}\text { 6:00 PM } \\
\text { Pacific }\end{array}$ & $\begin{array}{l}\text { Data-Driven Accelerogram } \\
\text { Synthesis Using Deep } \\
\text { Generative Models. Florez, } \\
\text { M. A., Caporale, M., } \\
\text { Buabthong, P., Ross, Z. E., } \\
\text { Asimaki, D., et al. }\end{array}$ & $\begin{array}{l}\text { Hydrochemical Variations } \\
\text { in the Pu'er Well } \\
\text { Associated With the Five } \\
\text { Earthquakes (M5.9-7.2) } \\
\text { Since } 2001 \text { to } 2018, \text { SW } \\
\text { China. Zhou, Z. H., } \\
\text { Zhong, J., Zhao, J., Yan, R., } \\
\text { Tian, L., et al. }\end{array}$ & $\begin{array}{l}\text { STUDENT: The Ambiguous } \\
\text { Fault Geometry Derived } \\
\text { From Insar Measurements } \\
\text { of Buried Thrust } \\
\text { Earthquakes: A Synthetic } \\
\text { Data Based Study. Zhang, } \\
\text { Y., Gong, W., Shan, X., } \\
\text { Zhang, G. }\end{array}$ & $\begin{array}{l}\text { An Earthquake Early } \\
\text { Warning System for } \\
\text { Northern Chile. Medina, } \\
\text { M., Sanchez, R., Riquelme, } \\
\text { S., Barrientos, S. E., } \\
\text { Henson, I., et al. }\end{array}$ \\
\hline $\begin{array}{l}6: 15- \\
6: 45 \text { PM } \\
\text { Pacific }\end{array}$ & \multicolumn{4}{|c|}{ Oral Session Discussion } \\
\hline
\end{tabular}


5:15 PM

Pacific

5:30 PM

Pacific

5:45 PM

Pacific

6:00 PM

Pacific

$6: 15-$

6:45 PM

Pacific
Mechanisms of Induced Seismicity: Pressure, Diffusion...

STUDENT: Stress Field Variations and Earthquake Source Mechanisms Associated with Wastewater Induced Seismicity in Southern Kansas, USA. Amemoutou, A., Martinez-Garzon, P., Kwiatek, G., Bohnhoff, M.

Roles of Aseismic Slip and Earthquake Interactions in the Evolution of Induced Earthquake Sequences. Chen, X., Abercrombie, R. E.

INVITED: Injection-Induced Seismicity: The Role of Poroelastic Stresses. Zhai, G., Shirzaei, M., Manga, $M$.

Distinguishing the Causal Factors of Induced Seismicity in West Texas: Hydraulic Fracturing Versus Wastewater Disposal. Grigoratos, I., Savvaidis, A., Rathje, E.
Data Fusion and Uncertainty Quantification in Shallow Crust...

Student: An H/V Geostatistical

Approach for Developing

Pseudo-3D Vs Models to Account

for Spatial Variability in Site

Response. Hallal, M. M.

Heterogeneous Data Assimilation for Site Characterization Using the Ensemble Kalman Method. Seylabi, E., Bas, E. E., Asimaki, D., Stuart, A., Yong, A.

STUdent: A Procedure for

Developing Uncertainty-Consistent Vs Profiles From Inversion of Surface Wave Dispersion Data. Vantassel, J. P., Cox, B. R.

A Gross Picture of the S-Wave Site Amplification Factors Throughout Japan Based on the Generalized Spectral Inversion and OneDimensional Theoretical Prediction. Kawase, H., Nakano, K., Ito, E., Nagashima, F.
Back to the Future: Innovative New Research with Legacy Seismic Data

Student: Can the Copy Fully Replace the Original: Fidelity of Legacy Seismic Data. Lee, T. A., Ishii, M., Okubo, P.

Source Characterization of 1944 Tonankai Earthquake from Observed and Simulated Damage Ratios Based on the Stochastic Representation of Complex Source Process and Damage Prediction Models for Old Wooden Houses. Ito, E., Nakano, K., Sekiguchi, H., Kawase, $\mathrm{H}$.

Using Legacy Data to Improve

Seismic Hazard Assessments in the Caucasus. Onur, T., Gök, R., Bondár, I., Herrera, C., Yetirmishli, G., et al.

Searching for the Oldest

Seismogram. Rademacher, $\mathbf{H}$.

\section{Oral Session Discussion}




\section{Morning Poster Session}

11:30 AM-12:30 PM Pacific

Back to the Future: Innovative New Research with Legacy Seismic Data (see page 1321)

- Creating Fair Legacy Seismic Data. Ahern, T., Hwang, L. J.

- ISC-EHB Dataset for 1964 to 2017: Complementing the Bulletin with In-House Depth Phase Picks. Sakarya, B., Engdahl, E. R., Gkarlaouni, C. G., Garth, T. I. M., Franek, P., et al.

- Reinvestigation of the Major Early to Mid 20th Century Earthquakes of Central Asia. Walker, R., Bergman, E., Gruetzner, C., Krueger, F., Kulikova, G., et al.

- Rotation and Structure of the Inner Core Illuminated by Repetitive Ancient Nuclear Tests. Vidale, J. E., Wang, W.

- Rupture History of the 1952 Kern County, California Earthquake: Application of Historical Seismic and Geodetic Datasets. Condon, S. J., Ji, C.

Beyond Poisson: Seismic Hazards and Risk Assessment for the Real Earth (see page 1323)

- Aftershocks Preferentially Occur in Previously Active Areas. Page, M. T.

- Assessing the Hazard of Highly Clustered M 5 Caldera Collapse Earthquakes in Kîlauea Volcano, Hawai'i. Llenos, A. L., Michael, A., Moschetti, M. P., Powers, P. M., McNamara, D. E., et al.

- Earthquake Rate Forecasting in New Zealand Using Multiplicative Hybrid Models Including Strain-Rate Covariates: Performance Analysis in Forward and Reverse Time. Rastin, S. J., Rhoades, D. A.

- Ensemble Earthquake Forecasting With a Logistic Regression Model. Herrmann, M., Marzocchi, W.

- Student: Improving Earthquake Doublet Rate Predictions in Etas by Using Modified Spatial Trigger Distributions. Grimm, C., Käser, M., Hainzl, S., Pagani, M., Küchenhoff, $\mathrm{H}$.

Explosion Seismology Applications and Advances (see page 1358)

- Analysis of Seismic P/S Ratios From Chemical Explosions at the Surface and Buried in Contrasting Geologies. Pyle, M. L., Walter, W. R.

- Analysis of the Source Physics Experiment, Dry Alluvium Geology Ball Drop Sources. Ford, S. R., Ichinose, G. A., Walter, W. R.

- Student: Assessing the Accuracy of a BoreholeControlled Velocity Model of Yucca Flat, Nevada Using
Large N Seismic Data. Vieceli, R. E., Abbott, R. E., Preston, L., Prothro, L.

- Damage Characterization for the SPE Phase of the Source Physics Experiment. Larmat, C., Swanson, E., Lei, Z., Crawford, B. M., Schultz-Fellenz, E., et al.

- Discrimination of Seismic Events (2006 to 2020) in North Korea Using P/Lg Amplitude Ratios from Regional Stations and a Bivariate Discriminant Function. Tibi, R.

- The Effects of 3D Heterogeneity on Regional Moment Tensor Source-Type Discrimination: Application to the Western United States. Chiang, A., Rodgers, A. J., Krischer, L., Afanasiev, M., Boehm, C., et al.

- Estimating Explosion Source Time Functions From Seismic Data: Are Linear Inversions Good Enough? Poppeliers, C., Preston, L., Eliassi, M.

- Near Field Modeling of the Large Surface Explosion Coupling Experiment (LSECE). Vorobiev, O. Y., Ford, S. R., Keehoon, K., Walter, W. R.

- Recording Tragedy: The Seismic Signal of the Arecibo Radio Telescope Collapse. Vanacore, E. A., MartinezCruzado, J. A.

- Short-Period Surface Wave Propagation in the Bighorn Mountains Region, Wyoming. Kintner, J., Cleveland, M. K., Modrak, R., Dunham, A.

Subduction Processes Along Latin America Subduction

Zones (see page 1437)

- Student: 3D Shear Velocity Structure of the Northwestern South America-Caribbean Subduction Zone From Ambient Noise and Ballistic Rayleigh Wave Tomography. Miao, W., Cornthwaite, J., Levander, A., Niu, F., Schmitz, M., et al.

- Student: A Bayesian Approach for Geodetic Data Inversion and Model Selection of the Mw 8.82010 Maule Earthquake Coseismic Slip Distribution. Nunez Jara, S., Bataille, K., Benavente, R.

- Student: Imaging the South American Active Margin and Continental Interior with Waveform Tomography. Chagas de Melo, B., Lebedev, S., Celli, N. L., De Laat, J. I., Assumpção, M.

- Student: Quantifying the Aftershock Sequences of Two Chilean Megathrust Earthquakes: The 2014 Iquique and the 2015 Illapel Events. Geng, Y., Frank, W. B., AdenAntoniow, F.

The UN Decade of Ocean Science for Sustainable Development and Seismology (see page 1450)

- Fully Integrated OBS Platform for Multi-Use Case Deployments and Future OBS Components for LongTerm Deployments. Parker, T., Perlin, M., Pelyk, N. 
- Student: Regional Pn Magnitude Scale for Earthquakes Along the Equatorial Atlantic Ocean. Sampaio de Melo, G., Kim, W.

\section{Afternoon Poster Session}

\section{3:45-4:45 PM Pacific}

Exploring Rupture Dynamics and Seismic Wave

Propagation Along Complex Fault Systems (see page 1354)

- Student: Analyzing Stress Drops and Other Earthquake Parameters from the 2019 Ridgecrest Earthquake Sequence. Rosas, V. G., Baltay, A., Abercrombie, R. E.

- Multi-Fault Rupture Plausibility Inferred From a Deterministic Earthquake Simulator. Milner, K., Shaw, B. E., Field, E. H., Jordan, T. H., Goulet, C. A.

- New Insights Into How the 2016 Mw7.8 Kaikoura (New Zealand) Multi-Fault Earthquake Nucleated, Propagated and Arrested From a Dense 10-Year Earthquake Catalog. Chamberlain, C. J., Frank, W. B., Lanza, F., Townend, J., Warren-Smith, E.

- The Relation of Fault Geometry to High-Frequency Radiation: Insights from the 2019 Ridgecrest Sequence. Chu, S., Tsai, V., Hirth, G., Trugman, D. T.

- Seismogenic Cutoff Depths and Thermal State of the Late-Interseismic Central Alpine Fault, New Zealand: Implications for Coseismic Slip in Future Large Earthquakes. Townend, J., Michailos, K., Sutherland, R., Savage, M. K., Chamberlain, C. J.

Modern Geodesy for Observation and Its Modeling of Earthquake Deformation (see page 1398)

- Student: Empirical Earthquake Scaling Relationships Derived From Geodetic Slip Distributions. Brengman, C., Barnhart, W. D.

- Student: The InSAR-Derived gCent Earthquake Catalog: August 2019-August 2020. Shea, H. N., Barnhart, W. D.

- Student: Interseismic Deformation and Fault Kinematics along the Keping Foreland Thrust-Fold Belt of the South Tian Shan from InSAR and GPS Observations. Li, C., Zhang, G., Shan, X., Zhao, D.

New Insights Into the Preparatory Phase of Earthquakes From Tectonic, Field and Lab Experiments (see page 1406)

- Analysis on Anomaly Characteristics of Litang Hot Spring Temperature Before Major Earthquakes. Tian, L., Wang, B., Zhou, Z.

- Earthquake Transformer Can be Used to Study the Fault of the Western Tibet M6.3 Earthquake, 2020. Ma, Y., Wang, $\mathrm{Y}$.
- Geochemical Characteristics of Fault Hydrogen in Aksu and its Seismic Reflection Efficiency. Wang, B., Zhong, J.

- Groundwater Level Changes in the Chinese Mainland Following the 2011 Tohoku Japan Earthquake and the 2015 Gorkha Nepal Earthquake. Ma, Y., Huang, Q. F.

- Maximum Magnitude Estimation of the Aftershocks of the M6 Earthquake Sequence, Mainland China. Xie, M., Meng, L., Han, Y., Zang, Y., Ma, Y., et al.

- Prediction of Seismicity in Sichuan-Yunnan Region Based on Several Kinds of Recurrent Neural Networks. Zang, Y.

- Research and Application of Seismological Parameter Methods in Earthquake Prediction. Han, Y., Zang, Y., Meng, L., Jiang, X., Xie, M., et al.

- The Seismic Probability of the Faults in Boundary Area of Gansu and Qinghai Provinces Influenced by the 2008 Wenchuan Mw7.9 Earthquake and the 2017 Jiuzhaigou Mw6.5 Earthquake. Song, J., Meng, L., Jiang, H., Han, Y.

Seismic Hazard Analysis for Critical Infrastructure (see page 1428)

- Magnitude Thresholds to Evaluate the Damage From Induced-Seismicity Earthquakes. Macedo, J. E., Abrahamson, N., Ramesh, V.

- Invited: Student: National Liquefaction Loss Database and Fragility Functions. Chansky, A. A.

- Response of an Asymmetrical Five-Story Building in Fairbanks, Alaska During the 30 November 2018 M7.1 Anchorage, Alaska Earthquake. Celebi, M., Ruppert, N. A.

- Scientific Strong Motion Nodes for Diverse Use Cases. Parker, T., Pelyk, N., Perlin, M.

- Student: Shallow Seismicity in Long Beach-Seal Beach Area Detected by Dense Arrays. Yang, Y., Clayton, R. W.

When Seismology Meets Machine Learning, Data Science, HPC, Cloud Computing and Beyond (see page 1471)

- Student: Application of the U-Net Neural Network Architecture to 2D Partially Non-Ergodic Ground Motion Modeling. Lilienkamp, H., von Specht, S., Weatherill, G., Cotton, F., Caire, G.

- Damage Building Detection from Crowdsourcing Images Using Transfer Learning. Chachra, G., Kong, Q., Huang, J., Korlakunta, S., Robson, A., et al.

- The Hidden Induced Seismicity in Oklahoma Revealed by Machine Learning. Ma, X., Chen, T.

- Student: Performance Evaluation of Machine Learning Phase Detection Models on a Megathrust Aftershock Sequence. Reichard-Flynn, W., Meltzer, A., Agar, J., Hoskins, M. C., Stachnik, J.

- Quality Control Seismic Waveforms Using Transfer Learning. Ortega, R., Carciumaru, D., Malagnini, L. 


\section{Tuesday, 20 April 2021—Morning Oral Session}

Presenting author is indicated in bold.

\begin{tabular}{|c|c|c|c|c|}
\hline \multirow[t]{2}{*}{$\begin{array}{l}8: 30-9: 30 \\
\text { AM Pacific }\end{array}$} & \multicolumn{4}{|c|}{$\begin{array}{c}\text { Machine Learning in Seismology: A Fireside Chat. Where are We Now and Where Are We Going? } \\
\text { Karianne Bergen, Harvard University; Qingkai Kong, University of California, Berkeley; Daniel T. Trugman, } \\
\text { University of Texas at Austin }\end{array}$} \\
\hline & $\begin{array}{l}\text { Tectonics, Seismicity and } \\
\text { Recent Significant Events } \\
\text { in the Caribbean (see page } \\
1438 \text { ) }\end{array}$ & $\begin{array}{l}\text { Probabilistic Seismic } \\
\text { Hazard Assessment: } \\
\text { Where Do We Go from } \\
\text { Here? I (see page 1417) }\end{array}$ & $\begin{array}{l}\text { Infrasound and the } \\
\text { Seismo-Acoustic } \\
\text { Wavefield I (see page } \\
1378 \text { ) }\end{array}$ & $\begin{array}{l}\text { Earthquake Early } \\
\text { Warning System in the } \\
\text { Americas: The On-Going } \\
\text { Effort and the State of the } \\
\text { Art II (see page 1342) }\end{array}$ \\
\hline $\begin{array}{l}45 \text { AM } \\
\text { cific }\end{array}$ & $\begin{array}{l}\text { Double Difference } \\
\text { Relocations of the } 2020 \\
\text { Southwestern Puerto } \\
\text { Rico Seismic Sequence. } \\
\text { Vanacore, E. A., Joyce, J., } \\
\text { Ten Brink, U., Fielding, E. } \\
\text { J., Lopez-Venegas, A. }\end{array}$ & $\begin{array}{l}\text { STUDENT: Probabilistic } \\
\text { Seismic Hazard } \\
\text { Assessment of the Eastern } \\
\text { Betics Shear Zone (SE } \\
\text { Spain) Using a Geological } \\
\text { Fault-Based Source } \\
\text { Modelling Approach. } \\
\text { Gómez-Novell, O., } \\
\text { Gracía-Mayordomo, J., } \\
\text { Ortuño, M., Masana, E., } \\
\text { Chartier, T. }\end{array}$ & $\begin{array}{l}\text { INVITED: STUDENT: A } \\
\text { Novel Approach for } \\
\text { the Reconstruction of } \\
\text { Microbarom Soundscapes. } \\
\text { den Ouden, O. F. C., } \\
\text { Smets, P. S. M., Assink, J. } \\
\text { D., Evers, L. G. }\end{array}$ & $\begin{array}{l}\text { Performance of the } \\
\text { Seismic Alert System of } \\
\text { Mexico During the } 23 \text { June } \\
\text { 2020, Oaxaca Earthquake } \\
\text { (Mw 7.4). Suarez, G., } \\
\text { Espinosa-Aranda, J., } \\
\text { Cuellar, A., Uribe, A., } \\
\text { Ibarrola, G., et al. }\end{array}$ \\
\hline $\begin{array}{l}\text { 10:00 AM } \\
\text { Pacific }\end{array}$ & $\begin{array}{l}\text { STUDENT: Characterization } \\
\text { of Swarm and Aftershock } \\
\text { Behavior in Puerto Rico. } \\
\text { Ventura-Valetin, W. A., } \\
\text { Brudzinski, M. R. }\end{array}$ & $\begin{array}{l}\text { Seismic Response of } \\
\text { Rock Towers at the Trona } \\
\text { Pinnacles, California. } \\
\text { Garcia-Suarez, J. }\end{array}$ & $\begin{array}{l}\text { The Spectrogram, Method } \\
\text { of Reassignment and } \\
\text { Frequency-Domain } \\
\text { Beamforming. Averbuch, } \\
\text { G. }\end{array}$ & $\begin{array}{l}\text { Smartphone-Based } \\
\text { Earthquake Early Warning } \\
\text { in Costa Rica. Brooks, B. } \\
\text { A., Protti, M., Ericksen, T., } \\
\text { Bunn, J., Vega, F., et al. }\end{array}$ \\
\hline $\begin{array}{l}10: 15 \text { AM } \\
\text { Pacific }\end{array}$ & $\begin{array}{l}\text { Back-Arc Tsunami Hazard } \\
\text { in the Gulf of Mexico } \\
\text { From Oaxaca Earthquakes. } \\
\text { Salaree, A., Huang, Y. }\end{array}$ & $\begin{array}{l}\text { STUDENT: Do PSHA Maps } \\
\text { Overpredict or Are There } \\
\text { Shaking Deficits in the } \\
\text { Historic Record? Salditch, } \\
\text { L., Stein, S., Gallahue, M. }\end{array}$ & $\begin{array}{l}\text { Seismo-Acoustic Data } \\
\text { Fusion: Determining } \\
\text { the Best Acquisition } \\
\text { Designs for Multi- } \\
\text { Phenomenological } \\
\text { Monitoring Campaigns. } \\
\text { Albert, S. A., Berg, E. M., } \\
\text { Brogan, R. }\end{array}$ & $\begin{array}{l}\text { Towards Performance- } \\
\text { Based Earthquake Early } \\
\text { Warning. Minson, S., } \\
\text { Cochran, E. S., Wu, S., } \\
\text { Saunders, J. K., Baltay, A., } \\
\text { et al. }\end{array}$ \\
\hline $\begin{array}{l}\text { 10:30 AM } \\
\text { Pacific }\end{array}$ & $\begin{array}{l}\text { Revision of the Earthquake } \\
\text { Source Parameters and } \\
\text { Moment Magnitude } \\
\text { of the } 7 \text { January } 2020 \\
\text { Earthquake, South of } \\
\text { Indios, Offshore Puerto } \\
\text { Rico. Huerfano, V. A., } \\
\text { Cameron, A. }\end{array}$ & $\begin{array}{l}\text { STUDENT: Site-Specific } \\
\text { Velocity Corrections Do } \\
\text { Not Improve Seismic } \\
\text { Hazard Map Performance } \\
\text { for California When } \\
\text { Compared With Historical } \\
\text { Shaking Data. Gallahue, } \\
\text { M., Salditch, L., Lucas, M. } \\
\text { C., Neely, J. S., Hough, S. } \\
\text { E., et al. }\end{array}$ & $\begin{array}{l}\text { Assessing the Temporal } \\
\text { Coherency of Infrasound } \\
\text { Generated by Repeated } \\
\text { Explosions in McAlester, } \\
\text { Oklahoma. Giannone, M., } \\
\text { Averbuch, G., Arrowsmith, } \\
\text { S., Anderson, J. }\end{array}$ & $\begin{array}{l}\text { Empowered by ShakeAlert: } \\
\text { The Development and } \\
\text { Assessment of Educational } \\
\text { Resources for Earthquake } \\
\text { Early Warning in the } \\
\text { United States. Sumy, D. } \\
\text { F., Olds, S., Magura, B., } \\
\text { Johnson, J., Crayne, J., et } \\
\text { al. }\end{array}$ \\
\hline
\end{tabular}




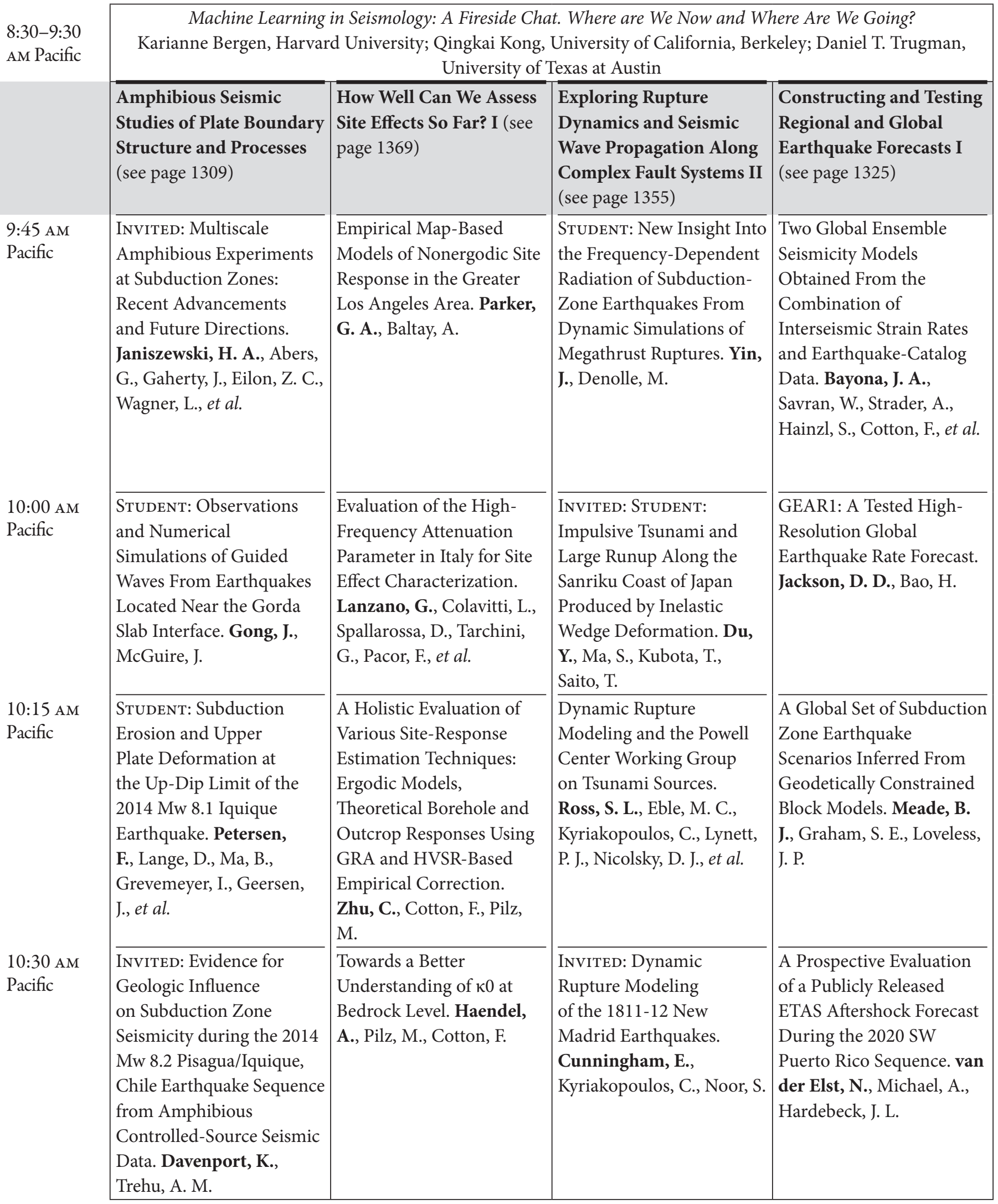


Tuesday, 20 April (continued)

\begin{tabular}{|c|c|c|c|c|}
\hline & $\begin{array}{l}\text { Tectonics, Seismicity and } \\
\text { Recent Significant... }\end{array}$ & $\begin{array}{l}\text { Probabilistic Seismic } \\
\text { Hazard Assessment... }\end{array}$ & $\begin{array}{l}\text { Infrasound and the } \\
\text { Seismo-Acoustic... }\end{array}$ & $\begin{array}{l}\text { Earthquake Early } \\
\text { Warning System... }\end{array}$ \\
\hline $\begin{array}{l}10: 45 \text { AM } \\
\text { Pacific }\end{array}$ & $\begin{array}{l}\text { Numerical Simulation of } \\
\text { Flow, Transport of Heat } \\
\text { and Chemical Transport } \\
\text { Processes in Volcanic } \\
\text { Chambers Partially } \\
\text { Filled With Molten Rock } \\
\text { and Consequence on } \\
\text { Dynamic Seismo-Acoustic } \\
\text { Signatures. Ezzedine, S. M., } \\
\text { Antoun, T. H., Walter, W. R. }\end{array}$ & $\begin{array}{l}\text { Development of a Non- } \\
\text { Ergodic GMPE for France. } \\
\text { Sung, C., Abrahamson, } \\
\text { N., Kuehn, N., Traversa, P., } \\
\text { Zentner, I. }\end{array}$ & $\begin{array}{l}\text { Thousands of Explosion- } \\
\text { Triggered Seismo- } \\
\text { Acoustic Waveforms Over } \\
\text { Oklahoma for Studying } \\
\text { Multi-Scale Atmospheric } \\
\text { Variability. Carmichael, J. } \\
\text { D., Thiel, A., Dannemann } \\
\text { Dugick, F. K., Walter, J., } \\
\text { Arrowsmith, S., et al. }\end{array}$ & $\begin{array}{l}\text { Low-Latency Digitization, } \\
\text { Communication and } \\
\text { Alerting for Earthquake } \\
\text { Early Warning Systems: } \\
\text { Güralp Minimus. Reis, } \\
\text { W., Lindsey, J., Hill, P., } \\
\text { Watkiss, N. }\end{array}$ \\
\hline $\begin{array}{l}\text { 11:00-11:30 } \\
\text { AM Pacific }\end{array}$ & \multicolumn{4}{|c|}{ Oral Session Discussion } \\
\hline $\begin{array}{l}12: 30 \mathrm{PM} \\
\text { Pacific }\end{array}$ & \multicolumn{4}{|c|}{ Morning Poster Session (see page 1260) } \\
\hline
\end{tabular}

\section{Early Afternoon Oral Session}

\begin{tabular}{|c|c|c|c|}
\hline \multirow{3}{*}{$\begin{array}{l}\text { 12:30- } \\
2: 15 \mathrm{PM} \\
\text { Pacific } \\
2: 15- \\
2: 30 \mathrm{PM} \\
\text { Pacific }\end{array}$} & \multicolumn{3}{|c|}{$\begin{array}{l}\text { Can We Talk? } \\
\text { Film and Discussion with Kendall Moore, University of Rhode Island }\end{array}$} \\
\hline & & Break & \\
\hline & $\begin{array}{l}\text { Earthquake Science, Hazards and } \\
\text { Policy in Cascadia I (see page 1346) }\end{array}$ & $\begin{array}{l}\text { Probabilistic Seismic Hazard } \\
\text { Assessment: Where Do We Go } \\
\text { from Here? II (see page } 1417 \text { ) }\end{array}$ & $\begin{array}{l}\text { Utilizing Earthscope and AACSE } \\
\text { Datasets in Alaska and Canada to } \\
\text { Unravel Earth Science Mysteries } \\
\text { (see page } 1457 \text { ) }\end{array}$ \\
\hline $\begin{array}{l}2: 30 \mathrm{PM} \\
\text { Pacific }\end{array}$ & $\begin{array}{l}\text { INVITED: Using Deep Learning } \\
\text { to Identify Small Magnitude } \\
\text { Earthquakes in } 32 \mathrm{~TB} \text { of Continuous } \\
\text { Seismic Data from the Pacific } \\
\text { Northwest. Thomas, A. M., Searcy, J. }\end{array}$ & $\begin{array}{l}\text { Maximum Shaking Earthquake } \\
\text { Catalog: A Ground-Motion Based } \\
\text { Procedure to Select Earthquakes } \\
\text { That Are Relevant to the Seismic } \\
\text { Hazard. Anderson, J. G., Cotton, F., } \\
\text { Bindi, D. }\end{array}$ & $\begin{array}{l}\text { STUDENT: Radial and Azimuthal } \\
\text { Anisotropy of Alaskan Lithosphere } \\
\text { Revealed by Multi-Component } \\
\text { Ambient-Noise Adjoint } \\
\text { Tomography. Liu, T., Wang, K., } \\
\text { Tape, C., He, B., Yang, Y., et al. }\end{array}$ \\
\hline $\begin{array}{l}2: 45 \text { PM } \\
\text { Pacific }\end{array}$ & $\begin{array}{l}\text { Using Small Earthquakes and the } \\
\text { Amphibious Cascadia Initiative } \\
\text { Dataset to Probe Cascadia } \\
\text { Subduction Zone Heterogeneities. } \\
\text { Morton, E. A., Bilek, S. L., Rowe, } \\
\text { C. A. }\end{array}$ & $\begin{array}{l}\text { STUDENT: Regional Path Effects } \\
\text { for Ground Motion Analysis in } \\
\text { Sacramento-San Joaquin River } \\
\text { Delta, California. Buckreis, T. E., } \\
\text { Brandenberg, S. J., Stewart, J. P. }\end{array}$ & $\begin{array}{l}\text { STUDENT: Plate-Bending } \\
\text { Extensional Earthquake Depths } \\
\text { Constrain Hydration at the Alaska } \\
\text { Subduction Zone. Matulka, P., Li, } \\
\text { Z., Wiens, D. A. }\end{array}$ \\
\hline $\begin{array}{l}\text { 3:00 PM } \\
\text { Pacific }\end{array}$ & $\begin{array}{l}\text { Sensitivity Testing of Cascadia } \\
\text { Marine Turbidite Ages and } \\
\text { Comparison With Onshore } \\
\text { Megathrust Evidence. Staisch, L. M., } \\
\text { Goldfinger, C. }\end{array}$ & $\begin{array}{l}\text { STUDENT: Exploring Probabilistic } \\
\text { Seismic Hazard Assessment in the } \\
\text { Energy Domain. Ziebarth, M. J., } \\
\text { Anderson, J. G., Cotton, F., von } \\
\text { Specht, S., Heidbach, O. }\end{array}$ & $\begin{array}{l}\text { Along-Strike Variations of } \\
\text { Intermediate-Depth Seismicity } \\
\text { Along the Alaska Peninsula. Wei, S., } \\
\text { Gable, S., Ruppert, N. A., Zhang, H. }\end{array}$ \\
\hline
\end{tabular}


10:45 AM

Pacific

11:00-11:30

AM Pacific

11:30 AM-

12:30 PM

Pacific

\section{Amphibious Seismic}

Studies of Plate...

Shallow Deformation

Features of the Imperial

and Michoacán Fault

Systems From Subsurface

Imaging. Sahakian, V.,

Derosier, B., Rockwell, T.

K., Stock, J., Driscoll, N.
How Well Can We Assess

Site Effects So Far? I...

Assessing One-

Dimensional Site Response

From Single-Station

Earthquake Records. Pilz,

M., Cotton, F., Zhu, C.
Exploring Rupture

Dynamics...

STUDENT: A Joint

Dynamic Model of Seismic

and Postseismic Slip of

the 2014 South Napa

Earthquake. Premus, J.,

Gallovič, F., Ampuero, J.
Constructing and Testing Regional...

STUdENT: Bayesian

Etas: Towards Improved

Earthquake Rate Models

in the Pacific Northwest.

Schneider, M., Guttorp, P.

Morning Poster Session (see page 1260)

$12: 30-$

2:15 PM

Pacific

2:15-

2:30 PM

Pacific

2:30 PM

Pacific

2:45 PM

Pacific

3:00 PM

Pacific

\begin{tabular}{|c|c|c|}
\hline \multicolumn{3}{|c|}{$\begin{array}{l}\text { Can We Talk? } \\
\text { Film and Discussion with Kendall Moore, University of Rhode Island }\end{array}$} \\
\hline \multicolumn{3}{|c|}{ Break } \\
\hline $\begin{array}{l}\text { Intermountain West Earthquakes } \\
\text { in the Spring of } 2020 \text { I (see page } \\
\text { 1386) }\end{array}$ & $\begin{array}{l}\text { Mechanisms of Induced } \\
\text { Seismicity: Pressure Diffusion, } \\
\text { Elastic Stressing and Aseismic Slip } \\
\text { III (see page 1390) }\end{array}$ & $\begin{array}{l}\text { How Well Can We Assess Site } \\
\text { Effects So Far? II (see page 1369) }\end{array}$ \\
\hline $\begin{array}{l}\text { Backprojection Imaging of the } 2020 \\
\text { Mw } 5.5 \text { Magna, Utah Earthquake. } \\
\text { Mesimeri, M., Zhang, H., Pankow, } \\
\text { K. L. }\end{array}$ & $\begin{array}{l}\text { The Importance of Accurate } \\
\text { Earthquake Source Information for } \\
\text { Understanding the Cause of Induced } \\
\text { Seismicity: The Case of Mentone } \\
\text { M4.9 Earthquake in West Texas. } \\
\text { Savvaidis, A., Hicks, S., Lomax, A., } \\
\text { Shirley, M. }\end{array}$ & $\begin{array}{l}\text { Characterization of Hard Rock } \\
\text { Site Effects on Ground Motions } \\
\text { in Western Canada. Hassani, B., } \\
\text { Atkinson, G. M., Stewart, J. P., } \\
\text { Fairhurst, M., Sheffer, M., et al. }\end{array}$ \\
\hline $\begin{array}{l}\text { Geologic Effects of the } 18 \text { March } \\
\text { 2020, Mw } 5.7 \text { Magna, Utah, } \\
\text { Earthquake. Kleber, E. J., Hiscock, } \\
\text { A. I., McDonald, G. N., Giraud, R. } \\
\text { E., Erickson, B. A., et al. }\end{array}$ & $\begin{array}{l}\text { What Induced Seismicity From CO2 } \\
\text { Injection Can Tell Us About Fluid } \\
\text { Migration Pathways. Williams- } \\
\text { Stroud, S., Leetaru, H., Bauer, R., } \\
\text { Greenberg, S., Langet, N. }\end{array}$ & $\begin{array}{l}\text { An Overview of the National } \\
\text { Academies-Sponsored Project: } \\
\text { Guidance on Seismic Site Response } \\
\text { Analysis With Pore Water Pressure } \\
\text { Generation (NCHRP 12-114). } \\
\text { Matasovic, N. }\end{array}$ \\
\hline $\begin{array}{l}\text { Robust Estimates of Moment } \\
\text { Magnitude for Small- to Moderate- } \\
\text { Size Aftershocks of the Mw } 5.7 \\
\text { Magna, Utah Earthquake. Holt, } \\
\text { J., Whidden, K. M., Koper, K. D., } \\
\text { Pankow, K. L., Mayeda, K., et al. }\end{array}$ & $\begin{array}{l}\text { Insights on the Criticality of Faults } \\
\text { From Dense Monitoring of Induced } \\
\text { Seismicity from Moment Tensor } \\
\text { Based Stress Inversion. Baig, A. }\end{array}$ & $\begin{array}{l}\text { Smooth Crustal Seismic Velocity } \\
\text { Models Cause a Depletion of High- } \\
\text { Frequency Ground Motions on Soil. } \\
\text { Huang, Y. }\end{array}$ \\
\hline
\end{tabular}




\begin{tabular}{|c|c|c|c|}
\hline & $\begin{array}{l}\text { Earthquake Science, Hazards and } \\
\text { Policy in Cascadia I... }\end{array}$ & $\begin{array}{l}\text { Probabilistic Seismic Hazard } \\
\text { Assessment: Where Do We Go... }\end{array}$ & $\begin{array}{l}\text { Utilizing Earthscope and AACSE } \\
\text { Datasets in Alaska and Canada... }\end{array}$ \\
\hline $\begin{array}{l}\text { 3:15 PM } \\
\text { Pacific }\end{array}$ & $\begin{array}{l}\text { The } 26 \text { January } 1700 \text { Cascadia } \\
\text { Earthquake as Part of an Event } \\
\text { Sequence. Melgar, D. }\end{array}$ & $\begin{array}{l}\text { The Internet Application of the } \\
\text { Current Version of the Mexico } \\
\text { City Building Code to Compute } \\
\text { Earthquake Design Spectra and } \\
\text { Strong Ground Motion Records } \\
\text { for Non-Linear Time History } \\
\text { Analysis. Ordaz, M. G., Arroyo, D., } \\
\text { Velazquez, J., Velazquez, M. }\end{array}$ & $\begin{array}{l}\text { STUDENT: Crust and Uppermost } \\
\text { Mantle Structure of the Alaska } \\
\text { Subduction Zone From Joint } \\
\text { Inversion of Rayleigh Wave } \\
\text { Dispersion and Receiver Functions. } \\
\text { Li, Z., Wiens, D. A., Shen, W. }\end{array}$ \\
\hline $\begin{array}{l}\text { 3:30 PM } \\
\text { Pacific }\end{array}$ & $\begin{array}{l}\text { Most Hazardous Segments of the } \\
\text { Cascadia Rupture-Challenging the } \\
\text { Worst-Case Scenario. Salaree, A., } \\
\text { Huang, Y., Ramos, M., Stein, S. }\end{array}$ & $\begin{array}{l}\text { STUDENT: Impact of Declustering } \\
\text { on Probabilistic Seismic Hazard } \\
\text { Estimates in the United States. } \\
\text { Maher, E. L., Zaliapin, I., Anderson, } \\
\text { J. G. }\end{array}$ & $\begin{array}{l}\text { Imaging the Magma Plumbing } \\
\text { System Beneath Mount Cleveland } \\
\text { Volcano, Alaska Using Ps-P } \\
\text { Crustal Tomography. Portner, D. } \\
\text { E., Wagner, L., Janiszewski, H. A., } \\
\text { Roman, D. C., Power, J. A. }\end{array}$ \\
\hline $\begin{array}{l}3: 45-4: 15 \\
\text { PM Pacific }\end{array}$ & \multicolumn{3}{|c|}{ Oral Session Discussion } \\
\hline $\begin{array}{l}\text { 4:15-5:15 } \\
\text { PM Pacific }\end{array}$ & \multicolumn{3}{|c|}{ Afternoon Poster Session (see page 1261) } \\
\hline
\end{tabular}

\section{Late Afternoon Oral Session}

\begin{tabular}{|c|c|c|c|}
\hline & $\begin{array}{l}\text { Earthquake Science, Hazards and } \\
\text { Policy in Cascadia II (see page } \\
1346 \text { ) }\end{array}$ & $\begin{array}{l}\text { Effects and Uses of Aseismic } \\
\text { Deformation and Fault Creep in } \\
\text { Seismic Hazard and Warning (see } \\
\text { page 1350) }\end{array}$ & $\begin{array}{l}\text { Recent Development in Ultra- } \\
\text { Dense Seismic Arrays with Nodes } \\
\text { and Distributed Acoustic Sensing } \\
\text { (see page } 1421 \text { ) }\end{array}$ \\
\hline $\begin{array}{l}5: 30 \mathrm{PM} \\
\text { Pacific }\end{array}$ & $\begin{array}{l}\text { The Effect of Fore-Arc Deformation } \\
\text { on Shallow Earthquake Rupture } \\
\text { Behavior in the Cascadia } \\
\text { Subduction Zone. Aslam, K., } \\
\text { Thomas, A. M., Melgar, D. }\end{array}$ & $\begin{array}{l}\text { STUDENT: The Relationship Between } \\
\text { Seismic and Aseismic Slip on the } \\
\text { Creeping Segment of the Philippine } \\
\text { Fault: Insight to Earthquake } \\
\text { Recurrence and Fault Mechanics. } \\
\text { Dianala, J. B., Jolivet, R., Thomas, M. } \\
\text { Y., Fukushima, Y., Parsons, B., et al. }\end{array}$ & $\begin{array}{l}\text { INVITED: Reducing the } \\
\text { Computational Cost of Seismic } \\
\text { Interferometry With Compressed } \\
\text { Array Data. Martin, E., Kump, J. L. }\end{array}$ \\
\hline $\begin{array}{l}5: 45 \text { PM } \\
\text { Pacific }\end{array}$ & $\begin{array}{l}\text { Development and Application of } \\
\text { Near-Surface Soil Velocity Models } \\
\text { for Seismic Hazard in the Pacific } \\
\text { Northwest. Grant, A., Wirth, E. A. }\end{array}$ & $\begin{array}{l}\text { Dynamic Rupture Scenarios of } \\
\text { Large Earthquakes on the Rodgers } \\
\text { Creek-Hayward-Calaveras-Northern } \\
\text { Calaveras Fault System, California. } \\
\text { Harris, R., Barall, M., Ponce, D., } \\
\text { Moore, D., Graymer, R., et al. }\end{array}$ & $\begin{array}{l}\text { Combining Horizontal Strain DAS } \\
\text { and Local Seismic Stations in a } \\
\text { Full Waveform Attribute Stacking } \\
\text { Detector/Locator Algorithm: } \\
\text { Verification Test for the Thorbjörn, } \\
\text { Iceland, } 2020 \text { Unrest Episode. } \\
\text { Heimann, S., Isken, M., Milkereit, } \\
\text { C., Jousset, P., Wollin, C., et al. }\end{array}$ \\
\hline $\begin{array}{l}\text { 6:00 PM } \\
\text { Pacific }\end{array}$ & $\begin{array}{l}\text { STUDENT: Spectral Acceleration } \\
\text { Basin Amplification Factors for } \\
\text { Interface Cascadia Subduction } \\
\text { Zone Earthquakes in Canada's } 2020 \\
\text { National Seismic Hazard Model. } \\
\text { Kakoty, P., Molina-Hutt, C. }\end{array}$ & $\begin{array}{l}\text { INViTED: STUDENT: Coupling } \\
\text { Between the Northern and Southern } \\
\text { Central San Andreas Fault via } \\
\text { Triggered Creep. Hirao, B. W., } \\
\text { Savage, H. M., Brodsky, E. E. }\end{array}$ & $\begin{array}{l}\text { INVITED: STUDENT: Seismological } \\
\text { Evidence for the Earliest Global } \\
\text { Subduction Network at } 2 \text { Ga. Yang, } \\
\text { X., Wan, B., Tian, X., Yuan, H., } \\
\text { Kirscher, U., et al. }\end{array}$ \\
\hline
\end{tabular}


3:15 PM

Pacific

:30 PM

Pacific

$3: 45-4: 15$

PM Pacific

4:15-5:15

PM Pacific
Intermountain West Earthquakes in the Spring of $2020 \mathrm{I}$...

Hypothetical Structural Model for the 18 March 2020, Mw 5.7 Magna, Utah, Earthquake. McKean, A. P., Hardwick, C. L., Kleber, E. J., Hylland, M. D., Anderson, Z. W., et al.

The March 2020, Mw6.5 Stanley, Idaho Earthquake-Complex Faulting at the Northern End of the Basin and Range Province From Earthquake Relocation and Source Mechanisms. Braunmiller, J., Wetmore, $\mathrm{P}$.

\section{Mechanisms of Induced} Seismicity...

Induced Acoustic Emission Activity

Associated With the Stimtec-X

In-Situ Hydraulic-Fracturing

Experiment at the URL Reiche Zeche Mine, Germany. Boese, C.

M., Renner, J., Dresen, G., Adero, B., Bohnen, B., et al.

STUDEnT: Monitoring Thermoelastic

Effects from a Closed-Loop

Geothermal System. Eaton, D. W.,

Marion, K. P., Salvage, R. O.

\section{STUDENT: Reproduction of a}

Damage Belt in Downtown Mashiki,

Kumamoto, Japan Considering

Liquefaction Effects on Estimated

Ground Motions. Sun, J., Kawase,

H., Nagashima, F., Fukutake, K.,

Matsushima, S.

\section{Oral Session Discussion}

Afternoon Poster Session (see page 1261)

Intermountain West Earthquakes in the Spring of 2020 II (see page 1386)

5:30 PM

Pacific

5:45 PM

Pacific

6:00 PM

Pacific

J., Morton, E. A., Bormann, J. M., Hatch-Ibarra, R., Smith, K. D., et al.

Widely Distributed Rupture Along an Array of LeftLateral, Normal and Right-Lateral Faults in the 15 Elliott, A. J., Dee, S., Koehler, R. D., Hatem, A. E., Pierce, I. K. D., et al.
Student: Complex Rupture and Source Model of the 15 May 2020 Mw 6.5 Monte Cristo Range Earthquake From Insar and Earthquake Relocation. Sethanant, I., Nissen, E., Pousse-Beltran, L., Bergman, E.
Mechanisms of Induced Seismicity: Pressure Diffusion, Elastic Stressing and Aseismic Slip IV (see page 1390)

The Occurrence of Persistent Seismicity in a HydraulicFracturing Dominated Area During Operational Shutdown. Salvage, R. O., Eaton, D. W. May 2020 M6.5 Monte Cristo Range, NV Earthquake.

Seismicity Associated With 2018 and 2020 Hydraulic Stimulations at EGS in Helsinki, Finland, Shows Limited Earthquake Interaction: Implication for Seismic Hazard Assessment. Kwiatek, G., Leonhardt, M., Martinez-Garzon, P., Pentti, M., Bohnhoff, M., et al. 


\begin{tabular}{|c|c|c|c|}
\hline & $\begin{array}{l}\text { Earthquake Science, Hazards and } \\
\text { Policy in Cascadia II... }\end{array}$ & $\begin{array}{l}\text { Effects and Uses of Aseismic } \\
\text { Deformation and Fault Creep... }\end{array}$ & $\begin{array}{l}\text { Recent Development in Ultra- } \\
\text { Dense Seismic Arrays... }\end{array}$ \\
\hline $\begin{array}{l}\text { 6:15 PM } \\
\text { Pacific }\end{array}$ & $\begin{array}{l}\text { Predicted Warning and Triggering } \\
\text { Rate, and Sensor Self-Noise } \\
\text { Constraints for an Earthquake Early } \\
\text { Warning System in Canada. Crane, } \\
\text { S., Ackerley, N., Adams, J., Seywerd, } \\
\text { H., McCormack, D. }\end{array}$ & $\begin{array}{l}\text { INVITED: Developing a Mechanical } \\
\text { Explanation for Slip Reduction Near } \\
\text { Earth's Surface on Seismogenic and } \\
\text { Creeping Continental Strike-Slip } \\
\text { Faults. Nevitt, J., Brooks, B. A., } \\
\text { Lockner, D., Catchings, R., Ericksen, } \\
\text { T., et al. }\end{array}$ & $\begin{array}{l}\text { STUDENT: Earthquake Locations } \\
\text { in the Pecos, TX Region of the } \\
\text { Delaware Basin. Faith, J. L., Karplus, } \\
\text { M., Doser, D. I., Veitch, S., Savvaidis, } \\
\text { A., et al. }\end{array}$ \\
\hline $\begin{array}{l}\text { 6:30 PM } \\
\text { Pacific }\end{array}$ & $\begin{array}{l}\text { STUDENT: Effective Uncertainty } \\
\text { Visualization for Aftershock } \\
\text { Forecast Maps. Schneider, M., } \\
\text { McDowell, M., Guttorp, P., Steel, A., } \\
\text { Fleischhut, N. }\end{array}$ & $\begin{array}{l}\text { INVITED: Aseismic Deformation } \\
\text { in and Around the North Brawley } \\
\text { Geothermal Field. Materna, K. }\end{array}$ & $\begin{array}{l}\text { Reverse-Time Migration of Fault } \\
\text { Zone Reflected Waves: Methodology } \\
\text { and Application to the Southern } \\
\text { San Andreas Fault. Chi, B., Qiu, H., } \\
\text { Share, P., Vernon, F., Ben-Zion, Y. }\end{array}$ \\
\hline $\begin{array}{l}6: 45- \\
7: 15 \text { PM } \\
\text { Pacific }\end{array}$ & \multicolumn{3}{|c|}{ Oral Session Discussion } \\
\hline
\end{tabular}

\section{Morning Poster Session}

11:30 AM-12:30 PM Pacific

Constructing and Testing Regional and Global Earthquake Forecasts (see page 1328)

- A Bayesian Framework for Aftershock Forecasting and Testing. Shcherbakov, R.

- A Big Problem for Small Earthquakes: Benchmarking Routine Magnitudes and Conversion Relationships With Coda-Envelope-Derived $\mathrm{Mw}$ in Southern Kansas and Northern Oklahoma. Shelly, D. R., Mayeda, K., Walter, W. R., Gök, R., Barno, J., et al.

- The Global Centroid Moment Tensor Catalog: Heterogeneities and Improvements. González, Á.

- PyCSEP: An Open-Source Toolkit for Evaluating Earthquake Forecast Models. Savran, W., Werner, M. J., Schorlemmer, D., Rhoades, D. A., Jackson, D. D., et al.

Earthquake Early Warning System in the Americas: The On-Going Effort and the State of the Art (see page 1345)

- Approaching EEW in Central America: The Readiness of Seismic Network Processing Hubs. Burgoa Rosso, B., Clinton, J., Massin, F., Racine, R., Marroquin, G., et al.

- Evolution of EEW Instrumentation. Parker, T., Pelyk, N.

- The Importance of Earthquake Education in Free Choice Learning Environments. Jenkins, M. R., Sumy, D. F., McBride, S. K., de Groot, R.
Earthquake Science, Hazards and Policy in Cascadia (see page 1348)

- A 2700 Year Record of Megathrust and Crustal/Slab Earthquakes From Squaw Lakes, Oregon. Morey, A. E., Goldfinger, C., Shapley, M., Gavin, D. G.

- Application of the Paleoseismic Record of Great Cascadia Earthquakes for Use in the 2015 CanadaSHM5 and 2020 CanadaSHM6 Seismic Hazard Models. Adams, J.

- Basin and Site Effects in the U.S. Pacific Northwest Estimated From Small-Magnitude Earthquakes. Rekoske, J. M., Moschetti, M. P., Thompson, E. M.

- Building a Resilient Earthquake Early Warning System in Canada: Sensor Spacing and Station Design. Crane, S., Mowla, F., Nykolaishen, L., Seywerd, H., McKee, L., et al.

- Estimating Earthquake Rupture Directivity Using Surface Wave Empirical Greens Functions: How Low Can You Go? Paul, C., Cassidy, J. F.

- Student: MHVSR 'Big Data' to Outline Standard Procedures for Data Acquisition, Processing, Interpretation and Presentation. Sirohey, A., Molnar, S.

- A Paleoseismic Investigation of the Little Salmon Fault and Goose Lake Fault: Inference Into the Role of Upper-Plate Faults in the Southern Cascadia Subduction Zone. Ladinsky, T. C., Kelsey, H., Michalak, M., Bold, S., Witter, R.

Intermountain West Earthquakes in the Spring of 2020 (see page 1389)

- Student: 1D Crustal Velocity Model for West-Central Montana. Duzet, C. J., Martens, H. R., Stickney, M. C. 


\begin{tabular}{|c|c|c|}
\hline & $\begin{array}{l}\text { Intermountain West Earthquakes in the Spring of } \\
2020 \text { II... }\end{array}$ & $\begin{array}{l}\text { Mechanisms of Induced Seismicity: Pressure } \\
\text { Diffusion, Elastic Stressing and Aseismic Slip IV... }\end{array}$ \\
\hline $\begin{array}{l}\text { 6:15 PM } \\
\text { Pacific }\end{array}$ & $\begin{array}{l}\text { Modeling Coseismic Slip and Afterslip of the } 2020 \\
\text { Mw6.5 Monte Cristo Range (Nevada) Earthquake Using } \\
\text { InSAR and GPS. Dutta, R., Barnhart, W. D. }\end{array}$ & $\begin{array}{l}\text { Mechanisms Inducing Earthquakes in the Weiyuan } \\
\text { Shale Gas Field, Sichuan, China, Inferred From Dense } \\
\text { Array Recordings. Yang, H., Zi, J. }\end{array}$ \\
\hline $\begin{array}{l}\text { 6:30 PM } \\
\text { Pacific }\end{array}$ & $\begin{array}{l}\text { STUDENT: Testing Models of Active Tectonics in } \\
\text { the Central Walker Lane Using Satellite Geodetic } \\
\text { Measurement of the Mw 6.5 Monte Cristo Range } \\
\text { Earthquake. Crandall-Bear, A. T., Hammond, W. C. }\end{array}$ & $\begin{array}{l}\text { STUdEnT: Shallow Induced Seismicity in Sichuan, } \\
\text { China: A Coupled Flow-Geomechanics Modeling } \\
\text { Analysis. Liu, C., Choo, J., Liu, F., Yang, H. }\end{array}$ \\
\hline $\begin{array}{l}\text { 6:45- } \\
7: 15 \text { PM } \\
\text { Pacific }\end{array}$ & \multicolumn{2}{|c|}{ Oral Session Discussion } \\
\hline
\end{tabular}

- Student: Focal Mechanisms for the 2020 Magna, Utah Earthquake Sequence Using Manual and Deep-Learning First Motions From a Temporary Large-N Array and Permanent Seismic Network. Holt, M. M., Baker, B., Pechmann, J. C., Koper, K. D., Farrell, J.

- Student: Machine Learning Aftershock Detection for the M6.5 31 March 2020 Stanley, Idaho Earthquake. Wilbur, S. F., Liberty, L., Mikesell, T. D., Bockholt, B., Johnson, J. B.

- The Monte Cristo Range Mw 6.5 Nodal Geophone Rapid Deployment. Zeiler, C., McLin, K., Champion, D., Scalise, M., Sheridan, M., et al.

- Overview of Data Quality, Availability and Performance of the 31 March 2020 Stanley, Idaho Event Aftershock Deployment. Bockholt, B., Mikesell, T. D., Wilbur, S. F., Liberty, L.

- Present-Day Deformation Mechanism of the Northeastern Mina Deflection Revealed by the 2020 Mw 6.5 Monte Cristo Range Earthquake. Zheng, A., Xu, W., Chen, X.

\section{Probabilistic Seismic Hazard Assessment: Where Do We}

Go from Here? (see page 1420)

- Earthquake Event Selection for Regional Seismic Hazard Analysis of Levee Systems. Wang, P., Liu, Z., Brandenberg, S. J., Zimmaro, P., Stewart, J. P.

- Effects of Inputs on PSHA Results: A Case Study Hydropower Cascade Projects in Georgia (Sakartvelo). Tsereteli, N. S.

- Student: Improving Estimation of the Magnitude of Historical California Earthquakes using IPEs. Lucas, M.
C., Salditch, L., Gallahue, M., Hough, S. E., Neely, J. S., et al.

- Optimizing Grids for National Earthquake Hazard Mapping Projects. Kolaj, M., Halchuk, S., Adams, J.

Tectonics, Seismicity and Recent Significant Events in the Caribbean (see page 1444)

- Earthquake Distributions Along Northern Caribbean Faults: Effects of Segmentation and Interdependence. Geist, E. L., Ten Brink, U.

- A High-Resolution View of the 2020 Puerto Rico Earthquake Sequence With Machine Learning. Yoon, C.

- Monitoring the Seismicity in the Pantanal Basin, Western Brazil. Tadeu, E., Assumpção, M., Bianchi, M., Facincani, E., Collaço, B.

- Student: A Secondary Wave Field and the Seismic Site Response of Mexico City During Recent Earthquakes. Aquino-Sándoval, G. C., Cárdenas-Soto, M.

\section{Afternoon Poster Session}

\section{4:15-5:15 PM Pacific}

Amphibious Seismic Studies of Plate Boundary Structure and Processes (see page 1311)

- Student: Amphibious Receiver Function Imaging of the Pacific Plate Using Tuned Dereverberation Filters. Zhang, Z., Olugboji, T.

- Student: Anisotropic S-Wave Tomography at the Eastern North American Margin: Constraints on Mantle 
Structure and Dynamics. Brunsvik, B. R., Eilon, Z. C., Lynner, C.

- Student: Incoming Plate and Forearc Structure of the East-Central Alaska-Aleutian Subduction Zone From 3D Local Earthquake Tomography. Moser, L., Canales, J., Bécel, A.

- Nature of Intermediate-Depth Earthquakes in the Eastern Aleutian Subduction Zone. Plourde, A. P., Nedimovic, M. R., Waldhauser, F., Kuehn, H., Bécel, A., et al.

- Strong Motions on Land and Ocean Bottoms in and Around Kanto Basin From Two Nearby Moderate Earthquakes East Off the Chiba Prefecture. Dhakal, Y. P., Kunugi, T.

Effects and Uses of Aseismic Deformation and Fault Creep in Seismic Hazard and Warning (see page 1351)

- Spatially Variable Creep on the Bartlett Springs Fault Inferred From Bayesian, Stress-Driven Models. Murray, J. R., Johnson, K.

Infrasound and the Seismo-Acoustic Wavefield (see page 1381)

- Student: 3D Simulations of Seismo-Acoustic Coupling Over Topography. Bishop, J. W., Fee, D., Modrak, R., Tape, C., Kim, K.

- An Analysis of Air-to-Ground Coupled Seismic Arrivals From the Camp Minden, U.S., Explosion, 16 October 2012. Wills, G., Green, D., Nippress, A., Spence, P.

- Resolving Complex Infrasound Wavefields Using a Dense Array. Anderson, J., Johnson, J. B., Mikesell, T. D., Liberty, L., Arrowsmith, S.

- Student: Tracking Secondary Lahar Flow Paths and Characterizing Pulses and Surges Using Infrasound Array Networks at Volcán De Fuego, Guatemala. Bosa, A. R., Johnson, J. B., de Angelis, S., Lyons, J., Escobar-Wolf, R., et al.

- Student: Utilizing Advanced Acoustic Modeling Techniques to Inform Experimental Field Deployments. Dannemann Dugick, F. K., Bowman, D. C.

Mechanisms of Induced Seismicity: Pressure Diffusion, Elastic Stressing and Aseismic Slip (see page 1395)

- Dynamic Triggering and the State of Stress in Oklahoma. Alfaro-Diaz, R. A., Chen, T., Ma, X.

- Student: Laboratory Observation of Large Fluid Pressure Amplification in a Fluid-Filled Fracture. Jin, Y., Dyaur, N., Zheng, Y.

- Student: Modeling Injection Induced Stress Changes in the Fort Worth Basin. Quinones, L. A., DeShon, H.
- One-Year Seismic Hazard and Risk Maps Due to Wastewater Disposal in Oklahoma. Grigoratos, I., Bazzurro, P., Rathje, E., Savvaidis, A.

- Student: Spatial-Temporal Evolution Pattern of Earthquakes Illuminated by Machine Learning Method and Waveform Correlation in Weiyuan Shale Gas Field, Sichuan China. Wong, W., Zi, J., Zhou, P., Yang, H., Su, J.

- Statistical Modelling of Induced Seismicity in the Western Canada Sedimentary Basin. Kothari, S., Shcherbakov, R., Atkinson, G. M.

Recent Development in Ultra-Dense Seismic Arrays with Nodes and Distributed Acoustic Sensing (see page 1422)

- Characteristics of the Seismic Waves From a New Experiment of Methane Gaseous Detonation Source in Tibet. Ji, Z., He, R., Li, Z., Niu, X., Wu, W., et al.

- Student: Classifying the Records of DAS Using Neural Network. Lv, H., Zeng, X., Song, Z., Bao, F., Lin, R.

- Student: Imaging Shallow S-Wave Structure Using Telecom Fiber-Optic Cable in Urban Areas. Song, Z., Zeng, X.

- Student: Imaging the Crustal Structure Beneath the Northwest Yunnan From a High-Density Seismic Array. Sun, T.

- Student: Mineralization Study by Squeezing of Northward Indian Plate in the Gangdese Metallogenic Belt. Wu, W., Ji, Z., Jin, Z., He, R., Wei, Y., et al.

- New Community Resource for Rapidly Responding to Geohazards. Sweet, J., Anderson, K., Meltzer, A., Woodward, R.

- Student: Shallow Active-Source Seismic Modeling of Old Faithful Geyser in the Upper Geyser Basin of Yellowstone National Park Using a Dense Seismic Array. Caylor, J. R., Karplus, M., Farrell, J., Veitch, S., Kaip, G.

- Student: Subduction Zone Interface Structure Beneath Kodiak Island, Alaska: Constraints from Receiver Functions Across a Spatially Dense Node Array. Onyango, E. A., Worthington, L. L., Schmandt, B., Nakai, J., Abers, G.

Utilizing Earthscope and AACSE Datasets in Alaska and Canada to Unravel Earth Science Mysteries (see page 1458)

- Enhanced Regional Earthquake Catalog With Alaska Amphibious Community Seismic Experiment Data. Ruppert, N. A., Barcheck, G., Abers, G.

- Student: Imaging the Upper Plate Lithosphere and Asthenosphere Beneath Alaska With Sp Converted Waves. Gama, I., Fischer, K. M., Hua, J.

- Magnetic Field Variations in Alaska: Recording Space Weather Events on the Transportable Array. Ringler, A., Anthony, R., Claycomb, A., Spritzer, J., Tape, C., et al. 


\section{Wednesday, 21 April 2021-Morning Oral Session}

Presenting author is indicated in bold.

\begin{tabular}{|c|c|c|c|c|}
\hline \multirow[t]{2}{*}{$\begin{array}{l}\text { 8:30-9:30 } \\
\text { AM Pacific }\end{array}$} & \multicolumn{4}{|c|}{$\begin{array}{l}\text { Effective Earthquake Communication to Three Different Players } \\
\text { Xyoli Pérez-Campos, Instituto de Geofísica, Universidad Nacional Autónoma de México }\end{array}$} \\
\hline & $\begin{array}{l}\text { Updating the US National } \\
\text { Seismic Hazard Models I } \\
\text { (see page } 1451 \text { ) }\end{array}$ & Overdue? (see page 1411) & $\begin{array}{l}\text { What Can We Infer } \\
\text { About the Earthquake } \\
\text { Source Through Analyses } \\
\text { of Strong Ground } \\
\text { Motion? I (see page 1464) }\end{array}$ & $\begin{array}{l}\text { Infrasound and the } \\
\text { Seismo-Acoustic } \\
\text { Wavefield II (see page } \\
1378 \text { ) }\end{array}$ \\
\hline $\begin{array}{l}: 45 \mathrm{AM} \\
\text { acific }\end{array}$ & $\begin{array}{l}2023 \text { U.S. National Seismic } \\
\text { Hazard 50-State Model: } \\
\text { Science Objectives and } \\
\text { Products. Petersen, M. D., } \\
\text { Field, E. H., Jaiswal, K. S., } \\
\text { Moschetti, M. P., Powers, P. } \\
\text { M., et al. }\end{array}$ & $\begin{array}{l}\text { INVITED: Why Are Large } \\
\text { Earthquakes Rarely } \\
\text { Overdue for New Zealand } \\
\text { Faults? Nicol, A., Van } \\
\text { Dissen, R. J. }\end{array}$ & $\begin{array}{l}\text { What Can the Data Inform } \\
\text { Us About the Earthquake } \\
\text { Source? Archuleta, R. J. }\end{array}$ & $\begin{array}{l}\text { INVITED: On the Effect } \\
\text { of Bathymetry on } \\
\text { Microbaroms Signals. De } \\
\text { Carlo, M., Le Pichon, A., } \\
\text { Ardhuin, F. }\end{array}$ \\
\hline $\begin{array}{l}\text { 10:00 AM } \\
\text { Pacific }\end{array}$ & $\begin{array}{l}\text { Updates to the Earthquake } \\
\text { Geology Parameters } \\
\text { for Use in the } 2023 \text { U.S. } \\
\text { National Seismic Hazard } \\
\text { Model. Hatem, A. E., } \\
\text { Collett, C. M., Gold, R. D., } \\
\text { Briggs, R. W., Angster, S. } \\
\text { J., et al. }\end{array}$ & $\begin{array}{l}\text { STUDENT: What } \\
\text { Controls the Along- } \\
\text { Strike Segmentations } \\
\text { of Shallow Slow Slip } \\
\text { Events? Insights From } \\
\text { 3D Numerical Modeling } \\
\text { of Slow Slip Events Along } \\
\text { the Hikurangi Margin, } \\
\text { New Zealand. Perez, A., } \\
\text { Kaneko, Y., Savage, M. K., } \\
\text { Wallace, L., Li, D., et al. }\end{array}$ & $\begin{array}{l}\text { STUDENT: Stress Drops } \\
\text { Estimates of the } 2019 \\
\text { Ridgecrest Aftershock } \\
\text { Sequence Based on Finite } \\
\text { Source Modeling. Magana, } \\
\text { J. A., Dreger, D. S., Taira, } \\
\text { T. }\end{array}$ & $\begin{array}{l}\text { Predicting Atmospheric } \\
\text { Structure for Infrasound } \\
\text { Propagation Using } \\
\text { Machine Learning. Albert, } \\
\text { S. A., Downey, N. }\end{array}$ \\
\hline $\begin{array}{l}10: 15 \text { AM } \\
\text { Pacific }\end{array}$ & $\begin{array}{l}\text { Fault Slip Rates } \\
\text { Contributed by Crustal } \\
\text { Deformation Models to } \\
\text { the } 2023 \text { Update to the } \\
\text { National Seismic Hazard } \\
\text { Model. Pollitz, F. F., Elliott, } \\
\text { J. L., Evans, E. L., Field, E. } \\
\text { H., Hatem, A. E., et al. }\end{array}$ & $\begin{array}{l}\text { INVITED: Evaluation of } \\
\text { the Magnitude-Frequency } \\
\text { Distribution of the } \\
\text { Maximum Rupture Model } \\
\text { for the Southern San } \\
\text { Andreas and San Jacinto } \\
\text { Faults. Scharer, K., Yule, } \\
\text { D. }\end{array}$ & $\begin{array}{l}\text { A Slip Model and Stress } \\
\text { Drops From Source } \\
\text { Time Functions for a } \\
\text { M4.5 Aftershock of the } \\
\text { Ridgecrest Earthquake. } \\
\text { Fletcher, J. B., Erdem, J. E., } \\
\text { Baker, L. M. }\end{array}$ & $\begin{array}{l}\text { An Acoustic Metamaterial } \\
\text { Sensing Unit for } \\
\text { Infrasound Direction of } \\
\text { Arrival Determination. } \\
\text { Rouse, J. W., Bowman, D. } \\
\text { C., Walsh, T. F. }\end{array}$ \\
\hline
\end{tabular}




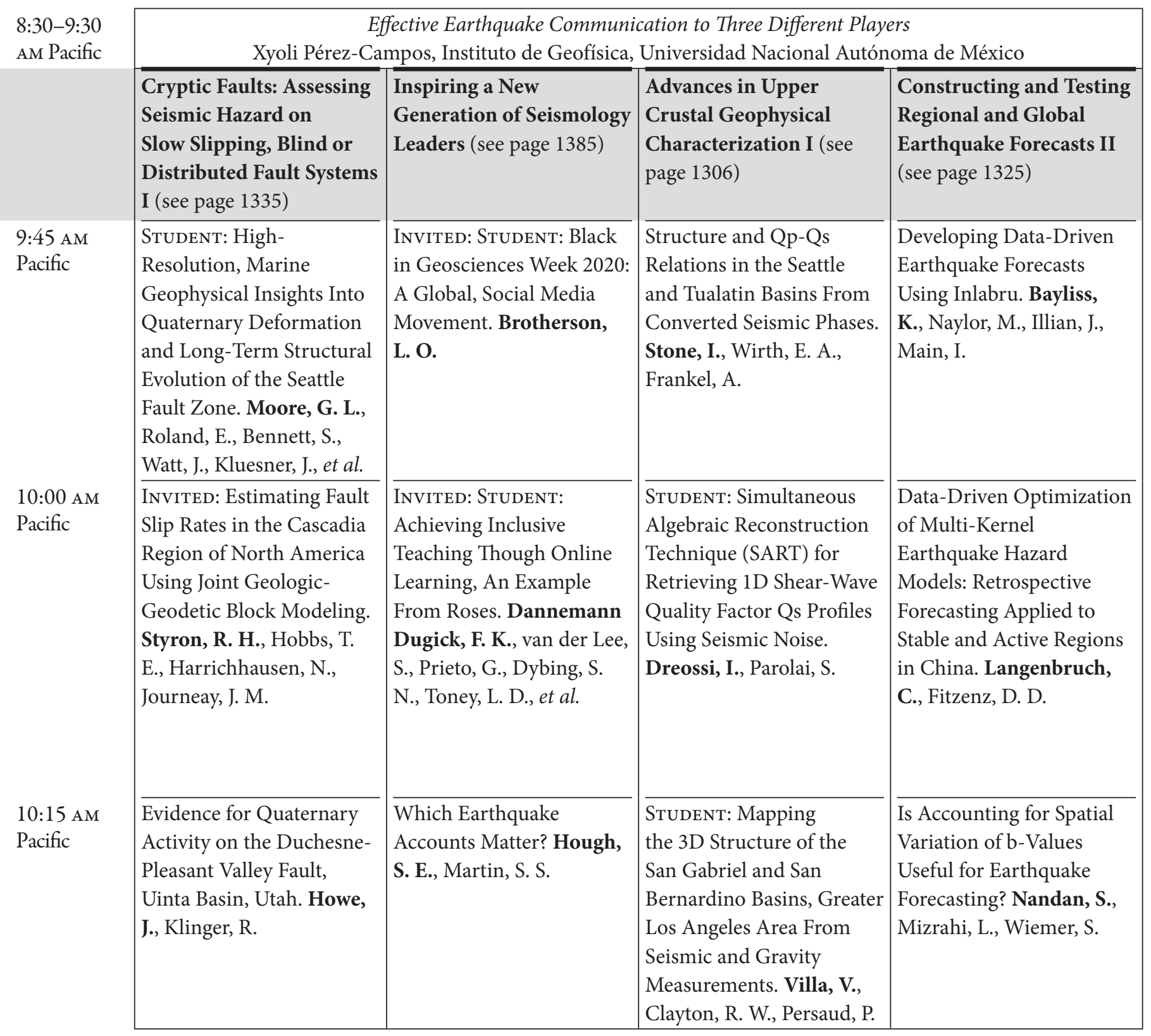


Wednesday, 21 April (continued)

\begin{tabular}{|c|c|c|c|c|}
\hline & $\begin{array}{l}\text { Updating the US National } \\
\text { Seismic Hazard Models... }\end{array}$ & Overdue? & $\begin{array}{l}\text { What Can We Infer } \\
\text { About the Earthquake... }\end{array}$ & $\begin{array}{l}\text { Infrasound and the } \\
\text { Seismo-Acoustic... }\end{array}$ \\
\hline $\begin{array}{l}\text { 10:30 AM } \\
\text { Pacific }\end{array}$ & $\begin{array}{l}\text { Generalizing the } \\
\text { Inversion-Based PSHA } \\
\text { Source Model for an } \\
\text { Interconnected Fault } \\
\text { System. Field, E. H., } \\
\text { Milner, K., Page, M. T. }\end{array}$ & $\begin{array}{l}\text { Rebuild of the Bulletin } \\
\text { of the International } \\
\text { Seismological Centre } \\
\text { (ISC). Storchak, D. A., } \\
\text { Harris, J., Lieser, K., Di } \\
\text { Giacomo, D. }\end{array}$ & $\begin{array}{l}\text { Rupture Complexity } \\
\text { of Small and Moderate } \\
\text { Earthquakes in the } 2019 \\
\text { Ridgecrest Earthquake } \\
\text { Sequence and the Effects } \\
\text { on Stress Drop Estimation } \\
\text { and Ground Motions. Wu, } \\
\text { Q., Chen, X. }\end{array}$ & $\begin{array}{l}\text { Seismoacoustic and } \\
\text { Hydroacoustic Responses } \\
\text { of Explosions in Different } \\
\text { Geological Materials: } \\
\text { A Parametric Study of } \\
\text { Different Emplacements } \\
\text { and Different Energy } \\
\text { Depositions and } \\
\text { Comparisons With } \\
\text { Experimental Data. } \\
\text { Ezzedine, S. M., Vorobiev, } \\
\text { O. Y., Rodgers, A. J., Walter, } \\
\text { W. R., Antoun, T. H. }\end{array}$ \\
\hline $\begin{array}{l}10: 45 \text { AM } \\
\text { Pacific }\end{array}$ & $\begin{array}{l}\text { Development of Inversion- } \\
\text { Based Source Models for } \\
\text { the New Zealand NSHM. } \\
\text { Gerstenberger, M. C., Van } \\
\text { Dissen, R. J., Wallace, L., } \\
\text { Thingbaijam, K., Milner, } \\
\text { K., et al. }\end{array}$ & $\begin{array}{l}\text { Is California Overdue } \\
\text { for Large Earthquakes? } \\
\text { Jackson, D. D. }\end{array}$ & $\begin{array}{l}\text { STUDENT: Characterizing } \\
\text { Multi-Subevent } \\
\text { Earthquakes Using the } \\
\text { Brune Source Model. Liu, } \\
\text { M., Huang, Y., Ritsema, J. }\end{array}$ & $\begin{array}{l}\text { Local Explosion } \\
\text { Infrasound Propagation } \\
\text { at Dawn: Insight From the } \\
\text { Large Surface Explosion } \\
\text { Coupling Experiment. } \\
\text { Kim, K., Bowman, D. C. }\end{array}$ \\
\hline $\begin{array}{l}\text { 11:00-11:30 } \\
\text { AM Pacific }\end{array}$ & \multicolumn{4}{|c|}{ Oral Session Discussion } \\
\hline $\begin{array}{l}\text { 11:30 AM- } \\
\text { 12:30 PM } \\
\text { Pacific }\end{array}$ & \multicolumn{4}{|c|}{ Morning Poster Session (see page 1270) } \\
\hline
\end{tabular}

\section{Early Afternoon Oral Session}

\begin{tabular}{|c|c|c|c|c|}
\hline \multirow{3}{*}{$\begin{array}{l}\text { 12:30- } \\
1: 30 \text { PM } \\
\text { Pacific } \\
1: 30- \\
2: 00 \text { PM } \\
\text { Pacific }\end{array}$} & \multicolumn{4}{|c|}{ Innovation Showcase } \\
\hline & \multicolumn{4}{|c|}{ Break } \\
\hline & $\begin{array}{l}\text { Updating the US National } \\
\text { Seismic Hazard Models II } \\
\text { (see page } 1451 \text { ) }\end{array}$ & $\begin{array}{l}\text { Waveform Cross- } \\
\text { Correlation-Based } \\
\text { Methods in Observational } \\
\text { Seismology I (see page } \\
1459)\end{array}$ & $\begin{array}{l}\text { What Can We Infer } \\
\text { About the Earthquake } \\
\text { Source Through Analyses } \\
\text { of Strong Ground } \\
\text { Motion? II (see page 1464) }\end{array}$ & $\begin{array}{l}\text { Strategies and Actions } \\
\text { for Fostering a Diverse } \\
\text { Seismology Community } \\
\text { (see page } 1431 \text { ) }\end{array}$ \\
\hline $\begin{array}{l}\text { 2:00 PM } \\
\text { Pacific }\end{array}$ & $\begin{array}{l}\text { INVITED: NGA-Subduction } \\
\text { Research Project: } \\
\text { Overview of Database, } \\
\text { Models and Computer } \\
\text { Tools. Bozorgnia, Y. }\end{array}$ & $\begin{array}{l}\text { STUDENT: Rock Valley } \\
\text { Fault Zone Absolute } \\
\text { and Relative Earthquake } \\
\text { Relocation to Improve } \\
\text { Geologic Models. Scalise, } \\
\text { M., Zeiler, C., Prothro, L., } \\
\text { Hatch-Ibarra, R., Smith, K. } \\
\text { D., et al. }\end{array}$ & $\begin{array}{l}\text { What Is the Magnitude } \\
\text { in Earthquake Early } \\
\text { Warning? Baltay, A., } \\
\text { Hanks, T. C. }\end{array}$ & $\begin{array}{l}\text { Learning in a Crisis: Online } \\
\text { Skill Building Workshop } \\
\text { Addresses Immediate } \\
\text { Pandemic Needs and } \\
\text { Offers Possibilities for } \\
\text { More Inclusive Trainings. } \\
\text { Brudzinski, M. R., } \\
\text { Hubenthal, M., Fasola, S., } \\
\text { Schnorr, E. }\end{array}$ \\
\hline
\end{tabular}


10:30 AM

Pacific

10:45 AM

Pacific

11:00-11:30

AM Pacific

11:30 AM-

12:30 PM

Pacific
Cryptic Faults: Assessing Seismic Hazard...

How Many Samples Do

You Need to Date That

Paleoearthquake? A Field

Test of Portable OSL

Using 345 Samples From

a Single Colluvial-Wedge

Exposure. DuRoss, C. B.,

Gray, H. J., Gold, R. D.,

Nicovich, S. R., Mahan,

S. A.

Searching for an Invisible

Holocene Fault Beneath

an Urban Region: A

Case From Datong City,

Northern China. Ren, J.,

Guo, F., Li, K., Guo, H.,

$\mathrm{Xu}, \mathrm{X}$
Inspiring a New

Generation...

Justice, Equity, Diversity

and Inclusion at

Incorporated Research

Institutions for

Seismology. Aderhold, K.,

Bohon, W., Mathurin, J.,

Poitra, K., Porter, R., et al.

STUDENT: But What

Can We Do? Developing

Strategies for Change.

Fernando, B.
Advances in Upper Crustal Geophysical...

INVITED: Spatial Statistics

of Densely Measured

Seismic-Velocity

Variations. Louie, J. N.,

Simpson, A., Scalise, M.,

Eckert, E.
Constructing and Testing Regional and Global...

Towards a Prospective Test of the Foreshock Traffic Light System. Wiemer, S., Gulia, L., Reyes, C.

\section{Using Seismic}

Interferometry to Map and Monitor Fluids in Geothermal Systems. Matzel, E., Morency, C., Templeton, D.
Prospective Evaluation of Multiplicative Hybrid Earthquake Forecast Models for California. Bayona, J. A., Savran, W., Werner, M. J., Rhoades, D. A.

Oral Session Discussion

Morning Poster Session (see page 1270)

12:30-

1:30 PM

Pacific

$1: 30-$

2:00 PM

Pacific

\section{2:00 PM}

Pacific

\begin{tabular}{|c|c|c|c|}
\hline \multicolumn{4}{|c|}{ Innovation Showcase } \\
\hline \multicolumn{4}{|c|}{ Break } \\
\hline $\begin{array}{l}\text { Cryptic Faults: Assessing } \\
\text { Seismic Hazard on } \\
\text { Slow Slipping, Blind or } \\
\text { Distributed Fault Systems } \\
\text { II (see page 1335) }\end{array}$ & $\begin{array}{l}\text { How Well Can We Assess } \\
\text { Site Effects So Far? III } \\
\text { (see page 1369) }\end{array}$ & $\begin{array}{l}\text { Advances in Upper } \\
\text { Crustal Geophysical } \\
\text { Characterization II (see } \\
\text { page 1306) }\end{array}$ & $\begin{array}{l}\text { Tsunami Warning System } \\
\text { in Latin America and } \\
\text { the Caribbean: COVID- } \\
19 \text { Challenges (see page } \\
1448 \text { ) }\end{array}$ \\
\hline $\begin{array}{l}\text { Cycles of Earthquake } \\
\text { Deformation on the Patton } \\
\text { Bay Splay-Fault System } \\
\text { Implied by Late Holocene } \\
\text { Shoreline Evolution on } \\
\text { Montague Island, Alaska. } \\
\text { Witter, R., DePaolis, J., } \\
\text { Haeussler, P. J., Bender, A. } \\
\text { M., Curran, J., et al. }\end{array}$ & $\begin{array}{l}\text { STUDENT: Temporal } \\
\text { Change of Shallow } \\
\text { Material During } \\
\text { Kumamoto Earthquake by } \\
\text { Autocorrelation Function } \\
\text { and Interfrometry Method. } \\
\text { Dokht Dolatabadi } \\
\text { Esfahani, R., Cotton, F., } \\
\text { Bonilla, L. }\end{array}$ & $\begin{array}{l}\text { High-Resolution Bayesian } \\
\text { Spatial Auto-Correlation } \\
\text { (Spac) Pseudo-3D vs } \\
\text { Model of Utah Forge Site } \\
\text { With a Dense Geophone } \\
\text { Array. Zhang, H., Pankow, } \\
\text { K. L. }\end{array}$ & $\begin{array}{l}\text { Operational Capabilities } \\
\text { During Crisis: The Chilean } \\
\text { Seismographic Network. } \\
\text { Barrientos, S. E., } \\
\text { Riquelme, S., Team, C. }\end{array}$ \\
\hline
\end{tabular}


Wednesday, 21 April (continued)

2:15 PM

Pacific

2:30 PM

Pacific

2:45 PM

Pacific

3:00 PM

Pacific

$3: 15-3: 45$

PM Pacific

$3: 45-4: 45$

PM Pacific
Updating the US National Seismic Hazard Models..

INVITED: Use of Non-

Ergodic Ground-Motion

Models for National

Seismic Hazard Maps.

Abrahamson, $\mathrm{N}$.

STUdent: A Non-Ergodic

Ground-Motion Model for

California. Lavrentiadis,

G., Abrahamson, N.,

Kuehn, N.

Near-Source Ground

Motion Directivity and

Heterogeneity Modeling

for Seismic Hazard

Applications. Rowshandel,

B.

A Rupture Directivity

Adjustment Model

Applicable to the NGA-

West2 Ground Motion

Models and Complex Fault

Geometries. Bayless, J.

\begin{tabular}{l} 
Waveform Cross- \\
Correlation... \\
\hline InviTED: Space-Time \\
Variations in Earthquake \\
Waveform Similarity: \\
Implications for Stress \\
Heterogeneity and Faulting \\
Complexity. Trugman, \\
D. T.
\end{tabular}

One-Year of Near-Real-

Time Matched-Filtering to

Build Dense Earthquake

Catalogs in New Zealand

Using the Open-Source

RT-EQcorrscan Software

Package. Chamberlain,

C. J., Townend, J.,

Gerstenberger, M. C.

\section{STUDENT: Spatio-}

Temporal Changes of

Microseismicity in Taiwan

Around the 2009 Typhoon

Morakot. Zhai, Q., Peng,

Z., Chuang, L. Y., Chao, K., Wu, Y., et al.

STUDENT: Near-Repeating

Earthquakes as a Proxy for Transient Aseismic Slip.

Shaddox, H. R., Schwartz, S. Y., Barlow, N. M.

STUdENT: Near-Field

Corner Frequency Analysis of Data-Integrated Large-

Scale Dynamic Rupture

Simulations of the 2019

Ridgecrest and the 1992

Landers Earthquakes.

Schliwa, N., Gabriel, A.,

Taufiqurrahman, $\mathrm{T}$.
Implementing Diversity,

Equity and Inclusion

(DEI) Best Practices to

Design Introductory

Undergraduate

Modules for Increasing

Participation from

Students of All

Backgrounds into

Geophysics. Parsekian,

A., Houlton, H., Kruse,

S., Ormand, C., Slater, L., et al.

USGS Geologic Hazard

Science Center's Strategies

and Actions for Fostering

a Diverse Geoscience

Community. Allstadt, K.,

Jaiswal, K. S., Khteian, A.,

Luco, N., Schaefer, L. J.,

Shiro, B., Shumway, A. M., et al.

Equity, Inclusion and

Diversity Efforts at the

USGS Earthquake Science

Center. The Earthquake

Science Center Equity,

Inclusion and Diversity

Working Group.
Oral Session Discussion

Afternoon Poster Session (see page 1272) 
2:15 PM

Pacific

2:30 PM

Pacific

2:45 PM

Pacific

3:00 PM

Pacific

$3: 15-3: 45$

PM Pacific

3:45-4:45

PM Pacific
Cryptic Faults: Assessing Seismic Hazard...

Investigating the Slip

History of the Multi-

Stranded Patton Bay

Megasplay Fault System,

Montague Island, Alaska.

Haeussler, P. J., Tobin, H.

J., Witter, R., Bender, A.

M., LeWinter, A. L., et al.

Assessing Seismic Hazard on Offshore Fault Sources

Using New Coastal Record Techniques: Example From the Central Hikurangi Subduction Zone, New Zealand. Litchfield, N., Morgenstern, R., Clark, K., Howell, A.

Multidisciplinary

Quaternary Deformation Analysis in a Complex Low Tectonic Setting-The Example of SW Portugal, Europe. Figueiredo, P. M., Rockwell, T. K., Cabral, J.

Stairways to Hazard:

Quantifying Geologic Slip Rate Variability Along Low Strain Rate Faults. Hatem, A. E., Gold, R. D., Briggs, R. W.
How Well Can We Assess Site Effects So Far? III...

INVited: STUDENT:

Comparison of State-

of-the-Art Approaches

Used to Account for Vs

Variability in 1D Ground

Response Analyses. Hallal,

M. M., Cox, B. R.

STUDENT: Inter-Method

HVSR Bias and the

Resultant Vs30-fd

Relationship for

Measured-Vs30 Stations in the Western United States.

Hudson, K. S., Palmer, S.

M., Ahdi, S. K., Hassani,

B., Toro, G., et al.

Consistency of Earthquake and Microtremor HVSRs Derived for California Sites. Wang, P., Gospe, T., Zimmaro, P., Ahdi, S. K., Yong, A., et al.

\section{STUdENT: Site}

Amplification in Glaciated

Terrain: HVSR and MASW

Measurements in New

England. Pontrelli, M. A.,

Baise, L. G., Ebel, J.
Advances in Upper Crustal Geophysical...

Site Response in the

Illinois Basin From S-Wave $\mathrm{H} / \mathrm{V}$ and Spectral-Element Modeling. Carpenter, S., Yassminh, R., Hickman, J. B., Wang, Z.

Inversion of Dispersion and $\mathrm{H} / \mathrm{V}$ Curves for Shear-Wave Velocity Versus Depth Profiles in the Atlantic Coastal Plain of the Eastern U.S. Using Legacy Crustal-Scale Refraction Seismic Data. Pratt, T. L., Parolai, S., Poggi, V., Dreossi, I.

\section{Correcting Horizontal-} to-Vertical Spectral Ratio Fundamental Resonance Amplitudes on Flat Sediments: An Example From the Atlantic Coastal Plain, Eastern United States. Schleicher, L. S., Pratt, T. L. Student: Fundamental Resonant Frequencies Derived From Shallow Sediment Properties for the Charleston, South Carolina Area. Schermerhorn, W. D., Liberty, L.
Tsunami Warning System in Latin America...

Tsunami Generated From

Asteroids Impacting Earth's

Oceans: Consequences

on Coastlines of Latin

America and the

Caribbean Region for

Disaster Response and Management Preparedness.

Ezzedine, S. M., Seiffert, E. R., Syal, M. B., Dearborn, D. S., Miller, P. L.

Tsunami Exercises on a Remote Basis: Costa Rican Experiences. RiveraCerdas, F. A., ChaconBarrantes, S. E.

Geophysical and Sea Level Monitoring in Puerto Rico, A Resilience Experience.

Huerfano, V. A., Martinez-Cruzado, J. A.

PRSN Annual

Communications Exercise Caribe Wave 2020

During the COVID-19

Pandemic, A Comparison With Previous Exercises.

Báez-Sánchez, G., Colon

Rodriguez, B., Santiago Perez, Y., Feliciano Ortega, A., Cordero Nieves, H., et al.

Oral Session Discussion

Afternoon Poster Session (see page 1272) 


\section{Late Afternoon Oral Session}

\begin{tabular}{|c|c|c|c|}
\hline & & & \\
\hline & $\begin{array}{l}\text { Updating the US National Seismic } \\
\text { Hazard Models III (see page 1451) }\end{array}$ & $\begin{array}{l}\text { Waveform Cross-Correlation- } \\
\text { Based Methods in Observational } \\
\text { Seismology II (see page 1459) }\end{array}$ & $\begin{array}{l}\text { The } 2020 \text { Simeonof Island, Alaska, } \\
\text { Earthquake: Observations, } \\
\text { Modeling and Tectonic Insights } \\
\text { (see page 1292) }\end{array}$ \\
\hline $\begin{array}{l}00 \mathrm{PM} \\
\text { acific }\end{array}$ & $\begin{array}{l}\text { Should Site Response Be } \\
\text { Incorporated Into Central U.S. } \\
\text { Hazard Maps? Carpenter, S., Wang, } \\
\text { Z., Zhu, Y., Woolery, E. W. }\end{array}$ & $\begin{array}{l}\text { Near the Trench Seismic Activity } \\
\text { Along the Guerrero Gap, Mexico } \\
\text { Explored Through an OBS Network. } \\
\text { Dominguez, L. A., Cruz-Atienza, V. } \\
\text { M., Ito, Y., Taira, T., Villafuerte, C., } \\
\text { et al. }\end{array}$ & $\begin{array}{l}\text { Persistent Late Holocene Megathrust } \\
\text { Creep Probably Accompanied M7-8 } \\
\text { Seismicity in the Region of the } \\
2020 \text { M7.8 Simeonof Island, Alaska, } \\
\text { Earthquake. Witter, R., Briggs, R. } \\
\text { W., Engelhart, S. E., Koehler, R. D., } \\
\text { Dura, T., et al. }\end{array}$ \\
\hline $\begin{array}{l}15 \mathrm{PM} \\
\text { acific }\end{array}$ & $\begin{array}{l}\text { Modeling Hazard From Induced } \\
\text { Seismicity in the Central and } \\
\text { Eastern U.S.. Kraner, M. L., Wang, } \\
\text { F., Shen-Tu, B. }\end{array}$ & $\begin{array}{l}\text { STUDENT: Novel Location Method } \\
\text { for ETS Tremor in Northern } \\
\text { Cascadia. Bombardier, M., Cassidy, } \\
\text { J. F., Kao, H., Dosso, S. }\end{array}$ & $\begin{array}{l}\text { The } 22 \text { July } 2020 \text { MW } 7.8 \text { Shumagin } \\
\text { Seismic Gap Earthquake: Partial } \\
\text { Rupture of a Weakly Coupled } \\
\text { Megathrust. Ye, L., Lay, T., } \\
\text { Kanamori, H., Yamazaki, Y., } \\
\text { Cheung, K. F. }\end{array}$ \\
\hline $\begin{array}{l}\text { 5:30 PM } \\
\text { Pacific }\end{array}$ & $\begin{array}{l}\text { Updating the USGS National } \\
\text { Seismic Hazard Model for Alaska. } \\
\text { Powers, P. M., Mueller, C. S., } \\
\text { Haeussler, P. J., Witter, R., Bender, } \\
\text { A. M. }\end{array}$ & $\begin{array}{l}\text { INViTED: Successes, Challenges and } \\
\text { Opportunities in Using Waveform } \\
\text { Cross-Correlation for Volcano } \\
\text { Monitoring. Hotovec-Ellis, A. J., } \\
\text { Thelen, W. A., Dawson, P. B., Shiro, } \\
\text { B., Wellik, J. J., et al. }\end{array}$ & $\begin{array}{l}\text { Postseismic Deformation Following } \\
\text { the July } 2020 \text { Simeonof Earthquake. } \\
\text { Freymueller, J. T., Elliott, J. L., } \\
\text { Grapenthin, R., Xiao, Z. }\end{array}$ \\
\hline $\begin{array}{l}5: 45 \text { PM } \\
\text { Pacific }\end{array}$ & $\begin{array}{l}\text { The } 2020 \text { M7.8 and M7.5 Alaska } \\
\text { Peninsula Earthquake Ground } \\
\text { Motions and Alaska-Specific } \\
\text { Ground Motion Models. Cramer, C. } \\
\text { H., Mahanama, A. }\end{array}$ & $\begin{array}{l}\text { Denoising Surface Waves Extracted } \\
\text { From Ambient Noise Using } \\
\text { Three-Station Interferometry: } \\
\text { Methodology and Application to 1D } \\
\text { Linear Array. Qiu, H., Niu, F., Qin, } \\
\text { L. }\end{array}$ & $\begin{array}{l}\text { Multi-Fault Rupture of the Mw } 7.6 \\
\text { Sand Point, Alaska, Earthquake. } \\
\text { Crowell, B. W., Melgar, D. }\end{array}$ \\
\hline $\begin{array}{l}\text { 6:00 PM } \\
\text { Pacific }\end{array}$ & $\begin{array}{l}\text { Web Tools for Users of the } 2018 \\
\text { USGS National Seismic Hazard } \\
\text { Model. Powers, P. M., Clayton, B. S., } \\
\text { Altekruse, J. M. }\end{array}$ & $\begin{array}{l}\text { STUDENT: Evidence of Shallow Fault } \\
\text { Zone Deformation in the Ridgecrest } \\
\text { Region From Ambient Noise } \\
\text { Tomography. Zhou, Z., Gerstoft, P., } \\
\text { Bianco, M., Olsen, K. B. }\end{array}$ & $\begin{array}{l}\text { STUDENT: Megathrust Earthquakes } \\
\text { Controlled by Incoming Plate } \\
\text { Geometry: The } 2020 \mathrm{M}>7.5 \\
\text { Shumagin, Alaska, Megathrust } \\
\text { Earthquake Doublet. Jiang, Y., } \\
\text { González, P. J., Bürgmann, R. }\end{array}$ \\
\hline $\begin{array}{l}: 15- \\
: 45 \mathrm{PM} \\
\text { acific }\end{array}$ & & Oral Session Discussion & \\
\hline
\end{tabular}

\section{Morning Poster Session}

11:30 AM-12:30 PM Pacific

Advances in Upper Crustal Geophysical Characterization (see page 1308)

- Student: Analysis of the 2016 Deep Remi Survey in Reno, NV. Scalise, M., Louie, J. N., Pancha, A., Smith, K. D.
- Calibration of the U.S. Geological Survey National Crustal Model for Seismic Hazard Studies. Boyd, O. S.

- Shallow Fault Location and Characterization in Complexly Deformed Zones Using Novel 3D Gravity Tomography: Examples From Dam Construction and Geothermal Assessment in Colorado. Levandowski, W., Turner, J., O'Connell, D., Steele, L., Isaacson, M., et al.

- Shallow Shear-Wave Velocity and Crustal Structure in the Seattle and Tacoma Basins From Microtremor Array Analysis. Stephenson, W. J., Odum, J. K., Leeds, A. 
5:00 PM

Pacific

5:15 PM

Pacific

5:30 PM

Pacific

5:45 PM

Pacific

6:00 PM

Pacific

6:15-

6:45 PM

Pacific
Application of Remote Sensing and Space-Based Earth Observations

Data in Earthquake Research I (see page 1315)

InVITED: The Latest Scientific

Results of CSES Mission. Zhima, Z.,

Shen, X., Misson, C.

Magnetospheric-Ionospheric-

Lithospheric Coupling Model-

Observations During the 5 August

2018 Bayan Earthquake. Piersanti,

M., Materassi, M., Battiston, R.,

Carbone, V., Cicone, A., et al.

Analyzing the Efficiency of Space-

Based Geodesy Data for the

Systematic Forecast of Earthquakes.

Gitis, V., Derendyaev, A., Petrov, K.

Satellite and Ground Based

Measured Ionospheric Variations

Over Seismic Active Areas.

Schirninger, C., Eichelberger, H.,

Boudjada, M., Schwingenschuh, K.,

Magnes, W., et al.

\section{Multi-Parameter Observation}

of Pre-Earthquake Signals in

Atmosphere-Ionosphere. Case Study

for M7.1 Ridgecrest, CA Earthquake

of July 2019. Ouzounov, D., Shen,

X., Pulinets, S., Rozhnoi, M.,

Davidenko, D., et al.
Sensors, Seismicity and Imaging

(see page 1429)

Very Broad Band (VBB) Borehole

Sensor With 5 Decades of Flat

Frequency Response From 0.00277

$\mathrm{Hz}$ (360 Seconds) to $277 \mathrm{~Hz}$ Is

Presented. Guralp, C. M.

Student: Analysis of Differences in

Seismic Moment Tensors Between

Global Catalogs. Rösler, B., Stein, S.

SH-SV Polarization Anisotropy:

Isotropic Interpretation of

Experimentally Measured Love and

Rayleigh Wave Phase Velocities and

Amplitude Attenuations. Schwab, F., Gurung, G., Lee, W., Jo, B.

P-Wave Arrival-Time Tomography

and Subsequent Full-Waveform

Inversion of the Middle East.

Desilva, S., Bozdag, E., Nolet, G.,

Gök, R., Ali, A., et al.

Shear-Wave Velocity Structure

Beneath North-Western Himalaya

and Adjoining Areas. Mir, R. R.,

Parvez, I. A., Gaur, V. K.

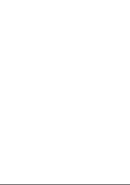

How Well Can We Assess Site

Effects So Far? IV (see page 1369)

Primary Linear Site Response

Parameters From Transfer Functions

and Ratios of Response Spectra.

Wang, Z., Carpenter, S.

High-Resolution Site Response

Study of the Los Angeles Basin From the 2019 Ridgecrest Earthquake

Sequence. Filippitzis, F., Kohler, M.,

Heaton, T., Clayton, R. W., Guy, R., et al.

Velocity Structure Identification at a Rock Site in Japan Based on Diffuse

Field Concept for Earthquake.

Nagashima, F., Kawase, H., Ito, E.

STUdENT: Development of a New

Methodology for Evaluation of Site

Fundamental Frequency and Its

Associated Uncertainty Based on

H/V Spectral Ratio Using an NGA-

West2 Dataset. Yazdi, M., Motamed,

R., Anderson, J. G.

Passive Site Response

Characterization Using Teleseismic

Receiver Functions From Wideband

Optical Accelerometers. Ball, J. S.,

Schulte-Pelkum, V., Meremonte, M.,

Schwarzer, J., Levish, D., et al.
Application of Remote Sensing and Space-Based Earth

Observations Data in Earthquake Research (see page 1318)

- Student: ALOS-2 Time Series of Deformation Near the Mendocino Triple Junction. Lindsay, D., Bürgmann, R., Materna, K.

- Student: Analysis of Swarm Satellite Magnetic Field Data Before the 2016 Ecuador (Mw=7.8) Earthquake Based on
Oral Session Discussion
Non-Negative Matrix Factorization. Fan, M., Zhu, K., He, X., Li, K., Marchetti, D., et al.

- LiCSAR Catalogue and Response System of Sentinel-1 Earthquake-Related Interferograms. Lazecky, M., Elliott, J., Watson, S., Maghsoudi Mehrani, Y., Wright, T.

- The Changes of the Tidal Force and the Land Surface Temperature During the Indonesia Mw7.5 Earthquake. Lu, X., Huang, Q. F. 
Cryptic Faults: Assessing Seismic Hazard on Slow Slipping, Blind or Distributed Fault Systems (see page 1337)

- Distributed Quaternary Faulting in the Española Basin, Central Rio Grande Rift. Thompson Jobe, J. A., Chupik, C. M., Longnecker, P.

- New Paleoseismic Data Demonstrate Holocene Activity Along the Dog Valley Fault, Truckee, CA. Pierce, I. K. D., Koehler, R. D.

Sensors, Seismicity and Imaging (see page 1430)

- Student: Catalog Update: A Detailed Earthquake Catalog for the San Jacinto Fault Zone Region in Southern California. White, M. C. A., Ben-Zion, Y., Vernon, F.

- An Initial Map of Scatterers in the Inner Core. Wang, W., Vidale, J. E.

- Testing a Rotational Seismometer in the Byerly Vault (BKS.BK). Hellweg, M., Rademacher, H.

The 2020 Simeonof Island, Alaska, Earthquake: Observations, Modeling and Tectonic Insights (see page 1293)

- Aftershock Sequence of the 22 July 2020 M7.8 Simeonof Earthquake, Alaska-Aleutian Subduction Zone. Ruppert, N. A., Karasozen, E.

- Coseismic Rupture Model of the 2020 Simeonof Earthquake Estimated from GPS, InSAR and Waveform Data. Freymueller, J. T., Xiao, Z., Grapenthin, R., Elliott, J. L., Fusso, L.

- Triggering an Unexpected Earthquake in an Uncoupled Subduction Zone. Herman, M. W., Furlong, K. P.

Updating the US National Seismic Hazard Models (see page 1454)

- Student: An Alternative Ground Motion Prediction Model for Induced Earthquake in Central and Eastern United States. Farajpour, Z., Pezeshk, S.

- Average Slip Profile of Earthquake Ruptures. Thingbaijam, K., Van Dissen, R. J., Shaw, B. E., Gerstenberger, M. C.

- Basin Amplification in Southern California From SCEC Cybershake Simulations. Moschetti, M. P., Rekoske, J. M., Withers, K. B., Thompson, E. M.

- Earthquake Catalog Completeness Threshold for California and Nevada. Zeng, Y., Petersen, M. D., Wang, W.

- Evaluation and Integration of Seismic Directivity Models for the USGS National Seismic Hazard Model. Withers, K. B., Moschetti, M. P., Thompson, E. M., Frankel, A., Moriarty, E., et al.
- Impacts on Catastrophe Risk Assessments from MultiSegment and Multi-Fault Ruptures in the UCERF3 Model. Lee, Y., Hu, Z., Daneshvaran, S., Sedaghati, F., Graf, W.

- Migrating USGS National Seismic Hazard Models to the Cloud. Clayton, B. S., Powers, P. M.

- MyShake: Using Smartphone Seismic Data to Map Site Effects Across Urban Environments. Allen, R., Kong, Q., Patel, S., Strauss, J.

- New Zealand Community Fault Model-Towards Version 1.0. Van Dissen, R. J., Seebeck, H.

- Properly Separating Uncertainties of Ground Motion Estimates Conditioned Upon Observational Data. Engler, D. T., Worden, C. B., Thompson, E. M., Jaiswal, K. S.

- Sensitivity and Preliminary Uncertainty Analysis for the USGS 2021 National Seismic Hazard Model for Hawaii. Shumway, A. M., Petersen, M. D., Powers, P. M., Altekruse, J. M.

- Simplification of Fault Traces for Use in the U.S. National Seismic Hazard Model. Collett, C. M., Hatem, A. E., Briggs, R. W., Gold, R. D.

- Updated Creep Rate Data Base and Models for the National Seismic Hazard Model. Wespestad, C., Johnson, K., Murray, J. R.

- USGS National Seismic Hazard Model Fault Section Database. Altekruse, J. M., Powers, P. M., Field, E. H.

\section{Afternoon Poster Session}

3:45-4:45 Pм Pacific

How Well Can We Assess Site Effects So Far? (see page

1374)

- Invited: The Applicability of Using HVSR to Evaluate SiteEffects, Verification of Vertical Arrays and Application for Stations in Western China. Rong, M.

- Student: Comparison of Site Amplifications Estimated Using Three Techniques in the Fort Worth Basin, Texas. Jeong, S., Stump, B., DeShon, H.

- An Open-Source Site Database of Strong-Motion Stations in Japan: K-Net and KiK-Net. Zhu, C., Weatherill, G., Cotton, F., Pilz, M., Kwak, D., et al.

- Student: Regional Attenuation Estimates for California Using Coda Waves. Ji, C., Cabas, A., Pilz, M., Kottke, A.

- Seismic and Liquefaction Hazard Maps for Four Western Tennessee Counties. Cramer, C. H., Van Arsdale, R., Arellano, D., Pezeshk, S., Horton, S., et al.

- Student: Seismic Site Response in the Binchuan Basin, Yunnan, China Inferred From Records at a Dense Linear Array. Song, J., Yang, H.

- Student: Site Response Study in the Greater Boston Area With an Investigation of the Magnitude 3.6 Bliss Corner 
Earthquake of November 2020. Salerno, J. A., Baise, L. G., Pontrelli, M. A., Ferris, A. N.

- The Soft Soil Effect of Marine Soil on Ground Motion Parameters. Peng, Y., Zhou, X., Zhao, Q., Liu, Y., Fang, Y.

- Student: Testing Site-Proxy and Non-Linear Amplification Models Using Site-Specific Variability. Loviknes, K., Kotha, S. R., Cotton, F., Schorlemmer, D.

- Three-Dimensional S-Wave Velocity Model of the South San Francisco Bay Area Obtained From Microtremor Array Measurements and Horizontal to Vertical Spectral Ratio. Hayashi, K., Burns, S.

- Student: An Update to the Global Geospatial Liquefaction Model With Uncertainty Propagation. Akhlaghi, M. M., Baise, L. G., Moaveni, B., Chansky, A. A., Meyer, M.

Waveform Cross-Correlation-Based Methods in Observational Seismology (see page 1461)

- Student: Analysis of Repeating Earthquakes Near the Locking Transition of New Zealand's Hikurangi Subduction Zone. Pita-Sllim, O. D., Chamberlain, C. J., Townend, J.

- Student: Clusty, A Versatile Waveform-Based Network Similarity Clustering Toolbox. Niemz, P., Petersen, G. M., Cesca, S., Mouslopoulou, V., Bocchini, G.

- Student: A Cross-Correlation Algorthim for Detecting Small Earthquakes in Frequency Domain. Ramirez Pina, C. R. P., Leon Soto, G. L. S., Hernandez Servin, J. H. S., Escudero Ayala, C. E. A.

- Student: Determination of the Near Surface Shear Wave Velocities in the Central Los Angeles Basin Using Dense Arrays. Jia, Z., Clayton, R. W.

- Student: New Microearthquake Catalog for the Parkfield Section of the San Andreas Fault, California. Neves, M., Peng, Z., Lin, G.

- Student: Persistent Seismicity and Missing Eruptivity: Analysis and Classification of 2003-2019 Earthquakes Recorded at Gareloi Volcano, Aleutian Islands, Alaska. Harris, K. T., Caplan-Auerbach, J., Power, J. A.
- Student: The Scattering Signal in Ambient Noise Correlation. Li, Y., Clayton, R. W.

- Seasonal Variations of Seismic Velocity From Air Gun and Ambient Noise Data in the Binchuan, Yunan, China. Liu, C., Yang, H.

- Student: Shallow Crustal Shear Velocity and Vp/Vs Across Southern California: Joint Inversion of ShortPeriod Rayleigh Wave Ellipticity, Phase Velocity and Onset of Teleseismic Receiver Functions. Berg, E. M., Lin, F., Schulte-Pelkum, V., Allam, A., Qiu, H.

- Student: Signatures of Seismic Waveguides in Los Angeles From Numerical Simulations and Noise Cross Correlations. Wang, N., Schmitt, J., Denolle, M., Olsen, K. B., Clements, T., et al.

What Can We Infer About the Earthquake Source Through Analyses of Strong Ground Motion? (see page 1466)

- A Community Stress Drop Validation Study Using the 2019 Ridgecrest Earthquake Dataset. Baltay, A., Abercrombie, R. E., Taira, T.

- Directly Inverting Strong-Motion Data for Fault Stress Evolution of the Coseismic Process. Duan, B., Meng, Q., Liu, D., Cai, Y.

- Student: Inferring Critical Slip-Weakening Distance From Near-Fault Accelerogram of the $2014 \mathrm{Mw} 6.2$ Ludian Earthquake. Chen, X., Yang, H.

- A Mechanism That Can Lead to a Slip Patch With Extremely Large Stress Drop. Nozu, A.

- Quantifying the Sensitivity of Microearthquake Slip Inversions to Station Distribution Using a Dense Nodal Array. Pennington, C. N., Chang, H., Rubinstein, J. L., Abercrombie, R. E., Nakata, N., et al.

- Seismic Energy Radiated by Earthquakes Near the Rupture Area of the $1887 \mathrm{Mw} 7.5$ Sonora, Mexico Earthquake. Castro, R. R., Villalobos-Escobar, G. P.

- Validating the Graves-Pitarka Broadband Simulation Method Using a Grid-Search Technique. Graves, R. W. 


\section{Thursday, 22 April 2021—Morning Oral Session}

Presenting author is indicated in bold.

\begin{tabular}{|c|c|c|c|c|}
\hline \multirow[t]{2}{*}{$\begin{array}{l}\text { 8:30-9:30 } \\
\text { AM Pacific }\end{array}$} & \multicolumn{4}{|c|}{ The Future of Space Geodesy in Earth Science and Hazards } \\
\hline & $\begin{array}{l}\text { Advances in the Science } \\
\text { and Observation of } \\
\text { Tsunamis (see page 1301) }\end{array}$ & $\begin{array}{l}\text { Fault Displacement } \\
\text { Hazard: New Data and } \\
\text { Modeling Advances I (see } \\
\text { page } 1360 \text { ) }\end{array}$ & $\begin{array}{l}\text { Infrasound and the } \\
\text { Seismo-Acoustic } \\
\text { Wavefield III (see page } \\
1378 \text { ) }\end{array}$ & $\begin{array}{l}\text { Network Seismology: } \\
\text { Keeping the Network } \\
\text { Running While } \\
\text { Integrating New } \\
\text { Technologies I (see page } \\
\text { 1398) }\end{array}$ \\
\hline $\begin{array}{l}9: 45 \text { AM } \\
\text { Pacific }\end{array}$ & $\begin{array}{l}\text { STUDENT: Anatomy of } \\
\text { Strike Slip Fault Tsunami- } \\
\text { Genesis. Elbanna, A., } \\
\text { Abdelmeguid, M., Ma, } \\
\text { X., Amlani, F., Bhat, H. S., } \\
\text { et al. }\end{array}$ & $\begin{array}{l}\text { An Overview of the Fault } \\
\text { Displacement Hazard } \\
\text { Initiative Research } \\
\text { Program. Bozorgnia, Y., } \\
\text { Abrahamson, N., Arcos, } \\
\text { M. E., Baize, S., Boncio, P., } \\
\text { et al. }\end{array}$ & $\begin{array}{l}\text { Detecting and Locating } \\
\text { Acoustic Events With } \\
\text { a Balloon Borne } \\
\text { Aeroseismometer. } \\
\text { Bowman, D. C., Rouse, J. } \\
\text { W., Krishnamoorthy, S. }\end{array}$ & $\begin{array}{l}\text { Keeping the Global } \\
\text { Seismographic Network } \\
\text { (GSN) Operational During } \\
\text { Covid. Hafner, K., Wilson, } \\
\text { D., Mellors, R., Davis, P. }\end{array}$ \\
\hline $\begin{array}{l}\text { 10:00 AM } \\
\text { Pacific }\end{array}$ & $\begin{array}{l}\text { How the Parameters of } \\
\text { a Seismic Surface Wave } \\
\text { Governs the Properties } \\
\text { of the FGSS Waves in } \\
\text { the Ocean. Sementsov, } \\
\text { K. A., Kolesov, S. V., } \\
\text { Nurislamova, G. N., } \\
\text { Nosov, M. A. }\end{array}$ & $\begin{array}{l}\text { A Next-Generation } \\
\text { Fault Displacement and } \\
\text { Surface Rupture Database. } \\
\text { Sarmiento, A., Baize, S., } \\
\text { Boncio, P., Bozorgnia, Y., } \\
\text { Dawson, T., et al. }\end{array}$ & $\begin{array}{l}\text { Infrasound Transmission } \\
\text { in the "Shadow Zone" } \\
\text { Observed on Balloons in } \\
\text { the Lower Stratosphere. } \\
\text { Kero, J., Bowman, D. C., } \\
\text { Bird, E. J. }\end{array}$ & $\begin{array}{l}\text { Seismic Monitoring } \\
\text { During Crises at the NEIC } \\
\text { in Support of the ANSS. } \\
\text { Earle, P. S., Benz, H., Yeck, } \\
\text { W. L., Hayes, G. P., Guy, } \\
\text { M., et al. }\end{array}$ \\
\hline $\begin{array}{l}\text { 10:15 AM } \\
\text { Pacific }\end{array}$ & $\begin{array}{l}\text { STUDENT: Measuring the } \\
\text { Background Open-Ocean } \\
\text { Tsunami Spectrum Using } \\
\text { the Pacific Basin Dart } \\
\text { Array. Santellanes, S., } \\
\text { Melgar, D. }\end{array}$ & $\begin{array}{l}\text { STUDENT: A Fault } \\
\text { Displacement Model } \\
\text { Formulated in } \\
\text { Wavenumber Domain. } \\
\text { Lavrentiadis, G., } \\
\text { Abrahamson, N. }\end{array}$ & $\begin{array}{l}\text { Near and Far-Field } \\
\text { Seismo-Acoustic Analysis } \\
\text { of Mb } 4.9 \text { Mining Induced } \\
\text { Earthquake Nearby } \\
\text { Kiruna, Sweden. Turquet, } \\
\text { A. L., Brissaud, Q., Kero, } \\
\text { J., Näsholm, S., Le Pichon, } \\
\text { A., et al. }\end{array}$ & $\begin{array}{l}\text { The Alaska Transportable } \\
\text { Array: Technical Advances } \\
\text { Among Challenges. } \\
\text { Busby, R. W., Aderhold, } \\
\text { K., Bierma, R., Miner, J., } \\
\text { Staats, M., et al. }\end{array}$ \\
\hline $\begin{array}{l}\text { 10:30 AM } \\
\text { Pacific }\end{array}$ & $\begin{array}{l}\text { STUDENT: Real-Time } \\
\text { Tsunami Data Assimilation } \\
\text { of S-Net Pressure Gauge } \\
\text { Records During the } 2016 \\
\text { Fukushima Earthquake. } \\
\text { Wang, Y., Satake, K. }\end{array}$ & $\begin{array}{l}\text { STUDENT: Probability } \\
\text { of Distributed Surface } \\
\text { Rupturing Occurrence and } \\
\text { Displacement Regression } \\
\text { for Normal and Reverse } \\
\text { Earthquakes. Nurminen, } \\
\text { F., Visini, F., Baize, S., } \\
\text { Boncio, P., Pace, B., et al. }\end{array}$ & $\begin{array}{l}\text { Seismo-Acoustic } \\
\text { Signatures of Proximal } \\
\text { Earthquakes From } \\
\text { the Stanley, ID, USA } \\
\text { Aftershock Sequence } \\
\text { in 2020. Johnson, J. B., } \\
\text { Anderson, J., Wilbur, S. F., } \\
\text { Arrowsmith, S., Mikesell, } \\
\text { T. D., et al. }\end{array}$ & $\begin{array}{l}\text { INVITED: Practical } \\
\text { Uncertainty for Network } \\
\text { Seismology with Machine } \\
\text { Learning. Dickey, J. T., } \\
\text { Pena, R. }\end{array}$ \\
\hline
\end{tabular}




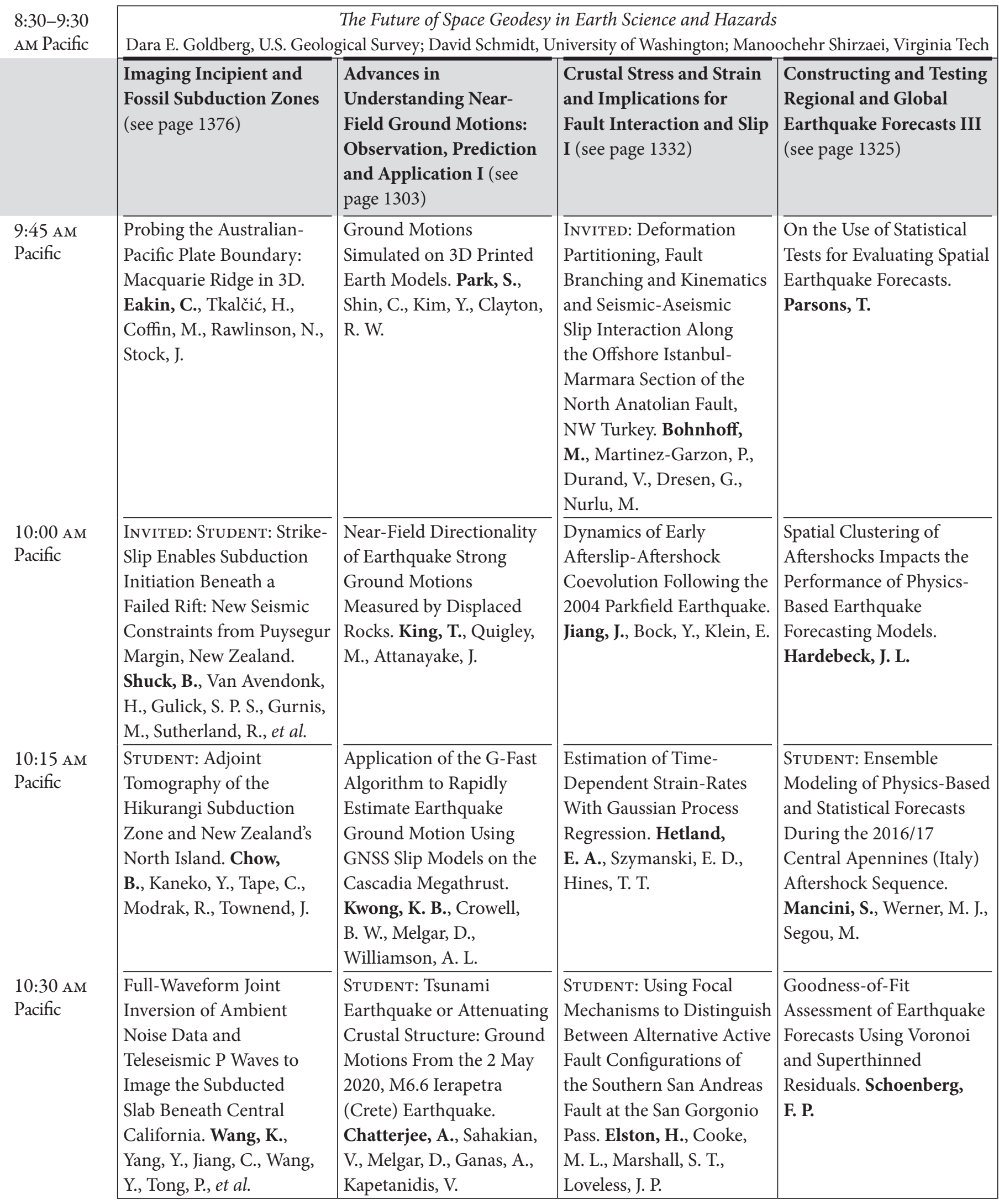




\begin{tabular}{|c|c|c|c|c|}
\hline & $\begin{array}{l}\text { Advances in the Science } \\
\text { and Observation... }\end{array}$ & $\begin{array}{l}\text { Fault Displacement } \\
\text { Hazard: New Data... }\end{array}$ & $\begin{array}{l}\text { Infrasound and the } \\
\text { Seismo-Acoustic... }\end{array}$ & $\begin{array}{l}\text { Network Seismology: } \\
\text { Keeping the Network... }\end{array}$ \\
\hline $\begin{array}{l}\text { 10:45 AM } \\
\text { Pacific }\end{array}$ & $\begin{array}{l}\text { Rapid GNSS Source and } \\
\text { DART Inversion Models } \\
\text { Comparison along the } \\
\text { Cascadia Subduction } \\
\text { Zone. Sannikova, N. K., } \\
\text { Wei, Y., Arcas, D., Kwong, } \\
\text { K. B., Williamson, A. L., } \\
\text { et al. }\end{array}$ & $\begin{array}{l}\text { Updating Reverse Fault } \\
\text { PFDHA Models and } \\
\text { Distributions. Moss, R. E. } \\
\text { S., Kuo, C., Thompson, S. } \\
\text { C., Chao, S., Younesi, K. }\end{array}$ & $\begin{array}{l}\text { STUDENT: Changes } \\
\text { in Ambient Urban } \\
\text { Infrasound During the } \\
\text { COVID-19 Pandemic. } \\
\text { Bird, E. J., Bowman, D. C., } \\
\text { Seastrand, D. R., Wright, } \\
\text { M. A., Lees, J. M., et al. }\end{array}$ & $\begin{array}{l}\text { Implementing Machine- } \\
\text { Learning Earthquake } \\
\text { Detection to Augment the } \\
\text { Public Regional Seismic } \\
\text { Network in Oklahoma. } \\
\text { Walter, J., Ogwari, P. } \\
\text { O., Thiel, A., Ferrer, F., } \\
\text { Woelfel, I. }\end{array}$ \\
\hline $\begin{array}{l}\text { 11:00-11:30 } \\
\text { AM Pacific }\end{array}$ & \multicolumn{4}{|c|}{ Oral Session Discussion } \\
\hline $\begin{array}{l}\text { 11:30 AM- } \\
\text { 12:30 PM } \\
\text { Pacific }\end{array}$ & \multicolumn{4}{|c|}{ Morning Poster Session (see page 1280) } \\
\hline
\end{tabular}

\section{Early Afternoon Oral Session}

\begin{tabular}{|c|c|c|c|c|}
\hline \multirow{3}{*}{$\begin{array}{l}\text { 12:30- } \\
1: 30 \mathrm{PM} \\
\text { Pacific } \\
1: 30- \\
2: 00 \mathrm{PM} \\
\text { Pacific }\end{array}$} & \multicolumn{4}{|c|}{$\begin{array}{c}\text { Rules and Outliers in Seismology-Implications for Hazard Mitigation Strategy } \\
\text { Hiroo Kanamori, Caltech }\end{array}$} \\
\hline & \multicolumn{4}{|c|}{ Break } \\
\hline & $\begin{array}{l}\text { Recent Engineering } \\
\text { Uses of National Seismic } \\
\text { Hazard Models I (see page } \\
1424 \text { ) }\end{array}$ & $\begin{array}{l}\text { Physics-Based } \\
\text { Earthquake Rupture } \\
\text { Modeling and Strong } \\
\text { Motion Simulations I (see } \\
\text { page 1413) }\end{array}$ & $\begin{array}{l}\text { The } 7 \text { January } 2020 \\
\text { South of Indios (M6.4) } \\
\text { Earthquake in Puerto } \\
\text { Rico, Response and } \\
\text { Lessons (see page 1294) }\end{array}$ & $\begin{array}{l}\text { Network Seismology: } \\
\text { Keeping the Network } \\
\text { Running While Integrating } \\
\text { New Technologies II (see } \\
\text { page 1398) }\end{array}$ \\
\hline $\begin{array}{l}\text { 2:00 PM } \\
\text { Pacific }\end{array}$ & $\begin{array}{l}\text { The 6th Generation } \\
\text { Seismic Hazard Model of } \\
\text { Canada. Kolaj, M., Adams, } \\
\text { J., Halchuk, S. }\end{array}$ & $\begin{array}{l}\text { STUDENT: 3D Wave } \\
\text { Propagation Simulations of } \\
\text { the } 2019 \text { M7.1 Ridgecrest, } \\
\text { CA, Earthquake. Yeh, T., } \\
\text { Olsen, K. B. }\end{array}$ & $\begin{array}{l}\text { Assisting the Puerto Rico } \\
\text { Seismic Network as a } \\
\text { Science Communicator } \\
\text { During the } 7 \text { January } 2020 \\
\text { S of Indios Earthquake in } \\
\text { Puerto Rico. Jaramillo- } \\
\text { Nieves, L. G. }\end{array}$ & $\begin{array}{l}\text { Machine Learning and } \\
\text { the } 2020 \text { Magna, Utah } \\
\text { Earthquake Sequence. } \\
\text { Baker, B., Holt, M. M., } \\
\text { Pankow, K. L., Koper, K. } \\
\text { D., Farrell, J. }\end{array}$ \\
\hline $\begin{array}{l}2: 15 \text { PM } \\
\text { Pacific }\end{array}$ & $\begin{array}{l}\text { INVITED: National } \\
\text { Building Code of Canada } \\
\text { (NBCC)-Earthquake } \\
\text { Design Philosophy and } \\
\text { Perspective, New Low } \\
\text { Damage Performance } \\
\text { Checks for } 2020 \text { Edition, } \\
\text { Impact Analysis of New } \\
\text { Items, Summary of NBCC } \\
\text { Process for Revisions } \\
\text { to Earthquake Code } \\
\text { Provisions. Sherstobitoff, J. }\end{array}$ & $\begin{array}{l}\text { Deterministic } 0-5 \mathrm{~Hz} \\
\text { Ground Motion } \\
\text { Simulations of the Mw 6.5, } \\
30 \text { October } 2016 \text { Norcia, } \\
\text { Italy Earthquake. Pitarka, } \\
\text { A., Akinci, A., Buttinelli, } \\
\text { M., De Gori, P. }\end{array}$ & $\begin{array}{l}\text { Preliminary Shakemap } \\
\text { Computation for the } \\
\text { Indios M6.4 Earthquake, } \\
7 \text { January 2020, Puerto } \\
\text { Rico. Huerfano, V. A., } \\
\text { Martinez-Cruzado, J. A., } \\
\text { Hernandez, F. }\end{array}$ & $\begin{array}{l}\text { Modeling Seismic Network } \\
\text { Detection Thresholds } \\
\text { Using Production Picking } \\
\text { Algorithms. Wilson, D., } \\
\text { Wolin, E., Ringler, A., } \\
\text { Anthony, R., Yeck, W. L. }\end{array}$ \\
\hline
\end{tabular}


10:45 AM

Pacific

11:00-11:30 AM Pacific

11:30 AM-

12:30 PM

Pacific

\section{Advances in}

Understanding...

Student: Modelling Rapid

Near Field Attenuation

from Shallow Induced

Earthquakes, Case Study:

Preston New Road, UK.

Suroyo, P. M. T., Edwards,

B.

Wehner, D., Blom, N.,

Rawlinson, N., Miller, M.

S., Widiyantoro, S., et al.

Crustal Stress and Strain and Implications...

Student: Analyzing Strain Partitioning in the Pacific

Northwest with Block Models. Chong, J., Evans, E. L.
Constructing and Testing Regional and Global...

Retrospective Evaluation of Weekly UCERF3-ETAS forecasts of California Seismicity. Savran, W., Milner, K., Field, E. H., Werner, M. J.

Morning Poster Session (see page 1280)

12:30-

$1: 30 \mathrm{PM}$

Pacific

$1: 30-$

2:00 PM

Pacific

2:00 PM

Pacific

2:15 PM

Pacific

\section{Rules and Outliers in Seismology-Implications for Hazard Mitigation Strategy} Hiroo Kanamori, Caltech

Break

Analyses and Implications of the 4 August 2020 Beirut Explosion Series I (see page 1312)

A Seismic Yield Estimate for the 2020 Beirut Explosion Using FullWaveform Envelope Predictions and Calibrated Site and Path Models. Yoo, S., Reiter, D.

Seismoacoustic Summary Analysis of the 2020 Beirut Explosion.

Begnaud, M. L., Blom, P. S., Phillips, W. S., Babikoff, J., Rowe, C. A., et al.
Advances in Understanding Near-Field Ground Motions: Observation, Prediction and Application II (see page 1303)

An Empirical Ground-Motion Model Based on Truncated Regression: A Case Study in the Middle East. Kuehn, N., Kishida, T., AlHamaydeh, M., Bozorgnia, Y., Ahdi, S. K.

Student: Source, Path and Site Parameters: Validation and Calibration for the Northern Marmara Region, Turkey. Suleyman, H., Çaktı, E.
Crustal Stress and Strain and Implications for Fault Interaction and Slip II (see page 1332)

INVITED: How Stressed Out Are Faults? Estimating Co-Seismic Stress Using Measurements of 3D Surface Deformation With Optical Image Correlation. Milliner, C. W. D.

\section{Stress-Strain Characterization} of Seismic Source Fields Using Moment Measures of Mechanism Complexity. Jordan, T. H., Juarez, A. 


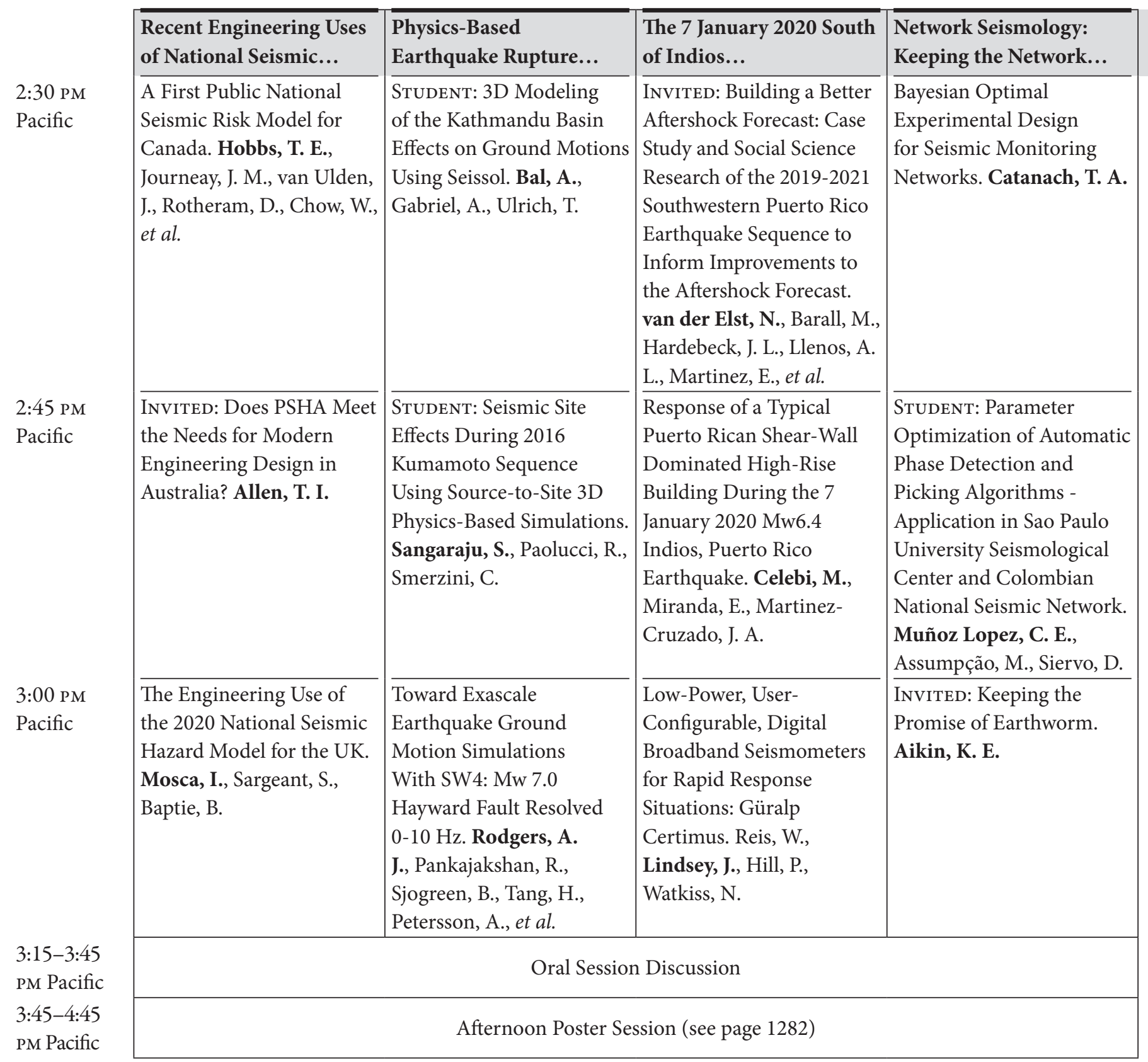

\section{Late Afternoon Oral Session}

\begin{tabular}{|c|c|c|c|}
\hline & $\begin{array}{l}\text { Recent Engineering Uses of } \\
\text { National Seismic Hazard Models II } \\
\text { (see page } 1424 \text { ) }\end{array}$ & $\begin{array}{l}\text { Advances in Real-Time } \\
\text { Geophysical Network Operations } \\
\text { and Data Analytics (see page 1296) }\end{array}$ & $\begin{array}{l}\text { Advances in Seismic } \\
\text { Interferometry: Theory, } \\
\text { Computation and Applications } \\
\text { (see page 1298) }\end{array}$ \\
\hline $\begin{array}{l}\text { 5:00 PM } \\
\text { Pacific }\end{array}$ & $\begin{array}{l}\text { The Interplay Between the } 2018 \\
\text { USGS National Seismic Hazard } \\
\text { Model and Forthcoming Updates to } \\
\text { U.S. Building Codes. Rezaeian, S., } \\
\text { Luco, N. }\end{array}$ & $\begin{array}{l}\text { INviTED: Application of Big Data } \\
\text { Technologies on Real-Time Seismic } \\
\text { Data Stream Processing. Huang, X., } \\
\text { Ma, Y., Chen, T., Han, X., Chen, H. }\end{array}$ & $\begin{array}{l}\text { Ambient Noise Surface-Wave } \\
\text { Tomography of the San Francisco } \\
\text { Bay Area, California. Nayak, A., } \\
\text { Taira, T. }\end{array}$ \\
\hline
\end{tabular}




\begin{tabular}{|c|c|c|c|}
\hline & $\begin{array}{l}\text { Analyses and Implications of the } 4 \\
\text { August } 2020 \text { Beirut Explosion... }\end{array}$ & $\begin{array}{l}\text { Advances in Understanding Near- } \\
\text { Field Ground Motions... }\end{array}$ & $\begin{array}{l}\text { Crustal Stress and Strain and } \\
\text { Implications... }\end{array}$ \\
\hline $\begin{array}{l}2: 30 \mathrm{PM} \\
\text { Pacific }\end{array}$ & $\begin{array}{l}\text { Seismo-Acoustic Yield } \\
\text { Determination of the } 4 \text { August } 2020 \\
\text { Beirut Explosion. Pasyanos, M. E., } \\
\text { Kim, K. }\end{array}$ & $\begin{array}{l}\text { STUDENT: San Francisco Bay Area } \\
\text { Kappa Model. Nye, T., King, E., } \\
\text { Klimasewski, A., Sahakian, V., } \\
\text { Baltay, A. }\end{array}$ & $\begin{array}{l}\text { STUDENT: Stress-Strain } \\
\text { Characterization of Seismic } \\
\text { Sequences in Southern California } \\
\text { Using Moment Measures of } \\
\text { Mechanism Complexity. Juarez, A., } \\
\text { Jordan, T. H. }\end{array}$ \\
\hline $\begin{array}{l}\text { 2:45 PM } \\
\text { Pacific }\end{array}$ & $\begin{array}{l}\text { Non-Linear Simulation of the } 2020 \\
\text { Beirut Explosion: Energy Coupling } \\
\text { at Ground-Air-Sea Interfaces, } \\
\text { Cratering, Hydroacoustic and } \\
\text { Seismoacoustic Conversion and } \\
\text { Signatures. Ezzedine, S. M. }\end{array}$ & $\begin{array}{l}\text { P-Phase Arrival Time Picking for } \\
\text { Near-Field Data. Zhou, R., Lee, R. } \\
\text { F., McCleave, J. }\end{array}$ & $\begin{array}{l}\text { STUDENT: Beyond the Damage } \\
\text { Zone: Characterizing Widespread } \\
\text { Inelastic Deformation From } \\
\text { Integrated Fracture, Aftershock and } \\
\text { Strain Maps of the } 2019 \text { Ridgecrest } \\
\text { Sequence. Rodriguez Padilla, A. } \\
\text { M., Oskin, M. E., Milliner, C. W. D., } \\
\text { Plesch, A. }\end{array}$ \\
\hline $\begin{array}{l}\text { 3:00 PM } \\
\text { Pacific }\end{array}$ & $\begin{array}{l}\text { Blast Impacts of August } 2020 \\
\text { Beirut Explosion From Ground } \\
\text { Observations and Satellite Data. } \\
\text { Sadek, S., Dabaghi, M., Zimmaro, P., } \\
\text { O’Donnell, T., Yun, S., Hashash, Y. } \\
\text { M. A., Stewart, J. P. }\end{array}$ & $\begin{array}{l}\text { Application of Polarization Analysis } \\
\text { to Direction-Finding in the Urban } \\
\text { Environment. Lee, R. F., Zhou, R. }\end{array}$ & $\begin{array}{l}\text { Strain Compatibility Between the } \\
\text { Intersecting Airport Lake and } \\
\text { Garlock Faults, California. Walker, } \\
\text { J., Andrew, J. E., Kirby, E. }\end{array}$ \\
\hline $\begin{array}{l}\text { 3:15-3:45 } \\
\text { PM Pacific }\end{array}$ & \multicolumn{3}{|c|}{ Oral Session Discussion } \\
\hline $\begin{array}{l}3: 45-4: 45 \\
\text { PM Pacific }\end{array}$ & \multicolumn{3}{|c|}{ Afternoon Poster Session (see page 1282) } \\
\hline
\end{tabular}

Application of Remote Sensing and Space-Based Earth Observations Data in Earthquake Research II (see page 1315)

5:00 PM Pacific
INVITED: Earthquake Precursory Signals in Ionosphere From Swarm and CSES Satellites. De Santis, A., Campuzano, S. A., Cianchini, G., Di Mauro, D., Marchetti, D., et al.
Critical Zone, Environmental and Cryospheric Seismology (see page 1329)

Multidisciplinary Analysis of the Deadly Snow Avalanche of 18 January 2017 at Rigopiano (Central Italy). Braun, T., Bartelt, P., Chiaia, B., Frigo, B., Famiani, D., et al. 


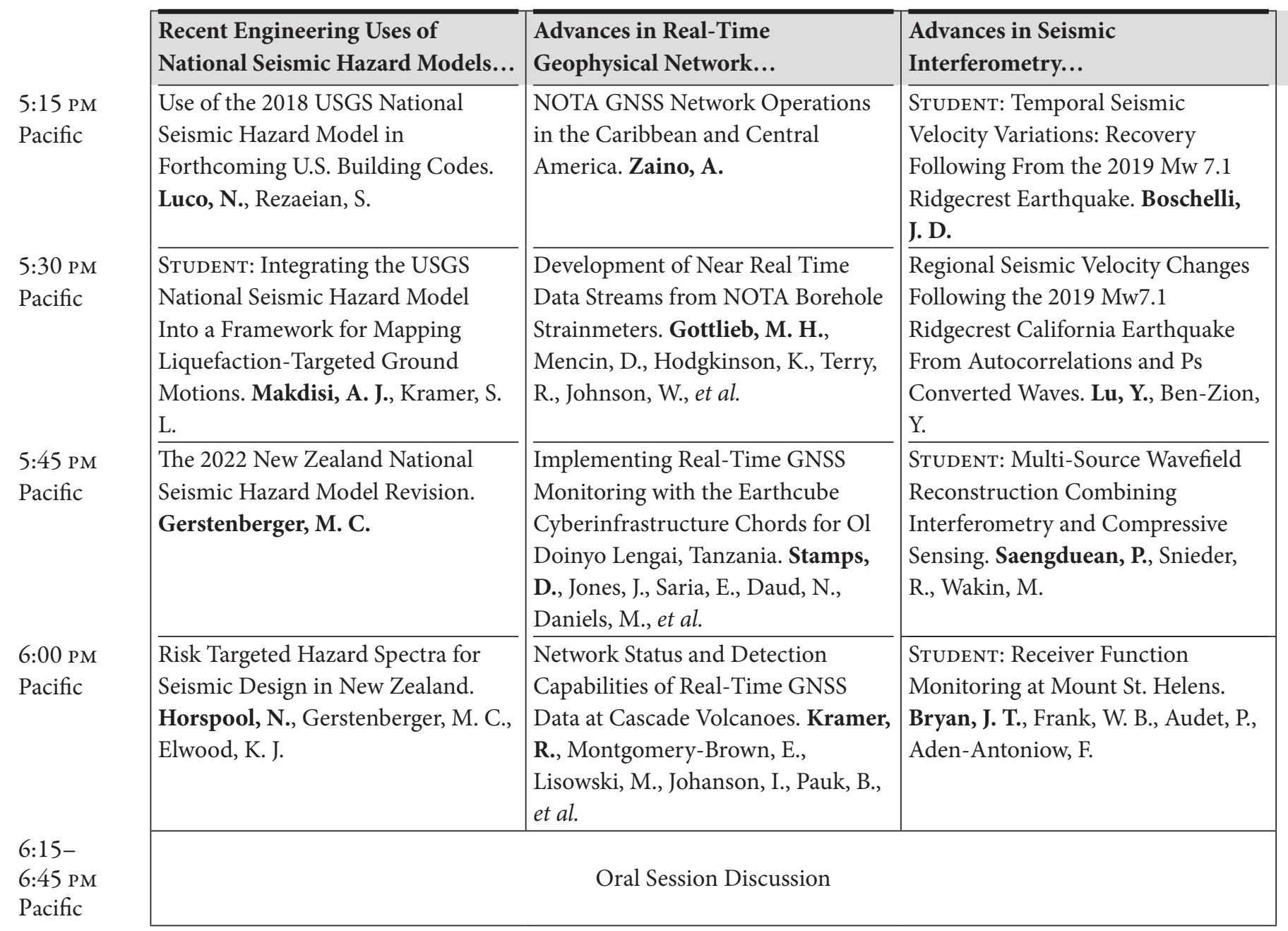

\section{Morning Poster Session}

11:30 AM-12:30 PM Pacific

The 7 January 2020 South of Indios (M6.4) Earthquake in Puerto Rico, Response and Lessons (see page 1295)

- Operational Response of the PRSN for the Puerto Rico 6.4 M Earthquake and the South of Puerto Rico Seismic Sequence. Báez-Sánchez, G., Miranda Berrocales, V. M., Colon Rodriguez, B., Perez Paulino, J. E., Cordero Nieves, $\mathrm{H}$.

- Towards a Local-Regional Coda Source Calibration for Puerto Rico: Modeling Moment Tensors, Apparent Stress and Scaled Energy From the 2019-2020 Earthquake Sequence. Roman-Nieves, J. I., Mayeda, K., SotoCordero, L.
Advances in Seismic Interferometry: Theory, Computation and Applications (see page 1299)

- Student: Bayesian Analysis of Ambient Noise Cross Correlation Functions Using a Low-Quality Seismic Network. Xue, S., Zhang, Z., Olugboji, T.

- Full Waveform Tomography for the Upper South Island Region, New Zealand Using Ambient Noise Data. Nguyen, $T$.

- Imaging Yellowstone's Melt Distribution With Full Waveform Inversion of Ambient Noise. Maguire, R. R., Chen, M., Schmandt, B., Jiang, C., Wilgus, J., et al.

- Impact of Atmospheric Pressure Variations on NoiseBased Seismic Velocity Changes Measurements. Gradon, C., Brenguier, F., Mordret, A., Stammeijer, J., Hindriks, K., et al.

- On the Feasibility of Long-Term Seismic Monitoring Using Freight Train Signals. Sheng, Y., Brenguier, F., Boué, P., Mordret, A., Ben-Zion, Y., et al. 
5:15 PM

Pacific

5:30 PM

Pacific

5:45 PM

Pacific

6:00 PM

Pacific

$6: 15-$

6:45 PM

Pacific
Application of Remote Sensing and Space-Based Earth Observations Data...

Student: A Feature-Based Liquefaction Repository From Aerial and Satellite Imagery for Computer Vision Analysis. Sanon, C.

Atmospheric Parametric Spatiotemporal Characteristics of the 2008 Wenchuan, 2010 Yushu, 2013 Lushan and 2017 Jiuzhaigou Earthquakes in the Eastern Margin of Bayan Har Block and Discussion on Genesis and Prediction of Continental Earthquakes. Cui, J., Shen, X., Ma, W., Wang, X.

CSES Electron Density Background Characterization and Preliminary Investigation of Possible Ne Increase Before Earthquake Occurrence. Marchetti, D., Perrone, L., Zhu, K., De Santis, A., He, X., et al.

Ionospheric Layer Variability Prior to Strong Earthquakes During Quiet Geomagnetic Conditions. Boudjada, M., Eichelberger, H., Zhang, X., Magnes, W., Denisenko, V., et al.
Critical Zone, Environmental and Cryospheric Seismology...

Can Machine Learning improve Debris Flow Warning?

Chmiel, M., Walter, F., Wenner, M., Zhang, Z., McArdell, B., et al.

Seismic Elastic Waveform Inversion for Characterizing Vp and Vs Models of Critical Zone. Liu, X., Zhu, T.

Analysis of Seismic Signals Generated by Vehicle Traffic with Application to Derivation of Subsurface Q Values. Meng, H., Ben-Zion, Y., Johnson, C.

STudent: A Robust Time-Domain Early-Arrival Seismic Waveform Inversion Method Using Data Uncertainties. Cai, A., Zelt, C. A.

Oral Session Discussion

- Optimize the Stacking of Noise Correlation Functions. Yang, X., Bryan, J. T., Okubo, K., Jiang, C., Clements, T., et al.

- Virtual Seismometer Method for Fault Orientation Analysis in Southern Kansas. Morency, C., Matzel, E., Kroll, K.

- Wave Propagation in an 18-Story Steel Building and the Changes of Wave Filed With the Progression of Damages. Wang, $X$.

Advances in Understanding Near-Field Ground Motions: Observation, Prediction and Application (see page 1305)

- Developing a Near-Field Ground Motion Model With GNSS Peak Ground Displacement. Goldberg, D. E., Melgar, D., Hayes, G. P., Crowell, B. W., Benz, H.

- Student: Within and Between-Event Variability of Mw 6-7 Earthquakes Velocity Pulses in Taiwan and Japan. Yen, M., von Specht, S., Lin, Y., Cotton, F., Ma, K.
Crustal Stress and Strain and Implications for Fault Interaction and Slip (see page 1334)

- Student: Constraints on Crustal Stress in South Island, New Zealand from Coseismic Slip Models of the 2016 Kaikoura, 2010 Darfield and 2011 Christchurch Earthquakes. Helprin, O. L., Hetland, E. A.

- Crustal Stress Orientations in Japan Islands Inferred From Focal Mechanism Solutions of Small and Microearthquakes. Uchide, T., Imanishi, K.

- Student: Investigation of Stress Field in Northeast of Iran With Iterative Joint Inversion of Earthquakes Focal Mechanisms. Khojasteh, F., Beyranvand, M., Mirzaei, N.

- Spatiotemporal Variations of Stress in the Crust Near 2019 Ridgecrest Sequence Earthquakes. Abolfathian, N., Fielding, E. J. 
Network Seismology: Keeping the Network Running While Integrating New Technologies (see page 1401)

- A Hybrid-Cloud Approach to Improving Resilience of Seismic Data Acquisition at Alaska Volcano Observatory. Parker, T. J., Benavidez, A.

- Improving Regional Earthquake Focal Depth Location in Oklahoma Using 3D Velocity Model. Ogwari, P. O., Walter, J., Thiel, A., Ferrer, F., Woelfel, I., et al.

- Student: Local Magnitude (Ml) Calibration for the Puerto Rico Seismic Network. Rosero-Rueda, S., Huerfano, V. A., Vanacore, E. A., Lopez-Venegas, A.

- Monitoring Performance at the U.S. Geological Survey's National Earthquake Information Center. Yeck, W. L., Earle, P. S., Guy, M., Ambruz, N. B., Patton, J., et al.

- Mw From Coda Envelopes for Small Earthquakes in Utah. Whidden, K. M., Holt, J., Mayeda, K., Gök, R., Shelly, D. R., et al.

- A Review of Timing Accuracy Across the Global Seismographic Network. Ringler, A., Anthony, R., Wilson, D., Auerbach, D., Bargabus, S., et al.

- ROBUST, An Earthquake Early Warning System in the Lower Rhine Embayment, Germany. Najdahmadi, B., Pilz, M., Bindi, D., Njara Tendrisoa Razafindrakoto, H., Oth, A., et al.

- Student: Seismic Noise Tests in Mammoth Cave, USA. Schmidt, J. P.

Recent Engineering Uses of National Seismic Hazard Models (see page 1426)

- Evaluation of Earthquake Scenarios for the Greater Montreal Area. Chouinard, L., Rosset, P., Nollet, M.

- Long-Term Averaged Earthquake Loss Estimations for Istanbul. Hancilar, U., Şeşetyan, K., Çaktı, E.

\section{Afternoon Poster Session}

\section{3:45-4:45 PM Pacific}

Advances in the Science and Observation of Tsunamis (see page 1302)

- Student: Comparison of Machine Learning Approaches for Tsunami Forecasting. LeVeque, R. J., Liu, C. M., Rim, D., Baraldi, R.

- Contribution of Smart Cables to Earthquake and Tsunami Early Warning in the Sumatra and Java Regions. Salaree, A., Howe, B., Huang, Y.

- Student: Moment and Rupture Duration From Seismogeodetic Data for Local Tsunami Warnings. Golriz, D., Hirshorn, B., Bock, Y., Weinstein, S.
- Speed vs. Precision: The Tsunami Warning Center Duty Scientists' Dilemma. Sardina, V., Weinstein, S., McCreery, C.

- Student: Tsunami Squares: Earthquake Driven Inundation Mapping and Validation by Comparison to the Regional Ocean Modeling System. Grzan, D., Rundle, J. B., Wilson, J., Ward, S. N., Song, T., et al.

Critical Zone, Environmental and Cryospheric Seismology (see page 1330)

- Detecting Repeating Icequakes at Llaima and Villarrica Volcanoes, Chile. Lamb, O., Lees, J. M., Franco Marin, L., Lazo, J., Rivera, A., et al.

- Student: Evaluating Landslide Forecasting in British Columbia, Canada. Wong, S., Hobbs, T. E., Geertesema, M.

- Seismic Attenuation Illuminates Fluid Pathways in Glacial Ice. Matzel, E., Morency, C.

- Student: Seismic Imaging of Active and Ancient CO2 Pathways in the Little Grand Wash Fault. Yelton, J.

- Student: Seismic Response of Natural CO2 Gas Migration Through the Little Grand Wash Fault, Utah Slivicki and Liberty. Slivicki, S. J., Liberty, L.

Fault Displacement Hazard: New Data and Modeling Advances (see page 1363)

- Teaching Active Fault Mapping and Applications Towards Developing New Fault Displacement Hazard Datasets. Koehler, R. D., Scott, C. P., Arrowsmith, R., Sarmiento, A., Dawson, T., et al.

- A Probabilistic Fault Displacement Analysis (PFDHA) Hazard Model for Rail Transportation Systems. Youngs, R., Arcos, M. E., Coppersmith, K. J., Coppersmith, R., Hanson, K. L.

Imaging Incipient and Fossil Subduction Zones (see page 1378)

- Student: Variation of Pn Velocity and Anisotropy Around the Mantle Wedge Beneath the Eastern Gangdese Belt, Southern Tibet. Li, Y., Wang, B., He, R.

Physics-Based Earthquake Rupture Modeling and Strong Motion Simulations (see page 1415)

- Student: 3D 0-5 Hz Wave Propagation Simulations of the 2014 Mw5.1 La Habra Earthquake With Small-Scale Heterogeneities, Q(f) and Topography. Hu, Z., Olsen, K. B.

- Student: Constraining Stochastic Slip Rupture Models with Geodetic Coupling Models: An Example Application 
to PTHA at the Cascadia Subduction Zone. Small, D. T., Melgar, D.

- Dynamic Source Scenarios Constrained by NGA-West2 GMPEs. Valentova, L., Gallovič, F.

- Student: The Enhancement of Coseismic Slip and Ground Motion Due to the Accretionary Wedge and Sedimentary Layer in the 2011 Tohoku-Oki Earthquake. Li, X., Huang, Y.

- Student: Estimate of Earthquake Potential from Dynamic Rupture Simulation Along the Anninghe Fault, Sichuan, China. Yao, S., Yang, $\mathrm{H}$.

- Impact of CyberShake on Risk Assessments for Distributed Infrastructure Systems. Lee, Y., Goulet, C. A., Hu, Z., Eguchi, R. T.
- Student: MCMC-MTpy: A Python Package for Simultaneous Inversion of Source Location, Focal Mechanism and Rupture Directivity. Yin, F., Wang, B.

- Source and Path Effects Analysis From a Series of Sw4 Simulations of Mw 7.0 Earthquake Ground-Motions in Three-Dimensional Earth Models. Aguiar Moya, A. C., Pitarka, A., Rodgers, A. J.

- Student: Validation and Calibration of Simulation Parameters for the Marmara Region Through Stochastic Simulation of the 26 September 2019 Mw 5.8 Silivri Earthquake. Yenihayat, N., Çaktı, E., Şeşetyan, K.

- Validation of Broadband CyberShake Simulations. Callaghan, S. A., Goulet, C. A., Silva, F., Meng, X., Maechling, P. J., et al. 


\section{Friday, 23 April 2021-Morning Oral Session}

Presenting author is indicated in bold.

\begin{tabular}{|c|c|c|c|c|}
\hline \multirow{2}{*}{$\begin{array}{l}\text { 8:30-9:30 } \\
\text { AM Pacific }\end{array}$} & \multicolumn{4}{|c|}{ Monitoring COVID-19 Lockdown with Seismology } \\
\hline & $\begin{array}{l}\text { How Should Low- } \\
\text { Probability Earthquakes } \\
\text { be Considered in Hazard } \\
\text { Assessments? (see page } \\
1368 \text { ) }\end{array}$ & $\begin{array}{l}\text { Fault Displacement } \\
\text { Hazard: New Data and } \\
\text { Modeling Advances II } \\
\text { (see page } 1363 \text { ) }\end{array}$ & $\begin{array}{l}\text { Numerical Modeling } \\
\text { of Earthquake Motion, } \\
\text { Rupture Dynamics, } \\
\text { Seismic Noise, Wave } \\
\text { Propagation and Inverse } \\
\text { Problems I (see page } \\
1408)\end{array}$ & $\begin{array}{l}\text { Fiber-Optic Seismology I } \\
\text { (see page } 1363 \text { ) }\end{array}$ \\
\hline $\begin{array}{l}45 \mathrm{AM} \\
\text { acific }\end{array}$ & $\begin{array}{l}\text { Paleoseismic Investigation } \\
\text { of the Levan and Fayette } \\
\text { Segments of the Wasatch } \\
\text { Fault Zone, Central } \\
\text { Utah. McDonald, G. N., } \\
\text { Hiscock, A. I., Hylland, M. } \\
\text { D., Kleber, E. J. }\end{array}$ & $\begin{array}{l}\text { The Displacement } \\
\text { Approach to Probabilistic } \\
\text { Fault Displacement Hazard } \\
\text { Analysis; Issues and an } \\
\text { Example. Thompson, } \\
\text { S. C., Zandieh, A., } \\
\text { Abrahamson, N., } \\
\text { Lewandowski, N. S., } \\
\text { Baldwin, J., et al. }\end{array}$ & $\begin{array}{l}\text { Sensitivity Kernels for } \\
\text { Basin Path and Site Effects. } \\
\text { Bowden, D., Pienkowska- } \\
\text { Cote, M., Brissaud, Q., } \\
\text { Fichtner, A. }\end{array}$ & $\begin{array}{l}\text { Seismicity Monitoring } \\
\text { With Long-Range DAS } \\
\text { Systems. Karrenbach, } \\
\text { M., Yartsev, V., Cole, S., } \\
\text { Hooper, R. }\end{array}$ \\
\hline $\begin{array}{l}\text { 10:00 AM } \\
\text { Pacific }\end{array}$ & $\begin{array}{l}\text { Basement Structure of } \\
\text { the Southern Fairbanks } \\
\text { Seismic Zone and Its } \\
\text { Relation to Large }(M>6) \\
\text { Earthquakes (1929-1947). } \\
\text { Doser, D. I., Baker, M. R. }\end{array}$ & $\begin{array}{l}\text { Validate Simulated Fault } \\
\text { Displacements from } \\
\text { Dynamic Rupture Against } \\
\text { the Observed in the } 1992 \\
\text { Landers Earthquake. } \\
\text { Wang, Y., Goulet, C. A. }\end{array}$ & $\begin{array}{l}\text { Modelling of Seismic } \\
\text { Waves in Biot and JKD } \\
\text { Poroelastic Medium With } \\
\text { Subcell-Resolution Finite- } \\
\text { Difference Scheme. Gregor, } \\
\text { D., Moczo, P., Kristek, J., } \\
\text { Mesgouez, A., Lefeuve- } \\
\text { Mesgouez, G., et al. }\end{array}$ & $\begin{array}{l}\text { Antarctic Icequakes Shed } \\
\text { Light on the Applicability } \\
\text { of DAS for Microseismic } \\
\text { Monitoring. Hudson, T. S., } \\
\text { Butcher, A. C., Baird, A. } \\
\text { F., Kendall, J., Kufner, S., } \\
\text { Brisbourne, A. M., Smith, } \\
\text { A. M., Stork, A. L., et al. }\end{array}$ \\
\hline $\begin{array}{l}\text { 10:15 AM } \\
\text { Pacific }\end{array}$ & $\begin{array}{l}\text { STUDENT: New } \\
\text { Perspectives on } \\
\text { Newport-Inglewood } \\
\text { Fault Geometry. } \\
\text { Toghramadjian, N., Shaw, } \\
\text { J. H., Plesch, A. }\end{array}$ & $\begin{array}{l}\text { STUDENT: Geomechanical } \\
\text { Modeling of Ground } \\
\text { Surface Deformation } \\
\text { Associated With Thrust } \\
\text { and Reverse Fault } \\
\text { Earthquakes. Chiama, K., } \\
\text { Chauvin, B., Plesch, A., } \\
\text { Shaw, J. H. }\end{array}$ & $\begin{array}{l}\text { STUDENT: Overset } \\
\text { Grid Finite Difference } \\
\text { Method for Seismic Wave } \\
\text { Simulation in the Presence } \\
\text { of the Complex Free } \\
\text { Surface Topography. Zang, } \\
\text { N., Zhang, W., Chen, X. }\end{array}$ & $\begin{array}{l}\text { Capturing Glacier-Wide } \\
\text { Cryoseismicity With } \\
\text { Distributed Acoustic } \\
\text { Sensing. Walter, F., Paitz, } \\
\text { P., Fichtner, A., Edme, P., } \\
\text { Gajek, W., et al. }\end{array}$ \\
\hline $\begin{array}{l}\text { 10:30 AM } \\
\text { Pacific }\end{array}$ & $\begin{array}{l}\text { A Three Kernel Approach } \\
\text { to Earthquake Source } \\
\text { Modeling: Incorporating } \\
\text { Incomplete or Low } \\
\text { Resolution Seismicity, } \\
\text { Fault and Deformation } \\
\text { Datasets in Continental } \\
\text { China. Fitzenz, D. D., } \\
\text { Langenbruch, C. }\end{array}$ & $\begin{array}{l}\text { Comparison of Surface } \\
\text { Fault Displacement } \\
\text { Interpretations From Field } \\
\text { and Aerial Data for the M } \\
6.4 \text { and } 7.12019 \text { Ridgecrest } \\
\text { Earthquake Ruptures. } \\
\text { Goulet, C. A., Wang, Y., } \\
\text { Nweke, C. C., Tang, B., } \\
\text { Wang, P., et al. }\end{array}$ & $\begin{array}{l}\text { Helmholtz Decomposition } \\
\text { of Seismic Wavefields with } \\
\text { SPECFEM3D. Langer, L., } \\
\text { Pollitz, F. F., McGuire, J. }\end{array}$ & $\begin{array}{l}\text { STUDENT: Combining } \\
\text { Distributed Acoustic } \\
\text { Sensing and Beamforming } \\
\text { in a Volcanic Environment } \\
\text { on Mount Meager, British } \\
\text { Columbia.. Klaasen, S. } \\
\text { A., Paitz, P., Dettmer, J., } \\
\text { Fichtner, A. }\end{array}$ \\
\hline
\end{tabular}




\begin{tabular}{|c|c|c|c|c|}
\hline \multirow{2}{*}{$\begin{array}{l}8: 30-9: 30 \\
\text { AM Pacific }\end{array}$} & \multicolumn{4}{|c|}{ Monitoring COVID-19 Lockdown with Seismology } \\
\hline & $\begin{array}{l}\text { Analyses and } \\
\text { Implications of the } 4 \\
\text { August } 2020 \text { Beirut } \\
\text { Explosion Series II (see } \\
\text { page 1312) }\end{array}$ & $\begin{array}{l}\text { Strong-Motion Data } \\
\text { Processing and } \\
\text { Dissemination: State-of- } \\
\text { the-Art and Outlook (see } \\
\text { page 1432) }\end{array}$ & $\begin{array}{l}\text { Earthquake Early } \\
\text { Warning Live in } \\
\text { California! Current } \\
\text { Status and Challenges I } \\
\text { (see page 1339) }\end{array}$ & $\begin{array}{l}\text { Tectonics and Seismicity } \\
\text { of Stable Continental } \\
\text { Interiors I (see page 1438) }\end{array}$ \\
\hline $\begin{array}{l}\text { 9:45 AM } \\
\text { Pacific }\end{array}$ & $\begin{array}{l}\text { Forensic Architecture: The } \\
\text { Beirut Port Explosion. } \\
\text { Moafi, S. }\end{array}$ & $\begin{array}{l}\text { State of the Art and } \\
\text { Future Perspectives of } \\
\text { the Engineering Strong } \\
\text { Motion Database Data } \\
\text { Processing. D'Amico, M., } \\
\text { Luzi, L., Mascandola, C., } \\
\text { Felicetta, C., Russo, E., et } \\
\text { al. }\end{array}$ & $\begin{array}{l}\text { STUDENT: The } \\
\text { Transformer Earthquake } \\
\text { Alerting Model: A Data } \\
\text { Driven Approach to Early } \\
\text { Warning. Münchmeyer, } \\
\text { J., Bindi, D., Leser, U., } \\
\text { Tilmann, F. }\end{array}$ & $\begin{array}{l}\text { Crustal Structure and } \\
\text { Intraplate Seismicity } \\
\text { Beneath the Southeastern } \\
\text { United States. } \\
\text { Cunningham, E., Wagner, } \\
\text { L., Lekic, V. }\end{array}$ \\
\hline $\begin{array}{l}\text { 10:00 AM } \\
\text { Pacific }\end{array}$ & $\begin{array}{l}\text { STUDENT: Behavioral } \\
\text { Response to a Rapid Onset } \\
\text { Disaster: The Case of the } \\
4 \text { August } 2020 \text { Beirut, } \\
\text { Lebanon, Port Explosions. } \\
\text { Iskandar, R., Beck, E., } \\
\text { Cornou, C., Harb, J., } \\
\text { Dugdale, J., et al. } \\
\end{array}$ & $\begin{array}{l}\text { New Webservice Tools } \\
\text { and Updates at the Center } \\
\text { for Engineering Strong- } \\
\text { Motion Data (CESMD). } \\
\text { Hagos, L. Z., Schleicher, L. } \\
\text { S., Haddadi, H., Steidl, J., } \\
\text { Thompson, E. M., et al. }\end{array}$ & $\begin{array}{l}\text { STUDENT: A Low-Cost } \\
\text { IoT Seismometer for } \\
\text { Consumers for On-Site } \\
\text { and Regional Earthquake } \\
\text { Early Warning. He, V. }\end{array}$ & $\begin{array}{l}\text { Integrating Seismic } \\
\text { and Magnetotelluric } \\
\text { Constraints on } \\
\text { Lithospheric Properties to } \\
\text { Explore the Geodynamic } \\
\text { Origin of the Southeastern } \\
\text { U.S. Stress Field. Murphy, } \\
\text { B. S., Liu, L., Egbert, G. D. } \\
\end{array}$ \\
\hline $\begin{array}{l}\text { 10:15 AM } \\
\text { Pacific }\end{array}$ & $\begin{array}{l}\text { Yield Estimation of the } \\
2020 \text { Beirut Explosion } \\
\text { Using Open Access } \\
\text { Waveform and Remote } \\
\text { Sensing Data. Pilger, } \\
\text { C., Gabeler, P., Hupe, P., } \\
\text { Kalia, A. C., Schneider, F., } \\
\text { Steinberg, A., et al. } \\
\end{array}$ & $\begin{array}{l}\text { Automated Data } \\
\text { Processing and } \\
\text { Dissemination Workflow } \\
\text { of the European Rapid } \\
\text { Raw Strong Motion } \\
\text { System. Cauzzi, C., } \\
\text { Bieńkowski, J., Clinton, J., } \\
\text { Sleeman, R. } \\
\end{array}$ & $\begin{array}{l}\text { Approximate Inference } \\
\text { of the EEW Event } \\
\text { Parameters Using MCMC } \\
\text { and Bayesian Networks. } \\
\text { Zaicenco, A. G., Weir- } \\
\text { Jones, I. }\end{array}$ & $\begin{array}{l}\text { Source Parameters of } \\
\text { the M5.1 Sparta, NC } \\
\text { Earthquake of } 9 \text { August } \\
\text { 2020. Horton, S., Withers, } \\
\text { M. M., Cramer, C. H., } \\
\text { Withers, H. }\end{array}$ \\
\hline $\begin{array}{l}\text { 10:30 AM } \\
\text { Pacific }\end{array}$ & $\begin{array}{l}\text { Unusual infrasound } \\
\text { Observations From } \\
\text { the August } 2020 \text { Beirut } \\
\text { Explosion. Assink, J. } \\
\text { D., Waxler, R., Blom, P. } \\
\text { S., Shani-Kadmiel, S., } \\
\text { Averbuch, G., et al. }\end{array}$ & $\begin{array}{l}\text { STUDENT: Automated } \\
\text { Detection of Clipping in } \\
\text { Broadband Earthquake } \\
\text { Records. Kleckner, J. K., } \\
\text { Withers, K. B., Thompson, } \\
\text { E. M., Rekoske, J. M., } \\
\text { Wolin, E., et al. }\end{array}$ & $\begin{array}{l}\text { Could a Decentralized } \\
\text { Onsite Earthquake Early } \\
\text { Warning System Help in } \\
\text { Mitigating Seismic Risk in } \\
\text { North-Eastern Italy? The } \\
\text { Case of the Ms } 6.51976 \\
\text { Friuli Earthquake. Parolai, } \\
\text { S., Moratto, L., Bertoni, } \\
\text { M., Scaini, C., Rebez, A. }\end{array}$ & $\begin{array}{l}\text { An Interpretation } \\
\text { of Ground Motions, } \\
\text { Intensities and Stress-Drop } \\
\text { for the M5.1 Sparta, North } \\
\text { Carolina, Earthquake. } \\
\text { Cramer, C. H., Powell, } \\
\text { C. A. }\end{array}$ \\
\hline
\end{tabular}


Friday, 23 April (continued)

\begin{tabular}{|c|c|c|c|c|}
\hline & $\begin{array}{l}\text { How Should Low- } \\
\text { Probability... }\end{array}$ & $\begin{array}{l}\text { Fault Displacement } \\
\text { Hazard: New Data... }\end{array}$ & $\begin{array}{l}\text { Numerical Modeling of } \\
\text { Earthquake Motion... }\end{array}$ & Fiber-Optic Seismology I \\
\hline $\begin{array}{l}\text { 10: } 45 \text { AM } \\
\text { Pacific }\end{array}$ & $\begin{array}{l}\text { STUDENT: Use of Scenario } \\
\text { Earthquakes for Seismic } \\
\text { Hazard Assessment } \\
\text { in the Central United } \\
\text { States. Sherrill, E. M., } \\
\text { Hamburger, M. W. }\end{array}$ & $\begin{array}{l}\text { Preliminary Mapping of } \\
\text { Surface Fault Rupture and } \\
\text { Ground-Deformation } \\
\text { Features of the } 2019 \text { M6.4 } \\
\text { and M7.1 Ridgecrest } \\
\text { Earthquake Sequence } \\
\text { From Post-Earthquake } \\
\text { Lidar Datasets. Rosa, C. } \\
\text { M., Dawson, T. }\end{array}$ & $\begin{array}{l}\text { New Absorbing Boundary } \\
\text { Condition for Elastic } \\
\text { Waves in Isotropic Layered } \\
\text { Waveguides. Lee, J. }\end{array}$ & $\begin{array}{l}\text { Vibrator-Source } \\
\text { Exploration Seismics in } \\
\text { Urban Environments } \\
\text { Using DAS, A Feasibility } \\
\text { Study in Potsdam, } \\
\text { Germany. Wollin, C., } \\
\text { Lüth, S., Lipus, M. P., } \\
\text { Cunow, C., Siebert, A., et } \\
\text { al. }\end{array}$ \\
\hline $\begin{array}{l}\text { 11:00-11:30 } \\
\text { AM Pacific }\end{array}$ & \multicolumn{4}{|c|}{ Oral Session Discussion } \\
\hline $\begin{array}{l}\text { 11:30 AM- } \\
\text { 12:30 PM } \\
\text { Pacific }\end{array}$ & \multicolumn{4}{|c|}{ Morning Poster Session (see page 1290) } \\
\hline
\end{tabular}

\section{Early Afternoon Oral Session}

$12: 30-$

$1: 30 \mathrm{PM}$

Pacific

$1: 30$

2:00 PM

Pacific

2:00 PM

Pacific
Seismology Career Panel: Pathways to National Laboratories, Data Science, the Oil and Gas Industry and Consulting/Risk Analysis

Yanet Cuddus, Schlumberger; Ivan Wong, Lettis Consultants International, Inc.; Jiayi Xie, Xaxis; Brian Young, Sandia National Laboratorie

Break

Physics-Based
Earthquake Rupture
Modeling and Strong
Motion Simulations II
(see page 1413)

Generation of Broadband
Ground Motion From
Dynamic Rupture
Simulations: A Group
Modeling Approach
Towards Better
Characterizing Seismic
Hazard for Engineering
Applications. Withers,
K. B., Ma, S., Wang, Y.,
Ulrich, T., Gabriel, A., et al.

\begin{tabular}{|l|}
\hline Numerical Modeling \\
of Earthquake Motion, \\
Rupture Dynamics, \\
Seismic Noise, Wave \\
Propagation and Inverse \\
Problems II (see page \\
1408) \\
\hline Inversion of Dynamic \\
Traction in a Bounded \\
Domain of SH Wave \\
Motions. Jeong, C., \\
Peruqui Guidio, B. \\
\end{tabular}

Fiber-Optic Seismology II (see page 1363)

Seismic Imaging Using DAS and Dark Fiber for Basin-Scale Geothermal System Characterization: Preliminary Results From the Imperial Valley Project. Ajo-Franklin, J., Rodríguez Tribaldos, V., Cheng, F., Dobson, P., Nayak, A., et al. 
$10: 45 \mathrm{AM}$

Pacific

11:00-11:30 AM Pacific

11:30 AM-

12:30 PM

Pacific

\section{Analyses and}

Implications of the...

Close-In Phenomenology

of the Beirut Explosion.

Euler, G. G., Best, J. S.,

Kunkle, T. D., Tierney, T.

E., Triplett, L. A., et al.

\section{Strong-Motion Data}

Processing...

Recent Improvements to

Strong Motion Monitoring

in Canada. Cassidy, J. F.,

Bent, A. L.

\section{.}

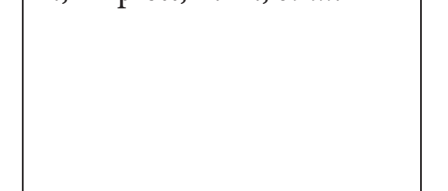

Earthquake Early
Warning Live...

Student: Deepshake:

A Machine-Learning

Approach to Rapid

Estimation of Shaking

Intensity. Wu, D., Datta,

A., Zhu, W., Ellsworth,

W. L.
Tectonics and Seismicity of Stable...

Correlating Seismic

Microzonation and

Intensity Data in Three

Urban Areas of Eastern

Canada. Bent, A. L.,

Rosset, P., Chouinard, L.,

Halchuk, S.

Morning Poster Session (see page 1290)

$12: 30-$

1:30 PM

Pacific

$1: 30-$

2:00 PM

Pacific

\section{2:00 PM}

Pacific

\section{Seismology Career Panel: Pathways to National Laboratories, Data Science, the Oil and Gas Industry and} Consulting/Risk Analysis

Yanet Cuddus, Schlumberger; Ivan Wong, Lettis Consultants International, Inc.; Jiayi Xie, Xaxis; Brian Young, Sandia National Laboratorie

Break
Towards an Integrated

View of Earthquake

Observations and

Numerical Models (see

page 1445)

INVITED: STUDENT:

Earthquake Cycles

in Fault-Bend Folds.

Sathiakumar, S., Barbot,

S., Hubbard, J.
Gates From Geologic
Insight Seismology on Mars: Results From the First Martian Year of Data and Prospects for the Future (see page 1382)

Results From the Insight Prime Mission. Banerdt, W. B., Lognonné, P., Giardini, D., Pike, W. T., Panning, M. P., et al.
Earthquake Early

Warning Live in California! Current Status and Challenges II (see page 1339)

Did You Feel That?

Examining the Transition Between Felt and Not-Felt Shaking. Saunders, J. K., Minson, S., Baltay, A., Aagaard, B., Quitoriano, V.
Tectonics and Seismicity of Stable Continental Interiors II (see page 1438)

Spatial Correlation in Ground Motion Prediction Errors in Central and Gibson, E. M., Bensi, M. T. Eastern North America.

\section{.} , 
Friday, 23 April (continued)

\begin{tabular}{|c|c|c|c|c|}
\hline & $\begin{array}{l}\text { Applications and } \\
\text { Technologies... }\end{array}$ & $\begin{array}{l}\text { Physics-Based } \\
\text { Earthquake Rupture... }\end{array}$ & $\begin{array}{l}\text { Numerical Modeling of } \\
\text { Earthquake Motion... }\end{array}$ & Fiber-Optic Seismology II \\
\hline $\begin{array}{l}\text { 2:15 PM } \\
\text { Pacific }\end{array}$ & $\begin{array}{l}\text { STUDENT: Expanding } \\
\text { Accessibility and } \\
\text { Scalability of Ambient } \\
\text { Noise Seismic Data } \\
\text { Processing Tools } \\
\text { Through an Open-Source } \\
\text { Cloud-Based Software } \\
\text { Application. Sukianto, T., } \\
\text { Mikesell, T. D., Clements, } \\
\text { T., Denolle, M. }\end{array}$ & $\begin{array}{l}\text { STUDENT: Linking Strong } \\
\text { Ground Motions and } \\
\text { Coseismic Landsliding } \\
\text { Associated With the } 25 \\
\text { April } 2015 \text { Mw } 7.8 \text { Gorkha } \\
\text { Earthquake. Dunham, } \\
\text { A., Kiser, E., Kargel, J., } \\
\text { Haritashya, U., Shugar, D., } \\
\text { et al. }\end{array}$ & $\begin{array}{l}\text { Full-Waveform Inversion } \\
\text { of Seismic Input Motions } \\
\text { in a Near-Surface Domain } \\
\text { Truncated by Wave- } \\
\text { Absorbing Boundary } \\
\text { Conditions. Peruqui } \\
\text { Guidio, B., Jeremic, B., } \\
\text { Peruqui Guidio, L., Jeong, } \\
\text { C. }\end{array}$ & $\begin{array}{l}\text { Multiple-Scale Seismic } \\
\text { Imaging Based on } \\
\text { Distributed Acoustic } \\
\text { Sensing and Ambient } \\
\text { Noise Interferometry. } \\
\text { Cheng, F., Rodríguez } \\
\text { Tribaldos, V., Chi, B., } \\
\text { Nayak, A., Robertson, M., } \\
\text { et al. }\end{array}$ \\
\hline $\begin{array}{l}\text { 2:30 PM } \\
\text { Pacific }\end{array}$ & $\begin{array}{l}\text { Preparing (for) Seismic } \\
\text { Data in the Cloud. } \\
\text { MacCarthy, J. K., Marcillo, } \\
\text { O. E. }\end{array}$ & $\begin{array}{l}\text { STUDENT: Spatial } \\
\text { Correlation of Earthquake } \\
\text { Ground Motion from 3D } \\
\text { Physics-Based Ground } \\
\text { Shaking Scenarios. } \\
\text { Infantino, M., Smerzini, } \\
\text { C., Lin, J. }\end{array}$ & $\begin{array}{l}\text { The Effects of Mantle } \\
\text { Heterogeneity on Shear } \\
\text { Wave Splitting Phases } \\
\text { Based on 3D Seismic Wave } \\
\text { Simulations. Creasy, N., } \\
\text { Bozdag, E. }\end{array}$ & $\begin{array}{l}\text { STUDENT: On the } \\
\text { Sensitivity of Optical } \\
\text { Polarization Transoceanic } \\
\text { Cables to Seismic and } \\
\text { Water Waves. Castellanos, } \\
\text { J. C., Zhan, Z., Cantono, } \\
\text { M., Kamalov, V., Mecozzi, } \\
\text { A., et al. }\end{array}$ \\
\hline $\begin{array}{l}2: 45 \text { PM } \\
\text { Pacific }\end{array}$ & $\begin{array}{l}\text { Caltech/USGS Southern } \\
\text { California Earthquake } \\
\text { Data Available in the } \\
\text { Amazon Cloud (AWS). Yu, } \\
\text { E., Bhaskaran, A., Chen, } \\
\text { S., Bhadha, R., Ross, Z. E., } \\
\text { et al. }\end{array}$ & $\begin{array}{l}\text { A Nonergodic Ground } \\
\text { Motion Model in Southern } \\
\text { California With Spatially } \\
\text { Varying Coefficients } \\
\text { Using a SCEC Cybershake } \\
\text { Dataset. Meng, X., } \\
\text { Goulet, C. A., Milner, K., } \\
\text { Callaghan, S. A. }\end{array}$ & $\begin{array}{l}\text { STUDENT: Stochastic } \\
\text { Simulation of the } 30 \\
\text { October } 2020 \text { Samos- } \\
\text { Sigacik (Mw 6.9) } \\
\text { Earthquake. Yenihayat, N., } \\
\text { Çaktı, E., Şeşetyan, K. }\end{array}$ & $\begin{array}{l}\text { Moment Magnitudes } \\
\text { (Mw) of Smaller Events } \\
\text { Using Distributed Acoustic } \\
\text { Sensing. Gök, R., Mellors, } \\
\text { R., Barno, J. }\end{array}$ \\
\hline $\begin{array}{l}\text { 3:00 PM } \\
\text { Pacific }\end{array}$ & $\begin{array}{l}\text { Developing a Next } \\
\text { Generation Platform } \\
\text { for Geophysical Data in } \\
\text { the Cloud. Trabant, C., } \\
\text { Mencin, D., Carter, J. }\end{array}$ & $\begin{array}{l}\text { Impacts of Fault } \\
\text { Rupture Characteristics } \\
\text { and Shallow Basin } \\
\text { Amplification on the } \\
\text { Response of Ductile } \\
\text { Buildings to Near-Fault } \\
\text { Physics-Based Simulated } \\
\text { Ground Motions. Kenawy, } \\
\text { M., McCallen, D., Pitarka, } \\
\text { A. }\end{array}$ & $\begin{array}{l}\text { STUDENT: Conditioned } \\
\text { Simulation of Ground } \\
\text { Motion Time Series } \\
\text { Using Gaussian Process } \\
\text { Regression With } \\
\text { Application to Ridgecrest } \\
\text { Ground Motions. } \\
\text { Tamhidi, A., Kuehn, N., } \\
\text { Ghahari, S., Rodgers, A. J., } \\
\text { Kohler, M., et al. }\end{array}$ & $\begin{array}{l}\text { A Fast Aftershock } \\
\text { Monitoring Network With } \\
\text { DAS and Internet Fiber- } \\
\text { Optic Cable in Tangshan, } \\
\text { China. Zeng, X., Bao, F., } \\
\text { Lin, R., Wang, S., Lv, H., } \\
\text { et al. }\end{array}$ \\
\hline $\begin{array}{l}\text { 3:15-3:45 } \\
\text { PM Pacific }\end{array}$ & \multicolumn{4}{|c|}{ Oral Session Discussion } \\
\hline $3: 45-4: 45$ & \multicolumn{4}{|c|}{ Afternoon Poster Session (see page 1291) } \\
\hline
\end{tabular}


2:15 PM

Pacific

:30 PM

Pacific

2:45 PM

Pacific

3:00 PM

Pacific

3:15-3:45

PM Pacific

3:45-4:45

PM Pacific
Towards an Integrated

View of Earthquake...

INVITED: Spatial

Heterogeneity in

Microseismicity and

Stress Near Repeated

Conditional Rupture

Terminations on the

Alpine Fault, New Zealand.

Warren-Smith, E.,

Townend, J., Chamberlain, C. J., Juarez Garfias, I. C., Abercrombie, R. E., et al.

Rupture Boundaries

Within the 1968-1997

Dasht-E Bayaz Earthquake Sequence, Iran. Pierce, I.

K. D., Elliott, A. J., Green,

L., Walker, R., Talebian, M.

Student: The Main

Kopeh Dagh Fault:

New Observations

Bearing on the Rupture

Boundaries of the Most

Recent Earthquake Cycle.

Marshall, N., Walker, R.,

Pierce, I. K. D., Dodds, N., Gruetzner, C., et al.

Kinematic Compatibility

of Fault Geometry and

Slip Rates Within the San

Gorgonio Pass Region,

Southern California.

Hatch, J., Cooke, M. L.,

Elston, $\mathrm{H}$.

\begin{tabular}{l}
\hline $\begin{array}{l}\text { Insight Seismology on } \\
\text { Mars... }\end{array}$ \\
\hline The Seismicity on Mars \\
as Recorded by Insight's \\
Marsquake Service. \\
Ceylan, S., Clinton, J., \\
Horleston, A., Giardini, D., \\
Kawamura, T., et al.
\end{tabular}

Kawamura, T., et al.

Accessing the Seismic

Event Catalog from the

Insight Mission to Mars.

Johnson, A., Clarke, A.,

Euchner, F., Casey, R.,

Clinton, J., et al.

STUDENT: Resonances and Lander Modes Observed by Insight on Mars

(1-9 Hz). Dahmen, N., Zenhäusern, G., Clinton,

J., Giardini, D., Stähler, S., et al.

H/V Spectral Ratios at the Insight Landing Site

Using Ambient Noise and Marsquakes Records.

Carrasco, S., Knapmeyer-

Endrun, B., Margerin, L., Schmelzbach, C., Clinton,

J., et al.
Earthquake Early Warning Live...

Real-Time Performance of the Plum Earthquake Early Warning Algorithm for Western U.S.. Kilb, D., Cochran, E. S., Bunn, J. J., Saunders, J. K., Minson, S., et al.

The Potential of FiberOptic Strain in Earthquake Early Warning. Farghal, N. S., Saunders, J. K., Parker, G. A.

MyShake: A Window Into Shakealert User Experience. Allen, R., Kong, Q., Patel, S., Pothan, S., Strauss, J.

STUDENT: Incorporating Smartphone Seismic Data for Improved Earthquake Early Warning Performance. Patel, S., Chung, A. I., Kong, Q., Strauss, J., Allen, R.
Tectonics and Seismicity of Stable...

Full Waveform Ambient

Noise Tomography for the Northern Mississippi

Embayment. Yang, Y., Langston, C. A., Powell, C. A., Thomas, W. A.

Locating and

Characterizing the CEUS/

WUS Boundary in Crustal Attenuation, Stress and Lithospheric Structure.

Levandowski, W., Boyd, O. S., Briggs, R. W., Zellman, M.

Compositional Weakening of the Crust and Intraplate Earthquakes: A Case Study for the Continental U.S. and its Intermountain West. Shen, W., Sui, S.

A Structural-Corridor Approach for InducedSeismicity Risk Assessment. Eaton, D. W. Weir, R. M., Eyre, T. S., Lawton, D. C.

\section{Oral Session Discussion}

Afternoon Poster Session (see page 1291) 


\section{Morning Poster Session}

11:30 AM-12:30 PM Pacific

Analyses and Implications of the 4 August 2020 Beirut Explosion Series (see page 1314)

- Impact of the 4 August 2020 Beirut, Lebanon, Port Explosion on Dynamical Building Properties. Guillier, B., Cornou, C., Harb, J., Youssef Abdel Massih, D., Gueguen, P., et al.

\section{Earthquake Early Warning Live in California! Current} Status and Challenges (see page 1341)

- Deep Learning Based Approach to Integrate MyShake's Trigger Data with ShakeAlert for Faster and Robust EEW Alerts. Kong, Q., Henson, I., Allen, R.

- Earthquake Early Warning Testing Developments: Automating the Generation of Realistic Warning Times Events in the Testsuite. Smith, D. E., McGuire, J., Good, A., Huynh, M., Bunn, J. J., et al.

- Examination of Event Dependent Latency Values for the Earthquakes Recorded by the Northern California Earthquake Data Center for Use in Shakealert. Terra, F., Boyd, O. S., Hellweg, M., Neuhauser, D., Henson, I., et al.

- Optimizing Plum Alerting Regions for Shakealert: A Test Case Tuning the Plum Prediction Radius. Cochran, E. S., Saunders, J. K., Minson, S., Bunn, J. J., Kilb, D., et al.

\section{Fiber-Optic Seismology I (see page 1366)}

- Student: Efficient Localization of Microseismic Clusters Using DAS. Tuinstra, K. B., Lanza, F., Grigoli, F., Rinaldi, A., Fichtner, A., et al.

- Noise Interferometry With Spatial Gradients. Paitz, P., Sager, K., Boehm, C., Fichtner, A.

- Potential of Distributed Acoustic Sensing Systems to Record Divergence and Curl Seismic Components. Edme, P., Paitz, P., Sollberger, D., Kiers, T. H., Schmelzbach, C., et al.

- Understanding Fiber Response With Lab-Scale Tests and Modeling. Thomas, P. J., Paap, B., Heggelund, Y., Butcher, A. C., Pitarka, A., et al.

\section{Insight Seismology on Mars: Results From the First Martian Year of Data and Prospects for the Future (see page 1383 )}

- Analyzing Low Frequency Seismic Events at Cerberus Fossae as Long Period Volcanic Quakes. Kedar, S., Panning, M. P., Smrekar, S. E., Stahler, S., King, S., et al.
- Beyond Insight: Mitigating Challenges Associated With Placing a Long-Term Seismometer on Venus. Tian, Y., Robert, H., West, M., Kremic, T.

- Seismology on Titan: A Seismic Signal and Noise Budget in Preparation for Dragonfly. Panning, M. P., Lorenz, R. D., Shiraishi, H., Yamada, R., Stähler, S., et al.

- A Study of Thermoelastic Effects in Seismic Monuments and Their Signature in Low-Frequency Seismic Data Collected on Earth and on Mars. Widmer-Schnidrig, R., Zürn, W., Forbriger, T., Stähler, S., van Driel, M., et al.

- Student: Super High Frequency Events: A New Class of Events Recorded by the Insight Seismometers on Mars. Dahmen, N., Clinton, J., Ceylan, S., van Driel, M., Giardini, D., et al.

- Student: Using Data From Insight to Locate and Explain Marsquakes. Sita, M., van der Lee, S.

Strong-Motion Data Processing and Dissemination: Stateof-the-Art and Outlook (see page 1434)

- Development of a University Seismic Network in Metropolitan Lima, Peru. Gonzáles Trujillo, C., Lazares La Rosa, L., Aguilar Bardales, Z., Alva Hurtado, J.

- The Quest for Rock Site Characterization and Reference Site Definition for the National Seismic Network of Greece. Ktenidou, O., Evangelidis, C., Gkika, F.

- Towards an Earthquake Ground-Motion Database for Western and Central Australia. Ghasemi, H., Allen, T. I.

Tectonics and Seismicity of Stable Continental Interiors I (see page 1440)

- Coda Envelope Moment Magnitudes for the Western Quebec Seismic Zone. Bent, A. L., Mayeda, K., RomanNieves, J. I.

- Student: Focal Mechanism Determination of 21 November in Ezgele-Sarpole Zahab. Khojasteh, F., Moradi, A.

- Ground Motion Characteristic Models for Vrancea Intermediate-Depth Earthquakes. Manea, E., Carmen, C. O., Laurentiu, D., Alexandru, M.

- Student: How Does the Distribution of Differing Sedimentary Deposits Influence the Location of Earthquake-Induced Liquefaction? Guven, C., Wolf, L. W., Tuttle, M. P., Rogers, S. R.

- Student: Joint Local and Teleseismic Tomography in the Central United States and Implications for the Origin of Intraplate Seismicity. Geng, Y., Powell, C. A., Saxena, A.

- Student: Mw vs Ml Relation for Small Earthquakes in Oklahoma and Kansas. Seydoux, Q., Herrmann, R. B.

- Seismotectonic Regions for Germany-Concept and Results. Hahn, T., Kley, J., Kaiser, D., Spies, T., Geissler, C. 
Towards an Integrated View of Earthquake Gates From Geologic Observations and Numerical Models (see page 1446)

- Dynamic Rupture Modeling of Coseismic Interactions on Orthogonal Strike-Slip Faults. Lozos, J.

- Fault Activity and Mechanical Conditions for Rupture of the Akatengneng Shan Earthquake Gate Along the Altyn Tagh Fault, Northwest China. Prush, V. B., Oskin, M. E., Liu-Zeng, J.

- Linking Northcoast NSAF Turbidite Event Beds to the San Francisco Region. Goldfinger, C.

- Student: Mapping Variations in Moderate-Magnitude Earthquake Source Properties Along the Alpine Fault, New Zealand, to Investigate Conditional Rupture Segmentation. Juarez Garfias, I. C., Warren-Smith, E., Townend, J., Abercrombie, R. E.

- Repeating Earthquakes Partially Reload Themselves in Parkfield. Rubinstein, J. L., Pennington, C. N., Kroll, K., Ellsworth, W. L.

\section{Afternoon Poster Session}

3:45-4:45 PM Pacific

Advances in Real-Time Geophysical Network Operations and Data Analytics (see page 1297)

- The Network of the Americas as a Distributed Event Streaming Platform. Hodgkinson, K., Terry, R., Sievers, C., Dittmann, S., Gottlieb, M. H., et al.

- Operational Testing of an Efficient Bayesian Framework for Updating Pager Fatality Estimates. Engler, D. T., Noh, H., Jaiswal, K. S., Wald, D. J.

- Real-Time, Higher Rate NOTA GNSS Analytics and Quality Control. Dittmann, T., Hodgkinson, K., Mencin, D., Sievers, C.

- Student: Training a Convolutional Neural Network to Identify Earthquake Onset in Real-Time GNSS Data. Dybing, S. N., Melgar, D., Thomas, A. M., Hodgkinson, K., Mencin, D.

- Unattended Ground Sensing and In-Situ Processing of Geophysical Data. O’Rourke, W. T., Morrow, T. J., Evans, B. R., DeKoning, M. W., Patel, A. A.

\section{Fiber-Optic Seismology II (see page 1366)}

- Characterizing Geothermal Systems in California's Imperial Valley Using Low-Frequency Passive Seismic Data Recorded Using Distributed Acoustic Sensing Deployed on Dark Fiber. Rodríguez Tribaldos, V., Cheng, F., Nayak, A., Wood, T., Robertson, M., et al.
- Distributed Acoustic Sensing Using Fiber Optic Cables of Opportunity - An Experiment at an Ecological Observatory. Rowe, C. A., Symons, N. P., Webster, J. D., Gammans, C. N. L., Romano, N. F., et al.

- Microearthquake Monitoring Using Dark Fiber and Distributed Acoustic Sensing (DAS). Templeton, D., Morency, C., Matzel, E., Maher, E. L., Ajo-Franklin, J.

- Prospects for Distributed Acoustic Sensing of Polar Environmental Processes: Initial Results From the Beaufort Sea, Alaska. Baker, M. G., Abbott, R. E.

- Seismic Array Analysis Using Fiber-Optic Distributed Acoustic Sensing on Small Local and Regional Earthquakes. Ichinose, G. A.

- Student: Wavefield Reconstruction Using Mixed DAS and Point-Sensor Networks. Muir, J., Zhan, Z.

Numerical Modeling of Earthquake Motion, Rupture Dynamics, Seismic Noise, Wave Propagation and Inverse Problems (see page 1411)

- Simulation of Long Duration Shaking in the Oakland Urban Region Using the USGS San Francisco Bay Area Seismic Velocity Model. Hirakawa, E. T., Aagaard, B.

- Student: Simulations of Localization and Coalescence Process Before Large Failure Events. Zhou, B., McBeck, J. A., Renard, F., Ben-Zion, Y.

- Student: Techniques for Producing Spatially Correlated Conditional Random Realizations of Ground Motion Fields. Bailey, M., Worden, C. B., Bandyopadhyay, S., Lahiri, S., Nychka, D., et al.

Tectonics and Seismicity of Stable Continental Interiors II (see page 1440)

- Basement Faults in the Charleston, South Carolina Seismic Zone From Aeromagnetic and Seismic Reflection Data: Roles of Optimal Orientation and Possible Fault Triggering. Shah, A. K., Pratt, T. L., Horton, Jr., J.

- Comparison of Internet-Based Macroseismic Observations for the 29 Dec 2020 M6.4 Croatia Earthquake. Quitoriano, V., Bossu, R., Landès, M., Wald, D. J.

- Complicated Lithospheric Structure Beneath the Contiguous United States Revealed by Teleseismic S Reflections. Liu, T., Shearer, P. M.

- Spatio-Temporal Changes of Seismicity Around Recent Large Earthquakes in Continental China. Li, L., Wang, B., Peng, Z.

- Two Shallow Earthquakes Located Within the Black Rock Volcanic Field in the Sevier Desert, Utah. Mesimeri, M., Pankow, K. L., Barnhart, W. D., Whidden, K. M., Hale, J. 


\section{Abstracts of the Annual Meeting}

\author{
The 2020 Simeonof Island, Alaska, Earthquake: \\ Observations, Modeling and Tectonic Insights \\ Oral Session · Wednesday $\cdot 21$ April · 5:00 PM Pacific \\ Session Chairs: Brendan W. Crowell, University of \\ Washington (crowellb@uw.edu); Natalia A. Ruppert, \\ University of Alaska Fairbanks (naruppert@alaska.edu)
}

\section{Megathrust Earthquakes Controlled by Incoming Plate Geometry: The 2020 M>7.5 Shumagin, Alaska, Megathrust Earthquake Doublet}

\IANG, Y., University of Liverpool, Liverpool, United Kingdom, yu.jiang@ liverpool.ac.uk; GONZÁLEZ, P. J., University of Liverpool, Liverpool, United Kingdom, pabloj.gonzalez@csic.es; BÜRGMANN, R., University of California, Berkeley, California, USA, burgmann@seismo.berkeley.edu

In 2020, an earthquake doublet, a M7.8 on Jul 22 and a M7.6 on Oct 19, hit the Alaska-Aleutian subduction zone. To our knowledge, this is the first documented earthquake doublet, of considerable size, involving a megathrust event and a strike-slip slab-breaking event, with both events occurred at depths within the megathrust locked zone. The first and largest event, M7.8, ruptured the 100-year Shumagin seismic gap, and the second event, M7.6, broke the incoming oceanic slab. We used InSAR wrapped phase and GPS offsets and an improved bayesian geodetic inversion to estimate the fault slip distribution for the Shumagin earthquake doublet. The geodetic inversions revealed the Shumagin seismic gap is multisegmented, and the M7.8 earthquake ruptured the eastern segment from 14 down to $44 \mathrm{~km}$ depth. The western and shallower segments of the Shumagin seismic gap did not fail and remain potential seismic and tsunami hazard sources. The models of the M7.6 event constrained the rupture depth, $23-37 \mathrm{~km}$, within the depth range of slip during the M7.8 event. We conclude that the rupture areas of the M7.8 and M7.6 events were controlled by the megathrust down-dip structure, with slip along a 26-degrees dipping segment bounded up-dip by a megathrust dip change. Elastic Coulomb stress change models indicated that the M7.6 event could have been triggered by the co-seismic and/or post-seismic slip caused by the M7.8 event. This earthquake doublet provides an opportunity to improve our knowledge of the mechanics of the subducting oceanic lithosphere in the Alaska subduction zone.

\section{Multi-Fault Rupture of the Mw 7.6 Sand Point, Alaska, Earthquake}

CROWELL, B. W., University of Washington, Washington, USA, crowellb@ uw.edu; MELGAR, D., University of Oregon, Oregon, USA, dmelgarm@ uoregon.edu

In October 2020, a Mw 7.6 earthquake occurred west of the Shumagin Islands and the July $2020 \mathrm{Mw} 7.8$ Simeonof Island earthquake. The initial model showed a steeply dipping vertical strike-slip earthquake within either the overriding plate or the downgoing slab. However, observations of the near and far-field tsunami indicated that a vertical strike-slip fault could not generate the vertical coseismic observations on the Shumagin Islands and the observed tsunami. Here we propose a multi-fault rupture that contains both strike-slip motion along an intraslab fault and megathrust rupture. We invert for a kinematic slip model using high-rate GNSS and seismic velocity observations. We explore a range of rupture speeds along both faults and find much slower rupture along the megathrust than the strike-slip fault, which helps to explain the lower radiated seismic energy. Furthermore, we independently model the required seafloor uplift to generate the tsunami observations and find a patch coincident with our megathrust slip patch and wrapping around the main slip patch from the July 2020 Simeonof Island earthquake. Finally, we analyze the total slip budget in the Shumagin Gap region from the two mainshocks and associated aftership and discuss how this pertains to future hazards in the region.

\section{Persistent Late Holocene Megathrust Creep Probably Accompanied M7-8 Seismicity in the Region of the 2020 M7.8 Simeonof Island, Alaska, Earthquake}

WITTER, R., U.S. Geological Survey, Alaska, USA, rwitter@usgs.gov; BRIGGS, R. W., U.S. Geological Survey, Colorado, USA, rbriggs@usgs. gov; ENGELHART, S. E., Durham University, Durham, United Kingdom, simon.e.engelhart@durham.ac.uk; KOEHLER, R. D., University of Nevada, Reno, Nevada, USA, rkoehler@unr.edu; DURA, T., Virgina Tech, Virginia, USA, tinadura@vt.edu; HAEUSSLER, P. J., U.S. Geological Survey, Alaska, USA, pheuslr@usgs.gov; VANE, C., British Geological Survey, Nottingham, United Kingdom, chv@bgs.ac.uk; NICOLSKY, D. J., University of Alaska Fairbanks, Alaska, USA, djnicolsky@alaska.edu

Coastal investigations on three Shumagin Islands, in Alaska, consistently revealed no geological evidence for giant $(M \geq 9)$ subduction earthquakes or high tsunami in the late Holocene. Rather, our observations along the Shumagin section of the Aleutian megathrust, a well-known seismic gap, imply a paleoseismic history of persistent aseismic slip and large (M7-8) subduction earthquakes, like the 2020 M7.8 Simeonof Island earthquake. Work on Simeonof Island found no evidence of uplifted marine terraces or subsided shorelines recording past earthquakes. Instead, freshwater peat draping coastal lowlands above present high tide implies long-term tectonic stability and gradual relative sea level (RSL) rise $(<0.2 \mathrm{~m} / \mathrm{ka})$ since $3.4 \mathrm{ka}$. At Unga Island we examined coastal deposits at Delarof Harbor, a site impacted by an earthquake and tsunami in 1788 per Russian written accounts. Terrestrial peat and tephra exposed along the bay margin indicate that past RSL has been near or at its present position since $\sim 6.0 \mathrm{ka}$. We find no evidence for earthquakerelated land-level change. Beach ridges facing the Aleutian trench contained no evidence of earthquake or tsunami impacts in the past $1.3 \mathrm{ka}$. On Nagai Island we examined marsh and dune deposits in coastal lowlands of trenchfacing Larsen Bay. Drift logs and thin $(<10 \mathrm{~cm})$, discontinuous sand sheets deposited $\leq 3 \mathrm{~m}$ above highest tide probably record storms and/or tsunami generated by M7-8 events. Saltmarshes contained no stratigraphic evidence for sudden coseismic vertical movements caused by past earthquakes. M7-8 earthquakes probably cause $<0.3 \mathrm{~m}$ of coseismic land-level change, which is less than our geological studies can detect. Our observations provide context for megathrust rupture models used in seismic and tsunami hazard assessments. Our findings suggest that $M \geq 9$ ruptures are rare, or nonexistent, in the Shumagin gap and emphasize the persistent role of creep and large (M7-8) earthquakes as fundamental strain release mechanisms on the Shumagin megathrust in the late Holocene.

\section{Postseismic Deformation Following the July 2020 Simeonof Earthquake}

FREYMUELLER, J. T., Michigan State University, Michigan, USA, freymuel@ msu.edu; ELLIOTT, J. L., Purdue University, Indiana, USA, julieelliott@ purdue.edu; GRAPENTHIN, R., University of Alaska Fairbanks, Alaska, USA, rgrapenthin@alaska.edu; XIAO, Z., Michigan State University, Michigan, USA, zhhxiaomsu@gmail.com

The July 2020 Simeonof earthquake was followed by substantial postseismic deformation. Over the four months between the mainshock and the November M7.6 aftershock, the cumulative postseismic displacements at sites near the rupture amounted to $25-50 \%$ of the coseismic displacements, but with a very different spatial pattern. Both the orientations of the postseismic displacement vectors and the ratio of vertical to horizontal displacement are clearly distinct from those of the coseismic displacements. The postseismic horizontal displacements from the three sites closest to the rupture are very close to a trench-normal orientation, while the coseismic displacements at two of those sites were rotated counter-clockwise from trench-normal. Postseismic vertical displacements were smaller overall than the coseismic vertical displacements. Together, these indicate that the postseismic afterslip has a different spatial distribution than the coseismic slip, and/or that viscoelastic relaxation plays a substantial role in the postseismic deformation.

We will test kinematic and stress-driven afterslip models as well as viscoelastic relaxation models to explain the postseismic deformation. Given the location of the coseismic rupture, which did not rupture the shallow part of the subduction interface, it is possible that afterslip could occur either updip or downdip of the coseismic rupture. The presence or absence of updip afterslip is particularly important for analysis of the overall slip budget for the 
interface. We will test alternative afterslip models with different constraints on the potential location of afterslip to evaluate how well the GPS (and potential InSAR) data constrain the postseismic slip pattern.

\section{The 22 July 2020 MW 7.8 Shumagin Seismic Gap Earthquake: Partial Rupture of a Weakly Coupled Megathrust}

YE, L., Sun Yat-Sen University, Zhuhai, China, yelingling@mail.sysu.edu.cn; LAY, T., University of California, Santa Cruz, California, USA, tlay@ucsc. edu; KANAMORI, H., Caltech, California, USA, hiroo@gps.caltech.edu; YAMAZAKI, Y., University of Hawaii at Manoa, Hawaii, USA, yoshikiy@ hawaii.edu; CHEUNG, K. F., University of Hawaii at Manoa, Hawaii, USA, cheung@hawaii.edu

The earthquake potential of the Shumagin seismic gap along the Alaskan Peninsula has been debated for more than 40 years. On 22 July 2020, the eastern half of the gap hosted an $M_{\mathrm{W}} 7.8$ earthquake involving a patchy rupture of the megathrust in the depth range 20 to $45 \mathrm{~km}$. The space-time slip distribution is determined by joint inversion of teleseismic $P$ and $S H$ waves and static displacements from regional GNSS stations. The event initiated near the epicenter of the $1938\left(M_{\mathrm{W}} 8.2\right)$ event, and ruptured westward, with little/no overlap with the 1938 rupture zone. The main slip patch has peak slip of $\sim 3.8$ $\mathrm{m}$ below the Shumagin Islands, and produced $\sim 30 \mathrm{~cm}$ uplift and $\sim 25 \mathrm{~cm}$ SSE horizontal displacement on Chernabura Island. The slip model predicts well the small $(<1 \mathrm{~cm})$ tsunami signals persisting for $>10$ hours observed at DART recordings along the Alaska-Aleutian arc. Aftershocks with depths of 20-40 $\mathrm{km}$ fringe the large-slip patches, and show westward concentration during the first month after the mainshock. Aftershocks up-dip of the $1948 M_{\mathrm{W}} 7.1$ event contribute to the high level of modest-size background seismicity extending to the trench in the very low seismic coupling $(0.0-0.1)$ western Shumagin gap east of the $1946\left(M_{\mathrm{W}} 8.6\right)$ rupture zone. The 1917 event is the last major earthquake to rupture the eastern half of the Shumagin gap, and appears to have somewhat lower surface wave magnitude $\left(M_{\mathrm{SG}-\mathrm{R}} 7.4\right)$ compared to the 2020 event $\left(M_{\mathrm{SG}-\mathrm{R}} 7.7\right)$. Comparison of instrument-equalized waveforms indicates similar size contrast and differences in overall rupture duration and slip complexity. The 2020 rupture has average slip of $\sim 1.9 \mathrm{~m}$ over the $3600 \mathrm{~km}^{2}$ region, much less than the $\sim 6.7 \mathrm{~m}$ of potentially accumulated slip deficit since 1917 , consistent with geodetic estimates of low average seismic coupling coefficient of 0.1-0.4. The megathrust seaward of the 2020 event has low seismicity and may either be aseismic or capable of comparable size ruptures. Comparisons are made with other subduction zones experienced relatively deep megathrust slip in regions with moderate seismic coupling.

\section{The 2020 Simeonof Island, Alaska, Earthquake: Observations, Modeling and Tectonic Insights Poster Session · Wednesday · 21 April · 11:30 Am Pacific Session Chairs: Brendan W. Crowell, University of Washington (crowellb@uw.edu); Natalia A. Ruppert, University of Alaska Fairbanks (naruppert@alaska.edu)}

\section{Aftershock Sequence of the 22 July 2020 M7.8 Simeonof Earthquake, Alaska-Aleutian Subduction Zone}

RUPPERT, N. A., University of Alaska Fairbanks, Alaska, USA, naruppert@ alaska.edu; KARASOZEN, E., University of Alaska Fairbanks, Alaska, USA, ekarasozen@alaska.edu

The July 22, 2020 M7.8 Simeonof earthquake occurred along a segment of the Alaska-Aleutian subduction plate interface previously identified as the seismic gap. It ruptured a lower portion of the interface believed to be only weakly coupled based on the GPS studies. The sequence is located offshore, which makes aftershock processing with a land-based seismic network challenging. As of the end of 2020, the Alaska Earthquake Center catalogued about 6,000 aftershocks, including the October 19, 2020 M7.6 sequence.

We use mloc, an implementation of the Hypocentroidal Decomposition technique, to achieve high resolution earthquake locations for the July and October aftershock sequences. To overcome the offshore station gap, we first relocate a set of well-recorded regional events (2004-2020), and then utilize these calibrated locations to relocate the recent seismicity.

Our subset of well-located 280 events, as well as the catalogued aftershocks, suggest that there are several notable differences between the July and October sequences: (1) The M7.6 aftershock zone is more spatially confined and extends from the trenchward edge of the 7.8 aftershock zone farther towards the trench. (2) Source mechanisms for the M7.8 event and its aftershocks are consistent with the megathrust rupture, while the M7.6 earthquake and its aftershocks have different source mechanisms indicating an oblique rupture on a N-S-oriented east-dipping plane. (3) The M7.8 aftershock sequence has lower b-value (0.6) and higher rate of larger aftershocks, than the M7.6 sequence ( $b$-value $=0.9$ ). (4) Our well-constrained relocations suggest that the July aftershock depths range between $10-50 \mathrm{~km}$, while the October aftershock sequence is confined to a much shallower depth range of $5-33 \mathrm{~km}$.

We intend to further investigate dependencies and differences between July and October earthquakes and subsequent aftershock sequences. Understanding such interdependencies is important for regional seismic hazard assessments.

\section{Coseismic Rupture Model of the 2020 Simeonof Earthquake Estimated from GPS, InSAR and Waveform Data}

FREYMUELLER, J. T., Michigan State University, Michigan, USA, freymuel@ msu.edu; XIAO, Z., Michigan State University, Michigan, USA, zhhxiaomsu@ gmail.com; GRAPENTHIN, R., University of Alaska Fairbanks, Alaska, USA, rgrapenthin@alaska.edu; ELLIOTT, J. L., Purdue University, Indiana, USA, julieelliott@purdue.edu; FUSSO, L., University of Alaska Fairbanks, Alaska, USA, lfusso@alaska.edu

On 22 July 2020, an Mw 7.8 megathrust earthquake struck offshore of the Alaska Peninsula. This earthquake was the largest event since 1917 in the Shumagin seismic gap. As this region was thought to be weakly locked in the interseismic period, the event provides a rare chance to understand relationships between earthquake slip behaviors and fault coupling. Near-field static coseismic deformation was measured by GNSS and interferometric synthetic aperture radar (InSAR) observations. Coherent regions in the coseismic interferograms that overlapped GNSS sites on Nagai and Chernabura islands were unwrapped and combined with the GNSS displacements to provide absolute line-of-sight displacements. We inverted for the fault's space-time slip history with a combination of global tele-waveforms, high-rate GNSS observations, and the static line-of-sight displacements.

Our results demonstrated that the mainshock rupture initiated at the hypocenter and propagated westward with an average rupture velocity of $\sim 2.7$ $\mathrm{km} / \mathrm{s}$. The whole rupture process lasted about $90 \mathrm{~s}$, with the mainshock occurring 20-30 s after the rupture initiation. The seismic moment released in this event was about, corresponding to Mw 7.85. The maximum slip happened at the west of the epicenter at a depth of $31.5 \mathrm{~km}$. Slip was concentrated right behind Big and Little Koniuji islands at depths of $25-35 \mathrm{~km}$.

The slip distribution and rupture limits are largely consistent with the idea that coseismic slip is confined to areas that were interseismically locked, although the entire region is only partially locked. The majority of the slip was located east of a prominent transition from less strongly locked to more strongly locked and occurred within the area of higher locking. Fitting the InSAR data requires a southwestward extension of slip located just seaward of Nagai Island, and it is not clear whether this slip fits the above pattern.

\section{Triggering an Unexpected Earthquake in an Uncoupled Subduction Zone}

HERMAN, M. W., California State University, Bakersfield, California, USA, mherman2@csub.edu; FURLONG, K. P., Pennsylvania State University, Pennsylvania, USA, kpf1@psu.edu

In the 1970's, the Shumagin Islands region of the Alaska subduction zone was identified as a seismic gap expected to host a future great $(\mathrm{Mw}>8.0)$ earthquake. More recent geodetic data indicate this region is poorly coupled, and the geologic record shows little evidence of past large events - leading to current thinking of the "Shumagin Gap" as a region of low seismic hazard. From July to October 2020 (with aftershocks continuing through the time of this abstract submission in January), a series of earthquakes occurred in this region, potentially incompatible with this low-coupling interpretation. The initial Mw 7.8 plate interface thrust faulting earthquake on July 21st straddled the eastern edge of the Shumagin Gap, followed by an Mw 7.6 strikeslip earthquake on October 19th within the slab under the eastern side of the Shumagin Gap. Stress modeling indicates that this strike-slip earthquake is in fact favored if the Shumagin Gap has low coupling, whereas a highly coupled Shumagin Gap would inhibit that type and location of earthquake. The initial thrust earthquake and its afterslip significantly enhanced the strike-slip stress loading within the subducting slab, helping to trigger that event. We find that although regions such as the Shumagin Gap have a low seismogenic potential for plate interface thrusting, the existence of this decoupled region increases the potential for intra-plate strike-slip faulting in association with more 
typical subduction earthquakes on adjacent coupled segments of the plate boundary. Therefore, the seismic and tsunami potential near these uncoupled regions might be greater than previously thought.

The 7 January 2020 South of Indios (M6.4) Earthquake in
Puerto Rico, Response and Lessons
Oral Session · Thursday · 22 April · 2:00 PM Pacific
Session Chairs: Victor A. Huerfano, Puerto Rico Seismic
Network (victor@prsnmail.uprm.edu); Lorna G. Jaramillo-
Nieves, Universidad de Puerto Rico, Recinto de Río Piedras
(lorna.jaramillo@upr.edu); Gisela Báez-Sánchez, Puerto
Rico Seismic Network (gisela.baez1@upr.edu); Wildaomaris
Gonzalez, Bureau of Emergency Management and Disaster
Administration, Puerto Rico (wgonzalez@premapr.
onmicrosoft.com)

\section{Assisting the Puerto Rico Seismic Network as a Science Communicator During the 7 January 2020 S of Indios Earthquake in Puerto Rico}

IARAMILLO-NIEVES, L. G., University of Puerto Rico, Río Piedras, Puerto Rico, USA, lorna.jaramillo@upr.edu

Correct and effective science communication to the general public is essential in times of emergency. An efficient science communication supports the general public's decision-making process on how to prepare, react and recover from natural events that potentially cause disasters. This presentation will describe the experience of a professor from the University of Puerto Rico as a science communicator when supporting the efforts of the Puerto Rican Seismic Network (PRSN) and the local government during the January 7 , 2020 S of Indios Earthquake in Puerto Rico.

During this emergency, emphasis on daily seismic activity, local tectonic setting, how and why earthquakes occur, lessons from previous local-historical seismic activity, safety and resilience composed the main topics of communication. Daily seismic activity was discussed based on products created by the PRSN and the US Geological Survey. Local tectonic setting included the description of the Caribbean Plate and local seismic activity to emphasize the location of Puerto Rico in an active seismic zone. Previous local-historical seismic activity was discussed mainly on the 1918 earthquake in Puerto Rico, the major seismic event before the seismic sequence of 2020. Safety and resilience messages included the importance of a family or workplace plan, the development of seismic awareness and drills, among others.

Social media, TV and radio supported this science communication task and were also the principal tools for learning about the general public perception of risk and misconceptions. Lessons learned during this period of emergency respond and recovery include the importance of (1) recognizing local knowledge, (2) understanding the origin of science misconceptions, (3) the capacity of communicating science in simple words but maintaining the same depth intended for peers, (4) a brief and clear message and (5) acknowledging how much energy is required to be a science communicator during an emergency.

\section{Building a Better Aftershock Forecast: Case Study and Social Science Research of the 2019-2021 Southwestern Puerto Rico Earthquake Sequence to Inform Improvements to the Aftershock Forecast}

VAN DER ELST, N., U.S. Geological Survey, California, USA, nvanderelst@ usgs.gov; BARALL, M., Invisible Software, California, USA, mbarall@ contractor.usgs.gov; HARDEBECK, J. L., U.S. Geological Survey, California, USA, jhardebeck@usgs.gov; LLENOS, A. L., U.S. Geological Survey, Colorado, USA, allenos@usgs.gov; MARTINEZ, E., U.S. Geological Survey, Colorado, USA, emartinez@usgs.gov; MCBRIDE, S. K., U.S. Geological Survey, California, USA, skmcbride@usgs.gov; MICHAEL, A., U.S. Geological Survey, California, USA, ajmichael@usgs.gov; PAGE, M. T., U.S. Geological Survey, California, USA, mpage@usgs.gov; SANTOS-HERNÁNDEZ, J., University of Puerto Rico, Puerto Rico, USA, jenniffer.santos1@upr.edu

A sequence of earthquakes offshore Guayanilla and Guánica, Puerto Rico, began in December 2019 and continues as of January 2021. The USGS began issuing Operational Aftershock Forecasts for this sequence after the first M5.0 event occurred on 29 December. Initial forecasts used the Reasenberg and
Jones (RJ89) model (Science, 1989) as updated in Page et al. (BSSA, 2016). That model ties all aftershocks to the mainshock and so the forecasts for the 29 December event were superseded when a M5.8 earthquake occurred on 6 January. And that forecast was superseded when an M6.4 event occurred the next day. The forecast was updated throughout 2020 and into 2021. After an M5.9 aftershock on 11 January, the RJ89 model did not sufficiently capture the complexity of the sequence, and we began using an Epidemic Type Aftershock Sequence model (Ogata, JAmStat, 1988). Although the initial sequence displayed some swarm-like features (elevated background rate), the postmainshock sequence appears to be dominated by inter-event triggering. The sequence has maintained rigorous productivity, consistent with the forecast.

Our standard aftershock forecasts are presented on the USGS earthquake event pages and contain text commentary and a table of expected numbers of events and probabilities. To help people interpret the probabilities, we developed a set of three aftershock sequence scenarios based on experience from past sequences in New Zealand. The scenarios were released via the USGS web site in English and Spanish. To support FEMA and local government decisions, an Open-File report on the expected duration of the sequence was released. Further research is being conducted regarding product testing, engaging with key stakeholders and publics within Puerto Rico. This research, led by the University of Puerto Rico and funded by the Natural Hazards Center, aims to inform the development of the forecast template 2.0, including visualizations to express the forecast better.

\section{Low-Power, User-Configurable, Digital Broadband Seismometers for Rapid Response Situations: Güralp Certimus}

REIS, W., Güralp Systems Ltd, Reading, United Kingdom, wreis@guralp. com; LINDSEY, I., Güralp Systems Ltd, Reading, United Kingdom, jlindsey@ guralp.com; HILL, P., Güralp Systems Ltd, Reading, United Kingdom, phill@ guralp.com; WATKISS, N., Güralp Systems Ltd, Reading, United Kingdom, nwatkiss@guralp.com

Rapid response and ease-of-installation are driving the seismic community towards low power, portable and user-friendly seismometers in a broad range of scenarios. Operators are increasingly in favour of low-maintenance, lowlogistics installations with minimal surface impact without compromising on performance when responding to seismic events quickly and in unknown terrain.

The Güralp Certimus is a digital broadband seismometer which goes beyond these goals, utilising recent advancements in ocean bottom, borehole and digitiser technology to deliver a complete seismic station in a compact and lightweight package deployable as a surface or posthole instrument.

User-configurable long-period corners and sensitivity options allow Certimus to be adapted to the installation environment by individual users before each installation. Certimus uses well-proven digital feedback control to operate at any angle without the use of a gimbal, thereby dramatically improving tilt tolerance and allowing automated self-correction throughout deployment if the station is affected by unstable ground or lack of time to build a more permanent seismic station.

An integrated high-performance digitiser allows simple interaction operated via remote user-friendly web interface. Additionally, Certimus is available with a touchscreen LCD display or full anodised aluminium for surface or burial versions. When buried, the Certimus can be equipped with a small surface storage module in line with the GNSS receiver containing a removable microSD card and allowing interaction with the seismometer via Bluetooth, minimising disturbance of the instrument. Ultra-low power consumption is a direct benefit from incorporating OBS technology, with ability to disable unnecessary features and for temporary deployments without rechargeable power supplies.

The inbuilt flexibility of Certimus benefits instrument pools where the same instruments can be used for different purposes by different operators and simply configured to suit the current installation as well as dedicated networks with permanent installations.

\section{Preliminary Shakemap Computation for the Indios M6.4 Earthquake, 7 January 2020, Puerto Rico}

HUERFANO, V. A., Puerto Rico Seismic Network, Puerto Rico, USA, victor@ prsnmail.uprm.edu; MARTINEZ-CRUZADO, J. A., University of Puerto Rico at Mayagüez, Puerto Rico, USA, jose.martinez44@upr.edu; HERNANDEZ, F., University of Puerto Rico at Mayagüez, Puerto Rico, USA, francisco. hernandez@upr.edu

A M4.7 earthquake around Dec. 28, 2019 started a series of multiple strong and damaging earthquakes in southern Puerto Rico, being the more intense a M6.4, $8 \mathrm{~km}$ south of the Indios sector of Guayanilla, Puerto Rico (Jan/07/2020). 
The main event killed at least one person, caused many serious injuries and collapsed numerous buildings, including a school in the town of Guánica that luckily was empty at the time. These sequence, represent the most damaging earthquakes to strike Puerto Rico since 1918, leading the island to a declaration of emergency.

The ShakeMaps provide vital information within minutes after an earthquake to emergency response agencies, this tool was developed by the USGS as a tool for near real time generation of ground shaking following an earthquake. The PR network (Puerto Rico Seismic Network/PRSN and the Puerto Rico Strong Motion Program/PRSMP) computed ShakeMaps based on (1) rapid earthquake location and size, (2) user DYFI/CIIM reports and (3) instrumental data from seismometers and accelerometers. The PRSN earthquake detection system which is based on the EarthWorm package, and the rapid location and size estimation review wich is is done using the EarlyBird software, provide the first empirical ShakeMap estimation. And using all the PR network which consist of more than 30 broadbands, 50 strong motion, and more than 100 stand alone strong motion stations, the ShakeMap is gradually corrected. And as additional data, the user reports from the PRSN/CIIM system is added to the computation. The site corrections are based on the local average shear-wave velocity values for the uppermost 30 meters (Vs30) and a combination between HAZUS generic GMPE's and the Kanno regressions.

In this abstract we will report on the final computation of the main shock ShakeMap after the incorporation of all available data, including the DYFI/CIIM reports collected by the USGS.

\section{Response of a Typical Puerto Rican Shear-Wall Dominated High-Rise Building During the 7 January 2020 Mw6.4 Indios, Puerto Rico Earthquake}

CELEBI, M., U.S. Geological Survey, California, USA, celebi@usgs.gov MIRANDA, E., Stanford University, California, USA, emiranda@stanford. edu; MARTINEZ-CRUZADO, J. A., University of Puerto Rico, Puerto Rico, USA, jose.martinez44@upr.edu

On January 7, 2020, a $\mathrm{M}_{\mathrm{w}} 6.4$ offshore earthquake (8:24:26.56 UTC, 4:24 am local time, epicentral coordinates $17.916^{\circ} \mathrm{N},-66.813^{\circ} \mathrm{W}$, depth $\sim 10 \mathrm{~km}$ ) shook the island of Puerto Rico (www.strongmotioncenter.org, last accessed December 30, 2020) - causing damage to property, loss of one life, and disruption. Detailed reconnaissance of the earthquake is documented in two Structural Extreme Events Reconnaissance (Steer) reports (Miranda, E., et al. 2020a, b) and an Earthquake Engineering Research Institute (EERI) Virtual Earthquake Reconnaissance Team (Vert) Report (Alam, M. et al., 2020). We studied the records retrieved from the 24-channel monitoring system of the 19-story (53.26 m [174'9"]) tall El Castillo Building, which includes two basement stories at a depth of $6.0 \mathrm{~m}$ (19'8"). This building is a typical Puerto Rican reinforced concrete shear-wall structure, located in Mayaguez, approximately $50 \mathrm{~km}$ from the mainshock epicenter. The building is founded on bedrock, with in-plan dimensions of: $45.97 \mathrm{~m}$ (150'10") longitudinal by $15.37 \mathrm{~m}$ (50'5") transverse and a shear-wall-to-floor area of 0.97 and 3.49 in the longitudinal and transverse directions, respectively. Records from a free-field station located $\sim 200$ feet from the structure indicate a site period of $0.16 \mathrm{~s}$; the nearby free-field station is not expected to affect the building response. No visible damage was observed. Basement and top-floor peak accelerations were $5 \%$ $\mathrm{g}$ and $12.8 \% \mathrm{~g}$, respectively. We use spectral ratios and system identification methods to identify the north-south (transverse), east-west (longitudinal), and torsional fundamental frequencies $[\mathrm{f}(\mathrm{Hz})] /$ periods $[\mathrm{T}(\mathrm{s})]$ as $1.03 / 0.97$, $1.14 / 0.88$, and $1.23 / 0.81$, respectively, and critical damping percentages of 4.5 , 3.4 , and $2.2 \%$, respectively. For a 19 -story shear-wall building, this fundamental period of $\sim 0.8-0.9 \mathrm{~s}$ is consistent with the empirical formula by Goel and Chopra (1998): $\mathrm{T}_{\mathrm{s}}=0.02 \mathrm{H}^{0.75}$, where $\mathrm{H}$ is the height of the building in feet. The maximum drift ratios in the longitudinal and transverse directions are 0.20 and $0.12 \%$, respectively.
The 7 January 2020 South of Indios (M6.4) Earthquake in Puerto Rico, Response and Lessons

Poster Session · Thursday $\cdot 22$ April $\cdot$ 11:30 Am Pacific

Session Chairs: Victor A. Huerfano, Puerto Rico Seismic

Network (victor@prsnmail.uprm.edu); Lorna G. Jaramillo-

Nieves, Universidad de Puerto Rico, Recinto de Río Piedras

(lorna.jaramillo@upr.edu); Gisela Báez-Sánchez, Puerto

Rico Seismic Network (gisela.baez1@upr.edu); Wildaomaris

Gonzalez, Bureau of Emergency Management and Disaster

Administration, PR (wgonzalez@premapr.onmicrosoft.com)

\section{Operational Response of the PRSN for the Puerto Rico 6.4 M Earthquake and the South of Puerto Rico Seismic Sequence}

BÁEZ-SÁNCHEZ, G., Puerto Rico Seismic Network, Puerto Rico, USA, gisela.baez1@upr.edu; MIRANDA BERROCALES, V. M., Puerto Rico Seismic Network, Puerto Rico, USA, viridis.miranda@upr.edu; COLON RODRIGUEZ, B., Puerto Rico Seismic Network, Puerto Rico, USA, benjamin. colon1@upr.edu; PEREZ PAULINO, J. E., Puerto Rico Seismic Network, Puerto Rico, USA, jonathan.perez30@upr.edu; CORDERO NIEVES, H., Puerto Rico Seismic Network, Puerto Rico, USA, haniel.cordero@upr.edu

Last January 7, 2020 Puerto Rico experienced a local earthquake that was greater in magnitude and caused more damages than any other earthquake during this past century, This event with a magnitude of $6.4 \mathrm{Mww}$ occurred on the southern coast of Puerto Rico at 4:24 am with a location of $11 \mathrm{~km} \mathrm{S-SW}$ of Guayanilla. It had an intensity close to IX; multiple structures collapsed and many people were left without homes. The analysts that were on shift during the event responded with dedication and responsibility, just like any other event within Puerto Rico and the Virgin Islands Region. However, when working on the response, they were also concerned for their family, friends, and coworkers. Within the first five minutes of the event, protocols were followed and implemented while experiencing strong telluric movement within the facility of the Puerto Rico Seismic Network (PRSN). This caused strong effects within the nonstructural aspects and human nature. The response implied the activation of various personnel from different work divisions and analysts within the PRSN in order to support and work together with the various alarms (automatic detection systems) and felt events within the south region of Puerto Rico. This seismic sequence started December 28, 2019 with a felt event of $4.7 \mathrm{Ml}$; over 13,000 earthquakes that have been located are associated with this seismic sequence, with thousands of felt events and over 45 events greater than $4.5 \mathrm{Ml}$ that continued to damage structures. The geophysical data analysts of the PRSN have faced the greatest challenge during the response within this sequence which is still ongoing. This discussion will go over the response of PRSN during the 6.4 Mww event, the organization and situations faced during operations, the response due to multiple felt events that affected the Puerto Rican population the following days after the main event. Communications with emergency management agencies of the PR/VI region, information disseminated to the general public, and lessons learned during the response of the seismic sequence will also be discussed.

\section{Towards a Local-Regional Coda Source Calibration for Puerto Rico: Modeling Moment Tensors, Apparent Stress and Scaled Energy From the 2019-2020 Earthquake Sequence}

ROMAN-NIEVES, J. I., Air Force Technical Applications Center, Florida, USA, jorge.roman-nieves.1@us.af.mil; MAYEDA, K., Air Force Technical Applications Center, Florida, USA, kevin.mayeda@us.af.mil; SOTOCORDERO, L., Air Force Technical Applications Center, Florida, USA, lillian. soto-cordero@us.af.mil

Following an increase in offshore seismicity in southwest Puerto Rico (PR) in late December 2019, which included two Mw 5.0 \& 4.7 events on December 29 , we began collecting local and near-regional broadband waveforms for the determination of moment tensors and apparent stress. Rather than following conventional mainshock-aftershock behavior, the initial events were followed by an Mw 5.7 (Jan. 6), and the Mw 6.4 January 7, 2020 'Indios' earthquake. The high-level activity included hundreds of offshore and onshore events, including $78 \mathrm{Mw} \geq 4.0$ within 3 weeks from the sequence onset. We use this rich dataset to obtain stable estimates of $\mathrm{Mw}$, apparent stress, and scaled energy, and for the development of a preliminary local-regional coda source calibration for PR. 
Our preliminary results show that a $1 \mathrm{D}$ velocity model based on LITHO 1.0 in conjunction with upper crustal structure from Huerfano and Bataille (1994), provide excellent fits to the data in the 18-50 s period range for tens of events located within $25 \mathrm{~km}$ from the Mw 6.4 event. Most moment tensor solutions support fairly shallow oblique, east-west trending, left-lateral strikeslip mechanisms (consistent with the regional tectonics) while $\mathrm{Mw} \geq 5$ events appear as shallow, normal faulting earthquakes. For apparent stress calculation, we use the coda spectral ratio method outlined in Mayeda et al. (2007) which provides very stable, averaged apparent stress estimates that are free of path, site and source mechanism effects. This sequence is characterized by low apparent stress ( 0.5 to 8 bars) but fall within the range of other large magnitude strike-slip crustal sequences worldwide (Malagnini et al., 2014). Using several well-constrained source spectra calculated from this sequence and other events around PR, we obtain a preliminary local-regional coda source calibration using the open source Coda Calibration Tool that can be used for routine magnitude processing by the Puerto Rico Seismic Network

Advances in Real-Time Geophysical Network Operations
and Data Analytics
Oral Session · Thursday ·22 April · 5:00 PM Pacific
Session Chairs: Kathleen Hodgkinson, UNAVCO
(hodgkinson@unavco.org); David J. Mencin, UNAVCO
(dmencin@unavco.org)

\section{Application of Big Data Technologies on Real-Time Seismic Data Stream Processing}

HUANG,X., China Earthquake Networks Center, Beijing, China, hsxyhq@126. com; MA, Y., China Earthquake Networks Center, Beijing, China, mayl@ seis.ac.cn; CHEN, T., China Earthquake Networks Center, Beijing, China, chentong@seis.ac.cn; HAN, X., China Earthquake Networks Center, Beijing, China, hxj@seis.ac.cn; CHEN, H., China Earthquake Networks Center Beijing, China, chf@seis.ac.cn

The ever-growing seismic data connected to a real-time seismic data stream processing system requires a robust processing capacity, a stable message exchanging center, and a scalable data cache. One practical solution is to divide and conquer, in which parallel processing and distributed storage and caching are essential. The newly developed seismic monitoring technologies also face challenges when integrating with traditional tight-coupled earthquake monitoring systems. In this study, we developed a real-time seismic data stream processing system named SeisFLINK based on big data technologies with a completely different architecture from previously. The architecture of the system has three layers; the bottom layer provides hardware and operating system support; the middle layer is the big data technology supporting system that provides solutions for message distribution, distributed real-time stream processing, caching, and archiving, which are powered by Apache Kafka, Apache Flink, Redis, and TDengine, respectively; and seismic applications and additional tools are developed on the top layer and could exchange message and seismic data with message exchanging center and data caching center by universal standard interfaces. Big data stream processing systems guarantee a powerful seismic data flow system and their features naturally fulfill the requirements of parallel processing and distributed storage and caching. Loose-coupled architecture makes the system more modular, easier to integrate newly developed applications and upgrade or replace modules and subsystems separately. The independence of the operating system and hardware increases its flexibility that can be configured on a cluster of physical computers or virtual machines in the Cloud.

\section{Development of Near Real Time Data Streams from NOTA Borehole Strainmeters}

GOTTLIEB, M. H., UNAVCO, Oregon, USA, gottlieb@unavco.org; MENCIN, D., UNAVCO, Colorado, USA, dmencin@unavco.org; HODGKINSON, K., UNAVCO, Colorado, USA, hodgkinson@unavco.org; TERRY, R., UNAVCO, Colorado, USA, terry@unavco.org; JOHNSON, W., UNAVCO, Colorado, USA, johnson@unavco.org; VAN BOSKIRK, E., UNAVCO, Colorado, USA, boskirk@unavco.org; MATTIOLI, G., UNAVCO, Colorado, USA, mattioli@ unavco.org

The National Science Foundation (NSF) funded Network of the Americas (NOTA) borehole strainmeter (BSM) network is made of 85 Gladwin Tensor Strainmeters (GTSMs), which have been operated for the last 15 years returning data as hourly downloads. Recent interest in potentially using BSMs in earthquake early warning (EEW) has driven a development effort to upgrade the network to near real time.

A team at UNAVCO is currently developing modern tools for data processing and distribution based on a publish-subscribe messaging system using the Apache Kafka platform. The goal is to create a robust and scalable framework that can handle sensor agnostic timeseries data input. We plan to publish data at multiple processing levels to individual topics, allowing users to subscribe to a topic and receive the data product that best suits their needs. To date we have begun development for GNSS, Strain, Tilt, and Met data on a local 10-node Kubernetes cluster.

We detail here the prototype system being built to stream data in near real time from the NOTA BSMs. Due to their age, the GTSM data loggers are unable support streaming directly. Instead, we have new firmware that supports writing a local data file every few seconds. These 20 sps files will be pulled from the logger, parsed, and produced into Kafka messages. Users interested in the lowest latency data can subscribe to these raw messages. We also plan to build modules that consume the raw streams and produce higher level products including dynamic, areal, and shear strains. These raw and processed streams can also be directed to a database such as TimescaleDB, which users can query to recover past data. We are also experimenting with a frontend such as Grafana for viewing the data streams.

A prototype system currently on test achieves latencies of roughly one to four seconds for 20 sps data over the cell network. This effort is very much a work in progress, and we look forward to discussing these issues with others working on similar problems.

\section{Implementing Real-Time GNSS Monitoring with the Earthcube Cyberinfrastructure Chords for Ol Doinyo Lengai, Tanzania}

STAMPS, D., Virginia Tech, Virginia, USA, dstamps@vt.edu; JONES, J. Virginia Tech, Virginia, USA, joshj55@vt.edu; SARIA, E., Ardhi University, Dar Es Salaam, Tanzania, United Republic of, saria.elifuraha@gmail.com; DAUD, N., Virginia Tech, Virginia, USA, dntambila@vt.edu; DANIELS, M., Colorado State University, Colorado, USA, 303miked@gmail.com; MENCIN, D., UNAVCO, Colorado, USA, dmencin@unavco.org; JI, K., KIGAM, Daejeon, Korea, Democratic People’s Republic of, khji@kigam.re.kr; ADAMS, A., Colgate University, Florida, USA, aadams@colgate.edu

Monitoring of volcanoes in real-time has increased over the past decade as data transmission and cyberinfrastructure capabilities evolve. Since 2016 the multinational GNSS network TZVOLCANO was initiated to (1) improve our understanding of volcano-tectonic interactions during continental rift initiation at a range of temporal scales and (2) provide volcano deformation monitoring capabilities for local constituents. The TZVOLCANO network consists of 6 continuous GNSS stations with 3 streaming 1 second $\sim 4$ $\mathrm{cm}$ precision positions and 1 co-located compact broadband seismometer. Here, we describe our implementation of the EarthCube cyberinfrastructure CHORDS (Cloud-HOsted Real-time Data Services for the Geosciences) that we use to evaluate real-time streaming positioning data available through UNAVCO Real-Time GPS/GNSS Data Services, send email alerts for vertical velocities exceeding thresholds, and provide information about GNSS station health. In conclusion, we describe a Python-based brokering code that connects UNAVCO Real-Time GPS/GNSS Data Services with CHORDS such that additional users of real-time GNSS data can easily stream data into a CHORDS portal and build their own additional capabilities via its simplified interface.

\section{Network Status and Detection Capabilities of Real-Time GNSS Data at Cascade Volcanoes}

KRAMER, R., U.S. Geological Survey, Washington, USA, rkramer@usgs.gov; MONTGOMERY-BROWN, E., U.S. Geological Survey, Washington, USA emontgomery-brown@usgs.gov; LISOWSKI, M., U.S. Geological Survey, Washington, USA, mlisowski@usgs.gov; JOHANSON, I., U.S. Geological Survey, Hawaii, USA, ijohanson@usgs.gov; PAUK, B., U.S. Geological Survey, Washington, USA, bpauk@usgs.gov; GUILLEMOT, C., U.S. Geological Survey, California, USA, cguillemot@usgs.gov

The U.S. Geological Survey's Cascades Volcano Observatory (CVO) operates 33 continuous, telemetered GNSS stations on six of the eight very-high-threat volcanoes in Oregon and Washington. Recent expansions of the network at Mount Hood and telemetry and power improvements at existing stations have enabled streaming of $1 \mathrm{~Hz}$ GNSS data from 31 of these stations. In addition, CVO serves real-time data for California Volcano Observatory (CalVO) stations at Lassen Peak, Long Valley/Mammoth, and Mount Shasta volcanoes. Real-time network maps, raw time series, and data latency information are 
available on the USGS Earthquake Science Center GNSS processing website (https://earthquake.usgs.gov/monitoring/gps).

Historic geodetic observations at Cascade volcanoes have not shown deformation signals that would be detectable in real-time GNSS data, with the exception of the meters-per-day deformation rates on the north side of Mount St. Helens in the weeks prior to its May 18, 1980 eruption and periods of dome growth during its 2004-2008 eruption. However, this does not preclude the importance of real-time GNSS data in the event of unrest at a Cascade volcano, especially for sites closest to likely eruptive vents. Tracking real-time data latencies also facilitates identification and troubleshooting of GNSS data degradation and station outages.

Synthetic models allow us to determine detection capabilities at Cascade volcanoes with established networks. Experience with real-time GNSS data during the 2018 Kilauea eruption will help to integrate real-time GNSS into CVO monitoring practices.

Although CVO is committed to incorporating real-time GNSS data in future network planning, several challenges remain. These include frequent winter outages due to harsh Pacific Northwest weather, as well as sharing of limited bandwidth with broadband seismic and infrasound data as we aspire to co-locate geophysical equipment to minimize station footprints, especially in wilderness areas.

\section{NOTA GNSS Network Operations in the Caribbean and Central America \\ ZAINO, A., UNAVCO, Colorado, USA, zaino@unavco.org}

UNAVCO and the GAGE Facility currently operate a network of permanent, continuously operating GNSS stations throughout the Americas (known as Network of the Americas), which incorporates many of the stations that were previously part of COCONet. These 80 legacy COCONet stations, located in 23 countries throughout the Caribbean Basin, provide data that is used for tectonic studies, earthquake and volcano hazards analyses, atmospheric water vapor studies, tsunami early warning, local infrastructure, and many other applications. UNAVCO partners closely with local collaborators to facilitate the continuing operation of these stations. The goal of this presentation is to provide context for the network as it exists now, and to discuss the current capabilities and challenges of operating this network. We will detail dataflow and communications strategies, along with planned upgrades to full GNSS capabilities and the expansion of 1 sps real time data flow from all stations where practicable.

\section{Advances in Real-Time Geophysical Network Operations and Data Analytics \\ Poster Session · Friday · 23 April · 3:45 Pм Pacific \\ Session Chairs: Kathleen Hodgkinson, UNAVCO \\ (hodgkinson@unavco.org); David J. Mencin, UNAVCO \\ (dmencin@unavco.org)}

\section{Operational Testing of an Efficient Bayesian Framework for Updating Pager Fatality Estimates}

ENGLER, D. T., U.S. Geological Survey, Colorado, USA, dengler@contractor usgs.gov; NOH, H., Stanford University, California, USA, noh@stanford.edu; JAISWAL, K. S., U.S. Geological Survey, Colorado, USA, kjaiswal@usgs.gov; WALD, D. J., U. S. Geological Survey, Colorado, USA, wald@usgs.gov

Loss estimates and alert levels produced by the U.S. Geological Survey's Prompt Assessment of Global Earthquakes for Response (PAGER) system have not traditionally considered event-specific reported data on casualties. However, as discussed in recent research (Noh et al., 2020), we have derived an algorithmic method for updating PAGER fatality estimates based on evolving, uncertain, initial fatality reports. That work, funded by the U.S. Agency for International Development, involves recursive Bayesian updating based upon the loss projection model and uncertainties from loss reporting and the loss model. After establishing a credible framework, we hindcasted fatalities for several past earthquakes where archived media reports showed increasing fatalities for a day or two following those events and found robust results, even when initial estimates were substantially different than the actual casualties. While that work gave us the proper tools, we had insufficient experience in an operational setting. We have since been evaluating this framework in a realtime, offline, capacity and herein report on results for two significant events in 2020: M6.4 Petrinja, Croatia (December 29) and M7.0 Western Greece (October 30 ). In both cases the median fatality estimates converge quickly to the actual losses and uncertainties were rapidly reduced when compared to our independent loss estimates. From a reporting perspective, the modified medians and lower uncertainties manifest as much tighter PAGER fatality histograms. Significant challenges identified in our testing include: (1) updating framework enhancements (i.e., the versatility of loss model projections and better use of training data), (2) recognizing and accessing reputable sources of loss information, (3) communicating updates and determining which warrant alert renotifications, and (4) modifying associated economic losses, since unlike fatalities, losses are not available in real-time.

\section{Real-Time, Higher Rate NOTA GNSS Analytics and Quality Control}

DITTMANN, T., UNAVCO, Colorado, USA, dittmann@unavco.org; HODGKINSON, K., UNAVCO, Colorado, USA, hodgkinson@unavco.org; MENCIN, D., UNAVCO, Colorado, USA, dmencin@unavco.org; SIEVERS, C., UNAVCO, Colorado, USA, csievers@unavco.org

The network of the America's (NOTA) is the hemispheric geodetic facility operated by UNAVCO in support of the NSF GAGE agreement, and is the union of several pre-existing geodetic sensor networks constructed to support investigations requiring lower frequency signals and post-processed data. In addition to its original scientific goals, this network is evolving to capitalize on its primary investment to support a number of real-time, lower latency and higher frequency end users. UNAVCO is continually developing analytics to support these end users and improve overall data quality.

Currently UNAVCO provides "raw" GNSS data and precise point position (PPP) streams via NTRIPcaster in real-time with low latency $(<2 \mathrm{sec}-$ onds) from $\sim 1140$ stations. Measured end to end latencies as well as completeness as a percentage of total possible epochs are provided as daily averages. In terms of data quality, daily observational files are run through TEQC QC and postion scatter and wander plots are updated daily.

In this presentation we will share some of the ongoing efforts to better align analytics with the higher frequency, lower latency samples of the products provided. UNAVCO-NOTA is in the process of developing a new publish-subscribe model for the data streams to support a variety of scalable, distributed applications. We will present some data analytics proposed to be generated in real-time or on demand in this system, with particular emphasis on those that affect real-time/near-real time magnitude estimates such as the USGS ShakeAlert effort. Such metrics include multi-level latency measurements at the 1 second level and completeness as a function of latency, station PPP ambient noise characterizations and real-time PPP integrity. Finally, we will discuss early results of comparisons of the current server based PPP estimates with edge computing estimates generated "on-board" the GNSS receivers supported by a USGS ShakeAlert agreement.

\section{The Network of the Americas as a Distributed Event Streaming Platform}

HODGKINSON, K., UNAVCO, New Mexico, USA, hodgkinson@unavco. org; TERRY, R., UNAVCO, Colorado, USA, terry@unavco.org; SIEVERS, C., UNAVCO, Colorado, USA, csievers@unavco.org; DITTMANN, S., UNAVCO, Colorado, USA, dittmann@unavco.org; GOTTLIEB, M. H., UNAVCO, Colorado, USA, gottlieb@unavco.org; GALLAHER, W., UNAVCO, Colorado, USA, warreng@unavco.org; REINER, D., UNAVCO, Colorado, USA, reiner@unavco.org; FOX, O., UNAVCO, Colorado, USA, fox@unavco. org; OUSBORNE, M., UNAVCO, Colorado, USA, ousborne@unavco.org ENLOE, K., UNAVCO, Colorado, USA, enloe@unavco.org; WASHINGTON, T., UNAVCO, Colorado, USA, washington@unavco.org; MENCIN, D. UNAVCO, Colorado, USA, dmencin@unavco.org

The Network Of the Americas (NOTA) is an international geoscience project which, in 2018, integrated existing NSF-funded geodetic networks into a single pan-American network that encompassed the EarthScope Plate Boundary Observatory (USA), TLALOCNet (Mexico) and COCONet (the Caribbean). Although primarily a GNSS network, NOTA also includes strainmeters, seismometers, tiltmeters and meteorological sensors. Today, the network which is managed by UNAVCO for NSF as part of the GAGE facility, consists of over 1,300 sensors, the majority of which are streaming real-time at rates of 1-sps.

The original network was built in the mid 2000's and has functioned well in recording transient tectonic deformation and measuring tropospheric phenomena. But, by increasing sampling rates, reducing latencies and expanding the range of observations made, the network has become much more useful to a wider community than originally anticipated. Examples include Earthquake and Tsunami Early Warning systems and capturing space weather events. The transition to high rate, low latency measurements plus the need for reliability and failover has meant UNAVCO is rethinking its data flow and internal archiving systems entirely. 
In this presentation we will describe the prototype system UNAVCO has been developing to rebuild NOTA as a cloud-native distributed event streaming platform. Each sensor produces a stream of data which is input to a publish-subscribe messaging system such as Kafka. Once in Kafka the data are directed to a long-term TimeScaleDB database which can be queried to retrieve historic data sets. In addition, researchers will be able to subscribe to receive real-time streams at a range of sample rates. This new system has the potential to give UNAVCO the higher throughput, fault-tolerance, reliability and real-time stream processing ability that will both allow us to manage the NOTA sensor network as part of the Internet of Things and make the data sets more usable to those pursing the study of geophysical phenomena using integrated multi-sensor and machine learning approaches.

\section{Training a Convolutional Neural Network to Identify Earthquake Onset in Real-Time GNSS Data}

DYBING, S. N., University of Oregon, Oregon, USA, sdybing@uoregon.edu; MELGAR, D., University of Oregon, Oregon, USA, dmelgarm@uoregon.edu; THOMAS, A. M., University of Oregon, Oregon, USA, amthomas@uoregon. edu; HODGKINSON, K., UNAVCO, New Mexico, USA, hodgkin@unavco. org; MENCIN, D., UNAVCO, Colorado, USA, dmencin@unavco.org

Global Navigation Satellite Systems (GNSS) data are an important source of information about earthquakes as they occur, as they do not saturate in the near field with high magnitudes as traditional broadband seismic data do. For this reason, integration of real-time GNSS data into earthquake early warning (EEW) systems is a subject of great interest. However, GNSS data have a much higher noise floor than traditional seismic data, particularly in real-time, making it difficult to identify the early onset signals of earthquakes. For this project, we will develop a machine learning algorithm for identifying earthquakes in real-time GNSS data by modifying an existing convolutional neural network $(\mathrm{CNN})$ code designed for picking P-waves in seismic data. This CNN will be trained using synthetic earthquakes generated by FakeQuakes (Melgar et al., 2016), as well as real-time noise from 237 UNAVCO GNSS stations located within $300 \mathrm{~km}$ of the Ridgecrest Sequence. The algorithm will then be tested on UNAVCO position solutions spanning June 2019-July 2020 from the same 237 GNSS stations to see how well it can identify the onsets the major Ridgecrest earthquakes, as well as smaller foreshocks and aftershocks. These position solutions are the same types of data that an EEW system would receive, so the success of this algorithm could have implications on how realtime GNSS data is incorporated into EEW systems.

\section{Unattended Ground Sensing and In-Situ Processing of Geophysical Data}

O’ROURKE, W. T., Sandia National Laboratories, New Mexico, USA, wtorour@ sandia.gov; MORROW, T. J., Sandia National Laboratories, New Mexico, USA, tmorro@sandia.gov; EVANS, B. R., Sandia National Laboratories, New Mexico, USA, brevan@sandia.gov; DEKONING, M. W., Sandia National Laboratories, New Mexico, USA, mdekoni@sandia.gov; PATEL, A. A., Sandia National Laboratories, New Mexico, USA, anipate@sandia.gov

Seismic monitoring systems are typically emplaced along with a complementary infrastructure for power and data exfiltration. In some instances, it may be desirable to deploy a system in a location where it is not feasible or reasonable to provide such infrastructure. In this case there are numerous commercial options that can provide continuous recording and indefinite operation using solar power. However, these locations must still be visited on occasion to retrieve data. We have developed a system that allows for both continuous monitoring and deployment of semi-complex algorithms. Satellite and cellular communications provide both the ability to retrieve data and command/ control of the sensor platform. This platform provides the ability to deploy complex detection and/or classification algorithms to reduce the need to send back continuous data. A system has been deployed at the Redmond Salt Mine in southwestern Utah, USA since October of 2018. A 1-D convolutional neural network (CNN) inference model has been implemented on the unit as an exemplar to demonstrate the ability to identify seismic signals from explosive blasting at the salt mine. The CNN was trained on a dataset labeled by mine level and achieved a F1 Score of 0.80 with the testing set. This result is significantly better than our goal score of 0.70 which was achieved on the same data set using a standard cross-correlation technique.
Advances in Seismic Interferometry: Theory, Computation and Applications

Oral Session · Thursday $\cdot 22$ April · 5:00 pM Pacific

Session Chairs: Doyeon Kim, University of Maryland, College Park (dk696@cornell.edu); Ross Maguire, University of New Mexico (rmaguire@unm.edu); Tieyuan Zhu, Penn State University (tuz47@psu.edu); Nori Nakata, Massachusetts Institute of Technology (nnakata@mit.edu); Ved Lekic, University of Maryland (ved@umd.edu); Marine Denolle, Harvard University (mdenolle@fas.harvard.edu)

\section{Ambient Noise Surface-Wave Tomography of the San Francisco Bay Area, California}

NAYAK, A., Lawrence Berkeley National Laboratory, California, USA, anayak7@lbl.gov; TAIRA, T., Berkeley Seismological Laboratory, California, USA, taira@berkeley.edu

The characterization of $3 \mathrm{D}$ seismic wave propagation in accurate velocity models and the effects it has on strong ground motions from earthquakes is important for accurate estimates of seismic hazard utilizing wavefield simulations. The San Francisco Bay area in California, USA is a highly urbanized active tectonic region facing high seismic hazard and crisscrossed by numerous faults. Our study aims to improve the shear wave velocity model in this region using ambient noise derived surface-wave tomography. We use continuous waveform data recorded by permanent and temporary stations in specific epochs between 1995 and 2020. We derive fundamental mode Lovewave and Rayleigh-wave phase velocity dispersion measurements at periods 3-16 s using automatic frequency-time analysis applied on multi-component noise cross-correlations. The measurements are used to invert for phase velocity maps using the $2 \mathrm{D}$ fast-marching tomography method. The phase velocity maps are used to invert for a $3 \mathrm{D}$ Vs model at a horizontal grid spacing of $\sim 10$ $\mathrm{km}$. The Vs model clearly shows low velocities in the top $\sim 1 \mathrm{~km}$ of known sedimentary basins $\sim$ San Pablo Bay, Livermore basin, Santa Clara valley and the Sacramento-San Joaquin delta and strong velocity contrasts across the Hayward fault and the San Andreas Fault at depth $\sim 2.5 \mathrm{~km}$. Assuming prograde elliptical particle motion, we identify and incorporate dispersion measurements for the $1^{\text {st }}$ higher mode Rayleigh wave on the radial-vertical plane of the noise cross-correlations over the Sacramento-San Joaquin Delta, which is a deep sedimentary basin. Higher mode Rayleigh waves in the period range $\sim 3-9$ s provide further constraints on the velocity structure. We compare the resulting velocity model to the current US Geological Survey Bay area velocity model (version 8.3.0, year 2010 ) in terms of velocities and geologic discontinuities. We forward model synthetic seismograms for a few virtual sources and the two $3 \mathrm{D}$ velocity models using a finite-difference based seismic wave propagation method and present waveform comparisons.

\section{Multi-Source Wavefield Reconstruction Combining Interferometry and Compressive Sensing}

SAENGDUEAN, P., Colorado School of Mines, Colorado, USA, psaengduean@ mymail.mines.edu; SNIEDER, R., Colorado School of Mines, Colorado, USA, rsnieder@mines.edu; WAKIN, M., Colorado School of Mines, Colorado, USA, mwakin@mines.edu

Seismic interferometry makes it possible to determine the waves that propagate between seismometers, any one of which can act as a virtual source for the other receivers. These wavefields can then be used for tomography and imaging. However, high resolution processing and interpretation in seismic interferometry typically require seismic profiles acquired from dense and regular seismic arrays. In practice, dense and regular seismic arrays cannot always be used due to restricted receiver installation, receiver malfunction, and low signal-to-noise ratio (SNR) records in some receivers. Thus, regularization and reconstruction methods such as compressive sensing are required for incomplete and irregular seismic profiles.

We propose a joint technique called multi-source reconstruction. The method cross-correlates signals of all available virtual sources before reconstructing the missing interferometric signals using compressive sensing. We show a numerical example using a line array with different numbers of available receivers. Using SNR as a comparison, our joint method statistically improves the reconstruction of interferometric signals by approximately $5 \mathrm{~dB}$ (without additive noise) and $15 \mathrm{~dB}$ (with additive noise), compared to the reconstruction when the compressive sensing is performed before interferometry. 
We also compare our technique to a conventional method, called singlesource reconstruction, where cross-correlation interferometry of only one virtual source is performed before the compressive sensing reconstruction. Our reconstruction uses Fourier and Curvelet as the sparse transforms. The Fourier multi-source reconstruction considerably improves the reconstruction quality at traces close to the virtual sources, compared to the Fourier and Curvelet single-source reconstruction. The total SNR of the Fourier multisource reconstruction also improves by $20 \mathrm{~dB}$ and $15 \mathrm{~dB}$ at $20 \%$ and $40 \%$ of available receivers along the line array, respectively.

\section{Receiver Function Monitoring at Mount St. Helens}

BRYAN, J. T., Massachusetts Institute of Technology, Massachusetts, USA, jtbryan@mit.edu; FRANK, W. B., Massachusetts Institute of Technology, Massachusetts, USA,wfrank@mit.edu; AUDET, P., University of Ottawa, Ottawa, Canada, paudet.uottowa@gmail.com; ADEN-ANTONIOW, F., Massachusetts Institute of Technology, Massachusetts, USA, faden@mit.edu

Mount St. Helens (MSH) is the most active volcano in the Cascadia volcanic arc. To forecast its future eruptions and understand their driving processes, we need observations spanning the volcanic system. Noise-based seismic interferometry has emerged as a useful tool for monitoring magma transfer and the pressurization state of volcanic systems, but its sensitivity to velocity perturbations decreases rapidly with depth. New methods are needed to monitor deep crustal processes and to detect localized velocity changes, as well as to independently validate the velocity changes measured with the ambient seismic field.

Receiver functions (RFs), a form of event-based seismic interferometry, provide point measurements of the crustal velocity structure beneath a station. With 1500+ magnitude 5.0+ teleseismic earthquakes every year, RFs permit semi-continuous monitoring of the subsurface velocity structure. RFs are body-wave measurements and are uniformly sensitive to velocity perturbations at all depths, complementing the dispersive surface-wave measurements from noise-based seismic interferometry.

We first validate the suitability of RFs for seismic monitoring by characterizing the changes in synthetic RFs that result from velocity perturbations and changes in raypath. We then build a catalog of 27,000+ P and PP phase RFs at MSH using magnitude 5.0+ teleseismic earthquakes from 2009-2020. Considering the seismic monitoring problem within the optimal transport framework, we use the Wasserstein metric and associated transport plan to characterize nonlinear time-warping deformations between full RF ensembles, rather than their stacks. We discuss the possible mechanisms of these waveform variations, including slow-slip events on the nearby Cascadia megathrust, volcanic processes at MSH, and climatological effects.

\section{Regional Seismic Velocity Changes Following the 2019 Mw7.1 Ridgecrest California Earthquake From Autocorrelations and Ps Converted Waves}

LU, Y., University of Southern California, California, USA, ylu12658@usc. edu; BEN-ZION, Y., University of Southern California, California, USA, benzion@usc.edu

We examine regional transient changes of seismic velocities generated by the Mw7.1 2019 Ridgecrest earthquake in California, using autocorrelations of moving time windows in continuous waveforms recorded at regional stations. We focus on travel time differences in prominent phases generated by an interface around $2 \mathrm{~km}$ depth, associated with transmitted Pp waves and converted Ps waves from the ongoing microseismicity. Synthetic tests demonstrate the feasibility of the method for monitoring seismic velocity changes. Taking advantage of the numerous aftershocks in the early period following the occurrence of mainshock, we obtain high temporal resolution of velocity changes up to $20 \mathrm{~min}$ following the mainshock. The results reveal regional coseismic velocity drops in the top $1-3 \mathrm{~km}$ with an average value of $\sim 2$ percent over distances up to $100 \mathrm{~km}$ from the Ridgecrest event. The velocity drops are likely dominated by changes in the top crust and are followed by rapid recoveries on timescales of days. In the nearby Coso geothermal region, the observed coseismic velocity drops are up to $\sim 8$ percent. The method allows monitoring temporal changes of seismic velocities with high temporal resolution, quick computation and precise spatial mapping of changes. The results suggest that temporal changes of seismic velocities at the subsurface are commonly generated on a regional scale by large events.
Temporal Seismic Velocity Variations: Recovery Following From the 2019 Mw 7.1 Ridgecrest Earthquake

BOSCHELLI, J. D., Saint Louis University, Missouri, USA, joshua.boschelli@ slu.edu

We investigated seismic velocity changes $(d v / v)$ associated with the 2019 Ridgecrest earthquake sequence with high-frequency auto-correlations of ambient seismic noise data. Daily auto-correlation functions were computed for the entirety of 2019 and the first quarter of 2020 for broadband stations within the region, including the temporary broadband stations installed during the aftershock deployment. Travel time shifts in the daily auto-correlation functions, relative to the mean auto-correlation waveform, were computed to produce $d v / v$ time series, which are sensitive to the evolving material properties of the shallow crust surrounding the Ridgecrest fault zone (RFZ). A shortterm velocity drop follows the $M_{\mathrm{w}} 7.1$ earthquake at stations in the vicinity of the $M_{\mathrm{w}} 7.1$ earthquake, while those greater than $50 \mathrm{~km}$ away showed no such drop. Additionally, the maximum, absolute seismic velocity changes are proportional to the logarithm of distance from the fault rupture; the seismic velocity changes exhibit a weak correlation with peak horizontal ground accelerations. Near the areas of the highest coseismic slip within the RFZ, seismic velocities recovered over 3 months. However, in the vicinity of the nearby Garlock fault, where triggered slip manifested, and north of the RFZ, seismic velocities recovered within a month. We interpret the seismic velocity changes and their recovery to be largely due to changes in the physical properties of the shallow crust, such as fault zone damage recovery caused by the earthquake rupture process, and perhaps in response to the large dynamic stresses of passing seismic waves from the earthquake.

Advances in Seismic Interferometry: Theory, Computation
and Applications
Poster Session·Thursday·22 April·11:30 AM Pacific
Session Chairs: Doyeon Kim, University of Maryland, College
Park (dk696@cornell.edu); Ross Maguire, University of New
Mexico (rmaguire@unm.edu); Tieyuan Zhu, Penn State
University (tuz47@psu.edu); Nori Nakata, Massachusetts
Institute of Technology (nnakata@mit.edu); Ved Lekic,
University of Maryland (ved@umd.edu); Marine Denolle,
Harvard University (mdenolle@fas.harvard.edu)

\section{Bayesian Analysis of Ambient Noise Cross Correlation} Functions Using a Low-Quality Seismic Network

XUE, S., University of Rochester, New York, USA, sxue3@u.rochester.edu; ZHANG, Z., University of Rochester, New York, USA, ziqi.zhang@rochester. edu; OLUGBOJI, T., University of Rochester, New York, USA, tolulope. olugboji@rochester.edu

Although ambient noise dispersion measurements are being published on the African continent, how these measurements compare to previous results, affect updates to global lithospheric models, or should be used in joint inversion schemes, is not well understood or often rarely investigated. In this study, we apply a hierarchical Bayesian technique to extract ambient noise phase dispersion and its uncertainties using station-pairs within sub-arrays from different classes of networks on the continent. Unlike iterative schemes, this approach requires limited a-priori constraints, and employs a global search for constraining the measurement uncertainty during the inversion for phase and group velocity dispersion using the ambient noise cross correlation functions. Since data quality varies across the entire region, we report on how the uncertainties in phase dispersion measurements depend on structural and non-structural parameters: i.e., duration of operation, metadata quality and sediment or low-velocity zones. A continent-wide reference dataset with uncertainties derived from data will be useful for updating lithospheric models during joint inversions with other seismic datasets. For example, global lithospheric models are heavily cited and widely used across the broader geoscience community, so ensuring that they fully incorporate short-wavelength, short-period ambient noise surface wave measurements, especially in regions that have only recently been instrumented, e.g., Africa, will be beneficial. 
Full Waveform Tomography for the Upper South Island Region, New Zealand Using Ambient Noise Data

NGUYEN, T., University of Canterbury, Christchurch, New Zealand, andrei. nguyen@canterbury.ac.nz

In this research, we apply Full Waveform Tomography (FWT) based on the Adjoint-Wavefield (AW) method using ambient noise data to iteratively invert an existing 3-D velocity model for the upper South Island region, New Zealand. Through the AW method, gradients of model parameters (compressional and shear wave velocity) were computed by implementing the crossadjoint of forward and backward wavefields simulated for each station acting like a source. We used L-BFGS/ line search algorithms to obtain a model update. Continuous time-series data recorded for one year by 10 seismic broadband stations in South Island was downloaded, and cross-correlations were computed and stacked to extract the empirical Green's functions (EGFs). Multi-taper misfits between the EGFs and the simulated Green's functions (SGFs) were measured at periods from $10-40$ s and minimized along the inversion to iteratively update the velocity model. To improve the existing velocity structure, we can start the inversion from a New Zealand wide velocity model (NZVM 2020) or from an inverted velocity model using FWT of the earthquake events. The simulated seismograms computed using our inverted velocity models and earthquake events show the relative waveform misfit to the earthquake recorded data has been reduced consistently along the iterations. This suggests that using ambient noise data in FWT can supplement for the inversion with only earthquake data.

\section{Imaging Yellowstone's Melt Distribution With Full Waveform Inversion of Ambient Noise}

MAGUIRE, R. R., Michigan State University, Michigan, USA, maguir12@ msu.edu; CHEN, M., Michigan State University, Michigan, USA, chenmi22@ msu.edu; SCHMANDT, B., University of New Mexico, New Mexico, USA, bschmandt@unm.edu; JIANG, C., Australian National University, Canberra, Australia, chengxin.jiang1@anu.edu.au; WILGUS, J., University of New Mexico, New Mexico, USA, jwilgus@unm.edu; LI, J., Michigan State University, Michigan, USA, lijiaqi9@msu.edu

The Yellowstone hotspot hosts a complex crustal magmatic system that drives hydrothermal activity, seismicity, and periodic ground deformation. Seismic tomography has constrained the presence of a partially molten magma reservoir at middle-to-upper crustal depths centered below the Yellowstone caldera, but key aspects of the system such as the total volume and distribution of melt remain open questions. Interpretations of previous tomographic images of Yellowstone are complicated by an incomplete understanding of how large crustal magmatic systems affect seismic waveforms. In particular, tomographic studies based on asymptotic methods may underestimate the seismic wave speed anomaly of the magma reservoir because first arriving energy may be diffracted around strong low wave speed anomalies. Compared to asymptotic methods, full waveform inversion approaches enable improved resolution since they incorporate more accurate sensitivity kernels based on realistic wave propagation physics. Here, we present the initial iterations of a new ambient noise dataset based full waveform inversion of Yellowstone's crust and uppermost mantle. Our starting model, which is based on inverting Rayleigh wave dispersion measurements of vertical component noise correlation functions, shares many key features with previous tomography results, including a roughly $10 \%$ slow shear wave speed anomaly centered below the Yellowstone caldera. The continued iterations of the full waveform inversion promise to sharpen features in the model and more accurately recover the strength of the anomaly associated with Yellowstone's crustal magmatic system, which is critical for understanding the volume and distribution of melt.

\section{Impact of Atmospheric Pressure Variations on Noise-Based} Seismic Velocity Changes Measurements

GRADON, C., ISTerre, Université Grenoble Alpes, Grenoble, France, chloe. gradon@univ-grenoble-alpes.fr; BRENGUIER, F., ISTerre, Université Grenoble Alpes, Grenoble, France, florent.brenguier@univ-grenoble-alpes. fr; MORDRET, A., ISTerre, Université Grenoble Alpes, Grenoble, France, aurelien.mordret@univ-grenoble-alpes.fr; STAMMEIJER, J., Petroleum Developement Oman, Mascate, Oman, johannes.js.stammeijer@pdo.co.om; HINDRIKS, K., Shell Global, Amsterdam, Netherlands, kees.k.hindriks@ shell.com; CHMIEL, M., ETH Zürich, Zürich, Switzerland, chmielm@ ee.ethz.ch; CAMPMAN, X., Shell Global, Amsterdam, Netherlands, xander. campman@shell.com

Environmental perturbations, such as rainfalls, atmospheric pressure loading, and temperature changes can affect crustal seismic velocities. Their respec- tive impacts on seismic velocities in the shallow crust are difficult to untangle as they are often acting together at similar spatial and temporal scales. We take advantage of high-quality seismic data from 40 three-component sensors distributed in 5 boreholes deployed in the desert of the Sultanate of Oman to measure velocity variations in the first top hundred meters depth over four months. During these four months, significant atmospheric perturbations (1 $\mathrm{kPa}$ ) occurred at different time scales ranging from diurnal to monthly but no precipitation is reported. To explain the observed velocity variations we use a model that accounts for 1) the loading and 2) the fluid pore pressure diffusion within a trapped aquifer located around $50 \mathrm{~m}$ below the surface, both induced by air pressure variations. By providing a model for explaining the effects of atmospheric pressure variations on crustal seismic velocities we contribute to better understanding the impact of the environment on the shallow crust.

\section{On the Feasibility of Long-Term Seismic Monitoring Using Freight Train Signals}

SHENG, Y., ISTerre, Université Grenoble Alpes, Gières, France, yixiao.sheng@ univ-grenoble-alpes.fr; BRENGUIER, F., ISTerre, Université Grenoble Aples, Gières, France, florent.brenguier@univ-grenoble-alpes.fr; BOUÉ, P., ISTerre, Université Grenoble Aples, Gières, France, pierre.boue@univ-grenoblealpes.fr; MORDRET, A., ISTerre, Université Grenoble Aples, Gières, France, aurelien.mordret@univ-grenoble-alpes.fr; BEN-ZION, Y., University of Southern California, California, USA, benzion@usc.edu; VERNON, F., IGPP, University of California, San Diego, California, USA, flvernon@ucsd.edu

Recent studies (Brenguier et al., 2019; Pinzon-Rincon et al., 2020) have successfully retrieved body waves between seismic arrays through the correlations of train-generated seismic signals. It remains uncertain whether these train-derived body waves are suitable for long-term seismic monitoring, which requires repeatable measurements over the years. This study tests the feasibility of obtaining stable body waves between individual broadband stations, using freight trains as noise sources. We use stations close to the railroad as markers to identify trains and pinpoint their potential locations. We select proper station pairs and perform seismic interferometry, focusing on the time windows when trains are detected. We test our workflow in southern California, with the freight trains running through the Coachella Valley. We successfully retrieve stable body-wave signals over ten years. We perform a weekly stacking to improve the signal-to-noise ratio and estimate the relative time shift. Our preliminary time-shift measurements reveal a systematic longterm increasing trend for station pairs locating on two sides of the San Jacinto fault. The next step is to examine the results statistically to reduce the bias introduced by moving sources. Despite that the long-term trend still needs further study, our experiment demonstrates that it is possible to perform longterm seismic monitoring using train generated seismic signals.

\section{Optimize the Stacking of Noise Correlation Functions}

YANG, X., Purdue University, Indiana, USA, xtyang@purdue.edu; BRYAN, J. T., Massachusetts Institute of Technology, Massachusetts, USA, jtbryan@ mit.edu; OKUBO, K., National Research Institute for Earth Science and Disaster Resilience, Tsukuba, Japan, kokubo@bosai.go.jp; JIANG, C., Australian National University, Acton, Australia, chengxin.jiang1@anu.edu. au; CLEMENTS, T., Harvard University, Massachusetts, USA, thclements@g. harvard.edu; DENOLLE, M., University of Washington, Washington, USA, mdenolle@uw.edu

The cross-correlation of ambient seismic noise provides propagation information of seismic waves in the three dimensional Earth. A common step in extracting Noise Correlation Functions (NCFs) is the stacking of individual correlations performed at short time windows, e.g. a day or an hour, over a longer period. However, one important characteristic of resultant NCFs is the variation of the overall quality through time, which is commonly ignored in the final stacking. This temporal variation may be the consequence of either the seasonal change of microseisms, the contamination from local transient signals, or the influence of instrumental performance. These factors lead to noisy or useless individual NCFs, which would consequently contaminate the final stack. In this study, we explore seven different temporal stacking methods and evaluate their performance, in terms of signal-to-noise ratios, the preservation of relative amplitudes, and computational expenses, to optimize the final stack of NCFs.

Virtual Seismometer Method for Fault Orientation Analysis in Southern Kansas

MORENCY, C., Lawrence Livermore National Laboratory, California, USA, morency1@llnl.gov; MATZEL, E., Lawrence Livermore National Laboratory, 
California, USA, matzel1@llnl.gov; KROLL, K., Lawrence Livermore National Laboratory, California, USA, kroll5@llnl.gov

We analyze spatial and temporal changes in fault rupture styles and orientations near a site of active fluid disposal in Southern Kansas. Our approach is based on the virtual seismometer method (VSM), an interferometric technique which uses the reciprocity principle to capture the wavefield between seismic events (Curtis et al., 2009, Nature Geoscience). VSM is very sensitive to the source parameters (location, mechanism and magnitude) and we can use it to invert for full moment tensor solutions, particularly for events within dense clouds of microseismicity.

In this study, we apply VSM to induced events in Southern Kansas. The data are records of micro events from a dense seismicity catalog created with matched filter techniques (Cochran et al., 2018, JGR). From this, we calculate full moment tensor solutions for individual events and use the results to determine fault rupture and orientation information. Focusing on a subset of events of magnitude 1-3 that occurred during 2015, we first derive a normalized waveform similarity coefficient map (Trugman, 2020, GRL), which confirms spatial changes in fault rupture. Results of VSM-based full moment tensor inversion of this same subset of events show a range of non-double couple components. The presence of non-double couple components has also been suggested in fluid related mechanism of induced seismicity in other studies (e.g., Wang et al, 2018, GRL).

The advantage of VSM, contrary to other classical moment tensor inversion techniques, is to considerably reduce the modeled numerical domain to the region directly around the micro events cloud, which lowers computational cost, permits to reach higher frequency resolution, and suppresses the impact of the Earth structural model uncertainties outside the micro events cloud.

This work was performed under the auspices of the U.S. Department of Energy by Lawrence Livermore National Laboratory under Contract DE-AC5207NA27344. LLNL-ABS-818264

\section{Wave Propagation in an 18-Story Steel Building and the Changes of Wave Filed With the Progression of Damages \\ WANG, X., Tokyo University of Science, Noda, Japan, wangxin@rs.tus.ac.jp}

From the aspect of wave propagation, the response of a building can be seen as the traveling of the input wave from the base and multiply reflected by the base and top until the energy of the input motion is consumed by the damping and scattering to the ground. Because wave propagation depends on the properties of upper structures, it is possible to examine the damages of the structure from the changes of characteristics of wave filed, such as the wave velocity, the dispersion, the reflection by inter stories, and so on. In order to demonstrate the damage detection from changes of wave filed practically, in this study, the shake-table test of a 1/3-scale specimen of an 18-story steel building are used. The specimen was excited by a synthesized long-period strong ground motion, whose amplitude was increased by ten steps to lead the structure from elastic condition to the occurrence of plastic deformation, fractures at the beam ends, buckling at the column feet, until the collapse of lower stories. Also, the changes of wave filed under white noise after the progression of damages are examined. Because it is difficult to examine the wave propagation from the waveforms directly, in this study, new wave fields are constructed using the seismic interferometry method as considering the virtual source at the top of the building. The effect of dispersion due to the bending deformation of stories is considered to examine the changes of shear-wave phase velocities with the progression of damages.

\section{Advances in the Science and Observation of Tsunamis \\ Oral Session · Thursday · 22 April · 9:45 AM Pacific \\ Session Chairs: Vasily V. Titov, National Oceanic and Atmospheric Administration (vasily.titov@noaa.gov); Bruce Jaffe, U.S. Geological Survey (bjaffe@usgs.gov)}

\section{Anatomy of Strike Slip Fault Tsunami-Genesis}

ELBANNA, A., University of Illinois at Urbana Champaign, Illinois, USA, elbanna2@illinois.edu; ABDELMEGUID, M., University of Illinois at UrbanaChampaign, Illinois, USA, meguid@illinois.edu; MA, X., University of Illinois at Urbana Champaign, Illinois, USA, xiaoma5@illinois.edu; AMLANI, F., University of Southern California, California, USA, famlani@gmail.com;
BHAT, H. S., École Normale Supérieure, Paris, France, harshasbhat@gmail com; SYNOLAKIS, C., University of Southern California, California, USA, costas@usc.edu; ROSAKIS, A. J., Caltech, California, USA, arosakis@caltech. edu

Tsunami generation from earthquake induced seafloor deformations has long been recognized as a major hazard to coastal areas. Strike-slip faulting has generally been believed as insufficient for triggering large tsunamis, except through the generation of submarine landslides. Herein, we demonstrate that ground motions due to strike-slip earthquakes can contribute to the emergence of large tsunamis $(>1 \mathrm{~m})$ under rather generic conditions. In this work, we present a physics driven computational framework that couples models for earthquake rupture dynamics with models of tsunami generation and propagation. The three-dimensional time dependent ground motions from the spontaneous dynamic ruptures are used as the driving boundary motions in the tsunami model. Our results indicate that strike-slip faults have the unexpected potential for generating devastating tsunamis under the proper conditions. We show that supershear ruptures propagating along strike-slip fault, traversing narrow and shallow bays generate significant horizontal motions that can be a critical driver of tsunami hazard. Our work identifies intrinsic mechanisms for considerable tsunami generation, without necessarily having co-seismic underwater landslides or slumps. The tsunami model points out to three different phases in the tsunami motion; an instantaneous dynamic phase, a lagging coseismic and a classical postseismic phase, each of which may affect coastal areas differently. In addition to supershear rupture, we evaluate the case of sub-Rayleigh rupture propagating along the same strike-slip fault and demonstrate that supershear rupture generate significantly higher water wave amplitude. Finally, we highlight the important role bathymetry motion have on the tsunami generation by comparing a basin like bathymetry versus a uniform depth bathymetry.

\section{How the Parameters of a Seismic Surface Wave Governs the Properties of the FGSS Waves in the Ocean}

SEMENTSOV, K. A., Lomonosov Moscow State University, Moscow, Russian Federation, sebbest@yandex.ru; KOLESOV, S. V., Lomonosov Moscow State University, Moscow, Russian Federation, kolesov@ocean. phys.msu.ru; NURISLAMOVA, G. N., Lomonosov Moscow State University, Moscow, Russian Federation, nurislamova@physics.msu.ru; NOSOV, M. A. Lomonosov Moscow State University, Moscow, Russian Federation, nosov@ phys.msu.ru

The key factor that determines the generation of gravity waves in the ocean by submarine earthquakes is the displacement of water by the coseismic bottom displacement (Murty, 1977). However, seismic surface waves are also capable of exciting gravity waves in the water layer (Gutenberg, 1939; Levin \& Nosov, 2016; Sementsov et al., 2019). Because Free Gravity waves excited by Seismic Surface waves have not been relatively well studied, there is still no conventionally agreed-upon name for them. In the (Sementsov et al., 2019) we proposed the abbreviation FGSS waves for them. In the (Sementsov et al., 2019) we studied the FGSS waves, recorded by the DONET bottom observatories during the 2011 Tohoku event. The results showed that (1) horizontal, rather than vertical, bottom movements play a key role in their generation, (2) the amplitude of the excited gravity waves is determined by the amplitude of the dynamic horizontal bottom motions, while the contribution of horizontal static bottom displacements is insignificant, and (3) the amplitude of the excited gravity waves depends on the relative orientation of the slope and the propagation direction of the seismic surface waves. The mechanisms of the FGSS waves generation require further study and refinement using numerical experiments. Experiments are carried out using a combined 3D / 2D model of the evolution of tsunami waves (Sementsov et al., 2019). The results of these new experiments will be discussed.

This work was supported by the Russian Foundation for Basic Research (Projects 20-35-70038, 19-05-00351, 20-07-01098).

References.

1. Mutry, T. S. (1977). Seismic sea waves-Tsunamis. Ottawa: Fisheries and Marine Service.

2. Gutenberg, B. (1939). Tsunamis and Earthquakes, Bulletin of the Seismological Society of America, 29 (1), 517-526.

3. Levin, B. W., Nosov, M. A. (2016). Physics of Tsunamis, Second Edition. - Springer International Publishing AG Switzerland. - $388 \mathrm{p}$

4. Sementsov, K. A. et al. (2019). Journal of Geophysical Research: Oceans, 124(11), 8468-8484. 
Measuring the Background Open-Ocean Tsunami Spectrum Using the Pacific Basin Dart Array

SANTELLANES, S., University of Oregon, Oregon, USA, ssantel2@uoregon. edu; MELGAR, D., University of Oregon, Oregon, USA, dmelgarm@uoregon. edu

The background open-ocean tsunami spectrum (BOOTS) is an under-studied topic. It describes the spectrum of oscillations that occur out in the openocean in the tsunami band ( $\sim 1 \mathrm{~min}-2 \mathrm{hrs})$. It is important because it plays a key role in understanding the local site response at a tide gauge, and it can be extended to show the tsunami site response at locations with no tide gauges. The objective of this study is to measure the BOOTS and its associated noise using long time series of noise from DART deployments in the Pacific Basin.

In order to accomplish do these calculations, data is used from the recovered bottom pressure recorders of the DART buoys which has a time-spacing of 15 seconds. As a consequence of this sampling rate, it is possible to measure the BOOTS over the full tsunami band. The quality-controlled de-tided pressure is used in the calculation of the spectra. These are computed every two weeks for each DART buoy for as long as fidelity data is available. Tsunami events anywhere in the Pacific Basin over the time frame of 2000-2018 are filtered out to ensure that the spectra are mainly that of the background oscillations. Spectra generally have a simple log-linear decay, so a least-squares inversion is done for every spectrum in order to compute the slope and intercept. From this we obtain time-series of each of the set wo parameters to study the temporal variation of the BOOTS for each DART.

Preliminary results show that the BOOTS is neither simple nor constant for each DART. Some DARTs, like those in the Aleutians and Cascadia, experience seasonal fluctuations in both the slope and intercept. Meanwhile, other regions, like the SE Pacific and the NE Pacific, have little seasonal variability in slope and noise. Ongoing work is being done to understand the physical mechanism behind this result. Overall, the study will provide much needed insights into the behavior of the BOOTS in the Pacific Basin. The broader impact of this being that understanding it can be used to study the tsunami site effect in areas with or without tide gauges.

\section{Rapid GNSS Source and DART Inversion Models Comparison along the Cascadia Subduction Zone}

SANNIKOVA, N. K., Joint Institute for Marine and Atmospheric Research; National Oceanic and Atmospheric Administration, Washington, USA, natalia.sannikova@noaa.gov; WEI, Y., Cooperative Institute for Climate, Ocean and Ecosystem Studies; National Oceanic and Atmospheric Administration, Washington, USA, yong.wei@noaa.gov; ARCAS, D., National Oceanic and Atmospheric Administration, Washington, USA, Diego.Arcas@ noaa.gov; KWONG, K. B., University of Washington, Washington, USA, kbkwong@uw.edu; WILLIAMSON, A. L., National Tsunami Warning Center, Alaska, USA, amy.williamson@noaa.gov; MELGAR, D., University of Oregon, Oregon, USA, dmelgarm@uoregon.edu

Tsunami warning systems have improved significantly since the devastating 2004 Indonesian quake providing coastal communities with the possibility of a rapid tsunami forecast in a timely and more accurate way. One of the problems that needs an improvement is a near-field forecast for the areas located close to the tsunami source. Recent efforts to mitigate the near-field problem have been focused on the computation of rapid GNSS-based (Global Navigation Satellite Systems) seismic solutions. While this technique can generate very fast solutions, its accuracy in forecasting when compared with forecast generated from DART buoy data has yet to be evaluated. In this study we compare the results of GNSS-based source characterization model and DART inversion model using synthetic megathrust ruptures of Cascadia subduction zone for its near-field forecasting potential. The tsunami inundation modeling results demonstrated higher accuracy for the DART-based forecasts in a majority of coastal locations than the GNSS-based forecast. However, the latency in the acquisition of DART data during a real event renders this approach impractical for near-field forecasting. The GNSS-based finite-fault source derived from the Slab 2 characteristics demonstrates its potential as a quick solution in terms of both model accuracy and time contingency of an event.

\section{Real-Time Tsunami Data Assimilation of S-Net Pressure} Gauge Records During the 2016 Fukushima Earthquake

WANG, Y., The University of Tokyo, Bunkyo, Japan, ywang@eri.u-tokyo.ac.jp; SATAKE, K., The University of Tokyo, Bunkyo, Japan, satake@eri.u-tokyo. ac.jp

The 2016 Fukushima earthquake (M7.4) generated a moderate tsunami, which was recorded by the offshore pressure gauges of the Seafloor Observation Network for Earthquakes and Tsunamis (S-net). We used 28 S-net pressure gauge records for tsunami data assimilation and forecasted the tsunami waveforms at four tide gauges on the Sanriku coast. The S-net raw records were processed using two different methods; in the first method, we removed the tidal components by polynomial fitting and applied a low-pass filter. In the second method, we used a real-time tsunami detection algorithm based on Ensemble Empirical Mode Decomposition to extract the tsunami signals, imitating real-time operations for tsunami early warning. The scores of forecast accuracy of the two detection methods are $60 \%$ and $74 \%$, respectively, for a time window of $35 \mathrm{~min}$, but they improve to $89 \%$ and $94 \%$ if we neglect the stations with imperfect modeling or insufficient offshore observations. Hence, the tsunami data assimilation approach can be put into practice with the help of the real-time tsunami detection algorithm.

Advances in the Science and Observation of Tsunamis

Poster Session · Thursday · 22 April · 3:45 PM Pacific

Session Chairs: Vasily V. Titov, National Oceanic and

Atmospheric Administration (vasily.titov@noaa.gov); Bruce

Jaffe, U.S. Geological Survey (bjaffe@usgs.gov)

Comparison of Machine Learning Approaches for Tsunami Forecasting

LEVEQUE, R. J., University of Washington, Washington, USA, rjl@uw.edu; LIU, C. M., University of Washington, Washington, USA, cmhl@uw.edu; RIM, D., New York University, New York, USA, dr1653@nyu.edu; BARALDI, R., University of Washington, Washington, USA, rbaraldi@uw.edu

We have explored three different machine learning (ML) approaches for forecasting tsunami amplitudes (or full time series) at a set of forecast points, based on hypothetical short-time observations at one or more observation points. As a case study, we chose an observation point near the entrance of the Strait of Juan de Fuca, and two forecast points in the Salish Sea, one in Discovery Bay and the other in Admiralty Inlet, the waterway leading to southern Puget Sound. One ML approach considered is to extract features from the observed time series and use the extracted features in training a support vector machine (SVM) to predict the maximum amplitude at the forecast points. We also explored the use of two deep convolutional neural networks, a denoising autoencoder and a variational autoencoder to predict the full time series at the forecast points. These approaches also provide an estimate of the uncertainty in the predictions. As training data we use a subset of the 1300 synthetic CSZ earthquakes generated in the work of Melgar et al. 2016 [10.1002/2016JB013314] that is archived at [10.5281/zenodo.59943], reserving some as test data. As additional tests, the trained ML models have also been applied to other hypothetical CSZ earthquakes produced by very different approaches, such as the "L1 event" from the work of Witter et al. 2013 [10.1130/GES00899.1] that is used in the generation of tsunami inundation maps in Washington State. The ML models are capable of providing very good predictions from short duration observations, even when truncated before the first wave peak has reached the observation point.

\section{Contribution of Smart Cables to Earthquake and Tsunami Early Warning in the Sumatra and Java Regions}

SALAREE, A., University of Michigan, Michigan, USA, salaree@umich.edu; HOWE, B., University of Hawaii, Hawaii, USA, bhowe@hawaii.edu; HUANG, Y., University of Michigan, Michigan, USA, yiheh@umich.edu

SMART (Science Monitoring And Reliable Telecommunications) cables as a potential next generation of marine sensors with both societal and scientific applications are powerful solutions to monitoring natural hazards such as earthquakes and tsunamis. In this framework and considering the high societal risk and spatial and financial scales of these hazards in Indonesia, we propose the deployment of such a network in eastern Indian Ocean. We present results from a series of exploratory numerical experiments regarding the deployment of a linear array of SMART stations seaward of the trench in the Sumatra-Java region. We use a number of static earthquake rupture scenarios $\left(8.5<\mathrm{M}_{\mathrm{w}}<9.3\right)$ at various locations along the trench and calculate tsunami propagation using hydrodynamic simulations. Through these experiments we show that the proposed array improves the detection of earthquake tsunamis up to several hours compared to the existing DART system in the Indian Ocean. Similarly, we simulate the tsunamis from a large number of submarine landslide scenarios in the region and show that the SMART system can provide invaluable information for use in early warning against landslide tsunamis. We also calculate seismic phase arrival times from our source scenarios at both the existing seismic stations and our proposed SMART cables. Our 
results show that inclusion of such a SMART array can expedite the detection of seismic events in the region by siginifcantly reducing event-to-station distances and therefore seismic arrival times. Also, by means of closing the $>180^{\circ}$ southern and western azimuthal gaps along the entire span of Sumatra and Java, the proposed array would drastically decrease inaccuracies in the earthquake location process in the region.

Moment and Rupture Duration From Seismogeodetic Data for Local Tsunami Warnings

GOLRIZ, D., Scripps Institution of Oceanography, University of California, San Diego, California, USA, dgolriz@ucsd.edu; HIRSHORN, B., Seismologist, Hawaii, USA, barryhirshorn@mac.com; BOCK, Y., Scripps Institution of Oceanography, University of California, San Diego, California, USA, ybock@ ucsd.edu; WEINSTEIN, S., Pacific Tsunami Warning Center, NOAA, Hawaii, USA, stuart.weinstein@noaa.gov

Because earthquakes generate most tsunamis, the first indication that a tsunami may have been generated is the earthquake itself. Therefore, tsunami warning centers provide their initial tsunami warnings to coastal populations based entirely on real-time seismic data. Prior to the $2004 \mathrm{M}_{w} 9.2$ Sumatra earthquake, no near real-time magnitude determination method existed that would correctly estimate the size of so large an event. Since then, Kanamori and Rivera (2008) developed the W-phase source inversion method which now provides unsaturated estimates of $\mathrm{M}_{\mathrm{w}}$ and centroid moment tensor (CMT) solutions within 6-15 minutes of earthquake origin time. Tsunam warning centers must also rapidly identify slow "tsunami" earthquakes, for which the traditional methods using relatively short period seismic waves are not effective. Because tsunami earthquakes produce much less radiated high frequency energy than normal, even a large tsunami earthquake may not be strongly felt in the near field, making self-evacuation based upon feeling strong ground shaking problematic. Combining GNSS with strong-motion data via a Kalman filter (Bock et al., 2011) yields unclipped broadband velocity and displacement waveforms, and are sensitive to the entire spectrum of ground motions from the Nyquist frequency of the accelerometer (typically $50 \mathrm{~Hz}$ ) to the static offset of the GNSS displacement. Using this data, we test a method to estimate moment magnitude, and rupture duration within 3-5 minutes of rupture initiation. We use the velocity time series to define the appropriate co-seismic time window for the displacement record, the end of which provides a proxy for source duration. We then estimate the seismic moment from the maximum value of the integrated displacement within this window. The time that this maximum value occues provides a second proxy for rupture duration. Using seismogeodetic data for earthquakes in the $M_{w} 7.1$ to 9.1 range, we obtain accurate and reliable moment magnitudes, and rupture duration estimates within minutes of rupture initiation.

\section{Speed vs. Precision: The Tsunami Warning Center Duty Scientists' Dilemma}

SARDINA, V., Pacific Tsunami Warning Center, NOAA, NWS, Hawaii, USA, victor.sardina@noaa.gov; WEINSTEIN, S., Pacific Tsunami Warning Center, NOAA, NWS, Hawaii, USA, stuart.weinstein@noaa.gov; MCCREERY, C., Pacific Tsunami Warning Center, NOAA, NWS, Hawaii, USA, charles. mccreery@noaa.gov

We analyzed strong motions and their durations from two moderate magnitude earthquakes that occurred off the Chiba prefecture in 2018 and 2020, respectively. The two earthquakes occurred in an extremely complicated tectonic area north of the Sagami trough (a triple junction) where the Philippine Sea Plate overrides the Pacific Plate and the both plates subduct beneath the Kanto basin. The earthquakes had Mw values of 5.9 estimated by F-net, NIED. The JMA focal depths of the former and latter events were 56 and $36 \mathrm{~km}$, respectively. The ground motion records on the Kanto basin were taken from the dense MeSO-net, while the ground motions on the ocean bottom were taken from newly established ocean bottom network, S-net. The seismographs of MeSO-net are set up at the depth of $20 \mathrm{~m}$ in a borehole. The S-net seismographs are housed inside inline-type cylindrical vessels, which are buried to the depth of about one meter in the shallow water region $(\leq 1500 \mathrm{~m})$ while the vessels are laid freely on the ocean bottom in the deeper region. PGAs, PGVs, and significant durations based on Arias intensity were compared between the two events on the Kanto basin and offshore area. To make a meaningful comparison between the data sets from the two networks, the waveforms at the MeSO-net stations were compared with the waveforms at the nearby K-NET and KiK-net stations. It was found that the waveforms at the $20 \mathrm{~m}$ depth were very similar to the waveforms at the nearby surface stations within one kilometer at frequencies lower than about 0.5 to $1.0 \mathrm{~Hz}$. Our comparison at applicable frequencies showed that the PGAs were very similar between the two events at the MeSO-net sites despite the difference of the focal depths, but the PGVs were larger for the shallow event. The PGAs and PGVs were, on average, larger at the ocean bottom sites than those at the land sites for the deeper event. The horizontal component PGAs and PGVs were larger at the ocean bottom sites for the deeper event, while the values for the vertical component were similar. The significant durations between the two earthquakes and the two networks were comparable.

\section{Tsunami Squares: Earthquake Driven Inundation Mapping and Validation by Comparison to the Regional Ocean Modeling System}

GRZAN, D., University of California, Davis, California, USA, dgrzan@ ucdavis.edu; RUNDLE, J. B., University of California, Davis, California, USA, jbrundle@ucdavis.edu; WILSON, J., University of California, Davis, California, USA, jhnwilson@ucdavis.edu; WARD, S. N., University of California, Santa Cruz, California, USA, ward@es.ucsc.edu; SONG, T., NASA Jet Propulsion Laboratory, California, USA, tony.song@jpl.nasa gov; DONNELLAN, A., NASA Jet Propulsion Laboratory, California, USA, andrea.donnellan@jpl.nasa.gov

A promising tsunami warning system outlined here links Total Electron Content (TEC) disturbances in the ionosphere detected by GNSS satellites to maps of inundated areas along the affected coastlines. This will be accomplished through a pipeline of earthquake, ionosphere, and tsunami simulations. The focus of this paper is to demonstrate the feasibility and validity of our tsunami simulator for use in this simulation pipeline. The simulator we have developed is called Tsunami Squares, a computationally inexpensive program that employs a unique method of propagating water according to shallow water theory. Unlike other wave simulators, Tsunami Squares can easily propagate waves from sea to land, allowing flooded areas along the coast to be mapped. To validate its accuracy, a comparison is made to the Regional Ocean Modeling System tsunami simulator, which solves the Navier Stokes equations directly using a finite-difference method. The two simulation techniques show good agreement when compared over the 2011 Japan event, the 2010 Chile event, and the Indian Ocean event of 2004. Examples of inundation plots along with runup height comparisons between Tsunami Squares and observed data are displayed here to demonstrate our ability to produce accurate inundation plots for such a warning system.

Advances in Understanding Near-Field Ground Motions:
Observation, Prediction and Application
I: Oral Session· Thursday·22 April · 9:45 AM Pacific
II: Oral Session· Thursday·22 April·2:00 PM Pacific
Session Chairs: Jessie K. Saunders, U.S. Geological Survey
(jksaunders@usgs.gov); Dara E. Goldberg, U.S. Geological
Survey (degoldberg@usgs.gov); Tara Nye, University of
Oregon (tnye@uoregon.edu); Valerie Sahakian, University of
Oregon (vjs@uoregon.edu)

\section{Application of the G-Fast Algorithm to Rapidly Estimate} Earthquake Ground Motion Using GNSS Slip Models on the Cascadia Megathrust

KWONG, K. B., University of Washington, Washington, USA, kbkwong@ uw.edu; CROWELL, B. W., University of Washington, Washington, USA, crowellb@uw.edu; MELGAR, D., University of Oregon, Oregon, USA dmelgarm@uoregon.edu; WILLIAMSON, A. L., National Tsunami Warning Center, Alaska, USA, amy.williamson@noaa.gov

Ground motion prediction equations (GMPE) play a critical role in probabilistic seismic hazard analysis. In this study, we highlight our method to rapidly determine GMPE using finite-fault (FF) rupture models derived from near-field Global Navigation Satellite System (GNSS) stations. The geodetic approach using GNSS data is applicable for real-time monitoring of moderate to large destructive earthquakes. We use the Geodetic First Approximation of Size and Time (G-FAST) algorithm (Crowell et al., 2016) to compute FF rupture models using a synthetic dataset of 1300 simulated earthquake ruptures (M7.5-M9.5) distributed throughout the Cascadia subduction zone margin. We investigate whether the spatial distribution of slip from geodetic models can accurately constrain ground motion. Fault location and geometry are determined from either the geodetic CMT solution on a single rectangular fault plane or from a prescribed subduction zone megathrust geometry with two rectangular fault segments. We estimate horizontal ground motion ampli- 
tudes from the FF solutions using the Next Generation Attenuation Model (NGA) presented in Chiou and Youngs (2008). The geodetic derived ground motion predictions highlight a useful way to calculate Modified Mercalli Intensity (MMI) values within a few minutes of the mainshock rupture. We highlight uncertainties between the predicted versus observed ground motion. Geodetic algorithms such as G-FAST add important value in timely and robust estimation of earthquake magnitude and ground motion.

\section{Ground Motions Simulated on 3D Printed Earth Models}

PARK, S., Caltech, California, USA, sunnyp@caltech.edu; SHIN, C., Seoul National University, Seoul, Korea, Republic of, cssmodel@snu.ac.kr; KIM, Y., Korea Advanced Machinery Inc., Seoul, Korea, Republic of, younglib.kim@ kami.biz; CLAYTON, R. W., Caltech, California, USA, clay@gps.caltech.edu

Complex structure such as small-scale heterogeneities, rough topography and basin interfaces can significantly amplify the ground motion. Understanding the path and site effects caused by such small-scale features is particularly important for near-field scenarios where abundant high-frequency energy is present. However, challenges arise not only from the limitations in computing resources, but also from inaccuracies in forward models and approximations that are being imposed in numerical studies.

Here, we present a novel physical modeling approach to understand near-field ground motions. We take advantage of 3D printing techniques to create physical models for seismic experiments. We mainly use metal as the $3 \mathrm{D}$ printing material since it can represent material properties as rigid as the Earth's lower crust. By adjusting the printing parameters, i.e., the laser power and the scanning speed, during the printing process, we change the density structure within a printed model. This approach allows us to effectively represent a broad range of material properties, e.g., P-wave speeds of about 1-6 $\mathrm{km} / \mathrm{s}$. Based on the relationship between the printing parameters and seismic wave speeds, seismic velocity models with different levels of complexity are printed, including a basin model derived from a southern California velocity model (CVM-H model). We perform seismic experiments on the 3D printed models using laser generators and laser doppler vibrometers as sources and receivers. The experiments result in record sections where a variety of seismic phases, e.g., direct and reflected body and surface waves, are identified. The measured travel times of major phases are consistent with predictions based on the input velocity models. We also "simulate" a local earthquake in the Los Angeles basin area and find ground motion amplified by shallow basin structure, in particular, in the vicinity of the basin edges. Our study demonstrates that seismic experiments on 3D printed Earth models provide unprecedented opportunities of understanding seismic ground motions.

\section{Modelling Rapid Near Field Attenuation from Shallow Induced Earthquakes, Case Study: Preston New Road, UK} SUROYO, P. M. T., University of Liverpool, Liverpool, United Kingdom, p.suroyo@liverpool.ac.uk; EDWARDS, B., University of Liverpool, Liverpool, United Kingdom, edwardsb@liverpool.ac.uk

The significant growth of human-induced earthquakes in recent years has drawn public attention. Many attempts have been made to model seismicinduced ground motion, typically by implementing, and frequently adapting, pre-existing tectonic ground motion prediction equations (GMPEs). However, tectonic GMPEs are often unsuitable for adaptation to induced seismicity. In particular, they offer insufficient functional flexibility to fully adapt to the near-field shallow source scenarios typical of such events. For instance, rapid near field decay is often observed owing to travel paths that propagate predominantly through shallow sedimentary layers. Estimating attenuation behavior specific to shallow source events in the near field is therefore an important factor to consider in the development of GMPEs for induced seismicity applications. Here we investigate physical mechanisms of the difference between shallow induced and tectonic seismicity by directly modeling seismic attenuation of UK seismicity, with focus on the Preston New Road (PNR) shale gas induced seismicity sequences.

Measurements of seismic attenuation quality factor $(Q)$ are non-unique and may differ depending on the method and the seismic windows used, particularly at high frequency. These inconsistencies may be due to methodological aspects or represent different physical processes. The PNR, UK dataset recorded between 2018-2019 with $\mathrm{M}_{\mathrm{L}}<3$ at distances less than 25 $\mathrm{km}$ is utilised to model $Q$ using two different approaches: (1) spectral fitting, and (2) coda envelope decay methods. The results from the spectral fitting method show three different frequency-independent $Q$ models with respect to different parts of the recorded seismograms (S-wave, $Q_{S}$, coda wave, $Q_{C}$, and $S+$ coda windows, $Q_{S C}$, while a frequency-dependent $Q$ model was found from the coda envelope decay method $\left(Q_{\mathrm{Clt}}\right)$. These $Q$ models of shallow induced seismicity tend to be smaller than the regional $Q\left(Q_{\mathrm{Lg}}(\mathrm{f})=266 f^{0.53}\right)$ (Sargeant \& Ottemöller, 2009).

\section{Near-Field Directionality of Earthquake Strong Ground Motions Measured by Displaced Rocks}

KING, T., University of Oxford, Oxford, United Kingdom, tamarah.king@ earth.ox.ac.uk; QUIGLEY, M., University of Melbourne, Melbourne, Australia, mark.quigley@unimelb.edu.au; ATTANAYAKE, J., University of Melbourne, Melbourne, Australia, januka.attanayake@unimelb.edu.au

This study documents coseismic displacement of 1437 rocks in the near-field $(<5 \mathrm{~km})$ of the $2016 \mathrm{M}_{\mathrm{W}} 6.1$ reverse surface-rupturing earthquake near the Petermann Ranges, Central Australia. The data show variable directions of displacement over an area of $100 \mathrm{~km}^{2}$ along and across the surface rupture and preserve variable hanging-wall and foot-wall effects. We interpret our field data to record combinations of co-seismic directional permanent ground displacements associated with elastic rebound (fling) and transient ground shaking, with intensities of motion increasing with proximity to the surface rupture. We compare field data with theoretical finite-fault modelling of static and dynamic strong ground motions for uni-lateral and bi-lateral rupture scenarios, with field observations best represented by bi-lateral rupture models. These field data provide a proxy test for available rupture models for directionality of near-field strong ground motions in the absence of near-field instrumental data for dip-slip earthquakes.

\section{Tsunami Earthquake or Attenuating Crustal Structure: Ground Motions From the 2 May 2020, M6.6 lerapetra (Crete) Earthquake}

CHATTERJEE, A., University of Oregon, Oregon, USA, avigyanc@uoregon. edu; SAHAKIAN, V., University of Oregon, Oregon, USA, vjs@uoregon.edu MELGAR, D., University of Oregon, Oregon, USA, dmelgarm@uoregon.edu; GANAS, A., National Observatory of Athens, Athens, Greece, aganas@noa.gr; KAPETANIDIS, V., National and Kapodistrian University of Athens, Athens, Greece, vkapetan@geol.uoa.gr

Preliminary analysis of the ground-motions from the shallow M6.6 reverseslip earthquake that struck the island of Crete on May 2nd, 2020 12:51 UTC indicates low shaking for the earthquake's magnitude. Such behavior is common to 'Domain-A' or tsunami earthquakes according to Lay, et.al (2012). However, low ground motion onshore Crete (and areas on the back-arc) from such an event could also be a property of the path the earthquake signal traverses. Local shallow subduction zone structure and its high attenuation (due to the overlying thick accretionary wedge) could also explain the low ground motions. Analyzing the ground-motions and rupture properties of this earthquake will greatly help us refine our understanding of its source processes and augment our grasp over building better early warning systems. We perform a regional analysis of the ground-motions of the M6.6 2020 Ierapetra (Crete) tsunamigenic earthquake, its aftershocks, as well as historical seismicity, to understand whether the ground motions we observe are due to source, or path effects. To detangle these effects, we decompose event, path and site residuals from ground-motion models for all earthquakes in this dataset. Finally, if found to be a "Domain A" tsunami earthquake, implementation of recent algorithms of combined near-field seismic and geodetic data could determine how well such early warning methods will perform in real-time, for this event and for other similar events.

\section{An Empirical Ground-Motion Model Based on Truncated Regression: A Case Study in the Middle East}

KUEHN, N., University of California, Los Angeles, California, USA, kuehn@ ucla.edu; KISHIDA, T., Khalifa University of Science and Technology, Abu Dhabi, United Arab Emirates, tadahiro.kishida@kustar.ac.ae; ALHAMAYDEH, M., American University of Sharjah, Sharjah, United Arab Emirates, malhamaydeh@aus.edu; BOZORGNIA, Y., University of Californa, Los Angeles, California, USA, yousefbozorgnia@ucla.edu; AHDI, S. K., University of California, Los Angeles, California, USA, sahdi@ucla.edu

We present an empirical earthquake ground-motion model (GMM) for the Middle East. The model is developed on a database of about 9500 strongmotion records from the Middle East, from which abou 2800 are used in model development. The model is developed as a Bayesian multi-level model, which accunts for any systematic group effects (event, site, region). Prior distributions for the parameters are based on physical considerations and predictions from global ground-motion models.

The strong-motion observations come from stations that only record data if the peak ground acceleration (PGA) exceeds a certain trigger threshold. This presents a problem, since no observations with PGA smaller than the 
trigger threshold are available. This results in a truncated distribution for PGA and spectral acceleration. If this is not taken into account during the model development, the model will be biased. Typically, this is done by using only data up to a certain (magnitude-dependent) distance, making the assumption that the effect of data truncation only has an influence at larger distances on the model. Such an approach would lead to a great reduction in the usable number of records for the database, which would lead to a poorly constrained model. Hence, we directly model the truncation of PGA and spectral periods in the regression. We model the joint occurrence of PGA and pseudo-spectral acceleration, while conditioning on the truncation for PGA.

The parameters of the model are estimated via Bayesian inference, with strong informative prior distributions based on published global GMMs. The estimated model, based on truncated regression, is in reasonable agreement with previously published global models, with a notably steeper attenuation compared to models that do ot account for truncation. We pay attention to epistemic uncertainty associated with the model predictions, which can be assessed from the posterior distribution of the model parameters.

\section{Application of Polarization Analysis to Direction-Finding in the Urban Environment}

LEE, R. F., U.S. Army Corps of Engineers, Mississippi, USA, rebekah.f.lee@ usace.army.mil; ZHOU, R., U.S. Army Corps of Engineers, Mississippi, USA, rongmao.zhou@erdc.dren.mil

Polarization analysis is frequently used in both exploration geophysics and earthquake seismology. Although each of these areas covers the near-surface, the technique is also useful in the very near field in terms of perimeter security. Oftentimes the security applications are located in urban environments with a great deal of noise. The purpose of this research was to determine the applicability of polarization analysis to direction-finding in an urban environment. We present results of an experiment conducted in an urban environment where the majority of the noise came from two major roads with near constant traffic of tractor-trailers. We compare results of a basic azimuthal scanning method to a polarization technique based on the covariance matrix.

The results of the polarization techniques greatly depend on several user-defined parameters. These parameters include the type and bandwidth of filtering and the length of the window. Urban noise presents a significant challenge as the same inputs in terms of filtering and window length can result in different azimuthal outputs for the same source at different times. Though challenging, localization of repeated signals in the near-field is not impossible.

Permission to publish was granted by Director, Geotechnical \& Structures Laboratory.

\section{P-Phase Arrival Time Picking for Near-Field Data}

ZHOU, R., U.S. Army Corps of Engineers, Mississippi, USA, rongmao.zhou@ erdc.dren.mil; LEE, R. F., U.S. Army Corps of Engineers, Mississippi, USA rebekah.f.lee@usace.army.mil; MCCLEAVE, J., U.S. Army Corps of Engineers, Mississippi, USA, william.j.mccleave@erdc.dren.mil

Detecting and identifying the useful signals in the noisy and complex urban environment have posed challenges for seismic event detection and monitoring. Automatically detecting and accurately picking the first wave arrivals are important steps for seismic event identification and event location.

We collected near-field $(<100 \mathrm{~m})$ data from some shallow sources. To develop an automatic, quick, and accurate P-phase arrival time picking for these near-field data, we tested different arrival time pickers including the Short-Term-Average/Long-Term-Average (STA/LTA) method, the Modified Energy Ratio (MER) method, the Akaike Information Criteria (AIC) method, and the $\mathrm{P}_{\text {PHASE }} \mathrm{P}_{\mathrm{I}}$ CKER algorithm.

Our results indicate the AIC picker works well for the near-field data, and it outperforms other methods, particularly for data with poor signalto-noise ratio (SNR). AIC-picked P-phase arrival times are very close to the manual pickings.

\section{San Francisco Bay Area Kappa Model}

NYE, T., University of Oregon, Oregon, USA, tnye@uoregon.edu; KING, E., University of Oregon, Oregon, USA, eliask@uoregon.edu; KLIMASEWSKI, A., University of Oregon, Oregon, USA, aklimase@uoregon.edu; SAHAKIAN, V., University of Oregon, Oregon, USA, vjs@uoregon.edu; BALTAY, A., U.S. Geological Survey, California, USA, abaltay@usgs.gov

Understanding local site attenuation is important for removing site effects for regional seismological source and path studies, as well as for designing ground-motion models, a critical component of seismic hazard estimation. Kappa (k), the high frequency attenuation at a site, is representative of high frequency site conditions. It is widely used in earthquake simulations and has recently been considered as a site parameter in certain ground-motion models. In particular, this parameter may be of use for fully non-ergodic groundmotion models, which require spatially varying parameters, such as anelastic attenuation or site conditions. The San Francisco Bay Area is a seismically active region, yet no such $\mathrm{k}$ models currently exist, so we produce a $\mathrm{k}$ model for this area. Following the method of Klimasewski et al. (2019), we obtain site spectra for Bay Area seismic stations via spectral decomposition. However, we improve on this method by first removing crustal attenuation (Q) from the records with the model of Eberhart-Phillips (2016) to remove path effects from the site term, as our stations are located farther away from our events than those used in Klimasewski et al. (2019). We compute $\mathrm{k}$ on the resulting site spectra. Our dataset is composed of $\sim 3000$ events from the NCEDC database, ranging from $\mathrm{M} 2.5-6$, and 30 stations. Thus far, we see strong regional variations in $\mathrm{k}$ in the Bay Area. We specifically see higher $\mathrm{k}$ values in the Sacramento San Joaquin River Delta and along the Hayward fault, which corroborate the expected attenuation effects for such geologic features. We present the resulting $\mathrm{k}$ values in the San Francisco Bay Area and discuss the applicability of these values to represent local site effects to accurately predict ground motion for seismological and hazards studies.

\section{Source, Path and Site Parameters: Validation and Calibration for the Northern Marmara Region, Turkey} SULEYMAN, H., Bogazici University, Istanbul, Turkey, hakan_suleyman@ live.com; ÇAKTI, E., Bogazici University, Istanbul, Turkey, eser.cakti@boun. edu.tr

This study presents estimation of source, path and site parameters for Istanbul, needed for stochastic ground motion modeling. We made use of strong ground motion records from the Istanbul Earthquake Rapid Response and Early Warning System operated by the Department of Earthquake Engineering of Boğaziçi University. These data are used to: (I) compute the horizontal-tovertical spectral ratios (HVSR) using S-wave windows, by defining the soil profile in seven categories by considering $\mathrm{Vs}_{30}$ values; (II) estimate $\kappa_{0}$, the site component of $\kappa$, which is controlling the amplitude decay at high frequencies observed in Fourier amplitude spectra of S-wave time windows of strong ground motions; (III) estimate the frequency-dependent anelastic attenuation parameter for $\mathrm{S}$-waves, $\mathrm{Q}_{\mathrm{S}}$, by considering two subregions in the Marmara Sea; (IV) to simulate six medium magnitude earthquakes that are associated with the main Marmara fault for the validation and calibration of the stochastic ground motion simulation model that eventually will be used for the regional simulation of $\mathrm{M} 7+$ earthquakes.

\section{Advances in Understanding Near-Field Ground Motions: Observation, Prediction and Application}

Poster Session · Thursday $\cdot 22$ April · 11:30 Am Pacific Session Chairs: Jessie K. Saunders, U.S. Geological Survey (jksaunders@usgs.gov); Dara E. Goldberg, U.S. Geological Survey (degoldberg@usgs.gov); Tara Nye, University of Oregon (tnye@uoregon.edu); Valerie Sahakian, University of Oregon (vjs@uoregon.edu)

\section{Developing a Near-Field Ground Motion Model With GNSS} Peak Ground Displacement

GOLDBERG, D. E., U.S. Geological Survey, Colorado, USA, degoldberg@ usgs.gov; MELGAR, D., University of Oregon, Oregon, USA, dmelgarm@ uoregon.edu; HAYES, G. P., U.S. Geological Survey, Colorado, USA, ghayes@ usgs.gov; CROWELL, B. W., University of Washington, Washington, USA, crowellb@uw.edu; BENZ, H., U.S. Geological Survey, Colorado, USA, benz@ usgs.gov

Earthquake ground motion models (GMM) inform a range of earth science and engineering applications, including seismic hazard evaluations, loss estimates, and seismic design standards. A typical GMM is characterized by simple metrics describing the earthquake source (e.g., magnitude, mechanism), observation distance, and site terms (e.g., Vs30). GMMs are used within U.S Geological Survey earthquake response products such as ShakeMap, a ground shaking model that allows rapid assessment of the impact of an earthquake. Most often, GMMs are derived from broadband seismometer and strongmotion accelerometer observations, yet these traditional seismic instruments saturate during strong shaking, leading to inaccurate recordings of the lowfrequency ground motions. The integration of geodetic data sources, particu- 
larly for characterizing the unsaturated ground motion of large-magnitude events, has proven valuable as a complement to traditional seismic approaches and led to the development of a GMM based on peak ground displacement (PGD) estimated from high-rate Global Navigation Satellite Systems (GNSS) data. We present an updated GMM for M6-9 earthquakes based on GNSSestimated PGD that more effectively accounts for fault finiteness, slip heterogeneity, and observation distance. We evaluate the limitations of the currently available GNSS earthquake dataset to calibrate the GMM. In particular, the historical dataset lacks observations within $100 \mathrm{~km}$ of large magnitude events (>M8), inhibiting evaluation of fault dimensions for earthquakes too large to be represented as point-sources in the near-field. In response, we separately consider previously validated synthetic GNSS waveforms within $10-1000 \mathrm{~km}$ of M7.8-9.3 Cascadia subduction zone scenario ruptures (Melgar et al., 2016). The synthetic data highlight the importance of fault-distance metrics and improve our preparedness for large magnitude earthquakes with spatiotemporal qualities unlike those in our existing dataset.

\section{Within and Between-Event Variability of Mw 6-7 Earthquakes Velocity Pulses in Taiwan and Japan}

YEN, M., GFZ German Research Centre for Geosciences, Potsdam, Germany, ming-hsuan.yen@gfz-potsdam.de; VON SPECHT, S., Institute of Earth Sciences, Academia Sinica, Taipei, Taiwan, specht@gfz-potsdam.de; LIN, Y., National Central University, Taoyuan, Taiwan, yenyulin@ncu.edu.tw; COTTON, F., GFZ German Research Centre for Geosciences, Potsdam, Germany, fcotton@gfz-potsdam.de; MA, K., Institute of Earth Sciences, Academia Sinica, Taipei, Taiwan, fong@earth.sinica.edu.tw

Ground motion with strong-velocity pulses can cause significant damage to buildings and structures. The period and the velocity amplitude of such pulses are critical for structural engineering and seismic hazard assessment. However, the physical factors relating the scaling of pulse periods with magnitude are poorly understood. In this study, we investigate moderate, but damaging earthquakes (Mw 6-7) in Taiwan and Japan. We characterize ground motion pulses by using the method of Shahi and Baker (2014) while taking into account potential static effects. We confirm that the within-event variability of the pulses is large. In addition, we further perform simulations using the frequency-wavenumber (FK) algorithm to investigate the causes of the variability of the pulse periods within and between events. We test the effect of fault dips and the impact of the asperity locations and sizes. The simulations reveal that the asperity properties have a high impact on the pulse periods and amplitudes at nearby stations. Our results emphasize the importance of asperity characteristics in addition to earthquake magnitudes for the occurrence and properties of pulses. We quantify and discuss within- and between-event variabilities of pulse properties at short distances.

\section{Advances in Upper Crustal Geophysical Characterization \\ I: Oral Session · Wednesday · 21 April · 9:45 AM Pacific II: Oral Session · Wednesday · 21 April · 2:00 PM Pacific Session Chairs: Oliver S. Boyd, U.S. Geological Survey (olboyd@usgs.gov); William J. Stephenson, U.S. Geological Survey (wstephens@usgs.gov); Lee Liberty, Boise State University (lliberty@boisestate.edu)}

\section{Mapping the 3D Structure of the San Gabriel and San Bernardino Basins, Greater Los Angeles Area From Seismic and Gravity Measurements}

VILLA, V., University of California, Los Angeles, California, USA, valeriavillag@gmail.com; CLAYTON, R. W., Caltech, California, USA, clay@ gps.caltech.edu; PERSAUD, P., Louisiana State University, Louisiana, USA, ppersaud@lsu.edu

The Basin Amplification Seismic Investigation (BASIN) project focuses on improving the seismic velocity model of the San Gabriel and San Bernardino basins. In the event of the anticipated magnitude 7.8 San Andreas fault earthquake rupture, these northern basins are thought to amplify propagating seismic waves and channel them towards the densely populated Los Angeles area. To investigate this amplification effect and improve ground shaking models, a better understanding of the subsurface structure of these basins is necessary. Here, we incorporate gravity data and receiver function interpretations, along the 10 seismic profiles of the project, to map the 3-dimensional structure of the San Gabriel and San Bernardino basins. The travel time to the sedimentbasement interface obtained from P-to-S receiver functions was combined with Bouguer gravity data to determine the basin depth along the seismic profiles. We then extrapolated the $2 \mathrm{D}$ results to a complete $3 \mathrm{D}$ structure of the basins using the residual Bouguer gravity anomaly as a constraint. The basement interface shows a variable structure, with the deepest part of the basins near the San Jacinto fault on the southeastern side of the San Bernardino basin. In the western San Gabriel basin, the gravity data show a sharp increase near the active Raymond fault. Modeling of this abrupt change in the residual gravity anomaly aided the identification of a possible fault-related offset in the sediment-basement interface in one of our N-S trending receiver function profiles. Thus, the inclusion of gravity data with seismic measurements aids in identifying subsurface interfaces and can delineate subtle faults.

\section{Simultaneous Algebraic Reconstruction Technique (SART) for Retrieving 1D Shear-Wave Quality Factor Qs Profiles Using Seismic Noise}

DREOSSI, I., National Institute of Oceanography and Applied Geophysics - OGS, Udine, Italy, idreossi@inogs.it; PAROLAI, S., National Institute of Oceanography and Applied Geophysics - OGS, Sgonico, Italy, sparolai@inogs.

Nowadays seismic noise has become a useful tool in site effects estimation. Although generally it is used to retrieve the shear-wave velocity $\left(\mathrm{V}_{\mathrm{s}}\right)$ and the fundamental resonance frequency of sedimentary covers, it also has potential to estimate the seismic waves attenuation characteristics and, in particular, the related shear-wave quality factor $\left(Q_{S}\right)$

Parolai (2014) proposed a method based on a least squares algorithm with positivity $Q_{S}$ constraint (Menke, 1989) for obtaining $1 D Q_{S}$ versus depth profiles from microarrays. The results were compared with $\mathrm{Q}_{S}$ results derived from independent geophysical surveys and showed a good agreement. However, the proposed approach requires accurate trial-and-error tests of the damping factors in the preliminary phase, in order to obtain robust $\mathrm{Q}_{\mathrm{S}}$ outcomes.

This work investigates whether the Simultaneous Algebraic Reconstruction Technique (SART) (Andersen and Kak, 1984) can be used in the approach of Parolai (2014) as an alternative to the least squares algorithm for avoiding the trial-and-error procedure. SART is an iterative reconstruction algorithm, that offers the advantage of setting a positivity $\mathrm{Q}_{\mathrm{S}}$ constraint to the solutions with ease. First, the new technique is tested and calibrated in two test sites where $1 \mathrm{D} \mathrm{Q}_{\mathrm{S}}$ profiles were retrieved in previous works with the approach of Parolai (2014). The results show that the new method can be useful to obtain robust $\mathrm{Q}_{\mathrm{S}}$ values by setting the relaxation parameter and the number of iterations in the SART procedure in pre-defined narrow value ranges. Then, the technique is applied in another test site placed at Piana di Toppo, Travesio (North-East Italy), where Q estimates are available from independent geophysical methods. The results obtained by setting the inversion parameters in the ranges previously estimated indicate that SART can be promising for calculating $1 \mathrm{D} \mathrm{Q}_{\mathrm{S}}$ profiles at a local scale.

\section{Spatial Statistics of Densely Measured Seismic-Velocity Variations}

LOUIE, J. N., University of Nevada Reno, Nevada, USA, louie@seismo.unr. edu; SIMPSON, A., University of Nevada, Reno, Nevada, USA, arsimpson@ nevada.unr.edu; SCALISE, M., University of Nevada, Reno, Nevada, USA, michelledunn@nevada.unr.edu; ECKERT, E., University of Nevada, Reno, Nevada, USA, eeckert@nevada.unr.edu

Seismic velocity measurements show high degrees of spatial variability, even when taken at close spacing. P- and S-wave well logs have long shown substantial, apparently stochastic vertical variability in velocity values to a degree similar to the deterministic velocity variability related to the different formations logged. Transects of Vs30 measurements (the geotechnical time-averaged Vs from the surface to $30 \mathrm{~m}$ depth) show similar characteristics. Reno and Las Vegas, Nevada, have each hosted $15 \mathrm{~km}$ transects with $300 \mathrm{~m}$ spacing between refraction microtremor measurements. A $60 \mathrm{~km}$ transect with the same spacing crosses San Gabriel Valley and the Los Angeles Basin in Southern California. These transects show apparently stochastic and deterministic velocity variations. Both types of variation represent aleatory variability in the ground, well above the level of epistemic uncertainty of the measurements. Vs30 transect spatial spectra suggest fractal variations horizontally. Fractal dimensions D are 1.5 to 1.8. Deep ROSRINE well logs of Vs near the Los Angeles Basin transect show a very similar D, for vertical variations, of 1.7. Covering over $80 \%$ of Las Vegas Valley, Nevada, the Clark County Parcel Map (CCPM) incorporates over 10,000 refraction microtremor measurements of Vs 30 , generally spaced at $300 \mathrm{~m}$. Horizontal Vs 30 variations across the CCPM yield a fractal dimension of 1.7. Wave-propagation modeling to $1.0 \mathrm{~Hz}$ of earthquake scenarios in and around Las Vegas Valley, through 
a 3D velocity model with a geotechnical layer including the CCPM, produce similarly fractal-appearing maps of peak ground velocity (PGV) estimates. The fractal dimensions of the horizontal variations in PGV are lower, from 1.1 to 1.4. Wave propagation averages over and smooths the rapid lateral velocity variations to some extent. Even with the small $300 \mathrm{~m}$ spacing between measurements, the CCPM can only resolve near-surface wave-propagation effects at frequencies up to $0.5 \mathrm{~Hz}$.

\section{Structure and Qp-Qs Relations in the Seattle and Tualatin Basins From Converted Seismic Phases}

STONE, I., U.S. Geological Survey, Washington, USA, istoneuw@gmail.com; WIRTH, E. A., U.S. Geological Survey, Washington, USA, emoriarty@usgs. gov; FRANKEL, A., U.S. Geological Survey, Washington, USA, afrankel@ usgs.gov

We use converted body wave phases from local earthquakes to constrain depth-to-basement and average attenuation relations for the Seattle Basin in Washington State and the Tualatin Basin in Oregon. P-, P-to-S- (Ps), S-to-P(Sp), and S-wave arrivals from M2.5-4.0 earthquakes are present in threecomponent seismic records from these basins. Based on their relative travel times, these phases are attributed to body wave conversions at the basementto-basin contact, or to high impedance contrast interfaces within the basins. Depth-to-basement values are calculated using the differential travel times between direct and converted phases, as well as average P- and S-wave velocity values. We also identify a high impedance contrast layer in the Tualatin Basin that likely represents a laterally extensive deposit of volcanic materials embedded between the basement contact and the Columbia River Basalt Group. In addition, we calculated the average Qp-Qs attenuation relation for each station by taking the spectral ratio of converted phases to their parent body wave arrivals. For the Seattle Basin, our analysis yields an average Qp value of 73 and an average Qs value of 60 for waves with frequencies between $2-25 \mathrm{~Hz}$. In the Tualatin Basin, a much reduced Qp-Qs relation suggests that average body wave attenuation is likely higher than in the Seattle Basin. The converted phase techniques presented here provide a reliable way to develop estimates of basin depth and attenuation structure for under-characterized regions using simple passive source seismic records.

\section{Using Seismic Interferometry to Map and Monitor Fluids in Geothermal Systems}

MATZEL, E., Lawrence Livermore National Laboratory, California, USA, matzel1@llnl.gov; MORENCY, C., Lawrence Livermore National Laboratory, California, USA, morency1@llnl.gov; TEMPLETON, D., Lawrence Livermore National Laboratory, California, USA, templeton4@llnl.gov

Seismic interferometry in combination with waveform modeling is used to measure the seismic properties within geothermal systems, illuminating changes that occur as water moves through the subsurface. We apply "virtual earthquake" methods ( ambient noise correlation and active source interferometry ) to obtain seismic Green functions (GF) which are then used to calculate material properties, in particular VS, VP, QS and QP. Individually, these properties have complex sensitivity to geologic fabric, composition and temperature, but in combination they can be used to highlight fractured media through which fluids are transported. In particular, seismic attenuation is highly sensitive to the contrast along fluid filled fractures. Mapping the ratio of the attenuation of $\mathrm{P}$ wave energy to $\mathrm{S}$ wave energy (QP/QS) illuminates the fluid paths in the geothermal system. When pressures change, such as during plant operations, fluids move through the system and create measurable changes in the observed amplitudes.

The key goal of this study is to understand how fluids travel along faults and fractures through geothermal reservoirs. We focus on two geothermal sites in Nevada: the Brady geothermal field, which was the subject of a multiphysics poroelastic tomography experiment (PoroTomo) (Feigl et al., 2017) and the Blue Mountain geothermal field which has been the subject of several geophysical studies over the last decade, including gravity, magneto-telluric, seismic reflection and refraction surveys.

We discuss the use of seismic interferometry to image the physical properties of the subsurface. These images help capture the detailed changes in velocity and attenuation that may indicate permeable zones and potential drilling targets.

\section{Correcting Horizontal-to-Vertical Spectral Ratio Fundamental Resonance Amplitudes on Flat Sediments: An Example From the Atlantic Coastal Plain, Eastern United States}

SCHLEICHER, L. S., U.S. Geological Survey, California, USA, lschleicher@ usgs.gov; PRATT, T. L., U.S. Geological Survey, Virginia, USA, tpratt@usgs. gov

Damaging ground motions from the $2011 \mathrm{M}_{\mathrm{w}} 5.8$ Virginia earthquake were likely increased due to site amplification from the unconsolidated sediments of the Atlantic Coastal Plain (ACP), highlighting the need to understand site responses on these widespread strata in the coastal regions of the eastern U.S. The horizontal-to-vertical spectral ratio (HVSR) method, using earthquakes or ambient noise, offers an appealing method for measuring site response because it requires a single seismometer rather than the two or more seismometers necessary to compute a horizontal sediment-to-bedrock spectral ratio (SBSR). Although previous studies show mixed results when comparing these methods, the majority of these studies investigated site responses in confined sedimentary basins that can generate substantial three-dimensional effects. In contrast, the flat ACP strata and the underlying bedrock reflector cause 1D resonance effects to dominate site response, with the amplification of the fundamental resonance peaks controlled by the impedance contrast between the base of the sediments and the underlying bedrock. We compare site response estimates for the ACP strata derived using the HVSR and SBSR methods from teleseismic signals recorded by regional arrays and observe a close match in the frequencies of the fundamental resonance peak $\left(f_{0}\right)$ determined by both methods. We find that the HVSR method yields an amplification at $f_{0}$ within a factor of 2 of the SBSR for ACP strata up to $100 \mathrm{~m}$, but for sites with thicknesses between 100 to $1800 \mathrm{~m}$, correcting the HVSR amplitude using source term information from a bedrock site and multiplying the peak by a factor of 1.2 results in amplitude peaks that on average match SBSR results. Therefore, the HVSR method may successfully estimate regional linear site response amplifications from the ACP, or similar geologic environments, when appropriate amplitude ratio adjustment factors are used.

\section{Fundamental Resonant Frequencies Derived From Shallow Sediment Properties for the Charleston, South Carolina} Area

SCHERMERHORN, W. D., Boise State University, Idaho, USA, williamschermerh@u.boisestate.edu; LIBERTY, L., Boise State University, Idaho, USA, lliberty@boisestate.edu

For the Charleston, South Carolina area, predominant peaks in the acceleration response spectra match fundamental periods of many existing buildings. Spectral characteristics above one $\mathrm{Hz}$ are driven mostly by soil thickness and shallow shear wave velocities (Vs). We acquired $14 \mathrm{~km}$ of seismic land streamer data, in profile, to map faults related to the 1886 Charleston earthquake. From seismic field records, we pick fundamental surface wave dispersion curves to derive two-layer, two-dimensional Vs models. Here, Quaternary sediments are upwards of $30 \mathrm{~m}$ thick. These unconsolidated, mostly saturated sediments lie directly upon more competent carbonate Tertiary rock. Previous studies show little velocity-depth dependence within Quaternary strata, and our results are consistent with this observation. Using a grid search approach and rock physics relationships, we obtain Vs models, in profile, that minimize the misfit between observed and calculated dispersion. We derive seismic impedance and fundamental resonant frequencies (Fn) using the quarter wavelength criteria with Quaternary Vs estimates and layer thickness. We compare our $>2700$ Vs profiles to regional seismic cone penetrometer measurements, surficial geology, and detailed stratigraphic logs that identify a top of Tertiary boundary and provide additional constraints. We find consistent Vs and Quaternary layer thickness estimates between each dataset, allowing us to develop a regional relationship of Fn to soil thickness for the greater Charleston region. We compare this map to faults identified with seismic reflection data and liquefaction features documented from the 1886 earthquake. We suggest that our approach to estimating Fn may be applicable for other areas within the Atlantic Coastal Plain, when in the presence of a similar shallow high impedance boundary.

\section{High-Resolution Bayesian Spatial Auto-Correlation (Spac) Pseudo-3D vs Model of Utah Forge Site With a Dense Geophone Array}

ZHANG, H., University of Utah, Utah, USA, zhang@seis.utah.edu; PANKOW, K. L., University of Utah, Utah, USA, pankowseis2@gmail.com

The Utah Frontier Observatory for Research in Geothermal Energy (FORGE) project aims to establish an enhanced geothermal systems (EGS) laboratory to 
develop and test new technologies that improve geothermal energy extraction from low-permeability host rocks. In support of the FORGE project, a highresolution three-dimensional (3D) basin-scale velocity model is required to: (1) improve seismic event locations, (2) improve ground motion predictions for seismic hazard analysis, and (3) provide additional constraints on the uplift of the Mineral Mountains and resulting structures and the formation of the adjacent basin. Spatial autocorrelation (SPAC) methods use the noise field to construct coherent surface waves in the frequency domain and are typically applied to resolve one-dimensional (1D) shallow Vs structure (e.g. upper 30 meters) at individual sites. Here, we expand the application of SPAC from typical 1D Vs profiles to pseudo-3D imaging via Bayesian Monte-Carlo inversion (BMCI) using a dense nodal array (49 nodes) located at the Utah Frontier Observatory for Research in Geothermal Energy (FORGE) site. Using combinations of 4 and 9 geophones in subarrays provides for 36 and 25 1D Vs profiles, respectively. Profiles with error bars are determined by calculating coherency functions that fit observations in a frequency range of $0.2-5$ $\mathrm{Hz}$. Thus, a high-resolution pseudo-3D Vs model from the surface to $2.0 \mathrm{~km}$ depth is derived and shows that surface-parallel sedimentary strata deepen to the west, consistent with a 3D seismic reflection survey. Moreover, the resulting $V s$ profile is consistent with a $V s$ profile derived from distributed acoustic sensing (DAS) data located in a borehole at the FORGE site. The pseudo-3D velocity model shows that the base of the basin dips $\sim 22^{\circ}$ to the west and topography on the basement interface coincident with the Mag Lee Wash suggests that the bedrock interface is an unconformity.

\section{Inversion of Dispersion and H/V Curves for Shear-Wave Velocity Versus Depth Profiles in the Atlantic Coastal Plain of the Eastern U.S. Using Legacy Crustal-Scale Refraction Seismic Data}

PRATT, T. L., U.S. Geological Survey, Virginia, USA, tpratt@usgs.gov: PAROLAI, S., Istituto Nazionale di Oceanografia e di Geofisica Sperimentale - OGS, Sgonico, Italy, sparolai@inogs.it; POGGI, V., Istituto Nazionale di Oceanografia e di Geofisica Sperimentale - OGS, Udine, Italy, vpoggi@inogs. it; DREOSSI, I., Istituto Nazionale di Oceanografia e di Geofisica Sperimentale - OGS, Udine, Italy, idreossi@inogs.it

Shallow shear-wave velocities for site response often are estimated using joint inversions of ambient-noise horizontal-to-vertical $(\mathrm{H} / \mathrm{V})$ spectral ratios and dispersion curves derived from ambient noise or small active sources. Here we evaluate carrying out these inversions using crustal-scale seismic refraction data, which have been acquired over many sedimentary basins of interest for hazard studies. We use data from the 2014-2015 Eastern North American Margin (ENAM) experiment in Virginia and North Carolina. The ENAM project deployed a pair of $\sim 215-\mathrm{km}$-long, NW-SE linear arrays with $\sim 300-\mathrm{m}$ receiver spacing to record 11 dynamite shots, and offshore airguns were recorded by 80 continuously recording seismometers with $\sim 4 \mathrm{~km}$ spacing. The arrays crossed the onland portion of the Atlantic Coastal Plain sediments, which are a seaward-thickening wedge of Cretaceous and younger sediments up to $1.1 \mathrm{~km}$ thick beneath the ENAM arrays and deposited mostly on crystalline bedrock. Atlantic Coastal Plain strata are known to substantially amplify ground motions. We compute dispersion curves from 2- to 6-km-long portions of the dense arrays near each dynamite shot, and we compute ambientnoise $\mathrm{H} / \mathrm{V}$ ratios from 24 half-hour recordings from the continuously recording seismometers. We use a genetic inversion algorithm in which 50 forward 1-D velocity models in each "generation" are evaluated for misfits compared to the observed data, with subsequent generations constructed from elements of the models with the smallest misfits. At each site we iterate for 150 to 300 generations from five initial sets of models, resulting in 37,000 to 70,000 forward models. Velocities to depths of about $400 \mathrm{~m}$ are defined well, with deeper velocities less defined. Best-fit models show large velocity increases near the estimated depth of basement rocks. Reliability of the results is supported by the consistency of the profiles from different starting models and nearby sites, small misfits to the observed data, and correspondence of large velocity increases with depths of basement rocks.

\section{Site Response in the Illinois Basin From S-Wave H/V and Spectral-Element Modeling}

CARPENTER, S., Kentucky Geological Survey, University of Kentucky, Kentucky, USA, seth.carpenter@uky.edu; YASSMINH, R., University of Missouri, Missouri, USA, ry6d9@mail.missouri.edu; HICKMAN, J. B., Kentucky Geological Survey, University of Kentucky, Kentucky, USA, john. hickman@uky.edu; WANG, Z., Kentucky Geological Survey, University of Kentucky, Kentucky, USA, zmwang@uky.edu

In engineering seismology, ground-motion site response in the frequency band of concern-i.e., $0.1-10 \mathrm{~Hz}$-is determined from the dynamic param- eters of near-surface, unlithified sediments. Frequency-specific amplifications observed in this band have also been attributed to impedance contrasts from stratigraphic boundaries beneath the sediment-bedrock contacts in global basins, however, suggesting S-wave resonance between those horizons and the surface. The horizontal-to-vertical ratios of local-earthquake $\mathrm{S}$-wave amplitude spectra $\left(\mathrm{HV}_{\mathrm{S}}\right)$ have been used to estimate site responses at sites with strong underlying subsurface impedance contrasts. $\mathrm{HV}_{\mathrm{S}}$ calculated at EarthScope flexible arrays that traversed the Illinois Basin reveal a nearly continuous band of spectral amplifications within the band of engineering concern, approximately $1 \mathrm{~Hz}$ to $4 \mathrm{~Hz}$, that correlates with the top of a Pennsylvanian-aged formation. This unit contains numerous low-density coal beds among interbedded shales and sandstones, and the frequencies of the $\mathrm{HV}_{\mathrm{S}}$ peaks are inversely related to the depths of the formation's base. Using borehole logs and published crustal models, we constructed a 2D earth model of the sedimentary basin and underlying crystalline crust along the trend of a linear array of selected stations. We used the SpecFEM2D spectral-element algorithm and multiple scenario earthquakes distributed in our earth model to calculate mean $\mathrm{HV}_{\mathrm{S}}$ and basin/no-basin spectral ratios. We also modeled simplified crustal and basin earth structures (e.g., one-layer basin). Our results suggest that the entire basin contributes to frequency-specific amplifications, but the Pennsylvanian-aged formation is needed to explain the spectral-ratio peaks observed in the approximately $1-4 \mathrm{~Hz}$ band. Thus, deeper $\left(10^{2}\right.$ to $10^{3}$ $\mathrm{m}$ below the surface) stratigraphic layers in the Illinois Basin are important for linear site response for engineering purposes.

\section{Advances in Upper Crustal Geophysical Characterization \\ Poster Session · Wednesday · 21 April · 11:30 Am Pacific Session Chairs: Oliver S. Boyd, U.S. Geological Survey (olboyd@usgs.gov); William J. Stephenson, U.S. Geological Survey (wstephens@usgs.gov); Lee Liberty, Boise State University (lliberty@boisestate.edu)}

\section{Analysis of the 2016 Deep Remi Survey in Reno, NV}

SCALISE, M., University of Nevada Reno, Nevada, USA, michelledunn@ nevada.unr.edu; LOUIE, J. N., University of Nevada, Reno, Nevada, USA, louie@seismo.unr.edu; PANCHA, A., Aurecon, Wellington, New Zealand, aasha.pancha@aurecongroup.com; SMITH, K. D., University of Nevada, Reno, Nevada, USA, ken@unr.edu

Advancements in high-performance computing has enabled seismologists to simulate ground motion through structurally complex 3D earth models. As the bandwidth of these computations increases, it is necessary to resolve the $3 \mathrm{D}$ velocity models used to simulate ground motion to finer scales. Towards improving the resolution and accuracy of the Reno-Sparks community velocity model, a series of Refraction Microtremor (ReMi) lines have been collected across the urban basin. Originally designed to determine the shearwave velocity of the upper 100 meters for geotechnical applications, ReMi surveying has been expanded to sample velocity structure to greater depths, by expanding array lengths and the use of $120 \mathrm{sec}$ records during data analysis. Previously, this was adapted to seven NEHRP-sponsored ReMi lines by Optim, mostly $3 \mathrm{~km}$ long, that imaged the basin floor at $0.5-1 \mathrm{~km}$ depth. The performance and limitations of this "Deep ReMi" technique have not yet been fully explored. In 2016, the longest Deep ReMi survey was conducted, which transected Reno in a $22 \mathrm{~km}$ north-south trending line and a $15 \mathrm{~km}$ east-west trending line. These data sample deep basin velocity structure, which so far are only approximately constrained by gravity analyses. Current models suggest the Pliocene to Quaternary lakebeds, alluvium, and outwash is underlain by Tertiary volcanic and sedimentary rocks, which are underlain by Mesozoic basement. The 2016 Deep ReMi data help constrain the thickness of these units to build a more robust velocity model, with velocity profiles compared to adjacent Deep ReMi surveys and analyzed in the larger context of the RenoSparks community velocity model. These data highlight the limitations of the 2016 survey and inform future survey design. Results provide insight into the feasibility of generating new velocity models with a low-cost passive method practical for urban settings.

\section{Calibration of the U.S. Geological Survey National Crustal Model for Seismic Hazard Studies}

BOYD, O. S., U.S. Geological Survey, Colorado, USA, olboyd@usgs.gov

The U.S. Geological Survey National Crustal Model (NCM) is being developed to improve estimates of site response in seismic hazard assessments. Primary 
outputs of the NCM are continuous velocity and density profiles from the Earth's surface to the mantle at each location on a 1-kilometer grid across the conterminous United States. Basic subsurface information is provided by the NCM geologic framework (NCMGF), thermal model, and petrologic and mineral physics database. In this study, velocities and densities within the NCM are calibrated through the development of a porosity model using Biot-Gassmann theory and over $2000 \mathrm{P}$ - and/or S-wave velocity profiles $(<10$ $\mathrm{km}$ deep) from across the conterminous United States and southwest Canada.

Sediment and rock porosities are derived from S-wave velocity and are found to depend on effective pressure, rock type, and age (in the case of sedimentary and extrusive volcanic deposits: SEVR). Porosity-effective pressure functions are then estimated for each rock type (and age for SEVR) unconsolidated sediments are found to have higher porosities than consolidated units, which have higher porosities than unweathered igneous units; young sedimentary units tend to have higher porosity than older sedimentary units; porosity decreases with increasing effective pressure; and porosities can decrease quickly through the weathered layer of intrusive rocks.

Upon comparison with the cvmh and cvms426m01 Los Angeles area velocity models and the USGS Bay Area velocity model, the NCM does a better job of reproducing observed S-wave velocities below $1 \mathrm{~km} / \mathrm{s}$, having less bias and spread. Approaching and above $1 \mathrm{~km} / \mathrm{s}$, the NCM tends to underpredict observed S-wave velocity. While several factors could contribute to this, the primary factor is probably bias in the NCMGF. For example, cases in which the NCM will predict lower velocities include places where the depth to bedrock and basement appear shallower in the measured velocity profiles than specified in the NCMGF

\section{Shallow Fault Location and Characterization in Complexly Deformed Zones Using Novel 3D Gravity Tomography: Examples From Dam Construction and Geothermal Assessment in Colorado}

LEVANDOWSKI,W., Tetra Tech, Inc., Colorado, USA, will.levandowski@ tetratech.com; TURNER, J., Tetra Tech, Inc., Colorado, USA, jamey.tuner@ tetratech.com; O'CONNELL, D., Tetra Tech, Inc., Colorado, USA, dan oconnell@tetratech.com; STEELE, L., Tetra Tech, Inc., Colorado, USA, lincoln.steele@tetratech.com; ISAACSON, M., Tetra Tech, Inc., Colorado, USA, mitch.isaacson@tetratech.com; NUTTALL, J., Tetra Tech, Inc., Colorado, USA, jeff.nuttall@tetratech.com

Shallow geophysics is often called upon to identify faults and determine their orientation, sense of slip, and depth range. Numerous seismic methods can achieve these goals, yet 3D imaging is often cost- or time-prohibitive. Gravity is comparatively affordable and can rapidly locate faults but typically has poor depth sensitivity when using sparse data. We have developed a suite of $3 \mathrm{D}$ microgravity tomography methods, including forward, inverse, gradient-/ Euler Deconvolution-based, and wavenumber-domain elements. We first present results from a $40-\mathrm{km}^{2}$ dam and reservoir development project in a heavily faulted intermontane basin (South Park, CO) underlain by complex volcanic assemblages and Paleozoic evaporites. Gravity tomography provided the basis for reservoir layout, dam alignment, and pre-construction by quickly imaging structure to $3 \mathrm{~km}$ depth and capturing $~ 100-\mathrm{m}$ scale shallow features, identifying multiple generations of cross-cutting faults buried by 100 s of meters of mixed volcanics, and delineating evaporite zones to be avoided. Six seismic reflection lines were also acquired to bolster resolution at dam foundations, and gravity images compare favorably with seismic results. Moving on to a previously unmapped geothermal prospect in southwestern Colorado, gradient-based methods delineate a complex shallow fault network, and stress analyses determine which are suitably oriented to serve as geothermal conduits. Existing methods, however, could not map fault interactions at depth nor judge fault connectivity with basement heat sources. Joint analysis of 3D tomography and regional well data reveals that several previously unidentified faults may reach basement, while known structures peter out in the sedimentary cover. These newly identified faults provide targets for drilling, aqueous geochemistry, and higher-resolution geophysics as the next step toward geothermal viability. Both sites are also exceptionally scenic, so we will have some nice photographs to accompany the science in this presentation.

\section{Shallow Shear-Wave Velocity and Crustal Structure in the Seattle and Tacoma Basins From Microtremor Array Analysis \\ STEPHENSON, W. J., U.S. Geological Survey, Colorado, USA, wstephens@} usgs.gov; ODUM, J. K., U.S. Geological Survey, Colorado, USA, jacksonodum@ gmail.com; LEEDS, A., U.S. Geological Survey, Colorado, USA, aleeds@usgs. gov

We characterize shear-wave velocity (Vs) structure in the Seattle and Tacoma basins, Washington State, by analyzing three microtremor array datasets with either the 1) multi-mode spatial autocorrelation (MMSPAC) method coupled with a Bayesian Monte Carlo inversion (BMCI) or 2) the wavenumber-normalized SPAC (krSPAC) method. Dataset 1 included seven sites in the western Seattle and Tacoma basins acquired to image Vs in the upper $1 \mathrm{~km}$ that are suitable for krSPAC analysis; each array consisted of 10 sensors deployed simultaneously in an asymmetric nested triangular pattern, with the largest interstation spacings of roughly $1 \mathrm{~km}$ and minimal spacings of about $57 \mathrm{~m}$. When compared to the regional Cascadia velocity model (CVM) the unconsolidated sedimentary thickness interpreted in the krSPAC Vs profiles generally agrees with the CVM; however, the krSPAC profiles suggest lower Vs in the upper $100 \mathrm{~m}$ and a typically higher velocity gradient to the interpreted rock interface. Dataset 2 consisted of microtremor data at 17 sites located within the city of Seattle. The microtremor data were acquired with four sensors deployed in three sequentially recorded equilateral triangles with interstation spacings of $33.3 \mathrm{~m}, 100 \mathrm{~m}$ and $300 \mathrm{~m}$, respectively. Dataset 3 consisted of microtremor data at 20 sites in the Tacoma basin simultaneously acquired with 10 sensors in nested equilateral triangular arrays similar in size to dataset 2. Both datasets 2 and 3 were analyzed using the MMSPAC/BMCI approach and imaged to no greater than $300 \mathrm{~m}$ depth. Comparison of Vs30 (time averaged Vs to $30 \mathrm{~m}$ depth) for each of the datasets suggests the shallowest sediments within the southern Puget Lowland are broadly comparable between the three data regions (nominally $\sim 420 \mathrm{~m} / \mathrm{s}$ ), with mean Vs30 in the Seattlearea data being $\sim 13 \%$ less than the other areas. Interpreted Vs within the basin sediments generally ranges from $250 \mathrm{~m} / \mathrm{s}$ to $700 \mathrm{~m} / \mathrm{s}$ in the upper $150 \mathrm{~m}$, with shallow rock $\mathrm{Vs}$ ranging from $900 \mathrm{~m} / \mathrm{s}$ to $>1200 \mathrm{~m} / \mathrm{s}$.

\section{Amphibious Seismic Studies of Plate Boundary Structure and Processes \\ Oral Session · Tuesday · 20 April · 9:45 Am Pacific \\ Session Chairs: Jenny S. Nakai, University of New Mexico (jenakai@unm.edu); Lindsay Lowe-Worthington, University of New Mexico (lworthington@unm.edu); Anne M. Trehu, Oregon State University (anne.trehu@oregonstate.edu)}

\section{Evidence for Geologic Influence on Subduction Zone Seismicity during the 2014 Mw 8.2 Pisagua/lquique, Chile Earthquake Sequence from Amphibious Controlled-Source Seismic Data}

DAVENPORT, K., Sandia National Laboratories, New Mexico, USA kdavenp@sandia.gov; TREHU, A. M., Oregon State University, Oregon, USA, anne.trehu@oregonstate.edu

The $2014 \mathrm{Mw} 8.2$ Iquique earthquake offshore northern Chile partially ruptured a seismic gap that had not experienced a great earthquake since 1877 . The spatial distribution of fore- and aftershocks associated with the 2014 event is correlated to residual gravity anomalies and variations in forearc structure, indicating that crustal structure affected the distribution of subduction-zone related seismic deformation. To provide insight into the relationship between geologic characteristics of the upper and lower plates and observed seismic behavior in the source region we acquired $3 \mathrm{D}$ controlled-source seismic data across the forearc in northern Chile. The coordinated marine and onshore efforts of the 2016 PICTURES (Pisagua/Iquique Crustal Tomography to Understand the Region of the Earthquake Source) project included deployment of 70 ocean-bottom and 50 onshore stations to record $\sim 4400 \mathrm{~km}$ of seismic reflection/refraction lines using the tuned airgun array on the $R / V$ Langseth. The wide-aperture amphibious data provide $3 \mathrm{D}$ ray coverage across the forearc from the trench into the Coastal Cordillera from $\sim 19^{\circ} \mathrm{S}-20.5^{\circ} \mathrm{S}$ Data include arrivals parallel and perpendicular to the trench, including crustal $\mathrm{Pg}$ arrivals and reflections from the Moho of the subducting plate. Using traveltime tomography, we image high-resolution 3D P-wave seismic velocity structure in the region of the 2014 earthquake sequence. Results illuminate along-strike heterogeneity in upper plate seismic velocity structure, and correlations between seismic structure, residual gravity anomalies, and the 2014 earthquake sequence highlight the importance of geologic structure in controlling plate boundary evolution and the potential for megathrust seismic activity. 
The PICTURES science team includes: Andreas Rietbrock, Felipe Gonzales Rojas, Bo Ma, Emma Myers, Florian Petersen, Eduardo ContrerasReyes, Emilio Vera, Heidrun Kopp, Dietrich Lange, Michael Riedel, Dirk Klaeschen. Work presented in this abstract was performed at Oregon State University. SNL is managed and operated by NTESS under DOE NNSA contract DE-NA0003525.

\section{Multiscale Amphibious Experiments at Subduction Zones: Recent Advancements and Future Directions}

IANISZEWSKI, H. A., University of Hawaii at Manoa, Hawaii, USA, hajanisz@ hawaii.edu; ABERS, G., Cornell University, New York, USA, abers@cornell. edu; GAHERTY, J., Northern Arizona University, Arizona, USA, james. gaherty@nau.edu; EILON, Z. C., University of California, Santa Barbara, California, USA, eilon@ucsb.edu; WAGNER, L., EPL, Carnegie Institution for Science, District of Columbia, USA, lwagner@carnegiescience.edu; ROMAN, D. C., EPL, Carnegie Institution for Science, District of Columbia, USA droman@carnegiescience.edu; POWER, J. A., Alaska Volcano Observatory, USGS, Alaska, USA, jpower@usgs.gov; PORTNER, D. E., EPL, Carnegie Institution for Science, District of Columbia, USA, dportner@carnegiescience. edu; HANEY, M., Alaska Volcano Observatory, USGS, Alaska, USA, mhaney@ usgs.gov

The amphibious setting of subduction zones has traditionally limited seismic imaging of these regions, particularly within coastal forearcs and oceanic island arc environments that require a mixture of onshore and offshore seismic instrumentation. This is additionally complicated by the multiscale nature of seismic imaging targets at subduction zones that are relevant for understanding earthquake and volcanic processes. Recent amphibious seismic experiments offer an unprecedented view of subduction zones, allowing continuous seismic imaging from the incoming oceanic plate, across the forearc, and into the arc and backarc regions. Here we highlight both active and natural-source amphibious seismic imaging results from the Cascadia subduction zone. Ship-to-shore airgun shots and offshore receiver function imaging reveal a heterogenous plate interface with variations in velocity and reflectivity on the scale of tens of kilometers. In particular, regions of low velocities along the plate interface, which may be related to variations in plate locking, are observed. Along the subduction margin, extending from northern California to northern Washington, surface wave imaging yields new images of the oceanic Juan de Fuca plate and forearc, and improves phase velocity maps onshore near the coastline relative to prior results using only land-based data. Obtaining these results, which rely on data from broadband ocean-bottom seismometers deployed in shallow water on the continental shelf, requires careful analysis and preprocessing to remove oceanographic noise. Such challenges broadly impact subduction studies, as many geographic regions share similar, technical challenges. Lastly, we discuss future directions for amphibious targets and experiment design, highlighting recent onshore results from the Aleutian island arc and current limitations due to an absence of offshore instrumentation.

\section{Observations and Numerical Simulations of Guided Waves From Earthquakes Located Near the Gorda Slab Interface} GONG, J., Woods Hole Oceanographic Institution, Massachusetts, USA jgongseismo@gmail.com; MCGUIRE, J., U.S. Geological Survey, California, USA, jmcguire@usgs.gov

The interplate boundary in a shallow subduction zone is potentially a thick zone of materials with diverse properties. We report the observation of guided waves generated by a thin low-velocity layer on top of the oceanic crust of the subducted Gorda plate and use numerical simulations to understand their propagation.

From the Cascadia Initiative dataset, we observed long-duration $\mathrm{S}$ waves (up to $4 \mathrm{~s}$ at $2-10 \mathrm{~Hz}$ ) on station KCT in northern California from earthquakes clustered near the slab interface at $\sim 15 \mathrm{~km}$ depth. In contrast, earthquakes located just a few $\mathrm{km}$ deeper only show impulsive direct arrivals. We hypothesize that the extended S-wave reflects velocity anomalies near the slab interface. To study the origin of the $S$ waves, we deployed a 20 -station array near KCT. We applied 2D beamforming on P and S waves from one earthquake close to a slab interface cluster occurring during the deployment. 2D beamforming shows that the $\mathrm{P}$ wave contains two arrivals with different apparent slowness that we refer to as $\mathrm{P} 1$ and $\mathrm{P} 2$, and the $\mathrm{S}$ wave similarly contains two arrivals S1, S2 and lower frequency late coda. P1's (S1's) apparent slowness is larger than P2 (S2). We infer that P1 and S1 share similar raypaths, while P2 and $\mathrm{S} 2$ phases share a different raypath.

To investigate possible near-source velocity anomalies causing multiple P- and S-wave arrivals, we constructed simple, layered velocity models for $2 \mathrm{D}$ wave propagation simulations. Simulations using velocity models with a 6-km-thick layer representing the subducted oceanic crust indicate that the S1 and S2 are likely the direct S wave and the top side Moho reflection phase. Simulations using velocity models with a thin, truncated low S-wave-velocity layer on top of the subducted oceanic crust best replicate the $S$ coda in terms of arrival time, frequency content and amplitude. The coda is likely generated by leaked guided waves from the thin low-velocity layer due to scattering from a discontinuity in the waveguide. The low velocity layer requires $\sim 40 \% \mathrm{~S}$-wave velocity reduction to match the observed amplitude of the coda waves.

\section{Shallow Deformation Features of the Imperial and Michoacán Fault Systems From Subsurface Imaging}

SAHAKIAN, V., University of Oregon, Oregon, USA, vjs@uoregon.edu; DEROSIER, B., Scripps Institution of Oceanography, University of California, San Diego, California, USA, bderosie@ucsd.edu; ROCKWELL, T. K., San Diego State University, California, USA, trockwell@sdsu.edu; STOCK, J., Caltech, California, USA, jstock@gps.caltech.edu; DRISCOLL, N., Scripps Institution of Oceanography, University of California, San Diego, California, USA, ndriscoll@ucsd.edu

Accommodating $30-45 \mathrm{~mm} / \mathrm{yr}$ of slip and hosting two $>\mathrm{M} 6$ earthquakes in the past century, the Imperial Fault (IF) is a large player in Southern California's fault system. Despite its contribution to regional seismic hazard and Pacific/North American plate boundary motion, both the IF system and its interactions with other faults are not as well-understood as other regional faults. Seismicity studies identify event concentrations along linear structures west of the main trace of the IF, likely the El Centro-Weinert, Dixieland, and Michoacán faults. In addition, a geodetic investigation reveals deformation west of the main trace of the IF, best fit by a fault structure with a slip rate of $\sim 15 \mathrm{~mm} / \mathrm{yr}$, aligning with the area near the Dixieland and Michoacán faults, and possibly accommodating a portion of the IF's slip rate. It is difficult to obtain a full picture of this system and the interaction between structures, as we lack shallow subsurface geologic and imaging data.

To fill this gap, we collected high-resolution subsurface seismic data within the All American Canal in the Imperial Valley. These data focus on the mapped IF trace, and suggested westward fault traces by the US-Mexico border. With an acoustic compressed high intensity radar pulse (CHIRP) system, we imaged shallow deformation ( $~ 5-25 \mathrm{~m}$ depth) on the mapped trace of the IF, as well as in the western regions proposed to accommodate slip. This deformation occurs as close as $10 \mathrm{~km}$ west of the IF, and some of the most prominent shallow displacement occurs $\sim 20 \mathrm{~km}$ west of the IF. Here, we will show these findings, fault interpretations, and implications for tectonics in the region, as well as discuss possible corroborations between our data nearby cone penetration tests (CPT) and cores across the IF. These data may be useful to support or direct future paleoseismic and geophysical studies along this fault trace, and to understand better the interactions between the IF system and other fault systems in the region.

\section{Subduction Erosion and Upper Plate Deformation at the Up-Dip Limit of the 2014 Mw 8.1 lquique Earthquake} PETERSEN, F., GEOMAR Helmholtz Centre for Ocean Research Kiel, Kiel, Germany, flpetersen@geomar.de; LANGE, D., GEOMAR Helmholtz Centre for Ocean Research Kiel, Kiel, Germany, dlange@geomar.de; MA, B., GEOMAR Helmholtz Centre for Ocean Research Kiel, Kiel, Germany, bma@geomar.de; GREVEMEYER, I., GEOMAR Helmholtz Centre for Ocean Research Kiel, Kiel, Germany, igrevemeyer@geomar.de; GEERSEN, J., Kiel University, Kiel, Germany, science@geersen.de; KLAESCHEN, D., GEOMAR Helmholtz Centre for Ocean Research Kiel, Kiel, Germany, dklaeschen@ geomar.de; CONTRERAS-REYES, E., Universidad de Chile, Santiago, Chile, econtreras@dgf.uchile.cl; BARRIENTOS, S. E., Centro Sismológico National, Facultad de Ciencias Físicas y Matemáticas, Universidad de Chile, Santiago, Chile, sbarrien@csn.uchile.cl; VERA, E., Departamento de Geofísica, Facultad de Ciencias Físicas y Matemáticas, Universidad de Chile, Santiago, Chile, evera@dgf.uchile.cl; TREHU, A. M., Oregon State University, College of Earth, Ocean, and Atmospheric Sciences, Oregon, USA, anne.trehu@ oregonstate.edu; KOPP, H., GEOMAR Helmholtz Centre for Ocean Research Kiel, Kiel, Germany, hkopp@geomar.de

The $2014 \mathrm{Mw} 8.1$ Iquique earthquake ruptured the boundary between the subducting Nazca Plate and the overriding South American Plate in the North Chilean subduction zone. The broken segment of the South American subduction zone had likely accumulated elastic strain since an $\mathrm{M} \sim 9$ earthquake in 1877 and what therefore considered a mature seismic gap. The moderate magnitude of the 2014 earthquake and its compact rupture area, which only broke the central part of the seismic gap, did not result in a significant tsunami in the Pacific Ocean. To investigate the seismo-tectonic segmentation of the North Chilean subduction zone in the region of the 2014 Iquique earthquake 
at the shallow seismic/aseismic transition, we combine two years of local aftershock seismicity observations from ocean bottom seismometers and long-offset seismic reflection data from the rupture area. Our study links short term deformation associated with a single seismic cycle to the permanent deformation history of an erosive convergent margin over millions of years. A high density of aftershocks following the 2014 Iquique earthquake occurred in the up-dip region of the coseismic rupture, where they form a trench parallel band. The events spread from the subducting oceanic plate across the plate boundary and into the overriding continental crust. The band of aftershock seismicity separates a pervasively fractured and likely fluid-filled marine forearc farther seaward from a less deformed section of the forearc farther landward. At the transition, active subduction erosion during the postseismic and possibly coseismic phases of the 2014 Iquique earthquake leads to basal abrasion of the upper plate and associated extensional faulting of the overlying marine forearc. Landward migration of the seismogenic up-dip limit, possibly at similar rates compared to the trench and the volcanic arc, leaves behind a heavily fractured and fluid-filled outermost forearc. This most seaward part of the subduction zone might be too weak to store sufficient elastic strain to nucleate a large megathrust earthquake.

\section{Amphibious Seismic Studies of Plate Boundary Structure and Processes \\ Poster Session · Tuesday · 20 April · 4:15 PM Pacific \\ Session Chairs: Jenny S. Nakai, University of New Mexico (jenakai@unm.edu); Lindsay Lowe-Worthington, University of New Mexico (lworthington@unm.edu); Anne M. Trehu, Oregon State University (anne.trehu@oregonstate.edu)}

\section{Amphibious Receiver Function Imaging of the Pacific Plate Using Tuned Dereverberation Filters}

ZHANG, Z., University of Rochester, New York, USA, ziqi.zhang@rochester. edu; OLUGBOJI, T., University of Rochester, New York, USA, tolulope. olugboji@rochester.edu

The Alaska Amphibious Community Seismic Experiment (AACSE) presents a unique opportunity to conduct high-resolution seismic imaging of the lithosphere-asthenosphere system of the Pacfic plate prior to subduction, and investigate the role that temperature, or hydration plays in influencing sharp seismic discontinuities detected at the bottom boundary layer of the plate as it ages to $\sim 40-60$ Myrs. A popular tool for high-resolution seismic imaging of the oceanic plate is the receiver function (RF) method which is specifically suited for detecting sharp subsurface discontinuities close to and beneath a seismic station. When the technique is applied to land-based stations near a subduction zone, or ocean bottom stations (OBS) buried in a borehole, the $\mathrm{RF}$ approach is less susceptible to instabilities caused by signal-generated noise from two well-known sources: (1) strong reverberations in the overlying ocean layer, and (2) trapped waves within the underlying sediments. Both cases do not apply to the OBS stations in the AACSE network. Recent work shows how stable high-resolution receiver function imaging of the oceanic lithosphere can be obtained using dereverberation filters designed to eliminate the water and sediment reverberations that hamper the detection of subsurface discontinuities. Here, we apply an extension of their approach to the 75 OBS stations in the AACSE array. Since these stations are deployed across the trench into the deep oceans, we quantify the relationship between the observed resonances and the ocean depth and sediment properties across the array, using a multi-taper spectral coherence approach. By tuning the parameters of our dereverberation filter to the spectral peaks and implementing a stacking approach that improves time-domain semblance and coherence of migrated receiver function, we expect to improve detection of seismic discontinuities across the AACSE array.

\section{Anisotropic S-Wave Tomography at the Eastern North American Margin: Constraints on Mantle Structure and Dynamics}

BRUNSVIK, B. R., University of California, Santa Barbara, California, USA, brennanbrunsvik@ucsb.edu; EILON, Z. C., University of California, Santa Barbara, California, USA, eilon@ucsb.edu; LYNNER, C., University of Delaware, Delaware, USA, clynner@udel.edu

The eastern North American passive margin (ENAM) is the ultimate result of the rifting of North America from Africa and Europe during the breakup of Pangea. As part of the ENAM Community Seismic Experiment designed to target this GeoPRISMS focus site, a 2014-2015 deployment of oceanbottom seismometers (OBS) off the coast of North Carolina extends broadband seismic coverage from the EarthScope Transportable Array across the ocean-continent transition of the rifted passive margin. Shear wave splitting results in the area, which indicate seismic anisotropy and -by proxy- mantle dynamics, show several unexplained patterns. For instance, neither marginparallel offshore fast azimuths nor null splitting on the continental coast obviously accord with margin-perpendicular continental extension or the current motion of the North American plate. Shear wave splitting, however, offers no depth constraint on anisotropy, and mantle structures have not been imaged in detail below the ocean-continent transition using the ENAM-CSE OBSs.

Using teleseismic travel times and shear wave splitting delay times measured at OBS, Transportable Array, and regional network stations, we conduct joint isotropic/anisotropic S- and S(K)KS-wave velocity tomography. Our velocity model, which accounts for the trade-off between azimuthal anisotropy and velocity, shows several anomalies which may be associated with edge-driven convection, delamination, or the edge of the subducted Farallon slab. We find multiple layers of anisotropy which suggest depth varying mantle flow. The combined constraints on velocity and anisotropy provide new evidence for the structure and dynamics of the mantle across the ocean-continent transition of ENAM.

\section{Incoming Plate and Forearc Structure of the East-Central Alaska-Aleutian Subduction Zone From 3D Local Earthquake Tomography}

MOSER, L., Woods Hole Oceanographic Institution, Massachusetts, USA, lmoser@whoi.edu; CANALES, J., Woods Hole Oceanographic Institution, Massachusetts, USA, jpcanales@whoi.edu; BÉCEL, A., Lamont-Doherty Earth Observatory, Columbia University, New York, USA, annebcl@ldeo. columbia.edu

The Alaska Amphibious Community Seismic Experiment (AACSE) deployed 75 broadband ocean bottom seismometers and 30 land seismometers over the east-central Alaska peninsula region. This dense array was deployed for $\sim 15$ months between 2018 and 2019. The campaign crosses the Alaska-Aleutian subduction zone from the arc to the incoming Pacific plate, and encompasses the SW Kodiak segment, the Semidi segment, and part of the Shumagin seismic gap. These are segments with a history of large earthquake (>M7.4) ruptures, and distinct along-strike variations in plate locking fraction and seismic behavior. We aim to address whether these variations can be correlated with properties or geologic features that can be seismically imaged with the AACSE earthquake data. Are subducted seamounts, subducted fracture zones, variations in incoming plate hydration, or structural anomalies in the overriding plate associated with present-day seismic behavior of the plate interface? We will present 3-D seismic velocity ( $\mathrm{Vp}, \mathrm{Vs}, \mathrm{Vp} / \mathrm{Vs}$ ) models of the region encompassed by the AACSE array. We use a local earthquake tomography code (LOTOS, Koulakov (2009), doi:10.1785/0120080013) and a catalog of P and S arrival times from events detected by the AACSE and other regional networks during the first four months of the AACSE deployment. To build our dataset we chose 1760 earthquakes, detected at 178 stations in the study region, with the criteria that events have at least $9 \mathrm{P}$-wave arrivals, $4 \mathrm{~S}$-wave arrivals, a rms travel time residual less than 1.2 seconds, and are shallower than $150 \mathrm{~km}$. Checkerboard tests show that structural anomalies in the horizontal plane are detectable down to at most $\sim 30$ by $\sim 30 \mathrm{~km}$. Results from the preliminary inversion for $\mathrm{Vp}$ and $\mathrm{Vs}$ structures show a first order boundary that likely corresponds to the top of the slab. These are promising initial results; at the 2021 SSA Annual Meeting we will present results from our on-going analysis.

\section{Nature of Intermediate-Depth Earthquakes in the Eastern Aleutian Subduction Zone}

PLOURDE, A. P., Geological Survey of Canada, Dartmouth, Canada, ap.plourde@dal.ca; NEDIMOVIC, M. R., Dalhousie University, Halifax, Canada, mladen@ldeo.columbia.edu; WALDHAUSER, F., Columbia University, New York, USA, felixw@ldeo.columbia.edu; KUEHN, H., Dalhousie University, Halifax, Canada, harold.kuehn@dal.ca; BÉCEL, A., Columbia University, New York, USA, annebcl@ldeo.columbia.edu; SHILLINGTON, D. J., Northern Arizona University, Arizona, USA, donna. shillington@nau.edu

It is challenging to determine with confidence what geological units of subducting oceanic plates host intermediate-depth earthquakes, specifically those in the upper-plane of the double seismic zone, because beyond $\sim 40 \mathrm{~km}$ depth earthquake hypocenters are the primary constraint on the location of the plate interface. The 2011 ALEUT seismic reflection survey in the eastern Aleutian subduction zone, Alaska, imaged clear plate-interface reflections to depths of $\sim 60 \mathrm{~km}$, providing a rare opportunity to study intermediate-depth earthquake 
hypocenters with respect to robust, independent constraints on the interface. This survey encompasses the Shumagin gap, the Semidi segment and the SW portion of the Kodiak asperity. We use grid-search and double-difference methods to relocate earthquake catalogs from the Alaska Earthquake Center (AEC) and the Alaska Amphibious Community Seismic Experiment (AACSE) using a local 3D velocity model derived from the ALEUT reflection experiment, ensuring consistency between hypocenter and reflection depths. There are relatively few earthquakes recorded in the AEC catalog between the trench and where the plate interface reaches depths of $\sim 25 \mathrm{~km}$, and initial earthquake catalogs from the AACSE suggest that this is not merely because of poor station coverage offshore. Our initial results indicate that, where the plate interface is deeper than $50 \mathrm{~km}$, there is a distinct gap between the plate interface and the top of the upper-plane earthquakes. It is not yet clear whether these deeper earthquakes are entirely constrained to the oceanic mantle, or whether some occur in the lower crust. We additionally investigate along-strike trends in upper-plane seismicity and consider their relations to varying properties of the incoming oceanic plate.

\section{Strong Motions on Land and Ocean Bottoms in and Around Kanto Basin From Two Nearby Moderate Earthquakes East Off the Chiba Prefecture}

DHAKAL, Y. P., National Research Institute for Earth Science and Disaster Resilience, Tsukuba, Japan, ydhakal@bosai.go.jp; KUNUGI, T., National Research Institute for Earth Science and Disaster Resilience, Tsukuba, Japan, kunugi@bosai.go.jp

We analyzed strong motions and their durations from two moderate magnitude earthquakes that occurred off the Chiba prefecture in 2018 and 2020 respectively. The two earthquakes occurred in an extremely complicated tectonic area north of the Sagami trough (a triple junction) where the Philippine Sea Plate overrides the Pacific Plate and the both plates subduct beneath the Kanto basin. The earthquakes had Mw values of 5.9 estimated by F-net, NIED. The JMA focal depths of the former and latter events were 56 and $36 \mathrm{~km}$, respectively. The ground motion records on the Kanto basin were taken from the dense MeSO-net, while the ground motions on the ocean bottom were taken from newly established ocean bottom network, S-net. The seismographs of MeSO-net are set up at the depth of $20 \mathrm{~m}$ in a borehole. The S-net seismographs are housed inside inline-type cylindrical vessels, which are buried to the depth of about one meter in the shallow water region $(<1500 \mathrm{~m})$ while the vessels are laid freely on the ocean bottom in the deeper region. PGAs, PGVs, and significant durations based on Arias intensity were compared between the two events on the Kanto basin and offshore area. To make a meaningful comparison between the data sets from the two networks, the waveforms at the MeSO-net stations were compared with the waveforms at the nearby K-NET and KiK-net stations. It was found that the waveforms at the $20 \mathrm{~m}$ depth were very similar to the waveforms at the nearby surface stations within one kilometer at frequencies lower than about 0.5 to $1.0 \mathrm{~Hz}$. Our comparison at applicable frequencies showed that the PGAs were very similar between the two events at the MeSO-net sites despite the difference of the focal depths, but the PGVs were larger for the shallow event. The PGAs and PGVs were, on average, larger at the ocean bottom sites than those at the land sites for the deeper event. The horizontal component PGAs and PGVs were larger at the ocean bottom sites for the deeper event, while the values for the vertical component were similar. The significant durations between the two earthquakes and the two networks were comparable.

\section{Analyses and Implications of the 4 August 2020 Beirut} Explosion Series

I: Oral Session · Thursday · 22 April · 2:00 PM Pacific

II: Oral Session · Friday · 23 April · 9:45 Am Pacific

Session Chairs: Joshua D. Carmichael, Los Alamos National

Laboratory (joshuac@lanl.gov); Fransiska K. Dannemann

Dugick, Sandia National Laboratories (fdannemanndugick@

gmail.com); Seung-Hoon Yoo, Applied Research Associates

(syoo@ara.com); Stephen J. Arrowsmith, Southern Methodist University (sarrowsmith@mail.smu.edu)

\section{A Seismic Yield Estimate for the Using Full-Waveform Envelope Predictions and Calibrated Site and Path Models}

YOO, S., Applied Research Associates, Inc., Virginia, USA, syoo@ara.com; REITER, D., Applied Research Associates, Inc., Massachusetts, USA, dreiter@ ara.com

On August 4, 2020, a large chemical explosion occurred in a storage depot in the port of Beirut, Lebanon. A large network of local- and regional-distance seismic stations recorded waveforms from the explosion, which we analyzed to estimate seismic yield. We calculated a prompt diagnostic yield by applying a new full-waveform processing technique, which incorporates improved waveform envelope predictions that better account for the complexity in the direct-wave and early-coda $\mathrm{P}$ waves. Our initial analysis of the Beirut event indicated a seismic yield of $2.75 \mathrm{kt}(0.44 \pm 0.39 \mathrm{in} \log 10 \mathrm{kt})$ of TNT-equivalent at the free surface, which agrees reasonably well with published estimates of the explosive material stored at the detonation site. We achieved this 'quicklook' result in the absence of a priori information by utilizing a proxy onedimensional path attenuation model and an average site correction.

In this study, we will present results from further characterization of the highly complex propagation effects in the local and regional recordings of the Beirut event. We will analyze an extensive earthquake dataset from the region to estimate optimal waveform envelopes and a propagation model that accounts for laterally varying attenuation structure. This analysis will produce a fully calibrated yield estimate that we will compare to our previous prompt results. We will then thoroughly analyze the uncertainties of seismic yields estimated with fast one-dimensional versus optimized two-dimensional path and site models, as well as the time it takes to generate each yield estimate. Our goal is to demonstrate that it is possible to create an automated framework for the calibration process and quickly obtain an optimized model in a new and uncalibrated region.

\section{Blast Impacts of August 2020 Beirut Explosion From Ground Observations and Satellite Data}

SADEK, S., American University of Beirut, Beirut, Lebanon, salah@aub.edu. lb; DABAGHI, M., American University of Beirut, Beirut, Lebanon, md81@ aub.edu.lb; ZIMMARO, P., University of Calabria, Cosenza, Italy, paolo. zimmaro@unical.it; O’DONNELL, T., University of California, Los Angeles, California, USA, tmo32@g.ucla.edu; YUN, S., Jet Propulsion Laboratory, California, USA, sang-ho.yun@jpl.nasa.gov; HASHASH, Y. M. A., University of Illinois at Urbana-Champaign, Illinois, USA, hashash@illinois.edu; STEWART, J. P., University of California, Los Angeles, California, USA, jstewart@seas.ucla.edu

At 18:08 on 4 August 2020, a large explosion occurred at Hangar 12 in the Port of Beirut. The size of the explosion was equivalent to that of an earthquake with local magnitude $\left(\mathrm{M}_{\mathrm{L}}\right)$ of 3.3 (USGS). Following the event, several organizations mobilized to examine its impact. The Order of Engineers and Architects of Beirut (OEA) undertook building inspections with the aim of identifying structures unsafe for human occupancy. The American University of Beirut Urban Lab (AUB-UL) engaged with several outside agencies including Rice University Spatial Studies Lab and OpenMap Lebanon to map the impacts of the explosion on building using broad damage descriptors (e.g., minor damage, major damage, etc.).

This abstract is an outcome of a combined effort of the American University of Beirut (AUB), NASA-Jet Propulsion Laboratory (JPL), and the NSF-sponsored Geotechnical Extreme Events Reconnaissance Association (GEER). AUB and GEER have partnered to collect and document the perishable data on the impacts of the explosion, particularly in connection with Port of Beirut infrastructure and building structures.

In this presentation, we will describe the ground based observations of building impacts, which emphasized mapping of structural damage (i.e., 
impacts, or lack thereof, on load-carrying structural system) and façade damage (i.e., impacts on exterior windows and doors). Both types of impacts can be compared to damage proxies produced by NASA-JPL following the event based on satellite data. We find the damage proxies are more strongly correlated with façade damage than with structural damage.

\section{Non-Linear Simulation of the 2020 Beirut Explosion: Energy Coupling at Ground-Air-Sea Interfaces, Cratering, Hydroacoustic and Seismoacoustic Conversion and Signatures}

EZZEDINE, S. M., Lawrence Livermore National Laboratory, California, USA, ezzedine1@llnl.gov

Predicting a propagating blast wave in urban environment is a complicated task especially when dealing with a dense and a complex urban environment such as Beirut city. Furthermore, when the shockwave is simultaneously interacting with sea water, air, and ground, then it further complicates the non-linear interaction of the shockwave with the environment and its response to the urban geometry and structures. Empirical and semi-empirical engineering tools are then limited, and it is required to use state-of-the-art hydrodynamic codes which has led us to develop a physics-based framework to seamlessly simulate the event from source, chemical explosion, to ground and sea-water impacts, to wave generation, propagation. The non-linear effects of the explosion are simulated using the hydrocode GEODYN to create the nearfield source for the shallow water wave propagation code, SWWP and the ground propagation SW4. The GEODYN-SWWP coupling is based on the structured adaptive mesh refinement infrastructure; SAMRAI developed at LLNL, while GEODYN-SW4 coupling is based on mapping the explosion source as a boundary condition to SW4. We illustrate both couplings and compare them to a direct solution where all the physics are solved fully using GEODYN. Only a fraction of the total explosion energy is converted into hydroacoustic and seismoacoustic waves that have the ability to propagate beyond the source region. The remaining energy is consumed by the "evaporation" of the waterWilson cloud-and pulverization of the surrounding ground and structures. We predicted the crater at ground zero and assessed key parameters and their uncertainty on the overall hydroacoustic and seismoacoustic responses.

This work performed under the auspices of the U.S. Department of Energy by Lawrence Livermore National Laboratory under Contract DE-AC52-07NA27344.

\section{Seismo-Acoustic Yield Determination of the 4 August 2020 Beirut Explosion \\ PASYANOS, M. E., Lawrence Livermore National Laboratory, California, USA, pasyanos1@llnl.gov; KIM, K., Lawrence Livermore National Laboratory, California, USA, kim84@llnl.gov}

The 4 August 2020 Beirut explosion of ammonium nitrate produced multiphenomenological signals (seismic, acoustic and hydroacoustic) that were well recorded at local and regional distances. The clear seismic signals allowed us to perform a seismic yield determination with waveform envelopes, a method which we have developed and refined over the past decade (Pasyanos et al., 2012). The method calculates synthetic waveform envelopes by propagating an earthquake or explosion source out to recording stations by accounting for geometrical spreading, attenuation, local site effects, and coda decay. Source parameters can then be estimated by minimizing the misfit between the observed waveform envelopes and the synthetic envelopes for a range of yields and depths. The misfit analysis is estimated for multiple frequency bands and potentially multiple stations. While the solid earth structure is well-known for this analysis, one major source of uncertainty is the material properties beneath the explosion.

Infrasound signals recorded on regional arrays have also allowed us to make an acoustic yield determination. In this method, transmission loss of acoustic energy is calculated by $2-\mathrm{D}$ finite-difference method including a range-dependent weather specification and used to invert for explosion energy near the source. The yield is determined by the inverted explosion energy and an acoustic source model for chemical explosions (Kim et al., 2020). In contrast to the seismic analysis, a major source of uncertainty is the atmospheric conditions. We attempt to quantify the atmospheric variability by using stochastic realization. While estimates made using both methods have uncertainties that are not insignificant, combining the results can reduce the overall range of acceptable yields, which includes the likely true explosive yield. In both yield estimation methods, we are sensitive to energy partitioning at the earth-air-water interface, but this event should provide insight into the details of this coupling.

\section{Seismoacoustic Summary Analysis of the 2020 Beirut Explosion}

BEGNAUD, M. L., Los Alamos National Laboratory, New Mexico, USA, mbegnaud@lanl.gov; BLOM, P. S., Los Alamos National Laboratory, New Mexico, USA, pblom@lanl.gov; PHILLIPS, W. S., Los Alamos National Laboratory, New Mexico, USA, wsp@lanl.gov; BABIKOFF, J., Brown University, Rhode Island, USA, jordyn_babikoff@brown.edu; ROWE, C. A., Los Alamos National Laboratory, New Mexico, USA, char@lanl.gov; GAMMANS, C. N. L., Los Alamos National Laboratory, New Mexico, USA, cgammans@lanl.gov; STEAD, R., Los Alamos National Laboratory, New Mexico, USA, stead@lanl.gov

We describe a summary analysis of the August 4, 2020 surface explosion in the Port of Beirut. The explosion involved $\sim 2.75 \mathrm{kt}$ of ammonium nitrate that was accidentally detonated. The event was detected by local, regional, and global seismic and infrasound stations and had unique signal characteristics. We made manual arrival picks and amplitude measurements on ocean-bottom and island seismic arrays and stations in the eastern Mediterranean as well as at stations out to $\sim 3000 \mathrm{~km}$ where possible. We observed many unique signals at the stations and arrays and were able to use FK analysis to get azimuth and slowness measurements. Using the seismic arrival measurements, we utilize the event as ground-truth (GT) to test various seismic velocity models for location. Source spectra for the event were also obtained via propagation corrections, enabling an estimate of moment magnitudes $(\mathrm{Mw})$ for several phases $(\mathrm{Pg}=3.6, \mathrm{Lg}=3.3) . \mathrm{Pg}$ is more heavily excited by this source, and appears explosion-like. Using the Pg and Lg Mw range of 3.3-3.6, the yield estimate is 1.0-2.75 kt. Infrasound analysis found 5 International Monitoring Stations detected signals plus the nearby IMA (Israeli) infrasound station. Infrasound signals were observed at distances up to $6000+\mathrm{km}$ and localization is biased northward. An infrasound signal yield estimate was made using a periodyield relationship. Peak infrasonic frequencies observed cover $0.14-0.19 \mathrm{~Hz}$, and correspond to $0.8-2.0 \mathrm{kT}$ equivalent TNT yield.

\section{Behavioral Response to a Rapid Onset Disaster: The Case of} the 4 August 2020 Beirut, Lebanon, Port Explosions

ISKANDAR, R., Université Grenoble Alpes, Grenoble, France, rouba. iskandar@univ-grenoble-alpes.fr; BECK, E., Laboratoire Pacte, Université Grenoble Alpes, Grenoble, France, elise.beck@univ-grenoble-alpes.fr; CORNOU, C., ISTerre, Université Grenoble Alpes, Grenoble, France, cecile. cornou@univ-grenoble-alpes.fr; HARB, J., Notre Dame University, Zouk Mosbeh, Lebanon, jharb@ndu.edu.lb; DUGDALE, J., LIG, Université Grenoble Alpes, Grenoble, France, julie.dugdale@univ-grenoble-alpes. fr; GÉRARD, J., Université Saint Joseph, Beirut, Lebanon, jgerard@usj.edu. lb; CARTIER, S., Laboratoire Pacte, Université Grenoble Alpes, Grenoble, France, stephane.cartier@univ-grenoble-alpes.fr

On August 4th 2020, a double explosion detonated in the port of Beirut. This double explosion, which caused more than 200 deaths and 7500 injuries, was considered by seismological monitoring networks to be equivalent to a tremor of a magnitude of 3.4 (CSEM). We are interested in the behavioral response of individuals in Lebanon to earthquakes in order to model seismic crises in Beirut. Although earthquakes and explosions are two distinct phenomena and may invoke different behaviors, both events are rapid onset disasters. Moreover, previous post-seismic surveys have shown that in an earthquake some individuals may recognize an explosion in the first few moments.

In order to better understand the behavioral response of the population following the double explosion, an online survey was launched on August 18th, 2020. The link to the survey was diffused through personal and professional networks, as well as social media platforms and websites of local partners. The questionnaire was made available in three languages: Arabic, French and English. The survey questioned what people felt and perceived (environmental signals), the way they gathered information regarding the event, what people did following both explosions and the reason why they behaved in such a way, especially when they were outside a building. Survey data were obtained from 559 persons, 223 located in Beirut during the explosions and 336 outside Beirut. While the first explosion was thought to be an earthquake by $48 \%$ of the 326 respondents who felt it, the scond was identified as a nontectonic event by $70 \%$ of the 479 respondents who felt it.

Out of the 389 people who were in buildings during the second explosion, $25 \%$ reported leaving the building. Going outside is found to be correlated with the building's damage level. Once outside, the adopted behaviors were linked to social ties: joining a family member and going home are found to be the modal behavioral responses. The survey results also highlight the population's lack of knowledge in the location of open spaces to take shelter in case of emergency. 


\section{Close-In Phenomenology of the Beirut Explosion}

EULER, G. G., Los Alamos National Laboratory, New Mexico, USA, ggeuler@ lanl.gov; BEST, J. S., Los Alamos National Laboratory, New Mexico, USA, jbest@lanl.gov; KUNKLE, T. D., Los Alamos National Laboratory, New Mexico, USA, u091007@lanl.gov; TIERNEY, T. E., Los Alamos National Laboratory, New Mexico, USA, tierney@lanl.gov; TRIPLETT, L. A., Los Alamos National Laboratory, New Mexico, USA, ltriplett@lanl.gov; RISTVET, B. L., Sandia National Laboratories, New Mexico, USA, bristve@sandia.gov

On August 4, 2020 nearly 2750 tons of ammonium nitrate stored in a warehouse at the port in Beirut, Lebanon violently exploded as a result of a large fire caused by welding activity at the warehouse. Because of the spectacle presented by the fire, an array of videos were taken at the time of the explosion from several angles. We took advantage of these videos uploaded to social media and news sites to examine the close-in phenomenology of the explosion in some detail. We review the HE source, the video perspectives and imagery, fireball growth, shock wave propagation, blast damage to surrounding structures, cratering and cloud-rise (in the context of observations from nuclear and non-nuclear legacy testing) to assess the yield of the Beirut explosion. Our analysis results in a best fit yield of $0.82 \mathrm{KT}$ or about $40 \%$ detonation efficiency given a 0.70 TNT equivalence for ammonium nitrate with the remainder of the HE source converted to nitrogen dioxide by deflagration to produce the orange-red smoke cloud seen erupting out of the fireball.

\section{Forensic Architecture: The Beirut Port Explosion}

MOAFI, S., Forensic Architecture, Goldsmiths University of London, London, United Kingdom, sm@forensic-architecture.org

This submission puts forward a research into the August 2020 explosions at the port of Beirut. Developed as a collaboration between the London based research unit Forensic Architecture and the Cairo based independent media outlet Mada Masr, it examines open-source information including videos, photographs, and documents to provide a timeline and a precise 3D model to help investigate the events of August 4th.

The study combines an accurate reconstruction of the warehouse's interior developed from open source data with expert opinion from a UN explosion expert Gareth Collett CBE to provide an account of the momentby-moment development of the fire within the warehouse. In doing so, it demonstrates the ways in which the organization of goods within the warehouse was in violation of internationally accepted safety standards. Findings are further contextualised in relation to a report by Legal Action Worldwide, showing that as early as December 2014, various port and customs officials in Lebanon were warned of the dangers posed by its storage but the public was never warned at any stage.

\section{Unusual infrasound Observations From the August 2020 Beirut Explosion}

ASSINK, I. D., Royal Netherlands Meteorological Institute, De Bilt, Netherlands, assink@knmi.nl; WAXLER, R., University of Mississippi, Mississippi, USA, rwax@olemiss.edu; BLOM, P. S., Los Alamos National Laboratory, New Mexico, USA, pblom@lanl.gov; SHANI-KADMIEL, S., Royal Netherlands Meteorological Institute, De Bilt, Netherlands, shahar. shani.kadmiel@knmi.nl; AVERBUCH, G., Southern Methodist University, Texas, USA, gaverbuch@mail.smu.edu; EVERS, L. G., Royal Netherlands Meteorological Institute, De Bilt, Netherlands, laslo.evers@knmi.nl; BEN HORIN, Y., Soreq Nuclear Research Center, Yavne, Israel, yochai@ndc.soreqndc.gov.il

On 4 August 2020, a warehouse of ammonium nitrate exploded in Beirut, Lebanon, leading to loss of life and property. Infrasonic signals from this event have been detected across the Middle East, Europe and North-Africa. The furthest IMS station that detected the signal was IS11 (Cape Verde) at over 6000 $\mathrm{km}$ distance.

The features of the observed infrasonic signals were unusual for the time of year. (1) Signals with tropospheric celerities were observed at IS26 and IS48, the nearest IMS arrays to the west and northwest, as well as the national arrays in Hungary (PSZI) and Romania (IPLOR). (2) At IS26 and PSZI, curious trace velocity trends were observed, starting at high values and decreasing along the wave train, contrary to what is typically observed. (3) The fastest arrivals at IS26 and PSZI appear to have significant back azimuthal scatter.

These observations suggest that the propagation conditions were more complex than a single stratospheric duct which is typical for mid-summer conditions in the Northern Hemisphere. It is hypothesized that the tropospheric phases interacted significantly with topography. This hypothesis is supported by wind and temperature forecasts derived from numerical weather prediction models. An analysis of the propagation conditions is presented.
Yield Estimation of the 2020 Beirut Explosion Using Open Access Waveform and Remote Sensing Data

PILGER, C., Bundesanstalt für Geowissenschaften und Rohstoffe, Hanover, Germany, Hanover, Germany, christoph.pilger@bgr.de; GABELER, P., Bundesanstalt für Geowissenschaften und Rohstoffe, Hanover, Germany, peter.gaebler@bgr.de; HUPE, P., Bundesanstalt für Geowissenschaften und Rohstoffe, Hanover, Germany, patrick.hupe@bgr.de; KALIA, A. C., Bundesanstalt für Geowissenschaften und Rohstoffe, Hanover, Germany, andre.kalia@bgr.de; SCHNEIDER, F., GFZ German Research Centre for Geosciences, Potsdam, Germany, felix.schneider@gfz-potsdam.de; STEINBERG, A., Bundesanstalt für Geowissenschaften und Rohstoffe, Hanover, Germany, andreas.steinberg@bgr.de; SUDHAUS, H., Christian Albrechts University, Kiel, Germany, henriette.sudhaus@ifg.uni-kiel.de; CERANNA, L., Bundesanstalt für Geowissenschaften und Rohstoffe, Hanover, Germany, lars.ceranna@bgr.de

We report on a multi-technique analysis using publicly available data for investigating the huge, accidental explosion that struck the city of Beirut, Lebanon, on August 4, 2020. Its devastating shock wave led to thousands of injured with more than two hundred fatalities and caused immense damage to buildings and infrastructure. Our combined analysis of seismological, hydroacoustic, infrasonic and radar remote sensing data allows us to characterize the source as well as to estimate the explosive yield. The latter ranges between 0.8 and $1.1 \mathrm{kt}$ TNT (kilotons of trinitrotoluene) equivalent and is plausible given the reported $2.75 \mathrm{kt}$ of ammonium nitrate as explosive source. Data from the International Monitoring System of the CTBTO are used for infrasound array detections. Seismometer data from GEOFON and IRIS complement the source characterization based on seismic and acoustic signal recordings, which propagated in solid earth, water and air. Copernicus Sentinel data serve for radar remote sensing and damage estimation. As there are strict limitations for an on-site analysis of this catastrophic explosion, our presented approach based on openly accessible data from global station networks and satellite missions is of high scientific and social relevance that furthermore is transferable to other explosions.

Analyses and Implications of the 4 August 2020 Beirut Explosion Series

Poster Session · Friday · 23 April · 11:30 Am Pacific

Session Chairs: Joshua D. Carmichael, Los Alamos National

Laboratory (joshuac@lanl.gov); Fransiska K. Dannemann

Dugick, Sandia National Laboratories (fdannemanndugick@ gmail.com); Seung-Hoon Yoo, Applied Research Associates (syoo@ara.com); Stephen J. Arrowsmith, Southern Methodist University (sarrowsmith@mail.smu.edu)

\section{Impact of the 4 August 2020 Beirut, Lebanon, Port Explosion on Dynamical Building Properties}

GUILLIER, B., ISTerre, Grenoble, France, bertrand.guillier@ird.fr; CORNOU, C., ISTerre, Grenoble, France, cecile.cornou@univ-grenoble-alpes. fr; HARB, J., Notre-Dame University, Louaize, Lebanon, jharb@ndu.edu.lb; YOUSSEF ABDEL MASSIH, D., Lebanese University, Beirut, Lebanon, dalia. abdelmassih@ul.edu.lb; GUEGUEN, P., ISTerre, Grenoble, France, philippe. gueguen@univ-grenoble-alpes.fr; MERCERAT, D., CEREMA, Nice, France, diego.mercerat@cerema.fr; SALAMEH,C., TRACTEBEL, Paris, France, christelle.salameh@live.com; ASLAN, Y., Lebanese University, Beirut, Lebanon, yara.aslan1998@hotmail.com; ATWI, Y., Lebanese University, Beirut, Lebanon, yomnaatwi@outlook.com; BEDRAN, E., Notre-Dame University, Louaize, Lebanon, efbedran@ndu.edu.lb; CHEDRAOUI, R., Lebanese University, Beirut, Lebanon, rosy.chedraoui@gmail.com; EL HAJJ, M., Lebanese University, Beirut, Lebanon, maria_hajj97@hotmail.com; FAHED, M., Lebanese University, Beirut, Lebanon, michelle.fahed97@gmail. com; MANNAH, J., Lebanese University, Beirut, Lebanon, julienmannah@ gmail.com; NASSIF, H., Notre-Dame University, Louaize, Lebanon, hynassif@ ndu.edu.lb; ROUHANA, C., Lebanese University, Beirut, Lebanon, christelle. rouhana58@gmail.com; SAGHBINI, C., Notre-Dame University, Louaize, Lebanon, cksaghbini@ndu.edu.lb; TANNOUS, C., Lebanese University, Beirut, Lebanon, cynthiatannous96@gmail.com

Thousands of buildings have been more or less damaged after the August 4, 2020, explosion in Beirut, Lebanon. Operational Modal Analysis method 
based on seismic ambient noise recordings in buildings can be used to assess their modal parameters (e.g. resonance frequency). This is thus a valuable tool to assess and monitor the structural health of civil engineering structures Between 2012 and 2014, a seismic ambient noise campaign was carried out on a set of $328 \mathrm{RC}$ buildings in Beirut covering various building typologies and soil types (Salameh et al., 2016). These measurements were used to derive empirical relationships between the number of stories and the fundamental resonance frequency. Following the August 4, 2020 explosion in Beirut, a set of these buildings (132) of various height and located at different distances from the explosion was re-measured in order to evaluate if the variation in resonance frequencies before and after the explosion can be related to buildings damage. Some buildings (41) located very close to the port area were also measured in order to check variation in resonance frequency compared to the empirical relationship. Results show a decrease in resonance frequencies ranging from up to $20 \%$ to about $3 \%$ for buildings located $1 \mathrm{~km}$ away to about 4 $\mathrm{km}$ from the port area, respectively, taller buildings exhibiting systematically a higher relative decrease in resonance frequency before and after the explosion. Interestingly, we also observe a large variability of the difference of frequencies in-between buildings with the same height and located at a similar distance from the explosion, as well as between frequencies extracted from seismic sensor horizontal components aligned or perpendicular to the longitudinal direction of the buildings. Spatial decay from the explosion of difference in resonance frequencies are compared to the damage assessment of buildings inferred from satellite images or visual inspection. The contribution of the blast and the seismic waves generated by the explosion on the building damages is then discussed.

\begin{tabular}{l}
\hline Application of Remote Sensing and Space-Based Earth \\
Observations Data in Earthquake Research \\
I: Oral Session· Wednesday·21 April·5:00 PM Pacific \\
II: Oral Session· Thursday·22 April ·5:00 PM Pacific \\
Session Chairs: Xuhui Shen, National Institute of Natural \\
Hazards, MEMC (shenxh@seis.ac.cn); Dimitar Ouzounov, \\
Chapman University (dimitar.p.ouzounov@nasa.gov); \\
Zhima Zeren, National Institute of Natural Hazards, \\
MEMC (zerenzhima@qq.com); Ramesh P. Singh, Chapman \\
University (rsingh@chapman.edu); Angelo D. Santis, Istituto \\
Nazionale di Geofisica e Vulcanologia (angelo.desantis@ingv. \\
it); Shun-Rong Zhang, Massachusetts Institute of Technology \\
(shunrong@mit.edu); Jing Cui, National Institute of Natural \\
Hazards, MEMC (jingcui_86@yahoo.com)
\end{tabular}

\section{Analyzing the Efficiency of Space-Based Geodesy Data for} the Systematic Forecast of Earthquakes

GITIS, V., Russian Academy of Sciences, Moscow, Russian Federation, gitis@ iitp.ru; DERENDYAEV, A., Russian Academy of Sciences, Moscow, Russian Federation, wintsa@gmail.com; PETROV, K., Russian Academy of Sciences, Moscow, Russian Federation, stranger12@list.ru

The efficiency of using space-based geodesy data for earthquake prediction is estimated. Prediction is based on our machine learning technique called the method of minimum area of alarm. The system makes forecast regularly with $d t$ step. At each time $t$, it converts all types of input data (earthquake catalogs, time series, and raster data) into uniform spatio-temporal grid fields, trains on all data available at time $t$, and calculates the alarm zone in which the epicenter of the target earthquake is expected in the interval $(t, t+d t)$. A demo version of the system since 2018 is available at https://distcomp.ru/geo/ prognosis/.

The estimate was obtained from the results of the forecast of earthquakes in Japan with a magnitude of $m \geq 6.0$ and a hypocenter depth of up to 60 $\mathrm{km}$, which occurred from 2016 to 2020. The forecast results from GPS data are compared with the results of a random forecast, a forecast based on the spatial density of earthquake epicenters, a forecast based on spatio-temporal seismic data, and a forecast based on combined GPS and seismological data. It is shown that the coherence of changing the rates of various types of the earth's surface deformation fields in combination with the value of the change in the shear deformation rate can be a precursor to strong earthquakes. It is shown that the probability of forecasting earthquakes with magnitudes $m \geq$ 6.0 according to GPS data is statistically significantly higher than the prob- ability of forecasting from random data and forecasting from the spatial density of earthquakes. The probability of a successful prediction of earthquakes using seismological data is higher than the probability of forecasting using GPS data. Adding the fields calculated from GPS data to the fields calculated from the earthquake catalog practically does not change the forecast probability. The obtained results are preliminary and require additional research in other seismically active regions.

\section{Magnetospheric-lonospheric-Lithospheric Coupling Model-Observations During the 5 August 2018 Bayan Earthquake}

PIERSANTI, M., Instituto Nazionale di Fisica Nucleare, L’Aquila, Italy, mirko. piersanti@roma2.infn.it; MATERASSI, M., Institute for Complex Systems, Florence, Italy, massimo.materassi@isc.cnr.it; BATTISTON, R., University of Trento, Trento, Italy, roberto.battiston@unitn.it; CARBONE, V., Università della Calabria, Cosenza, Italy, vincenzo.carbone@fis.unical.it; CICONE, A., University of L'Aquila, L'Aquila, Italy, antonio.cicone@univaq.it; D'ANGELO, G., Istituto di Astrofisica e Planetologia Spaziali, Rome, Italy, giulia.dangelo@ inaf.it; DIEGO, P., Istituto di Astrofisica e Planetologia Spaziali, Rome, Italy, piero.diego@inaf.it; UBERTINI, P., Istituto di Astrofisica e Planetologia Spaziali, Rome, Italy, pietro.ubertini@inaf.it

The short-term prediction of earthquakes is an essential issue connected with human life protection and related social and economics matter. Recent papers have provided some evidence of the link between the lithosphere, lower atmosphere, and ionosphere, even though with marginal statistical evidence. The basic coupling hypothesized being via atmospheric gravity wave $(\mathrm{AGW}) /$ acoustic wave (AW) channel. In this work we analyse the scenario of the low latitude earthquake $(\mathrm{Mw}=6.9)$ occurred in Indonesia on August 5,2018 , through a multi-instrumental approach, using ground and satellites high quality data. As a result, we derive a new analytical lithospheric-atmospheric-ionospheric-magnetospheric coupling model with the aim to provide quantitative indicators to interpret the observations around 6 hours before and at the moment of the earthquake occurrence.

\section{Multi-Parameter Observation of Pre-Earthquake Signals in Atmosphere-Ionosphere. Case Study for M7.1 Ridgecrest, CA Earthquake of July 2019}

OUZOUNOV, D., Chapman University, California, USA, dim.ouzounov@ gmail.com; SHEN, X., National Institute of Natural Hazards, MEMC, Beijing, China, xuhuishen@ninhm.ac.cn; PULINETS, S., Space Research Institute, Moscow, Russian Federation, pulse1549@gmail.com; ROZHNOI, M., The Schmidt Institute of Physics of the Earth, Moscow, Russian Federation, roznoi@ifz.ru; DAVIDENKO, D., Space Research Institute, Moscow, Russian Federation, davidenkoe5@rambler.ru; ZHIMA, Z., National Institute of Natural Hazards, MEMC, Beijing, China, zerenzhima@qq.com; HUANG, J., National Institute of Natural Hazards, MEMC, Beijing, China, xhhjp@126. com; LIU, J., National Central University, Taoyuan, Taiwan, tigerjyliu@gmail. com; HATTORI, K., Chiba University, Chiba, Japan, hattori@earth.s.chiba-u. ac.jp; KAFATOS, M., Chapman University, California, USA, kafatos@ chapman.edu

We present a multi-parameter analysis of transient phenomena observed in the Earth's atmosphere-ionosphere environment plausibly associated with M6.4 of Jul 4, 2019, and M7.1 of Jul 6, 2019, Ridgecrest California. We collect operational data from two satellites, ground data, and one assimilation model probing atmosphere/ ionosphere, such as 1. Outgoing long-wavelength radiation (OLR obtained from NPOESS) on the top of the atmosphere (TOA); 2. Electron Density (Te) from the ionospheric plasma data (Langmuir Probe, LAP) from China Seismo-Electromagnetic Satellite (CSES, also called ZhangHeng-1); 3. Very Low Frequency (VLF) modulated signals from several VLF/LF transmitters; 4 . Weather Data -Temperature, Atm. Pressure and Relative humidity; 5. Atmospheric chemical potential (ACP) obtained from weather models and 6 . The electron density variations in the ionosphere via GPS Total Electron Content (GPS/TEC). NOAA satellite thermal observations on Jun 24 show an increase of OLR near the future epicenter. The VLF signal received at Orange, CA, was strongly disturbed on all tracks on Jun 22 , and the signal perturbations were also observed on Jun 25 and on Jul 6 . The increases in ACP on June 30/Jul 1 was measured near the epicentral area and coincided with the anomaly of Te from LAP of CSES1 satellite. The GPS/TEC data indicated an increase of electron concentration in the ionosphere on Jun 30 and Jul 1 . We compare the precursory phenomena in the ionosphere and atmosphere of 2019 Ridgecrest compared to Hector Mine 1999 in the same areas. We analyzed two strong earthquakes of the same magnitude M7.1 in the same region with a time span of 20 years. We provide comprehensive analysis, determine the precursory period for both earthquakes, and demonstrate 
the self-similarity and uniqueness of atmospheric and ionospheric precursors. We show that only by integrating data from multiple sensors in space and on the ground we could observe the pre-earthquake evolution patterns in the atmosphere-ionosphere environment.

\section{Satellite and Ground Based Measured Ionospheric Variations Over Seismic Active Areas}

SCHIRNINGER, C., Austrian Academy of Sciences, Graz, Austria, christoph. schirninger@oeaw.ac.at; EICHELBERGER, H., Austrian Academy of Sciences, Graz, Austria, hans.ulrich.eichelberger@oeaw.ac.at; BOUDJADA, M., Austrian Academy of Sciences, Graz, Austria, mohammed.boudjada@ oeaw.ac.at; SCHWINGENSCHUH, K., Austrian Academy of Sciences, Graz, Austria, konrad.schwingenschuh@oeaw.ac.at; MAGNES, W., Space Research Institute, Austrian Academy of Sciences, Graz, Austria, werner.magnes@ oeaw.ac.at; POLLINGER, A., Space Research Institute, Austrian Academy of Sciences, Graz, Austria, andreas.pollinger@oeaw.ac.at; LAMMEGGER, R., Institute of Experimental Physics, Graz University of Technology, Graz, Austria, roland.lammegger@tugraz.at; SHEN, X., National Institute of Natural Hazards, MEMC, Beijing, China, xuhuishen@ninhm.ac.cn; WANG, J., National Space Science Center, CAS, Beijing, China, wjd@nssc.ac.cn; CHENG, B., National Space Science Center, CAS, Beijing, China, chengbj@ nssc.ac.cn; ZHOU, B., National Space Science Center, CAS, Beijing, China, zhoubin@nssc.ac.cn; GALOPEAU, P. H. M., LATMOS-CNRS, UVSQ Université Paris-Saclay, Guyancourt, France, patrick.galopeau@latmos.ipsl.fr; SOLOVIEVA, M., Russian Academy of Sciences, Moscow, Russian Federation, mcsolovieva@gmail.com; BIAGI, P. F., University of Bari, Bari, Italy, pf.biagi@ gmail.com; STACHEL, M., Austrian Academy of Sciences, Graz, Austria, manfred.stachel@oeaw.ac.at; BESSER, B. P., Austrian Academy of Sciences, Graz, Austria, bruno.besser@oeaw.ac.at; DELVA, M., Austrian Academy of Sciences, Graz, Austria, magda.delva@oeaw.ac.at

In this study we investigate ionospheric disturbances over earthquake prone areas with two methods.

The satellite based approach - in our case magnetic field measurements from CSES-01 and Swarm mission - shed light on ionospheric F-region plasma variations at low-earth orbit (LEO) altitudes around $500 \mathrm{~km}$. The complementary second technique is based on variations of the so-called Earth-ionosphere waveguide, the cavity between Earth's surface and the lower ionospheric D/E (day/night) upper boundary at approx. 70-90 km altitude. Electric field amplitude and phase perturbations of paths between several narrowband VLF/LF transmitter and a receiver network are continuously recorded.

In both cases the lithosphere-atmosphere-ionosphere coupling (LAIC) is a key area and of vital importance in order to establish the propagation characteristics from the seismic zone up to high altitudes. Possible mechanisms are discussed in the literature, e.g. [1], [2]. In this presentation we focus on acoustic waves and atmospheric gravity waves (AGW) as energy-momentum transport channel (and filter) to connect the different regions from bottom to top.

We examine events form the United States Geological Survey (USGS) earthquake catalog, assign a spatial box of a few degrees in latitude and longitude around the epicenter, investigate measurements from satellite- and/or VLF/LF paths which crosses the box, and report on differences in variations prior and after the events.

These findings could point to regular automated procedures in order to disentangle seismic from nonseismic ionospheric pattern and are equally important for upcoming satellite missions and extended ground based networks.

References: [1] Molchanov, O. A. and Hayakawa, M., "Seismoelectromagnetics and related phenomena. History and latest results.", 189 p., Terrapub, 2008. ISBN 978-4-88704-143-1 [2] Ouzounov, D., Pulinets, S., Hattori, K. and Taylor P., "Pre-Earthquake Processes: A Multidisciplinary Approach to Earthquake Prediction Studies", 384 p., Geophysical Monograph Series, 2018. ISBN: 978- 1-119-15693-2

\section{The Latest Scientific Results of CSES Mission}

ZHIMA, Z., National Institute of Natural Hazards, Ministry of Emergency Management of China, Beijing, China, zerenzhima@qq.com; SHEN, X., National Institute of Natural Hazards, Ministry of Emergency Management of China, Beijing, China, xuhuishen@ninhm.ac.cn; MISSON, C., National Institute of Natural Hazards, Ministry of Emergency Management of China, Beijing, China, zerenzhima@ninhm.ac.cn

The China Seismo-Electromagnetic Satellite (CSES) is the first platform of China Geophysical fields observation satellite mission (Zhangheng mission), with the main objectives to monitor the global geomagnetic field, ionosphere background environment and possible abnormal signals with strong natural disasters. The Zhangheng mission which is planned to launch 2 or 3 microsat- ellites within next decades in order to monitor the electromagnetic environment, gravitational field. CSES operates in a Sun-synchronous polar orbit with a high inclination degree of $97.4^{\circ}$ at an altitude around $507 \mathrm{~km}$, measuring the electromagnetic field, energetic particles and ionosphere plasma parameters. The first-hand scientific observations show that CSES has recorded a number of interesting natural events, showing its good inflight observing capability on natural phenomenon. In this presentation, we mainly introduce the operation status of satellite platform, payloads; as well as the first-hand scientific results obtained from CSES including the geomagnetic field modeling, the electromagnetic waves, the geomagnetic event and earthquake activities et $c$. The follow-up plans for the Zhangheng mission will be briefly presented.

\section{A Feature-Based Liquefaction Repository From Aerial and Satellite Imagery for Computer Vision Analysis}

SANON, C., Tufts University, Massachusetts, USA, christina.sanon@tufts.edu

Mapping of seismic-induced soil liquefaction is a common practice after earthquakes to help local authorities devise better disaster preparedness plans after a seismic event and to provide data for the research community. Many of those reports provide limited and inconsistent geographic information. Some of the reconnaissance reports provide coordinate-based region locators, and others provide more qualitative, general locations, while some more recent efforts provide digital polygons. The inconsistencies in how the liquefaction field investigations are communicated have led to the need for more uniform datasets.

In addition, with the increase in availability and resolution of both aerial and satellite imagery, there is the potential for automatic detection and mapping of liquefaction after earthquakes using image processing and artificial intelligence algorithms. Therefore, the aim of this research is to build a uniform liquefaction image library or repository from aerial and satellite imagery which will provide digital polygons for individual liquefaction features - sand boils, lateral spreading, and settlement. The liquefaction image library will include labels providing such information as infrastructure impacted and confidence level in the feature type and boundary. To ensure higher accuracy of liquefaction detection, image analysis methods require that the liquefaction features be outlined with polygons and that those polygons be limited to only liquefaction features. We present our preliminary liquefaction image library and demonstrate its use in automated models of liquefaction detection from post-event imagery.

\section{Atmospheric Parametric Spatiotemporal Characteristics of the 2008 Wenchuan, 2010 Yushu, 2013 Lushan and 2017 Jiuzhaigou Earthquakes in the Eastern Margin of Bayan Har Block and Discussion on Genesis and Prediction of Continental Earthquakes}

CUI, I., National Institute of Natural Hazards, MEMC, Beijing, China, jingcui_86@yahoo.com; SHEN, X., National Institute of Natural Hazards, MEMC, Beijing, China, xuhuishen@ninhm.ac.cn; MA, W., China Earthquake Networks Center, Beijing, China, weiyuma@163.com; WANG, X., Institute of Disaster Prevention, Sanhe, China, 516211532@qq.com

Since 2008, Wenchuan, Yushu, Lushan and Jiuzhaigou strong earthquakes happened in in the eastern margin of Bayan Har block, in the northeastern Tibetan Plateau. Whether the strong tectonic activities of the four earthquakes are regular or not, and whether there is genetic relationship among them, is of great significance for understanding intra-continental plate earthquakes and developing continental prediction with new ideas.

In this study, $\mathrm{CH} 4$ was taken as medium- and long-term observation factor, and RST algorithm was used to extract abnormal information. Combined with atmospheric parameters (SKT, OLR, TCWV, O3 and SLHF), the tide force was considered to analyses short-impending anomaly information.

Our results shows that $\mathrm{CH} 4$ can be used as a well precursor of seismic activeity. The anomaly appears 1-4 months before the main earthquake, and the closer to the epicenter, the larger the amount of emitted gas. The peak values were found at intersection areas. The $\mathrm{CH} 4$ anomaly appeared about 1 month before Wenchuan EQ, about 2 month before Lushan EQ, about 3 month before Yushu EQ and about 4 month before Jiuzhaigou EQ. It may be that the activity of Bayan Har block has increased since the Wenchuan earthquake. The cumulative number of earthquakes in the study area can prove that. The similarity of time sequence of the other anomalies between that atmospheric parameters may be related to the same process. The evolution of these parameters in time and space goes through the process of micro enhancement-enhancementmicro attenuation-enhancement-calmness, which was consistent with the process of micro rupture - rupture - locking - Accelerated rupture - rupture experienced by rock stress strain - rupture. The observed anomalies maybe as the consequence of the upraising of gases from a fluid-rich middle/upper crust 
along pre-existing seismogenic faults, and of their release into the atmosphere. It also shows that in the practice of earthquake prediction our method used in this paper will help to improve the earthquake prediction ability.

\section{CSES Electron Density Background Characterization and Preliminary Investigation of Possible Ne Increase Before Earthquake Occurrence}

MARCHETTI, D., Jilin University, Changchun, China, dedalo.marchetti@ ingv.it; PERRONE, L., Istituto Nazionale di Geofisica e Vulcanologia, Rome, Italy, loredana.perrone@ingv.it; ZHU, K., Jilin University, Changchun, China, zhukaiguang@jlu.edu.cn; DE SANTIS, A., Istituto Nazionale di Geofisica e Vulcanologia, Rome, Italy, angelo.desantis@ingv.it; HE, X., Jilin University, Changchun, China, hexd19@mails.jlu.edu.cn; SABBAGH, D., INGV, Rome, Italy, dario.sabbagh@ingv.it; SHEN, X., Space Observation Research Center, National Institute of Natural Hazards, Ministry of Emergency Management of China, Beijing, China, xuhuishen@ninhm.ac.cn; ZHIMA, Z., Space Observation Research Center, National Institute of Natural Hazards, Ministry of Emergency Management of China, Beijing, China, zerenzhima@qq.com; CAMPUZANO, S. A., Instituto de Geociencias IGEO (CSIC-UCM), Madrid, Spain, saioa.arquerocampuzano@ingv.it; CIANCHINI, G., Istituto Nazionale di Geofisica e Vulcanologia, Rome, Italy, gianfranco.cianchini@ingv.it; DI MAURO, D., Istituto Nazionale di Geofisica e Vulcanologia, Rome, Italy, domenico.dimauro@ingv.it; FAN, M., Jilin University, Changchun, China, jbjwyqgmszgg@qq.com; ORLANDO, M., Istituto Nazionale di Geofisica e Vulcanologia, Rome, Italy, orlandomartina93@gmail.com; PISCINI, A., Istituto Nazionale di Geofisica e Vulcanologia, Rome, Italy, alessandro. piscini@ingv.it; SOLDANI, M., Istituto Nazionale di Geofisica e Vulcanologia, Rome, Italy, maurizio.soldani@ingv.it; WANG, T., Jilin University, Changchun, China, 1223421197@qq.com; WEN, J., Jilin University, Changchun, China, 1819359059@qq.com; YU, Z., Jilin University, Changchun, China, yuzn18@mails.jlu.edu.cn; ZHANG, Y., Jilin University, Changchun, China, 1342320442@qq.com

This year will be the third one that the China Seismo Electromagnetic Satellite (CSES-01), is successfully in orbit, from its launch on 2nd February 2018. At present, this is the only satellite in orbit fully dedicated to search for earthquake precursors in the ionosphere. The payload on board consists of a High Precision Magnetometer (HPM) and a Search-Coil Magnetometer (SCM) to monitor the magnetic field, an Electric Field Detector (EFD) to measure the electric field, a Plasma analyzer (PAP), two Langmuir probes (LAP), a GNSS Occultation Receiver and a Tri-Band Beacon, to measure the plasma properties in ionosphere, and two High-Energy Particle Detectors (HEPD, HEPP) to measure the particle flux and energy spectrum (the HEPD is provided by the Italian National Institute of Nuclear Physics, in an international agreement between China National Space Administration, China Earthquake Administration and Italian Space Agency).

In this work, the first monthly background of the electron density $(\mathrm{Ne})$ measured by CSES-01 LAP is provided. Due to the Sun-synchronous orbit, it is possible to characterise the ionosphere at two fixed local times: $\sim 2 \mathrm{AM}$ for nighttime and $\sim 2$ PM for daytime. The data inside equatorial and mid-latitude regions (i.e. inside -50 and +50 latitude) are analysed. Only the geomagnetic quiet time has been considered because the ultimate purpose of estimating this background is to search for possible anomalies induced by seismic activity. Each year (2018, 2019 and 2020) has been separately analysed to take into account the variation of the solar activity (from minimum of solar cycle 24 toward next maximum of the present solar cycle 25). The long-term trend of the background has been depicted.

Finally, a preliminary analysis of the satellite Ne anomalous samples that are significantly higher than the background are investigated for a possible correlation with the concurring earthquakes, as proposed by previous works on past and present other satellites, such as DEMETER (e.g. Li and Parrot, JGR, 2013) and Swarm (e.g. De Santis et al., SR, 2019).

\section{Earthquake Precursory Signals in Ionosphere From Swarm and CSES Satellites}

DE SANTIS, A., Istituto Nazionale di Geofisica e Vulcanologia, Roma, Italy, angelo.desantis@ingv.it; CAMPUZANO, S. A., Instituto de Geociencias
IGEO (CSIC-UCM), Madrid, Spain, saioa.arquerocampuzano@ingv.it; CIANCHINI, G., Istituto Nazionale di Geofisica e Vulcanologia, Roma, Italy, gianfranco.cianchini@ingv.it; DI MAURO, D., Istituto Nazionale di Geofisica e Vulcanologia, Roma, Italy, domenico.dimauro@ingv.it; MARCHETTI, D. Istituto Nazionale di Geofisica e Vulcanologia, Roma, Italy, dedalo.marchetti@ ingv.it; ORLANDO, M., Istituto Nazionale di Geofisica e Vulcanologia, Roma, Italy, martina.orlando@ingv.it; PERRONE, L., Istituto Nazionale di Geofisica e Vulcanologia, Roma, Italy, loredana.perrone@ingv.it; PISCINI, A., Istituto Nazionale di Geofisica e Vulcanologia, Roma, Italy, alessandro.piscini@ingv. it; SABBAGH, D., Istituto Nazionale di Geofisica e Vulcanologia, Roma, Italy, dario.sabbagh@ingv.it; SOLDANI, M., Istituto Nazionale di Geofisica e Vulcanologia, Roma, Italy, maurizio.soldani@ingv.it; SHEN, X., Space Observation Research Center, National Institute of Natural Hazards, MEMC, Beijing, China, xuhuishen@ninhm.ac.cn; ZHIMA, Z., Space Observation Research Center, National Institute of Natural Hazards, MEMC, Beijing, China, zerenzhima@qq.com

A superposed epoch and space approach is applied to abnormal variations of magnetic field and electron density as observed by Swarm and CSES satellites between +50 and -50 degrees in magnetic latitude and a worldwide dataset of shallow M5.5+ earthquakes. A statistical analysis reveals that the concentrations of anomalies found before the occurrence of earthquakes are significant higher than any homogeneous random anomaly distribution in the same time and space intervals. Focusing the attention on the cases of single bands of magnitude, the anticipation times of the ionospheric precursors tend to scale with the earthquake magnitude, as indicated by Rikitake law for ground precursors. In addition, also their duration seems to depend on the magnitude of the impending earthquake. A simple scheme of potential earthquake forecast on the base of these characteristics is finally proposed.

\section{Ionospheric Layer Variability Prior to Strong Earthquakes During Quiet Geomagnetic Conditions}

BOUDJADA, M., Austrian Academy of Sciences, Graz, Austria, moahmmed. boudjada@oeaw.ac.at; EICHELBERGER, H., Austrian Academy of Sciences, Graz, Austria, hans.ulrich.eichelberger@oeaw.ac.at; ZHANG, X., China Earthquake Administration, Beijing, China, zhangxm96@126.com; MAGNES, W., Austrian Academy of Sciences, Graz, Austria, werner.magnes@ oeaw.ac.at; DENISENKO, V., Russian Academy of Sciences, Krasnoyarsk, Russian Federation, denisen@icm.krasn.ru; POLLINGER, A., Austrian Academy of Sciences, Graz, Austria, andreas.pollinger@oeaw.ac.at; SHEN, X., China Earthquake Administration, Beijing, China, xuhuishen@ninhm.ac.cn; SCHIRNINGER, C., Austrian Academy of Sciences, Graz, Austria, christoph schirninger@oeaw.ac.at; GALOPEAU, P. H. M., LATMOS-CNRS, UVSQ Université Paris-Saclay, Guyancourt, France, patrick.galopeau@latmos.ipsl.fr; HUANG, J., China Earthquake Administration, Beijing, China, xhhjp@126. com; NESTEROV, S., Siberian Federal University, Krasnoyarsk, Russian Federation, twist3r0k@yandex.ru; SCHWINGENSCHUH, K., Austrian Academy of Sciences, Graz, Austria, konrad.schwingenschuh@oeaw.ac.at; PARROT, M., LPC2E/CNRS, Université d'Orléans, Orléans, France, michel. parrot@cnrs-orleans.fr; STACHEL, M., Austrian Academy of Sciences, Graz, Austria,manfred.stachel@oeaw.ac.at

We report on electric field measurements recorded by the Electric Field Detector (EFD) and the Instrument Champ Electrique (ICE) onboard, respectively, CSES and DEMETER satellites. We study the variations of Very Low Frequency (VLF) ground-based transmitter signals detected by both satellites during periods of low solar and geomagnetic activities. We consider the variation of VLF power spectra density in the frequency range between few Hertz to $20 \mathrm{kHz}$. We emphasize on ionospheric disturbances associated to earthquakes occurrences. Such disturbances are linked to waves generated by coupling of neutral particles and electrons related, through the atmosphere, to lithospheric ground displacements. The main peculiarities of seismic ionospheric anomalies are summarized taken into consideration technical complementary of both satellites. 


\begin{abstract}
Application of Remote Sensing and Space-Based Earth Observations Data in Earthquake Research

Poster Session · Wednesday · 21 April · 11:30 AM Pacific Session Chairs: Xuhui Shen, National Institute of Natural Hazards, MEMC (shenxh@seis.ac.cn); Dimitar Ouzounov, Chapman University (dimitar.p.ouzounov@nasa.gov);

Zhima Zeren, National Institute of Natural Hazards, MEMC (zerenzhima@qq.com); Ramesh P. Singh, Chapman University (rsingh@chapman.edu); Angelo D. Santis, Istituto Nazionale di Geofisica e Vulcanologia (angelo.desantis@ingv. it); Shun-Rong Zhang, Massachusetts Institute of Technology (shunrong@mit.edu); Jing Cui, National Institute of Natural Hazards, MEMC (jingcui_86@yahoo.com)
\end{abstract}

\section{ALOS-2 Time Series of Deformation Near the Mendocino Triple Junction \\ LINDSAY, D., University of California, Berkeley, California, USA, danielle. lindsay@berkeley.edu; BÜRGMANN, R., University of California, Berkeley, California, USA, burgmann@seismo.berkeley.edu; MATERNA, K., University of California, Berkeley, California, USA, kmaterna@usgs.gov}

We seek to separate contributions from interseismic deformation associated with plate-boundary faults and those from potential geodynamic processes around the Mendocino Triple Junction. A velocity map of Northern California for the period 2015--2020 is generated using ALOS-2 ScanSAR data. Spatially heterogeneous ionosphere delays are estimated and removed using the range split-spectrum method of Liang et. al., (2018) as implemented in ISCE. Initial mean InSAR and GNSS velocities are compared to determine the agreement between the two.

The capacity to observe vertical crustal deformation with spatial patterns spanning 10-100's $\mathrm{km}$ has been improved by the larger footprint of ALOS-2 ScanSAR frames, the extended data collection period, and the implementation of new ionosphere corrections. We investigate firstly if we can use InSAR to observe vertical deformation driven by geodynamic processes. And following, do the deformation patterns onshore from the Mendocino Triple Junction support those predicted from geodynamic processes.

\section{Analysis of Swarm Satellite Magnetic Field Data Before the 2016 Ecuador (Mw=7.8) Earthquake Based on Non-Negative Matrix Factorization}

FAN, M., Jilin University, Changchun, China, jbjwyqgmszgg@qq.com; ZHU, K., Jilin University, Changchun, China, zhukaiguang@jlu.edu.cn; HE, X., Jilin University, Changchun, China, hexd19@mails.jlu.edu.cn; LI, K., FAW Jiefang Co., Ltd., Changchun, China, 1475897252@qq.com; MARCHETTI, D., Jilin University, Changchun, China, dedalo.marchetti@ingv.it; YU, Z., Jilin University, Changchun, China, yuzn18@mails.jlu.edu.cn; CHI, C., Hainan Normal University, Haikou, China, 575104711@qq.com; SUN, H., Jilin University, Changchun, China, 1643544504@qq.com; CHENG, Y., Jilin University, Changchun, China, 547670158@qq.com

Based on the Non-negative Matrix Factorization (NMF), we analyzed the ionosphere magnetic field data of Swarm Alpha satellite before the $2016 \mathrm{Mw}=7.8$ Ecuador earthquake (April $16,0.35^{\circ} \mathrm{N}, 79.93^{\circ} \mathrm{W}$ ), including the data under quiet geomagnetic conditions and those under strong geomagnetic conditions. The data of each track were decomposed into basis features and their corresponding weights. We found that the energy and entropy for one of the weight components were more concentrated inside the earthquake-sensitive area, which meant that this weight component was more likely to reflect the activity inside the earthquake-sensitive area. Then we focused on this weight component, and found that for this weight component, the cumulative number of tracks, which had anomalies inside the earthquake sensitive area, showed accelerated growth before the Ecuador earthquake and recovered to linear growth after. Then we excluded the influence of the geomagnetic activity and the plasma bubble on the accelerated cumulative anomaly. Also, through the random earthquake study and the low-seismicity period study, the accelerated cumulative anomaly was proved not to be obtained by chance. Moreover, we found the cumulative Benioff strain $S$ which reflected the lithosphere activity, had similar acceleration behavior to the accelerated cumulative anomaly of the ionosphere magnetic field, that suggested that the anomaly we obtained were possibly associated the Ecuador earthquake and it was also correspond well to the Lithosphere Atmosphere Ionosphere Coupling (LAIC) model.

\section{LiCSAR Catalogue and Response System of Sentinel-1 Earthquake-Related Interferograms}

LAZECKY, M., University of Leeds, Leeds, United Kingdom, m.lazecky@ leeds.ac.uk; ELLIOTT, J., University of Leeds, Leeds, United Kingdom, j.elliott@leeds.ac.uk; WATSON, S., University of Leeds, Leeds, United Kingdom, c.s.watson@leeds.ac.uk; MAGHSOUDI MEHRANI, Y., University of Leeds, Leeds, United Kingdom, y.maghsoudi@leeds.ac.uk; WRIGHT, T., University of Leeds, Leeds, United Kingdom, t.j.wright@leeds.ac.uk

Global seismological catalogues are now a long-established record of worldwide seismic events, which provide important starting points for many followon studies in terms of source locations and fault parameters. Until recently, the use of geodetic datasets (particularly InSAR) for measuring deformation associated with moderate to large earthquakes has been on a case-by-case basis performed by individual research groups globally.

Here we present an emerging catalogue of earthquake deformation using the LiCSAR processing system by COMET, which harnesses the global land coverage of ESA's Sentinel-1 SAR products. The catalogue is aiming to capture continental and subduction related moderate and major events since 2015 by generating coseismic interferograms in 0.001 degrees resolution (WGS-84 system).

As part of the LiCSAR system, we have also developed a fast-responding Earthquake Interferometric Data Provider (EIDP) to generate pre-, coand post-seismic interferograms over latest earthquake events. The LiCSAR EIDP is triggered by USGS alerts following magnitude 5.5+ shallow continental and larger subduction zone earthquakes, and acts in near-real time, with latencies from when data has been ingested by ESA of a few hours. Depending upon the size of the event, the processing of postseismic data continues for weeks to months following the mainshock. Interferometric products are then served through a web portal: https://comet.nerc.ac.uk/ comet-lics-portal-earthquake-event.

The catalogue offers the prospective of being incorporated into disaster response, and the longer-term disaster risk management cycle. Next steps involve analysis of times series approaches to improve estimates of coseismic deformation and automation of modelling of individual events to provide fault parameters and uncertainties to establish a geodetic catalogue of earthquake solutions.

\section{The Changes of the Tidal Force and the Land Surface Temperature During the Indonesia Mw7.5 Earthquake} LU, X., China Earthquake Networks Center, Beijing, China, luxian@radi. ac.cn; HUANG, Q. F., China Earthquake Networks Center, Beijing, China, hfqiong@seis.ac.cn

The variation of LST (Land Surface Temperature) before and after Indonesia Mw7.5 earthquake on September 28, 2018 was studied. The LST data come from NCEP (National Center for Environmental Prediction). The background value was needed in the temperature calculation method, and the specific date of background value was determined by the analyzation of the Tidal force. The Tidal force has a certain relationship with the occurrence of earthquakes. The Mw7.5 Indonesia earthquake occurred at the peak of the Tidal force. In order to detect the cloud covered situation in the study area, the meteorological cloud maps of China FY-2F were used during the study period. Moreover, the LST data of NCEP could reduce the influence of the cloud on the land surface temperature as much as possible, and the results also proved that the LST warming caused by earthquake was showed clearly even in the period with a lot of clouds. The warming law of LST before and after Indonesia Mw7.5 earthquake was temperature increasing slightly-enhance graduallypeak of the temperature (the earthquake occurred)-temperature attenuationdisappear; in addition, the LST warming region was mainly concentrated in the Sunda Land with abundant underground heat flow near the epicenter of Indonesia Mw7.5 earthquake. In all, this study provided a more method for the earthquake exploration. 
Applications and Technologies in Large-Scale Seismic Analysis

Oral Session · Friday · 23 April · 2:00 Pм Pacific

Session Chairs: Jonathan K. MacCarthy, Los Alamos National Laboratory (jkmacc@lanl.gov); Chad Trabant, Incorporated Research Institutions for Seismology (chad@iris.washington. edu)

\section{Caltech/USGS Southern California Earthquake Data Available in the Amazon Cloud (AWS)}

YU,E., Caltech, California, USA, eyu@caltech.edu; BHASKARAN, A., Caltech, California, USA, aparnab@caltech.edu; CHEN, S., Caltech, California, USA, schen@caltech.edu; BHADHA, R., Caltech, California, USA, rayo@caltech. edu; ROSS, Z. E., Caltech, California, USA, zross@caltech.edu; HAUKSSON, E., Caltech, California, USA, hauksson@caltech.edu; CLAYTON, R. W., Caltech, California, USA, clay@gps.caltech.edu

The Southern California Earthquake Data Center (SCEDC) has made the Caltech/USGS Southern California Seismic Network (SCSN) data archive available in the cloud as part of the Amazon Open Dataset Program. The AWS bucket name is s3://scedc-pds and it is hosted in the us-west-2 (Oregon) region.

We describe the contents of this dataset and show that cloud based archives reduce time and efforts needed for completing research as compared to traditional data gathering from a data center and local data processing. We also present our reasoning behind design decisions such as archive organization and data formats and discuss what a cloud archive means for community standards in software and software APIs.

The main contents of the SCEDC/SCSN public data set are:

1. The SCSN event catalog (1932-present) and phase picks for these events in ascii format.

2. Continuous recorded waveforms (1999 to present) from 603 seismic stations recorded by the SCSN. Each file contains one channel day in mSEED format.

3. Event-windowed waveforms (1977-present) in mSEED format.

4. Metadata from CI stations in FDSN StationXML format. Users that process large volumes of data in ambient noise correlations, template matching, and machine-learning studies for example, will find that the $\mathrm{I} / \mathrm{O}$ time is considerably reduced when the processing is done in the cloud in the same AWS region (us-west-2). I/O costs from the AWS public dataset are no-cost. We have put some simple scripts and examples at https://github. com/SCEDC/cloud that can be used as templates to get started with data processing. The poster will also present cost estimates for a variety of research activities to give users an idea of the processing speed, ease of operating in the cloud, and costs incurred working with a cloud archive. Such costs can be compared with the costs of purchasing a computer server and a disk array, and weeks or months spent on downloading and processing data.

\section{Developing a Next Generation Platform for Geophysical Data in the Cloud}

TRABANT, C., Incorporated Research Institutions for Seismology, Washington, USA, chad@iris.washington.edu; MENCIN, D., UNAVCO, Colorado, USA, dmencin@unavco.org; CARTER, J., Incorporated Research Institutions for Seismology, Washington, USA, jerry.carter@iris.edu

The data service groups of IRIS and UNAVCO have embarked on a joint project to develop a Common Cloud Platform (CCP). The project aims to create a common cloud-based platform to handle the needs of both data facilities, and the communities they support, by 2023. Beyond the migration of repositories and support systems, we intend to combine components and adopt existing solutions whenever possible. Major anticipated advantages of CCP include: 1) cost-effective, 2) scalable capacity, 3) easier accommodation of new data types, and 4) simplicity. The project affords an opportunity to retire technical debt and include modernizations at a low-level to support enhanced FAIR data capabilities and identity management, while leveraging existing opensource software whenever possible.

For the research communities supported by the facilities, this new platform will offer a number of benefits. The continued operation of many current services will ensure that disruption to researchers is minimized, and, in fact, enhanced by more capacity. New services will be developed that support the discovery of data across all types of geophysical repositories managed in the platform. To address the increasing need to process large volumes of data, new capability will be developed to transfer large volumes robustly and efficiently.
A key goal is to operate the platform in an environment that would allow researchers to access and process data without transferring it over the internet. With guidance by the supported communities through the facility advisory groups and facility management, the project is currently in the planning and evaluation stages. We will report on the status of the project, anticipated directions and challenges identified.

\section{Expanding Accessibility and Scalability of Ambient Noise Seismic Data Processing Tools Through an Open-Source Cloud-Based Software Application}

SUKIANTO, T., Boise State University, Idaho, USA, theophiliasukian@u. boisestate.edu; MIKESELL, T. D., Boise State University, Idaho, USA, dylanmikesell@boisestate.edu; CLEMENTS, T., Harvard University, Massachusetts, USA, thclements@g.harvard.edu; DENOLLE, M., University of Washington, Washington, USA, mdenolle@uw.edu

Seismology has historically spearheaded the use of high-performance computing (HPC) resources for numerical modeling. However, most currently available seismic noise processing software packages are not yet adequately equipped to fully exploit such resources nor address the challenges in processing continuously-sampled seismic data on a petabyte scale. The studies that have shown such expertise may require high-level knowledge and computing skills, thus low-level accessibility to the community. Furthermore, few tools are accessible to researchers who desire to take advantage of HPC, but do not have access to a dedicated supercomputing facility. In a new project supported by Earth Science Information Partners (ESIP), we are developing an open-source, cloud-based application in order to democratize HPCenabled processing tools for high-volume seismic data. We host the application on Amazon Web Services (AWS) S3 and interface with the Incorporated Research Institutions for Seismology (IRIS) data services to query station data and metadata for seismic noise cross-correlation. To maximize efficiency on large datasets, the correlation processing is parallelized in Julia, a modern computing language developed to make full use of HPC resources from the cloud. In this way, the cross-correlations are able to be conducted from a laptop or workstation. This project is a gateway to further development beyond noise cross-correlation so that ultimately, anyone can process and interpret high-volume seismic data. In this presentation we report on the current state of this project and discuss future directions.

\section{Preparing (for) Seismic Data in the Cloud}

MACCARTHY, I. K., Los Alamos National Laboratory, New Mexico, USA, jkmacc@lanl.gov; MARCILLO, O. E., Oak Ridge National Laboratory, Tennessee, USA, marcillooe@ornl.gov

As research in seismology continues to identify valuable new signals in evergrowing data streams, it becomes more important to explore tools and platforms that can scale from small exploratory analyses to large survey-style applications. The commercial cloud offers a diverse and powerful platform to quickly perform large-scale research, but it also comes with a number of practical challenges. Much existing research software in seismology was not designed for a remote distributed system like the cloud, there is a significant learning curve in using a such a system, and common seismic formats, such as miniSEED, SAC, or ASDF may not be optimal for access on distributed systems where the balance between compression, file size, and network communication is different compared to local or HPC systems. In this work, we use the Xarray, Dask, and Zarr libraries in the Python software ecosystem to address some of the challenges outlined above. We perform a seismic noise analysis using the Amazon Web Services cloud platform to demonstrate an interactive and fully in-cloud research workflow that accelerates time-to-result.

\section{The Influence of Geography and Geology in Seismic Background Noise Levels Across the United States as Revealed by the Transportable Array}

ANTHONY, R., U.S. Geological Survey, New Mexico, USA, reanthony@usgs. gov; RINGLER, A., U.S. Geological Survey, New Mexico, USA, aringler@usgs. gov; WILSON, D., U.S. Geological Survey, New Mexico, USA, dwilson@usgs. gov; MACCARTHY, J. K., Los Alamos National Laboratory, New Mexico, USA, jkmacc@lanl.gov; KOPER, K. D., University of Utah, Utah, USA, koper@seis.utah.edu

The EarthScope USArray Transportable Array (TA) has now covered the US with 3-component broadband seismometers at approximately $70 \mathrm{~km}$ station spacing and deployment durations of approximately 2 years. This unprecedented coverage, combined with high-quality and near homogenous installation techniques, offers a novel dataset in which to characterize spatially varying levels of background seismic noise across the United States. We present 
background noise maps in period bands of interest to earthquake and imaging seismology across the US (lower 48 states and Alaska). Early results from the contiguous 48 states demonstrate that ambient noise levels within the body wave period band (1-5 s) vary by $>20 \mathrm{~dB}\left(\mathrm{rel} .1\left(\mathrm{~m} / \mathrm{s}^{2}\right)^{2} / \mathrm{Hz}\right)$ with the highest noise levels occurring at stations located within sedimentary basins and lowest within the mountain ranges of the Western US. Additionally, stations around the Great Lakes observe heightened noise levels in this band beyond the aforementioned basin amplification. We attribute this observation to local swell activity in the Great Lakes generating short-period microseism signals. This suggests that lake-generated microseisms may be a significant source of noise for Alaskan deployments situated in close proximity to lakes to facilitate float plane access. We further investigate how basin amplification and shortperiod lake microseism signals may noticeably impact detection and signalto-noise of teleseismic body wave signals during certain time periods. At longer-periods (> $20 \mathrm{~s}$ ), we generally observe larger noise levels on the horizontal components of stations situated in basins or on soft sediment, likely caused by locally induced tilt of the sensor. We will present similar analysis from the initial Alaska TA dataset to quantitatively assess how utilization of posthole sensors affects signal-to-noise for the long-period horizontal wavefield.

Back to the Future: Innovative New Research with Legacy

\section{Seismic Data}

Oral Session · Monday · 19 April · 5:00 PM Pacific

Session Chairs: Garrett G. Euler, Los Alamos National

Laboratory (ggeuler@lanl.gov); Brian Young, Sandia National

Laboratories (byoung@sandia.gov); Ana C. Aguiar Moya,

Lawrence Livermore National Laboratory (aguiarmoya1@llnl. gov); Thomas Lee, Harvard University (thomasandrewlee@g. harvard.edu); Qi Ou, University of Oxford (qi.ou@earth.

ox.ac.uk); Richard Lewis, Defense Threat Reduction

Agency (richard.d.lewis1.civ@mail.mil); James Dewey, U.S.

Geological Survey (jdewey@usgs.gov)

\section{Can the Copy Fully Replace the Original: Fidelity of Legacy Seismic Data}

LEE, T. A., Harvard University, Massachusetts, USA, thomasandrewlee@g. harvard.edu; ISHII, M., Harvard University, Massachusetts, USA, ishii@eps. harvard.edu; OKUBO, P., The University of Hawai'i at Mānoa, Hawaii, USA, okubop@hawaii.edu

Over the long recording history of seismology, seismic data have been stored on many different types of media. Two of the most prolific among these are the original paper records and the corresponding microfiche with replicate seismograms. Today, there still exist large archives of both of these media, and it is highly likely that there exists overlap between these collections. Under the assumption that the microfiche records are exact duplicates of the original recordings, holders of paper collections may come under pressure to discard these bulky records in order to use the storage space for other purposes. However, before a decision can be made, it is necessary to understand what limitations exist for seismic data digitized from microfiche as opposed to from the original paper. While seismic data on microfiche can generally be recovered with similar fidelity to that on paper, we undertake a detailed comparison between corresponding records to note the existence of important differences. These arise mainly from distortion of the images, and the resolution and tonal-depth of scans. These effects can give rise to inaccuracies in the timing of records and in the recovery of data from large amplitude traces. Dependent upon the scientific problem, these issues can lead to misinterpretation. For example, the loss of information in the microfiche record indicate that earthquake signals with large undulations can become difficult to detect or digitize while they may be clearly perceptible in the paper version. Additionally, non-linear distortion in time may provide inaccurate timing of various phase arrivals and hence, inaccurate differential travel times with implications for topics like inner-core super-rotation. More broadly, when decisions regarding the allocation of resources for legacy data preservation efforts are made, it is crucial that the larger size and weight of the original paper records are balanced with the generally higher fidelity of data recoverable from these "master" copies of records.

\section{Searching for the Oldest Seismogram}

RADEMACHER, H., University of California, Berkeley, California, USA, horst@berkeley.edu

Several of the earliest seismograms still in existence - either in their original, as a copy or as a facsimile reproduced in a publication - from the last two decades of the 19th century will be shown. I present what I found to be the oldest existing records from North America, Europe and Asia. The oldest record currently known is a recording of a strong local earthquake in the Tokyo region on 8 March 1881. I ask all members of the seismological community to prove me wrong and point to seismograms recorded at an even earlier date.

\section{Securing Seismic Legacy Data}

HWANG, L. J., University of California, Davis, California, USA, ljhwang@ ucdavis.edu; AHERN, T., IRIS, Emeritus, Washington, USA, tim-ahern@ comcast.net; EBINGER, C., Tulane University, Louisiana, USA, cebinger@ tulane.edu; ELLSWORTH, W. L., Stanford University, California, USA, wellsworth@stanford.edu; EULER, G. G., Los Alamos National Laboratory, New Mexico, USA, ggeuler@lanl.gov; OKAL, E., Northwestern Univeristy, Illinois, USA, e-okal@northwestern.edu; OKUBO, P., University of Hawaii at Manoa, Hawaii, USA, okubop@hawaii.edu; WALTER, W. R., Lawrence Livermore National Laboratory, California, USA, walter5@llnl.gov

New seismological data mining methods are supporting discoveries and cross-disciplinary research across Earth system science. Modern research methods are currently limited by the relatively short time period of observation for which digital records are readily available. Historical data, recorded on paper and other physical media, extend the time period of Earth observation to many decades. However, if such data are to be preserved and made available digitally to harness the data revolution there are significant challenges to overcome. Among these are dispersal of historical data across multiple institutions, the loss of the physical media, and the retirement of the last generation of scientists knowledgeable in their use and collection. If converted to digital media, these collections conservatively represent upwards of 100 's of petabytes of raw data.

To confront these challenges, the first U.S. workshop focused on seismic legacy data, the 2019 Securing Legacy Seismic Data to Enable Future Discoveries, was held September 18-19, 2019 in Albuquerque, New Mexico. Building upon community interests, the workshop activities were designed to lay the foundation to progress on two broad goals: developing the framework for preservation of longitudinal seismic data and creating an interdisciplinary network of data, domain, and computational scientists to facilitate management, access, and use of digitally imaged legacy data. The workshop engaged an international group of researchers representing universities, national laboratories, and governmental agencies over two days in discussions that included science drivers, new and old, and the state of preservation of collections worldwide.

The workshop participants outlined 8 community needs to advance these goals: creating a catalog of analog data, creating a publications database that use analog data, creating metadata standards, establishing a pilot project, enabling future research, identifying enabling technologies, attracting a crossdisciplinary community of users, and enlarging the user community through outreach.

\section{Source Characterization of 1944 Tonankai Earthquake from Observed and Simulated Damage Ratios Based on the Stochastic Representation of Complex Source Process and Damage Prediction Models for Old Wooden Houses}

ITO, E., Disaster Prevention Research Institute, Kyoto University, Uji, Japan, ito@sere.dpri.kyoto-u.ac.jp; NAKANO, K., Technical Research Institute, HAZAMA-ANDO CORP., Tsukuba, Japan, nakano.kenichi@ad-hzm.co.jp; SEKIGUCHI, H., Disaster Prevention Research Institute, Kyoto University, Uji, Japan, sekiguchi.haruko.6u@kyoto-u.ac.jp; KAWASE, H., Disaster Prevention Research Institute, Kyoto University, Uji, Japan, kawase@sere.dpri. kyoto-u.ac.jp

It is very important to investigate the complex source process of repeated subduction-zone earthquakes for quantitative seismic hazard assessment. However, quantification of the rupture process for an earthquake before the implementation of strong-motion networks is difficult, if not impossible. In this study, we try to delineate the complex rupture process from the observed structural damage distribution in the past, instead of strong-motion records, based on the simulated strong motions and damage prediction models for old wooden-houses in Japan. We start to reproduce the observed damage ratios during the 1944 Tonankai earthquake, in which we have more than 50 cities 
and towns with reliable damage ratios higher than $1 \%$. The strong ground motion waveforms are obtained from the statistical Green's function and the heterogeneous source model. The site characteristic is obtained by our original method of converting the theoretical S-wave characteristic from the unified velocity model (by NIED) above the seismological bedrock in the Kanto and Tokai regions to the empirical site characteristics derived by the generalized spectral inversion. We first construct a heterogeneous source model with four asperities (SMGAs) as a standard model and prepare 36 heterogeneous source models in total, varying parameters of which are the location of hypocenters, the location of asperities, and their stress drops. Then, we calculate the strong ground motions from the prescribed complex source models and estimate the damage ratios of wooden houses using the corresponding damage prediction models as of 1944 to compare them with the observed damage ratios during the 1944 Tonankai earthquake. We found that the case with the second asperity stress drop of $60 \mathrm{MPa}$ is the model that best explains the observed damage ratios. The proposed damage prediction scheme and the observed damage ratios provide us a prospect to clarify the detailed source rupture processes of the historical mega-thrust earthquakes in Japan.

\section{Using Legacy Data to Improve Seismic Hazard Assessments in the Caucasus}

ONUR, T., Onur Seemann Consulting, Inc., Victoria, Canada, tuna@ onurseemann.com; GÖK, R., Lawrence Livermore National Lab, California, USA, gok1@llnl.gov; BONDÁR, I., Research Centre for Astronomy and Earth Sciences, Budapest, Hungary, bondar.istvan@csfk.mta.hu; HERRERA, C., University of Victoria, Victoria, Canada, carlosfherrera@ uvic.ca; YETIRMISHLI, G., Azerbaijan National Academy of Sciences, Baku, Azerbaijan, gyetirmishli@gmail.com; GODOLADZE, T., Ilia State University, Tbilisi, Georgia, tea_godoladze@iliauni.edu.ge

Significant amounts of earthquake bulletin, catalogue and waveform data from Soviet era are kept in seismological institutions across the Caucasus. Much of the data is in paper archives and slowly deteriorating. Lawrence Livermore National Laboratory, through the Seismic Cooperation Program, initiated a project to systematically digitize these paper based bulletins and waveforms in the past five years. The project allowed many previously unreported events to be added to the region's earthquake catalogue. We present a new probabilistic seismic hazard assessment for Azerbaijan taking advantage of this new dataset. The digitization of the data allowed relocation of earthquakes, which previously had low resolution locations, concentrated on grid points. In addition, it allowed direct calculation of moment magnitudes for over 100 events for which Soviet era magnitudes (including K Class) were also available (using data from co-located analogue and digital instruments), providing us with a solid basis to generate magnitude conversion relations specific to this region. In addition to the new hazard results, we present sensitivity analyses related to seismic source and ground motion characterization in Azerbaijan.

\begin{tabular}{l}
\hline Back to the Future: Innovative New Research with Legacy \\
Seismic Data \\
Poster Session· Monday · 19 April · 11:30 AM Pacific \\
Session Chairs: Garrett G. Euler, Los Alamos National \\
Laboratory (ggeuler@lanl.gov); Brian Young, Sandia National \\
Laboratories (byoung@sandia.gov); Ana C. Aguiar Moya, \\
Lawrence Livermore National Laboratory (aguiarmoya1@llnl. \\
gov); Thomas Lee, Harvard University (thomasandrewlee@g. \\
harvard.edu); Qi Ou, University of Oxford (qi.ou@earth. \\
ox.ac.uk); Richard Lewis, Defense Threat Reduction \\
Agency (richard.d.lewis1.civ@mail.mil); James Dewey, U.S. \\
Geological Survey (jdewey@usgs.gov)
\end{tabular}

\section{Creating Fair Legacy Seismic Data}

AHERN, T., IRIS, Emeritus, Washington, USA, tim-ahern@comcast.net; HWANG, L. J., University of California, Davis, California, USA, ljhwang@ ucdavis.edu

Efforts to preserve analog seismic data and make them available digitally are underway at a limited number of institutions world-wide. While these preservation efforts provide leadership in best practices in conservation, imaging, and vectorization, little community discussion has transpired on standards and how the collections can meet FAIR data principles. That these data be
Findable, Accessible, Interoperable, and Reusable provides guidance for data management and stewardship in the modern digital ecosystem allowing centers managing these products to develop uniform tools for discovery and return legacy data in formats and accompanied with metadata to ensure its usability. Establishing standards before significant work begins will help to ensure continuity and consistency in data preservation projects, high-quality products, and comprehensive capture of key information.

A focus of 2019 Securing Legacy Seismic Data to Enable Future Discoveries held September 18-19, 2019 in Albuquerque, New Mexico was to understand the preservation lifecycle and research uses towards identifying the core metadata for legacy data preservation and use. Prior to the workshop individuals representing 10 projects worldwide identified 39 metadata elements. These elements were grouped into 6 broad categories that parameterized the data: 1) Time of Data, 2) Station/Channel, 3) Sensor, 4) Recording System, 5) Image File, and 6) Other. Workshop participants were asked to consider each of the elements and identify whether they should be Required, Recommended, Optional, or Omitted. Participants also requested 20 other elements be added. These metadata elements and survey results will be presented. Based on the results of this initial metadata survey and meeting feedback, the next activity will be to incorporate the new and/or modified elements into an updated survey and submit it to the international community for broader consideration and consensus. This will set the stage for FAIR legacy data.

This presentation will update the community on the current state of standards for legacy data.

\section{ISC-EHB Dataset for 1964 to 2017: Complementing the Bulletin with In-House Depth Phase Picks}

SAKARYA, B., International Seismological Centre, Thatcham, United Kingdom, burak@isc.ac.uk; ENGDAHL, E. R., University of Colorado, Colorado, USA, bob.engdahl@colorado.edu; GKARLAOUNI, C. G., International Seismological Centre, Thatcham, United Kingdom, hara@isc. ac.uk; GARTH, T. I. M., International Seismological Centre, Thatcham, United Kingdom, tom.garth@isc.ac.uk; FRANEK, P., International Seismological Centre, Thatcham, United Kingdom, peterf@isc.ac.uk; HARRIS, J., International Seismological Centre, Thatcham, United Kingdom, james@ isc.ac.uk; DI GIACOMO, D., International Seismological Centre, Thatcham, United Kingdom, domenico@isc.ac.uk; STORCHAK, D. A., International Seismological Centre, Thatcham, United Kingdom, dmitry@isc.ac.uk

The original EHB dataset, as developed with procedures described by Engdahl et al. (1998), has been widely used in the past in various types of earth science studies. The original EHB stopped in 2008, and since then the volume and quality of data has significantly improved. To take this into account we have re-constructed the ISC-EHB dataset for the period 1964-2017 with the updated criteria defined in Weston et al. (2018). Event selection for the ISCEHB is made from the Reviewed ISC Bulletin, and ISC Bulletin relies on data contributed by seismological agencies from around the world. In the past decade there has been a consistent decline in the number of depth phase picks reported to the ISC. Depth phases are crucial for the ISC-EHB dataset as they directly influence the quality of the depth constraint. In order to address this issue, we have been routinely picking depth phases for earthquakes across the globe with $\mathrm{mb}^{\text {NEIC }} \geq 4.8$ recorded at $28^{\circ}-72^{\circ}$ distance range and data period from April 2016 using SeisAn Earthquake analysis software (Havskov and Ottemoller, 1999).

In this contribution we describe the procedures used to construct the newly refined ISC-EHB dataset covering earthquakes from 1964 to 2017 We also illustrate noteworthy features in several regions, including some of those presented in Engdahl et al. (2020). The ISC-EHB now includes 177,416 earthquakes with prime magnitude $>3.75$. This advanced dataset of wellrecorded seismic events can be used for regional and global seismicity and tomographic studies, especially in subduction zones where significant spatial and structural characteristics are revealed. The ISC-EHB is now one of the most refined global seismicity catalogues and is freely available from the ISC website (www.isc.ac.uk/isc-ehb), where seismicity maps and cross sections along all subduction zones are shown. The ISC-EHB dataset will be extended beyond the data year 2017 as soon as the review of each following annual ISC Bulletin is completed.

\section{Reinvestigation of the Major Early to Mid 20th Century Earthquakes of Central Asia}

WALKER, R., University of Oxford, Oxford, United Kingdom, richard. walker@earth.ox.ac.uk; BERGMAN, E., Global Seismological Services, Colorado, USA, bergman@seismo.com; GRUETZNER, C., Friedrich-Schiller University, Jena, Germany, christoph.gruetzner@uni-jena.de; KRUEGER, F., University of Potsdam, Potsdam, Germany, frank.krueger@geo.uni-potsdam. de; KULIKOVA, G., University of Potsdam, Potsdam, Germany, galina 
kulikova@yahoo.com; OU, Q., Oxford University, Oxford, United Kingdom, qi.ou@earth.ox.ac.uk

We have only a very small database of modern examples for understanding the occurrence, style, and potential magnitudes of large earthquakes in continental interior settings. A number of large earthquakes that occurred within the interior of Asia in the early to mid-20th century are therefore of particular importance, in allowing us to explore scaling between slip, length and magnitude, and to assess the complexity of rupture. They also form an important bridge between the modern and historical eras as they allow direct comparison of early instrumental seismic data, historical documentary data, and the source parameters gleaned from study of the preserved surface ruptures. These studies fit within a new program, funded by the Leverhulme Trust, aimed at improving and enlarging the database of well-studied large magnitude continental interior earthquakes through a comprehensive mapping and forensic study of their ruptures, ancient and modern, across the interior of Asia. Our study encompasses a region spanning from Iran in the west, through the ex-soviet Central Asian republics, to China in the East. The program combines investigation of the major $20^{\text {th }}$ century earthquakes, in which we combine seismological investigation of source parameters and location with field-based and remote sensing investigation of the surface ruptures and long-term geomorphic expression of faulting. This combination of methods enable identification, mapping, and characterisation of the causative active faults and rupture processes with detail.

\section{Rotation and Structure of the Inner Core Illuminated by Repetitive Ancient Nuclear Tests}

VIDALE, J. E., University of Southern California, California, USA, jvidale@ usc.edu; WANG, W., University of Southern California, California, USA, wwang071@usc.edu

We are continuing to examine waves backscattered from within the inner core, which can robustly evaluate rotation and locate fine-scale structural heterogeneities. The rate that Earth's inner core (IC) rotates relative to the mantle has been debated for decades. Non-rotational processes, including internal deformation and flow in the outer core, have also been proposed to explain observed seismic changes. Delineating and interpreting internal IC structure has proven challenging.

We look at three pairs of nuclear tests that are one to three years apart, which are a subset of the 73 globally distributed events recorded on the superb LASA array in Montana, summarized by Wang \& Vidale (this meeting). The waves follow after PKiKP, in the subsequent 250s, scattered during two pairs of large nuclear tests in Novaya Zemlya, Russia, one in 1971 and 1974, the other in 1973 and 1974, and a pair in 1969 and 1971 in Amchitka Island, Alaska. We are extending our previous analysis of these explosions using precise station corrections, the full Large Aperture Seismic Array, more sophisticated trace selection based on correlation between the pair of events, and knowledge of which arrivals changed over the years.

We confirm the rate of $0.07^{\circ}$ year inner core super-rotation derived from 1971 to 1974 . For the rest of the results, come to the presentation to see what's new.

\section{Rupture History of the 1952 Kern County, California Earthquake: Application of Historical Seismic and Geodetic Datasets}

CONDON, S. J., AECOM, California, USA, scott.condon@aecom.com; JI, C., University of California, Santa Barbara, California, USA, ji@geol.ucsb.edu

Today we have the ability to resolve details surrounding historic earthquakes through modern analysis of historical datasets. Here, combining reported geodetic observations with a collection of previously unused strong-motion seismic recordings, we conduct a series of inversions to constrain a slip model for the 1952 Kern County, California earthquake (one of the largest events to strike California). Our analysis suggests that the 1952 event initiated with a strike-slip dominant nucleation-event on a low-angle fault plane ( strike $=49 \pm 3^{\circ}$; $\operatorname{dip}=35 \pm 1^{\circ}$; and rake $=11 \pm 5^{\circ}$ ) that subsequently triggered an abnormally energetic rupture on a high-angle fault plane (strike $=51^{\circ}$, dip $=$ $75^{\circ}$ ). Shortly thereafter, the rupture propagated northeast along the White Wolf fault releasing $7.61 \times 10^{19} \mathrm{Nm}$ cumulative moment $\left(\mathrm{M}_{\mathrm{W}}\right.$ 7.18) over 23-26 s. The powerful sub-event contained within a $9 \times 6 \mathrm{~km}$ patch near the earthquake hypocenter accumulates 6-7 $\mathrm{m}$ of slip and releases a significant amount of static stress (average static stress-drop larger than $50 \mathrm{MPa}$ ). The majority of moment-release occurs within the southwest portion of White Wolf fault, located between Wheeler Ridge and Comanche Point. The weightedaverage rake-angle over this section is $47-57^{\circ}$, which falls between previous results based on individual seismic or geodetic datasets. Investigation into the regional velocity structure reveals that high $\mathrm{P}$-wave and S-wave velocities are coincident with regions of high slip in our model.

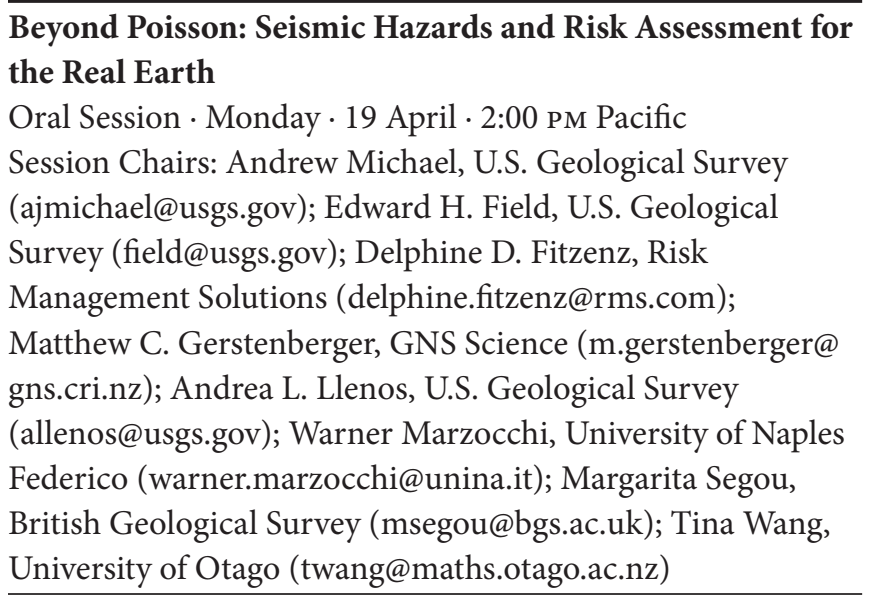

\section{Embracing Data Incompleteness for Better Earthquake Forecasting}

MIZRAHI, L., Swiss Seismological Service, ETH Zürich, Zürich, Switzerland, leila.mizrahi@sed.ethz.ch; NANDAN, S., Swiss Seismological Service, ETH Zürich, Zürich, Switzerland, snandan@ethz.ch; WIEMER, S., Swiss Seismological Service, ETH Zürich, Zürich, Switzerland, stefan.wiemer@sed. ethz.ch

The magnitude of completeness $m_{c}$ of an earthquake catalog is of crucial importance for any statistical analysis of seismicity, and hence for PSHA. The threshold magnitude above which all earthquakes are assumed to be detected has been found to vary with space and time, depending in the longer term on the configuration of the seismic network, but also depending on temporarily increased seismicity rates in the form of short-term aftershock incompleteness. Most seismicity studies assume a constant $m_{c}$ for the entire catalog, enforcing a compromise between deliberately misestimating $m_{c}$ and excluding large amounts of valuable data.

Epidemic-Type Aftershock Sequence (ETAS) models have been shown to be the most successful earthquake forecasting models, both for short- and long-term hazard assessment. To be able to leverage historical data with high $m_{c}$ as well as modern data which is complete at low magnitudes, we developed a method to calibrate the ETAS model when time-varying completeness magnitude $m_{c}(t)$ is given as a step function. As a further refinement of the model, we designed a self-consistent algorithm to jointly estimate high-frequency detection incompleteness and ETAS parameters. For this, we generalized the concept of $m_{c}$ and consider a rate- and magnitude-dependent detection probability - embracing incompleteness instead of avoiding it.

Preliminary results of pseudo-prospective forecasting experiments in California indicate that the newly gained information leads to significantly improved forecasts. Two features of our model are distinguished: Small earthquakes are allowed and assumed to trigger aftershocks, and ETAS parameters are estimated differently. We compare the forecasting performance of a model having both features, and two additional models each having one of the features, to the current state-of-the-art base model. This will shed light on which aspect is the most promising to pursue in the search of the next generation earthquake forecasting model.

\section{How Well Does Poissonian PSHA Approximate Hazard Implied by Clustered Seismicity? A Synthetic Study} WANG, S., Institute of Geophysics, China Earthquake Administration, Beijing, China, hnnxwshq@126.com; WERNER, M. J., School of Earth Sciences, University of Bristol, Bristol, United Kingdom, max.werner@bristol. ac.uk; YU, R., Institute of Geophysics, China Earthquake Administration, Beijing, China, yrfang126@126.com

Classical Poissonian probabilistic seismic hazard assessment (PSHA) determines rates of mainshocks by removing foreshocks and aftershocks. However, earthquakes and ground motions cluster in multi-generational cascades of triggered seismicity. Here, we assess how well classical declustered Poissonian (DP) and nondeclustered (NDP) PSHA, and single-generation Sequencebased PSHA (SPSHA, Iervolino et al., 2014) approximate the hazard levels implied by the Epidemic Type Aftershock Sequence (ETAS) model. For sim- 
plicity, we focus on the time domain. We simulate a 5-million-year ETAS cata$\log$ of seismicity and ground motions. We then take these as quasi-real, use the above methods to assess hazard and compare with the ETAS-implied hazard. The degree to which traditional PSHA and SPSHA approximate ETAS-PSHA depends on probability levels and engineering demands. At design-oriented probability levels (2\% and $10 \%$ in 50 years), DP-PSHA under-estimates, and NDP-PSHA and SPSHA over-estimate, ETAS-PSHA by less than 7\%, suggesting the approximations work well at these levels. For probability levels larger than $\sim 45 \%$ in 50 years, all methods over-estimate ETAS-PSHA: DP-PSHA by at most $7 \%$; NDP-PSHA and SPSHA by at least $8 \%$ and $12 \%$, respectively. This is due to higher median and mode seismicity rates estimated by the methods than implied by ETAS. Greater differences appear in the hazard curves of multiple exceedances, important for cumulative damage assessments. At and below $2 \%$ in 50 years, the probabilities of at least 5 and 10 exceedances are underestimated by more than $25 \%$ by traditional PSHA and SPSHA. Finally, we present a new simple model of the ensemble-averaged decay of hazard after large quakes that shows it can take years to centuries for the conditional hazard after M6.5 to M9 events to return to the long-term average. We conclude that refined PSHA should consider the influence of ETAS-like earthquake cascades for select engineering demands.

\section{MMPP Models of Background Seismicity: A Comparative} Analysis for Different Declustering Algorithms

VARINI, E., Consiglio Nazionale delle Ricerche, Istituto di Matematica Applicata e Tecnologie Informatiche "Enrico Magenes", Milano, Italy, elisa.varini@cnr.it; PERESAN, A., Institute of Oceanography and Applied Geophysics, Seismological Research Centre, Udine, Italy, aperesan@inogs it; BENALI, A., Université Des Sciences Et de La Technologie Houari Boumediene, Département de Probabilités Et Statistiques, Faculté Des Mathématiques, Algiers, Algeria, benali.amel1992@gmail.com

Declustering a seismic catalog is a relevant preliminary step in many applications, such as earthquake forecasting and seismic hazard assessment Declustering aims partitioning an earthquake catalog into background seismicity, which is supposed to reflect the steady tectonic loading, and clustered seismicity, which is formed by dependent events, possibly reflecting the transient changes in the stress field in the aftermath of moderate and large earthquakes occurrence. Accordingly, various methods have been proposed in the literature for declustering seismic catalogs; however, their application to a given catalog may discriminate differently between background and clustered events. Hence the need to compare the different declustered versions of a catalog, with the aim of identifying common features relevant for background seismicity modeling.

In this study we compare the background time series obtained from two data-driven declustering algorithms: the nearest-neighbor (Zaliapin and BenZion, J Geophys Res, 2013), which classifies the earthquakes on the basis of a nearest-neighbor distance between events in the space-time-energy domain, and the stochastic declustering (Zhuang et al., J Geophys Res, 2004), which is based on the space-time ETAS point process model.

The steps of our analysis are as follows (Benali et al., Stoch. Environ Res Risk Assess, 2020). Once the background sequences are obtained from the two declustering methods, we investigate if they meet the stationary Poissonian assumption by performing suitable statistical tests. In case the simple Poissonian hypothesis is rejected, then we resort to a model capable to capture the possible heterogeneity in the background time series. Specifically, we propose the Markov modulated Poisson process, which allows the Poisson seismicity rate to change over time, according to a finite number of states of the system. We exemplify the analysis for two different seismic regions: North-Eastern Italy and Central Italy.

\section{Modeling Earthquake Occurrence and Recurrence for Supercycles and Clusters}

NEELY, J. S., Northwestern University, Illinois, USA, james@earth. northwestern.edu; SALDITCH, L., Northwestern University, Illinois, USA, leah@earth.northwestern.edu; STEIN, S., Northwestern University, Illinois, USA, s-stein@northwestern.edu; SPENCER, B. D., Northwestern University, Illinois, USA, bspencer@northwestern.edu

Long records often show large earthquakes occurring in supercycles-temporal clusters of seismicity, cumulative displacement, and cumulative strain release separated by less active intervals. Presently used earthquake recurrence models do not account for the time dependence and clustering. Poisson models assume that earthquake recurrence is time-independent, but seismicity studies have shown that time is needed to accumulate strain along a fault before another large earthquake. Seismic cycle/renewal models account for this time-dependence but assume that all strain is released after large earth- quakes and fail to replicate clustered earthquake behavior. The resulting probability estimates for recurrence of the next earthquake thus depend crucially on whether the cluster is treated as ongoing or over.

In this study, we have reformulated our previously developed Long-Term Fault Memory (LTFM) earthquake model as a Markov process to better quantify long-term earthquake behavior and the probability of future earthquakes. In the LTFM model, the probability of a large earthquake reflects accumulated strain rather than elapsed time. The probability increases with accumulated strain (and time) until an earthquake happens, after which the probability decreases, but not necessarily to zero. This simple, strain-driven recurrence model yields realistic sequences of large earthquakes with periods of elevated activity followed by longer quiescence. Using the Markov formulation, we explore long-term earthquake behavior and how to use paleoseismic records to better estimate the recurrence and probability of future large earthquakes.

\section{Removing the Poisson Assumption From Probabilistic Seismic Hazard Assessment Without Paying the Penalty} MICHAEL, A., U.S. Geological Survey, California, USA, ajmichael@usgs.gov; LLENOS, A. L., U.S. Geological Survey, Colorado, USA, allenos@usgs.gov

In his seminal paper on Probabilistic Seismic Hazard Assessment (PSHA) Allin Cornell wrote, "the assumption that the occurrences of earthquakes follow the behavior of the Poisson process model can be removed only at a great penalty" (Cornell, BSSA, 1968). Cornell suggested that the Poisson assumption was sufficient for the low exceedance probabilities over the long timescales used for many engineering purposes (e.g., $2 \%$ in 50 years), even if it was inconsistent with both elastic rebound and the occurrence of aftershocks. That view was supported by Marzocchi and Taroni (BSSA, 2014). However, they also showed that the assumption breaks down for higher probabilities and shorter periods of time. Therefore, the Poisson assumption may not be sufficient for the higher exceedance probabilities currently used for infrastructure operating standards or for the shorter time periods and considerations of multiple exceedances used in the insurance industry. While simulations can be used to compute seismic hazard including behavior such as aftershocks (e.g. Field et al., BSSA, 2017), the computational requirements may be daunting for many applications. In fact, a clear goal of Cornell was an analytic model to allow users to explore the impact of a variety of parameters. We introduce an analytic method for PSHA that allows for arbitrary distributions of earthquake occurrence and that satisfies Cornell's goal without an appreciable computational penalty. We apply this method to the highly clustered seismicity associated with caldera collapses at Kilauea and explore the implications of non-Poissonian behavior for PSHA as a function of the degree of clustering in seismicity. Understanding the difference between a non-Poissonian distribution and a Poisson distribution with the same mean rate requires examining the probability, rather than the commonly used rate, of exceedance. Thus, including non-Poissonian behavior in PSHA requires changing how we plot and talk about hazard.

\section{Beyond Poisson: Seismic Hazards and Risk Assessment for} the Real Earth

Poster Session · Monday · 19 April · 11:30 Am Pacific Session Chairs: Andrew Michael, U.S. Geological Survey (ajmichael@usgs.gov); Edward H. Field, U.S. Geological Survey (field@usgs.gov); Delphine D. Fitzenz, Risk Management Solutions (delphine.fitzenz@rms.com); Matthew C. Gerstenberger, GNS Science (m.gerstenberger@ gns.cri.nz); Andrea L. Llenos, U.S. Geological Survey (allenos@usgs.gov); Warner Marzocchi, University of Naples Federico (warner.marzocchi@unina.it); Margarita Segou, British Geological Survey (msegou@bgs.ac.uk); Tina Wang, University of Otago (twang@maths.otago.ac.nz)

Aftershocks Preferentially Occur in Previously Active Areas PAGE, M. T., U.S. Geological Survey, California, USA, mpage@usgs.gov

The clearest statistical signal in aftershock locations is that most aftershocks occur close to their mainshocks. More precisely, aftershocks are triggered at distances following a power-law decay in distance (Felzer and Brodsky, 2006). This distance decay kernel is used in Epidemic-type Aftershock Sequence 
(ETAS) modeling and is typically assumed to be isotropic, even though individual sequences show more clustered aftershock occurrence. The assumption of spatially isotropic triggering kernels can impact the estimation of ETAS parameters themselves, such as biasing the magnitude-productivity term alpha and assigning too much weight to secondary rather than primary (direct) triggering. Here we show that aftershock locations, at all mainshockaftershock distances, preferentially occur in areas of previous seismicity.

\section{Assessing the Hazard of Highly Clustered M 5 Caldera Collapse Earthquakes in Kīlauea Volcano, Hawai'i}

LLENOS, A. L., U.S. Geological Survey, Colorado, USA, allenos@usgs.gov; MICHAEL, A., U.S. Geological Survey, California, USA, ajmichael@usgs.gov; MOSCHETTI, M. P., U.S. Geological Survey, Colorado, USA, mmoschetti@ usgs.gov; POWERS, P. M., U.S. Geological Survey, Colorado, USA, pmpowers@usgs.gov; MCNAMARA, D. E., U.S. Geological Survey, Colorado, USA, daniel.e.mcnamara@gmail.com; PETERSEN, M. D., U.S. Geological Survey, Colorado, USA, mpetersen@usgs.gov

The complicated volcanic and tectonic processes in Hawai'i present challenges for estimating the probabilities of earthquakes using methods developed for standard probabilistic seismic hazard analysis (PSHA). A particular problem is that the volcanic processes vary over time, and PSHA usually considers only tectonic earthquakes with stationary rate. A distinct challenge lies in quantifying the hazard due to seismicity associated with the 2018 Kilauea eruption and the collapse of the summit caldera. During the eruption, $\mathrm{M} \sim 5$ caldera collapse earthquakes, characterized by long period ground motions, occurred almost daily from mid-May until the beginning of August. While such caldera collapses happen infrequently, these caldera collapse earthquakes damaged nearby structures, and these events should therefore be included in a complete seismic hazard assessment. We present an approach to forecast the rate of these caldera collapse events for use in seismic hazard assessments. We model their occurrence by combining a distribution for the occurrence of the underlying process of caldera collapses with a distribution for the number of earthquakes that occur in response to those collapses. We use a Poisson distribution for the number of collapses and a negative binomial distribution for the number of earthquakes in a collapse, using distribution parameters based on historical observations at Kilauea. This rate model can then be combined with an appropriate ground motion model that accounts for the deficiency in short period ground motions observed in 2018 to assess the seismic hazard posed by caldera collapse events. The event occurrence model is non-Poissonian but can be approximated as Poissonian for low exceedance probabilities (e.g., $<10 \%$ in 50 years). This approach could also be used more generally to model the hazard due to aftershocks, which can be considered the earthquake response to the underlying process of mainshocks.

\section{Earthquake Rate Forecasting in New Zealand Using Multiplicative Hybrid Models Including Strain-Rate Covariates: Performance Analysis in Forward and Reverse Time}

RASTIN, S. I, GNS Science, Wellington, New Zealand, s.rastin@gns.cri.nz; RHOADES, D. A., GNS Science, Wellington, New Zealand, d.rhoades@gns. cri.nz

Long term earthquake rate forecasting is an essential part of the National Seismic Hazard Model of New Zealand (NZNSHM). Multiplicative hybrid models including strain rates by Beavan (2012) and other contributing covariates based on fault and earthquake data were previously fitted to NZ earthquakes with $M \geq 5.0$ over 1987 to 2006. Such models serve to improve the long term seismicity rate forecast for the NZNSHM. The strain rate covariates were based on geodetic data from 1991-2011. Maximum shear strain rate was the most informative of the covariates and all hybrid models including strain rates were more informative than models excluding them. The same was true in forward testing from 2012-2015 - a period independent of data contributing to strain rate estimates. We incorporate an updated shear strain rate model (Haines and Wallace 2020) based on geodetic data up to 2019 and obtain multiplicative rate models using the same earthquakes and fitting period. In forward testing hybrids with Haines and Wallace (2020) shear strain rate outperform all others. We investigate information gains for the models when performing reverse testing on an independent period 1951-1986. All hybrid models including Beavan (2012) and Haines and Wallace (2020) perform poorly over this period and are less informative than hybrids excluding strain rates. We evaluate competency of covariates as predictors using Molchan error diagrams and area skill score (ASS). Although the shear strain rates are positively correlated with earthquake occurrence over the reverse period, other covariates like proximity to mapped faults have higher ASS and are better correlated. Smoothed scatter plots of covariates for targeted earthquakes against time 1951-2020 show the association between shear strain and earthquake occurrence is strongest during the time on which the strain rate model was based. These results are relevant to question of how strongly strain rate estimates based on a few decades of geodetic data should be weighted when constructing earthquake source models for assessment of long term seismic hazard.

\section{Ensemble Earthquake Forecasting With a Logistic Regression Model}

HERRMANN, M., Università degli Studi di Napoli 'Federico II', Naples, Italy, marcus.herrmann@unina.it; MARZOCCHI, W., Università degli Studi di Napoli 'Federico II', Naples, Italy, warner.marzocchi@unina.it

Combining individual forecast models into an ensemble model is proving beneficial in many research areas and applications (e.g., weather/climate forecasting, medical diagnosis, computer security). An ensemble emphasizes the individual strengths of various types of models (e.g., physical and statistical models), typically yields a superior performance than the best individual model, is more flexible than a single model, and provides a more realistic uncertainty quantification.

Constructing an ensemble relates to the performance evaluation of individual models. Marzocchi et al. 2014 [doi: 10.1785/0220130219] presented an operational earthquake forecasting (OEF) experiment for Italy, which launched in 2009 according to the standards of the Collaboratory for the Study of Earthquake Predictability (CSEP). The experiment includes three statistical models and an ensemble of them, with weights assigned using a Bayesian approach. The models provide weekly earthquake forecasts for magnitudes M3.95+ and are still running as of 2021.

Here we present a different ensemble strategy using a logistic regression. Instead of weighting the forecast models according to their individual skill (as in the Bayesian ensemble), the optimal weights are those that maximize the skill of the ensemble (via goodness of fit). The multivariate logistic regression is fit between the forecast rates of the individual models and the spatiotemporal target bins (i.e., target earthquakes with $M 3.95+$ binned to the testing region's grid resulting in ' 0 ' [no targets] or ' 1 ' [one or more targets]). We evaluate the performance of the two ensemble strategies using metrics such as their likelihood ratio or the information gain compared to a reference model. We experiment with various weighting schemes to address the multi-purpose character of OEF (i.e., with a focus on spatial skill, recent seismicity, overall rate, etc.) and try to understand when and why the logistic ensemble outperforms individual models.

\section{Improving Earthquake Doublet Rate Predictions in Etas by Using Modified Spatial Trigger Distributions}

GRIMM, C., Ludwig-Maximilians Universität, Munich, Germany, christian. grimm@stat.uni-muenchen.de; KÄSER, M., Ludwig-Maximilians Universität, Munich, Germany, martin.kaeser@geophysik.uni-muenchen.de; HAINZL, S., GFZ German Research Centre for Geoscience, Potsdam, Germany, hainzl@ gfz-potsdam.de; PAGANI, M., Global Earthquake Model, Pavia, Italy, marco. pagani@globalquakemodel.org; KÜCHENHOFF, H., Ludwig-Maximilians Universität, Munich, Germany, kuechenhoff@stat.uni-muenchen.de

Earthquake sequences add significant hazard beyond the solely declustered perspective of common probabilistic seismic hazard analysis (PSHA). A particularly strong driver for both social and economic losses are so-called earthquake doublets (more generally multiplets), i.e. sequences of two (or more) comparatively large events in spatial and temporal proximity. Not differentiating between foreshocks and aftershocks, we hypothesize three main drivers of doublet occurrence: (1) the number of direct aftershocks triggered by an earthquake; (2) the underlying, independent background seismicity in the same time-space window; and (3) the magnitude size distribution of triggered events (in contrast to independent events). We tested synthetic catalogs simulated by a common, isotropic epidemic type aftershock sequence (ETAS) model for both Japan and Southern California. Our findings show that the standard ETAS approach dramatically underestimates doublet frequencies compared to observations in historical catalogs. Among others, the results partially smooth out pronounced peaks of temporal and spatial event clustering. Focusing on the impact on direct aftershock productivity, we propose two modifications of the ETAS spatial kernel in order to improve doublet rate predictions: (a) a restriction of the spatial function to a maximum distance of 2.5 estimated rupture lengths; (b) an anisotropic function with contour lines constructed by a box with two semicircular ends around the estimated rupture line. The restriction of the spatial extent shifts triggering potential from weaker to stronger events and in consequence improves doublet rate predictions for larger events. However, this improvement goes at the cost of a weaker 
overall model fit according to AIC. The anisotropic models improve the entire model fit, but have only little impact on doublet occurrence rate predictions.

\section{Constructing and Testing Regional and Global Earthquake} Forecasts

I: Oral Session · Tuesday · 20 April · 9:45 Am Pacific II: Oral Session · Wednesday · 21 April • 9:45 Am Pacific III: Oral Session · Thursday · 22 April · 9:45 AM Pacific Session Chairs: Maximilian Werner, University of Bristol (max.werner@bristol.ac.uk); David D. Jackson, University of California, Los Angeles (djackson@g.ucla.edu); Danijel Schorlemmer, GFZ German Research Centre for Geosciences (ds@gfz-potsdam.de)

\section{A Global Set of Subduction Zone Earthquake Scenarios Inferred From Geodetically Constrained Block Models} MEADE, B. I., Harvard University, Massachusetts, USA, meade@fas. harvard.edu; GRAHAM, S. E., The College of New Jersey, New Jersey, USA shannonegraham@gmail.com; LOVELESS, J. P., Smith College, Massachusetts, USA, jloveles@smith.edu

The past 100 years have seen the occurrence of $5 \mathrm{M}_{\mathrm{W}}>9$ earthquakes and 94 $\mathrm{M}_{\mathrm{W}}>8$ earthquakes. Here we assess the potential for future great earthquakes using inferences of interseismic subduction zone coupling from a global block model incorporating both tectonic plate motions and earthquake cycle effects. Interseismic earthquake cycle effects are represented using a first-order quasistatic elastic approximation and include $\sim 10^{7} \mathrm{~km}^{2}$ of interacting fault system area across the global fault system. We use spatial variations in decadalduration coupling at 15 subduction zones and the Himalayan range front to estimate the potential locations and magnitude of future seismic events using empirical scaling relationships relating rupture area to moment magnitude. At an interseismic coupling threshold of $30 \%$, we estimate 14 potential $\mathrm{M}_{\mathrm{W}}>9$ earthquakes globally. At higher coupling thresholds, estimates of potential earthquake magnitudes decrease, but the total number of large earthquakes varies non-monotonically. We also combine slip deficit rate and potential event magnitudes to estimate earthquake recurrence intervals for large earthquake scenarios

\section{A Prospective Evaluation of a Publicly Released ETAS Aftershock Forecast During the 2020 SW Puerto Rico Sequence}

VAN DER ELST, N., U.S. Geological Survey, California, USA, nvanderelst@ usgs.gov; MICHAEL, A., U.S. Geological Survey, California, USA, ajmichael@ usgs.gov; HARDEBECK, J. L., U.S. Geological Survey, California, USA, jhardebeck@usgs.gov

The magnitude 6.4 earthquake that struck the SW coast of Puerto Rico on January 7, 2020, was accompanied by a robust fore- and aftershock sequence, with 12 magnitude 5 and larger aftershocks recorded in the first year of the sequence. The USGS issued an automated Reasenberg and Jones (RJ) aftershock forecast [Reasenberg and Jones, 1989] following the first magnitude 5.0 foreshock on 29 December 2019, and switched to a Epidemic-Type Aftershock Sequence (ETAS) [Ogata, 1988] forecast on 11 January 2020 as it became clear that this was an unusually productive sequence with many large aftershocks. The ETAS forecasts were generated using the Aftershock Forecaster software, developed in OpenSHA. The USGS additionally released an open-file report [van der Elst et al., 2020] on the potential duration of the aftershock sequence, based on an extrapolation of the sequence as of 17 January 2020. These products were disseminated along with press releases and infographics via the USGS website and social media. Over the last year, the USGS public forecasts have been updated on a daily to biweekly basis, allowing for a public, prospective test of the forecast methodology. Here we evaluate the performance of the regularly updated daily, weekly, and monthly ETAS forecasts, published on the USGS website, with respect to the sequence as observed. We also compare the evolution of the forecasts to the expectations published in the Open-File report. We supplement the analysis with a retrospective comparison between the ETAS and RJ forecast models. While the ETAS-based forecast performed reasonably well, the exercise highlights issues related to non-stationarity of model parameters, which are possibly linked to network and catalog changes made in response to the earthquake and are likely to confound even the most sophisticated statistical seismicity models.

\section{Bayesian Etas: Towards Improved Earthquake Rate Models in the Pacific Northwest}

SCHNEIDER, M., University of Washington, Washington, USA, maxs15@ uw.edu; GUTTORP, P., University of Washington, Washington, USA, guttorp@uw.edu

The Pacific Northwest (PNW) has substantial earthquake risk, both due to the Cascadia megathrust fault but also crustal faults that lie under population centers such as Seattle. Stable models of its earthquake rates and clustering parameters are thus key to probabilistic seismic hazard assessment and aftershock forecasts for the continental PNW. The Epidemic-Type Aftershock Sequence model (ETAS) is a spatiotemporal point process model which parameterizes the rates of earthquakes and aftershocks within a seismic region, using a cata$\log$ of its past earthquakes. Typically, maximum likelihood estimation is used to fit ETAS to an earthquake catalog; however, the ETAS likelihood suffers from flatness near its optima, parameter correlation and numerical instability, making likelihood-based estimates less reliable. We present a Bayesian procedure to estimate ETAS parameters, such that parameters can be reliably estimated and their uncertainties resolved. The procedure is conditional on knowing which earthquakes triggered which aftershocks; this latent structure and the ETAS parameters are estimated stepwise, similar to the expectationmaximization algorithm. The procedure uses a Gibbs sampler to conditionally estimate the posterior distributions of each part of the model. We experiment with several prior distributions, which represent different hypotheses on aftershock properties. We simulate several synthetic catalogs and test the modelling procedure, showing posterior distributions that are well-centered on true values and follow previously reported patterns. We also demonstrate the procedure on a new catalog for the continental PNW. This catalog is merged from three existing catalogs with automated procedures for duplicate detection and identification of earthquake swarms. More detailed information about PNW aftershocks can be estimated using Bayesian ETAS than using simpler seismicity models.

\section{GEAR1: A Tested High-Resolution Global Earthquake Rate Forecast}

JACKSON, D. D., University of California, Los Angeles, California, USA, djackson@ucla.edu; BAO, H., University of California, Los Angeles, California, USA, hbrandon@ucla.edu

In the Global Earthquake Activity Rate (GEAR) project we have constructed and are continuing to test a forecast model (rate of earthquake epicenters within location, magnitude, and time windows) at high resolution ( 0.1 by 0.1 degree), over the whole earth surface, for events of magnitude 5.8 and larger. Earthquake rates are inferred from a weighted combination of smoothed seismicity and tectonic deformation estimated from plate tectonic and geodetic data. Magnitudes are assumed to follow the Tapered GutenbergRighter distribution with corner magnitude values depending on regional tectonics. The first version (GEAR1) was published in 2015 and submitted to the Collaboratory for Study of Earthquake Predictability (CSEP) for testing against the GCMT catalog. GEAR1 was published in BSSA (Bird et al, 2015a) and tested prospectively by CSEP (Strader et al., 2018). The biggest outliers have lat-lon coordinates of $(74.39,-92.43$, Lahore, Pakistan), (86.92, 55.2, Arctic Ocean), and (-22.68, 25.16, Botswana). The highest estimated earthquake rate is at $(-11.2,165.1$, in the Coral Sear southeast of the Solomon Islands). We are presently determining whether large earthquakes $(\mathrm{m} 7+)$ can be forecast effectively from observed smaller ones (m5+); refining the model by incorporating regional earthquake catalogs and strain rate variations to evaluate potential improvements over the generic GEAR1 model, and testing the GEAR1 model against regional forecast models in California, Japan, and other areas where large-earthquake forecasts have been developed.

\section{Two Global Ensemble Seismicity Models Obtained From the Combination of Interseismic Strain Rates and Earthquake-Catalog Data}

BAYONA, J. A., University of Bristol, Bristol, United Kingdom, jose.bayona@ bristol.ac.uk; SAVRAN, W., University of Southern California, California, USA, wsavran@usc.edu; STRADER, A., GFZ German Research Centre for Geosciences, Potsdam, Germany, seismo.strader@gmail.com; HAINZL, S., GFZ German Research Centre for Geosciences, Potsdam, Germany, hainzl@ gfz-potsdam.de; COTTON, F., GFZ German Research Centre for Geosciences, Potsdam, Germany, fcotton@gfz-potsdam.de; SCHORLEMMER, D., GFZ 
German Research Centre for Geosciences, Potsdam, Germany, ds@gfzpotsdam.de

Global seismicity models provide scientific hypotheses about the rate, location and magnitude of earthquakes that will occur around the world. Given the aleatory variability of earthquake activity and epistemic uncertainties in seismicity forecasting, the veracity of these hypotheses can only be confirmed or rejected after prospective forecast evaluation. Here, we present the construction of and test results for two updated global earthquake models, aimed at providing mean estimates of shallow $(\mathrm{d} \leq 70 \mathrm{~km})$ seismicity for seismic hazard assessment. These approaches, referred to as the Tectonic Earthquake Activity Model (TEAM) and the World Hybrid Earthquake Estimates based on Likelihood scores (WHEEL) model, use a seismicity model for subduction zones that relies on geodetic strain rates, earthquake-catalog information and regional "geodesy-to-seismicity" parameters, such as fault-dipping angles, seismic coupling coefficients and estimates of corner magnitude. Thus, these ensemble models capture two independent components necessary for longterm earthquake forecasting, namely interseismic crustal strain accumulation and sudden lithospheric stress release. The calibration period for TEAM and WHEEL extends from January 1, 1977 to December 31, 2013. Accordingly, we use $m \geq 5.95$ earthquakes recorded during the 2014-2019 period to pseudoprospectively evaluate the forecasting skills of these earthquake models, and statistically compare their performances to that of the Global Earthquake Activity Rate (GEAR1) model. Our pseudo-prospective test results show that GEAR1 and WHEEL are the most informative global seismicity models, as they overperform their individual model components during the six-year evaluation period. Nonetheless, further prospective evaluations are required to more accurately describe the abilities of these global ensemble seismicity models to forecast longer-term earthquake activity.

\section{Data-Driven Optimization of Multi-Kernel Earthquake Hazard Models: Retrospective Forecasting Applied to Stable and Active Regions in China}

LANGENBRUCH, C., Risk Management Solutions, California, USA, cornelius.langenbruch@rms.com; FITZENZ, D. D., Risk Management Solutions, California, USA, delphine.fitzenz@rms.com

Earthquake rates are driven by a complex interplay of processes spanning a broad range of scales in time and space. Methods that are solely based on instrumented earthquake catalogs can miss intermediate or long-term behavior of seismic activity. In particular, application to stable intraplate regions can be problematic, because driving mechanisms of seismicity are not fully understood, and instrumented catalogs reveal only a small part of any fault recurrence.

Fitzenz and Langenbruch (2021, this meeting) propose a three-kernel earthquake hazard model for China incorporating past seismicity, mapped faults and surface strain rates. Here, we demonstrate how to optimize kernel weights by maximizing the Log Likelihood (LL) score of retrospective earthquakes forecasting tests. Our study shows that (1) our three-kernel model ranks higher (higher LL), compared to single kernel smoothed seismicity models, (2) larger earthquakes tend to occur closer to mapped faults, compared to smaller events and (3) joint LL scores of single kernel models cannot be used to optimize weights of multi-kernel models.

Finally, we assess uncertainties of our data-driven optimization to understanding kernel weight variability for seismic hazard and risk model calibration. Our method helps to improve the performance of upcoming multikernel earthquake hazard and risk models based on past seismicity, mapped faults and surface strain rates.

\section{Developing Data-Driven Earthquake Forecasts Using Inlabru}

BAYLISS, K., University of Edinburgh, Edinburgh, United Kingdom, kirsty. bayliss@ed.ac.uk; NAYLOR, M., University of Edinburgh, Edinburgh, United Kingdom, mark.naylor@ed.ac.uk; ILLIAN, J., University of Glasgow, Glasgow, United Kingdom, janine.illian@glasgow.ac.uk; MAIN, I., University of Edinburgh, Edinburgh, United Kingdom, ian.main@ed.ac.uk

To develop robust and reliable earthquake forecasts, we must have a good understanding of spatial patterns of seismicity. Log-Gaussian Cox processes with a spatially varying, random intensity field may be used to flexibly model the spatial pattern formed by the locations of earthquakes. Using a Bayesian approach implemented with the R pacakge inlabru, we fit models that use different combinations of spatial covariates that might help describe observed seismicity, including different geophysical and geological observations such as past seismicity, strain rate, mapped fault information, and slip rate on individual faults, and derived products such as distance from nearest fault. The models include a random field component to model remaining spatial structure that cannot be explained by the included components. These models have the advantage of not requiring expert judgement in defining seismic zones using similar input data, while greatly reducing the number of free model parameters. They also allow a finite likelihood of having an event in areas where seismicity is low or absent, hence allowing for 'surprises'. The flexibility of the inlabru approach makes it possible to easily construct and compare models containing different combinations of potentially useful spatial covariates. This allows us to assess the extent to which individual components and combinations of these improve a spatial model of observed seismicity. The best-performing spatial models can then be extended to time-independent forecasts by considering the magnitude distributions of modelled event rates. We demonstrate this method with application to California data. We find that fault distance maps and strain rate data can be particularly useful for constraining spatial seismicity and that fault slip rate models can be useful for describing the spatial distribution of large earthquakes.

\section{Is Accounting for Spatial Variation of b-Values Useful for Earthquake Forecasting?}

NANDAN, S., Swiss Seismological Service, ETH Zürich, Zürich, Switzerland, snandan@ethz.ch; MIZRAHI, L., Swiss Seismological Service, ETH Zürich, Zürich, Switzerland, leila.mizrahi@sed.ethz.ch; WIEMER, S., Swiss Seismological Service, ETH Zürich, Zürich, Switzerland, stefan.wiemer@sed. ethz.ch

The b-value is the most studied parameter in the field of statistical seismology. It has been widely used as the proxy of the current state of stress in the earth's crust. Numerous phenomenological studies have been conducted to establish its credibility as the parameter that holds the key to improving our understanding of seismogenesis. Given the importance of this parameter, we want to assess its usefulness for earthquake forecasting. Specifically, we want to understand if accounting for the spatial variation of b-values can significantly improve the Epidemic-Type-Aftershock-Sequence (ETAS) models' performance. In this study, we first consider several methods widely used to infer the underlying spatial variation of the b-value and an additional method that we develop in this study. We then apply these methods to synthetic catalogs, generated using a known underlying spatial variation of b-values, and assess their ability to infer this albeit known but hidden pattern. We then apply the same methods to the Californian earthquake catalog. The usefulness of the inferred spatial variation of b-values by the different methods for the real catalog is then evaluated using numerous pseudo-prospective forecasting experiments. The spatial variation of b-values inferred from the training periods is coupled with the ETAS model to get forecasts for the testing periods in these experiments. The forecasts resulting from the different methods are validated against the earthquakes in the testing periods. The resulting scores for each method are mutually compared, and to the score of a null model, which does not consider the spatial variation of b-values. This comparison allows us to establish if considering spatial variation of b-values is useful for earthquake forecasting and which of the widely used methods leads to the most useful forecast.

\section{Prospective Evaluation of Multiplicative Hybrid Earthquake Forecast Models for California}

BAYONA, J. A., School of Earth Sciences, University of Bristol, Bristol, United Kingdom, jose.bayona@bristol.ac.uk; SAVRAN, W., Southern California Earthquake Center, University of Southern California, California, USA, wsavran@usc.edu; WERNER, M. J., School of Earth Sciences, University of Bristol, Bristol, United Kingdom, max.werner@bristol.ac.uk; RHOADES, D. A., GNS Science, Lower Hutt, New Zealand, d.rhoades@gns.cri.nz

The Regional Earthquake Likelihood Models (RELM) group designed a joint forecasting experiment, with associated models, data and tests to evaluate earthquake predictability in California. After five years of prospective evaluation, the RELM experiment found that the smoothed seismicity (HKJ) model by Helmstetter et al. (2007) was the most informative. The diversity of competing forecast hypotheses in RELM was suitable for combining multiple models that could provide more informative earthquake forecasts than HKJ. Thus, Rhoades et al. (2014) created multiplicative hybrid models that involve the HKJ model as a baseline and one or more conjugate models. According to retrospective analyses, some hybrid models showed significant information gains over the HKJ forecast. Here, we assess in a prospective setting the predictive skills of 16 hybrids and 6 original RELM forecasts, using a suite of tests of the Collaboratory for the Study of Earthquake Predictability (CSEP). The evaluation dataset contains $40 \mathrm{M} \geq 4.95$ events recorded within the California CSEP-testing region from 1 January 2011 to 31 December 2020, including the $2016 \mathrm{Mw}$ 5.6, 5.6, and 5.5 Hawthorne earthquake swarm, and the Mw 6.4 foreshock and Mw 7.1 mainshock from the 2019 Ridgecrest sequence. We 
evaluate the consistency between the observed and the expected number, spatial, likelihood and magnitude distributions of earthquakes, and compare the performance of each forecast to that of HKJ. Our prospective test results show that none of the hybrid models are significantly more informative than the HKJ baseline forecast. These results appear to be mainly due to the occurrence of the 2016 Hawthorne and 2019 Ridgecrest earthquake sequences, as these clusters of seismicity are exceptionally unlikely in all models and are insufficiently captured by the Poisson distribution that the likelihood functions of tests assume. Currently, we are examining alternative likelihood functions to better understand the discrepancies between prospective and retrospective test results for multiplicative hybrid forecasts.

\section{Towards a Prospective Test of the Foreshock Traffic Light System}

WIEMER, S., ETH Zürich, Zürich, Switzerland, stefan.wiemer@sed.ethz. ch; GULIA, L., University of Bologna, Bologna, Italy, laura.gulia@unibo.it; REYES, C., ETH Zürich, Zürich, Switzerland, reyes@sed.ethzch

Traffic Lights are a tool for quantitatively recognizing risk to initiate risk reduction measures and they have been used to manage risk behaviour in various contexts. Gulia and Wiemer (2019) proposed a traffic light classification, known as Foreshock Traffic Light System (FTLS), based on the b-value space-time variations as a first-order discriminator between normal aftershocks and likely precursory sequences. The model, to be implemented after the occurrence of an $M>=6$ to assess if this event was the mainshock, is based on the widely established inverse dependence of the b-value on differential stress. The authors define three levels of alert based on the b-value difference in percentage between the background value and the sequence-specific values.

So far, the FTLS had been tested retrospectively on 58 sequences, reaching an accuracy of 0.95 in a confusion matrix analysis. After the publication of the model, we tested it in a pseudo-prospective application to the 2019 Ridgecrest sequence. Results are fully in line with the FTLS hypothesis: After analyzing carefully the magnitude of completeness of the sequences, we find that in the hours after the first Mw6.4 Ridgecrest event, the b-value drops by $23 \%$ on average, when compared to the background value, resulting in a red foreshock traffic light. After the second, M7.1 mainshock, the b-value subsequently increased by $26 \%$ over the background value, triggering a green traffic light setting.

We are currently preparing the next step in testing the FTLS model: a fully prospective test embedded in a CSEP style testing framework, as provided by the EU project RISE. Implementing such a fully prospective test is highly challenging since several data quality analysis steps need to be fully automated. For example, the magnitude of completeness varies strongly with time in an aftershock sequence, robust procedures to access $\mathrm{Mc}(\mathrm{t})$ are thus needed to assess b-values. The automatic selection of the faults plane is also challenging. We discuss in our contribution the current status and future direction of testing the FTLS model.

\section{Ensemble Modeling of Physics-Based and Statistical Forecasts During the 2016/17 Central Apennines (Italy) Aftershock Sequence}

MANCINI, S., British Geological Survey, Edinburgh, United Kingdom, simone@bgs.ac.uk; WERNER, M. J., University of Bristol, Bristol, United Kingdom, max.werner@bristol.ac.uk; SEGOU, M., British Geological Survey, Edinburgh, United Kingdom, masegou@bgs.ac.uk

Developing ensemble models is an increasingly popular strategy for shortterm earthquake forecasting, as they allow merging different model types and better accounting for their epistemic uncertainties. Also, ensembles offer the theoretical advantage of not having to a priori select one single model when multiple competing forecasts are available, which is a desirable feature in operational applications. However, different model weighting methods exist and there is no clear consensus on the best way to combine models, so that their actual performance remains a controversial subject.

Here, we present a retrospective daily forecast experiment for the first year of the 2016/17 Central Italy seismic cascade, where nine M5+ earthquakes occurred within five months of the initial Mw 6.0 event. First, we produce a set of forecasts belonging to two different modeling approaches, that is, the physics-based Coulomb rate-and-state (CRS) and the statistical Epidemic-Type Aftershock Sequence (ETAS) models. As input/target dataset, we use a high-resolution, high-density earthquake catalog recently released for the sequence, with $\sim 400,000 \mathrm{M} 1+$ events. We quantify the absolute and relative model performance using the likelihood-based statistical tests (e.g., S and T-test) introduced by the Collaboratory for the Study of Earthquake Predictability (CSEP). We then form ensemble models from the highest ranked CRS and ETAS realizations using the Bayesian (BMA) and Score
Model Averaging (SMA) schemes. We evaluate the ensembles adopting the same CSEP scoring metrics and we benchmark them against their individual components to assess whether they provide enhanced predictive skills.

Results from the 1-year forecast show that while the SMA model is less informative than its sub-components, the Bayesian ensemble performs better than the worse individual model and comparably to the best one.

\section{Goodness-of-Fit Assessment of Earthquake Forecasts Using Voronoi and Superthinned Residuals}

SCHOENBERG, F. P., University of California, Los Angeles, California, USA, frederic@stat.ucla.edu

Many versions of the Epidemic-Type Aftershock Sequence (ETAS) model of Ogata (1988) have been proposed to model the occurrence times and locations of earthquakes. Variants proposed by Zhuang et al. (2003) and by Helmstetter et al. (2007) have been shown to fit best to data for prospective forecasting in the Collaboratory Study for Earthquake Predictability (CSEP), according to analyses by Schorlemmer et al. (2010) and Zechar (2013). However, Gordon (2017) showed retrospectively that his proposed version of the ETAS model, which uses the Model Independent Stochastic Declustering (MISD) method of Marsan and Lengliné (2008) to estimate a spatial triggering function varying direction, magnitude, and region, would have outperformed prior versions of the ETAS model, using the Helmstetter et al. (2007) model as a benchmark and using data from 2005-2015. Here we evaluate the prospective fit of the nonparametric ETAS model of Gordon (2017) using earthquake data from 2017, comparing it to the Zhuang et al. (2003) model. The fit of both prospective model forecasts is evaluated using deviance and Voronoi residuals. We find slightly superior performance of the Gordon (2017) model compared to Zhuang et al. (2003) in various regions.

\section{On the Use of Statistical Tests for Evaluating Spatial Earthquake Forecasts}

PARSONS, T., U.S. Geological Survey, California, USA, tomparsons@ earthlink.net

Spatial forecasts of triggered earthquake distributions have been ranked using statistical tests, such as the Receiver Operating Characteristic (ROC) test and the Collaboratory for the Study of Earthquake Predictability (CSEP) S-Test. The ROC test is a binary comparison between regions of positive and negative forecast against positive and negative presence of earthquakes. Forecasts predicting only positive changes score higher with the ROC test than Coulomb methods, which predict positive and negative changes. We hypothesize that removing the possibility of failures in negative forecast realms yields better ROC scores. We create a 'perfect' Coulomb forecast where all earthquakes only fall into positive stress change areas and compare with an informationless all-positive forecast (stress as a function of distance as $\mathrm{r}^{-3}$ ). The 'perfect' Coulomb forecast barely beats the informationless forecast, and adding as few as 4 earthquakes occurring in the negative stress regions causes the Coulomb forecast to be no better than an informationless forecast under a ROC test. ROC tests also suffer from data imbalance when applied to earthquake forecasts because there are many more negative cases than positive. This imbalance also affects the CSEP S-Test, which normalizes forecasts, comparing rates at places where earthquakes occurred. A forecast that identifies places where earthquakes won't happen (like Coulomb calculations) is not rewarded for being correct under the S-Test.

There are acknowledged issues with rapid, and/or simplified Coulomb stress changes being able to forecast the position of every triggered earthquake, and static stress changes are only part of the overall effect that a mainshock has on the stress field. However, Coulomb stress change calculations that account for the complexity in the mainshock rupture and the surrounding fault structures can provide resolution on where earthquake rates will be suppressed as well as where they will be enhanced.

\section{Retrospective Evaluation of Weekly UCERF3-ETAS forecasts of California Seismicity}

SAVRAN, W., University of Southern California, California, USA, wsavran@ usc.edu; MILNER, K., University of Southern California, California, USA, kmilner@usc.edu; FIELD, E. H., U.S. Geological Survey, Colorado, USA, field@usgs.gov; WERNER, M. J., University of Bristol, Bristol, United Kingdom, max.werner@bristol.ac.uk

Earthquakes are known to exhibit clustering behavior on short time scales causing seismicity rates to vary with time, which implies that seismic hazard can increase immediately following large events. To model this behavior, Uniform California Earthquake Rupture Forecast v.3 with epidemic-type aftershock sequences (UCERF3-ETAS) implements a model for time-dependent 
seismicity in California that includes the clustering observed in earthquake sequences. UCERF3-ETAS generates synthetic earthquake catalogs whose events retain the spatiotemporal dependencies prescribed by the model, and represents a candidate model for operational earthquake forecasting. We compute UCERF3-ETAS forecasts from 01 January 1986 until 01 January 2020 in disjoint weekly intervals to provide a time-dependent estimate of the statewide seismicity for earthquakes with $\mathrm{M}>2.5$. Using newly developed consistency tests for synthetic catalogs, we evaluate UCERF3-ETAS, retrospectively, to better understand the uncertainties present in the model. The consistency tests target the seismicity rate, magnitude distribution, and spatial distributions of the forecast. In particular, we evaluate competing modeling assumptions including elastic rebound and the variability in aftershock productivity. To first order we find that UCERF3-ETAS captures the spatiotemporal behavior of seismicity. Quantifying the differences between forecasts and observations is crucial for improving our forecasting models by testing their assumptions, and understanding their uncertainties.

\section{Spatial Clustering of Aftershocks Impacts the Performance of Physics-Based Earthquake Forecasting Models}

HARDEBECK, J. L., U.S. Geological Survey, California, USA, jhardebeck@ usgs.gov

I explore why physics-based models of earthquake triggering, such as those based on Coulomb stress changes, rarely outperform statistical models in prospective testing, outside of limited spatial-temporal windows. I consider the hypothesis that statistical models like the Epidemic Type Aftershock Sequence (ETAS) model are able to perform as well as physical models because of the tight spatial clustering of aftershocks. In many aftershock sequences, while most aftershocks may occur within the Coulomb-stress-increase lobes, the aftershocks do not uniformly fill these lobes, and instead cluster in a few locations. Pseudo-prospective tests on suites of synthetic aftershock sequences show that the level of spatial clustering of the direct aftershocks impacts the relative performance of physical versus statistical models. The synthetic sequences are generated from generalized "physical" triggering models, superimposed on background heterogeneity that controls the level of clustering. The statistical ETAS model performs relatively better the more clustered the direct aftershocks, while the true generalized "physical" model performs relatively worse. ETAS must successfully, although incorrectly, model the spatial clusters as secondary triggering. Real aftershocks appear to be sufficiently clustered to allow ETAS to perform as well as or better than physical models. A likely cause of the spatial clustering of direct aftershocks is heterogeneity of the background physical conditions, which typically isn't modeled in physicsbased forecasts. This implies that the forecast performance of physical models could be substantially improved through a better understanding of the interaction between earthquake stress changes and variable background physical conditions such as stress state, fault strength, and fluid pressure. The performance of physical models can also be improved through the incorporation of ETAS-like features, such as modeling secondary triggering from aftershocks.

Constructing and Testing Regional and Global Earthquake Forecasts

Poster Session · Tuesday · 20 April · 11:30 Am Pacific

Session Chairs: Maximilian Werner, University of Bristol

(max.werner@bristol.ac.uk); David D. Jackson, University

of California, Los Angeles (djackson@g.ucla.edu); Danijel

Schorlemmer, GFZ German Research Centre for Geosciences (ds@gfz-potsdam.de)

\footnotetext{
A Bayesian Framework for Aftershock Forecasting and Testing

SHCHERBAKOV, R., University of Western Ontario, London, Canada, rshcherb@uwo.ca

Earthquakes trigger subsequent earthquakes. They form clusters and swarms in space and in time. This is a direct manifestation of the non-Poisson behavior in the occurrence of earthquakes, where earthquake magnitudes and time intervals between successive events are not independent and are influenced by past seismicity. As a result, the distribution of the number of earthquakes is no longer strictly Poisson and the statistics of the largest events deviate from the GEV distribution. In statistical seismology, the occurrence of earthquakes
}

is typically approximated by a stochastic marked point process. Among different models, the ETAS model is the most successful in reproducing several key aspects of seismicity. Recent analysis suggests that the ETAS model generates sequences of events which are not Poisson. This becomes important when the ETAS based models are used for earthquake forecasting (Shcherbakov et al., Nature Comms., 2019). In this work, I consider the Bayesian framework combined with the ETAS model to constrain the magnitudes of the largest expected aftershocks during a future forecasting time interval. This includes the MCMC sampling of the posterior distribution of the ETAS parameters and computation of the Bayesian predictive distribution for the magnitudes of the largest expected events. To validate the forecasts, the statistical tests developed by the CSEP are reformulated for the Bayesian framework. In addition, I define and compute the Bayesian p-value to evaluate the consistency of the forecasted extreme earthquakes during each forecasting time interval. The Bayesian p-value gives the probability that the largest forecasted earthquake can be more extreme than the observed one. The suggested approach is applied to the recent 2019 Ridgecrest earthquake sequence to forecast retrospectively the occurrence of the largest aftershocks (Shcherbakov, JGR, 2021). The results indicate that the Bayesian approach combined with the ETAS model outperformed the approach based on the Poisson assumption, which uses the extreme value distribution and the Omori law.

\section{A Big Problem for Small Earthquakes: Benchmarking Routine Magnitudes and Conversion Relationships With Coda-Envelope-Derived Mw in Southern Kansas and Northern Oklahoma}

SHELLY, D. R., U.S. Geological Survey, Colorado, USA, dshelly@usgs.gov; MAYEDA, K., AFTAC, California, USA, kevin.mayeda@us.af.mil; WALTER, W. R., Lawrence Livermore National Laboratory, California, USA, walter5@ llnl.gov; GÖK, R., Lawrence Livermore National Laboratory, California, USA, gok1@lanl.gov; BARNO, J., Lawrence Livermore National Laboratory, California, USA, barno1@llnl.gov; WHIDDEN, K. M., University of Utah, Utah, USA, katherine@whidden.net; RUBINSTEIN, J. L., U.S. Geological Survey, California, USA, jrubinstein@usgs.gov; EARLE, P. S., U.S. Geological Survey, Colorado, USA, pearle@usgs.gov; YECK, W. L., U.S. Geological Survey, Colorado, USA, wyeck@usgs.gov; LLENOS, A. L., U.S. Geological Survey, Colorado, USA, allenos@usgs.gov; MOSCHETTI, M. P., U.S. Geological Survey, Colorado, USA, mmoschetti@usgs.gov

Earthquake magnitudes are fundamental measures of earthquake size and represent critical inputs in earthquake forecasts. Although moment magnitude $\left(M_{\mathrm{w}}\right)$ has become the established standard for moderate and large earthquakes, difficulty in reliably measuring seismic moment for small (generally $M_{\mathrm{w}}<4$ ) earthquakes has meant magnitudes for these events remain plagued by a patchwork of inconsistent measurement scales. Because of this, magnitudes of small earthquakes and statistics derived from them can be biased. Furthermore, because small earthquakes are much more numerous than large ones, many applications, such as seismic hazard analysis, depend critically on analysis of events characterized by magnitudes other than $M_{\mathrm{w}}$. To assess this problem, we apply coda-envelope analysis to reliably determine moment magnitudes for a case study of small earthquakes from northern Oklahoma and southern Kansas. Not surprisingly, we find significant differences among $M_{\mathrm{L}}, m_{\mathrm{b}} L g$ and $M_{\mathrm{w}}$ for $M \sim 2-4$ earthquakes examined here. More troublingly, we find that relations designed to convert other magnitudes to $M_{\mathrm{w}}$, which are relied upon for important applications such as seismic hazard analysis, often increase rather than decrease this bias for our dataset. Converted magnitudes can result in a systematic bias sometimes exceeding 0.5 magnitude units, a difference that typically corresponds to a factor of $\sim 3$ in seismicity rate. Moreover, we find a correspondingly large bias in Gutenberg-Richter $b$-values, caused primarily by inaccurate magnitude scaling in the conversion relationships. Although this study focuses on a relatively small geographic area, we can expect similar issues exist with varying severity in other regions. Therefore, magnitudes of small earthquakes and their associated statistics (including seismicity rates and $b$-values), should be treated with extreme caution.

\section{PyCSEP: An Open-Source Toolkit for Evaluating Earthquake Forecast Models}

SAVRAN, W., University of Southern California, California, USA, wsavran@ usc.edu; WERNER, M. J., University of Bristol, Bristol, United Kingdom, max. werner@bristol.ac.uk; SCHORLEMMER, D., GFZ German Research Centre for Geosciences, Potsdam, Germany, ds@gfz-potsdam.de; RHOADES, D. A., GNS Science, California, USA, d.rhoades@gns.cri.nz; JACKSON, D. D., University of California, Los Angeles, California, USA, djackson@ucla.edu; 
MAECHLING, P. J., University of Southern California, California, USA, maechlin@usc.edu

For government officials and the public to act on real-time forecasts of earthquakes, the seismological community needs to develop confidence in the underlying scientific hypotheses and assess models' predictive skills. The Collaboratory for the Study of Earthquake Predictability (CSEP) provides the cyberinfrastructure and computational tools for an international effort to evaluate earthquake forecasts. The design of the existing software, for use in testing centers, made it difficult for researchers to use on their own system and in their own research. We are developing an open-source earthquake forecast evaluation toolkit, called PyCSEP, that is designed for use both within CSEP testing centers and by the wider earthquake forecast research community. PyCSEP is a Python package that provides routines from testing centers in the following modules: (1) earthquake catalog access and processing, (2) representing earthquake forecasts, (3) statistical tests for evaluating earthquake forecasts, and (4) visualization routines. PyCSEP is designed to evaluate forecasts expressed as expected rates in space-magnitude bins, and models, including candidate models for Operational Earthquake Forecasting that can simulate thousands of synthetic seismicity catalogs, which express important dependency structures between triggered earthquakes. Most importantly, PyCSEP contains community-endorsed implementations of statistical tests to evaluate earthquake forecasts - with a goal of embedding model evaluation into the model development process. The toolkit will facilitate integrating new forecasting models into testing centers, as the models can be built to use wel defined file formats and standards provided by PyCSEP. Our intention is that providing useful tools to model developers will broaden the CSEP community and promote earthquake forecasting research.

\section{The Global Centroid Moment Tensor Catalog: Heterogeneities and Improvements}

GONZÁLEZ, Á., GFZ German Research Centre for Geosciences, Potsdam, Germany, alvaro@geonaut.eu

Statistical seismology relies on earthquake catalogs as homogeneous and complete as possible. However, heterogeneities in earthquake data compilation and reporting are common and frequently are not adverted.

The Global Centroid Moment Tensor Catalog (www.globalcmt.org) is considered as the most homogeneous global database for large and moderate earthquakes occurred since 1976, and it has been used for developing and testing global and regional forecast models.

Changes in the method used for calculating the moment tensors (along with improvements in global seismological monitoring) define four eras in the catalog (1976, 1977-1985, 1986-2003 and 2004-present). Improvements are particularly stark since 2004, when intermediate-period surface waves started to be used for calculating the centroid solutions.

Fixed centroid depths, used when the solution for a free depth did not converge, have followed diverse criteria, depending on the era. Depth had to be fixed mainly for shallow earthquakes, so this issue is more common, e.g. in the shallow parts of subduction zones than in the deep ones. Until 2003, 53\% of the centroids had depths calculated as a free parameter, compared to $78 \%$ since 2004.

Rake values have not been calculated homogenously either. Until 2003, the vertical-dip-slip components of the moment tensor were assumed as null when they could not be constrained by the inversion (for 3.3\% of the earthquakes). This caused an excess of pure focal mechanisms: rakes of $-90^{\circ}$ (normal), $0^{\circ}$ or $\pm 180^{\circ}$ (strike-slip) or $+90^{\circ}$ (thrust). Even disregarding such events, rake histograms until 2003 and since 2004 are not equivalent to each other.

The magnitude of completeness $\left(M_{c}\right)$ of the catalog is analyzed here separately for each era. It clearly improved along time (average $M_{\mathrm{c}}$ values being $\sim 6.4$ in $1976, \sim 5.7$ in $1977-1985, \sim 5.4$ in 1986-2003, and $\sim 5.0$ since 2004). Maps of $M_{\mathrm{c}}$ for different eras show significant spatial variations.
Critical Zone, Environmental and Cryospheric Seismology

Oral Session · Thursday · 22 April · 5:00 PM Pacific

Session Chairs: Julien Chaput, University of Texas at El Paso (jchaput82@gmail.com); Tieyuan Zhu, Pennsylvania State University (tyzhu@psu.edu); Richard Aster, Colorado State University (rick.aster@colostate.edu); Wei Wang, Pennsylvania State University (wpw5162@psu.edu); Lucia Gonzalez, University of Texas at El Paso (lgonzalez5@miners. utep.edu); Jonathan Ajo-Franklin, Rice University (ja62@rice. edu); Paul Winberry, Central Washington University (paul. winberry@gmail.com); Grace Barcheck, Cornell University (grace.barcheck@cornell.edu); James St Clair, Pacific Northwest National Laboratory (james.stclair@pnnl.gov)

\section{A Robust Time-Domain Early-Arrival Seismic Waveform} Inversion Method Using Data Uncertainties

CAI, A., Rice University, Texas, USA, ac98@rice.edu; ZELT, C. A., Rice University, Texas, USA, czelt@rice.edu

Early-arrival waveform inversion (EWI) is a technique for high-resolution near-surface velocity estimation, by iteratively updating the velocity model to minimize the difference between observed and calculated diving wave and refraction waveforms. Traditional EWI uses least-squares error as a penalty function that is sensitive to outliers in the data. In addition, the iteration of EWI stops when there is no further decrease in data misfit or when the maximum number of iterations is reached. These stopping criteria can result in overfitting the noise in the data. To overcome the problem of sensitivity to outliers and overfitting, we develop a robust inversion method by estimating and incorporating data uncertainties into the penalty function of EWI. The data uncertainties are estimated based on waveform reciprocal errors. In the situation where full waveform reciprocity is not available in the data, we apply seismic trace interpolation to compensate for the missing reciprocities. Comparing with conventional EWI, the proposed method minimizes the weighted least-squares error and prevents the waveform inversion from closely fitting the data with low signal-to-noise ratio (SNR). The proposed method avoids overfitting by stopping the iterations when the normalized chi-square $\left(\chi^{2}\right)$ waveform misfit of 1 is achieved. Numerical examples suggest the final models using EWI with data uncertainties is more accurate than the corresponding EWI model, at the same level of misfit. A practical example of applying the proposed method to a real $2 \mathrm{D}$ near-surface seismic refraction data is presented.

\section{Analysis of Seismic Signals Generated by Vehicle Traffic with Application to Derivation of Subsurface Q Values}

MENG, H., Scripps Institution of Oceanography, University of California, San Diego, California, USA, h2meng@ucsd.edu; BEN-ZION, Y., University of Southern California, California, USA, benzion@usc.edu; JOHNSON, C., Los Alamos National Laboratory, New Mexico, USA, cwj@lanl.gov

Correct identification and modeling of anthropogenic sources of ground motion are of considerable importance for many studies including detection of small earthquakes and imaging seismic properties below the surface. To understand signals generated by common vehicle traffic, we use seismic data recorded by closely spaced geophones normal to roads at two sites on San Jacinto fault zone. To quantify the spatiotemporal and frequency variations of the recorded ground motions, we develop a simple analytical solution accounting for propagation and attenuation of surface waves. The model reproduces well observed bell-shaped spectrograms of car signals recorded by geophones close to roads, and it can be used to estimate frequency-dependent $Q$ values of the subsurface materials. The data analysis indicates $Q$ values of 3 to 40 for frequencies up to $150 \mathrm{~Hz}$ for road-receiver paths at the two examined sites. The derived $\mathrm{Q}$ values are consistent with attenuation factors of surface waves previously obtained with other methods. The analytical results and analysis procedure provide a highly efficient method for deriving $Q$ values of shallow subsurface materials.

Can Machine Learning improve Debris Flow Warning? CHMIEL, M., ETH Zürich, Zürich, Switzerland, chmielm@ee.ethz. ch; WALTER, F., ETH Zürich/Swiss Federal Institute for Forest, Snow and Landscape Research, Zürich, Switzerland, walter@vaw.baug.ethz. 
ch; WENNER, M., ETH Zürich/Swiss Federal Institute for Forest, Snow and Landscape Research, Zürich, Switzerland, wenner@vaw.baug.ethz.ch; ZHANG, Z., Chinese Academy of Sciences, Chengdu, China, zhangzhen@ imde.ac.cn; MCARDELL, B., Swiss Federal Institute for Forest, Snow and Landscape Research, Zürich, Switzerland, brian.mcardell@wsl.ch; HIBERT, C., Institut de Physique du Globe de Strasbourg, CNRS UMR 7516, University of Strasbourg/EOST, Strasbourg, France, hibert@unistra.fr

Debris flows are complex mixtures of water, fragmented rock, and sediments moving rapidly down steep torrents. They are mobilized by intense precipitation and their volumes often exceed tens of thousands of cubic meters. Debris flows have a high destructive potential which is amplified at the flow front, where large boulders concentrate. The significant hazard to human life and infrastructure in alpine regions calls for reliable warning systems to reduce risk in vulnerable areas.

The basic assumption for most detection systems is that the debris flows move at moderate velocities (below $10 \mathrm{~m} / \mathrm{s}$ ) and cover several kilometer distances before they hit infrastructure. For that reason, rapid detection is indispensable to maximize warning times. Seismic monitoring has received particular attention in this regard as debris flows induce ground unrest over kilometer distances. However, automatic identification of debris flow signals in continuous seismic records remains a challenge.

Here, we introduce a machine-learning approach to detect debris flows and hazardous debris floods based on their seismic signature. For the Illgraben torrent, Switzerland, seismic records from an 8-station network allow detecting debris flows in the upper catchment area, which is practically inaccessible. A machine learning model based on the random forest algorithm recognizes early stages of debris flow formation with an accuracy exceeding $90 \%$. Trained with 20 events from previous years, our detection algorithm detected all 13 hazardous torrential events with no false alarms during a threemonths, realtime test phase in 2020 . The independently confirmed detections include mostly debris flows, but also smaller floods with high water content. Our approach provides up to an additional hour of warning time to the earliest possible in-torrent detection. The proposed seismic machine-learning detector increases warning times using simpler instrumentation compared to existing operational systems, which is a major step towards the next generation of debris-flow warning systems.

\section{Multidisciplinary Analysis of the Deadly Snow Avalanche of 18 January 2017 at Rigopiano (Central Italy)}

BRAUN, T., Istituto Nazionale di Geofisica e Vulcanologia Rome Headquarters, Arezzo, Italy, thomas.braun@ingv.it; BARTELT, P., WSL Institute for Snow and Avalanche Research SLF, Davos, Switzerland, bartelt@ slf.ch; CHIAIA, B., Department of Structural, Building and Geotechnical Engineering, Politecnico di Torino, Torino, Italy, bernardino.chiaia@polito.it; FRIGO, B., Department of Structural, Building and Geotechnical Engineering, Politecnico di Torino, Torino, Italy, barbara.frigo@polito.it; FAMIANI, D., Istituto Nazionale di Geofisica e Vulcanologia, Roma, Italy, daniela.famiani@ ingv.it; WASSERMANN, J., Geophysical Observatory, Munich University, Fürstenfeldbruck, Germany, jowa@geophysik.uni-muenchen.de

On January 2017, a snow avalanche devastated a Resort-hotel in the municipality of Rigopiano in Abruzzo (Central Italy), unfortunately killing 29 people. Due to the bad weather conditions, no visual observation was made; many are the questions and hypotheses around this tragic event.

On-site inspections revealed that the hotel was horizontally cut by shear forces and dislocated by $48 \mathrm{~m}$ in $70^{\circ} \mathrm{N}$ direction, once the increasing avalanche pressure exceeded the structural shear strength of the building. Analyses of phone calls and inspections of the victims' mobile phones revealed that the avalanche struck sometime between 15:40 and 15:54 (UTC). Within this eligible 24 min time window, we scanned regional seismograms for any "suspicious" signal that could have been generated by the avalanche and found three weak seismic transients, starting at 15:42:38 UTC, recorded by the nearest operating station GIGS located in the Gran Sasso underground laboratory at a distance of approximately $17 \mathrm{~km}$ from Rigopiano. Directional analysis of the strongest seismic avalanche signal, as well as of the synthetic seismograms, match best when assuming a single force seismic source, attacking in direction of $120^{\circ} \mathrm{N}$.

Hundreds of simulations of the avalanche dynamics - calculated by using a $2 \mathrm{D}$ rapid mass movement simulator - indicate that the seismic signals were rather generated as the avalanche flowed through a narrow and twisting canyon directly above the hotel. Once the avalanche enters the canyon it is travelling at maximum velocity $(37 \mathrm{~m} / \mathrm{s})$ and is twice strongly deflected by the rock sidewalls. These impacts created a distinct linearly polarized seismic "avalanche transient" that had be used to time the destruction of the hotel Concluding, the avalanche of Rigopiano detached at 15:41:59 (UTC), entered in a canyon (15:42:35), entrained trees and boulders - increasing the mass significantly - an hit the hotel on 15:43:20 at a speed of $100 \mathrm{~km} / \mathrm{h}$.

Our results demonstrate that seismic recordings combined with simulations of mass movements are indispensable to remotely monitor snow avalanches.

\section{Seismic Elastic Waveform Inversion for Characterizing Vp and Vs Models of Critical Zone}

LIU,X., The Pennsylvania State University, Pennsylvania, USA, xuejianliu17@ gmail.com; ZHU, T., The Pennsylvania State University, Pennsylvania, USA tuz47@psu.edu

Seismic refraction methods play an important role in providing seismic properties of CZO structure. The important data processing following the seismic data collection is to conduct refraction tomography using picked traveltimes to provide a well smooth background P-wave velocity model that helps constrain the fluid properties (e.g., porosity) and fractures. While the P-wave velocity model by traveltime tomography provides a low resolution image by only preserving low wavenumber information, our previous work on acoustic full waveform inversion of early arrivals showed promising to invert high resolution P-wave velocity model of CZO subsurface (Huang et al., 2019). However, the amplitude-versus-offset (AVO) effect and residual S-wave energy in early arrival waveform could not be reconciled by acoustic full waveform inversion. Here we design an elastic waveform inversion procedure to tackle this issue by forward modeling of elastic waves to capture the AVO effect and S-waves. The nonlinearity of the elastic waveform matching is primarily caused by unknown source energy, complex AVO properties, and some errors in the initial velocity models. Several strategies are used to alleviate this nonlinearity. First, elastic seismic wave modeling data will be able to take the AVO effect and S-wave into account. We then estimate a source wavelet from high quality early arrivals in the seismic data. The waveform matching will adopt an optimized cross-correlation based misfit and the total-generalized variation based regularization. We demonstrate our elastic waveform inversion method using synthetic experiments and field data from the Garner Run in the Susquehanna Shale Hills Critical Zone Observatory.

Critical Zone, Environmental and Cryospheric Seismology Poster Session · Thursday · 22 April · 3:45 PM Pacific Session Chairs: Julien Chaput, University of Texas at El Paso (jchaput82@gmail.com); Tieyuan Zhu, Pennsylvania State University (tyzhu@psu.edu); Richard Aster, Colorado State University (rick.aster@colostate.edu); Wei Wang, Pennsylvania State University (wpw5162@psu.edu); Lucia Gonzalez, University of Texas at El Paso (lgonzalez5@miners. utep.edu); Jonathan Ajo-Franklin, Rice University (ja62@rice. edu); Paul Winberry, Central Washington University (paul. winberry@gmail.com); Grace Barcheck, Cornell University (grace.barcheck@cornell.edu); James St Clair, Pacific Northwest National Laboratory (james.stclair@pnnl.gov)

\section{Detecting Repeating Icequakes at Llaima and Villarrica Volcanoes, Chile}

LAMB, O., University of North Carolina at Chapel Hill, North Carolina, USA, olamb@email.unc.edu; LEES, J. M., University of North Carolina at Chapel Hill, North Carolina, USA, jonathan.lees@unc.edu; FRANCO MARIN, L., OVDAS-Sernageomin, Temuco, Chile, luis.franco@sernageomin.cl; LAZO, J., OVDAS-Sernageomin, Temuco, Chile, jonathan.lazo@sernageomin. cl; RIVERA, A., Universidad de Chile, Santiago, Chile, arivera@uchile.cl; SHORE, M., University of North Carolina at Chapel Hill, North Carolina, USA, mshore@email.unc.edu; LEE, S., US Army Research Laboratory/Army Research Office, North Carolina, USA, stephen.j.lee28.civ@mail.mil

The evaluation of seismic activity at ice-covered volcanoes is challenging as volcanic and glacial earthquakes (i.e. icequakes) can have overlapping characteristics (i.e. frequencies, waveform shape and magnitude). However, icequakes have only been described at a handful of volcanoes around the world that currently host one or more glaciers. Here we present results from the first study to target glacial activity at active ice-covered volcanoes in the Southern Chile. The primary focus so far has been on Llaima volcano, one of the larg- 
est and most active volcanoes in the region while hosting $>14 \mathrm{~km}^{2}$ of glacial ice on the flanks. A combination of automatic multi-station event detection and waveform cross-correlation to find candidate repeating icequakes in seismic data from the permanent volcano monitoring network recorded in early 2019. We identified dozens of low magnitude families of repeating seismic events across two months, the largest of which included over 200 events. These results are comparable to observations from seismic data recorded at Llaima volcano during the same time period in 2015. The persistent, repetitive nature of these events combined with their waveform characteristics and source locations suggest they originated from multiple sub-glacial stick-slip sources around the upper flanks of the volcano. We also targeted Villarrica volcano in early 2020 with a network of seismo-acoustic sensors to record glacial activity in concurrence with the ongoing eruptive activity at the summit. Altogether, results so far suggest icequakes may be more common than previously thought and has implications for how seismic data at ice-covered volcanoes may be used for assessing future eruptive potential. Furthermore, this study highlights how existing volcano seismic networks could be used to evaluate sub-glacial properties at hundreds of volcanoes around the world.

\section{Evaluating Landslide Forecasting in British Columbia, Canada}

WONG, S., Kwantlen Polytechnic University, Surrey, Canada, sydneynicolewong@gmail.com; HOBBS, T. E., Natural Resources Canada, Vancouver, Canada, thobbs@eoas.ubc.ca; GEERTESEMA, M., Ministry of Forests, Lands, Natural Resource Operations and Rural Development, Prince George, Canada, marten.geertsema@gov.bc.ca

The natural disasters that happen after an earthquake, termed secondary hazards, can be more dangerous than the earthquake alone, causing more casualties than expected. This research utilizes the ground failure code developed by the United States Geological Survey to detect potential landslide locations and improve emergency response planning. The code uses multiple geospatial datasets describing soil, precipitation, and slope conditions as well as a ShakeMap file, resulting in an estimate of the probability of a landslide or liquefaction occurring within a given area. Data from the October $2012 \mathrm{Mw}$ 7.8 Haida Gwaii earthquake in the North Coast Regional District of British Columbia were used to test the accuracy of the methodology. The output dataset was compared visually and statistically with an inventory of observed landslides that happened during and immediately post earthquake. The methodology performs well, as it assigns a high probability of landsliding where they did in fact happen in 2012. However, sensitivity of results is lower than would be needed for response as a large percentage of the study area would have been in the 'high probability of landslides' category. Although the USGS ground failure code can be easily and quickly adapted for use across the globe, future work should incorporate regional datasets or try varying the threshold for 'high' landslide probability to make this tool more impactful in Canada.

\section{Seismic Attenuation Illuminates Fluid Pathways in Glacial Ice}

MATZEL, E., Lawrence Livermore National Laboratory, California, USA, matzel1@llnl.gov; MORENCY, C., Lawrence Livermore National Laboratory, California, USA, morency1@llnl.gov

Water at the base of ice sheets has a significant impact on the speed at which they can move and on their potential for collapse, and identification of basal water is critical to a full understanding of their stability. In geothermal environments, seismic attenuation is known to be highly sensitive to the presence of fluids along faults and fractures. The goal of this study was to determine whether this can be adapted and applied to the ice-water contact within glaciers.

We used publicly available data archived at IRIS to address two key objectives: first using active source data, to identify the attenuation characteristics of glacial ice and its contrast with fractured and fluid-filled zones, and second to determine whether these features are observable using passive seismic arrays.

The attenuation of seismic energy is highly sensitive to the presence of fractures and water within glacial ice. The $\mathrm{Qp} / \mathrm{Qs}$ ratio, in particular, is highly sensitive to porous regions where water is free to flow. $\mathrm{Qp} / \mathrm{Qs}$ is typically larger than unity in hard, rocklike portions of the glacier, but drops below unity where fractures are common. We are able to identify these characteristic features within Antarctic glaciers. We see significant variation along the
Beardmore glacier, with high values beneath the slow moving areas where the ice is solid throughout and much lower values within the dynamic region. Upstream, where the glacier is grounded, attenuation appears lowest in large crevasse-like structures, a few of which extend down to the base of the glacier, suggesting regions where the ice is most susceptible to sliding. At the terminus, where the glacier floats freely and is subject to tidal forcing, we see evidence of substantial fracturing extending throughout the glacial column. Significantly, this methodology works even when applied to passive seismic data. At the Whillans Ice Stream, we have excellent resolution of the subglacial lake along with what appear to be channels for the transport of water beneath the glacier.

\section{Seismic Imaging of Active and Ancient $\mathrm{CO} 2$ Pathways in the Little Grand Wash Fault \\ YELTON, I., Boise State University, Idaho, USA, jonyelton@u.boisestate.edu}

Understanding the migration behavior of carbon dioxide during long-term geological storage is crucial to the success of carbon capture and sequestration technology as an effective strategy to diminish the effects of anthropogenic climate change. We explore $\mathrm{p}$-wave and s-wave seismic properties across the Little Grand Wash fault in east-central Utah, a natural CO2 seep and analogue for a long-failed sequestration site. Travertines dated to at least 113,000 k.y. and geochemical surveys confirm CO2 leakage. Outgassing is focused in damage zones where the total fluid pressure reduces the minimum horizontal effective stress; regional stress changes may be responsible for decadal- to millennialscale changes in $\mathrm{CO} 2$ pathways. We identify subsurface structure in the upper few hundred meters and define surface $\mathrm{CO} 2$ outgassing zones via seismic reflection and first arrival tomography. We tie our results to borehole logs, geology from outcrops, and geochemical data. Our seismic imaging results constrain the fault architecture of both active and ancient outgassing within the system. We present velocity tomograms of the fault zone and construct rock physics models from our hammer seismic data. First arrival tomography results and diffraction analysis suggest a $\sim 100 \mathrm{~m}$ wide fault zone is mostly responsible for the $\mathrm{CO} 2$ delivery to the surface. Reflection results show that this low velocity zone lies above a broad anticline. We identify low seismic velocities along 4 of 5 seismic profiles that are consistent with unconsolidated saturated sediments within the fault. In contrast, low $\mathrm{CO} 2$ flux regions outside the fault zone and at higher elevations show seismic velocities consistent with unsaturated host rock. Anomalously high seismic velocities along the fault are consistent with fault sealing. Studying the behavior of $\mathrm{CO} 2$ in this system can give insight of potential risks in future sequestration projects.

\section{Seismic Response of Natural CO2 Gas Migration Through the Little Grand Wash Fault, Utah Slivicki and Liberty} SLIVICKI, S. I., Boise State University, Idaho, USA, stsliv@hotmail.com; LIBERTY, L., Boise State University, Idaho, USA, lliberty@boisestate.edu

We explore the seismic response to $\mathrm{CO} 2$ charged eruptions and to gas migration within shallow reservoirs along the Little Grand Wash fault in eastcentral Utah. We deployed $2005 \mathrm{~Hz} 3-\mathrm{C}$ Nodal geophones for 30 days in late 2020 to track seismic tremors throughout the eruption/recharge cycle. Additionally, we conducted a 30-hour active source time-lapse surface seismic survey across the fault to capture reservoir and water elevation changes. We installed a pressure and temperature sensor in the Crystal Geyser that captured 30 days of $\mathrm{CO} 2$ changed eruption signals that were sourced from a range of reservoir depths. Geyser eruptions of 1-3 $\mathrm{m}$ in height ranged from minutes to hours, with deeper eruptions expelling higher water temperatures. We captured 13 eruptions at the geyser that were likely sourced from the $200-300 \mathrm{~m}$ deep Navajo sandstone. These eruptions lasted between one and 23 hours with a near-constant $16.9 \mathrm{dC}$ water temperature recorded at the well. Preliminary seismic analysis reveals reservoir-derived seismic signals on stations spaced as far as $1300 \mathrm{~m}$ apart. These signals appear as $1-30 \mathrm{~Hz}$ tremor that each last between 5 to 20 minutes. Ongoing analysis of the complete dataset will unravel the relationship of geyser eruptions to gas migration at reservoirs that range from 100 to $400 \mathrm{~m}$ depth. Our active source experiment consisted of $1205-\mathrm{m}$ spaced $10 \mathrm{~Hz}$ vertical geophones. This array extended across the fault where elevated $\mathrm{CO} 2$ values are observed in previous studies and where surface outgassing bubbles are visible. We observe changing surface and body wave signals over the scale of minutes to hours that relate to changing hydrostatic pressures and to gas migration at reservoir depths. 
Crustal Stress and Strain and Implications for Fault Interaction and Slip

I: Oral Session · Thursday · 22 April · 9:45 AM Pacific

II: Oral Session · Thursday · 22 April · 2:00 PM Pacific

Session Chairs: Niloufar Abolfathian, Jet Propulsion

Laboratory, Caltech (niloufar.abolfathian@jpl.nasa.gov);

Thomas Goebel, University of Memphis (thgoebel@memphis. edu); Mong-Han Huang, University of Maryland (mhhuang@ umd.edu)

\section{Analyzing Strain Partitioning in the Pacific Northwest with Block Models}

CHONG, I., California State University, Northridge, California, USA, javiercj7@gmail.com; EVANS, E. L., California State University, Northridge, California, USA, eileen.evans@csun.edu

At the Cascadia subduction zone, the Juan de Fuca plate (JdF) subducts obliquely under, and deforms, the North American plate (NA). Subduction deformation dominates deformation on land, as observed by geodetic measurements such as GNSS, limiting the resolution of surface faults on the overriding North American plate. The goal of this project is to better understand how oblique JdF-NA convergence is partitioned between surface faults in the Pacific Northwest region and the subduction zone using block models. Specifically, we apply an $\mathrm{L}_{1}$ regularization known as Total Variation Regularization (TVR) to algorithmically select the most active faults from a dense block model. We constrain the subduction zone to accumulate dip-sliponly motion and test how many surface faults are involved in strain partitioning. We find a tradeoff between megathrust activity and surface fault activity: A dip-slip-only megathrust requires more active surface faults along with greater fault slip rates than a freely slipping (oblique) megathrust. However, even with a dip-slip-only megathrust, parallel strike-slip faults near the trench are neither active nor form a simple forearc sliver. Furthermore, geologic slip rates appear to be more consistent with estimated fault slip rates in models with a freely slipping subduction zone than in models with a constrained dipslip subduction zone. In other words, near trench strike-slip faults are not required to explain onshore GNSS observations or geologic slip rates.

\section{Deformation Partitioning, Fault Branching and Kinematics and Seismic-Aseismic Slip Interaction Along the Offshore Istanbul-Marmara Section of the North Anatolian Fault, NW Turkey}

BOHNHOFF, M., GFZ German Research Centre for Geosciences, Berlin, Germany, bohnhoff@gfz-potsdam.de; MARTINEZ-GARZON, P., GFZ German Research Centre for Geosciences, Berlin, Germany, patricia@gfzpotsdam.de; DURAND, V., GFZ German Research Centre for Geosciences, Berlin, Germany, vdurand@gfz-potsdam.de; DRESEN, G., GFZ German Research Centre for Geosciences, Berlin, Germany, dre@gfz-potsdam.de; NURLU, M., AFAD, Ankara, Turkey, murat.nurlu@afad.gov.tr

The Marmara section of the North Anatolian Fault zone (NAFZ) is late in its seismic cycle and expected to produce a large (M7+) earthquake in direct vicinity to the Istanbul metropolitan region. The efforts to image and monitor the individual offshore branches of the NAFZ segment were substantially intensified following the 1999 Izmit M7.4 earthquake. However, near-fault monitoring along large portions of the offshore fault section is challenging. Distinct seismicity features now allow to identify seismically active and inactive fault branches. The observation of seismic repeaters suggest that the western portion of the Marmara fault may be creeping to a substantial extent. In contrast, the central and eastern fault segments are largely locked.

The Sea of Marmara represents a pull-apart basin. In line with regional tectonics and the GPS-derived velocity field, the crustal stress field from inversion of earthquake focal mechanisms shows overall transtension. Local fault kinematics allow identifying distinct local normal or strike-slip segments, likely reflecting the close proximity of the vertical and maximum horizontal stress magnitudes.

Recently implemented borehole-based multi-sensor deployments focus on the eastern Marmara section immediately south of Istanbul. We observe distinct slow-slip transients detected by borehole strainmeters that occur in conjunction with local moderate $(\mathrm{M}>4)$ earthquakes. Furthermore, lower magnitude-detection thresholds now allow identifying systematic preparation processes leading to $\mathrm{M}>4$ mainshocks as well as extended aftershock sequences complementing postseismic slow slip.
These observations show that further reducing the observational gap and broadening the signal frequency bandwidth allows to decipher deformation processes that previously remained undetected, now providing means for improved seismic hazard and risk models for the Istanbul metropolitan region.

\section{Dynamics of Early Afterslip-Aftershock Coevolution Following the 2004 Parkfield Earthquake}

IIANG, I., University of Oklahoma, Oklahoma, USA, jiang@ou.edu; BOCK, Y., Scripps Institution of Oceanography, University of California, San Diego, California, USA, ybock@ucsd.edu; KLEIN, E., Laboratoire de Géologie, Département de Géosciences, ENS, CNRS, UMR 8538, PSL Research University, Paris, France, klein@biotite.ens.fr

Large earthquakes often lead to transient deformation and enhanced seismic activity, with their fastest evolution occurring at the early, ephemeral postseismic period. Our knowledge of this transitional phase remains limited, due to the scarcity of on-scale broadband observations, high instrumental noise and confounding signals of source processes during this phase. Here we use high-rate geodetic and seismological observations to study the dynamics of early afterslip and aftershock evolution following the $2004 \mathrm{M}_{\mathrm{w}} 6.0$ Parkfield, California, earthquake. We image the continuous evolution of afterslip, along with aftershocks, on the San Andreas fault over a postseismic timespan from minutes to days. Our results reveal a multistage scenario, which includes immediate onset of afterslip following tens-of-seconds-long coseismic shaking, short-lived slip reversals within minutes, expanding afterslip within hours, and slip migration between sub-parallel fault strands within days. At shallower depths, the amplitude of evolving afterslip largely follows a logarithmic function of time, consistent with the prediction of velocity-strengthening rate-and-state friction using near-constant effective parameter, $(a-b)$, over extended postseismic periods, whereas deeper afterslip has an apparent time delay, suggesting the dependence of effective $(a-b)$ values on time and probably slip rates. The earliest afterslip episodes and associated stress changes appear synchronized with local aftershock rates, with aseismic moment rates larger than seismic moment rates by three orders of magnitude. In addition, growing afterslip precedes two M5 aftershocks to the northwest of the peak-slip region, further suggesting a control of aseismic slip on fine-scale aftershock behavior. We interpret the shallow afterslip-aftershock processes as dynamic signatures of a $3 \mathrm{D}$ fault-zone structure. These findings highlight important roles of aseismic source processes and structural factors in controlling seismicity evolution and offer potential prospects for improving aftershock forecasts.

\section{Estimation of Time-Dependent Strain-Rates With Gaussian Process Regression}

HETLAND, E. A., University of Michigan, Michigan, USA, ehetland@umich. edu; SZYMANSKI, E. D., University of Michigan, Michigan, USA, szymaner@ umich.edu; HINES, T. T., Maxar Technologies, Michigan, USA, hinest@ umich.edu

We use a Gaussian process regression (GPR) to determine spatiotemporally continuous maps of time-varying strain-rates from GNSS measurements, implemented as Python-based Geodetic Network Smoother (PyGeoNS). GPR is a Bayesian method, which we use to interpolate the GNSS data in both space and time. Within our framework, the prior is placed on the covariance structure of the interpolated field, and not on any assumed parameterization of the displacement field. The prior effectively constrains the spatial variation of strain-rates, along with the degree to which transient displacements are allowed, and hence the prior can be used to determine strain-rate fields at various spatial and temporal scales. The posterior is then a distribution of arbitrary functions that interpolate the GNSS data, which we then differentiate using a radial basis function, finite difference scheme to determine the strain-rates. The resolved strain-rates have quantified uncertainties and can include discontinuities in surface displacements across fault segments with potential creep. We have applied PyGeoNS to resolve transient strain-rates in the Pacific Northwest, along with Southern California (resolving minimal strain across the creeping segment of the San Andreas fault) and South Island, New Zealand. Our specific focus in this presentation is on strain-rates prior to, and following, the 2010 El Mayor-Cucapah, 2019 Ridgecrest, 2010 Darfield/Canterbury, and 2016 Kaikoura earthquakes.

\section{Using Focal Mechanisms to Distinguish Between Alternative Active Fault Configurations of the Southern San Andreas Fault at the San Gorgonio Pass}

ELSTON, H., University of Massachusetts Amherst, Massachusetts, USA, helston@umass.edu; COOKE, M. L., University of Massachusetts Amherst, Massachusetts, USA, cooke@umass.edu; MARSHALL, S. T., Appalachian 
State University, North Carolina, USA, marshallst@appstate.edu; LOVELESS, J. P., Smith College, Massachusetts, USA, jloveles@smith.edu

Debate persists on the activity of the northern pathway of the southern San Andreas fault (SAf) through the San Gorgonio Pass and recent studies propose alternative dips for faults within the southern pathway based on interpretations of seismic imaging. To delineate between plausible models, we assess the match of interseismic forward model results from four alternative 3D active subsurface fault configurations for the SAf (two variations of the southern pathway and two variations of active geometry of the northern pathway) to interseismic geodetic surface velocities and slip sense of off-fault microseismicity as well as geologic slip rates. Slip rates from the models generally all fit the geologic data with equal mismatch. Model predicted surface velocities differ by less than the GPS station uncertainties and cannot resolve activity of the northern pathway. Interseismic focal mechanisms occur at a range of depths making them more sensitive to variations in deformation below the locking depth during the interseismic period than GPS velocities at Earth's surface. Thus, the focal mechanism catalog provides additional and valuable constraints on crustal stress that drives slip. Stress states inverted from focal mechanisms generally show north-south compression for the region, consistent with expectations. Where the forward model results for microseismicity slip sense differ, the single-pathway model predicts mostly strike-slip microseismicity and matches the observed focal mechanisms better than the dual pathway model, which predicts mostly reverse slip microseismicity. We show that interseismic focal mechanisms from off-fault microseismicity record the crustal stress state such that they can be used to delineate between alternative active fault configurations. Furthermore, stress states derived from focal mechanisms can be inverted for the fault slip distribution to provide additional insight on active fault configuration and locking depth.

\section{Beyond the Damage Zone: Characterizing Widespread Inelastic Deformation From Integrated Fracture, Aftershock and Strain Maps of the 2019 Ridgecrest Sequence}

RODRIGUEZ PADILLA, A. M., University of California, Davis, California, USA, arodriguezpadilla@ucdavis.edu; OSKIN, M. E., University of California, Davis, California, USA, meoskin@ucdavis.edu; MILLINER, C. W. D., Caltech, California, USA, milliner@caltech.edu; PLESCH, A., Harvard, Massachusetts, USA, plesch@fas.harvard.edu

Fault damage zones are a key component of the earthquake energy budget and seismic hazard assessment, as they constitute a permanent sink of strain energy, modify the elastic properties of the shallow crust, threaten lifelines, and amplify ground shaking during earthquakes. Measurements of the extent of inelastic zones are typically generated from a single dataset (e.g. fracture or aftershock distribution) and capture an integrated history of deformation spanning multiple earthquakes and aseismic processes. The 2019 Ridgecrest earthquake sequence provides an unprecedented view of the distribution of inelastic deformation from high-resolution imaging, geodetic data, and earthquake catalogs. This rich dataset lets us understand how inelastic strain observed in a single event compares to and contributes to its longer-term cumulative history. We integrate high-resolution maps of fractures derived from post-earthquake lidar and drone imagery, 2D strain maps generated from cross-correlated satellite imagery, and aftershock hypocenters from the Ridgecrest QTM earthquake catalog to characterize the distribution of inelastic deformation around the fault during the coseismic and early postseismic periods. Inelastic deformation extends up to $17 \mathrm{~km}$ away from the fault and the decay of fracture density, aftershock density, and geodetic strain with distance from the main rupture is well described by an inverse power law with exponents ranging between 0.8 and 1.1. We compare our measurements of the decay of inelastic deformation to measurements of the extent of the Ridgecrest damage zone from other authors to investigate the relationship between yield strain, shear modulus contrasts, and fracture density, and its implications for the rheology of damage zones. Our analysis shows that discrete inelastic deformation extends kilometers beyond the localized damage zone $(<100 \mathrm{~m})$ and suggests that distributed, far-field yielding may account for a meaningful part of the fracture energy expenditure of earthquakes, building up over multiple earthquake cycles.

\section{How Stressed Out Are Faults? Estimating Co-Seismic Stress Using Measurements of 3D Surface Deformation with Optical Image Correlation}

MILLINER, C.W. D., Caltech, California, USA, milliner@caltech.edu

Constraining the variation of stress throughout the crust and over time has importance for improving our understanding of the mechanics of faulting.
However, estimating the orientation and amplitude of the stress state that drives coseismic fault slip is highly challenging, as slickenlines and offset geomorphic features, which are the only approach that can quantify the full coseismic slip vector, are either rare or spatially limited along ruptures. Here we use geodetic imaging based on multi-temporal and multi-sensor stereooptical imagery to measure the full 3D coseismic surface deformation pattern in high spatial detail (at meter scale pixel resolution with decimeter accuracy) that can measure the full slip vector. Using this technique, we measure the $3 \mathrm{D}$ surface deformation and coseismic slip vectors every $\sim 100 \mathrm{~m}$ along a number of surface rupturing, continental oblique strike-slip earthquakes including, the $2010 \mathrm{M}_{\mathrm{w}} 7.2$ El-Mayor Cucapah, $2016 \mathrm{M}_{\mathrm{w}} 7.1$ Kumamoto, $2016 \mathrm{M}_{\mathrm{w}}$ 7.8 Kaikoura and $2019 \mathrm{M}_{\mathrm{w}} 7.3$ Ridgecrest earthquakes. From the coseismic surface slip vector data we then invert for the coseismic 3D stress tensor in a manner similar to that of inverting focal mechanisms to estimate the interseismic and postseismic stress orientations. With estimates of the co-seismic stress state for a number of surface rupturing events we will discuss how the strength of faults varies as a function of structural maturity, whether the stress orientation is spatially homogenous or varies significantly along the rupture length, whether stresses rotate from the far-field towards the fault-zone and if there are any significant temporal changes of stress between the inter-, co- and post-seismic periods.

\section{Strain Compatibility Between the Intersecting Airport Lake and Garlock Faults, California}

WALKER, J, University of Kansas, Kansas, USA, jdwalker@ku.edu; ANDREW, J. E., University of Kansas, Kansas, USA, jeandrew@ku.edu; KIRBY, E., University of North Carolina at Chapel Hill, North Carolina, USA, ekirby@unc.edu

How dextral shear along the Eastern California shear zone (ECSZ) is sustained across the Garlock fault without apparent cross-cutting geologic relationships remains a long-standing problem in the Cenozoic tectonics of the Mojave Desert that has implications for the mechanical interactions of intersecting fault networks. Our mapping following the 2019 Ridgecrest Earthquake and improved geodetic and seismological perspective from this event gives us clues into how the intersections of dextral strike-slip faults of the ECSZ with the sinistral Garlock fault can be relatively stable and maintain strain compatibility during accumulated deformation. The earthquake sequence along the Airport Lake fault generated surface deformation within $500 \mathrm{~m}$ of the Garlock fault. Following the event, the Garlock fault saw triggered creep resulting in minor sinistral motion.

The Garlock fault has almost $65 \mathrm{~km}$ of total slip and shows rates from 5 to $15 \mathrm{~mm} / \mathrm{yr}$. Pliocene strata immediately north of the Garlock fault are displaced $\sim 1.6 \mathrm{~km}$ dextrally across the Airport Lake fault, as are Mesozoic basement rocks. This indicates that the time-average slip rate on the Airport Lake fault is likely $1 \mathrm{~mm} / \mathrm{yr}$ or less. Despite the accrued displacement, the Garlock fault trace at the projected intersection appears to be undeformed. These kinematic and geometric relationships suggest a model by which strain passes from the Airport Lake fault to the Garlock fault zone. Airport Lake strain is absorbed by distributed deformation adjacent to the Garlock fault zone by $\mathrm{P}, \mathrm{R}$, and R' shears related to that fault. We suggest that strain accumulates within a broad, up to $1 \mathrm{~km}$ wide, zone of fault damage and shear parallel to the Garlock fault. This region acts as a compliant buffer zone, into which displacements along ECSZ structures are absorbed. The slip rate difference of nearly a factor of 10 between individual ECSZ structures and the Garlock fault essentially leads to finite strain accumulated along the broad Garlock fault zone that effectively overprints and absorbs deformation on the Airport Lake fault.

\section{Stress-Strain Characterization of Seismic Sequences in Southern California Using Moment Measures of Mechanism Complexity}

JUAREZ, A., University of Southern California, California, USA, alanjuar@ usc.edu; JORDAN, T. H., University of Southern California, California, USA, tjordan@usc.edu

We develop a probabilistic model for characterizing stress and strain fields using mechanism complexity measures derived from moment tensor fields. Distributions of source mechanisms in seismic sequences and earthquake ruptures are used to estimate the ratio of the Aki moment to the total moment and the moment partitioning of the moment tensor field over an orthonormal basis of five deviatoric mechanisms. These complexity measures are then used to estimate the principal-stress directions, a differential stress ratio (R), and a strain-sensitivity parameter $(\kappa)$. Larger values of $\kappa$ indicate higher sensitivity to stress magnitude and thus lower complexity. We apply the model to characterize the stress and strain fields of seismic sequences in Southern California. Temporal monitoring of San Jacinto Fault seismicity from 1981 
2019 does not reveal any significant changes in the principal stress orientation; during this period, $\mathrm{R}=0.42 \pm 0.1$, and $\kappa=5.5 \pm 2$. The seismicity associated with El Mayor-Cucapah earthquake of 2010 shows a relatively low complexity before the mainshock $(\kappa=10.5 \pm 4.6)$ and higher complexity during the aftershock sequence $(\kappa=5 \pm 2.5)$, suggesting that the stress change during the mainshock promoted fault ruptures with more diverse orientations. In contrast, the seismicity before the Ridgecrest earthquake of 2019 shows a relatively high complexity $(\kappa=3.5 \pm 2)$, while the aftershocks show less complexity $(\kappa=6 \pm 2)$ indicating that the aftershocks are more aligned with the mainshock mechanisms and have less complexity than the background seismicity.

\section{Stress-Strain Characterization of Seismic Source Fields Using Moment Measures of Mechanism Complexity} LORDAN, T. H., University of Southern California, California, USA, tjordan@ usc.edu; JUAREZ, A., University of Southern California, California, USA, alanjuar@usc.edu

Earthquake ruptures and seismic sequences can be very complex, involving slip in various directions on surfaces of variable orientation. How is this geometrical complexity in seismic energy release, here called mechanism complexity, governed by tectonic stress? We address this question by formulating a probabilistic model for the distribution of double couples consistent with three assumptions commonly used in regional stress inversions: the tectonic stress is constant, slip vectors are aligned with the maximum shear traction in the plane of slip, and higher shear stress promotes more seismic energy release. We characterize the moment-tensor field of a stress-aligned source process by an ordered set of principal-stress directions, a differential stress ratio $R$, and a strain-sensitivity parameter $\kappa$. The latter governs the dependence of the seismic moment density on the shear-traction magnitude and therefore parameterizes the seismic strain response to stress. The stress-strain characterization (SSC) parameters are determined by moment measures of mechanism complexity that can be observed in large earthquakes and seismic sequences. These moment measures are the ratio of the Aki moment to the total moment and the total-moment fractions partitioned by the projection of the momenttensor field onto an orthonormal basis of five deviatoric source mechanisms We construct this basis to be stress-oriented by choosing its leading member to be the centroid moment tensor (CMT) mechanism and three others to represent orthogonal rotations of the CMT mechanism about its principal axes. From the projections of the stress-aligned field onto this stress-oriented basis, we derive explicit expressions for the moment-fraction integrals as functions of $R$ and $\kappa$. The SSC model provides a theoretical foundation for the stressstrain characterization of any moment-tensor field, including earthquake stress gluts, fault-zone seismicity, and seismic sequences.

\section{Crustal Stress and Strain and Implications for Fault Interaction and Slip \\ Poster Session - Thursday · 22 April - 11:30 Am Pacific Session Chairs: Niloufar Abolfathian, Jet Propulsion Laboratory, Caltech (niloufar.abolfathian@jpl.nasa.gov); Thomas Goebel, University of Memphis (thgoebel@memphis. edu); Mong-Han Huang, University of Maryland (mhhuang@ umd.edu)}

\section{Constraints on Crustal Stress in South Island, New Zealand from Coseismic Slip Models of the 2016 Kaikoura, 2010 Darfield and 2011 Christchurch Earthquakes}

HELPRIN, O. L., University of Michigan, Michigan, USA, ohelprin@umich. edu; HETLAND, E. A., University of Michigan, Michigan, USA, ehetland@ umich.edu

We estimate the tensorial seismogenic stresses that led to the $2016 \mathrm{M}_{\mathrm{w}} 7.8$ Kaikoura, $2010 \mathrm{M}_{\mathrm{w}} 7.1$ Darfield, and $2011 \mathrm{M}_{\mathrm{w}} 6.3$ Christchurch earthquakes, using published geodetically and seismically derived coseismic slip models. We estimate the orientations of the principal stresses and the relative magnitudes of the least and intermediate compressive stresses relative to the most compressive stresses (MCS; the MCS magnitude cannot be constrained from coseismic slip data). Our estimation of stress relies on the Wallace-Bott assumption, which posits that when a fault slips, it does so in the direction in which it was loaded, and thus our estimated stresses are those prior to the individual earthquakes. We consider eleven coseismic slip models, seven of the Kaikoura earthquake, and two each of the Darfield and Christchurch earth- quakes. We estimate the stress using a Markov Chain Monte Carlo strategy. For all of the earthquakes, we find that the relative magnitudes of the principal stresses are poorly constrained, and that each of the coseismic slip models are individually consistent with a single stress state, despite the complexity in some of the slip models. There are noticeable differences in the stress orientations estimated from the coseismic slip models of the three earthquakes, although most of the models indicate a roughly EW trending, sub-horizontal to shallowly plunging MCS direction. Preliminary results indicate significant changes in stress from the Kaikoura earthquake to the two earthquakes to the south. The least compressive stress (LCS) direction estimated from the Kaikoura coseismic slip models is near vertical, while LCS is estimated to be sub-horizontal from the Darfield and Christchurch earthquakes, indicating a transition from a thrust-like to a strike-slip stress regime from north to south along the east coast of South Island, New Zealand.

\section{Crustal Stress Orientations in Japan Islands Inferred From Focal Mechanism Solutions of Small and Microearthquakes UCHIDE, T., Geological Survey of Japan, AIST, Tsukuba, Japan, t.uchide@ aist.go.jp; IMANISHI, K., Geological Survey of Japan, AIST, Tsukuba, Japan, k.imanishi@aist.go.jp}

Understanding of crustal deformation and forecast of inland earthquakes need knowledge on the crustal stress orientation. Estimated stress orientations have been compiled as the World Stress Map (Heidbach et al., 2018). In the case of Japan Islands, Terakawa et al. (2010) estimated the stress orientations using moment tensor solutions from the routine catalog of NIED F-net for typically $M \geq 3.5$. The resolution of the stress field estimation is limited by data. Moreover, there are many areas with no focal mechanism solutions. The stress orientations in no data areas may be different from their surroundings (e.g., Imanishi et al. (2012)). Therefore, we desire the focal mechanisms of even smaller earthquakes. Thanks to the recent development of deep learning, Uchide (2020) studies focal mechanisms of $\sim 110$ thousand events with M 1.5 or larger beneath Japan Islands. Using this technique, we estimate the crustal stress orientation of the Japan Islands.

First, we determined focal mechanisms of small to microearthquakes around Japan Islands by HASH method (Hardebeck and Shearer, 2002) using P-wave first-motion polarities. Seismic data were from NIED Hi-net, JMA, and GSJ/AIST. P-wave arrival times were from the JMA catalog and firstmotion polarities were picked by the neural network model of Uchide (2020). We selected earthquakes with JMA magnitudes greater than 0.5 , inside of or within $50 \mathrm{~km}$ from coastlines of Japan Islands, and at depths less than $20 \mathrm{~km}$. As a result, we analyzed $\sim 573$ thousand events.

The stress orientation was estimated using the SATSI code (Hardebeck and Michael, 2006). The grid interval was $0.2^{\circ}$ for both latitude and longitude. Several small-scale stress anomalies were seen: normal faulting areas in northeast Japan; stress orientation changed at the southern end of ItoigawaShizuoka Tectonic Line; and stress anomaly around Cape Shionomisaki of Kii peninsula, beneath which a high-density block was detected (Honda and Kono, 2005). This study will help discover and understand seismotectonics.

\section{Investigation of Stress Field in Northeast of Iran With Iterative Joint Inversion of Earthquakes Focal Mechanisms} KHOJASTEH, F., University of Tehran, Tehran, Iran, Islamic Republic Of, sahar.khojaste7773@gmail.com; BEYRANVAND, M., University of Tehran, Tehran, Iran, Islamic Republic Of, mbeiranvand@iran.ir; MIRZAEI, N., University of Tehran, Tehran, Iran, Islamic Republic Of, nmirzaii@ut.ac.ir

Northeastern Iran is one of the active seismic zones which has experienced many destructive earthquakes throughout history. The purpose of this study is to investigate the stress field using the focal mechanism solution of the earthquakes in the area with Iterative Joint Inversion Method. For this purpose, the focal mechanisms of earthquakes with a magnitude greater than 4.5 which occurred between 1992 and 2017 are reviewed. Information about these earthquakes has been gathered from the International Seismological Center (ISC). In this research, two zones for inversion and also assumption of the independence of events are considered. In this assumption, the focal mechanisms considered for the inversion are supposed to sample the unperturbedregional stress field. Hence they must be independent of each other, i.e. they mustinvolve events that are far enough from each other so that stress variations associated with any previous earthquake do not influence in a significant manner the stress field nearthe event under consideration. With this assumption, 15 earthquakes were used in the inversion. The obtained stress regime governing the region compression with a strike-slip component and strike-slip with compressive component, The maximum horizontal stress directions in two zones are N36.46W and N29.65W, respectively, which show the dominance of local pressure structures such as Freeman, Kasf-Rood and 
Mozurdan faults (the end section of the Kashf-Rud fault) in the region. Also, the stress regime obtained for the second zone indicates the existence of a strike slip faulting mechanism. Finally, global stress map was used to compare the results of this research.

Keywords: Maximum Horizontal Stress, Focal mechanisms, Stress field, Inversion.

\section{Spatiotemporal Variations of Stress in the Crust Near 2019 Ridgecrest Sequence Earthquakes}

ABOLFATHIAN, N., Jet Propulsion Laboratory, Caltech, California, USA, niloufar.abolfathian@jpl.nasa.gov; FIELDING, E. J., Jet Propulsion Laboratory, Caltech, California, USA, eric.j.fielding@jpl.nasa.gov

Advances in geodetic and seismic data acquisition, analysis methods, and computational capabilities allow spatiotemporal estimations of stress in high-resolution in the Earth's crust. Geodetic imaging observations of surface displacements provide information on the crustal deformation and strain variations within the earthquake cycle (i.e., interseismic, coseismic, and postseismic), and can be used to model for the stress distribution. Whereas, seismicity provides detailed information on failures within the seismogenic zone. In this study, we use interferometric synthetic aperture radar (InSAR) to measure the postseismic surface deformation and infer afterslip on faults near or in the main coseismic ruptures from the Ridgecrest sequence between 2019-2020. The Caltech-JPL Advanced Rapid Imaging and Analysis (ARIA) project has been systematically processing InSAR data from the Copernicus Sentinel- 1 satellites, and include data every 6 and 12 days over the Ridgecrest area. Moreover, we examine the associated stress field inverting the seismic data and estimate the $4 \mathrm{D}$ spatiotemporal stress field variations to compare it to the afterslip estimates. The ultimate goal is detecting zones with higher stress accumulations that are potential for seismic hazard. Further research will improve the understanding of deformation processes, fault mechanics, fault system interactions, and rheology of the lithosphere and enhance our knowledge on long term earthquake forecasting.

Cryptic Faults: Assessing Seismic Hazard on Slow Slipping, Blind or Distributed Fault Systems

I: Oral Session · Wednesday · 21 April · 9:45 AM Pacific

II: Oral Session · Wednesday · 21 April · 2:00 PM Pacific

Session Chairs: Jessica A. T. Jobe, U.S. Bureau of Reclamation (jessietjobe@gmail.com); Stephen J. Angster, U.S. Geological Survey (sangster@usgs.gov)

Estimating Fault Slip Rates in the Cascadia Region of North America Using Joint Geologic-Geodetic Block Modeling

STYRON, R. H., GEM Foundation, Oregon, USA, richard.styron@ globalquakemodel.org; HOBBS, T. E., Natural Resources Canada, Vancouver, Canada, thobbs@eoas.ubc.ca; HARRICHHAUSEN, N., University of California, Santa Barbara, California, USA, nharrichhausen@ucsb.edu; JOURNEAY, J. M., Natural Resources Canada, Squamish, Canada, murray. journeay@canada.ca

The western margin of North America in the Cascadia region is known to be seismically active, but the locations, geometries, kinematics and slip rates of the primary upper plate faults are very incompletely known. This is in large part due to environmental challenges, including rugged terrain, dense vegetation, and rapid geomorphic processes that quickly modify or erase the surface signature left by crustal faulting. To improve seismic hazard analysis in the area, we are characterizing hundreds of faults throughout British Columbia Washington, Oregon and their periphery through the construction of a largescale, high-resolution tectonic block model. In the model, independentlymoving blocks are separated by faults, which slip at the rate of local relative block motion. This technique allows us to incorporate and integrate a range of datasets including geologic mapping, high-resolution topography data, GNSS geodetic data, and Quaternary fault slip rate data. To make the model, fault traces are mapped in GIS. Then, blocks are constructed by connecting fault traces, considering these same data as well as earthquake hypocenters as well as other available information. The block modeling program then solves for the rotation poles of all blocks by inverting GNSS and Quaternary fault slip rate data, and accounting for the effects of locking of faults and the Cascadia megathrust on GNSS velocities, and predicts internally-consistent slip rates for each fault in the model. As this work is in progress, we will present provi- sional results, and discuss the possibilities and challenges of the work, including the nature of fault connectivity and off-fault deformation.

\section{Evidence for Quaternary Activity on the Duchesne-Pleasant} Valley Fault, Uinta Basin, Utah

HOWE, I., U.S. Bureau of Reclamation, Colorado, USA, juliachowe@gmail. com; KLINGER, R., U.S. Bureau of Reclamation, Colorado, USA, rklinger@ usbr.gov

The Duchesne-Pleasant Valley fault is an east-west oriented fault zone in eastern Utah near the boundary between the Basin and Range and the northern Colorado Plateau; an area where the style and magnitude of active deformation is not well-understood. The fault zone is $\sim 70 \mathrm{~km}$ in length and is composed of two primary fault strands separated by an $\sim 4 \mathrm{~km}$-wide right step about midway along the fault zone. Although the fault has strong geomorphic expression in aerial imagery and prominent scarps, previous workers have disputed whether it is Quaternary-active. An alternative hypothesis suggested that differential erosion along faulted bedrock contacts, related to faulting of the Eocene Green River and Uinta Formations, has formed these prominent scarps along the fault.

In a preliminary study, we mapped fault-related lineaments using a publicly available lidar dataset encompassing the Uinta basin and identified multiple previously unmapped fault scarps across Quaternary deposits. Field reconnaissance was limited to an area of distributed faulting within the fault step-over, where scarps with greater vertical displacement are coincident with more abundant Quaternary deposits. Within the step-over, there are low amplitude scarps (up to $\sim 1 \mathrm{~m}$ ) that cross a mapped gravel pediment surface (estimated $\sim 800-250 \mathrm{ka}$ ). Fault scarps varying in height from $\sim 0.5 \mathrm{~m}-1 \mathrm{~m}$ also cross surfaces (latest Quaternary?), adjacent to and topographically lower than the pediment surface, that grade to the active drainage. Although bedrock scarps are prevalent along the fault, we observed a nonresistant mudstone unit on the up-thrown side of the fault in various locations, which is inconsistent with the idea that scarps are formed by differential erosion of bedrock. These new lines of evidence suggest that the Duchesne-Pleasant Valley fault is Quaternary-active.

\section{High-Resolution, Marine Geophysical Insights Into Quaternary Deformation and Long-Term Structural Evolution of the Seattle Fault Zone}

MOORE, G. L., University of Washington, Washington, USA, ginevra@ uw.edu; ROLAND, E., Western Washington University, Washington, USA rolande2@wwu.edu; BENNETT, S., U.S. Geological Survey, Oregon, USA, sekbennett@usgs.gov; WATT, J., U.S. Geological Survey, California, USA jwatt@usgs.gov; KLUESNER, J., U.S. Geological Survey, California, USA, jkluesner@usgs.gov; BROTHERS, D. S., Pacific Coastal and Marine Science Center, California, USA, dbrothers@usgs.gov; MYERS, E., University of Washington, Washington, USA, ekmyers@uw.edu

The Seattle fault zone (SFZ) is a distributed, N-vergent thrust fault system that underlies the Seattle metropolitan area. Evidence of Holocene land-level changes, landslides, liquefaction, and a local tsunami indicate that this $70-\mathrm{km}$ long fault system is active and can host M7-7.5 earthquakes. Here we use $>325$ $\mathrm{km}$ of co-located multichannel seismic reflection imagery and chirp profiles to image the upper $\sim 300 \mathrm{~m}$ of the subsurface at $<1 \mathrm{~m}$ resolution across active faults in Puget Sound and Lake Washington. We use near-surface images of bedrock unconformities and overlying Quaternary geology to connect deeper crustal-scale structural interpretations from legacy seismic data with geomorphic and paleoseismic evidence of onshore Holocene fault slip to develop an improved structural model of the SFZ.

In Rich Passage, south of Bainbridge Island, we image the nearsurface expression of the Orchard Point fault (OPF), one of many primary S-dipping strands of the SFZ mapped from regional-scale geophysics. Here the Oligocene Blakeley Harbor formation dips $45-80^{\circ}$ to the north, likely in the forelimb of a fault propagation fold on the OPF and Blakely Harbor fault, another nearby S-dipping strand of the SFZ. Onlapping Quaternary glacial units and Holocene deformation patterns indicate that the OPF is inactive, and that the Rich Passage is now overprinted by backthrusting and folding in the hanging wall of a blind, S-dipping fault strand farther north. These shallow subsurface interpretations, integrated with existing bedrock geology, crustalscale geophysics, and kinematic modeling of the 900-930 AD Restoration Point earthquake, suggest that the SFZ is a fault propagation fold, with an active deformation front that has stepped forward (north) over time. Trishear forward modeling of the proposed multi-phase, normal-sequence fault propagation fold geometry indicates that the SFZ could be accommodating 20\% of the 4-6 mm/yr north-south shortening throughout the Puget Lowland over the last 13 million years. 


\section{How Many Samples Do You Need to Date That Paleoearthquake? A Field Test of Portable OSL Using 345 Samples from a Single Colluvial-Wedge Exposure} DUROSS, C. B., U.S. Geological Survey, Colorado, USA, cduross@usgs.gov; GRAY, H. J., U.S. Geological Survey, Colorado, USA, hgray@usgs.gov; GOLD, R. D., U.S. Geological Survey, Colorado, USA, rgold@usgs.gov; NICOVICH, S. R., Bureau of Reclamation, Colorado, USA, snicovich@usbr.gov; MAHAN, S. A., U.S. Geological Survey, Colorado, USA, smahan@usgs.gov

Paleoseismic records for slow slip rate and cryptic fault systems are typically spatially and/or temporally limited. For these faults, few surface-rupturing earthquakes, geochronological constraints, and/or paleoseismic sites provide the basis for estimates of earthquake timing, recurrence, rupture extent, and ultimately, estimates of seismic hazard. With this in mind, we set out to test several aspects of normal fault colluvial sedimentation and surface burial using radiocarbon and portable optically stimulated luminescence (OSL) dating. Our principal goal is to explore spatial and temporal age variability, colluvial-wedge deposition and soil-burial processes, and the extent to which earthquake-timing uncertainties relate to sample quantity and stratigraphic context. To achieve this, we investigated the Wasatch fault in central Utah at the Deep Creek site. Here, a natural exposure records a single prehistoric surface-rupturing earthquake and includes alluvial-fan gravel and a paleosol that are vertically displaced $\sim 1.8 \mathrm{~m}$ and buried by a $\leq 1.5-\mathrm{m}$-thick deposit of fault-scarp-derived colluvial sediment. We extensively sampled the $\sim 3$-m-long fault exposure for both radiocarbon and OSL dating. Radiocarbon ages for charcoal from 35 bulk soil samples together with 11 traditional OSL ages complement $\sim 345$ portable OSL samples evenly spaced across the soilcolluvium contact and yield a total density of $\sim 70$ samples $/ \mathrm{m}^{2}$. Together, these samples approximate an age map of the exposure and resolve vertical (age versus depth) and horizontal (age versus distance from the fault) trends in the alluvial fan, paleosol, and colluvium. Our results highlight processes of soil formation, colluvial-wedge deposition, and postdepositional disturbance, and have implications for the sampling and dating of paleoseismic exposures, the use of portable OSL in the field, and how sample quantity, spatial distribution, and stratigraphic context influence estimates of earthquake-timing uncertainty.

\section{Searching for an Invisible Holocene Fault Beneath an Urban Region: A Case From Datong City, Northern China} REN, I., National Institute of Natural Hazards, Ministry of Emergency Management of China, Beijing, China, renjunjie@gmail.com; GUO, F., National Institute of Natural Hazards, Ministry of Emergency Management of China, Beijing, China, 1225501669@qq.com; LI, K., National Institute of Natural Hazards, Ministry of Emergency Management of China, Beijing, China, likang8899@aliyun.com; GUO, H., National Institute of Natural Hazards, Ministry of Emergency Management of China, Beijing, China, huiguo@ninhm.ac.cn; XU, X., National Institute of Natural Hazards, Ministry of Emergency Management of China, Beijing, China, xiweixu@vip.sina.com

A large earthquake in a city always causes a huge loss in the economy and big casualties. This type of large earthquake is related to Holocene faults generally with displaced landforms. Therefore, finding active faults under a city will be essential for disaster prevention and mitigation. In the urban active fault surveying project, the popular techniques are seismic reflection exploration and drilling that are expensive and time-consuming but include big uncertainties. In the middle part of the Datong Basin, the Shuiyu fault crosses the Yudong District of the Datong City, north China. While the urbanization in the past 20 years brings about dense buildings and cement roads that have erased the origin landforms and make the possibly visible fault trace invisible. Although the seismic reflection results show evidence for a potentially active fault beneath the Yudong District, the fault trace is hard to accurately determine, and the late Quaternary activity of the fault remains unclear. Here, we introduce the stereo-photographic technique of old aerial photos taken in the1960's to reconstruct the original DEM data along the fault. We use trenching and radiocarbon dating to recover the paleoearthquake in the late Quaternary. Trenching results show at least five normal surface-rupturing events occurred in the late Quaternary along the Shuiyu fault, and the original DEM data indicate two or three clear scarps along the strike of the Shuiyu fault. The fault exposures in the foundation excavation of the buildings validate that the scarps are related to displaced terrace T3 by the Shuiyu fault. The height of the scarp and dating of terrace T3 indicates that the Shuiyu fault has a normal slip rate of about $0.12-0.21 \mathrm{~mm} / \mathrm{yr}$. Given the elapsed time of $\sim 10 \mathrm{ka}$, the Shuiyu fault beneath the Yudong District will increase the risk of a large earthquake in the future. Besides, the old aerial photos before the urbanization can provide unique clues for active faults beneath a city and make the invisible fault visible.
Assessing Seismic Hazard on Offshore Fault Sources Using New Coastal Record Techniques: Example From the Central Hikurangi Subduction Zone, New Zealand

LITCHFIELD, N., GNS Science, Lower Hutt, New Zealand, n.litchfield@ gns.cri.nz; MORGENSTERN, R., GNS Science, Lower Hutt, New Zealand, r.morgenstern@gns.cri.nz; CLARK, K., GNS Science, Lower Hutt, New Zealand, k.clark@gns.cri.nz; HOWELL, A., GNS Science, Christchurch, New Zealand, a.howell@gns.cri.nz

A large proportion of the world's population live on coasts, and in tectonic settings these communities are increasingly vulnerable to seismic and tsunami hazards. Characterising earthquake fault sources in coastal settings can be challenging, particularly if faults are wholly submarine and so cannot be studied by conventional paleoseismic techniques. Nearshore faults are particularly challenging to characterise because of the difficulties in obtaining geophysical data in shallow water and yet are likely to present the highest hazard. Conventional techniques studying coastal paleoearthquake records such as coseismic marine terraces are increasingly being complemented by new techniques such as lidar, UAV and high-resolution dating using Bayesian statistical modelling. We present a paleoseismic study of marine terraces using these techniques at Aramoana, southern Hawke's Bay region, New Zealand, in the central Hikurangi Subduction Margin. This area overlies a partially locked part of the subduction interface and has a system of poorly-constrained upper plate thrust faults mapped $\sim 6 \mathrm{~km}$ offshore. Three Holocene marine terraces are well expressed in lidar and UAV data and a trench confirms each is underlain by a subhorizontal shore platform separated by large (1-4.5 m) steps, a morphology interpreted to have formed by shore platform erosion interrupted by three earthquakes. OxCal modelling of 38 radiocarbon ages from the beach deposits in the trench constrain three discrete clusters of shell ages in the last 7000 years, with uncertainties of 300-400 years. Some of these correlate with paleoearthquake ages from other marine terrace and subsiding lagoon sites up to $75 \mathrm{~km}$ north of Aramoana, but not with earthquake ages from the northern Hikurangi Subduction Margin, suggesting the earthquake sources are not great (M8+) subduction earthquakes. Results from simple elastic dislocation models suggest that the earthquake sources are unlikely to be individual nearshore faults but could be multi-fault ruptures on the upper plate faults or localised subduction earthquakes.

\section{Cycles of Earthquake Deformation on the Patton Bay Splay-Fault System Implied by Late Holocene Shoreline Evolution on Montague Island, Alaska}

WITTER, R., U.S. Geological Survey, Alaska, USA, rwitter@usgs.gov; DEPAOLIS, J., Virginia Tech, Virginia, USA, jessicad@vt.edu; HAEUSSLER, P. J., U.S. Geological Survey, Alaska, USA, pheuslr@usgs.gov; BENDER, A. M., U.S. Geological Survey, Alaska, USA, abender@usgs.gov; CURRAN, J., U.S. Geological Survey, Alaska, USA, jcurran@usgs.gov; HEMPHILL-HALEY, E., Hemphill-Haley Consulting, California, USA, ehhaley@gmail.com; LEONI, M., University of Alaska Anchorage, Alaska, USA, mplleoni@gmail. com; LEWINTER, A. L., Cold Regions Research \& Engineering Laboratory, New Hampshire, USA, adam.llewinter@erdc.dren.mil; FILIANO, D. L., Cold Regions Research \& Engineering Laboratory, New Hampshire, USA, dominic.l.filiano@erdc.dren.mil

The coastal geomorphology of Montague Island, Prince William Sound (PWS), Alaska reveals a history of relative sea-level change recorded by emergent marine terraces, orphaned beach ridges, and drained lagoons along the active Patton Bay Splay-Fault System (PBFS). The PBFS, including the Hanning Bay, Patton Bay and Cape Cleare faults, ruptured coseismically with the subduction megathrust in the 1964 Great Alaska Earthquake, contributed to tsunami generation, and vertically displaced shorelines by as much as $10 \mathrm{~m}$. However, few data exist to reconstruct the slip history of the PBFS, or assess how often splay faults rupture in concert with the megathrust. Here we investigate a sequence of drained lagoons barred by constructional beach ridges that chronicle 4200 yrs of prograding shorelines on the island's western coast. Accounts of British explorers, tidal observations and satellite geodesy imply gradual, vertical subsidence of Montague Island before and after the 1964 earthquake - measured presently at $-2.0 \mathrm{~mm} / \mathrm{yr}$. We test the hypothesis that the island's coastal geology records repeated cycles of coseismic uplift on the PBFS followed by interseismic subsidence. Interpretations of lidar maps and historical aerial imagery show a series of 3-4 beach ridges that delineate coastal terraces, including lagoons that drained after the 1964 earthquake. Some ridges define older lagoons that drained prior to the 1964 earthquake. Underlying the lagoons, sharp contacts between inorganic sand/silt and overlying peat mark sudden changes in depositional environment. Fossil bivalves in the sand/silt and fossil diatoms in peat indicate changes from brackishmarine to freshwater environments. These observations suggest that earth- 
quake uplift prior to 1964 also drained lagoons and shifted shorelines seaward. If sharp stratigraphic contacts mark episodes of coseismic uplift, then ${ }^{14} \mathrm{C}$ ages suggest that the PBFS ruptured in $4.2 \mathrm{ka}, 2.6 \mathrm{ka}, 2.0 \mathrm{ka}$, and $0.8 \mathrm{ka}-$ times, within error, of megathrust earthquakes in PWS.

\section{Investigating the Slip History of the Multi-Stranded Patton} Bay Megasplay Fault System, Montague Island, Alaska

HAEUSSLER, P. I., U.S. Geological Survey, Alaska, USA, pheuslr@usgs. gov; TOBIN, H. J., University of Washington, Washington, USA, htobin@ uw.edu; WITTER, R., U.S. Geological Survey, Alaska, USA, rwitter@usgs. gov; BENDER, A. M., U.S. Geological Survey, Alaska, USA, abender@usgs. gov; LEWINTER, A. L., Cold Regions Research and Engineering Laboratory, New Hampshire, USA, adam.l.lewinter@erdc.dren.mil; FILIANO, D L., Cold Regions Research and Engineering Laboratory, Alaska, USA, dominic.l.filiano@erdc.dren.mil; O’SULLIVAN, P., GeoSep Services, Idaho USA, posullivan@geoseps.com; BROTHERS, D. S., U.S. Geological Survey, California, USA, dbrothers@usgs.gov

We investigated the southwestern end of the Patton Bay megathrust splay fault system on Montague Island, Alaska, to map 1964 surface rupture, characterize fault rock and off-fault deformation and evaluate linkages to offshore fault strands. The Patton Bay fault ruptured to the surface in the $1964 \mathrm{M}_{w} 9.2$ Great Alaska earthquake, contributed to tsunami generation and displaced shorelines up to $10 \mathrm{~m}$ vertically. We collected new LiDAR data over this region to identify both the "Strike Creek" fault strand that ruptured in the 1964 earthquake and the "Deception Creek" fault strand $2 \mathrm{~km}$ to the northwest. Plafker (1967, USGS PP543-G) mapped both faults and found no evidence of surface rupture of the Deception Creek strand during the 1964 earthquake. During our fieldwork, we located the Strike Creek strand in forested uplands as one or two fault traces with NW-side-up scarps up to 1-m high. Tilted trees, open fissures, and left-transtensional fractures also defined the scarps. On the shoreline and beach bluffs, we were unable to precisely locate the fault in bedrock, despite excellent exposure and Plafker's (1967) careful documentation of this part of the rupture. Similar Paleogene bedrock sandstone beds are on both sides of the fault and the relationships do not require significant offsets. These observations are consistent with the hypothesis that the 1964 rupture was the first rupture of this strand of the fault. Despite the lack of evidence of 1964 rupture of the Deception Creek strand, we documented a large NW-side-up scarp up to $\sim 15 \mathrm{~m}$ tall, a well-developed fault gouge zone up to 1 -m wide, and an associated damage zone. This strand is co-linear with the offshore trace of the Patton Bay fault, which we mapped with multibeam sonar. We conclude the Deception Creek is the main strand of the Patton Bay fault system on SW Montague Island, despite not rupturing in 1964. The different geomorphic expressions and geological characteristics of these two strands illustrate the variability of splay fault activation in megathrust events.

\section{Multidisciplinary Quaternary Deformation Analysis in a Complex Low Tectonic Setting-The Example of SW Portugal, Europe}

FIGUEIREDO, P. M., North Carolina State University, North Carolina, USA, paula_figueiredo@ncsu.edu; ROCKWELL, T. K., San Diego State University, California, USA, trockwell@sdsu.edu; CABRAL, J., Universidade de Lisboa, Lisboa, Portugal, jcabral@fc.ul.pt

Studies of active tectonics can be challenging in areas with low strain rates and long recurrence periods. Increased difficulty can arise from complex surface processes that mask or obliterate deformation. Nonetheless, these are tectonically active areas capable of infrequent moderate to large magnitude seismicity that can impact and disrupt society. One such case is the SW of Portugal, close to theAfrica-Eurasia plate boundary $(4-5 \mathrm{~mm} / \mathrm{yr}$ ) which drives the Quaternary reactivation of several inherited structures. Individual slip-rates are low, ranging up to a few $0.1 \mathrm{~mm} / \mathrm{yr}$ with recurrence periods of tens of $\mathrm{ka}$ however some structures are large enough to produce large magnitude events like the $\mathrm{Mw} \geq 81755$ Lisbon $\mathrm{EQ}$. Erosion processes are dominant, affecting preservation of $\mathrm{Q}$ sediments and landforms. To overcome the challenges, we performed a multidisciplinary analysis combining and cross-correlating different tools and approaches. Long and short term deformations were investigated primarily by geologic and geomorphologic analyses complemented with geophysics, remote sensing and geodesy. The dominance of erosion constraint applying geochronology methods and led to difficulties to interpret distribution of deformation in time and space. To overcome this, we did a regional morphotectonic analyses built on a set of morphotectonic indices As expected, different indices show different sensibilities to the landscape and by themselves may not provide sufficient information. However, their crosscorrelation allowed an adequate interpretation for a tectonic forcing, even in a low tectonic rate setting. Results demonstrate that SW Portugal is undergoing uplift at higher rates than neighboring areas and is delimited by major active structures. A geodetic analysis based on $\sim 20$ years data suggests that SW Portugal is accommodating deformation differently, behaving as a tectonic block. A careful "geo" multidisciplinary approach is crucial to validate observations and recognize "non-obvious" yet hazardous "slow" active structures.

\section{Stairways to Hazard: Quantifying Geologic Slip Rate Variability Along Low Strain Rate Faults}

HATEM, A. E., U.S. Geological Survey, Colorado, USA, ahatem@usgs. gov; GOLD, R. D., U.S. Geological Survey, Colorado, USA, rgold@usgs.gov; BRIGGS, R. W., U.S. Geological Survey, Colorado, USA, rbriggs@usgs.gov

Geologic slip rates are time-averaged measurements of earthquake behavior calculated over $10^{2}-10^{6-}$-year time scales and thus represent a coarse metric of the rate of strain release along faults. Slip rates are a primary input for seismic hazard analyses, which forecast expected ground shaking in future earthquakes. Despite the importance of this metric in calculating seismic hazard, geologic slip rates are typically low-resolution approximations of potentially complex, high-resolution faulting histories. The issue of simplification is exacerbated when calculating geologic slip rates along low strain rate faults, given that very few earthquake cycles are included in a single slip rate. Averaging over only one or two earthquake cycles, including an open interval, may yield spurious slip-rate estimates. It can also be difficult to quantify the uncertainty in slip rates from short records. We developed a numerical approach that explicitly addresses these issues by constructing models of time-displacement paths (or 'stairways') that rely on field-based observations of dated offsets, mean recurrence interval and mean slip per event. We apply this approach to faults in the Basin and Range Province, which are generally characterized by low $(<1 \mathrm{~mm} / \mathrm{yr})$ slip rates with a limited number of recurrence intervals. This numerical methodology allows us to extrapolate slip rate records further into the past utilizing available field measurements, yielding more robust estimates of geologic slip rates over multiple earthquake cycles. Using numerous simulations of displacement-time paths, we derive a distribution of modeled slip rates constrained by the field observations. Modeled slip rate distributions expand and quantify the uncertainties about these median geologic slip rate values. Slip rate estimates can also be extended into the future to estimate the probability of future events. Results from this work will be considered for use in the geologic deformation model component of the U.S. National Seismic Hazard Model.

\section{Cryptic Faults: Assessing Seismic Hazard on Slow Slipping, Blind or Distributed Fault Systems}

Poster Session · Wednesday · 21 April · 11:30 AM Pacific

Session Chairs: Jessica A. T. Jobe, U.S. Bureau of Reclamation (jessietjobe@gmail.com); Stephen J. Angster, U.S. Geological Survey (sangster@usgs.gov)

\section{Distributed Quaternary Faulting in the Española Basin, Central Rio Grande Rift}

THOMPSON JOBE, J. A., U.S. Geological Survey, Colorado, USA, jessietjobe@ gmail.com; CHUPIK, C. M., Bureau of Reclamation, Colorado, USA cchupik@usbr.gov; LONGNECKER, P., Bureau of Reclamation, Colorado, USA, paullongnecker@hotmail.com

The Española Basin in the central Rio Grande Rift of northern New Mexico is a slowly deforming, $60-\mathrm{km}$-wide region, with low rates of extension constrained geodetically $(\sim 1 \mathrm{~mm} / \mathrm{yr})$ and low slip rate Quaternary-active faults. Prior work suggests late Quaternary deformation is concentrated on faults bounding the western basin margin, with a segmented primary fault system comprising the Pajarito, Santa Clara, and Embudo faults. Faults within and on the eastern margin of the Española Basin are described as antithetic or secondary faults and have previously been considered inactive during the late Quaternary. Faults outside and west of the Española Basin are also considered inactive, as strain focused on the primary fault system in the MiocenePliocene. For seismic hazard assessment, we seek to understand if the secondary or antithetic faults accommodate Quaternary deformation, to assess the recency, style, and rate of faulting, and to characterize strain distribution in the basin. Analysis of lidar, optical imagery, and field observations, combined with previous mapping, yields evidence for low-rate Quaternary activity on four faults away from the primary fault system in the Española Basin. The Picuris-Pecos and Nambe-Santa Fe faults are located on the eastern margin while the La Cañada del Amagre and Cañones faults are located farther west 
of the primary fault system. These faults have distributed, short $(<15 \mathrm{~km})$, N-S to NNE-SSW strands that vertically offset Pleistocene and possibly Holocene terraces and glacial deposits by $<4 \mathrm{~m}$, with limited evidence for oblique motion. The presence of low-rate active faults away from the primary fault system suggests that strain is distributed on several faults across the basin. However, the small vertical offsets and subtle evidence of deformation on the Picuris-Pecos, Nambe-Santa Fe, La Cañada del Amagre, and Cañones faults indicates that the primary fault system has likely accommodated most of the strain during the late Quaternary.

\section{New Paleoseismic Data Demonstrate Holocene Activity Along the Dog Valley Fault, Truckee, CA}

PIERCE, I. K. D., University of Oxford, Oxford, United Kingdom, ian@ nevada.unr.edu; KOEHLER, R. D., University of Nevada, Reno, Nevada, USA, rkoehler@unr.edu

The Dog Valley fault is a left-lateral strike-slip fault in the Northern Walker Lane near Truckee, California and Reno, Nevada. Lidar data reveal youthful fault scarps along much of the $\sim 25$-km-long northeast striking fault, including in close proximity to the Stampede Reservoir dam. East of the Stampede dam, near Hoke Valley, CA, we excavated a series of 14 3-D paleoseismic trenches across an $\sim 2 \mathrm{~m}$ high scarp. The trenches revealed a sequence of low energy fluvial deposits and buried meadow soils that were clearly displaced by a sequence of fault planes. A new methodology combining an iPad Pro lidar scanner with photo based structure-from-motion image reconstruction was developed to record and spatially reference each of the 14 trench slices. Using these referenced trench slices we were able to reconstruct an offset channel margin composed of interbedded thin carbon-rich peats and sand layers. The reconstruction shows that the channel intersects the fault at a high angle and is left-laterally displaced across the fault by $\sim 80 \mathrm{~cm}$ with negligible vertical motion. The reconstructed fault geometry also reveals a right-stepping enechelon fault pattern along strike. We observed clear evidence for at least one Holocene event. Here, the fault mapping, trench results, and radiocarbon ages demonstrate that this is a Holocene active fault that poses a significant seismic hazard to the Stampede Dam and surrounding communities.

Data Fusion and Uncertainty Quantification in Shallow Crust Characterization and Modeling

Oral Session · Monday · 19 April · 5:00 PM Pacific

Session Chairs: Elnaz Seylabi, University of Nevada, Reno

(elnaze@unr.edu); Domniki Asimaki, Caltech (domniki@ caltech.edu); Alan Yong, U.S. Geological Survey (yong@usgs. gov); Nori Nakata, Massachusetts Institute of Technology (nnakata@mit.edu)

\section{A Gross Picture of the S-Wave Site Amplification Factors Throughout Japan Based on the Generalized Spectral Inversion and One-Dimensional Theoretical Prediction} KAWASE, H., Disaster Prevention Research Institute, Kyoto University, Uji, Japan, kawase@sere.dpri.kyoto-u.ac.jp; NAKANO, K., Technical Research Institute, HAZAMA-ANDO CORP., Tsukuba, Japan, nakano.kenichi@ ad-hzm.co.jp; ITO, E., DPRI, Kyoto University, Uji, Japan, ito@sere.dpri. kyoto-u.ac.jp; NAGASHIMA, F., DPRI, Kyoto University, Uji, Japan, nagashima.fumiaki.6v@kyoto-u.ac.jp

We have been applying the generalized spectral inversion to strong-motion data in Japan (Nakano et al., 2015) in order to separate source, path, and site terms in the frequency range from $0.12 \mathrm{~Hz}$ to $15 \mathrm{~Hz}$. We first focus our attention on the spatial distribution of the horizontal site amplification factors (HSAFs) of the S-wave part (5 to 15 s from the onset of S-wave). We have been using various kinds of site proxies to represent HSAFs empirically, however, we should see their spatial distribution before delineating the phenomenological correlations for these proxies. Thus, we plot a gross picture of the separated HSAF throughout Japan using GMT (Wessel and Smith, 1998) for 2600 sites of K-NET and KiK-net by NIED, JMA networks, and CEORKA network. The observed HSAF from the generalized inversion is the site amplification relative to the seismological bedrock with the S-wave velocity of $3.45 \mathrm{~km} / \mathrm{s}$. The gross picture of the observed HSAFs clearly shows that large sedimentary basins such as the Kanto, Osaka, Nobi, Sapporo, and Kumamoto basins are creating large amplifications. Amplifications in eastern Japan tend to be higher than those in the west.
A deep velocity structure from the engineering bedrock to the seismological bedrock throughout Japan, called JIVSM (Koketsu et al., 2012), was constructed to calculate theoretical long-period responses for selected scenarios of mega-thrust earthquakes along the Philippine-Sea Plate as a part of the activities in the National Headquarter of Earthquake Research Promotion. For shallow structures, we can use PS logging information published by NIED for K-NET and KiK-net. By combining these two structures directly, we can construct a pointwise $1 \mathrm{D}$ velocity model at each site and calculate its theoretical HSAF at 1700 sites of K-NET and KiK-net. In the same manner, we plot the gross picture of the theoretical HSAFs all over Japan. We can see quite similar spatial characteristics of site amplification in the theoretical HSAFs, however, we found that their amplifications are systematically deficient in comparison to the observed ones.

A Procedure for Developing Uncertainty-Consistent Vs
Profiles From Inversion of Surface Wave Dispersion Data
VANTASSEL, J. P., The University of Texas at Austin, Texas, USA, jvantassel@
utexas.edu; COX, B. R., Utah State University, Utah, USA, brady.cox@usu.edu

Non-invasive surface wave methods have become a popular alternative to traditional invasive forms of site-characterization for inferring a site's subsurface shear wave velocity (Vs) structure. The advantage of surface wave methods over traditional forms of site characterization is that measurements made solely at the ground surface can be used routinely and economically to infer the subsurface structure of a site to depths of engineering interest (20-50m), and much greater depths $(>1 \mathrm{~km})$ in some special cases. However, the quantification and propagation of uncertainties from surface wave measurements into the Vs profiles used in subsequent engineering analyses remains challenging. While this has been the focus of much work in recent years, and while considerable progress has been made, no approach for doing so has been widely accepted, leading analysts to either address the propagation of uncertainties in their own specialized manner or, worse, to ignore these uncertainties entirely. In response, we present a new, effective, and verifiable method for developing uncertainty-consistent Vs profiles from inversion of surface wave dispersion data. The new approach is shown to be superior to current approaches in two specific ways. First, it is shown to produce suites of Vs profiles whose theoretical dispersion quantitatively reproduces the uncertainties in the experimental dispersion data. Second, beyond appropriate considerations that must be given to all inversions, the method is governed by only one user-defined input parameter, to which it is not overly sensitive. Using two synthetic tests and a real-world example, the procedure is shown to produce suites of Vs profiles that accurately capture the site's Vs structure, while rigorously propagating the dispersion data's uncertainty through the inversion process.

\section{An H/V Geostatistical Approach for Developing Pseudo-3D Vs Models to Account for Spatial Variability in Site Response}

HALLAL, M. M., The University of Texas at Austin, Texas, USA, mhallal@ utexas.edu

Many recent studies have shown that we are generally unable to accurately replicate recorded ground motions at most borehole array sites using a single shear wave velocity (Vs) profile and one-dimensional (1D) ground response analyses (GRAs), presumably due to the presence of spatially variable subsurface conditions. While 3D GRAs are possible and believed to be more accurate, there is rarely a $3 \mathrm{D}$ subsurface model available for these analyses. The lack of affordable and reliable 3D site characterization methods, particularly regarding Vs measurements needed for GRAs, has pushed researchers to adopt stochastic methods, such as Vs randomization and spatially correlated random fields. However, these stochastically generated models require the assumption of generic, or guessed, input parameters, introducing significant uncertainties into the site response predictions.

To address these challenges, this study proposes a new approach that can be used to build pseudo-3D Vs models by integrating simple, cost- and time-effective horizontal-to-vertical spectral ratio measurements $(\mathrm{H} / \mathrm{V})$ with geostatistical modeling tools. Importantly, it requires only a single measured Vs profile and a number of $\mathrm{H} / \mathrm{V}$ noise measurements. Using Gaussian geostatistical regression, irregularly sampled estimates of fundamental site frequency from $\mathrm{H} / \mathrm{V}$ measurements $\left(\mathrm{f}_{0, \mathrm{H} / \mathrm{V}}\right)$ are used to generate a uniform grid of $\mathrm{f}_{0, \mathrm{H} / \mathrm{V}}$ across the site with accompanying Vs profiles that have been scaled to match each $\mathrm{f}_{0, \mathrm{H} / \mathrm{V}}$ value, thereby producing a pseudo-3D Vs model. While the pseudo-3D Vs models can be used to incorporate spatial variability into $1 \mathrm{D}$, 2D, or 3D GRAs, their implementation in 1D GRAs at the Treasure Island and Delaney Park Downhole Array sites is assessed, where the proposed approach is shown to produce superior fits to the small-strain recorded site response relative to other approaches used to account for spatial variability in 1D GRAs. 
We also investigate the lateral area likely influencing site response and show that it could extend to significant distances (as much as $1 \mathrm{~km}$ ) from the borehole arrays.

\begin{abstract}
Heterogeneous Data Assimilation for Site Characterization Using the Ensemble Kalman Method

SEYLABI, E., University of Nevada, Reno, Nevada, USA, elnaze@unr.edu; BAS, E. E., University of Nevada Reno, Nevada, USA, basel@nevada.unr.edu; ASIMAKI, D., Caltech, California, USA, domniki@caltech.edu; STUART, A. Caltech, California, USA, astuart@caltech.edu; YONG, A., U.S. Geological Survey, California, USA, yong@usgs.gov

We present an algorithm based on the ensemble Kalman inversion to estimate the near-surface S- and P-wave velocity profiles when heterogeneous datasets and a priori information in the form of equality/inequality constraints are available. We use synthetic and real data to examine the proposed framework's performance in estimating soil mechanical properties, i.e., $\mathrm{S}$ and $\mathrm{P}$ wave velocity and damping ratio, at the Garner Valley downhole array in Southern California and compare them against estimates from previous studies at the same site. Due to the complementary characteristics of the body and surface waves, we show that formulating the inversion problem using heterogeneous data (e.g., Rayleigh wave phase velocity, earthquake horizontal-tovertical spectral ratio, and acceleration time series) can reduce the margins of uncertainty in the estimation. We also show how systematic modifications of the proposed algorithm to incorporate constraints further enhances the algorithm's well-posedness.
\end{abstract}

\section{Urban Seismic Site Characterization With Fiber-Optic Seismology}

BEROZA, G. C., Stanford University, California, USA, beroza@stanford. edu; SPICA, Z., University of Michigan, Michigan, USA, zspica@umich.edu; PERTON, M., Universidad Nacional Autónoma de México, Mexico City, Mexico, mathieu.perton@gmail.com; MARTIN, E., Virginia Tech, Virginia, USA, eileenrmartin@vt.edu; BIONDI, B., Stanford University, California, USA, biondo@stanford.edu

Accurate ground-motion prediction requires accurate site effect assessment In urban settings, where such assessments are most important, geotechnical surveys are difficult to perform, which limits their availability. Distributed acoustic sensing (DAS) presents an appealing alternative by repurposing existing fiber-optic cables, which are plentiful in urban environments where they are deployed for telecommunication, as an array of seismic sensors. We present a proof-of-concept demonstration by using DAS to produce highresolution maps of the shallow subsurface with the Stanford DAS array. We describe new methods, and their assumptions, that allow us to assess the H/V spectral ratio - a technique widely used to estimate the natural frequency of the site, and to extract Rayleigh-wave dispersion curves from the ambient seismic field. These measurements are jointly inverted to provide models of shallow seismic velocities and sediment thicknesses above bedrock. The good agreement with an independent survey validates the methodology and demonstrates the potential of DAS for microzonation.

\section{Earthquake Early Warning Live in California! Current Status and Challenges \\ I: Oral Session · Friday · 23 April · 9:45 AM Pacific \\ II: Oral Session · Friday · 23 April · 2:00 PM Pacific \\ Session Chairs: Angela I. Chung, University of California, Berkeley (aichung@berkeley.edu); Men-Andrin Meier, Caltech (mmeier@caltech.edu)}

\section{A Low-Cost loT Seismometer for Consumers for On-Site and Regional Earthquake Early Warning}

HE, V., Palos Verdes Peninsula High School, California, USA, vivien.g.he@ gmail.com

While there has been significant development in earthquake early warning (EEW) systems, there are still challenges, one being large blind zones near the epicenter where alerts are most needed. Another issue is slow/missed alerts due to low seismometer density and variability in on-site intensity and user alert threshold preference. Even with emerging less-expensive devices targeting citizen scientists, costs of seismometers, installation, and maintenance are still high. This contributes to limited EEW growth, exacerbated by heavy dependence on public funding.

This research pursues a different consumer-based approach, developing a low-cost on-site IoT seismometer that can be mass deployed at homes and buildings, much like a standard smoke detector. In addition to an alarm at the user's location with personalized settings, the IoT device sends text messages to local subscribers, uploads waveform data for further research, and is controllable via smartphone. A large number of these devices can form a dense network for regional EEW.

This paper presents such an IoT device integrated with seismometer, alarm, wifi, software, and packaging, for under $\$ 100$ at prototype volume and much less with increased production. The device is palm-sized $(7 \mathrm{~cm} \mathrm{x}$ $7 \mathrm{~cm} \times 5 \mathrm{~cm}$ ) and samples ground motion at $100 \mathrm{~Hz}$ with a geophone and a 32-bit ADC. The device successfully detected recent earthquakes in Southern California (for example, the M4.6 earthquake on September 19, 2020 UTC) with high signal-to-noise ratio, sounded the alarm, sent text message alerts to subscribers, and produced standard earthquake waveform miniSEED files. The alert level is customizable by each consumer, and the alarm is managed by a smartphone application or on the device itself.

Further developments are underway, such as deploying many devices for better regional EEW, as well as an AI-based software to recognize ground motion signatures of human activities for security applications to further enable mass adoption.

\section{Approximate Inference of the EEW Event Parameters Using MCMC and Bayesian Networks}

ZAICENCO, A. G., Weir-Jones Engineering Consultants, Vancouver, Canada anton.zaicenco@weir-jones.com; WEIR-JONES, I., Weir-Jones Engineering Consultants, Vancouver, Canada, iainw@weir-jones.com

An efficient earthquake early warning system (EEWS) requires accurate estimates of the seismic event parameters in order to translate them into reliable warning times. From the seismic risk reduction prospective, it is critical to perform uncertainty analysis of the event parameters derived from the first few stations which detected the $\mathrm{P}$ wave. This sparse data set, which provides warning in the region with the largest ground shaking, tends to exhibit the largest uncertainties in the magnitude and location estimates. At the same time, increasing the data set by incorporating additional stations will increase the blind zone around the epicenter. The use of alternative methods to compute the event parameters allows us to maximize the entropy and place additional constraints on the density functions. We employ the Bayesian networks to propagate the updates and compute the distributions associated with the nodes. The presence of large networks or non-Gaussian distributions suggests the use of the approximate inference methods. Markov chain Monte Carlo method offers an efficient tool to sample from the probability space in order to construct posterior distributions of the required event parameters. We illustrate our approach using a set of records in terms of accelerations and velocities from M4.8 earthquake occurred 19km NNE of Victoria, British Columbia on December 29th, 2015. Some of these records were obtained from the dedicated EEWS stations operating since 2009.

\section{Could a Decentralized Onsite Earthquake Early Warning System Help in Mitigating Seismic Risk in North-Eastern Italy? The Case of the Ms 6.5 1976 Friuli Earthquake}

PAROLAI, S., Istituto Nazionale di Oceanografia e di Geofisica Sperimentale, Sgonico, Italy, sparolai@inogs.it; MORATTO, L., Istituto Nazionale di Oceanografia e di Geofisica Sperimentale, Udine, Italy, Imoratto@inogs. it; BERTONI, M., Istituto Nazionale di Oceanografia e di Geofisica Sperimentale, Udine, Italy, mbertoni@inogs.it; SCAINI, C., Istituto Nazionale di Oceanografia e di Geofisica Sperimentale, Udine, Italy, cscaini@inogs.it; REBEZ, A., Istituto Nazionale di Oceanografia e di Geofisica Sperimentale, Sgonico, Italy, arebez@inogs.it

In May 1976, an earthquake of Ms=6.5 occurred in Friuli (Italy), resulting in 976 deaths, 2,000 injured, and 60,000 homeless. Due to two further shocks that occurred in September 1976, some 40,000 people were displaced to the coast, far away from the epicentral area. It is notable that at the time of the earthquake, only one seismological station was installed in the affected region. The resulting lack of information, combined with a dearth of mitigation planning for responding to such events, lead to a clear picture of the impact of the disaster being available only after a few days.

This region is now covered by nearly 100 seismological and strong motion stations operating in real- time. Furthermore, 54 new average-cost real-time strong motion stations have been recently added, with the aim of improving the density of ground motion observation, and to measure the level of shaking recorded at selected buildings. The final goal is to allow rapid 
impact estimations to be made in order to improve upon the response of civil protection authorities. Today, considering the higher density seismological network, new efforts in terms of the implementation and testing of earthquake early warning (EEW) systems as a possible tool for mitigating seismic risk are certainly worthwhile.

In this presentation, we show the results obtained by analyzing in playback, and using an algorithm for Decentralized On-Site Earthquake Early Warning (DOSEEW), broad-band synthetic strong motion data calculated at 18 of the stations installed in the region, while considering the magnitude and location of the 1976 Friuli earthquake The analysis shows that the anisotropy of the lead-times is not only related to the finite nature of the source, but also on the slip distribution. A reduction of $10 \%$ of injured persons appears to be possible if appropriate mitigating actions are employed. The safety of strategic industrial facilities could benefit from the development of efficient automatic procedures.

\section{Deepshake: A Machine-Learning Approach to Rapid Estimation of Shaking Intensity}

WU, D., Stanford University, California, USA, danjwu@stanford.edu; DATTA, A., Stanford University, California, USA, avoy.datta@stanford.edu; ZHU, W., Stanford University, California, USA, zhuwq@stanford.edu; ELLSWORTH, W. L., Stanford University, California, USA, wellsworth@stanford.edu

The rollout of the ShakeAlert warning system in California has created an impetus for the development of rapid, robust and resilient earthquake early warning algorithms. Early warning systems, provided with a set of real-time ground motion measurements from a network of seismic monitoring stations, aim to predict the intensity of earthquake ground motion at various locations before strong shaking arrives. Traditional methods for earthquake early warning generally consist of two steps-determining earthquake location and magnitude and calculating ground motion based on ground motion prediction equations (GMPE). These steps are subject to errors due to complex fault rupture patterns and various path and site effects. This makes obtaining accurate ground motion a challenging problem.

We propose a deep spatiotemporal recurrent neural network, DeepShake, to classify future shaking intensity directly from current ground motion observations. DeepShake is a network-based forecasting model, able to predict future shaking intensity at all stations given measured ground shaking from the previous 15 seconds. The model is not given any a priori knowledge of station locations; instead, it learns wave propagation amplitudes and delays solely from training data. We trained DeepShake on 28,543 earthquakes from the 2019 Ridgecrest sequence. Three-component acceleration data is downsampled and smoothed into a single-channel $1 \mathrm{~Hz}$ feed, diminishing telemetry bandwidth, before being fed into DeepShake. Tasked with alerting for MMI III+ waveforms on 3,568 validation earthquakes at least 5 seconds in advance, DeepShake achieves an equal error rate of 7.9\%. For the Mw 7.1 earthquake that hit Ridgecrest on July 5th, 2019, DeepShake was able to provide targeted alerts to stations inside the network between 7 and 13 seconds prior to arrival of MMI III+ waveforms. DeepShake demonstrates that deep spatiotemporal neural networks can effectively provide one-step earthquake early warning with reasonable accuracy and latency.

\section{The Transformer Earthquake Alerting Model: A Data Driven Approach to Early Warning}

MÜNCHMEYER, J., GFZ German Research Centre for Geosciences, Potsdam, Germany, munchmej@gfz-potsdam.de; BINDI, D., GFZ German Research Centre for Geosciences, Potsdam, Germany, bindi@gfz-potsdam.de; LESER, U., Humboldt University Berlin, Berlin, Germany, leser@informatik. hu-berlin.de; TILMANN, F., GFZ German Research Centre for Geosciences, Potsdam, Germany, tilmann@gfz-potsdam.de

Traditionally, earthquake early warning relies on relatively simple empirical relationships between observables, source parameters and ground shaking. Examples are relationships between magnitude and early waveform parameters, but also ground motion prediction equations. These simplified assumptions result in apparent aleatoric uncertainty, that materialize as false or missed warnings.

Given the huge amount of waveform data that became available over the last two decades, we suggest that new models do not need to rely on approximate relationships, but can be constructed in a purely data driven manner. Here, we introduce the transformer earthquake alerting model (TEAM), a deep learning based early warning model that is trained to directly make probabilistic predictions of ground shaking based on a few seconds of recorded earthquake waveforms.

We apply TEAM to two large scale strong motion datasets from Japan (13,512 events, 372,661 traces) and Italy (7,055 events, 494,183 traces), regions with complementary seismic hazard. TEAM consistently outperforms two prototypical early warning baselines in terms of precision and recall, as well as warning times, across PGA thresholds from $1 \% \mathrm{~g}$ to $20 \% \mathrm{~g}$. For example, for $10 \% \mathrm{~g}$ in Japan, TEAM achieves precision/recall of $0.50 / 0.60$, while a point source approach achieves $0.27 / 0.36$ and a PLUM-like approach achieves $0.18 / 0.39$. Average warning times for TEAM are $0.31 \mathrm{~s}$ longer than for the point source and $5.01 \mathrm{~s}$ longer than for the PLUM-like approach.

While purely data driven models generally perform well when presented with sufficient training data, they often struggle with scenarios with few training examples. Therefore, we also analyze TEAM on scenarios where the largest test event is considerably larger than the largest training event, using the Norcia and Tohoku sequences. For the Norcia sequence, we show that using domain adaptation, TEAM can accurately assess even the largest events. For the Tohoku sequence, TEAM underestimates the main shock, but considerably outperforms the baselines in the aftershock sequence.

\section{Did You Feel That? Examining the Transition Between Felt and Not-Felt Shaking}

SAUNDERS, J. K., U.S. Geological Survey, California, USA, jksaunders@usgs. gov; MINSON, S., U.S. Geological Survey, California, USA, sminson@usgs. gov; BALTAY, A., U.S. Geological Survey, California, USA, abaltay@usgs. gov; AAGAARD, B., U.S. Geological Survey, Colorado, USA, baagaard@usgs. gov; QUITORIANO, V., U.S. Geological Survey, Colorado, USA, vinceq@ contractor.usgs.gov

We use a dataset of nearly one million individual U.S. Geological Survey (USGS) Did You Feel It? (DYFI) reports from M4.0+ earthquakes in the U.S. ShakeAlert System's reporting region to examine the transition between felt and not-felt shaking for use in earthquake early warning (EEW) applications. In EEW, alerting strategies must balance the tradeoffs between reducing missed alerts to locations that experience strong shaking and reducing incorrect alerts to regions that do not need to take protective actions. As incorrect alerts to locations where most people do not experience felt shaking may decrease the public's confidence in EEW, it is necessary to accurately model the probability of felt and not-felt shaking to determine the quality of an EEW alert. The DYFI system provides the most comprehensive dataset of observed earthquake shaking intensities in the United States. These observations have been used as ground-truth for developing the empirical ground-motion-tointensity conversion equations used in EEW and in rapid-response products such as USGS ShakeMap. However, because the DYFI system is a self-reporting system, reports of not-felt shaking are usually lacking, and as such, our understanding of the transition between felt and not-felt ground motions is limited. Furthermore, the definitions of Modified Mercalli Intensity at low intensities use descriptions like "felt only by few persons at rest" which contributes to the large range of ground motions that correspond to low MMI levels. We investigate the reporting bias of different shaking intensity levels as well as region-specific adjustments to DYFI-based intensities in locations where felt shaking is under-reported relative to population. These adjusted DYFI data will provide improved estimates of the distribution of low-intensity shaking levels, which can then be used to update the ground-motion models used by ShakeAlert and other products.

\section{Incorporating Smartphone Seismic Data for Improved Earthquake Early Warning Performance}

PATEL, S., University of California, Berkeley, California, USA, sarina.patel@ berkeley.edu; CHUNG, A. I., University of California, Berkeley, California, USA, aichung@berkeley.edu; KONG, Q., University of California, Berkeley, California, USA, kongqk@berkeley.edu; STRAUSS, J., University of California, Berkeley, California, USA, jastrauss@berkeley.edu; ALLEN, R., University of California, Berkeley, California, USA, rallen@berkeley.edu

MyShake is a citizen science smartphone application which uses an algorithm to filter anthropogenic noise and detect earthquake onsets in data recorded by the phones' onboard accelerometer. ShakeAlert is the US Earthquake Early Warning (EEW) system built on a dispersed network of permanent seismic stations that feed realtime data to a detection algorithm. Each of these systems is independently capable of rapidly detecting earthquakes and generating alerts of impending shaking. The goal of our research is to assess the potential of MyShake to augment the speed and accuracy of the ShakeAlert system in the US, with a focus on the state of California where alerts are publicly available. As MyShake has been providing alerts in California since October 2019, MyShake now has a substantial user base in the state, roughly 500,000 users (compared to the $\sim 1000$ ShakeAlert stations), with the densest clusters in urban areas.

We compare the detection capabilities of MyShake and ShakeAlert in combination and independently, using real data collected by both systems 
in earthquakes since October 2019. On an event-by-event basis, we assess whether incorporating MyShake data in the ShakeAlert system could have sped up detection and/or improved initial estimates of location and size. Preliminary results find that MyShake triggers can arrive at a server a full second earlier than the first ShakeAlert triggers. Both when added to ShakeAlert or when assessed independently, MyShake can speed event creation by up to half a second without compromising the quality of the location estimate, as compared to ShakeAlert operating alone. We also explore the efficacy of different algorithm approaches to incorporating MyShake data to best improve ShakeAlert performance.

MyShake: A Window Into Shakealert User Experience ALLEN, R., University of California, Berkeley, California, USA, rallen@ berkeley.edu; KONG, Q., University of California, Berkeley, California, USA, kongqk@berkeley.edu; PATEL, S., University of California, Berkeley, California, USA, sarina.patel@berkeley.edu; POTHAN, S., University of California, Berkeley, California, USA, spothan@berkeley.edu; STRAUSS, J., University of California, Berkeley, California, USA, jastrauss@berkeley.edu

MyShake is a smartphone app designed to harness and synergize public interest in earthquakes. The app provides users the information they need, and also collects acceleration waveforms and user experience data. In 2019 the app was launched by Governor Gavin Newsom in California becoming the official state app to deliver earthquake early warnings generated by ShakeAlert. This resulted in over a million downloads by users wanting alerts, and simultaneously harnessed over a million new accelerometers that now provide ground motion data in earthquakes.

After operating for 18 months, the MyShake data is now providing key insights into the effectiveness of earthquake early warning alerts, and the ground motions that our users experience. By recording the time that a phone receives an alert and the acceleration waveform from the same phone, we make direct observations of the warning time and peak ground acceleration across the alert region. ShakeAlert's public alerting goal is to alert all those who experience shaking intensity of 3 or greater. With the direct PGA observations from MyShake phones we can assess how close we come to that goal, and how significant are the limitations of current ground motion prediction equations.

\section{Real-Time Performance of the Plum Earthquake Early Warning Algorithm for Western U.S.}

KILB, D., Scripps Institution of Oceanography, University of California, San Diego, California, USA, dkilb@ucsd.edu; COCHRAN, E. S., U.S. Geological Survey, California, USA, ecochran@usgs.gov; BUNN, J. J., Caltech and U.S Geological Survey, California, USA, julian.bunn@caltech.edu; SAUNDERS, J. K., U.S. Geological Survey, California, USA, jksaunders@usgs.gov; MINSON, S., U.S. Geological Survey, California, USA, sminson@usgs.gov; BALTAY, A., U.S. Geological Survey, California, USA, abaltay@usgs.gov; O'ROURKE, C., U.S. Geological Survey, Washington, USA, corourke@usgs.gov

We report results from running the Propagation of Local Undamped Motion (PLUM) EEW algorithm for one-year (2019-08-15 to 2020-08-14) on realtime data from stations in the ShakeAlert earthquake early warning (EEW) System for the West Coast, USA. Testing EEW algorithms on real-time data can uncover issues that offline data tests cannot. In contrast to current ShakeAlert algorithms, PLUM is ground motion based and designed to issue alerts when ground motions exceed a specified intensity. PLUM issues an event detection when two or more neighboring stations report ground motions above Modified Mercalli Intensity (MMI) 4 and 2.5 for the first and neighbor stations, respectively. PLUM then forward-predicts the observed ground motions to sites within $30 \mathrm{~km}$ of any triggering stations, which are used to determine the alerting region. During the one-year test period, PLUM detected 62 events, of which five were M5+. PLUM missed two M5+ events, but both were theoretically not detectable by PLUM because they were either offshore or at the edge of the network. PLUM did detect the 2020-03-09 M5.8 offshore Petrolia earthquake, which the operational ShakeAlert System missed. Of the 62 earthquakes detected by PLUM, the elapsed time between the earthquake origin time and the PLUM detection (not including alert dissemination that might take $\sim 5 \mathrm{~s}$ ) ranged from $2-27 \mathrm{~s}$, with a mean elapsed time of $6.2 \pm 5.1 \mathrm{~s}$ and median elapsed time of $4.8 \mathrm{~s}$. PLUM's trigger times are consistent with a seismic wave speed of $3 \pm 1.3 \mathrm{~km} /$ second, suggesting most of the triggers occurred during the $\mathrm{S}$-wave. An approximate earthquake location can be derived with a weighting scheme using the station's MMI values and trigger times, which nets median and mean location errors of $4.8 \mathrm{~km}$ and 9.7 $\mathrm{km}$, respectively, which are on par or smaller than ShakeAlert errors. We conclude PLUM can successfully identify the occurrence of strong shaking and is a promising candidate for integration into the U.S. ShakeAlert EEW System.

\section{The Potential of Fiber-Optic Strain in Earthquake Early Warning}

FARGHAL, N. S., U.S. Geological Survey, California, USA, nfarghal@usgs. gov; SAUNDERS, J. K., U.S. Geological Survey, California, USA, jksaunders@ usgs.gov; PARKER, G. A., U.S. Geological Survey, California, USA, gparker@ usgs.gov

The potential of using strain data in earthquake early warning (EEW) applications has been demonstrated in recent studies using borehole strainmeter records from stations along the U.S. West Coast. Fiber-optic distributed acoustic sensing (DAS) has been increasingly utilized in seismology with applications ranging from microseismic monitoring to vertical seismic profiling. DAS arrays seem to be a practical, scalable option for strain sensing, especially in areas where the installation of seismometers is neither easy nor cost-effective, such as in dense offshore arrays. In this work, we examine the data requirements for the U.S. ShakeAlert EEW System and present ways in which DAS strain data can be ingested by the different existing alerting algorithms, with and without modifications to the System. For example, using recently-developed empirical equations, a new algorithm entirely based on strain could also be developed in the future to feed estimated earthquake parameters, such as peak ground velocities and accelerations, and earthquake magnitudes directly to the ShakeAlert Solution Aggregator, where results from multiple EEW algorithms are combined into one solution. We also discuss the current state of DAS for EEW applications and what capabilities are under-studied or need to be developed, such as accurate strain amplitudes and array calibration techniques. Accurate amplitudes are needed for groundmotion parameter estimation and for earthquake magnitude estimation from strain data, but if the amplitudes are ambiguous, DAS data can still be utilized in EEW systems, for wave arrival and travel times for earthquake detection and location estimation.

\section{Earthquake Early Warning Live in California! Current Status and Challenges \\ Poster Session · Friday · 23 April · 11:30 Am Pacific \\ Session Chairs: Angela I. Chung, University of California, Berkeley (aichung@berkeley.edu); Men-Andrin Meier, Caltech (mmeier@caltech.edu)}

\section{Deep Learning Based Approach to Integrate MyShake's Trigger Data with ShakeAlert for Faster and Robust EEW Alerts}

KONG, Q., University of California, Berkeley Seismological Laboratory, California, USA, kongqk@berkeley.edu; HENSON, I., University of California Berkeley Seismological Laboratory, California, USA, ihenson@berkeley.edu; ALLEN, R., University of California, Berkeley Seismological Laboratory, California, USA, rallen@berkeley.edu

In this presentation, we propose a new earthquake detection method for earthquake early warning for the dense smartphone array in a region as well as the traditional seismic stations. The goal is to integrate these two sensor networks. The method is inspired by the scene detection in movies, that a machine learning algorithm is monitoring each frame in the movie to make the decision. For detection, each region can be divided into 10 by $10 \mathrm{~km}$ or 1 by 1 meter square cells to aggregate the triggers within the cells. A sequence of images will feed into a deep learning model to make the decision whether an earthquake is occurring, which the model can both handle temporal and spatial coherent signals to detect the earthquake. The training dataset was generated by using a simulation platform, so that we can generate cases with sensors at different locations without considering specific network configuration. The performance of the model will be discussed in this presentation. In addition, using the simulation platform, we can also evaluate how the smartphone seismic network helps the traditional seismic network, which will be also discussed in this presentation. This work is funded by USGS through $2020 \mathrm{EHP}$ Award G20AP00058.

\section{Earthquake Early Warning Testing Developments: Automating the Generation of Realistic Warning Times Events in the Testsuite}

SMITH, D. E., U.S. Geological Survey, California, USA, deborahsmith@usgs. gov; MCGUIRE, J., U.S. Geological Survey, California, USA, jmcguire@usgs. gov; GOOD, A., Caltech, California, USA, agood@caltech.edu; HUYNH, M. U.S. Geological Survey, California, USA, mhuynh@usgs.gov; BUNN, J. J., 
Caltech, California, USA, julian.bunn@caltech.edu; MEIER, M., ETH Zürich, Zürich, Switzerland, mmeier@caltech.edu; BOESE, M., ETH Zürich, Zürich, Switzerland, maren.boese@googlemail.com

Earthquake early warning (EEW) algorithms must undergo rigorous realtime and offline testing before being accepted into the ShakeAlert production system. The ShakeAlert Testing and Certification platform attempts to simulate how the production system will perform by deploying the proposed algorithms, configurations, earthworm rings/modules, and ActiveMQ messaging on separate, nearly identical hardware. For real-time testing, the test servers are fed the same West Coast input waveform data as the production servers, and the algorithms' performance is compared between the test and existing production systems after a minimum of two weeks. For offline testing, four simultaneous instances of the algorithms are run on one machine with a historic test suite of earthworm tankplayer files (a format used for replaying data into an earthworm ring with realistic timing).

One important development of the test system that is underway, is generating realistic estimates of EEW warning times. We have already gathered many large magnitude events for the new test suite, including crustal and subduction zone events from Japan, events from Ridgecrest, Anchorage, and older events; we have estimated warning times for some of these events at different MMI levels. We currently have a program that can be applied to the large magnitude events to calculate MMI as a function of time directly from the waveform data and are developing an accompanying program that interpolates these estimates onto a regular grid. In addition, we are working with playbacks that incorporate realistic latencies and realistic packet timing using the earthworm ringplayer program. Currently, we are working on techniques to automatically visualize and analyze the test results in terms of ground motion space to help us quickly assess the performance and warning times in an aggregate fashion.

\section{Examination of Event Dependent Latency Values for the Earthquakes Recorded by the Northern California Earthquake Data Center for Use in Shakealert}

TERRA, F., University of California, Berkeley Seismological Laboratory, California, USA, terra@berkeley.edu; BOYD, O. S., University of California, Berkeley Seismological Laboratory, California, USA, olboyd@usgs. gov; HELLWEG, M., University of California, Berkeley Seismological Laboratory, California, USA, peggy@seismo.berkeley.edu; NEUHAUSER, D., University of California, Berkeley Seismological Laboratory, California USA, doug@seismo.berkeley.edu; HENSON, I., University of California, Berkeley Seismological Laboratory, California, USA, ihenson@berkeley.edu; MILLIGAN, P., University of California, Berkeley Seismological Laboratory, California, USA,millpaul@seismo.berkeley.edu

Realtime seismic waveform data from some SCSN stations for the mainshock of the Ridgecrest Earthquake sequence were delayed by varying amounts, causing delays to both ShakeAlert earthquake early warning (EEW) alerts and production of earthquake information. Detailed investigation found that two major factors contributing to the latency of data arriving at the data processing centers were 1) data tunneling and 2) passage of data through telemetry hubs. The former describes a situation in which the amount of data being transferred was greater than normal due to reduced compression. In the latter case data from many stations were telemetered to a single hub, and then all transported together through one cell modem.

L1Z, a latency measure, recorded for several years in the SCSN, was instrumental in investigating the problems. This parameter is the time it takes after a data packet is created in the data logger to enter the EEW processing system, and is symptomatic of the telemetry. It is now being calculated at all ShakeAlert data centers, including in the NCSS. L1Z is measured on the data of the high sample rate, causally filtered data from the vertical channel of the accelerometer (typically HNZ) at each station and is stored at one sample per second, in units of milliseconds. It allows the latency of data for each station contributing to ShakeAlert to be monitored continuously. We select a suite of earthquakes in Northern California with different magnitudes and examine the continuous L1Z data values for stations at various distances and with a variety of telemetry paths and types of equipment, to investigate which factors influence latency in these situations. We also evaluate sizes of data packets and compression rates to examine how variations in these parameters affect latency. Minimizing latency in ShakeAlert is important, particularly for large earthquakes, in reducing the time to produce EEW alerts.

\section{Optimizing Plum Alerting Regions for Shakealert: A Test} Case Tuning the Plum Prediction Radius

COCHRAN, E. S., U.S. Geological Survey, California, USA, ecochran@usgs. gov; SAUNDERS, J. K., U.S. Geological Survey, California, USA, jksaunders@ usgs.gov; MINSON, S., U.S. Geological Survey, California, USA, sminson@ usgs.gov; BUNN, J. J., Caltech, California, USA, julian.bunn@caltech.edu; KILB, D., University of California, San Diego, California, USA, dkilb@ucsd. edu; BALTAY, A., U.S. Geological Survey, California, USA, abaltay@usgs. gov; O’ROURKE, C., U.S. Geological Survey, Washington, USA, corourke@ usgs.gov; HOSHIBA, M., JMA, Tsukuba, Japan, mhoshiba@mri-jma.go.jp; KODERA, Y., JMA, Tsukuba, Japan, y_kodera@mri-jma.go.jp

We optimize performance of the Propagation of Locally Undamped Motion (PLUM) Earthquake Early Warning (EEW) algorithm in the ShakeAlert system by testing a range of distances used to forecast ground motions. ShakeAlert aims to provide advance warning of potentially damaging shaking to the residents of California, Oregon, and Washington. EEW systems must balance the primary goal of providing timely alerts for moderate to strong ground shaking while limiting unnecessary alerts (alerts for ground motions too low to be of concern). PLUM forecasts ground motion directly from realtime observations of ground motion without estimating the source parameters of the earthquake. PLUM is already used by the Japan Meteorological Agency's EEW system, and currently is under consideration for inclusion in ShakeAlert. PLUM forward-predicts observed ground motions to nearby prediction sites within a defined radius without any attenuation. PLUM was originally developed in Japan where alerts are issued to districts with sizes ranging from approximately 500 to $5,000 \mathrm{~km}^{2}$, and uses a prediction radius of $30 \mathrm{~km}$. In contrast, ShakeAlert uses a generally smaller alerting grid of $0.2^{\circ}$ by $0.2^{\circ}$ cells $\left(\sim 500 \mathrm{~km}^{2}\right)$. Given this contrast in alert region size, we test a range of prediction radii $(20-100 \mathrm{~km})$ to examine whether PLUM's alert performance for ShakeAlert can be optimized. We calculate PLUM's optimum prediction radius by applying ground motion-based performance assessments to the ShakeAlert historical event test suite. We compare predicted ground motions from PLUM alerts to ShakeMap-reported ground motions. We find the prediction radius that maximizes the correct (algorithm correctly predicts that ground motion will be above a given threshold at a site) and timely (alert is issued prior to ground motions exceeding a given threshold at a site) alerts while minimizing unnecessary alerts for a range of different ground motion levels of interest.

Earthquake Early Warning System in the Americas: The On-Going Effort and the State of the Art

I: Oral Session · Monday · 19 April · 5:00 PM Pacific II: Oral Session · Tuesday · 20 April · 9:45 Am Pacific Session Chairs: Esteban J. Chaves, Volcanological and Seismological Observatory of Costa Rica, Universidad Nacional (esteban.j.chaves@una.cr); Marino Protti, Volcanological and Seismological Observatory of Costa Rica, Universidad Nacional (marino.protti.quesada@una. cr); Edmundo Norabuena, Instituto Geofísico del Perú (enorabuena@igp.gob.pe); Gerardo Suarez, Universidad Nacional Autónoma de México (gersua@yahoo.com)

An Earthquake Early Warning System for Northern Chile MEDINA, M., University of Chile, Santiago, Chile, miguel.medina@dgf. uchile.cl; SANCHEZ, R., University of Chile, Santiago, Chile, rodrigo@csn. uchile.cl; RIQUELME, S., University of Chile, Santiago, Chile, sebastian@csn. uchile.cl; BARRIENTOS, S. E., University of Chile, Santiago, Chile, sbarrien@ csn.uchile.cl; HENSON, I., University of California, Berkeley, California, USA, ihenson@berkeley.edu; CHUNG, A. I., University of California, Berkeley, California, USA, aichung@berkeley.edu; MELGAR, D., University of Oregon, Oregon, USA, dmelgarm@uoregon.edu; MUHR, R., Antofagasta Minerals, Santiago, Chile, rmuhr@aminerals.cl; MPODOZIS, C., Antofagasta Minerals, Santiago, Chile, cmpdodozis@aminerals.cl; HELLWEG, M., University of California, Berkeley, California, USA, peggy@seismo.berkeley.edu; ALLEN, R., University of California, Berkeley, California, USA, rallen@berkeley.edu

In 2020, the National Seismological Center (CSN) implemented an earthquake early warning (EEW) system in northern Chile, which has one of the largest seismic gaps in Chile. Here, a $\mathrm{Mw} \sim 9.0$ earthquake is possible, even likely, in a region with a population of more than 1.4 million. From an economic perspective, this region hosts $90 \%$ of the copper mining companies and production in Chile, with more than $15 \%$ of the Gross National Product coming from the mining industry. With the goal of keeping both the popu- 
lation and mining industry safe, Antofagasta Minerals (AMSA) decided to finance an EEW prototype for this region, that could potentially save lives and support critical mining operations. Twenty-six new seismic stations have been added to the CSN permanent network to support this EEW system that will issue alerts for strong shaking. We successfully locate and calculate the magnitude of more than 1000 earthquakes using the EPIC (Earthquake Pointsource Integrated Code) algorithm developed for the U.S. ShakeAlert system. The average alert time per event is $~ 20$ seconds and $95 \%$ of earthquakes larger than magnitude 5 were alerted.

\section{Cooperation With Stakeholders of the Future Earthquake Early Warning System (EEW) in Nicaragua}

STRAUCH, W., Instituto Nicaragüense de Estudios Territoriales, Managua, Nicaragua, wilfried.strauch@yahoo.com; TALAVERA, E., Instituto Nicaraguense de Estudios Territoriales, Managua, Nicaragua, emilio. talavera@ineter.gob.ni

Seismic hazard is high in the Nicaragua and it is the second poorest country of the Americas. Thus, the main EEW targets should be the millions of poor people living in homes very vulnerable for seismic shaking. Since 2016, we develop EEW in Nicaragua and Central America, supported by Swiss Technical Cooperation and Swiss Seismological Service at University of Zürich.

INETER's seismology section transformed into a warning center on earthquakes and tsunamis including accelerographic monitoring of facilities in Nicaragua. Following a call from the regional community (CEPREDENACRegional Disaster Prevention Center) and a development project with the Japanese Cooperation we operate, since 2019, the Central American Tsunami Advisory Center (CATAC) guided by IOC/UNESCO. We use INETER's Seismic Network (2015: 50 stations; 2021: 150 projected) and additional data from Central America and surroundings and are integrating GPS data for extreme earthquakes and fast tsunami warnings (support: UNAVCO, NASA, UNESCO).

We approached stakeholders interested in EEW. Since 2016, EEW is internally used at INETER and we provide it to the Nicaraguan government. Starting 2019, we facilitate EEW to SINAPRED (disaster prevention system) and Civil Defense (Army). In 2020, we formed working groups of stakeholders at Central and local governmental institutions, universities, enterprises, to cooperate with monitoring, distribution of warning messaging systems using a TV/Radio stations and Apps, information and education. In 2021, EEW will extend to larger groups of decision makers and target institutions of CATAC. Experimental EEW will be included in disaster exercises of SINAPRED paving the way for the future EEW to the general public.

\section{Developing EEW Capabilities at the OVSICORI Seismic Processing Center}

CHAVES, E. J., Volcanological and Seismological Observatory of Costa Rica, Universidad Nacional, Heredia, Costa Rica, esteban.j.chaves@una.ac.cr; GARITA, C., Volcanological and Seismological Observatory of Costa Rica, Universidad Nacional, Heredia, Costa Rica, christian.garita.hidalgo@una ac.cr; PROTTI, M., Volcanological and Seismological Observatory of Costa Rica, Universidad Nacional, Heredia, Costa Rica, marino.protti.quesada@una. cr; MASSIN, F., ETHZ-SED, Swiss Seismological Service, Zürich, Switzerland, frederick.massin@sed.ethz.ch;BURGOA ROSSO,B., Independent Consultant, La Paz, Bolivia, billyburgoa@gmail.com; SUÁREZ BONILLA, F., Independent Consultant, Heredia, Costa Rica, felixdavidsuarezbonilla@gmail.com

Developing efforts for understanding and monitoring tectonic and volcanic activity and its imposed risk to the country have fruitfully converged towards the creation of the Volcanological and Seismological Observatory of Costa Rica at Universidad Nacional (OVSICORI-UNA). With more than 90 stateof-the-art seismological stations distributed across the country, OVSICORI records more than 12000 earthquakes per year. Multiple and relatively large $(M>6.0)$ subduction zone and continental earthquakes imposed a continuous risk to the local communities and the growing economy, increasing the necessity for the establishment of an Earthquake Warning System. Since 2019, as part of the EWARNICA project, a Swiss initiative, OVSICORI-UNA has been part of the evaluation and fine-tuning process of the earthquake early warning system (EEWS) being implemented in Central America. The current density of the network has proved to be good enough, but still needs coverage in other parts of the country, such as the Caribbean region. We will present several examples of how the current network has performed and how to densify it to optimize its performance for EEW. We will also show results of the first tests we will perform early in 2021, together with JTEC using their early warning broadcast system (EWBS) and the digital television transmission system of Costa Rica.

\section{Extending the National Seismic Network in Guatemala}

ALVARADO SOSA, R., Instituto Nacional de Sismología, Vulcanología, Meteorología e Hidrología, INSIVUMEH, Guatemala City, Guatemala, ralvarado@insivumeh.gob.gt; YANI QUIYUCH, R., Instituto Nacional de Sismologia, Vulcanología, Meteorología e Hidrología, INSIVUMEH, Guatemala City, Guatemala, royani@insivumeh.gob.gt; CASTRO, D. Instituto Nacional de Sismologia, Vulcanología, Meteorología e Hidrología, INSIVUMEH., Guatemala City, Guatemala, dcastro@insivumeh.gob.gt; MASSIN, F., ETHZ-SED, Swiss Seismological Service, Zürich, Switzerland, frederick.massin@sed.ethz.ch; CLINTON, J., ETHZ-SED, Swiss Seismological Service, Zürich, Switzerland, jclinton@sed.ethz.ch

For more than 40 years, INSIVUMEH has been the public institute tasked with monitoring and studying seismic activity in Guatemala. Over the course of the year 2021, at least 32 new seismic stations are planned to be installed in strategic points across the territory of the Republic of Guatemala, which will result in a significant enhancement of the national seismic network operated by INSIVUMEH. This increase in the number of stations has two concrete objectives: the first is to achieve a more comprehensive monitoring of the principal seismogenic zones in Guatemala, whereas the second is to be able to provide an important contribution to the early warning efforts currently being taken in Central America, under the umbrella of a collaboration between national seismic monitoring agencies and the Swiss Seismological Service at ETHZ. As such, one of the principal challenges is to distribute all 32 stations in a manner that would address both objectives, while choosing sites of low seismic noise without compromising the safety of the equipment to be installed. Several regions to locate the station sites have already been chosen, but specific sites are yet to be found for a few sensors.

Towards Earthquake Early Warning Across Central America MASSIN, F., ETHZ-SED, Swiss Seismological Service, Zürich, Switzerland, frederick.massin@sed.ethz.ch; BÖSE, M., ETHZ-SED, Swiss Seismological Service, Zürich, Switzerland, mboese@sed.ethz.ch; SUÁREZ BONILLA, F., Independent Consultant, San Jose, Costa Rica, felixdavidsuarezbonilla@ gmail.com; BURGOA ROSSO, B., Independent Consultant, Bogota, Bolivia, billyburgoa@gmail.com; CHAVES, E. J., OVSICORI-UNA, Volcanological and Seismological Observatory of Costa Rica, Universidad Nacional, Heredia, Costa Rica, esteban.j.chaves@una.ac.cr; CLINTON, J., ETHZSED, Swiss Seismological Service, Zürich, Switzerland, jclinton@sed.ethz. ch; MARROQUIN, G., MARN, Ministerio de Medio Ambiente y Recursos Naturales, San Salvador, El Salvador, gmarroquin@marn.gob.sv; PROTTI, M., OVSICORI-UNA, Volcanological and Seismological Observatory of Costa Rica, Universidad Nacional, Heredia, Costa Rica, marino.protti.quesada@ una.cr; RACINE, R., ETHZ-SED, Swiss Seismological Service, Zürich, Switzerland, racine@sed.ethz.ch; STRAUCH, W., Instituto Nicaragüense de Estudios Territoriales, Managua, Nicaragua, wilfried.strauch@yahoo com; YANI QUIYUCH, R., Instituto Nacional de Sismología, Vulcanología, Meteorología e Hidrología, Guatemala City, Guatemala, royani@insivumeh. gob.gt

Central America is exposed to frequent damaging earthquakes, from tsunamigenic thrust events and on-shore shallow crustal events often near densely urbanized areas. An effective Earthquake Early Warning (EEW) system will not prevent the losses from such kinds of damaging earthquakes but can mitigate some of their consequences.

Since 2016, a collaboration between national seismic monitoring agencies and the Swiss Seismological Service aims to build national EEW systems that together can provide public alerts across the region. This initiative builds on the existing national seismic networks; the long-existing regional cooperation in earthquake monitoring and data sharing; and the close coordination with national and regional civil protection agencies. Currently, prototype EEW systems based on the Virtual Seismologist and Finder algorithms are implemented within SeisComP3 and are providing internal EEW alerts in Nicaragua, El Salvador, and Costa Rica.

In this contribution, we report on the progress towards EEW readiness throughout the project to date. Optimizing EEW systems have led to demonstrate the possible speed and quality of earthquake parameter estimations. 70 EEW-ready class A force balance accelerographs are being installed across the region to reduce EEW delays and improve reliability. These network upgrades also have a broader value for general seismological, tsunami and volcano monitoring. Through a collaboration with Japanese providers organization JTEC, their Emergency Warning Broadcast System via DigitalTV services will start providing prototype minimal latency EEW alerts. We further highlight key non-technical challenges including long-term funding of operational and governance structures and designing appropriate outreach messages for each 
nation. Additionally, work needs to begin across the region in order to prepare the population on how to react once an earthquake early warning is declared.

\section{Empowered by ShakeAlert: The Development and Assessment of Educational Resources for Earthquake Early Warning in the United States}

SUMY, D. F., Incorporated Research Institutions for Seismology, District of Columbia, USA, danielle.sumy@iris.edu; OLDS, S., UNAVCO, Colorado, USA, olds@unavco.org; MAGURA, B., Incorporated Research Institutions for Seismology, Oregon, USA, magura@comcast.net; JOHNSON, J., Incorporated Research Institutions for Seismology, Oregon, USA, jendaj@ gmail.com; CRAYNE, J., Oregon Museum of Science and Industry, Oregon, USA, jcrayne@omsi.edu; DERAS, K., Oregon Museum of Science and Industry, Oregon, USA, kderas@omsi.edu; HERRAN, C., Oregon Museum of Science and Industry, Oregon, USA, cherran@omsi.edu; JENKINS, M. R., U.S. Geological Survey, California, USA, mrjenkins@contractor.usgs. gov; CARDIEL, C., Oregon Museum of Science and Industry, Oregon, USA, ccardiel@omsi.edu; ANDERSON, M., Washington Department of Natural Resources, Washington, USA, megan.anderson@dnr.wa.gov; PRIDMORE, C., California Geological Survey, California, USA, cynthia.pridmore@ conservation.ca.gov; MCBRIDE, S. K., U.S. Geological Survey, California, USA, skmcbride@usgs.gov; DE GROOT, R., U.S. Geological Survey, California, USA, rdegroot@usgs.gov

Over 55 million people live in the earthquake prone states of Washington, Oregon, and California. A moderate-to-large magnitude earthquake in a dense population center, such as Los Angeles or Seattle, has the potential to cause severe damage which could threaten the national economy and its security. In light of this, the U. S. Geological Survey and its partners developed the Advanced National Seismic System's ShakeAlert, the earthquake early warning system for the west coast of the United States. However, many people in these three states are not very aware of their earthquake hazards and risk, and what actions they need to take to protect themselves before, during, and after an earthquake. A robust education program in both formal and informal learning environments, such as museums, libraries, national parks, and the K-12 classroom is needed to reach everyone. The ShakeAlert Educational Resources Working Group's suite of educational resources aims to present scientifically accurate information on earthquake hazards particularly on the west coast. We use several short (2-3 minute) animations and scaffolded activities of varying time lengths (5-, 15-, and 30-45 minutes, depending on learning environment) to address basic earthquake and related natural hazard (e.g., tsunamis, volcanoes, and landslides) concepts. Our learning objectives include what to do in the event of an earthquake and if/when you receive a ShakeAlert message. We also aim to address misconceptions many may have about earthquakes, such as the relationship between earthquake magnitude and intensity and that early warning is not earthquake prediction. Evaluation of our educational resources determines whether knowledge about earthquake early warning has improved. To this end, we have formed a collaboration with the Oregon Museum of Science and Industry to help build our resources with cultural inclusion in mind and to assess their effectiveness. In this presentation, we will showcase the educational activities and animations that we have developed, as well as our preliminary assessment tools and findings.

\section{Low-Latency Digitization, Communication and Alerting for Earthquake Early Warning Systems: Güralp Minimus}

REIS, W., Güralp Systems Ltd, Reading, United Kingdom, wreis@guralp. com; LINDSEY, J., Güralp Systems Ltd, Reading, United Kingdom, jlindsey@ guralp.com; HILL, P., Güralp Systems Ltd, Reading, United Kingdom, phill@ guralp.com; WATKISS, N., Güralp Systems Ltd, Reading, United Kingdom, nwatkiss@guralp.com

Earthquake Early Warning Systems (EEWS) must combine low latency digitization, communication and computational processes to be effective. This maximises the time between the characterization of an event and the warning of the population, thereby providing the longest warning time. Güralp Systems Ltd. (GSL) has developed the Minimus digitizer with a range of smart features that reduces latency to $40 \mathrm{~ms}$ from signal input to output.

The Minimus makes use of industry standard processing techniques such as causal FIR filters to reduce the digitization delay within the digitizer. GSL has also developed and equipped Minimus with our GDI-link streaming protocol to further reduce the delays in data communication. GDI-link streams data sample-by-sample upstream and will dynamically adjust to the available bandwidth, therefore providing a fast a reliable communication protocol than traditional packetization protocols. This results in the received data packets having a dramatically lower mean latency when compared to conventional SEED-link for example.
Minimus combines familiar STA/LTA algorithms with simple machinereadable event messages to alert operators and populations to impending ground shaking. When in a triggered state, the Minimus will instantly send a Common Alert Protocol (CAP) event message to a designated receiver containing the station metadata that indicates an event has occurred. The Minimus will locally compute the PGA, PGV and PGD parameters from the triggered event and will subsequently send these calculations as a secondary CAP message. CAP messaging makes use of existing internet infrastructure and is already widely used in public communications which will aid EEW network operators with regards to implementation.

The Minimus has been designed as either a standalone digitizer or can be integrated into the Fortimus accelerometer and the Certimus digital seismometer. The integrated systems provide compact and easy to deploy systems that are suitable for widescale EEW deployments.

\section{Performance of the Seismic Alert System of Mexico During the 23 June 2020, Oaxaca Earthquake (Mw 7.4)}

SUAREZ, G., Instituto de Geofísica, National Autonomous University of Mexico, Mexico, gersua@yahoo.com; ESPINOSA-ARANDA, J., CIRES, Mexico City, Mexico, maranda@unam.mx; CUELLAR, A., CIRES, Mexico City, Mexico, a.cuellar@cires-ac.mx; URIBE, A., CIRES, Mexico City, Mexico, a.uribe@cires-ac.mx; IBARROLA, G., CIRES, Mexico City, Mexico, g.ibarrola@cires-ac.mx; GARCÍA, A., CIRES, Mexico City, Mexico, a.garcia@ cires-ac.mx; ISLAS, R., CIRES, Mexico City, Mexico, r.islas@cires-ac.mx; CAMARILLO, L., CIRES, Mexico City, Mexico, 1.camarillo@cires-ac.mx

The Mexican Seismic Alerting System (SASMEX) successfully detected and screened the 23 June 2020 earthquake $\left(M_{\mathrm{w}} 7.4\right)$ in southern Mexico. The alert was activated simultaneously in seven cities. The time between the alert broadcast and the initiation of strong shaking ranged from $30 \mathrm{~s}$ in the city of Oaxaca and $134 \mathrm{~s}$ in Mexico City. Here, we dissect SASMEX messages from the time the earthquake was detected to the generation of maps of peak ground acceleration in Mexico City. Based on the $t_{\mathrm{S}}-t_{\mathrm{p}}$ algorithm, the first magnitude estimation $\left(M_{\mathrm{w}} \geq 6.5\right)$ was from a station located $3 \mathrm{~km}$ away from the epicenter. On this basis, a pre-alert message was issued. Confirmation of the magnitude came from an adjacent station located $43 \mathrm{~km}$ from the epicenter. The same algorithm confirmed the magnitude threshold and triggered the general alert $16 \mathrm{~s}$ after the origin time. In this case, the decision to broadcast the alert took longer than in previous large earthquakes. This was due to the relatively large interstation spacing in this region. An algorithm called $t_{\mathrm{p}}+3$, that estimates magnitude based on the first three seconds after the onset of the $P$ wave, would have issued the alert $4 \mathrm{~s}$ before. However, the triggering procedures in place today require that the same algorithm is used to issue the alert. SASMEX warned all cities where it operates with ample time. Also, the earthquake of 23 June 2020 provided important lessons to further improve the performance of SASMEX. Peak ground acceleration in key sites in Mexico City was estimated 3.5 minutes after the origin time of the earthquake and one minute after strong shaking began, allowing authorities to take the appropriate measures.

Smartphone-Based Earthquake Early Warning in Costa Rica BROOKS, B. A., U.S. Geological Survey, California, USA, bbrooks@usgs. gov; PROTTI, M., Observatorio Vulcanologico y Sismologico de Costa Rica, San Jose, Costa Rica, marino.protti.quesada@una.cr; ERICKSEN, T., U.S. Geological Survey, California, USA, tericksen@usgs.gov; BUNN, J. J., Caltech, California, USA, julian.bunn@caltech.edu; VEGA, F., Observatorio Vulcanologico y Sismologico de Costa Rica, San Jose, Costa Rica, floribeth. vega.solano@una.cr; COCHRAN, E. S., U.S. Geological Survey, California, USA, ecochran@usgs.gov; DUNCAN, C., GISmatters, Massachusetts, USA, duncan@gismatters.com; AVERY, J., University of Hawaii, California, USA, aj35@hawaii.edu; MINSON, S., U.S. Geological Survey, California, USA, sminson@usgs.gov; BAEZ, J., Centro Sismologico Nacional de Chile, Santiago, Chile, jcbaez@csn.uchile.cl; FOSTER, J., University of Stuttgart, Stuttgart, Germany, james.foster@gis.uni-stuttgart.de; GLENNIE, C., University of Houston, Texas, USA, clglenni@central.uh.edu

We find that off-the-shelf smartphones deployed in a fixed network can provide earthquake early warning performance comparable to scientific-grade systems. In 2020 we constructed the ASTUTI (Alerta Sismica Temprana Utilizando Teléfonos Inteligentes) smartphone network of more than 80 stations affixed to walls in baseboards of buildings distributed throughout Costa Rica. We evaluate an accelerometer-based non-parametric ground-motion detection and alerting strategy that considers the dominant source of shaking hazard to be Middle America Trench subduction zone earthquakes. Our strategy focuses on Costa Rica's densely populated interior region near San Jose city where most of the population experiences shaking during earth- 
quakes $>$ M6. We evaluate issuing alerts when an acceleration threshold is exceeded at four stations. For 6 months of operation and a small group (15) of participants, data latency over cell-phone networks (phones to processing machine) is acceptably low, $0.35-0.45$ secs. From on-phone vibration simulation of the 2012 M7.6 Nicoya earthquake we find median first-alert latency of $\sim 9-13$ secs and alert-receipt latency of $\sim 4$ secs. Greater latency may occur when alerting larger numbers of recipients. 13 earthquakes caused felt shaking "did-you-feel-it" (DYFI) reports in Costa Rica in our evaluation period. We detected and alerted on 5 of these events (offline re-runs), each of which produced shaking in San Jose. Our system issued no false alerts and undetected events were out-of-network and did not produce wide-spread felt shaking near San Jose. We further evaluate alerting the entire country after detecting an earthquake and find that $15-70 \%$ of Costa Rica's population could receive alerts preceding shaking with enough time to carry out drop-cover-hold-on (DCHO). As suggested by current social science research, if populations tend to be false-alarm tolerant, this more inclusive alerting approach may be effective for populations with geographic distribution and hazard exposure similar to Costa Rica.

\section{Towards Performance-Based Earthquake Early Warning}

MINSON, S., U.S. Geological Survey, California, USA, sminson@usgs.gov; COCHRAN, E. S., U.S. Geological Survey, California, USA, ecochran@usgs. gov; WU, S., Institute of Statistical Mathematics, Tachikawa, Japan, stewu@ ism.ac.jp; SAUNDERS, J. K., U.S. Geological Survey, California, USA, jksaunders@usgs.gov; BALTAY, A., U.S. Geological Survey, California, USA, abaltay@usgs.gov; MCBRIDE, S. K., U.S. Geological Survey, California, USA, skmcbride@usgs.gov

Earthquake shaking forecasts are uncertain, and so it will be impossible to always alert for earthquakes that cause significant shaking (whether the definition of "significant" is felt shaking, damaging shaking, or something else) while never alerting unnecessarily for earthquakes that produce insignificant shaking. In practice, most earthquake early warning (EEW) systems alert for lower levels of shaking than desired so as to avoid missing an alert should the shaking turn out to be significant. But this margin of error is often determined haphazardly. The earthquake engineering community already provides a methodological framework for building infrastructure that achieves some desired level of performance: performance-based earthquake engineering (PBEE). In PBEE, structures are designed so that there is an acceptably high probability that they will experience the desired outcome (such as prevention of building collapse or immediate occupancy following an earthquake) over some set time horizon. We can take the same approach to EEW, and calculate the alerting criteria necessary for an early warning system to produce desired performance specified as an acceptably high probability of receiving an alert before shaking exceeds some critical threshold. Similarly, we can also compute expected system outcomes, such as the rate at which users will receive unnecessary alerts for insignificant shaking. We will present the mathematical foundation for this approach, present sample system designs and outcomes, and discuss how the expected performance of EEW systems can be communicated to the public.

\section{Earthquake Early Warning System in the Americas: The On-Going Effort and the State of the Art}

Poster Session · Tuesday · 20 April · 11:30 Am Pacific Session Chairs: Esteban J. Chaves, Volcanological and Seismological Observatory of Costa Rica, Universidad Nacional (esteban.j.chaves@una.cr); Marino Protti, Volcanological and Seismological Observatory of Costa Rica, Universidad Nacional (marino.protti.quesada@una. cr); Edmundo Norabuena, Instituto Geofísico del Perú (enorabuena@igp.gob.pe); Gerardo Suarez, Universidad Nacional Autónoma de México (gersua@yahoo.com)

\section{Approaching EEW in Central America: The Readiness of Seismic Network Processing Hubs}

BURGOA ROSSO, B., Independent Consultant, La Paz, Bolivia, billyburgoa@ gmail.com; CLINTON, J., ETH Zürich, Zürich, Switzerland, jclinton@sed. ethz.ch; MASSIN, F., ETH Zürich, Zürich, Switzerland, frederick.massin@sed. ethz.ch; RACINE, R., ETH Zürich, Zürich, Switzerland, racine@sed.ethz.ch; MARROQUIN, G., MARN, San Salvador, El Salvador, gmarroquin@marn. gob.sv; STRAUCH, W., INETER, Managua, Nicaragua, wilfried.strauch@ yahoo.com; PROTTI, M., OVSICORI, Heredia, Costa Rica, marino.protti. quesada@una.cr; GARITA HIDALGO, C., OVSICORI, Heredia, Costa Rica, christian.garita.hidalgo@una.cr; CHAVES, E. J., OVSICORI, Heredia, Costa Rica, esteban.j.chaves@una.ac.cr; YANI QUIYUCH, R., INSIVUMEH, Guatemala City, Guatemala, royani@insivumeh.gob.gt; ALVARADO SOSA, R., INSIVUMEH, Guatemala City, Guatemala, ralvarado@insivumeh.gob.gt

The core component of Earthquake Early Warning (EEW) is a dense seismic network which streams the data in real-time in a reliable and low latency manner. Furthermore, EEW needs an always-on, efficient and fast computation platform to process the data with minimal. Further processing like dissemination, generating alerts and publication of reliable information to the public stakeholders and others are based on the outcomes from the computational seismological systems. It is a challenge to create these infrastructures anywhere, and in particular in Central America where independent networks tend to be small in size and support, and already have significant responsibilities monitoring multiple geohazards that also include volcanoes and tsunamis

Central America is aiming to develop reliable, highly available national EEW systems based on the current seismic networks that national agencies operate and maintain, as well as on their technical and scientific capabilities. To reinforce the EEW capabilities in this very active seismic region in America, the seismic data centers of Nicaragua, Costa Rica, Guatemala and El Salvador in collaboration with Swiss Seismological Service are building EEW capabilities based on a uniform usage of the same seismological processing system SeisComP and its embedded EEW algorithms Virtual Seismologist and FinDer.

Each seismological center in Central America has its own attributes mainly in terms of instrumentation and computational systems. Nevertheless, adoption of similar processing architectures as well as uniform software usage, configuration and monitoring are critical in terms of maintaining high quality performance at a limited cost and can also allow networks to support each other in the long term. Staff training - for both seismologists and IT - is an important component of building centers that can optimal level of operation. This presentation is focused on the current ability of each network hub in the Central America region to provide EEW.

\section{Evolution of EEW Instrumentation}

PARKER, T., Nanometrics, Kanata, Canada, timparker@nanometrics.ca; PELYK, N., Nanometrics, Kanata, Canada, nickpelyk@nanometrics.ca

Nanometrics has responded to EEW program requirements with innovative instrument developments, specifically a wide dynamic range instrument, the Cascadia, combining strong and weak motion sensors in a single case. This instrument has a very large dynamic range, $200 \mathrm{~dB}$, wide bandwidth and low noise floor with a configurable clip level. The sensors are packaged in a robust case that can be deployed in shallow direct burial deployments used in aftershock studies or in state-of-the-art boreholes used for combined EEW monitoring sites/regional arrays and scientific studies. We have released a new version of the Cascadia, the Cascadia Slim with a lower noise floor at the long period frequencies based on the Trillium T120 Slim broadband sensor. The Cascadia Slim has a wide dynamic range, $215 \mathrm{~dB}$, in a similar environmental package and will improve the magnitude of completeness (Mc) of a seismic network where it was limited by broadband sensor performance and in most EEW networks will only be limited by the site noise and emplacement techniques. Using this new instrument the economy and confidence of station performance in a network can be measurably improved and enables new station installs to be lower cost and with better emplacement technologies through use of properly built and deeper cased holes.

\section{The Importance of Earthquake Education in Free Choice Learning Environments}

IENKINS, M. R., U.S. Geological Survey, California, USA, mrjenkins@ contractor.usgs.gov; SUMY, D. F., Incorporated Research Institutions for Seismology, District of Columbia, USA, danielle.sumy@iris.edu; MCBRIDE S. K., U.S. Geological Survey, California, USA, skmcbride@usgs.gov; DE GROOT, R., U.S. Geological Survey, California, USA, rdegroot@usgs.gov

Free choice learning environments, such as museums, national parks, and libraries, are trusted sources of information in their communities and sup port lifelong learning beyond the formal classroom. Earthquake education in these spaces creates communal awareness of earthquake hazards and risk in areas in which people live or vacation, and in turn, may increase engagement in preparedness behavior if or when an earthquake strikes. The ShakeAlert Earthquake Early Warning System aims to help communities prepare by warning in advance of shaking from significant earthquakes along the West 
Coast of the United States. ShakeAlert has the ability to minimize earthquake damage by prompting automated actions (e.g., stopping trains, opening firehouse doors) and prompt personal protective actions, like Drop, Cover, and Hold On. As the testing of public alerting to wireless devices, like smartphones, expands throughout the West Coast, raising awareness of ShakeAlert and earthquake education, in general, is integral to reach the broadest audience possible, and to reduce damage, injury, and loss of life. For these reasons, engaging people in environments where they choose to learn, such as free choice learning environments, better facilitates earthquake education, and contributes to increased awareness. Currently, there is a dearth in the literature on how free choice learning environments approach earthquake education through display themes and development. We analyzed a global sample of existing earthquake exhibits and their themes in order to better understand exhibits across common informal learning environments, while also exploring how different display types can be uniquely engaging. We anticipate that this work will set a foundational framework, using a combination of pedagogical and communication theories, for how best to incorporate ShakeAlert and earthquake hazard education into centers of free choice learning and support place-based learning.

\begin{tabular}{l}
\hline Earthquake Science, Hazards and Policy in Cascadia \\
I: Oral Session· Tuesday · 20 April · 2:30 PM Pacific \\
II: Oral Session · Tuesday· 20 April · 5:30 PM Pacific \\
Session Chairs: Valerie Sahakian, University of Oregon \\
(vjs@uoregon.edu); Erin A. Wirth, U.S. Geological Survey, \\
Earthquake Science Center (emoriarty@usgs.gov); Janet Watt, \\
U.S. Geological Survey, Pacific Coastal and Marine Science \\
Center (jwatt@usgs.gov); Carlos Molina-Hutt, University of \\
British Columbia (carlos.molinahutt@civil.ubc.ca); Grace \\
Parker, U.S. Geological Survey, Earthquake Science Center \\
(gparker@usgs.gov); Ann Bostrom, University of Washington \\
(abostrom@uw.edu)
\end{tabular}

\section{Most Hazardous Segments of the Cascadia Rupture-} Challenging the Worst-Case Scenario

SALAREE, A., University of Michigan, Michigan, USA, salaree@umich.edu; HUANG, Y., University of Michigan, Michigan, USA, yiheh@umich.edu; RAMOS, M., University of Michigan, Michigan, USA, ramosmd@umich.edu; STEIN, S., Northwestern University, Illinois, USA, s-stein@northwestern.edu

The lateral extent as well as the final size of potential future ruptures in Cascadia are poorly known. As a result, previous Cascadia tsunami studies are usually based on either "reasonable" or "worst-case" scenarios.

In this study, we calculate the tsunami hazard of M7-9 earthquakes using more realistic models that systematically vary both the geographic extent and slip of the rupture. To achieve this goal, we use rupture simulations derived from geodetic locking models to provide estimates of coseismic deformation at the ocean floor, and design rupture scenarios with variable hypocenters and rupture propagation. We then apply a non-linear algorithm to simulate full tsunami waveforms and generate tsunami amplitude profiles along the Cascadia coastline. By varying rupture dimensions and thus the seismic moment thresholds of these models, we find that while regional maximum coastal amplitudes are not unique for a given rupture size, increasing the rupture size beyond a magnitude of $\mathrm{M}_{\mathrm{w}} \approx 8.5$ will not significantly vary the tsunami hazard, especially in southern Cascadia, with the central segments playing the most crucial role. Numerical experiments attribute this property to the peculiar concave coastal morphology which also heightened hazard in central Cascadia (Oregon). Application of slip distribution from dynamic rupture scenarios in tsunami simulations also reveals that the possible coastal tsunami amplitude profiles in the US west coast from large Cascadia ruptures are largely insensitive to the choice of slip model. These results have significant implications in identifying the main sources of tsunami hazard along the US west coast, especially as a single worst-case rupture scenario does not uniquely correspond to the worst-case tsunami scenario at a given location.
Sensitivity Testing of Cascadia Marine Turbidite Ages and Comparison With Onshore Megathrust Evidence

STAISCH, L. M., U.S. Geological Survey, Oregon, USA, 1staisch@usgs.gov; GOLDFINGER, C., Oregon State University, Oregon, USA, chris.goldfinger@ oregonstate.edu

Marine turbidite studies infer $\sim 19$ full margin $\sim \mathrm{M} 9$ earthquakes in the past $10 \mathrm{kyr}$ along the Cascadia subduction zone. This conclusion relies on several assumptions for turbidite age analysis: (1) sedimentation rate is accurately calculated from correlation between offshore turbidites and onshore subsidence events (2) basal erosion is accurately estimated from core stratigraphy and (3) local ${ }^{14} \mathrm{C}$ marine reservoir corrections from shallow coastal sites apply to offshore foraminifera dated for marine core chronology. Furthermore, the published radiocarbon calibration used software that employs an outdated ${ }^{14} \mathrm{C}$ marine reservoir age correction.

In this work, I isolate each variable and systematically test how prior assumptions and new calibration curves affect estimated turbidite ages. I use Calib software version 8.1.0 with the most recent Marine20 calibration curve. This new calibration curve differs from past iterations by permitting more complex and realistic changes in the carbon cycle over time. I calculate turbidite age and uncertainty using a Monte Carlo approach, where I sample each variable's probability distribution 10,000 times. By simply updating the software used, the calculated turbidite age is $~ 60$ years younger on average and up to several hundred years different for specific data points, compared to the published estimates. The combined effect of updating software version, slightly modifying local reservoir correction, and by uniformly sampling a wide range of sedimentation rate, rather than prescribing a single value, the calculated turbidite age is $\sim 125$ years younger on average compare to published estimates. These results highlight how recent advancements on the global marine radiocarbon calibration have a major impact on coseismic marine turbidite chronology in Cascadia. Future work on improving constraints on the spatial and temporal variation in local reservoir correction and sedimentation rate in the Pacific Northwest is critical for accurate turbidite age estimates and comparison with onshore megathrust records.

\section{The 26 January 1700 Cascadia Earthquake as Part of an Event Sequence}

MELGAR, D., University of Oregon, Oregon, USA, dmelgarm@uoregon.edu

Coastal subsidence, dating of soil samples and tree rings, and sedimentological evidence of a tsunami point to coseismic activity on a sizable portion of the Cascadia subduction zone circa 1700. Documents from Japan reveal that on January $26^{\text {th }}$ of that year there were tsunami impacts across distant locations in the country and modeling shows that a large Cascadia earthquake is the source. The prevailing hypothesis is that only a single large event rupturing the entire plate boundary explains this. Here we simulate tens of thousands of ruptures and compute their subsidence and tsunami signals and show that it is possible that the 1700 earthquake was instead part of a sequence of several earthquakes. Partial rupture of the megathrust in one large $\sim$ M8.7+ earthquake explains the tsunami in Japan and a part of the coastal subsidence. As many as four more earthquakes with $\mathrm{M}<8.6$ can complete the coseismic subsidence signal without their tsunamis being large enough to be recorded in Japan. Given the spatial gaps in the subsidence data it is also possible that short segments of the megathrust have remained unbroken. The findings have significant implications for Cascadia geodynamics and how earthquake and tsunami hazards in the region are quantified.

\section{Using Deep Learning to Identify Small Magnitude Earthquakes in 32TB of Continuous Seismic Data from the Pacific Northwest}

THOMAS, A. M., University of Oregon, Oregon, USA, amthomas@uoregon. edu; SEARCY, J., University of Oregon, Oregon, USA, jsearcy@uoregon.edu

The Cascadia Subduction Zone (CSZ) is known to host both great earthquakes and very small magnitude low-frequency earthquakes. Despite this, there is a remarkable dearth of megathrust earthquakes with magnitudes between these two endmembers making Cascadia one of the least seismic subduction zones in the world. The identification of small magnitude earthquakes in the region could improve knowledge of diagnostic properties of the CSZ and controls on seismogenesis. We develop a machine learning framework that will be used to identify small magnitude earthquakes in $32 \mathrm{~TB}$ of continuous seismic data from 42 seismic networks that operated in the Pacifc Northwest between 2005 and 2020. We train a U-shaped convolutional neural network (CNN) to pick earthquake body waves using three-component waveforms containing phase picks from the Pacific Northwest Seismic Network (PNSN) and the Northern California Earthquake Data Center (NCEDC). We explore several different 
network sizes, target functions, and variations in architecture. Our preferred network has a peak accuracy of $95 \%$ when identifying signal vs. noise in the testing data. Additionally, $97 \%$ of both P- and S-wave picks were made within 10 samples (0.1 seconds) of the true pick. For phase association, we generate synthetic earthquake catalogs with locations, magnitudes, and recurrence intervals representative of seismicity in the Pacific Northwest. We compute travel times using regional velocity models, attenuation from ground motion prediction equations, and false and missed picks by removing true and add ing spurious picks to the datasets and use the result to train a long short-term memory network (LSTM). The LSTM performs both classification, to determine whether a given phase pick is associated with an earthquake, and regression to estimate hypocentral location and origin time. The LSTM is over 99\% accurate at classifying true and false picks and predicts location and timing with low uncertainty on the training data. As a test, we apply the model to the July 2019 M4.6 Monroe, WA earthquake and aftershock sequence.

\section{Using Small Earthquakes and the Amphibious Cascadia Initiative Dataset to Probe Cascadia Subduction Zone Heterogeneities}

MORTON, E. A., University of Reno, Nevada, USA, emilymorton@unr.edu; BILEK, S. L., New Mexico Institute of Mining and Technology, New Mexico, USA, susan.bilek@nmt.edu; ROWE, C. A., Los Alamos National Laboratory, New Mexico, USA, char@lanl.gov

The Cascadia Subduction Zone (CSZ) has a rich paleoseismic history of large to great earthquake ruptures, the most recent being a M9 in 1700. Historically, the margin is notable for being seismically quiet and lacking even small- to moderate-magnitude (<M4) earthquakes. Given the potential of a future megathrust rupture, mapping high coseismic slip patches/strong asperities on the plate interface is imperative in order to best estimate expected ground motions and tsunami inundation potential for the high population centers along the margin. We improve upon existing land-seismometer derived catalogs for the CSZ by using the amphibious Cascadia Initiative (CI; 2011-2015) seismic array and robust subspace detection. We identify small offshore and coastal earthquakes within the seismogenic zone and use them to map alongstrike variations in frictional conditions on the plate interface.

We have detected and located more than 2000 earthquakes over most of the CI deployment (July 2011-August 2014). 1594 of these earthquakes were previously undetected, and a few thousand detections remain to be located. Small earthquake locations generally agree with previously identified offshore paleo-rupture segment extents, and with the M9 1700 rupture model. Along the northern end of the margin, small earthquakes indicate that the identified 1700 asperities may be smaller than modeled or smooth over smaller, closely located asperities. Possible rupture barriers exist at the tip of the Olympic Peninsula and at the OR-CA border, which correlate with paleo-rupture segments, but are absent from the 1700 model and geodetic locking model. Both the geodetic locking model and the small earthquakes presented here point to weak coupling offshore central OR, which is inconsistent with the 1700 rupture model. The small earthquakes presented here demonstrate broad agreement with previous models of locking and asperities along the margin, but refine these with illumination of small-scale locking variations.

\section{Development and Application of Near-Surface Soil Velocity} Models for Seismic Hazard in the Pacific Northwest

GRANT, A., U.S. Geological Survey, California, USA, agrant@usgs.gov; WIRTH, E. A., U.S. Geological Survey, Washington, USA, emoriarty@usgs. gov

Site response is a critical component of ground motion propagation and can significantly impact the amplitude and frequency content of surficial shaking. To improve estimates of earthquake shaking in the Pacific Northwest (Oregon and Washington, as well as British Columbia, Canada), we developed regionspecific soil velocity models to compute site response. A regional shear wave velocity model was derived from 580 measured velocity profiles across the Pacific Northwest (Ahdi et al., 2017), to capture generic regional conditions as well as sub-regional models for basin/non-basin and specific geologic settings. These soil velocity profiles were modeled as a function of site condition (Vs30) and depth, to facilitate regional application with limited inputs. Representative Pacific Northwest soil velocity profiles were found to be more constant with depth in the near-surface $(<100 \mathrm{~m})$ than generic profiles from elsewhere (e.g., California), likely due to the glacial origin of surficial deposits across the region. These Pacific Northwest representative soil profiles were then used to compute site adjustment factors for incident synthetic earthquake ground motions. Using maps of estimated Vs30 of the region, we then developed site-corrected ensemble ShakeMaps for a M9.0 earthquake along the
Cascadia Subduction Zone (CSZ) from a suite of 30 simulated earthquakes. New ensemble ShakeMaps are generally in agreement with GMM-based existing ShakeMaps but show significant increases in shaking intensity within basins, where 3D ground motion simulations better capture low-frequency amplification and some smaller-scale changes in high-frequency response due to site amplifications. Ensemble ShakeMaps developed in this work are being adopted for national and state-level emergency planning exercises. Ongoing work will incorporate these soil velocity profiles in the generation of highfrequency ground motion content for next-generation crustal earthquake simulations in the Pacific Northwest.

\section{Effective Uncertainty Visualization for Aftershock Forecast Maps}

SCHNEIDER, M., University of Washington, Washington, USA, maxs15@ uw.edu; MCDOWELL, M., Harding Center for Risk Literacy, Potsdam, Germany, mcdowell@mpib-berlin.mpg.de; GUTTORP, P., University of Washington, Washington, USA, guttorp@uw.edu; STEEL, A., Food and Agriculture Organization of the United Nations, Rome, Italy, asteel.usfs@ gmail.com; FLEISCHHUT, N., Max Planck Institute for Human Development, Berlin, Germany, fleischhut@mpib-berlin.mpg.de

Seismicity rate estimates and the earthquake forecasts they yield vary spatially and are usually represented as heat maps. While visualization literature suggests that displaying forecast uncertainty can improve how forecast maps are used, research on uncertainty visualization (UV) is missing from earthquake science. We present a pre-registered online experiment to test the effectiveness of three UV techniques for displaying aftershock forecasts. These maps show the expected number of aftershocks at each location for a week following a hypothetical mainshock, and we develop maps of the uncertainty around each location's forecast. Human participants complete experimental tasks using the aftershock forecast displayed with its uncertainty. The forecast is derived from seismicity rate estimates for onshore Pacific Northwest earthquakes. Three different UVs are considered: (1) forecast and uncertainty maps adjacent to one another; (2) the forecast map depicted in a color scheme, with the uncertainty shown by the transparency of the color; (3) two maps that show the lower and upper bound of the forecast distriubiton at each location. We compare task performance using UVs versus using the forecast map shown without its uncertainty (the current practice). Subjects complete two map-reading tasks that target several dimensions of the readability of the UV. They then perform a comparative prediction task, which demonstrates whether a UV is successful in reaching two key communication goals: indicating where an aftershock and no aftershocks are likely ("sure bets") and where the forecast is low but the uncertainty is high enough to imply potential risk ("potential surprises"). All UVs perform equally well in the goal of communicating "sure bet" situations. But the UV with lower and upper bounds is significantly better than the other UVs at communicating "potential surprises." We discuss the implications of these results for better communication of not only forecast maps but other spatially-varying model products (e.g., seismic hazard maps).

\section{Predicted Warning and Triggering Rate, and Sensor Self-Noise Constraints for an Earthquake Early Warning System in Canada}

CRANE, S., Natural Resources Canada, Ottawa, Canada, stephen.crane@ canada.ca; ACKERLEY, N., Natural Resources Canada, Ottawa, Canada, nicholas.ackerley@canada.ca; ADAMS, J., Natural Resources Canada, Ottawa, Canada, john.adams@canada.ca; SEYWERD, H., Natural Resources Canada, Ottawa, Canada, henry.seywerd@canada.ca; MCCORMACK, D., Natural Resources Canada, Ottawa, Canada, david.mccormack@canada.ca

The utility of an EEWS depends on how often events requiring warnings occur, and how reliably the system can be operated. Events which are too small to warrant alerts but which nevertheless trigger the system provide a valuable way to validate system operation. We estimate both warning and trigger rates for Canada based on a synthetic earthquake catalog. For Metro Vancouver, it is estimated that there will be a broadcast warning at MMI IV issued once every four years, while for Montreal the estimates are one such warning every five years. Setting the trigger threshold to yield 25-30 triggers per year for each region, so that each month there is a high probability of a system test, requires a detection threshold of approximately Mw2.0. The requirement of detection on four sensors, together with the planned sensor density, implies detections are required to epicentral distances of c. $35 \mathrm{~km}$. We fit models of Mw2.0 P-wave spectra at $35 \mathrm{~km}$ for eastern and western Canada together with observed ambient noise at existing sites to constrain the acceptable sensor self-noise. 


\section{Spectral Acceleration Basin Amplification Factors for Interface Cascadia Subduction Zone Earthquakes in Canada's 2020 National Seismic Hazard Model}

KAKOTY, P., University of British Columbia, Vancouver, Canada, pkakoty@ mail.ubc.ca; MOLINA-HUTT, C., University of British Columbia, Vancouver, Canada, carlos.molinahutt@civil.ubc.ca

Canada's 2020 national seismic hazard model provides hazard estimates from interface Cascadia Subduction Zone (CSZ) earthquakes in southwestern Canada using four ground motion models (GMMs) with equal weights: Abrahamson et al. (2016), Zhao et al. (2006), Ghofrani and Atkinson (2014), and Atkinson and Macias (2009). Because Zhao et al. (2006) and Ghofrani and Atkinson (2014) were derived from data primarily from subduction earthquakes in Japan, their use in Canada's national seismic hazard model includes a "Cascadia" factor to account for local site conditions. Despite this regional factor, the GMMs do not explicitly consider basin amplification effects from the Georgia sedimentary basin below Metro Vancouver. This study benchmarks ground motion shaking from a suite of 30 physics-based simulations of M9 CSZ earthquake scenarios, which explicitly account for the basin effects by means of a three-dimensional velocity model, to corresponding GMMs in Canada's 2020 national seismic hazard model. We extend the site-specific and period-dependent basin amplification factors proposed by Kakoty et al. (2021) to consider all relevant GMMs. The weighted basin amplification factors at the deepest basin location range from 1.8 to 3.2 for periods in the 1 to 5 -second range. We validate the proposed basin factors by comparing amplifications from simulations against those from strong motion recordings from the 2001 Nisqually earthquake and the 2015 Victoria earthquake.

\section{The Effect of Fore-Arc Deformation on Shallow Earthquake Rupture Behavior in the Cascadia Subduction Zone} ASLAM, K., University of Oregon, Oregon, USA, akhurram98@gmail.com; THOMAS, A. M., University of Oregon, Oregon, USA, amthomas@uoregon. edu; MELGAR, D., University of Oregon, Oregon, USA, dmelgarm@uoregon. edu

Observational studies find along-strike variations in the geometrical properties of the Cascadia subduction zone (CSZ) megathrust. The megathrust of offshore Oregon is steeper and rougher than the megathrust of the offshore Washington region. Additionally, active source seismic surveys reveal significant along-strike differences in both the orientation of splay faults and sediment consolidation within the fore-arc of the CSZ. To investigate how the difference in the geometrical properties of megathrust and the difference in the fore-arc deformation style may affect the seismic and tsunami hazard during a future megathrust earthquake, we perform $2 \mathrm{D}$ dynamic earthquake rupture simulations on different realizations of a fault system that incorporate forearc properties representative of offshore Oregon and Washington. We find that both the shallow up-dip rupture behavior and the geometry of the fault affect the ground motions. The peak ground velocity (PGV) is larger for the Oregon models as compared to the Washington model at near-fault distances (due to larger fault slip in the shallow region) while it is lower at far-fault distances (since Oregon megathrust is steeper). Furthermore, we find that splay faults are activated irrespective of their orientation, but that slip is larger on the faults with seaward orientations. This amplifies seafloor uplift above these splays. Meanwhile, the difference in the consolidation of the CSZ sediments does not significantly influence seafloor uplift. If anelastic deformation of the material is allowed, uplift above the splay faults increases, and the difference between the uplift above the splay faults of the Washington and Oregon model is reduced. Our results suggest that the existence of splay faults, and their orientation can be a first-order control in the tsunami hazard model for the region as the predicted tsunami heights are significantly larger for Oregon than for Washington.
Earthquake Science, Hazards and Policy in Cascadia

Poster Session · Tuesday · 20 April · 11:30 Am Pacific

Session Chairs: Valerie Sahakian, University of Oregon

(vjs@uoregon.edu); Erin A. Wirth, U.S. Geological Survey, Earthquake Science Center (emoriarty@usgs.gov); Janet Watt, U.S. Geological Survey, Pacific Coastal and Marine Science Center (jwatt@usgs.gov); Carlos Molina-Hutt, University of British Columbia (carlos.molinahutt@civil.ubc.ca); Grace Parker, U.S. Geological Survey, Earthquake Science Center (gparker@usgs.gov); Ann Bostrom, University of Washington (abostrom@uw.edu)

\section{A 2700 Year Record of Megathrust and Crustal/Slab Earthquakes From Squaw Lakes, Oregon}

MOREY, A. E., Oregon State University, Oregon, USA, morey@coas. oregonstate.edu; GOLDFINGER, C., Oregon State University, Oregon, USA, chris.goldfinger@oregonstate.edu; SHAPLEY, M., LacCore, University of Minnesota, Minnesota, USA, shap0029@umn.edu; GAVIN, D. G., University of Oregon, Oregon, USA, dgavin@uoregon.edu

Finding evidence of megathrust earthquakes in small Cascadia lakes would provide the opportunity to better determine the source, and therefore hazard potential, of southern Cascadia earthquakes. An analysis of the sedimentary record from Lower Squaw Lake, a landslide dammed lake in southern Oregon, identified a disturbance deposit dated to 1680-1780 CE. This deposit has a sharp basal contact with evidence of loading, is composed of watershedsourced silt (suspected to result from liquefaction of the lake's delta), and has a long $(5-20 \mathrm{~cm})$ organic tail. To determine if this deposit was formed in response to the $1700 \mathrm{CE}$ Cascadia megathrust earthquake, deposits with similar characteristics were identified downcore and the timing of these deposits was compared to the timing of published record of offshore and coastal paleoseismic records.

Deposits with characteristics most similar to the deposit attributed to the 1700 CE Cascadia earthquake are temporal equivalents to offshore deposits T1-T6, where T2 and T4 equivalents in the lake record are thinner than the other events, similar to correlatives in the offshore record. A younger deposit (deposit H, dated to 1820-1880 CE; attributed to a slab earthquake which occurred in $1873 \mathrm{CE}$ ) also has similar characteristics. Deposit D, dated to 1870-1940 CE (possibly the result of the 1906 San Andreas earthquake), is also composed of watershed-sourced silt. A deposit, possibly equivalent to T2a (550-660 BP), is composed of schist, similar to deposit I (attributed to the failure of the landslide dam attributed to the $1873 \mathrm{CE}$ earthquake), suggesting a different source. The record may also include equivalents to events $\mathrm{T} 5 \mathrm{~b}$ and $\mathrm{T} 5 \mathrm{c}$, prominent in the offshore record, but are of uncertain attribution sedimentologically. These results suggest that Lower Squaw Lake contains evidence of both Cascadia and other seismic (and possibly aseismic) events, and suggest that southern Cascadia lakes may provide useful information that can be used to determine the seismic sources influencing the offshore record.

A Paleoseismic Investigation of the Little Salmon Fault and Goose Lake Fault: Inference Into the Role of Upper-Plate Faults in the Southern Cascadia Subduction Zone

LADINSKY, T. C., California Geological Survey, California, USA, tyler. ladinsky@conservation.ca.gov; KELSEY, H., Humboldt State University, California, USA, harvey.kelsey@humboldt.edu; MICHALAK, M., Humboldt State University, California, USA, melanie.michalak@humboldt.edu; BOLD, S., Humboldt State University, California, USA, samuel.bold@humboldt.edu; WITTER, R., United States Geolgical Survey, California, USA, rwitter@usgs. gov

The Southern Cascadia subduction zone (SCSZ) accommodates both northwest dextral shear from the San Andreas fault zone and northeast contraction from the convergent margin. Coastal paleoseismic studies in southern-most Cascadia suggest that upper-plate structures may participate in megathrust strain accumulation and release. However, how upper-plate faults accommodate strain along the SCSZ in space and time remains uncertain. Here, we investigate the earthquake history and deformation style of two SCSZ upperplate faults: the central segment of the Little Salmon fault (LSF) and central trace of the Goose Lake fault (GLF) within the lower Van Duzen River Valley near Hydesville, California. The LSF trench exposed three shallow $\left(9^{\circ}\right.$ to $\left.11^{\circ}\right)$ northeast- to north-dipping thrust faults where Pleistocene and Holocene 
strata of the hanging wall were folded around the fault tip and thrust over the footwall. The most recent earthquake (MRE) is well expressed by a distinct colluvial wedge. Four ${ }^{14} \mathrm{C}$ ages from the associated colluvial wedge indicate the MRE occurred prior to 90-480 yr BP (CE 1860-CE 1470). In addition, we observed moderate evidence for both another late Holocene earthquake and a third, early Holocene earthquake. Bayesian age modeling is planned to interpret earthquake chronology for the LSF. The GLF trench revealed discrete subvertical faulting expressed as a pronounced vertically imbricated shear fabric that juxtaposes the Plio-Pleistocene Carlotta Formation against inferred lateQuaternary fluvial deposits. The presence of a high-angle fault and laterally discontinuous gravel units indicate the GLF is an oblique-reverse fault with an unknown amount of lateral slip. We interpret three earthquakes from trench stratigraphy. Results from optical stimulated luminescence dating are pending for both trench sites. Given fault proximity $(1.7 \mathrm{~km})$ and the notable differences in fault characteristics observed in the trenches, we propose the LSF and GLF may act to partition strain between contraction and oblique translation within the lower Van Duzen River Valley.

\section{Application of the Paleoseismic Record of Great Cascadia Earthquakes for Use in the 2015 CanadaSHM5 and 2020 CanadaSHM6 Seismic Hazard Models}

ADAMS, I., Natural Resources Canada, Ottawa, Canada, john.adams@ canada.ca

The CanadaSHM3 model (used for the1985 National Building Code of Canada, NBCC1985) did not include great Cascadia subduction interface events, but CanadaSHM4 (NBCC2005) added a deterministic model whose values were used for design only if they exceeded the hazard values from other sources. CanadaSHM5 introduced a probabilistic treatment of Cascadia's Juan de Fuca, Explorer and Winona segments for NBCC2015. The 2015 Juan de Fuca rate of great earthquakes was based on the turbidite chronology of Goldfinger et al. (2012 pre-print). Partial, southern ruptures were not included, as being too distant from Canada to contribute significantly. The 2015 analysis used 18 turbidites of a 10,097-year record, giving a mean interval of 532 years and a standard deviation of 234 years. The analysis neglected the possibility of event clustering. The rupture intervals (time since the last earthquake) were turned into magnitudes using fixed rupture length and width together with choices for slip rate and crustal rigidity to give central, upper and lower recurrence rates. Magnitudes were in the range 8.55-9.28. To capture the uncertainty in how close the energy release would be to sites on land, three choices for the down-dip extent of the rupture For CanadaSHM6 our interpretation of Goldfinger et al.s 2017 updated turbidite history adds 4 events off Washington to decrease the mean interval to 434 years and reduce the standard deviation to 164 years; the events now appear more regular than clustered. The interface model was combined with crustal and inslab sources to give probabilistic seismic hazard estimates. Considered alone, the 2020 interface rate increased the 2015 seismic hazard estimate by about 9\%. Juan de Fuca interface shaking dominates the 2020 design values in Victoria and Vancouver for periods $>1$ second

\section{Basin and Site Effects in the U.S. Pacific Northwest Estimated From Small-Magnitude Earthquakes}

REKOSKE, J. M., U.S. Geological Survey, Colorado, USA, jrekoske@usgs.gov; MOSCHETTI, M. P., U.S. Geological Survey, Colorado, USA, mmoschetti@ usgs.gov; THOMPSON, E. M., U.S. Geological Survey, Colorado, USA, emthompson@usgs.gov

We analyze ground motions recorded in the U.S. Pacific Northwest to better understand basin and regional site effects. Toward this end, we compile a database of recordings from crustal, interface, and intraslab earthquakes with magnitudes ranging from 3.5 to 6.8 and hypocentral depths up to $62 \mathrm{~km}$, resulting in more than 6,000 records. Our analysis begins with the Fourier amplitude spectrum (FAS) of these ground motion acceleration records, and we compute residuals relative to a ground motion model (GMM) developed for shallow crustal events and perform a series of linear, crossed, mixedeffects regressions. We consider a series of models, starting with a simple linear mixed-effects model for event terms, and incrementally add site, region, seismotectonic regime, and interaction terms. The regionalization taxonomy includes three classes: Seattle basin, Puget Lowlands, and non-Puget Lowlands. The scaling of site response, parameterized with respect to the time-averaged shear-wave velocity to a depth of 30 meters and shear-wave velocity horizon depths, is broadly consistent with the GMM. Additionally, the region terms capture significant frequency-dependent spatial patterns of amplification and de-amplification. With respect to the non-Puget Lowlands, we observe that the Seattle basin amplifies ground motions up to a factor of four at low frequencies $(f<\sim 5 \mathrm{~Hz})$, and de-amplifies ground motions at high frequencies $(f>\sim 5 \mathrm{~Hz})$, with the smallest average amplification factor of $\sim 0.65$ occurring at $10.0 \mathrm{~Hz}$. The regional-seismotectonic interactions are less pronounced than the other terms in our analysis, but indicate stronger (up to $40 \%$ ) amplifications from interface and intraslab earthquakes relative to shallow crustal earthquakes.

\section{Building a Resilient Earthquake Early Warning System in Canada: Sensor Spacing and Station Design}

CRANE, S., Natural Resources Canada, Ottawa, Canada, stephen.crane@ canada.ca; MOWLA, F., Natural Resources Canada, Ottawa, Canada, farzana. mowla@canada.ca; NYKOLAISHEN, L., Natural Resources Canada, Victoria Canada, lisa.nykolaishen@canada.ca; SEYWERD, H., Natural Resources Canada, Ottawa, Canada, henry.seywerd@canada.ca; MCKEE, L., Natural Resources Canada, Ottawa, Canada, lorne.mckee@canada.ca; ADAMS, J., Natural Resources Canada, Ottawa, Canada, john.adams@canada.ca; BIRD, A., Natural Resources Canada, Victoria, Canada, alison.bird@canada.ca; MCCORMACK, D., Natural Resources Canada, Ottawa, Canada, david. mccormack@canada.ca

An Earthquake Early Warning System (EEWS) needs to meet onerous uptime requirements to be capable of warning for incoming strong ground motions when required, even under adverse conditions. Failures of components of the system are inevitable, with variable consequences for the overall system. Careful consideration of redundancy is required to ensure required levels of system uptime.

Modelling of sensor-spacing on a grid indicates $\sim 20 \mathrm{~km}$ spacing provides a reasonable trade-off between station density and warning times, based on depths of Canadian earthquakes. Reducing spacing to $\sim 15 \mathrm{~km}$ within and near urban areas provides a degree of redundancy to protect against random station failures without compromising warning times. Larger station spacing of $\sim 40 \mathrm{~km}$ in more remote regions simplifies logistics without significant sacrifice of warning time. Simple failure modelling shows the loss of one or two randomly-distributed stations has a negligible effect on system performance.

Station reliability is estimated using data from the last 3 years of Canadian National Seismograph Network (CNSN) operation. With almost 200 recently refurbished or newly installed stations in a variety of settings across Canada, CNSN failure rates provide a reasonable proxy for uptime performance of future EEWS stations. As with the CNSN, the station design for the EEWS seeks to optimize operational aspects by standardizing installation components, maximizing redundancy, availability and reliability of communications and power, and ensuring physical security.

\section{Estimating Earthquake Rupture Directivity Using Surface Wave Empirical Greens Functions: How Low Can You Go?} PAUL, C., Geological Survey of Canada, Victoria, Canada, collin.paul@ canada.ca; CASSIDY, J. F., Natural Resources Canada, Sidney, Sidney, Canada john.cassidy@canada.ca

Earthquake rupture directivity is a parameter that has important applications for understanding earthquake impacts. There are many techniques used to evaluate directivity and slip distribution, most of which require dense seismic networks and high-quality digital data. One relatively simple method involves the use of empirical Green's functions with regional and teleseismic surface waves. This has been successfully applied to large (typically M7-8+) earthquakes in the past. As a few examples where rupture directivity and slip distribution have successfully been estimated include the 1992 M7.3 Landers, CA earthquake, the M7.8 Haida Gwaii earthquake of 2012, and the 1992 M6.8 earthquake offshore British Columbia.

In this study, we examine the application of this technique to a smaller (M6.4) offshore Vancouver Island earthquake. This 2014 event was well recorded by a temporary OBS array and has a well-determined aftershock pattern and focal mechanism - making it an ideal 'calibration event'.

For the surface wave EGF analysis we used a nearby Mw 5.3 earthquake as the primary EGF source. To improve SNR we applied stacking of relative source time functions. We considered a Mw 4.8 aftershock as a secondary EGF source. We used broadband seismic data from 105 regional and teleseismic stations in our analysis. The relative source time functions we obtained show an overall rupture direction of $143 \pm 6^{\circ}$ and extent of $28 \pm 2 \mathrm{~km}$. This is in good agreement with the double-difference aftershock relocations (using both onshore and offshore data) that indicated a $32 \pm 2 \mathrm{~km}$ unilateral rupture with strike of $146 \pm 2^{\circ}$ and the centroid moment tensor with a nodal plane striking $150 \pm 6^{\circ}$

By demonstrating that this surface wave technique works for smaller ( $M \sim 6.4)$ earthquakes, it provides confidence that we can examine historic moderate earthquakes (that have well-recorded surface waves, but otherwise 
limited datasets) to better assess seismic patterns, active faults, and rupture directivity.

\section{MHVSR 'Big Data' to Outline Standard Procedures for Data} Acquisition, Processing, Interpretation and Presentation

SIROHEY, A., University of Western Ontario, London, Canada, asirohey@ uwo.ca; MOLNAR, S., University of Western Ontario, London, Canada, smolnar8@uwo.ca

The microtremor horizontal-to-vertical spectral ratio (MHVSR) method has introduced as a cost-effective and non-invasive way to estimate shear-wave resonant frequencies at a site. For the MHVSR to become a standard tool in site classification, stricter standards for acquisition, processing and interpretation need to be established. Using a database of $\sim 1700$ measurements collected throughout the Metro Vancouver region from 2018-20, the effects of acquisition parameters, processing choices, and peak detection strategies were investigated. We initially analysed each measurement individually using the opensource software Geopsy. All peaks identified were manually inspected to assess clarity and reliability. The simple GUI allows easy, real-time observation of the effect of altering processing parameters on the computed MHVSR. Though time consuming, this process provides information about how to optimally design an automatic routine to batch process MHVSRs, that makes intelligent decisions regarding processing inputs, and picks peaks in a statistically robust manner. We utilized recent MHVSR algorithms (OpenHVSR, HVSRPy, in-house software) to batch process the database of measurements, and automatically identify peaks. Processing decisions and peak definition were guided by logic determined from initial analysis. These automatic processing algorithms reduce workload but must be used with care if measurement quality is low. A database of the measurements was created to allow access to not only the interpreted peak frequency values and amplitudes, but also the individual spectra for each individual time window and component, and the meta-data related to acquisition and processing choices. Finally, a map of the lowest resonant frequency interpreted from each measurement was produced. Future work involves understanding if the shape of the MHVSR can be related to earthquake site effects experienced at a site, as well as if it is possible to invert MHVSRs for soil profile models.

Effects and Uses of Aseismic Deformation and Fault Creep in Seismic Hazard and Warning

Oral Session · Tuesday · 20 April · 5:30 PM Pacific

Session Chairs: Nicholas Beeler, U.S. Geological Survey

(nbeeler@usgs.gov); Amanda M. Thomas, University of

Oregon (amt.seismo@gmail.com); Manoochehr Shirzaei,

Virginia Tech (shirzaei@vt.edu)

\section{Aseismic Deformation in and Around the North Brawley Geothermal Field \\ MATERNA, K., U.S. Geological Survey, California, USA, kmaterna@usgs.gov}

The North Brawley Geothermal Field, located within the Brawley Seismic Zone of Southern California, presents a case study for understanding the impacts of active geothermal energy production on seismic hazard. The geothermal field has been associated with both induced seismicity and aseismic ground deformation in the past decade. In particular, an earthquake swarm in 2012 resulted in two M5+ earthquakes and was likely preceded by an aseismic slip transient. To better understand this ground deformation, including its evolution with time and its causative mechanisms, we construct a comprehensive deformation time series using multiple ground- and satellite-based geodetic techniques between 2009 and 2019. We integrate observations from GNSS, Sentinel-1, TerraSAR-X, UAVSAR, and leveling surveys into a single deformation history. We then test whether models of aseismic slip and/or poroelastic deformation can explain this time history. We find evidence for both aseismic fault slip and poroelastic deformation during the last decade, including some episodes not previously identified or quantified. We also identify geodetic transients that may indicate very shallow interseismic creep on nearby strike-slip faults of the San Andreas fault system. In the geothermal field, we compare the deformation history with injection and production parameters and seismicity catalogs over the past decade. This long-term deformation history allows us to probe the geothermal field's response to both long-term and short-term temporal changes in operational parameters, which has implications for other geothermal operations around the world.

\section{Coupling Between the Northern and Southern Central San} Andreas Fault via Triggered Creep

HIRAO, B. W., University of California, Santa Cruz, California, USA, bhirao@ ucsc.edu; SAVAGE, H. M., University of California, Santa Cruz, California, USA, hsavage@ucsc.edu; BRODSKY, E. E., University of California, Santa Cruz, California, USA, brodsky@ucsc.edu

Episodic creep is one of the most poorly understood aspects of fault motion. In particular, the interaction between creep events and earthquakes at the regional scale has implications for earthquake cycles, yet few examples of such interaction have been found on continental faults. Here we report creep triggering along the northern edge of the creeping section of the San Andreas fault following the 2003 San Simeon Mw 6.5 and 2004 Parkfield Mw 6.0 earthquakes. Following the San Simeon earthquake, we observe a delayed creep event on two creepmeters, as well as a larger one-day delayed event beginning at depth on SJT strainmeter and continuing on the nearby San Juan Bautista creepmeter (XSJ). Following the Parkfield earthquake, the XSJ creepmeter and SJT strainmeter again record a delayed, creep event. In addition, the regional earthquakes produced long-term creep rate changes. After the San Simeon earthquake, the average slip rate at XSJ increased from $10 \mathrm{~mm} / \mathrm{yr}$ to $30 \mathrm{~mm} /$ $\mathrm{yr}$, and returned to $10 \mathrm{~mm} / \mathrm{yr}$ after the Parkfield earthquake. The combination of the creep event and rate change data indicate that triggering couples the northern San Andreas Fault to both the southern locked section and other regional faults.

\section{Developing a Mechanical Explanation for Slip Reduction Near Earth's Surface on Seismogenic and Creeping Continental Strike-Slip Faults}

NEVITT, I., U.S. Geological Survey, California, USA, jnevitt@usgs.gov; BROOKS, B. A., U.S. Geological Survey, California, USA, bbrooks@usgs.gov; LOCKNER, D., U.S. Geological Survey, California, USA, dlockner@usgs.gov; CATCHINGS, R., U.S. Geological Survey, California, USA, catching@usgs. gov; ERICKSEN, T., U.S. Geological Survey, California, USA, tericksen@usgs. gov; MORROW, C., U.S. Geological Survey, California, USA, cmorrow@usgs. gov; MOORE, D., U.S. Geological Survey, California, USA, dmoore@usgs. gov; GOLDMAN, M., U.S. Geological Survey, California, USA, goldman@ usgs.gov; GLENNIE, C., University of Houston, Texas, USA, clglenni@ central.uh.edu; HUDNUT, K., Southern California Edison, California, USA, hudnutken@gmail.com; CRILEY, C., U.S. Geological Survey, California, USA, ccriley@usgs.gov; MELOSH, B., U.S. Geological Survey, California, USA, bmelosh@usgs.gov; EKHTARI, N., University of Houston, Texas, USA, nima. ekhtari@gmail.com

Earth's crust often transitions from fluid-saturated, competent bedrock confined at depth to unsaturated, weakly-consolidated material at its traction-free surface. How the unique combination of factors in the shallow crust $(<\sim 100$ $m$ depth) affects fault behavior remains unknown, with significant ramifications for earthquake science, engineering, and hazard modeling. Fundamental questions include: Is a shallow slip reduction ubiquitous on strike-slip faults and how does it relate to off-fault plastic strain? Do ruptures systematically break down into echelon segments near Earth's surface and how does segmentation affect the kinematics and dynamics of the system? Do mechanical changes across the water table impede shallow fault rupture? And importantly, can we understand shallow faulting as a quasi-static process with models that are numerically tractable and by examining creeping faults rather than waiting for the next earthquake?

We begin to address these questions with a synthesis of studies from two earthquakes and a creeping fault. The 2019 M7.1 Ridgecrest earthquake provides a spectacular example of rupture segmentation at Earth's surface, which we relate to slip variation both along strike and with depth using optical imagery, mobile laser scanning (MLS), and mechanical modeling. For the 2014 M6.0 South Napa earthquake, we combine MLS with fault zone drilling, lab experiments, and mechanical modeling to show that the shallow coseismic slip and afterslip were nearly indistinguishable, both with buried rupture tips seemingly affected by off-fault plastic strain and increased frictional strength in the unsaturated material above the water table. At Mee Ranch along the Creeping Section of the San Andreas fault, elastic modeling of a 50-year-old alignment array indicates that shallow slip distributions can vary in time, with the most recent epoch indicating a reduction in slip at Earth's surface.

Thus, shallow slip may vary spatially and temporally, raising new questions for how we use static field measurements in long-term hazard models. 
Dynamic Rupture Scenarios of Large Earthquakes on the Rodgers Creek-Hayward-Calaveras-Northern Calaveras Fault System, California

HARRIS, R., U.S. Geological Survey, California, USA, harris@usgs.gov; BARALL, M., Invisible Software, California, USA, mbarall@contractor.usgs. gov; PONCE, D., U.S. Geological Survey, California, USA, ponce@usgs.gov; MOORE, D., U.S. Geological Survey, California, USA, dmoore@usgs.gov; GRAYMER, R., U.S. Geological Survey, California, USA, rgraymer@usgs.gov; LOCKNER, D., U.S. Geological Survey, California, USA, dlockner@usgs.gov MORROW, C., U.S. Geological Survey, California, USA, cmorrow@usgs.gov; FUNNING, G., University of California, Riverside, California, USA, gareth@ ucr.edu; KYRIAKOPOULOS, C., The University of Memphis, Tennessee, USA, christos.k@memphis.edu; EBERHART-PHILLIPS, D., GNS Science, Dunedin, New Zealand, eberhartphillips@ucdavis.edu

The Rodgers Creek-Hayward-Calaveras-Northern Calaveras fault system in California dominates the hazard posed by active faults in the San Francisco Bay Area. Given that this fault system runs through a densely populated area, a large earthquake in this region is likely to affect millions of people. This study produced scenarios of large earthquakes in this fault system, using spontaneous (dynamic) rupture simulations. These types of physics-based computational simulations require information about the 3D fault geometry, physical rock properties, fault friction, and initial stress conditions. In terms of fault geometry, the well-connected multi-fault system includes the Hayward fault, at its southern end the Central and Northern Calaveras faults, and at its northern end the Rodgers Creek fault. Geodetic investigations of the fault system's slip-rate pattern provide images of where the fault surfaces at depth are creeping or locked interseismically, and this helped us choose appropriate initial stress conditions for our simulations. A 3D geologic model of the fault system provides the $3 \mathrm{D}$ rock units and fault structure at depth, while field samples from rocks collected at Earth's surface provide frictional parameters. We used this suite of information to investigate the behavior of large earthquake ruptures nucleating at various positions along this partially creeping fault system. We found that large earthquakes starting on the Hayward fault or on the Rodgers Creek fault may be slowed, stopped, or unaffected in their progress, depending on how much energy is released by the creeping regions of the Hayward and Central Calaveras faults during the time between large earthquakes. Large earthquakes starting on either the Hayward fault or the Rodgers Creek faults will likely not rupture the Northern Calaveras fault, and large earthquakes starting on either the Northern Calaveras fault or the Central Calaveras fault will likely remain confined to those fault segments.

\section{The Relationship Between Seismic and Aseismic Slip on the Creeping Segment of the Philippine Fault: Insight to} Earthquake Recurrence and Fault Mechanics

DIANALA, J. B., COMET, Department of Earth Sciences, University of Oxford, U.K.; National Institute of Geological Sciences, University of the Philippines - Diliman, Quezon City, Philippines, jddianala@nigs.upd.edu.ph; JOLIVET, R., Laboratoire de Géologie, Département de Géosciences, Ecole Normale Supérieure, PSL Université, UMR98538, Paris, France, romain.jolivet@ens. fr; THOMAS, M. Y., Sorbonne Université, CNRS-INSU, Institut des Sciences de la Terre Paris, ISTeP UMR 7193, F-750, Paris, France, marion.caltech@ gmail.com; FUKUSHIMA, Y., International Research Institute of Disaster Science, Tohoku University, Sendai, Japan, fukushima@irides.tohoku.ac.jp; PARSONS, B., COMET, Department of Earth Sciences, University of Oxford, Oxford, United Kingdom, barry.parsons@earth.ox.ac.uk; WALKER, R., COMET, Department of Earth Sciences, University of Oxford, Oxford, United Kingdom, richard.walker@earth.ox.ac.uk

Shallow creep on the Leyte island section of the Philippine Fault was first estimated with campaign GPS data in the early 1990s. With the occurrence of a significant moment magnitude $\left(\mathrm{M}_{\mathrm{w}}\right) 6.5$ earthquake in July 2017 in northern Leyte, exploring the variability of the slip mode and the seismogenic potential of the "creeping segment" is important for furthering our understanding of fault mechanics and seismic hazard.
We present the first distributed interseismic slip model of the Philippine Fault, along $\sim 100 \mathrm{~km}$ of the mappable trace on Leyte island. We make a direct comparison of the interseismic slip distribution (from ALOS InSAR timeseries) to the coseismic slip (from Sentinel-1 and ALOS-2 interferograms), with models derived in a Bayesian framework.

Assuming a linear velocity between 2007-2011, we find fast aseismic slip rates throughout most of the fault across the seismogenic zone, around the $3.3 \pm 0.2 \mathrm{~cm} / \mathrm{yr}$ secular slip rate. The only exception is an area of significant slip deficit on a $20-\mathrm{km}$ long, $7-\mathrm{km}$ deep segment in the middle of the fault (the 'Tongonan Segment'). Our coseismic models of the July $2017 \mathrm{M}_{\mathrm{w}}$ 6.5 mainshock and a $M_{w} 5.8$ aftershock suggest that the extent of seismic slip was largely complementary to the interseismic distribution, hence suggesting that the Tongonan segment is a seismogenic asperity. The time between a similar earthquake in 1947 falls within the $95 \%$ probability range of the earthquake return period based on a moment budget analysis from the slip models. Geological factors, such as the abundance of fluids from the active hydrothermal systems along the fault, as well as the presence of rate-weakening minerals, may provide conditions suitable for the aseismic slip on the fault.

Effects and Uses of Aseismic Deformation and Fault Creep in Seismic Hazard and Warning

Poster Session · Tuesday · 20 April · 4:15 PM Pacific

Session Chairs: Nicholas Beeler, U.S. Geological Survey

(nbeeler@usgs.gov); Amanda M. Thomas, University of

Oregon (amt.seismo@gmail.com); Manoochehr Shirzaei,

Virginia Tech (shirzaei@vt.edu)

\section{Spatially Variable Creep on the Bartlett Springs Fault Inferred From Bayesian, Stress-Driven Models}

MURRAY, J. R., U.S. Geological Survey, California, USA, jrmurray@usgs.gov; JOHNSON, K., Indiana University, Indiana, USA, kajjohns@indiana.edu

Near-surface creep, if it extends to seismogenic depths, can reduce a fault's potential for generating damaging earthquakes by influencing dynamic rupture propagation. Murray et al. (2014) inferred spatially-variable creep rates on the Bartlett Springs (BSF) and Maacama faults, and slip rates below assumed locking depths on these faults and the San Andreas Fault, by developing kinematic models using Bayesian inversion applied to GPS-derived velocities. The resulting spatially averaged creep rate estimates suggest that the BSF has substantial creep $(\sim 4.5-7.5 \mathrm{~mm} / \mathrm{yr})$ at all depths, and the data permitted a shallow locking depth $(\sim 5 \mathrm{~km})$.

Lozos et al. (2015) used the creep rate distribution from Murray et al. (2014), and one estimated by Lienkaemper et al. (2014) using different data and methods, as initial conditions for dynamic rupture models of BSF earthquakes. The resulting ruptures varied substantially in the amplitude and along-strike extent of slip, with magnitudes ranging from $M_{w} 6.32-M_{w} 7.24$. However, the kinematic creep rate models have low spatial resolution and lack information about where stress is accumulating, thus limiting how much detail the dynamic rupture models could provide.

The depth-extent of creep, the along-strike extent of non-creeping zones, and the creep rate relative to the deep slip rate are the primary factors generating the different dynamic rupture behavior seen using the Lienkaemper et al. (2014) versus Murray et al. (2014) models. Johnson (2013) outlined a Bayesian stress-driven modeling approach in which locations on a fault are either locked (and accumulate stress) or creep at a constant stress. This physically -constrained approach resolves the size of creeping patches better than purely kinematic inversions. We apply this method to an expanded version of the Murray et al. (2014) GPS velocity field to explore the range of BSF creep models that result under the different assumptions and constraints inherent in this physics-based approach with the goal of narrowing the range of initial conditions for future dynamic rupture modeling. 


\section{Exploring Rupture Dynamics and Seismic Wave Propagation Along Complex Fault Systems}

I: Oral Session · Monday · 19 April · 9:45 AM Pacific

II: Oral Session · Tuesday · 20 April · 9:45 Am Pacific Session Chairs: Kenny Ryan, Air Force Research Laboratory (0k.ryan0@gmail.com); Roby Douilly, University of California, Riverside (roby.douilly@ucr.edu); Christos Kyriakopoulos, University of Memphis (Christos.K@ memphis.edu); Eric L. Geist, U.S. Geological Survey (egeist@ usgs.gov); Ruth Harris, U.S. Geological Survey (harris@usgs. gov); David D. Oglesby, University of California, Riverside (david.oglesby@ucr.edu)

\section{Frequency-Difference Backprojection of Earthquakes}

NEO, J., University of Michigan, Michigan, USA, neoj@umich.edu; FAN, W., University of California, San Diego, California, USA, wenyuanfan@ucsd. edu; HUANG, Y., University of Michigan, Michigan, USA, yiheh@umich.edu; DOWLING, D. R., University of Michigan, Michigan, USA, drd@umich.edu

Back-projection has proven useful to image large earthquake rupture processes. It utilizes array techniques to estimate the spatial and temporal evolution of earthquake rupture over time, and can help us identify interesting earthquake phenomena like supershear rupture. However, the method does not directly solve an inverse problem and has difficulty in quantifying epistemic uncertainties, which can be caused by seismic array configurations, structural heterogeneities in the Earth's crust, unknown seismic phases, and variations in the focal mechanism. These uncertainties may cause erroneous interpretations of earthquake physics, which is particularly challenging to distinguish for complex earthquake rupture processes.

In this study, we develop and apply a new frequency-difference backprojection method to image earthquake rupture processes. The method is developed from a frequency-difference beamforming approach, which was originally designed to locate acoustic sources. Frequency-difference beamforming utilizes frequencies below the bandwidth of the signal, which are less affected by multipathing and structural inhomogeneities. This method can potentially allow us to locate sources more accurately even in the presence of strong scattering, albeit with lower resolution. We will first verify robustness of the method through both synthetic simulations and analysis of M6 earthquakes. We will then apply the method to the 2015 M7.8 Nepal earthquake to unveil its early rupture evolution. Our research aims to address how Nepal earthquake rupture evolved during the first 20 s and overcame a geometric fault barrier, which is challenging to resolve because of the difficulties in imaging early rupture propagation process using other kinds of back-projection approaches.

\section{Geometric Controls on Pulse-Like Rupture in a Dynamic Model of the $\mathbf{2 0 1 5}$ Gorkha Earthquake}

WANG, Y., University of Southern California, California, USA, yongfeiw@ usc.edu; DAY, S. M., San Diego State University, California, USA, sday@sdsu. edu; DENOLLE, M., University of Washington, Washington, USA, mdenolle@ uw.edu

The 15 April 2015 Mw 7.8 Nepal Gorkha earthquake occurred on a shallowly dipping portion of the Main Himalayan Thrust (MHT). Notable features of the event include (1) the dominance of a slip pulse of about 6-s duration that unlocked the lower edge of the MHT and (2) the near-horizontal fault geometry, which, combined with proximity of the free surface, allows surfacereflected phases to break the across-fault symmetries of the seismic wavefield. Our dynamic rupture simulations in an elastoplastic medium yield earthquake parameters comparable to those deduced from kinematic inversions, including seismic moment and rupture velocity. The simulations reproduce pulse-like behavior predicting pulse widths in agreement with those kinematic studies and supporting an interpretation in which the pulse-like time dependence of slip is principally controlled by rupture geometry. This inference is strongly supported by comparison of synthetic ground velocity with the near-field high-rate GPS recording at station KKN4, which shows close agreement in pulse width, amplitude, and pulse shape. That comparison also constrains the updip extent of rupture and disfavors significant coseismic slip on the shallow ramp segment. Over most of the rupture length, the simulated rupture propagates at a near-constant maximum velocity ( $\sim 90 \%$ of the $S$ wave speed) that is controlled by the antiplane geometry and off-fault plastic yield- ing. Simulations also reveal the role of reflected seismic waves from the free surface, which may have contributed $\sim 30 \%$ elongation of the slip pulse, and show the potential for significant free-surface interaction effects in shallow events of similar geometry.

\section{Geometrical Fault Complexity and the Rupture Dynamics of the 2019 M6.4 and M7.1 Ridgecrest, California Earthquakes}

LOZOS, I., California State University, Northridge, California, USA, julian. lozos@csun.edu; HARRIS, R., U.S. Geological Survey, California, USA, harris@usgs.gov

The largest earthquakes of the 2019 Ridgecrest, California earthquake sequence were a M6.4 earthquake on the morning of July $4^{\text {th }}$, followed 34 hours later by a M7.1 on the evening of July $5^{\text {th }}$. The primary fault for the M6.4 was a NE-striking left-lateral strike-slip fault, while the primary M7.1 rupture occurred on a NW-striking right-lateral strike-slip fault. However, many smaller NE-striking and NW-striking fault strands activated in one or both Ridgecrest mainshocks. Here, we use 3D dynamic rupture modeling to simulate the interactions between high-slip primary rupture traces in the Ridgecrest M6.4 and M7.1 earthquakes, as well as to investigate the roles of secondary lower-slip fault strands. We find that a model with one left-lateral fault for the M6.4 and one right-lateral fault for the M7.1 is able to produce a good first-order match for the magnitude and ground surface slip distributions for both events. In this model, dynamic clamping and shear stress reduction from the M6.4 rupture onto the future M7.1 fault plane confined surface rupture in the M6.4 to the left-lateral fault. We also run simulations on a more complex multi-strand fault geometry, to determine the role of these additional faults in the rupture dynamics and resulting slip distribution of the M6.4 and M7.1 Ridgecrest earthquakes. In particular, we investigate whether any right-lateral fault strands were involved in the M6.4, and whether surface expression of slip on smaller fault strands is due to their hosting dynamic rupture and producing significant moment release, or due to more passive effects such as triggered slip.

\section{Observationally Constrained Multi-Scale Dynamic Rupture Modeling of the 2019 Ridgecrest Earthquakes}

TAUFIQURRAHMAN, T., Ludwig-Maximilians-Universität, Munich, Germany, taufiqurrahman@geophysik.uni-muenchen.de; GABRIEL, A., Ludwig-Maximilians-Universität, Munich, Germany, gabriel@geophysik.unimuenchen.de; LI, D., Ludwig-Maximilians-Universität, Munich, Germany, dli@geophysik.uni-muenchen.de; ULRICH, T., Ludwig-MaximiliansUniversität, Munich, Germany, ulrich@geophysik.uni-muenchen.de; WIRP, S. A., Ludwig-Maximilians-Universität, Munich, Germany, sara.wirp@ geophysik.uni-muenchen.de; CARENA, S., Ludwig-Maximilians-Universität, Munich, Germany, scarena@iaag.geo.uni-muenchen.de; VERDECCHIA, A., McGill University, Montreal, Canada, alessandro.verdecchia@mail.mcgill.ca; GALLOVIC, F., Charles University, Prague, Czech Republic, gallovic@karel. troja.mff.cuni.cz

Advances in high-performance computing allow us to combine and crossverify observational constraints with physics-based modeling to provide mechanically viable insight into earthquake dynamics across complex fault systems. We present observationally and Coulomb stress modeling constrained 3D dynamic rupture scenarios combining the 2019 Mw6.4 Searles Valley and Mw7.1 Ridgecrest earthquakes, complemented by aftershock calibrated back-projection (Li \& Ghosh, 2016) and kinematic parametric source inversion (PSI, Hallo and Gallovič, 2020). A detailed 3D non-vertical fault model of the quasi orthogonal intersecting fault network is built from relocated aftershocks and surface ruptures constrained by space geodesy and field observations. All faults are embedded in modeled cumulative (coseismic plus postseismic) Coulomb stresses ( $\triangle \mathrm{CFS}$ ), heterogeneous 3D SCEC community models of tectonic stresses, and subsurface materials. The faults intersect high-resolution topography and may cause off-fault plastic deformation during frictional failure. We validate a unified multi-scale scenario of both events with key observations including fault surface offsets, GPS and InSAR surface deformation, moment rate release, slip distribution, teleseismic, and strong ground motion waveforms. The dynamic model ruptures two conjugate faults simultaneously in the Mw6.4 event whereas only the SW-segment breaks the surface. The Mw7.1 dynamic rupture scenario includes the full state of stress: $3 \mathrm{D}$ tectonic loading, $\triangle \mathrm{CFS}$, and the dynamic and static stresses transferred by the Searles Valley scenario. We model complex rupture evolution including re-activation of the conjugate Mw6.4 segment, mixed crack- and pulse-like propagation, and delayed tunneling beneath the fault intersection. We quantify the considerable dynamic and static stress changes the Mw6.4 dynamic rupture model induces in the Mw7.1 hypocentral region, which is not enough 
to trigger rupture across the stress-shadowed main fault. We additionally analyse low-velocity fault zone effects (Qiu et al., 2020) on rupture speed and waveforms.

\section{Structural Control of 2015 Mw 7.8 Gorkha Rupture}

GHOSH, A., University of California, Riverside, California, USA, aghosh. earth@gmail.com; MENDOZA, M., University of California, Riverside, California, USA, mmend028@ucr.edu; DOUILLY, R., University of California, Riverside, California, USA, robyd@ucr.edu; ZHOU, Y., University of California, Riverside, California, USA, yijian.zhou@email.ucr.edu; LI, B., Ludwig-Maximilians Universität, Munich, Germany, bli017@ucr.edu

Rupture of Mw 7.8 Gorkha earthquakes is thought to be unilateral and relatively simple. Starting at the hypocenter, it propagates unilaterally eastward to unzip about $150 \mathrm{~km}$ alongstrike the Main Himalayan Thrust (MHT). We use four global seismic arrays and a local temporary dense seismic network to reveal the rupture dynamics and structural details of the rupture area. Our study shows that it is a relatively complex rupture controlled by intricate fault structures along MHT. Rupture started with unilateral ESE-ward propagation but bifurcated into two branches near the end. This is likely due to presence of a strong fault patch that eventually is broken after two weeks of the mainshock to produce the largest aftershock in this sequence - Mw 7.3 Kodari earthquake. Aftershock distribution obtained by the dense local NAMASTE network reveals a duplex structure that is responsible for generating the majority of the aftershocks to the east [Mendoza et al., 2019]. The western part is relatively quiet in terms of aftershock activity and appears to be structurally simple. Seismic tomography also shows lateral variations consistent with this interpretation. The rupture is arrested abruptly at its eastern end by welldefined structures that may mark alongstrike segment boundary in this area.

\section{A Joint Dynamic Model of Seismic and Postseismic Slip of the 2014 South Napa Earthquake}

PREMUS, J, Charles University, Prague, Czech Republic, janpremus@seznam. cz; GALLOVIČ, F., Charles University, Prague, Czech Republic, gallovic@ karel.troja.mff.cuni.cz; AMPUERO, J., Université Côte d'Azur, Geoazur Laboratory, Valbonne, France, ampuero@geoazur.unice.fr

Elastic energy on fault planes, accumulated due to the relative motion of tectonic plates, is released abruptly in the form of an earthquake. Part of the energy often releases after the event in the form of a postseismic slip (afterslip) observed over the longer time period in the areas surrounding the ruptured region. An example of earthquake with abundance of coseismic and afterslip records is the 2014 South Napa, California, earthquake. The earthquake produced a significant surface rupture over the length $\sim 12 \mathrm{~km}$, most of which occurred aseismically within the first month after the main event. We employ a novel code FD3D_TSN that simulates the dynamic rupture propagation on a fault during an earthquake and the long-term development of afterslip using a joint framework of laboratory-derived rate-and-state friction with fast velocity weakening. We carry out a Bayesian inversion to infer spatially varying controlling dynamic parameters to fit a variety of data: seismograms capturing the co-seismic rupture and long-term geodetic observations (GPS stations with continuous reading and surface slip measurements). Resulting model is not only in good agreement with kinematic models of both seismic and postseismic slip, but it provides a deeper insight through the joint dynamic model of the co- and post-seismic rupture process.

\section{Dynamic Rupture Modeling and the Powell Center Working Group on Tsunami Sources}

ROSS, S. L., U.S. Geological Survey, California, USA, sross@usgs.gov; EBLE, M. C., NOAA/Pacific Marine Environmental Laboratory, Washington, USA, marie.c.eble@noaa.gov; KYRIAKOPOULOS, C., University of Memphis, Tennessee, USA, christos.k@memphis.edu; LYNETT, P. J., University of Southern California, California, USA, plynett@usc.edu; NICOLSKY, D. J., University of Alaska Fairbanks, Alaska, USA, djnicolsky@alaska.edu; OGLESBY, D. D., University of California, Riverside, California, USA, doglesby@ucr.edu; RYAN, K., Air Force Research Laboratory, New Mexico, USA, 0k.ryan0@gmail.com; THIO, H., AECOM, California, USA, hong.kie. thio@aecom.com; WILSON, R. I., California Geological Survey, California, USA, rick.wilson@conservation.ca.gov; WU, B., University of California, Riverside, California, USA, bwu015@ucr.edu

Members of the National Tsunami Hazard Mitigation Program and other researchers have formed a working group, partially supported by the USGS Powell Center. The goal is to define and implement a transparent and scientifically based methodology and evaluation process for characterizing historical and realistic hypothetical sources of tsunamis that pose a potential hazard to U.S. populations, commerce, and infrastructure.

Using a logic tree process, and including regional experts, the working group is synthesizing existing geological and geophysical knowledge of submarine earthquake faults and coastal landslide sources to produce a database of source models for use in creating hazards assessments for risk reduction. We will also address the scientific question of how increasing sophistication in tsunami source models impacts products such as evacuation plans, mitigation of damage, and land-use planning.

The first week-long meeting adopted a probabilistic evaluation process where possible. The second and third meetings focused on Alaska tsunami sources and on tsunami sources that impact the U.S. East Coast, Gulf Coast, and Caribbean Territories. Future meetings will focus separately on the Cascadia Subduction Zone and on Pacific tsunami sources other than Cascadia and Alaska. Results and discussions from the meetings are being used to understand and fill knowledge gaps within the earthquake and tsunami modeling communities.

One aspect of the meetings is that participants are informed about results from physics-based rupture models, with a goal of simulating more realistic tsunami sources for input into the logic tree process. In particular, researchers from this group are working on 2D dynamic rupture models that incorporate topography, ambient stress, and frictional parameter spaces to help elucidate possible rupture scenarios in the regions of interest.

\section{Dynamic Rupture Modeling of the 1811-12 New Madrid Earthquakes}

CUNNINGHAM, E., Center for Earthquake Research and Information, University of Memphis, Tennessee, USA, cunningham.erin4@gmail.com; KYRIAKOPOULOS, C., Center for Earthquake Research and Information, University of Memphis, Tennessee, USA, ckyrkpls@memphis.edu; NOOR, S., Center for Earthquake Research and Information, University of Memphis, Tennessee, USA, snoor1@memphis.edu

The New Madrid seismic zone has produced damaging earthquakes in the past such as the infamous 1811-12 sequence. However, large magnitude earthquakes are infrequent in the New Madrid Seismic Zone and little is known about the rupture propagation process. Here we use three-dimensional dynamic rupture models to simulate the rupture propagation process during the large magnitude 1811-12 earthquakes. The three largest earthquake events in the 1811-12 sequence are likely to have occurred on major nearby or intersecting faults in the area: the Cottonwood Grove strike-slip fault, the northern new madrid strike-slip fault, and the Reelfoot thrust fault.

Variations in fault geometry become crucial when considering complex rupture propagation and fault interactions. For example, depending on fault geometry and prestress conditions, rupture can "jump" from one fault to nearby or intersecting fault segments generating larger magnitude events and significantly increasing hazard. Therefore, we introduce a fault geometry which contains two strike-slip faults linked by the Reelfoot thrust fault with variable strike. We use our fault geometry to run dynamic rupture models and investigate variations in rupture propagation due to nucleation location and different prestress conditions. We aim to understand how the major faults in the New Madrid seismic zone interact during events similar to those in 181112 and to gain insight to the maximum magnitude event. Our preliminary results suggest that for events nucleating on the Cottonwood Grove fault, the strike of the Reelfoot thrust plays a significant role in the partitioning of slip and state of stress north and south of the intersection.

\section{Impulsive Tsunami and Large Runup Along the Sanriku Coast of Japan Produced by Inelastic Wedge Deformation}

DU, Y., San Diego State University, California, USA, ydu0755@sdsu.edu; MA, S., San Diego State University, California, USA, sma@sdsu.edu; KUBOTA, T., National Research Institute for Earth Science and Disaster Resilience, Tsukuba, Japan, kubotatsu@bosai.go.jp; SAITO, T., National Research Institute for Earth Science and Disaster Resilience, Tsukuba, Japan, saito-ta@ bosai.go.jp

The Sanriku coast of Japan was hit by several of the worst tsunamis in the recorded history. In the 2011 Tohoku tsunami the largest tsunami heights (up to $40 \mathrm{~m}$ ) were observed on the Sanriku coast, more than $100 \mathrm{~km}$ north of the epicenter. The tsunami heights on the Sanriku coast were consistently $2-3$ times larger than in the south. The 1896 Sanriku earthquake $\left(\sim \mathrm{M}_{\mathrm{W}} 8\right)$ also generated similar tsunami heights on the Sanriku coast as in the $2011 \mathrm{M}_{W}$ 9.0 Tohoku earthquake. In order to explain the large 2011 Tohoku tsunami heights, elastic dislocation models require large trench slip (up to $36 \mathrm{~m}$ ) more than $100 \mathrm{~km}$ north of the epicenter, which is, however, inconsistent with the differential bathymetry data (Fujiwara et al., 2017). Ma and Nie (2019) showed 
that inelastic wedge deformation due to thick sediments in the region can efficiently generate seafloor uplift while reducing near-trench slip, which is more consistent with the observations. Here we simulate tsunami propagation of the 1896 Sanriku earthquake by using the seafloor uplift of Ma and Nie (2019) and high-resolution bathymetry data. We show that the short-wavelength seafloor uplift by inelastic wedge deformation produces impulsive tsunami signals (such as those recorded at TM1, TM2 and three Iwate GPS wave gauges in the 2011 Tohoku tsunami) and generates large runup consistent with the observations of the 1896 Sanriku tsunami.

\section{New Insight Into the Frequency-Dependent Radiation of Subduction-Zone Earthquakes From Dynamic Simulations of Megathrust Ruptures}

YIN, J., Harvard University, Massachusetts, USA, jiuxun_yin@g.harvard.edu DENOLLE, M., University of Washington, Washington, USA, mdenolle@ uw.edu

The recent observation that the radiation of megathrust earthquakes exhibits frequency-depth dependence seems ubiquitous: most the low frequency (LF) seismic radiation is emitted at shallow depths while the high frequency (HF) seismic radiation is emitted at greater depths. The explanation most evoked is a systematic depth variation in stress or frictional properties along the plate interface. In this study, we build dynamic rupture models for megathrust earthquakes in realistic 2D elastic structure. We use P-wave velocity Vp of the Tohoku area from Miura et al. (2005) and also explore a large parameter space for on-fault frictional and pre-stress properties.

All 28 modeled ruptures present the common patterns: the slip motions near the trench are those of crack-like ruptures with smooth slip rate functions, while the slip motions on the downdip are those of pulse-like ruptures with sharp slip rate functions. We further quantify the depth-frequency relation along slab by (1) calculating the power ratio of HF and LF slip acceleration and (2) fitting a Brune-type spectral model for the spectral falloff rate. Both quantifications show the same patterns for those dynamic models: the HF-LF power ratio increases and the falloff rate decreases from the updip to downdip to confirm that HF radiation is more efficient downdip and LF radiation is more efficient updip. Our findings suggest that i) the effect of the Earth free surface on dynamic rupture is the dominant factor that explains the frequency-depth variation, ii) the low-velocity zone of a hydrated down-going slab aggravates the contrast in radiation, and that iii) realistically high $\mathrm{Vp} / \mathrm{Vs}$ in the frontal prism yield greater potential for tsunamigenesis.

\section{Exploring Rupture Dynamics and Seismic Wave Propagation Along Complex Fault Systems}

Poster Session · Monday · 19 April · 3:45 PM Pacific Session Chairs: Kenny Ryan, Air Force Research Laboratory (0k.ryan0@gmail.com); Roby Douilly, University of California, Riverside (roby.douilly@ucr.edu); Christos Kyriakopoulos, University of Memphis (christos.k@memphis. edu); Eric L. Geist, U.S. Geological Survey (egeist@usgs. gov); Ruth Harris, U.S. Geological Survey (harris@usgs.gov); David D. Oglesby, University of California, Riverside (david. oglesby@ucr.edu)

\section{Analyzing Stress Drops and Other Earthquake Parameters from the 2019 Ridgecrest Earthquake Sequence} ROSAS, V. G., University of Texas at El Paso, Texas, USA, viviangrosas@gmail. com; BALTAY, A., U.S. Geological Survey, California, USA, abaltay@usgs.gov; ABERCROMBIE, R. E., Boston University, Massachusetts, USA, rea@bu.edu

As part of the Community Stress Drop Validation Study, we examine stress drops from the 2019 Ridgecrest Earthquake sequence to understand the sources of variability. Because earthquake stress drop is related to the energy released from an earthquake rupture, how it scales with different variables such as magnitude, moment, depth, is of interest. However, considerable scatter and uncertainty in estimates makes this difficult. The 2019 Ridgecrest earthquake sequence had 3,557 earthquakes of magnitude $\mathrm{M} 2+$ recorded in the first two weeks alone, the largest magnitude being 7.1. This earthquake sequence provided a wealth of high-quality data that has been analyzed by multiple researchers using multiple methods.
To understand how stress drops from different researchers and approaches differ, we examine two stress drop data sets: Trugman (2020) who uses a spectral decomposition method, and Arias stress drops calculated in Parker et al. (2020). We compare these stress drops by making correlation plots in MATLAB to understand which events are similar or different. We examine not just the stress drop values, but also how the seismic moments and corner frequencies compare between methods. We try to understand if the similarities and differences between the datasets are indicators of other physical earthquake information, to get better knowledge of the foundation of these events. We then choose several specific earthquakes, including earthquakes whose stress drops both agree and disagree, studied by Trugman (2020) and Parker et al. (2020). We analyze these events in more detail to measure and compare their spectral properties. This research informs how to model future earthquakes and helps us to better prepare for upcoming seismic events.

\section{Multi-Fault Rupture Plausibility Inferred From a \\ Deterministic Earthquake Simulator}

MILNER, K., Southern California Earthquake Center, California, USA, kmilner@usc.edu; SHAW, B. E., Columbia University, New York, USA, shaw@ ldeo.columbia.edu; FIELD, E. H., Geologic Hazards Science Center, U.S Geological Survey, Colorado, USA, field@usgs.gov; JORDAN, T. H., University of Southern California, California, USA, tjordan@usc.edu; GOULET, C. A., Southern California Earthquake Center, California, USA, cgoulet@usc.edu

When building an earthquake rupture forecast (ERF) for probabilistic seismic hazard analysis (PSHA), a key step involves the enumeration of all plausible significant earthquakes in a region (i.e., those likely to damage the built environment or result in casualties). The $3^{\text {rd }}$ Uniform California Earthquake Rupture Forecast (UCERF3) was the first comprehensive ERF to include multi-fault ruptures, consistent with many examples in nature. The set of ruptures included in UCERF3 was determined through binary filters which aimed to reduce the near-infinite fault section combinations to a tractable set of physically plausible ruptures. These plausibility criteria used hard cutoff values that were ad hoc or based on limited modeling, e.g., maximum jump distance $(5 \mathrm{~km})$ and maximum fault-to-fault azimuth change (60 degrees) A physical constraint was included that assessed the Coulomb compatibility of jumps between faults, though it was only applied to the portion of faults immediately before and after each jump.

We test the UCERF3 multi-fault rupture plausibility criteria against physically-consistent synthetic seismicity catalogs generated with the RateState Earthquake Simulator (RSQSim) on the UCERF3 fault system. Prior studies have shown agreement between PSHA results obtained from RSQSim and UCERF3; here we examine individual ruptures in detail. We find that RSQSim catalogs produce multi-fault ruptures at a similar rate to UCERF3, and most ( $>80 \%$ of $M \geq 6.5$ ruptures) pass all UCERF3 plausibility criteria. We identify a number of plausible fault jumps that occur in RSQSim catalogs but are not allowed under the UCERF3 rules, and propose modifications to the plausibility criteria for the next UCERF model to incorporate inferences from RSQSim. Specifically, we propose removal of the azimuth change criteria, which were most appropriate for jumps between faults with similar rakes, and improvements to the Coulomb criterion that assess the physical consistency of the entire rupture.

\section{New Insights Into How the 2016 Mw7.8 Kaikōura (New Zealand) Multi-Fault Earthquake Nucleated, Propagated and Arrested From a Dense 10-Year Earthquake Catalog} CHAMBERLAIN, C. J., Victoria University of Wellington, Wellington, New Zealand, calum.chamberlain@vuw.ac.nz; FRANK, W. B., Massachusetts Institude of Technology, Massachusetts, USA, wfrank@mit.edu; LANZA, F., Swiss Seismological Service, Zürich, Switzerland, federica.lanza@sed.ethz.ch; TOWNEND, J., Victoria University of Wellington, Wellington, New Zealand, john.townend@vuw.ac.nz; WARREN-SMITH, E., GNS Science, Lower Hutt, New Zealand, e.warren-smith@gns.cri.nz

The $2016 \mathrm{M}_{\mathrm{W}} 7.8$ Kaikoura earthquake in northern South Island, New Zealand, was a complex rupture involving at least 13 different faults and spanning two separate tectonic domains. Despite many studies on this earthquake, several fundamental questions remain, including: (1) what structure did the earthquake nucleate on?; (2) how did the rupture propagate through a complex array of faults with large apparent step-overs?; (3) how did the Papatea Fault accommodate significant slip despite its short length?; (4) why did the earthquake arrest at Cook Strait?; (5) what was the role of the underlying subduction interface co-seismically and post-seismically?

To answer these questions we have constructed a 10 -year long catalog of well-located earthquakes on and around the faults that ruptured in the Kaikōura earthquake. We used well-constrained Kaikōura aftershocks as 
templates in a matched-filter search between 2009 and 2019. We were able to compute local magnitudes and precise relocations for 25,877 earthquakes and focal mechanisms for 1,755 template events, providing an unprecedented view of the pre- and post-seismic seismic slip around the Kaikoura earthquake.

Our earthquake catalog highlights the continuity of faults throughout the ruptured region, including offshore thrust faulting linking the southern and northern domains. We also observe an inland continuation of the Papatea Fault, and provide a new interpretation of the large-slip on this fault as the corner at the edge of a thrust block. We demonstrate that the Kaikoura earthquake nucleated on the Humps Fault, and that previous locations were erroneous mostly due to incorrect velocity models. We also show that the faults that ruptured in the 2013 and 2014 Cook Strait earthquake sequence were re-ruptured by the Kaikoura earthquake and the stress-drop from these earthquakes may have played a role in the Kaikoura arrest. Finally, our catalog contains no subduction zone earthquakes beneath the vast majority of the ruptured faults, suggesting that if the interface did slip either co- or post-seismically, it was likely aseismic.

\section{Seismogenic Cutoff Depths and Thermal State of the Late-Interseismic Central Alpine Fault, New Zealand: Implications for Coseismic Slip in Future Large Earthquakes}

TOWNEND, J., Victoria University of Wellington, Wellington, New Zealand, john.townend@vuw.ac.nz; MICHAILOS, K., University of Lausanne, Lausanne, Switzerland, konstantinos.michailos@unil.ch; SUTHERLAND, R., Victoria University of Wellington, Wellington, New Zealand, rupert. sutherland@vuw.ac.nz; SAVAGE, M. K., Victoria University of Wellington, Wellington, New Zealand, martha.savage@vuw.ac.nz; CHAMBERLAIN, C. J., Victoria University of Wellington, Wellington, New Zealand, calum. chamberlain@vuw.ac.nz

Observations made during last decade of microseismicity near the central section of the Alpine Fault reveal marked along-strike variations in seismogenic cutoff depths late in the fault's $<300$-year interseismic period. We use the entire microseismicity catalog ( 7700 events) in conjunction with thermochronological data to estimate the rates and thermal effects of ongoing exhumation of the Southern Alps orogen, which forms the hanging-wall of the Alpine Fault. We obtain uplift rates of between 1 and $8 \mathrm{~mm} / \mathrm{yr}$, with maximum values coinciding with the area of highest topography near Aoraki/Mount Cook: these estimates compare well with recent geodetic measurements and with independent thermochronological data not used in our modeling. The mean brittle-ductile transition temperature beneath the Southern Alps we obtain $\left(410-430^{\circ} \mathrm{C}\right)$ is higher than expected for a quartz-dominated rheology, and may reflect unmodeled effects of elevated fluid pressures or strain rate heterogeneity. The variation in seismogenic cutoff depths along strike of the Alpine Fault is well accounted for by the temperature structure and likely affects both down-dip and along-strike patterns of coseismic slip in large Alpine Fault earthquakes. Using all events in the microseismicity catalog as templates, we are now undertaking a comprehensive matched-filter analysis in order to detect additional lower-magnitude seismicity and explore spatial variations in moment release and susceptibility to triggering by regional earthquakes. In this presentation we discuss the ramifications of the seismological and thermal results for the distribution of coseismic slip and outline methods by which these findings are being incorporated in virtual earthquake models of future earthquakes.

\section{The Relation of Fault Geometry to High-Frequency Radiation: Insights from the $\mathbf{2 0 1 9}$ Ridgecrest Sequence} CHU, S., Brown University, Rhode Island, USA, shanna_chu@brown.edu; TSAI, V., Brown University, Rhode Island, USA, victor_tsai@brown.edu; HIRTH, G., Brown University, Rhode Island, USA, greg_hirth@brown.edu; TRUGMAN, D. T., University of Texas at Austin, Texas, USA, dtrugman@ jsg.utexas.edu

The 2019 Ridgecrest earthquake sequence illuminated a large network of previously unmapped cross-cutting structures in the eastern California shear zone. Preliminary observations of regional stress drops display along-strike variability possibly related to local heterogeneities in fault geometry, which are delineated at high resolution by the density of recorded events. Coseismic damage in the immature fault zone may have contributed further temporal variation to this spatial variability, due to structural collisions or crack opening. In this study, we investigate the possible link between variations in fault geometry and spacing and the observed seismic spectrum. Existing measures of fault complexity, such as RMS roughness, are generally limited to a single fault strand and thus cannot describe interactions between cross-cutting faults. Revisiting the 20-year Ridgecrest stress drop catalogue of Trugman
(2020), we investigate several novel ways to quantify fault network density, based on the geometry and relative orientations of mapped fault traces. We proceed to draw spatiotemporal correlations between observed stress drops and fault spacing. We search for characteristic frequencies at which the highfrequency seismic spectrum may be enriched due to fault geometry, which may affect the observed corner frequency. The relation of correlation frequency to spatial variations in fault orientation and spacing can constrain physical processes that contribute to the high-frequency seismic spectrum. This in turn has the potential to improve regional hazard characterization and ground motion prediction based off of fault maps.

Explosion Seismology Applications and Advances

I: Oral Session · Monday · 19 April · 9:45 Am Pacific

II: Oral Session · Monday · 19 April · 2:00 PM Pacific

Session Chairs: Catherine M. Snelson, Los Alamos National

Laboratory (snelsonc@lanl.gov); William R. Walter, Lawrence Livermore National Laboratory (walter5@llnl.gov); Rigobert Tibi, Sandia National Laboratories (rtibi@sandia.gov); Cleat P. Zeiler, Nevada National Security Site (zeilercp@nv.doe.gov)

\section{Comparing Higher-Dimensional Velocity Models for} Seismic Location Accuracy Using a Consistent Travel Time Framework

BEGNAUD, M. L., Los Alamos National Laboratory, New Mexico, USA, mbegnaud@lanl.gov; BALLARD, S., Sandia National Laboratories, New Mexico, USA, sballar@sandia.gov; CONLEY, A., Sandia National Laboratories, New Mexico, USA, acconle@sandia.gov; HAMMOND, P., Sandia National Laboratories, New Mexico, USA, phammon@sandia.gov; YOUNG, C. J., Sandia National Laboratories, New Mexico, USA, cjyoung@sandia.gov

Historically, location algorithms have relied on simple, one-dimensional (1D, with depth) velocity models for fast, seismic event locations. The speed of these 1D models made them the preferred type of velocity model for operational needs, mainly due to computational requirements. Higher-dimensional (2D-3D) seismic velocity models are becoming more readily available from the scientific community and can provide significantly more accurate event locations over 1D models. The computational requirements of these higherdimensional models tend to make their operational use prohibitive. The benefit of a 1D model is that it is generally used as travel-time lookup tables, one for each seismic phase, with travel-time predictions pre-calculated for event distance and depth. This simple, lookup structure makes the travel-time computation extremely fast.

Comparing location accuracy for $2 \mathrm{D}$ and $3 \mathrm{D}$ seismic velocity models tends to be problematic because each model is usually determined using different inversion parameters and ray-tracing algorithms. Attempting to use a different ray-tracing algorithm than used to develop a model almost always results in poor travel-time prediction compared to the algorithm used when developing the model.

We will demonstrate that using an open-source framework (GeoTess, www.sandia.gov/geotess) that can easily store 3D travel-time data can overcome the ray-tracing algorithm hurdle. Travel-time lookup tables (one for each station and phase) can be generated using the exact ray-tracing algorithm that is preferred for a specified model. The lookup surfaces are generally applied as corrections to a simple 1D model and also include variations in event depth, as opposed to legacy source-specific station corrections (SSSCs), as well as estimates of path-specific travel-time uncertainty. Having a common travel-time framework used for a location algorithm allows individual $2 \mathrm{D}$ and $3 \mathrm{D}$ velocity models to be compared in a fair, consistent manner.

\section{Examining the Complex Relationship Between Seismic Moment and Explosive Yield}

PASYANOS, M. E., Lawrence Livermore National Laboratory, California, USA, pasyanos1@llnl.gov; CHIANG, A., Lawrence Livermore National Laboratory, California, USA, chiang4@llnl.gov; GÖK, R., Lawrence Livermore National Laboratory, California, USA, gok1@llnl.gov

We have calculated full (six-component) moment tensor solutions for dozens of chemical and nuclear explosions at the Nevada National Security Site (NNSS). The explosions are located through various locations at the test site (Pahute Mesa, Rainier Mesa, Yucca Flat, and Climax Stock) and in a variety of materials (granite, rhyolite, tuff, and alluvium). For all chemical explosions 
and a small subset of nuclear explosions, we have ground truth yield, depth, and shot point material while, for the other explosions, we have depth and shot point material, along with a yield range (Springer et al., 2002; DOE NV-209).

While seismic moment and explosive yield are obviously related, they are complicated by differences in material properties (including gas porosity), source depth (and scaled depth), and between chemical and nuclear explosions. Using this large database, we examine this complex relationship, first through simple regressions and progressing to more complicated approaches. One method is to model the source spectra through a combination of estimated seismic scalar moments and corner frequencies predicted through an explosion source model. Another approach is through the use of corner frequencies provided by coda-derived spectra. From these spectra, we can make estimates of the radiated seismic energy and relate those to explosive yield.

Understanding the complex relation between moment and yield would allow us to have a new method to estimate yield, independent of typical methods based on the teleseismic body wave magnitude mb, and applicable to new classes of explosions that cannot be observed teleseismically. We apply the methods to estimating the yield of the six recent declared DPRK nuclear explosions, and compare them to other estimates from teleseismic magnitudes, regional magnitudes, and regional envelopes.

\section{Regional-Scale Crustal and Mantle Structure of the Western United States From Adjoint Waveform Tomography for Improved Source Characterization} RODGERS, A. I., Lawrence Livermore National Laboratory, California, USA, rodgers7@llnl.gov; KRISCHER, L., Mondiac, Zürich, Switzerland, lion.krischer@gmail.com; AFANASIEV, M., Mondaic, Zürich, Switzerland michael.afanasiev@mondaic.com; BOEHM, C., Mondaic, Zürich, Switzerland, christian.boehm@mondaic.com; CHIANG, A., Lawrence Livermore National Laboratory, California, USA, chiang4@llnl.gov; DOODY, C., University of California, Berkeley, California, USA, claired@berkeley.edu; MORENCY, C., Lawrence Livermore National Laboratory, California, USA, morency1@llnl. gov; SIMMONS, N., Lawrence Livermore National Laboratory, California, USA, simmons27@llnl.gov

Recent application of moment tensor estimation promises to improve explosion monitoring. Moment tensor methods have proven effective for large magnitude and explosive yield events using average plane-layered (onedimensional, 1D) Earth models. However, the extension of these methods to lower magnitudes and longer (regional) distances is challenging because three-dimensional (3D) Earth structure causes significant deviations in waveform Green's functions from assumed 1D models. To address this challenge, we are using adjoint waveform tomography to obtain an improved 3D Earth model for full waveform simulations. We are focusing on the western United States (WUS) where we have ample broadband waveform data and well characterized earthquakes and explosions to test the efficacy of our model. We are inverting waveforms using the Salvus package which coordinates the workflow (e.g., forward and adjoint simulations, gradients, measurements). For the 3D starting model we used SPiRaL (Simmons et al., 2020), which is a radially anisotropic global model based on body-wave travel times and surface wave dispersion. We followed a multiscale approach starting with long-period waveforms (50-120 seconds), iteratively inverting waveforms and relaxing smoothing. As misfit reduction ceased, we then repicked windows and inverted shorter period data. Currently we have performed over 50 iterations and inverted data with periods as short as 30 seconds. We hope to reduce the minimum period further to resolve features in the crust and uppermost mantle. Results so far for the WUS are consistent with the SPiRaL starting model but show sharper features with higher amplitude wavespeed perturbations and good correlation with known crustal-scale geologic and physiographic regions. The efficacy of our new 3D model is explored in this presentation and in an accompanying presentation by Chiang et al. (2021).

\section{The Finite-Interval Spectral Power-A Tool for Identification of Underground Cavities}

KRISTEKOVA, M., Earth Science Institute, Slovak Academy of Sciences, Bratislava, Slovakia, kristekova@savba.sk; KRISTEK, I., Comenius University Bratislava, Bratislava, Slovakia, kristek@fmph.uniba.sk; MOCZO, P., Comenius University Bratislava, Bratislava, Slovakia, moczo@fmph.uniba.sk; LABAK, P., Earth Science Institute, Slovak Academy of Sciences, Bratislava, Slovakia, peter.labak@savba.sk

Undetected underground cavities of natural or artificial origin pose a serious geotechnical hazard. Detecting and locating underground cavities mainly in urban development and civil construction is therefore important for increasing human safety.
Underground cavities also arise due to underground nuclear explosions. Therefore, detection and location of a cavity generated by an underground nuclear explosion is an important proof in case of suspicion of violating the Comprehensive Nuclear-Test-Ban Treaty (CTBT), an international treaty banning nuclear weapon test explosion or any other nuclear explosion which is yet to come into force.

We have developed a new method for detecting and locating a horizontal position of an underground cavity. We have defined the Finite-interval Spectral Power (FISP) of seismic ambient noise. Mapping FISP makes it possible to identify the position of the cavity. The method can utilize single-station measurements at a set of potentially irregularly distributed points in the area on the Earth's free surface over a suspected cavity.

Because the method gives better results for undistorted segments of noise records, we have also developed an automatic identification of such segments.

We validated our method using records of noise from a site near the Felsőpetény, Hungary, which were collected for the CTBT Organization during a field test in the framework of developing on-site inspection (OSI) capabilities. The method is ready for further tests in different cavity conditions and applications.

\section{Using Empirical Source Templates as Mother Wavelets in the Continuous Wavelet Transform}

LANGSTON, C. A., University of Memphis, Tennessee, USA, clangstn@ memphis.edu

A mother wavelet can be constructed from a template derived from observations of a seismic event. Using the entire signal of a template event as a wavelet within the continuous wavelet transform produces the ultimate sparse representation of repeating events since, in principle, the detected event can be represented by a single wavelet coefficient in the scale-time domain. Use of empirical wavelets generalizes template correlation since the time scaling of the empirical wavelet mimics changes in relative arrival times between phases. A template derived from an event at one seismic station might be appropriate for a close by station or for other events of similar mechanism close to the template event. This hypothesis is tested using local explosion data recorded by the 2016 IRIS Wavefields Community Experiment. Use of an empirical wavelet derived from the $2000 \mathrm{lb}$ shot approximately $35 \mathrm{~km}$ from the IRIS experiment clearly detects the same explosion from noisy data at other stations in the array and for the 500lb explosion at the same shotpoint. The two $250 \mathrm{lb}$ explosions were not detected because of relatively higher levels of background noise. These results suggest the additional possibility of reconstructing waveforms from small events using a template event as the mother wavelet.

\section{Developing a Joint Regional Waveform-Insar Moment Tensor Inversion: Application to 6th North Korean Nuclear Test}

CHI-DURAN, R., University of California, Berkeley, California, USA, rodrigo.chi@berkeley.edu; DREGER, D. S., University of California, Berkeley, California, USA, ddreger@berkeley.edu; RODGERS, A. J., Lawrence Livermore National Laboratory, California, USA, rodgers7@llnl.gov

On 3 September 2017, the Democratic People's Republic of Korea conducted its largest nuclear test (DPRK2017). This event is the largest man-made explosion ever recorded by orbital radar systems and provides a unique dataset with which to develop new methods of source inversion (Wang et al. 2018). Even though regional distance seismic MT inversion methods have identified this event as an explosion (Chiang et al., 2018), we have found that the best surface wave and first motion solution fails to fit the static deformation field from the SAR data (e.g. Dreger et al., 2017). However, we have found that a subspace of best-fitting models can satisfy the surface deformation field and reduce the overall uncertainty in the moment tensor solution. To develop a joint inversion method we develop Green's functions using the SW4 finite-difference code to accurately model surface topography effects on the seismic wave field. We have generated Green's functions for a source volume comprised of XYZ sources. We perform a grid search of moment tensor solutions over the source volume to find the best fitting location, depth and moment tensor for the event. We also compare different velocity models for this inaccessible region. Our initial results show that we can explain 50\% horizontal static ground deformation using a composition of 3 different point-sources that accounts for the finite extent of the explosive source with a layered model (Pabian and Coblentz, 2015). We have succeeded in constraining the large subset of possible MT solutions in a waveform and first-motion inversion (Nayak and Dreger, 2015). We will present static field only, joint static, regional waveform 
and first-motion point-source solutions, and multiple point-source solutions to account for source finiteness.

\section{Effects of Multi-Scale Structure on Shear Wave Generation} and Propagation Using Source Physics Experiment Data

CHEN, T., Los Alamos National Laboratory, New Mexico, USA, tchen@lanl. gov; LARMAT, C., Los Alamos National Laboratory, New Mexico, USA carene@lanl.gov; ALFARO-DIAZ, R. A., Los Alamos National Laboratory, New Mexico, USA, raalfarodiaz@lanl.gov; ROWE, C. A., Los Alamos National Laboratory, New Mexico, USA, char@lanl.gov; ABRAMS, J. R., Los Alamos National Laboratory, New Mexico, USA, rabrams@lanl.gov; MAY, A. Los Alamos National Laboratory, New Mexico, USA, asher.may.98@lanl.gov; PHILLIPS, W. S., Los Alamos National Laboratory, New Mexico, USA, wsp@ lanl.gov

We study the generation and propagation of shear waves from chemical explosion sources by focusing a multidisciplinary effort on the Source Physics Experiment (SPE) Phase I, located in a granite outcrop, and Phase II located at a dry alluvium geology site (DAG). Using data recorded by dense networks of seismic stations and fiber optic cables, we have conducted first arrival analysis, Rg propagation analysis, and horizontal-to-vertical spectral ratio analysis to constrain the geological structure. Our results differentiate between alluvium, volcanic tuff, and Paleozoic basement units, depending on site, and identify clear 3-D variations at different scales. Body wave analyses (first arrival) and $\mathrm{Rg}$ phase propagation studies focus on reconciling models produced using different data types. To understand the generation of shear energy within the 3D subsurface from DAG explosions, we have undertaken full waveform modeling using the spectral element code SPECFEM3D, varying the velocity of each geological unit in the model to account for uncertainties assessed by an in-situ mapping campaign and material characterization of borehole samples. We quantify the shear energy in the modeled wavefield by measuring the amplitude of the transverse component and $\mathrm{P} / \mathrm{S}$ ratio for about 900 stations. Our results show that the $\mathrm{P} / \mathrm{S}$ ratio is strongly affected by the subsurface properties. We will compare the $\mathrm{P} / \mathrm{S}$ ratio modeling results to observations and will refine the model by changing attenuation properties and by studying the effects of random heterogeneities and anisotropy.

\section{Insights From the Source Physics Experiment on Seismic Waves Generated by Explosions}

WALTER, W. R., Lawrence Livermore National Laboratory, California, USA, walter5@llnl.gov; FORD, S. R., Lawrence Livermore National Laboratory, California, USA, sean@llnl.gov; PITARKA, A., Lawrence Livermore Nationa Laboratory, California, USA, pitarka1@llnl.gov; PYLE, M. L., Lawrence Livermore National Laboratory, California, USA, pyle4@llnl.gov; PASYANOS, M. E., Lawrence Livermore National Laboratory, California, USA, pasyanos1@ llnl.gov; ICHINOSE, G. A., Lawrence Livermore National Laboratory, California, USA, Ichinose1@llnl.gov; CHIANG, A., Lawrence Livermore National Laboratory, California, USA, chiang4@llnl.gov; MELLORS, R., University of California, San Diego, California, USA, rmellors@ucsd.edu; EZZEDINE, S. M., Lawrence Livermore National Laboratory, California, USA, ezzedine1@llnl.gov; VOROBIEV, O. Y., Lawrence Livermore Nationa Laboratory, California, USA, vorobiev1@llnl.gov; DODGE, D., Lawrence Livemore National Laboratory, California, USA, dodge1@llnl.gov; MATZEL, E., Lawrence Livermore National Laboratory, California, USA, matzel1@llnl. gov; WAGONER, J., Lawrence Livermore National Laboratory, California, USA, wagoner1@llnl.gov

The NNSA DNN R\&D sponsored Source Physics Experiment (SPE) is a large, multi-institutional (LANL, LLNL, SNL, MSTS and UNR) effort to improve our understanding of how explosions generate seismic waves, particularly shear waves, to improve nuclear monitoring capabilities. The SPE includes a series of chemical explosions in southern Nevada in two different boreholes in contrasting geologies. The explosions vary in size and depth and for each location they are recorded on a common network, allowing ratios between events to be formed, canceling path and site effects and illuminating near source effects. Surface explosions were also conducted above the boreholes: at the SPE Phase I granite site in 2016, and under DTRA sponsorship at the SPE Phase II dry alluvium geology (DAG) site during the Large Surface Explosive Coupling Experiment (LSECE) in 2020.

Near-field chemical SPE and historic nuclear data show high-frequency tangential motion is $20-30 \%$ of radial amplitudes, although the mechanisms that cause this vary with emplacement media. Within a few kilometers, farfield seismic amplitudes at $1-10 \mathrm{~Hz}$ are comparable across the 3 components, and the buried and surface explosions have comparable $\mathrm{P} / \mathrm{S}$ amplitude ratios both effects requiring rapid scattering and conversion to explain. The spectral ratios formed between small explosions used as Green's functions and larger explosions are not well matched by existing explosion models, and the dry alluvium geology produces smaller amplitudes and appears deficient in highfrequency energy relative to explosions in granite. This shows the importance of material effects on explosive wave generation, which must be taken into account for monitoring analyses. We are examining factors such as absolute depth, scale depth, and material effects on shear wave generation, $\mathrm{P} / \mathrm{S}$ and low/high frequency amplitude discrimination performance, and correlation behavior. These results are being used to develop a new explosion spectral model.

\section{Modeling Source Physics Explosions Recorded on a Distributed Fiber Optic Sensor}

MELLORS, R., University of California, San Diego, California, USA, rmellors@ucsd.edu; ABBOTT, R. E., Sandia National Laboratory, New Mexico, USA, reabbot@sandia.gov; STEEDMAN, D., Los Alamos National Laboratory, New Mexico, USA, dwsteed@lanl.gov; PITARKA, A., Lawrence Livermore National Laboratory, California, USA, pitarka1@llnl.gov

Fiber optic distributed acoustic sensors (DAS) are becoming a widely used tool for seismic sensing. We model waveforms of two subsurface chemical explosions at depths of 385 and $150 \mathrm{~m}$, each of which was about one metric ton TNT equivalent, that were recorded from a helical fiber $\left(30^{\circ}\right)$ installed in two boreholes $80 \mathrm{~m}$ away from the source location. The boreholes were 450 and $390 \mathrm{~m}$ in depth and were equipped with both a vertical fiber cable and accelerometers at multiple levels. The fiber sensors remain on scale and several phases including the initial $\mathrm{P}$ wave, a weak $\mathrm{S}$ wave, and a downgoing reflected $\mathrm{P}$ wave are observed. The fiber waveforms are compared using cross-correlation with the downhole accelerometer records. The best match was achieved between the vertical accelerometer component and the DAS strainrate data after converting from strainrate to acceleration. We had difficulty matching the exact amplitudes between the fiber and the accelerometers using the nominal transfer function for the fiber data and used an empirical factor. We estimate a velocity model using arrival times measured from the fiber and then use this velocity model to generate synthetic strain-rate seismograms using both wavenumber and finite difference algorithms. A shallow low-velocity layer which may be a transient feature caused by spall was necessary to match the timing of the downgoing reflected wave. The strainrate synthetics matched the observed DAS data waveform in shape. The helical fiber appears to be sensitive to both P and S waves. We find that the DAS data can be modelled successfully to provide insight into the wavefield generation and propagation. This work was performed under the auspices of the U.S Department of Energy by Lawrence Livermore National Laboratory under Contract DE-AC52-07NA27344. SNL is managed and operated by NTESS under DOE NNSA contract DE-NA0003525. LLNL publication LLNLABS-818077. LANL publication LA-UR-21-20078.

\section{Simulation of Underground Chemical Explosions in Soft Alluvium, Hard Granite and Brittle Tuff Using Anisotropic Near-Field Hydrodynamic Generated Source Coupled to Far- Field Linear Anisotropic Wave Propagation}

EZZEDINE, S. M., Lawrence Livermore National Laboratory, California, USA, ezzedine1@llnl.gov; VOROBIEV, O. Y., Lawrence Livermore National Laboratory, California, USA, vorobiev1@llnl.gov; PITARKA, A., Lawrence Livermore National Laboratory, California, USA, pitarka1@llnl.gov; WALTER, W. R., Lawrence Livermore National Laboratory, California, USA, walter5@llnl.gov; ANTOUN, T. H., Lawrence Livermore National Laboratory, California, USA, antoun1@llnl.gov

The Source Physics Experiment (SPE) is an ongoing effort to improve explosion monitoring by conducting a controlled series of chemical explosions at the Nevada National Security Site (NNSS) and using the resulting observations to improve and validate physics-based simulations of explosion phenomena. Phase I of SPE was conducted in granite which contains a network of joints. It has been shown through hydrodynamic source modeling that sliding on these pre-existing joints may be the cause of the observed tangential motion. Near-field motions generated with hydrodynamic non-linear source models have been coupled to elastic wave propagation codes to propagate these resulting motions into the far-field domain which is assumed to be elastic. However, one simplification that has been made is that the far-field elastic media is isotropic. This is likely not the case as the network of pre-existing joints also continues outside of the inelastic source region of the SPE and can be shown to result in an anisotropic stiffness for the granite. We use a hybrid modeling approach with one-way hydrodynamic-to-elastic coupling. Near source hydrodynamic motions are computed using GEODYN-L while anisotropic elastic wave propagation is modeled using SW4. The anisotropic material model employed in the SW4 domain is derived from the properties of an 
observed fracture network with relatively well-constrained joint orientations, spacing, and stiffnesses. We show that consideration of anisotropic material in the elastic regime has an important effect on the propagation of tangential motion. Propagation of motions generated in an anisotropic source region into an isotropic far-field domain will introduce some biases. To illustrate the versatility of the proposed approach, the current GEODYN-L/SW4 coupling has also been applied to model Phase II of SPE, conducted in a dry alluvium geology (DAG) and it is being extended to consolidated pyroclastic or volcaniclastic rocks such as tuffs. Simulation results from anisotropic alluvium, granite and tuff will be presented.

\section{Explosion Seismology Applications and Advances \\ Poster Session · Monday $\cdot 19$ April $\cdot$ 11:30 Am Pacific \\ Session Chairs: Catherine M. Snelson, Los Alamos National Laboratory (snelsonc@lanl.gov); William R. Walter, Lawrence Livermore National Laboratory (walter5@llnl.gov); Rigobert Tibi, Sandia National Laboratories (rtibi@sandia.gov); Cleat P. Zeiler, Nevada National Security Site (zeilercp@nv.doe.gov)}

\section{Analysis of Seismic P/S Ratios From Chemical Explosions at} the Surface and Buried in Contrasting Geologies

PYLE, M. L., Lawrence Livermore National Laboratory, California, USA, pyle4@llnl.gov; WALTER, W. R., Lawrence Livermore National Laboratory, California, USA, walter5@llnl.gov

Historically, discrimination for large explosions, such as nuclear tests, from surrounding seismicity could be achieved on the basis of lower shear generation for explosive sources, particularly at higher frequencies, by using seismic P/S amplitude ratios. This method proved effective at many test sites and emplacement conditions around the world for explosions that could be recorded at regional distances $(>200 \mathrm{~km})$. Few studies exist that test this method for smaller events that may only be observed at local distances $(<200 \mathrm{~km})$, and results are mixed. Single-station ratios appear to be unreliable; while some stations show separation between explosion and earthquake populations, many do not. Network-averaging of $\mathrm{P} / \mathrm{S}$ ratios may provide more consistent discrimination performance, however, more work is necessary to understand the reasons for success or failure of the $\mathrm{P} / \mathrm{S}$ ratios at local distances.

Previous work has looked at the $\mathrm{P} / \mathrm{S}$ discriminant at local distances using data from the Source Physics Experiment (SPE). Phase I of this experiment consisted of a series of chemical explosions in a single borehole located in granite. We extend our analysis here to include data from Phase II of SPE, a second series of explosions in a contrasting dry alluvium geology (DAG), as well as a series of surface explosions from the Large Surface Explosion Coupling Experiment (LSECE) at the same site. Preliminary results show no significant differences in the scatter of $\mathrm{P} / \mathrm{S}$ ratios from the buried explosions in contrasting geologies or the surface explosions. Network-averaged ratios for the DAG explosions and the LSECE explosions show strong similarity, suggesting a similar scattering and conversion shear-wave generation for both buried and surface sources.

\section{Analysis of the Source Physics Experiment, Dry Alluvium Geology Ball Drop Sources}

FORD, S. R., Lawrence Livermore National Laboratory, California, USA, sean@llnl.gov; ICHINOSE, G. A., Lawrence Livermore National Laboratory, California, USA, ichinose1@llnl.gov; WALTER, W. R., Lawrence Livermore National Laboratory, California, USA, walter5@llnl.gov

The Source Physics Experiment (SPE) is a multiphase experiment to better understand explosion source physics and thereby improve explosion monitoring. The second phase of the SPE consisted of four chemical explosions in alluvium referred to as the Dry Alluvium Geology (DAG) series of chemical explosions. The second of the DAG chemical explosions (DAG-2) resulted in an energy release of 51 TNT-equivalent tonnes and created a large cavity and damage region around the working point resulting in an energetic aftershock sequence.

One potential source of explosion aftershocks is rubble collapsing into the borehole and cavity. In order to better identify which events in the aftershock sequence could be due to such a mechanism an attempt was made to replicate their signals. About 3 months after the DAG-2 detonation two ball weights were dropped from a height of $150.9 \mathrm{~m}$ above the bottom of the borehole. The bottom of the borehole at this time was about $150 \mathrm{~m}$ above the DAG-2 working point to make a floor for the DAG-3 canister. The first ball drop was a $14.27 \mathrm{~kg}$ concrete-filled basketball and the second was a $7.24 \mathrm{~kg}$ bowlingball.

The ball drop signals were used as templates to search for similar events in the DAG-2 aftershock sequence recorded on the local array of stations distributed near the DAG borehole. The bowlingball template correlated with zero events and the basketball correlated with four events in a 75 day period beginning with the DAG-2 detonation. During the same period Ichinose et al. (2021) report more than a thousand events. A synthetic sensitivity study showed that the high-frequency template detections were only sensitive to a small region near where the balls landed at $150.9 \mathrm{~m}$ that did not extend to the actual location of the DAG-2 cavity near a depth of $300 \mathrm{~m}$. Therefore, it appears that the four detected events were probably from debris falling in the borehole and striking the floor near $150.9 \mathrm{~m}$ depth just as the ball drops had done and the majority of aftershocks have a different source type and location.

Prepared by LLNL under Contract DE-AC52-07NA27344.

\section{Assessing the Accuracy of a Borehole-Controlled Velocity} Model of Yucca Flat, Nevada Using Large N Seismic Data

VIECELI, R. E., New Mexico Institute of Mining and Technology, New Mexico, USA, rev5028@gmail.com; ABBOTT, R. E., Sandia National Laboratories, New Mexico, USA, reabbot@sandia.gov; PRESTON, L., Sandia National Laboratories, New Mexico, USA, lpresto@sandia.gov; PROTHRO, L., Mission Support and Test Services, Nevada, USA, prothrlb@nv.doe.gov

With geologic data from over 950 boreholes, the Yucca Flat basin, residing on the Nevada National Security Site (NNSS), has excellent borehole control on stratigraphy. These data were used to create a Geologic Framework Model (GFM) of the basin. 188 of these boreholes have corresponding downhole seismic survey data which were used to determine average P-wave velocities of the geologic units. With the acquisition of five new active-source Large-N datasets in Yucca Flat, we can now quantitatively assess the accuracy of the seismic model previously controlled only by borehole data. To do this, for each of the five datasets, we subset the GFM to the region of interest and create a forward model of P-wave travel times for the GFM given the Large-N source-receiver geometries. We then compare the empirical Large N P-wave travel times to the GFM-derived travel times. We first make trial-and-error adjustments to the unit velocities (while keeping the layer geometry intact) to improve the travel time residuals. Updating the models in this way indicates that the borehole-controlled model overestimates alluvium velocities across Yucca Flat, and overestimates them in southeastern Yucca Flat. The trial-anderror method reduced the travel time error by a factor of five. We then implement a Bayesian grid search to more systematically determine optimal velocity models and provide uncertainty analysis. This work was done by Mission Support and Test Services, LLC, under Contract No. DE-NA0003624 with the U.S. Department of Energy. DOE/NV/03624--0962. SNL is managed and operated by NTESS under DOE NNSA contract DE-NA0003525.

\section{Damage Characterization for the SPE Phase of the Source Physics Experiment}

LARMAT, C., Los Alamos National Laboratory, New Mexico, USA, carene@ lanl.gov; SWANSON, E., Los Alamos National Laboratory, New Mexico, USA, emswanson@lanl.gov; LEI, Z., Los Alamos National Laboratory, New Mexico, USA, zlei@lanl.gov; CRAWFORD, B. M., Los Alamos National Laboratory, New Mexico, USA, bcrawford@lanl.gov; SCHULTZ-FELLENZ, E., Los Alamos National Laboratory, New Mexico, USA, eschultz@lanl.gov; PATTON, H. J., Los Alamos National Laboratory, New Mexico, USA, patton@ lanl.gov; CLEVELAND, M. K., Los Alamos National Laboratory, New Mexico, USA, mcleveland@lanl.gov

Monitoring capabilities heavily rely on the ability to link seismic features such as amplitude of a particular seismic phase to characteristics of explosions such as their yield and depth of burial. An underground explosion interacts with the surrounding material, creating damage which may include fracture generation or permanent surface deformation.

In this presentation, we study how the creation of damage may affect the efficiency of explosions in generating seismic energy. We use data collected during the first phase of the Source Physics Experiment (SPE), which is a series of highly instrumented chemical explosions at the Nevada National Security Site. During the first phase, 6 explosions, ranging from 89 to $5,035 \mathrm{~kg}$ TNT equivalent, were conducted in a borehole in a granite outcrop between 2010 and 2016. Scaled depths of burial range from 190 to $1550 \mathrm{~m} / \mathrm{kt} / 3$. Analysis of the 2-8 Hz Rg waves recorded by a network of GS11D geophones situated within a range of $2 \mathrm{~km}$ from the borehole is consistent with late-time damage acting as a secondary source of high-frequency Rg waves (Larmat, Rougier, \& Patton, 2017). High-resolution Digital Elevation Models have been collected to measure surface deformation resulting from each explosion in the 
series (Schultz-Fellenz et al. 2018; 2020). Our goal is to test and investigate a link between deformation observations and seismic signatures. Our approach is a combination of analyses of disparate physical manifestations of damage fractures, surface deformation and seismic features. This analysis is guided by hydrodynamic modeling using the LANL Hybrid Optimization Software Suite (HOSS), which uses a macro-scale material models mixing elastic plastic, discrete fracture and pore-crush regimes. Seismic analysis includes seismic moment inversions and spallation analysis. This work is the first step in investigating and quantifying differences between spallation and surface deformation in the SPE series. LA-UR-21-20087.

\section{Discrimination of Seismic Events (2006 to 2020) in North Korea Using P/Lg Amplitude Ratios from Regional Stations and a Bivariate Discriminant Function}

TIBI, R., Sandia National Laboratories, New Mexico, USA, rtibi@sandia.gov

Two events of magnitude $\left(m_{\mathrm{b}}\right)$ 3.6-3.8 occurred in southern North Korea (NK) on 27 June 2019 and 11 May 2020. Although these events were located about $330-400 \mathrm{~km}$ from the known nuclear test site, the fact that they occurred within the territory of NK, a country with a recent history of underground nuclear tests, made them events of interest for the monitoring community. We used $P$ / $\mathrm{Lg}$ ratios from regional stations to categorize seismic events that occurred in NK from 2006 to May 2020, including these two recent events, the six declared NK nuclear tests, and the cavity collapse and triggered earthquakes that followed the 3 September 2017 nuclear explosion. We were able to separate the cavity collapse from the population of nuclear explosions. However, based on $P / L g$ ratios, the distinction between the earthquakes and the cavity collapse is ambiguous. The performed discriminant analyses suggest that combining cross-spectral $\mathrm{Pg} / \mathrm{Lg}$ and $\mathrm{Pn} / \mathrm{Lg}$ results in improved discriminant power compared with any of the ratio types alone. We used the two ratio types jointly in a quadratic discriminant function and successfully classified the six declared nuclear tests and the triggered earthquakes that followed the September 2017 explosion. Our analyses also confirm that the recent southern events of June 2019 and May 2020 are both tectonic earthquakes that occurred naturally.

\section{Estimating Explosion Source Time Functions From Seismic Data: Are Linear Inversions Good Enough?}

\section{POPPELIERS, C., Sandia National Laboratories, New Mexico, USA, cpoppel@} sandia.gov; PRESTON, L., Sandia National Laboratories, New Mexico, USA lpresto@sandia.gov; ELIASSI, M., Sandia National Laboratories, New Mexico, USA,meliass@sandia.gov

When inverting seismic data for seismic source parameters, it's common to simplify the forward model by using linear approximations. However, by their very nature, linear inversion schemes cannot account for, or predict, the effects arising from nonlinear phenomena of the source. Such phenomena may include processes like rock fragmentation, pore space crushing, and heat generation. These phenomena may give rise to spurious seismic waveforms that are not predicted by our linear models. Therefore, our motivating questions for this study are 1) how well do linear inversion schemes estimate source parameters when the data are known to be affected by nonlinear, nearsource processes, and 2) how well can the linear inversions fit the this data? We perform a series of idealized numerical experiments on synthetic data and illustrate various nonlinear source-related phenomena on the seismic data as well as their effects on the inversion results. To produce the simulated data we numerically couple a nonlinear shock physics code to a linear, finite difference code. The shock physics codes simulates the nonlinear phenomenology associated with a buried chemical explosion, where the resulting seismic wavefield is coupled into the linear finite difference code. We simulate data for several different explosion-source emplacement scenarios: a fully tamped explosion and several explosions that are detonated inside air-filled cavities of various volumes and shapes. In all cases, the simulated sources are the same yield. For our tests, we found that the average $\mathrm{P}$-wave amplitude is inversely proportional the volume of the air-filled cavity, which is the well-known decoupling problem. Also, we observed that hemispherical, air-filled cavities generate shear waves, which simple linear inversions do not predict. Although the data is predicted reasonably well using our linear inversion scheme for all the tests here, the quality of the data fit decreased as the volume and/or geometrical complexity of the air-filled cavities increased.

\section{Near Field Modeling of the Large Surface Explosion Coupling Experiment (LSECE)}

VOROBIEV, O. Y., Lawrence Livermore National Laboratory, California, USA, vorobiev1@llnl.gov; FORD, S. R., Lawrence Livermore National Laboratory, California, USA, sean@llnl.gov; KEEHOON, K., Lawrence Livermore
National Laboratory, California, USA, kim84@llnl.gov; WALTER, W. R. Lawrence Livermore National Laboratory, California, USA, walter5@llnl.gov

The Large Surface Explosion Coupling Experiment (LSECE) was conducted at Nevada National Security Site (NNSS) site in alluvium geology. The goal of the LSECE was to study the seismoacoustic wave generation for two consecutive surface chemical exposions of the same yield. The first chemical explosion was conducted on the surface and the second chemical explosion was conducted at the bottom of the crater created during the first chemical explosion. We have performed hydrocode simulations for both chemical explosions to investigate the role of the coupling factor on seismoacoustic wave generation. Also, we investigate the role of material properties for alluvium in the top layer on the energy partitioning. In these calculations we determine the fraction of the energy released in each chemical explosion which goes into seimic waves (both $\mathrm{P}$-waves, $\mathrm{S}$-waves and the surface waves) as well as the fraction of energy which goes into the shock waves propagating into the air. Results of the simulations can be useful for development better analytical source models for surface explosions.

\section{Recording Tragedy: The Seismic Signal of the Arecibo Radio Telescope Collapse}

VANACORE, E. A., University of Puerto Rico at Mayagüez, Puerto Rico, USA, elizabeth.vanacore@upr.edu; MARTINEZ-CRUZADO, J. A., University of Puerto Rico at Mayagüez, Puerto Rico Strong Motion Program, Puerto Rico, USA, jose.martinez44@upr.edu

It has long been recognized that seismic stations record more than just earthquake signals and that those signals can be interpreted among these nonearthquake signals are mine blasts, nuclear tests, and storms. On December 1, 2020, the radio telescope at the Arecibo observatory tragically collapsed. The observatory however houses more scientific instrumentation including collocated 3 component broadband and strong motion instrumentation run by the Puerto Rico Seismic Network/Puerto Rico Strong Motion Program. The on-site instrument AOPR recorded the collapse in full. Coincidently, the collapse occurred during the end of a surface wave train from a regional earthquake located in the Dominican Republic. This earthquake "noise" while small amplitude relative to the collapse signal was nonetheless filtered out through the application of a high pass filter with a corner frequency of $3 \mathrm{~Hz}$ Seismic signals of the collapse initiated at 11:52:20 with a small amplitude vibrational signal with a marked increase of signal energy at 11:52:27.6 UTC and a further increase at 11:52:34 UTC. This can be interpreted as vibrations from the supporting structures as cables supporting the radio telescope failed in cascade. With the collapse signal two distinct impact signals are present at 11:52:38.4 UTC and 11:52:41.9 UTC. The latter impact signal is dominated by the shear wave which is indicative of a shear wave source. Here this is preliminarily interpreted as the impact of the instrument along the bedrock wall that contained the telescope as it swung into the wall. The first impact signal can be interpreted as either the vertical impact of the hub as it fell or the collapse of towers near the seismic instrument. Seismic signals from the collapse taper out by 11:52:54 UTC. This seismic record has the advantage in that it has accurate timings relative to other devices recording the collapse; combing the seismic signals presented here with video evidence can aid engineers in unravelling the sequence of this tragic event.

\section{Short-Period Surface Wave Propagation in the Bighorn Mountains Region, Wyoming}

KINTNER, I., Los Alamos National Laboratory, New Mexico, USA, jonas. kintner@gmail.com; CLEVELAND, M. K., Los Alamos National Laboratory, New Mexico, USA, mcleveland@lanl.gov; MODRAK, R., Los Alamos National Laboratory, New Mexico, USA, rmodrak@lanl.gov; DUNHAM, A., University of Arizona, Arizona, USA, amd95@email.arizona.edu

Short-period locally-observed Rayleigh waves, Rg, are of particular interest for monitoring small explosive sources. They can be the largest observed seismic phase at local distances $(<300 \mathrm{~km})$ and provide unique sensitivity to the source depth of shallow seismic events. Characterizing the seismic sources that generate Rg requires an understanding of how propagation affects the observed signals at local distances. This study uses observed seismograms to assess changes in surface wave amplitude and radial motion in a region with diverse near-surface geology. We determine how waveform characteristics change depending on source and receiver emplacement conditions and during propagation through basins, foothills, and mountains. Using surface wave eigenfunction analysis and simulations using a $2 \mathrm{D}$ finite spectral element solver, we reproduce many features within the observed waveforms. Our observational and modeling results suggest that deep sedimentary basins in the region allow for the presence of prograde-polarized first higher mode 
and retrograde-polarized fundamental mode surface waves, while the adjacent mountains only support retrograde motion. Each mode provides distinct constraints on Earth structure and source characteristics, potentially enabling targeted inversions in future studies. Our findings provide insight into $\mathrm{Rg}$ propagation through complex Earth structure, improving our understanding of shallow propagation and source effects.

\section{The Effects of 3D Heterogeneity on Regional Moment Tensor Source-Type Discrimination: Application to the Western United States}

CHIANG, A., Lawrence Livermore National Laboratory, California, USA chiang4@llnl.gov; RODGERS, A. J., Lawrence Livermore National Laboratory, California, USA, rodgers7@llnl.gov; KRISCHER, L., Mondaic, Zürich, Switzerland, lion.krischer@mondaic.com; AFANASIEV, M., Mondaic, Zürich Switzerland, michael.afanasiev@mondaic.com; BOEHM, C., Mondaic, Zürich, Switzerland, christian.boehm@mondaic.com; SIMMONS, N., Lawrence Livermore National Laboratory, California, USA, simmons27@llnl. gov; MORENCY, C., Lawrence Livermore National Laboratory, California, USA, morency1@llnl.gov; DOODY, C., University of California, Berkeley, California, USA, claired@berkeley.edu

The use of regional distance long-period, complete waveform data to determine the seismic moment tensor is now a routine and reliable approach in determining the source mechanism of natural and manmade seismicity and is used to identify or discriminate different types of seismic sources. However, seismic source characterization is dependent upon having a well-calibrated Earth model to compute the synthetic Green's functions for the inverse problem. Although 1D Earth models are good approximations for real Earth structure to model regional-distance, long period surface waves, to extend the moment tensor inversion method to lower magnitude events and to greater distances requires higher fidelity Earth models to capture the 3D variations in subsurface material properties. Recent advancements in computational capabilities have greatly improved the performance of 3D-wavefield simulations, thus greatly reducing the computational resources needed to calculate $3 \mathrm{D}$ synthetic Green's functions for full waveform inversion. Using a waveform-based 3D Earth model from adjoint tomography we investigate and quantify the improvements in seismic source characterizations by working with an existing waveform data set of explosions and earthquakes from the western United States. The details of the 3D Earth model can be found in the accompanying presentation by Rodgers et al., 2021. From this data set we calculated a catalog of $1 \mathrm{D}$ moment tensor solutions to establish the baseline performance in order to examine how the regional-scale waveform-based 3D model improves the waveform fits at shorter periods ( $<20$ seconds) and at greater distances $(>300$ $\mathrm{km})$ relative to current methods using $1 \mathrm{D}$ models. To quantitatively compare $1 \mathrm{D}$ and 3D moment tensor solutions we explore the model's effect on solution uncertainty in the moment tensor source-type space.

\section{Fault Displacement Hazard: New Data and Modeling Advances \\ I: Oral Session · Thursday · 22 April · 9:45 Am Pacific \\ II: Oral Session · Friday · 23 April · 9:45 Ам Pacific \\ Session Chairs: Yousef Bozorgnia, University of California, Los Angeles (yousefbozorgnia@ucla.edu); Christine A. Goulet, Southern California Earthquake Center (cgoulet@ usc.edu); Yongfei Wang, Southern California Earthquake Center (yongfeiw@usc.edu)}

\section{A Fault Displacement Model Formulated in Wavenumber Domain}

LAVRENTIADIS, G., University of California, Berkeley, California, USA, glavrent@berkeley.edu; ABRAHAMSON, N., University of California, Berkeley, California, USA, abrahamson@berkeley.edu

A new model for calculating the fault rupture hazard for sites crossing faults is presented in this study. The model is developed for the principal aggregate displacements, that is the sum of principal displacements perpendicular to the strike of the fault from overlapping ruptures, and it is formulated in the wavenumber domain following the Lavrentiadis and Abrahamson (2019) approach. The benefits of this approach are that it avoids the surfacerupture length normalization and that it considers the along strike correlation of displacements. The amplitude spectrum is expressed as a two-corner
Butterworth filter, the phase-derivative distribution is defined as a normal distribution, and the site-specific slip variability as a mixture model of two normal distributions. The global scaling relationships are expressed in terms of the moment magnitude and surface-rupture segment length; the coefficients of the scaling relationships are estimated using the October 2020 version of the FDHI database, which contains 66 events of all styles ranging from M 5.0 to 8.2. One difference to other fault displacement models is that it is developed for individual segments and not for the entire rupture; to perform a PFDHA analysis for future scenarios, prediction equations for the rupture segment length and number of segments are also developed. The current model can replicate well the distribution of the displacement data across all along-strike bins. Comparisons with current fault displacement models and PFDHA calculations are also shown.

\section{A Next-Generation Fault Displacement and Surface Rupture Database}

SARMIENTO, A., University of California, Los Angeles and GeoPentech, Inc., California, USA, sarmiento.alexandrac@gmail.com; BAIZE, S., Institut de Radioprotection et de Sûreté Nucléaire, Fontenay-aux-Roses, France, stephane.baize@irsn.fr; BONCIO, P., Università G. d'Annunzio di Chieti-Pescara, Chieti, Italy, paolo.boncio@unich.it; BOZORGNIA, Y., University of California, Los Angeles, California, USA, yousef.bozorgnia@ ucla.edu; DAWSON, T., California Geological Survey, California, USA, timothy.dawson@conservation.ca.gov; LAVRENTIADIS, G., University of California, Berkeley, California, USA, glavrent@berkeley.edu; MADUGO, D., University of California, Los Angeles, California, USA, madugo@g.ucla.edu; NURMINEN, F., Università G. d'Annunzio di Chieti-Pescara, Chieti, Italy, fiia.nurminen@unich.it; SHEN, A., University of California, Los Angeles and Tongji University, Shanghai, China, adshen1993@gmail.com; THOMPSON, S. C., Lettis Consultants International, Inc., California, USA, thompson@ lettisci.com

The Fault Displacement Hazard Initiative (FDHI) database is a new relational database containing data bearing on ruptures and displacements from historical surface-rupturing earthquakes. The database is being used to develop next-generation fault displacement models for probabilistic fault displacement hazard analysis (PFDHA) through the FDHI program. Currently, the database contains rupture and displacement data for 66 historical earthquakes occurring between 1872 and 2019, ranging from $M 5.0$ to 8.0. The relational database format uses a defined schema to hold different data types in individual tables and relate the data between tables using key fields. This structure improves efficiency, quality control, and expandability, relative to conventional data repository formats which are typically collections of spreadsheets with limited or no cross-referencing. All data are geospatially-controlled with latitude and longitude coordinates. Additionally, all data are also represented in an event-specific coordinate system in which data are transformed to an along-strike dimension in units of meters. Strike, dip, rake, and slip azimuth measurements are included when available. Displacement measurements from new remote sensing techniques, such as optical image correlation, are also included. Typical metadata consists of data sources, dataset originator identifiers and notes, and site geology. Following the conventions in existing fault displacement models, the database also includes interpreted metadata that classify ruptures and measurements as principal or distributed. Finally, for a subset of earthquakes in the database, mapped ruptures prior to the most recent earthquake are included to develop new models correlating mapped faults and observed ruptures. A robust quality assurance and quality control effort has grown through interactions between the database team, modeling teams, and dataset originators, resulting in a high-quality final product.

\section{An Overview of the Fault Displacement Hazard Initiative Research Program}

BOZORGNIA, Y., University of California, Los Angeles, California, USA, yousef.bozorgnia@ucla.edu; ABRAHAMSON, N., University of California, Berkeley, SC Solutions, California, USA, abrahamson@berkeley.edu; ARCOS, M. E., John Wood Group, PLC, Colorado, USA, beth.arcos@woodplc.com; BAIZE, S., Institut de Radioprotection et de Sûreté Nucléaire, Fontenay-auxRoses, France, stephane.baize@irsn.fr; BONCIO, P., Università G. d'Annunzio di Chieti-Pescara, Chieti, Italy, paolo.boncio@unich.it; CHAO, S., National Center for Research on Earthquake Engineering, Taipei, Taiwan, shchao@ narlabs.org.tw; CHEN, R., California Geological Survey, California, USA, rui.chen@conservation.ca.gov; CHIOU, B., Caltrans, California, USA, brian. chiou@dot.ca.gov; DAWSON, T., California Geological Survey, California, USA, timothy.dawson@conservation.ca.gov; DONAHUE, J., University of California, Los Angeles, JL Donahue Engineering, Inc., Oregon, USA, jennifer@jldengineering.com; GOULET, C. A., Southern California Earthquake Center, California, USA, cgoulet@usc.edu; HANSON, K. L., 
KL Hanson Consulting, Minnesota, USA, kathryn@klhansonconsult.com; KOTTKE, A., Pacific Gas and Electric Company, California, USA, arkk@ pge.com; KUEHN, N., University of California, Los Angeles, California, USA, kuehn@ucla.edu; KUO, C., National Central University, Taoyuan City, Taiwan, chkuo@ncu.edu.tw; LAVRENTIADIS, G., University of California, Berkeley, California, USA, glavrent@berkeley.edu; MADUGO, D., University of California, Los Angeles, California, USA, madugo@g.ucla.edu; MAZZONI, S., University of California, Los Angeles, California, USA, smazzoni@ucla.edu; MILLINER, C. W. D., Caltech, California, USA, milliner@caltech.edu; MOSS R. E. S., California Polytechnic State University, California, USA, rmoss@ calpoly.edu; NURMINEN, F., Università G. d’Annunzio di Chieti-Pescara, Chieti, Italy, fiia.nurminen@unich.it; PACE, B., Università G. d’Annunzio di Chieti-Pescara, Chieti, Italy, bruno.pace@unich.it; PETERSEN, M. D., U.S Geological Survey, Colorado, USA, mpetersen@usgs.gov; SARMIENTO, A., University of California, Los Angeles, GeoPentech, Inc., California, USA, sarmiento.alexandrac@gmail.com; SHEN, A., University of California Los Angeles, Tongji University, Shanghai, China, adshen1993@gmail.com THOMAS, K., California Geological Survey, California, USA, kate.thomas@ conservation.ca.gov; THOMPSON, S. C., Lettis Consultants International, Inc., California, USA, thompson@lettisci.com; VISINI, F., Istituto Nazionale di Geofisica e Vulcanologia, L'Aquila, Italy, francesco.visini@ingv.it; WANG Y., Southern California Earthquake Center, California, USA, yongfeiw@usc. edu; YOUNGS, R., John Wood Group, PLC, California, USA, bob.youngs@ woodplc.com

The Fault Displacement Hazard Initiative (FDHI) program was launched in 2018 to develop a modern fault rupture and displacement database, nextgeneration fault displacement models, and engineering guidelines for fault displacement analysis. Quantifying fault rupture hazard is necessary for the seismic design of infrastructure that cannot mitigate the hazard by avoidance, and modern design criteria can require both deterministic and probabilistic displacement analyses. The current models are ergodic and constrained by datasets typically dating to the early 2000s. These datasets are limited in that they contain irregularly-spaced slip measurements for the primary/ principal rupture, sparse data on secondary/distributed faults or shears, and incomplete reporting on measurement uncertainties and geologic structure Consequently, existing fault displacement models are based on relatively few historical earthquakes with incomplete, uneven, or biased measurement sampling, resulting in large uncertainties that impact both deterministic and probabilistic hazard. For the FDHI program, we are developing a comprehensive global database of geospatially-controlled historical surface-rupturing earthquake displacement measurements and rupture maps. The database currently contains 66 events of all styles of faulting, ranging from $M 5.0$ to 8.0 . Five modeling teams are participating in the FDHI program to develop new fault displacement models for principal displacement, distributed displacement, and/or "total" wide-aperture displacement (i.e., discrete slip and continuous inelastic deformation), and one dynamic rupture simulations team is modeling total displacement and fault zone width with distributed displacement. The teams are using the FDHI database, which was developed in collaboration with the modelers. Trial hazard analyses using the displacement models will be performed at representative sites to support guidelines and recommendations for use in engineering applications.

\section{Probability of Distributed Surface Rupturing Occurrence and Displacement Regression for Normal and Reverse Earthquakes}

NURMINEN, F., Università degli Studi “G. d'Annunzio" Chieti, Chieti, Italy, fiia.nurminen@unich.it; VISINI, F., Istituto Nazionale di Geofisica e Vulcanologia, Pisa, Italy, francesco.visini@ingv.it; BAIZE, S., Institut de Radioprotection et de Sûreté Nucléaire, Fontenay-aux-Roses, France, stephane.baize@irsn.fr; BONCIO, P., Università degli Studi "G. d'Annunzio" Chieti, Chieti, Italy, paolo.boncio@unich.it; PACE, B., Università degli Studi "G. d'Annunzio" Chieti, Chieti, Italy, bruno.pace@unich.it; SCOTTI, O., Institut de Radioprotection et de Sûreté Nucléaire, Fontenay-aux-Roses, France, oona.scotti@irsn.fr; VALENTINI, A., Università degli Studi "G. d’Annunzio" Chieti, Chieti, Italy, a.valentini@iaea.org

Probabilistic fault displacement hazard analysis (PFDHA) estimates the probability of occurrence and the expected exceedance of on-fault (principal fault rupturing; PF) and off-fault (distributed rupturing; DR) surface displacement during an earthquake. Here we concentrate on off-fault rupturing on dip-slip earthquakes, and present an original probability model for the occurrence of $\mathrm{DR}$ and for the expected exceedance of displacement distribution based on an approach named "slicing" (an alternative to the "gridding" approach commonly used). The method is developed based on the compilation and reappraisal of surface ruptures from 32 historical crustal dip-slip earthquakes, with magnitudes ranging from $\mathrm{M}_{\mathrm{w}} 4.9$ to 7.9 . A ranking scheme is applied to distinguish PF (rank 1) from simple DR (rank 2) and triggered faulting (rank 3). Thus modellers can use prediction equations based on or excluding ruptures strongly related to local structural setting depending on the site of concern. In the case of a structural setting at a site where large-scale bending (rank 21, 22) and pre-existing faults (rank 1.5, 3) is considered irrelevant, modelling can be performed considering only the unpredictable DR (rank 2). To minimize bias due to the incomplete nature of the database, we introduce the "slicing" approach, which considers that the probability of having a surface rupture within slices parallel to the PF is homogeneous along the strike of each slice. "Slicing" probabilities, computed as a function of magnitude of the earthquake and distance from the PF, are then combined with Monte Carlo simulations that model the dependence of the probability of occurrence of rupture and exceedance of displacement with the dimensions and position of the site of interest with respect to the PF. Finally, both probabilities are combined with existing predictive equations of exceedance of displacement on the PF to calculate fault-displacement hazard curves for sites of interest.

\section{Updating Reverse Fault PFDHA Models and Distributions}

MOSS, R. E. S., California Polytechnic State University, California, USA rmoss@calpoly.edu; KUO, C., Department of Earth Sciences, National Central University/E-DREaM/NCREE, Taoyuan, Taiwan, chkuo@ncu.edu. tw; THOMPSON, S. C., Lettis Consultants International, Inc., California, USA, thompson@lettisci.com; CHAO, S., National Center for Research on Earthquake Engineering, Taipei, Taiwan, shchao@narlabs.org.tw; YOUNESI, K., Science and Research Branch of Azad University, Tehran, Iran, Islamic Republic Of, k.younesi@gmail.com

The FDHI (fault displacement hazard initiative) working group has assembled an improved and expanded database of surface fault rupture measurements. This database has enabled our team to reevaluate the prior reverse fault PFDHA (probabilistic fault displacement hazard analysis) models and distributions and update as needed. The FDHI database increases the data that inform the statistics on the exceedance probability of principle displacement normalized by average $(\mathrm{D} / \mathrm{AD})$ and maximum displacement (D/MD). We find that the gamma distribution is still the best fit, but the increase in data has provided a more robust estimate of the distribution moments. We also confirm that on average there is asymmetry in the displacement along the length of a fault rupture $(\mathrm{x} / \mathrm{L})$ with the majority occurring near the center $(\mathrm{x} / \mathrm{L} \sim 0.5)$ and tapering towards the ends of the rupture $(\mathrm{x} / \mathrm{L} \sim 0)$. The new statistics are used to update the prior statistics using Bayesian conjugate priors. Other distributions for performing PFDHA for reverse faults, such as the probability of surface rupture given earthquake magnitude (SR $\mid \mathrm{M})$, probability of exceedance of principle displacement given magnitude and surface rupture $\left(D>D_{0} \mid\right.$ $\mathrm{M}, \mathrm{SR}$ ), probability of distributed displacement at a site given magnitude, surface rupture and closest distance from the principal rupture $(\mathrm{d} \neq 0 \mid \mathrm{M}, \mathrm{SR}, \mathrm{R})$, and probability of exceedance of distributed displacement given magnitude, surface rupture and distance from the principal rupture $\left(d>d_{0} \mid M, S R, R\right)$, are informed by other databases along with the FDHI database. PFDHA calculations for reverse mechanisms, more so than for normal and strike-slip mechanisms, are sensitive to the probability of surface rupture given magnitude (SR $\mid \mathrm{M})$. We are addressing this by using a statistical approach as well as a geometric approach to provide more than one method for assessing the hazard and quantifying the associated epistemic uncertainty.

\section{Comparison of Surface Fault Displacement Interpretations From Field and Aerial Data for the M 6.4 and 7.1 2019 Ridgecrest Earthquake Ruptures}

GOULET, C. A., Southern California Earthquake Center, California, USA, cgoulet@usc.edu; WANG, Y., University of Southern California, California, USA, yongfeiw@usc.edu; NWEKE, C. C., University of Southern California, California, USA, chukwueb@usc.edu; TANG, B., University of California, Los Angeles, California, USA, bursontung97@g.ucla.edu; WANG, P., University of California, Los Angeles, California, USA, wltcwpf@ucla.edu; HUDSON, K. S., University of California, Los Angeles, California, USA, khud27@g.ucla. edu; AHDI, S. K., University of California, Los Angeles, California, USA sahdi@ucla.edu; MENG, X., University of Southern California, California, USA, xiaofenm@usc.edu; HUDSON, M. B., Turner Construction Company, California, USA, mbhudson@tcco.com; DONNELLAN, A., NASA Jet Propulsion Laboratory, California, USA, andrea.donnellan@jpl.nasa.gov LYZENGA, G., Jet Propulsion Laboratory, California, USA, lyzenga@g.hmc edu; BRANDENBERG, S. J., University of California, Los Angeles, California, USA, sibrandenberg@g.ucla.edu; STEWART, J. P., University of California, Los Angeles, California, USA, jstewart@seas.ucla.edu; GALLIEN, T., University of California, Los Angeles, California, USA, tgallien@seas.ucla.edu; WINTERS M. A., University of California, Los Angeles, California, USA, mariawinters@ 
ucla.edu; DELISLE, M., University of California, Los Angeles, California, USA, mpdelisle@ucla.edu; LUCEY, J., University of California, Los Angeles, California, USA, Jlucey@ucla.edu; KIM, Y., University of California, Los Angeles, California, USA, yarkim@ucla.edu

Surface fault rupture presents a significant potential hazard for structures and lifelines. Predictive fault displacement (FD) models are poorly constrained due to limited numbers of detailed observations. FD data has been traditionally difficult to collect in a comprehensive way because 1) surface displacement evidence is highly perishable and 2) secondary off-fault rupture features, which occur over relatively large areas and affect a large number of sites, are seldom systematically characterized by reconnaissance teams. Documentation of surface rupture features can be achieved using traditional field mapping, but aerial technologies developed in recent years quantify surface rupture features more efficiently and more comprehensively, given the limited human resources available immediately post-event. Small Uninhabited Aerial Systems (sUAS) provide rapid and low-cost detection of surface ruptures and allow imaging of regions that may be difficult to access by roads or on foot. Airborne light detection and ranging (lidar) can also capture high-resolution surface ruptures in a large area, but is more costly than sUAS techniques. The accuracy of sUAS and lidar methods, as well as the human effort level required, are assessed for their resolution and suitability for hazard modeling using the largest two events from the 2019 Ridgecrest Earthquake Sequence. As part of the reconnaissance work, we defined a study area and coordinated with multiple groups for ground surface observations, sUAS, and lidar surveys. The comparison of interpreted results allows for a validation of the data collected across various techniques and provides constraints for the data that can only be accessed via aerial imaging. In this study, we present an interpretation of results from these techniques, provide an assessment of their ability to capture FDs, and summarize recommendations for future data collection following earthquakes.

\section{Geomechanical Modeling of Ground Surface Deformation Associated With Thrust and Reverse Fault Earthquakes} CHIAMA, K., Harvard University, Massachusetts, USA, kchiama@g.harvard. edu; CHAUVIN, B., Mira Geoscience Ltd., Westmount, Canada, benjaminc@ mirageoscience.com; PLESCH, A., Harvard University, Massachusetts, USA, plesch@fas.harvard.edu; SHAW, J. H., Harvard University, Massachusetts, USA, shaw@eps.harvard.edu

We seek to improve our physical understanding of the factors that control the style, distribution, and intensity of ground surface ruptures on thrust and reverse faults during large earthquakes. Our study combines insights from the patterns of coseismic ground surface rupture from historic earthquakes and paleoseismic studies to inform the development of a suite of geomechanical models using the discrete element method (DEM). We explore how various parameters, such as fault geometry and sediment/soil properties, control ground deformation patterns including scarp dip, width, and patterns of secondary folding and fracturing. The DEM method is well suited to this investigation as it can effectively model the geologic processes of faulting and folding at depth, as well as the granular mechanics of soil and sediment deformation in the shallow subsurface. The method can also directly represent surface and subsurface infrastructure in rupture models, to explore how various patterns of ground surface deformation may impact the built environment. We present an initial suite of models to illustrate characteristic patterns of ground surface deformation and show how these vary as a function of sediment/soil properties, fault dip, and other factors. Our initial results show that localized fault scarps are most prominent in cases with homogenous sediment strength and steeply dipping faults, whereas broader fold scraps are more prominent with vertical gradients in sediment strength and shallowly dipping faults.

\section{Preliminary Mapping of Surface Fault Rupture and Ground- Deformation Features of the 2019 M6.4 and M7.1 Ridgecrest Earthquake Sequence From Post-Earthquake Lidar Datasets}

ROSA, C. M., California Geological Survey, California, USA, carla.rosa@ conservation.ca.gov; DAWSON, T., California Geological Survey, California, USA, timothy.dawson@conservation.ca.gov

We present preliminary mapping of surface ruptures and ground-deformation features associated with the 2019 Ridgecrest Earthquake Sequence. The mapping utilizes high-resolution (up to 80 pulses per square meter) airborne lidar flown post-earthquake by the National Center for Airborne Laser Mapping (Hudnut et al., 2020). The $\mathrm{M}_{\mathrm{w}} 6.4$ and $\mathrm{M}_{\mathrm{w}} 7.1$ earthquakes produced rupture and ground deformation zones approximately $18 \mathrm{~km}$ and $50 \mathrm{~km}$ in length, respectively, with widespread deformation occurring off the main fault strands. Our goal is to produce a comprehensive, spatially accurate dataset depicting surface ruptures associated with the Salt Wells Valley and Paxton Ranch Fault Zones. We used seamless lidar-derived hillshades, illuminated at 45- and 315-degrees and supplemented with a multi-directional hillshade as the base imagery. Mapping was done at a consistent (1:500 - 1:1000) scale, the largest scale at which imagery resolution is not degraded. Use of this large scale increases our confidence that we have only mapped features that are related to ground deformation from the earthquake. The surface rupture was mapped to highlight the width of deformation zones and to characterize the rupture's expression through varying terrain, such as along pre-existing fault scarps, hillslopes, fan surfaces, and relatively flat playa surfaces. Our mapping shows that the lidar can reliably resolve ruptures with tens of centimeters and more of relative vertical displacement. Areas with known surface rupture, mapped either in the field or on aerial imagery, but with little relative vertical displacement, are less likely to be well-resolved on the lidar. Thus, characterizing zones of deformation, important for the assessment of fault displacement hazard, will likely require a paired approach using both lidar and highresolution aerial imagery. We plan to produce a comprehensive comparison of what ground deformation features can be resolved using post-earthquake orthoimagery vs. lidar.

\section{The Displacement Approach to Probabilistic Fault Displacement Hazard Analysis; Issues and an Example}

THOMPSON, S. C., Lettis Consultants International, Inc., California, USA, thompson@lettisci.com; ZANDIEH, A., Lettis Consultants International, Inc., California, USA, zandieh@lettisci.com; ABRAHAMSON, N., University of California, Berkeley, California, USA, abrahamson@berkeley.edu; LEWANDOWSKI, N. S., Lettis Consultants International, Inc., California, USA, lewandowski@lettisci.com; BALDWIN, J., Lettis Consultants International, Inc., California, USA, baldwin@lettisci.com; GRAY, B. T., Lettis Consultants International, Inc., California, USA, bgray@lettisci.com; WELDON, R. J., University of Oregon, Oregon, USA, ray@uoregon.edu; LETTIS, W. R., Lettis Consultants International, Inc., California, USA, lettis@ lettisci.com

Most publications and current application of probabilistic fault displacement hazard analysis (PFDHA) are focused on the earthquake approach, whereby hazard at a site is calculated from a "traditional" fault source model (that produces the magnitude-recurrence-location distribution of earthquakes on a fault source) and one or more fault displacement models (consisting of conditional probabilities of rupture at a site and displacement exceedance equations). This is appropriate when studies lack detailed site-specific information on the timing and amount of past displacements. For cases where paleoseismic information is available, the displacement approach to PFDHA is recommended. The displacement approach relies on geologic information to estimate mean slip per event and recurrence rate directly, as opposed to estimating these parameters from an arbitrary or general fault source model. By incorporating site-specific paleoseismic data, the displacement approach has smaller aleatory variability compared to the earthquake approach leading to steeper hazard curves that result in more stable design displacement values. However, proper implementation of the displacement approach requires a clear methodology for capturing model epistemic uncertainty given the oftenlimited number of interpreted paleoseismic events available and the uncertainties in those interpreted events. We build on a displacement approach developed by Abrahamson that accounts for a small number of past displacement estimates using a maximum-likelihood approach that adjusts the mean site-specific displacement based on the number of observations and an average displacement "prior" calculated using earthquake approach fault displacement models. We show an example of its implementation that includes logic trees to capture uncertainties in interpretations of paleoseismic displacementper-event and event timing.

\section{Validate Simulated Fault Displacements from Dynamic Rupture Against the Observed in the 1992 Landers Earthquake}

WANG, Y., University of Southern California, California, USA, yongfeiw@ usc.edu; GOULET, C. A., University of Southern California, California, USA, cgoulet@usc.edu

Coseismic fault displacements in large earthquakes have caused significant damage to structures and lifelines located on or near fault lines. Fault displacements represent an important seismic hazard, especially for distributed infrastructure systems that may cross faults in multiple locations. Predictive fault displacement models are sparse and poorly constrained partly due to the scarcity of detailed fault displacement observations. Advancements in physics-based dynamic rupture simulation methods make them an attractive 
approach to address this important problem. Dynamic ruptures construct the earthquake rupture evolution and seismic wave propagation under plausible physical conditions. They can therefore be used to quantify fault displacement through physical causative parameters. When used with appropriate constitutive models to characterize the bulk medium around the fault, dynamic rupture models can also capture off-fault inelastic distributed fault displacements In this project, we first validate a suite of models against well-documented case histories, and we then extend the simulations to predict displacement for scenarios and events we have not yet experienced. Our initial validation is based on the 1992 Landers M7.3 earthquake for which we compare simulations to on- and off-fault displacement data. We also perform a validation of ground motions against recordings from the event, to ensure that all physics important to modeling have been properly parameterized and that the results are defensible. In the predictive step, we aim to provide a range of expected displacements that capture several aspects of modeling uncertainties. For the Landers scenario, we developed an ensemble of spontaneous dynamic rupture models with varying imposed stresses and geometrical fault roughness profiles, resulting in a suite of 48 simulation datasets. We present the validation results and provide insight on the uncertainty of resulting ruptures including their magnitude, length, propagation velocity and displacement distributions.

\section{Fault Displacement Hazard: New Data and Modeling}

\section{Advances}

Poster Session · Thursday · 22 April · 3:45 PM Pacific

Session Chairs: Yousef Bozorgnia, University of California,

Los Angeles (yousefbozorgnia@ucla.edu); Christine A.

Goulet, Southern California Earthquake Center (cgoulet@

usc.edu); Yongfei Wang, Southern California Earthquake

Center (yongfeiw@usc.edu)

\section{A Probabilistic Fault Displacement Analysis (PFDHA) Hazard Model for Rail Transportation Systems}

YOUNGS, R., Wood Environment and Infrastructure Solutions, Inc. California, USA, bob.youngs@woodplc.com; ARCOS, M. E., Wood Environment and Infrastructure Solutions, Inc, California, USA, beth arcos@woodplc.com; COPPERSMITH, K. J., Coppersmith Consulting, Inc., California, USA, kevin@coppersmithconsulting.com; COPPERSMITH, R., Coppersmith Consulting, Inc, California, USA, ryan@coppersmithconsulting. com; HANSON, K. L., KL Hanson Consulting, Minnesota, USA, kathryn@ klhansonconsult.com

We present a PFDHA model for performing assessments at rail alignment crossings, where displacements are needed for both the principal fault trace and total tectonic displacement across the fault zone based on the formulation of Youngs et al. (2003). Past assessments of the components of PFDHA have been primarily ergodic in which data from multiple earthquakes have been combined to develop the needed probability distributions that are treated as aleatory variability in the PFDHA, leading to broad distributions for the displacement that may occur at a single point on a fault, which are not consistent with the geologic observations of Hecker et al (2013) showing a COV of about 0.5 . Therefore, we partition the overall uncertainty in PFDHA into aleatory and epistemic components, with an aleatory COV for displacement consistent with the Hecker et al (2013) assessments.

An initial database consisting of reported fault displacements along the length of mapped ruptures was developed from published sources for 25 strike slip and 15 reverse earthquakes. The data consists of displacements at mapped locations and components of motion. These distributions were used to assess average displacement for each rupture and to update empirical models of average displacement versus magnitude. Normalizing the displacements for each rupture by the average displacement effectively removed event-to-event correlations in $\mathrm{D} /$ Daverage. The model treats the distribution of $\mathrm{D} /$ Daverage as aleatory and the distribution of Daverage given the earthquake as epistemic. The distributions for the variability in D/Daverage along the length of a rupture were assessed accounting for spatial correlation in observations using an exponential semi-variance model.

We summarize the initial model development and example PFDHA results, as well as illustrating the effect of alternative partitioning between aleatory variability and epistemic uncertainty on hazard assessments.
Teaching Active Fault Mapping and Applications Towards Developing New Fault Displacement Hazard Datasets KOEHLER, R. D., University of Nevada, Reno, Nevada, USA, rkoehler@unr edu; SCOTT, C. P., Arizona State University, Arizona, USA, cpscott1@asu. edu; ARROWSMITH, R., Arizona State University, Arizona, USA, ramon. arrowsmith@asu.edu; SARMIENTO, A., University of California, Los Angeles, California, USA, sarmiento.alexandrac@gmail.com; DAWSON, T., California Geological Survey, California, USA, timothy.dawson@conservation.ca.gov; THOMPSON, S. C., Lettis Consultants International, Inc., California, USA thompson@lettisci.com

A reasonable assumption in fault displacement hazard assessment is that future coseismic surface-fault ruptures will coincide with fault traces that can be mapped from geologic and geomorphic data. The extent to which this is true on a site-specific basis, however, is a current gap in probabilistic fault displacement hazard (PFDHA) models. Whereas some current PFDHA models have terms for aleatory variability in surface-fault rupture location, a goal for the next-generation PFDHA models is to develop statistical models for how the conditional probability of rupture may depend on the location, distribution, and quality of fault traces identified through or near a site. To develop new datasets applicable to these rupture probability models, we developed a course to teach fault zone mapping techniques to undergraduate and graduate students. The jointly offered course (ASU and UNR) focused on documenting tectonic features along fault zones. Instruction included demonstration of the geomorphic expression of faults in a range of environments. Students produced digital maps of Quaternary geology and fault traces using imagery and topographic datasets that predated historic ruptures. The pre-rupture mapping was performed for the 1983 Borah Peak, 1966 and 2004 Parkfield, 2010 El Mayor-Cucapah, 2011 Fukushima, 2013 Balochistan, 2014 Napa, 2016 Kaikoura, 2016 Kumamoto, and 2020 Monte Cristo events. The student maps, which include qualitative uncertainty in fault trace line work, represent a relatively unbiased indication of mappable fault trace locations and provide new comparison datasets to evaluate the uncertainties and relationships between pre-rupture fault mapping and post-earthquake surface rupture distribution. Our intention for these maps is to inform next-generation PFDHA models that may explicitly account for pre-rupture fault trace information and lead to improved site-specific rupture probability and fault displacement hazard characterization.

\section{Fiber-Optic Seismology}

I: Oral Session · Friday · 23 April · 9:45 Am Pacific

II: Oral Session · Friday · 23 April · 2:00 PM Pacific

Session Chairs: Patrick Paitz, ETH Zürich (patrick.paitz@

erdw.ethz.ch); Verónica Rodríguez Tribaldos, Lawrence

Berkeley National Laboratory (vrodrigueztribaldos@lbl.gov);

Ariel Lellouch, Stanford University (ariellel@stanford.edu)

\section{Antarctic Icequakes Shed Light on the Applicability of DAS} for Microseismic Monitoring

HUDSON, T. S., University of Oxford, Oxford, United Kingdom, thomas. hudson@earth.ox.ac.uk; BUTCHER, A. C., University of Bristol, Bristol, United Kingdom, antony.butcher@bristol.ac.uk; BAIRD, A. F., NORSAR, Kjeller, Norway, alan.baird@norsar.no; KENDALL, J., University of Oxford, Oxford, United Kingdom, mike.kendall@stx.ox.ac.uk; KUFNER, S., British Antarctic Survey, Cambridge, United Kingdom, sofner@bas.ac.uk; BRISBOURNE, A. M., British Antarctic Survey, Cambridge, United Kingdom, aleisb@bas.ac.uk; SMITH, A. M., British Antarctic Survey, Cambridge, United Kingdom, amsm@bas.ac.uk; STORK, A. L., Silixa, Ltd., Elstree, United Kingdom, anna.stork@silixa.com; CHALARI, A., Silixa, Ltd., Elstree, United Kingdom, athena.chalari@silixa.com; CLARKE, A., Silixa, Ltd., Elstree, United Kingdom, andy.clarke@silixa.com

Microseismic monitoring has applications in a wide range of environmental and industrial settings. Although contexts vary, the instrumentation and data analysis techniques are generally universally applicable. This study shows how Distributed Acoustic Sensing (DAS) methods used to study basal icequakes (earthquakes in ice) can be applied to microseismic monitoring for Carbon Capture and Storage (CCS) projects under the ACT DigiMon project.

For the first time in the Antarctic, we explore the use of DAS as a new approach to study icequakes. These icequakes offer insight into how the ice slides over the glacier bed and can be used to image the internal ice column structure. A fibre-optic cable was deployed on the ice surface at Rutford Ice 
Stream in a linear and triangular configuration, with data recorded using a $1 \mathrm{kHz}$ sampling rate with a $10 \mathrm{~m}$ gauge length. We compare the performance of DAS with a conventional geophone network for: microseismic detection and location; source mechanism inversion; and seismic anisotropy. For microseismic detection, we compare migration and radon transform methods. Radon transform methods exploit the spatial resolution of DAS and provide a robust method to identify arrivals. This approach significantly increases the number of events detected by the DAS network, compared to standard migration methods. Compared to the geophone network, the linear DAS array has a much higher detection rate while fewer events are identified with the triangular array due to its smaller spatial extent. Full-waveform source mechanism inversions using DAS successfully constrain the horizontal stick-slip nature of the icequakes. Furthermore, we demonstrate that the 2D DAS array can successfully measure the seismic anisotropy of the ice fabric.

The methodology and implications of this work are relevant for employing DAS for microseismic detection, source and path analysis elsewhere, such as at CCS projects.

\section{Capturing Glacier-Wide Cryoseismicity With Distributed Acoustic Sensing}

WALTER, F., ETH Zürich, Zürich, Switzerland, walter@vaw.baug.ethz.ch; PAITZ, P., ETH Zürich, Zürich, Switzerland, patrick.paitz@erdw.ethz.ch; FICHTNER, A., ETH Zürich, Zürich, Switzerland, andreas.fichtner@erdw. ethz.ch; EDME, P., ETH Zürich, Zürich, Switzerland, pascal.edme@erdw. ethz.ch; GAJEK, W., ETH Zürich, Zürich, Switzerland, gajek@vaw.baug. ethz.ch; LIPOVSKY, B. P., University of Washington, Washington, USA, BradLipovsky@gmail.com; MARTIN, E., Virginia Tech, Virginia, USA, eileenrmartin@vt.edu

Over the past 1-2 decades, seismological measurements have provided new and unique insights into glacier and ice sheet dynamics. At the same time, sensor deployment is typically limited as it requires installations in harsh environments, which are difficult to access. Distributed Acoustic Sensing (DAS) may overcome this limitation of sensor coverage in the cryosphere.

First DAS applications on the Greenland and Antarctic ice sheets and on Alpine glacier ice have highlighted the technique's superiority. Signals of natural and man-made seismic sources can be resolved with an unrivaled level of detail offering new perspectives for studies of ice structure, basal boundary conditions and source locations. However, previous studies employed only relatively small network scales with a point-like borehole deployment or $<1$ $\mathrm{km}$ cable aperture at the ice surface.

Here we present a DAS installation, which aims to cover the majority of an Alpine glacier catchment: For one month in summer 2020 we deployed a 9 $\mathrm{km}$ long fiber optic cable on Rhonegletscher, Switzerland, to gather continuous DAS data. The cable followed the glacier's central flow line starting in the lowest kilometer of the ablation zone and extending well into the accumulation area. Even for a relatively small mountain glacier such as Rhonegletscher, cable deployment was a considerable logistical challenge. Manual cable transport via sled required installation of separate cable sections, which had to be spliced together in the field. Given high-melt conditions, the cable was simply placed on the glacier's snow and ice surface. Nevertheless, the DAS records yielded clear signals of englacial seismic sources, which can be compared to co-located geophone and seismometer records. Moreover, the fiber optic setup is sensitive to low frequencies $(<0.1 \mathrm{~Hz})$, which are difficult to capture with conventional on-ice stations in high-melt glacial regions. We discuss these signals and their possible sources together with environmental noise (wind, meltwater flow, precipitation), typical for high Alpine terrain.

\section{Combining Distributed Acoustic Sensing and Beamforming in a Volcanic Environment on Mount Meager, British Columbia}

KLAASEN, S. A., ETH Zürich, Zürich, Switzerland, sara.klaasen@erdw.ethz. ch; PAITZ, P., ETH Zürich, Zürich, Switzerland, patrick.paitz@erdw.ethz.ch; DETTMER, J., University of Calgary, Calgary, Canada, jan.dettmer@ucalgary. ca; FICHTNER, A., ETH Zürich, Zürich, Switzerland, andreas.fichtner@erdw. ethz.ch

We present one of the first applications of Distributed Acoustic Sensing (DAS) in a volcanic environment. There are two main goals: (1) To search for active volcanic signals of Mount Meager to study the volcanic complex, and (2) to study the feasibility of DAS as a tool in a remote and extreme environment.

The Mount Meager massif is an active volcanic complex in British Columbia that is estimated to have the largest geothermal potential in Canada and caused its largest recorded landslide in 2010. Climate change is thinning the glacier on top of Mount Meager, which may further destabilize the complex. We installed $3 \mathrm{~km}$ of fiber-optic cable at $2000 \mathrm{~m}$ elevation that crosses an alpine ridge and traverses the uppermost part of a glacier, yielding continuous measurements from 19 September to 17 October 2019.

We identify $\sim 30$ low-frequency $(0.01-1 \mathrm{~Hz})$ and 3000 high-frequency $(5-45 \mathrm{~Hz})$ events. The low-frequency events are not correlated with microseismic ocean or atmospheric noise sources. The frequency-power distribution of the high-frequency events indicate a natural origin, and beamforming on these events reveals distinct event clusters, predominantly in the direction of the main peaks of the complex. We hypothesize that the low-frequency events are volcanic tremor and that clusters of high-frequency events are also caused by volcanic activity.

The large data quantities of DAS enable most of our analysis, and this quantity outweighs the limitations due to the lower quality of individual channels and the limited aperture of the array when compared to conventional seismic arrays. We conclude that DAS holds promise to study volcanoes and warrants further developments in volcano seismology.

\section{Seismicity Monitoring With Long-Range DAS Systems}

KARRENBACH, M., OptaSense, California, USA, martinkarrenbach@att.net; YARTSEV, V., OptaSense, California, USA, victor.yartsev@optasense.com; COLE, S., OptaSense, California, USA, steve.cole@optasense.com; HOOPER, R., OptaSense Ltd, Portishead, United Kingdom, richard.hooper@optasense. com

Distributed Acoustic Sensing (DAS) interrogator units can utilize either existing or temporarily deployed fiber-optic cables to sense ground motion or subsurface strain. A multitude of recent investigations make use of these telecom-grade fiber optic cables that are widely installed for a variety of purposes including data communication and monitoring of powerlines, pipelines, and other permanent infrastructure. These cables can be interrogated to obtain information about the surrounding or the subsurface medium. Deploying DAS systems on such cables saves cost, increases efficiency and allows us to easily produce Large-N sensor networks. The large number of fiber-based sensors (thousands to many tens of thousands on a single fiber) lends itself to multi-channel processing techniques and machine learning algorithms. Over the last several years, we have seen a steady increase in the extent of the sensing arrays that one DAS interrogation system can support. For example, a current system is capable of supporting a sensing array of $100 \mathrm{~km}$ with a channel spacing of $10 \mathrm{~m}$. It is important to note that this is achieved without the need to install additional amplification devices along the sensing fiber, thus simplifying rapid and temporary deployments tremendously. We show several data examples of small local or regional earthquakes detected and recorded on a $100 \mathrm{~km}$ sensing array.

\section{Vibrator-Source Exploration Seismics in Urban Environments Using DAS, A Feasibility Study in Potsdam, Germany}

WOLLIN, C., GFZ German Research Centre for Geosciences, Potsdam, Germany, wollin@gfz-potsdam.de; LÜTH, S., GFZ German Research Centre for Geosciences, Potsdam, Germany, slueth@gfz-potsdam.de; LIPUS, M. P., GFZ German Research Centre for Geosciences, Potsdam, Germany, mlipus@ gfz-potsdam.de; CUNOW, C., GFZ German Research Centre for Geosciences, Potsdam, Germany, cunow@gfz-potsdam.de; SIEBERT, A., GFZ German Research Centre for Geosciences, Potsdam, Germany, ariane.siebert@gfzpotsdam.de; JOUSSET, P., GFZ German Research Centre for Geosciences, Potsdam, Germany, pjousset@gfz-potsdam.de; FUCHS, S., GFZ German Research Centre for Geosciences, Potsdam, Germany, fuchs@gfz-potsdam. de; KRAWCZYK, C. M., GFZ German Research Centre for Geosciences, Potsdam, Germany, lotte@gfz-potsdam.de

In the frame of its de-carbonization strategy, the city of Potsdam, Germany, seeks the utilization of its geothermal potential. Consequently, the Stadtwerke Potsdam conducted an urban seismic exploration campaign in preparation for the development of a deep geothermal project for district heating. The seismic campaign took place in December 2020 in the city center of Potsdam and we complemented the contractor-performed vibroseismics along three profiles by distributed acoustic sensing (DAS). In close cooperation with the municipal utilities, we interrogated a $21 \mathrm{~km}$-long dark telecommunication fiber whose trajectory followed the seismic lines as close as possible. This was accompanied by a network of 15 three-component geophones for further control and research.

In this contribution we present the data set, the approach for geo-referencing the fiber, and first results regarding DAS recording capabilities of vibroseismic signals in an urban environment. We address questions regarding the accuracy of localization of sensing points along dark-fiber, their sensitivity and their coupling to the ground as well as the range of active stimulation. DAS has the potential to tap the seismic wavefield over the dense and 
spacious extent of telecommunication networks to close gaps in the explored underground there. Following this paradigm, we strive to further shed light on the possibilities of its employment for urban exploration, which promises a sought for low-footprint supplement or alternative to classical point-like seismological interrogation techniques.

\section{A Fast Aftershock Monitoring Network With DAS and Internet Fiber-Optic Cable in Tangshan, China}

ZENG, X., Innovation Academy for Precision Measurement Science and Technology, CAS, Wuhan, China, zengxf@whigg.ac.cn; BAO, F., State Kay Laboratory of Geodesy and Earth's Dynamics, Academy of Precision Measurement Science and Technology, Chinese Academy of Sciences, Wuhan, China, baofeng@whigg.ac.cn; LIN, R., State Kay Laboratory of Geodesy and Earth's Dynamics, Academy of Precision Measurement Science and Technology, Chinese Academy of Sciences, Wuhan, China, robin_lin@163. com; WANG, S., State Kay Laboratory of Geodesy and Earth's Dynamics, Academy of Precision Measurement Science and Technology, Chinese Academy of Sciences, Wuhan, China, wangshuofan@whigg.ac.cn; LV, H., State Kay Laboratory of Geodesy and Earth's Dynamics, Academy of Precision Measurement Science and Technology, Chinese Academy of Sciences, Wuhan, China, lh17@mail.ustc.edu.cn; SONG, Z., State Kay Laboratory of Geodesy and Earth's Dynamics, Academy of Precision Measurement Science and Technology, Chinese Academy of Sciences, Wuhan, China, zhhsong6@ mail.ustc.edu.cn

The aftershock provides valuable information on rupture zone, stress change, triggering etc. Since the aftershock number rapidly decays after the mainshock according to the Omori-Utsu law, it is better to deploy monitoring networks as soon as possible. Distributed Acoustic Sensing can turn the internet fiberoptic cable into dense seismic network with small cost in a short time. A 7.6 $\mathrm{km}$ long DAS array was deployed after the 12 July, 2020 Tangshan Ms5.1 earthquake, which is the strongest earthquake in Beijing surrounding region since 2006. During the seven-days deployment, most aftershocks in CENC catalog were recorded by the DAS array while dozens new events were detected by eye-scan. The high-quality waveform makes it possible to pick arrivals of $\mathrm{P}$ and $\mathrm{S}$ waves, which were used to locate several aftershocks. Our study also suggests that the small aperture of DAS array introduce large location uncertainty. Besides event detection and location, the ground-motion duration is also be obtained in real time. However, the various coupling of fiber-optic cable strongly dominates amplitude that leads difficulties in magnitude estimation. In summary, combining DAS technology and existing internet fiberoptic cable make it possible to deploy dense seismic monitoring network in short time and provides useful information for event detection, location, and strong-motion studies.

\section{Moment Magnitudes (Mw) of Smaller Events Using Distributed Acoustic Sensing}

GÖK, R., Lawrence Livermore National Laboratory, California, USA, gok1@ llnl.gov; MELLORS, R., University of California, San Diego, California, USA, rmellors@ucsd.edu; BARNO, J., Lawrence Livermore National Laboratory, California, USA, barno1@llnl.gov

During a geothermal monitoring experiment at Brady Hot Springs, Nevada both Quantitative Distributed Acoustic Sensing (DAS) and nodal geophones were deployed on the surface for two weeks in March 2016. DAS array consisted of $\sim 8 \mathrm{~km}$ of fiber-optic cable deployed in zig-zag pattern in shallow trench and the conventional seismometer array was composed of shallowly buried three-component geophones (Fairfield Nodal systems). Both DAS and geophones recorded continuously for fifteen days during which two moderate-sized earthquakes with a local magnitude of $\mathrm{Mw}=4.3(3 / 21 / 16)$ and $\mathrm{Mw}=4.1(3 / 22 / 16)$ were recorded. The epicenters of both events were at similar epicentral distances $(129 \mathrm{~km}$ and $156 \mathrm{~km})$ and backazimuth $\left(172^{\circ}\right.$ and $159^{\circ}$ ) with respect to Brady Hot Springs. These earthquakes provided a unique opportunity to investigate coda amplitude response similarity of envelopes between DAS and geophone and potential to estimate Mw using coda waves. Several DAS line segments with co-located geophone stations were used to compare the amplitude variation using narrow-band S-wave coda envelopes. Initial calculations of DAS coda envelope decay at each point showed remarkable similarity with geophone coda envelopes at all frequencies. Final source spectra and Mw matched source spectra from regional stations without any major scatter. As coda waves arrive from a range of azimuths, the azimuthal sensitivity of DAS is somewhat ameliorated. We will also show the recent software toolkit for straightforward and faster processing using the necessary large datasets which would provide an easier source parameters and subsurface imaging.

\section{Multiple-Scale Seismic Imaging Based on Distributed Acoustic Sensing and Ambient Noise Interferometry} CHENG, F., Rice University, Texas, USA, marscfeng@rice.edu; RODRÍGUEZ TRIBALDOS, V., Lawrence Berkeley National Laboratory, California, USA vrodrigueztribaldos@lbl.gov; CHI, B., Rice University, Texas, USA, benxin. chi@rice.edu; NAYAK, A., Lawrence Berkeley National Laboratory, California USA, anayak7@lbl.gov; ROBERTSON, M., Lawrence Berkeley National Laboratory, California, USA, mcrobertson@lbl.gov; WOOD, T., Lawrence Berkeley National Laboratory, California, USA, tjwood@lbl.gov; MELLORS, R., University of California San Diego, California, USA, rmellors@ucsd edu; DOBSON, P., Lawrence Berkeley National Laboratory, California, USA, pfdobson@lbl.gov; AJO-FRANKLIN, J., Rice University, Texas, USA, ja62@ rice.edu

Ambient noise interferometry techniques have been demonstrated to be a powerful tool to characterize multiple scales of earth structure with examples ranging from global earth structure to near-surface soil characterization. However, sparse observation networks often limit the spatial resolution of ambient noise studies for near-surface characterization as well as for highly localized features such as small fault systems. Distributed Acoustic Sensing (DAS) is a recently developed technique which utilizes fiber optical cables to measure dynamic strain at the meter scale. DAS enables seismic observations with an intriguing combination of broad frequency band (from $\mathrm{mHz}$ to $\mathrm{kHz}$ ), large spatial coverage (tens of $\mathrm{km}$ ) and fine spatial sampling $(1 \mathrm{~m})$, which is typically unavailable with conventional sensors at moderate costs.

We present a case study of using DAS and ambient noise interferometry for multiple-scale seismic imaging with an unlit fiber-optic telecommunication infrastructure (dark fiber) in Imperial Valley, California. The study utilizes passive DAS data acquired from early November 2020 over a $27 \mathrm{~km}$ section of dark fiber from Calipatria, CA to Imperial, CA. We apply ambient noise interferometry to retrieve coherent signals from DAS records, and highquality surface waves as well as body waves are observed. We demonstrate a new roll-along strategy for surface wave imaging which utilizes localized supergathers to improve signal-to-noise levels for the fundamental and higher order modes. As a result, we are able to obtain high-resolution $\mathrm{S}$ wave velocity (Vs) structure to $\sim 800 \mathrm{~m}$ depth and an averaged $\mathrm{S}$ wave velocity structure to close to $2 \mathrm{~km}$. Ambient noise autocorrelation imaging provides consistent results and has assisted in resolving sharp lateral contrasts in subsurface properties. Our results provide improved constraints on subsurface features in the Imperial Valley and provide some hints concerning structures related to the Brawely Seismic Zone.

\section{On the Sensitivity of Optical Polarization Transoceanic Cables to Seismic and Water Waves}

CASTELLANOS, I. C., Caltech, California, USA, jacastil@caltech.edu; ZHAN, Z., Caltech, California, USA, zwzhan@caltech.edu; CANTONO, M., Google Inc., California, USA, mcantono@google.com; KAMALOV, V., Google Inc., California, USA, vkamalov@google.com; MECOZZI, A., University of L'Aquila, L'Aquila, Italy, antonio.mecozzi@univaq.it; MULLER, R., Google Inc., California, USA, rafaelmuller@google.com; YIN, S., Google Inc., California, USA, shuangyin@google.com

Over the last couple of years, fiber-optic sensing systems have emerged as a promising technology for real-time earthquake and tsunami hazard assessment. In a recent investigation, Zhan et al. (2021) showed that by monitoring the polarization of regular telecommunication traffic, a 10,000 km long submarine cable that connects Los Angeles, California, and Valparaiso, Chile, could be used to detect passing seismic and oceanic waves. In this work, we use light-polarization data from the same submarine cable to probe the sensitivity of this type of instrumentation to both elastic and pressure waves. For the above matter, we use fully-coupled 3D wavefield simulations to calculate the multidimensional strain along the cable. We then compare these estimations with several of the earthquake recordings to draw inferences on the type of deformation that dominates the state of polarization of the instrument. We also combine seismic recordings of water waves generated by distant storms to map the different sections of the cable that are most sensitive to pressure changes in the water column. The understanding of the capabilities and limitations of submarine telecommunication cables to seismic monitoring is crucial as they hold the enormous potential of becoming standardized real-time earthquake and tsunami observatories on a global scale.

\section{Seismic Imaging Using DAS and Dark Fiber for Basin-Scale Geothermal System Characterization: Preliminary Results From the Imperial Valley Project}

AJO-FRANKLIN, J., Rice University, Texas, USA, ja62@rice.edu; RODRÍGUEZ TRIBALDOS, V., Lawrence Berkeley National Laboratory, 
California, USA, vrodrigueztribaldos@lbl.gov; CHENG, F., Rice University, Texas, USA, marscfeng@rice.edu; DOBSON, P., Lawrence Berkeley National Laboratory, California, USA, pfdobson@lbl.gov; NAYAK, A., Lawrence Berkeley National Laboratory, California, USA, anayak7@lbl.gov; MELLORS, R., University of California, San Diego, California, USA, rmellors@ucsd.edu; ROBERTSON, M., Lawrence Berkeley National Laboratory, California, USA, mcrobertson@lbl.gov; WOOD, T., Lawrence Berkeley National Laboratory, California, USA, tjwood@lbl.gov; ROTERMUND, C., Lawrence Berkeley National Laboratory, ESnet, California, USA, crotermund@es.net; DONG B., Lawrence Berkeley National Laboratory, California, USA, dbin@lbl.gov; WU, K., Lawrence Berkeley National Laboratory, California, USA, kwu@ lbl.gov; POPESCU, A., University of California, Berkeley, California, USA, alexcpopescu@ischool.berkeley.edu; TEMPLETON, D., Lawrence Livermore National Laboratory, California, USA, templeton4@llnl.gov; MORENCY, C., Lawrence Livermore National Laboratory, California, USA, morencyl@llnl. gov; MATZEL, E., Lawrence Livermore National Laboratory, California, USA, matzel1@llnl.gov

Distributed Acoustic Sensing (DAS) is a relatively new technique that utilizes short pulses of laser light to measure strain or strain-rate at thousands of locations along an optical fiber, effectively transforming fiber optic cables currently part of the telecommunication network into massive distributed arrays of seismometers. Such large-N seismic arrays can be utilized for detecting and locating natural seismic events or imaging at the meter to $\mathrm{km}$ scale using ambient noise approaches. Because of their dense spatial sampling, broad bandwidth, and linear extent $(\sim 30 \mathrm{~km})$, such measurements can be used to generate high resolution profiles of shear wave velocity as well as surface wave scattering maps that can assist in structural characterization.

We are conducting an evaluation of DAS coupled to dark fiber for basinscale seismic imaging in the Imperial Valley, CA within the Salton Trough, an on-shore spreading center with high heat flow and abundant geothermal potential. Our goal is both to detect seismicity at a finer scale than existing regional networks and image velocity structures related to the Brawley Seismic Zone (BSZ) and the Imperial Valley Fault, two features associated with existing produced (Brawley) and potential geothermal resources. Our fiber optic array, extending from Calipatria to El Centro, was established in Nov. 2020 and has been continuously recording over a $28 \mathrm{~km}$ section (7000 channels) of telecom fiber crossing the Brawley Field. We will present early results from this project including (a) the design, layout, telemetry system, and noise characteristics of the array, (b) a growing catalog of events ranging from M0.7 to M4 recorded on the major faults within our study area, and (c) initial ambient noise results showing surface wave velocity structure for the top kilometer of sediment below the array. We also demonstrate that ambient noise approaches can be generalized to utilize both the existing regional network and the DAS array to improve areal coverage beyond an essentially linear array.

\section{Fiber-Optic Seismology \\ I: Poster Session · Friday · 23 April · 11:30 AM Pacific \\ II: Poster Session · Friday · 23 April · 3:45 PM Pacific \\ Session Chairs: Patrick Paitz, ETH Zürich (patrick.paitz@ \\ erdw.ethz.ch); Verónica Rodríguez Tribaldos, Lawrence \\ Berkeley National Laboratory (vrodrigueztribaldos@lbl.gov); Ariel Lellouch, Stanford University (ariellel@stanford.edu)}

\section{Efficient Localization of Microseismic Clusters Using DAS}

TUINSTRA, K. B., ETH Zürich, Zürich, Switzerland, katinka.tuinstra@sed. ethz.ch; LANZA, F., ETH Zürich, Zürich, Switzerland, federica.lanza@sed. ethz.ch; GRIGOLI, F., ETH Zürich, Zürich, Switzerland, francesco.grigoli@ sed.ethz.ch; RINALDI, A., ETH Zürich, Zürich, Switzerland, antoniopio. rinaldi@sed.ethz.ch; FICHTNER, A., ETH Zürich, Zürich, Switzerland, andreas.fichtner@erdw.ethz.ch; WIEMER, S., ETH Zürich, Zürich, Switzerland, stefan.wiemer@sed.ethz.ch

Efficient detection and localization of seismic activity is a key research topic in microseismic monitoring. Distributed Acoustic Sensing (DAS) is explored as a monitoring measurement technique, as it provides a dense sampling in space capable of capturing the wavefield such that it may provide better earthquake detection and localization. Since DAS acquires substantial data volumes and measures strain predominantly in the axial direction of the fiber, it demands new and efficient techniques to localize the detected earthquakes.

We adapt a novel earthquake localization method to DAS data, that is based on a protein structure determination method from biochemistry
$\left(\mathrm{HADES}^{1}\right)$. This method has already been proven successful for a single seismic station approach. The inputs are the distances between earthquakes and a seismic station, which are used to compute the inter-event distance. In this way, it is possible to find the relative position of earthquakes within a cluster. Four events with known locations are then required to retrieve the correct absolute position of this cluster. DAS measurements can extend this method to a line of densely spaced channels that allows for more accurate computation of the relative distances. We improve the method to obtain the absolute position and orientation of the earthquake cluster relative to the fiber-optic cable, by eliminating the need for master events. This is done by conducting a grid search to minimize the L2-norm between the observed and calculated Ts-Tp, where Ts and Tp are the S- and P-wave first arrival times, respectively. The method is tested first on synthetic data and later applied on a real data application.

${ }^{1}$ HADES: https://github.com/wulwife/HADES

\section{Noise Interferometry With Spatial Gradients}

PAITZ, P., ETH Zürich, Zürich, Switzerland, patrick.paitz@erdw.ethz.ch; SAGER, K., Brown University, Rhode Island, USA, korbinian_sager@brown. edu; BOEHM, C., ETH Zürich, Zürich, Switzerland, christian.boehm@erdw. ethz.ch; FICHTNER, A., ETH Zürich, Zürich, Switzerland, andreas.fichtner@ erdw.ethz.ch

In recent years, new seismic instruments including Distributed Acoustic Sensing (DAS) and rotation sensors are becoming more and more popular. Due to an increase in the availability of instruments and in public datasets, we need to incorporate those data types into our geophysical workflows.

For long continuous installations of sensors, noise interferometry is a well-established method to obtain subsurface information from passive recordings - resting on the assumption of Green's Function retrieval by crosscorrelation. We drop this assumption and derive a generalized formulation for seismic interferometry that can utilize not only displacement measurements, but also gradients thereof - such as velocity, strain and rotation.

This formulation enables us to model interferometric wavefields between arbitrary combinations of these observables. Based on these simulations, we can compute finite-frequency sensitivity kernels, indicating the sensitivity of the measurement - on arbitrary interferometric wavefields - to the subsurface structure as well as to the noise source distribution.

The developed framework accounts for potential source-structure tradeoff in environments where the noise source distribution is heterogeneous, and enables inversions utilizing correlations of combinations of different seismic observables, bringing us one step closer to multi-observational full waveform ambient noise inversion.

\section{Potential of Distributed Acoustic Sensing Systems to Record Divergence and Curl Seismic Components}

EDME, P., ETH Zürich, Zürich, Switzerland, pascal.edme@erdw.ethz.ch; PAITZ, P., ETH Zürich, Zürich, Switzerland, patrick.paitz@erdw.ethz.ch SOLLBERGER, D., ETH Zürich, Zürich, Switzerland, david.sollberger@ erdw.ethz.ch; KIERS, T. H., ETH Zürich, Zürich, Switzerland, tkiers@ student.ethz.ch; SCHMELZBACH, C., ETH Zürich, Zürich, Switzerland, cedric.schmelzbach@erdw.ethz.ch; FICHTNER, A., ETH Zürich, Zürich, Switzerland, andreas.fichtner@erdw.ethz.ch; ROBERTSSON, J. O. A., ETH Zürich, Zürich, Switzerland, johan.robertsson@erdw.ethz.ch

Distributed Acoustic Sensing (DAS) is gaining significant attention in the seismological community. This maturing technology is based on optical interferometry to detect broad-band ground deformation over long distances with an unprecedented high spatial resolution, making it a very attractive tool for seismological observation, in particular when long dark fibers can be interrogated. Temporary surveys to monitor urban areas, volcanoes and glaciers, for example, can also take advantage of the DAS technology thanks to the robust fiber-optic cables that are much cheaper to acquire and easier to deploy than a large-N seismic station network.

One limitation, however, is that DAS provides longitudinal strain variations instead of vector ground displacement as with conventional multicomponent seismometers. With a typical linear cable layout, DAS is poorly sensitive to broadside events like vertically incident P-waves or orthogonally propagating Rayleigh waves. Helically wound cables partly address this directional sensitivity issue but such engineered cables are significantly more expensive and still do not provide omni-directional responses as typically do the vertical component seismometers or accelerometers.

In this work, we discuss the possibility of utilizing DAS technology to replace or complement conventional translational multi-component measurements. In particular, we show how non-linear cable layout configurations could enable a more complete description of the wavefield by providing access 
to the curl and the divergence of the displacement wavefield, thereby extending future applications of DAS.

\section{Understanding Fiber Response With Lab-Scale Tests and Modeling}

THOMAS, P. J., NORCE Norwegian Research Centre, Bergen, Norway, peth@ norceresearch.no; PAAP, B., TNO, Applied Geosciences, Utrecht, Netherlands, bob.paap@tno.nl; HEGGELUND, Y., NORCE Norwegian Research Centre, Bergen, Norway, ynhe@norceresearch.no; BUTCHER, A. C., University of Bristol, Bristol, United Kingdom, antony.butcher@bristol.ac.uk; PITARKA, A., Lawrence Livermore National University, California, USA, pitarka1@ llnl.gov; MATZEL, E., Lawrence Livermore National Laboratory, California, USA, matzel1@llnl.gov; MELLORS, R., University of California, San Diego, California, USA,rmellors@ucsd.edu

Understanding the exact nature of the fiber coupling to seismic waves in a variety of settings is key to quantitative interpretation and modeling of seismic data. Using a small-scale $(20 \mathrm{~cm}$ by $30 \mathrm{~cm})$ laboratory setup, we measure the exact strain response of a fiber to a known source. The source is a small metal ball on a pendulum that impacts the side of the testbed. The fiber is embedded in dry sand. The strain in the fiber is measured using a high SNR interferometric approach and represents total strain rather than a distributed measurement. The signal is also measured by a co-located geophone in the testbed. Tests of repeatability show that the source is highly repeatable and that the geophone signal (velocity) is consistent with the measured strain. Initial 3D finite difference models demonstrate a reasonable fit to the data. We plan to test other materials such as partially and fully saturated sand and conduct modelling in parallel.

\section{Characterizing Geothermal Systems in California's Imperial Valley Using Low-Frequency Passive Seismic Data Recorded Using Distributed Acoustic Sensing Deployed on Dark Fiber RODRÍGUEZ TRIBALDOS, V., Lawrence Berkeley National Laboratory, California, USA, vrodrigueztribaldos@lbl.gov; CHENG, F., Rice University, Texas, USA, marscfeng@rice.edu; NAYAK, A., Lawrence Berkeley National Laboratory, California, USA, anayak7@lbl.gov; WOOD, T., Lawrence Berkeley National Laboratory, California, USA, tjwood@lbl.gov; ROBERTSON, M., Lawrence Berkeley National Laboratory, California, USA, mcrobertson@lbl. gov; MELLORS, R., University of California, San Diego, California, USA, rmellors@ucsd.edu; DOBSON, P., Lawrence Berkeley National Laboratory, California, USA, pfdobson@lbl.gov; AJO-FRANKLIN, J., Rice University, Texas, USA, ja62@rice.edu}

Characterization of basins associated with geothermal systems is critical to understanding the availability of geothermal resources. However, large portions of these basins remain poorly understood, especially regarding buried structures that may control fluid flow. One of the main reasons is the difficulty of acquiring high-resolution geophysical data at regional scale, including high costs of active seismic surveys and long-term deployments, and limited coverage of dense arrays. These issues decrease understanding of relevant regional structures and can lead to missed geothermal resources.

Here, we explore the use of Distributed Acoustic Sensing (DAS) deployed on existing, unused telecommunication fiber-optic cables (dark fibers) to seismically characterize subsurface structures associated with geothermal systems. DAS enables acquisition of seismic data along a single fiber out to 10's of $\mathrm{km}$ at spatial densities of a few meters. Using dark fibers provides a cost-effective way of acquiring regional, high-resolution data. We present preliminary results of a proof-of-concept study being conducted in the Imperial Valley, $\mathrm{CA}$, which combines a complex geologic context with extensive and productive geothermal systems. In November 2020, a DAS system was deployed on a $25 \mathrm{~km}$ long dark fiber that traverses the northern portion of the valley between Calipatria and El Centro, crossing significant tectonically active areas and the eastern margin of the Brawley geothermal field. We investigate the feasibility of recording low-frequency $(<2 \mathrm{~Hz})$ ambient seismic noise and teleseismic surface waves for seismic velocity imaging at depth. Microseismic noise from the Pacific Ocean, as well as possible seismic noise originating in the neighboring Salton Sea are explored. Observations are contrasted with seismic data from co-located and nearby broadband seismometers, and with local strain-meters. Our observations will shed light into the potential of using DAS and dark fiber for basin-scale, high-resolution characterization of deep structure and its utility as a tool for geothermal exploration.

Distributed Acoustic Sensing Using Fiber Optic Cables of Opportunity - An Experiment at an Ecological Observatory ROWE, C. A., Los Alamos National Laboratory, New Mexico, USA, char@ lanl.gov; SYMONS, N. P., Los Alamos National Laboratory, New Mexico,
USA, Symons@lanl.gov; WEBSTER, J. D., Los Alamos National Laboratory, New Mexico, USA, jwebster@lanl.gov; GAMMANS, C. N. L., Los Alamos National Laboratory, New Mexico, USA, cgammans@lanl.gov; ROMANO, N. F., Battelle, Colorado, USA, nromano@battelleecology.org; BANKS, F. D., Battelle, Colorado, USA, banksf@battelle.org; PODRASKY, D., Silixa, Ltd., Montana, USA, david.podrasky@silixa.com; PODRASKY, A., Silixa, Ltd., Montana, USA, agatha.podrasky@silixa.com

During August of 2019, members of Battelle's National Ecological Observatory Network (NEON) team and Los Alamos National Laboratory's geophysics group undertook an experiment to explore application of Distributed Acoustic Sensing (DAS) technology for detection of seismic signals observed using an existing fiber optic cable at a Colorado field site. The NEON program is a 30- year, continental-scale ecology program funded by the National Science Foundation (NSF) and operated by Battelle. Many of the NEON sites across the country are equipped with fiber optic cable. Our experiment site was at the Central Plains Experimental Range (CPER) site in northern Colorado. A Silixa digital data acquisition system was installed to record strains on the $\sim 1$ $\mathrm{km}$ length of cable, while two Kinemetrics MBB-2 broadband three component seismometers were installed at roughly $.33 \mathrm{~m}$ depth, adjacent to the fiber optic cable. The seismometers were recorded with Digos Data-Cube Type 2 digitizers with timing set by GPS. The collaboration and field deployment in the midst of COVID-19 operational restrictions provided an example of creative problem-solving and leveraging technology to facilitate remote interaction for installation under challenging conditions.

A preliminary examination of the large data volume acquired during the two-week experiment suggests that the in-situ cable was not well coupled for sensitivity to ground displacements from reported regional and teleseismic earthquakes (compared to the adjacent geophones), while no local seismicity occurred during this time. At the same time, the system proved highly sensitive to nearby foot traffic, wildlife activities and other high-frequency disturbances. We present the project and its preliminary results.

\section{Microearthquake Monitoring Using Dark Fiber and Distributed Acoustic Sensing}

TEMPLETON, D., Lawrence Livermore National Laboratory, California, USA, templeton4@llnl.gov; MORENCY, C., Lawrence Livermore National Laboratory, California, USA, morency1@llnl.gov; MATZEL, E., Lawrence Livermore National Laboratory, California, USA, matzel1@llnl.gov; MAHER, E. L., University of Nevada Reno, Nevada, USA, emaher@nevada.unr.edu; AJO-FRANKLIN, J., Rice University, Texas, USA, ja62@rice.edu

We compare results from two experimental studies using distributed acoustic sensing (DAS) on dark fiber for microearthquake monitoring. Dark fiber consists of pre-existing fiber optic cables, installed as part of larger telecommunication networks, that are currently not in use. In this study, we refine seismic processing techniques to identify and map local microseismic events within the Sacramento Basin, CA and the Imperial Valley, CA. These two sites are tectonically quite different: relatively few seismic events occur within the Sacramento Basin, while the Imperial Valley has a number of active faults. Using these high-density passive seismic datasets, we investigate optimal preprocessing strategies and techniques to identify small natural tectonic events while excluding common anthropogenic seismic sources, such as cars driving along nearby highways.

Furthermore, we investigate the capability of the virtual seismometer method (VSM) on fiber datasets. VSM is an interferometric technique that allows us to measure the Green's function between seismic sources. It is very sensitive to the individual source parameters and to the earth structure in the source region. The aim of this project is to help transform this type of data collection and processing techniques into products useful for basin-scale geothermal system characterization and subsurface mapping.

This work was performed under the auspices of the U.S. Department of Energy by Lawrence Livermore National Laboratory under Contract DE-AC52-07NA27344. LLNL-ABS-818120

\section{Prospects for Distributed Acoustic Sensing of Polar Environmental Processes: Initial Results From the Beaufort Sea, Alaska}

BAKER, M. G., Sandia National Laboratories, New Mexico, USA, mgbaker@ sandia.gov; ABBOTT, R. E., Sandia National Laboratories, New Mexico, USA, reabbot@sandia.gov

Distributed acoustic sensors (DAS) deployed along marine seafloors have the potential to observe a broad range of solid-Earth elastic, ocean acoustic, and ocean gravity wavefields generated by an equally diverse collection of environmental (e.g., ocean waves), anthropogenic (e.g., commercial shipping), and 
biogenic (e.g., whale and seal vocalizations) sources. In polar regions, these near-shore wavefields are further complicated by a seasonally variable sea ice layer that 1) supports exotic floating-elastic-plate wave modes that may couple into fluid acoustic modes; 2) dramatically alters the dynamics of ocean wave propagation and coupling with the solid Earth; and 3) generates diffuse, shortperiod cryoseismic noise that may occult anthropogenic or biogenic signals To evaluate the efficacy of DAS for continuous and in situ monitoring of polar environmental processes, we present initial observations from a $30 \mathrm{~km}$ long seafloor telecommunications fiber located on the continental shelf of the Beaufort Sea, Alaska, collected during one week of continuous recording in February, 2021, under conditions of total sea ice coverage. We also characterize meteorologic noise and anthropogenic signals from a nearby ice road serving an offshore oil production well. SNL is managed and operated by NTESS under DOE NNSA contract DE-NA0003525.

\section{Seismic Array Analysis Using Fiber-Optic Distributed} Acoustic Sensing on Small Local and Regional Earthquakes ICHINOSE, G. A., Lawrence Livermore National Laboratory, California, USA, ichinose1@llnl.gov

Seismic array beamforming analysis is used to measure signal features including the wave propagation slowness vector (i.e.,apparent horizontal velocity and back-azimuth). We compare the array analysis of several small local to regional distance earthquakes using both fiber-optic distributed acoustic sensing (DAS) and nodal geophone array collected in northern Nevada from the PoroTomo experiment (e.g., Feigl et al., 2020). The DAS improves seismic array analysis by reducing spatial aliasing due to the dense sampling of the wavefield. One challenge in working with DAS as a seismic array is with the orientation of the cable with respect to the incoming seismic wave. Traditional seismic array stacking and beamforming is successful due to the high coherency of the waveforms between sensors with a consistent orientation typically all vertical components. Alignment of the waveform phase between receivers is therefore a simple function of the horizontal slowness vector. A bend in the fiber-optic cable will add an unknown phase changes that would require corrections before array stacking. We use a technique that only uses phase differences along linear parts of the fiber-optic cable with the highest correlation to measure the slowness vector in two different directions and compare the result with the traditional array beamforming method estimated from the co-located nodal array. Prepared by LLNL under Contract DE-AC5207NA27344. Release number LLNL-ABS-818339.

\section{Wavefield Reconstruction Using Mixed DAS and Point- Sensor Networks \\ MUIR, I., Caltech, California, USA, jmuir@caltech.edu; ZHAN, Z., Caltech,} California, USA, zwzhan@caltech.edu

Distributed Acoustic Sensing (DAS) networks promise to revolutionize observational seismology by providing cost-effective, highly dense spatial sampling of the seismic wavefield, especially by utilizing pre-deployed telecomm fiber in urban settings for which dense seismic network deployments are difficult to construct. However, each DAS channel is sensitive only to one projection of the horizontal strain tensor and therefore gives an incomplete picture of the horizontal seismic wavefield. We utilize compressive sensing to develop a framework within which a DAS deployment, or mixed DAS and point-seismic deployment, generates a representation of the horizontal seismic wavefield as a signle unified data product. We illustrate this method using the Porotomo seismic deployment at Brady, Nevada, and find that the DAS network can successfully recover both components of the horizontal $\mathrm{P}$ wavefield for the regional ML4.3 Hawthorne NV earthquake. We also find that the inclusion of a small number of point sensors significantly improves overall recovery, and reaches similar levels of performance to much denser point sensor arrays.
How Should Low-Probability Earthquakes be Considered in Hazard Assessments?

Oral Session · Friday · 23 April · 9:45 Am Pacific

Session Chairs: Tiegan E. Hobbs, Natural Resources Canada (tiegan.hobbs@canada.ca); Chris Rollins, University of Leeds (j.c.rollins@leeds.ac.uk); Kristin Morell, University of California, Santa Barbara (kmorell@geol.ucsb.edu)

A Three Kernel Approach to Earthquake Source Modeling: Incorporating Incomplete or Low Resolution Seismicity, Fault and Deformation Datasets in Continental China FITZENZ, D. D., Risk Management Solutions, California, USA, delphine. fitzenz@rms.com; LANGENBRUCH, C., Risk Management Solutions, California, USA, cornelius.langenbruch@rms.com

Low probability, high impact events are hard to model in slow deforming regions or in regions that have just started being investigated. In both cases the instrumental catalog is too short to represent a stationary window. Fault databases can be incomplete, surface deformation might not be available at the resolution needed to resolve slip rates on faults. Moreover, historical or archeological records might indicate past large events, but not enough evidence is available to develop individual recurrence models. Overall, current seismicity might not be the best predictor of where the next large events will occur.

We developed and applied a modeling strategy to stable and active regions in China to account for this spatial non-stationarity. It is based on a magnitude-frequency distribution computed on the combined historical and instrumental catalog for each seismotectonic zone. The rate is then apportioned on a spatial grid based on three types of spatial probability density functions to inform where earthquakes might happen in the future. Those kernels are, resp., catalog-based, strain rate-based and fault-based. The strain rate kernel uses elements of the strain rate tensor normalized over the seismotectonic zone, while the fault kernel can incorporate information on dip or mechanism and on mapping resolution into choices for the smoothing distance. Various schemes can impart a hierarchy between faults using either quantitative or qualitative information. This method integrates fault and background events into a seamless synthetic event set. A necessary step to make sure the model created is relevant to the zone is the use of retrospective forecast tests to determine the optimal spatial PDF (i.e., the kernel weights) as a function of magnitude. This part is developed in Langenbruch and Fitzenz (2021, this conference). As expected, both forecast scores and loss metrics are very sensitive to the kernel weights, showing the importance of using all data types even when the datasets are not complete.

\section{Basement Structure of the Southern Fairbanks Seismic Zone and Its Relation to Large $(M>6)$ Earthquakes (1929- 1947)}

DOSER, D. I., University of Texas at El Paso, Texas, USA, doser@utep.edu; BAKER, M. R., Geophysical Consultant, Texas, USA, bakergrd@cs.com

We are using topographic, gravity and aeromagnetic information to better define the basement structure of the southern Fairbanks Seismic Zone (SFSZ), a region that could represent northward growth of the Northern Foothills Fold and Thrust Belt (NFFTB), serving to accommodate additional contraction in central Alaska north of the Denali fault. At least 5 earthquakes of $M>6$ have occurred within the SFSZ between 1929 and 1947. Comparison of waveforms of the smaller events to the well-studied October 16, 1947 (M 7.1) mainshock suggest northward directed thrusting in an area with limited surficial geology. Aeromagnetic data indicate these events may have nucleated at the edges of east-west trending magnetic highs, while topographic information suggests changes in the character of stream erosion within the vicinity of the 1947 sequence. We will evaluate 4 gravity/aeromagnetic/topographic profiles extending from the Denali fault across the NFFTB and SFSZ to the Tanana River to determine the extent of thrusting within this region.

New Perspectives on Newport-Inglewood Fault Geometry TOGHRAMADIIAN, N., Harvard University, Massachusetts, USA, natasha_toghramadjian@g.harvard.edu; SHAW, J. H., Harvard University, Massachusetts, USA, shaw@eps.harvard.edu; PLESCH, A., Harvard University, Massachusetts, USA, plesch@fas.harvard.edu

As illustrated by the 2019 Ridgecrest earthquake sequence, the instrumental and computational capabilities that define seismology today enable us to cap- 
ture the geometric and kinematic complexity of seismogenic fault systems and their rupture processes with increasing precision.

The Newport-Inglewood fault, however, has not had a comparable event in the modern seismic period-and thus aspects of its subsurface geometry and seismogenic potential remain poorly understood. This tectonically active right-lateral system extends for more than $40 \mathrm{~km}$ across the Los Angeles basin, California, and last ruptured in the $1933 \mathrm{Mw} 6.4$ Long Beach earthquake. The fault poses significant seismic hazard to the nearly 20 million people living in the greater Los Angeles metropolitan area.

We generate 3D models of the Newport-Inglewood fault's subsurface geometry by leveraging numerous diverse, independent data sets-the best alternative in the absence of data from a recent large earthquake. We integrate $2 \mathrm{D}$ and $3 \mathrm{D}$ seismic reflection surveys, robust stratigraphic controls from decades of oil industry well records, and hypocenter and focal mechanism catalogs recently expanded through template-matching (Yang et al., 2012, Ross et al., 2019) to characterize the subsurface geometry of the fault. To develop $3 \mathrm{D}$ fault representations, we follow the objective and reproducible method of Riesner et al. (2017), treating these data as weighted interpolation constraints.

Our initial 3D fault models highlight the complexity of the fault geometry, which includes multiple splays and complex linkage patterns at depth. Some portions of this fault system appear to reactivate Miocene-age normal faults, which have been rotated into near-vertical geometries conducive to strike-slip motion in the present transpressional regime. Overall, these models show similar levels of complexity to recent strike-slip earthquake ruptures (e.g., the 2019 Ridgecrest sequence, Plesch et al., 2020), which has important implications for seismic hazard assessment.

\section{Paleoseismic Investigation of the Levan and Fayette Segments of the Wasatch Fault Zone, Central Utah} MCDONALD, G. N., Utah Geological Survey, Utah, USA, gregmcdonald@ utah.gov; HISCOCK, A. I., Utah Geological Survey, Utah, USA, adamhiscock@utah.gov; HYLLAND, M. D., Utah Geological Survey, Utah, USA, mikehylland@utah.gov; KLEBER, E. J., Utah Geological Survey, Utah, USA, ekleber@utah.gov

The eastern margin of the extensional Basin and Range Province is defined by the Wasatch fault zone (WFZ). The Levan segment (LS) and Fayette segment (FS) in central Utah are the WFZ's southernmost segments and have received little paleoseismic investigation. A large discrepancy between regional geologic and geodetic slip rates could implicate evaporite-related tectonics at depth as a contributor to displacement on the LS and FS. We excavated paleoseismic trenches on the LS and FS to determine earthquake timing and to investigate if any fault displacement may be attributed to salt tectonics. A trench on the LS across a 3-m-high scarp showed evidence for a single Holocene surface-faulting earthquake. The exposure revealed $\sim 2.6 \mathrm{~m}$ of vertical offset and a complex 4.4-m-wide zone of tilted, overturned, and sheared blocks of alluvial-fan strata indicating oblique displacement. A distinct soil buried by scarp colluvium on the hanging wall provides good evidence for a single surface-faulting earthquake. Numerical dating results and OxCal modeling constrain the earthquake time to $1.6 \pm 0.1 \mathrm{ka}(2 \sigma)$, and stratigraphic data indicate a penultimate earthquake (PE) occurred sometime prior to $14.73+$ $2.5 \mathrm{ka}(2 \sigma)$. A trench on the FS across a 1-m-high scarp revealed evidence for two Holocene surface-faulting earthquakes. Numerical dating results and OxCal modeling constrain the most recent earthquake time to $5.4 \pm 0.1 \mathrm{ka}$ $(2 \sigma)$, and stratigraphic evidence in the lower part of the trench indicated a PE time of $11.2 \pm 1.4 \mathrm{ka}(2 \sigma)$. From these data and stratigraphic offsets, we determined earthquake recurrence intervals of 12.2-17.2 kyr (minimum) for the LS and 4.3-7.3 kyr 6300 for the FS, and vertical slip rates of $0.20-0.28 \mathrm{~mm} / \mathrm{yr}$ (maximum) for the LS and $0.17-0.33 \mathrm{~mm} / \mathrm{yr}$ for the FS. Both trenches showed faulting consistent with discrete, rapid, meter-scale displacements and long earthquake recurrence intervals that favor a seismogenic origin, rather than evaporite-related deformation.

\section{Use of Scenario Earthquakes for Seismic Hazard Assessment in the Central United States}

SHERRILL, E. M., Indiana University, Indiana, USA, sherrile@indiana.edu; HAMBURGER, M. W., Indiana University, Indiana, USA, hamburg@indiana. edu

Moderate-sized crustal earthquakes originating close to populated areas can have grave impacts on the built environment in the mid-continental United States. While large earthquakes have been documented in this intraplate area in the historic and paleoseismic record, they occur too infrequently to provide reliable observations of earthquake-related impacts. We present here four deterministic scenarios that could affect Indiana residents; a M7.3 Wabash Valley event in southern Illinois, a M6.2 event in west-central Ohio, a M6.2 event near Evansville and a M5.8 central Indiana event near Indianapolis. The locations and magnitudes were based on known fault locations and credible interpretations of the earthquake history in the region. We used a combination of the US Geological Survey's ShakeMap and FEMA's Hazus-MH software packages to assess earthquake-triggered ground-shaking and its effect on the built environment. We also used a recently developed ground failure estimation tool to examine the spatial distribution of anticipated earthquakeinduced landslide and liquefaction probabilities. Our results indicate that the state's built environment is significantly vulnerable to these moderate-sized urban earthquakes, which could lead to hundreds of casualties and tens of billions of dollars in economic losses. Deterministic case studies are by definition arbitrary scenarios representing individual cases of a virtually infinite set of possible combinations of earthquake location, magnitude, source type, depth, and wave propagation characteristics that might influence the impact of earthquakes. To gain better understanding on which parameters have the greatest influence on impacts, we conducted a sensitivity analysis for earthquakes near Indianapolis and Evansville, where we reviewed losses due to differences in magnitude, depth, strike, and dip. We found that magnitude and depth have first-order influence on losses and the orientation and dip of the causative fault in relation to populated areas can increase economic losses for an event of the same magnitude by $20-35 \%$.

\section{How Well Can We Assess Site Effects So Far?}

I: Oral Session · Tuesday · 20 April · 9:45 Am Pacific

II: Oral Session · Tuesday · 20 April $\cdot$ 2:30 PM Pacific

III: Oral Session · Wednesday · 21 April · 2:00 PM Pacific

IV: Oral Session · Wednesday · 21 April · 5:00 PM Pacific

Session Chairs: Chuanbin Zhu, GFZ German Research

Centre for Geosciences (chuanbin.zhu@gfz-potsdam.de);

Marco Pilz, GFZ German Research Centre for Geosciences (pilz@gfz-potsdam.de); Yefei Ren, Institute of Engineering Mechanics, China Earthquake Administration (renyefei@ iem.net.cn); Fumiaki Nagashima, Disaster Prevention Research Institute, Kyoto University (nagashima.fumiaki.6v@ kyoto-u.ac.jp)

\section{A Holistic Evaluation of Various Site-Response Estimation Techniques: Ergodic Models, Theoretical Borehole and Outcrop Responses Using GRA and HVSR-Based Empirical Correction}

ZHU, C., GFZ German Research Centre for Geosciences, Potsdam, Germany, chuanbin@gfz-potsdam.de; COTTON, F., GFZ German Research Centre for Geosciences, Potsdam, Germany, fcotton@gfz-potsdam.de; PILZ, M., GFZ German Research Centre for Geosciences, Potsdam, Germany, pilz@gfzpotsdam.de

In this study, we assess the performance of site-response estimation techniques. The first approach is to use ergodic models based on site characterization proxy(s), e.g., VS30, f0, slope gradient and surface geology. The second method is via GRA which requires more detailed site information, i.e., 1D ground models. The third technique is to correct the single-station earthquake HVSR using predefined correction spectra. Site-response estimates from these approaches are compared with observations (benchmark) at $145 \mathrm{KiK}$ net sites. Benchmark site-responses are derived using the surface-to-borehole spectral ratio (SBSR, borehole response) and the general inversion technique (GIT, outcrop response). We will present the preliminary results of the comparison in this session.

\section{Assessing One-Dimensional Site Response From Single- Station Earthquake Records}

PILZ, M., GFZ German Research Centre for Geosciences, Potsdam, Germany, pilz@gfz-potsdam.de; COTTON, F., GFZ German Research Centre for Geosciences, Potsdam, Germany, fcotton@gfz-potsdam.de; ZHU, C., GFZ German Research Centre for Geosciences, Potsdam, Germany, chuanbin@ gfz-potsdam.de

The one-dimensional (1D) site response analysis dominates engineering practice as it is based on the assumption that it can provide an unbiased estimate of site effects. In this case, epistemic uncertainty in site response mainly arises 
from uncertain soil properties. This approach has ruled practice for projects in which site-specific site response is assessed. However, the $1 \mathrm{D}$ representation of the soil column can account neither for topographic effects nor for horizontally propagating surface waves, meaning that local $2 \mathrm{D} / 3 \mathrm{D}$ models are required at many sites at which the site response is considered to be complex. As observational evidence, we develop a classification scheme based on the variability and similarity of the horizontal Fourier spectra from earthquake recordings for grading the site response complexity. The classification is based on the surface stations of the KiK-net network in Japan for which a large number of additional information is available. We see that a large number of sites is affected by 2D/3D effects. Quantifying the epistemic uncertainty reduction using the within-event standard deviation, we see that it can be decreased by $15 \%$ accounting for $2 \mathrm{D} / 3 \mathrm{D}$ effects.

\section{Empirical Map-Based Models of Nonergodic Site Response in the Greater Los Angeles Area}

PARKER, G. A., U.S. Geological Survey, California, USA, gparker@usgs.gov; BALTAY, A., U.S Geological Survey, California, USA, abaltay@usgs.gov

We develop empirical estimates of nonergodic site response factors at seismic stations in the greater Los Angeles area using a dataset of recorded ground motions from 473 M 3-7.3 earthquakes in Southern California. The data are a combination of those from the NGA-West2 project (Ancheta et al. 2014), the 2019 Ridgecrest earthquake sequence (Rekoske et al. 2020), and about 10,000 newly-processed records. We estimate site response using an iterative mixed-effects approach that takes into account azimuthal variations in anelastic attenuation and potential bias due to large spatial clusters of co-located earthquake sources. This process yields site response factors for peak ground acceleration (PGA), peak ground velocity, and pseudo-spectral acceleration (PSA) relative to a $760 \mathrm{~m} / \mathrm{s}$ reference condition as defined by the Boore et al. (2014; BSSA14) ground motion model. We employ regression kriging to interpolate the nonergodic site response factors to a densely-spaced grid between stations in the greater Los Angeles area. We find our interpolated model resolution ranges from about 20 arcsec for PGA to about 38 arcsec for 10s PSA. We validate the model using site response calculated at denselyspaced stations in the Community Seismic Network (CSN) that were not considered in model development. We find good agreement between the interpolated model and CSN data, especially for long periods $\left(R^{2}=0.81\right.$ for $5.0 \mathrm{~s}$ PSA). We demonstrate that using the model in the USGS ShakeAlert Earthquake Early Warning System for the 1994 M6.7 Northridge earthquake improves the accuracy and timeliness of alerts for Modified Mercalli Intensity 5 shaking. Incorporating the model into nonergodic probabilistic seismic hazard analyses allows for a reduction of aleatory variability to the single-station sigma value and for the use of spatially varying epistemic uncertainty, thus improving hazard estimates especially at long return periods.

\section{Evaluation of the High-Frequency Attenuation Parameter in Italy for Site Effect Characterization}

LANZANO, G., Istituto Nazionale di Geofisica e Vulcanologia, Milano, Italy, giovanni.lanzano@ingv.it; COLAVITTI, L., Istituto Nazionale di Geofisica e Vulcanologia, Milano, Italy, leonardo.colavitti@ingv.it; SPALLAROSSA, D., University of Genoa, Genoa, Italy, daniele@dipteris.unige.it; TARCHINI, G., University of Genoa, Genoa, Italy, gabriele.tarchini@outlook.it; PACOR, F., Istituto Nazionale di Geofisica e Vulcanologia, Milano, Italy, francesca.pacor@ ingv.it; SGOBBA, S., Istituto Nazionale di Geofisica e Vulcanologia, Milano, Italy, sara.sgobba@ingv.it; KTENIDOU, O., National Observatory of Athens, Athens, Greece, olga.ktenidou@noa.gr

The parameter $\kappa_{0}$ describes the deviation at high frequencies between the amplitude of the acceleration Fourier spectrum (FAS) computed from a seismic record and a source model proportional to $\omega^{-2}$ (Ktenidou et al., 2014). $\kappa_{0}$ is broadly used in the classical framework of ground-motion models (GMMs), both as an input parameter for the host-to-target correction of GMMs (Cotton et al., 2006; Douglas et al., 2006) and as explanatory variables in the functional forms of predictive models.

In this work, we develop a semi-automatic procedure to compute the values of $\kappa_{0}$ for several recording sites, mainly located in Central and Southern Italy. The estimated values of $\kappa_{0}$ for the reference rock sites in Central Italy (Lanzano et al., 2020) are compared with high-frequency spectral amplitudes of the systematic site error $\left(\delta S 2 \mathrm{~S}_{\text {ref }}\right)$ obtained from the non-ergodic model of the horizontal component for the FAS. The statistical coefficient between $\delta S 2 S_{\text {ref }}$ values in FAS and $\kappa_{0}$ shows a significant level of anti-correlation in the 5-25 Hz frequency range (i.e., as $\kappa_{0}$ increases, we observe an overall reduction in $\delta S 2 \mathrm{~S}_{\text {ref }}$ ). Moreover, we study the relation between $\kappa_{0}$ and other site-effect proxies, such as the average shear-wave velocity $V_{S, 30}$, usually adopted to represent the site response in GMMs and seismic codes. $\kappa_{0}$ and $\mathrm{V}_{\mathrm{S}, 30}$ are only weakly correlated, confirming that they can be considered as independent parameters for site effects characterization. We also observe a dependency of $\kappa_{0}$ on the lithological characteristics of the recording sites: lower values of the attenuation parameters correspond to rigid formations composed of limestone, while higher values are mainly located on flyschoid units. As a final step, a preliminary map of $\kappa_{0}$ in Central Italy has been built by means of spatial correlation analysis.

\section{Towards a Better Understanding of $\mathrm{k0}$ at Bedrock Level}

HAENDEL, A., GFZ German Research Centre for Geosciences, Potsdam, Germany, annabel.haendel@gmail.com; PILZ, M., GFZ German Research Centre for Geosciences, Potsdam, Germany, pilz@gfz-potsdam.de; COTTON, F., GFZ German Research Centre for Geosciences, Potsdam, Germany, fcotton@gfz-potsdam.de

Site-specific hazard estimates adjust ground motion models from surface (and soft) outcrop rock to deep (and hard) bedrock conditions below the soil column where the soil column is used to compute the site-specific amplification. Such adjustments imply the knowledge of the high-frequency attenuation parameter $\kappa_{0 \text {,bedrock }}$ at depth. Bedrock refers in this context to the rock below the soil column where shear-wave velocities are 1500-2500 m/s (defined differently by different authors) or higher.

In this study, we will try to answer two questions:

1. Can $\kappa_{0, \text { bedrock }}$ be obtained from surface recordings?

2. Is $\kappa_{0 \text {,bedrock }}$ more related to the regional attenuation or is there still some influence of the site?

To address these issues we use data from Kik-net in Japan where each site is equipped with a surface and a borehole station. We select only deep sites where the shear-wave velocity at depth is $800 \mathrm{~m} / \mathrm{s}$ or larger (soft rock to hard rock conditions).

Mayor et al. (2018) and Pilz et al. (2019) have shown that scattered coda waves might be independent of the local site response. We therefore compute $\kappa$ on the coda wave and compare it to the S-wave $\kappa$ at borehole depth. Furthermore, we directly infer the quality factor of coda waves in time domain (Qc) for comparison with $\kappa_{0}$ of S-waves. Finally, we use the program Qopen from Eulenfeld and Wegler (2016) to measure the intrinsic and scattering quality factor at the surface and at depth.

Our results show that it is not possible to derive $\kappa_{0, \text { bedrock }}$ from surface recordings. The discrepancy between $Q$ measurements and $\kappa_{0}$ values, and a strong correlation between $\kappa_{0}$ measured at the surface and at depth suggests that $\kappa_{0 \text {,bedrock }}$ is more influenced by site-specific properties than by the regional attenuation structure. We finally discuss the implication of the sitedependency of $\kappa_{0 \text {,bedrock }}$ for site-specific hazard assessment.

\section{An Overview of the National Academies-Sponsored Project: Guidance on Seismic Site Response Analysis With Pore Water Pressure Generation (NCHRP 12-114)}

MATASOVIC, N., Geo-Logic Associates, California, USA, nmatasovic@ icloud.com

National Cooperative Highway Research Program, NCHRP 12-114 is an ongoing project under the auspices of the National Academies of Sciences, Engineering, and Medicine. The objective of NCHRP 12-114 is to develop guidance on the selection and use of methods for one-dimensional (1D) nonlinear site response analysis with porewater pressure generation and dissipation. Field work will include in-situ testing and sampling at the Wildlife Site liquefaction array in southern California. The laboratory testing program will include resonant column (RC) and cyclic direct simple shear testing of silty sand. Geotechnical centrifuge testing of a Wildlife Site profile, consisting of lean clay and silty sand recovered during Wildlife Site sampling is also planned. Analytical work includes element tests and evaluation of six recorded and centrifuge case histories using four effective-stress computer programs and five advanced constitutive models. Based on guidance to be developed for this project, practicing engineers will be able to quantify the effects of site-specific soil and groundwater conditions on earthquake (design) ground motions. The prospective guidance document (i.e., the NCHRP 12-114 Final Report) is expected to be published in August 2022. It will provide information about the following: (i) input parameters needed for 1D nonlinear effective-stress SRA (e.g., site characterization information, required type of seismic loading, and information required to calibrate the model); (ii) selection, validation, and limitations of analytical methods; (iii) the process of model setup; and (iv) how to interpret the results of the analytical methods. The Principal Investigator, PI, is Dr. Neven Matasovic of Geo-Logic Associates, Inc. The NAS/NCHRP Program Manager is Dr. Waseem Dekelbab. The project is overseen by two technical review panels (GLA and NAS/NCHRP) that includes consulting engineers, representatives of several state Departments of 
Transportation (DOTs), and academics. The project web site is http://apps.trb. org/cmsfeed/TRBNetProjectDisplay.asp?ProjectID=4366

\section{Characterization of Hard Rock Site Effects on Ground Motions in Western Canada}

HASSANI, B., BC Hydro, Burnaby, Canada, behzad.hassani@bchydro.com; ATKINSON, G. M., Western University, London, Canada, gmatkinson@aol. com; STEWART, J. P., University of California, Los Angeles, California, USA, jstewart@seas.ucla.edu; FAIRHURST, M., BC Hydro, Burnaby, Canada, mike. fairhurst@bchydro.com; SHEFFER, M., BC Hydro, Burnaby, Canada, megan. sheffer@bchydro.com; YAN, L., BC Hydro, Burnaby, Canada, li.yan@bchydro. com; CATACOLI MOSQUERA, S., BC Hydro, Burbany, Canada, seku. catacolimosquera@bchydro.com

The seismic response of many important structures (e.g. concrete dams) is sensitive to the high frequency content of ground motions. Common ground-motion models (GMMs) are usually referenced to soft-rock site condition $\left(V_{\mathrm{S} 30}=760 \mathrm{~m} / \mathrm{s}\right)$ (time averaged shear-wave velocity on the top $30 \mathrm{~m}$ ). However, many of the critical structures in British Columbia (B.C.), are located on hard-rock site condition (i.e. $V_{\mathrm{S} 30}$ of $1500 \mathrm{~m} / \mathrm{s}-2800 \mathrm{~m} / \mathrm{s}$ ). Therefore, the seismic hazard results based on soft-rock site condition should be adjusted accordingly. Generic hard-rock adjustment factors (i.e. hard-rock to soft-rock amplification ratio) from the literature show large amount of variability at high frequencies with amplification or de-amplification of up to a factor of 2 to 3 being common. Specific to individual sites, BC Hydro (BCH) uses Vs-kappa corrections to account for these conditions.

Here we present recent work carried out at $\mathrm{BCH}$ to investigate another approach to quantifying the hard-rock adjustment factors, by estimating the non-ergodic site response for selected $\mathrm{BCH}$ facilities located on hard-rock sites. The scope of the work consists of four main tasks: 1) compilation of an empirical ground-motion database for rock seismograph sites in B.C., from which to determine regional source, attenuation and site terms; 2) development of regionally-calibrated hard-rock GMMs; 3) site-specific instrumental deployments at selected $\mathrm{BCH}$ facilities to enable direct computation of non-ergodic site terms relative to the developed GMMs; and 4) derivation of non-ergodic site response for selected $\mathrm{BCH}$ facilities using the site-specific ground motion records. Preliminary results have been obtained for the first three tasks. The outcomes of this work will enhance our understanding of the hard-rock site effects on ground motions, especially on the high-frequency response, and may ultimately reduce the uncertainty in seismic hazard analysis for selected BCH facilities through reduction of site-to-site variability.

\section{General Regression Neural Network (GRNN)-Based Seismic Site Classification Scheme for Chinese Seismic Code Using HVSR Curves}

I, K., China Earthquake Administration, Harbin, China, jkingn@163.com; REN, Y., China Earthquake Administration, Harbin, China, renyefei@iem. net.cn; WEN, R., China Earthquake Administration, Harbin, China, ruizhi@ iem.net.cn

Seismic site classification, which is fundamental for site-specific seismic hazard assessment, also plays an important role in accurate interpretation of ground motion data. However, detailed borehole information is not always available in many countries, e.g., China. Therefore, this study investigated application of the generalized regression neural network (GRNN) method to seismic site classification according to Chinese seismic code. First, stations from KiK-net in Japan were classified based on their borehole information and individually assigned to I, II, III, and IV site classes as defined in Chinese seismic code. Then, mean horizontal-to-vertical spectral ratio (HVSR) curves for each site class were calculated. Owing to the wide ranges of shear wave velocity and thickness of the soil layer for the II site class, an unsupervised $\mathrm{K}$-means clustering algorithm was proposed to separate this class into two groups and two corresponding reference curves were derived. Receiver operating characteristic curves indicated that non-normalization of the reference curves and the K-means clustering strategy in our proposed scheme could improve overall classification performance. After exclusion of HVSR curves without significant peaks, the overall recall rates for I, II, and III sites could reach $66.60 \%, 67.57 \%$, and $68.42 \%$, respectively, regarding use of KiK-net stations. The GRNN-based classification scheme was validated using borehole information of K-NET stations, with recall rates for I and II site classes reaching $68 \%$ and $60 \%$, respectively. Finally, based on HVSR curves calculated using strong ground motion data acquired during 2007-2015 in China, the site conditions of 165 National Strong Motion Observation Network System stations were estimated using the GRNN-based classification scheme. The results were partially validated using borehole information of 73 stations. The similarity between the mean curves and reference curves indicated that the
GRNN-based seismic site classification scheme is robust and could produce plausible results succinctly.

\section{Reproduction of a Damage Belt in Downtown Mashiki, Kumamoto, Japan Considering Liquefaction Effects on Estimated Ground Motions}

SUN, J., Kyoto University, Uji, Japan, sunjikai00@gmail.com; KAWASE, H., Kyoto University, Uji, Japan, kawase@sere.dpri.kyoto-u.ac.jp; NAGASHIMA, F., Kyoto University, Uji, Japan, nagashima.fumiaki.6v@kyoto-u.ac.jp; FUKUTAKE, K., Shimizu Corporation, Tokyo, Japan, kiyoshi.fukutake@ shimz.co.jp; MATSUSHIMA, S., Kyoto University, Uji, Japan, matsushima@ sds.dpri.kyoto-u.ac.jp

A building damage belt was generated in Mashiki Town along the local Road 28 of Kumamoto prefecture, Japan, during the mainshock of 2016 Kumamoto earthquake in Japan. The building damage distribution based on the ground motions estimated by the equivalent linear analysis (ELA) was obtained. However, the estimated building damage probabilities in the area near the Akitsu river, where soil liquefaction was observed by the Ministry of Land, Infrastructure, Transport, and Tourism (MLIT), were larger than the field survey results published by the Architectural Institute of Japan (AIJ). Thus, we need to discuss the effects of soil liquefaction on the strong ground motions and subsequently the local building damages during the mainshock. Nonlinear analysis (NA) which combines the Ramberg-Osgood (RO) relationship and Bowl model were performed to study soil liquefaction. Moreover, the nonlinear structural analysis model was used to estimate the building damage probability of wooden houses (WDP). 592 one-dimensional velocity structures, the seismological bedrock (Vs $=3.4 \mathrm{~km} / \mathrm{s})$ ground motions, construction periods of wooden houses, and distribution of water table depth were obtained for Mashiki. Nonlinear properties of four borehole drilling sites in Mashiki were constructed based on the laboratory tests, and 592 sites were classified into four categories. Finally, the estimated soil liquefaction distribution was similar to the MLIT field survey results. The PGV distributions by NA showed similar to that by ELA, and they were correlated to the AIJ building damage distribution. Both the estimated PGAs and PGVs by NA were smaller than that of ELA, which indicates the strong effects of nonlinear soil properties, especially in the soil liquefaction area. Furthermore, the NA-WDP distribution was similar to the field survey by AIJ, and also similar to ELA-WDP distribution, except for the liquefaction area where NA-WDPs were obviously smaller than ELA-WDPs. Thus, the soil liquefaction has a strong effect to decrease the estimated ground motions and subsequent structure damages.

\section{Smooth Crustal Seismic Velocity Models Cause a Depletion of High-Frequency Ground Motions on Soil \\ HUANG, Y., University of Michigan, Michigan, USA, yiheh@umich.edu}

A depletion of high-frequency ground motions on soil sites has been observed in recent large earthquakes and is often attributed to the nonlinear soil response. Here we show that this behavior of soil can also be caused by a smooth crustal seismic velocity model with low shear wave velocities underneath soil sites. We calculate near-fault ground motions using both 2-D dynamic rupture simulations and point source models for both rock and soil sites. The 1-D velocity models used in the simulations are derived from empirical relationships between seismic wave velocities and depths in northern California. The simulations for soil sites feature lower shear wave velocities and thus larger Poisson's ratios at shallow depths than those for rock sites. The lower shear wave velocities cause slower shallow rupture and smaller shallow slip, but both soil and rock simulations have similar rupture speeds and slip for the rest of the fault. However, the simulated near-fault ground motions on soil and rock sites have distinct features. Compared to ground motions on rock, horizontal ground acceleration on soil is only amplified at low frequencies, whereas vertical ground acceleration is deamplified for the whole frequency range. Thus, the horizontal-to-vertical spectral ratios on soil, though overall higher than those on rock, exhibit a depletion of high-frequency energy. Our results reveal the significant role of shallow crustal velocity structure in the generation of high-frequency ground motions on soil sites.

\section{Comparison of State-of-the-Art Approaches Used to} Account for Vs Variability in 1D Ground Response Analyses HALLAL, M. M., The University of Texas at Austin, Texas, USA, mhallal@ utexas.edu; COX, B. R., Utah State University, Utah, USA, brady.cox@usu.edu

Over the past decade, a significant amount of seismic site response research has focused on our ability to replicate recorded ground motions at borehole array sites in the U.S., Japan, and elsewhere globally, where both the input (rock) and output (surface) ground motions are known. While findings from 
these studies vary somewhat, on average more than $50 \%$ of borehole array sites are poorly modeled using $1 \mathrm{D}$ ground response analyses (GRAs) based on a single shear wave velocity (Vs) profile, presumably due to the variable subsurface conditions at most sites. Even though the engineering community is aware of these limitations, 1D GRAs continue to be overwhelmingly used in practice. As such, a crucial task is to explore whether site response predictions can be improved through modifications to traditional 1D GRAs.

We investigate five alternative approaches that can be used to account for spatial variability in 1D GRAs: (1) stochastic Vs randomization, (2) stochastic shear wave cumulative travel time randomization, (3) utilization of Vs profile suites derived from surface wave testing covering a large spatial area, (4) incorporation of pseudo-3D Vs models derived from a new horizontal-to-vertical spectral ratio (H/V) geostatistical approach, and (5) damping modifications. These approaches are investigated at two U.S. downhole array sites (Treasure Island and Delaney Park) and the results are compared with recorded small-strain ground motions. Through qualitative and quantitative comparisons, we find that using pseudo-3D Vs models derived from the H/V geostatistical approach best predicts the site response at both sites. However, all methods tend to overestimate fundamental mode amplification, apparently failing to fully account for wave scattering effects. This study suggests that while attempting to account for spatial variability in 1D GRAs is important and can in fact improve site response predictions at most sites, existing approaches work better at sites that are not very complex, and it is likely that 3D GRAs are needed at sites that have significant spatial variability.

\section{Consistency of Earthquake and Microtremor HVSRs Derived for California Sites}

WANG, P., University of California, Los Angeles, California, USA, wltcwpf@ ucla.edu; GOSPE, T., University of California, Los Angeles, California, USA, tbgospe@g.ucla.edu; ZIMMARO, P., University of Calabria, Rende, Italy, paolo.zimmaro@unical.it; AHDI, S. K., U.S. Geological Survey, Colorado, USA, sahdi@usgs.gov; YONG, A., U.S. Geological Survey, California, USA, yong@usgs.gov; STEWART, J. P., University of California, Los Angeles, California, USA, jstewart@seas.ucla.edu

Frequency-dependent horizontal-to-vertical spectral ratios (HVSRs) of threecomponent recordings provide information on site resonant frequencies, which are potentially useful for predicting site response. We compute HVSRs from Fourier amplitude spectra (FAS) using a relational database for site data mainly in California. We investigate the consistency of HVSRs derived from microtremors using temporary and permanent instruments (mHVSRs), and earthquake recordings (eHVSRs). We find microtremors and earthquake recordings are consistent for $60 \%$ of sites, with both showing significant peaks at similar frequencies $(<20 \%$ difference). We also compare mHVSRs derived from co-located temporary instruments (as would be used in a site characterization study) vs. permanent instruments (which could be applied to characterize ground motion stations) to evaluate the effectiveness of the latter, enabling us to query microtremors from permanent stations to boost the HVSR database. While eHVSRs can be measured from accelerometers, we find mHVSRs are reliably captured by accelerometers only in limited cases, even when utilizing 24-bit data recorders. This might be due to the relatively high intrinsic noise and low sensitivity of accelerometers. Therefore, our comparisons are made using seismometer (velocimeter) data, and we find about $75 \%$ consistency in this case.

These findings are important to consider when contemplating the development or use of site response models derived from HVSR-based parameters such as site frequency. In engineering applications, these parameters will almost always be derived from mHVSRs. However, for model development, it is tempting to use eHVSRs, because such information is most widely available for ground motion stations. Because mHVSRs and eHVSRs do not always match, it may be important to derive models solely from mHVSRs to ensure consistency between parameters used in model development and forward applications. However, such models do not yet exist.

\section{Inter-Method HVSR Bias and the Resultant Vs30-fd Relationship for Measured-Vs30 Stations in the Western United States}

HUDSON, K. S., University of California, Los Angeles, California, USA, khud27@g.ucla.edu; PALMER, S. M., Western University, London, Canada, spalme22@uwo.ca; AHDI, S. K., U.S. Geological Survey, Colorado, USA, sahdi@usgs.gov; HASSANI, B., BC Hydro, Burnaby, Canada, behzad.hassani@ bchydro.com; TORO, G., Lettis Consultants International, Inc., California,
USA, toro@lettisci.com; YONG, A., U.S. Geological Survey, California, USA, yong@usgs.gov

Two important ground motion modeling parameters are currently used to account for seismic site effects at network strong-motion monitoring stations: 1) the time-averaged shear wave velocity $\left(V_{S}\right)$ of the upper $30 \mathrm{~m}$ from the surface $\left(V_{\mathrm{S} 30}\right)$, derived through $V_{\mathrm{S}}$ profiles determined from in situ multi-station array-based measurements; and 2) the dominant site frequency $\left(f_{d}\right)$, derived from the horizontal-to-vertical spectral ratio (HVSR) of ground motions recorded by the single-station method. Although the effectiveness of using one or more (or the combination) of these indices as site terms is an ongoing research topic, $f_{\mathrm{d}}$-particularly, based on microtremor sources-is substantially less costly to determine than $V_{\mathrm{S} 30}$. As both indexes are known to fundamentally represent seismic site conditions, we follow previous studies and regress measured $V_{\mathrm{S} 30}$ against $f_{\mathrm{d}}$ but use newly available data consisting of 60 network stations in the Western U.S. However, there exist many different methods for computing HVSR, which may result in varying $f_{\mathrm{d}}$ estimates, whereas $V_{\mathrm{S} 30}$ methods are relatively better established. We examine possible $f_{\mathrm{d}}$ -related biases by using a common set of microtremor recordings from each network station and by computing their Fourier amplitude spectrum (FAS), power spectral density (PSD), and response spectrum (RS) based HVSRs. The RS approach is shown to be inappropriate for use on microtremor data because the damping in the single-degree-of-freedom (SDOF) system does not allow for a significant accumulation of energy during the long-duration, low-amplitude microtremor recordings. HVSR computed from FAS and PSD produce similar shapes; however, from $0.2-50 \mathrm{~Hz}$ the amplitudes generally differ by a factor of up to two, and $f_{\mathrm{d}}$ varies between the two methods on average by $\pm 0.5 \mathrm{~Hz}$. We discuss the pros and cons of the FAS, PSD, and RS approaches to computing $f_{\mathrm{d}}$, then present a relationship between $V_{\mathrm{S} 30}$ and $f_{\mathrm{d}}$, and compare the relationship to those proposed in recent studies.

\section{Site Amplification in Glaciated Terrain: HVSR and MASW Measurements in New England}

PONTRELLI, M. A., Tufts University, Massachusetts, USA, marshall. pontrelli@tufts.edu; BAISE, L. G., Tufts University, Massachusetts, USA, laurie.baise@tufts.edu; EBEL, J., Boston College, Massachusetts, USA, john. ebel@bc.edu

Near surface geology plays an important role in earthquake ground motion estimation and thus is a vital area of study for infrastructure resilience. Soil profiles with lower velocity sediments overlying higher velocity bedrock amplify energy at certain frequencies due to resonance effects and conservation of energy across an impedance boundary. The NEHRP estimates this site amplification using $V s_{30}$ : the average shear wave velocity of the top 30 meters of soil. $V s_{30}$ is a good preliminary step in estimating site amplification, but it does not 1) provide information concerning the depth to the impedance boundary which determines the frequency of shaking and 2) capture effects from soil deeper than 30 meters. In this study, we use two measurements, Multi-channel Analysis of Surface Waves (MASW) (Park 1998, 1999) and the Horizontal to Vertical Spectral Ratio (HVSR) (Nakamura, 1989) to provide greater constraint on site near surface S-wave velocity profile than $V s_{30}$ alone. MASW estimates S-wave velocity profiles using surface wave dispersion and HVSR provides the site fundamental frequency, $f_{0}$. We can combine these measurements to estimate two parameters that define the site amplification: 1) $f_{0}$ and 2) the average shear wave velocity to the impedance contrast. We study three glacially derived surficial geologic units in New England: 1) glacial lakes, 2) river basins and 3) marine clay deposits and within each unit, calculate the fundamental resonance using the HVSR and a dispersion curve using MASW at multiple sites and identify variability within and between units. We find that in the field, the addition of an HVSR measurement is easy and well worth the time to supplement the MASW derived S-wave profile and show that a site can be characterized this way using $f_{0}$ and shear wave velocity to the impedance boundary, a similar, but slightly more robust classification than $\mathrm{Vs}_{30}$ alone. Our results will ultimately be used to develop updated soil amplification maps for the New England region.

\section{Temporal Change of Shallow Material During Kumamoto Earthquake by Autocorrelation Function and Interfrometry Method}

DOKHT DOLATABADI ESFAHANI, R., Universitat Potsdam, potsdam, Germany, dokhtdolatabadie@uni-potsdam.de; COTTON, F., GFZ German Research Centre for Geosciences, potsdam, Germany, fcotton@gfz-potsdam. 
de; BONILLA, L., Université Gustave Eiffel, Marne-la-Vallée, France, luisfabian.bonilla-hidalgo@univ-eiffel.fr

We analyze the variations of subsurface seismic properties associated to the successive shaking of the $2016 \mathrm{Mw} 7.3$ Kumamoto foreshocks, mainshock and aftershocks. We use autocorrelation functions and interferometery methods as suggested recently by Bonilla et al. (2019). The used data was recorded by surface and borehole sensors at the KiK-net stations over a period of 8 years. The seismic velocity of subsurface exhibits clear changes during the earthquake followed by a recovery phase. We observe a decrease of about $30 \%$ of seismic velocity during the mainshock, showing average changes of shallow material properties between borehole and surface stations by using the interferometry method. Using autocorrelation technique, we detect about $60 \%$ decrease of seismic velocity during the mainshock ground motion, showing the velocity changes of material properties just below the surface sensor. In a further analysis, we analyze the memory properties of material by using the velocity changes during the peak ground acceleration. It shows a gradual decrease in velocity changes after the mainshock. In addition, we analyze the variation of shear modules based on shear strain and also Vs30, which show degradation of shear modulus in the mainshock and healing process of shear modulus. Such observation can be used to improve estimate of seismic shaking hazard, site effect, and healing process of material.

\section{Development of a New Methodology for Evaluation of Site Fundamental Frequency and Its Associated Uncertainty Based on H/V Spectral Ratio Using an NGA-West2 Dataset \\ YAZDI, M., University of Nevada Reno, Nevada, USA, m_yazdi@nevada.unr. edu; MOTAMED, R., University of Nevada Reno, Nevada, USA, motamed@ unr.edu; ANDERSON, J. G., University of Nevada Reno, Nevada, USA, jga@ seismo.unr.edu}

A new automated methodology is developed for estimating the site fundamental frequency $\left(\mathrm{f}_{0}\right)$, its corresponding amplitude $\left(\mathrm{A}_{0}\right)$, and their associated uncertainty using Horizontal-to-Vertical Spectral Ratio (HVSR) of ground motion records. Over the last decades, many studies have been carried out for developing ground motion prediction equations (GMPEs). In the GMPE, the local site effect is mainly addressed by $\mathrm{V}_{\mathrm{S} 30}$. However, recent studies show that site fundamental frequency $\left(\mathrm{f}_{0}\right)$ is another useful proxy in reducing the uncertainties associated with the GMPEs. Using HVSR is an efficient and inexpensive measure to estimate $\mathrm{f}_{0}$ as it does not require a reference rock site. It has been found that the peak in the HVSR curve is associated with $f_{0}$. In general, there are more than one peak in the site's HVSR curve. Therefore, peak selection relies on the analysts' decisions while they are only using the average HVSR curve of the site, so a single number for the $f_{0}$ is estimated. In other words, $\mathrm{f}_{0}$ might be estimated subjectively, and it does not incorporate uncertainty. This study uses selected sites in the NGA-West2 dataset to evaluate the performance of a new fully automated method in estimating the site characteristics (i.e., $\mathrm{f}_{0}$ and $\mathrm{A}_{0}$ ). In addition to using the site's average HVSR curve, individual HVSR curves from the recorded events are also considered for estimating the site proxies. In this methodology, the average HVSR curve is used to find a rough estimation of the site fundamental frequency $\left(\mathrm{f}_{0, \mathrm{~m}}\right)$, which is assumed to be the lowest frequency peak in the average HVSR curve. Then, the peaks in individual events that are more consistent with $\mathrm{f}_{0, \mathrm{~m}}$ are selected as flagged peaks. In the next step, the statistical parameters (i.e., mean, standard deviation) are calculated using the flagged peaks. The whole process is programmed in a way to be completely automated, hence unbiased. Overall, this study presents this new automated methodology for estimating the site fundamental frequency, its corresponding amplitude, and their associated uncertainty using HVSR.

\section{High-Resolution Site Response Study of the Los Angeles Basin From the 2019 Ridgecrest Earthquake Sequence} FILIPPITZIS, F., Caltech, California, USA, ffilippi@caltech.edu; KOHLER, M., Caltech, California, USA, kohler@caltech.edu; HEATON, T., Caltech, California, USA, heatont@caltech.edu; CLAYTON, R. W., Caltech, California, USA, clay@gps.caltech.edu; GUY, R., Caltech, California, USA, rguy@gps. caltech.edu; BUNN, J. J., Caltech, California, USA, julian.bunn@caltech.edu

We study site response in urban Los Angeles during the two largest events of the 2019 Ridgecrest earthquake sequence, using recordings from multiple regional seismic networks as well as a subset of 350 stations from the much denser Community Seismic Network (www.csn.caltech.edu). We calculate response spectral amplitudes for a selection of periods of engineering significance $(1,3,6$, and $8 \mathrm{~s})$ and compute site amplification factors relative to three bedrock sites. The site effects present in urban Los Angeles are significant and reproducible between the M7.1 and M6.4 events. Coherent longer-period amplification patterns are present in the Los Angeles basin with the maximum amplifications found in the central and western Los Angeles basin regions for both events (amplification factors of up to 7, for 6-s period). We observe the largest amplification factors for the shorter periods in the south-eastern Los Angeles basin region (amplification factors of up to 6 for 1-s period); however the amplifications are less spatially coherent. The high network density provides an increase in the spatial resolution of the observations and an opportunity to capture these smaller scale variations. We observe high amplifications in the south-eastern quadrant of the San Fernando Valley basin at all periods up to factors of 9 at 6-s period. We examine possible correlations of the site amplifications with geophysical parameters such as the depth-to-basement and the uppermost 30-m average shear-wave velocity (VS30). We found no significant correlation for the 1-s period, while a weak correlation appears for the 3-s period and gets stronger for the longer periods, which likely reflects the correlation of Vs30 with sedimentary basins.

Passive Site Response Characterization Using Teleseismic Receiver Functions From Wideband Optical Accelerometers BALL, J. S., Bureau of Reclamation, Colorado, USA, jball@usbr.gov; SCHULTE-PELKUM, V., CIRES, University of Colorado, Colorado, USA, vera.schulte-pelkum@colorado.edu; MEREMONTE, M., Bureau of Reclamation, Colorado, USA, mmeremonte@usbr.gov; SCHWARZER, J., Bureau of Reclamation, Colorado, USA, jschwarzer@usbr.gov; LEVISH, D., Bureau of Reclamation, Colorado, USA, DLevish@usbr.gov; MCCAFFERY, E., Bureau of Reclamation, Colorado, USA, emccaffery@usbr.gov

Since 2018, the Bureau of Reclamation Strong Motion Monitoring Program (SMMP) has deployed 23 ultra-low-noise optical accelerometers at 7 dams across the western US, replacing traditional Force-Balance Accelerometers (FBAs) used in our legacy systems. In contrast to standard FBA sensors, which usually exhibit self-noise exceeding the NHNM at frequencies below $\sim 1 \mathrm{~Hz}$, the noise floor of our optical sensors is comparable to a broadband seismometer.

Because the optical sensor is capable of measuring both strong and weak motion accurately, it unlocks new potential for teleseismic imaging techniques which were never before possible on FBA systems. We utilize several such methods in this study to estimate site response and constrain basin properties beneath three SMMP stations at Jackson Lake Dam, WY.

In 1986, crosshole Vp and Vs tomography was performed in the vicinity of SMMP's Jackson Dam toe station (JKLK1). While Vp and Vs were measured to a depth of 465 feet by the study, boreholes did not penetrate basement, therefore basin depth underlying JKLK1 remains poorly-constrained.

Here, we combine the crosshole velocity model with analysis of teleseismic receiver functions (RFs), body-wave H/V spectral ratios (HVSR) and $\mathrm{P}-\mathrm{SV}$ polarization to estimate basin depth using a suite of distant earthquakes recorded by the optical sensors.

Comparison of HVSR between freefield and toe stations indicate fundamental basin resonance of $\sim 0.8 \mathrm{~Hz}$, corresponding to a basin depth of 500 $600 \mathrm{ft}$ beneath JKLK1, in general agreement with prior seismic studies conducted in the area.

The first 5 s of RFs from JKLK1 closely agree with synthetic data generated using the crosshole model, while fitting subsequent reverberations using a basin model based on HVSR data yields mixed results. Azimuthal variation of RFs suggests the influence of horizontal scattering at basin boundaries. However, the stability of near-surface impulse responses shown here implies that inversion of teleseismic RFs can potentially characterize site responses at other upgraded SMMP stations where shallow shear structure is unknown.

\section{Primary Linear Site Response Parameters From Transfer Functions and Ratios of Response Spectra}

WANG, Z., University of Kentucky, Kentucky, USA, zmwang@uky.edu; CARPENTER, S., University of Kentucky, Kentucky, USA, seth.carpenter@ uky.edu

Site response is determined by the velocity structure and other dynamic parameters and input ground motion at a site and measured by the soil-torock spectral ratio (SSR) or borehole transfer function (TF) in seismology and ratio of response spectra (RRS) in earthquake engineering. Thus, quantification of site response is nonergodic, or site-specific. A response spectrum is a plot of the peak response of a series of a single-degree-of-freedom system with a natural period and damping to an input ground motion; it is fundamentally different from the Fourier spectrum of the input ground motion. In other words, site response is quantified differently in seismology and earthquake engineering. The site response parameters (i.e. base-mode and peak frequencies or periods and corresponding amplifications) are of primary importance and are the subject of this investigation. We used weak ground-motion record- 
ings $(\mathrm{PGA}<0.05 \mathrm{~g})$ to measure these parameters from empirical TFs and RSS at 13 U.S. borehole arrays. We also performed 1D linear site-response analyses to obtain theoretical TF and RSS at each site. Our theoretical and empirical results are consistent with each other and show that TFs are significantly different from RRSs. We also observed that 1) the fundamental site period, $T_{\mathrm{f}}$, measured from TF and from RRS are nearly identical, 2) the maximum RRS, $R R S_{\max }$, occurs at $T_{\mathrm{f}}$, and 3 ) the magnitude of TF at $T_{\mathrm{f}}, A_{0}$, is larger than $R R S_{\max }$ at all sites. Furthermore, we found that $R R S_{\max }$ and $A_{0}$ are correlated. Therefore, the $T_{\mathrm{f}}$ and $R R S_{\max }$ or $T_{\mathrm{f}}$ and $A_{0}$ are of primary important and can be considered as the primary parameters for quantifying linear site response, site resonance in particular, in earthquake engineering. We also compared $T_{\mathrm{f}}$ and $R R S_{\max }$ with Vs30 and found no correlation between them. Therefore, Vs30 is not an appropriate proxy to parameterize site response in engineering design and other applications.

\section{Velocity Structure Identification at a Rock Site in Japan Based on Diffuse Field Concept for Earthquake} NAGASHIMA, F., Disaster Prevention Research Institute, Kyoto University, Uji, Japan, nagashima.fumiaki.6v@kyoto-u.ac.jp; KAWASE, H., Disaster Prevention Research Institute, Kyoto University, Uji, Japan, kawase@sere. dpri.kyoto-u.ac.jp; ITO, E., Disaster Prevention Research Institute, Kyoto University, Uji, Japan, ito@sere.dpri.kyoto-u.ac.jp

Many approaches have been proposed to estimate the site amplification factor, but the estimation of the detailed site amplification factor at the rigid rock site is still difficult because the amplification features at such a rock site does not clearly appear on the observed data such as the dispersion curve in the array microtremor measurements. Based on the diffuse field concept for earthquake (DFCe, Kawase et al., 2011) the Horizontal-to-Vertical spectral Ratio of earthquake (EHVR) is interpreted as the absolute solution of the ratio of the horizontal and vertical amplification factors between the ground surface and the seismic bedrock. If the ground motion is not amplified in both horizontal and vertical directions at a rock site, the theoretical EHVR should be flat, therefore we can identify the ground structure of the rock site as the one with no impedance contrast. We applied DFCe to the EHVR observed at a KiK-net site in Japan named as YMGH01 which is installed on the stiff rock. The observed EHVR of YMGH01 does not have any large peaks between $0.08 \mathrm{~Hz}$ and 20 $\mathrm{Hz}$, but have two small $(\sim 2)$ peaks around $0.12 \mathrm{~Hz}$ and $0.4 \mathrm{~Hz}$, as well as small fluctuations in the higher frequency range. These peaks at $0.12 \mathrm{~Hz}$ and 0.4 $\mathrm{Hz}$ are also measured at a K-NET site named as YMG013 which is located on the same deep ground structure at a distance of $3.2 \mathrm{~km}$ from YMGH01, so we concluded that these small peaks reflected the amplification generated at the deep ground structure in this region. We identified the velocity structure shallower than the seismic bedrock based on DFCe using the EHVR in the wide frequency range of $0.08 \mathrm{~Hz}$ to $20 \mathrm{~Hz}$. The obtained velocity structure reproduces the observed EHVR well, especially the small peaks at $0.12 \mathrm{~Hz}$ and $0.4 \mathrm{~Hz}$. This means that we can identify the velocity structure at a rock site which explains the whole shape of the EHVR, not only its amplification characteristics but also their detailed features.

\section{How Well Can We Assess Site Effects So Far?}

Poster Session · Wednesday · 21 April · 3:45 PM Pacific

Session Chairs: Chuanbin Zhu, GFZ German Research Centre for Geosciences (chuanbin.zhu@gfz-potsdam.de); Marco Pilz, GFZ German Research Centre for Geosciences (pilz@gfz-potsdam.de); Yefei Ren, Institute of Engineering Mechanics, China Earthquake Administration (renyefei@ iem.net.cn); Fumiaki Nagashima, Disaster Prevention Research Institute, Kyoto University (nagashima.fumiaki.6v@ kyoto-u.ac.jp)

\section{An Open-Source Site Database of Strong-Motion Stations in Japan: K-Net and KiK-Net}

ZHU, C., GFZ German Research Centre for Geosciences, Potsdam, Germany, chuanbin@gfz-potsdam.de; WEATHERILL, G., GFZ German Research Centre for Geosciences, Potsdam, Germany, gweather@gfz-potsdam.de; COTTON, F., GFZ German Research Centre for Geosciences, Potsdam, Germany, fcotton@gfz-potsdam.de; PILZ, M., GFZ German Research Centre for Geosciences, Potsdam, Germany, pilz@gfz-potsdam.de; KWAK,
D., Hanyang University, Ansan, Korea, Republic of, dkwak@hanyang.ac.kr; KAWASE, H., Kyoto University, Kyoto, Japan, kawase@sere.dpri.kyoto-u.ac.jp

We present an open-source site database for a total number of 1742 earthquake recording sites in the K-NET (Kyoshin network) and KiK-net (Kiban Kyoshin network) networks in Japan. This database contains site characterization parameters directly derived from available velocity profiles, including average wave velocities, bedrock depths, and velocity contrast. Meanwhile, it also consists of earthquake horizontal-to-vertical spectral ratio (HVSR) and peak parameters, for example, peak frequency, amplitude, width, and prominence. In addition, the site database also comprises topographic and geological proxies inferred from regional models or maps.

Each parameter is derived in a consistent manner for all sites. This site database can benefit the application of machine learning techniques in studies on site amplification. Besides, it can facilitate, for instances, the search of the optimal site parameter(s) for the prediction of site amplification, the development and testing of ground-motion models or methodologies, as well as investigations on spatial or regional variability in site response. All resources (the site database, earthquake HVSR data at all sites, and the MATLAB script for peak identification) can be freely accessed via: https:// doi.org/10.5880/ GFZ.2.1.2020.006

\section{An Update to the Global Geospatial Liquefaction Model With Uncertainty Propagation}

AKHLAGHI, M. M., Tufts University, Massachusetts, USA, mehdi.akhlaghi@ tufts.edu; BAISE, L. G., Tufts University, Massachusetts, USA, laurie.baise@ tufts.edu; MOAVENI, B., Tufts University, Massachusetts, USA, babak. moaveni@tufts.edu; CHANSKY, A. A., Tufts University, Massachusetts, USA, alexander.chansky@tufts.edu; MEYER, M., Tufts University, Massachusetts, USA, michelle.meyer@tufts.edu

This paper presents an update to the global liquefaction model developed by Zhu et al. $(2015,2017)$ using geospatial data from earthquakes around the world. An updated liquefaction inventory includes 54 earthquakes, with 7 earthquakes without liquefaction observations. We test 18 explanatory variables as proxies for soil saturation, soil density and the earthquake load including variables such as PGV, PGA, slope-derived $\mathrm{Vs}_{30}$ and water table depth (Fan et al. 2013). Uncertainty in the explanatory variables is defined so that uncertainty can be propagated through the model. In order to study the correlation between the explanatory variables, interaction terms are included in some of the initial predictive models. The area under the receiver operating characteristic (ROC) curve is used as a metric to identify the models with the better performances. The identified candidate models are then studied in a probabilistic framework to estimate the uncertainties of the predictions. The estimated prediction uncertainties guide the choice of the optimal global geospatial liquefaction model and more importantly can help better define the level of confidence in the prediction which is a valuable asset in the decisionmaking process.

\section{Comparison of Site Amplifications Estimated Using Three Techniques in the Fort Worth Basin, Texas}

JEONG, S., Southern Methodist University, Texas, USA, seongjuj@smu.edu; STUMP, B., Southern Methodist University, Texas, USA, stump@smu.edu; DESHON, H., Southern Methodist University, Texas, USA, hdeshon@smu. edu

Following the development of unconventional oil and gas production across the Fort Worth Basin (FWB) in Texas, a rapid increase in seismicity across the basin began in 2008 that grew to include earthquakes affecting a substantial portion of the urban metropolitan area. In order to assess and mitigate the seismic hazard in the area, motivated by the thickness of the sedimentary basin and the accompanying soft soil layer, we estimate site effects at 22 seismic stations deployed to record these events. Site responses are derived using three different approaches: 1) a modified generalized inversion technique (GIT), 2) horizontal-to-vertical spectral ratio (HVSR), and 3) quarterwavelength approximation (QWA). The site effects from the GIT and HVSR are based on the observed S-wave Fourier amplitude spectra from earthquake recordings, while the QWA is calculated using estimates of average shear wave velocities in the upper $30 \mathrm{~m}\left(\mathrm{~V}_{\mathrm{S} 30}\right)$. We find that site amplification estimates based on the three techniques are consistent with one another over resonance frequencies that range from 2.5 to $10 \mathrm{~Hz}$. The mean amplification values from the three site factors are found to be on average about 3 times larger than the vertical site response derived from GIT, which is averaged to unity. These site amplification estimates also correlate with the geology proxy $\mathrm{V}_{\mathrm{S} 30}$ determined by rock types and geologic age. Old and harder rocks (e.g., Pennsylvania lime- 
stone and sandstone) show lower site amplification while young and soft rocks indicate the higher amplification (e.g., Quaternary alluvium).

\section{Regional Attenuation Estimates for California Using Coda Waves}

I, C., North Carolina State University, North Carolina, USA, cji3@ncsu. edu; CABAS, A., North Carolina State University, North Carolina, USA, amcabasm@ncsu.edu; PILZ, M., GFZ German Research Center for Geosciences, Postdam, Germany, pilz@gfz-potsdam.de; KOTTKE, A., Pacific Gas and Electric Company, California, USA, arkk@pge.com

The effect of site conditions on the characteristics of ground motions is a complex function of several factors such as the stiffness and attenuation characteristics (both scattering and absorption) of local materials near the surface and at depth. Finding an effective proxy for site effects is necessary for the development of ground motion models and the assessment of site-specific seismic hazards. The high-frequency spectral decay parameter kappa has recently gained popularity in the aforementioned applications because its site-specific component, $\mathrm{k}_{0}$, can capture the near-surface attenuation at a site. The attenuation characteristics of reference rock sites are of particular interest in seismic hazard evaluations, but the lack of ground motion records at hard-rock sites makes the estimation of $\mathrm{k} 0$ from the classic Anderson and Hough (1984) approach (hereafter referred to as $\mathrm{k} 0 \_\mathrm{AH}$ ) challenging. Recently, $\mathrm{k} 0$ _coda values estimated from multiple-scattered coda waves were found to correlate well with k0 at hard rock sites in France, while highlighting regional variations. In this work, regional attenuation characteristics of hard-rock sites in California are analyzed through the lens of k0_coda. First, a catalog of ground motion records across the region is compiled, including motions from the recent Ridgecrest earthquake sequence. Then, $\mathrm{k} 0$ _coda values are computed to evaluate hard-rock regional characteristics in the region. Additionally, the availability of multiple ground motions and site information in California offers a unique opportunity to validate the performance of $\mathrm{k} 0$ _coda in the region via comparisons to classical $\mathrm{k} 0 \_\mathrm{AH}$ values.

\section{Seismic and Liquefaction Hazard Maps for Four Western Tennessee Counties}

CRAMER, C. H., CERI, University of Memphis, Tennessee, USA, ccramer@ memphis.edu; VAN ARSDALE, R., DES, University of Memphis, Tennessee, USA, rvanrsdl@memphis.edu; ARELLANO, D., Civil Engineering, University of Memphis, Tennessee, USA, darellan@memphis.edu; PEZESHK, S., Civil Engineering, University of Memphis, Tennessee, USA, spezeshk@memphis. edu; HORTON, S., CERI, University of Memphis, Tennessee, USA, shorton@ memphis.edu; WEATHERS, T., DES, University of Memphis, Tennessee, USA, tayweathers@gmail.com; NAZEMI, N., Civil Engineering, University of Memphis, Tennessee, USA, nnazemi@memphis.edu; TOHIDI, H., Civil Engineering, University of Memphis, Tennessee, USA, htohidi@memphis. edu; REICHENBACHER, R., DES, University of Memphis, Tennessee, USA, rmrchnbc@memphis.edu; HARRISON, V., DES, University of Memphis, Tennessee, USA, vjoyner@memphis.edu; BHATTARAI, R., CERI, University of Memphis, Tennessee, USA, rrbhttri@memphis.edu; BOUZID, K., DES, University of Memphis, Tennessee, USA, karimbouzid@yahoo.com

A five-year seismic and liquefaction hazard mapping project for five western Tennessee counties began in 2017 under a Disaster Resilience Competition grant from the U.S. Department of Housing and Urban Development to the State of Tennessee. The project supports natural hazard mitigation efforts in Lake, Dyer, Lauderdale, Tipton, and Madison counties. The county seismic hazard maps for Lake County in northwestern most Tennessee were completed in early 2018. Similar maps for Dyer County were completed in 2019. Maps for Lauderdale County were completed in early 2020 and for Tipton County in early 2021. Additional geological, geotechnical, and geophysical information has been gathered in Lake, Dyer, Lauderdale, and Tipton Counties to improve the base northern Mississippi Embayment hazard maps of Dhar and Cramer (2017). Information gathered includes additional geological and geotechnical subsurface exploration logs, water table level data collection, new measurements of shallow and deep shear-wave velocity (Vs) profiles, and the compilation of existing Vs profiles in and around the counties. Improvements have been made in the 3D geological model, water table model, the geotechnical liquefaction probability curves, and the Vs correlation with lithology model for these counties. The resulting improved soil response amplification distributions on a $0.5 \mathrm{~km}$ grid were combined with the 2014 U.S. Geological Survey seismic hazard model (Petersen et al., 2014) earthquake sources and attenuation models to add the effect of local geology for Lake, Dyer, and Lauderdale Counties. The resulting products will be similar to the Memphis and Shelby County urban seismic hazard maps recently updated by Cramer et al. (2018).
Seismic Site Response in the Binchuan Basin, Yunnan, China Inferred From Records at a Dense Linear Array SONG, J., The Chinese University of Hong Kong, Hong Kong, sjh2019@link. cuhk.edu.hk; YANG, H., The Chinese University of Hong Kong, Hong Kong, hyang@cuhk.edu.hk

The earthquake ground motions atop basins could be significantly amplified and prolonged by the uppermost unconsolidated sediments and the deeper impedance contrasts. In this study, ground motion records of both local and teleseismic earthquakes from a temporary dense linear array are used to investigate the site response parameters in and near the Binchuan Basin in northwestern Yunnan, China. We first calculate the spectrum of all events at each individual station. Then we derive the spectral ratios between the spectrum from one single station and the average from 10 stations outside the lowest velocity zone. The results show that (1) the amplification effects are most prominent in the middle of the array, where a prominent low-velocity zone was discovered from ambient noise tomography, and (2) the spectral ratios show peaks at the frequencies from $0.4 \mathrm{~Hz}$ to $0.6 \mathrm{~Hz}$ for local earthquakes and slightly higher frequencies for teleseismic earthquakes with smaller incident angles. We interpret that the amplification at lower frequencies $(<1.0 \mathrm{~Hz})$ results from the basin resonance. Therefore, deeper structures such as the sediments/bedrock impedance contrasts should also be taken into consideration while characterizing the site response. The amplification at higher frequencies $(1 \mathrm{~Hz}$ to $5 \mathrm{~Hz}$ ) is attributed to the loose sediments in the uppermost tens of meters, which could be further verified by ground motion modeling based on the shallow subsurface Vs structures. We demonstrate that the dense array recordings could be used to quantify the site responses with higher spatial resolution and more appropriate parameters.

\section{Site Response Study in the Greater Boston Area With an Investigation of the Magnitude 3.6 Bliss Corner Earthquake of November 2020}

SALERNO, I. A., Tufts University, Massachusetts, USA, jeremy.salerno@ tufts.edu; BAISE, L. G., Tufts University, Massachusetts, USA, laurie.baise@ tufts.edu; PONTRELLI, M. A., Tufts University, Massachusetts, USA, marshall.pontrelli@tufts.edu; FERRIS, A. N., Applied Research Associates, Massachusetts, USA, aferris@ara.com

The magnitude 3.6 Bliss Corner, Massachusetts earthquake occurred on November 8th, 2020 causing weak to light shaking (II-IV ShakeMap MMI) along the southern and eastern shores of the state, including in the city of Boston. Although the event only caused minor damage to buildings in the vicinity of the epicenter, there were still app. 29,000 USGS Did You Feel It? reports generated in the Eastern US. Most reports were concentrated in New England, with some reports hundreds of kilometers from the epicenter, possibly indicative of the low attenuating properties of the bedrock underneath the Central and Eastern US (CEUS) region. The Boston Basin and surrounding surficial geology is composed of various soil types including thick layers of resonating clay, sand and till. These glacial sediments and clays are relatively low-velocity (200-300 m/s) and overlay competent, high-velocity (>2000 m/s) bedrock, causing an amplification of seismic waves within engineering frequencies of interest in certain locations (Baise et al. 2016). Using strong and weak motion seismic stations in and around Boston, we compute Horizontalto-Vertical Spectral Ratios (HVSR) to estimate soil fundamental frequency from both ambient waveforms and the Bliss Corner earthquake. We compare these empirical estimates to synthetic estimates produced using local geologic and engineering data. Additionally, we measure and map Peak Ground Accelerations in the Boston area during the earthquake. Events of this magnitude are rare in Massachusetts, and thus provide an excellent opportunity to understand soil resonance and amplification in a densely populated, urban region.

\section{Testing Site-Proxy and Non-Linear Amplification Models Using Site-Specific Variability}

LOVIKNES, K., GFZ German Research Centre for Geosciences, Potsdam, Germany, karinalo@gfz-potsdam.de; KOTHA, S. R., Univ. Grenoble Alpes, Univ. Savoie Mont Blanc, CNRS, IRD, IFSTTAR, ISTerre, Grenoble, France, sreeram-reddy.kotha@univ-grenoble-alpes.fr; COTTON, F., GFZ German Research Centre for Geosciences, Potsdam, Germany, fcotton@gfz-potsdam. de; SCHORLEMMER, D., GFZ German Research Centre for Geosciences, Potsdam, Germany, ds@gfz-potsdam.de

Variations in near surface geology have a strong effect on earthquake ground motions. Such site effects are restrained in ground-motion models (GMM) and seismic hazard assessments using site proxies. The most common site proxy is the time-averaged shear-wave velocity in the top $30 \mathrm{~m}$ of a 1-D soil 
column, $\mathrm{V}_{\mathrm{S} 30}$. We develop a GMM without any site term and only based on magnitude and distance. The site-specific variability term derived from the residuals between the prediction and observation therefore captures the local response at a site. We use this site-specific variability to evaluate site proxies and test non-linear site-amplification models. The non-linear site-amplification models are tested against a linear site-amplification model using data from the Japanese Kiban-Kyoshin network. Instead of grouping the stations by proxies, the amplification models are tested on single stations with a high number of records. The results show that site response varies greatly between sites, even within similar site proxy groups. This suggests that conventional site proxies, like $\mathrm{V}_{\mathrm{S30}}$, do not characterize non-linear site response sufficiently. Furthermore, for most of the stations used in the test, the linear amplification model performs better than the non-linear models. For the range of ground motions used in the test (peak ground acceleration $<0.2 \mathrm{~g}$ ), including nonlinear site amplification in ground-motion models and building codes may therefore not be justified.

\section{The Applicability of Using HVSR to Evaluate Site-Effects, Verification of Vertical Arrays and Application for Stations in Western China}

RONG, M., Beijing University of Technology, Beijing, China, waltrong@126. com

The horizontal-to-vertical spectral ratio (HVSR) method is an efficient tool to evaluate the site-effects of engineering sites, but there seems no consensus whether its amplitude indicates the absolute amplification at the location of measurements. To further explore the applicability of using HVSR to evaluate site-effects, the HVSR and Empirical Transfer Function (ETF) analyses were performed on the S-wave recordings from two vertical borehole strong motion arrays: the Garner Valley Downhole Array in southern California and the KiK-net Rikuzentakata Vertical Array in Iwateken, Japan. The results show that the discrepancy between the HVSR and the ETF is mainly caused by the significant site response of the vertical component, thus, vertical incident $P$-waves are proposed to play an important role in the vertical amplification. The $P$-wave amplification is frequency-dependent. In the low-frequency range within $f_{0}$ (the fundamental frequency of the site), the effect of the vertical $P$-wave amplification is slight, this is why HVSR and ETF match in this frequency range. In the high-frequency range near $2 f_{0}$ or larger, the $P$-wave amplification is obvious, which maybe explain the discrepancy between the HVSR and the ETF. These results indicate that the HVSR can be used to evaluate site-effects in relative low-frequency range within $f_{0}$. Based on upper analysis, site-effects of many strong motion stations in western China has been investigated, the results show that the HVSRs agree quite well with the observation in low-frequency range within $f_{0}$ even when velocity profiles change during severe earthquakes.

\section{The Soft Soil Effect of Marine Soil on Ground Motion Parameters}

PENG, Y., National Institute of Natural Hazards, MEMC, Beijing, China, pengyj408@126.com; ZHOU, X., National Institute of Natural Hazards, MEMC, Beijing, China, lz2616@163.com; ZHAO, Q., China National Offshore Oil Corporation, Tianjin, China, zhaoqk@cnooc.com.cn; LIU, Y., China National Offshore Oil Corporation, Tianjin, China, liuyb13@cnooc. com.cn; FANG, Y., National Institute of Natural Hazrds, MEMC, Beijing, China, fyyyfyyy@vip.qq.com

Most offshore seabed is covered by a thick layer of soft soil that is nearly in the viscous liquid state or semi-plastic state. It magnifies or reduce the seismic site effect, thereby it is an important factor for the determination of seismic design parameters of offshore facilities and the compilation of ground motion zonation map of marine area. This research is based on the dynamic property experimental data of marine soil and the nonlinearity site response simulation to investigate the effect of soft soil on site ground motion parameters. The liquidity index or the shear wave velocity is recommended as the index of marine soft soil. The soil volume with a liquidity index less than 1.0 or the shear wave velocity less than $150 \mathrm{~m} / \mathrm{s}$ is considered as soft soil and it should be paid more attention on its seismic site effect. The investigation shows that the thickness of the soft soil is the key factor to determine its effect on ground motion parameters. The soft soil with a thickness less than 4 meters will magnify the peak ground motion acceleration. With the increasement of input ground motion, the amplification becomes more remarkable, and the characteristic period extends to the lower frequency. When the thickness of the soft soil is greater than 4 meters, it deamplifies the site ground motion parameters. The equivalent shear wave velocity of the top $40 \mathrm{~m}$ soil is recommended as the site classification index of marine site. And the site is classified into 4 classes. It presents the initial study of the characteristic and site effect of thick soft sediment on the seabed, the marine site classification index and site types. The research can provide the assessment of site effects for the seismic ground motion zonation in the marine area and the determination of seismic design parameters for the offshore facilities. This will benefit the structural safety of offshore facilities and speed up the compilation of ground motion zonation map in China.

\section{Three-Dimensional S-Wave Velocity Model of the South San Francisco Bay Area Obtained From Microtremor Array Measurements and Horizontal to Vertical Spectral Ratio} HAYASHI, K., OYO Corporation, California, USA, khayashi@geometrics. com; BURNS, S., Geometrics Inc., California, USA, sburns@geometrics.com

We estimated three-dimensional (3D) S-wave velocity (Vs) model of the South San Francisco Bay Area using microtremor array measurements (MAM) and horizontal to vertical spectral ratio (H/V). Data acquisition included MAM at approximately 20 sites and single station $3 \mathrm{C}$ microtremor measurements at approximately 100 sites. The MAM used two to twenty $2 \mathrm{~Hz}$ geophones or long-period accelerometers. Maximum distance between stations ranged from several tens of meters to several kilometers, depending on the site. We recorded 20 minutes to one-hour seismic ambient noises at each array. A spatial auto-correlation (SPAC) method calculated phase velocities from the vertical component of ambient noise. Minimum frequency of dispersion curves ranged from 0.2 to $2 \mathrm{~Hz}$, depending on the site, corresponding to maximum wavelengths of $10 \mathrm{~km}$ to $200 \mathrm{~m}$. The $3 \mathrm{C}$ microtremor measurements used a single 3C $2 \mathrm{~Hz}$ geophone or 3C long-period accelerometer. We recorded 20 minutes to one-hour seismic ambient noises at each site. Horizontal to vertical spectral ratio $(\mathrm{H} / \mathrm{V})$ was calculated from $3 \mathrm{C}$ seismic ambient noise. The peak frequency of $\mathrm{H} / \mathrm{V}$ ranged from 0.15 to $2.0 \mathrm{~Hz}$ depending on the site. A joint inversion of a dispersion curve and a $\mathrm{H} / \mathrm{V}$ spectrum consisting of a non-linear least squares method and/or a Genetic Algorithm estimated Vs profiles to a depth of 100 to $3000 \mathrm{~m}$, depending on the site. We compiled all Vs profiles and $\mathrm{H} / \mathrm{V}$ and estimated an approximate 3D Vs model to a depth of $3000 \mathrm{~m}$. Depth to bedrock of Vs $=2000 \mathrm{~m} / \mathrm{s}$ is the deepest $(>2000 \mathrm{~m})$ to the Southwest (Cupertino) and northeast (San Jose - Milpitas) of downtown San Jose. The peak frequency of $\mathrm{H} / \mathrm{V}$ is less than $0.2 \mathrm{~Hz}$ in this region. Bedrock depth appears to be relatively shallow (700 to $1500 \mathrm{~m}$ ) in the middle of the South Bay, from downtown San Jose to San Jose Airport and Alviso. The peak frequency of $\mathrm{H} / \mathrm{V}$ ranged from 0.3 to $2.0 \mathrm{~Hz}$ in the region. This high-velocity ridge in the South Bay appears parallel to the Silver Creek Fault and may continue west to Mountain View.

\author{
Imaging Incipient and Fossil Subduction Zones \\ Oral Session · Thursday · 22 April · 9:45 Am Pacific \\ Session Chairs: Simone Pilia, University of Cambridge \\ (sp895@cam.ac.uk); Min Chen, Michigan State University \\ (chenmi22@msu.edu); Caroline Eakin, Australian National \\ University (caroline.eakin@anu.edu.au)
}

\section{Adjoint Tomography of the Hikurangi Subduction Zone and New Zealand's North Island}

CHOW, B., Victoria University of Wellington, Wellington, New Zealand, bryant.chow@vuw.ac.nz; KANEKO, Y., Kyoto University, Kyoto, Japan, y.kaneko@gns.cri.nz; TAPE, C., University of Alaska Fairbanks, Alaska, USA, ctape@alaska.edu; MODRAK, R., Los Alamos National Laboratory, New Mexico, USA, rmodrak@lanl.gov; TOWNEND, J., Victoria University of Wellington, Wellington, New Zealand, john.townend@vuw.ac.nz

We undertake the first application of adjoint tomography in New Zealand to improve an existing 3D tomography model. We have developed an automated, open-source workflow for full-waveform inversion using spectralelement and adjoint methods (Chow et al., 2020). As a study area we focus on the North Island of New Zealand, which encompasses the Hikurangi subduction zone and associated tectonic features. The chosen domain offers a unique opportunity for imaging material properties near an active subduction zone, due to the availability of well-recorded earthquakes in close proximity to the plate interface. We performed realistic synthetic inversions using New Zealand source and receiver distributions to determine a set of parameters usable in real-data inversions. We have then undertaken an iterative inversion using 2000 unique source-receiver pairs to fit waveforms up to $2.5 \mathrm{~s}$ period, relating to a minimum spatial resolution of roughly $5 \mathrm{~km}$. Velocity changes are resolved at shallow crustal depths in tectonically active areas, such as the 
Taupō Volcanic Zone, regions of geodetically detected slow slip, and in the vicinity of the locked-to-creeping transition within the subduction zone. Datasynthetic misfit is reduced considerably at the periods of interest. We present an accurate, high-resolution tomographic model of the North Island of New Zealand, alongside post-hoc validation of model accuracy, and interpretations of enigmatic tectonic processes related to an active subduction zone.

Full-Waveform Joint Inversion of Ambient Noise Data and Teleseismic P Waves to Image the Subducted Slab Beneath Central California

WANG, K., Macquarie University, Sydney, Australia, wangkaim8@gmail.com YANG, Y., Macquarie University, Sydney, Australia, yingjie.yang@mq.edu.au; JIANG, C., Australian National University, Canberra, Australia, chengxin. jiang1@anu.edu.au; WANG, Y., Sun Yat-sen University, Guangzhou, China, ghost-zzz@163.com; TONG, P., Nanyang Technological University, Nanyang Ave, Singapore, tongping@ntu.edu.sg; LIU, T., University of Toronto, Toronto Canada, tianshi.liu@mail.utoronto.ca; LIU, Q., University of Toronto, Toronto, Canada, liuqy@physics.utoronto.ca

Adjoint tomography (i.e., full-waveform inversion) has been recently applied to ambient seismic noise and teleseismic $\mathrm{P}$ waves separately to unveil finescale lithospheric structures beyond the resolving ability of traditional raybased traveltime tomography. In this study, we propose a joint inversion scheme that alternates between frequency-dependent traveltime inversions of ambient noise surface waves and waveform inversions of teleseismic $\mathrm{P}$ waves to take advantage of their complementary sensitivities to the Earth's structure. We apply our method to ambient noise empirical Green's functions from 60 virtual sources, direct $\mathrm{P}$ and scattered waves from 11 teleseismic events recorded by a dense linear array ( $7 \mathrm{~km}$ station spacing) and other regional stations ( $\sim 40 \mathrm{~km}$ average station spacing) in central California. To evaluate the performance of the method, we compare tomographic results from ambient noise adjoint tomography, full-waveform inversion of teleseismic $\mathrm{P}$ waves, and the joint inversion of the two data sets. Both applications to practical field data sets and synthetic checkerboard tests demonstrate the advantage of the joint inversion over individual inversions as it combines the complementary sensitivities of the two independent data sets towards a more unified model. The 3D model from our joint inversion not only shows major features of velocity anomalies and discontinuities in agreement with previous studies, but also reveals small-scale heterogeneities which provide new constraints on the geometry of the Isabella Anomaly and mantle dynamic processes in central California. The proposed joint inversion scheme can be applied to other regions with similar array deployments for high-resolution lithospheric imaging.

\section{Probing the Australian-Pacific Plate Boundary: Macquarie Ridge in 3D}

EAKIN, C., Australian National University, Acton, Australia, caroline. eakin@anu.edu.au; TKALČIĆ, H., Australian National University, Acton, Australia, hrvoje.tkalcic@anu.edu.au; COFFIN, M., University of Tasmania, Hobart, Australia, mike.coffin@utas.edu.au; RAWLINSON, N., University of Cambridge, Cambridge, United Kingdom,nr441@cam.ac.uk; STOCK, J., Caltech, California, USA, jstock@gps.caltech.edu

The Macquarie Ridge Complex (MRC) along the Australian-Pacific plate boundary in the southwest Pacific Ocean is thought to be one of the few locales on the planet where subduction initiation may be imminent. While currently a transpressional boundary, it has played host to some of the largest submarine earthquakes in the world outside of an active subduction zone (for example a M8.2 in 1989), and may hold significant future tsunamigenic potential. Furthermore, Macquarie Island, located within the MRC, is an UNESCO World Heritage site for its unique geology, composed of oceanic crust and mantle that has been thrust from the seafloor to above sea-level since the Late Miocene.

To better understand the intriguing underlying dynamics and tectonics of this plate boundary, an array of 27 ocean-bottom seismometers was deployed in October 2020 by RV Investigator, a first of its kind voyage for Australia's national research vessel. While OBS instruments are currently recording on the seafloor until late 2021, an overview of the project and its future seismological objectives will be presented.

\section{Strike-Slip Enables Subduction Initiation Beneath a Failed Rift: New Seismic Constraints from Puysegur Margin, New Zealand}

SHUCK, B., University of Texas at Austin, Texas, USA, brandon.shuck@ utexas.edu; VAN AVENDONK, H., University of Texas at Austin, Texas, USA, harm@ig.utexas.edu; GULICK, S. P. S., University of Texas at Austin, Texas,
USA, sean@ig.utexas.edu; GURNIS, M., Caltech, California, USA, gurnis@ gps.caltech.edu; SUTHERLAND, R., Victoria University of Wellington, Wellington, New Zealand, rupert.sutherland@vuw.ac.nz; STOCK, J. Caltech, California, USA, jstock@gps.caltech.edu; PATEL, J., Victoria University of Wellington, Wellington, New Zealand, pateljiten93@gmail.com; HIGHTOWER, E., Caltech, California, USA, ehightow@caltech.edu

Subduction zones are fundamental to Earth's plate tectonic history, yet the details of how they initiate remain enigmatic. It is thought that subduction initiation often takes advantage of previously weakened lithosphere and may preferentially nucleate along pre-existing plate boundaries. To evaluate how past tectonic regimes and inherited lithospheric structure might facilitate underthrusting and lead to self-sustaining subduction, we present an analysis of the Puysegur Trench, a young subduction zone with a rapidly evolving tectonic history. The Puysegur Margin, south of New Zealand, has experienced a transformation from continental rifting to strike-slip, and most recently to incipient subduction, all in the last $\sim 45$ million years. Here we present deeppenetrating multichannel reflection (MCS) and ocean-bottom seismometer (OBS) tomographic images to document crustal structures and their evolution along the margin. Our images reveal that the overriding Pacific Plate contains stretched continental crust with magmatic intrusions, which formed from Eocene-Oligocene rifting between Zealandia continental plateaus. Rifting was more advanced to the south, yet never proceeded to breakup and seafloor spreading as previously thought. Subsequent strike-slip deformation translated continental crust northward causing an oblique collisional zone, with trailing $\sim 10 \mathrm{Myr}$ old oceanic lithosphere. Incipient subduction transpired as oceanic lithosphere from the south forcibly underthrust the continent-collision zone. We suggest that subduction initiation at the Puysegur Trench was assisted by inherited buoyancy contrasts and structural weaknesses that were imprinted into the lithosphere during earlier phases of continental rifting and strike-slip along the plate boundary. The Puysegur Margin demonstrates that forced nucleation along a strike-slip boundary is a viable subduction initiation scenario and should be considered throughout Earth's history.

\section{Towards 3D Multiscale Adjoint Waveform Tomography of the Lithosphere and Underlying Mantle Beneath Southeast Asia}

WEHNER, D., University of Cambridge, Cambridge, United Kingdom, dw545@cam.ac.uk; BLOM, N., University of Cambridge, Cambridge, United Kingdom, nienke.blom@esc.cam.ac.uk; RAWLINSON, N., University of Cambridge, Cambridge, United Kingdom, nr441@cam.ac.uk; MILLER, M. S., Australian National University, Canberra, Australia, meghan.miller@anu.edu. au; WIDIYANTORO, S., Institut Teknologi Bandung, Indonesia, Bandung, Indonesia, sriwid@geoph.itb.ac.id; DARYONO, M., Meteorology, Climatology and Geophysical Agency, Indonesia, Jakarta, Indonesia, daryono@idu.ac.id

Southeast Asia is one of the most complex tectonic regions on Earth. This is mainly a result of its location within the triple junction of the Australian, Eurasian and Philippine Sea plates which has created a complicated configuration of active plate tectonic boundaries. Adjoint waveform tomography is especially suitable for imaging such complex regions. By simulating the 3D wavefield, it is possible to directly compare observed and simulated seismograms, thereby taking into account both body and surface waves. The method can account for the effects of anisotropy, anelasticity, wavefront healing, interference and (de)focusing that can hamper other seismological methods.

To date, sparse instrument coverage in the region has contributed to a heterogeneous path coverage. In this project, we make use of publicly available data as well as our recently deployed networks of broadband seismometers on Borneo and Sulawesi. This, in addition to access to national permanent networks, provides data from over 300 stations which promises a significant improvement in data coverage around the Banda Arc, Borneo and Sulawesi. We employ a geographical weighting scheme to minimise the effect of dense regional arrays and compile a catalogue of 118 well-constrained earthquakes, optimising for coverage, signal-to-noise ratio and data availability. An optimised window selection algorithm allows us to balance amplitude differences and include as much signal as possible while avoiding noisy data.

Here, we present a seismic waveform tomography for upper mantle structure in Southeast Asia, imaging radially anisotropic S velocity, P velocity and density. We use a gradient-based optimisation scheme (L-BFGS) and adjoint methods to obtain sensitivity kernels as the corresponding gradients. In the first part of the inversion, periods down to $50 \mathrm{~s}$ are used to update a $1 \mathrm{D}$ initial model, adapting a multi-scale approach in which long periods are inverted for first to avoid cycle skipping. In our long-period results, we observe a strong regional low S-velocity structure with an underlying highvelocity anomaly. 
Imaging Incipient and Fossil Subduction Zones

Poster Session · Thursday · 22 April · 3:45 pm Pacific

Session Chairs: Simone Pilia, University of Cambridge

(sp895@cam.ac.uk); Min Chen, Michigan State University

(chenmi22@msu.edu); Caroline Eakin, Australian National

University (caroline.eakin@anu.edu.au)

Variation of Pn Velocity and Anisotropy Around the Mantle Wedge Beneath the Eastern Gangdese Belt, Southern Tibet LI, Y., USTC, Hefei, China, yulanlee@mail.ustc.edu.cn; WANG, B., USTC, Hefei, China, bwgeo@ustc.edu.cn; HE, R., CAGS, Beijing, China, herizheng@ cags.ac.cn

Since Cenozoic, the Indian subcontinent and the Eurasian continent have been subducting continuously, which forms the present Tibetan Plateau. In the Yarlung Zangbo Suture Zone and its north and south sides, the crust and mantle materials were strongly compressed and metasomatized. Those not only created the Gangdese metallogenic belt, but also led the deep source seismicity. All of these suggest that the continent convergent mantle wedge, as the energy transfer and material exchange between crust and mantle, retains a large number of 'relic'. Therefore, the exploration of structural features of uppermost mantle is a key to reveal the tectonic environment where crustmantle structure and material evolved.

Pn wave is the main seismic phase at the uppermost mantle, and Pn tomography provides a possibility to study its structure. Base on the interstation Pn traveltime difference tomography, we used the data recorded by 113 seismograph, screened out 1640 rays, and obtained the eastern segment of Gangdese by inversion.

We carried out the Pn traveltime difference tomography calculation using an initial model with average Moho depth $75 \mathrm{~km}$, which is obtained by receiver function method.

The variation of Pn velocity in the uppermost mantle of Gangdese ranges from $7.73 \mathrm{~km} / \mathrm{s}$ to $8.43 \mathrm{~km} / \mathrm{s}$, showing strong lateral heterogeneity, which is consistent with the regional geological structure characteristics. Based on the results, it is inferred that $\sim 31^{\circ} \mathrm{N}$ is an important deep fault / boundary. In the south of $\sim 31^{\circ} \mathrm{N}$, the low velocity anomaly under YGR divides the high velocity body on the south side into two high velocity bodies, Xianza-Nimu and South-Lhasa body. Combined with the results of regional geochemical exploration, we can speculate that it is the result of the enrichment of waterrich mantle material related to the subduction of Indian plate and Neo-Tethys Ocean. On the whole, the anisotropic variation of Pn wave velocities at the uppermost lithospheric mantle in the eastern Gangdese shows the evolution process of mantle wedge material in the subduction tectonic environment.

\begin{tabular}{l}
\hline Infrasound and the Seismo-Acoustic Wavefield \\
I: Oral Session · Tuesday · 20 April · 9:45 AM Pacific \\
II: Oral Session· Wednesday · 21 April · 9:45 AM Pacific \\
III: Oral Session · Thursday · 22 April · 9:45 AM Pacific \\
Session Chairs: Jordan W. Bishop, University of Alaska \\
Fairbanks (jwbishop2@alaska.edu); Fransiska Dannemann \\
Dugick, Sandia National Laboratories, Southern Methodist \\
University (fdannemann@mail.smu.edu); Gil Averbuch, \\
Southern Methodist University (gil.averbuch@gmail.com); \\
Jeffrey B. Johnson, Boise State University (jeffreybjohnson@ \\
boisestate.edu)
\end{tabular}

A Novel Approach for the Reconstruction of Microbarom Soundscapes

DEN OUDEN, O. F. C., KNMI, TU Delft, De Bilt, Netherlands, olivierdenouden@gmail.com; SMETS, P. S. M., TU Delft, KNMI, Delft, Netherlands, p.s.m.smets@tudelft.nl; ASSINK, J. D., KNMI, De Bilt, Netherlands, assink@knmi.nl; EVERS, L. G., KNMI, TU Delft, De Bilt, Netherlands, evers@knmi.nl

A comparison is made between in-situ infrasound recordings in the microbarom band and simulations using a microbarom source model. The recordings are obtained by the 'Infrasound-Logger' (IL), a miniature sensor deployed as a biologger near the Crozet Islands in January 2020. The sensors provide barometric and differential pressure observations obtained directly above the sea surface. As the full wavefield consists of multiple spatially distributed sources, a method is introduced to account for all microbarom source contributions surrounding the IL appropriately. In this method, the realistic source field is coupled to a semi-empirical propagation model to consider the entire radiating sea-surface area. While the method relies on several assumptions, a good agreement can be observed: the reconstructed soundscape is found to be within $+-5 \mathrm{~dB}$ for $80 \%$ of the measurements in the microbarom band of 0.1-0.3 Hz. Microbarom soundscapes are essential for understanding the ambient infrasonic noise field, and infrasonic remote sensing of the upper atmosphere. Moreover, insights in the ambient noise field will improve natural hazards monitoring and verify the Comprehensive Nuclear-Test-Ban Treaty.

\section{Assessing the Temporal Coherency of Infrasound Generated by Repeated Explosions in McAlester, Oklahoma GIANNONE, M., Southern Methodist University, Texas, USA, mronacgiannone@smu.edu; AVERBUCH, G., Southern Methodist University, Texas, USA, gaverbuch@smu.edu; ARROWSMITH, S., Southern Methodist University, Texas, USA, sarrowsmith@mail.smu.edu; ANDERSON, J., Boise State University, Idaho, USA, jacobanderson152@boisestate.edu}

Current state-of-the-art atmospheric specification systems lack the temporal resolution necessary to resolve short timescale atmospheric dynamics that impact infrasound propagation. Infrasound observations, however, can provide additional information on the atmospheric state. During the summer of 2016, repeated detections were made by six regional infrasound sensors associated with the IRIS Wavefields Demonstration Community Experiment. It was determined that these signals were generated by explosions conducted at the McAlester Army Ammunitions Plant (McAAP) in McAlester, Oklahoma. The repeated detonation of sequences of $\sim 50$ explosions over short time intervals ( 20 mins) from McAAP provides an opportunity to quantify the impact of short timescale atmospheric variability on stratospheric infrasound.

The analysis of IRIS Wavefields infrasound data has yielded several interesting results, but interpretation is limited by the sub-optimal array configuration and lack of near-source capture of the acoustic waves. In order to further our research, we conducted an experiment that involved the deployment of three infrasound arrays. The first array was deployed near-source, at approximately 1-2 kilometers away from the blasting site. The second deployment was located Eastern Oklahoma State College, situated roughly 50 kilometers away from McAAP. The third array was be located at the University of the Ozarks, at approximately 240 kilometers away to detect stratospheric infrasound. We report on initial observations and analysis of this dataset.

\section{Seismo-Acoustic Data Fusion: Determining the Best Acquisition Designs for Multi-Phenomenological Monitoring Campaigns}

ALBERT, S. A., Sandia National Laboratories, New Mexico, USA, salber@ sandia.gov; BERG, E. M., Sandia National Laboratories, New Mexico, USA, eliza.m.berg@gmail.com; BROGAN, R., ENSCO, Virginia, USA, brogan. ronald@ensco.com

For the monitoring of small events, the combined analysis of seismic and infrasound data could lead to significant improvements in our understanding of the processes that simultaneously generate both types of signals. Assembling datasets that contain seismic and infrasound signals generated by a single source can provide a better understanding of specific source processes. The successful combination of signals requires understanding the fidelity of infrasound measurements - especially for local or temporary instrumentation. Therefore, the first part of this presentation will focus on understanding and constructing methods by which the quality of infrasound data can be enhanced to match that of seismic data. Then, we present an in-depth analysis on the current state of seismo-acoustic data fusion and examine its use in monitoring applications. This presentation will cover a series of seismo-acoustic datasets that contain signals generated by a variety of source processes, including earthquake sequences, avalanche/landslide signals, rocket launches, and industrial explosions. We also present findings from joint analyses of these datasets to examine the unique properties of each source type. Ultimately, we determine the best acquisition designs for multi-phenomenological monitoring campaigns with a focus on seismo-acoustic data fusion.

This research was funded by the National Nuclear Security Administration, Defense Nuclear Nonproliferation Research and Development (NNSA DNN R\&D). The authors acknowledge important interdisciplinary collaboration with scientists and engineers from LANL, LLNL, MSTS, PNNL, and SNL. Sandia National Laboratories is a multimission laboratory managed and operated by National Technology \& Engineering Solutions of Sandia, LLC, a wholly owned subsidiary of Honeywell International Inc., for the U.S. 
Department of Energy's National Nuclear Security Administration under contract DE-NA0003525.

\section{The Spectrogram, Method of Reassignment and Frequency-} Domain Beamforming

AVERBUCH, G., Southern Methodist University, Texas, USA, gaverbuch@ smu.edu

A smeared spectrogram is a result of the smoothing kernel in the short-time Fourier-transform (STFT). Besides the smeared energy, time and frequency phase information is also smeared, i.e., spectral components may contain imprecise phase information. The STFT is also used as the basis for more advanced signal processing techniques such as frequency-domain beamforming and cross-correlation (CC). Both methods seek the delay time between signals by exploring phase-shifts in the frequency domain. Due to the inexact phase information in some of the time-frequency elements, their phase shifts are incorrect. This study re-introduces the reassigned spectrogram (RS) as a measure to fix the STFT artifacts. Moreover, it is shown that by using the RS, phase shifts can be optimized and improve beamforming and CC results. Synthetic and recorded data are used to show the advantage of using the RS in time-frequency analysis, CC, and beamforming. Results show that, subject to certain constraints, the RS provides exact time-frequency representation of deterministic signals and significantly improve CC and beamforming results. Array analysis of infrasonic signals shows that better results are obtained by either the RS- or STFT-based analysis depending on the signals' spectral components and noise levels.

\section{Thousands of Explosion-Triggered Seismo-Acoustic Waveforms Over Oklahoma for Studying Multi-Scale Atmospheric Variability}

CARMICHAEL, J. D., Los Alamos National Laboratory, New Mexico, USA, joshuac@lanl.gov; THIEL, A., Oklahoma Geological Survey, Oklahoma, USA, athiel@ou.edu; DANNEMANN DUGICK, F. K., Sandia National Laboratories, New Mexico, USA, fkdanne@sandia.gov; WALTER, J., Oklahoma Geological Survey, Oklahoma, USA, jwalter@ou.edu; ARROWSMITH, S., Southern Methodist University, Texas, USA, sarrowsmith@mail.smu.edu; BLOM, P. S., Los Alamos National Laboratory, New Mexico, USA, pblom@lanl.gov

We assemble nine-months of seismic data that record routine munition disposal operations conducted by the McAlester Army Ammunition Plant (McAAP) in Oklahoma state. The seismic stations that provide these data distribute over four neighboring US states and record sequences of repetitive, quasi-similar signals almost daily. These signals record small (100s of kg) to moderate (several ton) yield sources in the $5-15 \mathrm{~Hz}$ band as wavetrains of short duration pulses ( 1 - 3 s widths) that separate by 20 s intervals, and move near acoustic propagation speeds over regions instrumented by $\sim 150$ seismic sensors. Data collected from as far as $670 \mathrm{~km}$ from source often recorded 52 such pulses per day, and over durations of 1200s. We apply noise-adaptive, constant-false alarm rate power detectors against these data to construct detection maps that reveal multi-scale spatial and temporal atmospheric variability. We compare these data with infraGA modeling output to show that range-dependent raypath focusing and mechanical coupling significantly controls spatial detection variability. Our detection maps further reveal that concurrent, tropospheric and seasonally dependent stratospheric winds most reliably predict temporal detection variability. To conclude, we deliver our blasting records, seismic waveforms, videos, and processed data products as a comprehensive, ground-truth dataset to facilitate future atmospheric and seismo-acoustic studies.

\section{An Acoustic Metamaterial Sensing Unit for Infrasound Direction of Arrival Determination}

ROUSE, I. W., Sandia National Laboratories, New Mexico, USA, jwrouse@ sandia.gov; BOWMAN, D. C., Sandia National Laboratories, New Mexico, USA, dbowma@sandia.gov; WALSH, T. F., Sandia National Laboratories, New Mexico, USA, tfwalsh@sandia.gov

We present the design and simulated performance of a single-unit infrasound microbarometer that leverages acoustic metamaterial technology to achieve direction of arrival sensing capability. Acoustic metamaterials are specialized configurations of resonators that permit subwavelength-scale units to capture sound wavefields without the need for spatially extensive arrays. We show the simulated performance of the unit, which consists of channels and pressure sensors occupying a small footprint relative to a wavelength. We suggest that this technology could replace current decimeter to kilometer scale infrasound microbarometer arrays with a single station. This is particularly useful in harsh, access-controlled environments or where space is at a pre- mium. SNL is managed and operated by NTESS under DOE NNSA contract DE-NA0003525.

\section{Local Explosion Infrasound Propagation at Dawn: Insight From the Large Surface Explosion Coupling Experiment}

KIM, K., Lawrence Livermore National Laboratory, California, USA, kim84@ llnl.gov; BOWMAN, D. C., Sandia National Laboratories, New Mexico, USA, dbowma@sandia.gov

The Large Surface Explosion Coupling Experiment (LSECE) was conducted in Yucca Flat at the Nevada National Security Site (NNSS) in October 2020. The main goal of the experiment was to provide the ground-truth data for acoustic and seismic wave coupling generated by large chemical explosions. The experiment consisted of two surface explosions of $1000 \mathrm{~kg}$ TNT equivalent. It is well known that local propagation of explosion infrasound is substantially affected by the condition of the atmospheric boundary layer near the ground. Two detonations were executed before dawn and in the afternoon to collect data under two different atmospheric conditions. In general, explosion experiments are often conducted in the middle of the day, when local infrasound propagation is mainly governed by a negative temperature gradient in the boundary layer. However, the LSECE experiment provides rare groundtruth data generated and measured before dawn when the vertical temperature and wind variations are distinctly different from those in the afternoon. We compare explosion infrasound generation and propagation at dawn with other data collected in the daytime and test our modeling capability to predict the signal propagation.

\section{On the Effect of Bathymetry on Microbaroms Signals}

DE CARLO, M., CEA, DAM, DIF, Arpajon, France, marine.decarlo@gmail. com; LE PICHON, A., CEA, DAM, DIM, Arpajon, France, alexis.le-pichon@ cea.fr; ARDHUIN, F., LOPS / CNRS, Plouzané, France, ardhuin@ifremer.fr

Ocean wave interactions generate both seismic and acoustic noise in the frequency band $0.1-1 \mathrm{~Hz}$ respectively known as microseisms and microbaroms. Though the bathymetry is known as an essential feature for microseism modelling, its effect is less evident for microbaroms. In this study, we present a recent microbarom model in which the bathymetry effect depends on the vertical emission angle. The validation of this model using global infrasound observations from the International Monitoring System indicates that the bathymetry effect is weak for microbaroms detected at ground stations. It is expected that improved characterization of microbarom source model will enhance knowledge of the seismo-acoustic wavefield generated by coupling processes at the ocean-earth-atmosphere interface.

\section{Predicting Atmospheric Structure for Infrasound Propagation Using Machine Learning}

ALBERT, S. A., Sandia National Laboratories, New Mexico, USA, salber@ sandia.gov; DOWNEY, N., Sandia National Laboratories, New Mexico, USA njdowne@sandia.gov

Infrasound signals travel through the atmosphere, a dynamic medium. Therefore, it is important to have accurate atmospheric specification information for modeling infrasound propagation. The National Centers for Environmental Prediction (NCEP) and the European Centre for MediumRange Weather Forecasts' (ECMWF) weather forecast models and reanalysis products are often used to determine atmospheric profiles for infrasound propagation modeling before or after an event of interest. These models are based on physical principles but contain uncertainties that lead to inaccuracies in infrasound propagation modeling, especially for low signal-to-noise ratio (SNR), quickly-attenuating, waveforms generated by small events. Machine learning approaches have proven useful in predicting tropospheric weather. Using a Long Short-Term Memory (LSTM) network we predict the temperature, wind speed, and wind direction of the lower and middle atmosphere at radiosonde stations locations throughout the conterminous United States. We train the model using 10 years of historical radiosonde weather observations from 2009-2019 and predict temperature, wind speed, and wind direction up to an altitude of $\sim 50 \mathrm{~km}$. Predictions are made for 24 and 48 hours in the future and outperform the ECMWF weather reanalysis products for the same time and location.

This research was funded by the National Nuclear Security Administration, Defense Nuclear Nonproliferation Research and Development (NNSA DNN R\&D). The authors acknowledge important interdisciplinary collaboration with scientists and engineers from LANL, LLNL, MSTS, PNNL, and SNL. Sandia National Laboratories is a multimission laboratory managed and operated by National Technology \& Engineering Solutions of Sandia, LLC, a wholly owned subsidiary of Honeywell International Inc., for the U.S. 
Department of Energy's National Nuclear Security Administration under contract DE-NA0003525.

Seismoacoustic and Hydroacoustic Responses of Explosions in Different Geological Materials: A Parametric Study of Different Emplacements and Different Energy Depositions and Comparisons With Experimental Data

EZZEDINE, S. M., Lawrence Livermore National Laboratory, California, USA, ezzedine1@llnl.gov; VOROBIEV, O. Y., Lawrence Livermore National Laboratory, California, USA, vorobiev1@llnl.gov; RODGERS, A. J., Lawrence Livermore National Laboratory, California, USA, rodgers7@llnl.gov; WALTER, W. R., Lawrence Livermore National Laboratory, California, USA, walter5@llnl.gov; ANTOUN, T. H., Lawrence Livermore National Laboratory, California, USA, antoun1@llnl.gov

We have performed quasi-3D high-resolution numerical simulations of surface and underground explosions using LLNL's massively parallel eulerian hydrocode GEODYN to assess the impact of parameters such as yield, height of burst (HOB), depth of burst (DOB) and geological material on the resulting overpressure in air and seismic motions at distance. The material properties span a large spectrum from hard rock, such as granite with low porosity, limestone, sandstone, tuff, salt, and very weak material, such as dry and wet alluvium, water and muds. Arrival times to surface station are determined by the shock wave propagation and the coupling of ground motion. We show that overpressures and peak velocities due to the same yield at the same scaled $\mathrm{HOB} / \mathrm{DOB}$ are functionally very similar regardless the geological fabric and therefore the response can be scaled. Moreover, the impulse is calculated by integrating the initial positive pressure time-history. It was found that the functional form of the impulse as a function of scaled HOB/DOB is also consistent for emplacements above ground, at ground level and down to depths where cratering occurs regardless for all geological materials even though the material properties show drastic geomechanical variations. While the current study used numerical simulation from idealized blast and settings, additional factors can complicate observed seismic signals and bias the amplitudes and subsequent yield and HOB/DOB estimates. For example, we show that the emplacement lithology strongly impacts seismic amplitudes for deeply buried explosions. Furthermore, the behavior with $\mathrm{HOB} / \mathrm{DOB}$ is different for the materials considered. Results are compared with legacy experimental data, and the more recent forensic (LSECE) and proof-of-concept (MDE) surface explosions conducted at the Nevada National Security Site.

This work performed under the auspices of the U.S. Department of Energy by Lawrence Livermore National Laboratory under Contract DE-AC52-07NA27344.

\section{Changes in Ambient Urban Infrasound During the COVID- 19 Pandemic}

BIRD, E. J., The University of North Carolina at Chapel Hill, North Carolina, USA, elibird@live.unc.edu; BOWMAN, D. C., Sandia National Laboratories, New Mexico, USA, dbowma@sandia.gov; SEASTRAND, D. R., Nevada National Security Site, Nevada, USA, SeastrDR@nv.doe.gov; WRIGHT, M. A., Nevada National Security Site, New Mexico, USA, wrightma@nv.doe.gov; LEES, J. M., The University of North Carolina at Chapel Hill, North Carolina, USA, jonathan.lees@unc.edu; DANNEMANN DUGICK, F. K., Sandia National Laboratories, New Mexico, USA, fkdanne@sandia.gov

Infrasound is a valuable and poorly utilized resource in understanding urban environments. While studies of natural signals often make use of low-frequency acoustics, discussions of anthropogenic signals usually consider only the audio range. Shutdowns related to the COVID-19 pandemic in early 2020 reduced human activity throughout affected areas, greatly impacting urban acoustics. We consider data from an infrasound array in Las Vegas, NV, which recorded throughout the shutdowns. The array distinguishes the times of day and weeks during which acoustic power sees the greatest declines. It further displays variations in said declines geographically. These results provide a clearer view of low-frequency acoustics, both during and outside of shutdowns.

\section{Detecting and Locating Acoustic Events With a Balloon Borne Aeroseismometer}

BOWMAN, D. C., Sandia National Laboratories, New Mexico, USA, dbowma@sandia.gov; ROUSE, J. W., Sandia National Laboratories, New Mexico, USA, jwrouse@sandia.gov; KRISHNAMOORTHY, S., Jet Propulsion Laboratory, California, USA, siddharth.krishnamoothy@jpl.nasa.gov

Microbarometers on free flying balloons have enabled a whole new class of infrasound investigations. Because pressure is a scalar, however, typical microbarometers cannot determine the direction of arrival of an acoustic wave. On Earth's surface, this issue is solved by deploying sensor arrays with apertures of tens to thousands of meters. This is clearly not feasible in the air. Instead, we use accelerometers and inertial measurement units to capture the vibrations induced on the balloon by impinging acoustic waves. We show that we can form crude event locations without taking the flight system's impulse response into account. More sophisticated processing methods are in development and should greatly improve on this capability in the coming years. The "aeroseismometry" technique presented here has implications for effective sparse balloon networks on Earth as well as potential Venus seismology missions. SNL is managed and operated by NTESS under DOE NNSA contract DE-NA0003525.

\section{Infrasound Transmission in the "Shadow Zone" Observed on Balloons in the Lower Stratosphere}

KERO, I., Swedish Institute of Space Physics, Kiruna, Sweden, kero@irf. se; BOWMAN, D. C., Sandia National Laboratories, New Mexico, USA, dbowma@sandia.gov; BIRD, E. J., The University of North Carolina at Chapel Hill, North Carolina, USA, elibird@live.unc.edu

The temperature and wind structure of the lower atmosphere creates an "acoustic shadow", where infrasound propagation is not expected to occur from a ground based source. This region begins several tens of kilometers from the source and typically ends between one hundred and two hundred kilometers range in the downwind direction of the stratospheric jet. Ground microbarometers still occasionally record acoustic arrivals in this zone due to tropospheric waveguides and/or scattering off of stratospheric structure not accounted for in atmospheric models. However, the properties of these signals in the lower stratosphere (above the tropospheric duct) is unknown, because they have never been previously observed on sensors at these altitudes. Here we present a set of acoustic arrivals from ground explosions recorded on balloons in the lower stratosphere during the MINI-BOOST campaign in Sweden. Although some of the balloons were in the shadow zone, they still recorded a variety of waveforms from each event. Dual payloads on tethers show that the acoustic waves came from below in these instances. We discuss the provenance of these signals and implications for acoustic transmission in regions where geometric ray theory predicts their absence. SNL is managed and operated by NTESS under DOE NNSA contract DE-NA0003525.

\section{Near and Far-Field Seismo-Acoustic Analysis of Mb 4.9 Mining Induced Earthquake Nearby Kiruna, Sweden} TURQUET, A. L., Stiftelsen Norsar, Kjeller, Norway, antoine@norsar.no; BRISSAUD, Q., Stiftelsen Norsar, Kjeller, Norway, quentin@norsar.no; KERO, J., IRF - Swedish Institute of Space Physics, Kiruna, Sweden, kero@ irf.se; NÄSHOLM, S., Stiftelsen Norsar, Kjeller, Norway, peter@norsar.no; LE PICHON, A., CEA - French Alternative Energies and Atomic Energy Commission, Arpajon, France, alexis.le-pichon@cea.fr; KVÆRNA, T., Stiftelsen Norsar, Kjeller, Norway, tormod@norsar.no; LISTOWSKI, C., CEA

- French Alternative Energies and Atomic Energy Commission, Arpajon, France, constantino.listowski@cea.fr

An earthquake happened in 18 May 2020 early morning in the Kiruna underground iron ore mine, Northern Sweden having a magnitude $\mathrm{Mw}$ 4.9. Following the earthquake, the mine was immediately evacuated because of the risk of aftershocks. This event is the largest mining-induced earthquake that has ever taken place in Scandinavia and it produced signals recorded by three infrasound arrays at distances of $7 \mathrm{~km}$ (KRIS, Sweden), $155 \mathrm{~km}$ (IS37, Norway) and $286 \mathrm{~km}$ (ARCI, Norway). We explore seismo-acoustic features of this event recorded in near and far-field. This procedure allows us to track how the signal propagated in the solid earth until the seismometers located at various distances or transmitted to the atmosphere and propagated towards the infrasound stations. Our study also provides a detailed comparison between observed and predicted wave front characteristics at the arrays. We conduct a comparison of amplitude corrected for propagation effect versus magnitude and ground shaking amplitude. These results show that this mine-quake having "unconventional" source mechanism generated infrasound recorded up to $\sim 300 \mathrm{~km}$ and provided ground shaking information as well as local amplification caused by topographic and geological features.

\section{Seismo-Acoustic Signatures of Proximal Earthquakes From} the Stanley, ID, USA Aftershock Sequence in 2020

JOHNSON, J. B., Boise State University, Idaho, USA, jeffreybjohnson@ boisestate.edu; ANDERSON, J., Boise State University, Idaho, USA, jacobanderson152@boisestate.edu; WILBUR, S. F., Boise State University, Idaho, USA, spencerwilbur@u.boisestate.edu; ARROWSMITH, S., Southern Methodist University, Idaho, USA, sarrowsmith@mail.smu.edu; MIKESELL, 
T. D., Boise State University, Idaho, USA, dylanmikesell@boisestate.edu; LIBERTY, L., Boise State University, Idaho, USA, lliberty@boisestate.edu

Earthquakes as small as M2 produce infrasound that is detectable by infrasound arrays at proximal distances of several tens of kilometers. We report on observations from several hundred proximal earthquakes (M2.5-M4.0) recorded using seven infrasound mini-arrays ( 3 sensors) and broadband seismic data located less than $25 \mathrm{~km}$ from earthquake epicenters in the Stanley (Idaho) earthquake aftershock sequence. Analysis of many events permits comparison of earthquake source parameters and infrasound generation including relationships between source size, source depth, focal mechanism, and seismo-acoustic energy partitioning (i.e., energy radiated into the atmosphere compared to the ground).

A previous study focused on a single MWR3.6 from 7 April 2020 and used array back azimuth and back projection constraints to locate regions of infrasound generation. It found that the recorded infrasound wavefield is composed of both primary infrasound generation (at or near the infrasound arrays) and secondary radiators located throughout the region, which appear to be concentrated in areas of high topographic relief. Similar analysis is presented here for several hundred events and will permit the construction of 'heat' maps delineating areas of particularly pronounced infrasound generation.

\section{Infrasound and the Seismo-Acoustic Wavefield \\ Poster Session · Tuesday · 20 April · 4:15 PM Pacific \\ Session Chairs: Jordan W. Bishop, University of Alaska \\ Fairbanks (jwbishop2@alaska.edu); Fransiska Dannemann \\ Dugick, Sandia National Laboratories, Southern Methodist \\ University (fdannemann@mail.smu.edu); Gil Averbuch, \\ Southern Methodist University (gil.averbuch@gmail.com); \\ Jeffrey B. Johnson, Boise State University (jeffreybjohnson@ \\ boisestate.edu)}

\section{D Simulations of Seismo-Acoustic Coupling Over Topography}

BISHOP, J. W., University of Alaska Fairbanks, Alaska, USA, jwbishop2@ alaska.edu; FEE, D., University of Alaska Fairbanks, Alaska, USA, dfee1@ alaska.edu; MODRAK, R., Los Alamos National Laboratory, New Mexico, USA, rmodrak@lanl.gov; TAPE, C., University of Alaska Fairbanks, Alaska, USA, ctape@alaska.edu; KIM, K., Lawrence Livermore National Laboratory, California, USA, kim84@llnl.gov

Observations from field experiments have shown that a propagating acoustic wave can generate a variety of elastic waves as it impinges upon the earth. Theoretical treatments have thoroughly examined reflections and refractions at a planar interface, but nonplanar interfaces, particularly topography, can have considerable impact on local infrasonic propagation and have not been addressed in coupling scenarios. Numerical approaches to this problem are somewhat limited in the presence of topography, and it is typically assumed that the ground surface is a rigid interface. SPECFEM3D, a spectral finite element code, can numerically simulate the coupling between acoustic and elastic waves over meshed topography. With a series of halfspace models, we investigate the effect of the angle of incidence and subsurface structure on acoustic to elastic coupling. These simulations are sourced with acoustic analogs for a variety of moment tensor sources, and we show that the general diagonal moment tensor in a fluid medium can be related to a classical acoustic quadrupole source. When the moment tensor is isotropic, this expression collapses to an exact relationship between the seismic moment and a monopole acoustic source. Modeling results show significant deviation at steep incidence angles from the commonly assumed expressions for transfer coefficients, which has implications for propagation with multiple surface interactions and larger propagation distances. Large energy transfer occurs at steeper incidence angles when the shear wave speed of the earth is less than the sound speed of the incident acoustic wave, which we attribute to increased infrasound to S-wave and surface wave coupling. This effect appears to be broadly consistent with previously published observations by Edwards et al. (2007) on seismo-acoustic coupling. For comparison, we also simulate coupling over topography using a smoothed model of Sakurajima Volcano, Japan. Using a similar methodology to the halfspace cases, we estimate energy admittance values and possible spatial relationships to topographic relief.

\section{An Analysis of Air-to-Ground Coupled Seismic Arrivals} From the Camp Minden, U.S., Explosion, 16 October 2012 WILLS, G., AWE Blacknest, Reading, United Kingdom, gemma.wills@awe. co.uk; GREEN, D., AWE Blacknest, Reading, United Kingdom, david.green@ awe.co.uk; NIPPRESS, A., AWE Blacknest, Reading, United Kingdom, alex. nippress@awe.co.uk; SPENCE, P., AWE, Reading, United Kingdom, peter. spence@awe.co.uk

Co-located microbarometers and seismometers in the spatially dense USArray Transportable Array (TA) provide a unique opportunity to study airto-ground coupled signals (Vergoz et al., 2019). Infrasound signals, resulting from an accidental explosion which occurred 2012, October $16^{\text {th }} \sim 04: 25$ UTC, at Camp Minden Army Ammunition Plant, Louisiana, USA, were recorded up to $1482 \mathrm{~km}$ away in southern Florida, aided by a dominant stratospheric duct, enhancing propagation to the east, consistent with existing atmospheric specifications. Air-to-ground coupled seismic signals were recorded on co-located seismometers up to $1049 \mathrm{~km}$ east of the event. Air-to-ground coupling coefficients were calculated using maximum trough-to-peak amplitudes at each station that recorded both infrasound and seismic signals. These coefficients range from $3.96 \mathrm{E}-05$ to $9.76 \mathrm{E}-08 \mathrm{~ms}^{-1} / \mathrm{Pa}$ consistent with previous studies (Albert et al., 2013; Edwards et al., 2008). Despite significant scatter, calculated coefficients from soft rock sites in the Mississippi embayment exhibit coupling coefficients approximately an order-of-magnitude larger than those from hard rock sites in the Appalachian mountains. The high spatial density of recordings provides a clear observation of rapid lateral change from the ensonified region to the shadow zone, consistent with simulations of the stratospheric propagation using an in-house atmospheric acoustic modal modelling code.

UK Ministry of Defence (Crown Owned Copyright 2021/AWE

\section{Resolving Complex Infrasound Wavefields Using a Dense Array}

ANDERSON, I., Boise State University, Idaho, USA, ajakef@gmail.com; JOHNSON, J. B., Boise State University, Idaho, USA, jeffreybjohnson@ boisestate.edu; MIKESELL, T. D., Boise State University, Idaho, USA, dylanmikesell@boisestate.edu; LIBERTY, L., Boise State University, Idaho, USA, lliberty@boisestate.edu; ARROWSMITH, S., Southern Methodist University, Texas, USA, sarrowsmith@mail.smu.edu

Secondary infrasound from earthquakes may contain useful information on ground shaking, but the presence of many interfering waves from different radiators complicates source analyses. We address this problem using a dense array of approximately 20 sensors. Using both direct infrasound waves from a local earthquake approximately under the array (M3.5, $10 \mathrm{~km}$ depth, aftershock of central Idaho earthquake) and refracted infrasound waves from a regional event (M6.5, $720 \mathrm{~km}$ distance, Tonopah NV), we show that both the slowness resolution and ability to detect correlated signal improve dramatically by increasing the number of sensors in the array. As an additional benefit, redundancy of array elements makes the array's functionality less vulnerable to individual sensor dropout or loss.

Many routine applications of infrasound face the challenge of distinguishing wave sources of interest from superposed waves from many sources, and single-channel rapid-deploy instrumentation suitable for "large-N" recording is increasingly available (e.g., the Gem infrasound logger used in this work). Consequently, we expect our findings about dense array capabilities to be broadly applicable beyond our specific problem of earthquake infrasound.

\section{Tracking Secondary Lahar Flow Paths and Characterizing Pulses and Surges Using Infrasound Array Networks at Volcán De Fuego, Guatemala}

BOSA, A. R., Boise State University, Idaho, USA, ashleybosa@u.boisestate. edu; JOHNSON, J. B., Boise State University, Idaho, USA, jeffreybjohnson@ boisestate.edu; DE ANGELIS, S., University of Liverpool, Liverpool, United Kingdom, s.de-angelis@liverpool.ac.uk; LYONS, J., U.S. Geological Survey, Alaska, USA, jlyons@usgs.gov; ESCOBAR-WOLF, R., Michigan Technological University, Michigan, USA, rpescoba@mtu.edu; ROCA, A., INSIVUMEH, Guatemala City, Guatemala, a1000kr2611@gmail.com; ANDERSON, J., Boise State University, Idaho, USA, jacobanderson152@boisestate.edu; PINEDA, A., Independent, Guatemala City, Guatemala, pineda.armando@gmail.com

Lahars are one of the most impactful hazards at many volcanoes, including at Volcan Fuego (Guatemala). Due to their sudden onset, variations in initiation mechanisms (rainfall, eruption-induced, or spontaneous), and complex flow behavior, lahars remain a major challenge to those studying them. On 1 December 2018, a storm system at Volcan Fuego produced heavy rainfall and a subsequent lahar. This event was detected by permanent, telemetered 
seismo-acoustic stations along several of the river channels, particularly two stations located along the Las Lajas channel, approximately $7.5 \mathrm{~km}$ and $12 \mathrm{~km}$ from the summit, on the southeast side of the volcano. To establish the timing, duration, and speed of the lahar, cross-correlated lag times were calculated for the infrasound records within both the infrasound arrays and between the two different arrays. Co-located seismic and acoustic signals are highly correlated and indicate at least 4 or 5 pulses/surges in the lahar with approximately 10 minute intervals between pulses. Flow speeds appeared to decrease from $\sim 8.3 \mathrm{~m} / \mathrm{s}$ to $\sim 6.3 \mathrm{~m} / \mathrm{s}$ over the course of the event. We argue that varying sediment load is reflected by clear fluctuations in infrasound and seismic power recorded at one of the stations. This particular event studied with infrasound provides insight into how lahars occur around Volcán Fuego. When compared with the seismic records, infrasound signal analysis reinforces the importance and utility of this technology to detect and track rain-triggered lahars, as well as quantify the hydrological and geomorphic parameters that characterize these types of flows. Future studies of Volcán Fuego will focus on quantifying the occurrence of these events as rapid gravity mass movements.

\section{Utilizing Advanced Acoustic Modeling Techniques to Inform Experimental Field Deployments}

DANNEMANN DUGICK, F. K., Sandia National Laboratories, New Mexico, USA, fkdanne@sandia.gov; BOWMAN, D. C., Sandia National Laboratories, New Mexico, USA, dbowma@sandia.gov

Acoustic ray-tracing methodologies that predict direct signals arrivals from a geographic source of interest are often used as a first step for justifying seismoacoustic sensor deployments in the experimental planning phase. Results are typically presented as a series of predicted arrivals at a point in time and space and offer first order predictions of expected direct arrivals from source to receiver. Google Earth offers a complementary valuable tool for deployment planning by providing a high level overview of terrain, land ownership and accessibility; however in order to overlay results of interest Google Earth requires special formatted (KML) files, typically generated in ArcGIS or similar programs. We present a methodology for converting ray-tracing output to KML files for field planning purposes. This methodology offers the opportunity to produce experimental deployments that improve likelihoods of observing acoustic signals by applying data-driven decision making procedures.

SNL is managed and operated by NTESS under DOE NNSA contract DE-NA0003525

\section{Insight Seismology on Mars: Results From the First Martian Year of Data and Prospects for the Future Oral Session · Friday $\cdot 23$ April $\cdot$ 2:00 PM Pacific Session Chairs: Mark P. Panning, Jet Propulsion Laboratory, Caltech (mark.p.panning@jpl.nasa.gov); Sharon Kedar, Jet Propulsion Laboratory, Caltech (sharon.kedar@jpl.nasa. gov); William B. Banerdt, Jet Propulsion Laboratory, Caltech (william.b.banerdt@jpl.nasa.gov)}

\section{Accessing the Seismic Event Catalog from the Insight Mission to Mars}

IOHNSON, A., Incorporated Research Institutions for Seismology, Washington, USA, autumn@iris.washington.edu; CLARK, A., Incorporated Research Institutions for Seismology, Washington, USA, adam@iris. washington.edu; EUCHNER, F., ETH Zürich, Zürich, Switzerland, fabian. euchner@sed.ethz.ch; CASEY, R., Incorporated Research Institutions for Seismology, Washington, USA, rob@iris.washington.edu; CLINTON, J., ETH Zürich, Zürich, Switzerland, jclinton@sed.ethz.ch; BENSON, R., Incorporated Research Institutions for Seismology, Washington, USA, rick@ iris.washington.edu; CARTER, J., Incorporated Research Institutions for Seismology, Washington, USA, jerry.carter@iris.edu; BRAVO, T., Incorporated Research Institutions for Seismology, District of Columbia, USA, tkb@iris. edu; BANERDT, W. B., NASA Jet Propulsion Laboratory, California, USA, william.b.banerdt@jpl.nasa.gov

The IRIS DMC has long been a repository for Earth-based seismic data and has for the past year hosted the seismic data from the InSight lander on Mars. With the release of the mars-event web service, we are for the first time providing web service access to a catalog of seismic events from Mars ('marsquakes'). Funded by NASA's Jet Propulsion Laboratory, the RESTful service is an IRIS implementation of the FDSN-event specification, adapted to the unique features of Martian seismic events. It provides a query interface to the Mars Seismic Catalog, provided in QuakeML format with Mars-specific extensions by InSight's Marsquake Service team led by ETH Zürich. The community-based standards used are important to ensure the data are publicly available and easily accessible for the long-term.

The Marsquake Seismic Catalog aims to be a planetary-wide catalog of events generated from the seismic data recorded on SEIS, a single seismometer package. This instrument is part of NASA's InSight mission and was designed and produced by IPGP and the French Space Agency (CNES). It was deployed onto the surface of Mars in February 2019, and since this time has recorded nearly 500 marsquakes and over 700 thermal cracking events. In compiling the catalog, MQS developed new techniques for event detection, single station location and magnitude estimates that have been applied to the data received from Mars.

We will discuss how to use the mars-event service to access and query this exciting new dataset, and the unique ways in which events are located and characterized on Mars. The catalogue is updated by MQS every 3 months, with a delay of 3 months, and each version can be accessed by the service.

\section{H/V Spectral Ratios at the Insight Landing Site Using Ambient Noise and Marsquakes Records}

CARRASCO, S., University of Cologne, Cologne, Germany, acarrasc@unikoeln.de; KNAPMEYER-ENDRUN, B., University of Cologne, Cologne, Germany, brigitte.knapmeyer-endrun@uni-koeln.de; MARGERIN, L., Université Toulouse III Paul Sabatier, CNRS, CNES, Toulouse, France, ludovic.margerin@irap.omp.eu; SCHMELZBACH, C., ETH Zürich, Zürich, Switzerland, cedric.schmelzbach@erdw.ethz.ch; CLINTON, J., ETH Zürich, Zürich, Switzerland, jclinton@sed.ethz.ch; STÄHLER, S., ETH Zürich, Zürich, Switzerland, simon.staehler@erdw.ethz.ch; GIARDINI, D., ETH Zürich, Zürich, Switzerland, domenico.giardini@erdw.ethz.ch; KEDAR, S., Caltech, California, USA, sharon.kedar@jpl.nasa.gov; GROTT, M., DLR Institute of Planetary Research, Berlin, Germany, matthias.grott@dlr.de; GOLOMBEK, M., Caltech, California, USA, matthew.p.golombek@jpl.nasa. gov; LOGNONNÉ, P., Université de Paris, Paris, France, lognonne@ipgp.fr; BANFIELD, D., Cornell University, New York, USA, banfield@astro.cornell. edu

The InSight mission landed on Mars on November 26th, 2018 and its seismometer, the Seismic Experiment for Interior Structure (SEIS), has recorded continuous Martian seismic data since February 2019, consisting of mainly ambient seismic noise but also hundreds of seismic events.

We used the SEIS data to study the horizontal-to-vertical spectral ratios from both the ambient seismic noise (nHV) and the seismic events (eHV), for frequencies above $0.6 \mathrm{~Hz}$, in order to get further constraints on the first tens of meters at the Insight landing site. The nHV curve was obtained by using data segments of $50 \mathrm{~s}$ over more than 400 Sols. The preferred nHV curve is observed during the northern spring and summer at low wind levels and it is a mostly flat curve with a prominent trough around $\sim 2.4 \mathrm{~Hz}$. Outside of these time periods, the nHV curve is contaminated with artificial peaks likely related to lander modes. On the other hand, the eHV curve was created using 336 seismic events with quality either $\mathrm{A}, \mathrm{B}$ or $\mathrm{C}$, as defined by the Marsquake Service. For each seismic event, we computed the signal-to-noise ratio (SNR) at each frequency and only frequencies with $\mathrm{SNR}>3$ were used to obtain the final eHV curve. In addition to the $2.4 \mathrm{~Hz}$ trough, the final eHV curve shows a strong peak around $8 \mathrm{~Hz}$, which is not observed from the ambient noise data possibly due to a lack of seismic energy in this frequency band able to excite it.

A preliminary inversion of the eHV curve, considering the fundamental mode of the Rayleigh wave only, shows that the $2.4 \mathrm{~Hz}$ trough and the $8 \mathrm{~Hz}$ peak can be explained by a shear-wave velocity model increasing from the surface to a depth of 5-8 $\mathrm{m}$ (likely the boundary between the regolith and coarse ejecta), in good agreement with previous analysis based on compliance observations, hammering measurements and satellite images. At this depth, a discontinuity leading to a higher velocity layer is observed, which is followed by a deeper low-velocity layer about $20 \mathrm{~m}$ thick. The modeling assuming body waves only or a full diffuse seismic wavefield is currently under investigation.

\section{Resonances and Lander Modes Observed by Insight on Mars (1-9 Hz)}

DAHMEN, N., ETH Zürich, Zürich, Switzerland, nikolaj.dahmen@erdw. ethz.ch; ZENHÄUSERN, G., ETH Zürich, Zürich, Switzerland, geraldine. zenhaeusern@erdw.ethz.ch; CLINTON, J., ETH Zürich, Zürich, Switzerland, jclinton@sed.ethz.ch; GIARDINI, D., ETH Zürich, Zürich, Switzerland, domenico.giardini@erdw.ethz.ch; STÄHLER, S., ETH Zürich, Zürich, Switzerland, simon.staehler@erdw.ethz.ch; CEYLAN, S., ETH Zürich, Zürich, Switzerland, savas.ceylan@erdw.ethz.ch; CHARALAMBOUS, C., Imperial College London, London, United Kingdom, constantinos.charalambous05@ 
imperial.ac.uk; VAN DRIEL, M., ETH Zürich, Zürich, Switzerland, vandriel@ erdw.ethz.ch; HURST, K. J., Jet Propulsion Laboratory, California, USA, kenneth.j.hurst@jpl.nasa.gov; KEDAR, S., Jet Propulsion Laboratory, California, USA, sharon.kedar@jpl.nasa.gov; LOGNONNÉ, P., Institut de Physique du Globe de Paris, Paris, France, lognonne@ipgp.fr; MURDOCH, N., Institut Supérieur de l'Aéronautique et de l'Espace SUPAERO, Toulouse, France, naomi.murdoch@isae-supaero.fr; MYHILL, R., University of Bristol, Bristol, United Kingdom, bob.myhill@bristol.ac.uk; PANNING, M. P., Jet Propulsion Laboratory, California, USA, mark.p.panning@jpl.nasa.gov; PIKE, W. T., Imperial College London, London, United Kingdom, w.t.pike@ imperial.ac.uk; SCHMELZBACH, C., ETH Zürich, Zürich, Switzerland, cedric.schmelzbach@erdw.ethz.ch; SCHOLZ, J., Max Planck Institute for Solar System Research, Göttingen, Germany, scholz@mps.mpg.de; STOTT, A. E., Institut Supérieur de l'Aéronautique et de l'Espace SUPAERO, Toulouse, France, alexander.stott@isae-supaero.fr; BANERDT, W. B., Jet Propulsion Laboratory, California, USA, william.b.banerdt@jpl.nasa.gov

NASA's InSight lander successfully touched down on Mars in November 2018 and has continuous recordings from its seismometer since February 2019. The seismic recordings reveal diurnal and seasonal changes of the broad band noise level, which are consistent with variations of the local atmospheric conditions.

The seismic data include a variety of spectral peaks, which are interpreted as wind-excited mechanical resonances of the lander, resonances of the subsurface, or artifacts produced in the measurement system. Understanding the origin of these signals is critical for the detection and characterization of marsquakes.

We identify the major spectral peaks between 1 and $9 \mathrm{~Hz}$, corresponding to the frequency range most relevant to observed marsquake events. We track the variations in frequency, amplitude, and polarization of these peaks over the duration of the mission until Sol 650. The majority of these peaks can readily be classified as measurement artifacts or lander resonances. We find that some temporary peaks correlate well with movements of the robotic arm. Of particular interest is the prominent resonance at $2.4 \mathrm{~Hz}$, which is used to discriminate between seismic events and local noise. In contrast to the lander modes, the $2.4 \mathrm{~Hz}$ resonance has distinctly different features: 1) a broad and stable spectral shape, slightly shifted on each component; 2) predominantly vertical energy/polarization; 3) temperature-independent peak frequency; 4) weak or no amplification by local winds, though there is a slow change in the diurnal and seasonal amplitude; 5) excitation during all seismic events that excite this frequency band.

Based on these observations, we suggest that the $2.4 \mathrm{~Hz}$ resonance is the only mode that could be related to a local ground structure.

\section{Results From the Insight Prime Mission}

BANERDT, W. B., Jet Propulsion Laboratory, Caltech, California, USA william.b.banerdt@jpl.nasa.gov; LOGNONNÉ, P., Université de Paris, Institut de Physique du Globe de Paris; Institut Universitaire de France, Paris, France, lognonne@ipgp.fr; GIARDINI, D., Institute of Geophysics, ETH Zürich, Zürich, Switzerland, domenico.giardini@erdw.ethz.ch; PIKE, W. T., Imperial College London, London, United Kingdom, w.t.pike@imperial. ac.uk; PANNING, M. P., Jet Propulsion Laboratory, Caltech, California, USA, mark.p.panning@jpl.nasa.gov; BANFIELD, D., Cornell University, New York, USA, banfield@astro.cornell.edu; DEHANT, V., Royal Observatory of Belgium, Brussels, Belgium, veronique.dehant@oma.be; SPIGA, A., Laboratoire de Météorologie Dynamique/Institut Pierre Simon Laplace, Sorbonne Université, CNRS, École Polytechnique, École Normale Supérieure, Paris, France, aymeric.spiga@lmd.jussieu.fr

The InSight seismometer (SEIS) has now been operating continuously on the surface of Mars for more than 2 years. In addition to SEIS, InSight comprises a diverse geophysical observatory including a heat flow and sub-surface physical properties experiment (HP3), a geodesy (planetary rotation dynamics) experiment (RISE), and a suite of environmental sensors measuring the magnetic field and atmospheric temperature, pressure and wind (APSS). SEIS has been providing near-continuous seismic monitoring of Mars, with background noise levels orders of magnitude lower than that achievable on the Earth. Since the first detection of a marsquake in April of 2019, the SEIS team has identified more than 500 events that cannot be explained by local environment or spacecraft activity, at least several dozen of which clearly appear to be of tectonic origin and can be analyzed to derive planetary structure. We present a summary of observations and results from the SEIS instrument as well as a summary of other geophysical observations made by InSight during the past two years.

\section{The Seismicity on Mars as Recorded by Insight's Marsquake Service}

CEYLAN, S., ETH Zürich, Zürich, Switzerland, savas.ceylan@erdw.ethz.ch; CLINTON, J., Swiss Seismological Service, Zürich, Switzerland, jclinton@ sed.ethz.ch; HORLESTON, A., University of Bristol, Bristol, United Kingdom, anna.horleston@bristol.ac.uk; GIARDINI, D., ETH Zürich, Zürich, Switzerland, domenico.giardini@erdw.ethz.ch; KAWAMURA, T., Institut de Physique du Globe de Paris, Paris, France, kawamura@ipgp.fr; STÄHLER, S. ETH Zürich, Zürich, Switzerland, simon.staehler@erdw.ethz.ch; BANERDT, W. B., Jet Propulsion Laboratory, California, USA, william.b.banerdt@ jpl.nasa.gov; BÖSE, M., Swiss Seismological Service, Zürich, Switzerland, mboese@sed.ethz.ch; CHARALAMBOUS, C., Imperial College London, London, United Kingdom, constantinos.charalambous05@imperial.ac.uk; DAHMEN, N., ETH Zürich, Zürich, Switzerland, nikolaj.dahmen@erdw. ethz.ch; VAN DRIEL, M., ETH Zürich, Zürich, Switzerland, vandriel@erdw. ethz.ch; EUCHNER, F., ETH Zürich, Zürich, Switzerland, fabian.euchner@ sed.ethz.ch; KHAN, A., ETH Zürich, Zürich, Switzerland, amir.khan@erdw. ethz.ch; KNAPMEYER, M., German Aerospace Center, Berlin, Germany, martin.knapmeyer@dlr.de; LOGNONNÉ, P., Institut de Physique du Globe de Paris, Paris, France, lognonne@ipgp.fr; PANNING, M. P., Jet Propulsion Laboratory, California, USA, mark.p.panning@jpl.nasa.gov; PIKE, W. T., Imperial College London, London, United Kingdom, w.t.pike@imperial. ac.uk; PLASMAN, M., Institut de Physique du Globe de Paris, Paris, France, plasman@ipgp.fr; SCHOLZ, J., MPS, Göttingen, Germany, scholz@mps.mpg. de; SMREKAR, S. E., Jet Propulsion Laboratory, California, USA, ssmrekar@ jpl.nasa.gov; ZENHÄUSERN, G., ETH Zürich, Zürich, Switzerland, geraldine. zenhaeusern@erdw.ethz.ch

Twenty-five months after the InSight lander arrived on Mars, the first full martian year of continuous seismic data has been collected by the SEIS seismometer package. SEIS continues to exceed performance expectations in terms of the observed minimum noise. The Marsquake Service is tasked with creating and curating the seismicity catalogue for Mars. To date, about 500 distant marsquakes, and almost 800 events likely associated with local thermal cracking have been identified. The background noise recorded by SEIS is strongly sensitive to local winds, whose strength and duration is changing across the martian year. Marsquake signal amplitudes remain small and marsquakes can generally only be detected during the quietest periods that mostly occur during the evenings. For many regional marsquakes, crustal or mantle body phase arrivals may be identified and used to determine distances. However, polarised energy is rarely observed in marsquakes, so estimates of back azimuths, and hence also event locations, are rare. Here, we demonstrate how we detect and characterise marsquakes, and describe the challenges we face dealing with the Martian dataset. We summarise the content and the features of the marsquake catalogue recorded so far. Further, we review the seismicity on Mars, including location, magnitude, magnitude-frequency distribution, tectonic context and possible seismic sources.

\section{Insight Seismology on Mars: Results From the First Martian Year of Data and Prospects for the Future} Poster Session · Friday · 23 April · 11:30 Am Pacific Session Chairs: Mark P. Panning, Jet Propulsion Laboratory, Caltech (mark.p.panning@jpl.nasa.gov); Sharon Kedar, Jet Propulsion Laboratory, Caltech (sharon.kedar@jpl.nasa. gov); William B. Banerdt, Jet Propulsion Laboratory, Caltech (william.b.banerdt@jpl.nasa.gov)

\section{A Study of Thermoelastic Effects in Seismic Monuments and Their Signature in Low-Frequency Seismic Data Collected on Earth and on Mars}

WIDMER-SCHNIDRIG, R., University of Stuttgart, Wolfach, Germany, widmer@gis.uni-stuttgart.de; ZÜRN, W., Black Forest Observatory, Wolfach, Germany, Walter.Zuern@partner.kit.edu; FORBRIGER, T., Karlsruhe Institute of Technology, Wolfach, Germany, Thomas.Forbriger@kit.edu; STÄHLER, S. Eidgenössisch Technische Hochschule, Zürich, Switzerland, simon.staehler@ erdw.ethz.ch; VAN DRIEL, M., Eidgenössisch Technische Hochschule, Zürich, Switzerland, vandriel@erdw.ethz.ch; HURST, K. J., Caltech, California, USA, kenneth.j.hurst@jpl.nasa.gov

The NASA mission InSight to Mars observed a number of Phobos transits which resulted in a transient tilt of the VBB broad-band seismometer (Stähler et al., GRL, 2020). Triggered by these eclipse events which each last at most 
30 seconds we conducted experiments at Black Forest Observatory to corroborate the interpretation that the seismometer tilts result from changes in illumination and subsequent thermoelastic ground deformations.

While both the VBB on Mars and observatory grade terrestrial seismometers are furbished with extensive thermal shielding it is not a priori clear how a change in outside irradiation can lead to a seismometer tilt with a delay of only 5 to 10 seconds, as observed on Mars.

Our experimental setup consists of a 100 Watt incandescent light bulb with which we illuminate piers with thermally shielded seismometers in the BFO mine. By placing a bulb directly on the concrete pier and switching on the bulb for only 1 minute at each location we have mapped out the tilt response as a function of the bulb location. To first order the seismometer tilts away from the bulb location and the degree of tilting decays with distance away from the bulb.

While the skin depth for a heat pulse of 30s duration is only $2 \mathrm{~mm}$ for concrete and less than $0.5 \mathrm{~mm}$ for Martian regolith, this thin surface layer is still elastically coupled to the volume below and if the surface layer expands (light bulb experiments) or contracts (Phobos transit) the volume below must follow based on Hooke's law.

We find that only pier instruments show a clear response to illumination events while sensors installed in $160 \mathrm{~cm}$ deep post holes show almost no reaction. Our experiments also lead us to suggest that to further improve low-frequency horizontal component seismic recordings it may be beneficial to thermally isolate not only the sensors but also the pier on which they are installed.

Finite element calculations are planned to simulate these experiments and to further confirm the interpretation.

\section{Analyzing Low Frequency Seismic Events at Cerberus Fossae as Long Period Volcanic Quakes}

KEDAR, S., Jet Propulsion Laboratory, Caltech, California, USA, sharon. kedar@jpl.nasa.gov; PANNING, M. P., Jet Propulsion Laboratory, Caltech, California, USA, mark.p.panning@jpl.nasa.gov; SMREKAR, S. E., Jet Propulsion Laboratory, Caltech, California, USA, ssmrekar@jpl.nasa.gov; STÄHLER, S., Eidgenössische Technische Hochschule Zürich, Zürich, Switzerland, staehler@geophysik.uni-muenchen.de; KING, S., Virginia Tech, Virginia, USA, sking07@vt.edu; GOLOMBEK, M., Jet Propulsion Laboratory, Caltech, California, USA, matthew.p.golombek@jpl.nasa.gov; MANGA, M., University of California, Berkeley, California, USA, manga@seismo, berkeley.edu; JULIAN, B., Durham University, Durham, United Kingdom, bruce.r.julian@gmail.com; SHIRO, B., U.S. Geological Survey, Hawaii, USA, bshiro@usgs.gov; PERRIN, C., Laboratoire de Planétologie et Géodynamique, Nante, France, clement.perrin@univ-nantes.fr; POWER, J. A., U.S. Geological Survey, Alaska, USA, jpower@usgs.gov; MICHAUT, C., Ecole Normale Superieure de Lyon, Lyon, France, chloe.michaut@ens-lyon.fr; CEYLAN, S. Eidgenössische Technische Hochschule Zürich, Zürich, Switzerland, savas. ceylan@erdw.ethz.ch; GIARDINI, D., Eidgenössische Technische Hochschule Zürich, Zürich, Switzerland, domenico.giardini@erdw.ethz.ch; LOGNONNÉ, P., Institut de Physique du Globe de Paris et Université de Paris Diderot, Paris, France, lognonne@ipgp.fr; BANERDT, W. B., Jet Propulsion Laboratory, Caltech, California, USA, william.b.banerdt@jpl.nasa.gov

The InSight Mission began acquiring the first seismic data on Mars in early 2019 and has detected hundreds of events. The largest events recorded to date originate at Cerberus Fossae, a young volcanic region characterized by high volume, low viscosity lava flows. A handful of Low Frequency (LF) quakes that share key attributes of Long Period quakes recorded on Earth's volcanoes are also traced to Cerberus Fossae. This study explores whether a traditional volcanic source model that simulates the generation of tremor as pressurized fluid makes its way through a channel at depth, can explain these atypical LF events. We consider a wide range of physical parameters including fluid viscosity, the ratio of driving pressure to lithostatic pressure, aspect ratio of the channel, and the equilibrium channel opening. We find that the model can produce the observed seismic signature, with a combination of low-viscosity magma and high volume flux of $138410^{4}-10^{5} \mathrm{~m}^{3} / \mathrm{s}$ that are within an orderof-magnitude agreement with Cerberus Fossae lava flow properties deduced from analysis of lava flow dimensions. It is impossible, however, at this stage to conclude whether or not this is a likely explanation for Mars, as the model results in fluxes that are extreme for Earth, yet are just within bounds of what has been inferred for Cerberus Fossae. We therefore conclude that we cannot rule out active magma flow as the mechanism responsible for the atypical LF events that likely originate from Cerberus Fossae.

\section{Beyond Insight: Mitigating Challenges Associated With Placing a Long-Term Seismometer on Venus}

TIAN, Y., University of Alaska Fairbanks, Alaska, USA, ytian4@alaska.edu; ROBERT, H., University of Alaska Fairbanks, Alaska, USA, rrherrick@alaska. edu; WEST, M., University of Alaska Fairbanks, Alaska, USA, mewest@alaska. edu; KREMIC, T., National Aeronautics and Space Administration, Ohio, USA, tibor.kremic@nasa.gov

Engineers at NASA Glenn Research Center have been working through the challenges in high temperature electronics associated with operating a long duration seismometer on the Venusian surface [Kremic et al., 2020, Planet. Spa. Sci., v. 190, 104961], including testing an InSight-based sensor under ambient Venusian conditions. While sensor and associated electronics are likely to reach sufficient technical maturity within the next few years, a major design restriction is that the seismometer will have a battery-limited lifetime. Both data transmission and data storage are power-hungry operations, so neither transmitting data continuously nor storing data for later transmission are feasible. Power-dictated data-rate restrictions may also limit the highfrequency response of the seismometer. The starting point for mitigation is using an amplitude trigger to start seismometer transmission for a specified time. Two initial questions that arise from this plan, and the starting point for answers, are as follows: 1) What should the threshold be set to? - Determine best estimate for the nature and level of Venusian seismicity using analogs from Earth. 2) What should the transmission time be set to, and how interpretable will the returned data be from this operating scenario? - Take real-world continuous records from Venus-analog stations and evaluate what subset of events are captured, and where in the event transmission would occur, using different simulated trigger thresholds, frequency bandwidths and transmission times. For 1), the good news for instrument design is that Venus analog settings such as the African plate, rollback subduction zones, and "quiet" plate interiors have seismicity levels within about an order of magnitude variation. For 2), we began by analyzing the data from a station in Interior Alaska away from major plate boundaries. Initial results suggest that we can reasonably assess overall seismicity, but pre-triggering bandpass filtering would have a major impact on the efficacy of the triggering and the nature of events recorded.

\section{Seismology on Titan: A Seismic Signal and Noise Budget in Preparation for Dragonfly}

PANNING, M. P., Jet Propulsion Laboratory, Caltech, California, USA, mark.p.panning@jpl.nasa.gov; LORENZ, R. D., Johns Hopkins Applied Physics Laboratory, Maryland, USA, ralph.lorenz@jhuapl.edu; SHIRAISHI, H., JAXA Institute of Space and Astronautical Science, Sagamihara, Japan, siraisi@planeta.sci.isas.jaxa.jp; YAMADA, R., University of Aizu, AizuWakamatsu City, Japan, ryamada@u-aizu.ac.jp; STÄHLER, S., ETH Zürich, Zürich, Switzerland, simon.staehler@erdw.ethz.ch; TURTLE, E. P., Johns Hopkins Applied Physics Laboratory, Maryland, USA, Elizabeth.Turtle@ jhuapl.edu; HURFORD, T. A., NASA Goddard Space Flight Center, Maryland, USA, terry.a.hurford@nasa.gov; MURDOCH, N., ISAE-SUPAERO, Toulouse, France, naomi.murdoch@isae.fr; MARUSIAK, A., Jet Propulsion Laboratory, Caltech, California, USA, angela.g.marusiak@jpl.nasa.gov; BRYANT, A., University of Chicago, Illinois, USA, asbryant@uchicago.edu

The Dragonfly mission to Titan under the NASA New Frontiers Program is scheduled to launch in 2027 and explore Titan for $~ 3$ years in the mid-2030s, Among other instruments, it would include a geophysical and meteorological package (DraGMet), that would give us our first seismic measurements of an icy ocean world. While there are literature discussions of the kinds of seismic observations that we may expect to see in icy ocean worlds, quantitative estimates of the amplitudes and uncertainties of likely seismic signal and noise sources on Titan for the Dragonfly mission are critical. In this study we begin initial quantification of likely signal and noise from (a) icequakes in Titan's shell scaled by tidal dissipation energy based on generalized approaches applied to tidally active worlds, (b) published estimates of microseismic noise due to wave interaction in methane/ethane seas, and (c) atmospheric noise based on measurements from the InSight seismic deployment on Mars and limited data from Venera landers on Venus scaled by atmospheric acoustic impedance and solar energy flux or by expected dynamic wind pressure. We will also discuss possible noise from currents in the subsurface ocean, landergenerated noise (both due to Dragonfly activities and wind interactions with the lander), as well as more exotic sources like "booming dunes" which are observed on Earth and may be relevant to the Titan dunefields at Dragonfly's initial landing site. These signal and noise estimates will be compared with sensitivity of planetary seismic instrumentation to better constrain the probability of observing different seismic signals. 


\section{Super High Frequency Events: A New Class of Events}

\section{Recorded by the Insight Seismometers on Mars}

DAHMEN, N., ETH Zürich, Zürich, Switzerland, nikolaj.dahmen@erdw. ethz.ch; CLINTON, J., ETH Zürich, Zürich, Switzerland, jclinton@sed.ethz. ch; CEYLAN, S., ETH Zürich, Zürich, Switzerland, savas.ceylan@erdw. ethz.ch; VAN DRIEL, M., ETH Zürich,ZZürich, Switzerland, vandriel@ erdw.ethz.ch; GIARDINI, D., ETH Zürich, Zürich, Switzerland, domenico giardini@erdw.ethz.ch; KHAN, A., ETH Zürich, University of Zürich, Zürich, Switzerland, amir.khan@erdw.ethz.ch; STÄHLER, S., ETH Zürich, Zürich, Switzerland, simon.staehler@erdw.ethz.ch; BÖSE, M., ETH Zürich, Zürich, Switzerland, mboese@sed.ethz.ch; CHARALAMBOUS, C., Imperial College London, London, United Kingdom, constantinos.charalambous05@ imperial.ac.uk; HORLESTON, A., University of Bristol, Bristol, United Kingdom, anna.horleston@bristol.ac.uk; KAWAMURA, T., Université de Paris, Paris, France, kawamura@ipgp.fr; ORHAND-MAINSANT, G., Institut Supérieur de l'A'eronautique et de l'Espace SUPAERO, Toulouse, France, guenole.mainsant@outlook.fr; SCHOLZ, J., Max Planck Institute for Solar System Research, Göttingen, Germany, scholz@mps.mpg.de; EUCHNER, F., ETH Zürich, Zürich, Switzerland, fabian.euchner@sed.ethz.ch; PIKE, W. T., Imperial College London, London, United Kingdom, w.t.pike@imperial. ac.uk; WEBER, R., NASA Marshall Space Flight Center, Alabama, USA, renee.c.weber@nasa.gov; LOGNONNÉ, P., Université de Paris, Paris, France, lognonne@ipgp.fr; BANERDT, W. B., Jet Propulsion Laboratory, Caltech, California, USA, william.b.banerdt@jpl.nasa.gov

We present a new class of seismic signals recorded by InSight's seismometers on the surface of Mars, which we call super high frequency (SF) events [1] The signals are of short duration ( $20 \mathrm{~s})$, are often similar in amplitude, and feature high-frequency energy between $\sim 5$ and $30 \mathrm{~Hz}$ that is dominant on the horizontal components. With this, the SF events share several key characteristics with the much longer lasting very high frequency marsquakes [2].

We use the continuous 20 samples per second (sps) data from the Very Broadband instrument to detect and characterize SF events. 100 sps data from the Short Period sensor are only partially obtainable due to bandwidth limitations, but they aid in analyzing the high frequency content of selected events and in distinguishing them from high-frequency noise. From June 2019 to May 2020, 780 SF events were detected. The events observed occur in repeatable patterns that last for weeks. Initially, the SF events were clustered in the hours before sunset, but later, they have been distributed across the evening period. From June 2020 to the end of the year, the seasonal changes at InSight's location have led to persistently high levels of atmospherically-induced noise, and consequently, have greatly restricted the observation of SF events (In total 792 events until end of 2020).

Based on template matching techniques, we have identified 16 distinct event families that generally correspond to the temporal clusters. We infer these signals originate from close to the lander but not the lander itself. The majority of the events occur within 2 hours before or after sunset, a period with extreme temperature changes, which suggests that the origin of these events is thermal. The SF events resemble thermal events that have been observed on the Moon during the Apollo missions.

[1] Dahmen et al. (2020). Super high frequency events: a new class of events recorded by the InSight seismometers on Mars. JGR:Planets.

[2] Clinton et al. (2020). The Marsquake catalogue from InSight, sols 0-478. PEPI

Using Data From Insight to Locate and Explain Marsquakes SITA, M., University of Virginia, Virginia, USA, ms4sc@virginia.edu; VAN DER LEE, S., Northwestern University, Illinois, USA, suzan@northwestern. edu

We utilized event labels reported by the Marsquake Service (MQS) to create a visual catalog of waveform data from the InSight mission and characterize signals' origins. Four low frequency events were tagged as strong signals between 1-Jan-2019 and 31-Dec-2019. One of these events was originally thought to be a single event but after additional analysis was labeled as a series of two seismic events occurring in quick succession. For these four events, S0173a, S0235b, S0325aa, S0325ab, we estimated their epicenters and faulting mechanisms using differential arrival times, waveform polarity and amplitudes of $S$ and $\mathrm{P}$ waves. The strongest of the events were S0173a, occurring on 23-May2019 , and S0235b, occurring on 26-July-2019. They were found to be located $29^{\circ}$ and $27.5^{\circ}$ from the lander with back azimuths estimations of $91^{\circ}$ and $74^{\circ}$ respectively. These locations indicate these events originated east of the lander near the Cerberus Fossae region, which is in agreement with estimates provided by MQS. We located the third and fourth events on 26-Oct-2019 to the south east and east of the lander due to their respective back azimuths estimations of $123^{\circ}$ and $110^{\circ}$. With a distance of $38.5^{\circ}$, S0325aa was found to fall on the boundary between the Martian highlands and lowlands. Based on modeled arrival angles using the Martian interior model named Gudkova, the amplitude ratios of the main body wave phases $\mathrm{P}$ and $\mathrm{S}$ for all four events align most closely to near-vertical dip-slip faulting mechanisms.

Inspiring a New Generation of Seismology Leaders Oral Session · Wednesday · 21 April · 9:45 Am Pacific Session Chairs: Monique M. Holt, University of Utah (mholt@seis.utah.edu); Kevin B. Kwong, University of Washington (kbMa@uw.edu); Barrett N. Johnson, University of Washington (bnjo@uw.edu)

\section{Achieving Inclusive Teaching Though Online Learning, An Example From Roses}

DANNEMANN DUGICK, F. K., Sandia National Laboratories, New Mexico, USA, fkdanne@sandia.gov; VAN DER LEE, S., Northwestern University, Illinois, USA, suzan@northwestern.edu; PRIETO, G., Universidad Nacional de Columbia, Bogota, Colombia, gaprietogo@unal.edu.co; DYBING, S. N., University of Oregon, Oregon, USA, sdybing@uoregon.edu; TONEY, L. D., University of Alaska Fairbanks, Alaska, USA, ldtoney@alaska.edu; COLE, H., Colorado State University, Colorado, USA, hankcole@rams.colostate.edu

During the summer of 2020, we organized and delivered an 11-week online school for advanced graduate students worldwide. Remote Online Sessions for Emerging Seismologists (ROSES) consisted of live lectures accompanied by Python-based laboratory exercises. These were presented to a global community of seismology students from 24different countries, and 20 states within the US. In this presentation we will highlight a series of lessons learned for planning and executing similar programs with more lead time, particularly with regards to accessible computational resources. We will focus on specific ways that ROSES selected enriching and topical content, stimulated learning and retention, and promoted equity and inclusion through intentional programming, planning, and use of widely available co-working tools. In addition, we will suggest ways to enhance future educational programs to boost the retention and research application of learned material, and more broadly, foster inclusion and diversity within the seismology community.

\section{Black in Geosciences Week 2020: A Global, Social Media Movement}

BROTHERSON, L. O., University of Liverpool, Liverpool, United Kingdom, 1.brotherson@liverpool.ac.uk

Black in Geoscience Week (September 6th-12th 2020) emerged following the rise in grassroot movements such as Black AF In STEM, Black In the Ivory and Black In X (e.g. Neuro, Chemistry) on Twitter. Geosciences is one of the least diverse STEM subjects: in the USA, only 6\% of doctorate degrees in geoscience are awarded to students from underrepresented minorities, although they make up $31 \%$ of the population. In the UK, Black students represent $1.6 \%$ of Geology postgraduate researchers, while $3.8 \%$ of $18-24$ year olds are Black. Increasing diversity in geoscience is important as underrepresented groups, particularly Black geoscientists, lack visibility, opportunity and community.

Taking action, an international, multidisciplinary committee of geoscientists, ranging from marine scientists to astronomers, designed, promoted, and led a week of virtual activities across Twitter, Instagram, YouTube and other social media platforms. Through panel discussions, viral Twitter threads and live academic talks, \#BlackinGeoscienceWeek celebrated the richness and research breadth carried out by Black geoscientists globally, while also highlighting the need for more inclusivity and equality in geosciences. The week was a success, with over 6.1 million Twitter impressions and a 3.2\% engagement rate with tweets. Several follow up initiatives, such as Black in Marine Science, have emanated from the week, allowing Black geoscientists to network with those in their research field. Future events will focus on more specific work required to improve diversity within geoscience, such as decolonisation work.

\section{But What Can We Do? Developing Strategies for Change} FERNANDO, B., University of Oxford, Birmingham, United Kingdom, benjfernando@gmail.com

2020 saw the geosciences community reaffirm its commitment to the development of a fairer and more equal field, especially in terms of racial equality. However, developing strategies to address the challenges of poor representa- 
tion can be challenging, especially if we wish to do this in a way that does not further burden minority groups to make the changes we wish to see.

Here, I will present a potential strategy for identifying barriers to inclusion and retention within academic geoscience settings, based upon work first undertaken in the Department of Earth Sciences at the University of Oxford, and now being expanded across other departments in the UK [1].

Particular highlights apparent from this work included the importance of cultural context (for example understanding the reasons that students may choose not to study geosciences-related disciplines, rather than assuming that they are simply unaware of the potential), and the need to treat ethnic minority populations as a non-homogeneous population.

Finally, this work will discuss how similar strategies may be replicated (or preferably improved!) at other institutions, recognising that this is only one possible avenue to achieving change.

[1] https://bit.ly/oxford-bame-report - with many thanks to the other authors and contributors to this report

\section{Justice, Equity, Diversity and Inclusion at Incorporated Research Institutions for Seismology}

ADERHOLD, K., Incorporated Research Institutions for Seismology, District of Columbia, USA, kasey.aderhold@iris.edu; BOHON, W., Incorporated Research Institutions for Seismology, District of Columbia, USA, wendy. bohon@iris.edu; MATHURIN, J., Incorporated Research Institutions for Seismology, District of Columbia, USA, jeph.mathurin@iris.edu; POITRA, K., Incorporated Research Institutions for Seismology, District of Columbia, USA, krystin@iris.edu; PORTER, R., Incorporated Research Institutions for Seismology, District of Columbia, USA, rporter@iris.edu; SWANSON, M., Incorporated Research Institutions for Seismology, District of Columbia, USA, marlo.swanson@iris.edu; TABER, J., Incorporated Research Institutions for Seismology, District of Columbia, USA, taber@iris.edu; TEMPLETON, M., Incorporated Research Institutions for Seismology, Washington, USA, met@ iris.washington.edu; WOODWARD, R., Incorporated Research Institutions for Seismology, District of Columbia, USA, robert.woodward@iris.edu

In response to two calls from geoscientists of color: "Call for a Robust AntiRacism Plan for The Geosciences"1 and "A Call to Action for an Anti-Racist Science Community from Geoscientists of Color: Listen, Act, Lead"2, IRIS released a statement renewing our commitment to advance justice, equity, diversity, and inclusion within our organization and our larger scientific community. As a community-governed organization funded by the National Science Foundation to operate the Seismological Facility for the Advancement of Geoscience (SAGE) facility, Incorporated Research Institutions for Seismology (IRIS) looks to our community members to establish priorities within our organization. There are systemic inequalities in academia, particularly in the geosciences ${ }^{3}$, and we must make concrete actions to address inclusion and retention of Black, Brown, Indigenous, Latinx, and other people of color. We recognize that there has been a lot of previous work done to address racism in geosciences, especially work done by people of color, and these resources continue to guide our efforts.

The IRIS justice, equity, diversity, and inclusion (or JEDI) Working Group has met weekly since September 2020 to develop and discuss an AntiRacism Action Plan for IRIS through 2023. Actions are both internal-facing for IRIS staff as well as external-facing for stakeholders in the wider community we serve (researchers, educators, students, the public). These actions will be incorporated into all aspects of how we do our work at IRIS, in order to make lasting and effective organization and community change. An initial draft of this action plan will be released in early 2021, and feedback is strongly encouraged. We strive to be responsive to community needs, transparent, and accountable, especially to students and early career researchers who are the future of our scientific field.

${ }^{1}$ Ali et al. (2020) https://www.change.org/p/ geoscientists-call-for-a-robust-anti-racism-plan-for-the-geosciences

${ }^{2}$ Morris et al. (2020) https://notimeforsilence.org/

${ }^{3}$ R.E. Bernard and E.H.G. Cooperdock (2018)

\section{Which Earthquake Accounts Matter?}

HOUGH, S. E., U.S. Geological Survey, California, USA, hough@usgs.gov; MARTIN, S. S., The Australian National University, Canberra, Australia, stacey.martin@anu.edu.au

As we address the steps that should be taken to improve diversity of geosciences, it is important to note that systemic socioeconomic biases potentially impact not only our community, but also geosciences itself. In this presentation we focus on earthquake observations contributed by human observers, which provide invaluable sources of information to investigate both historical and modern earthquakes. Commonly, the observers whose eyewitness accounts are available to scientists are a self-selected minority of those who experience a given earthquake. As such these may not be representative of the overall population that experienced shaking from the event. Eyewitness accounts can contribute to modern science only if they are recorded and archived in an accessible repository. We explore the extent to which geopolitics and socioeconomic disparities can limit the number of eyewitnesses whose observations can contribute to science. We first revisit a late-19th century earthquake in the central U.S. in 1882 that provides an illustrative example of an event that has been poorly characterized due to a reliance on English-language archival materials. For modern earthquakes, we analyze data collected for recent earthquakes in California and India via the online "Did You Feel It?" system. In California, online data-collection systems appear to be effective in gathering eyewitness accounts from a broad range of socioeconomic groups. In India, however, where literacy and internet access remain more uneven, responses to the "Did You Feel It?" system reveal a strong bias towards responses from urban areas as opposed to rural settlements. The dissimilarity of our results from modern earthquakes in the U.S. and India provides a caution that, in some parts of the world, contributed felt reports can still potentially provide an unrepresentative view of earthquake effects, especially if online data collection systems are not designed to be broadly accessible. This limitation can in turn potentially shape our understanding of an earthquake's impact and the characterization of seismic hazard.

Intermountain West Earthquakes in the Spring of 2020

I: Oral Session · Tuesday · 20 April · 2:30 PM Pacific

II: Oral Session · Tuesday · 20 April · 5:30 PM Pacific

Session Chairs: Jayne Bormann, University of Nevada, Reno (jbormann@unr.edu); Ryan D. Gold, U.S. Geological Survey (rgold@usgs.gov); Keith Koper, University of Utah (koper@ seis.utah.edu)

\section{Backprojection Imaging of the 2020 Mw 5.5 Magna, Utah Earthquake}

MESIMERI, M., University of Utah, Utah, USA, maria.mesimeri@utah.edu; ZHANG, H., University of Utah, Utah, USA, zhang@seis.utah.edu; PANKOW, K. L., University of Utah, Utah, USA, pankowseis2@gmail.com

On 18 March 2020 a moderate earthquake $\left(M_{w} 5.5\right)$ struck the Salt Lake Valley in Utah, $\sim 5 \mathrm{~km}$ north of the town of Magna and $\sim 10 \mathrm{~km}$ west of downtown Salt Lake City. The Magna earthquake occurred in a very well instrumented area with tens of strong motion seismic stations. In this study, we present the application of a backprojection method for imaging the detailed rupture of the $\mathrm{M}_{\mathrm{w}} 5.5$ Magna, Utah earthquake by exploiting the very dense local strong motion network. For the backprojection we use envelopes of high frequency $S$-waves recorded on the transverse component at 45 seismic stations that are located at distances up to $100 \mathrm{~km}$ from the epicenter. Backprojection resolves the epicentral location of the mainshock with an absolute error of less than 1 $\mathrm{km}$, while the depth resolution is within the centroid depth range of multiple moment tensor solutions. We find an up-dip unilateral WNW-ESE 10km rupture resolved from the spatial distribution of the imaged subevents, consistent with the distribution of early aftershocks. The average rupture speed for the first $3 \mathrm{~s}$ is $2.9-3.2 \mathrm{~km} / \mathrm{s}$, which is $\sim 0.9$ times the shear wave velocity for the area at $12 \mathrm{~km}$ depth $[3.4-3.7 \mathrm{~km} / \mathrm{s}]$, whereas for the first $2 \mathrm{~s}$ the rupture speed is $\sim 2.9 \mathrm{~km} / \mathrm{s}(\sim 0.8 \mathrm{Vs})$. We perform two tests to check that the rupture propagation is not an artifact of site effects due to stations located on soft soil or a function of station distribution. In the first test we perform the backprojection for 22 strong motion stations located on rock sites, and in the second test we backproject a M4.1 aftershock back to the source region, assuming that an earthquake of that size approximates a point source. We argue that site effects did not bias the backprojection results, specifically the rupture propagation, even though we used stations located on both rock and soft soil. This study emphasizes the need for instrumenting metropolitan areas of high seismic risk and adopting backprojection techniques in the near real-time network products immediately after a local strong moderate earthquake.

\section{Geologic Effects of the 18 March 2020, Mw 5.7 Magna, Utah, Earthquake}

KLEBER, E. I., Utah Geological Survey, Utah, USA, ekleber@utah.gov; HISCOCK, A. I., Utah Geological Survey, Utah, USA, adamhiscock@ utah.gov; MCDONALD, G. N., Utah Geological Survey, Utah, USA, gregmcdonald@utah.gov; GIRAUD, R. E., Utah Geological Survey, Utah, 
USA, richardgiraud@utah.gov; ERICKSON, B. A., Utah Geological Survey, Utah, USA, benerickson@utah.gov; CASTLETON, J. J., Utah Geological Survey, Utah, USA, jessicacastleton@utah.gov; BOWMAN, S. D., Utah Geological Survey, Utah, USA, stevebowman@utah.gov; MCKEAN, A. P., Utah Geological Survey, Utah, USA, adammckean@utah.gov

The March 18, 2020, $\mathrm{M}_{\mathrm{w}} 5.7$ Magna, Utah, earthquake was widely felt along the Wasatch Front urban corridor. Ground accelerations near the epicentra region under springtime hydrologic conditions indicated the potential to produce liquefaction features. Post-earthquake rapid reconnaissance around the Salt Lake Valley on the ground and from a sUAS (small unmanned aircraft system) documented liquefaction near the earthquake epicenter, along the Jordan River, and along the southeastern shoreline of Great Salt Lake. Additionally, the foothills of the Wasatch Range and Oquirrh Mountains were checked for fresh rockfall and urban landslide reactivation; one possible earthquake-induced rockfall was identified. Areas with documented liquefaction features typically have seasonal or year-long near-surface groundwater or standing water due to their proximity to Great Salt Lake and its tributaries. Liquefaction features included syneresis cracking and pooling near the epicenter, lateral spreading along the Jordan River, collapse features, and sand boils. Subaerial and subaqueous sand boils occurred in areas with roadway infrastructure and artificial fill on and near the shores of Great Salt Lake. Several of these features are known to be caused by fluctuating groundwater levels and their appearance after the Magna earthquake suggests they are related to earthquake ground motions. Observed damage to roadway infrastructure concentrated near the Great Salt Lake Marina State Park included tension cracks with vertical separation in asphalt concrete roadways and parking areas, as well as a fractured natural gas line on a maintenance building. Despite its moderate magnitude, the Magna earthquake caused over $\$ 70$ million in public infrastructure damage and serves as a reminder of the critical importance of earthquake and geologic hazard research and preparedness in the Intermountain West.

\section{Hypothetical Structural Model for the 18 March 2020, Mw 5.7 Magna, Utah, Earthquake}

MCKEAN, A. P., Utah Geological Survey, Utah, USA, adammckean@ utah.gov; HARDWICK, C. L., Utah Geological Survey, Utah, USA christianhardwick@utah.gov; KLEBER, E. J., Utah Geological Survey, Utah, USA, ekleber@utah.gov; HYLLAND, M. D., Utah Geological Survey, Utah, USA, mikehylland@utah.gov; ANDERSON, Z. W., Utah Geological Survey, Utah, USA, zanderson@utah.gov; WILLIS, G. C., Utah Geological Survey, Utah, USA, grantwillis@utah.gov; CLARK, D. L., Utah Geological Survey, Utah, USA, donclark@utah.gov; BIEK, R. F., Utah Geological Survey, Utah, USA, bobbiek@utah.gov

The 18 March 2020, $\mathrm{M}_{\mathrm{w}} 5.7$ Magna, Utah, earthquake occurred beneath western Salt Lake Valley which is near the eastern margin of the Basin and Range Province and within the Intermountain Seismic Belt. Using recent geologic mapping, cross sections, deep borehole data, and seismic and gravity geophysical data, we created a subsurface structural model to elucidate the earthquake causative fault. The model depicts a complex system of faults in the hanging wall of the west-dipping Wasatch normal fault zone, including the Harkers fault, West Valley fault zone, and newly interpreted Saltair graben. The mainshock occurred between 9.0 and $11.9 \mathrm{~km}$ below sea level. Numerous aftershocks occurred in two main clusters: a large western cluster near the mainshock focus and a small, shallower eastern cluster in the vicinity of the east-dipping Granger fault of the West Valley fault zone. We hypothesize that the mainshock occurred on a major listric fault, likely the Warm Springs fault of the Salt Lake City segment of the Wasatch fault zone. The Warm Springs fault has an observed surface dip of $\sim 70^{\circ}$ to the west, but below a depth of about $7 \mathrm{~km}$ the aftershock locations suggest a $\sim 30^{\circ}$ dip. The eastern cluster of aftershocks roughly coincides with the modeled intersection of the Granger fault and the Warm Springs fault at depth. The western aftershock cluster appears to be near the intersection of the concealed Saltair graben faults and the Wasatch fault zone. The West Valley fault zone, Harkers fault, and Saltair graben may represent an accommodation zone between the Weber and Salt Lake City segments of the Wasatch fault zone. The accommodation zone is likely reoccupying a prior zone of weakness, the inferred Transverse fault zone, a suspected Sevier-age structure. Perhaps oblique-slip components observed in the moment tensor solutions of both the mainshock and major aftershocks are related to this hypothesized accommodation zone.

\section{Robust Estimates of Moment Magnitude for Small- to Moderate-Size Aftershocks of the Mw 5.7 Magna, Utah Earthquake}

HOLT, I., University of Utah, Utah, USA, jholt@seis.utah.edu; WHIDDEN, K. M., University of Utah Seismograph Stations, Utah, USA, katherine@ whidden.net; KOPER, K. D., University of Utah Seismograph Stations, Utah, USA, koper@seis.utah.edu; PANKOW, K. L., University of Utah Seismograph Stations, Utah, USA, pankowseis2@gmail.com; MAYEDA, K., Air Force Technical Applications Center, Florida, USA, kevin.mayeda@us.af.mil; PECHMANN, J. C., University of Utah Seismograph Stations, Utah, USA pechmann@seis.utah.edu; EDWARDS, B., University of Liverpool, Liverpool, United Kingdom, edwardsb@liverpool.ac.uk; GÖK, R., Lawrence Livermore National Laboratory, California, USA, gok1@llnl.gov; WALTER, W. R., Lawrence Livermore National Laboratory, California, USA, walter5@llnl.gov

To improve seismic hazard characterizations, particularly for induced seismicity, it is desirable to directly estimate moment magnitude $\left(M_{w}\right)$ for small earthquakes. $\mathrm{M}_{\mathrm{w}}$ is preferred over other magnitude types in most applications. However, $\mathrm{M}_{\mathrm{w}}$ is challenging to obtain for earthquakes with local magnitude $\left(\mathrm{M}_{\mathrm{L}}\right)<3-3.5$ using conventional moment tensor (MT) inversion methods. The $2020 \mathrm{M}_{\mathrm{ww}} 5.7$ Magna, Utah, seismic sequence presents an ideal opportunity to illustrate and evaluate the use of spectral methods to determine $M_{w}$ for small earthquakes. Using a catalog of 2103 earthquakes $\left(M_{L}<5.6\right)$, we estimate $\mathrm{M}_{\mathrm{w}}$ with two independent spectral methods-one based on direct waves $\left(\mathrm{M}_{\mathrm{w}, \mathrm{direct}}\right)$, and the other based on coda waves $\left(\mathrm{M}_{\mathrm{w}, \mathrm{coda}}\right)$. For the directwave method,we present a non-parametric (NP) inversion scheme that solves for apparent geometrical spreading and site corrections. The NP inversion is constrained using $\mathrm{M}_{\mathrm{w}} \mathrm{s}$ derived from MT inversion for nine Magna sequence earthquakes. We recover statistically robust and physically acceptable geometrical spreading and site corrections and compute $\mathrm{M}_{\mathrm{w}, \text { direct }}$ for 635 earthquakes down to $M_{L}$ 0.7. For the coda-wave method, we considered two separate calibrations using different sets of $\mathrm{M}_{\mathrm{w}} \mathrm{s}$ (from MT inversion) and computed $M_{w, \text { coda }}$ for 311 earthquakes down to $M_{L} 1.0$. There were 280 events that were assigned both an $\mathrm{M}_{\mathrm{w}, \text { direct }}$ and $\mathrm{M}_{\mathrm{w}, \mathrm{coda}}$, which show a high correlation ( $\left.\mathrm{r}=0.98\right)$, and their differences have a mean of 0.05 and a std. dev. of 0.13 . For $M_{L}<3.6$ both $\mathrm{M}_{\mathrm{w} \text {,direct }}$ and $\mathrm{M}_{\mathrm{w}, \text { coda }}$ agree with the theoretically predicted relationship of $\mathrm{M}_{\mathrm{w}}=(2 / 3) \mathrm{M}_{\mathrm{L}}+\mathrm{C}$, where $\mathrm{C}$ is a regional constant. Our results imply that seismic network operators can use spectral-based $\mathrm{M}_{\mathrm{w}}$ estimates to replace a significant number of $M_{L}$ estimates for events with $M_{L} \geq 1.0$, and possibly smaller. The main requirement is a small dataset ( 3 or more) of pre-computed MT solutions for calibration.

\section{The March 2020, Mw6.5 Stanley, Idaho Earthquake- Complex Faulting at the Northern End of the Basin and Range Province From Earthquake Relocation and Source Mechanisms}

BRAUNMILLER, J., University of South Florida, Florida, USA, jbraunmiller@ usf.edu; WETMORE, P., University of South Florida, Florida, USA, wetmore@ usf.edu

The 31 March $2020 \mathrm{M}_{\mathrm{w}} 6.5$ Stanley, Idaho earthquake was the largest earthquake in the Intermountain West (IMW) region since 1983. Unlike other IMW earthquakes, which rupture prominent range-bounding normal faults, the Stanley mainshock was a left-lateral strike-slip event on a 'blind' fault. The epicenter is north of the Sawtooth normal fault in a region intersected by the Tertiary, northeast trending trans-Challis fault zone (TCFZ) resulting in complex fault interplay. We relocate M2.5+ aftershocks to identify active faults and perform waveform modeling of M3.2+ events to determine deformation styles. We use local and regional waveforms from the IRIS DMC for analysis. Initial relocations place the mainshock near the center of the first-day aftershocks suggesting a bilateral, $30-\mathrm{km}$ long rupture on an NNW-SSE trending fault. The mainshock hypocenter is near the base of the aftershocks indicating rupture propagated upward. Aftershock activity near the mainshock epicenter remained vigorous throughout the sequence and shows a fault dipping $\sim 70$ 75 towards west. Further north, aftershocks follow a linear trend on a nearvertical fault. Focal mechanisms for the two segments are strike-slip with a steeply dipping NNW-SSE trending nodal plane consistent with aftershocks. Deformation south of the hypocenter area near the terminus of the Sawtooth fault is complex. Aftershocks are widely distributed and involve normal and strike slip mechanisms with varying orientations suggesting several distinct faults are active. Starting one week after the main event, aftershocks expanded south-easterly resulting in an overall L-shaped aftershock distribution; some aftershocks possibly occurred close to the Sawtooth fault. Aftershocks at the boundary between the Sawtooth fault and the strike-slip fault illustrate complex stress transfer at the terminus of faults. The Sawtooth fault seems to terminate at the TCFZ suggestive of fault control by preexisting structures. We 
found no clear evidence for activity on the TCFZ; the broad aftershock distribution occurs south of the TCFZ.

\section{Complex Fault Geometry of the 2020 Mww6.5 Monte Cristo Range, Nevada Earthquake Sequence}

RUHL, C. I., The University of Tulsa, Oklahoma, USA, cruhl@utulsa.edu; MORTON, E. A., Nevada Seismological Laboratory, University of Nevada, Reno, Nevada, USA, emilymorton@unr.edu; BORMANN, J. M., Nevada Seismological Laboratory, University of Nevada, Reno, Nevada, USA jbormann@unr.edu; HATCH-IBARRA, R., Nevada Seismological Laboratory, University of Nevada, Reno, Nevada, USA, rhatch@unr.edu; SMITH, K. D. Nevada Seismological Laboratory, University of Nevada, Reno, Nevada, USA ken@unr.edu; ICHINOSE, G. A., Lawrence Livermore National Laboratory, California, USA, ichinose1@llnl.gov

On 15 May 2020 an M6.5 earthquake occurred beneath the Monte Cristo Range in the Mina Deflection region of western Nevada. Rapid deployment of eight temporary seismic stations enable detailed analysis of its productive and slowly decaying aftershock sequence $(\mathrm{p}=0.8)$ which included $\sim 18,000$ autodetected events in 3.5 months. Double-difference, waveform-based relative relocation of 16,714 earthquakes reveals a complex network of faults, many of which cross the inferred east-northeast-striking, left-lateral mainshock rupture. Seismicity aligns with left-lateral, right-lateral, and normal mechanism moment tensors of 128 of the largest earthquakes. The mainshock occurred near the middle of the aftershock zone at the intersection of two distinct zones of seismicity. In the western section, numerous subparallel, shallow, northnortheast-striking faults form a broad flower-structure-like fault mesh that coalesces at depth into a near-vertical, left-lateral fault. We infer this to be a region of significant slip in the mainshock and an eastward extension of the left-lateral Candelaria fault. Near the mainshock hypocenter, seismicity occurs on a northeast-striking, west-dipping structure which extends north from the Eastern Columbus Salt Marsh normal fault. Together, these two intersecting structures bound the Columbus Salt Marsh tectonic basin. East of this intersection and the mainshock hypocenter, seismicity occurs in a narrow, near-vertical, east-northeast-striking fault zone through to its eastern terminus. At the eastern end, the aftershock zone broadens and extends northwest towards the southern extension of the northwest-striking, rightlateral Petrified Springs fault system. The eastern section hosts significantly fewer aftershocks than the western section, but has more moment release. We infer that shallow aftershocks throughout the system highlight fault-fracture meshes that connect mapped fault systems at depth. Comparing earthquake data to surface ruptures and a simple geodetic fault model sheds light on the complexity of this recent M6.5 Walker Lane earthquake.

\section{Complex Rupture and Source Model of the 15 May 2020 Mw 6.5 Monte Cristo Range Earthquake From Insar and Earthquake Relocation}

SETHANANT, I., University of Victoria, Victoria, Canada, isethanant@uvic. ca; NISSEN, E., University of Victoria, Victoria, Canada, enissen@uvic.ca; POUSSE-BELTRAN, L., University of Victoria, Victoria, Canada, leapousse@ uvic.ca; BERGMAN, E., Global Seismological Services, Colorado, USA bergman@seismo.com

The 15 May $2020 M_{\mathrm{w}} 6.5$ Monte Cristo Range earthquake in Nevada, USA occurred in the Mina Deflection (central Walker Lane) along previously-unmapped faults to the east of the Candelaria fault zone. We use Interferometric Synthetic Aperture Radar (InSAR) to characterize the mainshock deformation and model the causative faulting. Three 6-day interferograms, generated from radar images from the Sentinel-1B satellite, reveal phase patterns that suggest the earthquake ruptured along an ENE-striking fault zone. The interferograms are inverted to model the fault geometry in an elastic half space using, first, a uniform slip assumption, and subsequently, distributed slip. Results show that three modeled faults yield the lowest misfit between data and model interferograms, that there is at least $\sim 0.8 \mathrm{~m}$ of slip at depth on two of the modeled faults, and that the maximum slip in the top 2 $\mathrm{km}$ of the crust is less than $\sim 0.2 \mathrm{~m}$. Each fault has a length of $\sim 10 \mathrm{~km}$, with a total rupture length of at least $\sim 30 \mathrm{~km}$. The westernmost fault trends NE-SW and has a large extensional component $\left(\right.$ rake $\sim-47^{\circ}$ ), while the middle and easternmost faults trend ENE-WSW and have dominant left-lateral motions. We also relocate 155 events of this earthquake sequence to observe the seismicity distribution and source parameters. The calibrated relocation, which minimizes bias from unknown Earth structure, of the mainshock indicate that it initiated at $11.0 \mathrm{~km}$ depth, and aftershocks fall within the depth range of 1.0 $10.4 \mathrm{~km}$. These focal depths are in good agreement with the InSAR distributed slip model where most of the slip occurred above $12 \mathrm{~km}$ depth. The relocated events also illustrate clustering in two main areas-around the NE-SW and the ENE-WSW modeled faults. Both geodesy and seismology results suggest that the earthquake sequence occurred along a segmented, geometrically complex fault zone. Observations in this study help understand the kinematics and distribution of faulting within the Mina Deflection region.

\section{Modeling Coseismic Slip and Afterslip of the 2020 Mw6.5 Monte Cristo Range (Nevada) Earthquake Using InSAR and GPS}

DUTTA, R., University of Iowa, Iowa, USA, rishabh-dutta@uiowa.edu; BARNHART, W. D., University of Iowa, Iowa, USA, william-barnhart-1@ uiowa.edu

The $15^{\text {th }}$ May $2020 \mathrm{M}_{\mathrm{w}} 6.5$ Monte Cristo range, Nevada earthquake occurred in the Mina deflection step-over region of the eastern California shear zone (ECSZ) - Walker Lane Belt (WLB). The strike-slip earthquake ruptured ENE -striking fault(s) with a majorly left-lateral slip mechanism. Here we use InSAR and GPS to map the coseismic and early postseismic (four months) surface displacements associated with the earthquake in an effort to model the coseismic slip and afterslip. We use Bayesian inference to estimate the fault location, fault geometry and spatially-variable slip simultaneously from the coseismic surface displacements considering two cases: single planar fault solution (SPF), two planar faults solution (TPF). We also use a priori fault surface trace from sharp discontinuities in the postseismic surface displacement time-series. The maximum a posteriori (MAP) solution for the SPF case shows a maximum slip of $\sim 1.2 \mathrm{~m}$ left-lateral slip at $\sim 10 \mathrm{~km}$ depth on a $60^{\circ}$ southward dipping fault. In comparison, the MAP solution for TPF case shows an additional nearly vertical E-W striking fault plane, which is east of the planar fault estimated in the SPF case. The dominant slip asperity in both scenarios extends from $\sim 3-12 \mathrm{~km}$ depth and tapers to zero slip at the surface where coseismic interferograms remain coherent. From our postseismic time series, we infer shallow afterslip when inverting for slip onto the fault solutions derived from our coseismic analysis. The preliminary results show a cumulative shallow afterslip of about $>50 \mathrm{~cm}(\sim 45 \%$ of maximum coseismic slip) in the four months after the earthquake. The rupture's inability to reach the surface but aseismically slip at shallow depths may indicate variation in the fault plane's frictional properties.

\section{Testing Models of Active Tectonics in the Central Walker Lane Using Satellite Geodetic Measurement of the Mw 6.5 Monte Cristo Range Earthquake}

CRANDALL-BEAR, A. T., University of Nevada Reno, Nevada, USA, acrandallbear@unr.edu; HAMMOND, W. C., University of Nevada, Reno, Nevada, USA, whammond@unr.edu

The Monte Cristo Range Mw 6.5 earthquake occurred in the eastern central Walker Lane on May $15^{\text {th }}, 2020$. While the moment tensor shows a left lateral strike slip solution, geodetic data reveal subsidence to the west of the epicenter, possibly indicating a normal component of slip. The presence of normal slip is potentially important because it may be diagnostic of extension dominated transtension, whereas purely left-lateral slip is more consistent with wrench-style block rotations. Thus, if the normal component slip contributed significantly to the earthquake it has important implications for tectonic models of the region.

We address this question by investigating the rupture process of the earthquake using satellite geodesy, namely GPS and InSAR. Three-component coseismic surface motions due to the event are measured at over 200 GPS stations within $280 \mathrm{~km}$ of the epicenter. InSAR resolves coseismic motion in two descending plus one ascending line of sight (LOS). We use displacement data as input to a joint inversion for the best fit fault locations and slip distribution using forward and inverse modeling and global search optimization. The inversion method uses equations from Okada 1985, which are calculated in three components at each GPS location, and projected to LOS at each InSAR location. While the InSAR is most sensitive to east and vertical components, and least sensitive in the north component, the closest GPS station to the epicenter (COLU) shows north displacement greater than the east and vertical. Our method does not assume that the InSAR signal is the result of only eastwest and up-down movement, and constrains the north component movement with GPS observations.

Initial results indicate a normal component of slip on the western side of the preferred fault. The contribution of this slip to the total moment, its relationship to surface rupture, and implications for tectonic models will be explored with refinement of the joint inversion. 
Widely Distributed Rupture Along an Array of Left-Lateral, Normal and Right-Lateral Faults in the 15 May 2020 M6.5 Monte Cristo Range, NV Earthquake

ELLIOTT, A. I., U.S. Geological Survey, California, USA, ajelliott@usgs.gov; DEE, S., Nevada Bureau of Mines and Geology, Nevada, USA, sdee@unr. edu; KOEHLER, R. D., Nevada Bureau of Mines and Geology, Nevada, USA, rkoehler@unr.edu; HATEM, A. E., U.S. Geological Survey, Colorado, USA, ahatem@usgs.gov; PIERCE, I. K. D., University of Oxford, Oxford, United Kingdom, ian@nevada.unr.edu; PICKERING, A., U.S. Geological Survey, California, USA, apickering@usgs.gov; SEITZ, G., California Geological Survey, California, USA, gordon.seitz@conservation.ca.gov; XU, X., Scripps Institution of Oceanography, California, USA, xix016@ucsd.edu

On May 15, 2020 a M6.5 earthquake ruptured a collection of shallow faults in the Monte Cristo Range and Candelaria Hills of western Nevada. To identify how this event ruptured through a disorganized fault system, we conducted detailed field mapping at up to centimeter resolution and satellite InSAR analysis at $\sim 15 \mathrm{~m}$ resolution of the coseismic surface ruptures, revealing a network of wide, pervasively fractured fault zones with highly varied orientations and kinematics that discontinuously spans the entire $30 \mathrm{~km}$ east-west alignment of aftershocks. The coseismic faulting accommodated east-west left-lateral shear where the plate-boundary parallel dextral shear zone of the Walker Lane steps rightward in the Mina Deflection. While seismological and far-field geodetic evidence indicate that the main slip at depth was along an east-striking left-lateral fault plane-a projection of the previously mapped Candelaria fault-our results reveal that shallow slip occurred along a set of north-south oblique right-extensional faults, and along a previously unmapped pair of leftextensional faults that splay $7-9 \mathrm{~km}$ at $060^{\circ}$ strike from the main left-lateral fault on which the mainshock initiated. In addition to resolving the shallow structures involved in this earthquake, our comparison of field mapping and displacement maps derived from InSAR shows the km-wide distribution of surface strain that leads to surface rupture both on and off of the projected main faults. Our results suggest that both field mapping and satellite strainmapping are required to fully interpret the other; in particular the distinction of primary versus secondary ruptures as in probabilistic fault displacement hazard analyses requires full imaging of the displacement field for these lowoffset ruptures; and that this rupture in the Mina Deflection accommodated left-lateral shear in part via coherent right-lateral slip along high-angle conjugate faults in the upper few kilometers of the crust.

Intermountain West Earthquakes in the Spring of 2020

Poster Session · Tuesday · 20 April · 11:30 Am Pacific

Session Chairs: Jayne Bormann, University of Nevada, Reno (jbormann@unr.edu); Ryan D. Gold, U.S. Geological Survey (rgold@usgs.gov); Keith Koper, University of Utah (koper@ seis.utah.edu)

\section{D Crustal Velocity Model for West-Central Montana}

DUZET, C. I., University of Montana, Montana, USA, courtenay.duzet@ umconnect.umt.edu; MARTENS, H. R., University of Montana, Montana, USA, hilary.martens@mso.umt.edu; STICKNEY, M. C., Montana Technological University, Montana, USA, mstickney@mtech.edu

We derive a new 1-D crustal seismic-velocity model for west-central Montana by analyzing seismic-phase arrivals from the M 5.8, 6 July 2017 earthquake that occurred $11 \mathrm{~km}$ southeast of Lincoln, Montana, and hundreds of aftershocks that followed over a three-year period (2017-2020). The 2017 Lincoln earthquake was the largest event above M 5.5 to occur in western Montana in over half a century, the last being the 1959 M 7.3 Hebgen Lake earthquake in southwestern Montana. To determine the seismic-velocity model, we manually retrieve continuous seismic data recorded by broadband stations in the University of Montana Seismic Network (UMSN), which have been deployed specifically and strategically to study the Lincoln aftershock sequence, supplemented by telemetered data from the Montana Regional Seismic Network (MRSN). To constrain the model, we invert phase arrivals from several hundred well-recorded earthquakes (>20 phase arrivals) using the software program VELEST. The final model characterizes the crustal seismic-velocity structure as a function of depth, appropriate to an area in western Montana of about $5000 \mathrm{~km}^{2}$.

Developing a new, regional seismic-velocity model advances earthquake science in Montana. The velocity model currently in use to estimate hypocenter locations was last updated in 2003 and is most appropriate for southwestern Montana. Due to western Montana's proclivity towards infrequent, high-magnitude earthquakes, the 2017 Lincoln event has provided a prime opportunity to collect quality seismic data that will allow us to create a muchneeded crustal velocity model for this seismically active region of Montana. This will be the first model derived specifically for the west-central region of the state and will improve the accuracy of hypocenter locations, in addition to enhancing our understanding of the area's crustal velocity structure and crustal stress conditions.

\section{Focal Mechanisms for the 2020 Magna, Utah Earthquake Sequence Using Manual and Deep-Learning First Motions From a Temporary Large-N Array and Permanent Seismic Network}

HOLT, M. M., University of Utah, Utah, USA, mholt@seis.utah.edu; BAKER, B., University of Utah, Utah, USA, bbaker@seis.utah.edu; PECHMANN, J. C., University of Utah, Utah, USA, pechmann@seis.utah.edu; KOPER, K. D., University of Utah, Utah, USA, koper@seis.utah.edu; FARRELL, J., University of Utah, Utah, USA, jamie.farrell@utah.edu

On 18 March 2020 an $M_{w} 5.7$ earthquake occurred near Magna, Utah, USA, about $15 \mathrm{~km}$ west of downtown Salt Lake City. Immediately after the mainshock, $1805-\mathrm{Hz}$ nodal geophones, or nodals, were deployed for 30 days throughout the Salt Lake Valley. Between mid-March and mid-April 2020, there were over 300 seismic stations, including the nodals, operating within $200 \mathrm{~km}$ of the mainshock. The University of Utah located more than 2,500 aftershocks, ranging from M-0.6-4.6, not including those found via template matching. The aftershocks separate into two clusters: the eastern cluster, beneath the Salt Lake City International Airport, and the western cluster, in the vicinity of the mainshock. Due to a large number of first motion misfits, we were unable to resolve any focal mechanisms for the eastern cluster. The largest event in this cluster was an M3.25 with clear first motions on 158 stations, which suggests either non-double-couple sources or 3D velocity perturbations. For the western cluster, we combined manually picked first motions (MPFM) and machine learning first motions (MLFM) to create a dataset of 54,000 first motions from 370 stations. The first motions comprise 493 focal mechanisms; 71 are from MPFM and 422 are from MLFM. There are nine MPFM focal mechanisms that also have moment tensor solutions. The maximum angle between an MPFM mechanism and moment tensor mechanism for these events is $51^{\circ}$, well below the $180^{\circ}$ that indicates two mechanisms are perfectly dissimilar. There are 51 events with MPFM and MLFM focal mechanisms, and the maximum angle between the two types of mechanisms is $90^{\circ}$. These angles indicate good agreement between moment tensor, MPFM, and MLFM focal mechanisms. The MPFM mechanism nodal planes generally strike north-south and have a median dip of $50^{\circ}$, or $48^{\circ}$ when the strike-slip events are removed. This median dip is steeper than the $\sim 20^{\circ}$ dip of the relocated aftershocks and the $\sim 30^{\circ}$ dip of the mainshock.

\section{Machine Learning Aftershock Detection for the M6.5 31 March 2020 Stanley, Idaho Earthquake}

WILBUR, S. F., Boise State University, Idaho, USA, spencerwilbur@u. boisestate.edu; LIBERTY, L., Boise State University, Idaho, USA, lliberty@ boisestate.edu; MIKESELL, T. D., Boise State University, Idaho, USA, dylanmikesell@boisestate.edu; BOCKHOLT, B., Boise State University, Idaho, USA, blaine.bockholt@inl.gov; JOHNSON, J. B., Boise State University, Idaho, USA, jeffreybjohnson@boisestate.edu

The March 31, 2020, Mw6.5 Stanley, Idaho, earthquake was recorded by a sparse regional network of permanent seismic stations. Succeeding the mainshock, a local network of 15 seismic stations within and surrounding the epicentral zone was installed. The real-time part of the new network ( 2 stations) enabled local $\mathrm{P}$ and $\mathrm{S}$ wave phase picking and has helped to produce a robust event catalog. Since installing the temporary network after the mainshock in March, 2590 events have been detected (USGS catalog) with an initial completion magnitude of M2.4. Aftershocks provide critical insights in determining the where and potentially why the slip occurred. In addition, aftershock models and the spatial distribution of such events are of great importance when forecasting future seismicity. Thus moving forward, as aftershocks are detected on the still deployed temporary network, we will be able to lower the completion magnitude and further revise the local velocity model. To further reduce the completion magnitude of this sequence with the existing data, we began building a revised catalogue of small magnitude aftershocks by picking the arrival times of $\mathrm{P}$ and $\mathrm{S}$ waves across the temporary network and relocating existing events using HypoDD and a local velocity model we compiled from previous Vp and Vs imaging studies in the region. To detect lower magnitude events $(<\mathrm{M} 2.4)$ we employ deep learning. This method solves common problems associated with detecting low magnitude seismic events that have a low signal-to-noise ratio. Overall we conclude that machine learning will 
assist in small event identification, alongside STA/LTA detection and hypocenter relocation; therefore enabling us to determine with greater certainty the driving mechanisms of the M6.5 Stanley Earthquake.

\section{Overview of Data Quality, Availability and Performance of the 31 March 2020 Stanley, Idaho Event Aftershock Deployment}

BOCKHOLT, B., Idaho National Laboratory, Idaho, USA, blaine.bockholt@ inl.gov; MIKESELL, T. D., Boise State Univeristy, Idaho, USA, dylanmikesell@ boisestate.edu; WILBUR, S. F., Boise State University, Idaho, USA, spencerwilbur@u.boisestate.edu; LIBERTY, L., Boise State University, Idaho, USA, 1liberty@boisestate.edu

On March 31 ${ }^{\text {st }}, 2020$, an Mw 6.5 event occurred $30 \mathrm{~km}$ to the northwest of Stanley, Idaho. Boise State University deployed a number of different sensors to better characterize the seismicity from the aftershocks. The deployment included 16 broadband seismometers scattered around the aftershock zone, 24 three-component Nodal $5 \mathrm{~Hz}$ geophones installed in a linear array near Stanley, Idaho and an irregular array near the epicenter of the main shock, 6 mini-infrasound arrays and finally a 24 -element single infrasound array. In this presentation, we will present an overview of the deployment and instrumentation, data quality and noise levels of the broadband seismic instruments and finally, we will discuss the relocation of more than 1,000 aftershocks.

The 16 broadband stations consist of either a Nanometrics Meridian/ Trillium Compact connected to either a Nanometrics Centaur or RefTex RT130 recording at $500 \mathrm{~Hz}$ and $200 \mathrm{~Hz}$ respectively. The nodal array consists of 24 Fairfield three-component Zland geophones sampling at $500 \mathrm{~Hz}$. The average station spacing for the linear array is about $0.5 \mathrm{~km}$ and the irregular array was installed within $5 \mathrm{~km}$ of the epicenter of the mainshock with an aperture of about $1 \mathrm{~km}$.

We use the probabilistic power spectral density (PSD) tools found in the Obspy python package to calculate noise models for each of the broadband stations and overall, the PSDs show strong data quality for the broadband stations. We further pick around 1,000 earthquakes of magnitude 2.5+ during the duration of the temporary deployment ( $\sim 7$ months) and relocate these events using the HypoDD software package to obtain higher quality locations. Preliminary results from HypoDD show many event hypocenters line up in a nearly vertical NE-trending plane with hypocenters progressing to the south of the main shock over time.

\section{Present-Day Deformation Mechanism of the Northeastern Mina Deflection Revealed by the 2020 Mw 6.5 Monte Cristo Range Earthquake}

ZHENG, A., Southern University of Science and Technology, Shenzhen, China, zhenga@sustech.edu.cn; XU, W., Central South University, Changsha, China, wenbin.xu@csu.edu.cn; CHEN, X., Southern University of Science and Technology, Shenzhen, China, chenxf@sustech.edu.cn

The May 15, 2020 Monte Cristo Range $M_{\mathrm{w}} 6.5$ earthquake occurred in the northeast of the Mina deflection, which accommodates approximately a quarter of the relatively dextral motion between the Pacific and North American plates. The Monte Cristo Range event provides an opportunity to study the present-day regional deformation mechanism and active tectonics. In this study, we investigated the source rupture process of the event using joint inversion of interferometric synthetic aperture radar and broadband seismic data. We found that the rupture propagates almost simultaneously on two main segments, however, the fault motion changes from the predominantly sinistral slip near the epicenter on the eastern segment to the oblique slip on the western segment, with a maximum coseismic slip of $0.8 \mathrm{~m}$. Our results suggest that the accommodation of slip transfer localized in the northeastern Mina deflection tends to transform from the wrench- to extension-dominated transtension.

\section{The Monte Cristo Range Mw 6.5 Nodal Geophone Rapid Deployment}

ZEILER, C., Nevada National Security Site, Nevada, USA, zeilercp@nv.doe. gov; MCLIN, K., Nevada National Security Site, Nevada, USA, mclinkl@ nv.doe.gov; CHAMPION, D., Nevada National Security Site, Nevada, USA, champidj@nv.doe.gov; SCALISE, M., University of Nevada at Reno/NNSS, Nevada, USA, michelledunn@nevada.unr.edu; SHERIDAN, M., Texas A\&M/ NNSS, Nevada, USA, sheridanm@tamu.edu; WHITE, R., Nevada National Secuirty Site, Nevada, USA, whiterl@nv.doe.gov; SMITH, K. D., Univesity of Nevada at Reno, Nevada, USA, ken@unr.edu; PLANK, G., University of Nevada at Reno, Nevada, USA, gabe@seismo.unr.edu

The Nevada National Security Site deployed 48 nodal geophones within 34 hours of the Monte Cristo Range (MCR) Mw 6.5 earthquake that occurred at 11:13 UTC May 15, 2020. The first geophone was planted within 16 hours of the main shock and a series of four deployments were conducted to maintain near continuous recording from May 15 - August 19, 2020. The systems were deployed along roads, with the main line trending east-west for $15 \mathrm{~km}$ and a north-south line running $3 \mathrm{~km}$ along Highway 95 with approximately $500 \mathrm{~m}$ station spacing. The east-west line parallels a significant section of the ENE striking sinistral mainshock rupture. The systems recorded at 500 sps with orientation of the inline channel to the North and leveled vertically. Each deployment had fewer than two systems fail and collected a half terabyte of data, for a total of two terabytes of data over three months. Much of the energetic aftershock period was recorded on the dedicated nodal array near the main fault offsets of the MCR earthquakes. The main shock and subsequent large events were recorded by an additional nodal array that was already deployed at the Nevada National Security Site (NNSS) at $\sim 200 \mathrm{~km}$ epicentral distance. These complementary data sets provide a unique opportunity to demonstrate the use of geophones for deployment and the recording of significant events. The initial review of data shows that for every initial cataloged event there are likely a dozen additional events that can be visually identified on the geophone data. We are developing a micro seismic localization algorithm that detects additional events in the subsurface that do not correspond to published events. We will continue to refine event locations and develop an improved velocity model for the event region.

Mechanisms of Induced Seismicity: Pressure Diffusion, Elastic Stressing and Aseismic Slip

I: Oral Session · Monday $\cdot 19$ April · 2:00 PM Pacific

II: Oral Session · Monday · 19 April · 5:00 PM Pacific

III: Oral Session · Tuesday · 20 April · 2:30 PM Pacific

IV: Oral Session · Tuesday · 20 April · 5:30 PM Pacific

Session Chairs: Ruijia Wang, University of New Mexico (ruijia@unm.edu); Matthew Weingarten, San Diego State University (mweingarten@sdsu.edu); Thomas Goebel, University of Memphis (thgoebel@memphis.edu); Heather DeShon, Southern Methodist University (hdeshon@mail. smu.edu); Kyung Won Chang, Sandia National Laboratories (kchang@sandia.gov)

\section{Constraining the Stability of a Rate-and-State Fault Subjected to Fluid Injection}

LAROCHELLE, S., Caltech, California, USA, stacy.larochelle@caltech.edu; LAPUSTA, N., Caltech, California, USA, lapusta@caltech.edu; AMPUERO, J., Université Côte d'Azur, IRD, CNRS, Observatoire de la Côte d'Azur, Géoazur, Sophia Antipolis, France, ampuero@geoazur.unice.fr; CAPPA, F., Université Côte d'Azur, IRD, CNRS, Observatoire de la Côte d'Azur, Géoazur, Institut Universitaire de France, Sophia Antipolis, France, cappa@geoazur.unice.fr

Fluid injections are ubiquitous in the exploitation of geoenergy resources but can cause nearby faults to slip. This reactivation is often attributed to the reduced frictional resistance accompanying an increase in fault zone fluid pressure. Once a fault has been reactivated, however, it is still unclear what controls the stability and spatial extent of the ensuing slip. Here, we investigate these questions with a fully-dynamic model of a rate-and-state fault subjected to fluid injection. We first apply our model to a fluid-injection experiment on a well-instrumented natural fault and demonstrate how such field experiments can help constrain frictional parameters and hence fault stability. In particular, considering the fault response to a decrease in injection pressure allows us to discriminate between different frictional scenarios with indistinguishable slip signature at the injection site during pressurization but diverging spatial behavior and propensity to large run-away earthquakes with continued injection. Starting from this constrained parameter regime, we then explore how fluid injections and the associated pore pressure diffusion affect earthquake nucleation processes on a rate-and-state fault. Our findings indicate that avoiding injection near low-residual-friction faults and depressurizing upon slip acceleration could help prevent large-scale earthquakes. 


\section{Rapid Fluid Injection Into a Low Permeability Laboratory} Fault Promotes Seismic Swarms

CEBRY, S. B. L., Cornell University, New York, USA, sarabethleach@gmail. com; MCLASKEY, G. C., Cornell University, New York, USA, gcm8@cornell. edu

Fluid injection, from activities such wastewater disposal, hydraulic stimulation, or enhanced geothermal systems, decreases effective normal stress on faults and promotes slip. Earthquake nucleation models suggest the slip at low effective normal stress will be stable and aseismic - contrary to observed increases in seismicity that are often attributed to fluid injection. We conducted laboratory experiments using a biaxial loading apparatus that demonstrate how an increase in fluid pressure can induce "stick-slip" events along a $0.76 \mathrm{~m}$ preexisting saw-cut fault in a poly(methyl methacrylate) (PMMA) sample. We compared slip events generated by externally squeezing the sample (shear-triggered) to those due to direct fluid injection (fluid-triggered) and studied the effects of injection rate and stress levels. Shear-triggered slip events began on a localized nucleation patch and slip smoothly accelerated from slow and aseismic to fast and seismic. Fluid-triggered slip events initiated far more abruptly and were associated with swarms of tiny foreshocks. These foreshocks were able to bypass the smooth nucleation process and jump-start a mainshock resulting in an abrupt initiation. Analysis of these foreshocks indicates that the injection of fluid into a low permeability fault promotes heterogeneous stress and strength which can cause many events to initiate-some of which grow large. To further expand this study, experiments using the same procedure were conducted on a biaxial apparatus with a $3 \mathrm{~m}$ long, saw-cut fault in a granite sample. This second set of experiments highlights the strong effect of stress heterogeneities on resulting fault slip behavior. We conclude that while a reduction in effective normal stress stabilizes fault slip, rapid fluid injection into a low permeability fault increases multi-scale stress/strength heterogeneities which can initiate small seismic events that have the potential to grow rapidly, even into low stress regions.

\section{Simulation of Sequence of Induced Earthquakes and Aseismic Slip Due to Injection Into a Hydrologically Isolated Rate and State Fault}

MIA, M. University of Illinois at Urbana-Champaign, Illinois, USA, mmia2@illinois.edu; ABDELMEGUID, M., University of Illinois at UrbanaChampaign, Illinois, USA, meguid@illinois.edu; ELBANNA, A., University of Illinois at Urbana-Champaign, Illinois, USA, elbanna2@illinois.edu

Reducing hazard of induced seismicity continues to be a major challenge in several geo-energy applications and related activities including $\mathrm{CO} 2$ sequestration and waste-water injection. A key to address this challenge is developing tools for modeling the full fault history of earthquakes and aseismic slip in response to pore pressure and poroelastic stress perturbations to understand the interplay between different time and spatial scales involved with friction, fluid diffusion, and stress transfer. Here, we simulate sequence of earthquake cycles with evolving pore pressure for an anti-plane fault using a hybrid finite element-boundary integral method with alternating quasidynamic and fully dynamic schemes. We consider a vertical rate-and-state fault embedded at depth within a linear elastic half-space. Fluid is assumed to be injected directly to the fault core and pore pressure diffusion is determined analytically constraining it to the fault parallel direction with modification for free surface boundary condition.

We show that the seismicity pattern depends on the injection location and whether it is in the velocity strengthening (VS) or the velocity weakening (VW) regions in the fault. Pre-injection periodic pattern of seismicity is broken by injection leading to space time clustering of the events, accelerated slip accumulation, and reduced inter event time. There is also a delay in recovery to the original pre-injection state after stopping injection. During injection, clustering of intermediate events with partial rupture are found for injection near the transition between VS and VW regions. For injection within the VW region, we observe a period of seismic quiescence after injection shut off, followed by the largest seismic event in the sequence. Our results highlight the interplay between fault rheological heterogeneities and pore pressure diffusion and suggests that delayed seismicity after injection shut off may occur even in the absence of poroelastic effects. These observations are critical for planning mitigation scenarios of induced seismicity risk.

\section{The Combination of Long- and Short-Period "Deformation" Signals in Meter-Scale Hydraulic Fractures Provides New Insights Into the Cause of Induced Seismicity}

NIEMZ, P., GFZ German Research Centre for Geosciences, Potsdam, Germany, pniemz@gfz-potsdam.de; DAHM, T., GFZ German Research Centre for Geosciences, Potsdam, Germany, torsten.dahm@gfz-potsdam.de;
MILKEREIT, C., GFZ German Research Centre for Geosciences, Postdam, Germany, claus.milkereit@gfz-potsdam.de; CESCA, S., GFZ German Research Centre for Geosciences, Potsdam, Germany, cesca@gfz-potsdam.de; PETERSEN, G. M., GFZ German Research Centre for Geosciences, Potsdam, Germany, gesap@gfz-potsdam.de; ZANG, A., GFZ German Research Centre for Geosciences, Potsdam, Germany, zang@gfz-potsdam.de

During decameter-scale high-pressure injection experiments at Äspö Hard Rock Laboratory broadband seismometers installed in the near-field of the fractured rock volume (at distances of $\sim 20 \mathrm{~m}$ and $\sim 60 \mathrm{~m}$, respectively) recorded peculiar long-period signals. A clear correlation among long period signals and pressure and flow rate time series and the lack of long period signals on the vertical component support the interpretation as tilt-induced signals generated by the aseismic growth and opening of the hydraulic fractures. Similar signals on broadband seismometers were often reported in volcanic environments and attributed to tilt resulting from inflations or deflations of dykes or magma chambers. We find that the amplitude of the tilt signal correlates with the volume of water injected during the experiments, while the tilt duration correlates with the duration of the injection process. We are able to forward model a first-order approximation of the observed tilt signals by two different approaches: (1) tensile rectangular faults of constant opening (Okada solution in elastic full space) and (2) the theoretical response of a seismometer to an acceleration step to simulate the tilt-induced excursion on the horizontal components, a technique used in our laboratory for the calibration of seismometers. We show that the tilt signals provide an independent constraint on the the fracture orientations and aseismic growth for each individual injection and re-injection experiment. The orientation and the extent of the fracture planes in the Okada models are in agreement with orientations inferred indirectly from the clustering of acoustic emissions and their migration, which has been estimated by using a network of 11 piezoelectric sensors surrounding the injection borehole. The simultaneous measurement of deformation, tilt and seismicity, therefore, provides new insights in understanding hydraulicfracturing-induced seismicity.

\section{Understanding Controls on Maximum Induced Earthquake Magnitudes}

KROLL, K., Lawrence Livermore National Laboratory, California, USA, kroll5@llnl.gov; COCHRAN, E. S., U.S. Geological Survey, California, USA, ecochran@usgs.gov

Injection of fluids into the subsurface for industrial operations, such as wastewater disposal, geothermal energy production, and carbon sequestration is known to cause earthquakes. Forecasts of the hazard associated with such induced seismicity often require estimates of the maximum possible magnitude $\left(\mathrm{M}_{\max }\right)$ that may occur near a given site. Scaling relationships suggest that maximum magnitudes or expected numbers of earthquakes are related to the volume of fluid injected into the subsurface; however, notable induced events such as the M5.5 2017 Pohang, South Korea event defy this scaling. To understand the controls on $M_{\max }$, we perform a suite of 3-D physics-based earthquake simulations with rate- and state-dependent friction, where we systematically vary the area of the pressurized region and the amplitude of the initial homogeneous or heterogeneous shear stress. Using the resulting catalogs, we explore the conditions that result in pressure-controlled ruptures (confined within the pressurized area) versus runaway ruptures that extend well outside the pressurized zone. We find that proposed empirical scaling laws correctly predict $\mathrm{M}_{\max }$ when shear stresses are farther from failure ( $<=90 \%$ of maximum shear stress) and for short wavelength, high amplitude stress fields. Runaway ruptures are observed for higher initial shear stresses and smoother stress fields without low stress barriers to impede rupture. In these cases, runaway ruptures occur early after the onset of injection and are rarely proceeded by extensive foreshock activity.

Prepared by LLNL under Contract DE-AC52-07NA27344.

\section{Distinguishing the Causal Factors of Induced Seismicity in West Texas: Hydraulic Fracturing Versus Wastewater Disposal}

GRIGORATOS, I., University of Texas at Austin, Texas, USA, i.grigoratos@ utexas.edu; SAVVAIDIS, A., The University of Texas at Austin, Texas, USA, alexandros.savvaidis@beg.utexas.edu; RATHJE, E., University of Texas at Austin, Texas, USA, e.rathje@mail.utexas.edu

Identifying the direct cause of elevated seismicity rates in areas of multiple oil and gas activities has always been a challenging issue that is lacking a homogeneous response. A good example, is the Delaware basin, in West Texas, where the seismicity has been gradually increasing since 2009. In this study, we are examining the recent surge in the area expanding the framework 
presented in Grigoratos et al. $(2020 ; 10.1785 / 0120200079)$ to daily hydraulic fracturing (HF) operations and pressure-driven modeling of wastewater disposal (SWD). Our analysis hindcasts seismicity rates of $M \geq 1.5$ events after 2017 on a $5 \mathrm{~km}$ grid using volume and pressure data as input, and compares them against the null hypothesis of tectonic loading. In the end, each block is assigned a p-value between 0 and 1 , indicating our statistical confidence for the causal relationship of each human activity. Our results indicate that more seismicity clusters than previously identified are associated with HF. In the center of Reeves county, in particular, HF is associated with a uniform array of more than thirty $5 \mathrm{~km}$ blocks, and is not limited to scattered sequences as in other parts of the state. Furthermore, although shallow SWD is linked to several sequences, it is not responsible for the vast majority of events, as previously reported. Finally, large parts of the Delaware basin, especially around the city of Pecos, are affected by both oil and gas activities, with better depth resolution needed to fully decouple causality.

\section{Injection-Induced Seismicity: The Role of Poroelastic Stresses \\ ZHAI, G., University of California, Berkeley, California, USA, gzhai@seismo. berkeley.edu; SHIRZAEI, M., Virginia Tech, Virginia, USA, shirzaei@vt.edu; MANGA, M., University of California, Berkeley, California, USA, manga@ seismo.berkeley.edu}

Much of the U.S. midcontinent seismicity in the past decade has been linked to wastewater disposal into deep formations. The current efforts to evaluate and mitigate induced seismic hazard are either using the empirical relation established between seismic response and injection volume or modeling crustal stress fluctuations due to injection which are then linked to seismicity. However, there are debates on the role of poroelastic stresses in evaluating the induced seismic hazard and it remains an open question whether poroelastic stresses could dominate the occurrence of induced events. Answering these questions requires integrating injection, seismic, and hydrogeological data through a physics-based framework accounting for poroelastic coupling and rate-and-state earthquake nucleation. We study injection-induced seismicity in Texas, Oklahoma and Kansas. The results collectively show that (1) the relative effect of pore pressure and poroelastic stresses depends on subsurface geological structure; (2) poroelastic stresses, as secondary effects, can improve the forecasting of induced earthquake magnitude-time distribution; (3) in some cases, poroelastic stresses could act as the main driver and dominate induced earthquakes; (4) regional tectonics (fault and stress distributions) are important for the consequence of injection operations.

\section{Investigating the Influence of Site Effects and Spatial Stacking on Source Parameter Estimation for Induced Earthquakes Using a Large-N Array}

CHANG, H., Massachusetts Institute of Technology, Massachusetts, USA, hilarych@mit.edu; ABERCROMBIE, R. E., Boston University, Massachusetts, USA, rea@bu.edu; NAKATA, N., Massachusetts Institute of Technology, Massachusetts, USA, nnakata@mit.edu; PENNINGTON, C. N., U.S. Geological Survey, California, USA, cpennington@usgs.gov; KEMNA, K. B., Ruhr-Universität Bochum, Bochum, Germany, kilian.kemna@rub.de; COCHRAN, E. S., U.S. Geological Survey, California, USA, ecochran@usgs gov; HARRINGTON, R. M., Ruhr-Universität Bochum, Bochum, Germany, rebecca.harrington@rub.de

We take advantage of the high station density of the LArge-n Seismic Survey in Oklahoma (LASSO) to investigate how source parameter estimation for induced earthquakes would be affected by: (1) local site responses, and (2) spatial stacking. With $\sim 1825$ stations in a $25 \mathrm{~km}$ x $32 \mathrm{~km}$ region, the LASSO array recorded more than 1500 local events with unprecedented resolution in an area of extensive wastewater injection during spring 2016. These data are ideal for analyzing how spatially varying conditions across the array affect our estimation and if we can improve it by stacking.

We find that the earthquake corner frequencies ( $\mathrm{fc}$ ) estimated using the single spectrum method at each station negatively correlate with local site amplifications. Site amplifications are estimated at each station using 5 second RMS amplitude of P coda waves of a regional earthquake (Mw 3.7) $130 \mathrm{~km}$ away. The average RMS amplitude deviation among sites is about $50 \%$ of the $\mathrm{fc}$ deviation for one of the best recorded events. We find that sites with high amplification are typically located on young alluvial sedimentary deposits. Of the parameters estimated using the single spectrum method, corner frequencies are more affected by site amplification, whereas the seismic moments seem to be affected by the radiation pattern. We also apply an Empirical Green's Function (EGF) method to estimate source parameters from spec- tral ratios and remove the influences of site amplification on fc. We group the stations based on azimuth and distance and stack their spectral ratios and source time functions (STF) to estimate source parameters for some of the best recorded events (Mw 2.2 2.7) within the array. The STFs show gradual spatial variations that describe the rupture directivity, while the fc estimated using the EGF method are likely biased due to high frequency attenuation. We vary the station density, azimuth, and distance range of the sub-groups and analyze the effects on the fitting results.

\section{Roles of Aseismic Slip and Earthquake Interactions in the Evolution of Induced Earthquake Sequences}

CHEN, X., University of Oklahoma, Oklahoma, USA, xiaowei.chen@ou.edu; ABERCROMBIE, R. E., Boston University, Massachusetts, USA, rea@bu.edu

In July 2014, an induced earthquake sequence occurred near Guthrie, Oklahoma following rapidly increased injection at a nearby injection well (Chen et al., 2018). The sequence occurred from early 2014 to late 2015 with over 600 earthquakes between M2 and M4. Rapid fault activation in July 2014 led to diffusive migration. The largest earthquake (M4) occurred in April 2015, towards the end of the sequence. Chen \& Abercrombie (2020) performed detailed source parameter analyses using a stacking approach, and found that earthquakes near the beginning of the sequence had lower stress drop. Here we integrate new results from statistical modeling, detailed analyses of rupture directivity and source radius to interpret the roles of aseismic slip and earthquake interactions in the spatiotemporal evolution of the induced earthquake sequence. ETAS (Epidemic-Type-Aftershock-Sequence) modeling indicates three major states of aseismic forcing. The first two stages of aseismic forcing occurred at the beginning of the sequence following rapid increase in injection rate, likely due to fluid induced stress changes. However, the third stage of aseismic forcing occurred during a period with decreased injection rate. High resolution location indicates linear migration along the main fault during the third stage. Rupture modeling suggests several isolated M3 earthquakes (with their own aftershocks) along the linear migration path. These results suggest that an aseismic slip episode likely occurred during this stage. Aseismic forcing rate significantly decreased after the third stage. The largest (M4) earthquake occurred during the time period with low aseismic forcing rate, its early aftershock locations are consistent with rupture directivity to SE. We use empirical Green's function (EGF) analysis to calculate source time functions and hence rupture directivity of other events (M2-M4) to investigate the roles of earthquake interactions in the sequence evolution. Overall, our integrated analyses suggest that multiple triggering processes are involved in induced earthquake sequences.

\section{Stress Field Variations and Earthquake Source Mechanisms Associated with Wastewater Induced Seismicity in Southern Kansas, USA}

AMEMOUTOU, A., GFZ German Research Center for Geosciences, Potsdam, Germany, amandine@gfz-potsdam.de; MARTINEZ-GARZON, P., GFZ German Research Center for Geosciences, Potsdam, Germany, patricia@gfzpotsdam.de; KWIATEK, G., GFZ German Research Center for Geosciences, Potsdam, Germany, kwiatek@gfz-potsdam.de; BOHNHOFF, M., GFZ German Research Center for Geosciences, Potsdam, Germany, bohnhoff@ gfz-potsdam.de

During the last 10 years, a strong increase of seismicity rates was observed in the conterminous USA and linked to the injection of huge amounts of wastewater from oil and gas production in unconventional hydrocarbon reservoirs. Here, we calculated 549 moment tensors of induced earthquakes with a moment magnitude $M_{\mathrm{W}} \leq 4.9$ in southern Kansas to study their source mechanisms and their relation to injection activity. We observed that approximately $17 \%$ of the analyzed events had significant non-double-couple components, and these events mostly occurred near the two largest local earthquakes (the $M_{\mathrm{W}} 4.9$ Milan and $M_{\mathrm{W}} 4.3$ Harper earthquakes). Then, we inverted for the stress field orientation and determined that most of the region lies within a transtensional stress regime, with a maximum horizontal stress $\sigma_{\text {Hmax }}$ trending $\mathrm{N} 75^{\circ} \mathrm{E}$. Furthermore, in the epicentral area of the $M_{\mathrm{W}} 4.9$ Milan earthquake, the $\sigma H \max$ trend is rotated to about $\mathrm{S} 80^{\circ} \mathrm{E}$. Locally, we also highlighted two areas that display a change in the stress field orientation with depth, from transtensional above $5.5 \mathrm{~km}$ depth to strike-slip deeper in the basement. Finally by relating the resolved fault geometries to the obtained local stress field orientation, we find that most of the activated fault planes were optimally oriented to the current stress field and thus small stress perturbations caused by the water injection could lead to failure. 


\section{Induced Acoustic Emission Activity Associated With the Stimtec-X In-Situ Hydraulic-Fracturing Experiment at the URL Reiche Zeche Mine, Germany}

BOESE, C. M., GFZ German Research Centre for Geosciences, Potsdam, Germany, cboese@gfz-potsdam.de; RENNER, J., Ruhr-University, Bochum, Germany, joerg.renner@rub.de; DRESEN, G., GFZ German Research Centre for Geosciences, Potsdam, Germany, dre@gfz-potsdam.de; ADERO, B., Ruhr University, Bochum, Germany, bernard.adero@rub.de; BOHNEN, B., Geomecon GmbH, Berlin, Germany, ben.bohnen@geomecon.de FRUEHWIRT, T., Technical University, Freiberg, Germany, thomas fruehwirt@ifgt.tu-freiberg.de; FISCHER, T., GMuG mbH, Bad Nauheim, Germany, t.fischer@gmug.eu; JIMENEZ-MARTINEZ, V., Ruhr University, Bochum, Germany, Victoria.JimenezMartinez@ruhr-uni-bochum.de; KLEE, G., Mesy-Solexperts, Bochum, Germany, gerd.klee@mesy-solexperts. com; KONIETZKI, H., Technical University, Freiberg, Germany, heinz. konietzky@ifgt.tu-freiberg.de; KWIATEK, G., GFZ German Research Centre for Geosciences, Potsdam, Germany, kwiatek@gfz-potsdam.de; MEIER, T., Geomecon GmbH, Berlin, Germany, tobias.meier@geomecon.de; WONIK T., Leibniz Institute for Applied Geophysics, Hannover, Germany, thomas. wonik@liag-hannover.de; YADAV, V., Technical University, Freiberg, Germany, vishal-vilas.yadav@ifgt.tu-freiberg.de

In 2018-2019, the STIMTEC hydraulic stimulation experiment was conducted at the Reiche Zeche underground laboratory in Freiberg, Saxony/Germany, to investigate the role of hydro-mechanical processes for enhancement of hydraulic properties in deep geothermal projects. We applied the same injection protocol to each of the ten stimulated intervals in the $63 \mathrm{~m}$-long injection borehole. Yet, we observed significant small-scale variability in the seismic and hydraulic responses to stimulation and stress field heterogeneity on the meter scale. While acoustic emission (AE) activity was high in the upper part of the injection borehole, no AE events were detected in its deepest part, penetrating a high-permeability damage zone. To investigate the stress and seismic variability as well as their interrelation further, we started the follow-on experiment STIMTEC-X. It involved eleven local stress measurements in October 2020 in three existing monitoring boreholes, with varying orientations and lengths. We used an adaptive, high-resolution, real-time seismic monitoring network comprising six AE-type hydrophones, six regular AE sensors and four accelerometers. The hydrophones were installed in combination with hydraulic gauges to make best use of existing infrastructure. Hydrophones were optimally placed for each measurement configuration anew with at least one deployed within 3-4 m of the injection interval. We detected low-magnitude AE activity $(\mathrm{M}<-3.5)$ at high resolution, spatially distributed between distinct clusters identified previously, doubling of the seismically active volume. We also performed eight dilatometer tests to determine deformation characteristics of induced hydrofracs and pre-existing fractures. A circulation experiment between the injection borehole and two newly drilled boreholes of $23 \mathrm{~m}$ and $30 \mathrm{~m}$ depth is pending. Here, we present the seismicity associated with the STIMTEC and STIMTEC-X stimulation campaigns and focal mechanism solutions. We focus on how they contribute to 3-D volumetric stress field characterisation between local stress measurement points.

\section{Insights on the Criticality of Faults From Dense Monitoring of Induced Seismicity from Moment Tensor Based Stress Inversion}

BAIG, A., Nanometrics, Kanata, Canada, adambaig@nanometrics.ca

Seismic monitoring of waste-water injection, hydraulic fracturing, and other processes has increased across North America. With the increased injection concerns about induced seismicity have risen, and traffic-light systems (TLS) have become a model for managing the risk of shutting down operations. While locations and magnitudes are necessary input for these TLS, seismic monitoring can yield more products providing a detailed level of understanding of the geological and geomechanical setting of the array, allowing for proactive versus reactive reservoir management.

In this paper, I detail how the advanced products of a monitoring system-high-precision locations, moment tensors, and stress inversions derived therefrom-can be used to answer questions on the criticality of the faults, that gives insight into the triggering mechanisms. I look at an example in North America where sequences of large events have been detected over a number of hydraulic fracture completions. Large events, characterized by magnitude above ML2, are selected for moment tensor inversion. By selecting the moment tensors for events within $20 \mathrm{~km}$ of a grid point, I obtain a relatively high-resolution stress map using a stochastic stress inversion (if at least 10 mechanisms are within that radius). Simultaneously, cross-correlation-based repicking and double difference relocation is used to define lineations associ- ated with faults. By clustering the high-precision locations, these faults can be identified and imaged. Frequently, especially in strike-slip stress regimes in sedimentary basins, this workflow results in the first discovery of such faults as other geophysical means are not amenable. Finally,I assess how critically stressed these faults are in the moment-tensor determined stress regime by calculating the shear and normal stresses on these faults.

\section{Monitoring Thermoelastic Effects from a Closed-Loop Geothermal System}

EATON, D. W., University of Calgary, Calgary, Canada, eatond@ucalgary.ca; MARION, K. P., University of Calgary, Calgary, Canada, kienan.marion1@ ucalgary.ca; SALVAGE, R. O., University of Calgary, Calgary, Canada, rebecca. salvage1@ucalgary.ca

Closed-loop geothermal systems, a type of advanced geothermal system (AGS), use drilling technology adapted from the oil and gas industry. These differ from conventional geothermal systems because there is no fluid exchange with the subsurface reservoir. Apart from thermoelastic effects due to cooling of the reservoir, this difference is expected to obviate inducedseismicity risks. We report initial results from 9 months of monitoring using a temporary seismograph array installed above a prototype closed-loop geothermal system in west-central Alberta, Canada. The seismograph array is designed to detect microearthquakes that may be associated with the expanding cooling front from the closed-loop system. Taken together with coverage provided by a regional seismograph network, this array also enhances monitoring of nearby, previously documented seismicity clusters that are associated with hydraulic fracturing in the Duvernay East Shale basin and gas production in the foothills of the Rocky Mountains. Ongoing analysis is underway using the open-source software REDPy.

\section{The Importance of Accurate Earthquake Source Information for Understanding the Cause of Induced Seismicity: The Case of Mentone M4.9 Earthquake in West Texas}

SAVVAIDIS, A., University of Texas at Austin, Texas, USA, alexandros. savvaidis@beg.utexas.edu; HICKS, S., Imperial College London, London, United Kingdom, s.hicks@imperial.ac.uk; LOMAX, A., ALomax Scientific, Mouans-Sartoux, France, alomax@free.fr; SHIRLEY, M., University of Texas at Austin, Texas, USA, matthew.shirley@beg.utexas.edu

Since 2017 the Texas Seismological Network (TexNet) has increased the number of seismic stations in the Delaware Basin, West Texas. A one-dimensional earth model determined from earthquake tomography is used on daily operations to provide earthquake source information for the detected seismicity.

On March $26^{\text {th }}, 2020$ at 3:16pm (Local Time) an earthquake of M4.9 occurred in west Texas along the Culberson-Reeves County Line (CRCL). The nearest city to the epicenter, $43 \mathrm{~km}$ to the east is Mentone, TX, in Loving County. The earthquake was recorded on seismic stations up to $270 \mathrm{~km}$ away from the epicenter, with the closest station at $26 \mathrm{~km}$. Seismicity in this area is reported in the TexNet catalog from October 2019 and continued up to November of 2020.

In order to show that specific Oil and Gas operations in the area are the cause of seismicity it is necessary to provide accurate earthquake source information (i.e., epicenter distribution, hypocentral depth, focal mechanism, etc). We present earthquake relocation and full waveform moment tensor inversion using two local earth models and waveforms from close stations of two private arrays (less than $20 \mathrm{~km}$ epicentral distance). These results provide detailed information on the seismicity and on foreshock and main sock source characterization. These detailed analyses will also help to compare the characteristics and mechanisms of West Texas seismicity with the active and very well documented induced earthquakes in Oklahoma.

We examine these results through spatiotemporal association of seismicity and pore pressure modeling with respect to Oil and Gas operations. We discuss hypocentral depth uncertainty, the triggering mechanism of induced seismicity in the area and how the accumulation of stress may have caused the M4.9 event.

\section{What Induced Seismicity From CO2 Injection Can Tell Us About Fluid Migration Pathways}

WILLIAMS-STROUD, S., Illinois State Geological Survey, Illinois, USA, sherilyn@illinois.edu; LEETARU, H., Illinois State Geological Survey, Illinois, USA, hleetaru@illinois.edu; BAUER, R., Illinois State Geological Survey, Illinois, USA, rabauer@illinois.edu; GREENBERG, S., Illinois State Geologica 
Survey, Illinois, USA, sallieg@illinois.edu; LANGET, N., Norsar, Kjeller, Norway, nadege@norsar.no

Monitoring of induced seismicity before, during, and after injection of supercritical $\mathrm{CO} 2$ is being used to help determine pathways the fluid takes during migration over time and to assess the risk of felt seismicity the Illinois Basin - Decatur Project (IBDP). The microseismic activity at the site primarily indicates locations where existing fractures and faults were reactivated. Some microseismic events were large enough to determine focal mechanisms, but no injection-related felt seismicity has been detected. Most of the induced seismicity occurs below the reservoir in fractured low porosity/permeability igneous basement rocks. The reservoir itself, the Cambrian Mt. Simon Sandstone, has high porosity and permeability, with much less common fracturing and faulting. The temporal development of the microseismicity at IBDP indicates stress perturbations that migrate to the north and west of the injection location, concentrated in elongated clusters with NE-SW orientations. Horizontal fluid migration occurring in the Mt. Simon sandstone could be the dominant pathway for transmission of fluid and pressure away from the injection well to locations that are hydrologically connected to the basement rocks. To address the potential of upward migration of fluid pressure to cause slip on faults in overlying rocks that could lead to loss of top seal integrity, microseismic monitoring was combined with measurements of pressure and chemistry from subsurface monitoring wells. Shallow monitoring at the site surface has confirmed no $\mathrm{CO} 2$ leakage to the surface. We suggest that that fluid directional pathway is either accommodated by horizontal migration within the Mt. Simon, or by open fractures in the basement with orientations that connect the NE-SW oriented reactivated faults. We use this integrated data set to create a fault and fracture model that is consistent with the interpretation of the seismic reflection data and the observed microseismicity as a basis on which to test the potential for induced slip on existing fault planes and the risk for induced felt seismicity.f

\section{A 3D Stochastic Modelling Approach for Induced Seismicity Risk Mitigation}

EATON, D. W., University of Calgary, Calgary, Canada, eatond@ucalgary. ca; EYRE, T. S., ASEISMIC Solutions Inc., Calgary, Canada, thomas.eyre@ ucalgary.ca

Anthropogenic fluid injection into the subsurface is known to produce induced seismicity. Efforts to quantify induced-seismicity risk and to develop mitigation strategies are hampered by a dearth of numerical schemes that can accommodate realistic Earth models while capturing the full spectrum of applicable physics. Several models have been proposed to explain the mechanisms of fault activation by fluid injection. The most common is an increase in pore pressure within the fault zone, which leads to a reduction in effective normal stress acting on the fault. Alternatively, poroelastic coupling between hydraulic fractures and the rock matrix is capable of altering fault-loading conditions without any hydraulic connection. More recently, it has been recognized that aseismic slip triggered by the two mechanisms above may play a major in loading unstable regions of a fault. Here, we present a new 3D stochastic approach to modelling injection-induced seismicity, whereby each of these mechanisms are accounted for. Uncertainties in input parameters are addressed stochastically to provide a probabilistic assessment of inducedseismicity risk. Regions of modelled faults that exceed the assigned failure criteria are mapped and provide estimates for the magnitudes of any seismic events that may occur. Due to the stochastic approach, probabilities for the expected maximum magnitudes of events and the sensitivities of results to the different input parameters can be analyzed. This type of modelling can be used to give a site-specific assessment of how the probability of generating an induced event changes, based on different treatment designs. Case studies from western Canada are used to evaluate the applicability of this approach for unconventional oil and gas development; this methodology also has potential for other industries, including geothermal energy and gigatonne-scale carbon dioxide storage.

\section{Mechanisms Inducing Earthquakes in the Weiyuan Shale Gas Field, Sichuan, China, Inferred From Dense Array Recordings}

YANG, H., The Chinese University of Hong Kong, Shatin, Hong Kong, hyang@cuhk.edu.hk; ZI, J., The Chinese University of Hong Kong, Shatin, Hong Kong, zijinping@link.cuhk.edu.hk

As one of the major shale gas blocks in China, the Weiyuan shale gas field has been actively developed since 2010, accompanying numerous hydraulic fracturing (fracking) activities. Accordingly, the number of earthquakes has been increasing drastically, with a few damaging earthquakes $(M>4)$ in 2019, some of which led to fatalities in the region. Due to the relatively sparse seismic network, locations of these earthquakes bear appreciable uncertainties, in particular on focal depths. Thus, it remains unclear what mechanisms are dominant of inducing earthquakes in Weiyuan. Since April 2020, we have deployed a dense temporary array consisting of more than 130 short-period seismometers, forming a number of mini arrays. During the two-month deployment period, numerous earthquakes with magnitudes up to 3 have been recorded. We apply the machine learning detector, PhaseNet, to identify P and S arrivals. Then we associate the events and locate them by the double-difference method. The location results show a few different earthquake clusters. One cluster that well located within our mini-array stations exhibits clear lineations and temporal migration parallel to the horizontal wells, indicating that they are fracking-induced earthquakes. The earthquakes delineate dipping geometries and locate within $1 \mathrm{~km}$ below the Wufeng-Longmaxi formation where fracking was conducted, suggesting that they are likely induced by pore pressure diffusion. Benefiting from the temporary dense array, our location results with unprecedented resolution in the region advance our understanding of mechanisms of induced earthquakes in the Weiyuan shale gas field.

\section{Seismicity Associated With 2018 and 2020 Hydraulic Stimulations at EGS in Helsinki, Finland, Shows Limited Earthquake Interaction: Implication for Seismic Hazard Assessment}

KWIATEK, G., GFZ German Research Centre for Geosciences, Potsdam, Germany, kwiatek@gfz-potsdam.de; LEONHARDT, M., GFZ German Research Centre for Geosciences, Potsdam, Germany, leonhard@gfzpotsdam.de; MARTINEZ-GARZON, P., GFZ German Research Centre for Geosciences, Potsdam, Germany, patricia@gfz-potsdam.de; PENTTI, M., St1 Deep Heat Oy, Helsinki, Finland, matti.pentti@st1.fi; BOHNHOFF, M., GFZ German Research Centre for Geosciences, Potsdam, Germany, bohnhoff@ gfz-potsdam.de; DRESEN, G., GFZ German Research Centre for Geosciences, Potsdam, Germany, dre@gfz-potsdam.de

In this study we investigate the statistical spatio-temporal characteristics induced seismicity associated with two stimulation campaigns performed in 2018 and 2020 in a $6.1 \mathrm{~km}$ deep geothermal well near Helsinki, Finland as part of the St1 Deep Heat project. We aim to find out whether the seismic activity is passively responding to injection operations, or whether we observe signatures of significant stress transfer and strong interactions between events. The former suggests stable relaxation of seismic energy proportional to hydraulic energy input, while the latter includes stress transfer as an additional source of stress perturbation, hence implying larger seismic hazard.

The selected catalogs from 2018 and 2020 stimulation contained in total 60,814 and 4,368 seismic events, respectively, recorded during and after stimulation campaigns and above the local magnitude of $M-1.5$. The analyzed parameters include magnitude-frequency $b$-value, correlation integral (c-value), fractal dimension ( $D$-value), interevent time statistics, magnitude correlation, interevent time ratio and generalized spatio-temporal distance between earthquakes. The initial observations suggest significant timeinvariance of the magnitude-frequency $b$-value, and increased D and c-values only at high injection rates, the latter also guiding the rate of seismicity. The seismicity covering the stimulation period neither provide signatures of magnitude correlations, nor temporal clustering or anticlustering. The interevent time statistics are generally characterized with Gamma distribution (close to Poissonian distribution), and the generalized spatio-temporal distance suggest very limited triggering ( $90 \%$ of the catalog was classified as background seismicity). The observable parameters suggest the seismicity passively respond to hydraulic energy input rate with little to no time delay, and the total seismic moment is proportional to total hydraulic energy input. The performed study provides the base for implementation of time-dependent probabilistic seismic hazard assessment for the site.

\section{Shallow Induced Seismicity in Sichuan, China: A Coupled Flow-Geomechanics Modeling Analysis}

LIU, C., The University of Hong Kong, Hong Kong, chongliu@connect.hku. hk; CHOO, J., The University of Hong Kong, Hong Kong, jchoo@hku.hk; LIU, F., Zhejiang University, Hangzhou, China, fushenliu@zju.edu.cn; YANG, H., The Chinese University of Hong Kong, Hong Kong, hyang@cuhk.edu.hk

On 25 February 2019, an $\mathrm{M}_{\mathrm{L}} 4.9\left(\mathrm{M}_{\mathrm{w}}\right.$ 4.3) earthquake occurred in the Rongxian County, Sichuan, China, presumably related to hydraulic fracturing operations in the Weiyuan Shale Gas Field. The earthquake was located at a depth of $\sim 1 \mathrm{~km}$, which is extremely shallower than the typical locations of induced earthquakes. This peculiarity has attracted detailed investigations into the mechanism of the 2019 Rongxian $\mathrm{M}_{\mathrm{L}} 4.9$ earthquake. Recently, Yang et al. (2020) and Wang et al. (2020) have suggested that the earthquake was 
triggered by reactivation of the Molin fault - located around the same depth as the mainshock - as a result of poroelastic stress change followed by the hydraulic fracturing operations. Nevertheless, the precise mechanism of the shallow earthquake still remains elusive. To shed light on the mechanism of the 2019 Rongxian earthquake, we conduct a computational analysis of the earthquake sequence based on a coupled flow-geomechanics model. Using the extended finite element method (XFEM), the computational model incorporates the full two-way coupling of fluid flow and geomechanical processes on faults as well as off-fault domains. The main findings from the numerical analysis will be discussed.

\section{The Occurrence of Persistent Seismicity in a Hydraulic- Fracturing Dominated Area During Operational Shutdown}

SALVAGE, R. O., University of Calgary, Calgary, Canada, rebecca.salvage1@ ucalgary.ca; EATON, D. W., University of Calgary, Calgary, Canada, eatond@ ucalgary.ca

Seismicity in NE British Columbia is usually attributed to ongoing resource development, due to its characteristic temporal and spatial clustering. However, for the first time we have been able to detect seismicity not directly related to these operations, due to the global pandemic of COVID-19 where there was an extended period of anthropogenic quiescence. A total of 389 events were detected from April to August 2020 within the Kiskatinaw area of British Columbia, encompassing a period of no hydraulic-fracturing operations during a government-imposed lockdown. During this time period, observed seismicity had a maximum magnitude of $\mathrm{M}_{\mathrm{L}} 1.2$ but lacked temporal clustering that is often characteristic of hydraulic-fracturing induced sequences. Hypocenters occurred within a corridor orientated NW-SE, similar to previous years, with focal depths near the target Montney formation or shallower $(<2.5 \mathrm{~km})$. Based on the Gutenberg-Richter relationship, we estimate that a maximum of $21 \%$ of the detected events during lockdown may be attributable to natural seismicity, with a further $8 \%$ possibly due to dynamic triggering of seismicity from teleseismic events. However, the remaining $\sim 70 \%$ of events cannot be attributed to a primary activation process (e.g. tectonic forces, fluid injection) and has no obvious trigger (e.g. enhanced pressurization at the onset of seismicity). We deem this to be latent seismicity, which shows an unusually long delay following an activation processes. We can exclude direct pore-pressure diffusion from the most recent fluid injection, as there is no clear pattern of temporal or spatial seismicity migration. If elevated pore pressure from previous injections became trapped in the subsurface, this could explain the localization of seismicity within an operational corridor, but it does not explain the latency of seismicity on a timescale of months. Aseismic creep on weak surfaces such as faults, in response to tectonic stresses, in addition to trapped elevated pore-pressure could play a role in stress re-loading to sustain the observed pattern of seismicity.

Mechanisms of Induced Seismicity: Pressure Diffusion,
Elastic Stressing and Aseismic Slip
Poster Session· Tuesday · 20 April ·4:15 PM Pacific
Session Chairs: Ruijia Wang, University of New Mexico
(ruijia@unm.edu); Matthew Weingarten, San Diego State
University (mweingarten@sdsu.edu); Thomas Goebel,
University of Memphis (thgoebel@memphis.edu); Heather
DeShon, Southern Methodist University (hdeshon@mail.
smu.edu); Kyung Won Chang, Sandia National Laboratories
(kchang@sandia.gov)

Dynamic Triggering and the State of Stress in Oklahoma ALFARO-DIAZ, R. A., Los Alamos National Laboratory, New Mexico, USA, raalfarodiaz@lanl.gov; CHEN, T., Los Alamos National Laboratory, New Mexico, USA, tchen@lanl.gov; MA, X., Los Alamos National Laboratory, New Mexico, USA, xfma@lanl.gov

Induced seismicity has increased significantly in Oklahoma resulting from massive wastewater injection. Oklahoma has been subjected to several $M \geq$ 5 earthquakes including the Prague, Cushing, Fairview, and Pawnee earthquakes. In order to understand the mechanisms leading to earthquake failure, we examine seismicity leading up to these moderate earthquakes in Oklahoma and search for earthquake-triggering incited by natural transient stresses generated by the seismic waves of large remote earthquakes. We analyze $\sim 7$ years of data (2010-2016) from the Oklahoma Seismic Network, EarthScope's USArray Transportable Array (TA), and temporary local networks. We investigate 957 teleseismic earthquakes wit $M \geq 6$ and flag events that significantly increase seismicity throughout Oklahoma following the arrival of the teleseismic wave arrivals. We observe patterns of triggered seismicity indicative of evolving stress-state leading up to several large earthquake failures.

\section{Laboratory Observation of Large Fluid Pressure Amplification in a Fluid-Filled Fracture}

IN, Y., University of Houston, Texas, USA, jinyuesu14@gmail.com; DYAUR, N., University of Houston, Texas, USA, nidyaur@gmail.com; ZHENG, Y., University of Houston, Texas, USA, yc.zheng@gmail.com

It is a well-established observational phenomenon that earthquakes can be triggered by a weak-amplitude, long-period seismic waves in the geothermal and volcanic regions. The underlying mechanism, in particular, the frequency dependency and the affinity to fluids, have not been well-understood yet Zheng (2018) found a transient pressure surge (PS) phenomenon in numerical modeling that when a seismic wave interacts with a fluid-filled fracture, the fluid pressure inside the fracture could be amplified by 2-3 orders of magnitude compared to the incident wave pressure. The PS effect both depends on the incident wave frequency and the participation of fluid. It is a competitive candidate for the underlying physical mechanism in triggering.

Here we report results from laboratory experiments about the PS effect in the frequency range of 10's Hz. Because the PS effect happens in low frequencies. We developed a new low-frequency underwater experiment platform, including a low-frequency acoustic source (Xfrac-S), a new hydrophone (Xfrac-H) of small dimensions placed inside the thin fracture.

By adjusting the fracture aperture from $0.2 \mathrm{~mm}$ to $9.2 \mathrm{~mm}$ and sweeping the frequency from $12 \mathrm{~Hz}$ to $70 \mathrm{~Hz}$, we find that the fluid-pressure of the wave recorded inside the fractures can be amplified up to 25 times larger than the incident wave pressure. The amplification depends on fracture geometry and frequency.

This observation may provide a plausible explanation for both dynamic earthquake triggering because the pressure surge observed here can reduce the normal confining pressure across the fracture interfaces to trigger shear slip for earthquakes. The transient pressure surge can activate local fluid flow due to the pressure gradient. It may also be the underlying mechanism for permeability changes induced by passing seismic waves. Lastly, PS may also find new uses in induced seismicity, subsurface flow management in conventional/ unconventional/geothermal reservoirs, and novel subsurface imaging.

\section{Modeling Injection Induced Stress Changes in the Fort Worth Basin}

QUINONES, L. A., Southern Methodist University, Texas, USA, lquinones@ smu.edu; DESHON, H., Southern Methodist University, Texas, USA hdeshon@smu.edu

Ongoing seismicity within the crystalline basement of the Fort Worth Basin (FWB), Texas, has been causally linked to the injection of wastewater into the thick, directly overlying, limestone Ellenburger formation. The majority of earthquakes in the basin are located within $10 \mathrm{~km}$ of at least one fluid injection well with the exceptions being earthquakes located in the most northeastern portion of the basin. This includes the Dallas-Irving earthquake sequence of M3.4+ earthquakes directly below the densely populated urban area. Spatiotemporal correlation between earthquake and injection activities has led to the conclusion that pore fluid pressure and/or poroelastic stress changes induce seismicity on pre-existing, well-oriented normal faults, even at $10 \mathrm{~s}$ of $\mathrm{kms}$ distance. Here, we create a $3 \mathrm{D}$ fully-coupled geomechanical model to examine injection related time-dependent stress changes along faults within the FWB. The model incorporates updated 3D geometries and parameters of the main geologic formations, fault geometries from using earthquake and 3D seismic reflection data, and updated fluid injection data. Parameter testing of the model has focused on three aspects of the system: connectivity of the Ellenburger across the eastern boundary of the basin, which in prior FWB models is assumed to coincide at the intersection of the Ouachita Thrust Front and top of the Ellenburger formation; the matrix permeability of the Ellenburger formation; and the spatial distribution, width and permeability of faults. We find that treating the eastern boundary of the model as an impermeable feature leads to increased stress changes that better match observed seismicity. We show that assumptions regarding the matrix permeability of the Ellenburger have a greater influence on the absolute value of stress change than the connectivity of the NE-SW trending fault systems. We observe peak injection associated stress changes in the basin of $>2 \mathrm{MPa}$ for regions with high injection activities, however stress changes in the Dallas-Irving sequence area are $<0.1 \mathrm{MPa}$ for all end member parameterizations. 
One-Year Seismic Hazard and Risk Maps Due to Wastewater Disposal in Oklahoma

GRIGORATOS, I., University of Texas at Austin, Texas, USA, i.grigoratos@ utexas.edu; BAZZURRO, P., University School of Advanced Studies of Pavia (IUSS), Pavia, Italy, paolo.bazzurro@iusspavia.it; RATHJE, E., University of Texas at Austin, Texas, USA, e.rathje@mail.utexas.edu; SAVVAIDIS, A., Bureau of Economic Geology at the University of Texas at Austin, Texas, USA, alexandros.savvaidis@beg.utexas.edu

In the past decade, several parts of the United States, including Oklahoma, have experienced unprecedented seismicity rates that have been attributed to wastewater disposal activities carried out by the oil and gas industry. In this study, we perform a probabilistic assessment of the time-dependent seismic hazard in Oklahoma and incorporate these results into an integrated seismic risk model to assess the evolution of the state-wide economic losses, including a conservative forecast through 2030. Our risk model employs an injection-driven earthquake rate model, a region-specific ground motion model, a recent Vs30 map, HAZUS exposure data and updated vulnerability curves for both structural and non-structural elements, and contents. The calculations are performed using a stochastic Monte Carlo based approach implemented in the OpenQuake software engine. The resulting seismic hazard maps illustrate the incompatibility of the regional seismic provisions with the recent seismicity. In 2015 in particular, the induced seismic hazard in several places in Oklahoma was higher than along the San Andreas fault. During the peak of seismicity in 2015, the seismic risk was 275 times higher than the background level, with the vast majority of losses originating from damages to non-structural elements $(66 \%)$ and contents $(20 \%)$. We believe that our seismic risk model is a significant upgrade to previous efforts, with our loss estimates being in reasonable agreement with the paid insurance claims. Even though our risk estimates are fairly stable overall, they show significant sensitivity to the Ground Motion Model selection. Finally, our risk model can be adopted in an ongoing manner, helping stakeholders to quantify the benefits of various risk mitigation measures and to define acceptable production levels.

\section{Spatial-Temporal Evolution Pattern of Earthquakes Illuminated by Machine Learning Method and Waveform Correlation in Weiyuan Shale Gas Field, Sichuan China} WONG, W., The Chinese University of Hong Kong, Hong Kong, jwjeremy@ link.cuhk.edu.hk; ZI, J., The Chinese University of Hong Kong, Hong Kong, zijinping@link.cuhk.edu.hk; ZHOU, P., The Chinese University of Hong Kong, Hong Kong, pengcheng.zhou@link.cuhk.edu.hk; YANG, H., The Chinese University of Hong Kong, Hong Kong, hyang@cuhk.edu.hk; SU, J., Sichuan Earthquake Agency, Sichuan, China, sujr0816@163.com

The rapid development of hydraulic fracturing activities in the Sichuan Basin, China, has immediately followed by a surge of seismicity since 2015. In 2019, 3 magnitude $4+$ earthquakes and 2 magnitude $5+$ earthquakes struck the Weiyuan Shale Gas Field, causing casualties and damages. Albeit multiple research groups have conducted extensive studies on these major earthquakes, the centroid depth and inducing mechanisms are still in controversies. In contrast to most of the previous analysis based on a diffusive earthquake catalog constructed from phase arrivals on the local network, we aim to construct a high-resolution catalog using machine learning detector and waveform cross correlation, so as to derive spatial-temporal evolution of seismicity. In our study, we use the PhaseNet, a U-shaped neural network to automatically pick $\mathrm{P}$ and $\mathrm{S}$ arrivals from the 9 permanent stations across the Weiyuan area. The $\mathrm{P}$ and $\mathrm{S}$ arrival onset selection by the machine learning method has shown systematic improvements when compared to the catalog phase picks. The arrivals are associated with a grid search method and the events are located by VELEST. Then they are relocated by the double-difference algorithm with the arrival cross-correlation. The newly constructed catalogs detected one-third more earthquakes than the network catalog, despite using one-fourth of the available data from August 2018 to March 2019. The distribution of the earthquakes has delineated unmapped subsurface fault geometry possibly led to the $2019 \mathrm{Mw} 5.0$ earthquake in September, by far the largest earthquake in the region. The seismicity patterns display high spatial-temporal correlation of multiple earthquake clusters with the hydraulic fracturing wells, confirming a causal link between the emerged seismicity and the hydraulic fracturing in the region.

\section{Statistical Modelling of Induced Seismicity in the Western Canada Sedimentary Basin}

KOTHARI, S., Western University, Woodstock, Canada, sid.kothari7@ gmail.com; SHCHERBAKOV, R., Western University, London, Canada, rshcherb@uwo.ca; ATKINSON, G. M., Western University, London, Canada, gmatkinson@aol.com

In western Canada, there has been an increase in seismic activity linked to anthropogenic energy-related operations including conventional hydrocarbon production, wastewater fluid injection, and, more recently, hydraulic fracturing (HF). Statistical modelling and characterization of the space, time, and magnitude distributions of the seismicity are vital for a better understanding of induced earthquake processes and development of forecasting models. In this work, a statistical analysis of the seismicity in the Western Canada Sedimentary Basin was performed across past and present time periods by utilizing a compiled earthquake catalog for Alberta and eastern British Columbia. Specifically, the interevent space-time distance distributions of earthquakes were studied using the nearest-neighbor distance (NND) method. Additionally, the frequency-magnitude statistics and aftershock parameters of several clusters were analyzed using the Gutenberg-Richter relation and the epidemic-type aftershock sequence model. The results suggest that recent regional changes in the NND distributions, namely, a disproportionate increase in loosely and tightly clustered seismic activity over time, are unnatural and likely due to the rise in HF operations for the development of unconventional resources. It is concluded that both these loosely and tightly clustered earthquake subpopulations differ measurably from what may be the region's tectonic seismic activity. Additionally, HF treatments have a greater probability of triggering swarm-like sequences that sharply spike the seismicity rate and are characterized by larger Gutenberg-Richter b values. In contrast, conventional production and wastewater disposal operations largely trigger loosely clustered activity with more typical magnitude occurrence distributions.

\section{Modern Geodesy for Observation and Its Modeling of} Earthquake Deformation

Oral Session · Monday · 19 April · 5:00 PM Pacific

Session Chairs: Xinjian Shan, China Earthquake

Administration (xjshan@163.com); Benchun Duan,

Texas A\&M University (bduan@geos.tamu.edu); Jiankun

He, Chinese Academy of Sciences (jkhe@itpcas.ac.cn);

Mingsheng Liao, Wuhan University (liao@whu.edu.

cn); Guohong Zhang, China Earthquake Administration

(274990177@qq.com)

\section{A Study of Faulting Near Dushanbe (Tajikistan) from Time} Series InSAR and Tectonic Geomorphology

WILKINSON, R., COMET, Department of Earth Sciences, University of Oxford, Oxford, United Kingdom, roberta.wilkinson@earth.ox.ac.uk; DAOUT, S., COMET, Department of Earth Sciences, University of Oxford, Oxford, United Kingdom, simon.daout@earth.ox.ac.uk; ISCHUK, A., Institute of Geology, Earthquake Engineering and Seismology of the National Academy Science of Tajikistan, Dushanbe, Tajikistan, anatoly.ischuk@gmail. com; JOHNSON, B., COMET, Department of Earth Sciences, University of Oxford, Oxford, United Kingdom, benedict.johnson@st-annes.ox.ac.uk; PARSONS, B., COMET, Department of Earth Sciences, University of Oxford, Oxford, United Kingdom, barry.parsons@earth.ox.ac.uk; PIERCE, I. K. D., COMET, Department of Earth Sciences, University of Oxford, Oxford, United Kingdom, ian@nevada.unr.edu; WALKER, R., COMET, Department of Earth Sciences, University of Oxford, Oxford, United Kingdom, richard.walker@ earth.ox.ac.uk; WORDSWORTH, P., Institute of Archaeology, University of Oxford, Oxford, United Kingdom, paul.wordsworth@orinst.ox.ac.uk

Dushanbe (capital city of Tajikistan) sits at the northern margin of the Afghan-Tajik depression, a sedimentary basin bounded by the Tian Shan, Pamir, Hindu Kush and Afghan platform. A set of north-south trending anticlines sweep up the basin's interior and merge along the northern margin into the right-lateral Ilyak fault, immediately south of Dushanbe. A GPS analysis from Metzger et al., 2020 suggests the Ilyak fault accommodates $\sim 5 \mathrm{~mm} /$ $\mathrm{yr}$ of shortening and $8-15 \mathrm{~mm} / \mathrm{yr}$ of strike slip deformation. The $1989 \mathrm{MLH}$ 5.5 Gissar earthquake and a number of others $(1953,1968)$ occurred close to the western end of the Ilyak fault, but the exact faults they ruptured have not been identified. To the south of Dushanbe, sharp GPS velocity gradients across basin anticlines hint at localisation of strain and may indicate creep on the associated thrusts. However, sparse GPS data alone are insufficient to 
determine the extent to which the Ilyak fault or basin thrusts are locked or slipping aseismically.

In this study we combine high resolution mapping of the interseismic deformation from InSAR with detailed mapping of quaternary deformation using satellite-derived DEMs to gain a better understanding of the distribution and potential seismic or aseismic behaviour of active faults in the region. We apply a multi-temporal InSAR time series analysis over a $\sim 5$ year period using the New Small Baselines Subset (NSBAS) processing chain with data from ESA's Sentinel-1. The resulting line-of-sight velocity maps provide a continuous view of the rate of deformation across the basin. We find a sharp step in velocity across the Ilyak fault extending $\sim 60 \mathrm{~km}$ along strike, implying it is creeping at shallow depths. We also observe shallow creep on the Bobotag thrust, which lies at the base of an anticline extending into the basin directly southwest of Dushanbe. Past earthquakes show that fault segments within the Ilyak fault zone are capable of producing damaging earthquakes. We use DEMs to delineate previously unmapped faults, which may constitute sources of hazard, from their expression in the geomorphology.

\section{An Improved Quadtree Sampling Method for InSAR Seismic Deformation Inversion}

GAO, H., Wuhan University, Wuhan, China, gaohuastudent@163.com; LIAO, M., Wuhan University, Wuhan, China, liao@whu.edu.cn; FENG, G., Central South University, Changsha, China, fredgps@csu.edu.cn

With the development of interferometric synthetic aperture radar (InSAR), the seismic deformation observation density increases sharply. Data downsampling can effectively reduce the observation density and the computational cost for subsequent researches. Considering the saliency of the deformation field, we introduce a saliency-based quadtree algorithm for down-sampling (SQS). Three simulation experiments show that SQS can effectively distinguish the near-field and far-field deformation, reduce the amount of observations while keep the detailed information of the main deformation near the fault. SQS can avoid the interference of far-field local deformation better than the traditional quadtree sampling algorithm (QS), thus obtaining better inversion results. We obtain the co-seismic deformation from the ascending and descending Sentinel-1 for the Dingri, Tibet, China earthquake on March 20, 2020, using QS and SQS for sampling and inversion separately. The results show the advantages of SQS in data volume reduction, observation distribution, anti-interference of local deformation, and inversion accuracy. Our preferred solution based on SQS shows that the Dingri earthquake is an earthquake caused by a normal fault slip. The main slip area is $2.0-5.5 \mathrm{~km}$ deep with a maximum slip of $0.68 \mathrm{~m}$. The estimated geodetic moment is $3.14 \times 10^{17} \mathrm{Nm}$, corresponding to a magnitude of $\mathrm{Mw} 5.63$.

\section{Mapping Tectonic Strain in the Central Alpine-Himalayan Belt With Sentinel-1 Insar and GNSS Observations}

ROLLINS, C., University of Leeds, Leeds, United Kingdom, j.c.rollins@leeds. ac.uk

Geodetic measurements of crustal deformation provide crucial constraints on a region's tectonics, geodynamics and seismic hazard. However, such geodetic constraints have traditionally been hampered by poor spatial and/or temporal sampling, which can result in ambiguities about how the lithosphere accommodates strain in space and time, and therefore where and how often earthquakes might occur. High-resolution surface deformation maps address this limitation by imaging (rather than presuming or modelling) where and how deformation takes place. These maps are now within reach for the AlpineHimalayan Belt thanks to the COMET-LiCSAR InSAR processing system, which performs large-scale automated processing and time-series analysis of Sentinel-1 InSAR data. Expanding from our work focused on Anatolia, we are combining LiCSAR products with GNSS data to generate high-resolution maps of tectonic strain rates across the central Alpine-Himalayan Belt. Then, assuming that the buildup rate of seismic moment (deficit) from this geodetically-derived strain is balanced over the long term by the rate of moment release in earthquakes, we pair these strain rate maps with seismic catalogs to estimate the recurrence intervals of large, moderate and small earthquakes throughout the region. We also use arguments from dislocation modeling to identify two key signatures of a locked fault in a strain rate field, allowing us to convert the strain maps to "effective fault maps" and assess the contribution of individual fault systems to crustal deformation and seismic hazard. Finally, we address how to expand these approaches to the Alpine-Himalaya Belt as a whole.

\section{The Ambiguous Fault Geometry Derived From Insar Measurements of Buried Thrust Earthquakes: A Synthetic Data Based Study}

ZHANG, Y., China Earthquake Administration, Beijing, China, jingqing129@ gmail.com; GONG, W., China Earthquake Administration, Beijing, China, gwenyu@ies.ac.cn; SHAN, X., China Earthquake Administration, Beijing, China, xjshan@ies.ac.cn; ZHANG, G., China Earthquake Administration, Beijing, China, zhanggh@ies.ac.cn

The challenge of ruling out potential rupture nodal planes with opposite dip orientations during InSAR-based kinematic inversions has been widely reported. Typically, slip on two or more different fault planes can match the surface deformation measurements equally well. The ambiguous choice of the nodal plane for the InSAR-based models was thought to be caused by InSAR's one-dimensional measurement and polar orbiting direction, leading to its poor sensitivity to north-south crustal motion. Through synthetic experiments and simulations, this paper quantitatively demonstrates the main reason of the ambiguous InSAR-based models, which confuse researchers in the small-to-moderate thrust earthquake cases investigation. We propose the inherent one-dimensional measurement is not the principle cause of the fault plane ambiguity, since models derived from the same InSAR data predict similar, but not identical, 3-D deformation patterns. They key to differentiating between these different models is to be able to resolve the small asymmetry in the surface deformation pattern, which may be smaller in amplitude than the typical noise levels in InSAR measurements. We investigate the fault geometry resolvability when using InSAR data with different noise levels through " $R$ " value. We find that the resolvability does not only rely on the InSAR noise, but also on the fault geometry itself (i.e. depth, dips angle, strike). Our result shows that it is impossible to uniquely determine the dip orientation of thrust earthquakes with $\mathrm{Mw}<6.0$ and depth $>5.0 \mathrm{~km}$ with InSAR data at a noise level that is typical for mountain belts. This inference is independent from the specific dataset (i.e. interferogram or time series) and allows one to assess if one can expect to be able to resolve the correct fault plane at all.

\section{Viscoelastic Relaxation and Afterslip Inferred From a Decade of Geodetic Measurements After the 2001 Mw7.8 Kokoxili, China Earthquake}

ZHAO, D., China Earthquake Administration, Beijing, China, dezhengzhao@ ies.ac.cn; QU, C., China Earthquake Administration, Beijing, China, dqchy@ ies.ac.cn; SHAN, X., China Earthquake Administration, Beijing, China, xjshan@ies.ac.cn; ZHANG, G., China Earthquake Administration, Beijing, China, zhanggh@ies.ac.cn

The Mw 7.8 Kokoxili earthquake struck the northern Tibetan Plateau on 14 November 2001, rupturing over $\sim 400 \mathrm{~km}$ in total along the western section of the Kunlun fault. Significant, large-scale postseismic surface displacements have been geodetically observed using InSAR and GPS data in the $\sim 9$ years (2001-2010) following the Kokoxili earthquake, which provides important constraints on the rheology properties of the Tibetan Plateau. In this study, we model the time-dependent postseismic displacements following the Kokoxili earthquake, including both GPS (2001-2002 for near-field and 2001-2010 for far-field) and descending-track InSAR line-of-sight timeseries (2003-2010) to study three postseismic deformation processes. Far-field postseismic deformation ( $>200 \mathrm{~km}$ from rupture) is primarily induced by upper mantle viscoelastic relaxation beneath Tibet and the Qaidam Basin and places a lower bound on transient and steady-state viscosities on the order of $10^{19}-10^{20} \mathrm{Pas}$. Shallow stress-driven afterslip $(<20 \mathrm{~km})$ on the Kunlun Pass fault generates deformation patterns in the near-fault area and helps explain GPS-measured displacement gradient across the fault, which improves the fit to the early GPS data in the near-fault area. Deep stress-driven afterslip just beneath the downdip region of the coseismic rupture ( $>20 \mathrm{~km}$ ) has an amplitude of $\sim 1 \mathrm{~m}$ during the first 3 years. Our results also indicate that the consideration of deep afterslip increases our estimates of transient viscosity of the lower crust beneath Tibet and the Qaidam basin for this earthquake by as much as a factor of three. Our combined model incorporating viscoelastic relaxation and afterslip suggests that the effective transient and steady-state viscosities in the Tibetan lower crust are $5 \times 10^{18}$ Pas and $4 \times 10^{19}$ Pas, respectively (transient viscosity $=2 \times 10^{18}$ Pas without afterslip considered), while the effective transient and steady-state viscosities below the Qaidam Basin area are $1 \times 10^{19}$ Pas and $6 \times 10^{19}$ Pas (transient viscosity $=4 \times 10^{18}$ Pas without afterslip considered). 


\section{Modern Geodesy for Observation and Its Modeling of} Earthquake Deformation

Poster Session · Monday · 19 April · 3:45 PM Pacific

Session Chairs: Xinjian Shan, China Earthquake

Administration (xjshan@163.com); Benchun Duan,

Texas A\&M University (bduan@geos.tamu.edu); Jiankun

He, Chinese Academy of Sciences (jkhe@itpcas.ac.cn);

Mingsheng Liao, Wuhan University (liao@whu.edu.

cn); Guohong Zhang, China Earthquake Administration

(274990177@qq.com)

\section{Empirical Earthquake Scaling Relationships Derived From Geodetic Slip Distributions}

BRENGMAN, C., University of Iowa, Iowa, USA, clayton-brengman@uiowa edu; BARNHART, W. D., University of Iowa, Iowa, USA, william-barnhart-1@ uiowa.edu

Empirical earthquake scaling relationships describe expected relations between moment magnitude and spatial descriptors of the earthquake rupture (along-strike length, down-dip width, rupture area, and peak and mean slip). Most existing scaling relationships are derived from seismological observations (aftershock distributions or teleseismic finite fault models). Given that these methods may be biased by incorrect assumptions or inversion regularization issues, they may similarly bias expected scaling relationships. Earthquake slip distributions derived from geodetic observations provide an independent means to verify and explore earthquake scaling relationships. Here, we present earthquake scaling relationships derived from a database of 111 geodetically derived slip distributions from 73 different earthquakes ranging in magnitude from Mw 5.3 to 9.1. We find that our scaling relationships differ from existing scaling relationships, and that the source of this difference stems from the data source as opposed to a bias in our approaches for extracting spatial descriptors. One important difference is that our scaling relationships predict smaller fault area for a given magnitude earthquake than seismologically-determined scaling relationships. Geodetic slip distributions are likely contaminated with varying degrees of postseismic afterslip, so a smaller predicted fault area strongly suggests that existing earthquake scaling relationships overpredict fault area. We also find differences in scaling of along-strike length, downdip width, and peak and mean slip. These differences are more complex and magnitude dependent. We supplement this database with 31 new geodetically derived fault models derived from earthquakes ranging in magnitude from Mw 5.1 to 7.1 in the time period of August 2019 - August 2020.

\section{Interseismic Deformation and Fault Kinematics along the Keping Foreland Thrust-Fold Belt of the South Tian Shan from InSAR and GPS Observations}

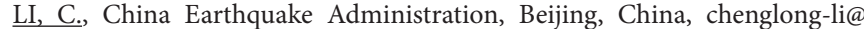
ies.ac.cn; ZHANG, G., China Earthquake Administration, Beijing, China, zhanggh@ies.ac.cn; SHAN, X., China Earthquake Administration, Beijing, China, xjshan@ies.ac.cn; ZHAO, D., China Earthquake Administration, Beijing, China, dezhengzhao@ies.ac.cn

Although previous large-scale interseismic GPS measurements have documented a shortening rate of $\sim 6-8 \mathrm{~mm} / \mathrm{yr}$ between the southwest Tian Shan and the northwest Tarim Basin, the question associated with how the shortening is accommodated by a suite of thrust and detachment fault and their interactions along the Keping foreland thrust-fold belt (hereinafter the Keping fault) are still poorly understood. It is largely due to complex fault interactions and their geometries plus limited geodetic observations in this region. Spatially dense geodetic observations may help to better resolve complex fault kinematics in a greater detail and thus leas to an update of seismic hazard assessment. In this study, we obtained line-of-sight (LOS) interseismic velocity fields around the Keping fault using small baseline subset (SBAS) analysis of C-band Sentinel-1 SAR data during 2015-2020 (ascending track T129 and descending T34). The LOS interseismic velocity indicates that obvious interseismic deformation occurred on the Keping fault, with an maximum LOS velocity of $\sim 2.8 \mathrm{~mm} / \mathrm{yr}$. By combining with GPS measurements, decomposition of descending and ascending InSAR observations demonstrates the spatial pattern of tectonic uplift on the Keping fault with a rate of $\sim 1-3 \mathrm{~mm} /$ yr. Compared with the N-S shortening rate of $\sim 6-8 \mathrm{~mm} / \mathrm{yr}$ inferred from GPS data, we argue that the vertical movement of the Keping fault is relatively moderate at present. The clear contrast between N-S shortening rate and uplift rate highlight the fact that the convergence between the southwest Tian Shan and the Tarim Basin is mainly aborted by the napped fold deformation in the form of the upward motion along the Keping fault.

\section{The InSAR-Derived gCent Earthquake Catalog: August 2019-August 2020}

SHEA, H. N., University of Iowa, Iowa, USA, hannah-shea@uiowa.edu; BARNHART, W. D., University of Iowa, Iowa, USA, william-barnhart-1@ uiowa.edu

Geodetic observations of earthquakes provide valuable constraints on the spatial characteristics of the ruptured fault including the location, orientation, and dimensions of the fault. These measurements and their associated models compliment seismological observations by providing independent constraints on the earthquake. In some cases, geodetic finite fault models can be incorporated directly into earthquake response products, such as USGS/ ANSS ShakeMaps.

Systematic acquisition and increased availability of interferometric synthetic aperture radar (InSAR) now make it tractable to undertake systematic global earthquake analysis with geodesy. Recognizing these capabilities, we introduced the Geodetic Centroid (gCent) Project in 2019. This presentation provides an overview of the gCent project and the first-year catalog that we generated from InSAR observations. Under gCent, we process Sentinel-1 interferograms of all earthquakes $>\mathrm{M}_{\mathrm{w}} 5.5$ with depths $<25 \mathrm{~km}$ (all events $\left.>\mathrm{M}_{\mathrm{w}} 7\right)$ and located beneath or immediately adjacent to land, as well as smaller events of special interest. From August 2019 to August 2020 we processed 65 earthquakes and successfully imaged 29 earthquakes ranging from $M_{w} 4.8$ to $M_{w}$ 7.4. We present source descriptions of these events that include fault location (longitude, latitude, depth), fault geometry (strike, dip, rake, length, width), and the slip characteristics (slip magnitude and slip direction). We additionally present comparisons between the derived products of our cata$\log$ (i.e., locations and fault geometries) and the USGS/ANSS Comprehensive Catalog (ComCat) and the Global CMT catalog. This project represents an effort to report earthquake solutions generated from InSAR and highlight comparisons with seismic global earthquake catalogs to provide additional constraints.

\section{Network Seismology: Keeping the Network Running While Integrating New Technologies}

I: Oral Session · Thursday · 22 April · 9:45 AM Pacific

II: Oral Session · Thursday $\cdot 22$ April $\cdot$ 2:00 PM Pacific

Session Chairs: William L. Yeck, U.S. Geological Survey

(wyeck@usgs.gov); Kris L. Pankow, University of Utah Seismograph Stations (pankowseis2@gmail.com); Renate Hartog, Pacific Northwest Seismic Network (jrhartog@ uw.edu)

\section{Implementing Machine-Learning Earthquake Detection to Augment the Public Regional Seismic Network in Oklahoma}

WALTER, J., University of Oklahoma, Oklahoma, USA, jwalter@ou.edu; OGWARI, P. O., University of Oklahoma, Oklahoma, USA, pogwari@ ou.edu; THIEL, A., University of Oklahoma, Oklahoma, USA, athiel@ou.edu; FERRER, F., University of Oklahoma, Oklahoma, USA, fernando.ferrer@ ou.edu; WOELFEL, I., University of Oklahoma, Oklahoma, USA, iewoelfel@ ou.edu

Last year we developed and publicly released a Python package, easyQuake (https://github.com/jakewalter/easyQuake), that consists of a flexible set of tools for detecting and locating earthquakes from FDSN-collected or field-collected seismograms. The package leverages a machine-learning driven phase picker, coupled with an associator, to produce a Quake Markup Language (QuakeML) style catalog complete with magnitudes and P-wave polarity determinations. The program outputs catalog QuakeML-formatted files that can be split into event QuakeML files. After the nightly runs on day-long seismograms we add the event QuakeML files into the real-time SeisComP system, which are then reviewed by OGS analysts. Since implementation, easyQuake has doubled the number of events that we are able to detect and enter into the ANSS catalog in Oklahoma. Because the fundamentals of the package are scale invariant, it has wide application to seismological earthquake analysis from regional to local arrays, and has great potential for identifying early aftershocks that are otherwise missed. While easyQuake is flexible enough 
that it can perform earthquake detection for regional networks and microseismicity studies in arbitrary user-defined regions, we discuss the public network application. We envision scenarios whereby networks can run easyQuake in parallel with other systems as a "check" on the performance of a real-time system, as a failsafe, or to supplement primary systems during the early aftershock period. In our presentation, we plan to showcase further progress on developing the next stages of easyQuake, including quasi real-time detection, the ability to choose from several pickers, and further refinements for plotting and seismicity visualization.

\section{Keeping the Global Seismographic Network (GSN) Operational During Covid}

HAFNER, K., Incorporated Research Institutions for Seismology, District of Columbia, USA, katrin.hafner@iris.edu; WILSON, D., ASL/USGS, New Mexico, USA, dwilson@usgs.gov; MELLORS, R., University of California, San Diego, California, USA, rmellors@ucsd.edu; DAVIS, P., University of California, San Diego, California, USA, pdavis@ucsd.edu

As with many geophysical networks, the COVID-19 pandemic had an impact on the operation and maintenance of the Global Seismographic Network (GSN) during 2020. Stations of the Global Seismographic Network (GSN) have been designed to operate autonomously with very little operator intervention for long periods of time. The reality of this model was strenuously tested with the advent of the COVID-19 pandemic, as travel by both local station operators and field engineers was severely curtailed. Planned sensor upgrades and preventative maintenance had to be postponed, and adaptive maintenance and repair strategies were put in place. Travel constraints led to increased use of tele-consulting by remote field engineers with local operators. Another strategy to reduce station downtimes included pre-positioning equipment spares that may be easily swapped for damaged elements by local personnel. These strategies helped the GSN maintain an overall network uptime of $86.7 \%$ during COVID. While this represented a decrease from the $88.7 \%$ network uptime reported in 2019 , the network continued to exceed our funding agencies' data availability metric of $85 \%$ during 2020 . We anticipate that continued implementation of the strategies imposed during the COVID19 will lead to enhanced local capabilities and long term improved overall efficiencies of ongoing maintenance and operations of the GSN network.

In addition to the COVID impact, we show examples of the continued improvements in both quality and overall data return produced by the replacement of the aging KS54000 borehole seismometers with the next generation VBB borehole sensors (STS6 and T360). The recent implementation of running station data servers in the cloud (as well as on physical disks) at IDA/ UCSD, has provided redundancy to the data path in case of local network issues. Looking forward, we will provide an overview of planned upgrades and enhancements in the coming year.

\section{Practical Uncertainty for Network Seismology with Machine Learning}

DICKEY, I. T., Air Force Technical Applications Center, Florida, USA, joshuadickey@gmail.com; PENA, R., Air Force Technial Applications Center, Florida, USA, raulpena7@gmail.com

Real-time seismic monitoring networks strive to create an automated event bulletin by coherently aggregating network-wide single-station predictions, such as arrival time, amplitude, period, backazimuth and slowness. Because these predictions often vary in quality, coherent aggregation necessitates that each prediction be accompanied by some statistical measure of uncertainty, in order to threshold or weight each prediction. Traditional seismic monitoring pipelines utilize carefully-tuned physics-based statistics to estimate prediction uncertainty. However, these physics-based uncertainty measures can be laborious to tune, and are often only loosely covariant with the actual prediction error. Machine Learning models offer an advantage here, in that statistical measures of uncertainty are readily integrated into the model itself, and can be optimized at scale during training. In this work, we present two case studies for machine learning uncertainty based on two single-station predictions: arrival time estimation and backazimuth estimation. In each case, we detail simple code to estimate the prediction uncertainty (quantile regression and softmax probability, respectively) and demonstrate its statistical validity alongside the traditional method.

\section{Seismic Monitoring During Crises at the NEIC in Support of the ANSS}

EARLE, P. S., U.S. Geological Survey, Colorado, USA, pearle@usgs.gov; BENZ, H., U.S. Geological Survey, Colorado, USA, benz@usgs.gov; YECK, W. L., U.S. Geological Survey, Colorado, USA, wyeck@usgs.gov; HAYES, G. P., U.S. Geological Survey, Colorado, USA, ghayes@usgs.gov; GUY, M.,
U.S. Geological Survey, Colorado, USA, mguy@usgs.gov; PATTON, J., U.S Geological Survey, Colorado, USA, jpatton@usgs.gov; KRAGNESS, D., U.S. Geological Survey, Colorado, USA, dkragness@contractor.usgs.gov; MASON, D., U.S. Geological Survey, Colorado, USA, dmason1@usgs.gov; SHIRO, B., U.S. Geological Survey, Colorado, USA, bshiro@usgs.gov; WOLIN, E., U.S. Geological Survey, New Mexico, USA, ewolin@usgs.gov; BELLINI, J., U.S. Geological Survey, Colorado, USA, bellini@usgs.gov; PURSLEY, J., U.S. Geological Survey, Colorado, USA, jpursley@usgs.gov; SANDERS, R., U.S. Geological Survey, Colorado, USA, rlsanders@usgs.gov

Over the past two decades, the U.S. Geological Survey (USGS) National Earthquake Information Center (NEIC) has overcome many operational challenges. These range from minor disruptions, such as power outages, to significant operational changes including system reconfiguration to handle unique earthquake sequences and the need to handle distributed work during a pandemic. Our ability to overcome crises is built on the development and implementation of a Continuity Of Operations Plan (COOP), well-designed infrastructure, adaptive software systems, experienced staff, and extensive collaboration. The NEIC benefits from contributions of U.S. and international seismic networks. Likewise, the overall resilience of earthquake monitoring in the U.S. and around the globe benefits from NEIC's role as the National Center for the Advanced National Seismic System (ANSS). Here we highlight significant adaptations the NEIC has made in the face of crises. First, we discuss the COVID-19 pandemic which represents the most significant operational crisis to impact the NEIC. The NEIC has maintained continuous operations during the ongoing COVID-19 pandemic by shifting from a fully on-site operations center to a distributed hybrid of on-site and telework staffing. Second, we discuss cases where the NEIC has supported regional monitoring in the face of a significant crisis. In 2018, the NEIC assisted the Hawaiian Volcano Observatory with the Kilauea volcano eruption by responding to large events, implementing contingency monitoring procedures, and calculating moment magnitudes for the low-frequency caldera collapses. Following the 2017 Hurricane Maria, the NEIC, the USGS National Strong Motion Program, and the USGS Albuquerque Seismological Laboratory worked with the Puerto Rico Seismic Network and the Puerto Rico Strong-Motion program to assess, plan, and implement upgrades at sites that experienced storm damage.

\section{The Alaska Transportable Array: Technical Advances Among Challenges}

BUSBY, R. W., Incorporated Research Institutions for Seismology, District of Columbia, USA, busby@iris.edu; ADERHOLD, K., Incorporated Research Institutions for Seismology, District of Columbia, USA, kasey.aderhold@ iris.edu; BIERMA, R., Incorporated Research Institutions for Seismology, Alaska, USA, ryan.bierma@iris.edu; MINER, J., Incorporated Research Institutions for Seismology, Alaska, USA, jeremy.miner@iris.edu; STAATS, M., Incorporated Research Institutions for Seismology, Alaska, USA, molly. staats@iris.edu; SODERQUIST, J., Incorporated Research Institutions for Seismology, Alaska, USA, john.soderquist@iris.edu

The Alaska Transportable Array (ATA) was installed from 2014-2017 and comprises 194 new stations and 87 existing stations currently operating through 2021. This dense, evenly spaced array of high quality broadband seismometers deployed throughout the region of Alaska and Northwestern Canada is the final phase of the NSF supported EarthScope project. During 2019 and 2020, nearly 100 stations were transferred and are now operated by the UA Fairbanks Alaska Earthquake Center (network code AK) and the Alaska Volcano Observatory (network code AV) with support from USGS and NSF. The intent was to remove the remaining 84 stations in the summer 2020 field season and close out the project. It was quickly recognized that COVID19 and travel restrictions rendered these plans impossible. NSF agreed to support ongoing data collection and operations, postponing removals until summer 2021.

Despite varied challenges over the years, ATA developed new methods and utilized new technologies to operate the network safely and effectively. We describe mitigation efforts undertaken during restricted field activity in 2020 to limit contact with remote villages. Data communication from stations to the Array Network Facility (ANF) at UC San Diego utilized VSAT or InMarSat BGAN satellite communications in addition to common techniques like cell modems. Dedicated VPN tunnels from vendor gateways direct to ANF kept connections secure, though it did introduce some complexity with transfers to a new operator. We describe how meteorological data is routed alongside seismic data using the same connection, and the final bridge from the IRIS DMC into NOAA data assimilation ensures easy access by both seismologists and non-seismologists (e.g. www.windy.com). Finally, we highlight State of Health monitoring paired with a low-cost satellite connection allowing status of the datalogger, station power, and simple commands several times a 
day. Technologies and methods presented here have potential for wider use in permanent networks, especially those with high logistical costs for servicing stations.

\section{Bayesian Optimal Experimental Design for Seismic Monitoring Networks CATANACH, T. A., Sandia National Laboratories, California, USA, tacatan@ sandia.gov}

The Bayesian optimal experimental design (OED) problem seeks to identify data, sensor configurations, or experiments which can optimally reduce uncertainty about quantities of interest (e.g. event location). The goal of OED is to find an experiment that maximizes the expected information gain (EIG) given prior knowledge and models of expected data. Therefore, within the context of seismic monitoring, we can use Bayesian OED to configure sensor networks by choosing sensor locations, types, and levels of fidelity in order to improve our ability to identify and locate seismic events. By developing Bayesian OED tools for analyzing and designing monitoring networks, we can explore many questions relevant to monitoring such as: how and what data phenomenologies can be used to optimally reduce uncertainty, how much is gained by reducing sensor noise or earth model uncertainty, and how do sensor types, number, and locations influence uncertainty?

We will discuss the general Bayesian OED framework for seismic monitoring and also the application of this framework for optimizing a local seismic monitoring network to improve its ability to locate seismic events from arrival time data. With this example, we will show how we develop the four basic elements for solving this Bayesian OED problem: 1) A likelihood function that describes the uncertainty of seismic phase detections and arrival times, 2) A Bayesian solver that takes a prior and likelihood to identify the posterior distribution of likely event locations, 3) an algorithm to compute EIG, and 4) An optimizer that finds a sensor network which maximizes EIG. Finally, we will present the results of this analysis and discuss how different modeling assumptions such as travel time error spatial correlations and different levels of measurement noise influence network sensitivity and the optimal placement of new monitoring stations.

SNL is managed and operated by NTESS under DOE NNSA contract DE-NA0003525.

\section{Keeping the Promise of Earthworm}

AIKIN, K. E., Introspective Systems LLC, Maine, USA, kay.aikin@ introspectivesystems.com

With the founding of the Advanced National Seismic System (ANSS) vision presented initially in the US Geological Survey Circular 1188, much has been accomplished in regional networks with increased efficiency and coherency of effort between regions. Organizing the US Reginal Seismic Networks (RSNs) into a national consortium provided many benefits and more focused funding; however, some negative consequences have become apparent over time. The focus of funding shifted toward public information emphasis while the community and education aspects of network operations diminished.

Dr. Caryl Johnson's designs developed over 40 years, who unfortunately passed away this past November 2019, provided much of the foundational network and seismic association technology utilized by RSNs in the US and much of the world. For the last two years of her life, Dr. Johnson had been working on a new approach designed to reinvigorate the operations and collaboration between smaller regional networks without interfering with the critical work of ANSS, restoring the community focus and international cooperation lost over the past two decades. This approach returns to the promise of the Earthworm development, providing (1) scalability, (2) flexibility, (3) longevity, (4) data exchange, and (5) support.

The $x Q u a k e$, open-source framework uses an executable graph foundation in a pipeline architecture that can be seamlessly integrated into current ANSS quake monitoring systems if desired. This approach incorporates new modern computer analytic methods, including multitopic Kafka exchange rings, cloud computing, a self-configuring phase associator, and machine learning. The $\mathrm{xQuake}$ system is designed to be free for noncommercial use, open-source, hardware-agnostic (Windows, Linux, Mac), with no requirement for commercial datastores.

While Dr. Johnson has developed much of the foundation of this new approach to Regional Seismic Network processing, however further work is needed to keep the promise and honor her legacy to the regional seismic community.

\section{Machine Learning and the 2020 Magna, Utah Earthquake Sequence}

BAKER, B., University of Utah Seismograph Stations, Utah, USA, bbaker@ seis.utah.edu; HOLT, M. M., University of Utah, Utah, USA, mholt@seis.utah. edu; PANKOW, K. L., University of Utah Seismograph Stations, Utah, USA, pankowseis2@gmail.com; KOPER, K. D., University of Utah Seismograph Stations, Utah, USA, koper@seis.utah.edu; FARRELL, J., University of Utah Seismograph Stations, Utah, USA, jamie.farrell@utah.edu

Responding to a notable seismic event is an important task for any regional seismic network (RSN). Complicating the RSN's response is that a large event may be followed by increases in both the volume of data collected and the number of events recorded. Such challenges can slow the generation of preliminary catalogs to be used by future scientific studies. Naturally, automated catalog creation methods become highly desirable. To this end, recent successes in machine learning (ML) may represent a paradigm shift in operational algorithms for signal detection, first-motion picking, and association. In this study, we apply an ML pipeline to the 18 March $2020 \mathrm{M}_{\mathrm{ww}} 5.7$ earthquake in Magna, Utah. The aftershock sequence was well-recorded by $\sim 40$ three-component stations operated by the University of Utah Seismograph Stations (UUSS) as well as 180 temporary nodal geophones. We then create an earthquake catalog from the aforementioned dataset using a U-Net deeplearning architecture for $\mathrm{P}$ and $\mathrm{S}$ wave detection and picking, a convolutional neural network for first-motion picking, and a recurrent neural network for the preliminary association of arrivals. To test the promised generalizability of these ML methods, no examples from the Magna sequence were included in the training datasets. Yet we still recovered $95 \%$ of the events in the UUSS's authoritative catalog and observed the same distribution of seismicity. We also compared the ML data products against products generated by our well-tuned real-time system. While our P picking accuracy was only marginally better than our production STA/LTA picker's accuracy our ML methodology generated a substantial number of S picks. Moreover, the ML first motion estimates led to focal mechanisms that were highly consistent with manually generated focal mechanisms computed in an auxiliary study. This suggests that pretraining ML models on existing network data and deploying these models during periods of enhanced seismicity can be a viable methodology in an RSN's event response strategy.

\section{Modeling Seismic Network Detection Thresholds Using Production Picking Algorithms}

WILSON, D., U.S. Geological Survey, New Mexico, USA, dwilson@usgs.gov; WOLIN, E., U.S. Geological Survey, New Mexico, USA, ewolin@usgs.gov; RINGLER, A., U.S. Geological Survey, New Mexico, USA, aringler@usgs.gov; ANTHONY, R., U.S. Geological Survey, New Mexico, USA, reanthony@usgs. gov; YECK, W. L., U.S. Geological Survey, Colorado, USA, wyeck@usgs.gov

The ability to estimate a network's detection threshold (the minimum magnitude earthquake that can be reliably detected) is a critical part of network design and can drive network maintenance efforts. A station's ability to detect an earthquake has typically been determined by modeling the predicted spectral amplitude for an earthquake (including computing attenuation for a range of epicentral distances) and comparing that amplitude to the average station background noise level. This approach has significant uncertainty because of unknown regional attenuation and complications in computing small event power spectra. We develop an approach to determine network detection thresholds using a multi-band picking algorithm that is currently in use at the USGS National Earthquake Information Center (NEIC). We apply this picking algorithm to cataloged earthquakes to determine an empirical relationship of the observability of earthquakes as a function of magnitude and distance. Using these relationships, we produce maps of detection thresholds as a function of station spacing, station spatial configuration, and station noise levels. We show how this approach allows for operational modeling of network capabilities and the assessment of individual station contributions. We also show that a single quiet station is exponentially more beneficial for earthquake monitoring than several closely spaced noisy stations.

\section{Parameter Optimization of Automatic Phase Detection and Picking Algorithms - Application in Sao Paulo University Seismological Center and Colombian National Seismic Network}

MUÑOZ LOPEZ, C. E., The University of São Paulo, Sao Paulo, Brazil, olimac@usp.br; ASSUMPÇÃO, M., The University of São Paulo, Sao Paulo, 
Brazil, marcelo.assumpcao@iag.usp.br; SIERVO, D., Colombian Seismological Network - Geological Survey, Bogotá, Colombia, dsiervo@sgc.gov.co

Two methodologies, Grid-search and Bayesian algorithm, were used to optimize the automatic detection and phase picking parameters in SeisComP. These methodologies were tested using a set of stations selected from two seismological networks Sao Paulo University in Brazil (IAG/USP) and Colombia's National Seismological Network (RSNC).

After comparing manual and automatic locations, we found numerous missing events and others with low-quality locations in automatic databases. We selected 508 manual events from 2017/07/01 to 2020/07/31 in Brazil, and 532 manual events from 2019/02/01 to 2019/02/15 near Bucaramanga Nest in Colombia, as training sets for the optimization process.

A code was implemented to use grid-search as an optimization methodology; this code does an iterative process that generates automatic picks modifying the parameters. On the other hand, the Optuna package was used to implement the Bayesian algorithm as optimization methodology. Selected events were used as a training set, and an iterative process according to the Bayesian method was used. The results of both methodologies were compared.

We reproduced automatically $70 \%$ of manual picks increasing automatic locations from $33 \%$ to $62 \%$ of manual events for IAG/USP using Grid-search In the RSNC the number of automatic picks increases by $81 \%$ and the number of automatic locations doubled using the Bayesian methodology.

Both methodologies showed excellent results. Grid-search allowed us to perform a complete analysis of the results examining the entire space of parameters. Grid-search, however, increases the computing time by adding parameters involved in the optimization process. On the other hand, the Bayesian algorithm can be implemented using several parameters without increased computing time.

Seismological centers could implement methodologies such as Gridsearch or Bayesian algorithm to improve their automatic processing systems. Besides, the standardization of these methodologies would help to make easier their implementation.

Network Seismology: Keeping the Network Running While Integrating New Technologies

Poster Session · Thursday · 22 April · 11:30 Am Pacific

Session Chairs: William L. Yeck, U.S. Geological Survey

(wyeck@usgs.gov); Kris L. Pankow, University of Utah

Seismograph Stations (pankowseis2@gmail.com); Renate

Hartog, Pacific Northwest Seismic Network (jrhartog@

uw.edu)

\section{A Hybrid-Cloud Approach to Improving Resilience of Seismic Data Acquisition at Alaska Volcano Observatory PARKER, T. I., U.S. Geological Survey, Alaska, USA, tparker@usgs.gov; BENAVIDEZ, A., U.S. Geological Survey, Alaska, USA, abenavidez@usgs.gov}

Alaska Volcano Observatory (AVO) maintains a network of 194 seismometers deployed on active volcanoes across the state. Real-time data from these instruments are acquired at the AVO facility in Anchorage, Alaska and routinely processed to better understand current activity and hazards at volcanoes in Alaska.

While tools have been developed which enable Observatory staff to access data and remain productive when they're unable to work in their office, the seismic processing system itself has remained dependent on the AVO Anchorage facility. This dependence has been driven by factors including the difficulty of establishing redundant long-haul telemetry paths and the costs of maintaining a remote processing facility. Expanded networking options and the availability of low-cost cloud services present an opportunity to begin eliminating AVO's dependence on the Anchorage facility. This first step provides redundant Earthworm acquisition capability, giving network architects a second endpoint to use while planning alternate data paths from the field, and application developers a second source for seismic data. Individual stations are grouped by network configuration and acquired concurrently at both acquisition nodes when possible. Where concurrent acquisition is not possible due to available bandwidth or routing limitations, the acquiring node forwards the data to its partner node. Through this configuration, both nodes are able to receive and serve all available data. As field networks are expanded and upgraded to modern instrumentation and telemetry, individual imports can easily be modified to take advantage of those improvements, fully leveraging the available data.

\section{A Review of Timing Accuracy Across the Global Seismographic Network}

RINGLER, A., U.S. Geological Survey, New Mexico, USA, aringler@usgs.gov; ANTHONY, R., U.S. Geological Survey, New Mexico, USA, reanthony@usgs. gov; WILSON, D., U.S. Geological Survey, New Mexico, USA, dwilson@usgs. gov; AUERBACH, D., University of California, San Diego, California, USA, dauerbach@ucsd.edu; BARGABUS, S., University of California, San Diego, California, USA, dbargabus@ucsd.edu; DAVIS, P., University of California, San Diego, California, USA, pdavi@ucsd.edu; GUNNELS, M., KBRwyle Albuquerque Seismological Laboratory, New Mexico, USA, mgunnels@ contractor.usgs.gov; HAFNER, K., Incorporated Research Institutions for Seismology, Colorado, USA, katrin.hafner@iris.edu; HOLLAND, J., U.S. Geological Survey, New Mexico, USA, jholland@usgs.gov; KEARNS A., KBRwyle Albuquerque Seismological Laboratory, New Mexico, USA, akearns@contractor.usgs.gov; KLIMCZAK, E., University of California, San Diego, California, USA, eklimczak@ucsd.edu

The accuracy of timing across a seismic network is important for locating earthquakes as well as additional studies that use phase arrival information (e.g., tomography). The Global Seismographic Network (GSN) was designed with a timing goal of $10 \mathrm{~ms}$. In this work, we provide a brief overview of how timing is kept across the GSN and discuss how clock quality metrics are embedded in Standard for the Exchange of Earthquake Data (SEED) data records. Specifically, blockette 1001 contains the timing quality field which can be used to identify time periods when poor clock quality could compromise timing accuracy. To verify the timing across the GSN we compare crosscorrelation lags between co-located sensors from January 1, 2000 to January 1,2020 . We find that the mean error is less than $10 \mathrm{~ms}$ with much of the difference likely coming from the method or uncertainty in the phase response of the instruments. This suggests that timing across the GSN is potentially better than $10 \mathrm{~ms}$. We conclude that unless clock quality is compromised (as indicated in blockette 1001), GSN data's timing accuracy should be suitable for most current seismological applications which require $10 \mathrm{~ms}$ accuracy. To assist users, the GSN network operators have implemented a "gsn_timing" metric available via the IRIS Data Management Center that helps users identify data with substandard timing accuracy (the 10ms design goal of the GSN).

\section{Improving Regional Earthquake Focal Depth Location in Oklahoma Using 3D Velocity Model}

OGWARI, P. O., Oklahoma Geological Survey, Oklahoma, USA, pogwari@ ou.edu; WALTER, J., Oklahoma Geological Survey, Oklahoma, USA, jwalter@ ou.edu; THIEL, A., Oklahoma Geological Survey, Oklahoma, USA, athiel@ ou.edu; FERRER, F., Oklahoma Geological Survey, Oklahoma, USA, fernando. ferrer@ou.edu; WOELFEL, I., Oklahoma Geological Survey, Oklahoma, USA, iewoelfel@ou.edu; CHEN, X., University of Oklahoma, Oklahoma, USA, xiaowei.chen@ou.edu; LIN, G., University of Miami, Florida, USA, glin@ rsmas.miami.edu

Earthquake activity in Oklahoma occurs in multiple geologic provinces characterized by dipping formations and stratigraphic layers of varying thickness The earthquakes in the region have traditionally been located using a 1D velocity model applied to both the regional seismic network and local arrays. The regional $1 \mathrm{D}$ velocity model, that has the top of the relatively higher velocity Precambrian basement at $1.5 \mathrm{~km}$ depth, provides high precision earthquake epicentral locations with relatively higher focal depth uncertainties especially within the Anadarko basin, in western Oklahoma, where the top of basement deepens up to $10 \mathrm{~km}$. Within the Anadarko basin, an upward focal depth shift of $3 \mathrm{~km}$ can place numerous current earthquake depths into the sedimentary layers thereby significantly altering the interpretation of the earthquakes' source analysis. We address the depth uncertainty by relocating the earthquakes using a $3 \mathrm{D}$ velocity model that reflects the varying stratigraphy of the region. The velocity model layering corresponds to the geologic deposition and the velocity of the structures atop the basement is constrained using sonic logs from wells near the 2010 Mw4.1 Lincoln County earthquake sequence. We[WJI1] apply the $3 \mathrm{D}$ velocity as the initial model in a local double-difference tomography inversion. We use the tomoDD inversion method to simultaneously solve both absolute and differential travel times in order to improve both the earthquake locations and the $3 \mathrm{D}$ velocity heterogeneity. We will be presenting the results of the focal depth changes and the resulting final velocity model. We intend to further test and evaluate whether the final 3D velocity model would be suitable for routine regional earthquake locations for ANSS catalog products. 


\section{Local Magnitude (MI) Calibration for the Puerto Rico Seismic Network}

ROSERO-RUEDA, S., University of Puerto Rico at Mayagüez, Puerto Rico, USA, sandra.rosero@upr.edu; HUERFANO, V. A., University of Puerto Rico at Mayagüez, Puerto Rico, USA, victor.huerfano@upr.edu; VANACORE, E. A., University of Puerto Rico at Mayagüez, Puerto Rico, USA, elizabeth vanacore@upr.edu; LOPEZ-VENEGAS, A., University of Puerto Rico at Mayagüez, Puerto Rico, USA, alberto.lopez3@upr.edu

Puerto Rico and the Virgin Islands region (PRVI) is seismically active due to its geographical location, averaging hundreds of earthquakes per year, mostly small events $(\mathrm{M}<4.0)$. However, Puerto Rico has been subject to many significant events throughout history, such as the recent seismic sequence in the southwestern region, with the principal M6.4 event occurring in January 2020 The Puerto Rico Seismic Network (PRSN) measures the magnitude earthquakes in the PRVI region with duration magnitude (Md). At this moment, it does not have a reliable local magnitude scale (Ml) measurement; for this reason, a calculation and calibration of $\mathrm{Ml}$ in the PRSN systems is proposed, based on the original Richter definition. Using data from 2000 earthquake events collected from the 31 multiple instruments from PRSN (including broadband and short-period seismometers). The results will be compared with the Early Bird system and United States Geological Survey (USGS) earthquake catalogs within the PRVI region and a graphical relationship between the published $\mathrm{Ml}$ vs the computed $\mathrm{Ml}$ can be established.

\section{Monitoring Performance at the U.S. Geological Survey's National Earthquake Information Center}

YECK, W. L., U.S. Geological Survey, Colorado, USA, wyeck@usgs.gov; EARLE, P. S., U.S. Geological Survey, Colorado, USA, pearle@usgs.gov; GUY, M., U.S. Geological Survey, Colorado, USA, mguy@usgs.gov; AMBRUZ, N. B., U.S. Geological Survey, Colorado, USA, nambruz@usgs.gov; PATTON, J., U.S. Geological Survey, Colorado, USA, jpatton@usgs.gov; KRAGNESS, D., U.S. Geological Survey, Colorado, USA, dkragness@contractor.usgs.gov; BENZ, H., U.S. Geological Survey, Colorado, USA, benz@usgs.gov

The core mission of the U.S. Geological Survey's (USGS) National Earthquake Information Center (NEIC) is to rapidly and accurately determine the location, size and impact of significant earthquakes both domestically and globally. The NEIC continues to develop and employ new algorithms and procedures aimed at improving its ability to fulfill this mission. These continual improvements vary dramatically in complexity and scope. Recent improvements include operationalizing new detection and association algorithms, determining criteria to test the publication of rapid automatic solutions, and integrating near-real-time parametric data from other global networks. In order to ensure that these changes improve NEIC's overall capabilities, it is critical that the performance of the NEIC is continuously monitored and evaluated. In this effort, the NEIC has been developing a suite of metrics and tools to evaluate the ongoing quality of NEIC's performance. Critical to this is process is determining metrics that capture the full range of factors that affect NEIC's performance, such as its ability to detect earthquakes, its ability to rapidly process large earthquake sequences, and the workload placed on human analysts. We discuss these tools, and the observed changes in NEIC's performance as the result of recent algorithm updates. For example, we show that recent changes in NEIC's associator and picker significantly improved NEIC's ability to automatically detect M2.5 earthquakes in Advanced National Seismic System regions, therefore dramatically improving NEIC's ability to support regional networks. We also look at metrics evaluating NEIC's recent efforts to publish global automatic solutions in our internal development systems.

\section{Mw From Coda Envelopes for Small Earthquakes in Utah} WHIDDEN, K. M., University of Utah, Utah, USA, katherine@whidden.net; HOLT, J., University of Utah, Utah, USA, jholt@seis.utah.edu; MAYEDA, K., Air Force Technical Applications Center, Florida, USA, kevin.mayeda@ us.af.mil; GÖK, R., Lawrence Livermore National Laboratory, California, USA, gok1@llnl.gov; SHELLY, D. R., U.S. Geological Survey, Colorado, USA, dshelly@usgs.gov; PANKOW, K. L., University of Utah, Utah, USA, pankowseis2@gmail.com; WALTER, W. R., Lawrence Livermore National Laboratory, California, USA, bwalter@llnl.gov; MESIMERI, M., University of Utah, Utah, USA, maria.mesimeri@utah.edu

Moment magnitude $(\mathrm{Mw})$ is now routinely assigned to moderate to large earthquakes $(\mathrm{M}>3.5)$ by most regional seismic networks. However, the regional waveform modeling techniques used to calculate $\mathrm{Mw}$ often can not reach the short periods required for earthquakes $\mathrm{M}<4$, and nearly impossible for $M<3$. Calculation of $\mathrm{Mw}$ for earthquakes $\mathrm{M}<4$ is desirable in order to have a uniform $\mathrm{Mw}$ catalog to accurately calculate earthquake catalog statistics for downstream seismic hazard calculations. Here, we calculate Mw utilizing the well-established coda envelope method (Mw,coda) for three regions and magnitude ranges in Utah: 1) the whole of Utah for $\mathrm{Mw}>3.5,2)$ the Magna sequence in Northern Utah for $1.5<=\mathrm{Mw}<=5.7$, and 3) southern Utah for $1.5<=\mathrm{Mw}<=3.5$. For all three regions, we start with a calibration based on waveform modeled Mw and apparent stress from the 2008 Wells, NV sequence. The Wells sequence is one of the few in the region that has previously-calculated apparent stress values, which allow for a more accurate calibration. For southern Utah, we also attempt a calibration to a local earthquake sequence. Mw,coda for earthquakes in the whole Utah calibration match well with Mw from moment tensor inversion for the same events. For the Magna sequence, most of the events are too small for moment tensor inversion, but Mw,coda is consistent with another small Mw technique, Mw,direct, which uses the spectra of direct phases and coda. We investigate an apparent bias in the Wellscalibrated Mw,coda between northern and southern Utah. Finally we compare catalog statistics from catalogs composed of Mw,coda, ML, and those converted to a uniform $\mathrm{Mw}$ using regional magnitude scaling relationships to see how this direct measurement of Mw,coda affects b-values and other parameters. This work is part of our expansion of the coda envelope method in Utah with the ultimate goal of including Mw,coda in routine University of Utah Seismograph Stations earthquake monitoring and reporting.

\section{ROBUST, An Earthquake Early Warning System in the Lower} Rhine Embayment, Germany

NAJDAHMADI, B., GFZ German Research Centre for Geosciences, Potsdam, Germany, bita@gfz-potsdam.de; PILZ, M., GFZ German Research Centre for Geosciences, Potsdam, Germany, pilz@gfz-potsdam.de; BINDI, D., GFZ German Research Centre for Geosciences, Potsdam, Germany, bindi@gfzpotsdam.de; NJARA TENDRISOA RAZAFINDRAKOTO, H., GFZ German Research Centre for Geosciences, Potsdam, Germany, hoby@gfz-potsdam.de; OTH, A., European Center for Geodynamics and Seismology, Luxemburg, Luxembourg, adrien.oth@ecgs.lu; COTTON, F., GFZ German Research Centre for Geosciences, Potsdam, Germany, fcotton@gfz-potsdam.de

The Lower Rhine Embayment in western Germany is one of the most important areas of earthquake recurrence north of the Alps, facing a moderate level of seismic hazard in the European context but a significant level of risk due to a large number of important industrial infrastructures. In this context, the project ROBUST aims at designing a user-oriented hybrid earthquake early warning and rapid response system where regional seismic monitoring is combined with smart, on-site sensors, resulting in the implementation of decentralized early warning procedures.

One of the research areas of this project deals with finding an optimal regional seismic network arrangement. With the optimally compacted network, strong ground movements can be detected quickly and reliably. In this work simulated scenario earthquakes in the area are used with an optimization approach in order to densify the existing sparse network through the installation of additional decentralized measuring stations. Genetic algorithms are used to design efficient EEW networks, computing optimal station locations and trigger thresholds in recorded ground acceleration. By minimizing the cost function, a comparison of the best earthquake early warning system designs is performed and the potential usefulness of existing stations in the region is considered as will be presented in the meeting.

\section{Seismic Noise Tests in Mammoth Cave, USA}

SCHMIDT, I. P., University of Kentucky, Kentucky, USA, jon.schmidt@uky. edu

Caves can offer environmentally stable and seismically quiet locations for recording small seismic signals. In September 2020, the Kentucky Geological Survey began testing locations in Mammoth Cave National Park, Kentucky, USA, to determine if they are suitable for the installation of a permanent broadband seismograph. To date, broadband instruments have occupied three candidate locations in the cave at subsurface depths of 71-88 m. They operated at each location for approximately $30-40$ days, and one to three more stations are planned. To investigate sources of local cultural noise and to quantify the effects of shallow stratigraphy on ground motions, an additional station was installed at the surface directly above the quietest site to date. Power spectral densities of the recordings were used to quantify noise levels and were compared with each other and with recordings from other permanent regional stations. At short periods $(0.08-1 \mathrm{~s})$, noise levels at the cave sites are comparable to levels observed at regional seismic stations in caves but quieter than levels at regional surface stations. Daytime short-period (0.08-0.4 s) noise levels at the cave sites increased by approximately $4-5 \mathrm{~dB}$ compared to noise levels at night. Daytime short-period noise increases at cave sites closer 
to Interstate 65 (ranging from $5.5-7.5 \mathrm{~km}$ away) suggest that the highway is a principal source of short-period noise. At long periods ( $>10 \mathrm{~s}$ ), the quietest cave site has noise levels comparable to those from other cave stations in the region and is quieter than the regional surface stations. Once the quietest cave site has been identified, it will be monitored for one year to test the installation and communications, in preparation for establishing the permanent station. Once the station is established, it will contribute to regional seismic monitoring efforts by KGS and to national and global monitoring through real-time data sharing.

New Insights Into the Preparatory Phase of Earthquakes From Tectonic, Field and Lab Experiments I: Oral Session · Monday · 19 April · 9:45 Am Pacific II: Oral Session · Monday · 19 April · 2:00 PM Pacific III: Oral Session · Monday · 19 April · 5:00 PM Pacific Session Chairs: Zhigang Peng, Georgia Institute of Technology (zpeng@gatech.edu); Yongxian Zhang, China Earthquake Administration (yxzhseis@sina.com); Maximilian Werner, University of Bristol (max.werner@ bristol.ac.uk); Vladimir Kossobokov, Russian Academy of Sciences (volodya@mitp.ru); John Ebel, Boston College (john.ebel.1@bc.edu); Weijun Wang, China Earthquake Administration (wjwang@cea-ies.ac.cn)

\section{Event Detection and Foreshock Characterization Using the} Ridgecrest and San Jacinto Dense Nodal Array Data

MENG, H., Scripps Institution of Oceanography, University of California, San Diego, California, USA, h2meng@ucsd.edu; SHEARER, P. M., Scripps Institution of Oceanography, California, USA, pshearer@ucsd.edu; FAN, W., Scripps Institution of Oceanography, California, USA, wenyuanfan@ucsd.edu

Understanding foreshocks is essential for deciphering the earthquake nucleation process and informing earthquake probabilistic forecasting. Using P-waves from catalog earthquakes as templates, we apply waveform auto-correlation to search for foreshocks adjacent to the mainshocks within the $100 \mathrm{~s}$ before each event. We detect immediate foreshocks for 292 earthquakes in the Ridgecrest sequence, with magnitudes ranging from 0.9 to 5.4. Because these foreshocks occur very close in space and time to the mainshock and have similar waveforms to the mainshock P-wave, they may be part of a nucleation process for the mainshock rupture initiation. However, because our observed precursory signal attributes do not scale with mainshock magnitude, the sequences appear to evolve stochastically. To better evaluate the role of foreshocks in the earthquake preparation process, we plan to develop techniques based on multichannel cross-correlation to detect small-magnitude earthquakes. The analysis will be performed on the 2019 Ridgecrest and 2014 San Jacinto dense nodal-array datasets, aiming to characterize foreshock statistics and properties of earthquake rupture development in both the Ridgecrest region and within an active strand of the San Jacinto Fault.

\section{Geometrical Implications for Calibrating Acoustic Sensors for Lab-Generated Earthquake Sources}

BROTHERSON, L. O., University of Liverpool, Liverpool, United Kingdom, l.brotherson@liverpool.ac.uk; FAULKNER, D. R., University of Liverpool, Liverpool, United Kingdom, faulkner@liverpool.ac.uk; EDWARDS, B., University of Liverpool, Liverpool, United Kingdom, edwardsb@liverpool. ac.uk

Spontaneous stick-slip motion and associated acoustic emissions (AEs), generated in laboratory frictional sliding experiments, are useful analogues for natural earthquake behaviour. In particular, they have been shown to be an important means of understanding earthquake nucleation and source properties. However, AE recording systems are usually uncalibrated and can only provide limited information, such as number and relative amplitude of AEs. Calibrating AE recording systems is advantageous as the absolute amplitude, time history and spectral character of AEs can be determined. We use the absolute acoustic sensor calibration method, based on momentum from a ball drop, by McLaskey et al. (2015), to estimate the seismic moment of labgenerated spontaneous stick-slip and acoustic emissions. A suite of different balls, ranging from $1 \mathrm{~mm}$ to $17 \mathrm{~mm}$ diameter, are used to calibrate acoustic (piezoelectric) sensors within two experimental setups: 1) a steel plate and 2) a seismic sample assembly used within triaxial deformation apparatus for frictional sliding experiments. In order to see the effect of geometry on instrument response and path effects, spectra from ball drop experiments are compared. Significant spectral differences between the two setups, caused by geometrical complexities of the apparatus, highlight the importance of accurately quantifying the instrument-apparatus response. Without this, the true source characteristics of lab-generated earthquakes may be masked in high frequency oscillations caused by the geometry of the seismic sample assembly. $\mathrm{AE}$ waveforms will be measured during frictional sliding experiments within the seismic sample assembly on Perspex, at confining pressures ranging from $10-40 \mathrm{MPa}$. Initial results reflect natural earthquake behaviour: for example, as confining pressure is increased, the amplitude of stick-slips increases. Using the calibrated sensors, future work will look to obtain source properties of labgenerated AEs, particularly those which precede the main stick-slip, to better understand earthquake nucleation and propagation.

\section{Investigating Earthquake Nucleation: What Do Foreshocks, Aftershocks and Sequences Tell Us?}

COLQUHOUN, R. L., University of Oxford, Oxford, United Kingdom, rebecca.colquhoun@univ.ox.ac.uk; HAWTHORNE, J., University of Oxford, Oxford, United Kingdom, jessica.hawthorne@earth.ox.ac.uk

Earthquake nucleation has two end member models: externally-driven and single-mode. In externally driven nucleation, earthquakes are triggered by aseismic slip or pore pressure changes, but in cascade nucleation a series of earthquakes occur, each triggering another event, and one of these happens to grow much bigger. We don't know whether earthquake nucleation cascades or is externally driven as we have a limited number of high quality observations of foreshocks and aftershocks.

We used phase coherence based template matching to identify foreshocks and aftershocks of thousands of earthquakes on the Hikurangi subduction zone between 2005 and 2020. This is an ideal location to test the two models as it could plausibly host externally driven earthquakes, as it undergoes pore pressure changes and has experienced episodes of slow slip in the past.

We examined the plausibility of 2 models by analysing the numbers of foreshocks and aftershocks. If earthquakes nucleate via cascade triggering, the relative ratios of foreshocks and aftershocks can be predicted using Omori's law. With our new detections, we identified events surrounding the mainshock down to magnitude 1. Initial results indicate that both foreshocks and aftershocks decay as a power law with time from the mainshock, which is consistent with single-mode triggering. However, foreshocks have a lower productivity than mainshocks. This disagreement between time-dependent decay and productivity could imply that single mode triggering dominates, but that fault properties are externally altered from before to after the earthquake.

Finally, we are currently further analysing the coherent detections to search for and assess the abundance of densely spaced sequences of foreshocks. Such sequences have occasionally been observed, and suggest the presence of externally driven processes, but we do not currently know how common foreshocks sequences are.

\section{Reassessing Foreshock Activity in Southern California}

MARSAN, D., Université de Savoie Mont Blanc, Le Bourget du Lac, France, david.marsan@univ-smb.fr; MOUTOTE, L., Institut de Physique du Globe de Strasbourg, Strasbourg, France, lmoutote@unistra.fr; LENGLINÉ, O., Institut de Physique du Globe de Strasbourg, Strasbourg, France, lengline@unistra. fr; DUPUTEL, Z., Institut de Physique du Globe de Strasbourg, Strasbourg, France, zacharie.duputel@unistra.fr

Earthquakes preceding large events are commonly referred as foreshocks. They are often considered as precursory signals reflecting the nucleation process of the main rupture. Such foreshock sequences may also be explained by cascades of triggered events. Recent advances in earthquake detection is a motivation to reevaluate seismicity variations prior to mainshocks. Based on a highly complete earthquake catalog, Trugman and Ross (2019) and van den Ende and Ampuero (2020) suggested that mainshocks in southern California are often preceded by anomalously elevated seismic activity. These studies assume a time-independent seismicity and thus neglect earthquake interactions. In this study, we test the same catalog against the Epidemic Type Aftershock Sequence model that accounts for earthquake clustering. We find that less than 5 out of 53 selected mainshocks (10\%) are preceded by significantly elevated seismicity rates. This suggest that foreshock observations can generally be explained by background seismicity and by cascades of earthquakes even in highly complete earthquakes catalogs. 
Tracking a Precursory Phase: The Case of the Mw 6.3 2009 L'aquila Earthquake

CABRERA, L., ISTerre, Université Grenoble Alpes, Grenoble, France, leonciocabrerac@gmail.com; POLI, P., ISTerre, Université Grenoble Alpes, Grenoble, France, piero.poli@univ-grenoble-alpes.fr; FRANK, W. B., EAPS, Massachusetts Institute of Technology, Massachusetts, USA, wfrank@mit.edu

Whether the precursory seismicity sequences can alert us about an upcoming earthquake is one of the biggest challenges and open questions in seismology. On April $6^{\text {th }} 2009$, the Mw 6.3 L'Aquila earthquake struck central Italy causing damage and fatalities, and was preceded by an intense foreshocks sequence. We create a high-resolution catalog using template matching to study the temporal evolution of the physical parameters and processes that played a role in the precursory phase of this earthquake. We thus track occurrence statistics, seismic moment release, effective stress drop and spatial evolution of the foreshock sequence. The spatio-temporal evolution of these parameters reveals how the sequence started as a swarm-type seismicity and evolved into mainshock-aftershock behavior. Our results suggest a complex precursory phase with interaction of several physical processes (diffusive fluid migration process, slow slip event and/or stress transfer). Our work highlights how a dense near-fault catalog can shed new light on the complex nucleation processes prior to major earthquakes.

\section{Investigating Potential Earthquake Preparatory Phase From Short-Term and Long-Term Seismic Observations} YAO, D., University of Michigan, Michigan, USA, dongdony@umich.edu; HUANG, Y., University of Michigan, Michigan, USA, yiheh@umich.edu; PENG, Z., Georgia Institute of Techonlogy, Georgia, USA, zpeng@gatech.edu; XUE, L., Syracuse University, New York, USA, lxue07@syr.edu; FU, Y., Bowling Green State University, Ohio, USA, yfu@bgsu.edu; CASTRO, R. R., Centro de Investigación Científica y de Educación Superior de Ensenada (CICESE), Ensenada, Mexico, raul@cicese.mx; FOX, J., The Ohio Seismic Network, Ohio Geological Survey, Ohio, USA, jeffrey.fox@dnr.ohio.gov; GRONEWOLD, A., University of Michigan, Michigan, USA, drewgron@umich.edu

Predicting the timing and location of an upcoming hazardous earthquake has been the ultimate goal in the seismological community. Although it's nearly infeasible to measure the in-situ stress field and rock strength at depths where majority earthquakes occur, both surface and borehole observations have shown evidence of seismic and aseismic deformation prior to the rupture of critically stressed faults. In this study, we present both a short-term foreshock study of the 2010 Mw7.2 El-Mayor Cucapah (EMC) earthquake and a long-term seismic analysis before the 2019 ML4.0 Ohio earthquake. For both cases, we apply waveform-based methods to identify hidden smaller events and further constrain their relative locations. The detailed analysis of the EMC foreshock sequence suggests a two-scale preparatory phase leading up to the mainshock: while an active chain of foreshocks occurred immediately (within $\sim 300$ s) before the mainshock suggesting cascading effect, the elongated sequence (lasting $\sim 21$ days) as well as migrating seismicity within last 8 hours also invokes a preslip mechanism. By comparison, the long-term seismicity (2013-2019) before the 2019 Ohio earthquake shows a higher but nearly constant rate (20-30 earthquake/year) when compared to the ANSS catalog. Although no pronounced accelerating seismicity was observed before the Ohio earthquake, the Coulomb stress change from water loading on the associated faulting system indicates a small positive loading effect $(\sim 0.2 \mathrm{kPa})$ when Lake Erie was in high water-level condition and the mainshock happened. Our study highlights the importance of near-field observations to capture weak seismic signals, and the complex nucleation process of faulting systems.

\section{Learning the Low Frequency Earthquake Activity on the Central San Andreas Fault}

JOHNSON, C., Los Alamos National Laboratory, New Mexico, USA, cwj@ lanl.gov; JOHNSON, P., Los Alamos National Laboratory, New Mexico, USA, paj@lanl.gov

Advances in machine learning based data processing have proven successful in predicting the timing of slip in controlled laboratory experiments and fault slow-slip in the Cascadia subduction zone. Low frequency earthquakes (LFEs) originating below the central San Andreas Fault are associated with slow-slip within the deeper, more ductile portion of the crust, with some evidence of activity changes before seismogenic events. Efforts to catalog LFEs using template matching techniques produced $>1$ million detections over 15 years and provide a data set to train models that predict LFE activity. We apply gradient boosted tree models using statistical features that describe seismic waveforms at different bandpass filters to estimate the LFE activity along the San Andreas
Fault. Five years of data are used to train thousands of models and obtain the best constrained set of model hyperparameters. Applying the trained model to 7 years of seismic waveforms the model has never seen reproduces the burst-like LFE behavior observed when applying template matching, with the greatest misfit occurs during the largest burst sequences for the 1 hour time intervals. During periods of low LFE activity, the model indicates more activity than template matching. The most informative features to the model are in the higher frequency bands, suggesting the model is utilizing information outside the typical frequency band associated with LFEs. Similarities are found between detecting LFEs and previous efforts to detect tremors, which provides additional evidence tremors are composed of LFEs. The ability to continuously monitor LFE activity provides insight to the occurrence of slow-slip activity, without the need for developing a computational-intensive template-matching catalog, and promotes ongoing efforts to relate slow slip to larger seismogenic events.

\section{Localization of Seismicity Prior to Large Earthquakes}

ZALIAPIN, I., University of Nevada, Reno, Nevada, USA, zal@unr.edu; BENZION, Y., University of Southern California, California, USA, benzion@usc. edu

We present results aimed at understanding preparation processes of large earthquakes by tracking progressive localization of earthquake deformation with three complementary analyses: (i) estimated production of rock damage by background events, (ii) spatial localization of background seismicity within damaged areas, and (iii) progressive coalescence of individual earthquakes into clusters. Techniques (i) and (ii) employ declustered catalogs to avoid the occasional strong fluctuations associated with aftershock sequences, while technique (iii) examines developing clusters in entire catalog data. The different techniques provide information on different time scales and on the spatial extent of weakened damaged regions. The analyses reveal generation of earthquake-induced rock damage on a decadal timescale around eventual rupture zones, and progressive localization of background seismicity on a 2-3 yr timescale before several $M>7$ earthquakes in southern and Baja California and M7.9 events in Alaska. This is followed by coalescence of earthquakes into growing clusters that precede the mainshocks. Corresponding analysis around the 2004 M6 Parkfield earthquake in the creeping section of the San Andreas fault shows contrasting tendencies to those associated with the large seismogenic faults. The results are consistent with observations from laboratory experiments and physics-based models with heterogeneous materials not dominated by a pre-existing failure zone. Continuing studies with these techniques, combined with analysis of geodetic data and insights from laboratory experiments and model simulations, may allow developing an integrated multi-signal procedure to estimate the approaching time and size of large earthquakes.

\section{Seismic Gap of Moderate Earthquakes, A Likely Typical Medium-Term Precursor Prior to Large Earthquakes Above M7 in the Joint Region of Southeast Tibet, West Sichuan and Northwest Yunan}

ZHANG, Y., China Earthquake Administration, Beijing, China, yxzhseis@ sina.com; ZHANG, S., China Earthquake Administration, Beijing, China, 085012104@163.com; XUE, Y., China Earthquake Networks Center, Beijing, China, xueyan@seis.ac.cn; TIAN, W., China Earthquake Administration, Beijing, China, tianweixi20@mails.ucas.ac.cn

There are two kinds of seismic gaps defined by two different features of seismic activity. The first one is a gap in the spatial distribution of rupture zones of the largest earthquakes in a seismic belt, and the second one is a gap in seismicity of smaller-magnitude earthquakes before larger earthquakes (Mogi, 1976, 1979). For the first kind of seismic gap, Sykes and Nishenko (1984) suggested that earthquake hazard is small immediately following the previous large earthquake and increases with time since the last large event on certain fault or plate boundaries. The hypothesis has been applied to long-term forecasting of earthquakes in many regions in the world (e.g. Kagan and Jackson, 1991; Wen Xueze, et al., 2008).

Seismic network has been broadly setup soon after Xingtai M7.2 earthquake in 1966 which was taken as a milestone event in China mainland for earthquake monitoring and forecasting, and the earthquake catalogue after 1970 produced by China Earthquake Network could be applied for study of seismic patterns for earthquake forecasting. In this talk, we will introduce the second kind of seismic gaps prior to the large earthquakes above $M 7$ in the joint region of southeast Tibet, west Sichuan and northwest Yunan since 1970. The result shows that there existed seismic gaps before four out of the five earthquakes of magnitude above $M 7$ since 1970 in this region, including Yushu M7.0 earthquake in 2010. These seismic gaps were formed by moderate 
earthquakes with magnitude above M3.5 or M4.0, and these seismic gaps were oval-shaped with the lengths of the long axis of about $800-1100 \mathrm{~km}$ and the lengths of the short axis of about $500-700 \mathrm{~km}$. The forming time durations of the gaps are within 580-1200 days and the future target earthquakes occurred soon after the gaps have well formed. The testing result shows that the quiescence of moderate earthquakes in the gaps is very prominent, suggesting the possibility to apply such gaps for medium-short term earthquake forecasting The mechanics of such large scale precursory seismic gaps remain unknown and need future studies.

\section{Using Recent $M \geq 4$ Seismicity to Estimate the Locations of Future $M \geq 6.7$ Earthquakes}

EBEL, J., Boston College, Massachusetts, USA, john.ebel@bc.edu

A previously published study (Ebel and Chambers, GJI, 2016) showed that the $\mathrm{M} \geq 4$ seismicity in the two or so decades prior to several large California earthquakes took place randomly along the future fault ruptures and at rates exceeding one $\mathrm{M} \geq 4$ earthquake every two years. Based on this association of a locally high rate of $M \geq 4$ earthquakes and a future $M \geq 6.7$ fault rupture, a prospective earthquake forecast was put together in 2017 that highlighted those California faults that may have the next $M w \geq 6.7$ earthquake. Eight known faults with rates of $\mathrm{M} \geq 4$ earthquakes greater than 0.5 earthquakes per year from 1997 to 2016 and with the $M \geq 4$ earthquakes spread along the faults were identified in the 2017 forecast: the creeping section of the San Andreas Fault, the Southern San Andreas Fault, the Calaveras Fault, the Little Lake Fault, the Maacama Fault, the Anza section of the San Jacinto Fault, the San Bernardino Section of the San Jacinto Fault and the San Clemente Fault. The Mw7.1 Searles Valley earthquake on 5 July 2019, the first $M \geq 6.7$ earthquake in California since the forecast was issued, appears to have fulfilled the Little Lake Fault forecast. When applied to earthquakes in Japan the $2000 \mathrm{M}_{\mathrm{w}} 6.6$ Western Tottori earthquake shows a premonitory pattern similar to that seen in California. Both the 2016 M7.3 Kumamoto, Kyushu earthquake and the 2016 Mw6.2 Central Tottori earthquake had some $M \geq 4$ earthquakes along the fault in the two decades before the mainshocks. However, the $1995 \mathrm{M}_{\mathrm{w}} 6.9$ Kobe earthquake had little $M \geq 4$ seismicity in the years prior to the mainshock. There was also a high rate of $M \geq 4$ earthquakes on the Wenchuan fault in China prior to the 2008 earthquake. The results of these analyses suggest that the locations of recent $M \geq 4$ earthquakes may indicate which faults could have strong earthquakes within the next decade or so.

\section{Hydrochemical Variations in the Pu'er Well Associated With the Five Earthquakes (M5.9-7.2) Since 2001 to 2018 SW China}

ZHOU, Z. H., China Earthquake Networks Center, Beijing, China, basalin@ hotmail.com; ZHONG, J., China Earthquake Networks Center, Beijing, China, zjadvance@126.com; ZHAO, J., China Earthquake Networks Center, Beijing, China, zhaojing@seis.ac.cn; YAN, R., China Earthquake Networks Center, Beijing, China, yanrui@seis.ac.cn; TIAN, L., China Earthquake Networks Center, Beijing, China, leitian@seis.ac.cn; FU, H., Yunnan Earthquake Agency, Kunming, China, ynfuhong@qq.com

Long-term observations of deep-well water ion concentrations record the precursory characteristics of earthquakes. In this study, we analyzed 18 years of continuous $\mathrm{Ca}^{2+}, \mathrm{Mg}^{2+}, \mathrm{HCO}_{3}{ }^{-}$, and $\mathrm{pH}$ data from an observation well in the Lanping-Simao fault basin, Yunnan province, China. The ion contents and $\mathrm{pH}$ values of the Pu'er observation well show clear precursory responses to earthquakes of $M \geq 5.9$ within a radius of $400 \mathrm{~km}$. Prior to five such earthquakes, all ion concentrations and $\mathrm{pH}$ values experienced a sudden fall; they then either recovered or remained low. These changes were controlled by two different genetic mechanisms: (1) $\mathrm{CO}_{2}$ injection related to epicentral distance and/or (2) mixing due to crustal dilation. $\mathrm{CO}_{2}$ injection occurred before earthquakes with an epicentral distance of $>90 \mathrm{~km}$, but not before earthquakes with epicentral distances of $<80 \mathrm{~km}$. Mixing due to crustal dilation was observed before all earthquakes. Groundwater chemistry was found to be controlled by two aquifers and the mixing proportion of the upper aquifer increased gradually with time, independent of epicentral distance or earthquake magnitude; the mixing proportion may have been controlled by a gradual increase in stress. The results indicate that deep $\mathrm{CO}_{2}$ injection and water-rock-gas reactions along new interfaces before an earthquake can rapidly change the water chemistry. This study provides potential hydrochemical indicators for earthquake monitoring based on high frequency well water data from active tectonic zones.

\section{Migrating Foreshocks Before the 2014 M6.5 Ludian, Yunnan Earthquake}

DENG, S., China Earthquake Networks Center, Beijing, China, dengsg@ seis.ac.cn; JIANG, H., China Earthquake Networks Center, Beijing, China, jianghaikun@seis.ac.cn; MA, Y., China Earthquake Networks Center, Beijing, China, yawei_m@seis.ac.cn; SONG, J., China Earthquake Networks Center, Beijing, China, songjinbent@seis.ac.cn; AN, Y., China Earthquake Networks Center, Beijing, China, anyanru@seis.ac.cn; WANG, Y., China Earthquake Networks Center, Beijing, China, wangyue@seis.ac.cn; XIE, M., China Earthquake Networks Center, Beijing, China, xiemengyu@seis.ac.cn

Large mainshocks are sometimes preceded by seismic activity also known as "foreshocks". Many researchers found acceleration/migration of foreshock activities before mainshock. The relationship between mainshock and foreshocks is still an open question. In this paper, we take the $2014 M_{\mathrm{S}} 6.5$ Ludian, Yunnan Earthquake as a case to study the seismic activity before the mainshock. We use the GPU-based Match and Locate method (Zhang and Wen, 2015; Liu, 2020) to detect and locate the small foreshocks that may be omitted in the original catalog. We first relocated the original earthquake sequence catalog by tomoDD method (Zhang and Thurber, 2003), and then use the waveforms of 857 earthquakes $\left(M_{\mathrm{L}} \geq 1.0\right.$ before mainshock and $M_{\mathrm{L}} \geq 2.0$ after mainshock) occurred in 2014 as templates to scan the continues waveforms, 9 seismic station near the mainshock is used for the detection. We identified 588 earthquakes in the study area $\left(26.7^{\circ}-27.5^{\circ} \mathrm{N}, 102.9^{\circ}-103.7^{\circ} \mathrm{E}\right)$ during the last 34 days before the Ludian mainshock. We plot the space-time evolution of the newly detected events with respect to the reference axis distance from the initial point of the main shock rupture. We found seismic activity is accelerated and earthquakes are migrated toward the rupture initial point of the mainshock during the last 24-19 days before the mainshock. However, after that until the mainshock, the seismicity near the seismogenic fault is relative quiet.

This study was supported by the National Key R \& D Program of China (2018YFC1503305)

References

Liu Ming et al. 2020. Graphics Processing Unit-Based Match and Locate (GPU-M\&L): An Improved Match and Locate Method and Its Application. Seismol. Res. Lett. 91, 1019-1029.

Zhang Haijiang and Turber H Clifford. 2003. Double-Difference Tomography: The Method and Its Application to the Hayward Fault, California. Bulletin of the Seismological Society of America, Vol. 93, No. 5 , pp. 1875-1889, October 2003.

Zhang Miao and Wen Lianxing. 2015. An effective method for small event detection: match and locate (M\&L). Geophys. J. Int. 200, 1523-1537.

\section{Phenomenology and Physics of Potential Precursors of Earthquakes: Lessons Learnt from the China Seismic Experimental Site (CSES)}

WU, Z., China Earthquake Administration, Beijing, China, wuzhl@ucas. ac.cn; ZHANG, Y., China Earthquake Administration, Beijing, China, yxzhseis@sina.com; ZHANG, X., China Earthquake Administration, Beijing, China, zxd@ief.ac.cn; SHAO, Z., China Earthquake Administration, Beijing, China, shaozh0911@126.com; LIU, J., China Earthquake Networks Center Beijing, China, liujie@seis.ac.cn

China Seismic Experimental Site (CSES), announced to be established since 2018 , is located within the territory of China in the range of $97.5^{\circ} \sim 105.5^{\circ} \mathrm{E}$ $21^{\circ} \sim 32^{\circ} \mathrm{N}$, with a total area of $780,000 \mathrm{~km}^{2}$. CSES is an extension and continuation of the Sino-US cooperative Western Yunnan Experimental Site for Earthquake Prediction (1980 ) and the Sichuan-Yunnan National Experimental Site for Earthquake Monitoring and Prediction (2014 2018). It locates near the 'eastern Himalayan syntaxis', playing the role of a natural laboratory for earthquake science. Since 1965, for every decade, there had been on average 14 earthquakes with $M_{S} \geq 6.0$, among which 3 with $M_{S} \geq 7.0$, occurred in that region. Recent 2008 Wenchuan $M_{\mathrm{S}} 8.0,2013$ Lushan $M_{\mathrm{S}} 7.0$ and Ludian $M_{\varsigma} 6.5$ earthquakes provide the investigation of potential precursors of earthquakes with opportunities of retrospective, and even prospective case studies. One of the important lessons learnt from previous earthquakes is that the association of a precursory anomaly with an earthquake seems complicated: The bigger the 'target' earthquake, the bigger the spatial-temporal range of the precursory anomalies would be observed; Spatial distribution of the precursory anomalies depends on the seismo-tectonics of the 'target' earthquake; For large earthquakes, the evolution of the distribution of precursory anomalies shows the features which seems to be associated with the criticality of the earthquake preparatory phase. When both large and intermediate earthquakes are taken into consideration, such association problem becomes complicated; Clustering of earthquakes further contributes to such complexity; When noise and perturbation are considered, the problem is even 
more complicated; This problem is further tangled with the degeneration of observational environment.

\section{Relocation of the 2019 Changning Ms6.0 Earthquake Sequence and Apparent Stress Analysis}

WANG, Y., China Earthquake Networks Center, Beijing, China, wangyue@ seis.ac.cn; MA, Y., China Earthquake Networks Center, Beijing, China, yawei_m@seis.ac.cn; XIE, M., China Earthquake Networks Center, Beijing, China, xiemengyu@seis.ac.cn

Recently, the seismicity of Sichuan Changning area presents the tendency of higher frequency and larger intensity. Considerable earthquake monitoring and scientific studies show that the change of seismicity in industrial activity is related to the activities of waste water injection and hydraulic fracturing. On June 17, 2019, an earthquake of $M_{\mathrm{S}} 6.0$ struck Changning County, and four aftershocks with magnitude larger than $M_{\mathrm{S}} 5.0$ occurred during the following days till to July 4,2019 . According to the history record, there is no any other earthquakes with magnitude larger than the Changning $M_{\mathrm{S}} 6.0$ earthquake in this area. In this study, based on the seismic data provided by China Earthquake Networks Center, we relocated the $M_{S} 6.0$ Changning earthquake sequence from June 17 to December 31, 2019 by using double-difference location method. Meanwhile, the apparent stress of $103 M_{\mathrm{S}} \geq 3.0$ earthquakes before December 31 were also calculated. Finally, the seismogenic structure of the sequence is preliminarily analyzed.

The distribution of relocated $5400 M_{\mathrm{L}} \geq 0.0$ events shows that the aftershock area is $25 \mathrm{~km}$ long and $5 \sim 8 \mathrm{~km}$ wide in a NW-SE trending. The focal depths range from 0 to $10 \mathrm{~km}$ and the total sequence is deep in the west and shallow in the east. The $M_{\mathrm{S}} 6.0$ earthquake is relocated at the southeastern end of the aftershock zone, showing its unilateral rupture behavior. According to the aftershocks upon the mainshock, there may exist an unnamed small scale fault. By analyzing the calculated apparent stress of earthquakes occurred from 2017 to 2019, we obtained two conclusions: (1) The stresses of $M_{\mathrm{S}} 3.0 \sim 3.4$ earthquakes were at a relative high level before the $M_{\mathrm{S}} 6.0$ earthquake, while the stresses of $M_{S} \geq 3.5$ earthquakes did not emerge high values. (2) Six of the seven $M_{\mathrm{S}} \geq 4.5$ earthquakes after the main shock were preceded by high apparent stresses of $M_{\mathrm{S}} 3.0 \sim 3.4$ earthquakes. Thus, for Changning area, the high apparent stresses of $M_{\mathrm{S}} 3.0 \sim 3.4$ earthquakes may be useful for prediction of $M_{S} \geq 4.5$ earthquakes.

\section{The Accelerated Slip Deficit Rate of the Longmenshan} Fault Plane Before the $\mathbf{2 0 0 8}$ M8.0 Wenchuan Earthquake $\underline{\mathrm{ZHAO}, \text { I. }}$, China Earthquake Networks Center, Beijing, China, zhaojing@ seis.ac.cn; YUAN, Z., China Earthquake Networks Center, Beijing, China, zhengyiy1989@seis.ac.cn; YUE, C., China Earthquake Networks Center, Beijing, China, yuechong@seis.ac.cn

Geodetic data can be used to invert the slip deficit rate at different depths of fault plane. In this study, GPS velocity field data of China from 1999-2001, 2001-2004 and 2004-2007 before the Wenchuan earthquake were used to construct the multi-fault system three-dimensional model of the Longmenshan structural belt, and the spatial-temporal evolution process of slip deficit rate at the Longmenshan fault plane before the 2008 M8.0 Wenchuan earthquake was obtained by the negative dislocation inversion. The results show that, under the background of strong coupling, the dextral slip deficit rate of the fault was about $6 \mathrm{~mm} / \mathrm{a}$ in 1999-2001 and 2001-2004, and the magnitude was stable, but it increased rapidly to about $9.5 \mathrm{~mm} / \mathrm{a}$ in 2004-2007. However, the compressive deficit rate of the fault plane changed little during the three time periods and basically remained at $3-4 \mathrm{~mm} / \mathrm{a}$.

The dextral slip deficit rate of $6-9.5 \mathrm{~mm} / \mathrm{a}$ on the deep fault plane obtained in this study is much higher than the slip rate of $2-3 \mathrm{~mm} / \mathrm{a}$ on the surface, but it is close to the slip rate of about $3.5-9.6 \mathrm{~mm} / \mathrm{a}$ in the $4-18 \mathrm{~km}$ range of the deep fault estimated by repeated earthquakes by Li et al. (2011) indicating that the slip rate on the deep fault plane of the Longmenshan fault is about 2-3 times that of the surface slip rate observed by GPS, geology and other superficial observations (Chen et al., 2018). At the same time, the dextral slip deficit rate increases rapidly to around $9.5 \mathrm{~mm} / \mathrm{a}$ in 2004-2007, and this result is consistent with the short-term acceleration of slip around 2006 in Hongkou-Wenchuan and Beichuan obtained by Chen et al. (2018) using repeated seismic sequence, which indicates that the Longmenshan fault plane may have accelerated deep slip rate before the Wenchuan earthquake.

References

Chen Q F, Li L. Deep deformation of the Longmenshan fault zone related to the 2008 Wenchuan earthquake (in Chinese). Chin Sci Bull, 2018, 63: $1917-1933$
Li L, Chen Q F, Niu F L, et al. Deep slip rates along the Longmen Shan fault zone estimated from repeating microearthquakes. J Geophys Res, 2011, 116: B09310

\begin{tabular}{l}
\hline New Insights Into the Preparatory Phase of Earthquakes \\
From Tectonic, Field and Lab Experiments \\
Poster Session · Monday · 19 April · 3:45 PM Pacific \\
Session Chairs: Zhigang Peng, Georgia Institute of \\
Technology (zpeng@gatech.edu); Yongxian Zhang, \\
China Earthquake Administration (yxzhseis@sina.com); \\
Maximilian Werner, University of Bristol (max.werner@ \\
bristol.ac.uk); Vladimir Kossobokov, Russian Academy of \\
Sciences (volodya@mitp.ru); John Ebel, Boston College \\
(john.ebel.1@bc.edu); Weijun Wang, China Earthquake \\
Administration (wjwang@cea-ies.ac.cn)
\end{tabular}

\section{Analysis on Anomaly Characteristics of Litang Hot Spring} Temperature Before Major Earthquakes

TIAN, L., China Earthquake Networks Center, Beijing, China, leitian@ seis.ac.cn; WANG, B., China Earthquake Networks Center, Beijing, China, wangbo313@163.com; ZHOU, Z., China Earthquake Networks Center, Beijing, China, zhouzhihua@seis.ac.cn

The changes of water temperature in underground fluid may reflect the change of thermal state caused by tectonic activity during earthquake gestation. For many years in the practice of earthquake gestation, the change of water temperature anomaly is also an important index of short-term and imminent anomaly (Liu et al., 2015) This research discusses the anomalies of Litang spring temperature based on the long-term observation data and the surrounding major earthquakes within $500 \mathrm{~km}$.

Litang hot spring is a mixture of cold and hot water, the hot water upwelling is mainly from the deep heat source in the crust (Qiu, 2018). Before the major earthquakes, the crustal stress accumulation led to the decrease of the heat source upwelling channel in Litang hot spring and the temperature would be abnormal with a decline of more than $5^{\circ} \mathrm{C}$ before these earthquakes and could last for more than 6 months. But the similar change of Litang temperature was not found before Wenchuan M8.0 earthquake. GNSS data also showed that the Longmenshan Fault and its surrounding areas were strongly coupled for a long time before the Wenchuan earthquake which led to the decrease of the hot water supply in Litang (Zhao et al., 2015; Zou et al., 2015).

References

Liu Y W, Ren H W, Zhang L, et al. 2015, Unerground fluid anomalies and the precursor mechanisms of the Ludian M6.5 earthquake (in Chinese). Seismology And Geology, 37(1): 307-318.

Qiu G L. 2018, The research of temperature anomaly of Maoya thermal spring in Litang, Sichuan and its ability on reflecting earthquake. Advances in Geosciences, 8(7): 1195-1204.

Zhao J, Jiang Z S, Niu A F, et al. 2015, Study on dynamic characteristics of fault locking and fault slip deficit in the eastern boundary of the SichanYunnan rhombic block(in Chinese). Chinese J. geophys, 58(3): 872-885.

Zou Z Y, Jiang Z S, Wu Y Q, et al. 2015, Dynamic characteristics of crustal movement in north-south seismic belt from GPS velocity field before and after the Wenchuan earthquake(in Chinese). Chinese J. geophys, 58(5):1597-1609.

\section{Earthquake Transformer Can be Used to Study the Fault of the Western Tibet M6.3 Earthquake, 2020}

MA, Y., China Earthquake Networks Center, Beijing, China, yawei_m@ seis.ac.cn; WANG, Y., China Earthquake Networks Center, Beijing, China, wangyue@seis.ac.cn

According to the U.S. Geological Survey, an M6.3 earthquake $\left(33.144^{\circ} \mathrm{N}\right.$, $86.864^{\circ} \mathrm{E}$ ) occurred in Western Tibet on July 22, 2020, with a focal depth of $10 \mathrm{~km}$. The focal mechanism solution shows that the earthquake is a tensile rupture with a strike of NNE. Using the catalogue given by China Earthquake Networks Center to study the distribution of aftershocks, it was found that the distribution of aftershocks was inconsistent with the rupture surface direction shown by the focal mechanism solution. The analysis suggested that the reason for this problem may be the area monitoring ability is limited, which 
leads to a higher Mc of earthquake catalogue. Therefore, it's hard to use current catalogue to depict the distribution of aftershocks.

A method of using deep learning to detect and pick up seismic phases was applied to the continuous waveforms of the 2000 Tottori earthquakes in Japan. Because of the high efficiency and high sensitivity of this method, more and smaller events were detected. Another advantage of this method is the ability to detect and locate more than two times earthquakes using a portion of seismic stations. In view of the low monitoring capability in western Tibet, this method can be used to detect more seismic events with lower magnitudes from the limited waveform data. This is helpful for analyzing the characteristics of seismic faults using the distribution of aftershocks.

\section{Geochemical Characteristics of Fault Hydrogen in Aksu and its Seismic Reflection Efficiency}

WANG, B., China Earthquake Networks Center, Beijing, China wangbo313@163.com; ZHONG, J., China Earthquake Networks Center, Beijing, China, zjadvance@126.com

Fault gas may carry important information in the process of earthquake preparation and occurrence, which is an effective way to study tectonic activity. The Aksu fault hydrogen is located in the southern Tianshan tectonic belt with frequent strong earthquakes. Since Aksu fault hydrogen locate in the active part of the tectonic belt, its concentration variation has a good correlation with the seismicity. Based on the hydrogen observation data of the Aksu, time-frequency analysis of its periodic components was carried out. The relationship between temperature, air pressure and the annual periodic components of hydrogen concentration was analyzed using the linear regression and cross-correlation method, and the seismic reflection efficiency of the fault hydrogen was quantified using the Molchan error diagram method. The results show that: (1) Aksu fault hydrogen has good annual and semi-daily cycle components; (2) It has a good positive correlation between the annual periodic dynamic changes of fault hydrogen and temperature, and a genera correlation with air pressure, indicating that its annual periodic changes are mainly affected by temperature; (3) Molchan's error diagram test results show that the hydrogen anomaly of Aksu is sensitive to the earthquakes around the observation point. The mechanism and possible sources of hydrogen are discussed, which provides a reference basis for monitoring faults and seismic activity with hydrogen. In the process of earthquake preparation, the increasing tectonic stress intensifies the water-rock reaction, resulting in the production of a large amount of hydrogen; at the same time, the fault fissure channel is more open, which is conducive to the rapid migration of hydrogen from underground to the surface. Therefore, the abnormal of hydrogen concentration can be observed before the earthquake.

\section{Groundwater Level Changes in the Chinese Mainland Following the 2011 Tohoku Japan Earthquake and the 2015 Gorkha Nepal Earthquake}

MA, Y., China Earthquake Networks Center, Beijing, China, mayuchuan@ seis.ac.cn; HUANG, Q. F., China Earthquake Networks Center, Beijing, China, hfqiong@seis.ac.cn

Groundwater level oscillations, or step-like rises and step-like drops were recorded in 184 wells throughout the Chinese mainland due to the 2011 Tohoku Japan earthquake, and 159 wells for the 2015 Gorkha Nepal earthquake. The earthquake magnitude, and the associated dynamic stresses, has positive roles in both the sensitivity of water level to earthquake induced change, and the amplitude and duration of resulting coseismic water level changes. Wells whose water levels are sensitive to Earth tides have high potential to response to earthquakes. Polarities of step-like changes (rises or drops) are locally controlled and spatially variable, with artesian wells generally recording water-level rises. Permeability enhancement was assessed as a mechanism responsible for step-like changes by analyzing the tidal phase responses. Permeability variations are inferred for 32 out of 105 wells with step-like changes during the Tohoku earthquake and for 17 out of 95 wells following the Gorkha earthquake; however, only 6 wells have permeability variations after both earthquakes.

\section{Maximum Magnitude Estimation of the Aftershocks of the M6 Earthquake Sequence, Mainland China}

XIE, M., China Earthquake Networks Center, Beijing, China, xiemengyu@ seis.ac.cn; MENG, L., China Earthquake Networks Center, Beijing, China, menglingyuan@seis.ac.cn; HAN, Y., China Earthquake Networks Center, Beijing, China, hanyy@seis.ac.cn; ZANG, Y., China Earthquake Networks Center, Beijing, China, zangyang@seis.ac.cn; MA, Y., China Earthquake Networks Center, Beijing, China, yawei_m@seis.ac.cn; WANG, Y., China Earthquake Networks Center, Beijing, China, wangyue@seis.ac.cn; DENG,
S., China Earthquake Networks Center, Beijing, China, dengsg@seis.ac.cn; SONG, J., China Earthquake Networks Center, Beijing, China, songjinbent@ seis.ac.cn; ZHANG, X., China Earthquake Networks Center, Beijing, China, zhangxiaotao@seis.ac.cn; YANG, W., China Earthquake Networks Center, Beijing, China, yangwen@seis.ac.cn; SHI, H., China Earthquake Networks Center, Beijing, China, shihaixia08@seis.ac.cn

It's well-known that large earthquakes are followed by abundant aftershocks which can last a long time and affect wide spatial areas. Among those aftershocks, the largest aftershock can cause additional injuries and damages, putting people and buildings at serious risk. Therefore, estimation of the largest aftershock's magnitude is of considerable importance for seismic hazard assessment and rescue operations. In this work, we estimate the largest aftershock's magnitude of the 69 M6 earthquake sequences in the Chinese Mainland which occurred from 1966 to the present by using the equation for the magnitude of the inferred largest aftershock proposed by Shcherbakov and Turcotte (2004). Moreover, we also analyze the results with different methods calculating the $b$-value and the magnitude of completeness $M_{\mathrm{C}}$ and estimate the maximum magnitude of aftershocks with different time intervals after the mainshocks. The results show that the estimation trends to be a certain value when time intervals become larger and this value is consistent with the magnitude of the real largest aftershock for about $50 \%$ earthquake sequences. And the percentage of successful estimation is more than $40 \%$ in one day after the mainshock. In addition, the percentage of successful estimation varies with the type of earthquake sequence with about $31 \%$ for swarm type, $52 \%$ for mainshock-aftershock type, and $71 \%$ for isolated type. For different estimation methods, we find that the estimations are more accurate and have a lower coefficient of variation when using GFT and modified MAXC to calculate the value of $M_{\mathrm{C}}$ and using the maximum likelihood method to calculate $b$-value. In a word, although we can't predict precisely when and where the largest aftershock will occur, the method we proposed can provide a rational magnitude estimation for the largest aftershock in a short period after the mainshock.

This study was supported by the National Key R \& D Program of China (2017YFC1500502, 2018YFC1503305) and the National Key Research and Development Project (2018YFE0109700).

\section{Prediction of Seismicity in Sichuan-Yunnan Region Based on Several Kinds of Recurrent Neural Networks} ZANG, Y., China Earthquake Networks Center, Beijing, China, zangyang@ seis.ac.cn

With the rapid development of artificial intelligence, a large number of application examples in the field of geophysics and seismology have emerged using the method of machine learning in recent years. Neural network as the commonly used method of machine learning was put forward very early and has now developed into a fairly large, multidisciplinary cross disciplines with the progress of computer performance. Inspired by the central nervous system of animals, neural networks can solve a wide variety of tasks that are difficult to solve with ordinary rule-based programming by adaptively learning large amounts of inputs, and have played a huge role in areas such as computer vision, speech recognition, and weather forecasting. The biggest advantage of artificial neural network is that it can approximate any function, which is very suitable for studying the complex empirical relationship between seismic activity and subsequent strong earthquakes. Meanwhile, the state of seismic activity changes dynamically with time, and the seismic activity in two adjacent periods is related to each other to some extent. This characteristic can be modeled properly using the recursive neural network (RNN) as it has memories of a sequence data and it can better reflect the characteristics of time dependence of seismic activities. Three different kinds of neural networks including Elman RNN, long short-term memory (LSTM) RNN, and gated recurrent unit (GRU) RNN have been applied to predict the seismicity in Sichuan-Yunnan region based on feature values which can represent the spatial and temporal characteristics of previous regional small earthquakes such as G-R relationship, seismic quasi-period, seismic energy, etc. This research provides an alternative approach for evaluating the short to long term seismic hazard potential of a study region and it has a broader space for development compared to traditional empirical earthquake prediction methods.

\section{Research and Application of Seismological Parameter Methods in Earthquake Prediction}

HAN, Y., China Earthquake Networks Center, Beijing, China, hanyy@ seis.ac.cn; ZANG, Y., China Earthquake Networks Center, Beijing, China, zangyang@seis.ac.cn; MENG, L., China Earthquake Networks Center, Beijing, China, menglingyuan@seis.ac.cn; JIANG, X., China Earthquake Networks Center, Beijing, China, jiangxh@seis.ac.cn; XIE, M., China Earthquake 
Networks Center, Beijing, China, xiemengyu@seis.ac.cn; WANG, Y., China Earthquake Networks Center, Beijing, China, wangyue@seis.ac.cn; MA, Y., China Earthquake Networks Center, Beijing, China, yawei_m@seis.ac.cn; DENG, S., China Earthquake Networks Center, Beijing, China, dengsg@ seis.ac.cn; YANG, W., China Earthquake Networks Center, Beijing, China, yangwen@seis.ac.cn; SHI, H., China Earthquake Networks Center, Beijing, China, shihaixia08@seis.ac.cn; SONG, J., China Earthquake Networks Center, Beijing, China, songjinbent@seis.ac.cn; ZHANG, X., China Earthquake Networks Center, Beijing, China, zhangxiaotao@seis.ac.cn

Seismicity is a very complex natural phenomenon, which involves many physical processes of time and space scales. It is one of the most commonly used methods for earthquake prediction and seismic risk assessment to describe the rule of seismicity based on the statistical empirical law obtained from observation. The seismological parameter methods are used to study the temporal and spatial characteristics of seismicity in the region and to explore the seismogenic regularity of strong earthquakes in the future. On the basis of previous studies, we selected 11 parameters with better prediction efficiency from the existing parameters for improvement and innovation. It includes seismological parameters such as seismic period spectrum, earthquake rate index, modulation ratio, wave velocity ratio, Benioff strain ratio, quiescence, creep, RTL, $C$ value, $D$ value, $b$ value and $\eta$ value. Based on the retrospective anomaly analysis before the historical earthquakes, the prediction indexes for long, medium, short and imminent earthquake prediction are established. During the process of earthquake trend prediction, we found a number of seismological parameters show significant anomalies before the strong earthquakes occurred since 2020. Taking the Nima, Tibet $M_{\mathrm{S}} 6.6$ earthquake on July 23 as an example, the earthquake rate index, modulation ratio and $b$ value show significant anomalies in the area near the epicenter before the earthquake, which means these parameters could provide effective prediction for the area with lower monitoring capacity. At present, we have carried out the nationwide dynamic cloud-image tracking method with multi parameters. The assessment results can provide an important scientific basis for the determination of the annual seismic risk regions and the short-term earthquake prediction.

This study was supported by the National Key R \& D Program of China (2017YFC1500502) and the Natural Science Foundation of China (41504047)

\section{The Seismic Probability of the Faults in Boundary Area of Gansu and Qinghai Provinces Influenced by the 2008 Wenchuan Mw7.9 Earthquake and the 2017 Jiuzhaigou Mw6.5 Earthquake}

SONG, I. China Earthquake Network Center, Beijing, China, songjinbent@ seis.ac.cn; MENG, L., China Earthquake Network Center, Beijing, China, menglingyuan@seis.ac.cn; JIANG, H., China Earthquake Network Center, Beijing, China, jianghaikun@seis.ac.cn; HAN, Y., China Earthquake Network Center, Beijing, China, hanyy@seis.ac.cn

On August 8, 2017, an earthquake with MW6.5 occurred in Jiuzhaigou, Sichuan Province, causing heavy casualties and property losses. After that, many studies concerned the stress effects on different faults in surrounding areas by the Jiuzhaigou earthquake (Shan et al, 2017; Xu et al, 2017; Wang et al, 2017; Cheng et al, 2018). Previous research mostly focused on the stress influence on faults by the 2008 Wenchuan MW7.9 earthquake and the 2017 Jiuzhaigou MW6.5 earthquake. In this paper, based on the rate- and statedependent friction law (Dieterich, 1994), combined with background seismicity and the Coulomb stress disturbance caused by both the two earthquakes, the seismic probabilities of the loaded faults were quantitatively calculated. The distribution of Coulomb stress show that the faults been loaded includes the northern part of Pingwu-Qingchuan fault, the western part of Tazang fault, the Kangxian fault, the southern part of Minjiang fault, the middle and western part of Liangdangjiangluo fault, the eastern part of Xueshan fault, the Maqu fault, the Maqin fault, and the eastern part of LintanDangchang fault, the western segment of Guanggaishan fault, the western segment of Bailongiiang fault and the western segment of Wenxian fault. The calculated results of the seismic probabilities of the loaded faults show that the areas nearby the southern part of Minjiang fault, the western part of Tazang fault, the western segment of Guanggaishan fault, the western segment of Bailongjiang fault, the eastern part of Lintan-Dangchang fault, the western segment of Wenxian fault have high probability of strong earthquake and seismic hazard.

This study was supported by the National Key R\&D Program of China (2018YFC1503305).

\section{Numerical Modeling of Earthquake Motion, Rupture Dynamics, Seismic Noise, Wave Propagation and Inverse} Problems

I: Oral Session · Friday · 23 April · 9:45 Am Pacific

II: Oral Session · Friday $\cdot 23$ April $\cdot$ 2:00 PM Pacific

Session Chairs: Peter Moczo, Comenius University Bratislava (moczo@fmph.uniba.sk); Wei Zhang, Southern University of Science and Technology (zhangwei@sustech.edu.cn); Jozef Kristek, Comenius University Bratislava (kristek@fmph. uniba.sk); Martin Galis, Comenius University Bratislava (martin.galis@uniba.sk); Chanseok Jeong, Central Michigan University (jeong1c@cmich.edu); Elnaz Seylabi, University of Nevada, Reno (elnaze@unr.edu)

\section{Helmholtz Decomposition of Seismic Wavefields with SPECFEM3D \\ LANGER, L., U.S. Geological Survey, California, USA, llanger@usgs.gov; POLLITZ, F. F., U.S. Geological Survey, California, USA, fpollitz@usgs.gov; MCGUIRE, J., U.S. Geological Survey, California, USA, jmcguire@usgs.gov}

The construction of seismic imaging conditions in elastic reverse time migration (RTM) often requires breaking down the seismic wavefield into its constituent $\mathrm{P}$ and $\mathrm{S}$ components. This is done by means of the Helmholtz decomposition, which involves taking the curl of the curl of the vector wavefield to obtain the $\mathrm{S}$ wavefield and the gradient of the divergence to obtain the $\mathrm{P}$ wavefield. These second spatial derivatives present certain challenges which make it difficult to perform this operation efficiently.

Here, we present a method for performing the Helmholtz decomposition of seismic wavefields in the time domain using SPECFEM3D, a spectral element elastic wave propagation code. Our technique is able to perform the decomposition of either forward or adjoint wavefields at any time step of a SPECFEM3D wavefield simulation. We show a few examples of decomposed wavefields and discuss some of the challenges associated with decomposition. Because the second spatial derivatives of the wavefield, particularly the gradient of the divergence, require a very high degree of spatial resolution, artifacts can arise when the Helmholtz decomposition is performed. This problem may be alleviated by filtering the data to remove high frequency information and by using a mesh with finer spatial resolution. We also present converted-wave elastic RTM images based on vector imaging conditions for a synthetic model that have been obtained using the decomposed $\mathrm{P}$ and $\mathrm{S}$ wavefields and discuss our plans to implement our imaging technique using adjoint wavefields produced from real seismic data.

\section{Modelling of Seismic Waves in Biot and JKD Poroelastic Medium With Subcell-Resolution Finite-Difference Scheme} GREGOR, D., Comenius University Bratislava, Bratislava, Slovakia, david. gregor@fmph.uniba.sk; MOCZO, P., Comenius University Bratislava, Bratislava, Slovakia, moczo@fmph.uniba.sk; KRISTEK, J., Comenius University, Bratislava, Slovakia, kristek@fmph.uniba.sk; MESGOUEZ, A., Avignon Universite, Avignon, France, arnaud.mesgouez@univ-avignon.fr; LEFEUVE-MESGOUEZ, G., Avignon Universite, Avignon, France, gaelle. Mesgouez@univ-avignon.fr; KRISTEKOVA, M., Slovak Academy of Sciences, Bratislava, Slovakia, kristekova@savba.sk

We have developed an efficient staggered-grid finite-difference (FD) scheme for modeling seismic waves in a heterogeneous poroelastic medium.

The scheme:

-can simulate seismic waves in a strongly heterogeneous poroelastic medium with a) zero resistive friction, b) non-zero constant resistive friction,c) JKD model of the frequency-dependent permeability and resistive friction;

-is capable of sub-cell resolution, that is, allows for an arbitrary shape and position of an interface in a uniform (and possibly discontinuous) spatial grid;

-keeps computational efficiency of the scheme for a smoothly and weakly heterogeneous medium (medium without material interfaces); this is because the number of algebraic operations for updating stress, fluid pressure, solid particle velocity and relative fluid particle velocity is the same; the only difference is that it is necessary to evaluate averaged grid material parameters once before the FD simulation itself. 
We carefully tested the FD simulations against the semi-analytical method developed by Mesgouez \& Lefeuve-Mesgouez (2009).

The developed FD scheme extends and proves the capabilities of the FD modelling of seismic waves in strongly heterogeneous media - building up on developments by Moczo et al. (2002, 2014, 2019), Kristek \& Moczo (2003), Kristek et al. $(2017,2019)$.

In the illustrative numerical example, we demonstrate differences between seismic wavefields and earthquake ground motion in the Biot's and JKD variants of the model of the surface sedimentary basin. The example indicates that it is desirable to perform an extensive parametric study in order to find out when it is necessary to apply relatively complicated and computationally more demanding JKD model and when much simpler Biot's model is sufficient.

\section{New Absorbing Boundary Condition for Elastic Waves in Isotropic Layered Waveguides}

LEE, J., Pukyong National University, Busan, Korea, Republic of, jholee0218@ gmail.com

The wave-propagation phenomena in infinite media has described various physics in the fields of engineering and natural science. In order to obtain solutions to the problems, analytical or numerical methods have been developed. The energy radiation into infinity must be considered for accurate solutions to the problems. Various numerical or mechanical models or boundary conditions have been developed. In this study, proposed is a new boundary condition that can be applied to elastic-wave propagation problems in isotropic layered waveguides. A governing equation for elastic waves, which is obtained by applying the finite-element discretization in the vertical direction of a waveguide, is modified to derive a boundary condition for the infinite region of the waveguide. The accuracy and stability are demonstrated by applying the proposed boundary condition to wave-propagation problems in isotropic layered waveguides.

\section{Overset Grid Finite Difference Method for Seismic Wave Simulation in the Presence of the Complex Free Surface Topography}

ZANG, N., University of Science and Technology of China, Hefei, China, zangnan@mail.ustc.edu.cn; ZHANG, W., Southern University of Science and Technology, Shenzhen, China, zhangwei@sustech.edu.cn; CHEN, X., Southern University of Science and Technology, Shenzhen, China, chenxf@ sustech.edu.cn

Efficient seismic wave simulation is an important tool for strong ground motion prediction and inverting high resolution structures by waveform inversion. Many numerical methods, e.g., the spectral-element method (SEM), discontinuous Galerkin (DG) method, Curvilinear-grid finite-difference method (CG-FDM), have been developed for seismic wave simulation considering surface topography, however, for large-scale problems, the highquality and efficient grid generation is not a trivial task.

In this work, we propose an overset grid finite-difference method with a collocated grid for the simulation of seismic waves in the presence of steep topography. The complex geological model is discretized into simpler subdomains, and the Cartesian grid is used as the background grid to discretize the whole model, while a few curvilinear grid layers are employed to fit the irregular topography at the free surface. The Cartesian grid and curvilinear grid overlap arbitrarily without requiring point-matched connectivity within the overlapping zone. For the data exchange between different grid blocks, we employ sixth-order explicit Lagrangian interpolation.

Then, some numerical tests are performed. A homogeneous full-space model and a layered velocity model with surface topography verify the proposed overset grid is sufficiently accurate and stable for numerical simulation of seismic wave propagation with steep topography. A rough topographic model that is discretized with a vertical deformed grid and overset grid illustrates that the overset grid can increase the maximum allowable time step by a factor of nearly 2-4 times. And the foothills model is utilized to show the proposed overset grid method can be applied to realistic complex models.

In summary, the overset grid can not only reduce the grid generation difficulty but also improve the computational efficiency. We can obtain stable and accurate results by employing an overset grid even in realistic geological models.

\section{Sensitivity Kernels for Basin Path and Site Effects}

BOWDEN, D., ETH Zürich, Zürich, Switzerland, daniel.bowden@erdw.ethz. ch; PIENKOWSKA-COTE, M., ETH Zürich, Zürich, Switzerland, marta. pienkowska@erdw.ethz.ch; BRISSAUD, Q., Stiftelsen Norsar, Kjeller, Norway, quentin@norsar.no; FICHTNER, A., ETH Zürich, Zürich, Switzerland, andreas.fichtner@erdw.ethz.ch

Numerous studies have explored how shallow wave propagation can amplify and focus seismic waves, significantly increasing seismic hazard. In complex basin structures, seismologists often must rely on simulations or careful timeseries analysis to determine whether the strongest shaking resulted from direct S-wave amplifications, from basin or topographic focusing, from converted surface waves at a basin's edge, etc.

In this work we explore a systematic method for characterizing which part of a sedimentary basin or other geologic structure was most responsible for the observed amplitudes. The use of adjoint, finite-frequency based sensitivity kernels is well developed for tomography applications but seldom applied to hazard. In tomographic applications, an adjoint kernel is generally used to characterize the region of a model which would need to be altered to reduce some misfit between observations and synthetics. Here we ask the question: what region of the model most significantly contributed to an observed high-amplitude signal?

We note such methods have been explored for source and path sensitivities hazard by Day, Roten and Olsen (2012), but while that work provided a detailed and thorough exploration of a large-scale Shakeout scenario, our approach in this work will be of smaller scale and systematic. By examining the kernels from numerous events and by slowly adding geologic complexity to the basin shape, we hope to shed light on when and how different wavetypes are excited or when they are important contributors to hazard.

\section{Conditioned Simulation of Ground Motion Time Series Using Gaussian Process Regression With Application to Ridgecrest Ground Motions}

TAMHIDI, A., University of California, Los Angeles, California, USA aidintamhidi@ucla.edu; KUEHN, N., University of California, Los Angeles, J. Garrick Institute for the Risk Science, California, USA, kuehn@ucla. edu; GHAHARI, S., University of California, Los Angeles, California, USA, ghahari@seas.ucla.edu; RODGERS, A. J., Lawrence Livermore National Laboratory, California, USA, rodgers7@llnl.gov; KOHLER, M., Caltech, California, USA, kohler@caltech.edu; TACIROGLU, E., University of California, Los Angeles, California, USA, etacir@ucla.edu; BOZORGNIA, Y., University of California, Los Angeles, California, USA, yousef.bozorgnia@ ucla.edu

Ground motion time series are critical elements of earthquake engineering for performance analysis of seismic regions. The number of available instruments to record free-field ground motions in the U.S. is currently too sparse. Thus ground motion simulation methods are developed to obtain input motion estimates at locations where there is no available instrumentation. We have constructed ground motion time series using a Gaussian Process Regression method, which models the real and imaginary parts of the Fourier spectrum as random Gaussian variables. The proposed models' training and validation are carried out using physics-based simulated ground motions of the 1906 M7.9 San Francisco Earthquake. The evaluation of the model's performance is also carried out using the physics-based simulated M7.0 Hayward fault earthquake and observed M7.1 2019 Ridgecrest earthquake ground motions recorded by the Community Seismic Network in Los Angeles. Most of the evaluations illustrate that the trained Gaussian Process Regression model is able to estimate the ground motion time series properly. The trained Gaussian Process Regression model has a decent performance in the prediction of the long-period content of the ground motions, including pulses due to directivity. Furthermore, the response spectra of the estimated ground motions are compatible with the corresponding observed ground motions' response spectra at the same locations. The results also illustrate that the prediction for locations either at the boundaries or in regions with fewer observations might be less accurate, and the predicted short-period content of the estimated ground motion time series is less reliable than the long-period content.

\section{Full-Waveform Inversion of Seismic Input Motions in a Near-Surface Domain Truncated by Wave-Absorbing Boundary Conditions}

PERUQUI GUIDIO, B., Central Michigan University, Michigan, USA, peruq1b@cmich.edu; JEREMIC, B., University of California, Davis, California USA, jeremic@ucdavis.edu; PERUQUI GUIDIO, L., The University of Campinas, Campinas, Brazil, leandroguidioo@gmail.com; JEONG, C. Central Michigan University, Michigan, USA, jeong1c@cmich.edu

There is a need to estimate complex seismic input motions in a near-surface domain, without resorting to the hypocenter, from restricted seismic measurement data. Thus, engineers can replicate responses within structures and 
soils after an earthquake occurrence by using the estimated seismic inputs and evaluate the impact of an earthquake on the built environment.

We present a partial differential equation (PDE)-constrained optimization method for solving the full waveform inverse problem of determining complex, incoherent $\mathrm{SH}$ wave input motions, which are modeled as traction on a wave-absorbing boundary condition (WABC), in a $2 \mathrm{D}$ domain that is truncated by a WABC. The method includes the discretize-then-optimize (DTO) approach, the finite element method (FEM), which is applied to solve state and adjoint problems, and the conjugate-gradient scheme, determining the desired search path throughout a minimization process.

The numerical results show that incident, inclined plane waves, cannot be fully reconstructed if using only the top surface sensors because some portions of the incident waves do not reach the top sensors in a truncated domain. In order to improve the inversion performance, a vertical array of sensors on the side boundary of a domain should be included. Second, a sufficiently large number of sensors must be employed to improve the algorithm's inversion performance. Third, the minimizer suffers more from solution multiplicity when it identifies incident waves of a higher dominant frequency. Fourth, the larger value of the inversion error in the reconstructed traction does not necessarily translate to an error of the same magnitude in the corresponding reconstructed wave responses in the computational domain due to the intrinsic low-pass filtering of the FEM wave solver. Lastly, our presented inversion algorithm's accuracy is not compromised by the material complexity of a background domain.

\section{Inversion of Dynamic Traction in a Bounded Domain of SH Wave Motions}

JEONG, C., Central Michigan University, Michigan, USA, jeong1c@cmich. edu; PERUQUI GUIDIO, B., Central Michigan University, Michigan, USA, peruq1b@cmich.edu

We present a full-waveform inversion method for reconstructing the temporal and spatial distribution of unknown, incoherent dynamic traction in a heterogeneous, bounded solid domain from sparse, surficial responses. This work considers SH wave motions in a two-dimensional (2D) domain. To mitigate the solution multiplicity of the presented inverse problem, we employ the Tikhonov (TN) regularization on the estimated traction function. We present the mathematical modeling and numerical implementation of both optimizethen-discretize (OTD) and discretize-then-optimize (DTO) approaches. The finite element method is employed to obtain the numerical solutions of state and adjoint problems. Newton's method is utilized for estimating an optimal step length in combination with the conjugate-gradient scheme, calculating a desired search direction, throughout a minimization process. Results present that the complexity of a material profile in a domain increases the error between reconstructed traction and its target. Second, the OTD and DTO approaches lead to the same inversion result. Third, when the sampling rate of the measurement is equal to the timestep for discretizing estimated traction, the ratio of the size of measurement data to the number of the control parameters can be as small as 1:12 in the presented work. Fourth, it is acceptable to tackle the presented inverse modeling of dynamic traction without the TN regularization. Fifth, the inversion performance is more compromised when the noise of a larger level is added to the measurement data, and using the TN regularization does not improve the inversion performance when noise is added to the measurement. Sixth, our minimizer suffers from solution multiplicity less when it identifies dynamic traction of lower frequency content than that of higher frequency content. The wave responses in a computational domain, induced by targeted traction and its reconstructed one, are in excellent agreement with each other.

\section{Stochastic Simulation of the $\mathbf{3 0}$ October 2020 Samos- Sigacik (Mw 6.9) Earthquake}

YENIHAYAT, N., Bogazici University, Istanbul, Turkey, yenihayat@live.nl; ÇAKTI, E., Bogazici University, Istanbul, Turkey, eser.cakti@boun.edu.tr; ŞEŞETYAN, K., Bogazici University, Istanbul, Turkey, karin@boun.edu.tr

The stochastic finite fault simulation approach with a dynamic corner frequency has been commonly used to generate strong ground motions all over the world. In this paper, stochastic ground motion simulation has been performed and calibrated for the recordings of the 30 October 2020, SamosSigacik (in the Aegean Sea) Mw 6.9 earthquake at 14:51:24 GMT+3. The earthquake was felt in a wide region, caused fatalities, and resulted in the collapse of 17 buildings, and severely damaging to hundreds of structures. Soft basin sediments in Bayraklı, Bornova, and Karşıyaka districts increased losses by amplifying the seismic waves. Horizontal components of the recordings have been obtained as 36 stations from AFAD (https://tadas.afad.gov.tr/), 6 stations from KOERI (http://www.koeri.boun.edu.tr/sismo/2/data-request/), 2 stations from NOAIG (https://accelnet.gein.noa.gr/) and one station from ITSAK (http://www.itsak.gr/en/db/data/strong_motion/after2000/) networks between $23-114 \mathrm{~km}$ epicentral distances. Our main target is validating the source, path, and site parameters and creating a valid synthetic model database for the region. To simulate high-frequency ground motions, we have used the last modified version of the EXSIM12 stochastic finite fault ground motion simulation algorithm. The calibrated model parameters are obtained with the comparison of the generated ground motions to the observed ones in frequency domain. The recorded and simulated PGAs have also been compared with GMPEs by plotting their median and \pm 1 standard deviation for GR and GS type soils. Besides, 5\% damped horizontal acceleration spectra of the records and the synthetics have been compared with the latest and former Turkish Building Earthquake Regulations for a design earthquake of 475 years return period. Lastly, spatial distributions of the ground motion intensity parameters were obtained by using the calibrated model and compared with the results of previously obtained estimations by the ELER earthquake loss estimation routine.

\section{The Effects of Mantle Heterogeneity on Shear Wave} Splitting Phases Based on 3D Seismic Wave Simulations CREASY, N., Colorado School of Mines, Colorado, USA, nmcreasy@mines. edu; BOZDAG, E., Colorado School of Mines, Colorado, USA, bozdag@ mines.edu

Constraining the pattern and properties of seismic anisotropy in the Earth can help reveal relationships between mineral physics, mantle convection, and seismology. Sources of anisotropy in the lithosphere as frozen-in anisotropy, transition zone, and D" complicate shear wave splitting measurements, resulting in shear wave splitting that can differ from plate motion. If we better understand seismic anisotropy sourced in the lithosphere, we could also better constrain D" anisotropy, which requires correcting for the upper mantle to some extent. The goal of this work is to investigate the effect of $3 \mathrm{D}$ mantle and crustal structure on waveforms based on 3D wave simulations and adjoint data sensitivity kernels. We will explore the common phases (SKS, SKKS, S, ScS, PKS, etc.) and the common distance ranges used for mantle shear wave splitting with a resolution down to $9 \mathrm{~s}$ by conducting numerical simulations via 3D global wave propagation solver SPECFEM3D_GLOBE. We show results for a 1D mantle model (i.e., PREM [Dziewonski and Anderson, 1981]) and at least three 3D mantle models (S20RTS [Ritsema et al., 2011], GLAD-M15 [Bozdag et al., 2015], GLAD-M25 [Lei et al., 2020]). We calculate a number of data sensitivity kernels for travel time, amplitude, and anisotropy for our phases of interest over a variety of event depths and distance ranges. This work will help improve the measurements of shear wave splitting. The long-running goal is to use shear wave splitting in global full waveform inversion by addressing appropriate parameterization to describe body-wave anisotropy in the mantle during the inversion process. All simulations were conducted on a Research Allocation on the high-performance computing environment of XSEDE resources (TACC Stampede2). 


\begin{abstract}
Numerical Modeling of Earthquake Motion, Rupture Dynamics, Seismic Noise, Wave Propagation and Inverse Problems

Poster Session · Friday · 23 April · 3:45 PM Pacific

Session Chairs: Peter Moczo, Comenius University Bratislava (moczo@fmph.uniba.sk); Wei Zhang, Southern University of Science and Technology (zhangwei@sustech.edu.cn); Jozef Kristek, Comenius University Bratislava (kristek@fmph. uniba.sk); Martin Galis, Comenius University Bratislava (martin.galis@uniba.sk); Chanseok Jeong, Central Michigan University (jeong1c@cmich.edu); Elnaz Seylabi, University of Nevada, Reno (elnaze@unr.edu)
\end{abstract}

\section{Simulation of Long Duration Shaking in the Oakland Urban Region Using the USGS San Francisco Bay Area Seismic} Velocity Model

HIRAKAWA, E. T., U.S. Geological Survey, California, USA, ehirakawa@usgs. gov; AAGAARD, B., U.S. Geological Survey, Colorado, USA, baagaard@usgs. gov

In this study, we test whether incorporating additional fine-scale information, e.g., Vs30 measurements and higher-resolution geologic maps, into the USGS San Francisco Bay Area 3D Seismic Velocity Model helps improve accuracy of synthetic motions in the Oakland - Alameda - Emeryville urban region in comparison with observations. In this area, long duration, high amplitude coda waves have been observed during moderate $(\mathrm{Mw} \sim 3.5-4.5)$ earthquakes but are not reproduced in simulations using the USGS velocity model (e.g., Aagaard et al., 2010; Hirakawa and Aagaard, 2021, in review). These late motions are especially prominent at stations close to the shoreline of the bay, where low-velocity bay mud and artificial fills are prominent on surface maps but are not explicitly represented in the $3 \mathrm{D}$ velocity model. The large amplitude coda waves likely represent seismic reverberations in the shallow, low-velocity Quaternary surface layer present in the East Bay. We use SW4, a finite-difference seismic wave propagation code, to simulate motions from 10 moderate magnitude earthquakes with hypocenters in the East Bay. Our goal is to make adjustments to the velocity model that lead to more accurate synthetic motions. We find that the current relationship that defines the velocity of the uppermost (Quaternary) rock in the velocity model overestimates measured Vs30 values and that, in general, the amplitudes of late reverberations in the synthetic records can be increased by reducing velocities in this layer.

\section{Simulations of Localization and Coalescence Process Before Large Failure Events}

ZHOU, B., University of Southern California, California, USA, zhou226@ usc.edu; MCBECK, J. A., University of Oslo, Oslo, Norway, j.a.mcbeck@geo. uio.no; RENARD, F., University of Oslo, Oslo, Norway, francois.renard@geo. uio.no; BEN-ZION, Y., University of Southern California, California, USA, benzion@usc.edu

Laboratory rock fracturing experiments indicate that large system-size failures are preceded by the generation of distributed cracks and progressive coalescence of individual fractures to large failure zones (e.g., Lockner et al. 1991; Paterson \& Wong 2005; Renard et al. 2019; Aben et al 2019). A recent analysis of seismicity provided techniques for quantifying localization in the spatial distribution of seismicity as a function of time, and found evidence for progressive localization before large earthquakes (Ben-Zion \& Zaliapin, 2020). To further understand the process of localization of deformation in heterogeneous media, we use three-dimensional discrete element method simulations with the ESyS-Particle code (Abe et al., 2003). The main goals are to investigate how fault strength, roughness, and geometry control the process of localization, and how large events occur on faults without clear surface traces (e.g., the 1992 Landers and 2019 Ridgecrest, CA, earthquakes). A potency magnitude catalog is calculated from all the broken bonds in the simulation using Ben-Zion and Lyakhovsky (2019). Results on the localization process will be presented in the meeting.

\section{Techniques for Producing Spatially Correlated Conditional} Random Realizations of Ground Motion Fields

BAILEY, M., Colorado School of Mines, Colorado, USA, mdbailey@usgs.gov; WORDEN, C. B., Synergetics, Inc. contractor in support of U.S. Geological
Survey, Colorado, USA, cbworden@contractor.usgs.gov; BANDYOPADHYAY, S., Colorado School of Mines, Colorado, USA, sbandyopadhyay@mines.edu; LAHIRI, S., Washington University in St. Louis, Missouri, USA, s.lahiri@ wustl.edu; NYCHKA, D., Colorado School of Mines, Colorado, USA, nychka@mines.edu; THOMPSON, E. M., U.S. Geological Survey, Colorado, USA, emthompson@usgs.gov; WALD, D. J., U.S. Geological Survey, Colorado, USA, wald@usgs.gov

For both scenario and real earthquakes, it is important to estimate the resulting shaking intensity in the near-epicentral region. These estimates can be constrained with ground motion recordings from real earthquakes, as is currently done in near-real-time by the USGS's ShakeMap software. For scenario earthquakes, the ground motions are only estimated by the application of empirical models. The ground motion estimates are expressed as maps of the mean and standard deviation of the estimated intensity, but the consequences of the shaking on society and the built environment depend critically on the spatially correlated aleatory variability of the ground motions. This variability has been accounted for by generating random, spatially correlated realizations of the ground motions. Methods for generating these realizations, however, are computationally demanding, especially when the estimates are conditioned on numerous observed intensity values. In this presentation, a new and approximate conditional simulation approach is applied for use in ShakeMap. This approach, termed circulant embedding (CE), is a fast and exact method for simulating Gaussian processes that takes advantage of the Fast Fourier Transform for computing eigenvalues and eigenvectors. However, traditional $\mathrm{CE}$ is restricted to simulating stationary Gaussian processes (possibly anisotropic) on regularly spaced grids. It is also known that if the range parameter of a spatial process is large relative to the domain, this method fails. In this work we explore two new algorithms that adapt CE for (a) irregularly spaced data points, (b) methods for working with large range parameters in order for $\mathrm{CE}$ to be widely applicable. We also illustrate the computational efficiency of this approach relative to previous methods. These ideas are illustrated with ground motion intensity measures and also validated using Monte Carlo simulation.

\section{Overdue?}

Oral Session · Wednesday · 21 April · 9:45 Am Pacific

Session Chairs: David D. Jackson, University of California, Los Angeles (djackson@g.ucla.edu); Danijel Schorlemmer, GFZ German Research Centre for Geosciences (ds@gfzpotsdam.de)

\section{Evaluation of the Magnitude-Frequency Distribution of the Maximum Rupture Model for the Southern San Andreas and San Jacinto Faults}

SCHARER, K., U.S. Geological Survey, California, USA, kscharer@usgs.gov; YULE, D., California State University, Northridge, California, USA, doug. yule@csun.edu

The Maximum Rupture Model for the southern San Andreas and San Jacinto faults (Scharer and Yule, 2020) presents an end-member rupture history constructed to accommodate ground-rupturing paleoearthquake ages by the fewest and thus longest ruptures. Rupture length for pre-historic ruptures (prior to $1800 \mathrm{CE}$ ) is limited by the location of paleoseismic sites with contemporaneous events and is converted empirically to moment magnitude (Mw). Rupture length and Mw for historic ruptures (since $1800 \mathrm{CE}$ ) are taken from published sources and informed by mapping and shaking intensity. The model produces 50 ruptures in 1600 years but short paleoseismic records at the northern and southern ends of the faults reduce the total modeled length from $730 \mathrm{~km}$ since $1350 \mathrm{CE}$ to $400 \mathrm{~km}$ in $400 \mathrm{CE}$. The average magnitude for the pre-historic and historic ruptures is similar ( Mw 7.2) but a few moderate (Mw 6.4-6.5) historic events broaden the magnitude distribution since $~ 1800$ CE. A traditional magnitude-frequency distribution since $1350 \mathrm{CE}$ shows a non-linear distribution for both the pre-historic and historic records, suggesting a relative dearth of events below $\sim \mathrm{Mw} 7.2$ range. To better examine the entire model, we scale moment release by the available fault extent. This approach reveals short-term (200-year) spikes and lulls in moment release around an otherwise linear trend over the last 1600 years. Overall, the results support the approach of long-term averaging employed by formal earthquake rupture forecasts but suggest that subregional clustering should be considered in earthquake mitigation planning. 
Is California Overdue for Large Earthquakes?

IACKSON, D. D., University of California, Los Angeles, California, USA, djackson@ucla.edu

The question itself suggests a budget of some events that must be balanced over some time period. What could control such a budget? What sort of events should be counted? Over what time interval is the budget due? Suggestions that California or other regions are overdue generally come from comparisons of seismologically observed earthquake catalogs with rates estimated from paleo-seismic, geologic, and/or geodetic data. Estimates rely on many unverified assumptions, including steady rates of fault slip or seismic moment release, equivalence of seismic and tectonic moment release, and in some cases quasi-periodic earthquake recurrence. Here I compare inferences based on observed paleo-seismic events in California with cataloged "large" ( $\mathrm{m} 7+)$ earthquakes. The paleo-seismic data suggest we are now overdue because six events were reported from 1820 to 1920 but none from 1920 to 2020. However, the seismic catalog includes 8 large earthquakes in the first interval and 9 in the second. The paleo-seismic event data remain puzzling, but California does not appear overdue for actual large earthquakes.

\section{Rebuild of the Bulletin of the International Seismological Centre (ISC)}

STORCHAK, D. A., International Seismological Centre, Thatcham, United Kingdom, dmitry@isc.ac.uk; HARRIS, J., International Seismological Centre, Thatcham, United Kingdom, james@isc.ac.uk; LIESER, K., International Seismological Centre, Thatcham, United Kingdom, kathrin@isc.ac.uk; DI GIACOMO, D., International Seismological Centre, Thatcham, United Kingdom, domenico@isc.ac.uk

The International Seismological Centre (ISC) produces the Bulletin which is regarded as the most long-term, comprehensive and homogeneous catalogue of instrumentally recorded seismicity on a global scale, primarily based on seismic bulletins from $\sim 150$ seismic networks worldwide. The Bulletin is used in a wide range of geophysical studies. Users benefit from the most comprehensive set of measurements from the majority of permanent networks and uniformity of included event parameters. The Bulletin also serves as a foundation for specialised derivative datasets such as the ISC-GEM catalogue, ISCEHB dataset, IASPEI GT-List and ISC Event Bibliography.

Despite a strict approach to preserving the operational procedures over the last $\sim 50$ years, changes are inevitable to achieve the best possible accuracy of earthquake parameters. The last fundamental change in procedures has affected the data years 2011 and beyond (Bondár and Storchak, 2011). This is why we had to rebuild the earlier part (1964-2010) to achieve compatibility in earthquake hypocentres and magnitudes through its entire period.

We announce that the entire reviewed part of the ISC Bulletin (19642018) is now based on the same $1 \mathrm{D}$ velocity model, ak135, and the same earthquake and magnitude computation procedures. We give an account of notable changes in the bulletin from the removal of poorly constrained events to the addition of many small events, based on additional reports from permanent and temporary seismic deployments. As a result, the rebuilt ISC Bulletin has $17 \%$ more seismic arrival times from $21 \%$ more stations. The rebuilt $\mathrm{mb}$ is on average larger than the original mb by only 0.05 unit of magnitude. The rebuilt MS is only 0.01 units larger than the original (Storchak et al., 2020). Another important feature was an inclusion of $~ 12,000$ ISC source mechanisms based on reported first motion polarities (Lentas, 2018).

What Controls the Along-Strike Segmentations of Shallow Slow Slip Events? Insights From 3D Numerical Modeling of Slow Slip Events Along the Hikurangi Margin, New Zealand PEREZ, A., Victoria University of Wellington, Wellington, New Zealand, perezan@staff.vuw.ac.nz; KANEKO, Y., Kyoto University, Kyoto, Japan, y.kaneko@gns.cri.nz; SAVAGE, M. K., Victoria University of Wellington, Wellington, New Zealand, martha.savage@vuw.ac.nz; WALLACE, L., GNS Science, Lower Hutt, New Zealand, 1.wallace@gns.cri.nz; LI, D., LudwigMaximilians-Universität, Munich, Germany, dli@geophysik.uni-muenchen. de; WILLIAMS, C., GNS Science, Lower Hutt, New Zealand, c.williams@gns. cri.nz

Over the last two decades, geodetic and seismic observations have revealed a spectrum of slow earthquakes along the Hikurangi margin in New Zealand. Of those, shallow slow slip events (SSEs) that occur at depths of less than 15 $\mathrm{km}$ show a strong along-strike segmentation in the location of slip patches and recurrence intervals, which vary from $\sim 1$ to 5 years from offshore Tolaga Bay in the northeast to Cape Turnagain $\sim 300 \mathrm{~km}$ to the southeast, respectively. To understand the factors that control this segmentation, we conduct numerical simulations of SSEs incorporating laboratory-derived rate-and-state friction laws and either a planar or a non-planar fault geometry. Among a wide range of parameters considered here, we find that a relatively simple model assuming non-planar fault geometry, derived from a recent model of the plate interface, can reproduce the observed segmentation of shallow SSEs. Our preferred model shows a spatial pattern of magnitudes and durations of SSEs that is consistent with observations, and captures the northward decrease of their recurrence interval. We also find that modeled SSEs release at least $60 \%$ of the slip accrued due to plate convergence, which suggests that SSEs are the main mechanism of strain release along the Hikurangi margin. Our results indicate that the segmentation of SSEs' recurrence intervals is favored by along-strike changes in both the plate dip angle and the plate convergence rate, in that modeled SSEs with longer recurrence times concentrate in the southern part of the fault (offshore Cape Turnagain) where the plate has a shallower dip angle and the plate convergence rate is lowest. Notably, the observed segmentation of shallow SSEs could not be reproduced as closely with a planar fault model, which indicates that a realistic plate interface is an important factor to account for in the modeling of SSEs. These results may help explain the segmentation of SSEs observed in other subduction zones as well, such as Nankai and Mexico.

\section{Why Are Large Earthquakes Rarely Overdue for New Zealand Faults?}

NICOL, A., University of Canterbury, Christchurch, New Zealand, andy. nicol@canterbury.ac.nz; VAN DISSEN, R. J., GNS Science, Lower Hutt, New Zealand, r.vandissen@gns.cri.nz

The timing and size of successive prehistoric earthquakes on individual faults provides key information for seismic hazards in the coming years. Future earthquakes can be considered overdue when the elapsed time since the last earthquake exceeds the average recurrence interval for each fault. In New Zealand paleoseismic data for over 50 faults with slip rates $<\sim 30 \mathrm{~mm} / \mathrm{yr}$ indicate that future earthquakes are rarely overdue. A similar conclusion can be reached for New Zealand's historical earthquakes where the duration of the most recent recurrence interval on each fault is typically less than the mean recurrence interval from paleoseismic trenching. Paleoseismic data on New Zealand faults may be incomplete, however, comparable measured and calculated mean recurrence intervals for individual faults are inconsistent with the relatively long mean recurrence intervals being entirely due to earthquakes missing from the record. We propose that the rarity of overdue earthquakes could also be partly attributed to a combination of earthquake 'clustering' on individual faults and sampling bias towards those faults presently in active phases of their earthquake histories. Sampling biases partly arise due to our tendency to collect paleoseismic data from clearly defined active fault traces that have been most active in the recent past (e.g., $<2 \mathrm{kyr}$ ) and, in many cases, are experiencing shorter than average recurrence intervals. Such sampling bias is less important for high slip-rate faults (e.g., $>10 \mathrm{~mm} / \mathrm{yr}$ ) for which welldefined fault scarps will be observed independent of temporal earthquake clustering and large earthquakes are more likely to be overdue. Independent of the number of seismically overdue faults, dating uncertainties are too large to test the hypothesis that the timing of large earthquakes was non-uniform across New Zealand in the Late Holocene, although the historical record appears to show both triggered slip and multi-fault ruptures associated with elevated numbers of large magnitude earthquakes every $70-100$ years. 


Physics-Based Earthquake Rupture Modeling and Strong
Motion Simulations
I: Oral Session · Thursday · 22 April · 2:00 PM Pacific
II: Oral Session · Friday · 23 April · 2:00 PM Pacific
Session Chairs: Arben Pitarka, Lawrence Livermore National
Laboratory (pitarka1@llnl.gov); Alice-Agnes Gabriel,
University of California (gabriel@geophysik.uni-muenchen.
de); Kyle B. Withers, Geologic Hazards Science Center, U.S.
Geological Survey (kwithers@usgs.gov); František Gallovič,
Charles University (gallovic@karel.troja.mff.cuni.cz);
Arthur Rodgers, Lawrence Livermore National laboratory
(rodgers7@llnl.gov)

3D Modeling of the Kathmandu Basin Effects on Ground Motions Using Seissol

BAL, A., University of California, California, USA, akbal@ucsd.edu; GABRIEL, A., University of California, California, USA, gabriel@geophysik. uni-muenchen.de; ULRICH, T., Ludwig-Maximilians-Universität, Munich, Germany, ulrich@geophysik.uni-muenchen.de

The 2015 Mw7.8 Gorkha earthquake unzipped a locked portion of the Main Himalayan Thrust, which caused nearly 9000 fatalities across Nepal. However, damage was less severe in the Kathmandu Valley when compared to empirical hazard estimates. Previous 3D strong motion simulations suggest that the Kathmandu sedimentary basin structures amplify ground shaking at a dominant frequency of $0.2 \mathrm{~Hz}$ (Wei et al 2018). It is believed that this dominant frequency within the basin caused the collapse of tall structures, while ground shaking at high frequencies above $1 \mathrm{~Hz}$ was limited, thereby reducing the severity of damage. A more detailed 3D model, one that includes complex topography and accounts for the complex geometries and structure of the sedimentary basin, is needed to effectively simulate seismic wave propagation and ground motions at higher frequencies beyond $0.3 \mathrm{~Hz}$. Incorporating topography and sedimentary basin effects in physics-based ground motion modeling is a challenge in computational seismology. Capturing wave interactions with realistic geological structure, specifically in the form of surface and interface waves, is increasingly important for hazard assessment. In this study, we use SeisSol, a simulation software that uses unstructured, tetrahedral meshes and high-performance computing to approximate complex 3D model geometries. We generate a detailed model of the Kathmandu Valley and simulate seismic wave propagation and ground motions of the Gorkha earthquake and its large aftershocks in a complex 3D sedimentary basin geometry shielded by strong local topography contrasts. We investigate the correlation between the $3 \mathrm{D}$ sedimentary basin geometry and the dominant resonance of surface waves within the basin. We explore frequency-dependent tradeoffs between topographic shielding and sedimentary amplifications, and the effect of sediment structure by introducing layers in the sedimentary basin in our model. Ideally, this study of 3D site effects and subsurface tradeoffs of 3D structures will lead to improved probabilistic seismic hazard assessments.

\section{D Wave Propagation Simulations of the 2019 M7.1 Ridgecrest, CA, Earthquake}

YEH, T., San Diego State University, University of California, San Diego, California, USA, tyyeh316@gmail.com; OLSEN, K. B., San Diego State University, California, USA, kbolsen@sdsu.edu

We have performed 3D numerical wave propagation simulations for the July 6 2019 M7.1 Ridgecrest, CA earthquake in a $200 \mathrm{~km}$ by $300 \mathrm{~km}$ model domain. The purpose of this study is to use a state-of-the-art 3D simulation tool to reproduce the broadband ground motions recorded close to the source and the greater Los Angeles area to better understand how different components of the model contribute to variability of broadband ground motions. We present the results of preliminary calculations up to $3 \mathrm{~Hz}$ with $500 \mathrm{~m} / \mathrm{s}$ minimum shear wave velocity. The calculations were carried out on ORNL Summit using the newest version of the GPU-enabled AWP which enables calculations with surface topography on curvilinear grids. We used velocity and density information from the SCEC UCVM model CVM-S4.26.M01 with built-in geotechnical layers. We tested 3-segment source rupture models inverted from seismic and geodetic data with enhanced high frequency content, as well as one by the Graves-Pitarka kinematic rupture generator.

We find that, as expected, the effects of surface topography increase with frequency, reducing peak ground velocities (PGV) and prolonging the dura- tion of shaking. In addition to topographic scattering, we find that small-scale heterogeneities of $5-10 \%$ strength are needed to predict the observed duration of shaking. The intrinsic attenuation model of $\mathrm{Q} s=0.1 \mathrm{Vs}, \mathrm{Qp}=2 \mathrm{Q}$ s produced the least biased PGVs throughout our model domain. Finally, we find that a general underprediction of the PGVs by our simulations at rock sites can be alleviated by incorporating more accurate near-surface velocities.

\section{Deterministic 0-5Hz Ground Motion Simulations of the Mw} 6.5, 30 October 2016 Norcia, Italy Earthquake

PITARKA, A., Lawrence Livermore National Laboratory, California, USA, pitarka1@llnl.gov; AKINCI, A., National Institute of Geophysics and Volcanology, Rome, Italy, aybige.akinci@ingv.it; BUTTINELLI, M., National Institute of Geophysics and Volcanology, Rome, Italy, mauro.buttinelli@ingv. it; DE GORI, P., National Institute of Geophysics and Volcanology, Rome, Italy, pasquale.degori@ingv.it

The October 302016 M6.5 Norcia, Italy earthquake caused extensive damage to buildings in the epicentral area. The earthquake was well recorded by a dense network of strong motion stations, including 14 stations located within a $5 \mathrm{~km}$ distance from the two causative faults. In this study we used numerical simulations, to analyze ground motion characteristics recorded during the earthquake. Sets of synthetic ground motions, accounting for seismic wave generation and propagation in a local $3 \mathrm{D}$ velocity model, and validated against recorded data, were used to investigate the sensitivity of near-fault ground motion amplitude to the spatial slip pattern, and surface topography effects on observed and simulated ground motion amplification.

The simulations were performed in the frequency range of $0-5 \mathrm{~Hz}$ using a physics based deterministic approach in modeling the earthquake rupture and elastic wave propagation. We used SW4, a finite difference code which uses a topography conforming curvilinear mesh, designed to model surface topography with high numerical accuracy.

Our results suggest that due to its direct correlation with the local slip pattern and upward rupture directivity effects, the spatial pattern of the horizontal near-fault ground motion generated during the earthquake, was complex, and can be characterized by several local minima and maxima. Because of the limited stations density, the network that recorded the earthquake might have missed the local minima and maxima in the near-fault region. Our simulations show that in several areas located above the fault planes, the computed PGV is higher than both the recorded PGV and that predicted by the empirical models. Also, ground motions computed with and without surface topography indicate that on average the PGV is $30 \%$ higher for models with surface topography, and that there is a clear correlation between the PGV and local topography, with the PGV being higher at mountains and hills peaks. In contrast, spatial variations of simulated PGA does not correlate with the surface topography.

\section{Seismic Site Effects During 2016 Kumamoto Sequence Using Source-to-Site 3D Physics-Based Simulations}

SANGARAJU, S., Politecnico di Milano, Milano, Italy, srihari.sangaraju@ polimi.it; PAOLUCCI, R., Politecnico di Milano, Mlano, Italy, roberto. paolucci@polimi.it; SMERZINI, C., Politecnico di Milano, Mlano, Italy, chiara.smerzini@polimi.it

Local site effects are evident in near-field ground motion records during the 2016 Kumamoto (Japan) seismic sequence. Micro-tremor studies reveal that fundamental peak frequencies for amplification range from $1-4 \mathrm{~Hz}$ and do not fit a specific pattern (Kawase et al., 2017). This can be related to fact that shallow layers consist of thin, soft sediments (shear wave velocity, Vs, of $100-500 \mathrm{~m} / \mathrm{s})$ with varying thickness $(0-60 \mathrm{~m})$. In this study, we carry out $3 \mathrm{D}$ physics-based simulated ground motions for three selected earthquakes of the Kumamoto seismic sequence, namely Mw7.0 mainshock, Mw6.2 foreshock an Mw5.5 aftershock, respectively, and considering a 1D velocity model (minimum Vs of $500 \mathrm{~m} / \mathrm{s}$ ) along with surface topography. The open-source spectral element code SPEED (http://speed.mox.polimi.it/) is used for the numerical simulations. For the MW7.0 mainshock, the seismic source is modelled kinematically as a complex fault system consisting of 6 segments with variable strike and dip angles (Kobayashi et al., 2017). Fling step-like pulses found in displacement waveforms derived from GNSS records are accurately captured in simulations, proving the reliability of source model. Broadband ground motions are then generated (Paolucci et al., 2018) by enriching the low-frequency waveforms simulated by SPEED in the high-frequency part using an artificial neural network, trained on earthquake recordings, and then, validated against near-source strong motion data.

We further attempt to perform detailed site-response analysis at KiKNet stations, where seismo-stratigraphic information is available, using simulated broadband signals as input at stiff soil outcrop and considering non-linearity 
of soil. This coupling of broadband simulations with soil response analysis is useful to study the spatial variability of local site effects and explain the uneven pattern of building damage (Yamada et al.,) near Kumamoto source region.

\section{Toward Exascale Earthquake Ground Motion Simulations} With SW4: Mw 7.0 Hayward Fault Resolved 0-10 Hz

RODGERS, A. J., Lawrence Livermore National Laboratory, California, USA, rodgers7@llnl.gov; PANKAJAKSHAN, R., Lawrence Livermore National Laboratory, California, USA, pankajakshan1@llnl.gov; SJOGREEN, B., Lawrence Livermore National Laboratory, California, USA, sjogreen2@llnl gov; TANG, H., Lawrence Berkeley National Laboratory, California, USA, htang4@lbl.gov; PETERSSON, A., Lawrence Livermore National Laboratory, California, USA, andersp@llnl.gov; PITARKA, A., Lawrence Livermore National Laboratory, California, USA, pitarka1@llnl.gov; MCCALLEN, D., University of Nevada, Nevada, USA, dmccallen@unr.edu

Numerical simulations of ground motions accounting for seismic wave excitation and propagation in fully three-dimensional (3D) Earth models provide a valuable constraint on the damaging effects of large earthquake where the available empirical data is extremely limited. Recent advances in numerical and computational methods to simulate ground motions on modern graphics-processing unit (GPU) platforms enable higher resolution results in shorter run times. We are running SW4 on GPU platforms to resolve ground motions from large ( $\mathrm{Mw}$ 7.0-7.5) earthquakes representing static displacements to frequencies of $10 \mathrm{~Hz}$. This presentation reports several important improvements to the SW4 3D summation-by-parts finite difference code. SW4 now supports refinement of the topography conforming curvilinear mesh to coarsen the grid spacing with depth and greatly improve the memory efficiency. This results in more than a $3 x$ reduction in the total number of grid points needed for typical simulations in our study area - the San Francisco Bay Area. We have improved input/output to run large problems on massively parallel systems. This involves using HDF5 structured data files to represent finely sampled Earth and rupture models and efficiently render material properties and sources on the mesh across many processes. For output, SW4 now writes time-series in HDF5 with optional downsampling. These new features have been exercised in an Mw 7.0 Hayward Fault rupture resolving motions 0-10 $\mathrm{Hz}$ at regional scale. We ran two simulations of the same rupture with different minimum shear wavespeed, vsmin of 500 and $250 \mathrm{~m} / \mathrm{s}$ resolving up to 10 or $5 \mathrm{~Hz}$, respectively, each taking about 7 hours on $1 / 4$ of the Summit platform. Results inform what is missed by assuming a higher vsmin than is known to be present in the shallow sub-surface. This research was support by the DOE Exascale Computing project EQSIM, the Summit computer access from the Oak Ridge Leadership Computing Facility is gratefully acknowledged.

\section{A Nonergodic Ground Motion Model in Southern California With Spatially Varying Coefficients Using a SCEC Cybershake Dataset}

MENG, X., Southern California Earthquake Center, California, USA, xiaofenm@usc.edu; GOULET, C. A., Southern California Earthquake Center, California, USA, cgoulet@usc.edu; MILNER, K., Southern California Earthquake Center, California, USA, kmilner@usc.edu; CALLAGHAN, S. A., Southern California Earthquake Center, California, USA, scottcal@usc.edu

A key input to PSHA is the total standard deviation of the misfits between ground motion observations and the median ground motion models (GMMs, a.k.a GMPEs). The most promising way to reduce hazard is to reduce the standard deviation through the removal of the ergodic assumption, and instead estimate the variability for site-specific ground motions. Although strong motion networks have been rapidly growing in recent decades, in most cases the empirical data are still too sparse to establish a fully nonergodic model. In comparison, numerical simulations can generate large ground motion datasets for controlled earthquake sources and sites, which are optimal to reduce the total standard deviation by identifying and removing repeatable effects in a fully nonergodic model. However, before such PSHA products based on simulations are accepted for engineering applications, it is crucial to validate the simulated ground motions against empirical data and models.

In this study, we evaluate the ability of the physics-based CyberShake platform to capture the repeatable site and path effects from the empirical data, by applying the spatially varying coefficient model (SVCM) as part of the regression analyses. We use ground motion simulation results at $5 \mathrm{~s}$ spectral period from CyberShake 15.4, which was computed for southern California and generated over 97 million ground motion seismograms at 336 sites. We first conduct a checkerboard test and examine SVCM's capability of capturing the input source, site and path terms in various settings. We then compute the total residuals from CyberShake datasets using linear regression with a simple
GMM functional form. Finally, we assign spatially varying source effects, site effects and cell-specific anelastic attenuation by applying the SVCM technique. Preliminary results show systematically large site effects within the Los Angeles and Ventura basins, which are expected from basin effects. The results are contrasted with those from sparser empirical datasets, using a similar regression technique, and discussion of discrepancy is also presented.

\section{Generation of Broadband Ground Motion From Dynamic Rupture Simulations: A Group Modeling Approach Towards Better Characterizing Seismic Hazard for Engineering Applications \\ WITHERS, K. B., U.S. Geological Survey, Colorado, USA, kwithers@usgs.gov} MA, S., San Diego State University, California, USA, sma@sdsu.edu; WANG, Y., Southern California Earthquake Center/ University of Southern California, California, USA, yongfeiw@usc.edu; ULRICH, T., Ludwig-Maximilians Universität, Munich, Germany, ulrich@geophysik.uni-muenchen.de; GABRIEL, A., Ludwig-Maximilians-Universität, Munich, Germany, gabriel@ geophysik.uni-muenchen.de; DALGUER, L., 3Q-Lab, Zürich, Switzerland, luis.dalguer@gmail.com; GOULET, C. A., Southern California Earthquake Center/ University of Southern California, California, USA, cgoulet@usc edu; DUAN, B., Texas A\&M University, Texas, USA, bduan@tamu.edu; LIU, D., Texas A\&M University, Texas, USA, dunyuliu@tamu.edu; AMPUERO, J., Université Côte d'Azur, Nice, France, ampuero@geoazur.unice.fr; ORAL, E., Géoazur, Valbonne, France, elif.oral@geoazur.unice.fr; ASIMAKI, D., Caltech, California, USA, domniki@caltech.edu

We present updated results from a recently formed SCEC-led project that focuses on a collaborative approach to validate ground motions produced from dynamic rupture simulations. We use physics-informed simulations to generate deterministic broadband ground motions; the synthetic median and variability of our simulations are compared with recently developed ground motion models (GMMs). By performing this verification and validation, our goal is to address relevant needs of the seismic hazard modelling community.

For source-to-site geometries with limited ground motion records, simulations provide an approach to constrain ground motion amplitudes and trends. We work toward improving methods for simulating earthquake ground motions for seismic hazard applications via a group modeling effort that incorporates features of the earthquake fault and rupture that have been demonstrated from both observations and numerical simulations to affect resulting ground motions. Each of the half dozen model groups generates suites of simulations using their preferred code and dynamic rupture method, creating a diverse distribution of rupture behavior and sampling epistemic uncertainty. For example, two end-member cases include: 1) a uniform regional stress field projected onto a rough-fault profile, and 2) superimposed stress heterogeneity along a planar fault. We focus on the magnitude (Mw) range of $\sim 5$ to 7 at distances up to $20 \mathrm{~km}$ from the source, comparing median spectral accelerations across a range of periods. We compare our synthetically generated ground motion with four GMMs. Additionally, we analyze synthetic ground motion variability (which can be isolated in terms of both within- and between-event terms) as a function of both distance and period. The aggregated level of ground motion compares well with GMMs' predictions, and the within-event variability is highly dependent on hypocenter location, resulting from azimuthal changes in ground motion amplification.

\section{Impacts of Fault Rupture Characteristics and Shallow Basin Amplification on the Response of Ductile Buildings to Near-Fault Physics-Based Simulated Ground Motions}

KENAWY, M., University of Nevada Reno, Nevada, USA, mkenawy@unr. edu; MCCALLEN, D., University of Nevada Reno, Nevada, USA, dmccallen@ unr.edu; PITARKA, A., Lawrence Livermore National Laboratory, California, USA, pitarka1@llnl.gov

Broadband physics-based earthquake simulations were utilized to study the impacts of fault rupture and site characteristics on the seismic risk to codecompliant modern reinforced concrete buildings with different dynamic properties. High-performance computers at Lawrence Berkeley National Laboratory were employed to conduct nonlinear structural response history simulations over large computational domains covering a $100-\mathrm{km} \times 40-\mathrm{km}$, and containing a highly dense grid of buildings spaced at $1 \mathrm{~km}$. The synthetic earthquake ground motions were generated using kinematic fault rupture models with varying rupture characteristics to represent canonical shallow crustal earthquakes, and resolved up to frequencies of $5 \mathrm{~Hz}$. The spatial variability of the ground motion intensity and structural demands was examined, with particular focus on two aspects: (1) the impact of incorporating regions of high slip (asperities) along the fault (also known as the hybrid rupture approach), and (2) the amplification due to the presence of the shallow sedi- 
mentary basin, and the proximity of the fault and the buildings to the basin edge. The study reveals substantial variability in the ground motion intensity and structural risk within about $15 \mathrm{~km}$ of the fault, particularly when the rupture incorporates concentrated high-slip patches. The effects of the slip asperities and the basin edge on the ground motion components normal and parallel to the rupturing fault appear to differ somewhat significantly in the near-fault region, prompting questions regarding appropriate selection of fault-normal and fault-parallel ground motion components for near-fault engineering risk analysis. Compared to available real recorded motions, the results of the study suggest that the simulated motions using the hybrid rupture approach may offer reasonable structural risk estimates for low-frequency structures and conservative estimates for high-frequency structures.

\section{Linking Strong Ground Motions and Coseismic Landsliding Associated With the 25 April 2015 Mw 7.8 Gorkha Earthquake}

DUNHAM, A., University of Arizona, Arizona, USA, amd95@email.arizona. edu; KISER, E., University of Arizona, Arizona, USA, ekiser@email.arizona. edu; KARGEL, J., University of Arizona, Arizona, USA, jeffreyskargel@ hotmail.com; HARITASHYA, U., University of Dayton, Ohio, USA uharitashya1@udayton.edu; SHUGAR, D., University of Calgary, Calgary, Canada, daniel.shugar@ucalgary.ca; WATSON, S., University of Leeds, Leeds, United Kingdom, c.s.watson@leeds.ac.uk; HUGHES, A., University of Arizona, Arizona, USA, anhughes@email.arizona.edu

The Mw 7.8 Gorkha earthquake occurred on April 25, $2015 \sim 80 \mathrm{~km}$ NW of Kathmandu, Nepal. The rupture was unilateral towards the southeast, unzipping the downdip edge of the locked zone of the Main Himalaya Thrust. Much of the damage and loss of life associated with this event was caused by coseismic landslides and related flooding events. Directly after the Gorkha earthquake, international efforts to characterize landslides and regions with high landslide potential were carried out in the form of field and satellite mapping of landslide source and deposition. 25,000 individual landslides were mapped, many of which failed at ridge tops presumably due to a combination of steep topography and seismic wave amplification. Yet, a lack of seismic instrumentation in the rugged terrain of this region has made it difficult to establish relationships between the characteristics of ground shaking and the distribution of landslides. In this study, we investigate these relationships using seismic wavefield simulations of the Mw 7.8 Gorkha earthquake with a focus on understanding the influence of topography on ground shaking. Using the SPECFEM3D software package, kinematic models of the Gorkha earthquake are simulated within meshes that include a topographically complex and a smoothed Earth surface. The comparison from these two models allows us to isolate the effects of topography on the seismic wavefield, with preliminary results showing that ridgetop amplification of seismic ground shaking plays an important role on the occurrence of landsliding throughout the rupture area. The spatial relationships between simulated ground shaking and the distribution/intensity of landslides from the 2015 Gorkha earthquake will inform hazard evaluation for future events in this region.

\section{Spatial Correlation of Earthquake Ground Motion from 3D Physics-Based Ground Shaking Scenarios}

INFANTINO, M., Politecnico di Milano, Milan, Italy, maria.infantino92@ gmail.com; SMERZINI, C., Politecnico di Milano, Milan, Italy, chiara smerzini@polimi.it; LIN, J., Politecnico di Milano, Milan, Italy, jiayue.lin@ polimi.it

One of the key issues in the seismic risk assessment of spatially distributed portfolios or infrastructural systems in large urban areas is the modeling of the spatial correlation of ground motion intensity measures. Recently, several spatial correlation models have been proposed on empirical basis using wide datasets of earthquake recordings in different areas worldwide and, therefore, they may be poorly representative of specific regions and/or near-source effects. Three-dimensional physics-based numerical simulations (PBS) of seismic ground motion allow to investigate region-specific features of spatial correlation, with a level of detail which could not be possible using sparse recordings, and to explore the dependence on physical factors in near-fault conditions, such as source directivity, path and site effects. This contribution focuses on the analysis of spatial correlation of earthquake ground motion from a wide set of broadband PBSs, generated through the spectral element code SPEED, coupled with an Artificial Neural Network technique for the high-frequency part. Geostatistical tools, based on the computation of both the semi-variogram and the Pearson's correlation map, are employed to assess the correlation between spatially distributed response spectral accelerations (SA) at different vibration periods. The numerical dataset encompasses seven areas worldwide (Po Plain, L'Aquila, Marsica, Sulmona, Norcia, in Italy;
Istanbul, in Turkey; Thessaloniki, in Greece) and moderate-to-severe earthquake scenarios $(\mathrm{M}=6-7+)$ in near-source conditions. The results point out that spatial correlation may be strongly region- and scenario-specific. Besides, factors, such as magnitude, source directivity, path propagation, directionality (fault normal versus fault parallel), may affect significantly the spatial correlation, making critical the use of isotropic and stationary models especially in near-fault conditions

Key words: spatial correlation; 3D physics-based numerical simulations; geostatistical analysis; near-fault conditions

Physics-Based Earthquake Rupture Modeling and Strong
Motion Simulations
Poster Session · Thursday · 22 April · 3:45 PM Pacific
Session Chairs: Arben Pitarka, Lawrence Livermore National
Laboratory (pitarka1@llnl.gov); Alice-Agnes Gabriel,
University of California (gabriel@geophysik.uni-muenchen.
de); Kyle B. Withers, Geologic Hazards Science Center, U.S.
Geological Survey (kwithers@usgs.gov); František Gallovič,
Charles University (gallovic@karel.troja.mff.cuni.cz);
Arthur Rodgers, Lawrence Livermore National laboratory
(rodgers7@llnl.gov)

3D 0-5 Hz Wave Propagation Simulations of the 2014 Mw5.1 La Habra Earthquake With Small-Scale Heterogeneities, Q(f) and Topography

HU, Z., San Diego State University, University of Caliornia, San Diego, California, USA, zhh076@ucsd.edu; OLSEN, K. B., San Diego State University California, USA, kbolsen@sdsu.edu

We perform a suite of $0-5 \mathrm{~Hz}$ deterministic simulations of the $2014 \mathrm{Mw} 5.1$ La Habra, CA, earthquake, with the parallel AWP-ODC-GPU code in a mesh from the Southern California Earthquake Center Community Velocity Model CVM-S4.26-M01. The finite-fault source is obtained from the Graves and Pitarka kinematic rupture generator, with statistics constrained by dynamic rough fault simulations. We include statistical distributions of small-scale crustal heterogeneities (SSHs) with an anisotropic von Karman autocorrelation to represent the effects of realistic velocity and density perturbations. In addition, frequency-dependent attenuation $\mathrm{Q}(\mathrm{f})$ and surface topography using a curvilinear grid are included in our simulations. We also explored the effects of different values of the minimum Vs in our model $(200 \mathrm{~m} / \mathrm{s}$ versus $500 \mathrm{~m} / \mathrm{s}$ ). The synthetics are compared to strong motion data at 259 sites in our model domain.

Our results show that, as expected, the effects of topography, SSHs and $\mathrm{Q}(\mathrm{f})$ become increasingly important as frequencies increase toward $5 \mathrm{~Hz}$. We find that SSHs, topography, and Q(f) all contribute significantly to the synthetic ground motion by increasing values of duration-dependent metrics (i.e., cumulative energy); SSHs and topography generally reduce and $\mathrm{Q}(\mathrm{f})$ with power law exponents less than one decrease the high-frequency ground shaking amplitude. The lower minimum Vs in the mesh can locally increase the PGV by as much as $40 \%$, but generally represents a second-order effect. We find that the CVM includes unrealistically high velocities at rock sites, where superimposing data-constrained Vs30 values produces larger ground shaking and improves the prediction of PGVs. At most stations, the best fit is obtained by including topography, SSHs and Q(f) in the simulations, indicating that these complexities need to be included in ground motion modeling for frequencies as high as $5 \mathrm{~Hz}$.

\section{Constraining Stochastic Slip Rupture Models with Geodetic Coupling Models: An Example Application to PTHA at the Cascadia Subduction Zone \\ SMALL, D. T., University of Oregon, Oregon, USA, dsmall2@uoregon.edu;} MELGAR, D., University of Oregon, Oregon, USA, dmelgarm@uoregon.edu

Although heterogeneities persist in fault zone characteristics and the ensuant rupture processes, these heterogeneities, for instance slip deficit associated with slab locking, are often overlooked in rupture modeling techniques. Slab locking may hold important information for future hazard preparedness since there is a noticeable correlation of high locking with high slip during large ruptures. In this work we model stochastic slip ruptures using the von Karman autocorrelation function (ACF) with application of the Karhunen- 
Loeve (KL) expansion for random slip patch generation. Here, we implement previously determined slip deficit models in the KL expansion to constrain rupture potentials. In order to understand the implication of the locking models in the stochastic modeling technique, we apply these models to probabilistic tsunami hazard assessment (PTHA) for the Cascadia subduction zone. The three classes of rupture models - two with inclusion of end member locking models, and one without - ranging in magnitude between M7.8 and M9.1 are then implemented into the open source tsunami modeling software GeoClaw in order to calculate estimated tsunami arrival heights along the Pacific northwest. Slip partitioning between models appreciably varies in terms of the mean locations of maximum slip. First-order observations at local tsunami hazards from the suite of ruptures detail variations in tsunami arrival heights between rupture classes. Influence in heterogeneity produced by locking models is apparent, however, our ability to further constrain locking models for subduction zones for authoritative hazard assessments depends on future advances in seafloor geodesy.

\section{Dynamic Source Scenarios Constrained by NGA-West2 GMPES}

VALENTOVA, L., Charles University, Prague, Czech Republic, valent@karel. troja.mff.cuni.cz; GALLOVIC, F., Charles University, Prague, Czech Republic, gallovic@karel.troja.mff.cuni.cz

Dynamic source inversions of individual earthquakes provide constraints on stress and frictional parameters inherent to the studied event (Gallovič et al., 2019). To provide more general properties on how dynamic and kinematic parameters are distributed, we stochastically generate dynamic source models and constrain them by common characteristics extracted from a large number of earthquakes - the ground motion prediction equations (GMPEs). Following Gallovič and Valentová (2020), we employ linear slip-weakening friction law characterized by three parameters (initial stress, characteristic slip-weakening distance, and friction drop) on a vertical strike-slip fault of $36 \times 20 \mathrm{~km}$. The rupture propagation is simulated numerically by a finite-difference method implemented in a highly efficient GPU-enabled code FD3D_TSN (Premus et al., 2020), which performs the dynamic calculation in seconds to a minute. The slip rates on the fault resulting from the dynamic simulations are convolved with precalculated Green's functions (GF) to calculate seismograms with a maximum frequency of $5 \mathrm{~Hz}$ for a prescribed set of phantom stations. The models are evaluated by their statistical fit in terms of response spectra (0.5-2 Hz) to adopted NGA-West2 GMPEs of Boore et al. (2014), considering both between-event and within-event variability. The dynamic parameter distributions on the fault are obtained by randomly sampling parameter space employing a Markov chain Monte Carlo approach, namely the parallel tempering method (Sambridge, 2014). The resulting plethora of dynamic scenarios are then treated as a synthetic event database and analyzed to extract dynamic and kinematic parameters, including their variability. The events exhibit various magnitudes in the range of 5.8-6.8 and degrees of complexity (e.g., one or more asperities) and are compatible with scaling relations extracted from the real earthquakes.

\section{Estimate of Earthquake Potential from Dynamic Rupture Simulation Along the Anninghe Fault, Sichuan, China}

YAO, S., Chinese University of Hong Kong, Hong Kong, suliyao@link.cuhk. edu.hk; YANG, H., The Chinese University of Hong Kong, Hong Kong, hyang@cuhk.edu.hk

The Anninghe fault, locating at the boundary between the Sichuan-Yunnan provinces, China, has been suggested as a long-existing seismic gap since the last large earthquake (M 7 1/2) in 1536. Based on the geodetic observations, the Anninghe fault is now accumulating energy thus features high seismic risk. Here, we investigate the earthquake potential on the Anninghe fault by numerical rupture simulations. We derive the stress accumulation pattern on the fault based on the interseismic locking model and conduct spontaneous rupture simulations. Our models indicate that the Anninghe fault is now capable of generating earthquakes with magnitudes up to 7.3. In addition, we find along-strike rupture segmentations near the Mianning city and at the middle way between Mianning and the Xichang city. Such segmentation phenomena are well consistent with the reports of historical earthquakes in this region. Furthermore, significant surface rupture has been found in our models, with surface slip comparable to the values identified in field surveys of the historical earthquakes. In addition, we find that the shallow slip varies significantly among models with different nucleation depths and among different segments, highlighting the complexity in estimating surface damages in future earthquakes.
Impact of CyberShake on Risk Assessments for Distributed Infrastructure Systems

LEE, Y., ImageCat, Inc., California, USA, yjl@imagecatinc.com; GOULET, C. A., Southern California Earthquake Center, University of Southern California, California, USA, cgoulet@usc.edu; HU, Z., ImageCat, Inc., California, USA, zh@imagecatinc.com; EGUCHI, R. T., ImageCat, Inc., California, USA, rte@ imagecatinc.com

In characterizing the system-level seismic risk of a spatially-distributed infrastructure network, empirical ground motion models (GMMs) are typically used to quantify the spatially correlated ground motion hazard. One current weakness of such empirical GMMs is that they are typically developed from global datasets representing "average" source, path attenuation, and site response characteristics of global earthquakes, and are associated with large variability reflecting a variety of crustal structures and conditions. Such differences in median and variability for a specific region can lead to poorly centered and wider than necessary distributions of the risk metrics.

The Southern California Earthquake Center CyberShake platform, designed as the first physics-based seismic hazard model to address the need for regional assessment of ground motions, simulates over 400,000 earthquake ruptures and propagates waves through $3 \mathrm{D}$ velocity models. Provided that the simulations have been properly validated, they should, in theory, include the source, path and site effects of a specific region.

For this work, we build on a recent probabilistic seismic risk analysis (PSRA) study of the entire underground water pipeline network for the City of Los Angeles, where the system-level risk - measured by the expected number of pipeline repairs, repair time, and repair cost - was established as a function of exceedance probability based on a large set of events sampled from the UCERF3 model. The study utilized the NGA-West2 GMMs to compute ground motions with a level of spatial correlation that is consistent with empirical geostatistic models developed from global earthquakes. By repeating our study using the events and simulations from CyberShake, we are exploring the impact of region-specific simulations on seismic risk assessments of distributed infrastructure. This work will serve as a proof-of-concept and is expected to provide guidance to the research and PSRA user communities.

\section{MCMC-MTpy: A Python Package for Simultaneous Inversion of Source Location, Focal Mechanism and Rupture Directivity}

YIN, F., University of Science and Technology of China, Hefei, China, yinfu@ mail.ustc.edu.cn; WANG, B., University of Science and Technology of China, Hefei, China, bwgeo@ustc.edu.cn

The source parameters (Source Location, Focal Mechanism, and Rupture Directivity) are of key importance in seismic source studies and seismic hazard assessments. Generally, different source parameters are estimated separately. Separate inversion of source parameters may induce some inconsistence. In this study, we proposed a new Bayesian inversion method MCMCMTpy. MCMC-MTpy takes phase (both P and S) travel times, first arrival $\mathrm{P}$-wave polarity and the waveform as input to invert the source location, focal Mechanism, and rupture directivity iteratively.

Different weighting factors were used in different stage of the inversion. First the highest weight was assigned to the travel time objective function, which effectively constrains the source location. Then higher weight was put on the waveform and the polarity to estimate the focal mechanism. The direction of epicentral and the centroid of the focal mechanism is used to describe the rupture directivity.

Synthetic tests suggest the newly package can effectively retrieve the source parameters. The effect of weight strategy was also investigated through synthetic tests. Both the package and Application Program Interface for Green's Function calculation were written in Python and will be accessible soon on the author's Github site.

\section{Source and Path Effects Analysis From a Series of Sw4 Simulations of Mw 7.0 Earthquake Ground-Motions in Three-Dimensional Earth Models}

AGUIAR MOYA, A. C., Lawrence Livermore National Laboratory, California, USA, aguiarmoya1@llnl.gov; PITARKA, A., Lawrence Livermore National Laboratory, California, USA, pitarka1@llnl.gov; RODGERS, A. J., Lawrence Livermore National Laboratory, California, USA, rodgers7@llnl.gov

The use of earthquake ground motions play a key role in engineering applications, such as identifying rupture conditions that generate large displacement steps and velocity pulses that impact tall buildings and essential fault-crossing structures. To this end, we investigate source and path effects from simulated MW 7.0 earthquake ground motions. In this study, the response has been 
computed for a wide range of source models generated following the method of Graves and Pitarka (GP; 2015, 2016) within generic basin models (with and without stochastic heterogeneity).

Simulations relied on the SW4 anelastic 3D seismic wave propagation code running on a graphics processing unit (GPU) accelerated platform to resolve frequencies $0-5 \mathrm{~Hz}$ on a regional scale $(\sim 100 \mathrm{~km})$. Source models varied the slip distribution, depth to the top of rupture (ZTOR), rupture speed (Vrup), rupture initiation and placement of large slip patches within a stochastic slip distribution.

We compare simulated ground motion intensities to ground motion models (GMMs) of the Pacific Earthquake Engineering Research (PEER) Center Next Generation Attenuation West2 (NGA-West2) project. We find good agreement of median motions and identified rupture characteristics and wave paths that caused deviations from the median response. Comparisons of simulated motions with GMMs for frequencies $0.1-5 \mathrm{~Hz}$ (periods 0.2-10 seconds) provide valuable constraints on rupture model parameters that can inform modifications of future improvements to the GP rupture generator.

This work was performed under the auspices of the U.S. Department of Energy by Lawrence Livermore National Laboratory under Contract DE-AC52-07NA27344. LLNL-ABS-801149.

\section{The Enhancement of Coseismic Slip and Ground Motion Due to the Accretionary Wedge and Sedimentary Layer in the 2011 Tohoku-Oki Earthquake}

LI, X., Institute of Geology and Geophysics, Chinese Academy of Sciences, Beijing, China, lixian@mail.iggcas.ac.cn; HUANG, Y., University of Michigan, Michigan, USA, yiheh@umich.edu

Low-velocity accretionary wedges and sedimentary layers overlying continental plates are widely observed in the subduction zones where historical large earthquakes $\left(M_{w}>8.5\right)$ have occurred. It was observed that the rupture of the $2011 \mathrm{M}_{\mathrm{w}} 9.0$ Tohoku-Oki earthquake propagated to the trench with large coseismic slip on the shallow fault, but what caused the huge shallow slip still remains a prominent problem. Here we aim at exploring how the low-velocity structures, accretionary wedge and sedimentary layer, affect the coseismic slip and near-fault ground motions during the 2011 Tohoku-Oki earthquake. Constrained by the observed seafloor deformation, we present a 2-D dynamic rupture model of the 2011 Tohoku-Oki earthquake with an accretionary wedge and a sedimentary layer. Compared to a homogeneous model with the same friction and stress parameters on the fault, we find that the co-existence of the accretionary wedge and sedimentary layer greatly enhances the shallow coseismic slip and amplifies ground accelerations near the accretionary wedge.

We then investigate a plausible scenario of a smaller Tohoku-Oki earthquake when its rupture does not reach the accretionary wedge. The sedimentary layer slightly enhances the coseismic slip while the accretionary wedge has almost no influence for the smaller earthquake scenario, but both structures significantly amplify the ground accelerations on the overriding plate. We suggest that the co-existence of an accretionary wedge and sedimentary layers tend to enhance coseismic slip, but the enhancement effect decreases as the up-dip limit of rupture zones terminates at a larger depth.

\section{Validation and Calibration of Simulation Parameters for the Marmara Region Through Stochastic Simulation of the 26 September 2019 Mw 5.8 Silivri Earthquake}

YENIHAYAT, N., Boğaziçi University, Istanbul, Turkey, yenihayat@live.nl; CAKTI, E., Boğaziçi University, Istanbul, Turkey, eser.cakti@boun.edu.tr; ŞEŞETYAN, K., Boğaziçi University, Istanbul, Turkey, karin@boun.edu.tr

In this presentation, stochastic simulations are performed on the recordings of the 26 September 2019 Silivri, Istanbul earthquake, that ld to damages in the city. Our aim is to create a valid synthetic model database with consistent source, path, and site parameters in the region. We have utilized recordings at 58 stations in Istanbul with epicentral distances ranging from 23 to $101 \mathrm{~km}$ and located on sites having different soil conditions. We utlized a stochastic finite fault simulation approach with a dynamic corner frequency.Four different frequency-dependent Q models were tested to obtain the best fit with the observations. With the comparison of the generated ground motions to the observed ones, optimum source, path and site parameters have been estimated. The calibrated model parameters have been obtained from the set of best-fitted data with observed ground motion in frequency domain. Synthetic PGAs have been compared with two well defined ground motion prediction equations (GMPEs). Furthermore, spatial distributions of the ground motion intensity parameters were obtained and compared with the available damage information. In conclusion, the results of the simulation were in good agreement with the recorded ones. The results indicate that the stochastic mode proposed herein can be used to simulate ground motion distributions in Istanbul for past and future events.

\section{Validation of Broadband CyberShake Simulations}

CALLAGHAN, S. A., University of Southern California, California, USA, scottcal@usc.edu; GOULET, C. A., University of Southern California, California, USA, cgoulet@usc.edu; SILVA, F., University of Southern California, California, USA, fsilva@usc.edu; MENG, X., University of Southern California, California, USA, xiaofenm@usc.edu; MAECHLING P. J., University of Southern California, California, USA, maechlin@usc.edu; GRAVES, R. W., U.S. Geological Survey, California, USA, rwgraves@usgs.gov OLSEN, K. B., San Diego State University, California, USA, kbolsen@sdsu. edu; KOTTKE, A., Pacific Gas and Electric Company, California, USA, arkk@ pge.com; BEN-ZION, Y., University of Southern California, California, USA, benzion@usc.edu

The Southern California Earthquake Center (SCEC) has developed the CyberShake platform to implement a physics-based probabilistic seismic hazard analysis (PSHA) approach using 3D wave propagation simulations to calculate seismograms and ground motions from sources defined in regional earthquake rupture forecasts. CyberShake has been used to calculate PSHA models for Southern California, Central California, and the San Francisco Bay Area, and is able to quantify effects such as $3 \mathrm{D}$ basin amplification and rupture directivity that are difficult to capture in typical empirical ground motion models.

Recently, CyberShake was integrated with the SCEC Broadband Platform (BBP), enabling deterministic low-frequency $(1 \mathrm{~Hz})$ physics-based results from CyberShake to be combined with stochastic high-frequency $(1-50 \mathrm{~Hz})$ seismograms generated with the Graves \& Pitarka BBP modules, producing broadband seismograms. This enables CyberShake to deliver results at highfrequency regimes not yet accessible to deterministic-only simulations, which are particularly useful to the earthquake engineering community.

To evaluate CyberShake broadband results, we have selected historica earthquakes from the BBP validation suite and performed a series of validation exercises, computing CyberShake broadband results for dozens of recording stations. We describe how CyberShake elements, including velocity model, rupture forecasts, and site response were configured to support BBP validation events. We present comparisons of CyberShake models against recorded data, and propose modifications to CyberShake and the BBP to improve their modeling of ground motions.

Probabilistic Seismic Hazard Assessment: Where Do We
Go from Here?
I: Oral Session · Tuesday · 20 April · 9:45 AM Pacific
II: Oral Session · Tuesday · 20 April · 2:30 PM Pacific
Session Chairs: Susan E. Hough, U.S. Geological Survey
(hough@usgs.gov); Seth Stein, Northwestern University
(s-stein@northwestern.edu)

\section{Development of a Non-Ergodic GMPE for France}

SUNG, C., University of California, Berkeley, California, USA, karensung@ berkeley.edu; ABRAHAMSON, N., University of California, Berkeley, California, USA, abrahamson@berkeley.edu; KUEHN, N., University of California, Los Angeles, California, USA, kuehn@ucla.edu; TRAVERSA, P., EDF-DIPNN-DI-TEGG, Aix-en-Provence, France, paola.traversa@edf.fr; ZENTNER, I., Électricité de France, EDF R\&D, Lab Saclay, Palaiseau, France, irmela.zentner@edf.fr

In this study, we use an ergodic ground motion model (GMM) of California of Bayless and Abrahamson (2019) as a backbone and incorporate the varying-coefficient model (VCM) to develop a new non-ergodic GMM for France based on the French RESIF data set (1996-2016). Most of the magnitudes of this database are small $(\mathrm{Mw}=2.0-5.2)$, so we adopt the Fourier amplitude spectral GMM rather than the spectral acceleration model, which allows the use of small magnitude data to constrain path and site effects without the complication of the scaling being affected by differences in the response spectral shape. For the VCM, the coefficients of GMPE can vary by geographica location and they are estimated using Gaussian process regression: there is a separate set of coefficients for each source and site coordinate, including both the mean coefficients and the epistemic uncertainty in the coefficients. Moreover, the epistemic uncertainty associated with the predicted ground motions also varies spatially: it is small in locations where there are many 
events or stations and it is large in sparse data regions. Finally, we modify the anelastic attenuation term of a GMM by the cell-specific approach of Kuehn et al. (2019) to allow for azimuth-dependent attenuation for each source which reduces the standard deviation of residuals at long distances. The results show that combining the above two methods (VCM \& cell-specific) to lead an aleatory standard deviation of residuals for the GMM that is reduced by $\sim 47 \%$. The combination of the non-ergodic median ground motion and the reduced aleatory variability can have large implications for seismic-hazard estimation for long return periods. For some sites, the estimated hazard will increase and for other sites the estimated hazard will decrease compared to the traditional ergodic GMM approach. Due to the skewed distribution of hazard, about $70 \%$ of the sites will see a decrease in the hazard at the 1E-4 hazard level and about $30 \%$ of the sites will see an increase.

\section{Do PSHA Maps Overpredict or Are There Shaking Deficits in the Historic Record?}

SALDITCH, L., Northwestern University, Illinois, USA, leah@earth. northwestern.edu; STEIN, S., Northwestern University, Illinois, USA, s-stein@ northwestern.edu; GALLAHUE, M., Northwestern University, Illinois, USA, mollygallahue2023@u.northwestern.edu

Probabilistic Seismic Hazard Assessment (PSHA) attempts to forecast the fraction of sites on a hazard map where ground shaking will exceed the mapped value within some time period. Because the maps are probabilistic forecasts, they explicitly assume that shaking will exceed the mapped value some of the time. At a point on a PSHA map, the probability $p$ that during $t$ years of observations shaking will exceed the value on a map with a $T$-year return period is assumed to be described by the exponential cumulative density function: $p=1-\exp (-t / T)$. The fraction of sites, $f$, where observed shaking exceeds the mapped value should behave the same way. To assess the 2018 USGS National Seismic Hazard Model maps for California, we created the California Historical Intensity Mapping Project (CHIMP), a 162-yr long dataset that combines and consistently reinterprets seismic intensity information (Salditch et al., 2020). We use two performance metrics; M0 based on the fraction of sites where modeled ground motion is exceeded, and M1 based on of the difference between the mapped and observed ground motion at all sites. M0 is implicit in PSHA because it measures the difference between the predicted and observed fraction of site exceedances and is therefore a key indicator of map performance. We explore these metrics for CHIMP. Assuming the dataset to be correct, it appears that the hazard maps overpredicted shaking even correcting for the time period involved. Assuming the model is also correct, a shaking deficit exists between the model and observations. Possible reasons for this apparent overprediction/shaking deficit include: 1) the observations in CHIMP are biased low; 2 ) the observation period has been less seismically active than typical; 3) the model overpredicts due to either the earthquake rupture forecast or the ground motion models. Similar overpredictions appear for past shaking data in Italy, Japan, and Nepal, implying that seismic hazards are often overestimated. Whether this reflects too-high models and/ or biased data remains an important question.

\section{Probabilistic Seismic Hazard Assessment of the Eastern Betics Shear Zone (SE Spain) Using a Geological Fault- Based Source Modelling Approach}

GÓMEZ-NOVELL, O., University of Barcelona, Barcelona, Spain, octgomez@ ub.edu; GRACÍA-MAYORDOMO, J., Instituto Geológico y Minero de España, Madrid, Spain, julian.garcia@igme.es; ORTUÑO, M., University of Barcelona, Barcelona, Spain, maria.ortuno@ub.edu; MASANA, E., University of Barcelona, Barcelona, Spain, eulalia.masana@ub.edu; CHARTIER, T., Global Earthquake Model, Pavia, Italy, thomas.chartier@globalquakemodel. org

In this study we present a probabilistic seismic hazard assessment (PSHA) for SE Spain including the Eastern Betics Shear Zone (EBSZ) faults as the main seismogenic sources. Contrasting with previous studies in Spain, here the earthquake occurrence is modelled considering different hypotheses of fault and multi-fault ruptures at the whole fault system scale and weighted in a logic tree. The modelling of the magnitude frequency distributions (MFDs) of each hypothesis is achieved by using the novel SHERIFS methodology with mainly geological fault data as inputs. The logic tree weighting is based on the MFD agreement with the rates of the regional seismic catalogue and the available paleoseismic data. The resulting hazard analysis shows a clear control of the EBSZ fault sources in the seismic hazard even for short return periods (e.g., 475 -year), increasing drastically the hazard levels in the regions close to the fault traces $(\sim 20 \mathrm{~km})$ with respect to area source-based PSHAs. These hazard values however, strongly depend on the fault slip rates, as both higher acceleration values and territorial extension of the fault influence appear around the highest slip rate faults of the system (Alhama de Murcia and Carboneras faults). Conversely, lower slip rate faults have a much more limited impact in the seismic hazard and in some cases even negligible (Palomares fault). For the 475-year return period and at near-fault sites, the models are more consistent with the ground motion recorded in the $2011 \mathrm{Mw} 5.2$ Lorca earthquake rather than the national hazard maps, suggesting a better performance of our approach. Among the limitations, slip rates related to the lack of paleoseismic studies in selected faults, have important repercussions on the seismic hazard that can bias the results and, therefore, compromise the reliability of the hazard estimations. These are key problematics to discuss that have an impact on the present study and set insights for further research in the study area or even in other similar regions worldwide.

\section{Seismic Response of Rock Towers at the Trona Pinnacles, California GARCIA-SUAREZ, J., Caltech, California, USA, ajgarcia@caltech.edu}

Precariously balanced rocks (PBRs) have been used to constrain the intensity of past earthquake shaking. We analyzed the seismic response of another category of fragile geologic features, rock towers (RTs), using finite-element simulations. RTs differ from PBRs in that RTs are materially connected to bedrock at their bases. We conducted the simulations using $\mathrm{cm}$-resolution photogrammetric shape models and compared the results to paired seismic recordings from RTs and far-field bedrock as well as other field observations at the Trona Pinnacles, a group of RTs in southern California. We also took a semi-analytical approach to define archetypical RT shapes and thereby extend the applicability of computationally intensive simulations to RTs elsewhere. The results of our simulations reproduce the seismic recordings in several important ways when using identical aftershock excitations. In particular, the simulations capture the first vibrational mode and the magnitude of amplification. However, simulations predict an important second vibrational mode that was not observed. We interpret the differences to result from variations in material properties such as density and stiffness. Both the numerical simulations and semi-analytic methods indicate that peak stresses occur near the base of the RT during shaking. We posit that an earthquake-driven, damageaccumulation process takes place on a geologic time scale, in which successive earthquakes progressively damage the base of the RT. Using a rebound hammer, we documented the effect of this stress localization in the field, showing that rebound numbers are systematically higher near the middle of RTs than near the base. Rebound number correlates well with rock strength, and we interpret lower values at the base to reflect the growth of fractures. Ongoing work aims to constrain the probability of toppling of a RT, given shaking intensity, geometric parameters, and bulk tensile strength.

\section{Site-Specific Velocity Corrections Do Not Improve Seismic Hazard Map Performance for California When Compared With Historical Shaking Data}

GALLAHUE, M., Northwestern University, Illinois, USA, mollygallahue2023@u.northwestern.edu; SALDITCH, L., Northwestern University, Illinois, USA, leah@earth.northwestern.edu; LUCAS, M. C., Northwestern University, Illinois, USA, mlucas12@uw.edu; NEELY, J. S. Northwestern University, Illinois, USA, james@earth.northwestern.edu; HOUGH, S. E., U.S. Geological Survey, California, USA, hough@usgs.gov; STEIN, S., Northwestern University, Illinois, USA, s-stein@northwestern. edu; ABRAHAMSON, N., University of California, Berkeley, California, USA, abrahamson@berkeley.edu; WILLIAMS, T., University of California, Berkeley, California, USA, tewillia2016@berkeley.edu

Probabilistic seismic hazard assessments forecast levels of earthquake shaking that should be exceeded with only a certain probability over a given period of time are important for earthquake hazard mitigation. These rely on assumptions about when and where earthquakes will occur, their size, and the resulting shaking as a function of distance as described by ground-motion models (GMMs).

To explore the robustness of maps' shaking forecasts, we consider how maps hindcast past shaking. We compiled the California Historical Intensity Mapping Project (CHIMP) dataset of the maximum observed shaking from the largest Californian earthquakes over the past 162 years. Prior comparisons between the maps for a constant $V_{S_{30}}$ (shear-wave velocity in the top $30 \mathrm{~m}$ of soil) of $760 \mathrm{~m} / \mathrm{s}$ and CHIMP based on metrics suggested that current maps overpredict shaking.

The differences between the $\mathrm{V}_{\mathrm{S} 30}$ at the CHIMP sites and the reference value of $760 \mathrm{~m} / \mathrm{s}$ could amplify or deamplify the ground motions relative to the mapped values. We evaluate whether the $\mathrm{V}_{\mathrm{S} 30}$ at the CHIMP sites could cause a possible bias in the models. By comparison with the intensity data in CHIMP, we find that using site-specific $\mathrm{V}_{\mathrm{S} 30}$ does not improve map per- 
formance, because the site corrections cause only minor differences from the original 2018 USGS hazard maps at the short periods relevant to PGA and hence MMI. The minimal differences reflect that the nonlinear deamplification due to increased soil damping largely offsets the linear amplification due to low $\mathrm{V}_{\mathrm{S} 30}$.

Possible reasons for this discrepancy include limitations of the dataset, bias in the hazard models, overestimation of the aleatory variability of the ground motion, or that seismicity throughout the historical period has been lower than the long-term average. Resolving this discrepancy could improve the performance of seismic hazard maps and earthquake safety for California and worldwide. We also explore whether new nonergodic GMMs, with reduced aleatory variability, perform better than presently used ergodic GMMs compared to historical data.

\section{Exploring Probabilistic Seismic Hazard Assessment in the Energy Domain}

ZIEBARTH, M. I., GFZ German Research Centre for Geoscience, Potsdam, Germany, ziebarth@gfz-potsdam.de; ANDERSON, J. G., University of Nevada, Nevada, USA, jga@seismo.unr.edu; COTTON, F., GFZ German Research Centre for Geoscience, Potsdam, Germany, fcotton@gfz-potsdam. de; VON SPECHT, S., National Central University, Taoyuan City, Taiwan, specht@gfz-potsdam.de; HEIDBACH, O., GFZ German Research Centre for Geoscience, Potsdam, Germany, heidbach@gfz-potsdam.de

Contemporary probabilistic seismic hazard assessment (PSHA) is formulated in terms of the moment magnitude. Based on static deformation, the seismic moment is a practical measure of earthquake size. However, it is not a direct measure of the dynamics of an earthquake. An alternative measure of earthquake size based on the dynamics is the radiated energy. While strong correlations between seismic moment and radiated energy exist, showing in empirical conversion relations between the two, recent research indicates that the radiated energy performs better in assessing ground shaking in the relevant frequency band 1 to $10 \mathrm{~Hz}$. This motivates a closer look PSHA in the energy domain.

In this contribution, we consider the seismicity model part of the hazard integral. We present recent results in modeling an area's stationary seismicity based on the conservation of externally-driven deformation energy. The energy-conserving seismicity framework is the counterpart of the balance of seismic moment in the energy domain. We discuss differences between the two approaches, which are centered on the interplay of stress with respect to strain rates. This leads to challenges but also presents opportunities of seismicity modeling in energy space. Throughout, Southern California serves as an illustrative example and is augmented by simple analytical examples.

Overall, our goal is to spark thought whether working in the energy domain can be a useful new angle to tackle some of the current challenges of PSHA.

\section{Impact of Declustering on Probabilistic Seismic Hazard Estimates in the United States}

MAHER, E. L., University of Nevada, Reno, Nevada, USA, emaher@nevada. unr.edu; ZALIAPIN, I., University of Nevada, Reno, Nevada, USA, zal@unr. edu; ANDERSON, J. G., University of Nevada, Reno, Nevada, USA, jga@ seismo.unr.edu

Hazard estimates from background seismicity differ by more than a factor of two, depending on the way that the catalog is declustered. In this study, we begin with the complete seismicity catalogs used by the U. S. Geological Survey (USGS) to develop the background seismicity model for the 2014 National Seismic Hazard Model. The first catalog that we use is declustered by the USGS based on the approach and parameters suggested by Gardner and Knopoff (1974). We also consider declustered catalogs using the nearestneighbor (NN) approach of Zaliapin and Ben Zion (2020). The NN approach randomly thins the catalog to obtain a stationary background earthquake rate, while preserving its spatial variability. The size of a declustered catalog is controlled by the estimated probability that a given event is independent, and parameterized with a threshold $\mathrm{a}_{0}$. Smaller $\mathrm{a}_{0}\left(\right.$ e.g. $\mathrm{a}_{0}=-1$ ) identifies as background only events that are highly likely to be independent, while larger $\mathrm{a}_{0}$ (e.g. $\mathrm{a}_{0}=1$ ) includes more events that have a higher probability of being part of a cluster. The number of background events and the hazard estimates thus increase with $\mathrm{a}_{0}$. Our results suggest that the hazard is practically independent of the variation between different realizations of the declustered catalog for the same $\mathrm{a}_{0}$. At a sample location in Nevada, where the background dominates the hazard, the hazard curve from declustering with $\mathrm{a}_{0}=1$ is similar to the hazard (PGA at $2 \%$ in 50 years) obtained by the USGS, and decrease to about half of that value when the threshold $\mathrm{a}_{0}$ decreases to -1 .

Gardner, J. K. \& Knopoff, L. (1974). Is the sequence of earthquakes in southern California, with aftershocks removed, Poissonian? Bulletin of the Seismological Society of America, 64, 1363-1367.

Zaliapin, I., \& Ben-Zion, Y. (2020). Earthquake declustering using the nearest-neighbor approach in spacetime-magnitude domain. Journal of Geophysical Research: Solid Earth, 125, e2018JB017120.

\section{Maximum Shaking Earthquake Catalog: A Ground-Motion Based Procedure to Select Earthquakes That Are Relevant to the Seismic Hazard}

ANDERSON, I. G., University of Nevada Reno, Nevada, USA, jga@seismo. unr.edu; COTTON, F., GFZ German Research Centre for Geoscience, Potsdam, Germany, fcotton@gfz-potsdam.de; BINDI, D., GFZ German Research Centre for Geoscience, Potsdam, Germany, bindi@gfz-potsdam.de

A method is proposed to identify within seismic catalogs those earthquakes that are most relevant to the seismic hazard. The approach contrasts with the classical approach to decluster the seismic catalog with the expectation that the remaining main shocks will be the relevant events for the seismic hazard analysis. We apply a time window as in the declustering approach of Gardner and Knopoff, but the time window is motivated by relevance to engineering. A ground motion criterion replaces the spatial window. An event in the time window is included in the "Maximum Shaking Earthquake Catalog (MSEQ catalog)" if the median ground motion at its epicenter exceeds the predicted median ground motion there from the main shock, using a locally appropriate ground motion prediction equation (GMPE). Ground motion can be measured by any parameter that is estimated by a GMPE. We consider peak acceleration and SA at periods of $0.2 \mathrm{~s}, 1.0 \mathrm{~s}$, and $3.0 \mathrm{~s}$. The longer period parameters systematically remove more small events. The purpose is not to produce a declustered catalog, in which each group of physically related earthquakes is represented by its largest event. Nonetheless, statistical properties of the MSEQ catalog somewhat resemble the corresponding declustered catalog in three tested regions. The MSEQ catalogs all retain more large-magnitude earthquakes. Thus the MSEQ catalog might be considered as an alternative to a declustered catalog, or be used to develop a list of earthquakes that are constrained to be included in a declustered catalog that is used for probabilistic seismic hazard analysis.

\section{Regional Path Effects for Ground Motion Analysis in Sacramento-San Joaquin River Delta, California} BUCKREIS, T. E., University of California, Los Angeles, California, USA, tristanbuckreis@ucla.edu; BRANDENBERG, S. J., University of California, Los Angeles, California, USA, sjbrandenberg@g.ucla.edu; STEWART, J. P., University of California, Los Angeles, California, USA, jstewart@seas.ucla. edu

As part of a long-term project to develop semi-empirical site amplification models for application to the peaty organic soil sites in the Sacramento-San Joaquin Delta region of California, we have investigated regional variations in source-to-site path effects. In these assessments, the "sites" are located in the Delta region and the source regions are geographically diverse, including (1) the north coast region north and west of the San Francisco Bay area; (2) the Bay Area region, extending from the Pacific coast to the western edge of the Delta; (3) the central coast region south and east of Hollister; and (4) the eastern Sierra region (approximately from Tahoe to Mammoth). We investigate differences in path effects, particularly with regard to anelastic attenuation, for earthquakes in these regions. These path assessments are important for non-ergodic site response evaluations at Delta sites, so that systematic errors in source-to-site path effects are not mapped into empirical estimates of elastic site response.

We use a data set consisting of 77 northern California and Nevada events that has produced 11,027 recordings. Mixed-effects residuals analyses are performed using the Boore et al. (2014; hereafter BSSA) ground motion model. We find no evidence of path bias for Bay Area and central coast events, whereas north coast and eastern Sierra events have attenuation rates faster and slower, respectively (i.e., lower and higher Q), than the standard BSSA model for California at high frequencies (> approximately $0.6 \mathrm{~Hz}$ ). We propose an iterative approach to investigate these path effects in which systematic site response effects are removed. The result of this work is period-dependent path adjustment models applicable to the north coast and eastern Sierra regions. 
The Internet Application of the Current Version of the Mexico City Building Code to Compute Earthquake Design Spectra and Strong Ground Motion Records for Non-Linear Time History Analysis

ORDAZ, M. G., Universidad Nacional Autónoma de México, Mexico City, Mexico, mors@pumas.iingen.unam.mx; ARROYO, D., Universidad Autonoma Metropolitana, Mexico City, Mexico, aresda@correo.azc.uam. mx; VELAZQUEZ, J., Universidad Nacional Autónoma de México, Mexico City, Mexico, jvelazquezg@iingen.unam.mx; VELAZQUEZ, M., Universidad Nacional Autónoma de México, Mexico City, Mexico, mvelazqueza@iingen. unam.mx

Several earthquakes have damaged Mexico City in the past, particularly interface thrust events located at distances larger than $200 \mathrm{~km}$ and intraslab normal faulting earthquakes at distances between 100 and $200 \mathrm{~km}$. The seismic response of Mexico City soil deposits is well known to produce dramatic site amplifications, whose frequency characteristics are crucial to explain the observed structural damages. The new version of the Mexico City Building code, issued in 2018, contains changes related to recent research findings.

In particular: a) The ability of estimating variations of soil response characteristics within tens of meters in some cases; b) The observation that soil properties in the lakebed zone change with time because of groundwater withdrawal; c) Recognition of the fact that certain structures should be analyzed via non-linear time history analysis in order to correctly asses their seismic performance.

When trying to incorporate in the Building Code the findings listed above, we realized that some of the new specifications became unmanageable in traditional Building Code format. Hence, an internet application was constructed to compute site-specific earthquake design spectra and site-specific strong ground motion records for non-linear time history analysis for any given site in Mexico City.

We named the application SASID (Spanish acronym of Sistema de Acciones Sísmicas de Diseño) and now it is part of the current seismic requirements of the Mexico City Building Code. To our best knowledge SASID is the first internet application that has been developed as a part of a Building Code. This presentation describes the operation and technical basis of SASID.

Probabilistic Seismic Hazard Assessment: Where Do We Go from Here?

Poster Session · Tuesday · 20 April · 11:30 Am Pacific

Session Chairs: Susan E. Hough, U.S. Geological Survey

(hough@usgs.gov); Seth Stein, Northwestern University

(s-stein@northwestern.edu)

\section{Earthquake Event Selection for Regional Seismic Hazard} Analysis of Levee Systems

WANG, P., University of California, Los Angeles, California, USA, wltcwpf@ ucla.edu; LIU, Z., University of California, Los Angeles, California, USA zhliu062394@g.ucla.edu; BRANDENBERG, S. J., University of California, Los Angeles, California, USA, sjbrandenberg@g.ucla.edu; ZIMMARO, P., University of California, Los Angeles, California, USA, paolo.zimmaro@ unical.it; STEWART, J. P., University of California, Los Angeles, California, USA, jstewart@seas.ucla.edu

Probabilistic seismic hazard analysis is generally performed at a single site, where ground motion hazard from all of the faults that might shake the site is integrated to express the annual probability of exceedance as a function of ground motion intensity. This site-based calculation is then often repeated at many different sites to develop uniform hazard maps, expressing the ground motion intensity measure values associated with a specific annual probability of exceedance. While such maps are useful for selecting a ground motion intensity measure for structures or other infrastructure systems with geographic footprints that may be approximated as a point, they are not appropriate for application to spatially distributed infrastructure systems such as levees. The problem is that many different earthquake events contribute to the hazard at each site, and none of those events on their own will produce uniform hazard shaking levels over a spatially distributed infrastructure system. Rather, spatially distributed infrastructure systems must be analyzed using an adequate number of scenario events to reasonably represent the hazard. In this paper, we present a method for selecting an event subset from a probabilistic seismic hazard disaggregation, and adjusting the rates of occurrence of the events in the subset to recover the target hazard curve. We select the event subset based on the percent contribution to the seismic hazard at a set of locations, and then utilize a weighted least squares regression approach to identify the rates for the event subset. We illustrate the procedure for the Sacramento / San Joaquin Delta region.

\section{Effects of Inputs on PSHA Results: A Case Study Hydropower Cascade Projects in Georgia (Sakartvelo)}

TSERETELI, N. S., I. Javakhishvili Tbilisi State University, Tbilisi, Georgia, nino_tsereteli@tsu.ge

Despite many investigation within several regional and global initiatives to harmonize methodology for probabilistic seismic hazard assessment (PSHA) there are still big incompatibility in PSHA results. That leads to disagreements among experts. In the present work we consider the different results of PSHA obtained by different scientific group for the same critical infrastructure like hydro power plant that is located in the north-western part of Georgia.

Analysis of thy conducted work gave us idea that the main rezone of obtained differences in PSHA results came due to inputs. Uncertainties associated with earthquake location and magnitude, homogenization of the earthquake catalogues in terms of moment magnitude $(\mathrm{Mw})$, model of area seismic sources, selection of GMPE models have a significant influence on seismic hazard assessment. For any seismic hazard assessment study following the classical probabilistic approach established by Cornell (1968) the declustering of the earthquake catalogue compiled for the region has become a standard practice. Meanwhile, some authors used non- declustering catalog, indicating that it does not effects of PSHA results. Though investigation show not only non-declustering catalogue influence on PSH results, but also the methods of declustering can influence on them and should be considered in PSHA.

Another important input that effects on PSHA is model of area seismic sources (ASS). Not always authors follow the main criteria that were developed in global project GEM. Free interpretation of area sources leads to different results of PSHA as their size effects very much on seismic productivity. Influence of GMPE models also is significant but if the main criteria of GMPE selection procedure is followed it reduce their effects on PSHA results.

Finally methodology of PSHA also has effects on seismic hazard assessment results. Avoiding such misunderstand it is essential following international standards that were developed recently by the global project GEM or established a new recommendations.

\section{Improving Estimation of the Magnitude of Historical California Earthquakes using IPEs}

LUCAS, M. C., University of Washington, Washington, USA, mlucas12@ uw.edu; SALDITCH, L., Northwestern University, Illinois, USA, leah@earth. northwestern.edu; GALLAHUE, M., Northwestern University, Illinois, USA, mollygallahue2023@u.northwestern.edu; HOUGH, S. E., U.S. Geological Survey, California, USA, hough@usgs.gov; NEELY, J. S., Northwestern University, Illinois, USA, james@earth.northwestern.edu; ABRAHAMSON, N., University of California, Berkeley, California, USA, abrahamson@ berkeley.edu; STEIN, S., Northwestern University, Illinois, USA, s-stein@ northwestern.edu

Estimating the magnitude of moderate to large historical earthquakes is crucial for assessing seismic hazard. These magnitudes are determined using instrumental records, field observations of fault slip, and/or the observed distribution of shaking intensity. However, instrumental data for earthquakes occurring in California prior to the 1960s were limited by a lack of nearby seismic stations and field observations of fault slip were often sparse or even nonexistent, making magnitude estimates for moderate to large historical earthquakes challenging and often uncertain. Using the new California Historical Intensity Mapping Project (CHIMP) dataset, we can better constrain magnitude estimates for these earthquakes by comparing their re-evaluated intensity distributions to those predicted by intensity prediction equations, or IPEs. This approach has become standard practice when instrumental and field data are limited or lacking. However, two first-order questions remain: (1) Which IPEs should be used to estimate magnitude? (2) How should we fit intensity data to an IPE? By comparing four commonly used IPEs to "Did You Feel It?" (DYFI) intensity distributions from moderate to large California earthquakes since 2000, which have well-constrained instrumental magnitudes, we find that no IPE significantly outperforms the others in fitting the intensity distributions or in estimating the earthquakes' magnitudes. We also find that logarithmic data binning, the most commonly used method to fit IPEs to intensity data, significantly influences the resulting magnitude estimates based on the arbitrary number of data bins chosen. These biases are especially apparent when binning intensity distributions from historical earthquakes, which often have a limited number of intensity observations available. 


\section{Optimizing Grids for National Earthquake Hazard Mapping Projects}

KOLAJ, M., Natural Resources Canada, Ottawa, Ottawa, Canada, michal. kolaj@canada.ca; HALCHUK, S., Natural Resources Canada, Ottawa, Canada, stephen.halchuk@canada.ca; ADAMS, J., Natural Resources Canada, Ottawa, Canada,john.adams@canada.ca

Traditionally, seismic hazard maps are generated by gridding and then contouring seismic hazard values which are calculated on a semi-fixed regular grid (e.g., $0.1^{\circ}$, or $10 \mathrm{~km}$, or 1 per $100 \mathrm{~km} 2$ ). The regular grid used for the Canadian seismic hazard maps prior to 2020 was composed of a $10 \mathrm{~km}$ equally spaced grid of roughly 206,000 points. In addition to being used to generate the hazard maps, this grid was also used to deliver online seismic hazard values for the National Building Code of Canada (NBCC) through the use of inverse distance weighted interpolation. For the 6th Generation model (CanadaSHM6, as proposed for NBCC 2020) the number of unique products has increased by more than an order of magnitude due to the move from a single reference site condition to a wide range of reference conditions based on $\mathrm{V}_{\mathrm{S} 30}$ and Site Class. As a result of the increased computational load, the fact that hazard values are generally spatially smooth, and that for large regions within Canada the gradient of hazard is low, it is not efficient or computationally-practical to use a dense fixed grid. This presentation will discuss a new strategy adopted for CanadaSHM6 which through adaptive sampling uses a variable grid of roughly 30,000 points (i.e., $1 / 7$ th the number of points) which results in interpolated hazard values in excellent agreement with those of the regular grid.

Recent Development in Ultra-Dense Seismic Arrays with Nodes and Distributed Acoustic Sensing

Oral Session · Tuesday · 20 April · 5:30 PM Pacific

Session Chairs: Marianne S. Karplus, University of Texas at El Paso (mkarplus@utep.edu); Nori Nakata, Massachusetts Institute of Technology (nnakata@mit.edu); Xiangfang Zeng, Chinese Academy of Sciences (zengxf@whigg.ac.cn); Xiaobo Tian, Institute of Geology and Geophysics (txb@mail.iggcas. ac.cn)

\section{Combining Horizontal Strain DAS and Local Seismic Stations in a Full Waveform Attribute Stacking Detector Locator Algorithm: Verification Test for the Thorbjörn, Iceland, 2020 Unrest Episode}

HEIMANN, S., GFZ German Research Center for Geosciences, Potsdam, Germany, sebastian.heimann@gfz-potsdam.de; ISKEN, M., GFZ German Research Center for Geosciences, Potsdam, Germany, marius.isken@gfzpotsdam.de; MILKEREIT, C., GFZ German Research Center for Geosciences, Potsdam, Germany, claus.milkereit@gfz-potsdam.de; JOUSSET, P., GFZ German Research Center for Geosciences, Potsdam, Germany, pjousset@gfzpotsdam.de; WOLLIN, C., GFZ German Research Center for Geosciences, Potsdam, Germany, wollin@gfz-potsdam.de; DAHM, R. A., Vrije Universiteit Amsterdam, Amsterdam, Netherlands, roman.dahm@gmx.de; HORÁLEK, J., Academy of Sciences, Prague, Czech Republic, jhr@ig.cas.cz; HESIR, G. P., ISOR, Reykjavik, Iceland, Gylfi.Pall.Hersir@isor.is; BLANCK, H., ISOR, Reykjavik, Iceland, hanna.blanck@isor.is; DAHM, T., GFZ German Research Center for Geosciences, Potsdam, Germany, torsten.dahm@gfz-potsdam. de; KEMAL, E., GFZ German Research Center for Geosciences, Potsdam, Germany, kemal.erbas@gfz-potsdam.de; REINSCH, T., Fraunhofer IEG, Fraunhofer Research Institution for Energy Infrastructures and Geothermal Systems IEG, Bochum, Germany, reinsch@gfz-potsdam.de; KRAWCZYK, C. M., GFZ German Research Center for Geosciences, Potsdam, Germany, lotte@gfz-potsdam.de

In recent years, the development of automatic routines for detecting and locating micro-earthquakes based on the full waveform has rapidly advanced the field of micro-seismic studies. Overall, the routines are very computationally intensive and do not reach their full potential until the seismic wavefield is sampled by ultra-dense sensor networks. Migration-based detector / locator techniques as for instance implemented in Lassie (Pyrocko) have demonstrated their robustness in a wide variety of applications in seismology. In this work, we have extended Lassie to efficiently combine linear ultra-dense sensor arrays with sparse seismological networks.
We use the seismicity unrest episode in the Svartsengi fissure swarm close to Mt. Thorbjörn, SW Iceland, which started in January 2020 and was still ongoing in at the time of writing in January 2021, producing more than 5 earthquake swarms comprising thousands of individual events each. We were able to combine local and regional seismic networks with 6 months recording of a $17 \mathrm{~km}$ long DAS cable with a channel resolution of $4 \mathrm{~m}$. The $\mathrm{kHz}$ DAS data were downsampled to $200 \mathrm{~Hz}$ and stacked every $64 \mathrm{~m}$.

We compare two different approaches in how to include DAS recordings into the stacking process: (1) by simple extraction of representative virtual single-component stations through pre-stacking and (2) by additionally exploiting information about the observed apparent slowness along the cable. Although our framework is already parallelized and suited to process real time data, we further improved the computational efficiency of Lassie by implementing the stacking algorithm on GPU architecture. The inclusion of DAS data significantly reduced the magnitude of completeness and improved the localisation of events

We discuss the implementation and the processing of the joined dataset and evaluate the performance in comparison to the location with seismic data only, and DAS data only.

\section{Earthquake Locations in the Pecos, TX Region of the Delaware Basin}

FAITH, J. L., University of Texas at El Paso, Texas, USA, jlfaith@miners.utep. edu; KARPLUS, M., University of Texas at El Paso, Texas, USA, mkarplus@ utep.edu; DOSER, D. I., University of Texas at El Paso, Texas, USA, doser@ utep.edu; VEITCH, S., University of Texas at El Paso, Texas, USA, saveitch@ utep.edu; SAVVAIDIS, A., Texas Bureau of Economic Geology, Texas, USA, alexandros.savvaidis@beg.utexas.edu; MERZLIKIN, D., Texas Bureau of Economic Geology, Texas, USA, dmitrii.merzlikin@utexas.edu

Since 2009, there has been a dramatic increase in seismicity in the Delaware Basin of west Texas in the Pecos, TX region. Seismicity has increased by over two orders of magnitude since 2009, corresponding with an increase in oil and gas production in the basin. Approximately 3,000 earthquakes with magnitudes greater than 1.5 have been recorded within a $50 \mathrm{~km}$ radius of Pecos, TX since the Texas Seismological Network (TexNet) was installed in January of 2017. From January 2017 to January 2021, this time range also includes 45 ML 3+ earthquakes, and approximately $900 \mathrm{ML}$ 2.0-2.9 earthquakes. Due to TexNet's typical $25 \mathrm{~km}$ spacing, precise hypocenter location is challenging. Absolute epicentral error is as great as $4 \mathrm{~km}$, and absolute depth error as great as $5 \mathrm{~km}$. Accurate hypocenters are critically needed in the Delaware Basin to identify the structures producing these earthquakes and to determine how they are related to unconventional petroleum development and production.

To determine accurate epicenters, focal depths, and velocity structure, we designed and deployed a network of 25 3C Magseis Fairfield Z-land 5- Hz nodes in and around the Pecos area, known as the Pecos Array. The array recorded data from November 2018 to January 2020. We performed an indepth analysis of how well a machine learning algorithm, PhaseNet, picked phase arrivals, which were used to associate and locate events for five months from January 2019 to May 2019. We compared earthquake locations using the PhaseNet automatic picks with earthquake locations using picks from analysts at TexNet. With these two databases, we are able to compare the two picking methods and determine seismicity patterns in the area.

\section{Reducing the Computational Cost of Seismic Interferometry With Compressed Array Data}

MARTIN, E., Virginia Tech, Virginia, USA, eileenrmartin@vt.edu; KUMP, J. L., Virginia Tech, Virginia, USA, josek97@vt.edu

Ambient seismic noise interferometry lets geophysicists perform seismic imaging in new locations, avoid the cost of seismic source crews and permits In exchange we have accepted computational analysis requiring increasingly more data movement as the number of sensors grows. This is problematic in the face of: (1) growing seismic array density due to new technologies (e.g. nodes, DAS, MEMS), (2) the growing ratio of data movement operations to arithmetic operations and (3) more frequent long-term monitoring. We are motivated to improve computational methods for ambient noise interferometry, particularly to reduce data movement required during analysis. We reduced costs of ambient noise dispersion images and double beamforming transforms via scalable algorithms with implicit frequency-domain interferometry (Martin, 2018; Martin, 2021), but imaging methods (e.g. tomography) still require explicit ambient noise interferometry.

We present two methods of crosscorrelating dense seismic data stored in lossy compressed forms without requiring raw data reconstruction. One method uses data stored in low-rank form, reducing the cost from being proportional to the product of the number of time samples with the number of 
sensors squared, to the sum (Martin, 2019). Low-rank compression does not capture some high-frequency features, so we turn to sparse wavelet compression. We propose a new algorithm to perform crosscorrelations via a sparse set of largest wavelet coefficients, essentially an outer product of wavelet coefficients with crosscorrelations of wavelet basis functions (precomputed, and independent of data). The resulting sparse coefficients can be accumulated prior to reconstruction of average time-domain crosscorrelations across many time windows. Redundancies in some wavelet bases greatly reduce the memory footprint. We introduce new software, show tradeoffs in compression ratio with accuracy in individual time windows as well as averages across many time windows.

\section{Reverse-Time Migration of Fault Zone Reflected Waves: Methodology and Application to the Southern San \\ Andreas Fault}

CHI, B., Rice University, Texas, USA, benxin.chi@rice.edu; QIU, H., Rice University, Texas, USA, hq7@rice.edu; SHARE, P., Oregon State University, Oregon, USA, pieter.share@oregonstate.edu; VERNON, F., Scripps Institution of Oceanography, University of California, San Diego, California, USA, flvernon@ucsd.edu; BEN-ZION, Y., University of Southern California, California, USA, benzion@usc.edu

High-resolution imaging of fault geometry at depth is challenging. Velocity models derived from tomography methods that utilize travel times and waveforms of body and surface waves only provide smoothed images. In contrast, waves refracted along or reflected from the impedance contrast across major faults have the potential to illuminate the geometry of fault interfaces at depth with unprecedented resolution. Such waves have been observed in data recorded by near-fault stations and dense fault zone arrays. In this study, we develop a novel method to infer fault-related reflection interfaces by applying the cross-correlation imaging condition to reflected and transmitted waves recorded by dense linear arrays crossing major faults. Compared to traditional reverse-time migration methods, our approach does not require accurate source information and works particularly well in imaging near-vertical interfaces. Migration images obtained using a smoothed velocity model and synthetic reflected and transmitted waves computed for a flower-shaped fault zone model show accurate geometry of the fault zone edges. The developed migration method is applied to data recorded by a $\sim 4-\mathrm{km}$-long dense linear 3-component nodal array crossing surface traces of the Mission Creek and Banning strands of the Southern San Andreas fault zone around the Thousand Palms Oasis Preserve, California. The resulting migration images from $\mathrm{P}$ and $\mathrm{S}$ waves generated by several regional earthquakes reveal high-resolution interfaces of the Mission Creek and Banning faults that are consistently dipping steeply toward the NE in the top $2-3 \mathrm{~km}$.

\section{Seismological Evidence for the Earliest Global Subduction Network at 2 Ga}

YANG, X., Institute of Geology and Geophysics, Chinese Academy of Sciences, Beijing, China, yxs@mail.iggcas.ac.cn; WAN, B., Institute of Geology and Geophysics, Chinese Academy of Sciences, Beijing, China, wanbo@mail.iggcas.ac.cn; TIAN, X., Institute of Geology and Geophysics, Chinese Academy of Sciences, Beijing, China, txb@mail.iggcas.ac.cn; YUAN, H., ARC Center of Excellence for Core to Fluid System, Macquarie University, Rider, Australia, huaiyu.yuan@gmail.com; KIRSCHER, U., Eberhard Karls University Tubingen, Tubingen, Germany, uwe.kirscher@uni-tubingen.de; MITCHELL, R., Institute of Geology and Geophysics, Chinese Academy of Sciences, Beijing, China, ross.mitchell@mail.iggcas.ac.cn

The theory of plate tectonics is one of the key scientific advances of the past century. It explains how Earth's crust is made of enormous rocky "plates" floating on the planet's molten interior, which slowly move around. When this happened, however, has remained controversial. The earliest evidence for subduction, which could have been localized, does not signify when plate tectonics became a global phenomenon. To test the antiquity of global subduction, we investigated Paleoproterozoic time, for which evidence is available from multiple continents. We studied an area geologists call the Ordos block, which is part of the North China craton, a very stable chunk of the Asian continent. In April 2019, we deployed 609 seismic recording stations spaced every 500 meters along a 300-kilometer line. By combining the earthquake data from these stations, we were able to form a detailed picture of Earth's crust in this area. Beneath the city of Dongsheng, we found a feature called a dipping Moho in which the bottom of Earth's crust dips from around $35 \mathrm{~km}$ deep to more than $50 \mathrm{~km}$ deep over a horizontal distance of only $40 \mathrm{~km}$. This dipping structure looks nearly identical to what is found beneath the Himalayan mountains, except it is around 2 billion years old.
Next, we collected seismic evidence from other studies around the world for similar dipping Moho structures that are about the same age. Putting observations from six continents together, we can form a picture of the creation of the ancient supercontinent Nuna. If Nuna was the first supercontinent, we can interpret these tectonic collisions that occurred around 2 billion years ago as the oldest evidence of plate tectonics in the global sense. Even though such collisions may have occurred here and there early on, it is likely that plate tectonics did not become a global network until this time. Global subduction by $\sim 2$ billion years ago can also explain why secular planetary cooling was not significant until Proterozoic time.

Recent Development in Ultra-Dense Seismic Arrays with Nodes and Distributed Acoustic Sensing

Poster Session · Tuesday · 20 April · 4:15 PM Pacific

Session Chairs: Marianne S. Karplus, University of Texas at

El Paso (mkarplus@utep.edu); Nori Nakata, Massachusetts Institute of Technology (nnakata@mit.edu); Xiangfang Zeng, Chinese Academy of Sciences (zengxf@whigg.ac.cn); Xiaobo Tian, Institute of Geology and Geophysics (txb@mail.iggcas. ac.cn)

\section{Characteristics of the Seismic Waves From a New Experiment of Methane Gaseous Detonation Source in Tibet}

II, Z., Chinese Academy of Geological Sciences, Beijing, China, jizhanbo@ cags.ac.cn; HE, R., Chinese Academy of Geological Sciences, Beijing, China, herizheng@cags.ac.cn; LI, Z., Chinese Academy of Geological Sciences, Beijing, China, 972615784@qq.com; NIU, X., Chinese Academy of Geological Sciences, Beijing, China, niuxiao18@mails.ucas.edu.cn; WU, W., Chinese Academy of Geological Sciences, Beijing, China, 365019452@qq.com; WEI, Y., Chinese Academy of Geological Sciences, Beijing, China, wweiyunhao@163. com

More and more artificial seismic sources are applied for exploration of underground medium in recent years. Seismologists trend to develop environment friendly, green sources for the environmental protection. In this study, we introduce a new type of green active source with gaseous detonation of methane and oxygen. We conducted three different types of methane detonation experiments in Xietongmen County, Tibet at October 2020.The experiment site is more than an elevation of 5100 meters with lower air-pressure. The methane detonation signals were recorded by nearby 49 seismometers that along a profile of east-west direction. In current work, we analyzed the characteristics of methane detonation signals. The analysis of source signals suggest that it is effective and environmental artificial seismic source for high resolution near surface imaging. The $\mathrm{P}$ waves of methane detonation signals could be observed in the station that is $6.5 \mathrm{~km}$ from the source. Dominant frequencies of source signals are $10-30 \mathrm{~Hz}$. We also identified fundamental mode surface waves in the nearby stations. Compared with traditional explosive sources, the methane source shows similar characteristics in time-frequency domain and duration time. The cross-correlation coefficients of methane source and traditional explosive source even could be greater than 0.75 . In consideration of the damage to surrounding medium and emission of harmful gases of traditional explosive, the methane source is a promising artificial source in exploration of underground mediums.

\section{Classifying the Records of DAS Using Neural Network}

$\mathrm{LV}, \mathrm{H}$., State Kay Laboratory of Geodesy and Earth's Dynamics, Academy of Precision Measurement Science and Technology, Chinese Academy of Sciences, Wuhan, China, Wuhan, China, 1h17@mail.ustc.edu.cn; ZENG, X., State Kay Laboratory of Geodesy and Earth's Dynamics, Academy of Precision Measurement Science and Technology, Chinese Academy of Sciences, Wuhan, China, zengxf@whigg.ac.cn; SONG, Z., State Kay Laboratory of Geodesy and Earth's Dynamics, Academy of Precision Measurement Science and Technology, Chinese Academy of Sciences, Wuhan, China, Wuhan, China, zhhsong6@mail.ustc.edu.cn; BAO, F., State Kay Laboratory of Geodesy and Earth's Dynamics, Academy of Precision Measurement Science and Technology, Chinese Academy of Sciences, Wuhan, China, baofeng@whigg. ac.cn; LIN, R., State Kay Laboratory of Geodesy and Earth's Dynamics, 
Academy of Precision Measurement Science and Technology, Chinese Academy of Sciences, Wuhan, China, robin_lin@163.com

One advantage of the Distributed Acoustic Sensing technology is ultra-dense spatial sampling, which helps to reduce wavefield alias. However, the data volume also significantly increases to terabytes per day and it is difficult to process by traditional approaches including automatic and manual ones. One of the typical data procedures of continuous seismic data is event classification The relative weak earthquake signal is strongly contaminated by the strong traffic noise in urban areas. Therefore, a new automatic event classification method based on the neural network was developed to detect earthquake signals recorded by a telecom fiber-optic array in a city. The neural network was trained by a dataset including more than 60 local events beneath the DAS array. Then, it was successfully used into the 7-days dataset and detected low signal-noise-ratio microearthquakes.

\section{Imaging Shallow S-Wave Structure Using Telecom Fiber- Optic Cable in Urban Areas}

SONG, Z., State Kay Laboratory of Geodesy and Earth's Dynamics, Academy of Precision Measurement Science and Technology, Chinese Academy of Sciences, Wuhan, China, zhhsong6@mail.ustc.edu.cn; ZENG, X., State Kay Laboratory of Geodesy and Earth's Dynamics, Academy of Precision Measurement Science and Technology, Chinese Academy of Sciences, Wuhan, China, zengxf@whigg.ac.cn

Surface wave signal extracted from the continuous ambient noise recorded by the DAS with fiber-optic buried in shallow trenches has been widely employed to construct S-wave velocity structure. DAS is easy to incorporate with existing cable (dark fiber) that significantly reduces deployment costs in urban areas. We investigated the shallow structure along a 5.2-km long telecom fiber-optic cable in a city with DAS continuous ambient noise.This DAS array includes two segments along Taihe Rd. and Jinniu Rd, which the traffic activities are significantly different. The $2 \mathrm{D}$ shear-wave velocity profile beneath the Taihe Rd was successfully construted with the 1-10 Hz Rayleigh wave signals emerged on the noise cross-correlation functions. The obtained velocity model explains the HVSR curves computed with collocated $3 \mathrm{C}$ geophone data. However, the direct Rayleigh wave signal is contaminated by the precursory signals on NCFs of channels along the Jinniu Rd. A series of synthetic tests were designed to analyze precursory signals and weak direct surface wave sginal. The result suggests that the imhomogeous noise distribution produces such precursory signals. The various coupling also contributes to the insufficient direct surface wave signal extraction.

\section{Imaging the Crustal Structure Beneath the Northwest Yunnan From a High-Density Seismic Array}

SUN, T., USTC, Hefei, China, damaisuntianwei@gmail.com

Emeishan igneous province (ELIP) is the only one widely recognized LIP in China, which can be divided into three different regions: inner zone, intermedia zone and outer zone. Previous studies show that the inner zone is characterized by a Moho doming, and a lower crustal high-velocity and highdensity anomaly, which may be result from the mantle plume underplating. Chenghai fault (CHF) is located at the eastern boundary of the inner zone of ELIP. Previous studies show that CHF is at the boundary of Bouguer gravity anomaly. And high-speed anomalies of lower crust are mainly exist in the east of CHF. These suggest that CHF may be in the position of thickness gradient of intrusive rock. However, this is in contradiction with the severe erosion of Maokou Formation in Binchuan. The study of the structure of ELIP inner zone, especially the fine structure around the CHF, will help us understand the thickening mechanism and evolution of the Yunnan crust. However, subject to the sparse observation, there were few studies on the fine structure of the inner zone. From March to May 2017, we deployed the dense short-period seismic array in the original position of Yunxian-Ninglang DSS profile which northern part is roughly parallel to the CHF and southern part is nearly perpendicular to the Red River Fault (RRF). In this study, 1873 receiver functions were extracted and then imaged by CCP stack. We find the Moho is continuous cross the RRF. However, we observed strong Vp/Vs contrast cross the RRF. Combined with other evidence, we inferred that the RRF has cut through the Moho. Two interfaces have been recognized under the $\mathrm{CHF}$, one of which we recognized as an artifact of multiples generated by the sedimentary layer, and the other is a inter crust interface with a depth of $\sim 35 \mathrm{~km}$. Combined with the Ariy isostasy along the profile, we speculated that the inter crust interface is the underplating interface formed by the ancient mantle plume. The results show that CHF was strongly underplated during the formation of ELIP.

\section{Mineralization Study by Squeezing of Northward Indian} Plate in the Gangdese Metallogenic Belt

WU, W., Chinese Academy of Geological Sciences, Beijing, China weiwu190@163.com; JI, Z., Chinese Academy of Geological Sciences, Beijing, China, jizhanbo@cags.ac.cn; JIN, Z., Chinese Academy of Geological Sciences, Beijing, China, 24575880@qq.com; HE, R., Chinese Academy of Geological Sciences, Beijing, China, herizheng@cags.ac.cn; WEI, Y., Chinese Academy of Geological Sciences, Beijing, China, wweiyunhao@163.com; NIU, X., Chinese Academy of Geological Sciences, Beijing, China, niuxiao18@mails.ucas.edu. cn; WANG, C., East China University of Technology, Nanchang, China, 463287902@qq.com

The Gangdise metallogenic belt in the southern Tibet Plateau is well studied for mineralization in mining scale. It is a breakthrough discovery for Jiama copper-polymetallic ore deposit in the Gangdise metallogenic belt. The deep structure of Jiama ore deposit and ore-forming system is still unclear.

Compared with active exploration methods, receiver function (RF) imaging based on a dense seismic array can provide the more detailed crustmantle discontinuity (Moho) structure with high resolution and detection accuracy. We applied P-wave RF imaging method to a dense array with 102 geophones and obtained the Moho topography beneath the Jiama ore deposit. Two parallel dense arrays are arranged in the north and south of the study area with station spacing of $\sim 500 \mathrm{~m}$. The Common Conversion Point (CCP) stacking technique is used to image the crustal structure along the profiles. The south profile is about $40 \mathrm{~km}$ away from the north profile, and the depth and deformation of Moho are different widely under the two profiles. It suggests that the different Moho structural features influence ore-forming and deposit.

\section{New Community Resource for Rapidly Responding to Geohazards}

SWEET, J., Incorporated Research Institutions for Seismology, New Mexico, USA, justin.sweet@iris.edu; ANDERSON, K., Incorporated Research Institutions for Seismology, New Mexico, USA, kent.anderson@iris.edu; MELTZER, A., Lehigh University, Pennsylvania, USA, ameltzer@lehigh. edu; WOODWARD, R., Incorporated Research Institutions for Seismology, District of Columbia, USA, robert.woodward@iris.edu

Geohazards, including earthquakes, volcanic eruptions, floods, and landslides, cause billions of dollars in U.S. economic losses, loss of life, injuries, and significant disruption to lives and livelihoods on an annual basis. The ability of the geoscience community to respond rapidly after a hazardous event or at the signs of precursors to these events, provides critical data to understand the physical processes responsible for these destructive events. These data are only available while these events are happening or in their immediate aftermath and have the potential to significantly improve hazard assessment and mitigation strategies. The current instrumentation and infrastructure for rapid response efforts available from the SAGE Portable Instrumentation Pool (IRIS/PASSCAL) is being upgraded to take advantage of newer technologies and updated installation techniques - enhancing the geoscience community's capability to effectively respond rapidly to geohazards.

As part of the current SAGE award from NSF, IRIS has funding to procure and operate a new pool of instrumentation for rapidly responding to geohazards. Beginning in 2019, IRIS convened a number of in-person and virtual gatherings to solicit community input on science objectives and observational requirements for conducting and advancing research related to geohazards. We have compiled this input into a recently-released community white paper (see www.iris.edu/rapid) that summarizes rapid response science drivers, defines needed instrument capabilities, and makes short and long-term recommendations for facility capabilities. With this community guidance, over the next two years IRIS, working with the PASSCAL community governance, will define technical specifications, evaluate and purchase a new set of instrumentation, and define policies and procedures to use this new capability enhancing the ability of PIs to rapidly respond to geohazard events. We anticipate that the new rapid response instrument pool will be fully operational and ready for community use no later than September 2023.

\section{Shallow Active-Source Seismic Modeling of Old Faithful Geyser in the Upper Geyser Basin of Yellowstone National Park Using a Dense Seismic Array}

CAYLOR, J. R., University of Texas at El Paso, Texas, USA, jrcaylor@miners. utep.edu; KARPLUS, M., The University of Texas at El Paso, Texas, USA, mkarplus@utep.edu; FARRELL, J., The University of Utah, Utah, USA, jamie. farrell@utah.edu; VEITCH, S., The University of Texas at El Paso, Texas, USA, 
saveitch@utep.edu; KAIP, G., The University of Texas at El Paso, Texas, USA, gkaip@utep.edu

The Upper Geyser Basin of Yellowstone National Park consists of active geysers which erupt hydrothermal water from a subsurface reservoir, the most famous of which is Old Faithful. To image the Old Faithful hydrothermal system, we process 2-D and 3-D active-source seismic data recorded in November 2016 using a densely spaced seismic array. Our 3-D array consists of 521 receivers and 343 shot locations. Our 2-D line trends SW-NE, centered on Old Faithful Geyser, with 39 receivers and 39 shot locations. Typically, $~ 5$ shots were stacked at each location in order to increase signal to noise ratio. Both arrays have a station spacing of $\sim 25 \mathrm{~m}$, but there is a $\sim 100 \mathrm{~m}$ gap in any direction from the Old Faithful Geyser orifice. The source in this experiment was a 12lb sledgehammer striking a metal plate. Our receivers are 3-component, 5-Hz Magseis Fairfield Z-Land seismometers recording at $1000 \mathrm{~Hz}$. We pick refracted $\mathrm{P}$-wave first arrivals and invert the picks to create a velocity model and tomographic profiles. We aim to visualize changes in lithology around Old Faithful geyser and the subsurface plumbing system in greater detail than previous studies. Results from our 2-D tomographic profile show slight differences from previous studies, with the P-wave refraction profiles allowing for more detailed lateral interpretation. We also present preliminary 3-D tomographic models. Tomographic models and profiles contribute to scientific understanding of the shallow subsurface structure of the Old Faithful hydrothermal system by allowing us to visualize in 2-D and 3-D anomalous velocity structure which we contribute to hydrothermal activity.

\section{Subduction Zone Interface Structure Beneath Kodiak Island, Alaska: Constraints from Receiver Functions Across a Spatially Dense Node Array}

ONYANGO, E. A., University of New Mexico, New Mexico, USA, eaonyango@ unm.edu; WORTHINGTON, L. L., University of New Mexico, New Mexico, USA, lworthington@unm.edu; SCHMANDT, B., University of New Mexico, New Mexico, USA, bschmandt@unm.edu; NAKAI, J., University of New Mexico, New Mexico, USA, jenakai@unm.edu; ABERS, G., Cornell University, New York, USA, abers@cornell.edu

Kodiak Island is an exposed part of an accretionary complex along the AlaskaAleutian subduction zone that formed as the Pacific plate subducted below the North American plate. Subduction of the Pacific plate beneath Alaska has produced more $>\mathrm{M} 8$ earthquakes than any other plate boundary system during the last $\sim 100$ yrs, including the 1964 M9.2 Great Alaska earthquake. Kodiak Island lies on a section of the subduction zone that ruptured in the 1964 event and experiences seismic tremor, suggesting multiple modes of plate interface slip. Unconsolidated sediment thickness and fluid distribution along the subduction zone interface are some of the factors thought to affect slip stability. We use Ps receiver functions to identify potential low seismic velocity anomalies and estimate $\mathrm{Vp} / \mathrm{Vs}$ within the oceanic crust to constrain metamorphism and fluid pressure. The study will allow us to test the hypothesis: Two distinct layers will compose the plate interface beneath Kodiak Island, a shallower LVL related to sediment subduction, and an oceanic layer that has higher velocity than the sediment but lower velocity than the underlying oceanic mantle. In May 2019, we deployed 398 autonomous three-component 5-Hz Fairfield Nodal Zland geophones on Kodiak Island as part of the Alaska Amphibious Community Seismic Experiment. The dense lines consisted of nodes at approximately $200-\mathrm{m}$ spacing recording continuously for about 30 days adjacent to the $\sim 40 \mathrm{~km}$-long Chiniak Highway system across northeastern Kodiak Island. A total of 86 events with an MW $>5.0$ were recorded during that time period with 12 events having an MW $>6.0$ and an epicentral distance between $30^{\circ}$ and $90^{\circ}$. Preliminary imaging results show the continental Moho, the top of the subducting Pacific Plate, the slab Moho and a highly variable amplitude positive arrival between 1 and $10 \mathrm{~km}$ that extends the entire length of the profile.

\section{Recent Engineering Uses of National Seismic Hazard Models}

I: Oral Session · Thursday · 22 April $\cdot$ 2:00 PM Pacific

II: Oral Session · Thursday · 22 April · 5:00 PM Pacific

Session Chairs: Nicolas Luco, U.S. Geological Survey (nluco@ usgs.gov); Michal Kolaj, Natural Resources Canada (michal. kolaj@canada.ca); Sanaz Rezaeian, U.S. Geological Survey (srezaeian@usgs.gov); Peter M. Powers, U.S. Geological Survey (pmpowers@usgs.gov); Matthew C. Gerstenberger, GNS Science (m.gerstenberger@gns.cri.nz); Ken Elwood, University of Auckland (k.elwood@auckland.ac.nz)

\section{A First Public National Seismic Risk Model for Canada}

HOBBS, T. E., Natural Resources Canada, Vancouver, Canada, thobbs@eoas. ubc.ca; JOURNEAY, J. M., Natural Resources Canada, Vancouver, Canada, murray.journeay@canada.ca; VAN ULDEN, J., Natural Resources Canada, Vancouver, Canada, joost.vanulden@canada.ca; ROTHERAM, D., Natural Resources Canada, Vancouver, Canada, drew.rotheram-clarke@canada.ca; CHOW, W., Natural Resources Canada, Vancouer, Canada, william.chow@ canada.ca; HERRING, J., Habitat Seven, Ottawa, Canada, jamie@habitatseven. com; PAGANI, M., Global Earthquake Model Foundation, Pavia, Italy, marco.pagani@globalquakemodel.org; JOHNSON, K. L., Global Earthquake Model Foundation, Pavia, Italy, kendra.johnson@globalquakemodel.org; RAO, A., Global Earthquake Model Foundation, Pavia, Italy, anirudh.rao@ globalquakemodel.org

The National Earthquake Risk Profile for Canada, scheduled for release in 2021, will establish an open and accessible base of evidence to inform disaster resilience planning in accordance with policy guidelines established as part of the Sendai Framework for Disaster Risk Reduction. The profile includes probabilistic and deterministic risk assessments, made uniformly across the country. The deterministic portion comprises a catalogue of scenario earthquakes, created with a consistent methodology for representative earthquake source zones across Canada, suitable for tabletop exercises and response planning. The probabilistic component extends the scope of probabilistic seismic hazard assessments (CanadaSHM6) currently used to inform Canada's National Building Code (NBCC). All modelling is done using the Global Earthquake Model Foundation's 'OpenQuake Engine' through a public partnership with Natural Resources Canada. Results from deterministic and probabilistic runs are expressed in terms of a structured framework of indicators that profile the physical, social and economic dimensions of earthquake risk at the neighborhood scale. Risk metrics are used to both analyze existing baseline conditions of earthquake risk, and to evaluate the potential for risk reduction through proactive investments in seismic mitigation and post-disaster recovery planning. The models and accompanying indicator framework are designed to support implementation of the Sendai framework at local and regional scales-and to help build capabilities for incorporating a disaster resilience lens into ongoing emergency management, sustainable land use and financial planning initiatives in Canada.

In addition to developing this model, Natural Resources Canada is developing a purpose-built web platform which will allow users to explore risk either by address, by municipality, or by high-level themes of impacts. This free service is tailored to average citizens as well as more technical users of risk information, with the aim of increasing uptake of risk information at multiple levels of governance.

\section{Does PSHA Meet the Needs for Modern Engineering Design in Australia?}

ALLEN, T. I., Geoscience Australia, Canberra, Australia, trevor.allen@ga.gov.

Damaging earthquakes in Australia and other regions characterised by low seismicity are considered low probability, high consequence events. Uncertainties in modeling earthquake occurrence rates and ground motions pose unique challenges to forecasting seismic hazard in these regions. In 2018 Geoscience Australia released its National Seismic Hazard Assessment (NSHA18). Results from the NSHA18 indicate significantly lower seismic hazard across almost all Australian localities at the 1/500 annual exceedance probability (AEP) relative to the factors in the Australian earthquake loading standard; the AS1170.4. Due to concerns that the 1/500 AEP hazard factors proposed in the NSHA18 would not assure life safety throughout the conti- 
nent, the amended AS1170.4 (revised in 2018) retains seismic demands developed in the early 1990s and also introduces a minimum hazard design factor of $Z=0.08 \mathrm{~g}$. The hazard estimates from the NSHA18 have challenged notions of seismic hazard in Australia in terms of the probability of damaging ground motions and raises questions as to whether current practices in probabilistic seismic hazard analysis (PSHA) deliver the outcomes required to protect communities in low-seismicity regions, such as Australia. By contrast, it is also important that the right questions are being asked of hazard modelers in terms of the provision of seismic demand objectives that are fit for purpose. In the United States and Canada, a 1/2475 AEP is used for national hazard maps due to concerns that communities in low-to-moderate seismicity regions are considerably more at risk to extreme ground-motions. The adoption of a 1/2475 AEP seismic demands within the AS1170.4 would bring it in to line with other international building codes in similar tectonic environments and would increase seismic demand factors to levels similar to the 1991 hazard map. This, together with other updates, may be considered for future revisions to the standard.

\section{National Building Code of Canada (NBCC)-Earthquake Design Philosophy and Perspective, New Low Damage Performance Checks for $\mathbf{2 0 2 0}$ Edition, Impact Analysis of New Items, Summary of NBCC Process for Revisions to Earthquake Code Provisions}

SHERSTOBITOFF, J., Ausenco, Vancouver, Canada, john.sherstobitoff@ ausenco.com

The National Building Code of Canada (NBCC) forms the basis for building design in Canada. The structural design provisions for 'Earthquake Load and Effects' in NBCC requires seismic hazard data for the $2 \%$ in 50 year probability of exceedance earthquake; the basis for design is unique $5 \%$ damped uniform hazard response spectra for all locations in Canada. The 2020 edition of the code (NBCC 2020) is expected to be released in late 2021 and is proposed to include significant advancements in the provisions for earthquake design. If adopted, NBCC 2020 will incorporate the latest national seismic hazard assessment as included in the $6^{\text {th }}$ Generation Seismic Hazard Model of Canada. Moreover, in lieu of scaling reference site hazard values from reference Site Class C values using code foundation factors, NBCC 2020 will directly incorporate seismic hazard values calculated for a continuous range of site conditions, with a preference to use Vs30 to define a site condition.

Furthermore, if adopted, NBCC 2020 will require additional 'low damage' performance checks for post-disaster buildings for the $5 \%$ in 50 year level earthquake, and for high importance buildings and portions of tall normal importance buildings for the $10 \%$ in 50 year level earthquake. An impact analysis was performed that indicated that these proposed changes would increase the aggregate new building cost for all of Canada by roughly $1 \%$.

This presentation will describe the process by which NBCC earthquake design provisions are developed and discuss the expected NBCC 2020 major changes and their impacts.

\section{The 6th Generation Seismic Hazard Model of Canada}

KOLAJ, M., Natural Resources Canada, Ottawa, Ottawa, Canada, michal. kolaj@canada.ca; ADAMS, J., Natural Resources Canada, Ottawa, Canada, john.adams@canada.ca; HALCHUK, S., Natural Resources Canada, Ottawa, Canada, stephen.halchuk@canada.ca

Damaging earthquakes have and will inevitably occur again in Canada. Correctly estimating the hazard posed by these events is of critical importance to ensure that earthquake resistance engineering is appropriately distributed across Canada. Modelling earthquake hazard through probabilistic seismic hazard assessments provides a quantitative means of determining and planning for future losses. The latest hazard assessment, the 6th Generation Seismic Hazard Model of Canada (CanadaSHM6), was released in 2020 and is currently proposed to be the basis for seismic design values for the 2020 edition of the National Building Code of Canada. In general, the new model predicts higher seismic hazard in most regions across Canada. The model incorporates recent research on the rate of great Cascadia earthquakes, includes a new potentially active fault in southern Vancouver Island and incorporates the latest updates of the ground motion predictions of large earthquakes. For the first time, hazard values are also provided for a continuous range of site conditions (expressed in terms of $\mathrm{V}_{\mathrm{S} 30}$ ), which expands the applicability of the results. The presentation will summarize the distribution of seismic hazard across Canada, describe the key new elements of CanadaSHM6 and provide perspective on future directions for Canadian seismic hazard models.

\section{The Engineering Use of the $\mathbf{2 0 2 0}$ National Seismic Hazard Model for the UK}

MOSCA, I., British Geological Survey, Edinburgh, United Kingdom, imosca@ bgs.ac.uk; SARGEANT, S., British Geological Survey, Edinburgh, United Kingdom, slsa@bgs.ac.uk; BAPTIE, B., British Geological Survey, Edinburgh, United Kingdom, bbap@bgs.ac.uk

The Eurocode 8 (EC8) is the European Standard for the design of civil engineering projects in seismic regions. It was published in 2004 and a revision is expected in 2025. The design seismic action of a structure depends on a building classification that consists of four classes depending on the consequence of failure: CC2 for standard commercial and residential buildings; CC3 for structures whose seismic resistance has important social consequences; and CC4 for structures with the large consequence of failure. The National Annexes to the EC8 set out Nationally Determined Parameters (NPDs) that are used to estimate the elastic response spectrum, such as the maximum response acceleration at $5 \%$ damping and the acceleration thresholds for different seismicity areas. The NDPs are derived from the national seismic hazard model (NHSM).

In the United Kingdom (UK), an intraplate region with low levels of seismicity, we have recently updated the NSHM. Since the 2007 NSHM, there have been significant advances in the seismic hazard methodology, particularly with respect to how ground motion and its uncertainties are modelled. The 2020 NSHM for the UK accounts for an updated earthquake catalogue, reassessment of the catalogue analysis and the seismic source model, and advances in the ground motion modelling. The national seismic hazard maps derived from the NSHM are expressed in terms of peak ground acceleration and response acceleration at $0.2 \mathrm{~s}$ and $1.0 \mathrm{~s}$ for $5 \%$ damping on rock and various return periods. The maps confirm that seismic hazard is generally low in the UK and slightly increases in Wales and north-central England.

The 2020 NSHM and the new seismic hazard maps for the UK are used to provide the NPDs in the National Annex for the revised EC8. For most CC2 structures, the 2020 seismic hazard maps suggest that the acceleration threshold is unlikely to be crossed for a given return period. The British Standard Institution sub-committee for EC8 is evaluating whether to recommend a seismic design for CC3 and CC4 structures to the entire UK as whole or on regional basis.

\section{Integrating the USGS National Seismic Hazard Model Into a Framework for Mapping Liquefaction-Targeted Ground Motions}

MAKDISI, A. I., University of Washington, Washington, USA, amakdisi@ uw.edu; KRAMER, S. L., University of Washington, Washington, USA, kramer@uw.edu

Current approaches for evaluating soil liquefaction potential in geotechnical engineering practice are largely based on simplified, cyclic stress procedures for estimating factors of safety against liquefaction $\left(F S_{\mathrm{L}}\right)$. Such procedures typically characterize cyclic loading imposed on soils using a combination of peak ground acceleration $(P G A)$ and earthquake magnitude $\left(M_{\mathrm{w}}\right)$ that correspond to a single return period of ground shaking, as obtained from national or regional seismic hazard maps. Such an approach, which combines probabilistic seismic hazard analyses (PSHA) with deterministic liquefaction triggering calculations, does not completely represent the range of ground shaking conditions that can cause liquefaction at a given site; this limitation has been shown to lead to inconsistent applications of liquefaction hazard assessment across different geographic regions in the United States. Alternatively, fully probabilistic liquefaction hazard analyses (PLHA), which consider the full range of ground motions to estimate $F S_{\mathrm{L}}$ hazard curves, can be used to produce more consistent representations of liquefaction hazards than conventional methods. However, such analyses require voluminous calculations on data that is not widely available to practitioners. An alternative framework is therefore presented for using large-scale PLHA calculations, in conjunction with data from the USGS National Seismic Hazard Model (NSHM), to map a liquefaction-targeted peak acceleration parameter, $P G A_{\mathrm{L}}$, that can be used in conventional liquefaction analyses to obtain $F S_{\mathrm{L}}$ estimates consistent with a target liquefaction return period. $P G A_{\mathrm{L}}$ can be mapped for a reference soil condition and target return period of $F S_{L}$ throughout the United States, and factors for adjusting the $P G A_{\mathrm{L}}$ from reference to site-specific soil conditions are shown to be readily predictable from NSHM deaggregation data at a given location. The result is a framework that provides practitioners with revised ground motion parameters to accurately and consistently characterize liquefaction hazards across the U.S. 
Risk Targeted Hazard Spectra for Seismic Design in New Zealand

HORSPOOL, N., GNS Science, Lower Hutt, New Zealand, n.horspool@gns. cri.nz; GERSTENBERGER, M. C., GNS Science, Lower Hutt, New Zealand, m.gerstenberger@gns.cri.nz; ELWOOD, K. J., University of Auckland, Auckland, New Zealand, k.elwood@auckland.ac.nz

The promotion of risk-targeted hazard spectra as the basis of seismic design internationally has increased over the past decade. Risk-targeted hazard spectra are derived through convolution of hazard curves with representative fragility functions and provide a means to target a uniform risk across a region. Using risk targets also allows performance objectives of building codes that are consistent with other life risks and enables societal input into the expected performance of structures. Risk-targeted hazard spectra are developed for New Zealand and proposed, with examples, to replace the existing uniformhazard spectra for seismic design. This study also extends the risk-targeted hazard framework through full quantification of epistemic uncertainty in seismic hazard and includes multiple risk targets for individual and societal risk at the building and city scales. A framework is proposed which can be used to target a uniform seismic risk for buildings designed according to New Zealand standards considering both the performance of individual buildings as well as the performance of cities.

\section{The 2022 New Zealand National Seismic Hazard Model Revision \\ GERSTENBERGER, M. C., GNS Science, Wellington, New Zealand, m.gerstenberger@gns.cri.nz}

We are currently undertaking the most significant revision of the New Zealand National Seismic Hazard Model (NSHM) in more than 20 years. An international team of more than 50 scientists is contributing to three working groups: 1) Seismicity Rate Models (SRM); 2) Ground Motion Characterisation Models (GMCM); and 3), Service Delivery (SD). Within the SRM and GMCM a critical focus is on understanding and modelling of uncertainty. Particularly, this is on uncertainty in our knowledge (i.e., epistemic uncertainty) that we can model via the use of alternative models. In the SRM we will consider more ruptures than in past NSHMs. This includes complex multi-fault ruptures which were difficult to model in the past. While still possible to include, we will no longer by limited by strict fault segmentation and strictly characteristic earthquake behaviour. We will accomplish this using the USGS "inversion models" methods. Preliminary results are encouraging about our ability to apply this to the New Zealand fault system. This focus includes the Hikurangi subduction zone and the use of multiple recent data sets to constrain and better model the distribution of potential earthquakes on the interface. GMCM will use multiple recent international ground motion models. Where feasible, and significant for hazard, regional adaptations to the models will be implemented. This includes necessary improvements for near-source large magnitude events and modelling of non-linear site response. As with the SRM, the Hikurangi is a critical focus of the model which requires better modelling of ground shaking from Auckland through to Wellington.

\section{The Interplay Between the 2018 USGS National Seismic Hazard Model and Forthcoming Updates to U.S. Building Codes}

REZAEIAN, S., U.S. Geological Survey, Colorado, USA, srezaeian@usgs.gov; LUCO, N., U.S. Geological Survey, Colorado, USA, nluco@usgs.gov

The U.S. Geological Survey (USGS) computes design ground motions by combining hazard results from the USGS National Seismic Hazard Models (NSHMs) with the site-specific design code procedures of the NEHRP Provisions. Prior to the 2020 NEHRP, these design code procedures were applied to the USGS ground motions at three spectral periods $(0,0.2$, and $1 \mathrm{~s})$ at a reference site class (BC). These procedures included risk-targeted calculations, multiplication by maximum-direction factors, and deterministic capping. To obtain design ground motions for other site classes, multiplication by NEHRP site amplification factors was required. Design ground motions for other spectral periods were then derived from a Two-Period-based Response Spectrum (TPRS) shape. As a result, the updates of the USGS NSHM have traditionally given much attention to the behavior of ground motion models (GMMs) at the three mentioned periods and one site class. However, the more recent USGS models such as the 2014 NSHM also included hazard results at additional periods, which motivated the Multi-Period Response Spectrum (MPRS) design procedures in the 2020 NEHRP Provisions.

For the 2020 NEHRP Provisions, the design code procedures have been updated to use MPRS in order to overcome the recognized shortcomings of the TPRS and site amplification factors. As a result, the site amplification fac- tors are eliminated from the provisions, which now rely on the USGS to provide hazard results for more periods (22) and site classes (8). We discuss how the MPRS affects the selection and modification of GMMs in the 2018 and future updates of USGS NSHMs. The 2018 NSHM update, which is used to compute the design ground motions of the forthcoming U.S. building codes, selected and modified GMMs such that they would be applicable for all periods and site classes of interest, and in some regions considered sedimentary basin effects. Outside of the conterminous U.S., generic spectral shapes are used to estimate MPRS.

\section{Use of the 2018 USGS National Seismic Hazard Model in Forthcoming U.S. Building Codes}

LUCO, N., U.S. Geological Survey, Colorado, USA, nluco@usgs.gov; REZAEIAN, S., U.S. Geological Survey, Colorado, USA, srezaeian@usgs.gov

For building codes in the United States, the 2020 NEHRP Recommended Seismic Provisions for New Buildings and Other Structures (Provisions for short) have updated the ground motions used in designing earthquake-resistant structures. The updates stem from the 2018 U.S. Geological Survey (USGS) National Seismic Hazard Model (NSHM) and recommendations from the Building Seismic Safety Council "Project '17," a collaboration with the USGS predominantly funded by the Federal Emergency Management Agency. Project ' 17 recommended updates to how the design ground motions of the Provisions should be derived from USGS NSHMs. Like previous editions, the 2020 Provisions continue to take the lesser of probabilistic and deterministic ground motions, although Project ' 17 did consider discontinuing this deterministic capping of probabilistic values. The probabilistic ground motions are so-called risk-targeted spectral accelerations (RTSAs), as introduced in the 2009 Provisions. Unlike the uniform-hazard (e.g., 2,475-year) ground motions of previous editions, RTSAs are derived from the entirety of the hazard curves (of return period vs. spectral acceleration) output from the USGS NSHM. Prior to the 2020 Provisions, the deterministic caps on the RTSAs corresponded to "characteristic earthquakes on all known active faults." Since the Uniform California Earthquake Forecast used in the latest two updates of the USGS NSHM (i.e., UCERF3) no longer defines characteristic earthquakes, the deterministic ground motions of the 2020 Provisions now correspond to scenario earthquakes from hazard disaggregation at the probabilistic ground motion values. In contrast to the single magnitude that was previously chosen for each characteristic earthquake, the mean magnitude for each scenario earthquake averages over all magnitudes that could occur on a fault. Further unlike characteristic earthquakes, the disaggregation-based scenario earthquakes are fully consistent with the UCERF3 rupture inventory.

Recent Engineering Uses of National Seismic Hazard Models

Poster Session · Thursday · 22 April · 11:30 Am Pacific Session Chairs: Nicolas Luco, U.S. Geological Survey (nluco@ usgs.gov); Michal Kolaj, Natural Resources Canada (michal. kolaj@canada.ca); Sanaz Rezaeian, U.S. Geological Survey (srezaeian@usgs.gov); Peter M. Powers, U.S. Geological Survey (pmpowers@usgs.gov); Matthew C. Gerstenberger, GNS Science (m.gerstenberger@gns.cri.nz); Ken Elwood, University of Auckland (k.elwood@auckland.ac.nz)

\section{Evaluation of Earthquake Scenarios for the Greater Montreal Area}

CHOUINARD, L., McGill University, Montreal, Canada, luc.chouinard@ mcgill.ca; ROSSET, P., Research In Motion, Les Gets, France, philippe.rosset@ affiliate.mcgill.ca; NOLLET, M., École de Technologie Supérieure, Montréal, Canada, Marie-Jose.Nollet@etsmtl.ca

Damage to residential buildings, as well as economic and social impacts, were estimated for 6 earthquake scenarios in the vicinity of the Greater Montreal, Canada using the Hazus software. The Greater Montreal Area is the second largest agglomeration ( 4 millions, about $48 \%$ of the Quebec province) in Canada and is located in a moderately seismic region (PGA around $0.38 \mathrm{~g}$ for a return period of 2475 years). Single family housing units represent $74 \%$ of the building stock and $90 \%$ of the $870,000+$ documented houses are wooden frame structures. On the island of Montreal, these values are 56\% and $81 \%$ respectively, due to the large number of duplexes and triplexes (35\% of the 
total number of buildings) and a large number of unreinforced masonry buildings ( $18 \%$ of the building stock). The building exposure is estimated around 300 billions of Can\$, the content accounting for 55\% of the total. The influence of the soil conditions on the ground motion calculations is taken into account by using $\mathrm{V}_{\mathrm{s} 30}$ data on a regular grid of $250 \mathrm{~m}$ derived from various seismic surveys as well as boreholes and geological data. For the scenarios considered, extensive and complete damage levels represent 0.9 to $12 \%$ of the building stock on the island of Montreal depending on the selected scenarios these numbers values range from 1.1 to $4.8 \%$ for off-island municipalities in the Greater Montreal Area. The total losses vary between 1 and $12 \%$ of the portfolio in the island of Montreal depending on the selected scenario. These percentages decrease to 0.02 to $0.07 \%$ for off-island municipalities, the nonstructural damage accounting for $80 \%$ of the total damage on average. Debris generated by the damage vary between 0.8 to 8 millions tons, wood and brick materials representing around $65 \%$ of the total. The need of temporary shelters is of the order of 5 to 60 thousands, the number of people needing hospita care varies from few tens to thousands depending on the scenario and the time of occurrence of the earthquake. The next step is to estimate the average annualized seismic losses at the same spatial scale.

\section{Long-Term Averaged Earthquake Loss Estimations for Istanbul \\ HANCILAR, U., Bogazici University, Istanbul, Turkey, hancilar@boun.edu. tr; ŞEŞETYAN, K., Bogazici University, Istanbul, Turkey, karin@boun.edu.tr; ÇAKTI, E., Bogazici University, Istanbul, Turkey, eser.cakti@boun.edu.tr}

We estimate the average annual losses (AELs) and loss ratios (AELRs) for Istanbul by making use of the state-of-the-art hazard input as well as the most recent building inventory dataset for the city. The ground motion input relies on the hazard model used in the latest version (2018) of national seismic hazard maps. The local soil information in terms of Vs30 distributions for Istanbul are incorporated in the computation of site specific ground motions The building inventory data compiled in 2018 includes information on the type of lateral load resisting system, number of floors, construction year, number of dwellings, footprint areas and the building usage functions. Spectral acceleration-displacement based damage assessment methodology is implemented. Number of damaged buildings at different damage states for each building class is obtained. On the basis of direct structural damages, economic losses are estimated. Grid- and district-based spatial distributions of AALs and AALRs are presented. The AALR estimations are further compared with the recently updated earthquake insurance premium rates by the Turkish Catastrophe Insurance Pool (TCIP).

\section{Seismic Hazard Analysis for Critical Infrastructure \\ Oral Session · Monday · 19 April · 9:45 AM Pacific \\ Session Chairs: Mark Zellman, BGC Engineering, Inc. \\ (mzellman@bgcengineering.com); Joanna R. Redwine, U.S. \\ Bureau of Reclamation (jredwine@usbr.gov); Laurel M. \\ Bauer, U.S. Nuclear Regulatory Commission (laurel.bauer@ \\ nrc.gov)}

\section{Analysis of Watts Bar Nuclear Power Plant Strong-Motion Records of the M 4.4 12 December 2018 Decatur Tennessee Earthquake}

GRAIZER, V., Nuclear Regulatory Commission, Maryland, USA, Vladimir. Graizer@nrc.gov; SEBER, D., Nuclear Regulatory Commission, Maryland, USA, Dogan.Seber@nrc.gov; STOVALL, S., Nuclear Regulatory Commission, Maryland, USA, Scott.Stovall@nrc.gov

The moment magnitude M 4.4 December 12, 2018 Decatur, Tennessee earthquake occurred in the Eastern Tennessee Seismic Zone (ETSZ). While the causative fault is not known, the earthquake had a predominantly strike-slip mechanism with an estimated hypocentral depth of about $8 \mathrm{~km}$. It was felt over a distance of $500 \mathrm{~km}$ stretching from Southern Kentucky to Georgia. Strong shaking, capable of causing slight damage, was reported near the epicenter area. The Watts Bar Nuclear power plant is only $4.9 \mathrm{~km}$ from the epicenter of the earthquake and experienced only slight shaking. The earthquake was recorded by the plant's seismic strong-motion instrumentation installed at four different locations. Near real time calculations by the plant operators indicated that the Operating Basis Earthquake (OBE) spectra was not exceeded during the earthquake. We obtained and processed the recorded motions to calculate corrected accelerations, velocities, displacements. In addition, we computed the Fourier and 5\% damped response spectra to compare them to the plant's OBE. Comparisons of the ground motion prediction models with the digital recordings at the plant site indicated that recorded ground motions were significantly below the predicted results calculated using the ground motions prediction models approved for regulatory use. Availability of highquality, digital recordings in this case helped make a quick decision about the ground motions not exceeding the OBE and hence prevented unnecessary shutdown of the nuclear power plant. Availability of earthquake recordings from different locations in the nuclear power plant also presented an opportunity to analyze linear response of plant structures.

\section{Fault Displacement Hazard Evaluation for a Gas Transmission Pipeline: Holocene Rupture and Paleoslip Measurements Along Reverse Fault Splays Formed by a Restraining Bend in the Calaveras Fault}

GIVLER, R. W., Lettis Consultants International, Inc., California, USA givler@lettisci.com; MADUGO, C., Pacific Gas and Electric Company, California, USA, c7m0@pge.com; PAGE,W., Pacific Gas and Electric Company, California, USA, wdp7@pge.com; BLOSZIES, C., Lettis Consultants International, Inc., California, USA, bloszies@lettisci.com; CLAHAN, K. Lettis Consultants International, Inc., California, USA, clahan@lettisci.com; THOMPSON, S. C., Lettis Consultants International, Inc., California, USA, thompson@lettisci.com; BUBECK, A., Lettis Consultants International, Inc. California, USA, bubeck@lettisci.com; BALDWIN, J., Lettis Consultants International, Inc., California, USA, baldwin@lettisci.com

Pacific Gas and Electric Company maintains a Transmission Integrity Management Program (TIMP) to evaluate the threat of gas pipeline damage resulting from fault displacement. This TIMP investigation evaluated second ary fault strands adjacent to the Calaveras fault (CF) that cross a gas transmission pipeline in the southern San Francisco Bay Area. In the study area, the CF forms a 6-9 $9^{\circ}$ left-restraining bend north of San Felipe Lake. A series of NW-striking splay faults extending west of the main CF have been mapped based on W- to SW-facing scarps, closed depressions, and stream deflections. Detailed mapping and paleoseismic trenching were conducted along one of these splays $0.5 \mathrm{~km} \mathrm{SW}$ of the main CF. At this location, the splay fault is expressed as a 12-m-high, W-facing scarp composed of Plio-Pleistocene Santa Clara Formation, and multiple inset alluvial fan surfaces are mapped at the base of the scarp. Two paleoseismic trenches across the scarp confirm it is composed of interbedded claystone, siltstone and conglomerate overlain by shallow colluvial deposits. Near the base of the scarp a NW-striking zone of low-angle $\left(5-30^{\circ}\right)$ thrust faults juxtapose Santa Clara Formation over finegrain Holocene alluvium/colluvial deposits. Although timing is poorly constrained due to an absence of datable material, several stacked thrust duplexes suggest multiple surface-faulting events in the late-Pleistocene and Holocene. Two paleoslip measurements of 1.4 and $2.1 \mathrm{~m}$ are interpreted in one trench. We interpret the splay fault at this site to be a Holocene-active strand that ruptures during large-magnitude earthquakes on the main CF. If the interpreted single-event displacements on the reverse splay faults scale with displacement on the principal fault, the $>1 \mathrm{~m}$ displacement amounts suggest earthquakes of $\mathrm{M}>6.5$ on the $\mathrm{CF}$.

\section{How to Present and Interpret Probabilistic Fault Displacement Hazard Analysis (PFDHA) Results to Improve Engineering Decision-Making}

THOMPSON, S. C., Lettis Consultants International, Inc., California, USA thompson@lettisci.com; ZANDIEH, A., Lettis Consultants International, Inc. California, USA, zandieh@lettisci.com; GIVLER, R. W., Lettis Consultants International, Inc., California, USA, givler@lettisci.com

Our recent experience indicates that there are important concepts associated with application of PFDHA hazard curves for engineering evaluation of critical facilities that need more attention. For example, it is common in project design criteria to adopt probabilities of exceedance for fault displacement hazard that are equal to those selected for ground motion hazard (e.g. the $2 \%$ in 50 year). In tectonically active areas, these probability levels commonly yield ground motions that represent larger than average shaking for controlling earthquake magnitudes and distances (positive epsilon values in deaggregation plots). However, it is common in PFDHA for these probability levels to correspond to negligible hazard (the mean hazard curve lies below the selected probability level), or the displacement is less than the median expected outcome (i.e., a negative epsilon value). This result is due to the low slip rates (a few millimeters or less) of many active faults and the fact that in PSHA many seismic sources contribute to hazard whereas in PFDHA hazard is usually dominated by a single fault source. Evaluating facility performance against a mean negative epsilon displacement may not give a complete view 
of risk, especially given the large epistemic and aleatory uncertainties in current PFHDA models. We propose in PFDHA practice to clearly document the epsilon values associated with mean displacements at different probability levels and to plot fractile hazard curves that highlight the immature state of fault displacement model development. We encourage practitioners to consider whether to adopt mean hazard results in cases of negative epsilons, or whether to evaluate critical facilities against higher hazard fractiles and/or a "floor" of a median deterministic displacement for projects that are known to cross an active fault. We believe such additional evaluations will lead to a better understanding of risk mitigation and evaluating performance versus cost.

\section{Sensitivity to Optimization for Scenario Maps for Performance Evaluation of Distributed Infrastructure} WALLING, M., GeoEngineers Inc., Washington, USA, mwalling@ geoengineers.com; KUEHN, N., University of California, Los Angeles, California, USA, kuehn@ucla.edu; GREGOR, N., California, USA, nick@ ngregor.com; AL ATIK, L., AlAtik, California, USA, linda.alatik@gmail.com; KOTTKE, A., Pacific Gas \& Electric, California, USA, arkk@pge.com

Evaluation of the seismic performance of distributed infrastructure requires estimates of the spatial dependence of earthquake ground motion from spatial correlation models of the ground motion. Previous spatial correlation models (e.g., Jayaram \& Baker, 2009) use global datasets to develop correlation models that are ergodic and are then applied to ergodic ground motion models (GMMs). One challenge facing optimization of scenario maps is the tradeoffs between the number of selected maps, the annual occurrence probabilities of the candidate earthquake sources and the ground-motion epsilon. The smaller the number of the selected map the larger the scale factors of the annual occurrence probabilities of the candidate earthquake sources and groundmotion epsilon values must be to match the target hazard at the individual sites. The scale factors of the annual occurrence probabilities of the candidate earthquake sources and ground-motion epsilon also trade-off between each other. The larger the scaled annual occurrence the less the ground motion epsilon needs to adjust for the suite of maps to meet the target hazard.

While the results from the optimization process for scenarios are analytically correct, the results may be unrealistic. For example, the scaled annual occurrence of the selected event may be on an order of five plus higher than the original event; or the scaled ground-motion epsilon is creating unrealistically high-ground motions. With this any value that optimization for scenario maps provided for risk calculations is negated.

In this study, we perform a rigorous analysis of the sensitivity of the optimization to the three key inputs: number of selected maps, the annual occurrence probabilities of the candidate earthquake sources and the groundmotion epsilon. For the results, we compare the scenario maps computed using alternative sets of constraints on the optimization and outline a process for optimizing for realistic scenario hazard maps.

\section{Sigma-2: Improving the Reliability of Seismic Hazard Assessment for Critical Facilities} DANIEL, G., EDF Group, Aix-en-Provence, France, guillaume.daniel@edf. com

SIGMA-2 is a research program on Seismic Hazard Assessment (SHA). It coordinate efforts at the international level to improve the reliability and the accuracy of seismic hazard studies for industrial critical facilities. This program is funded by a consortium of 7 industrial partners involved in the nuclear energy sector (EDF, CEA, PG\&E, SWISSNUCLEAR, ORANO, CEZ \& CRIEPI), and supports more than 50 research actions conducted by academic and private scientific partners.

Current local and international regulations require that the design of critical infrastructures prove its resilience up to very-low-probability seismic hazard levels. Given the importance of safety and financial stakes associated with such critical facilities, a particular effort is needed to make such sitespecific seismic hazard analysis realistic, adapted to local site conditions, and devoid of over-conservatism.

In this presentation, we present an overview of SIGMA-2 scope and research results of interest for the seismic hazard assessment of critical infrastructures. First, we summarize advances in site-response characterization and in the numerical simulation of site-effects. Then, we present groundmotion models for reference rock (i.e. unamplified) conditions, involving, among others, generalized inversion technique, and partially- or fully-nonergodic approaches. New strategies for estimating and propagating epistemic uncertainties in the PSHA calculation have also been investigated, with applications to the maximum magnitude, to seismic rate parameters, and to GMMs. Finally, we discuss methods and current applications on the objective evaluation of PSHA results (and input models), with respect to observations.
Using the principles of Bayesian inference, we illustrate how the confrontation of seismic/geophysical observations (e.g. instrumental records, macroseismic intensities, GPS measurements, earthquake catalogues) shed light on the importance of input model contributors on probabilistic SHA results.

Data, models and results are in open-access, and available at www. sigma-2net.

Seismic Hazard Analysis for Critical Infrastructure
Poster Session · Monday · 19 April · 3:45 PM Pacific
Session Chairs: Mark Zellman, BGC Engineering, Inc.
(mzellman@bgcengineering.com); Joanna R. Redwine, U.S.
Bureau of Reclamation (jredwine@usbr.gov); Laurel M.
Bauer, U.S. Nuclear Regulatory Commission (laurel.bauer@
nrc.gov)

\section{Magnitude Thresholds to Evaluate the Damage From Induced-Seismicity Earthquakes}

MACEDO, I. E., Georgia Institute of Technology, Georgia, USA, jorge. macedo@gatech.edu; ABRAHAMSON, N., University of California, Berkeley, California, USA, abrahamson@berkeley.edu; RAMESH, V., Georgia Institute of Technology, Georgia, USA, venkataramanr@gatech.edu

It is common practice in seismic hazard analysis to only consider ground motions from earthquakes with magnitudes greater than M5 based on the assumption that smaller earthquakes cannot damage engineered structures. We are evaluating this assumption for the case of small-to-moderate magnitude (M3-M4) earthquakes occurring at shallow depths from induced seismicity associated with wastewater injections and hydraulic fracturing. Due to the shallow depths, the distances from the source to the site can be small (just a few $\mathrm{km}$ ), and with the steep distance attenuation, the median short-period ground motions at $3 \mathrm{~km}$ distance from induced earthquakes can be significant. The combination of the increased median ground motion at short distances and the increased rate of earthquakes brings into question the assumption that earthquakes less than M5 cannot cause damage to earth structures.

We are currently evaluating the potential effects of induced-seismicity ground motions on the seismic performance of dykes, focusing on identifying the minimum magnitude that can cause damage. We selected ground motions with the frequency content of induced-seismicity ground motions and scaled them to have intensity measures (IM) that represent the aleatory variability. The selected ground motions are then used in dynamic analyses that consider analytical methods and advanced numerical modeling. The analytical methods relied on the transfer function model proposed by Hale (2020) and the stick-slip model proposed by Rathje and Bray (2000). The advanced numerical analyses were performed with the software FLAC and nonlinear constitutive models. For dykes with yield accelerations of $0.1 \mathrm{~g}$, our preliminary results show that the earthquake magnitude that can cause significant deformation $(>10 \mathrm{~cm}$ ) is between M3.5 to M4.0 for a rupture distance of $3 \mathrm{~km}$ using the ground motions with the spectral content from induced earthquakes at short distances. In addition, the results using FLAC are more conservative, which is associated with the assumptions in analytical models.

\section{National Liquefaction Loss Database and Fragility Functions}

CHANSKY, A. A., Tufts University, Massachusetts, USA, alexander.chansky@ tufts.edu

Liquefaction is a secondary hazard that occurs during earthquakes and can cause severe damage to overlying infrastructure. As a result, liquefaction can be a significant contributor to loss in earthquakes as observed during the 1964 Alaska event. A geospatial liquefaction model developed by Zhu et al. 2017 and implemented by the U.S. Geological Survey (USGS) on the ground failure tab of the earthquake overview page is used to estimate liquefaction spatial extent (LSE) after an earthquake. The model estimates LSE using two shaking parameters and four globally available environmental parameters.

The total areal extent over which soil is expected to liquefy in an earthquake is calculated for each event (TLSE) and evaluated against observed liquefaction (Rashidian and Baise, 2020). The USGS Pager system utilizes a slightly different algorithm to calculate a variation of TLSE referred to as "aggregate liquefaction hazard", abbreviated as Htot. The USGS Pager system also calculates "aggregate liquefaction population exposure", abbreviated as PopExp. However, neither the geospatial liquefaction model nor the 
USGS Pager system currently predicts infrastructure or economic loss due to liquefaction.

We present a liquefaction loss database of 12 United States events. Each entry in the database is labeled by an infrastructure category: transportation, utilities, and buildings. When possible, liquefaction loss is associated with a spatial location. This database is used to relate economic loss by infrastructure category to Htot and PopExp. We also present fragility functions for each infrastructure category using the national loss database and damage state thresholds defined by damage costs.

Additionally, we build on work by Bird and Bommer (2004), a global dataset of liquefaction damage states for 50 events, by expanding the dataset to 86 events and developing fragility functions for these damage states. These fragility functions provide probabilities of liquefaction causing minor/moderate damage or major damage relative to the overall event's damage based on one of two excitation measures: Htot or PopExp.

\section{Response of an Asymmetrical Five-Story Building in Fairbanks, Alaska During the 30 November 2018 M7.1 Anchorage, Alaska Earthquake}

CELEBI, M., U.S. Geological Survey, California, USA, celebi@usgs.gov; RUPPERT, N. A., University of Alaska Fairbanks, Alaska, USA, naruppert@ alaska.edu

A recently constructed, five-story, asymmetrical steel building on the campus of the University of Alaska, Fairbanks was equipped with a strong-motion array that recorded the M 7.1 Anchorage earthquake of November 30, 2018 at an epicentral distance of $408 \mathrm{~km}$. The largest recorded peak accelerations at the basement and top of the building are $0.021 \mathrm{~g}$ and $0.071 \mathrm{~g}$, respectively. The steel building is designed with several bays that utilize K-shaped buckling restrained braces. The building response records allow identification of fundamental periods (frequencies) as $0.73 \mathrm{~s}(1.4 \mathrm{~Hz}), 0.63 \mathrm{~s}(1.60 \mathrm{~Hz})$, and $0.56 \mathrm{~s}(1.78$ $\mathrm{Hz}$ ) in the NS, EW, and torsional directions, respectively. System identification computations resulted in estimated critical damping percentages as $7.7 \%$ and $4.7 \%$ in the NS and EW directions, respectively. At this low-level of shaking, the building is not expected to (and did not) experience observable damage, which is confirmed with very small average drift ratios. This is the first time a seismic response from this structural array has been analyzed.

\section{Scientific Strong Motion Nodes for Diverse Use Cases}

PARKER, T., Nanometrics, Kanata, Canada, timparker@nanometrics.ca; PELYK, N., Nanometrics, Kanata, Canada, nickpelyk@nanometrics.ca; PERLIN, M., Nanometrics, Kanata, Canada, michaelperlin@nanometric.ca

Nanometrics makes turnkey Class-A accelerometer systems for vibration monitoring with low latency telemetry needed for EEW and critical infrastructure. We also support quick deploy systems with Titan Accelerometers coupled with a Pegasus digitizer for rapid response after earthquakes. This technology was designed for very low SWaP (size, weight and power) enabling high density collection of critical strong motion data used as a key input into structural analysis of buildings, structures, and dams both before and after events. These kits can be used for research studies that define regional attenuation properties and site amplification maps. Ground motions studies before events also provide data used in models that are used in early prediction of ground shaking distribution as an input for emergency response. These new instruments packages are supported by a complete ecosystem of software to easily plan, deploy and manage a project including data and metadata automatically generated on site making it simpler to conduct these types of emergency responses and projects. There is also turnkey deploying, monitoring, analysis, engineering and data products available through services that use this same equipment.

\section{Shallow Seismicity in Long Beach-Seal Beach Area Detected by Dense Arrays}

YANG, Y., Caltech, California, USA, yanyang@caltech.edu; CLAYTON, R. W., Caltech, California, USA, clay@gps.caltech.edu

The Newport-Inglewood Fault (NIF) in the Long Beach-Seal Beach area was the site of the 1933 Long Beach M6.4 Earthquake, which caused substantial damage. A recent study suggests the NIF penetrates through the Moho into the mantle and splays out into a fairly wide zone above $6 \mathrm{~km}$. This has likely led the seismic hazard in this highly urbanized region to be underestimated. There also appears to be additional unmapped faults in the area.

To investigate the seismic hazard in the Long Beach-Seal Beach area, we use three dense oil exploration arrays covering this region to look for microseismicity. Our detection and location results show there is a large number of shallow events that are undetected in the SCSN catalog and recent tem- plate-matching studies. These appear to relate to splays of the NIF and other unnamed faults. In the Seal Beach area, these are compared to cross-sections produced by oil industry imaging.

\begin{tabular}{l}
\hline Sensors, Seismicity and Imaging \\
Oral Session· Wednesday · 21 April · 5:00 PM Pacific \\
Session Chairs: Rich Briggs, U.S. Geological Survey (rbriggs@ \\
usgs.gov); Diego Melgar, University of Oregon (dmelgarm@ \\
uoregon.edu); Jenny Nakai, University of New Mexico \\
(jenakai@unm.edu) \\
\hline
\end{tabular}

\section{Analysis of Differences in Seismic Moment Tensors} Between Global Catalogs

RÖSLER, B., Northwestern University, Illinois, USA, boris@earth. northwestern.edu; STEIN, S., Northwestern University, Illinois, USA, s-stein@ northwestern.edu

Catalogs of moment tensors form the foundation for a wide variety of studies in seismology. Despite their importance, assessing the uncertainties in the moment tensors and the quantities derived from them is difficult. To gain insight, we compare 5000 moment tensors in catalogs of the USGS and the Global CMT Project for the period from September 2015 to December 2020. The GCMT Project generally reports larger scalar moments than the USGS, with the difference between the reported moments decreasing with magnitude. The effect of the different definitions of the scalar moment between catalogs, reflecting treatment of the non-double-couple component, is consistent with that expected. However, this effect is small and has a sign opposite to the differences in reported scalar moment. Hence the differences are intrinsic to the moment tensors in the two catalogs. The differences in the deviation from a double-couple source and in source geometry derived from the moment tensors also decrease with magnitude. The deviations from a double-couple source inferred from the two catalogs are moderately correlated, with the correlation stronger for larger deviations. However, we do not observe the expected correlation between the deviation from a double-couple source and the resulting differences in scalar moment due to the different definitions. There is essentially no correlation between the differences in source geometry, scalar moment, or fraction of the non-double-couple component, suggesting that the differences reflect aspects of the inversion rather than the source process. Despite the differences in moment tensors, the reported location and depth of the centroids are consistent between catalogs.

\section{P-Wave Arrival-Time Tomography and Subsequent Full- Waveform Inversion of the Middle East}

DESILVA, S., Colorado School of Mines, Colorado, USA, susinidesilva@gmail. com; BOZDAG, E., Colorado School of Mines, Colorado, USA, bozdag@ mines.edu; NOLET, G., Université Côte d'Azur, Nice, France, nolet@geoazur. unice.fr; GÖK, R., Lawrence Livermore National Laboratory, California, USA, gok1@llnl.gov; ALI, A., Saudi Geological Survey, Jeddah, Saudi Arabia, ali.ah@sgs.org.sa; TARABULSI, Y., Saudi Geological Survey, Jeddah, Saudi Arabia, tarabulsi.ym@sgs.org.sa

The Middle Eastern region is forged by complex tectonic-driven deformations and is prone to significant seismic activity. It is vital to obtain highresolution seismic images of such regions, using more recent and reliable datasets, in order to gain better insights of underlying geodynamics. Our study aims to retrieve a detailed model down to lithospheric depths beneath the MiddleEastern region mainly using teleseismic $\mathrm{P}$ arrival times from the ISC-EHB bulletin (Engdahl et al., 1998). Starting with AK135 as the reference model we invert for tomographic models of Vp perturbations in an area bounded by longitudes $22 \mathrm{E}-66 \mathrm{E}$ and latitudes $8 \mathrm{~N}-48 \mathrm{~N}$. Additionally, by incorporating arrival times measured from waveforms collected at regional networks we managed to markedly improve coverage beneath the Arabian Peninsula. Our inversion results are consistent with previous regional tomographic studies. We unveil a low $\mathrm{P}$ velocity zone stretching from Afar to Sinai Peninsula consistent with a similar observation by Chang and van der Lee 2011. At lower smoothing levels we observe detailed structure on the Iranian Plateau similar to Simmons et al., 2011. In checkerboard tests, plus or minus 4 percent Vp perturbation amplitudes are fairly well covered for checker cells of width as low as 2.8 degrees (about $240 \mathrm{~km}$ at surface) beneath most of the Arabian Peninsula, Iranian Plateau, Zagros mountain region, Persian gulf, northeast Iraq, and the Anatolian-Caucasus region at depth ranges 34-135 $\mathrm{km}, 380-430 \mathrm{~km}, 650-700 \mathrm{~km}$, and around $950 \mathrm{~km}$. 
Our ultimate goal is to perform full-waveform inversion (FWI) of the region constrained by the constructed P-wave model. We initiate our FWI with the first-generation global adjoint tomography model GLAD-M15 (Bozdag et al.,2016) which has transverse isotropy confined to the upper mantle. Our full-waveform dataset constitutes seismograms from carefully selected 100-150 events located and recorded regionally. The inversion process adopts a double-difference (Yuan et al.2016, Orsvuran et al.,2020) misfit function for the observations and synthetics.

\section{SH-SV Polarization Anisotropy: Isotropic Interpretation of Experimentally Measured Love and Rayleigh Wave Phase Velocities and Amplitude Attenuations}

SCHWAB, F., University of California, Los Angeles, California, USA, schwab@ jumpy.igpp.ucla.edu; GURUNG, G., Jeonbuk National University, Calgary, Canada, moostang@gmail.com; LEE, W., Jeonbuk National University, Jeonju, Korea, Republic of, udongi@jbnu.ac.kr; JO, B., Jeonbuk National University, Jeonju, Korea, Republic of, bgjo@moak.jbnu.ac.kr

The Love-Rayleigh wave discrepancy is a well-known phenomenom in seismology, in which phase velocities computed for a single isotropic model are unable to fit both the observed fundamental mode Love and Rayleigh waves. While it has been shown that isotropic models with relatively thin, high-contrast layers inserted in them might be able to fit both the Love and Rayleigh phase-velocity data, many authors instead resort to body-wave, velocity anisotropy to explain this phenomenon. Here, we attempt to complete and extend the verification of these successful isotropic models, but with realistic, anelastic layers.

The use of very simple structural models with three thin high contrast layers superposed: an "olivine" LVZ at $152 \mathrm{~km}$ of depth, a "lower-crustal" LVZ at the Moho depth and a "granitic" LVZ at the Conrad-discontinuity depth resulted in a huge volume of isotropic solutions for the phase velocity data However, when we added the Love and Rayleigh wave amplitude-attenuation data to restrict our solutions, we found a single successful model for the central U.S.: (1) a preferred (idealized) physical model for the "olivine" LVZ: a building-block model of the crystal aggregate with a 3-D laminate of basaltmelt film separating crystals over a $0.1 \mathrm{~m}$ vertical region centered at the 152 $\mathrm{km}$ depth, i.e. lubricated inter-crystal interfaces with an average melt fraction of $0.001 \%$; and, appropriately modified, (2) a preferred, similar idealization for the "lower-crustal" LVZ which is distributed over a $5 \mathrm{~km}$ vertical region centered at a depth of $38 \mathrm{~km}$, with the region's average melt fraction below $0.1 \%$.

This completely isotropic mechanism: (1) successfully explains (removes) the apparent "discrepancy" between measured Love and Rayleigh wave phase velocities in the central U.S.; (2) contains a corrected form of the Gutenberg LVZ in the asthenosphere, with a mobile interface replacing the usual, thick, static LVZ layer; it (3) contains a like interface at the Moho; and thus (4) contains plausible bases for the continental portion of drift, or plate motion.

\section{Shear-Wave Velocity Structure Beneath North-Western Himalaya and Adjoining Areas}

MIR, R. R., CSIR - Fourth Paradigm Institute, Bangalore, India, ramizmir752@ gmail.com; PARVEZ, I. A., CSIR - Fourth Paradigm Institute, Bangalore, India, parvez@csir4pi.in; GAUR, V. K., CSIR - Fourth Paradigm Institute, Bangalore, India, gaurvinod36@gmail.com

Shear-wave velocity (Vs) structure, together with Moho depths have been estimated beneath the northwestern Himalaya, and adjoining regions by inverting fundamental mode Rayleigh wave group velocities calculated from regional earthquake (source-receiver distance $\leq 2500 \mathrm{~km}$ ) data, and also from their joint inversions with teleseismic receiver functions at 38 of the 59 broadband stations in the region that provided the data. The results yield a detailed shear-wave velocity structure of northwestern Himalaya extending from Hindu Kush through Kohistan-Nanga Parbat to Kashmir Himalaya, as well as the Pamirs in the north and Lesser Himalaya along with the foreland basin including the Hazara syntaxis in the south. In particular, main results obtained are, a) presence of ubiquitous low-velocity layer (Vs $\sim 3 \mathrm{~km} / \mathrm{s}$ ) at $\sim 30 \mathrm{~km}$ depth beneath the NW Himalaya but apparently absent beneath the Kashmir Himalaya b) characterization of the western Tarim and Tadjik basins by low velocities up to $\sim 20 \mathrm{~km} \mathrm{c})$ shallow $(\sim 10 \mathrm{~km})$ high velocities beneath Pamir and Ladakh Himalaya d) distinctly shallower Moho beneath the Himalayan arc apparently segmented by arc-normal shear zones that cross the rupture zones of the 1905 Kangra and the 2005 Kashmir earthquakes and e) Lower Vs roots of the Pamirs at $\sim 30$ and $40 \mathrm{~km}$.
Very Broad Band (VBB) Borehole Sensor With 5 Decades of Flat Frequency Response From $0.00277 \mathrm{~Hz}$ (360 Seconds) to $277 \mathrm{~Hz}$ Is Presented

GURALP, C. M., Gaiacode Ltd, Silchester Reading UK, United Kingdom, cguralp@gaiacode.com

Manufactured broad band Low noise velocity borehole sensors have limited high frequency response. In this paper results from $88.9 \mathrm{~mm}$ diameter measuring only $625 \mathrm{~mm}$ long VBB very low noise sensor with $277 \mathrm{~Hz}$ High frequency corners $(-3 \mathrm{~dB}$ ponts at 360 seconds and $277 \mathrm{~Hz})$ is presented. The high loop gain feedback sensor modules are based on mechanical long period suspension system. The modules are stacked 90 degrees to each other and the complete package with hole-lock weighs less than $24.5 \mathrm{Kg}$. Method used to test the three borehole sensors is described. The test results from triplet collocated borehole sensors with identical frequency responses are provided. The borehole sensor clamping mechanism is described. The topology of single jaw hole lock resonances is beyond $400 \mathrm{~Hz}$ providing resonant free sensor installation exceeding $400 \mathrm{~Hz}$.

Sensors, Seismicity and Imaging

Poster Session · Wednesday · 21 April · 11:30 AM Pacific

Session Chairs: Rich Briggs, U.S. Geological Survey (rbriggs@ usgs.gov); Diego Melgar, University of Oregon (dmelgarm@ uoregon.edu); Jenny Nakai, University of New Mexico (jenakai@unm.edu)

\section{An Initial Map of Scatterers in the Inner Core}

WANG, W., University of Southern California, California, USA, wwang071@ usc.edu; VIDALE, J. E., University of Southern California, California, USA, jvidale@usc.edu

The Earth's inner core (IC) is the youngest, fastest-growing, yet least understood part of the Earth. The IC grows from the solidification of the ironic outer core (OC). The latent heat and light elements are the energy source of the geodynamo, which generates the geomagnetic field.

The IC has been modeled mostly with radial layering and a hemispherical dichotomy in velocity, anisotropy, and attenuation. However, interpretation of these heterogeneous IC features has so far been incomplete and often contradictory. The features have been variously attributed to layering during formation, IC boundary deposition and melting, internal convection, anisotropic texturing, partial melt near the boundary, and perhaps modulated by interactions with the thermal boundary conditions of the overlying mantle.

Here, we applied novel beamforming and back-projection to 1970s data from the dense Large Aperture Seismic Array to build an initial 3D map of upper IC heterogeneity from the IC boundary to $500 \mathrm{~km}$ depth. Our model, which covers about $40 \%$ of the IC, has two strongly scattering regions, one beneath eastern Asia and the other beneath South America, both located where past local surveys have identified structure. These loci of strong finescale heterogeneity may be related to small dimensions and random alignments of IC crystals due to fast freezing. They correspond to areas identified as having high attenuation and lie beneath colder areas of the core-mantle boundary, perhaps providing constraints on the dynamics of the IC and the motions in the outer core.

Catalog Update: A Detailed Earthquake Catalog for the San Jacinto Fault Zone Region in Southern California

WHITE, M. C. A., University of Southern California, California, USA, malcolm.white@usc.edu; BEN-ZION, Y., University of Southern California, California, USA, benzion@usc.edu; VERNON, F., Scripps Institution of Oceanography, California, USA, flvernon@ucsd.edu

White et al. (2019) developed an automated processing procedure to derive a catalog of earthquakes from raw seismic waveform data and applied it to nine years of data (2008 through 2016) from the augmented Anza Regional Network to analyze microseismicity in the San Jacinto Fault Zone (SJFZ) region in Southern California. The White et al. (2019) catalog has 1.6 times more events in a focused study region around the SJFZ than the standard regional catalog published by the Southern California Seismic Network. We are now updating our previous catalog through 2020 using a modified procedure that leverages recent advances in machine learning to detect seismic phase arrivals. We acquire data from 131 stations from five regional networks via the Incorporated Research Institutions for Seismology Data Management Center and process them using only open-source software. We account for 3D 
velocity structure when locating earthquakes by coupling the Fast Marching Method for solving the eikonal equation with a global-search algorithm for minimizing the L2 norm of data residuals. High-precision relative event locations are obtained using differential arrival times measured by cross-correlating waveforms and a double-difference algorithm. The final catalog will be useful for various studies of seismicity patterns in the SJFZ. We will present a progress report and catalog overview at the conference.

M. C. A. White et al., (2019). A Detailed Earthquake Catalog for the San Jacinto Fault-Zone Region in Southern California. J. Geophy. Res.-Sol. Ea., 124, 6908-6930. doi: 10.1029/2019JB017641

\section{Testing a Rotational Seismometer in the Byerly Vault (BKS.BK)}

HELLWEG, M., University of California, Berkeley, California, USA, peggy@ seismo.berkeley.edu; RADEMACHER, H., University of California, Berkeley, California, USA, horst@berkeley.edu

A rotational seismometer, model iXblue BlueSeis 3A, was installed in the Byerly Vault, next to the seismic station BKS.BK operated by the UC Berkeley Seismological Lab, between 2020-03-24 and 2020-06-18. During this interval a variety of broadband translational seismometers were also in operation. This instrument uses three orthogonal optical fiber sensors to measure rotations around the North, East and Vertical axes, sampled at 200 sps, and with a sensitivity of 1 nanoradian/s/count. Its rotational response is flat between DC and $50 \mathrm{~Hz}$, and it nominally has no sensitivity to translational movement. During the deployment, the two largest regional earthquakes were the M6.5 event in southern Idaho $\left(44.465^{\circ},-115.118^{\circ}, 2020-03-31\right.$ 23:52:30 UTC) and the M6.5 event in the Monte Cristo Range of Nevada $\left(38.169^{\circ},-117.850^{\circ} \mathrm{W}, 2020-05-\right.$ 15 11:03:27 UTC) at epicentral distances and azimuths of $943 \mathrm{~km}$ and $37^{\circ}$, and 386 and $83^{\circ}$ from BKS.BK, respectively. While the Idaho quake was well recorded by all broadband seismometers, it produced signals on the BlueSeis that were only slightly above the rotational noise. Signals from the Nevada mainshock and many aftershocks down to M3.5 were also recorded well by the broadband seismometers, but only the mainshock produced signals on the all three components of the BlueSeis. The clearest and most interesting waveform on the rotational seismometer occurred during a M1.9 earthquake on the Hayward Fault at a depth of $8 \mathrm{~km}$ beneath BKS.BK. We present rotational and translational seismograms from these events and discuss our experience with the BlueSeis 3A.

\begin{tabular}{l}
\hline Strategies and Actions for Fostering a Diverse Seismology \\
Community \\
Oral Session · Wednesday · 21 April · 2:00 PM Pacific \\
Session Chairs: Valerie Sloan, National Center for \\
Atmospheric Research (vsloan@ucar.edu); Aradhna Tripati, \\
University of California, Los Angeles (atripati@g.ucla.edu); \\
Aubreya Adams, Colgate University (aadams@colgate. \\
edu); Wendy Bohon, Incorporated Research Institutions for \\
Seismology (wendy.bohon@iris.edu)
\end{tabular}

\section{Equity, Inclusion and Diversity Efforts at the USGS} Earthquake Science Center

The Earthquake Science Center Equity, Inclusion and Diversity Working Group, U.S. Geological Survey, California, USA

The U.S. Geological Survey (USGS) Earthquake Science Center (ESC) formed a volunteer Working Group on Equity, Inclusion, and Diversity (EIDWG) in 2020 in response to the widespread protests against systemic racism and structural inequities in American society, the lack of diversity in the Earth Science community, and how these issues affect the Earth Sciences, our work environments, and create inequitable impacts of earthquakes on minority communities. ESC is more than a group of geoscientists. One hundred and fifty colleagues in four states, with a wide range of expertise, carry out earthquake monitoring, hazards assessments, basic and applied research, outreach and public education, and administration and support. After initial meetings, the EIDWG formed three subgroups. The Education and Outreach subgroup seeks to engage youth to achieve future improvements in the diversity of the geosciences. An initial goal is to increase the interest level in the geosciences with outreach activities for elementary and middle schools with minority populations. The Hiring and Internships subgroup aspires to widen our recruitment pool and to use student internship and early-career hiring to build a more diverse workforce. Initial goals have been to streamline procedures for hiring students into paid internships at the USGS, to leverage collaborations with Minority Serving Institutions, and to encourage training in implicit bias for hiring committees. The Welcoming Environment subgroup strives to ensure that we become a good workplace for everyone. Initial goals include conducting a survey on experiences, attitudes, and sense of belonging; encouraging trainings and discussions on EID issues; and providing upward career paths for administrative, support, and operational personnel. We are also exploring ways to better serve minority communities as we apply our work. The EIDWG combines a grassroots approach with support from leadership and coordination with other USGS efforts.

\section{Implementing Diversity, Equity and Inclusion (DEI) Best Practices to Design Introductory Undergraduate Modules for Increasing Participation from Students of All Backgrounds into Geophysics}

PARSEKIAN, A., University of Wyoming, Wyoming, USA, aparseki@uwyo edu; HOULTON, H., Colorado School of Mines, Colorado, USA, heather houlton@gmail.com; KRUSE, S., University of South Florida, Florida, USA, skruse@usf.edu; ORMAND, C., SERC, Carleton College, Minnesota, USA cormand@carleton.edu; SLATER, L., Rutgers-Newark, New Jersey, USA 1slater@newark.rutgers.edu; SUMY, D. F., Incorporated Research Institutions for Seismology, District of Columbia, USA, danielle.sumy@iris.edu; TABER, J., Incorporated Research Institutions for Seismology, District of Columbia, USA, taber@iris.edu

To broaden representation of undergraduates in geophysics, the Incorporated Research Institutions for Seismology (IRIS) is working with community members to develop two resources that blend active-learning pedagogies with geophysics content. The IGUaNA project, Introducing Geophysics for Urban and Near-surface Applications, has developed a set of curricular modules, using evidence-based pedagogies, that apply seismic, electrical, and ground penetrating radar techniques to societally-relevant, real-world problems. Teaching materials are designed for introductory-level undergraduate courses to serve the most diverse student population and to reach students earlier in their studies than typical geophysics modules. The modules are designed to develop students' quantitative and critical thinking skills by using authentic datasets related to examining salt marsh pollution and restoration, identifying historical burial grounds and urban infrastructure, and urban renewal planning.

The second resource is a 3-hour asynchronous online careers module designed to supplement non-major introductory geoscience courses. The module will engage a diverse student population and reduce barriers to pursuing a geoscience degree by highlighting career opportunities using DEI best practices. The module has five objectives: 1) summarize geophysics concepts, 2) demonstrate how geophysics impacts society, 3) highlight the diversity of geophysics careers, 4) describe skills for careers, and 5) connect careers with students' diverse identities. Diverse role models and career examples are integrated throughout the content, as are community approaches to reducing implicit bias, microaggressions, and other DEI topics that might impact students. These NSF-funded resources will be peer-reviewed, tested in undergraduate classrooms, revised, and then shared on the Science Education Resource Center (SERC) and AGI GOLI websites and will be available upon completion of the ongoing pilot test program.

\section{IRIS's Inclusive Research Opportunities Contribute to a Diverse Seismology Community}

HUBENTHAL, M., Incorporated Research Institutions for Seismology, New York, USA, hubenth@iris.edu; TABER, J., Incorporated Research Institutions for Seismology, District of Columbia, USA, taber@iris.edu

The IRIS Undergraduate Internship Program has facilitated summer research opportunities for 245 students since 1998. Between 1998 and 2008 average participation rates for underrepresented minorities was just $6.7 \%$, and for females of all races and ethnicities $42.4 \%$. Through the combination of intentionality, effort, program evaluation and time, average participation rates have increased for both populations to $21.4 \%$ and $54.4 \%$ respectively (2009 - 2020), while maintaining a satisfied pool of mentors. Tracking of program alumni indicates these efforts positively contribute to a diverse geosciences workforce. However, it also finds differences in the career pathways between URM and majority alumni suggesting more work is needed.

This change began with intentional commitments through explicit program goals and success metrics and was enabled through research-informed adjustments to the program's operations. This included targeted recruitment efforts and partnerships, and modifications to the application to accommodate diverse populations and perspectives for success. Educating selection 
panels about diversity issues and bias and the development of a risk-based portfolio approach to selection have further supported this change. Once diverse students, including those with disabilities, LGBTQ+ students and non-traditional students were accepted, additional effort in the running of the program to ensure inclusivity and safety were critical. For example, IRIS, in collaboration with others, has led the development of anti-harassment/discrimination training for undergraduate geoscience students. Monitoring and adjusting this work through the collection and analysis of data to ensure the desired impact has been critical. The process has required patience. However, even annual small steps, aligned in the same direction, lead to the sort of change IRIS, and the geoscience community more broadly, seeks.

\section{Learning in a Crisis: Online Skill Building Workshop Addresses Immediate Pandemic Needs and Offers Possibilities for More Inclusive Trainings}

BRUDZINSKI, M. R., Miami University, Ohio, USA, brudzimr@muohio. edu; HUBENTHAL, M., Incorporated Research Institutions for Seismology, District of Columbia, USA, hubenth@iris.edu; FASOLA, S., Miami University, Ohio, USA, fasolasl@miamioh.edu; SCHNORR, E., University of California, Santa Cruz, California, USA, eschnorr@ucsc.edu

The COVID-19 pandemic led to the suspension of many summer research opportunities for STEM students. In response, the IRIS Education and Outreach program, in collaboration with Miami University, offered a free online Seismology Skill Building Workshop to increase undergraduates' knowledge, skills, self-efficacy, and interest in observational seismology and scientific computing. Registrations were received from 760 undergraduates representing 60 different countries. U.S. participants consisted of $59 \%$ women and $29 \%$ from populations traditionally underrepresented in geoscience. The workshop design consisted of a tailored Linux virtual machine, regular webinars, a Slack workspace, tutorial-style active e-learning assignments, and an optional final project. Every other week for 12 weeks, a module with $\sim 6$ assignments was released to build skills with Linux, webservices, Python, Jupyter notebooks, mapping software, seismic analysis code, and array processing. A final module focused on competitiveness for graduate school, summer internships, and professional jobs. Evaluation of the workshop relied on registration data, pre-/post- surveys, and performance data from the learning management system. 440 completed at least 1 assignment, 224 completed at least $80 \%$ of the assignments, and 191 completed all 35 assignments, significantly higher than most comparable large-scale, open-access courses. Participants invested $\sim 6$ hours per week and averaged a score of $88 \%$ on assignments. We identified $>60 \%$ normalized gain in scientific computing skills. There is evidence the inclusive design of the workshop was able to attract and retain a diverse population, but we are investigating whether benefits were evenly experienced. Regardless of the degree of completion, participants perceived the workshop quite positively: $96 \%$ described it as high to very high quality, $83 \%$ satisfied to very satisfied with their experience, and $70 \%$ very likely to recommend it to peers. We will discuss future directions for the workshop, including strategies to continue broadening participation and improving retention.

USGS Geologic Hazard Science Center's Strategies and Actions for Fostering a Diverse Geoscience Community ALLSTADT, K., U.S. Geological Survey, Colorado, USA, kallstadt@usgs. gov; JAISWAL, K. S., U.S. Geological Survey, Colorado, USA, kjaiswal@usgs. gov; KHTEIAN, A., U.S. Geological Survey, Colorado, USA, akhteian@usgs. gov; LUCO, N., U.S. Geological Survey, Colorado, USA, nluco@usgs.gov; SCHAEFER, L. J., U.S. Geological Survey, Colorado, USA, 1schaefer@usgs. gov; SHIRO, B., U.S. Geological Survey, Colorado, USA, bshiro@usgs.gov; SHUMWAY, A. M., U.S. Geological Survey, Colorado, USA, ashumway@usgs. gov; SLAUGHTER, R., U.S. Geological Survey, Colorado, USA, rslaughter@ usgs.gov; WALD, D. J., U.S. Geological Survey, Colorado, USA, wald@usgs. gov

Events in 2020 have brought to the forefront the importance of addressing issues and taking meaningful actions related to Diversity, Equity, and Inclusion (DEI) at all levels within academia, the private sector, and Government. In response to this call to action, the USGS Geologic Hazards Science Center (GHSC) formed a DEI Committee in late 2020. We maintain that DEI in our community is critical to long-term job satisfaction, quality of life at work, and staff retention, all while contributing to not only the productivity and the robustness of our science, and to social justice more broadly. While female representation in staff and leadership at the Center has increased from 2000 to 2020 , this success has not been paralleled in other areas of DEI. A more representative workforce is required to assure that research and products related to natural disaster mitigation address the needs for all communities. The DEI Committee developed a Charter that outlines our first-year activi- ties and goals, including: (1) Pursuing guidance from DEI professionals, and transferring that knowledge internally; (2) Surveying the GHSC community and identifying DEI-related gaps in our Center; (3) Recommending remedial actions and activities; (4) Working with Center personnel and leadership to implement these recommendations through attention to DEI in recruitment and hiring, employee performance plans, and other Center activities; and (5) Contributing to the adoption of a system of accountability to ensure external grants adhere to the principles of DEI. We also recommended that increased activities related to Communication, Education, and Outreach (CEO) by GSHC members-particularly those targeting STEM education and underrepresented groups-will help further promote participation in DEI goals. The Committee aims to firmly foster these DEI and CEO principles and activities as core cultural values of our Center and ensure that these activities complement broader USGS initiatives

Strong-Motion Data Processing and Dissemination: Stateof-the-Art and Outlook

Oral Session · Friday · 23 April · 9:45 Am Pacific

Session Chairs: Carlo Cauzzi, ORFEUS, ETH Zürich (carlo. cauzzi@sed.ethz.ch); Hamid Haddadi, California Geological Survey, California Department of Conservation, COSMOS (hamid.haddadi@conservation.ca.gov); Giovanni Lanzano, Istituto Nazionale di Geofisica e Vulcanologia (giovanni. lanzano@ingv.it); Eric M. Thompson, U.S. Geological Survey (emthompson@usgs.gov)

\section{Automated Data Processing and Dissemination Workflow of the European Rapid Raw Strong Motion System}

CAUZZI, C., ORFEUS \& Swiss Seismological Service at ETH Zürich, Zürich, Switzerland, carlo.cauzzi@sed.ethz.ch; BIEŃKOWSKI, J., ORFEUS Data Center and Royal Netherlands Meteorological Institute (KNMI), De Bilt, Netherlands, jarek.bienkowski@knmi.nl; CLINTON, J., Swiss Seismological Service, ETH Zürich, Zürich, Switzerland, jclinton@sed.ethz.ch; SLEEMAN, R., ORFEUS Data Center and Royal Netherlands Meteorological Institute (KNMI), De Bilt, Netherlands, reinoud.sleeman@knmi.nl

We present the data processing and publication workflow of the European Rapid Raw Strong Motion system (RRSM, http://orfeus-eu.org/rrsm), a service within ORFEUS (Observatories and Research facilities for European Seismology; http://orfeus-eu.org/) which delivers automatically computed peak ground motions (PGM) and engineering intensity measures (IM) within minutes of the occurrence of any M3.5+ earthquake in the greater European region. The automated data retrieval, processing and publication procedure of the RRSM system is triggered by earthquake alerts of the EMSC (https:// www.emsc-csem.org/Earthquake/) and uses all available on-scale high-sampling-rate data from the European Integrated Data Archive (EIDA; http:// orfeus-eu.org/data/eida/) within a given magnitude-dependent distance from the earthquake location. Data and metadata collection relies on federated FDSN (station, dataselect) and EIDA-specific (routing) web services (http:// orfeus-eu.org/data/eida/webservices/). Waveform processing is carried out by the SeisComP module scwfparam (https://www.seiscomp.de/doc/apps/ scwfparam.html) and follows the typical steps of digital signal processing, including saturation checks, restitution, filtering, integration / differentiation, based on a set of configurable options and parameters. Scwfparam also provides processed waveforms, response spectra, and formatted PGM input to ShakeMap. The results are disseminated via a web interface developed in Django (https://www.djangoproject.com/) and fed by ad-hoc PGM \& IM web services. Additional quality checks are performed by the web interface, aimed at automatically blanketing suspicious PGM values based on physical and seismological considerations. Among the aims of this contribution is to encourage community feedback for improvements.

\section{Automated Detection of Clipping in Broadband Earthquake Records}

KLECKNER, J. K., U.S. Geological Survey, Colorado, USA, jkleckner@usgs. gov; WITHERS, K. B., U.S. Geological Survey, Colorado, USA, kwithers@ usgs.gov; THOMPSON, E. M., U.S. Geological Survey, Colorado, USA, emthompson@usgs.gov; REKOSKE, J. M., U.S. Geological Survey, Colorado, USA, jrekoske@usgs.gov; WOLIN, E., Albuquerque Seismological Laboratory, 
New Mexico, USA, ewolin@usgs.gov; MOSCHETTI, M. P., U.S. Geological Survey, Colorado, USA, mmoschetti@usgs.gov

Waveform clipping, meaning that the amplitude exceeded the instrument's dynamic range limit, renders records useless for many applications. While clipping is typically easy to identify visually, automated clip detection approaches have not yet received much attention. We propose an automated algorithm for determining if a ground motion record is clipped (i.e., if the recorded motions exceed the dynamic range of the instrument and/or digitizer). We consider multiple algorithms for classifying the records as clipped. These methods include: (1) an algorithm based on the percentage difference in adjacent data points, (2) the standard deviation of the data within a moving window, (3) the histogram of the data values, (4) the second derivative of the data, and (5) the amplitude of the data. To assess the accuracy of these algorithms and to optimize the parameters of each algorithm, we compile records from earthquakes across a range of geographic regions, tectonic environments, and instrument types. We then manually classify each record for the presence of clipping, use the classified records to optimize the different algorithm parameters, and develop a model that combines the parameters of all of the different models with artificial neural networks. We find the histogram approach to be the most accurate algorithm with an accuracy of $94.8 \%$, and the artificial neural network method provides even further accuracy in clipping identification with a validation accuracy reaching $97 \%$.

\section{New Webservice Tools and Updates at the Center for Engineering Strong-Motion Data (CESMD)}

HAGOS, L. Z., California Geological Survey, California, USA, lijam.hagos@ conservation.ca.gov; SCHLEICHER, L. S., U.S. Geological Survey, California, USA, 1schleicher@usgs.gov; HADDADI, H., California Geological Survey, California, USA, hamid.haddadi@conservation.ca.gov; STEIDL, J., University of California, Santa Barbara, California, USA, steidl@ucsb.edu; THOMPSON, E. M., U.S. Geological Survey, Colorado, USA, emthompson@usgs.gov; GRABER, L., California Geological Survey, California, USA, laura.graber@ conservation.ca.gov; GEE, L., U.S. Geological Survey, California, USA, lgee@ usgs.gov

The Center for Engineering Strong-Motion Data (CESMD), an internationally utilized joint center of the U.S. Geological Survey (USGS) and the California Geological Survey (CGS), provides a single access point for earthquake strongmotion records and station metadata from the CGS California Strong-Motion Instrumentation Program (CSMIP), the USGS National Strong-Motion Project, the USGS Advanced National Seismic System, and other affiliates. The CESMD has developed new tools to facilitate access to strong-motion data and metadata for use in post-earthquake response and scientific and engineering research applications. The Center provides raw and processed strong-motion data via the Engineering Data Center (EDC) and Virtual Data Center (VDC) web portals currently hosting more than 52,000 records with peak ground accelerations greater than $0.1 \% \mathrm{~g}$ from over two thousand earthquakes. This presentation will highlight updates at CESMD and new tools available to the seismic and engineering community for accessing strong-motion datasets at CESMD. These updates include: 1) an initiative to merge the waveform databases at the EDC and VDC, 2) new access options to station metadata, earthquake information, and strong motion records via either the web-interface or a web-services client, 3) an interactive map interface to facilitate easy user viewing and access to earthquake, station, and record information, 4) development of a new web application tool for data conversion, 5) efforts to standardize the format of waveform records in the database into a consistent format, 6) a modernized compilation of seismic station site geology, measured or inferred Vs30 values, shear-wave profiles, NEHRP site class, and available structure instrument deployment schematics, and 7) a special studies page with several research topic-specific ground motion datasets that offer uniform processing of records from a variety of sources.

\section{Recent Improvements to Strong Motion Monitoring in Canada}

CASSIDY, J. F., Natural Resources Canada, Sidney, Sidney, Canada, john. cassidy@canada.ca; BENT, A. L., Natural Resources Canada, Ottawa, Canada, allison.bent@canada.ca

As of January, 2021, one of the most significant changes in strong motion monitoring in Canada since the first deployment of accelerometers in 1963, has been completed. This upgrade provides $\sim 100$ new strong motion instruments co-located with weak-motion instruments (6-component) at Canadian National Seismograph Network (CNSN) bedrock sites with an additional $\sim 40$ sites (mostly bedrock) having stand-alone strong motion instruments. The vast majority of these CNSN instruments are located in the high seismic hazard regions of Canada, especially Vancouver Island and southwest British Columbia, Haida Gwaii, and the St. Lawrence Valley region. Also, for the first time, strong motion instruments are located in northern Canada.

The Titan instruments are currently streaming data at $100 \mathrm{~s} / \mathrm{s}$ and have a maximum $4 \mathrm{~g}$ recording level. The continuous records from the Titan sensors are available by request to the NRCan's National Waveform Archive. To ensure high availability and resiliency, all seismic data are sent simultaneously to two data centers: one in Sidney, British Columbia and one in Ottawa, Ontario. The acquisition systems forward the data to an archive server, where the data are saved and available to the routine processing systems.

Strong motion waveform data and station metadata are freely available via a variety of methods.

In addition to these strong motion instruments there are an additional 350+ strong motion instruments across Canada (mostly in British Columbia) owned and operated by other organisations (e.g., B C Ministry of Transportation and Highways, BC Hydro, and more). These instruments are primarily located on soil sites.

With this recent CNSN upgrade, and the continued expansion of strong motion monitoring by other organisations across Canada, engineers will have access to more (and very valuable) strong motion data for Canadian earthquakes. This will lead to improved earthquake hazard models, improved seismic design for infrastructure, and safer communities.

\section{State of the Art and Future Perspectives of the Engineering Strong Motion Database Data Processing}

D’AMICO, M., Istituto Nazionale di Geofisica e Vulcanologia, Milano, Italy, maria.damico@ingv.it; LUZI, L., Istituto Nazionale di Geofisica e Vulcanologia, Milano, Italy, lucia.luzi@ingv.it; MASCANDOLA, C., Istituto Nazionale di Geofisica e Vulcanologia, Milano, Italy, claudia.mascandola@ ingv.it; FELICETTA, C., Istituto Nazionale di Geofisica e Vulcanologia, Milano, Italy, chiara.felicetta@ingv.it; RUSSO, E., Istituto Nazionale di Geofisica e Vulcanologia, Milano, Italy, emiliano.russo@ingv.it; PUGLIA, R., Istituto Nazionale di Geofisica e Vulcanologia, Milano, Italy, rodolfo.puglia@ ingv.it; LANZANO, G., Istituto Nazionale di Geofisica e Vulcanologia, Sezione di Milano, Milan, Italy, giovanni.lanzano@ingv.it

In this work, we present the new strong-motion service for the data processing of the Engineering Strong Motion database (ESM, https://esm-db.eu) and the future perspectives for automated quality screening and processing of large ground-motion datasets.

ESM is developed under the general coordination of the ORFEUS (Observatories and Research facilities for European Seismology; http://orfeuseu.org/) strong-motion management committee with the aim to enables users to access daily updated strong-motion waveforms related to events with magnitude greater than 4, mainly recorded in the Pan-European regions. ESM is fully compatible with the European Integrated Data Archive (EIDA; http:// orfeus-eu.org/data/eida/) and disseminates waveforms and related metadata according to the Federation of Digital Seismograph Networks (FDSN, https:// www.fdsn.org/networks/).

Accelerometric waveforms uploaded in the ESM database are routinely processed following a standard procedure (Paolucci et al., 2011; Puglia et al., 2018) and then visually inspected and revised by means of a renewed userfriendly web interface (https://esm-db.eu/processing/select). Although the expert judgment both on the data quality and the processing settings is an undeniable added value, the ever-increasing growth rate (currently about 2,000 records per year) requires the development of an automated protocol to reduce the need for manual intervention. In this regards the machine-learning-based method should open new perspectives to automatically classify and process large ground-motion datasets. Furthermore, it should be advisable to implement in the ESM data processing service alternative processing schemes accounting for specific features of the seismic records such as near-source effects (i.e., fling-step). 


\section{Strong-Motion Data Processing and Dissemination: State- of-the-Art and Outlook \\ Poster Session · Friday · 23 April · 11:30 Am Pacific \\ Session Chairs: Carlo Cauzzi, ORFEUS, ETH Zürich (carlo. cauzzi@sed.ethz.ch); Hamid Haddadi, California Geological Survey, California Department of Conservation, COSMOS (hamid.haddadi@conservation.ca.gov); Giovanni Lanzano, Istituto Nazionale di Geofisica e Vulcanologia (giovanni. lanzano@ingv.it); Eric M. Thompson, U.S. Geological Survey (emthompson@usgs.gov)}

\section{Development of a University Seismic Network in Metropolitan Lima, Peru}

GONZÁLES TRUIILLO, C., National University of Engineering, Peru, Lima, Peru, cgonzalest@uni.edu.pe; LAZARES LA ROSA, L., National University of Engineering, Peru, Lima, Peru, f_lazares@uni.edu.pe; AGUILAR BARDALES, Z., National University of Engineering, Peru, Lima, Peru, zaguilar@uni.edu. pe; ALVA HURTADO, J., National University of Engineering, Peru, Lima, Peru, jalvah@uni.edu.pe

In high seismic hazard zones, such as Metropolitan Lima, the development of regional and local seismic networks has always been a key aspect for the evaluation of path and site effects. In this regard, the National University of Engineering (UNI), through the Japan Peru Center for Earthquake Engineering Research and Disaster Mitigation (CISMID), has been working on this matter with the implementation of the CISMID's Accelerometer Network (REDACIS).

Starting with 13 RION analog equipment in 1988, which were replaced by digital Kinemetrics accelerometers in the early 2000s, REDACIS has collected important data related to the latest events in Peru, such as Atico (2001) and Pisco (2007) earthquakes. In recent years, and with funding from the Ministry of Economy, CISMID has enhanced its capabilities through the establishment of CISMID's Earthquake Engineering Observation Center (CEOIS) and the acquisition of 50 RefTek 130-SMA accelerometers to be deployed throughout Metropolitan Lima. At this time, 35 of these equipment are already installed in schools, universities, municipalities and health facilities which send continuous data to the CEOIS server by means of TCP/ UDP protocols. In case of a seismic event, raw data is remotely acquired from the server and processed by REDACIS's team, in order to generate reports containing relevant information, such as values of peak ground acceleration, Fourier and response spectra. One of the last important events that our team has dealt with was the Lagunas earthquake (2019), which was recorded in 24 stations. The information was shared with the public through social networks and the official CISMID website.

Among the current and planned improvements, within a project funded by the World Bank and Fondecyt-Peru, are installing the remaining accelerometers in soil deposits with diverse geomorphological conditions in the capital, implementing SeisComp software and SeedLink protocol for a more efficient acquisition system and obtaining seismic intensity maps by means of the use of amplification factors and simple Kriging interpolation schemes.

\section{The Quest for Rock Site Characterization and Reference} Site Definition for the National Seismic Network of Greece KTENIDOU, O., National Observatory of Athens, Athens, Greece, olga. ktenidou@noa.gr; EVANGELIDIS, C., National Observatory of Athens, Athens, Greece, cevan@noa.gr; GKIKA, F., National Observatory of Athens, Athens, Greece, gkika@noa.gr

The broadband seismic network of the National Observatory of Athens covers most mainland and island Greek territory with 50 broadband seismic stations. These are generally considered as rock, though without any in-situ site measurement of shear-wave velocity profiles or empirical seismic response estimation. Now, more than ever, ground-motion databases require more sophisticated, data-derived (rather than inferred by proxies) site metadata. Now, more than ever, the need for broadband sensor data, in addition to accelerometric data, is also becoming apparent, so as to better represent rock recordings - a site condition that is very much missing in international strong-motion databases to date. There are, hence, many good reasons now that render better site characterization of the Greek national seismic network's stations imperative. Moreover, certain stations that were up to now considered as rock were recently shown by the authors to exhibit significant variability or atypical seismic response with respect to their generic classification. Hence, the question of reference-station investigation becomes crucial, and the fastest and most economic method to attain this is using the recordings themselves. We use the traditional empirical approach known as the horizontal-to-vertical spectral ratio with a novel twist, as well as a more recent approach using groundmotion model residuals, namely the systematic deviation of a site compared to the average class prediction. It is important to investigate how the response within what is classified a priori as rock stations may vary, or even exhibit directional effects. The results can aid in the quest for a more harmonized and data-driven site characterization throughout Greece, which will in turn feed into the national and European data platforms for strong-motion services, assisting with automatic procedures such as data and metadata quality assurance and outlier identification.

\section{Towards an Earthquake Ground-Motion Database for Western and Central Australia}

GHASEMI, H., Geoscience Australia, Canberra, Australia, hadi.ghasemi@ ga.gov.au; ALLEN, T. I., Geoscience Australia, Canberra, Australia, trevor. allen@ga.gov.au

A ground-motion dataset from moderate-to-large magnitude earthquakes is compiled for earthquakes occurring in Proterozoic and Archean terranes of the Australian continental crust. Data, which are predominantly weak-motion velocity recordings, are compiled from low-sample-rate continuous waveform buffers and segmented high-sample-rate data (where available) recorded by the Australian National Seismograph Network (ANSN). Additional data are retrieved from various temporary deployments and, more recently, from the Incorporated Research Institutions for Seismology (IRIS) data centre. All raw data were first converted to a uniform miniSEED format from various binary and ASCII formats used over time. Corresponding instrument metadata is compiled in the standard FDSN StationXML format. The dataset currently contains 1497 earthquake recordings from 164 earthquakes occurring between 1990 and 2019. The magnitudes of earthquakes within the dataset range from $M_{\mathrm{W}} 2.5$ to 6.1 with hypocentral distances up to $1500 \mathrm{~km}$. The timeseries data are consistently processed to correct for the instrument response and to reduce the effect of background noise. A range of engineering parameters is calculated in time and frequency domains using the USGS's groundmotion processing software, "gmprocess". Numerous near-source recordings exceed peak accelerations of $0.10 \mathrm{~g}$ and range up to $0.66 \mathrm{~g}$, while the maximum peak velocity of the dataset exceeds $27 \mathrm{~cm} / \mathrm{s}$. Despite the limited number of seismic stations located throughout the Australian continental landmass, the dataset compiled herein will improve characterisation of ground-motion attenuation in the region and will provide an excellent supplement to groundmotion datasets collected in analogue seismotectonic regions worldwide.

\begin{tabular}{l}
\hline Subduction Processes Along Latin America Subduction \\
Zones \\
I: Oral Session· Monday · 19 April · 9:45 AM Pacific \\
II: Oral Session· Monday · 19 April · 2:00 PM Pacific \\
Session Chairs: Hans Agurto-Detzel, Géoazur, IRD (agurto@ \\
geoazur.unice.fr); Susan L. Beck, University of Arizona \\
(slbeck@arizona.edu); Isabella Gama, Brown University \\
(isabella_gama_dantas@brown.edu); Rafael Almeida, Yachay \\
Tech University (ralmeida@yachaytech.edu.ec)
\end{tabular}

Application of ISC-PPSM to Subduction Zone Seismicity in South and Central America

GARTH, T. I. M., International Seismological Centre, Thatcham, United Kingdom, tom.garth@isc.ac.uk; SIGLOCH, K., University of Oxford, Oxford, United Kingdom, karin.sigloch@earth.ox.ac.uk; STORCHAK, D. A., International Seismological Centre, Thatcham, United Kingdom, dmitry@isc. ac.uk

The precise depth of shallow earthquakes that occur outside the aperture dense seismic networks remains poorly constrained in both local and regional earthquakes. Even in well instrumented subduction zone settings this can lead to a lack of depth resolution for earthquakes occurring offshore. Earthquake locations and moment tensor solutions for these earthquakes can therefore often be set to a fixed depth, while significant variations can be seen between the moment tensors reported. In order to address these uncertainties, we report the earthquake depth and moment tensor uncertainties inferred for shallow $(<40 \mathrm{~km})$ subduction zone earthquakes in South and Central America, 
using the techniques of the newly implemented ISC-PPSM (International Seismological Centre - Probabilistic Point Source Model) catalogue. ISCPPSM is a global earthquake catalogue which employs a Bayesian inversion strategy to jointly solve for the earthquake moment tensor, source time function (STF) and depth. This allows the trade-offs between STF and depth to be investigated, while quantifying the uncertainty in the earthquake moment tensor. This inversion strategy allows new depth resolution to be added, especially to relatively shallow earthquakes, where tele-seismically observed depth phases would otherwise be subsumed into the STF. Earthquake depths determined in this way will then be used to inform the depth of earthquakes in the ISC-bulletin, where the depth would otherwise be uncertain or unconstrained. The ensemble of earthquake point source solutions produced also allows the error in the earthquake mechanism to be quantified. In this study, probabilistic moment tensor solutions for moderate magnitude (Mw $5.8-7.0$ ) earthquakes are compared to the geometry of the subducting slab in order to estimate the portion of offshore seismicity that occurs directly on the subduction zone interface, and add potential constraints to the roughness of the subduction interface.

\section{Repeating Earthquakes Cluster at the Edge of the Afterslip in the Aftermath of the 16 April 2016 M7.8 Pedernales Earthquake in Ecuador}

CHALUMEAU, C., Géoazur, Université Côte d’Azur, IRD, CRNS, Observatoire de la Côte d'Azur, Valbonne, France, caroline.chalumeau@geoazur.unice. fr; AGURTO-DETZEL, H., Géoazur, Université Côte d'Azur, IRD, CRNS, Observatoire de la Côte d'Azur, Valbonne, France, agurto@geoazur.unice.fr; DE BARROS, L., Géoazur, Université Côte d'Azur, IRD, CRNS, Observatoire de la Côte d'Azur, Valbonne, France, debarros@geoazur.unice.fr; CHARVIS, P., Géoazur, Université Côte d'Azur, IRD, CRNS, Observatoire de la Côte d'Azur, Valbonne, France, philippe.charvis@geoazur.unice.fr; GALVE, A., Géoazur, Université Côte d'Azur, IRD, CRNS, Observatoire de la Côte d'Azur, Valbonne, France, audrey.galve@geoazur.unice.fr; RIETBROCK, A., Geophysical Institute, Karlsruhe Institute of Technology, Karlsruhe, Germany, andreas rietbrock@kit.edu; ALVARADO, A., Instituto Geofísico, Escuela Politécnica Nacional, Quito, Ecuador, aalvarado@igepn.edu.ec; HERNANDEZ, S., Instituto Geofísico, Escuela Politécnica Nacional, Quito, Ecuador, hernandez. stephen@gmail.com; BECK, S. L., University of Arizona, Arizona, USA, slbeck@email.arizona.edu; FONT, Y., Géoazur, Université Côte d'Azur, IRD, CRNS, Observatoire de la Côte d'Azur, Valbonne, France, font@geoazur. unice.fr; HOSKINS, M. C., Lehigh University, Pennsylvania, USA, mac716@ lehigh.edu; LEON-RIOS, S., Geophysical Institute, Karlsruhe Institute of Technology, Karlsruhe, Germany, sergio.leon-rios@kit.edu; MELTZER, A. Lehigh University, Pennsylvania, USA, ameltzer@lehigh.edu; LYNNER, C., University of Delaware, Delaware, USA, clynner@udel.edu; ROLANDONE, F., Institut des Sciences de la Terre Paris, Sorbonne Université, CNRS-INSU, Paris, France, frederique.rolandone@upmc.fr; NOCQUET, J., Géoazur, Université Côte d'Azur, IRD, CRNS, Observatoire de la Côte d'Azur, Valbonne, France, nocquet@geoazur.unice.fr; REGNIER, M., Géoazur, Université Côte d'Azur, IRD, CRNS, Observatoire de la Côte d'Azur, Valbonne, France, marc. regnier@geoazur.unice.fr; RUIZ, M., Instituto Geofísico, Escuela Politécnica Nacional, Quito, Ecuador, mruiz@igepn.edu.ec; SOTO-CORDERO, L., Lehigh University, Pennsylvania, USA, lillian.soto-cordero@us.af.mil; VACA, S., Instituto Geofísico, Escuela Politécnica Nacional, Quito, Ecuador, svaca@ igepn.edu.ec; SEGOVIA, M., Instituto Geofísico, Escuela Politécnica Nacional, Quito,Ecuador, msegovia@igepn.edu.ec

The South American subduction zone is host to a variety of interacting seismic and aseismic processes. Among them are repeating earthquakes, earthquakes that repeatedly break a single, time-invariant fault patch. Repeating asperities are thought to be loaded by aseismic slip, leading to repeated rupture. Repeating earthquakes are therefore useful tools to study aseismic slip and fault mechanics, with possible applications to earthquake triggering, loading rates and earthquake forecasting.

In this study, we analyze one year of aftershocks following the 16th April $2016 \mathrm{Mw}$ 7.8 Pedernales earthquake in Ecuador to find repeating families, using data recorded by permanent and temporary seismological stations. In our area, seismicity during both the inter-seismic and post-seismic periods has been previously linked to aseismic slip. We calculate waveform crosscorrelation coefficients (CC) on all available catalogue events, which we use to sort events into preliminary families, using a minimum CC of 0.95 . These events were then stacked and used to perform template-matching on the continuous data. In total, 376 earthquakes were classified into 62 families of 4 to 15 earthquakes, including 8 from the one-year period before the mainshock. We later relocated these earthquakes using a double-difference method, which confirmed that most of them did have overlapping sources.
Repeating earthquakes seem to concentrate largely around the areas of largest afterslip release, where afterslip gradient is the highest. We also find an increase in the recurrence time of repeating events with time after the mainshock, over the first year of the postseismic period, which highlights a possible timeframe for the afterslip's deceleration. Our results suggest that while most repeating aftershocks are linked to afterslip release, the afterslip gradient may play a bigger role in determining their location than previously thought.

\section{Small Patches of the Cocos Megathrust in Mexico Ruptured by the June 2020 Mw 7.4 La Crucecita, March 2012 Mw 7.4 Ometepec and February 2018 Mw 7.2 Pinotepa Earthquakes}

FIELDING, E. I., Caltech, California, USA, eric.j.fielding@jpl.nasa.gov JOLIVET, R., École Normale Supérieure, Paris, France, romain.jolivet@ens. fr; GOMBERT, B., Collect Localisation Satellites, Ramonville Saint-Agne, France, baptiste.gombert@gmail.com; GONZÁLEZ-ORTEGA, A. J., CICESE, Ensenada, Mexico, aglez@cicese.mx; DUPUTEL, Z., Université de Strasbourg, Strasbourg, France, zacharie.duputel@unistra.fr; LIANG, C., Caltech, California, USA, cunrenl@caltech.edu; BEKAERT, D., Caltech, California, USA, David.Bekaert@jpl.nasa.gov; SAMSONOV, S., CCMEO, Ottawa Canada, sergey.samsonov@canada.ca; MINSON, S., U.S. Geological Survey, California, USA, sminson@usgs.gov; MAURER, J., Missouri S\&T, Missouri, USA, jmaurer@mst.edu; AMPUERO, J., Université Côte d'Azur, Géoazur, Nice, France, ampuero@geoazur.unice.fr

Three earthquakes with $M_{w} 7.2$ to 7.4 have ruptured the megathrust beneath Oaxaca in the last 9 years. The megathrust of the Cocos Plate beneath Southern Mexico has major variations in the geometry and behavior. The segment beneath the Mexican state of Oaxaca has relatively frequent magnitude 7-7.5 earthquakes on the shallow part of the megathrust and within the subducting slab, and it also has large aseismic slow-slip events. The recent magnitude $7+$ megathrust epicenters in 2012, 2018, and 2020 have been at similar depths between 20 and $25 \mathrm{~km}$ near the up-dip edge of the slow-slip zone. We study the ruptures of the 20 March $2012 \mathrm{M}_{\mathrm{w}} 7.4$ Ometepec earthquake near the Guerrero-Oaxaca border, the16 February $2018 \mathrm{M}_{\mathrm{w}} 7.2$ Pinotepa earthquake near Pinotepa Nacional in Oaxaca, and the 23 June $2020 \mathrm{M}_{\mathrm{w}} 7.4 \mathrm{La}$ Crucecita earthquake beneath southeast Oaxaca on the megathrust.

We use geodetic measurements from interferometric analysis of synthetic aperture radar (InSAR) and GNSS coseismic offsets to estimate finite-fault slip models for all three earthquakes. We analyzed InSAR data from Copernicus Sentinel-1A and -1B satellites and JAXA ALOS-2 satellite for 2018 Pinotepa and 2020 La Crucecita and Canadian RADARSAT-2 for 2012 Ometepec. Our Bayesian (AlTar) static slip models for the Pinotepa and Ometepec earthquakes shows all of the slip confined to very small (10-20 $\mathrm{km}$ diameter) ruptures, similar to some early seismic waveform fits, and the two ruptures do not overlap. Analysis of La Crucecita indicates rupture over slightly larger 20 by $40 \mathrm{~km}$ area. The earthquakes ruptured small areas in part of the Cocos megathrust that has been previously mapped as partially coupled; at least small asperities in that zone of the subduction interface are fully coupled and fail in high stress-drop earthquakes. Limited extent of these ruptures may leave large shallower portions of the megathrust locked and loaded.

\section{Synchronous Seismic Sequences and Slow Slip Events Along the South America Subduction Zone}

NOCQUET, I., Géoazur, IRD, Valbonne, France, nocquet@geoazur.unice. fr; VACA, S., IG-EPN, Quito, Ecuador, svaca@igepn.edu.ec; VILLEGASLANZA, J., IGP, Lima, Peru, jvillegas@igp.gob.pe; KLEIN, E., ENS Paris, Paris, France, klein@biotite.ens.fr; VALLEE, M., Institut de Physique du Globe de Paris, Paris, France, vallee@ipgp.fr; POTIN, B., DGF, Universidad de Chile, Santiago, Chile, bertrand.potin@uchile.cl; MOTHES, P., IG-EPN, Quito, Ecuador, pmothes@igepn.edu.ec; PASTEN-ARAYA, F., DGF, Universidad de Chile, Santiago, Chile, fpasten012@gmail.com; TISSANDIER, R., Institut de Physique du Globe de Paris, Paris, France, tissandier@ipgp.fr; VIGNY, C., ENS Paris, Paris, France, vigny@geologie.ens.fr; JARRIN, P., Sorbonne Université, ISTEP, Paris, France, paulalbertoj@gmail.com; DUPUTEL, Z., IPGS, Strasbourg, France, zacharie.duputel@unistra.fr; ROLANDONE, F., Sorbonne Université., ISTEP, Paris, France, frederique.rolandone@upmc. fr; RUIZ, S., DGF, Universidad de Chile, Santiago, France, sruiz@uchile.cl BATTAGLIA, J., Université Clermont Auvergne, LMV, Clermont-Ferrand, France, j.battaglia@opgc.univ-bpclermont.fr

While episodic tremor and slow slip events (ETS) downdip of the highlylocked portion of the subduction interface have been extensively studied, the South America subduction zone hosts a somewhat different strain release process where Slow Slip Events (SSE) are accompanied with intense micro- 
seismicity, that we hereafter referred as S5 (Synchronous Seismic Sequence and Slow Slip).

Such a S5 was first observed at shallow depth $(10 \mathrm{~km})$, where Vallée et al. (2013) document a one week long SSE of equivalent magnitude 6.1-6.3 Synchronous seismic swarm appears organized into families of repeating earthquakes, progressively activated as slow slip develops. A longer sequence was also documented at immediately north of the rupture of the Mw 7.8 2016 Pedernales earthquake (Vaca et al., 2018). For both events, seismicity accounts for only a few percent of the total moment release.

In northern Peru, a two months long sequence in 2009 generated several moderate earthquakes (Mw 6) that together account for about $25 \%$ of the total moment (Mw 6.7) released during the sequence (Villegas et al., 2016). A peculiar aspect of this sequence is that slow slip drastically accelerated after a Mw 5.8 earthquake, suggesting that successive interactions between seismic and aseismic slip controlled the evolution of the sequence.

Finally, a seismic sequence in the Atacama segment (Chile) initiated by a Mw 6.9 mainshock, (Klein et al., submitted). The sequence lasted severa weeks with abnormally large aftershocks up to Mw 6.4 and was associated to unusually large post-seismic slip, equivalent to Mw 6.8 developing in low coupling areas.

Unlike ETS, S5 usually occur at seismogenic depth, but at the edges of large locked asperities. Therefore, these processes span lateral changes in friction properties, rather than a transition with depth as ETS do. S5 highlight the evolving interplay between seismic and aseismic slip during the sequence, making them good observational targets to understand the physics of slip at faults.

\section{Using Physics-Based Models to Explore Physical Controls on Tsunami Earthquake Generation}

MENG, Q., Texas A\&M University, Texas, USA, qimeng@tamu.edu; DUAN, B., Texas A\&M University, Texas, USA, bduan@tamu.edu; LUO, B., Colorado School of Mines, Colorado, USA, robbin.binluo@gmail.com

"Tsunami earthquakes" generate tsunamis disproportionately large for their surface-wave magnitudes Ms (Kanamori, 1972). These earthquakes occur at the shallow portion of subduction zones, with characteristics of large discrepancy between Ms and Mw, long source duration, and depletion in highfrequency radiation. The 1992 Nicaragua earthquake along Latin America is the first tsunami earthquake recorded by modern seismic networks. Historical tsunami earthquakes also occurred along the Japan, Alaska, New Zealand, and Java subduction zones. Observational studies on these earthquakes have led to a conceptual model of tsunami earthquake generation, i.e., tsunami earthquakes are associated with ruptures on locally locked unstable patches within largely conditionally stable zones on shallow subduction interfaces. To test how well this conceptual model works for and to explore physical controls on tsunami earthquake generation, we use a recently developed dynamic earthquake simulator (Luo et al., 2020) to model slip behaviors of locked patches embedded within a conditionally stable subduction zone. The dynamic earthquake simulator is based on a finite element method to simulate both quasistatic (interseismic, nucleation, and postseismic) and dynamic (coseismic) processes of earthquake cycles on shallow-dipping thrust faults. We find that the normal stress level on locked patches and the rate-state friction parameter value of $a-b$ of the conditionally stable zone are two major factors that control the tsunami earthquake generation. Normal stress variations on locked patches can be caused by subducted topographic reliefs with various heights. We also find that locked patches show different rupture behaviors depending on their normal stress levels, and can have complex interactions among them, including ruptures of multiple patches in one event, compound ruptures of multiple patches with time delays from hours to days, and ruptures of signal patch.

\section{Adjoint Tomography of South America and Geometry of the Nazca Slab}

CIARDELLI, C., Institute of Astronomy, Geophysics and Atmospheric Sciences, USP, São Paulo, Brazil, caio.ciardelli@iag.usp.br; BOZDAĞ, E., Colorado School of Mines, Colorado, USA, bozdag@mines.edu; ASSUMPÇÃO, M., Institute of Astronomy, Geophysics and Atmospheric Sciences, USP, São Paulo, Brazil, marcelo.assumpcao@iag.usp.br; VAN DER LEE, S., Northwestern University, Illinois, USA, suzan@northwestern.edu

We use full-waveform adjoint tomography with 3D spectral-element and continental-scale seismic wave simulations (Komatitsch \& Tromp, 2002). 112 earthquakes recorded by 1311 stations were used. We detect and remove noisy and problematic data using our multi-stage algorithm before the time- window selection, reducing the likelihood of discarding useful data or assimilating bad-quality waveforms. Our misfit function is a complex-exponentiated instantaneous phase, which optimizes the information from each time series without the need for short time windows. We fine-tuned our windowselection algorithm to select long time windows as much as the data quality permits. We use a preconditioner based on the pseudo-Hessian kernel and weigh our misfit function to balance the source-receiver distribution for faster convergence. We performed 23 iterations, gradually increasing the frequency content of the data to avoid local minima. Our final model (SAAM23) shows a significant decrease in the misfit with periods down to $17 \mathrm{~s}$. The robustness of the model is confirmed by the misfit reduction of 53 independent earthquakes, not included in the inversion. At long wavelengths, SAAM23 is compatible with previous models, such SA2019 (Celli et al.,2020), and GLADM25 (Lei et al.,2020). SAAM23 consistently maps the thick, fast lithospheric velocities of the Amazon craton, the São Francisco craton, and the Paranapanema block, as well as the Andean subduction.

The Nazca slab is well imaged down to the transition zone. A continuous slab is seen at 300-400 km depth after the Peruvian flat segment, where a gap had been suggested previously. Beneath the Amazon, the slab crosses the transition zone and plunges directly into the lower mantle. In the South, the slab stagnates near the $660 \mathrm{~km}$ discontinuity for longer distances. A vertical, cylindrical low-velocity zone from 1100 to $200 \mathrm{~km}$ depth is confirmed, perhaps due to mantle upwards flow from beneath the slab or water from slab dehydration (Rodríguez et al., 2021).

\section{Caribbean Slab Dynamics Beneath Northwest South America From SKS and Local S Splitting}

CORNTHWAITE, J., Rice University, Texas, USA, jpcorn@rice.edu; NIU, F., Rice University, Texas, USA, niu@rice.edu; LEVANDER, A., Rice University, Texas, USA, alan@rice.edu; SCHMITZ, M., Fundación Venezolana de Investigaciones Sismológicas, Caracas, Venezuela, schmitzschutt@gmail. com; PRIETO, G., Universidad Nacional de Colombia, Bogotá, Colombia, gaprietogo@unal.edu.co; DIONICIO, V., Servicio Geológico Colombiano, Bogotá, Colombia, ldionicio@sgc.gov.co

The southernmost edge of the Caribbean (CAR) plate, a buoyant large igneous province, subducts shallowly beneath northwestern South America (NWSA) at a trench that lies northwest of Colombia. Recent finite frequency P-wave tomography results show a segmented CAR subducting at a shallow angle under the Santa Marta Massif to the Serrania de Perijá (SdP) before steepening while a detached segment beneath the Mérida Andes (MA) descends into the mantle transition zone. The dynamics of shallow subduction are poorly understood. Plate coupling between the flat subducting CAR and the overriding NWSA is proposed to have driven the uplift of the MA. In this study we analyze SKS shear wave splitting to investigate the seismic anisotropy beneath the slab segments to relate their geometry to mantle dynamics. We also use local S splitting to investigate the seismic anisotropy between the slab segments and the overriding plate. The data were recorded by a 65 -element portable broadband seismograph network deployed in NWSA and 40 broadband stations of the Venezuelan and Colombian national seismograph networks.

SKS fast polarization axes are measured generally trench-perpendicular (TP) west of the SdP but transition to trench-parallel (TL) at the SdP where the slab was imaged steepening into the mantle, consistent with previous studies. West of the MA the fast axis is again TP but transitions to TL under the MA. This second transition from TP to TL is likely due to mantle material being deflected around a detached slab under the MA. Local S fast polarization axes are dominantly TP throughout the study area west of the Santa Marta Massif and are consistent with slab-entrained flow. Under the Santa Marta Massif the fast axis is TL for reasons we do not yet understand.

\section{Cocos Tear Beneath Central-Southern Mexico}

ÁLVAREZ-RUEDAS, H. R., Universidad Nacional Autónoma de México, Mexico City, Mexico, heber.raz@gmail.com; PÉREZ-CAMPOS, X., Universidad Nacional Autónoma de México, Mexico City, Mexico, xyoli@ igeofisica.unam.mx

A decade ago, numerous interpretations cast doubt on the possibility that the Cocos plate extended continuously or had a tear underneath central-southern México, dividing Cocos into Central Cocos and South Cocos. Recent evidence reveals the tear model as the most feasible. We present a description of the plate behavior in the region, supporting the tear's presence, based on a $3 \mathrm{D}$ P-wave teleseismic tomography inversion of 7,043 first arrivals. The velocity models show discontinuous regions and the evolution of a tear perpendicular to the Mesoamerican trench towards the country's southeast 
Mantle Flow Pattern Through the Patagonian Slab Window and Around the South America From Shear Wave Splitting Analysis

BEN MANSOUR, W., Washington University in St. Louis, Missouri, USA, walid.benmansour@seismo.wustl.edu; WIENS, D. A., Washington University in St. Louis, Missouri, USA, doug@wustl.edu; MAGNANI, M., Southern Methodist University, Texas, USA, mmagnani@smu.edu; SHORE, P., Washington University in St. Louis, Missouri, USA, patrick@seismo.wustl.edu

It is well known that the physical state of the mantle (temperature, bulk composition, viscosity) controls the present-day surface topography and the stress distribution within the lithosphere. Locally, the slab geometry along a subduction zone also affects the mantle flow pattern and the mantle's properties. When a spreading ridge intersects a subduction zone, a slab window can be generated, and the mantle's properties will be then modified. Patagonia is the perfect example of a spreading ridge intersecting $16 \mathrm{Myr}$ ago a subduction zone and opening a window in the slab. The triple junction zone (Nazca, Antarctica, South America) splits a region with a strong seismic and volcanic hazard (northern part) to the southern region relatively quieter. Early studies with a poorly seismic network coverage support the idea of this slab window and its effect on the mantle flow pattern beneath South America. Recently, twenty-six broadband seismic stations were deployed in Southern Patagonia to fill the data gap between latitude $45^{\circ} \mathrm{S}$ and $55^{\circ} \mathrm{S}$. From this new set, we analyze core phases SKS and SKKS in the context of shear wave splitting to characterize the azimuthal seismic anisotropy as a proxy of the mantle flow pattern in this region. Shear-wave splitting parameters have been measured for using the minimum (transverse) energy method within the SplitRacer software package, which constrains the fast-polarization direction (phi) and the delay time (dt). We measure these two parameters and stack measurements to produce our final shear wave splitting datasets for each station. This new shear wave splitting set provides an extended view of the shear wave splitting in southern America and better constrain the mantle flow between the northern and southern Patagonia. This presentation will also compare recent seismic tomography studies (surface and body waves) in the region and discuss the potential effect of the slab on the mantle dynamic and surface expression.

\section{Ongoing Deformation and Earthquake Potential in Northwestern Colombia Due to the Slow Subduction of the Caribbean Plate Revealed by GPS Data}

LIZARAZO, S. C., Nagoya University, Nagoya, Japan, sindy@seis.nagoya-u. ac.jp; SAGIYA, T., Disaster Mitigation Research Center, Nagoya University, Nagoya, Japan, sagiya@nagoya-u.jp; MORA-PAEZ, H., Servicio Geologico Colombiano, Bogota, Colombia, hmora@sgc.gov.co

Colombia is a region of complex tectonics due to the interaction between the Caribbean, Nazca and South American plates, as well as other major tectonic blocks. Under this setting, the GPS network has become an important tool to study the regional kinematics, understand the crustal deformation and infer its potential implications in terms of geohazards.

GPS velocity data for the period 2008-2017 indicate a differential motion of the northern part of the North Andean Block, which also presents a mechanical interaction with the subducting Caribbean plate. Additionally, this region presents significant compressive GPS strain rates (65 nanostrain/ yr). Thus, we perform a 3D GPS data inversion to estimate the extent and degree of interplate locking along this boundary following Sagiya and MoraPáez (2020).

Our results show a shallow and fully locked patch south of Cartagena city, as the first indication of a possible seismic/tsunami hazard in this region. Considering a perfectly elastic behavior of the overriding plate, the source region would be able to generate a $\mathrm{M}_{\mathrm{w}} 8.2$ earthquake every 700 years. This long recurrence interval is due to the slow convergence of the Caribbean plate $(7 \mathrm{~mm} / \mathrm{yr})$. Another possibility is under the assumption of plastic deformation of the hanging wall of the subduction. However, discrepancy of one order of magnitude between long-term and geodetic strain rates do not support this interpretation.

Available evidence suggests that a careful attention is necessary for the first scenario due to its hazardous implications and the lack of a large earthquake in the last 500 years. Indeed, it has been reported that other slow subduction zones worldwide (e.g. Calabria and Gibraltar) are able to generate M8 earthquakes and tsunamis (Gutscher and Westbrook, 2009). Nevertheless, an integration of paleoseismological and paleotsunami records becomes urgent in order to identify recent crustal shortening or large past earthquakes/tsunamis in northwestern Colombia.
Subduction Processes Along Latin America Subduction

Zones

Poster Session · Monday · 19 April · 11:30 Am Pacific

Session Chairs: Hans Agurto-Detzel, Géoazur, IRD (agurto@

geoazur.unice.fr); Susan L. Beck, University of Arizona

(slbeck@arizona.edu); Isabella Gama, Brown University

(isabella_gama_dantas@brown.edu); Rafael Almeida, Yachay

Tech University (ralmeida@yachaytech.edu.ec)

\section{D Shear Velocity Structure of the Northwestern South America-Caribbean Subduction Zone From Ambient Noise and Ballistic Rayleigh Wave Tomography}

MIAO, W., Rice University, Texas, USA, wenpei.miao@rice.edu; CORNTHWAITE, J., Rice University, Texas, USA, jpcorn@rice.edu; LEVANDER, A., Rice University, Texas, USA, alan@rice.edu; NIU, F., Rice University, Texas, USA, niu@rice.edu; SCHMITZ, M., Fundación de Investigaciones Simológicas(FUNVISIS), Caracas, Venezuela, schmitzschutt@ gmail.com; PRIETO, G., Departamento de Geociencias, Universidad Nacional de Colombia - Sede Bogotá, Bogotá, Colombia, gaprietogo@unal.edu.co; DIONICIO, V., Servicio Geologico Colombiano - SGC, Bogotá, Colombia, ldionicio@sgc.gov.co

The Caribbean plate (CAR) collided with and initiated subduction beneath northwestern South America (SA) at about 60-55 Ma. Since the onset of subduction, it has formed the Lara nappes and subsequently the Laramide-style uplifts of the Merida Andes, Sierra de la Perija (SdP) and Santa Marta (SaM) ranges, with maximum elevations $>5 \mathrm{~km}$. The triangular Maracaibo block, bounded by the Santa Marta-Bucaramanga, Bocono and Oca-Ancon Faults, is currently escaping to the north relative to SA over both the subducting and nonsubducting elements of the CAR plate.

Previous geodetic studies have suggested that this region has potential for a great $(\mathrm{M} \sim 8+)$ earthquake (Bilham and Mencin, 2013). To investigate this complex region we fielded a 65 element broadband seismic array to complement the 48 existing stations of the Colombian and Venezuelan national seismic networks. The array is collectively referred to as the CARMArray.

We jointly inverted ambient noise Rayleigh wave $\mathrm{Z} / \mathrm{H}$ ratios, phase velocities in the 8-30s band and ballistic Rayleigh wave phase velocities in $30-80$ s band to construct a $3 \mathrm{D} \mathrm{S}$-wave velocity model in the area from $75^{\circ}-65^{\circ}$ west and $5^{\circ}-12^{\circ}$ north. Rayleigh wave $\mathrm{Z} / \mathrm{H}$ ratios are sensitive to the shallow sedimentary structure, while the phase velocity data have good resolution of the crust and upper mantle. The Vs model shows strong low-velocity anomalies beneath the Barinas-Apure and Maracaibo Basins, and the Paraguana Peninsula that are well correlated with surface geology. Crustal thickness beneath the SaM uplift is $27-30 \mathrm{~km}$, shallow for its nearly $4 \mathrm{~km}$ elevation. From the trench to the southeast, Moho depth increases from $25-30 \mathrm{~km}$ near the coast to $40-45 \mathrm{~km}$ beneath the Maracaibo Basin, with the thickest crust, $\sim 50$ $\mathrm{km}$, lying under the Merida Andes. From $50-150 \mathrm{~km}$ depth, the CAR plate shows $\sim 2 \%$ high Vs anomalies beneath the SaM uplift and the SdP range. Our slab image matches local slab seismicity very well (Cornthwaite et al. 2021, this session), and is consistent with and complements images from teleseismic P-wave tomography (Cornthwaite et al, 2021, submitted).

\section{A Bayesian Approach for Geodetic Data Inversion and Model Selection of the Mw 8.8 2010 Maule Earthquake Coseismic Slip Distribution}

NUNEZ JARA, S., Universidad de Concepcion Chile, Concepcion, Chile, sebalfnunez@gmail.com; BATAILLE, K., Universidad de Concepción, Concepción, Chile, bataille@udec.cl; BENAVENTE, R., Universidad Católica de la Santísima Concepción, Concepción, Chile, robenavente@gmail.com

We employ Bayesian Inference tools in order to compare two kinematic models for resolving the coseismic slip of subduction zone earthquakes: (i) A finite fault in the megathrust between the subducting and overriding plates and (ii) Two finite faults; a upper plane simulating inverse slip in the megathrust zone and a lower plane with normal slip, located roughly in the elastic limit within the slab. The proposed inverse problem for determining parameters for each model is nonlinear but can be linearized. We build an algorithm that determines the optimal solution and its uncertainties such that it maximizes the bayesian evidence. By using this algorithm in a geodetic data inversion for the Mw 8.8 2010 Maule Earthquake, we found that both models indicate two main slip patches, north and south of the epicenter, in agreement with past results. There exists more bayesian evidence for the two interface model, but high uncertainties in the lower plane slip distribution, possibly related to limited 
offshore resolution of geodetic data and/or modeling simplification, suggest to carefully assess this result. We conclude that Bayes Theory, by means of the evidence, gives support to the two fault planes model, which could have implications for the better understanding of the subduction process kinematics. Additionally, it allows to determine the ideal number of model parameters, the downdip extension of fault edge and the hyperparameters, among others, in a balanced manner without employing expensive computational methods.

\section{Imaging the South American Active Margin and Continental Interior with Waveform Tomography}

CHAGAS DE MELO, B., Dublin Institute For Advanced Studies, Dublin, Ireland, bmelo@cp.dias.ie; LEBEDEV, S., Dublin Institute for Advanced Studies, Dublin, Ireland, sergei@cp.dias.ie; CELLI, N. L., Dublin Institute for Advanced Studies, Dublin, Ireland, niscelli@cp.dias.ie; DE LAAT, J. I., Dublin Institute for Advanced Studies, Dublin, Ireland, dellaat@cp.dias.ie; ASSUMPÇÃO, M., Universidade de São Paulo, São Paulo, Brazil, marcelo. assumpcao@iag.usp.br

The Andean margin is a long-lived, continuous subduction zone, considered an archetypal example of the subduction of an oceanic plate beneath a continent. However, the complex system shows profound changes north-south along the trench and is far from steady-state; its structure and dynamics are widely debated. Diverse deformational styles, topographic changes, irregular seismicity and volcanism are indications of the heterogeneity of the structure of the subduction in depth.

Seismic tomography can resolve the 3D distribution of seismic-wave velocity, sensitive to temperature and composition in the crust and upper mantle. Until recently, seismic data sampling in South America was highly uneven, and high-resolution models were obtained mainly regionally. Here, we assembled all now available seismic data including the recently collected data from the FAPESP "3-Basins Thematic Project." The massive dataset includes data from the temporary deployments in South America that became available recently and is complemented by data from all the globe.

Our high-resolution, S-velocity tomographic model of South America and surrounding oceans is computed using the Automated Multimode Inversion of surface, S- and multiple S-waves. Our model has the data sampling to resolve regional-scale features such as the underthrusting of the Brazilian lithosphere beneath the Andes, slab stagnation in the transition zone, and slab windows in the upper mantle. We separate, for the first time, two different structures in the Northern Andes that are likely to represent two separate subducting slabs, relating to the Nazca and Caribbean Plates. In the Peruvian region, we image a very heterogeneous, $\sim 800 \mathrm{~km}$ long flat slab with irregular topography. In the stable platform, we image in detail the lateral extent and internal structure of the cratons that comprise the ancient core of the continent. Accurate imaging of the structure of the downgoing Nazca slab and the continent's lithosphere yields new insights into the evolution of South America and deformational processes involved in the cordillera build up.

\section{Quantifying the Aftershock Sequences of Two Chilean Megathrust Earthquakes: The 2014 lquique and the 2015 Illapel Events}

GENG, Y., Harvard University, Massachusetts, USA, yichen_geng@g.harvard. edu; FRANK, W. B., Massachusetts Institute of Technology, Massachusetts, USA, wfrank@mit.edu; ADEN-ANTONIOW, F., Massachusetts Institute of Technology, Massachusetts, USA, faden@mit.edu

To obtain a better understanding of the characteristics of aftershocks following megathrust earthquakes, we analyze aftershocks of the $2014 \mathrm{Mw} 8.1$ Iquique earthquake in Northern Chile from a dense and precisely relocated earthquake catalog built by Sippl et al., 2018. We first expand the aftershock catalog from 2014 to 2016 with a continuous matched-filter search using 4000 template events with local magnitudes between 3.0 and 4.0. We demonstrate that aftershocks expand logarithmically with time, consistent with aftershock activity controlled by afterslip, and measure the apparent aftershock migration speeds. We further examine the relationship between aftershock density and coseismic stress drop for a range of coseismic slip models. We will then extend this framework to systematically analyze the postseismic phases of other major megathrust earthquakes, starting with the $2015 \mathrm{Mw} 8.3$ Illapel earthquake in Central Chile.
Tectonics and Seismicity of Stable Continental Interiors

I: Oral Session · Friday · 23 April · 9:45 AM Pacific

II: Oral Session · Friday · 23 April · 2:00 PM Pacific

Session Chairs: Anjana K. Shah, U.S. Geological Survey

(ashah@usgs.gov); Christine A. Powell, CERI, University of

Memphis (capowell@memphis.edu); Will Levandowski, Tetra

Tech (will.levandowski@tetratech.com)

\section{An Interpretation of Ground Motions, Intensities and Stress-Drop for the M5.1 Sparta, North Carolina, Earthquake}

CRAMER, C. H., CERI, University of Memphis, Tennessee, USA, ccramer@ memphis.edu; POWELL, C. A., CERI, University of Memphis, Tennessee, USA, capowell@memphis.edu

Observed ground motions, intensities, and mainshock stress-drop can provide important insights into the earthquake setting both geophysically and geologically, particularly from a seismic hazard point of view. The observed mainshock Brune stress drop of $22+6 /-4 \mathrm{MPa}$ is consistent with published regional stress-drops for the eastern US and with the level of shaking and damage associated with the Sparta earthquake. The observed intensity 7 in the Sparta area suggests peak ground accelerations of 0.2-0.4 $\mathrm{g}$ and peak ground velocities of $6-8 \mathrm{~cm} / \mathrm{s}$ using a recently updated Ground Motion vs. Intensity Correlation Equation for Central and Eastern North America. The regional intensity pattern from the Sparta earthquake reinforces observations from the 2011 M5.7 Mineral, VA earthquake of differences in shaking attenuation along and across regional structure. From the Sparta earthquake intensities, we see more shaking attenuation to the $\mathrm{W}$ and $\mathrm{NW}$ and less shaking attenuation to the E, even before reaching the Atlantic Coastal Plain. A factor of 6 decrease in ground motions to the $\mathrm{W}$ and NW relative to those to the $\mathrm{E}$ develops between 50 and $100 \mathrm{~km}$ from the epicenter and appears consistent out to $900 \mathrm{~km}$. This increased seismic attenuation suggests a higher attenuation associated with the boundary between the Valley and Ridge sedimentary rocks and the Blue Ridge metamorphic rocks, possibly due to a strong velocity contrast reflecting energy back into the Blue Ridge. Intensities from the 1886 M7.0 Charleston, SC earthquake show a pocket of lower intensities associated with Eocene volcanic rocks and an area of mantle delamination near the West Virginia/Virginia border. Observations from the 2019 M4 Eastlake, OH earthquake show a region of higher crustal attenuation $(\mathrm{Qo}=213, \mathrm{~h}=0.55)$ in this same area extending into central Pennsylvania, possibly due to warmer crust over the shallower depth to mantle in the area due to the delamination.

\section{Correlating Seismic Microzonation and Intensity Data in Three Urban Areas of Eastern Canada}

BENT, A. L., Natural Resources Canada, Ottawa, Ottawa, Canada, allison. bent@canada.ca; ROSSET, P., McGill University, Montreal, Canada, philippe. rosset@affiliate.mcgill.ca; CHOUINARD, L., McGill University, Montreal, Canada, luc.chouinard@mcgill.ca; HALCHUK, S., Natural Resources Canada, Ottawa, Canada, stephen.halchuk@canada.ca

Seismic hazard assessments generally result in equal hazard values across any given community. Seismic risk analyses, however, paint a different picture where risk within some areas of a community may be elevated due to amplification of shaking levels by factors such as soft soils. Leda clay deposits from the old Champlain Sea are of particular concern for amplification in many parts of Quebec and Ontario. Seismic microzonation maps characterizing the upper $30 \mathrm{~m}$ of soil in terms of average shear wave velocity and predominant resonance frequency have been developed for Montreal, Ottawa and Quebec City. All three cities are in or near active seismic zones. The maps, derived from seismic and borehole measurements, have been used to develop Shakemap scenarios but have not been validated because there have not been any significantly large, close earthquakes in recent years and because the seismograph network coverage is not adequate to provide a detailed picture of variations in shaking across a city. Felt reports, although less precise than instrumental data, are numerous and provide a dense dataset showing relative shaking levels across a region. Using intensity data for several moderate earthquakes collected largely via an internet "Did You Feel It" page, we systematically compare reported shaking levels to soil conditions indicated by the microzonation maps. The work for Ottawa and Quebec City is ongoing. The study for Montreal has been completed and shows a strong correlation between high reported intensities and soft soils. The results suggest that intensity data collected via the internet and social media provide a viable method for validating microzonation maps and shaking scenarios. 


\section{Crustal Structure and Intraplate Seismicity Beneath the} Southeastern United States

CUNNINGHAM, E., CERI, University of Memphis, Tennessee, USA, cunningham.erin4@gmail.com; WAGNER, L., Earth and Planets Laboratory, Carnegie Institution for Science, District of Columbia, USA, lwagner@ carnegiescience.edu; LEKIC, V., University of Maryland, College Park, Maryland, USA, ved@umd.edu

The Southeastern United States (SEUS) lies on a passive margin far away from ongoing tectonic deformation, yet remains capable of hosting damaging earthquakes. Crustal and lithospheric structure within the SEUS preserves a complex history of continental collisions, rifting and volcanism that has shaped it over billions of years leaving behind a chaotic assortment of accreted terranes and faults. Zones of weakness in the lithosphere at structural boundaries inherited from past collisional events are a proposed explanation for the intraplate seismicity; however, the extent and magnitude of intra-lithospheric variations associated with intraplate seismicity has not been fully explored. Therefore, mapping variations in lithospheric structure can both clarify the tectonic history of the region and highlight possible mechanisms that control intraplate seismicity.

Typically, P-to-s converted waves, analyzed through the receiver function technique are used to constrain interfaces in the lithosphere, but their application to the SEUS has proven difficult as large amplitude reverberations from basins and Atlantic coastal plain sediments can overprint signal from deeper crustal and lithospheric structure. Therefore, we use reverberationcorrected P-to-s receiver functions (PRFs) and common conversion point (CCP) stacking to constrain crustal and lithospheric variations across the entire SEUS. We find evidence for deep mid-crustal layering (or a "doubleMoho") deepening westward beneath the Blue Ridge in eastern Tennessee as well as a shallow mid-crustal layer deepening eastward which has been interpreted to mark the location of the suture between Laurentia and Gondwana during the formation of Pangea (e.g. Hopper et al. 2017). While we find no evidence that a more prominent lithosphere-asthenosphere boundary or mid-lithospheric discontinuities are associated with the location of intraplate earthquakes, we do find evidence that laterally abrupt variations in crustal thickness are associated with regions hosting intraplate seismicity.

\section{Integrating Seismic and Magnetotelluric Constraints on Lithospheric Properties to Explore the Geodynamic Origin of the Southeastern U.S. Stress Field}

MURPHY, B. S., U.S. Geological Survey, Colorado, USA, bmurphy@usgs. gov; LIU, L., University of Illinois at Urbana-Champaign, Illinois, USA, ljliu@ illinois.edu; EGBERT, G. D., Oregon State University, Oregon, USA, gary. egbert@oregonstate.edu

Although the intraplate stress field in the southeastern United States (SEUS) has been viewed as part of a broadly uniform stress province controlled dominantly by far-field forces, data from the World Stress Map (WSM) as well as additional earthquake focal mechanisms and the attitude of Quaternary faults indicate substantial stress-field variability throughout this region. For example, in the Central Virginia Seismic Zone, focal mechanisms and faults that show evidence for Pleistocene-aged slip indicate a direction of maximum horizontal compression (SHmax) that is highly oblique to that inferred for Eastern North America from WSM data. Here, we examine the role of body forces in producing this heterogeneous stress field. We use CitcomS, a finiteelement geodynamic modeling code, to model local lithospheric stresses based on simple input composition, temperature, and viscosity fields. We superpose on this modeled stress field an estimate of the far-field stress contribution from ridge push and lithospheric basal shear. Our composition field largely reflects seismically-imaged crustal thickness variations. We use a onedimensional depth-dependent thermal field; although seismic studies have argued for substantial variations in thermal lithosphere thickness throughout the SEUS, joint analysis with magnetotelluric (MT) data indicates that present constraints cannot reject a uniformly thick thermal lithosphere throughout this region. For viscosity, we use a one-dimensional depth-dependent field as well as three-dimensional fields that are informed by MT imaging. With these simple models, we are able to reproduce many features of the SEUS stress field, including heterogeneous SHmax. Our results indicate that observed stresses arise from the superposition of far-field forces and local body forces. Crustal compositional buoyancy, controlled predominantly by crustal thickness variations, appears to be most important in reproducing observations, although we slightly better match the observed stress field by including laterally variable crustal viscosity mapped from MT imaging.

\section{Source Parameters of the M5.1 Sparta, NC Earthquake of 9} August 2020

HORTON, S., University of Memphis, Tennessee, USA, shorton@memphis. edu; WITHERS, M. M., University of Memphis, Tennessee, USA, mwithers@ memphis.edu; CRAMER, C. H., University of Memphis, Tennessee, USA, ccramer@memphis.edu; WITHERS, H., University of Memphis, Tennessee, USA, hlwithrs@memphis.edu

The M5.1 Sparta earthquake was strongly felt locally, with light to moderate damage (intensity VI), and potential surface rupture observed along a $\sim 1 \mathrm{~km}$ trend with azimuth about 106 degrees. A source radius of $\sim 1 \mathrm{~km}$ is compatible with the stress drop of $22 \mathrm{MPa}$ estimated for this event. The closest permanent station was $\sim 50 \mathrm{~km}$ distant (CERI deployed 4 real-time stations in the local area by August 12.) leading to main-shock location estimates that were poorly constrained and not generally compatible with the potential surface rupture; being either too deep or too far away. We employ a two-step method to improve the main shock location estimate. In step 1, P- and S-wave travel times at regional stations are forward modeled over a horizontal grid of potential earthquake locations while holding depth fixed. A best fitting horizontal location (minimum RMS residual) is determined for each discrete depth between 0.1 and $13 \mathrm{~km}$ below ground surface. First motion focal mechanisms are then calculated for each depth-location pair. In step 2, regional waveforms are modeled for each step-1 location and focal mechanism to obtain the best fitting depth. Our best fitting main shock location is $36.488 \mathrm{~N}, 81.106 \mathrm{~W}$ with depth 600 meters below ground surface. The first motion focal mechanism for the main shock has strike, dip and rake of 108, 60 and 24 degrees. This location and first motion focal mechanism are both consistent with left-lateral strike slip and a little vertical motion on a SW dipping fault that is parallel to and surfaces at the proposed surface rupture. Most early aftershocks (on August 12 and 13 , the first two days after our temporary network was deployed) appear to align along this SW dipping plane within the top $2 \mathrm{~km}$ below the ground surface. The distribution of later epicenters is more scattered with the potential ground rupture located in the midst of the distribution, although a large number of these later events also appear to align along the SW dipping plane.

\section{A Structural-Corridor Approach for Induced-Seismicity Risk Assessment}

EATON, D. W., University of Calgary, Calgary, Canada, eatond@ucalgary. ca; WEIR, R. M., University of Calgary, Calgary, Canada, ronald.weir@ ucalgary.ca; EYRE, T. S., University of Calgary, Calgary, Canada, thomas. eyre@ucalgary.ca; LAWTON, D. C., University of Calgary, Calgary, Canada, lawton@ucalgary.ca

We outline a new strategy for corridor-based induced-seismicity risk analysis in sedimentary basins that extends the fault-slip potential method using relevant regional analogs from structural geology. Our approach is guided by available subsurface well control, seismic data and catalogs of prior natural and induced seismicity. A basic tenet is that ancient fault systems contain potentially seismogenic structures, with spatial distributions and orientations that can be probabilistically characterized within a structural geological framework, but that fall below the resolution limits of available data. This approach is illustrated by a case study from the Duvernay play in Alberta, Canada, where subtle basement-rooted strike-slip faults and associated Riedel shears have been previously activated by hydraulic fracturing to produce sequences of induced seismicity. We combine analysis of several adjoining 3-D seismic and induced seismicity datasets in order to achieve coverage of a representative corridor. Given the infeasibility of exhaustively detecting and mapping all potentially seismogenic faults, our approach relies on established structural principles, analog settings (flower structures) and Monte Carlo analysis of fault-slip potential to quantify the expected likelihood of fault activation within a defined corridor of unconventional oil and gas development.

\section{Compositional Weakening of the Crust and Intraplate Earthquakes: A Case Study for the Continental U.S. and its Intermountain West}

SHEN, W., Stony Brook University, New York, USA, weisen.shen@stonybrook. edu; SUI, S., Stony Brook University, New York, USA, siyuan.sui@stonybrook. edu

Although the majority of earthquakes happen along the plate boundaries, intraplate earthquakes distributed across continental interiors and their origins are less well understood compared with their interplate counterparts. Mechanisms such as crustal composition, thermal anomalies, the existence of fluid, localized shear deformation, and tectonic inheritance have been proposed to be responsible for weakening the crust and generating intraplate earthquakes. In this talk, we summarize a recent effort to map the varia- 
tions in compositional and thermal properties of the crust of the continental US and to quantitatively examine their contributions to crustal weakening. Particularly, we show that by combining Vs and Poisson's ratio derived from the USArray, a crustal model of silica content for the continental US can be constructed. Based on this model, we construct the rheological and thermal models of the crust for the continental US, and a quantitative evaluation of its strength can be thus performed. The result shows that crustal composition contributes significantly to the strength of crust and intraplate seismicity. Notably, the Intermountain West region shows a weak crust caused by a lack of mafic lower crust and higher silica content in the crust. Seismicity of the Intermountain Seismic Belt, particularly, aligns along a boundary between the strong, stable Great Plains and weaker Basin and Range and the northern Rockies. For the central and eastern US, the crust bears a thick, mafic, lower crust, resulting in a significantly higher crustal strength, but with notable variations across tectonic provinces.

\section{Full Waveform Ambient Noise Tomography for the Northern Mississippi Embayment}

YANG, Y., University of Memphis, Tennessee, USA, yyang93924@gmail. com; LANGSTON, C. A., University of Memphis, Tennessee, USA, clangstn@ memphis.edu; POWELL, C. A., University of Memphis, Tennessee, USA, capowell@memphis.edu; THOMAS, W. A., Geological Survey of Alabama, Alabama, USA, geowat@uky.edu

We use seismic ambient noise data recorded by broadband stations around the northern Mississippi Embayment to develop a three-dimensional shear wave velocity model with full waveform inversion. Empirical Green's functions at periods between 8 and 40 s are extracted using a data processing flow based on the continuous wavelet transform. Synthetic waveforms are calculated with an isotropic model through a GPU-enabled, collocated finite-difference code. We use cross-correlation time shifts between the synthetic and observed waveforms as the misfit function. Starting from the Central United States Velocity Model, the shear wave velocity is iteratively updated with sensitivity kernels constructed using the adjoint method. Several mid-crustal velocity variations are related to major geological features including the Mississippi Valley graben (MVG), the Ouachita thrust belt, and the Missouri batholith. An intrusion is imaged in northwestern Alabama, coincident with a previously unexplained gravity high. A major change in mid-crustal velocity occurs across the MVG; much higher velocity crust is present southeast of the graben than northwest. The high velocities are attributed to numerous igneous intrusions, possibly related to formation of the Granite-Rhyolite province. A strength contrast produced by the change in mid-crustal velocities may have facilitated formation of the younger, shallower MVG. The rift pillow is interpreted as the deeper expression of the high velocity crust. Low velocity crust is present below southern Missouri starting a depth of roughly $20 \mathrm{~km}$. The boundary between the low velocity crust and higher velocity crust to the south and east is sharp and coincides with the Nd-line.

\section{Locating and Characterizing the CEUS/WUS Boundary in Crustal Attenuation, Stress and Lithospheric Structure}

LEVANDOWSKI, W., Tetra Tech, Inc., Colorado, USA, will.levandowski@ tetratech.com; BOYD, O. S., U.S. Geological Survey, Colorado, USA, olboyd@ usgs.gov; BRIGGS, R. W., U.S. Geological Survey, Colorado, USA, rbriggs@ usgs.gov; ZELLMAN, M., BGC Engineering, Colorado, USA, mzellman@ bgcengineering.ca

There are fundamental seismotectonic, structural, and physiographic differences between the nominally stable central and eastern United States (CEUS) and the western United States, yet there is not universal consensus on the location and nature (e.g., gradational vs. abrupt) of the boundary between the two regions. More specifically, how to lump or split the physiographic provinces of the Intermountain West-the southern Rockies, Colorado Plateau, Rio Grande Rift, Wyoming Craton, and northern Rockies-between CEUS and WUS is ambiguous. We first present crustal attenuation ( $\mathrm{Lg}$ Q) tomograms targeting the southern Rocky Mountain region that depict sharp boundaries between attenuation provinces yet defy simple East vs. West regionalization. The low-Q southern Rockies/Rio Grande Rift and Basin and Range are separated by the Colorado Plateau, which displays similarly high Q and merges with the Wyoming Craton and northern Great Plains to comprise a contiguous high-Q zone quite unrelated to the extent of Cenozoic tectonism and modern high topography. Instead, the dichotomous Lg Q mirrors patterns of upper mantle seismic velocity and heat flow. A causal relationship between crustal temperature and attenuation is not surprising, but it is at odds with most current regionalization schemes. We also find, however, that crustal stress follows identical spatial patterns. Extension dominates the entire study area (with the exception of central/northern Oklahoma), yet focal mechanism inversions document NNE-SSW maximum stretching independently in the Colorado Plateau, Wyoming Craton, and northern Plains that is significantly different from the $\sim \mathrm{E}-\mathrm{W}$ tension in the southern Rockies, Rio Grande Rift, and Basin and Range. Taken together, attenuation, stress, and crustal structure demonstrate that the Intermountain West is not merely part of the CEUS or WUS and instead suggest a need for more detailed regionalization than is currently applied.

\section{Spatial Correlation in Ground Motion Prediction Errors in Central and Eastern North America}

GIBSON, E. M., Schnabel Engineering, LLC., Pennsylvania, USA, egibson1313@gmail.com; BENSI, M. T., University of Maryland, College Park, Maryland, USA, mbensi@umd.edu

Risk analysis and risk-informed design of spatially-distributed infrastructure systems for earthquake hazards require an understanding of and ability to model the spatial correlation of ground motion prediction errors. Although models have been developed and studied to capture this correlation for shallow crustal tectonic regions, models have not been developed for stable continental interiors. The NGA-East database, which includes recordings from the U.S. Transportable Array, provides a useful data resource to assess the spatial correlation of ground motion prediction errors in Central and Eastern North America (CENA). Data limitations make it challenging to develop a comprehensive and reliable model to capture this correlation. However, we have performed multi-faceted analyses of available data using an existing mathematical framework, which has allowed us to make notable findings relevant to future risk assessments.

We present the results of our analyses involving calculation of ground motion residuals and semivariograms from earthquake recordings in the NGA-East database. We discuss some of the key differences in CENA seismicity and tectonics between shallow crustal regions as well as the resulting impacts on spatial correlation of ground motion prediction errors. Additionally, we highlight notable characteristics of large magnitude events recorded in CENA, selection of ground motion models, and observed differences in recordings from tectonic and induced events.

Tectonics and Seismicity of Stable Continental Interiors I: Poster Session · Friday · 23 April · 11:30 AM Pacific II: Poster Session · Friday · 23 April · 3:45 PM Pacific Session Chairs: Anjana K. Shah, U.S. Geological Survey (ashah@usgs.gov); Christine A. Powell, CERI, University of Memphis (capowell@memphis.edu); Will Levandowski, Tetra Tech (will.levandowski@tetratech.com)

\section{Focal Mechanism Determination of 21 November in Ezgele-Sarpole Zahab}

KHOJASTEH, F., University of Tehran, Tehran, Iran, Islamic Republic Of, sahar.khojaste7773@gmail.com; MORADI, A., University of Tehran, Tehran, Iran, Islamic Republic Of, asmoradi@gmail.com

On November 12th, 2017, at 18:18:16 UTC (21:41:16 local time) in the west part of Kermanshah, Iran, a massive earthquake happened. This earthquake occurred near the border of Iran and Iraq and was felt by those regions as well.This event followed by a lot of aftershocks in a variety of sizes. Also, three foreshocks happened with magnitude of 1.9,2.3 and the important one, 4.4, occurred about one hour before the main shock, so it caused people awareness. One of the ways for studying events and determining their focal mechanisms is using of the seismograms which contain an array of valuable information about the fracture process, waveforms propagating area and the ray paths of waveforms. Among the methods used to determine the mechanism of the source with the help of seismographs are methods based on waveform modeling.

In this research, we have tried to obtain the source parameters of the November 12 earthquake with magnitude of Mw7.3 and some of its aftershocks with magnitude 4.5 and above between the year of 2017 and 2019 and in coordinates range of $34-36 \mathrm{~N}$ and $47-49 \mathrm{E}$, using the ISOLA program (Sokos and Zahardnik, 2008). For this purpose, source parameters of these events have been determined with inversion of moment tensor and with use of the broadband station recordings of Geophysics Institute of University of Tehran and International Institute of Earthquake Engineering and Seismology.

The results have been obtained from the inversion of the moment tensor illustrate the source parameters for this event. According to this, a moment of 
$0.94 \times 10 \wedge 19 \mathrm{NM}$ has been released, which is equivalent to a magnitude of 7.3. We see the nodal planes of $143 / 12 / 338$ and $80 / 83 / 104$. Considering the fault system in this area and considering the right lateral and low slope of the dominant mechanism, 143/12/338 is a fault plane that has a slight slope of 12 degrees. One of the reasons why the fracture did not reach the surface is the low slope of the fault plane. Key words: Ezgele-Sar Pole Zahab Earthquake, Zagros, moment tensor inversion, focal mechanism

\section{Ground Motion Characteristic Models for Vrancea Intermediate-Depth Earthquakes}

MANEA, E., National Institute for Earth Physics, Romania, Magurele/Ilfov Romania, elena.manea@infp.ro; CARMEN, C. O., National Institute for Earth Physics, Mangurele, Romania, cioflan@infp.ro; LAURENTIU, D., ETH Zürich, Zürich, Switzerland, laurentiu.danciu@sed.ethz.ch; ALEXANDRU, M., National Institute for Earth Physics, Magurele/Ilfov, Romania, marmura@ infp.ro

A newly compiled high-quality ground-shaking dataset of 207 intermediate-depth earthquakes recorded in the Vrancea Region of Romania was used to develop region-specific empirical predictive equations for various intensity measures, as peak ground acceleration, velocity and 5\%-damped pseudo-spectral acceleration up to $10 \mathrm{~s}$. Beside common predictor variables (e.g. moment magnitude, depth, hypocentral distance and site conditions), a couple distance scaling parameters were added to describe the specific attenuation pattern observed at the stations located not only on the back- and fore- but also along the Carpathian arc. In this model, we introduce a proxy measure for the site as the fundamental frequency of resonance to characterize the site response at each seismic recording station beside the soil classes. To additionally reduce the site-to-site variability, a non-ergodic methodology was considered, resulting in a lower standard deviation of about $25 \%$.

The newly proposed ground motion models were tested against recorded data and other derived GMPEs for active subduction zones. The model shows significant improvements in describing the spatial variability (at different spectral ordinates), particularly for the fore-arc area of the Carpathians where a deep sedimentary basin is located. Furthermore, the model presented herein improves estimates of ground shaking at longer spectral ordinates $(>1 \mathrm{~s})$ in agreement with the observations. The proposed ground motion model is valid for hypocentral distances less than $400 \mathrm{~km}$, depths over $70 \mathrm{~km}$ and within the moment magnitude range 4.0-7.4.

This study represents the first attempt at incorporating realistic local site parameters in a ground motion model for intermediate to deep seismicity of the Vrancea region of Romania.

Seismotectonic Regions for Germany-Concept and Results HAHN, T., University of Goettingen, Goettingen, Germany, tim.hahn@unigoettingen.de; KLEY, I., University of Goettingen, Goettingen, Germany, jkley@gwdg.de; KAISER, D., Federal Institute for Geosciences and Natural Resources, Hannover, Germany, diethelm.kaiser@bgr.de; SPIES, T., Federal Institute for Geosciences and Natural Resources, Hannover, Germany, thomas.spies@bgr.de; GEISSLER, C., Federal Institute for Geosciences and Natural Resources, Hannover, Germany, claudia.geissler@bgr.de

Seismotectonic regions are a basic input in seismic hazard assessment. Several seismotectonic zonations for Germany have been proposed in the past. We have developed a new regionalization based on the definition in the German Nuclear Safety Standard: "A seismotectonic unit is a region for which uniformity is assumed regarding seismic activity, geological structure and development and, in particular, regarding neotectonic conditions". Our new concept aims for transparent implementation of geological criteria which we initially analyze separately from seismicity. We strive for a better documentation and justification of the geological elements used to delimit seismotectonic regions, based on an analysis of the geological evolution in six time slices from the Permian (300 Ma) to the Present. The time slices are separated by marked changes in the tectonic regime and associated with the development of new fault systems or reactivation of existing ones. The present-day fault network comprises faults from all time slices. For each time slice, a subset of active faults has been extracted based on geological evidence for fault activity at that time. Uncertainties of these age assignments are documented. The fault subsets delimit regions of different strain intensity. The superposition of strain intensity distributions across all time slices identifies regions affected by polyphase deformation and regions nearly undeformed over geological time, potentially indicating areas of increased or reduced present-day seismic hazard. Our new zonation consists of fewer regions than earlier ones. The geological zonation correlates well with recent seismicity in areas of Cenozoic rifting and rea- sonably well with less frequent EQ in a belt affected by Mesozoic extension and contraction. However, a few stronger EQ cluster in regions of low geological strain. The most prominent EQ clusters (Swabian Jura, Vogtland/ NW Bohemia) also defy a simple correlation with known geological structures.

\section{Basement Faults in the Charleston, South Carolina Seismic Zone From Aeromagnetic and Seismic Reflection Data: Roles of Optimal Orientation and Possible Fault Triggering SHAH, A. K., U.S. Geological Survey, Colorado, USA, ashah@usgs.gov; PRATT, T. L., U.S. Geological Survey, Virginia, USA, tpratt@usgs.gov; HORTON, JR., J., U.S. Geological Survey, Virginia, USA, whorton@usgs.gov}

The Charleston seismic zone (CSZ), which was the site of a $\sim$ M7.0 earthquake in 1886 , has potential for significant damage to heavily populated areas. Locations of seismogenic faults in this passive margin setting remain debated with studies limited by diffuse seismicity, sparse seismic reflection coverage, and older coarse-resolution aeromagnetic data. We combine new high-resolution aeromagnetic data with earlier seismic reflection data to image basement faults that correspond to deformation in overlying Cenozoic sediments. Aeromagnetic derivative and band-pass filtered anomaly maps show 6-15 km long, ESE-striking lineaments that are south of and parallel or sub-parallel to the northern edge of the Mesozoic South Georgia rift basin. These lineaments coincide with vertical displacements in the reflection profiles and are interpreted as Mesozoic rift basin faults. They terminate along NE-trending lineaments that are up to $50 \mathrm{~km}$ long and are parallel to mapped Paleozoic structures farther inland. The NE lineaments also correspond to reflector displacements and are interpreted as Paleozoic faults that influenced locations of Mesozoic faults. Near Summerville, where most CSZ seismicity is located (usually $\mathrm{M}<3.0$ ), is a rare SE-striking, $6-\mathrm{km}$ long fault that is favorably oriented in the modern stress field (reverse slip; s1= N50E) and associated with Cenozoic deformation visible in the reflection data. Adjacent ESE rift basin faults and contiguous NE-striking Paleozoic faults are also associated with Cenozoic deformation, but ESE rift basin faults $>10 \mathrm{~km}$ away from the SE-striking fault show the Cenozoic cover has flat reflectors. This suggests that slip on the shorter, favorably oriented SE-striking fault could trigger motion on nearby faults, including longer, NE-striking Paleozoic faults that are capable of generating a large earthquake. Slip along the Paleozoic faults would require transpressive motion, consistent with offsets observed along railways tracks following the 1886 event.

\section{Coda Envelope Moment Magnitudes for the Western Quebec Seismic Zone}

BENT, A. L., Natural Resources Canada, Ottawa, Ottawa, Canada, allison. bent@canada.ca; MAYEDA, K., Air Force Technical Applications Center, Patrick Air Fore Base, United States Territories and Minor Outlying Islands, kevin.mayeda@us.af.mil; ROMAN-NIEVES, J. I., Air Force Technical Applications Center, Patrick Air Force Base, United States Territories and Minor Outlying Islands, jorge.roman-nieves.1@us.af.mil

Although moment magnitude, Mw, has become the magnitude of preference for seismic hazard assessment, obtaining reliable $\mathrm{Mw}$ for small earthquakes that make up the bulk of most earthquake catalogs remains problematic. Modeling methods based on long-period waveforms used for moderate and large earthquakes are not appropriate for smaller earthquakes. Moment magnitudes for these are often determined by applying conversion relations to other magnitudes, which may not have been validated for the complete range of magnitudes. That many catalogs contain a variety of magnitude types compounds the problem. The coda envelope method has emerged as one of the most promising and stable techniques for direct determination of moment magnitude for small earthquakes. The coda, consisting of scattered waves, is only minimally affected by radiation pattern enabling the method to provide stable results with sparse or azimuthally unequal networks. Recent improvements to the software by Lawrence Livermore National Laboratory to facilitate the process, in particular the previously laborious step of station calibration, make it attractive for use as a standard magnitude. The Western Quebec Seismic Zone has been selected as the first region for application of the code envelope method in Canada. It is an ideal laboratory as it has experienced several recent, moderate earthquakes with well determined $\mathrm{Mw}$ that can be used as reference events as well as large numbers of smaller earthquakes. The variable density of both the seismic activity and station coverage in the region allow for a thorough testing of the method. At the same time, the relatively homogeneous and low attenuation geology simplifies the calibration procedure and ensures good quality coda waves across a wide range of magnitudes. Lessons learned will be applied as the study is expanded to other regions. 


\section{Comparison of Internet-Based Macroseismic Observations for the 29 Dec 2020 M6.4 Croatia Earthquake}

QUITORIANO, V., U.S. Geological Survey, Colorado, USA, vinceq@ contractor.usgs.gov; BOSSU, R., European-Mediterranean Seismological Centre, Arpajon, France, remy.bossu@emsc-csem.org; LANDÈS, M., European-Mediterranean Seismological Centre, Arpajon, France, matthieu. landes@emsc-csem.org; WALD, D. J., U.S. Geological Survey, Colorado, USA, wald@usgs.gov

The M6.4 Croatia earthquake on 29 December 2020 was one of the most widely felt earthquakes in Europe since the inception of internet macroseismic intensity (MI) questionnaires. The earthquake was widely reported on both the USGS "Did You Feel It?" (DYFI) system and the European-Mediterranean Seismological Centre (EMSC) LastQuake app. For direct comparison of DYFI MIs with LastQuake felt reports, we aggregate 2,515 DYFI reports and 15,869 EMSC reports into the same 1-km and $10-\mathrm{km}$ geocoded cells and then map the spatial distribution of MI using the USGS ShakeMap software. ShakeMap is already capable of supplementing ground motion estimates from seismic stations and ground motion prediction model (GMMs) with MI data from DYFI, and recent updates now allow for the incorporation of EMSC data. In order to combine different ground motion sources, ShakeMap requires the uncertainty quantification of the input data. We use a bootstrap method similar to that employed by Worden et al. (2012) for DYFI but applied to the global EMSC questionnaire response database, with additional heteroskedastic parameterization of uncertainty as a function of MI. We find that higher intensities $(\mathrm{MI} \geq \mathrm{VI})$ correspond to higher uncertainties, consistent with the known difficulty of assigning high intensities by nonexpert observers (i.e., higher MI assignments require damage and structural information that only expert observers are able to ascertain.) This method of uncertainty computation can be generalized to allow the inclusion of other MI sources into ShakeMap products. We also use independent, traditional EMS-98 assignments and a limited set of ground motion recordings for comparisons of DYFI and EMSC intensity values, their uncertainties, overall biases with respect to appropriate GMMs, and to one another.

\section{Complicated Lithospheric Structure Beneath the Contiguous United States Revealed by Teleseismic S Reflections}

LIU, T., University of California, San Diego, California, USA, til008@ucsd. edu; SHEARER, P. M., University of California, San Diego, California, USA, pshearer@ucsd.edu

Lithospheric discontinuities, including the lithosphere-asthenosphere boundary (LAB) and the enigmatic mid-lithospheric discontinuities (MLDs), hold important clues about the structure and evolution of tectonic plates. However, $\mathrm{P}$ - and S-receiver-function techniques (PRF and SRF), two traditional techniques to image Earth's deep discontinuities, have some shortcomings in imaging lithosphere discontinuities. Here, we propose a new method using reflections generated by teleseismic $S$ waves (hereafter $S$ reflections) to image lithospheric discontinuities, which is less affected by multiple phases than PRFs and has better depth resolution than SRFs. We apply this method to data collected by the Transportable Array and other regional seismic networks and obtain new high-resolution images of the lithosphere below the contiguous US. Beneath the tectonically active Western US, we observe a negative polarity reflector (NPR) in the depth range of $60-110 \mathrm{~km}$, with greatly varying amplitude and depth, which correlates with active tectonic processes. We interpret this feature as the lithosphere-asthenosphere boundary below the Western US. Beneath the tectonically stable Central and Eastern US, we observe two NPRs in the depth ranges of $60-100 \mathrm{~km}$ and $100-150 \mathrm{~km}$, whose amplitude and depth also vary significantly, and which appear to correlate with past tectonic processes. We interpret these features as mid-lithospheric discontinuities below the Central and Eastern US. Our results show reasonable agreement with results from PRFs, which have similar depth resolution, suggesting the possibility of joint inversion of $\mathrm{S}$ reflections and PRFs to constrain the properties of lithospheric discontinuities.

\section{How Does the Distribution of Differing Sedimentary Deposits Influence the Location of Earthquake-Induced Liquefaction? \\ GUVEN, C., Auburn University, Alabama, USA, czg0076@auburn.edu; WOLF, L. W., Auburn University, Alabama, USA, wolflor@auburn.edu; TUTTLE, M. P., M Tuttle \& Associates, Maine, USA, mptuttle@earthlink.net; ROGERS, S. R., Auburn University, Alabama, USA, s.rogers@auburn.edu}

In this investigation of a liquefaction site near Blytheville, AR, in the New Madrid seismic zone, electrical resistivity tomography (ERT) is used to test the hypothesis that the locations of the liquefaction features are controlled by the distribution of alluvial sediments associated with the Pemiscot Bayou (PB) and their inherent physical properties, such as porosity and permeability. This hypothesis is based on a previous interpretation of satellite imagery and examination of ditch exposures at the site. ERT data were collected along two $\mathrm{N}$-S parallel profiles with a length of 94 meters using a dipole-dipole array. In general, low resistivity values in ERT data indicate fine-grained sediment, such as silts and clays, whereas high resistivity values indicate coarser-grained sediment. The central portion of the ERT profiles shows an area of intermediate to low resistivity that is interpreted as an abandoned channel of the PB. Adjacent to both sides of the proposed abandoned channel, tabular areas of high resistivity are interpreted as sand dikes connecting surface sand blows to the source unit below. The postulated source layer is associated with high resistivity values and is interpreted as a braided stream deposit. At both ends of the profile, lower resistivity areas are interpreted as natural levee or overbank deposits. The results from the ERT survey support the hypothesis that sedimentary relationships influence where dikes and sand blows appear at the surface. We propose that during strong ground shaking, fine-grained sediment associated with abandoned channel, levee, and overbank deposits acted as confining layers, contributing to the increase in porewater pressure and eventual liquefaction of coarse-grained braided stream deposits below. The abandoned channel deposit, embedded within the layered sediment, guided the upward flow of liquefied sediment along its margins. Understanding how the sedimentary architecture influences the location of liquefaction deposits enhances our knowledge of how liquefaction deposits form and where liquefaction ground failure may occur.

\section{Joint Local and Teleseismic Tomography in the Central United States and Implications for the Origin of Intraplate Seismicity}

GENG, Y., CERI, University of Memphis, Tennessee, USA, ygeng1@memphis. edu; POWELL, C. A., CERI, University of Memphis, Tennessee, USA, capowell@memphis.edu; SAXENA, A., University of Florida, Florida, USA, saxena.arushi@ufl.edu

We present 3D crustal and upper mantle P-wave (Vp) and S-wave (Vs) velocity models for the northern Mississippi Embayment (NME) and the Illinois Basin using the USArray transportable network and stations deployed in the Northern Embayment Lithosphere Experiment (NELE) and the OzarkIllinois-Indiana-Kentucky (OIINK) FlexArrays. Our velocity models contain a narrow low-velocity zone (LVZ) below the NME, in agreement with several past studies. Our results bring new insight into the crust and upper mantle velocity structure associated with the Illinois Basin. A high-velocity anomaly is present in the crust beneath the central area of the Illinois Basin that coincides with the La Salle deformation belt, thought to represent compressional deformation associated with the distant Appalachian-Ouachita orogeny. We find a narrow mantle LVZ that extends from the NME to the northwest along the southwest boundary of the Illinois Basin. This LVZ dips to the northwest and reaches a depth of $250 \mathrm{~km}$. A broader LVZ is present below $300 \mathrm{~km}$, along the dip direction. The presence of the LVZ below the southwest boundary of the Illinois Basin corresponds to the location of the Ste. Genevieve seismic zone. A low velocity region extending from the base of the crust to a depth of about $100 \mathrm{~km}$ is present below the central portion of the Illinois Basin, in agreement with prior studies. The location of this LVZ roughly corresponds to the Wabash Valley seismic zone. We discuss possible origins of the imaged LVZs and their relationship to deeper mantle features as well as their possible influence on earthquake generation.

\section{Mw vs MI Relation for Small Earthquakes in Oklahoma and Kansas}

SEYDOUX, Q., Saint Louis University, Missouri, USA, quentinaseydoux@ gmail.com; HERRMANN, R. B., Saint Louis University, Missouri, USA, robert.b.herrmann@gmail.com

Seismic hazard analysis requires the counting of earthquakes with respect to a uniform magnitude scale. Often the desired scale is $\mathrm{Mw}$ but the magnitudes for small earthquakes are in some form of ML. We focus on the relation between $\mathrm{Mw}$ and ML for small earthquakes by using waveform modeling to estimate Mw. Because of reduced $\mathrm{S} / \mathrm{N}$ at lower frequencies, the necessary use of higher frequencies for modeling requires detailed velocity models for each source zone rather than generic ones. Focusing on four source zones in Oklahoma and Kansas, the models were constructed to fit teleseismic P-wave receiver functions, global and regional surface-wave dispersion estimates as well as newly obtained local earthquake P-wave receiver functions and short period surface-wave phase velocities. The new Love and Rayleigh wave phase velocities were obtained through a p-omega analysis of shallow earthquake 
signals passing through local aftershock deployments, which permitted the extension of regional dispersion estimates to periods as short as $1.5 \mathrm{~s}$. These data were inverted using the known depth to basement as a constraint to define the local velocity models. Using these models, small earthquake initial $\mathrm{P}$ - and SH-pulses were modeled. Because the rays from the source to the stations were nearly horizontal, the focal sphere was not well sampled to provide a definitive mechanism, but very shallow depths were rejected. Modeling with synthetics duplicated the characteristics of the inversion of real data and attested to the robustness of the Mw estimate. Comparing the Mw's to our ML's, we obtained the relation $\mathrm{Mw}=2 / 3 \mathrm{ML}+0.9$ for $1.9<\mathrm{ML}<4.0$. This is very close to that obtained using SMSIM with parameters that fit strong motion data in different regions of the US.

\section{Spatio-Temporal Changes of Seismicity Around Recent Large Earthquakes in Continental China}

LI, L., China Earthquake Administration, Beijing, China, sophia_lilu@163. com; WANG, B., University of Science and Technology of China, Hefei, China, bwgeo@ustc.edu.cn; PENG, Z., Georgia Institute of Technology, Georgia, USA, zpeng@gatech.edu

During the past 11 years, there were 32 large earthquakes ( $\mathrm{Ms} \geq 6.0$ ) occurred in Continental China, which caused significant casualties and losses in property. To better understand nucleation processes of earthquakes and aftershock behaviors, we conducted a systematic examination of spatio-temporal changes of seismic activities associated with these large earthquakes. To build a more complete earthquake catalog, we applied a GPU-accelerated matched filter technique (MFT) to detect possible missing earthquakes around each mainshock. We select the continuous waveforms recorded on the permanent stations from the China Seismic Network (CSN) within $300 \mathrm{~km}$ away and one month before and after each mainshock. Our analysis procedure is nearly automatic, which includes selecting template events, data preprocessing, scanning continuous waveforms, and building the final catalog. Using the MFT, the magnitude of completeness (Mc) for the detected catalogs decreased significantly. The detected catalogs include 156239 events, which are 4.7 times more earthquakes than the template catalogs. We systematically analyzed the foreshocks of each large earthquake. Most of the observations did not support an inference of accelerating foreshock activities that lead to the mainshock rupture, suggesting that accelerated nucleation process of a large earthquake was unlikely to be reliably observed for all the foreshock sequences. Our next step is to derive statistical parameters of both foreshock and aftershock sequences to better understand physical conditions/tectonic environments that control their behaviors.

\section{Two Shallow Earthquakes Located Within the Black Rock Volcanic Field in the Sevier Desert, Utah}

MESIMERI, M., University of Utah, Utah, USA, maria.mesimeri@utah.edu; PANKOW, K. L., University of Utah, Utah, USA, pankowseis2@gmail.com; BARNHART, W. D., University of Iowa, Utah, USA, william-barnhart-1@ uiowa.edu; WHIDDEN, K. M., University of Utah, Utah, USA, katherine@ whidden.net; HALE, J., University of Utah, Utah, USA, jmhale@seis.utah.edu

Two shallow earthquakes located in a relatively aseismic region within the Black Rock volcanic field, Utah. The first was an Mw 4.0 earthquake 12 September, 2018 and the second an Mw 4.1 earthquake 14 April, 2019. These events had shallow depths $(<2.5 \mathrm{~km}$ from the surface and $<1 \mathrm{~km}$ relative to sea level). These earthquakes and subsequent aftershock sequences are the only events located within a $10 \mathrm{~km}$ radius by the University of Utah Seismograph Stations since 1962. The seismic waveforms are dominated by long-period energy with no clear direct S-wave arrivals, and long signal duration $\sim 100$ s. Full moment tensor solutions rule out an isotopic source (like a blast or collapse), but suggest contributions from a compensated linear vector dipole (CLVD), especially for the 2018 earthquake. Co-seismic interferograms image clear and distinguishable surface deformation confirming the shallowness of the two mainshocks and for the 2019 event modeling of the interferograms resolves an Mw 4.4 to 4.5, which is larger than the seismic Mw of 4.1. At the time of the April 2019 sequence, a dense geophone array was located south of the epicentral region. We use this temporary network to enhance the UUSS catalog. The enhanced catalog indicates that $\sim 85 \%$ of aftershocks occur within the first three hours. Given the shallow source, CLVD contributions to the moment tensors, and aseismic deformation, we hypothesize that these earthquake sequences are probably directly related to processes in the Black Rock Desert volcanic field.

\section{Tectonics, Seismicity and Recent Significant Events in the Caribbean}

Oral Session · Tuesday · 20 April · 9:45 Am Pacific

Session Chairs: Victor A. Huerfano, Puerto Rico Seismic

Network (victor@prsnmail.uprm.edu); Guoqing Lin, University of Miami (glin@rsmas.miami.edu); Eugenio Polanco, Universidad Autonoma de Santo Domingo (eugenio. fisico@gmail.com); Joan Latchman, University of the West Indies Seismic Research Centre (j_latchman@uwiseismic. com); Wenyuan Fan, University of California, San Diego (wenyuanfan@ucsd.edu)

\section{Back-Arc Tsunami Hazard in the Gulf of Mexico From Oaxaca Earthquakes}

SALAREE, A., University of Michigan, Michigan, USA, salaree@umich.edu; HUANG, Y., University of Michigan, Michigan, USA, yiheh@umich.edu

The $\mathrm{M}_{\mathrm{w}}=7.4$ June 23, 2020 Oaxaca earthquake created a local tsunami in the Pacific Ocean. Numerical simulations show small but long-period tsunami waves in the back-arc Gulf of Mexico which were arguably recorded by a tide gauge on the U.S. coastlines. The moderate size of the Oaxaca rupture warrants an investigation of potential future tsunamis in case of large megathrusts filling the Oaxaca seismic gap, similar to the tsunami in the Sea of Japan during the 2011 Tohoku earthquake. In this study, we have simulated a large number of tsunami propagation scenarios in the Gulf of Mexico from earthquake sources with various geometries and sizes based on the dominant tectonic trend and seismic history of the Oaxaca region. Our analysis of the tsunami amplitudes in synthetic back-arc basins as well as the Gulf of Mexico shows that amplitude and dominant period of back-arc tsunamis are significantly affected by the dip angle of fore-arc faults. We also find that such coastal amplitudes are affected by the shape of the back-arc basin due to resonance of tsunami modes. An important result of this analysis, especially in the absence of active large thrust sources in the back-arc is that such basins (e.g., Gulf of Mexico) are not immune to various modes of tsunami propagation. It also underlines the need to re-examine the tsunami hazard in the countries around the Gulf of Mexico.

\section{Characterization of Swarm and Aftershock Behavior in Puerto Rico}

VENTURA-VALETIN, W. A., Miami University, Ohio, USA, venturwa@ miamioh.edu; BRUDZINSKI, M. R., Miami University, Ohio, USA, brudzimr@muohio.edu

The recent Indios, Puerto Rico earthquake sequence has drawn attention as the seismicity rate in this area has been unprecedented. The sequence began on December 28, caused a 6.4 magnitude earthquake on January 7 , and remains active. This sequence has fit the nominal definition of an earthquake swarm (sustained high seismicity without a clear triggering mainshock, an abrupt onset, and a lack of adherence to Bath's Law) while also having several mainshock-aftershock sequences embedded within it. In an effort to place this sequence in the context of the previous seismicity in Puerto Rico, we investigated the existence of swarms recorded by the Puerto Rico Seismic Network since 1987 by identifying sequences of increased seismicity rate when compared to the background rate. Potential sequences were identified using a seismicity rate algorithm and then manually verified and characterized. The categorization of aftershocks from swarms was based on the existence of an initial event that was at least 0.5 magnitudes higher than the other events and evidence for Omori decay. However, when we examined the relationship between the number of events in a sequence versus the maximum magnitude, we did not observe the expected separation between the two sequence types. This separation did emerge when we divided the study area into geographic regions, indicating that a higher magnitude of completeness in the northern offshore regions create artificially lower numbers per sequence. Focusing on sequences over the last five years, we observe a better magnitude of completeness in all regions and a clearer separation of swarm and aftershock behavior. Detailed characterization of the swarm and aftershock patterns for the Puerto Rico region will be a critical input for improved aftershock and swarm forecasts that are becoming a key component of hazard mitigation. 


\section{Double Difference Relocations of the 2020 Southwestern Puerto Rico Seismic Sequence}

VANACORE, E. A., University of Puerto Rico at Mayagüez, Puerto Rico, USA, elizabeth.vanacore@upr.edu; JOYCE, J., University of Puerto Rico at Mayagüez, Puerto Rico, USA, james.joyce@upr.edu; TEN BRINK, U., U.S. Geological Survey, Massachusetts, USA, utenbrink@usgs.gov; FIELDING, E. J., Jet Propulsion Laboratory, Puerto Rico, USA, eric.j.fielding@jpl.nasa.gov; LOPEZ-VENEGAS, A., University of Puerto Rico at Mayagüez, Puerto Rico, USA, alberto.lopez3@upr.edu

Since the initiation of the 2020 Southwest Puerto Rico Seismic Sequence (SWPRSS) on Dec 28, 2019, the Puerto Rico Seismic Network (PRSN) has located $>12,000$ earthquakes. The SWPRSS is characterized by diffuse seismicity in the region stemming from the interaction of multiple normal and strike slip faults. Relocating the seismicity is critical to understanding not only the time evolution of the SWPRSS but also identifying the fault structures associated with this sequence. Here the relocation of $>7,000$ earthquakes associated with the sequence recorded between December 28, 2019 and August 15, 2020 are presented. Earthquakes were relocated using the double difference algorithm of Waldhauser \& Ellsworth (2000), HypoDD, and using the PRSN $1 \mathrm{D}$ velocity model. Relocated events prior to the Mw 6.4 earthquake on Jan 7, 2020 cluster along an offshore extension of the Punta Montalva fault (PMf) with a series a left-lateral strike slip events limited to depths less than $10 \mathrm{~km}$ depth. Following the Mw 6.4 earthquake, the sequence exhibits activity along multiple interacting and intersecting suite of strike-slip and normal faults in the region. This behavior change is an example of stress transfer likely related to the end of the PMf offshore at the normal fault zone in the Guayanilla Canyon. This is supported by a permanent onshore subsidence up to 0.20 $\mathrm{m}$ based on interferometric synthetic aperture radar (InSAR) measurement associated with the Mw 6.4, consistent with a normal fault. The earthquake sequence along the offshore extension of the Punta Montalva triggered the Mw 6.4 and subsequent multiple fault seismic sequence. Given the complexity of this incipient fault zone, interpretation of the resultant relocated earthquakes while possible remains debatable. Coupling the relocations here with focal mechanisms calculations will create more robust interpretations in the future. These results highlight the need for large scale onshore offshore modern seismic surveys in the region to identify active faults and better understand the seismic hazard from this previously unnamed fault zone.

\section{Numerical Simulation of Flow, Transport of Heat and Chemical Transport Processes in Volcanic Chambers Partially Filled With Molten Rock and Consequence on Dynamic Seismo-Acoustic Signatures}

EZZEDINE, S. M., Lawrence Livermore National Laboratory, California, USA, ezzedine1@llnl.gov; ANTOUN, T. H., Lawrence Livermore National Laboratory, California, USA, antoun1@llnl.gov; WALTER, W. R., Lawrence Livermore National Laboratory, California, USA, walter5@llnl.gov

A transient numerical study of conjugate flow, heat and mass transfer by natural convection of gases - air, carbon dioxide, noble gases - within an underground cavity partially filled with molten rock is presented. The molten rock is initially considered to be at rest at an initial temperature and concentration. The molten rock is viscous and possesses strength that is temperature, viscosity, and crystal fraction dependent. Under natural conditions, convection cells are developed within the molten rock leading to circulation, mixing and degassing of the initially trapped gases. Furthermore, the molten rock as well the degassing enhances the conjugate convection flow in the air gap above the molten rock within the cavity and promote Bénard-Rayleigh-Taylor instabilities. We illustrate the onset of the different regimes of instabilities and their combined effect of flow, heat and mass transport of different gas species as function of the geometry of the cavity and the fraction of molten rock. The transient governing equations of mass, momentum, heat and chemical species were solved using the finite element method. Several numerical coupling schemes are presented, and numerical stability conditions are illustrated. We also present a sensitivity analysis of the effect of the outer cavity boundary condition on the heat loss and cooling to the adjacent rock formation and its effect on the convective mixing topology with the air gap and the molten rock. We present four- and three-dimensional synthetic sesimo-acoustic wave signatures generated on the dynamic time series of the evolving physicochemical processes in the chamber while assessing the interplay between frequencies of interest, material uncertainty, and significance of key the physical phenomena.

This work performed under the auspices of the U.S. Department of Energy by Lawrence Livermore National Laboratory under Contract DE-AC52-07NA27344.

\section{Revision of the Earthquake Source Parameters and Moment Magnitude of the 7 January 2020 Earthquake, South of Indios, Offshore Puerto Rico}

HUERFANO, V. A., Puerto Rico Seismic Network, Puerto Rico, USA, victor@ prsnmail.uprm.edu; CAMERON, A., Puerto Rico Seismic Network, Texas, USA, cameron.antonio@gmail.com

On January 07, 2020 at 4:24:27 a.m. local time (AST), a strong-size (M 6.4) and shallow ( $10 \mathrm{Km}$ focal depth) earthquake struck the island of Puerto Rico killing one person and casing vast destruction and significant damages to the Guánica, Yauco, Guayanilla and Ponce municipalities, south of Puerto Rico. Despite this particular earthquake only generated a small tsunami without threating the southern coast of Puerto Rico, and/or the entire circum-Caribbean Basin, the risk of having future damaging earthquakes, potentially tsunamigenic, remains high.

In this work, we present a revision of the earthquake source parameters and magnitude results of regional moment tensor (RMT) inversions using regional seismograms recorded by seismic stations around the Caribbean. We compared the inversion solutions with those reported by international agencies such as CMT and NEIC; and we will present the timeline procedure suggesting that the RMT inversion provide a timely estimate of the earthquake focal mechanism, depth and magnitude that would be beneficial for tsunami alerting within the region, and furthermore, to understand the seismicity of the area.

Tectonics, Seismicity and Recent Significant Events in the Caribbean

Poster Session · Tuesday · 20 April · 11:30 Am Pacific Session Chairs: Victor A. Huerfano, Puerto Rico Seismic Network (victor@prsnmail.uprm.edu); Guoqing Lin, University of Miami (glin@rsmas.miami.edu); Eugenio Polanco, Universidad Autonoma de Santo Domingo (eugenio. fisico@gmail.com); Joan Latchman, University of the West Indies Seismic Research Centre (j_latchman@uwiseismic. com); Wenyuan Fan, University of California, San Diego (wenyuanfan@ucsd.edu)

\section{A High-Resolution View of the 2020 Puerto Rico Earthquake Sequence With Machine Learning \\ YOON, C., U.S. Geological Survey, California, USA, cyoon@usgs.gov}

The unusually active 2020 Puerto Rico earthquake sequence, located just offshore in southwestern Puerto Rico, is still ongoing in January 2021. This sequence started on December 28, 2019 with a M4.7 strike-slip earthquake. The eventual M6.4 mainshock, an oblique normal fault earthquake, ruptured on January 7, 2020. One M6+, 15 M5+, 118 M4+, and 1,710 M3+ earthquakes have occurred since the sequence began.

To better understand the processes driving this sequence, I applied EQTransformer (Mousavi et al., 2020), a deep learning model trained on a global earthquake data set, to automatically detect earthquakes and pick $\mathrm{P}$ and $\mathrm{S}$ phases on continuous seismic data at 26 nearby stations during the time period 2018-01-01 to 2020-11-01. I then located all earthquakes with phase picks on at least 4 stations, using a 1D layered velocity model (Mendoza and Huerfano, 2005).

Deep learning models excel at identifying frequent small earthquakes, but they are not yet ready to completely replace standard earthquake monitoring methods. EQTransformer detected over 100,000 earthquakes in the Puerto Rico sequence; almost 90,000 of these earthquakes, mostly with magnitudes between 1 and 3, were not in the ComCat earthquake catalog. EQTransformer failed to detect about 2600 catalog earthquakes, including the M6.4 mainshock and several M>4 events.

The earthquake locations reveal activation of a complex fault system with a mix of normal and strike-slip faults, with a $\sim 60-\mathrm{km}$ east-west seismicity trend intersecting a $\sim 40-\mathrm{km}$ NE-SW seismicity trend. During the 2 weeks after the M6.4 mainshock, earthquakes occurred on both the eastwest and NE-SW trends. Later, swarm-like migration of clustered seismicity occurred to the east in May 2020, then to the west in June-September 2020. Two small seismicity bursts before the sequence started, in December 2018 and December 2019, were located near the eastern edge of the subsequent earthquake sequence. 
A Secondary Wave Field and the Seismic Site Response of Mexico City During Recent Earthquakes

AQUINO-SÁNDOVAL, G. C., Universidad Nacional Autónoma de México, Mexico City, Mexico, gilpin97@hotmail.com; CÁRDENAS-SOTO, M., Universidad Nacional Autónoma de México, MEXICO, Mexico, martinc@ unam.mx

The recent September 19, 2017, earthquake (Mw 7.1), which occurred less than $150 \mathrm{~km}$ away from Mexico City, caused damages in zones where the local dominant period is smaller than $1.5 \mathrm{~s}$. In this range of periods, the buildings located in the transition zone and part in the lake area were the most affected. To understand the interaction of the wavefield with the Mexico basin subsurface structure, we analyzed the seismic records of this earthquake and compared the results with the ground motion produced by two other earthquakes (April 18, 2014, Mw 72 and September 08, 2017, Mw 8.1). Using the accelerometric network of Mexico City, we explored the wavefield by polarization analysis in the Z-R plane and the f-k spectrum using the vertical component in sub-arrays of stations. In periods around $5 \mathrm{~s}$, the results show polarized waves with a different direction to the epicenter for the 2017 earthquakes, which have the same epicentral direction. The phase velocity is $1-1.2 \mathrm{~km} / \mathrm{s}$, which corresponds to waves propagating in volcano-sedimentary layers; 0.5 to $1.0 \mathrm{~km}$ depths. Our observations suggest a secondary wave field generated within the basin, which contains energetic arrivals that contribute to the violent movement in Mexico City. However, it seems that is not happening for all earthquakes. For the April 18 earthquake, Rayleigh-type surface waves predominantly come from the epicenter, and they cross the Mexico basin without any deviation.

\section{Earthquake Distributions Along Northern Caribbean Faults: Effects of Segmentation and Interdependence}

GEIST, E. L., U.S. Geological Survey, California, USA, egeist@usgs.gov; TEN BRINK, U., U.S. Geological Survey, Massachusetts, USA, utenbrink@usgs.gov

We simulate patterns of earthquake distributions along the complex fault system of the northern Caribbean plate boundary using the integer programming (IP) method. Input to the simulations is a regional synthetic catalog of $M \geq 6$ earthquakes drawn from a Gutenberg-Richter (G-R) distribution spanning 10 kyr. Integer programming globally optimizes the spatial distribution of the earthquakes according to target slip rates provided by previously published GPS block models for major faults, and by other data for secondary faults. All feasible IP solutions must fall within the uncertainty in these slip rates. In addition to fitting earthquake distributions to the target slip rate, the northern Caribbean study region has an extensive 500-yr record of large magnitude earthquakes that can be used to evaluate different assumptions about fault coupling and segmentation. Both the magnitude and location of historical earthquakes, with their attendant uncertainties, are used to determine which coupling and segmentation scenarios best explain the observations. Results are particularly sensitive to the seismic coupling coefficient ( $\alpha$ ) along the Puerto Rico Trench (PRT) plate boundary fault. Results that conform to the historical observations are obtained if the PRT fault is very weakly coupled $(\alpha=0.1)$ and if the PRT fault is segmented from the westward extension of the plate boundary fault north of Hispaniola. Further improvements to slip-rate fits and consistency with historical earthquake occurrences are obtained by segmenting the Septentrional and Hispaniola faults. An interesting observation from this study is that assumptions of fault slip rate and segmentation on one fault have significant effects on magnitude distributions on other faults farther away. In general, optimal on-fault magnitude distributions are more complex and interdependent than typically assumed in hazard analyses.

\section{Monitoring the Seismicity in the Pantanal Basin, Western Brazil}

TADEU, E., Arquitetura e Urbanismo (FAENG), UFMS, Campo Grande, Brazil, estevao.tadeu@ufms.br; ASSUMPÇÃO, M., Institute of Astronomy, Geophysics and Atmospheric Sciences (IAG), USP, São Paulo, Brazil, marcelo. assumpcao@iag.usp.br; BIANCHI, M., Institute of Astronomy, Geophysics and Atmospheric Sciences (IAG), USP, São Paulo, Brazil, m.bianchi@iag. usp.br; FACINCANI, E., Arquitetura e Urbanismo (FAENG), UFMS, Campo Grande, Brazil, edna_facincani@hotmail.com; COLLAÇO, B., Institute of Astronomy, Geophysics and Atmospheric Sciences (IAG), USP, São Paulo, Brazil, bruno@iag.usp.br

Since 2008, the seismically active intraplate Pantanal Basin has been a seismological research focus, first with installation of some permanent stations of the Brazilian Network, and now with the FAPESP-funded temporary deployment. The Pantanal region has been monitored by 18 permanent and up to 20 temporary stations covering the regions of the Chaco-Paraná and Paraná basins, as well as the Pantanal wetlands. Stations were spread in five different countries: Uruguay, Argentina, Paraguay, Bolívia, and Brazil. Today the Universidade Federal do Mato Grosso do Sul, with a partnership with Universidade de São Paulo, detect and locate seismicity in the Pantanal. The current procedure is based on the SeisComP3 software. It involves (1) to manual examination of filtered adapted station day plot, (2) using SeisComP3 to pick seismic phases, and (3) locating earthquakes and estimating magnitudes. We used 14 stations in this work and investigated the years of 2015 and 2016, detectting 250 new seismic events. Magnitudes ranged between 0.1 and $4.0 \mathrm{ML}$ and are located mainly around and within the Pantanal Basin. Quarry blasts are tentatively identified by their location and waveforms. The newly detected natural events confirm the higher seismicity of the Pantanal Wetlands compared with other neighboring regions.

\begin{tabular}{l}
\hline Towards an Integrated View of Earthquake Gates From \\
Geologic Observations and Numerical Models \\
Oral Session · Friday · 23 April · 2:00 PM Pacific \\
Session Chairs: Veronica B. Prush, McGill University \\
(vbprush@ucdavis.edu); Alba M. Rodriguez Padilla, \\
University of California, Davis (arodriguezpadilla@ucdavis. \\
edu); Julian C. Lozos, California State University, Northridge \\
(julian.lozos@csun.edu); Michele L. Cooke, University of \\
Massachusetts, Amherst (cooke@umass.edu)
\end{tabular}

\section{Earthquake Cycles in Fault-Bend Folds}

SATHIAKUMAR, S., University of Southern California, California, USA, sharadhask03@gmail.com; BARBOT, S., University of Southern California, California, USA, sbarbot@usc.edu; HUBBARD, J., Asian School of Environment, NTU, Singapore, Singapore, jhubbard@ntu.edu.sg

Subduction zones and fold-and-thrust belts host both the biggest earthquakes on Earth, as well as a variety of events that break different segments of the megathrust. Numerical modeling has been used to try to understand the diversity of earthquakes at these margins. However, these models typically do not incorporate the active fault-related folding processes that are accommodating much of the upper plate deformation. The aim of this study is to investigate the impact of fault bends and associated folding on earthquake cycles and associated behavior, including earthquake segmentation, off-fault plasticity, and the propagation of shallow ruptures. We perform sensitivity tests on geometric elements, namely the magnitude of the fault bend and angularity of the hanging wall cut-off, that influence different earthquake processes. We incorporate fault-bend fold theory into a fault dynamic modeling framework, and develop two-dimensional, quasi-dynamic numerical simulations of slip evolution under rate-and-state friction. This helps us understand the ways in which fault geometry and fault friction properties interact to shape the seismic cycle. We numerically incorporate axial surfaces in our models to simulate the kinematics of off-fault deformation associated with folding. We find that earthquake behavior is sensitive to fault friction parameters, the magnitude of fault bending, and the cut-off angle between incoming sediments and the fault. We find that fault bends can produce earthquake segmentation as a result of nonlinear fault dynamics, for both coseismic and interseismic slip. Shallow earthquakes that initiate, propagate, and terminate near the surface are facilitated when the stratigraphy within incoming thrust sheets is not parallel to the underlying fault, as this changes the loading rate across the fault bend. This study provides a first step towards creating more realistic rupture models that account for realistic geological structures and off-fault deformation.

\section{Kinematic Compatibility of Fault Geometry and Slip Rates Within the San Gorgonio Pass Region, Southern California} HATCH, J., Hotchkiss School, Connecticut, USA, jhatch@hotchkiss.org; COOKE, M. L., University of Massachusetts Amherst, Massachusetts, USA, cooke@umass.edu; ELSTON, H., University of Massachusetts Amherst, Massachusetts, USA, helston@umass.edu

Evidence suggests that the San Gorgonio Pass region is an earthquake gate along the San Andreas fault where some earthquakes follow the southern pathway through the pass while other earthquakes may follow a northern pathway. The uncertainties of the active fault geometry in the region complicate estimates of seismic hazard. Crustal deformation models with alternative and currently debated $3 \mathrm{D}$ active fault geometries through the region produce fault slip rates that match some, but not all, of the available geologic strike-slip rates 
at sites along the southern San Andreas fault. Sites with disagreement between the model and geologic slip rates indicate where the model fault geometry is incompatible with the interpreted geologic slip rate. Here, we investigate the kinematic compatibility of slip rates and fault geometry using mechanical models of four plausible subsurface fault configurations. The models limit the dextral strike-slip rates to within the range of geologic slip rates at the sites of the geologic investigations and the faults outside of these regions of known slip rate are allowed to slip freely in response to tectonic loading and fault interaction. Off-fault distortion maps of the model results reveal regions of kinematic incompatibility at the branch of the San Andreas fault near Indio Hills, in the hanging wall of the San Gorgonio Pass thrust, and near Cajon Pass. While the Cajon Pass and the hanging wall of the San Gorgonio Pass thrust show microseismicity that may be an expression of off-fault deformation, the Indio hills lack microseismicity. The locally high off-fault distortion predicted in the models for Indio Hills indicates that geologic fault slip rates are not effectively accommodated along the simulated fault surfaces in these regions. This innovative approach reveals kinematic incompatibilities that suggest that our current knowledge of the fault configuration and/or slip rates may not accurately inform seismic hazards of these regions.

\section{The Main Kopeh Dagh Fault: New Observations Bearing on the Rupture Boundaries of the Most Recent Earthquake Cycle}

MARSHALL, N., University of Oxford, Oxford, United Kingdom, neill. marshall@earth.ox.ac.uk; WALKER, R., University of Oxford, Oxford, United Kingdom, richard.walker@earth.ox.ac.uk; PIERCE, I. K. D., University of Oxford, Oxford, United Kingdom, ian@nevada.unr.edu; DODDS, N., University of Oxford, Oxford, United Kingdom, nicholas.dodds@st-annes. ox.ac.uk; GRUETZNER, C., Friedrich Schiller University Jena, Jena, Germany, christoph.gruetzner@uni-jena.de; BERGMAN, E., Global Seismological Services, Colorado, USA, bergman@seismo.com

The Main Kopeh Dagh fault is a west-northwest striking right-lateral fault that extends from the eastern shores of the Caspian Sea nearly $850 \mathrm{~km}$ to the Afghanistan/Iran/Turkmenistan border region. Historically, it produced the 1948 M 7.3 Ashgabat earthquake, killing over 35,000 people. We relocated the hypocentre using historical seismograms, and present a new focal mechanism. Here we present new geomorphic mapping along much of the fault using Pleiades satellite tri-stereo derived DEMs and imagery. The resulting mapping presents a clear picture of other recent Holocene-latest Pleistocene ruptures, along different sections of the fault than the 1948 earthquake. We show the extent of these ruptures and describe the structural characteristics of the rupture boundaries in the context of earthquake gates.

\section{Rupture Boundaries Within the 1968-1997 Dasht-E Bayaz Earthquake Sequence, Iran}

PIERCE, I. K. D., University of Oxford, Oxford, United Kingdom, ian@nevada. unr.edu; ELLIOTT, A. J., U.S. Geological Survey, California, USA, ajelliott@ usgs.gov; GREEN, L., University of Oxford, Oxford, United Kingdom, lawrencegreen1995@outlook.com; WALKER, R., University of Oxford, Oxford, United Kingdom, richard.walker@earth.ox.ac.uk; TALEBIAN, M., Research Institute of Earth Sciences, Geological Survey of Iran, Tehran, Iran, Islamic Republic Of, talebian@gsi-iran.org

The Dasht-E Bayaz fault system in the South Khorasan province of Iran hosted a sequence of 11 major destructive earthquakes from 1936-2008, representing an outstanding example of century-scale progressive rupture, involving multiple fault segments and intersecting perpendicular faults with left, right, and reverse slip. The three largest events, in 1968, 1979, and 1997, each produced substantial surface ruptures, however the specific relationships among and boundaries between the causative faults have not yet been fully defined. The 1968 M7.1 Dasht-E Bayaz and 1979 M7.1 Khuli-Buniabad events together ruptured $\sim 140 \mathrm{~km}$ of the east-striking left-lateral Dasht-E Bayaz fault, while the adjacent 1997 M7.2 Zirkuh earthquake ruptured $\sim 125 \mathrm{~km}$ of the perpendicular north-striking right-lateral Abiz fault at the earlier ruptures' eastern end. In this study we use high-resolution satellite imagery and derivative topography from 2015 along with aerial photographs from 1956 (pre-event) and 1969 (immediately post-event) to produce the most complete map to date of the ruptures of the 1968 Dasht-E Bayaz and 1979 Khuli-Buniabad earthquakes. We then use a previous satellite-derived optical image correlation study of the 1979 and 1997 events to better define the respective termini of these events, discerning the sequence of failure at their intersections. We finally compare the orthogonal geometry and rupture pattern of this sequence to those of the 1987 Superstition Hills and 2019 Ridgecrest earthquake sequences to explore the potential triggering relationships between perpendicular faults, and their modes of rupture termination.
Spatial Heterogeneity in Microseismicity and Stress Near Repeated Conditional Rupture Terminations on the Alpine Fault, New Zealand

WARREN-SMITH, E., GNS Science, Lower Hutt, New Zealand, e.warrensmith@gns.cri.nz; TOWNEND, J., Victoria University of Wellington, Wellington, New Zealand, john.townend@vuw.ac.nz; CHAMBERLAIN, C. J., Victoria University of Wellington, Wellington, New Zealand, calum. chamberlain@vuw.ac.nz; JUAREZ GARFIAS, I. C., Victoria University of Wellington, Wellington, New Zealand, ilmadelcarmen.juarezgarfias@vuw. ac.nz; ABERCROMBIE, R. E., Boston University, Massachusetts, USA, rea@bu.edu; BOULTON, C., Victoria University of Wellington, Wellington, New Zealand, carolyn.boulton@vuw.ac.nz; MICHAILOS, K., University of Lausanne, Lausanne, Switzerland, konstantinos.michailos@unil.ch; KANEKO, Y., GNS Science, Lower Hutt, New Zealand, y.kaneko@gns.cri.nz; HOWARTH, J., Victoria University of Wellington, Wellington, New Zealand, jamie.howarth@vuw.ac.nz

An earthquake's size is strongly controlled by the length of the fault that slips; but this is rarely the full length of the mappable fault zone. Understanding the on-fault processes that influence eventual rupture length is an ongoing challenge in earthquake science. Extensive paleoseismic studies along the Alpine Fault show that large (M7+) earthquakes occur remarkably regularly, every $291+/-23$ years. Yet the millennial-scale paleoseismic record shows that these earthquakes typically rupture different combinations of fault segments. Ruptures regularly terminate at the South Westland and Central segment boundary, near Haast, and near the Central and North Westland segment boundary near Inchbonnie at the intersection with the Hope Fault. However, some ruptures propagate through these boundaries in multi-segment events, increasing the earthquake magnitude from $\sim \mathrm{M} 7+$ to $\sim \mathrm{M} 7.8+$.

To understand the transitional behaviour of these segment boundaries, and their role in conditionally arresting through-going ruptures, we use the locations and physical properties of small earthquakes to quantify spatial heterogeneities in factors that have elsewhere been proposed to arrest rupture. Along the best studied central segment, such techniques have proved effective in constraining fault mechanics and deformation state, but the remote and sparsly instrumented nature of the segment boundaries has to date hindered comparable analysis for these important zones.

Using precise micro-earthquake catalogues from dense, new seismic networks near segment boundaries, we map along-strike variations in seismogenesis including: seismogenic depth, on-fault seismic slip, triaxial stress field orientations, aseismic fault patches, fault geometry/structure and connectivity with intersecting faults. We present results of the geometry and mechanical state of these complex rupture barrier regions and discuss how their behaviour contrasts with the more uniform central Alpine Fault segment in the context of processes that promote large-scale rupture nucleation and propagation.

\section{Towards an Integrated View of Earthquake Gates From Geologic Observations and Numerical Models \\ Poster Session · Friday · 23 April · 11:30 AM Pacific \\ Session Chairs: Veronica B. Prush, McGill University \\ (vbprush@ucdavis.edu); Alba M. Rodriguez Padilla, University of California, Davis (arodriguezpadilla@ucdavis. edu); Julian C. Lozos, California State University, Northridge (julian.lozos@csun.edu); Michele L. Cooke, University of Massachusetts, Amherst (cooke@umass.edu)}

\section{Dynamic Rupture Modeling of Coseismic Interactions on Orthogonal Strike-Slip Faults}

LOZOS, I. California State University, Northridge, California, USA, julian. lozos@csun.edu

The San Andreas Fault System is dominated by right-lateral strike-slip faulting. However, a large number of smaller orthogonal left-lateral structures also exist. Some, such as the Garlock Fault or Pinto Mountain Fault, are large enough to be mapped without having had a historic earthquake. However, the existence of other smaller orthogonal structures is often highlighted only when they rupture in conjunction or sequence with a larger mapped fault. The 2019 Ridgecrest sequence, which included a M6.4 rupture on a left-lateral fault followed 34 hours later by a M7.1 earthquake on an orthogonal right-lateral fault, exemplifies this. The Ridgecrest example raises questions as to what conditions led to the source faults rupturing in two closely-spaced earthquakes as 
opposed to one single larger event. That extends to broader questions about general behaviors of orthogonal strike-slip faults as earthquake gates: what conditions might make them rupture together versus separately, how likely is a rupture on one fault to activate a large cross-fault, and is this persisten behavior versus something changes over multiple earthquake cycles? Here, I use the 3D finite element method to simulate dynamic ruptures on orthogonal strike-slip fault systems with several geometrical configurations. In models in a homogeneous elastic half space with uniform initial stresses on both faults, which isolate the effects of fault geometry, I find that a stopping phase from rupture hitting the end of one fault is necessary to initiate rupture on the other. A rupture on one fault that crosses the other and continues on does not activate the second fault. Thus, the rupture pattern and earthquake size in an orthogonal fault system may be heavily dependent on the nucleation location, reinforcing the idea that such systems do function as earthquake gates. I compare these uniform stress models to ones in which the fault system is in a regional stress field, which produces different initial stresses on each fault, as well as to ones in which the faults are in a viscoplastic medium rather than an elastic one.

\section{Fault Activity and Mechanical Conditions for Rupture of the Akatengneng Shan Earthquake Gate Along the Altyn Tagh Fault, Northwest China}

PRUSH, V. B., McGill University, Montreal, Canada, vbprush@ucdavis.edu; OSKIN, M. E., University of California, Davis, California, USA, meoskin@ ucdavis.edu; LIU-ZENG, J., Tianjin University, Tianjin, China, liu_zeng@tju. edu.cn

Historical rupture mapping and numerical modeling demonstrate that geometric complexities along faults, such as bends and stepovers, act as barriers to earthquake propagation. The efficacy of a barrier to throughgoing rupture may be time-dependent and subject to local stress heterogeneities accumulated by the halting of prior earthquakes within a fault complexity. These factors lead to complexities acting as earthquake gates, which cycle between periods of more or less efficiency as rupture barriers. We use Quaternary slip rates to determine the efficacy of the Akatengneng Shan (AS) earthquake gate as a barrier to rupture by evaluating fault slip rate at seven sites along the main Altyn Tagh fault (ATF) strand and secondary structures. We find that the pattern of slip distribution within the AS is complex and varies with location in the range, likely due to rheological variation across the ATF

To determine the mechanical conditions under which rupture propagates through the complex fault geometry of the AS we apply 3D stress fields to a simplified AS fault geometry to determine their kinematic compatibility with field observations of fault slip direction. We show that no single stress field allows for the observed slip vectors on all active faults within the AS earthquake gate. We conclude that there must be rotation of the stress field near the fault to allow for sinistral slip along its more misoriented sections. Stress rotation could be accommodated by elevated pore pressure or a weakened fault core relative to a stronger surrounding crustal volume, as has been argued along other mature continental strike-slip faults, such as the San Andreas fault. Evaluating earthquake gate-like rupture behavior should account for the orientation, kinematics, and rate of activity of secondary structures that accommodate deformation away from the main fault, as this off-fault deformation provides useful information for understanding throughgoing rupture, as well as alternative pathways for gate-breaching events.

\section{Linking Northcoast NSAF Turbidite Event Beds to the San Francisco Region}

GOLDFINGER, C., Oregon State University, Oregon, USA, chris.goldfinger@ oregonstate.edu

We have acquired new CT imagery from many existing offshore cores between Cape Mendocino and Pioneer Canyon, near San Francisco. With the addition of CT data, some issues with the original radiocarbon data became apparent, showing that problematic radiocarbon samples were contaminated with fine grained reworked material. Unfortunately, this examination revealed that many of the NSAF ages (excepting Noyo Canyon) were contaminated, explaining the observed high variability from site to site. Iterative attempts were made to find consistency with both ages and correlation tie points, and this resulted in elimination of more ages as reversed. We closely examined the linkages of the North Coast cores to Noyo Canyon using several newer cores collected in 2009. TN0909-15 and 16 JC were collected at the base of the slope adjacent to the original cores in Noyo Channel, but out of the channel such that they monitor the adjacent continental slope. Using the physical property data from these cores, we establish a robust linkage between the high-resolution Noyo cores, and the lower resolution North Coast cores. Having linked the slope base cores to Noyo Canyon, we found that linking them to the North Coast cores from further south at Gualala, Albion, Cordell, Pioneer and Farallon Canyons was then relatively straightforward. With this linkage, we then use the chronology established at Noyo Canyon to examine the southward correlation of key events. Prominent beds do not include the probable 1906 bed which is prominent at Noyo Canyon, but quickly fades southward. We attribute the weakness of this bed to the declining late Holocene sediment supply, and southward increase in epicentral distance. The youngest prominent bed, NT 6 with an age of $\sim 820(690-940)$ cal BP is easily correlated southward to Pioneer Canyon. It is likely present at onshore sites and Lake Merced. Other prominent beds can be traced from Noyo Canyon southward, and most of them have prominent equivalents in Lake Merced, substantially improving the linkage of Northcoast segment NSAF events along-strike.

\section{Mapping Variations in Moderate-Magnitude Earthquake Source Properties Along the Alpine Fault, New Zealand, to Investigate Conditional Rupture Segmentation}

IUAREZ GARFIAS, I. C., Victoria University of Wellington, Wellington, New Zealand, ilmadelcarmen.juarezgarfias@vuw.ac.nz; WARREN-SMITH, E., GNS Science, Lower Hutt, New Zealand, e.warren-smith@gns.cri.nz; TOWNEND, J., Victoria University of Wellington, Wellington, New Zealand, john.townend@vuw.ac.nz; ABERCROMBIE, R. E., Boston University, Massachusetts, USA, rea@bu.edu

The Alpine Fault is a major active continental transform fault that is late in its typical cycle of large earthquakes: extensive paleoseismic research has revealed that the central section of the Alpine Fault ruptures in M7+ earthquakes every $291 \pm 23$ years and last ruptured in $1717 \mathrm{AD}$. The paleoseismic results also reveal that some small-scale segments of the fault, which coincide with pronounced along-strike changes in fault characteristics, act as conditional barriers to rupture. The geometry, seismicity rates and geology of the Alpine Fault change along three principal sections but it is unclear whether source properties (e.g. stress drop, directivity) of near-fault seismicity also vary between those fault segments, and whether these properties have some influence on conditional segmentation of the Alpine Fault during large earthquake rupture.

To test this, we calculate stress drops and directivity of moderate-magnitude earthquakes occurring on and close to the Alpine Fault, using an empirical Green's function (EGF) approach. We use data from dense, temporary seismometer networks, including DWARFS (Dense Westland Arrays Researching Fault Segmentation), a new two-part network designed to constrain seismogenic behaviour near key transitional boundaries on the Alpine Fault. Our results investigate the spatial variability of these source properties along the length of the Alpine Fault, focussing on whether earthquakes at the rupture segment boundaries behave differently to those in the middle of previously identified rupture segments.

\section{Repeating Earthquakes Partially Reload Themselves in Parkfield}

RUBINSTEIN, I. L., U.S. Geological Survey, California, USA, jrubinstein@ usgs.gov; PENNINGTON, C. N., U.S. Geological Survey, California, USA, cpennington@usgs.gov; KROLL, K., Lawrence Livermore National Laboratory, California, USA, kroll5@llnl.gov; ELLSWORTH, W. L., Stanford University, California, USA, wellsworth@stanford.edu

Analysis of repeating earthquakes on the San Andreas Fault in Parkfield California reveals that slip increases linearly with increasing hold time. This scaling, though, is not strictly slip-predictable, as at zero time there is a positive slip deficit. We propose that this linear scaling with a positive slip deficit at zero recurrence time arises from the combination of two difference sources of loading (1) a constant, background tectonic loading rate, and (2) a transient increase in loading rate on the slip-patch immediately following the rupture. The latter results from the interaction between the repeating earthquake asperity and the surrounding creeping zone. When the patch slips in an earthquake, stress increases adjacent to the rupture causing accelerated creep in the region surrounding the repeating earthquake asperity. The creep, decays with the logarithm of time back to the tectonic loading rate, and also partially reloads the locked asperity.

To test this hypothesis, we (1) analyze repeating aftershocks of the M6.0 Parkfield earthquake and (2) use numerical models to simulate repeating earthquake behavior.

For repeating aftershocks of the Parkfield earthquake, we find that the moment release rate decays from a peak at the time of the mainshock back to the tectonic rate over time. This moment rate is consistent with the geodetically observed afterslip, implying that the afterslip is driving the repeating events. This behavior is similar to the partial self-reloading we propose above. 
Numerical models of repeating events also yield a non-linear moment release rate that is most rapid immediately following the occurrence of the repeat. This behavior is consistent with our hypothesis that repeating earthquakes partially reload themselves.

\section{Tsunami Warning System in Latin America and the Caribbean: COVID-19 Challenges}

Oral Session - Wednesday · 21 April $\cdot$ 2:00 PM Pacific Session Chairs: Victor A. Huerfano, Puerto Rico Seismic Network (victor@prsnmail.uprm.edu); Christa von Hillebrandt-Andrade, National Oceanic and Atmospheric Administration (christa.vonh@noaa.gov); Silvia ChaconBarrantes, Universidad Nacional de Costa Rica (silviach@ una.ac.cr); Sergio E. Barrientos, University of Chile (sbarrien@dgf.uchile.cl)

\section{Geophysical and Sea Level Monitoring in Puerto Rico, A Resilience Experience}

HUERFANO, V. A., Puerto Rico Seismic Network, Puerto Rico, USA, victor@ prsnmail.uprm.edu; MARTINEZ-CRUZADO, J. A., University of Puerto Rico at Mayagüez, Puerto Rico, USA, jose.martinez44@upr.edu

The Puerto Rico Seismic Network and the Puerto Rico Strong Motion Program conform the PR network which is the regional authority for monitoring ground shaking and tsunamis in Puerto Rico and Virgin Islands. The mission of the PR is to monitor and rapidly determine the parameters of all earthquakes and support the Tsunami Service Provider to determine the Tsunami alert level in the Area of Responsibility, and to immediately disseminate this information to concerned agencies and stakeholders. The PR compiles the microseismic catalogue, continuous waveforms, and earthquake effects which serve as a foundation for basic and applied earth science \& oceanography research in Puerto Rico and the Caribbean. The PR net also promote the education and preparedness of our population to mitigate the effects of a significant earthquake or tsunami.

In September 2017, two severe hurricanes (Irma and Maria) devastated the Virgin islands and Puerto Rico causing a major emergency. Both, originally powerful Category 5, were the strongest storms to impact the islands of the northeastern Caribbean in nearly 90 years. In the case of Maria, it made landfall in Puerto Rico on September 20 as a category 4+, causing large storm surge, heavy rains, and destructive winds of more than $160 \mathrm{mph}$ gusts. In the aftermath, the US Federal government trough the USGS provided the assistance and help to repair the damaged seismic monitoring infrastructure.

Fortunately, these improvements were almost complete in the main island of Puerto Rico, when at the end of 2019 and early 2020, a severe seismic activity hit the island. The SW seismic sequence that struck the Island of Puerto Rico, casing vast destruction and significant damages to the southern municipalities of Puerto Rico. To complete the memories of 2020, in March under the worldwide pandemic, a lockdown was declared in Puerto Rico, and the network was required to continue the operations under that emergency.

The goal of this abstract is to describe the experiences of the PR network, the SOP's and how the response protocol was adjusted to the new reality.

\section{Operational Capabilities During Crisis: The Chilean Seismographic Network}

BARRIENTOS, S. E., Universidad de Chile, Santiago, Chile, sbarrien@csn. uchile.cl; RIQUELME, S., Universidad de Chile, Santiago, Chile, sebastian@ csn.uchile.cl; TEAM, C., Universidad de Chile, Santiago, Chile, mpardo@csn. uchile.cl

In Chile, authorities' severe mobility restrictions in response to the pandemic of SARS-CoV-2 have impacted all areas of activities, including seismic network maintenance. Travel limitations began in March 2020 with partial quarantines in the capital city, which later extended to other cities in the country, and it soon transformed into total confinement. We examine the evolution of the pandemic and its consequences on the field and headquarters operations of the National Seismological Center (CSN) as remote stations could not be visited to carry out maintenance work. Several indicators as a function of time, such as station operability percentage, timely reports, ability to deliver requested information, reveal some negative impact on the uptime of stations but not in the capability of the CSN to fulfill its mission, which is to provide timely seismic information to emergency services. The largest event in the country in 2020 took place on June 3, activating in a timely manner the new tools on finite fault modeling being developed within the center.

Continued efforts on integrating new tools to rapidly characterize large events and efforts on development and implementation of a prototype earthquake early warning system will be presented.

\section{PRSN Annual Communications Exercise Caribe Wave 2020 During the COVID-19 Pandemic, A Comparison With Previous Exercises}

BÁEZ-SÁNCHEZ, G., Puerto Rico Seismic Network, Puerto Rico, USA, gisela.baez1@upr.edu; COLON RODRIGUEZ, B., Puerto Rico Seismic Network, Puerto Rico, USA, benjamin.colon1@upr.edu; SANTIAGO PEREZ, Y., Puerto Rico Seismic Network, Puerto Rico, USA, yanira.santiago4@upr. edu; FELICIANO ORTEGA, A., Puerto Rico Seismic Network, Puerto Rico, USA, angel.feliciano3@upr.edu; CORDERO NIEVES, H., Puerto Rico Seismic Network, Puerto Rico, USA, haniel.cordero@upr.edu; ROSADO CLASS, J., Puerto Rico Seismic Network, Puerto Rico, USA, jonathan.rosado9@upr.edu

The PRSN monitors and studies the seismicity in Puerto Rico/Virgin Islands Region. At the beginning of 2020 we faced an unprecedented seismic sequence in the South Region of PR that began on December 28, 2019, with a $4.7 \mathrm{Ml}$ event. This event was a precursor to the principal event of $6.4 \mathrm{Mww}$ that occurred on January 7,2020 . This sequence produced the most damaging earthquake to hit PR/VI Region since 1918 (7.3M), a reminder to the entire region about the importance of tsunami preparedness. Understanding the high seismicity and the possibility of the occurrence of a tsunami that could affect our region, we have dedicated efforts in preparing earthquake and tsunami communication exercises, as well as leading the emergency management agencies and general public's participation. The Caribe Wave is the annual regional tsunami exercise in which the PRSN conducts communication tests for entire Puerto Rico and the Virgin Islands Region. In the last decade, we have been working tirelessly on tsunami exercises and supporting related educational initiatives. We never imagined that in 2020 during the response to a seismic sequence, we would be facing a pandemic emergency. During the preparations for the Caribe Wave 2020 we were impacted by the COVID19 pandemic. The COVID19 pandemic emergency affected what are usually the activities related to the Caribe Wave for PRSN, however, we moved forward with the Communications Exercise through our region. We will discuss our findings during the preparation and development of this exercise, as well as the lessons learned during the Caribe Wave 2020 Communications Exercise in the region as affected by the new regulations implemented during the COVID19 Pandemic. We will discuss the communications between emergency management agencies from the PR/Vi Region and the use of social media for public communications. The 2016 (pre-Hurricane Maria PR), and 2018 (post-Hurricane Maria) exercises will be used as a reference point to compare with the 2020 (COVID-19 Pandemic and the seismic sequence) PRSN Caribe Wave communications exercise and its challenges.

\section{Tsunami Exercises on a Remote Basis: Costa Rican Experiences}

RIVERA-CERDAS, F. A., Universidad Nacional Costa Rica, Heredia, Costa Rica, fabio.rivera.cerdas@una.ac.cr; CHACON-BARRANTES, S. E., Universidad Nacional Costa Rica, Heredia, Costa Rica, silvia.chacon. barrantes@una.ac.cr

As part of the guidelines to obtain the Tsunami Ready recognition from IOC/ UNESCO, the Pacific communities of Tamarindo and Uvita were required to perform a tsunami exercise. On the 16 March 2020 started in Costa Rica the lockdown because of the SARS-Cov2 virus. The measures corresponding to the lockdown have alternatively relaxed and tightened since then, but have implied telework for the University staff and the suspension of domestic trips. The National Emergency Commission (CNE), the Costa Rica disaster management office, suspended all gatherings that were not strictly necessary. Therefore, the tsunami exercises planned for both Tamarindo and Uvita were suspended. Despite all these limitations, it was possible to carry out remote table-top tsunami exercises with both communities, with representatives from SINAMOT participating in the video calls. In Tamarindo, the Community Emergency Committee (CCE in Spanish) met at a hotel in separate rooms, in this way the CCE was able to better control the exercise. In Uvita, each participant was in a separate location, from where they participated in a group video call as well as individual telephone calls. Having the table-top exercises on a remote basis had some advantages: 1 . it represented a more realistic scenario where the participants were not in the same room and had to make decisions on a remote basis. 2. It generated a better evaluation of the message disseminated within the participants and of the technological capacities of the CCE 
in case of emergency. 3. It simplified the evaluation process, as all the messages were recorded. Theoretically, the exercises completed the guidelines for both communities to become Tsunami Ready. However, Costa Rica National Tsunami Ready Board hasn't been able to meet, as authorities from CNE belonging to this board are completely devoted to the sanitary emergency.

\section{Tsunami Generated From Asteroids Impacting Earth's Oceans: Consequences on Coastlines of Latin America and the Caribbean Region for Disaster Response and Management Preparedness}

EZZEDINE, S. M., Lawrence Livermore National Laboratory, California USA, ezzedine1@llnl.gov; SEIFFERT, E. R., Lawrence Livermore National Laboratory, California, USA, seiffert2@llnl.gov; SYAL, M. B., Lawrence Livermore National Laboratory, California, USA, syal1@llnl.gov; DEARBORN, D. S., Lawrence Livermore National Laboratory, California USA, dearborn2@llnl.gov; MILLER, P. L., Lawrence Livermore National Laboratory, California, USA, miller3@llnl.gov

A hypothetical asteroid-impact scenario (https://cneos.jpl.nasa.gov/pd/cs/ pdc21/) designed by the International Academy of Astronautics (IAA) is used as the basis for discussion and analyses of the table-top exercise. The asteroid is classified as a potentially hazardous asteroid with a diameter initially estimated between $35-700$ meters. The asteroid's position uncertainty region at the time of the potential impact is much larger in both length and breadth than the size of the Earth. Impact could occur anywhere on the forward hemisphere during the hour or so when the Earth crosses the asteroid orbit and sweeps through the uncertainty region. Given the significant water-impact probability, and because most of the potentially affected coastal regions are heavily populated, we focused our simulation efforts on modeling water impacts at several locations along the asteroid risk corridor. We have simulated the problem from asteroid entry, to ocean impact, to wave/tsunami generation, propagation, interaction with the shoreline and the flooding of the coastline major cities. We have simulated four different asteroid diameters $(100,250,500$ and $700 \mathrm{~m})$ and we have delimited the zones of inundation for each scenario for risk assessment and disaster management \& response around the world. Here we emphasis the coastlines of Latin America and the Caribbean. The interaction of the asteroid with the ocean are simulated using the hydrocode GEODYN, creating a wave source for the Boussinesq-based water-wave-propagation code, WWP. Run-up and flooding were simulated using WAST - water/structure - a CFD code for urban flooding assessment. Results are displayed with high resolution in Google Earth for major coastal cities of interest. We will demonstrate these new capabilities and we illustrate the consequences at the local and global scales.

This work performed under the auspices of the U.S. Department of Energy by Lawrence Livermore National Laboratory under Contract DE-AC52-07NA27344.

The UN Decade of Ocean Science for Sustainable
Development and Seismology
Oral Session · Monday · 19 April · 9:45 AM Pacific
Session Chairs: Christa Von Hillebrandt-Andrade, National
Oceanic and Atmospheric Administration (christa.vonh@
noaa.gov); Monica Kohler, Caltech (kohler@caltech.edu)

Cabling a Tectonic Plate-A Decade of Geophysical Monitoring Enabled Through Ocean Networks Canada's Neptune Observatory

HEESEMANN, M., Ocean Networks Canada / University of Victoria, Victoria, Canada, mheesema@uvic.ca; DIEDERICHS, A., Ocean Networks Canada, Victoria, Canada, adiederi@uvic.ca; KUKOVICA, J., Ocean Networks Canada, Victoria, Canada, jkukovic@uvic.ca; SCHLESINGER, A., Ocean Networks Canada, Victoria, Canada, schlesin@uvic.ca; DAVIS, E., Natural Resources Canada, Sidney, Canada, earl.davis@canada.ca; WANG, K., Natural Resources Canada, Sidney, Canada, kelin.wang@canada.ca; KRAUSS, Z., University of Washington, Washington, USA, zkrauss@uw.edu; WILCOCK, W. S. D., University of Washington, Washington, USA, wilcock@uw.edu

Ocean Networks Canada (ONC; http://www.oceannetworks.ca/) operates the multidisciplinary NEPTUNE and VENUS cabled ocean observatories off the west coast of Canada. All data collected by these observatories are permanently archived and publicly available through ONC's Oceans 2.0 data portal (seismometer data are available from the Incorporated Research Institute for
Seismology (IRIS)). Much of the data are related to marine geohazards, such as earthquakes, submarine landslides, and tsunamis and are delivered in realtime, e.g. to early warning centers.

The NEPTUNE cabled observatory consists of a cable loop deployed off Vancouver Island that is over $800 \mathrm{~km}$ long and covers the northern part of the Cascadia subduction zone, Cascadia Basin, and the Endeavour Segment of the Juan de Fuca Ridge. It is uniquely located to study plate scale patterns of seismicity and strain created from the interplay of episodic spreading events at the Juan de Fuca Ridge, transform earthquakes on the Nootka Fault Zone, and slip events on the Cascadia megathrust. Cabled instruments supported by the observatory include a regional network of buried broadband seismometers, a local seismic network at the Endeavour Ridge Segment, seafloor tiltmeters, bottom pressure recorders, and CORK borehole observatories that allow volumetric strain measurements. A network of seven seafloor GPS-Acoustic (GPS-A) sites and an autonomous Deformation Front Laboratory will be operational in 2021. With upgraded onshore geodetic stations (operated by Natural Resources Canada) this will form the Northern Cascadia Subduction Zone Observatory (NCSZO).

Additionally, ONC is building an unique Earthquake Early Warning System that relies on eight subsea strong motion instruments as well as seismogeodetic stations on Vancouver Island.

We will review a decade of geophysical monitoring, instrument development, and research findings across ocean science disciplines and give an outlook for future plans.

\section{Earthscope-Oceans: Closing the Oceanic Coverage Gap for} Seismology and Environmental Sensing

SIMONS, F. J., Princeton University, New Jersey, USA, fisimons@gmail.com; CHEN, Y. J., Southern University of Science and Technology, Shenzhen, China, johnyc@sustech.edu.cn; SIMON, J. D., Princeton University, New Jersey, USA, jdsimon@princeton.edu; PIPATPRATHANPORN, S., Princeton University, New Jersey, USA, sirawich@princeton.edu; BONNIEUX, S., Géoazur, SophiaAntipolis, France, sebastien.bonnieux@geoazur.unice.fr; IRVING, J. C. E., University of Bristol, Bristol, United Kingdom, jessica.irving@bristol.ac.uk; OBAYASHI, M., JAMSTEC, Kanagawa, Japan, obayashi@jamstec.go.jp; HELLO, Y., Géoazur, Sophia-Antipolis, France, yann.hello@geoazur.unice. fr; SIGLOCH, K., Géoazur, Sophia-Antipolis, France, karin.sigloch@earth. ox.ac.uk; GUALTIERI, L., Stanford University, California, USA, gualtieri@ stanford.edu; AHERN, T., Incorporated Research Institutions for Seismology, Washington, USA, tim-ahern@comcast.net; NOLET, G., Géoazur, SophiaAntipolis, France, nolet@geoazur.unice.fr

While all of us are sequestered inside, planes are grounded, and ships are berthed, a fleet of forty-seven autonomous earthquake recorders are drifting at $1500 \mathrm{~m}$ depth along with the currents in the Pacific, surfacing every 4-7 days to report, via satellite, a good handful of recently recorded seismic records. The targets of the ongoing South Pacific Plume Imaging and Modeling project are teleseismic global earthquakes, but MERMAID lends itself equally well to recording local or regional seismicity, and making marine environmental observations. In its current commercially available third-generation incarnation one MERMAID costs about $\$ 40 \mathrm{k}$ to acquire, $\$ 100$ per month for data recovery, and as little to deploy (and never to recover) as can be had by using ships of opportunity. A fleet of autonomous marine instruments is a vital component of a modern-day seismological and environmental observing strategy. We will report on past successes and future directions, and invite community input.

\section{Science Monitoring and Reliable Telecommunications (SMART) Subsea Cables for Climate Monitoring and Disaster Risk Reduction: A Contribution to the UN Decade for Ocean Science for Sustainable Development}

HOWE, B., University of Hawaii at Manoa, Hawaii, USA, bhowe@hawaii.edu; BARNES, C. R., University of Victoria, Victoria, Canada, crbarnes@uvic.ca

Science Monitoring And Reliable Telecommunications (SMART) Subsea Cables integrate sensors into commercial submarine telecommunications systems for ocean-climate monitoring and disaster warning, resulting in a planetary scale array monitoring ocean heat and circulation and sea level rise and providing real-time data for earthquake and tsunami early warning and disaster mitigation. This is enabled by the trans-ocean cable infrastructure linking society together: 1.4 million $\mathrm{km}$ of cable with 20,000 repeaters every $70 \mathrm{~km}$ that can host sensors, constantly being refreshed and expanded over 10-25 years. Initial sensors are ocean bottom temperature, pressure and seismic acceleration. The first major SMART project is funded and underway in the northeast Atlantic off Portugal, motivated in part by the disastrous 1755 earthquake and tsunami (CAM2, $3700 \mathrm{~km}$ ring connecting the continent with 
the Azores and Madeira), with a number of other projects in various stages of planning and implementation.

SMART Cables, a large-scale, international, transformative programme will provide knowledge necessary to address the UN Decade of Ocean Science Challenges (\#5 Enhance understanding of the ocean-climate nexus, \#6 Enhance multi-hazard early warning services, and \#7 Ensure a sustainable ocean observing system) and Outcomes (\#4 A predicted ocean, \#5 A safe ocean, and \#6 An assessable ocean) and to achieve the SDGs (\#13 Climate, \#14 Oceans) by 2030. By providing seismic sensors throughout much of the 70 percent of the Earth covered by the oceans, great advances in understanding the geophysics and seismology of the Earth will be obtained.

\section{Successfully Proven Advancements in Autonomous Ocean Bottom Seismometers: Güralp Aquarius}

REIS, W., Güralp Systems Ltd, Reading, United Kingdom, wreis@guralp. com; LINDSEY, J., Güralp Systems Ltd, Reading, United Kingdom, jlindsey@ guralp.com; HILL, P., Güralp Systems Ltd, Reading, United Kingdom, phill@ guralp.com; WATKISS, N., Güralp Systems Ltd, Reading, United Kingdom, nwatkiss@guralp.com

Increasing broadband seismic station density in marine environments is crucial for understanding local and distant seismic activity. Technical, logistical and financial constraints on using traditional Ocean Bottom Seismometers (OBS) have been substantially reduced by Güralp Systems through 25 years of research and development. The recently engineered and successfully commercially deployed Güralp Aquarius OBS system overcomes these barriers and redefines boundaries for offshore seismic research.

Aquarius is a portable autonomous OBS combining a broadband seismometer with wireless acoustic communication while deployed at depths of up to $6000 \mathrm{~m}$ for up to 21 months. Communication on demand allows operators to retrieve specific data for download during deployment period, while a continuous record is preserved on the OBS for full analysis after retrieval. Possible surface acoustic modem platforms vary from fixed buoys with satellite communication, passing ships of opportunity, wave-gliders or small private boats for manned visits. Modular design allows configuration of additional hydrophone and pressure gauge sensors with acoustic modem variations available to suit operator priorities.

Well-proven digital feedback control allows Aquarius to operate at any angle, thereby reducing landing site risks while excluding noise inherently associated with gimbal-controlled levelling systems. Acoustic communication during installation allows operators to assess the quality of the landing site before committing or repositioning. During recovery, ultra-fast recharging facilitates rapid turnaround times for re-deployment (1-hour charge per month deployment) without returning to port.

Further avenues are being explored to adapt Aquarius technology for longer-term autonomous deployments, while current standard configurations continue to be deployed in major ocean basins as part of individual projects and national pools.

\section{UN Decade of Ocean Science for Sustainable Development (2021-2030): An Opportunity for the Transformation of Seismology \\ VON HILLEBRANDT-ANDRADE, C., National Oceanic and Atmospheric} Administration, Puerto Rico, USA, christa.vonh@noaa.gov

January 1, 2021 marked the beginning the United Nations Decade of Ocean Science for Sustainable Development. UNESCO's Intergovernmental Oceanographic Commission (IOC) prepared the Implementation Plan in consultation with Member States, UN bodies, institutional partners and other relevant stakeholders, including ocean and social scientists. The UN General Assembly approved the plan on December 31, 2020. The seven societal outcomes for the Decade include: A clean ocean, a healthy and resilient ocean, a productive ocean, a predicted ocean, a safe ocean, an accessible ocean and an inspiring and engaging ocean. The achievement of the Decades goals requires an acceleration and transformation of Ocean science, data and information exchange as well as solutions, thru new partnerships at the local, national, regional or global scales according to specific contexts and priorities. Several of the decade challenges are relevant to the seismological community: enhancement of multi-hazard early warning services, a sustainable observing system across all ocean basins that delivers accessible, timely, and actionable data and information to all users and development of a comprehensive digital representation of the ocean in a manner relevant to diverse stakeholders. January 15, 2021 was the deadline for the first call for proposals for decade programmes. The IOC will be making other calls for additional programmes, projects and activities. The global tsunami community has proposed to transform the tsunami warning system thru enhanced observations and analysis and community readiness. This presentation will provide an update on the Decade, proposed actions and other opportunities relevant to the seismological community.

\begin{tabular}{l} 
The UN Decade of Ocean Science for Sustainable \\
Development and Seismology \\
Poster Session · Monday · 19 April · 11:30 AM Pacific \\
Session Chairs: Christa Von Hillebrandt-Andrade, National \\
Oceanic and Atmospheric Administration (christa.vonh@ \\
noaa.gov); Monica Kohler, Caltech (kohler@caltech.edu) \\
\hline
\end{tabular}

Fully Integrated OBS Platform for Multi-Use Case Deployments and Future OBS Components for Long-Term Deployments

PARKER, T., Nanometrics, Kanata, Canada, timparker@nanometrics.ca; PERLIN, M., Nanometrics, Kanata, Canada, michaelperlin@nanometrics.ca; PELYK, N., Nanometrics, Kanata, Canada, nickpelyk@nanometrics.ca

Broadband seismic sciences in the oceans has been supported by many academic institutions, who have each developed a unique OBS platform which has made it complex and expensive to integrate new or updated equipment. Nanometrics has partnered with Scripps Institute of Oceanography to use their well proven Abalone OBS platform and create a fully integrated and updated OBS system, forward compatible with the newest and fully integrated Nanometrics digitizers and sensors. The OBS developments include a new low-power and low-noise PegasusOBS digitizer as well as gimbaled broadband OBS instruments based on the Horizon 120 and 360 long period sensors. Like the innovative Trillium Compact OBS, these new low noise broadband systems are smaller, lower power and have wider bandwidth and will be able to test new emplacement techniques for reduced noise resulting in higher quality seismic data. This updated Abalones platform will be able to support a diverse set of sensors and larger payloads for extended deployments along with important new development such as transferring data to autonomous robotic data harvesters and resyncing timing of the system. Along with these hardware developments a complete software ecosystem for station management, deployment and data harvesting including automated metadata creation has been completed. While these systems are fairly far along in development, we are seeking partners for prioritizing new developments such as for longer term autonomous GSN data quality OBS observatories and new cabled hazard monitoring multi-disciplinary broadband OBS systems based on these new components.

\section{Regional Pn Magnitude Scale for Earthquakes Along the Equatorial Atlantic Ocean}

SAMPAIO DE MELO, G., Federal University of Rio Grande do Norte, Natal, Brazil, gwsmelo@ufrn.edu.br; KIM, W., Columbia University, New York, USA, wykim@ldeo.columbia.edu

We developed a robust magnitude scale for earthquakes along the equatorial mid-Atlantic ridge by using Pn waves recorded at seismographic stations on land along with northeastern Brazil. For large earthquakes of magnitude greater than 5 , short-period teleseismic body waves and long- period surface waves can be used to assign magnitude. However, for small- to medium-sized earthquakes along the equatorial mid-Atlantic ridges and transform faults, regional high- frequency Pn waves appear to be well recorded and can be used to assign magnitudes. We selected about 200 events with moment magnitude greater than 5 from the global centroid moment tensor catalog during 2011-2019 for analysis. We collected waveform data from about 20 stations in northeastern Brazil. We analyzed over 1,600 Pn waves in the distance range from 1,000 to $3,500 \mathrm{~km}$. Peak amplitude measured after high-pass filtering with a Wood- Anderson instrument frequency response indicated that the Pn arrivals show apparent group velocity between $7 \mathrm{~km} / \mathrm{s}$ at short ranges $(\sim 1,000$ $\mathrm{km}$ ) and up to $9 \mathrm{~km} / \mathrm{s}$ at $3,500 \mathrm{~km}$. The peak amplitudes are measured with a frequency between 0.8 and $3 \mathrm{~Hz}$ at short distances $1,000-1,800 \mathrm{~km}$, but at greater distances, $1,800-3,500 \mathrm{~km}$, the peak amplitudes show remarkably consistent frequency about $0.8 \mathrm{~Hz}$. The peak amplitude attenuates with distance as those of Northern mid-Atlantic region reported by Kim \& Ottemöller in 2017 at distance range $1,000-2,000 \mathrm{~km}$, but at long distance ranges $(2,000$ and 3,500 km), the peak amplitude attenuates a much lower rate than at short ranges, within 0.3 logarithmic units (a factor of two). The low rate of amplitude decay with distance and nearly constant frequency content of the peak amplitudes may suggest that Pn waves propagate efficiently in the lower part of 
the upper mantle along the equatorial Atlantic Ocean basins. These are important attributes of oceanic Pn that can be used to assign magnitude for small to medium-size earthquakes in the equatorial mid-Atlantic Ocean region.

\begin{tabular}{l}
\hline Updating the US National Seismic Hazard Models \\
I: Oral Session · Wednesday·21 April ·9:45 AM Pacific \\
II: Oral Session · Wednesday·21 April ·2:00 PM Pacific \\
III: Oral Session·Wednesday·21 April·5:00 PM Pacific \\
Session Chairs: Peter M. Powers, U.S. Geological Survey \\
(pmpowers@usgs.gov); Allison M. Shumway, U.S. Geological \\
Survey (ashumway@usgs.gov); Mark D. Petersen, U.S. \\
Geological Survey (mpetersen@usgs.gov); Sanaz Rezaeian, \\
U.S. Geological Survey (srezaeian@usgs.gov)
\end{tabular}

\section{U.S. National Seismic Hazard 50-State Model: Science} Objectives and Products

PETERSEN, M. D., U.S. Geological Survey, Colorado, USA, mpetersen@usgs. gov; FIELD, E. H., U.S. Geological Survey, Colorado, USA, field@usgs.gov; JAISWAL, K. S., U.S. Geological Survey, Colorado, USA, kjaiswal@usgs.gov MOSCHETTI, M. P., U.S. Geological Survey, Colorado, USA, mmoschetti@ usgs.gov; POWERS, P. M., U.S. Geological Survey, Colorado, USA, pmpowers@usgs.gov; SHUMWAY, A. M., U.S. Geological Survey, Colorado, USA, ashumway@usgs.gov

The U.S. National Seismic Hazard Model (NSHM) is developed periodically by the USGS to account for new and improved data, models, and methods that have been developed since the previous model release. This probabilistic model is applied in building design criteria, risk assessments, and other public policy documents requiring that the best available and defensible science be considered. This 2023 NSHM will consider seismic hazard in all 50 states taking into account inherent differences in geological setting, tectonic strain rates, and earthquake rupture mechanics while allowing for more uniform methodologies and more consistent representation of epistemic uncertainties. The 2023 NSHM will be developed over the next three years and will include updates to both the source and ground motion inputs. For the statistical seismicity elements of the source model, we plan to update and decluster earthquake catalogs based on new algorithms, assess gridded seismicity rates using alternative statistical assessments, possibly evaluate application of time-dependent hazard branches, and calculate hazard. For applying new geologic and geodetic data in the source models, we are developing a database of geologic fault rupture rates and geodetic slip rates that will be used to construct multi-fault rupture models. For improving the ground motion models (GMM), we plan to update CEUS-WUS boundary, implement several new GMM including new NGA-Subduction models, consider how to better implement GMM uncertainty and variability by evaluating new nonergodic methods, and improve the assessment of ground shaking in basins using basin depth information and simulations. Several important implementation issues will also consider better non-linear ground shaking estimates for the CEUS, assessment of hazard near basin edges, and implementation of uncertainty analysis. Public workshops over the next three years will allow for critical discussions on important elements of the NSHMs.

\section{Development of Inversion-Based Source Models for the New Zealand NSHM}

GERSTENBERGER, M. C., GNS Science, Wellington, New Zealand, m.gerstenberger@gns.cri.nz; VAN DISSEN, R. J., GNS Science, Wellington, New Zealand, r.vandissen@gns.cri.nz; WALLACE, L., GNS Science, Wellington, New Zealand, l.wallace@gns.cri.nz; THINGBAIJAM, K., GNS Science, Wellington, New Zealand, k.thingbaijam@gns.cri.nz; MILNER, K., University of Southern California, California, USA, kmilner@usc.edu; STIRLING, M. W., University of Otago, Dunedin, New Zealand, mark. stirling@otago.ac.nz; NICOL, A., University of Canterbury, Christchurch, New Zealand, andy.nicol@canterbury.ac.nz; ROLLINS, C., University of Leeds, GNS Science, Leeds \& Wellington, New Zealand, j.c.rollins@leeds. ac.uk; SHAW, B. E., Columbia University, New York, USA, shaw@ldeo. columbia.edu; STAHL, T., University of Canterbury, Christchurch, New Zealand, timothy.stahl@canterbury.ac.nz

The first full revision of the New Zealand National Seismic Hazard model commenced in mid-2020. One key part of this revision is the development and implementation of a UCERF3-style "Grand Inversion" seismicity rate model for New Zealand. At the core of the development and constraint of an inversion model is earthquake geology data and, to a somewhat lesser but growing extent, geodetic data; NZ shares similar quality and quantity of this data with California and these similarities have enabled development of the NZ model. However, tectonically, New Zealand has some unique features (when compared to California) which bring additional challenges to the model development. NZ hazard features significant contributions from two subduction zones. Due to its shallow depth and proximity to the North Island, the Hikurangi Subduction Zone is the largest contributor to hazard (and risk) across the North Island; the hazard contribution from the Puysuger Subduction Zone is less significant though still important for the lower South Island. The enormity of the subduction interfaces create challenges in constraining potential subduction ruptures in both geometry and total numbers to produce a workable model. This challenge is increased due to the limited data available to constrain ruptures. Of particular interest is the potential for joint ruptures of the interface with crustal faults near large urban centres. Another potential difference is the prevalence of complex multi-fault ruptures in NZ. In this presentation we will present a progress update on the development of the NZ inversion model, including status of both geologically and geodetically based inversion models.

\section{Fault Slip Rates Contributed by Crustal Deformation Models to the 2023 Update to the National Seismic Hazard Model}

POLLITZ, F. F., U.S. Geological Survey, California, USA, fpollitz@usgs. gov; ELLIOTT, J. L., Purdue University, Indiana, USA, julieelliott@purdue. edu; EVANS, E. L., California State University, Northridge, California, USA, eileen.evans@csun.edu; FIELD, E. H., U.S. Geological Survey, Colorado, USA, field@usgs.gov; HATEM, A. E., U.S. Geological Survey, Colorado, USA, ahatem@usgs.gov; HEARN, E. H., Capstone Geophysics, California, USA, hearn.liz@gmail.com; JOHNSON, K., Indiana University, Indiana, USA, kajjohns@indiana.edu; MURRAY, J. R., U.S. Geological Survey, California, USA, jrmurray@usgs.gov; POWERS, P. M., U.S. Geological Survey, Colorado, USA, pmpowers@usgs.gov; SHEN, Z., University of California, Los Angeles, California, USA, zshen@ucla.edu; WESPESTAD, C., Indiana University, Indiana, USA, crystal.wespestad@gmail.com; ZENG, Y., U.S. Geological Survey, Colorado, USA, zeng@usgs.gov

The National Seismic Hazard Model (NSHM) will be updated in 2023. It will include a revision of the earthquake rate model in the Western US and Alaska, which is informed by background and historical seismicity, geologic slip rates, and geodetically inferred fault slip rates. Geodetic data forming the interseismic crustal velocity field potentially add much more information for quantifying slip rates because they are broadly and densely distributed. However, using geodetic data to directly address long term slip rates is challenging because they measure contemporary crustal deformation rates, which are a product of not only long term fault slip rates but also fault locking, aseismic creep, and transient deformation (e.g., viscoelastic relaxation, afterslip following earthquakes, slow slip events). To translate these data to long-term fault slip rates, they must be interpreted with models. Approaches being considered include elastic block models, fault-based dislocation models, a continuum model that also considers principal stress orientations, and viscoelastic-cycle models. A group effort is underway to explore each of these models, along with a purely geologic deformation model. We will summarize available observational constraints and preliminary modeling results. This early picture is intended to highlight the challenges of resolving slip on multiple, closely spaced faults and/or low-slip rate faults, quantifying uncertainties related to fault creep and transient deformation, reconciling geologic and geodetic slip rate estimates, and separating discrete from broadly-distributed slip.

\section{Generalizing the Inversion-Based PSHA Source Model for an Interconnected Fault System}

FIELD, E. H., U.S. Geological Survey, Colorado, USA, field@usgs.gov; MILNER, K., University of Southern California, California, USA, kmilner@ usc.edu; PAGE, M. T., U.S. Geological Survey, California, USA, mpage@usgs. gov

We present a step toward generalizing and simplifying the procedure for constructing an inversion-based seismic-hazard source model for an interconnected fault system, including the specification of adjustable segmentation constraints. A very simple example is used to maximize understandability and to counter the notion that an inversion approach is only applicable when an abundance of data is available. Also exemplified is how to construct a range of models in order to adequately represent epistemic uncertainties (which should be a high priority in any hazard assessment). Opportunity is also taken to address common concerns and misunderstandings associated with the $3^{\text {rd }}$ 
Uniform California Earthquake Rupture Forecast (UCERF3), including the seemingly disproportionate number of large-magnitude events, and how well hazard is resolved given the overall problem is very underdetermined. However, the main point is to provide a general protocol for constructing such models.

\section{Updates to the Earthquake Geology Parameters for Use in the 2023 U.S. National Seismic Hazard Model}

HATEM, A. E., U.S. Geological Survey, Colorado, USA, ahatem@usgs.gov; COLLETT, C. M., U.S. Geological Survey, Colorado, USA, ccollett@usgs. gov; GOLD, R. D., U.S. Geological Survey, Colorado, USA, rgold@usgs.gov BRIGGS, R. W., U.S. Geological Survey, Colorado, USA, rbriggs@usgs.gov; ANGSTER, S. J., U.S. Geological Survey, Washington, USA, sangster@usgs. gov; FIELD, E. H., U.S. Geological Survey, Colorado, USA, field@usgs.gov

In advance of the 2023 U.S. National Seismic Hazard Model (NSHM2023), we have compiled geologic inputs from publicly available, peer-reviewed publications into two related datasets: 1) A fault sections database, which depicts the simplified geometry of Quaternary active faults capable of hosting an independent earthquake, and 2) An earthquake geology site information database, which contains fault slip-rate constraints at points. We follow the approach of the Uniform California Earthquake Rupture Forecast, v3 (UCERF3), in terms of decoupling of fault sections from associated slip rates and the inclusion of faults without direct slip rate constraints. To that end, we have increased the number of fault sections by nearly a factor of two, with $\sim 1,000$ fault sections included in this dataset for use in NSHM2023 compared to the $\sim 650$ fault sections used in previous version of the NSHM from 2018. In addition, we have compiled $>450$ observations of slip rates at points along faults. In cases where a fault does not have a measured slip rate, a categorical slip rate bin is applied (e.g., $0-0.2 \mathrm{~mm} / \mathrm{yr}, 0.2-1 \mathrm{~mm} / \mathrm{yr}, 1-5 \mathrm{~mm} / \mathrm{yr}$ ). Typically, this is a range of slip rates obtained from the Quaternary Fault and Fold Database (QFFD). Incorporation of additional fault sections into the model allows for inclusion of more sources that are known to be Quaternary active ( $<2.58$ million years) but lack detailed slip rate studies. This will enable more connectivity of faults in multi-fault ruptures used in an inversion framework and more kinematically-realistic deformation models. These databases represent a communitybased effort to best represent the knowledge of Quaternary faulting across the western US through collaboration with State, federal, industry, and academic partners. Ongoing work will update the fault sections database and associated geologic slip rates across the Central and Eastern U.S., and Alaska.

\section{A Non-Ergodic Ground-Motion Model for California}

LAVRENTIADIS, G., University of California, Berkeley, California, USA glavrent@berkeley.edu; ABRAHAMSON, N., University of California, Berkeley, California, USA, abrahamson@berkeley.edu; KUEHN, N., University of California, Los Angeles, California, USA, kuehn@ucla.edu

A new approach is used in the development of a fully non-ergodic ground motion model (GMM) for pseudo-spectral accelerations (PSA). First, a nonergodic effective Fourier amplitude spectrum (EAS) GMM is developed, and then, through random vibration theory (RVT), it is converted to a PSA nonergodic GMM; the advantage of this two-step approach is that it can better capture the non-ergodic source, path, and site effects through the small magnitude earthquakes. Fourier transform is a linear operation, and therefore, the non-ergodic effects from the small magnitude events can be applied directly to the large magnitude earthquakes; the response spectrum is a non-linear operator, which makes the non-ergodic terms magnitude dependent, and so the small magnitude data cannot be used that easily to constrain the nonergodic behavior of the large events.

The Bayless and Abrahamson (2019) ergodic EAS GMM is used as a backbone for the non-ergodic EAS GMM; the non-ergodic effects related to the source and site are modeled as spatially varying coefficients, and the nonergodic effects related to the path are captured through a cell-specific anelastic attenuation. The PSA non-ergodic effects are expressed as ergodic to nonergodic PSA ratios, which is the adjustment that needs to be applied to an ergodic PSA GMM to incorporate the non-ergodic effects. To calculate these ratios, first both the ergodic and non-ergodic EAS are calculated for a scenario of interest ( $\mathrm{M}$, Rrup, VS30, $\mathrm{x}_{\mathrm{eq}}, \mathrm{x}_{\text {site }}$, etc.) and then, with RVT, the equivalent PSA values are computed; this second step is the one that introduces the magnitude dependence in the non-ergodic PSA terms. This approach leads to an approximately $40 \%$ reduction in the total aleatory standard deviation compared to the Abrahamson et al. (2014) ergodic GMM. The epistemic uncertainty associated with the PSA ratios is small in areas close to stations and past events; in areas with sparse data, the mean of the non-ergodic ratios goes to zero implying ergodic scaling and the epistemic uncertainty increases.
A Rupture Directivity Adjustment Model Applicable to the NGA-West2 Ground Motion Models and Complex Fault Geometries

BAYLESS, I., AECOM, California, USA, jeff.bayless@aecom.com

In their innovative paper, Somerville et al. (1997) developed an empirical model for the modification of ground motion models (GMMs) to account for spatial variations in near-source ground motion amplitude and duration, due to the effects of rupture propagation, source radiation pattern and the polarization of seismic waves. These effects, categorized jointly as rupture "directivity" effects, can have varying consequences on the ground motions in the near field, depending on the style of faulting and the source-site geometry. The effects of rupture directivity on near-fault ground motions are known to be significant and should be included to accurately estimate the hazard from long period ground motions (Abrahamson, 2000). However, these effects are not explicitly accounted for in most GMMs, and therefore not in typical PSHAs. A few directivity models have been proposed in the literature, but the primary obstacles preventing these from widespread use are the uncertainty in practice about which directivity model or models to use, how to use them, and treatment of aleatory variability.

In this work, we create a directivity adjustment model which supersedes our 2013 model (Spudich et al., 2013). This model is developed using the residuals of three NGA-West2 GMMs for response spectra. We supplement the data with a rich database of finite fault simulations to explore the directivity predictor variable space and to confirm that model predictions are consistent with recorded data. The upgraded functional form accommodates multisegment ruptures and ruptures with complex changes along strike, such as those in UCERF3 (Field et al, 2013) and features a narrow band adjustment which varies with magnitude. Models are provided for the adjustments to median predictions as well as to the aleatory variability.

\section{Near-Source Ground Motion Directivity and Heterogeneity Modeling for Seismic Hazard Applications}

ROWSHANDEL, B., California Earthquake Authority, California, USA, browshandel@calquake.com

Accounting for near-source effects is an important component of seismic hazard maps. This is particularly true for California. Implementation of directivity models into hazard codes would make this possible.

This presentation is on implementation and implications of a directivityheterogeneity model developed by the author based on ground motion residuals of the NGA-West2 GMMs and slip distributions of earthquakes in that database. The model has been extensively tested and fully implemented in a PSHA code.

Using a series of example results, it will be demonstrated how the model can be used to quantify source-induced ground motion effects in regions adjacent to faults of various levels of complexity. UCERF3 model, by relaxing fault segmentation and allowing rupture jumps along and across discontinuities of neighboring faults and fault segments, has complicated the analysis of ground motion hazards in California, especially for the near-source regions. UCERF3 fault complexities makes implementation in hazard assessment codes, of models for near-fault effects, quite challenging. Even with simplifications of UCERF3 fault data for site-specific applications, hazard modelers are often faced with complex fault systems, capable of producing multiple events of different mechanisms, by rupturing across a range of geometric discontinuities, potentially producing strong near-source effects.

Model results for faults of various levels of complexity, in the NGAWest2 and UCERF3 databases, will be presented to illustrate several features of near-source ground motions. Ramifications of simplifying assumptions regarding fault data will be discussed. Impacts of source heterogeneities, e.g., asperities and non-uniform slip distributions, and the influence of hypocenter locations and distributions on near-fault ground motions will be investigated. Influence of the model predictions on response spectra will be described and the potential use of the model for directivity pulse characterization will be discussed.

\section{NGA-Subduction Research Project: Overview of Database, Models and Computer Tools}

BOZORGNIA, Y., University of California, Los Angeles, California, USA, yousefbozorgnia@ucla.edu

Next generation ground motion models for subduction earthquakes (NGASub), is a large multidisciplinary community-based research initiative to develop a comprehensive ground-motion database and multiple groundmotion models (GMMs) for subduction events. In the NGA-Sub project, we developed a relational database of ground motions recorded in worldwide 
subduction events. The database includes intensity measures computed from the processed recordings and supporting source, path, and site metadata from Japan, Taiwan, the US Pacific Northwest (Cascadia), Alaska, Latin America (including Mexico, Central America, and South America), and New Zealand. The database includes a total of 214,020 individual records from 1,880 subduction events, with moment magnitudes ranging from 4.0 to 9.1 . This is by far the largest database of all the NGA programs. The subduction events are classified as interface, intraslab, or outer-rise events. Pseudo-spectral acceleration for oscillator periods from 0.01 to $10 \mathrm{sec}$ have been included in the database. Multiple ground-motion models (GMMs) have been developed using the ground-motion database and supporting ground-motion simulations. The scope of the NGA-Sub GMMs is to develop models for horizontal components of ground motion for PGA, PGV, and 5\% damped pseudoacceleration response spectra. At the time of writing this abstract, three global and regionalized GMMs, and one Japan-specific GMMs have been developed, and documentation reports have been published. At this SSA annual meeting, an overview of the NGA-Sub project, its database, main characteristics of the GMMs, and the developed computer tools are presented.

\section{Use of Non-Ergodic Ground-Motion Models for National Seismic Hazard Maps}

ABRAHAMSON, N., University of California, Berkeley, California, USA, abrahamson@berkeley.edu

The current national hazard maps are based on ergodic ground-motion models (GMMs) for SA for broad regions. As empirical ground-motion data sets have grown, large systematic deviations between the observed SA and the ergodic GMMs can be seen for specific site/event pairs on the scale of $10 \mathrm{~km}$. Systematic effects at even shorter length scales are seen in numerical simulations using 3-D crustal models. Accounting for the spatial differences by using non-ergodic GMM reduces the sigma of the GMM by about $40 \%$ for all sites and changes the median for each site/source pair: the median will be higher at some sites and lower at other sites. Trial applications of nonergodic GMMs to California show that the $2500-y r$ return period ground motion can increase or decrease by a factor of 2 compared to the ergodic GMM results. The move to non-ergodic GMMs is expected to lead to the largest changes in the estimates of the seismic hazard since the inclusion of the aleatory variability of the ground motion in the 1980s.

To use the non-ergodic GMMs in the national hazard maps, some changes to the PSHA software used by the USGS are needed. First, in addition to using M, R, and VS30 as the inputs to the GMM, the coordinates of the source and the site also need to be provided to the GMM subroutine. Second, capturing the epistemic uncertainty in the non-ergodic terms for each source/ site pair requires 100s of GMMs to be used on the logic tree. This is not practical for computing hazard maps with current methods of sampling each branch, so the PSHA program will need use more efficient methods, such as polynomial chaos expansions (PCE), to sample the spatially correlated epistemic uncertainty in the non-ergodic GMM. The PCE methods have been incorporated into the HAZ45 PSHA program. Currently, GEM is making modifications to the OpenQuake PSHA program to use non-ergodic GMMs with PCE. The results from these two open-source PSHA programs can be used to test the implementation of the non-ergodic GMMs in the USGS software.

\section{Modeling Hazard From Induced Seismicity in the Central and Eastern U.S.}

KRANER, M. L., AIR Worldwide, Massachusetts, USA, mkraner@airworldwide.com; WANG, F., AIR Worldwide, Massachusetts, USA, fwang@ air-worldwide.com; SHEN-TU, B., AIR Worldwide, Massachusetts, USA, BShen-Tu@air-worldwide.com

Following 2010, seismicity rates in the Central and Eastern US rose significantly due to human causes. This triggered a large-scale change in seismic hazard in comparison to the long term USGS forecast, especially in Oklahoma, Texas, and Kansas. In response, the USGS released short-term seismic hazard forecasts in 2016, 2017, and 2018, but ceased publication after 2018. This left the market with no new view of short-term hazard.

Earthquake risk assessment companies and organizations such as AIR Worldwide are tasked with providing an up to date view of risk for risk management and mitigation using the most scientifically advanced and accurate probabilistic seismic hazard analysis (PSHA) for a given region. Here we seek to quantify the latest human-induced seismic hazard in the Central and Eastern US using historical data from OGS, USGS, GCMT, SLU, NMTSO, KGS, and TexNet along with information regarding hydraulic fracking and injection/disposal well history, regional geology, and optimally-oriented fault information. Combining induced historical earthquake information with geological information, magnitude homogenization equations, and a ground motion model we develop an updated view of seismic hazard for spectral acceleration (SA) and peak ground acceleration (PGA) due to induced seismicity.

In comparison to USGS's 2018 one-year seismic hazard forecast, we observe an overall decrease in seismicity rates due to pumping regulations imposed by various state agencies across Central and Eastern US. After evaluation, higher weights are given to published GMPEs that use ground motion data from induced earthquakes. The updated model shows weaker magnitude scaling for short period ground motion $(<1 s)$, leading to smaller ground motions at larger magnitudes.

\section{Should Site Response Be Incorporated Into Central U.S. Hazard Maps?}

CARPENTER, S., Kentucky Geological Survey, University of Kentucky, Kentucky, USA, seth.carpenter@uky.edu; WANG, Z., Kentucky Geological Survey, University of Kentucky, Kentucky, USA, zmwang@uky.edu; ZHU, Y., Kentucky Geological Survey, University of Kentucky, Kentucky, USA, yichuan.zhu@uky.edu; WOOLERY, E. W., University of Kentucky, Kentucky, USA, ewoolery@uky.edu

Site response is primarily controlled by the shear-wave velocity (Vs) structure at a site and is thus site-specific, i.e., nonergodic. Therefore, reliably estimating site response using proxies requires regionally if not locally calibrated relationships. When site response is dominated by resonance, it can be characterized by the fundamental site frequency, $f_{0}$, and its associated amplification, $A_{0}$. In this study, we evaluated the skill of $V s 30$, average sediment $V s\left(V s_{\text {avg }}\right)$, and sediment thickness $(Z b)$ to predict the primary site-response parameters $f_{0}$ and $A_{0}$ in the New Madrid and Wabash Valley seismic zones. Using 1D Vs models that we developed and those available in the literature, we estimated $f_{0}$ and $A_{0}$ at 31 seismic stations in the New Madrid and Wabash Valley seismic zones via 1D linear site response analyses. We also developed a 3D Vs model, useful for 3D response modeling, in the Kentucky part of the sediment-filled upper Mississippi embayment and estimated $f_{0}$ and $A_{0}$ in a $500 \mathrm{~m}$-spaced grid using $1 \mathrm{D}$ Vs profiles extracted from the model and $1 \mathrm{D}$ linear analyses. We found that $V s 30$ correlates weakly with $f_{0}$ and $A_{0}$, but these parameters have large scatter at sites with the same NEHRP site class. In addition, $V s_{\text {avg }}$ correlates with $A_{0}$ but not with $f_{0}$. We also found that $Z b$ correlates with $f_{0}$ at sites inside but not outside the embayment border, and that the relationship between $Z b$ and $A_{0}$ is weak regardless of location. Thus, accurately characterizing uncertainties in central US ground-motion models, accounting for both $f_{0}$ and $A_{0}$, may not be possible using any single proxy. Also, reliable estimation of $f_{0}$ by proxy $(\mathrm{Zb})$ appears to be region dependent. Both velocity data into bedrock and the depth to bedrock are needed to estimate both $f_{0}$ and $A_{0}$ via proxies or otherwise. Lacking such data, even on the regional scale in the central US, we suggest that it is appropriate to account for site response separately in regional- and national-scale seismic hazard modeling.

\section{The 2020 M7.8 and M7.5 Alaska Peninsula Earthquake Ground Motions and Alaska-Specific Ground Motion Models}

CRAMER, C. H., CERI, University of Memphis, Tennessee, USA, ccramer@ memphis.edu; MAHANAMA, A., CERI, University of Memphis, Tennessee, USA, mahanama@memphis.edu

Appropriate ground motion models (GMMs) are needed to properly estimate seismic hazard in a region. The July 22, 2020 M7.8 and October 19, 2020 M7.5 Alaska Peninsula subduction interface and in-slab earthquakes provided significant ground motion observations to help evaluate Alaska subduction GMMs. Current GMMs tend to bracket the M7.8 and M7.5 observations with considerable scatter with distance. However, the Atkinson and Boore (2003) interface model tends to over predict the M7.8 observations and the in-slab model under predicts the M7.6 observations. The Youngs et al. (1997) GMM tends to over predict both sets of observations beyond $100 \mathrm{~km}$, but under predicts PGAs for the M7.5 event. The Abrahamson et al. (2016) interface model, with its fore-arc and back-arc alternatives, tends to bracket the observations (with fore-arc to the high side and back-arc to the low side), but underpredicts the M7.5 1.0s observations. And the Zhao et al. (2006) GMM tends to under predict both sets of observations, except it over predicts the 1.0s M7.6 observations. More importantly, the two Next Generation Attenuation Subduction (NGA Sub) interface GMMs tend to under predict the M7.8 observations, with the Kuehn et al. (2020) Vs $30=760 \mathrm{~m} / \mathrm{s}$ model coming the closest at the lower edge of the observations. For the shallow M7.6 in-slab observations, the two NGA Sub GMMs predictions match the observations well. Few Alaska interface subduction earthquake observations exist at distances less $100 \mathrm{~km}$, and the M7.8 earthquake only contributes one more. Three 2018 M5.5-6.0 shallow interface earthquakes in the same region provide additional con- 
straints at distances less than $100 \mathrm{~km}$. Stress parameter for the M7.8 and M7.5 mainshocks are 3 and $5 \mathrm{MPa}$, respectively, which are typical values for shallow subduction events and deeper in-slab aftershocks. Deeper in-slab mainshocks have stress parameters above $20 \mathrm{MPa}$, even for the shallower $2018 \mathrm{M} 7.1$ Anchorage earthquake at $40 \mathrm{~km}$ depth.

\section{Updating the USGS National Seismic Hazard Model for Alaska}

POWERS, P. M., U.S. Geological Survey, Colorado, USA, pmpowers@usgs. gov; MUELLER, C. S., U.S. Geological Survey, Colorado, USA, cmueller@ usgs.gov; HAEUSSLER, P. J., U.S. Geological Survey, Alaska, USA, pheuslr@ usgs.gov; WITTER, R., U.S. Geological Survey, Alaska, USA, rwitter@usgs. gov; BENDER, A. M., U.S. Geological Survey, Alaska, USA, abender@usgs. gov

The National Seismic Hazard Model for Alaska was last updated in 2007. Since then, abundant new geologic and earthquake data have been collected and published; here, we present our plans for including these data and models derived therefrom in the next Alaska NSHM update. On the source modeling side, we plan to update the earthquake catalogs and the declustering and smoothing methodologies used to create gridded seismicity forecasts for two classes of earthquakes: (1) shallow earthquakes not explicitly associated with crustal faults, and (2) deeper earthquakes associated with subduction intraslab seismicity. For fault models, we are currently soliciting new information on active faults heretofore not considered, or updates to existing fault sources. We also anticipate utilizing slip rates (or deformation models) derived from GPS data, consistent with recent model updates for the Conterminous U.S. The 2007 Alaska model included along-strike variations in slip rate on the DenaliTotschunda and Castle Mountain fault systems. For this update we are considering application of the Uniform California Earthquake Rupture Forecast, version 3, inversion methodology as an alternate approach to modeling rupture rates. The Alaska-Aleutian subduction zone is the primary contributor to hazard in the southern part of the state. In addition to reevaluating the 2007 interface segmentation model in light of new data, we also plan on using the SLAB 2.0 model to constrain interface and slab geometry and to discriminate between slab earthquakes and those in the overriding plate in the earthquake catalog. On the ground motion modeling side, we anticipate inclusion of the new NGA-Subduction models (Bozorgnia et al., this session), which mark a significant step forward in modeling both slab and interface ground motions. NGA-Subduction includes improved site and deep basin response models, as well as support for 22 spectral periods as required by the latest U.S. building codes for computing design ground motions.

\section{Web Tools for Users of the 2018 USGS National Seismic Hazard Model}

POWERS, P. M., U.S. Geological Survey, Colorado, USA, pmpowers@usgs. gov; CLAYTON, B. S., U.S. Geological Survey, Colorado, USA, bclayton@ usgs.gov; ALTEKRUSE, J. M., U.S. Geological Survey, Colorado, USA, jaltekruse@usgs.gov

The U.S. Geological Survey (USGS) earthquake hazards website (https://earthquake.usgs.gov/hazards/) is the central distribution point for the National Seismic Hazard Models (NSHMs), maps, and data for the United States and its territories. The website has evolved over time, moving increasingly from providing static data to delivering data and analyses dynamically through web services and interactive web applications. The Unified Hazard Tool (UHT, https://earthquake.usgs.gov/hazards/interactive/) web application is the current delivery platform for hazard data from the NSHMs, providing access to both static hazard data and dynamic hazard calculation and disaggregation. It is backed by web services that can be also accessed by third-party applications. We are now rolling out an update to the UHT, which will expand the set of available web tools and services. The updated UHT provides improved access to the seismic source and ground motion models (GMMs) in a NSHM, making it easier to query individual NSHM components. As examples, the updated UHT provides a GMM response spectrum plotting tool and tools to query and plot the magnitude frequency distributions associated with a specific source. Users can also obtain the source and site parameters used by GMMs when computing ground motions. The updated UHT will be the delivery mechanism for the recently published 2018 update to the NSHM for the conterminous United States. In addition, improvements to the codes and model input files underlying the UHT allow us to compute associated uncertainties in hazard. We provide an overview of the updated features of the UHT with examples that will be of use to earthquake engineers, geologists, and risk modelers, among others.
Updating the US National Seismic Hazard Models

Poster Session · Wednesday · 21 April · 11:30 AM Pacific

Session Chairs: Peter M. Powers, U.S. Geological Survey (pmpowers@usgs.gov); Allison M. Shumway, U.S. Geological Survey (ashumway@usgs.gov); Mark D. Petersen, U.S. Geological Survey (mpetersen@usgs.gov); Sanaz Rezaeian, U.S. Geological Survey (srezaeian@usgs.gov)

\section{An Alternative Ground Motion Prediction Model for} Induced Earthquake in Central and Eastern United States FARAJPOUR, Z., The University of Memphis, Tennessee, USA, zfrjpour@ memphis.edu; PEZESHK, S., The University of Memphis, Tennessee, USA, spezeshk@memphis.edu

Increased induced earthquake rate has resulted in a great interest among the engineering community and seismologists to develop new Ground Motion Prediction Models (GMPMs) for induced earthquakes caused by man-made activities in Central and Eastern United States (CEUS). GMPMs are the key component of probabilistic hazard analysis. The availability of well-recorded ground-motions data in CEUS has permitted scientists a chance to develop new predictive models. Induced events with small-to-moderate magnitude, shallow focal depth, and large amplitude ground-motion at short distances are used in this study to develop a new GMPM. The proposed GMPM is a calibrated version of the Pezeshk et al. (2018) hybrid empirical model, which was developed for Central and Eastern North America tectonic earthquakes. In this study, we used a combination of Gupta et al. (2017) and Rennolet et al. (2019) databases. The combined database includes earthquake events and recording stations that fall within suspected induced polygons identified by Peterson et al. (2015). The proposed GMM is derived for the peak ground acceleration and response-spectral ordinates at periods ranging from 0.01 to $10.0 \mathrm{sec}$, moment magnitudes ranging from 3.0 to 5.8 , and hypocentral distances up to $200 \mathrm{~km}$. The database used for developing the proposed GMPM excludes earthquakes and recording stations that fall within the Gulf Coast region. We assessed the performance of the proposed GMPM through a set of comprehensive residual analyses. Furthermore, we compared the proposed GMPM with recently published GMPMs for induced seismicity in CEUS. The proposed GMPM could apply in long-term and short-term USGS National Seismic Hazard Maps and for the hazard evaluation of induced seismicity.

\section{Average Slip Profile of Earthquake Ruptures}

THINGBAIJAM, K., GNS Science, Lower Hutt, New Zealand, k.thingbaijam@ gns.cri.nz; VAN DISSEN, R. J., GNS Science, Lower Hutt, New Zealand, r.vandissen@gns.cri.nz; SHAW, B. E., Columbia University, New York, USA, shaw@ldeo.columbia.edu; GERSTENBERGER, M. C., GNS Science, Lower Hutt, New Zealand, m.gerstenberger@gns.cri.nz

We investigate average coseismic slip profiles, using a selection of rupture models from the SRCMOD database (http://equake-rc.info.srcmod/). For each rupture model, the slip profiles were extracted from effective slip distribution that have been a priori interpolated on an uniform spatial gridding. To compute an overall average slip profile, we use a mean profile for each event, instead of that for individual rupture models, to minimize bias due to multiple intraevent rupture models. In general, we find that the power-of-sine function with index $=1 / 2$ (i.e., sinesqrt function) matches remarkably well with the averaged shape of along-strike profiles. This finding corroborates that of Biasi and Weldon (2006, Bull. Seismol. Soc. Am., 96, 1612-1623), despite their dataset being surface slip measurements. However, average slip profile on longer faults (aspect ratio $\geq 5$ ) is a flatter curve that conforms to power-of-sine function with index $=1 / 3$. At the same time, the fit of sinesqrt function also holds for down-dip profiles associated with buried ruptures. However, the average down-dip slip profile for surface rupture events have lesser tapering at the upper edge of fault. This lesser tapering can be modeled by a modified sinesqrt function. We further demonstrate that these observations are consistent with slip heterogeneity, through slip maps generated using a spatial random field model and scaling relations.

\section{Basin Amplification in Southern California From SCEC} Cybershake Simulations

MOSCHETTI, M. P., U.S. Geological Survey, Colorado, USA, mmoschetti@ usgs.gov; REKOSKE, J. M., U.S. Geological Survey, Colorado, USA, jrekoske@ usgs.gov; WITHERS, K. B., U.S. Geological Survey, Colorado, USA, 
kwithers@usgs.gov; THOMPSON, E. M., U.S. Geological Survey, Colorado, USA, emthompson@usgs.gov

We evaluate low-frequency $(\mathrm{f}<1 \mathrm{~Hz})$ basin amplification in the Southern California Earthquake Center (SCEC) CyberShake simulations for application in seismic hazards assessments. Our study makes use of ground motions from CyberShake version 15.4, which uses the SCEC community velocity model S4.26-M01. We compute ground motion residuals from the CyberShake database, relative to the Boore et al. (2014) ground motion model (GMM) with a Vs $30=760 \mathrm{~m} / \mathrm{s}$ reference condition, and compute site terms for all stations in the simulation domain using mixed-effects regressions. The site terms describe spatially varying, period-dependent, adjustments to the GMM, and they correspond to the combined effects of the shallow site and basin amplification in current GMMs. Scaling of the site terms with the basin depth parameters $Z_{1}$ and $Z_{2.55}$ (depths to 1 and $2.5 \mathrm{~km} / \mathrm{s}$ shear-wave velocity horizons), and the scaling of their variances, are compared with the site response models of the NGA-West-2 GMMs. We compute spatially varying adjustment terms to the Boore et al. (2014) GMM from spatially smoothed site terms. The adjusted GMM thus combines empirical ground-motion scalings with distance, magnitude, fault geometry, and sense of slip with the spatially varying basin effects from CyberShake. We evaluate the adjusted GMM with a database of ground motions from $\mathrm{M}>=3.5$ earthquakes from the Los Angeles region. The database contains good azimuthal coverage and multiple recordings per station, primarily from small- to moderate-sized earthquakes, thereby minimizing finite-fault effects and path-dependent amplifications. The study provides one framework for bringing 3D-simulation results into regional seismic hazards assessments, such as the U.S. National Seismic Hazard Model (NSHM).

\section{Earthquake Catalog Completeness Threshold for California and Nevada}

ZENG, Y., U.S. Geological Survey, Colorado, USA, zeng@usgs.gov; PETERSEN, M. D., U.S. Geological Survey, Colorado, USA, mpetersen@ usgs.gov; WANG, W., University of Southern California, California, USA, wwang071@usc.edu

We analyze the earthquake catalog completeness for declustered $M \geq 4$ earthquakes in California and Nevada to improve the statistical analyses required for earthquake hazard assessments. For large magnitudes, $M \geq 6.0$, the catalog completeness has been traced back to 1850 based on historical intensity documentation, while for smaller magnitudes the catalog completeness times are reliant on the temporal and spatial distribution of instrumental recordings. Given the significance of catalog completeness in studies of seismicity and earthquake source processes, we reexamine the catalog using: (1) a method assuming seismicity is steady-state and completeness levels may be detected based on temporal changes observed state-wide and (2) a method that assesses the historical seismic network detectability thresholds. In the first approach, a sharp fall-off of a steady-state average is considered to be caused by missing events in the catalog. In the second approach, the completeness of the catalog depends on the earthquake detection limits of the seismic network through historical times. We use modern-day seismic recordings converted to a WoodAnderson seismogram to investigate these detectability limits. We also exam the archived early Wood-Anderson seismograms to evaluate those limits. By combining the two approaches, we conclude that for $M \geq 4$, the earthquake catalog is complete since 1932 in California and most of Nevada.

\section{Evaluation and Integration of Seismic Directivity Models for the USGS National Seismic Hazard Model}

WITHERS, K. B., U.S. Geological Survey, Colorado, USA, kwithers@ usgs.gov; MOSCHETTI, M. P., U.S. Geological Survey, Colorado, USA, mmoschetti@usgs.gov; THOMPSON, E. M., U.S. Geological Survey, Colorado, USA, emthompson@usgs.gov; FRANKEL, A., U.S. Geological Survey, Washington, USA, afrankel@usgs.gov; MORIARTY, E., U.S. Geological Survey, Washington, USA, emoriarty@usgs.gov; GRAVES, R. W., U.S. Geological Survey, California, USA, rwgraves@usgs.gov; AAGAARD, B., U.S. Geological Survey, Colorado, USA, baagaard@usgs.gov; PETERSEN, M. D., U.S. Geological Survey, Colorado, USA, mpetersen@usgs.gov; LUCO, N., U.S. Geological Survey, Colorado, USA, nluco@usgs.gov; BALTAY, A., U.S. Geological Survey, California, USA, abaltay@usgs.gov; POWERS, P. M., U.S. Geological Survey, Colorado, USA, pmpowers@usgs.gov; REZAEIAN, S., U.S. Geological Survey, Colorado, USA, srezaeian@usgs.gov

We have recently begun an effort to synthesize the community's work in the field of rupture directivity into a unified representation that can be implemented in the U.S. Geological Survey (USGS) National Seismic Hazard Model (NSHM). Near-source ground motion amplitudes are known to exhibit a variety of spatial variations that are not currently included in most seismic hazard studies. One of these phenomena is seismic directivity, where ground motions vary as a function of azimuth and distance from the source, modified by the station's location with respect to both rupture propagation and slip direction. Several directivity models have been developed in recent years to describe these trends, but to date have not been incorporated into the USGS NSHMs.

We first evaluate preexisting directivity models (DMs) that compute geometrical factors for scaling of ground motions using both empirical and synthetic recordings for events with finite fault information. Our approach focuses on ground-motion residuals with respect to existing ground-motion models (GMMs) to calculate adjustment terms that capture seismic directivity effects over a range of magnitude, period, and style of faulting. Then, we develop an integrated approach to unify these models for adjustment of preexisting GMMs for incorporation into future NSHMs. We intend to consider several techniques for integration into the NSHMs, including a simple average of several DMs as well as an artificial neural network approach that uses machine learning to determine the best combination of DMs and weighting factors to minimize misfit with the empirical and synthetic data. The latter technique will also help us assess the relative importance of each DM input parameter. The integration will ultimately consider median adjustment terms as well as modification of standard deviation values, relating to both epistemic uncertainty and aleatory variabilities.

\section{Impacts on Catastrophe Risk Assessments from Multi- Segment and Multi-Fault Ruptures in the UCERF3 Model} LEE, Y., ImageCat, Inc., California, USA, yjl@imagecatinc.com; HU, Z., ImageCat, Inc., California, USA, zh@imagecatinc.com; DANESHVARAN, S., Aon I Impact Forecasting, Illinois, USA, siamak.daneshvaran@aon.com; SEDAGHATI, F., Aon | Impact Forecasting, Illinois, USA, farhad.sedaghati@ aon.com; GRAF, W., ImageCat, Inc., California, USA, wpg@imagecatinc.com

The Uniform California Earthquake Rupture Forecast Version 3 (UCERF3) relaxes fault segmentation, allowing multi-segment and multi-fault ruptures through fault-to-fault "jumps," with lengths up to $\sim 1200 \mathrm{~km}$ along the San Andreas Fault. Local faults are also highly interconnected, including ruptures on the order of hundreds of kilometers. These prescribed long ruptures did not exist in older models. Their plausibility and probability of occurring are being debated in the scientific community. Longer ruptures produce larger aggregate loss estimates for geographically dispersed assets ("portfolios") due to the wider areas that are affected by strong ground shaking. In this study, we model probabilistic earthquake losses of a hypothetical state-wide building portfolio in California. We develop two alternative risk deaggregation methods that identify multi-segment and multi-fault ruptures that contribute significantly to large portfolio-wide risks. Three risk measures are examined: Average Annual Loss (AAL), Return Period Loss $\left(\mathrm{RPL}_{\alpha}\right)$, and Tail Conditional Expectation $\left(\mathrm{TCE}_{\alpha}\right)$, for an annual exceedance probability ' $\alpha$.' Our results show that while the super long ruptures $(>500 \mathrm{~km})$ contribute modestly $(\sim 7 \%)$ to the portfolio AAL estimate, they are more influential to portfolio catastrophic loss estimates. Specifically, at a 250 -year return period, these long ruptures contribute about $26 \%$ and $32 \%$ to $\mathrm{RPL}_{\alpha}$ and $\mathrm{TCE}_{\alpha}$ estimates, respectively. At a 500 -year return period, the corresponding contributions reach about $35 \%$ and $39 \%$. Ruptures that connect complex local fault systems are also found to be highly influential to estimated portfolio risks. At a 500-year return period, a mere six rupture groups contribute nearly $70 \%$ to the $\mathrm{RPL}_{\alpha}$. Due to the importance of the UCERF3 model to catastrophe risk management decisions, a critical examination of the limit and uncertainty of fault connectivity and rupture lengths of future earthquakes is warranted in future model updates.

\section{Migrating USGS National Seismic Hazard Models to the Cloud}

CLAYTON, B. S., U.S. Geological Survey, Colorado, USA, bclayton@usgs.gov; POWERS, P. M., U.S. Geological Survey, Colorado, USA, pmpowers@usgs. gov

The USGS delivers National Seismic Hazard Models (NSHMs) both as published reports and static data. The latter, along with dynamic hazard calculations, are delivered via web-services and applications, the use of which has been increasing over time. Under the current architecture, all supported NSHMs are delivered via a single application, the Unified Hazard Tool (UHT), with a limited number of backing web-services that are hosted on USGS infrastructure. However, each model release requires more resources to be allocated, which is unsustainable as models become more complex and require more memory. To address this, the USGS has started to utilize cloud-based solutions, specifically Amazon Web Services (AWS), which allow for immense flexibility given a multitude of computing resource configurations available to end users. To facilitate cloud-based deployments, we now wrap individual models and associated web-services in Docker containers that can be deployed 
to Docker swarms or AWS using the AWS Elastic Kubernetes Service. This deployment model provides improved scalability support because additional containers can easily be spun up to accommodate any increased web-application computational load. A container-based deployment model also improves running hazard calculations and web-services locally because end users no longer have to deal with complex issues related to dependencies and compilation. At this time, we are also refactoring web-applications to use the Angular framework. Angular simplifies the building, testing, bundling, and running of USGS web applications. This framework is being adopted by other USGS development groups, for example earthquake real-time products and geomagnetism, which will improve long-term support of our applications and will provide greater opportunities for internal and external collaboration.

\section{MyShake: Using Smartphone Seismic Data to Map Site Effects Across Urban Environments}

ALLEN, R., University of California, Berkeley, California, USA, rallen@ berkeley.edu; KONG, Q., University of California, Berkeley, California, USA, kongqk@berkeley.edu; PATEL, S., University of California, Berkeley, California, USA, sarina.patel@berkeley.edu; STRAUSS, J., University of California, Berkeley, California, USA, jastrauss@berkeley.edu

MyShake is a smartphone app designed to harness and synergize public interest in earthquakes. The app provides users the information they need, and also collects acceleration waveforms and user experience data. In 2019 the app was launched by Governor Gavin Newsom in California becoming the official state app to deliver earthquake early warnings generated by ShakeAlert. This resulted in over a million downloads by users wanting alerts, and simultaneously harnessed over a million new accelerometers that now provide ground motion data in earthquakes.

As the acceleration waveform dataset grows across California, we are starting to use the data to understand ground motion effects across the urban environment. The sensors are inside buildings providing insights into not only the spacial variations of ground motions across a region due to site effects, but also the amplification effects of buildings. While this complicates the analysis of the data, it also provides a unique dataset with instrumental observations of shaking as experienced by people within their homes and offices. We will preset our findings mapping site effects across urban environments in California and relating Did You Feel It intensity reports to instrumental observations.

New Zealand Community Fault Model-Towards Version 1.0 VAN DISSEN, R. I., GNS Science, Lower Hutt, New Zealand, r.vandissen@gns. cri.nz; SEEBECK, H., GNS Science, Lower Hutt, New Zealand, h.seebeck@ gns.cri.nz

There has been a long-identified need in New Zealand for a community developed fault model that is accessible and available to all. GNS Science has long maintained products such as the Active Fault Database, related Active Fault Model, and QMAP, which provide a significant amount of basic fault information. However, a three-dimensional fault model that represents New Zealand's best scientific knowledge that can easily be used or adapted for multiple scientific and practical uses is not presently available.

The New Zealand Community Fault Model (NZ CFM) will serve as a unified and foundational resource for many societally important applications such as the New Zealand National Seismic Hazard model, Resilience to Natures Challenges Earthquake and Tsunami programme, physics-based fault systems modelling, earthquake ground-motion simulations, and tsunami hazard evaluation.

The NZ CFM is an object-oriented, three-dimensional representation of active faults in New Zealand and adjacent offshore regions. The model presently incorporates more than 600 objects (i.e., faults), which include triangulated surface representations of those faults and associated meta-data such as slip rate and movement type. The NZCFM faults are defined based on surface traces, seismicity, seismic reflection profiles, wells, and geologic cross sections following methodologies developed by SCEC.

Precise fault system geometries better define earthquake source parameters, such as the fault surface area and orientation, and have been shown to have an important influence on slip rate estimates derived from geodetic constraints and on earthquake rupture dynamics.

We present an initial model developed from an existing 2D fault model published in 2014, the formulation, parameterisation and documentation of that model in 3D; and the availability of that model in a readily accessible form(s) to support and facilitate multiple realisations and varied applications.

More information about this project can be found at: https://www. gns.cri.nz/Home/Our-Science/Natural-Hazards-and-Risks/Earthquakes/ Community-Fault-Model

\section{Properly Separating Uncertainties of Ground Motion Estimates Conditioned Upon Observational Data}

ENGLER, D. T., U.S. Geological Survey, Colorado, USA, dengler@contractor. usgs.gov; WORDEN, C. B., Synergetics, Inc. contractor in support of U.S. Geological Survey, Colorado, USA, cbworden@contractor.usgs.gov; THOMPSON, E. M., U.S. Geological Survey, Colorado, USA, emthompson@ usgs.gov; JAISWAL, K. S., U.S. Geological Survey, Colorado, USA, kjaiswal@ usgs.gov

The U.S. Geological Survey's ShakeMap product has historically provided estimates of both the mean and standard deviation of ground motions, but few users have made use of the estimated standard deviations. One important use of ShakeMap is to estimate an earthquake's potential impact on the affected population in terms of the expected number of fatalities and economic losses, which are sensitive to the modeling assumptions of the ground motion uncertainty. An accurate representation of ground motion uncertainty can be achieved by generating random ground motion fields based on the ShakeMap estimates. This work seeks to ensure the proper incorporation of the ground motion intensity records so that the ground motion realizations accurately describe the spatial distribution of the underlying statistical process. The standard for modeling ground motion uncertainties is to separate the residual processes into what are known as the within-event and between-event uncertainties. An efficient way to generate ground motion fields is to sample the within- and between-event processes separately. However, these uncertainties become convoluted and inseparable in the current ShakeMap conditioning process. The reason for this is that current process makes certain assumptions and steps which do not handle the intensity data conditioning in the strictest probabilistic manner. In order to remedy this, a new method for conditioning estimated ground motions on observational data is presented. This method conditions the ground motions on the data using the properties of conditional multivariate normal distributions while separating the between- and withinevent residuals throughout the conditioning process. The results indicate that this new formulation makes the post-conditioned between- and within-event spatial distributions easily separable and hence makes a proper and efficient simulation of these processes feasible.

\section{Sensitivity and Preliminary Uncertainty Analysis for the USGS 2021 National Seismic Hazard Model for Hawaii}

SHUMWAY, A. M., U.S. Geological Survey, Colorado, USA, ashumway@usgs. gov; PETERSEN, M. D., U.S. Geological Survey, Colorado, USA, mpetersen@ usgs.gov; POWERS, P. M., U.S. Geological Survey, Colorado, USA, pmpowers@usgs.gov; ALTEKRUSE, J. M., U.S. Geological Survey, Colorado, USA, jaltekruse@usgs.gov

The USGS plans to release the update to the National Seismic Hazard Model (NSHM) for Hawaii in 2021. The 2021 NSHM for Hawaii updates the twodecades-old model of Klein et al. (2001) by incorporating new data and modeling techniques to improve the probability-based shaking forecasts of earthquakes and volcano-tectonic events. Updates include: (1) seismicity catalog, declustering and smoothing methods, and rate and Mmax models for the smoothed seismicity model; (2) ground motion models (GMMs) for shallow and deep earthquakes, including two new Hawaii-specific models, and site response models; (3) geometry, rate, and Mmax models for décollement faults on the Island of Hawaii; and (4) development of a caldera collapse model for earthquakes associated with the Kilauea summit zone on the Island of Hawaii. Mean hazard curves are calculated for 21 spectral periods ( 0.01 to $10 \mathrm{~s})$ and peak ground acceleration, for a 5\% damping ratio, and for 8 different site classes corresponding to $\mathrm{V}_{\mathrm{S} 30}$ values ranging from 150 to $1500 \mathrm{~m} / \mathrm{s}$. Hazard maps are based on uniform-hazard ground motions interpolated at 2, 5, and $10 \%$ probability of exceedance in 50 years from the hazard curves.

As part of the 2021 NSHM for Hawaii, we performed a sensitivity analysis for the region by looking at how variations in each model component changes with mean hazard. Our analysis shows that mean hazard is particularly sensitive to both rate and GMMs. We also performed a preliminary uncertainty analysis at five test sites by calculating hazard on all logic tree branches. Our preliminary analysis shows that for ground motions at $2 \%$ in 50 -year probability of exceedance, the 0.2 s spectral acceleration branches vary by more than a factor of two at Honolulu and four at Hilo. These assessments allow us to show which branches of the logic tree most influence uncertainties in hazard at a particular site, and allows the user to better understand and make better decisions based on an assessment of the uncertainties.

\section{Simplification of Fault Traces for Use in the U.S. National} Seismic Hazard Model

COLLETT, C. M., U.S. Geological Survey, Colorado, USA, ccollett@usgs.gov; HATEM, A. E., U.S. Geological Survey, Colorado, USA, ahatem@usgs.gov; 
BRIGGS, R. W., U.S. Geological Survey, Colorado, USA, rbriggs@usgs.gov; GOLD, R. D., U.S. Geological Survey, Colorado, USA, rgold@usgs.gov

The geologic-based component of seismic hazard models requires the representation of active fault networks, which is typically accomplished by creating approximations of seismogenic sources. In previous releases of the U.S. National Seismic Hazard Model (NSHM), faults were considered for inclusion only if a published geologic slip rate was available for each fault. This requirement excluded numerous known Quaternary-active (since $2.58 \mathrm{Ma}$ ) faults with no direct slip rate constraints. While this approach is reasonable, many recent global ruptures have illustrated the importance of considering known, yet poorly characterized, Quaternary-active faults in seismic hazard models. We systematically represent published Quaternary active fault traces across the western U.S. for potential use in the next update of the NSHM (scheduled for 2023). To do so, we utilized the U.S. Geological Survey's Quaternary Fault and Fold Databases (QFFD) and newly published mapping. We developed an algorithmic approach to simplify high-resolution, detailed fault traces into representations for seismic hazard modeling (i.e., generalized seismogenic sources and coarse node spacing). The algorithm: 1) connects small gaps along strike of the detailed fault strands, maximizing fault length and 2) simplifies each fault strand by decreasing the number of nodes or vertices along strike. The QFFD-assigned slip rate category, recency of movement, gap distance, and dip direction were used to merge and further simplify fault strands. Over 2,000 QFFD traces were simplified ahead of the NSHM 2023 release, providing geometries used for both revision of existing 2018 NSHM fault sections and possible inclusion of new fault sections for use in NSHM 2023. Outstanding questions related to this fault trace simplification process include its influence on multi-fault rupture models, models of fault segmentation, and the best practices to represent spatially broad zones of distributed deformation in hazard analysis.

\section{Updated Creep Rate Data Base and Models for the National Seismic Hazard Model}

WESPESTAD, C., Indiana University, Indiana, USA, crystal.wespestad@ gmail.com; JOHNSON, K., Indiana University, Indiana, USA, kajjohns@ indiana.edu; MURRAY, J. R., U.S. Geological Survey, California, USA, jrmurray@usgs.gov

This ongoing work is part of a larger project to complete the 2023 update of the US National Seismic Hazards Model (NSHM). We use the location and magnitude of surface creep to infer the distribution of interseismic creep at depth. Interseismic creep may impede seismic rupture, and this is accounted for in hazard modeling by using creep rates to reduce the moment rate available for producing earthquakes on the fault. Specifically, we are developing an updated compilation of surface creep rate observations at locations along California faults. We will use these in inversions for the spatial distribution of interseismic creep on faults in the hazard model. The new data set primarily includes updated measurements from alignment arrays, creepmeters, and interferometric synthetic aperture radar (InSAR) compiled from published papers, actively-updated data repositories, and direct communication with researchers. The number of discrete measurements is several times more than was included in the previous update. Many of these additional measurements are due to recent advances in SAR data availability and analysis techniques. The measurements were thoroughly checked for quality, and informative metadata were included whenever available. We use the updated surface creep rate data set in a Bayesian inversion (Johnson and Fukuda, 2010) that is based on a stress-driven creep model in which locations on a fault are either locked, and accumulating stress, or creep at a constant stress. This physically-constrained approach provides better resolution of the size of creeping patches on faults than purely kinematic inversions. The resulting creep rate estimates can be used directly in hazard modeling through moment reduction on model faults. The creep rate models will also be used as a correction to the geodetically-derived surface velocity field used to constrain deformation models designed to estimate fault slip rates on faults in the hazard model, but that do not incorporate fault creep.

\section{USGS National Seismic Hazard Model Fault Section Database}

ALTEKRUSE, J. M., U.S. Geological Survey, Colorado, USA, jaltekruse@usgs. gov; POWERS, P. M., U.S. Geological Survey, Colorado, USA, pmpowers@ usgs.gov; FIELD, E. H., U.S. Geological Survey, Colorado, USA, field@usgs. gov

The U.S. Geological Survey's National Seismic Hazard Model (NSHM) fault section database is the central repository of geologic data used as inputs for all fault sections included in USGS NSHMs. Consolidation of fault section data from multiple databases and NSHM source codes facilitates: 1) change tracking of all NSHM fault section data, 2) enforcing consistent identification and naming conventions across multiple NSHM updates, 3) more direct access to NSHM data, and 4) participation from the broader earthquake science community. The NSHM fault section database consists of plain text GeoJSON files with associated README documentation files in folders for each fault section grouped by state or territory. The flat file database is stored as a Git repository (https://code.usgs.gov/ghsc/nshmp/nshm-fault-sections). Consistent structural representation of fault sections permits multi-section ruptures in hazard models to be stitched together dynamically by USGS hazard codes, thereby minimizing redundant section data. The initial version of the NSHM fault section database contains the 2008 edition of the Conterminous U.S. (CONUS) NSHM. The version presented here expands on the initial fault section database to include all current NSHM editions (CONUS, Alaska, Hawaii, Guam and the Northern Mariana Islands, Puerto Rico and the U.S. Virgin Islands, and American Samoa). This new database forms a baseline fault source model for development of future NSHM updates.

\section{Utilizing Earthscope and AACSE Datasets in Alaska and Canada to Unravel Earth Science Mysteries \\ Oral Session · Tuesday · 20 April · 2:30 Pм Pacific \\ Session Chairs: Natalia A. Ruppert, University of Alaska \\ Fairbanks (naruppert@alaska.edu); Meghan S. Miller, \\ Australian National University (meghan.miller@anu.edu.au)}

\section{Along-Strike Variations of Intermediate-Depth Seismicity Along the Alaska Peninsula}

WEI, S., Michigan State University, Michigan, USA, swei@msu.edu; GABLE, S., Michigan State University, Michigan, USA, gablesyd@msu.edu; RUPPERT, N. A., University of Alaska Fairbanks, Alaska, USA, naruppert@alaska.edu; ZHANG, H., University of Science and Technology of China, Hefei, China, zhang11@ustc.edu.cn

The Alaska Peninsula section of the Aleutian-Alaska subduction zone exhibits significant along-strike variations in plate coupling, earthquakes, and arc magmatism. We use regional and teleseismic data from 1990 to 2018 to investigate intermediate-depth intra-plate seismicity beneath the Alaska Peninsula. The distribution of these event shows five distinct segments from southwest to northeast: Unimak, Pavlof, Shumagin, Semidi, and Kodiak. We identify two double seismic zones (DSZs) in the Pavlof and Semidi segments but not in others. The magnitude-frequency relationship of these earthquakes (b-value) also varies along strike, suggesting more fluids in the southwestern segments and closer to the slab interface. These along-strike variations correlate well with trace elements of arc lavas in the Alaska Peninsula. Our observations suggest that the slab is more hydrated and thus undergoing more intensive dehydration in the southwest than in the northeast, whereas more sediments are subducted in the northeast than in the southwest. These along-arc changes are generally in agreement with previous studies of plate coupling and the crustal structure of the incoming plate. Moreover, the complexities beyond the monotonic changes imply that the intermediate-depth intra-plate seismicity and sub-arc melting are influenced by not only the pre-existing fabrics in the incoming plate, but also the subducted sediments and plate stress state.

\section{Crust and Uppermost Mantle Structure of the Alaska Subduction Zone From Joint Inversion of Rayleigh Wave Dispersion and Receiver Functions}

LI, Z., Washington University in St. Louis, Missouri, USA, zongshan.li@ wustl.edu; WIENS, D. A., Washington University in St. Louis, Missouri, USA doug@wustl.edu; SHEN, W., Stony Brook University, New York, USA, weisen. shen@stonybrook.edu

The Alaska subduction zone provides a unique opportunity to study the structure and hydration of the forearc and incoming plate in a region with strong along-strike gradients in seismogenic properties and incoming plate fabric. Here we image the crust and uppermost mantle structure of the Alaska subduction zone using data from the Alaska Amphibious Community Seismic Experiment (AACSE; May 2018 - September 2019) and existing broadband seismic land stations from the EarthScope Transportable Array and other Alaska regional networks. Altogether 61 AACSE ocean bottom seismographs and 118 land stations are utilized. We use ambient noise cross-correlation to retrieve the Rayleigh wave phase and group velocities at shorter periods (8-32 s) and Eikonal tomography to determine Rayleigh wave phase velocities from 
teleseismic surface waves at longer periods (24-100 s). The OBS data are preprocessed to remove the seafloor tilt and compliance noise. The local phase velocity dispersion curve at each node is obtained from ambient noise and earthquake measurements by weighted averaging in the overlapping period band. We also perform receiver function analysis for the land stations to better constrain the Moho depth. A 3-D isotropic shear velocity model is constructed by a joint Bayesian Monte Carlo inversion of Rayleigh wave phase/ group velocities and receiver functions. The results show $\sim 11 \%$ shear velocity reduction in the uppermost mantle of the incoming plate near Shumagin Islands, extending to more than $12 \mathrm{~km}$ below the Moho, which is likely due to the serpentinization. These observations are consistent with the previous active-source study (Shillington et al., 2015), but better resolve the maximum depth of hydration. Compared to that in the Mariana subduction zone (Cai et al., 2018), the incoming plate hydration in Shumagin Gap is still weaker in both magnitude and depth extent. In addition, we observe thick crust $(>40$ $\mathrm{km}$ ) and reduced lower crustal velocities in the forearc beneath the Kodiak and Semidi region, perhaps demarking the extent of the accreted Chugach Terrane.

\section{Imaging the Magma Plumbing System Beneath Mount Cleveland Volcano, Alaska Using Ps-P Crustal Tomography} PORTNER, D. E., Carnegie Institution for Science, District of Columbia USA, dportner@carnegiescience.edu; WAGNER, L., Carnegie Institution for Science, District of Columbia, USA, lwagner@carnegiescience.edu; JANISZEWSKI, H. A., University of Hawai'i at Mānoa, Hawaii, USA, hajanisz@hawaii.edu; ROMAN, D. C., Carnegie Institution for Science District of Columbia, USA, droman@carnegiescience.edu; POWER, J. A., U.S. Geological Survey, Alaska, USA, jpower@usgs.gov

Mount Cleveland is among the most active volcanoes in the Aleutian Arc, but a historic lack of seismic infrastructure monitoring the volcano has limited our knowledge of the underlying crustal structure. A recent GeoPRISMS seismic deployment provides the opportunity for applying traditional seismic imaging to the system, but a narrow array aperture and a lack of mid-to-lower crustal earthquake activity limits the depth range over which we can image the underlying crustal structure and characterize the volcano's magma plumbing system using these techniques. Here we circumvent these limitations by utilizing teleseismic receiver functions in our tomographic procedure. Our technique, called $P s-P$ crustal tomography, harnesses the complementary strengths of teleseismic receiver functions and traditional seismic tomography by processing $P s-P$ delay times derived from receiver functions in a tomographic $S$ wave inversion. Using our new inversion technique, we identify a heterogeneous velocity structure with relatively high lateral velocity perturbations. We image a narrow, vertically extensive high $V_{\mathrm{p}} / \mathrm{V}_{\mathrm{S}}$ anomaly directly beneath the volcano that likely signifies a mid-to-lower crustal magma reservoir that may supply the persistent low level eruptive activity at Mount Cleveland. We also image several surrounding anomalies of relatively low $V_{\mathrm{P}} / \mathrm{V}_{\mathrm{S}}$ that may indicate solidified magma intrusions. Assessed jointly with local earthquake phases, these observations can provide critical constraints on the velocity structure of the transcrustal magmatic system. Our technique provides a new means for advancing understanding of crustal magmatic systems in areas without broad aperture seismic networks or well-distributed local seismicity, such as ocean island volcanoes.

\section{Plate-Bending Extensional Earthquake Depths Constrain Hydration at the Alaska Subduction Zone}

MATULKA, P., Washington University in St. Louis, Missouri, USA, pmatulka@wustl.edu; LI, Z., Washington University in St. Louis, Missouri, USA, zongshan.li@wustl.edu; WIENS, D. A., Washington University in St. Louis, Missouri, USA, doug@wustl.edu

Plate-bending extensional faults form as a subducting plate bends beneath the overriding plate and generate some of the largest earthquakes and deadliest tsunamis in the world. The presence of these extensional faults may allow pathways for water to penetrate into the plate and serpentinize the mantle, increasing the amount of water subducted and affecting seismicity and arc volcanism. However, the amount of water subducted into the mantle is debated because of uncertainty in the degree of serpentinization. The depth extent of these plate-bending extensional faults likely controls the maximum depth of serpentinization and thus the amount of water subducted. The Alaska subduction zone from Kodiak to Shumagin Islands is a promising area to study the impact of plate-bending faulting on subduction zone processes because previous studies have identified along-strike variation in the amount of faulting and hydration.

We constrain the depths of these plate-bending extensional faults by relocating more than 90 earthquakes in a laterally varying velocity model using land and ocean bottom seismographs from the Alaska Amphibious Community Seismic Experiment. We use a nonlinear location program (NonLinLoc) that allows for the incorporation of a 3D velocity model. We also calculate the focal mechanisms and depths of the largest events with a waveform inversion wherein we compare synthetic and actual waveforms using a grid search. Previous studies estimate a maximum depth of $15 \mathrm{~km}$ for platebending extensional faults in the eastern Alaska subduction zone. Preliminary depths in our study range from $0-50 \mathrm{~km}$. If the deeper earthquakes are extensional, our findings would suggest that estimates of the amount of water input into the Alaska subduction zone may need to be increased to reflect the greater possible thickness of hydrated mantle resulting from plate-bending extensional faults. Deep penetration of extensional faults into the plate also increases the maximum estimated earthquake magnitude, implying that plate-bending earthquakes may be important tsunamigenic events.

\section{Radial and Azimuthal Anisotropy of Alaskan Lithosphere Revealed by Multi-Component Ambient-Noise Adjoint Tomography}

LIU, T., University of Toronto, Toronto, Canada, tianshi.liu@mail.utoronto.ca; WANG, K., Macquarie University, Sydney, Australia, wangkaim8@gmail.com; TAPE, C., University of Alaska Fairbanks, Alaska, USA, ctape@alaska.edu; HE, B., University of Toronto, Toronto, Canada, binhebj@gmail.com; YANG, Y., Macquarie University, Sydney, Australia, yingjie.yang@mq.edu.au; TONG, P., Nanyang Technological University, Singapore, Singapore, tongping@ntu. edu.sg; LIU, Q., University of Toronto, Toronto, Canada, liuqy@physics. utoronto.ca

The Alaskan lithosphere exhibits complex structures shaped by past and ongoing tectonic processes. The subsurface structures of the Alaskan lithosphere can be mapped using seismic imaging, and the mapped seismic velocity structures provide useful information in understanding the tectonic evolution of this region. In particular, radial and azimuthal anisotropy can provide important constraints on the lithology and deformation patterns of the lithosphere.

In this study, high-quality broadband seismic records covering the Alaska are used to image the radial and azimuthal anisotropy of the crust and uppermost mantle. We collect all available broadband continuous seismic data recorded from 2014 to 2019 and follow standard ambient noise data processing procedures to extract the vertical-vertical (Z-Z), radial-radial (R-R) and transverse-transverse (T-T) components of the empirical Green's functions (EGF) between all available station pairs. We measure the frequencydependent travel-time misfits between EGFs and simulated Green's functions of all three components at 12-50s. We iteratively update the velocity model on top of an isotropic 3D model we previously obtained using ambient-noise adjoint tomography to minimize to misfits.

We use the multi-component ambient-noise adjoint tomography technique (Wang et al. 2019) to efficiently carry out forward and adjoint simulations for the three components. The mini-batch technique (van Herwaarden et al. 2020) is used to further accelerate the inversion. A radially and azimuthally anisotropic model of the Alaskan lithosphere is constructed from the surface down to $\sim 70 \mathrm{~km}$ depth. This anisotropic model along with the isotropic Vs model helps better understand the evolution of the lithosphere beneath Alaska.

Utilizing Earthscope and AACSE Datasets in Alaska and Canada to Unravel Earth Science Mysteries

Poster Session · Tuesday · 20 April · 4:15 PM Pacific Session Chairs: Natalia A. Ruppert, University of Alaska Fairbanks (naruppert@alaska.edu); Meghan S. Miller, Australian National University (meghan.miller@anu.edu.au)

\section{Enhanced Regional Earthquake Catalog With Alaska Amphibious Community Seismic Experiment Data} RUPPERT, N. A., University of Alaska Fairbanks, Alaska, USA, naruppert@ alaska.edu; BARCHECK, G., Cornell University, New York, USA, grace. barcheck@cornell.edu; ABERS, G., Cornell University, New York, USA, abers@cornell.edu

The Alaska Amphibious Community Seismic Experiment (AACSE) comprised 75 ocean bottom seismometers and 30 land stations and covered about $650 \mathrm{~km}$ along the segment of the subduction zone that includes Kodiak Island, the Alaska Peninsula and the Shumagin Islands between May 2018 and September 2019. This unprecedented offshore dataset has the potential 
to support a greatly enhanced earthquake catalog by both increasing the number of detected earthquakes and improving the accuracy of their source parameters. We use all available regional and AACSE campaign seismic data to compile an enhanced earthquake catalog for the region between Kodiak and Shumagin Islands including Alaska Peninsula (51-59N, 148-163W). We apply the same processing and reporting standards to additional picks and events as the Alaska Earthquake Center currently uses for compilation of the authoritative regional earthquake catalog. As of December 2020, processing of May - October 2018 is complete. A total of 3,166 events (new and previously reported) have been processed with additional data. We added about $30 \%$ more events, $50 \%$ more phase picks, and lowered the magnitude of completeness by about 0.2 units. Most of the newly detected earthquakes are in the 2018 M7.9 Offshore Kodiak earthquake aftershock region, as well as under the Kodiak Island and the Alaska Peninsula. Next, we test the performance of several semi-automatic picking and location algorithms against the analystchecked picks and locations for this unique amphibious dataset. We compare pick times from the machine learning algorithm Earthquake Transformer, and picks and locations made by an iterative onset estimation and relocation algorithm. In our presentation we will report on uptoday catalog processing results.

\section{Imaging the Upper Plate Lithosphere and Asthenosphere Beneath Alaska With Sp Converted Waves}

GAMA, I., Brown University, Rhode Island, USA, igama@brown.edu; FISCHER, K. M., Brown University, Rhode Island, USA, karen_fischer@ brown.edu; HUA, J., Brown University, Rhode Island, USA, junlin_hua@ brown.edu

To resolve the signatures of subduction zone processes in the mantle wedge, and how subduction has interacted with the upper plate, we imaged seismic velocity gradients beneath Alaska with $\mathrm{Sp}$ receiver function common conversion point (CCP) stacking. We employed data from 123 stations of the NSF EarthScope Transportable Array, as well as from hundreds of stations of other portable arrays and permanent networks. We calculated waveform components using a free-surface transform with improved estimates of free-surface velocities that were determined from $\mathrm{P}$ and SV particle motions. Sp receiver functions were calculated with time-domain deconvolution, and the CCP stack was generated with weighting functions that incorporate the properties of Sp scattering kernels. The CCP stack shows a clear interface between the North American and underthrust Yakutat crust, as well as Yakutat Moho depths of up to $60 \mathrm{~km}$. Sp phases from the negative velocity gradient at the base of the upper plate are strongest in west-central Alaska, where lithosphere-asthenosphere boundary (LAB) depths lie at 65-100 km. In west-central Alaska, joint inversions of Sp data at single stations with Rayleigh phase velocities show comparable LAB depths as well as low asthenospheric velocities. This zone includes active magmatism and the upper plate appears to have been thinned by mantle wedge volatiles, melt, and flow. The LAB phase deepens to the north, reaching depths of $\sim 120 \mathrm{~km}$ beneath the northern Arctic Alaska terrane. This increase in the depth of the LAB phase from the arc to the back-arc is consistent with the sculpting of the upper plate by subductionrelated processes. Sp phases also delineate a prominent positive velocity gradient that represents the base of a low-velocity asthenospheric layer at depths of $100-130 \mathrm{~km}$. The positive velocity gradient is consistent with the onset of partial melting in the asthenosphere.

\section{Magnetic Field Variations in Alaska: Recording Space Weather Events on the Transportable Array \\ RINGLER, A., U.S. Geological Survey, New Mexico, USA, aringler@usgs.gov; ANTHONY, R., U.S. Geological Survey, New Mexico, USA, reanthony@usgs. gov; CLAYCOMB, A., U.S. Geological Survey, Colorado, USA, aclaycomb@ usgs.gov; SPRITZER, J., U.S. Geological Survey, Colorado, USA, jsprtizer@ usgs.gov; TAPE, C., University of Alaska Fairbanks, Alaska, USA, ctape@ alaska.edu; WILSON, D., U.S. Geological Survey, New Mexico, USA,} dwilson@usgs.gov

Seismometers are highly sensitive instruments to not only ground motion but many other non-seismic noise sources (e.g. temperature, pressure and magnetic field variations). Because magnetic flux variations are stronger at high latitudes, the Alaska component of the Transportable Array (TA) is particularly susceptible to recording space weather events. We show that verticalcomponent seismic records across Alaska are directly recording magnetic field variations between 40 to $800 \mathrm{~s}$ period, as opposed to ground motion during strong geomagnetic/auroral events. Using co-located magnetic field records, it is possible to remove this signal from the seismic record and attain as much as $10 \mathrm{~dB}$ in noise improvement. However, this correction does not work across large spatial distances (e.g. greater than $200 \mathrm{~km}$ ) and the magnetometer net- work in Alaska is sparse. We demonstrate that low-cost magnetometers, such as the Bartington Mag-690, are capable of recording magnetic field signals with a signal-to-noise ratio similar to observatory-grade magnetometers, operated by the U.S. Geological Survey Geomagnetic Program, at periods below $1000 \mathrm{~s}$. However, the accuracy of these low-cost magnetometers must be better constrained. Deploying low-cost magnetometers at seismic stations could provide a unique opportunity to reduce long-period vertical seismic noise as well as increase the spatial resolution of magnetic field observations.

\section{Waveform Cross-Correlation-Based Methods in Observational Seismology}

I: Oral Session · Wednesday · 21 April · 2:00 PM Pacific

II: Oral Session · Wednesday · 21 April · 5:00 PM Pacific

Session Chairs: Esteban J. Chaves, Volcanological and

Seismological Observatory of Costa Rica, Universidad Nacional (esteban.j.chaves@una.cr); Zhigang Peng, Georgia

Institute of Technology (zpeng@gatech.edu); Marine Denolle, Harvard University (mdenolle@g.harvard.edu); William Frank, Massachusetts Institute of Technology (wfrank@ mit.edu); Taka’aki Taira, University of California, Berkeley (taira@berkeley.edu); Haijiang Zhang, University of Science and Technology of China (zhang11@ustc.edu.cn)

\section{Near-Repeating Earthquakes as a Proxy for Transient Aseismic Slip}

SHADDOX, H. R., University of California, Santa Cruz, California, USA, hshaddox@ucsc.edu; SCHWARTZ, S. Y., University of California, Santa Cruz, California, USA, syschwar@ucsc.edu; BARLOW, N. M., University of Kansas, Kansas, USA, nbartlow@berkeley.edu

Slip on faults occurs as a spectrum, ranging from slow, continuous sliding (i.e., aseismic creep) to rapid movement during earthquakes. Within the fault slip spectrum lies the transient release of stress through aseismic slip, commonly referred to as slow slip events (SSEs). SSEs are too slow to generate seismic waves so we generally rely on surface geodetic systems (e.g., cGPS, strainmeters, creepmeters, InSAR) to detect transient deformation at depth. However, SSEs located offshore or small aseismic slip transients at depth often generate surface deformation signals beneath instrumental noise levels. To overcome this observational limitation, we use related microseismicity, such as tremor, low-frequency earthquakes (LFEs), and repeating earthquakes, to infer the location of aseismic slip. Tremor is thought to be made up of repeating LFEs that are driven to failure by aseismic slip on the surrounding fault. LFEs are grouped into families that repeatedly rupture a small patch, with individual LFEs likely rupturing multiple sub-patches within the family patch. We propose that similar to families of LFEs, sequences of near-repeating earthquake families (i.e., highly-correlated earthquakes rupturing closely-spaced or partially overlapping asperities) concentrated in time can similarly be indicators of transient aseismic slip and provide another way to indirectly detect and locate aseismic slip transients. Using template matching and land and ocean bottom seismic data, we identify families of near-repeating earthquakes related to two known SSEs at the northern Hikurangi Subduction Margin, New Zealand and four triggered aseismic slip transients at the Anza segment of the strike-slip San Jacinto fault, southern California. These findings indicate that families of near-repeating earthquakes are a reliable proxy for transient aseismic slip, similar to families of LFEs. This is particularly important for determining the full interplay of seismic and aseismic slip in areas that are not tremorgenic or well-instrumented geodetically.

\section{One-Year of Near-Real-Time Matched-Filtering to Build Dense Earthquake Catalogs in New Zealand Using the Open-Source RT-EQcorrscan Software Package}

CHAMBERLAIN, C. I., Victoria University of Wellington, Wellington, New Zealand, calum.chamberlain@vuw.ac.nz; TOWNEND, J., Victoria University of Wellington, Wellington, New Zealand, john.townend@vuw. ac.nz; GERSTENBERGER, M. C., GNS Science, Lower Hutt, New Zealand, m.gersetenberger@gns.cri.nz

Conventional earthquake detection methods suffer significant degradation in completeness during high-rate sequences such as aftershock sequences or 
volcanic swarms. Correlation-based detectors, known as matched-filters or template-matching methods, can be used to overcome some aspects of catalog incompleteness during high-rate sequences, by detecting similar events buried in the noise or coda of preceding events. Matched-filter detectors have received significant attention in the construction of earthquake catalogs in response to large events, or high-rate sequences, but are generally applied offline. Because such dense catalogs have the potential to be useful to inform responses to these events, we have developed the RT-EQcorrscan open-source software package, a near-real-time implementation of the matched-filter method to be used in response to significant events.

RT-EQcorrscan is designed to either run continuous near-real-time matched-filters or listen to web-services and "spin-up" near real-time detection runs when events of interest occur, using a continuously updated database of historical seismicity as templates. This system comprises several concurrent systems to allow for continued updates to the template database, multiple near-real-time workflows, multi-threaded waveform processing and correlation computation, and visualization. At the time of writing (January) this system has reacted to 189 sequences in the New Zealand GeoNet catalog, and has made 10,224 detections based on our configuration. In this presentation we will demonstrate the RT-EQcorrscan software package and it's application over the 12 months from April 2020 to April 2021 to react to large earthquakes and high-rate sequences in New Zealand.

\section{Rock Valley Fault Zone Absolute and Relative Earthquake} Relocation to Improve Geologic Models

SCALISE, M., University of Nevada Reno, Nevada, USA, michelledunn@ nevada.unr.edu; ZEILER, C., Mission Support and Test Services, Nevada, USA, zeilercp@nv.doe.gov; PROTHRO, L., Mission Support and Test Services, Nevada, USA, prothrlb@nv.doe.gov; HATCH-IBARRA, R., University of Nevada, Reno, Nevada, USA, rhatch@unr.edu; SMITH, K. D., University of Nevada, Reno, Nevada, USA, ken@unr.edu; LOUIE, J. N., University of Nevada, Reno, Nevada, USA, louie@seismo.unr.edu

In 1993 a sequence of unusually shallow earthquakes in the Rock Valley Fault Zone (Nevada), producing predominately left lateral slip, was recorded on the Great Basin Seismic Network managed by the Nevada Seismological Laboratory at the University of Nevada, Reno. The earthquakes were initially located using differential times between the P- and S-wave arrivals (S-P) Short S-P times measured at a station within the source area estimate depths between $1-2 \mathrm{~km}$ rather than the $5-15 \mathrm{~km}$ depth range that is typically observed from crustal earthquakes. We relocated seismicity within the Rock Valley Fault Zone from 1993-2020 using absolute and relative relocation methods. Results from the absolute and relative relocations provide better constraint on source depth and an improved understanding of subsurface structures for geologic models. With the shallow character of the earthquakes, a dense network of seismic stations provides better depth control using HypoInverse (Klein, 2002), an absolute relocation method that minimizes location error to improve initial catalog locations. However, results are highly dependent on the velocity model used in the relocation. To combat this issue, hammer surveys are incorporated to reduce uncertainty in the upper $2 \mathrm{~km}$ of the velocity structure and produce robust absolute relocations. In addition, we use the cross correlation based relative relocation program GrowClust (Trugman and Shearer, 2017) to relocate earthquakes and refine fault geometry. Relocation results are coupled with the 3D Geologic Framework Model of Rock Valley to refine fault geometry and build a robust subsurface model. This work was done by Mission Support and Test Service, LLC, under Contract No. DE-NA0003624 with the U.S. Department of Energy. DOE/NV/03624--0976.

\section{Space-Time Variations in Earthquake Waveform Similarity: Implications for Stress Heterogeneity and Faulting Complexity \\ TRUGMAN, D. T., University of Texas at Austin, Texas, USA, dtrugman@jsg.} utexas.edu

Cross-correlation methods can provide a measure of the waveform similarity of nearby earthquakes. Similar earthquake pairs have been extensively studied for the application of hypocentral relocation methods or for analyses of repeating earthquakes. In these contexts, waveform similarity is often a binary definition: either an earthquake pair is similar or it is not. In reality, earthquake similarity exists on a continuous spectrum from highly similar to highly dissimilar. When viewed in this way, waveform similarity can be used as a tool to gain insight into heterogeneity in the stress field and local fault network over short length scales $(<1 \mathrm{~km})$. In this work, we characterize waveform similarity for a dataset of tens of thousands earthquakes near Ridgecrest, California, focusing in particular on resolving changes in similar- ity in space and in time. To do this, we combine a high-precision relocated catalog with the cross-correlation of full waveforms across multiple stations to measure how similar each earthquake is to its nearest neighbors. The occurrence of the July 2019 Ridgecrest mainshocks causes a sharp and persistent reduction in waveform similarity throughout the region, implying complexity in the stress field and activated faults on length scales of hundreds of meters or less. Among the Ridgecrest aftershocks, we observe coherent variations of waveform similarity along the rupture trace of the M7.1 mainshock. We also find a selection of anti-similar aftershock pairs, which have waveforms that are nearly identical at multiple stations except with reversed polarity. Taken together, these methods and observations lay the foundation for new approaches into understanding faulting and stress heterogeneity during complex earthquake sequences.

\section{Spatio-Temporal Changes of Microseismicity in Taiwan Around the 2009 Typhoon Morakot}

ZHAI, Q., Georgia Institute of Technology, Georgia, USA, qszhai@gatech.edu; PENG, Z., Georgia Institute of Technology, Georgia, USA, zpeng@gatech.edu; CHUANG, L. Y., Georgia Institute of Technology, Georgia, USA, lchuang@ gatech.edu; CHAO, K., Northwestern University, Illinois, USA, kevinchao@ gmail.com; WU, Y., National Taiwan University, Taipei, Taiwan, drymwu@ ntu.edu.tw; HSU, Y., Academica Sinica, Taipei, Taiwan, yaru@earth.sinica. edu.tw; WDOWINSKI, S., Florida International University, Florida, USA, swdowins@fiu.edu

Typhoon Morakot brought up to 3 meters of rainfall within a few days in August 2009, leading to numerous landslides in Southern Taiwan. The subsequent erosional processes result in a reduction of normal load at depth. Previous studies have suggested that such transient stress change can trigger small to moderate-size earthquakes in Taiwan and elsewhere. In this study, we examine spatio-temporal changes of microseismicity in Taiwan around the 2009 Typhoon Morakot to better understand the possible triggering relationship between extreme weather events, landslides and sediment removal, and tectonic activities. Because many microearthquakes were missing from the standard earthquake catalogs (especially during and right after Typhoon Morakot), we apply the Matched Filter Technique to systematically detect microearthquakes in Taiwan half a year before to one year after Typhoon Morakot. We use 71 short-period stations in the Central Weather Bureau (CWB) and 31508 CWB catalog events around Taiwan as the templates to scan through the continuous seismic data. We detect about 7 times as many events as in the standard CWB catalog. After relocation with the double-difference technique, there are about 3 times as many events as in the standard CWB catalog. In addition, we train a deep learning model to measure the P-wave first motion polarities for events in our newly built catalog. Based on these polarities, we calculate the focal mechanisms for about 2500 events. We observe a transient decrease of microseismicity during and in the following few weeks following Typhoon Morakot, likely due to high noise levels and station outage caused by the typhoon and associated rainfalls/landslides. We find a possible seismicity rate decrease of the normal-fault events after Morakot in the heavy-rainfall region. However, such changes are not clear for strike-slip and thrust-fault events. In summary, Our results do not show a clear change in microseismicity before/after Typhoon Morakot in the analyzed time period.

\section{Denoising Surface Waves Extracted From Ambient Noise Using Three-Station Interferometry: Methodology and Application to 1D Linear Array}

QIU, H., Rice University, Texas, USA, hq7@rice.edu; NIU, F., Rice University, Texas, USA, niu@rice.edu; QIN, L., University of Southern California, California, USA, qinl@usc.edu

We develop an automatic workflow for enhancing surface wave signals in ambient noise cross correlations (ANCs) calculated for a dense linear array. The surface wave signal traveling between each station pair is first enhanced through three-station interferometry. Then, phase travel times at different periods are measured in the frequency domain. The proposed array-based method is applied to a 1.6-km-long dense linear nodal array crossing surface traces of the San Jacinto fault near Anza, California. Surface wave signals in ANCs of the nodal array are significantly enhanced after denoising, particularly at high frequencies $(>2 \mathrm{~Hz})$. Phase travel times are extracted reliably in the period ranges of 0.3-1.3 s and 0.3-1.6 $\mathrm{s}$ for Rayleigh and Love waves, respectively. The corresponding period-dependent phase velocity profiles derived from the eikonal equation reveal high-resolution details of fault zone internal structures beneath the array. A broad (500-1000 m) low-velocity zone that narrows with increasing period is observed, illuminating a flower-shaped structure of the San Jacinto fault damage zone. 


\section{Evidence of Shallow Fault Zone Deformation in the} Ridgecrest Region From Ambient Noise Tomography ZHOU, Z., University of California, San Diego, California, USA, zhz039@ ucsd.edu; GERSTOFT, P., University of California, San Diego, California, USA, pgerstoft@ucsd.edu; BIANCO, M., University of California, San Diego, California, USA, mbianco@ucsd.edu; OLSEN, K. B., San Diego State University, California, USA, kbolsen@sdsu.edu

We perform ambient noise tomography using data recorded from Nodal arrays within a $\sim 50 \mathrm{~km}$ by $50 \mathrm{~km}$ area including the July 2019 M7.1 and M6.4 Ridgecrest, CA, earthquakes. The imaging uses a locally sparse tomography (LST) approach with unsupervised dictionary learning and least-squares regularization that directly learns from local patches without requiring a large volume of training data. We resolve a $1-5 \mathrm{~km}$ wide region of shallow low S-wave velocities, reduced by about $40 \%$ relative to the surrounding host rock, and localizing from the surface to at least $1 \mathrm{~km}$ depth. This low-velocity zone (LVZ), surrounding the fault traces for the M7.1 and M6.4 events, is surprisingly well correlated with the extent of the distributed faulting as mapped by differences between daily passes of the PlanetLabs Satellite imagery, suggesting a possible causative relationship between the imaged LVZ and the rupture sequence. Our imaged LVZ likely consists of a combination of shallow sediments/weathered rock and a damage zone associated with the causative faults for the M6.4 and 7.1 ruptures. Our imaging results are consistent with a heterogeneous flower structure of (predominantly shallow, $<\sim 1 \mathrm{~km}$ ) rock damage, as found in nonlinear models caused by plastic reduction in velocities. Our results from LST tomography are consistent with those from conventional least-squares while the LST method achieves a smaller misfit error.

\section{Near the Trench Seismic Activity Along the Guerrero Gap, Mexico Explored Through an OBS Network}

DOMINGUEZ, L. A., Universidad Nacional Autónoma de México, Mexico City, Mexico, ladominguez@ucla.edu; CRUZ-ATIENZA, V. M., National Autonomous University of Mexico, Mexico City, Mexico, cruz.atienza@gmail. com; ITO, Y., Kyoto University, Kyoto, Japan, ito.yoshihiro.4w@kyoto-u.ac.jp; TAIRA, T., University of California, Berkeley, California, USA, taira@berkeley. edu; VILLAFUERTE, C., National Autonomous University of Mexico, Mexico City, Mexico, villafuerte.cd@gmail.com; GARZA-GIRON, R., University of California, Santa Cruz, California, USA, ricky.gargir@gmail.com

The Guerrero Gap is a segment of the trench along the Mexican subduction zone that stands out by a long quiescent period $(>100 \mathrm{yr})$ void of large megathrust events and a large variety of transient phenomena (i.e. slow slip events, tremors, etc.). This area has been considered as the largest seismic risk in Mexico, although the actual seismic potential is still under debate. Recent deployment of a submarine seismic network provides a novel dataset to investigate how near the trench activity unfolds. In this study, we apply a Match Filter technique [Liu et al., 2020], along with fingerprint analysis (Yoon et al. 2015) to detect unreported seismicity near the trench in an effort to characterize the frictional properties that control the seismicity. Starting November 2017, a set of 7 OBS stations were deployed along the Guerrero Gap. Hence, we explore the combined results to investigate possible associations between the occurrence of repeating earthquakes, tremors and slow slip events. Results for the first year of data using a Match Filter approached found 2,946 events more events than the events reported in the local catalog (900 events).

\section{Novel Location Method for ETS Tremor in Northern Cascadia}

BOMBARDIER, M., University of Victoria, Victoria, Canada, mlbombardier@ uvic.ca; CASSIDY, J. F., Geological Survey of Canada, Sidney, Canada, john. cassidy@canada.ca; KAO, H., Geological Survey of Canada, Sidney, Canada, honn.kao@canada.ca; DOSSO, S., University of Victoria, Victoria, Canada, sdosso@uvic.ca

Episodic tremor and slip (ETS) in Cascadia is characterized by a transient reversal of long-term crustal movement and low-frequency, semi-continuous seismic signals. These near-annual episodes are generally considered to be related to subduction processes; however, the depths of tremor sources and their relation to the subduction interface remain uncertain. This study presents a modified version of the Seismicity-Scanning based on Navigated Automatic Phase-picking (S-SNAP) method (Tan et al., 2019), which is used to examine tremor source distribution. The modified S-SNAP method includes a sequence of the Source Scanning Algorithm (Kao and Shan, 2004), cross-correlation-based onset-time determination, the maximum intersection location technique (Font et al., 2004), and a maximum likelihood inversion. The modified S-SNAP method produces a selective catalogue of high-quality location solutions, each of which are represented by a $4 \mathrm{D}$ probability distribu- tion. Tremor from select recent episodes are located using all available seismic stations, including the PGC/IOS Seismic Array (PISA), and analyzed with respect to independent tremor locations and the subduction plate interface. The goal of this research is to locate ETS tremor with improved spatial resolution using no a priori information about source locations. Understanding the nature of tremor may improve our understanding of the Cascadia subduction zone structure and its potential for megathrust earthquakes.

\section{Successes, Challenges and Opportunities in Using Waveform Cross-Correlation for Volcano Monitoring} HOTOVEC-ELLIS, A. I., U.S. Geological Survey, California, USA, ahotovecellis@usgs.gov; THELEN, W. A., U.S. Geological Survey, Washington, USA, wthelen@usgs.gov; DAWSON, P. B., U.S. Geological Survey, California, USA, dawson@usgs.gov; SHIRO, B., U.S. Geological Survey, Colorado, USA, bshiro@usgs.gov; WELLIK, J. J., U.S. Geological Survey, Washington, USA, jwellik@usgs.gov; WECH, A. G., U.S. Geological Survey, Alaska, USA, awech@usgs.gov; PREJEAN, S. G., U.S. Geological Survey, Alaska, USA, sprejean@usgs.gov

Volcanoes produce repeating (i.e., highly correlated) earthquakes as part of their normal background seismicity and often at incredible rates prior to and during their eruptions. Research on many eruption datasets shows that using cross-correlation to build expanded catalogs and observing the behavior of individual families of events over time can provide valuable information about the volcano, such as its pressurization state, time to eruption, and plumbing architecture. Among the many challenges for volcano observatories is finding a way to deploy techniques from the research realm in a rapid, automated, and accessible manner while the volcano is in unrest. In this talk, we highlight the techniques and parameters from retrospective repeating earthquake analyses which show the most promise for near real-time monitoring (e.g., rate of new family creation, frequency content, repeater percentage of total seismicity). We will also discuss the current progress and challenges in implementing these techniques. In particular, we focus on the open-source code REDPy, its performance as a monitoring tool in the last five years and the path forward for improving it.

\begin{tabular}{l}
\hline Waveform Cross-Correlation-Based Methods in \\
Observational Seismology \\
Poster Session· Wednesday · 21 April · 3:45 PM Pacific \\
Session Chairs: Esteban J. Chaves, Volcanological and \\
Seismological Observatory of Costa Rica, Universidad \\
Nacional (esteban.j.chaves@una.cr); Zhigang Peng, Georgia \\
Institute of Technology (zpeng@gatech.edu); Marine Denolle, \\
Harvard University (mdenolle@g.harvard.edu); William \\
Frank, Massachusetts Institute of Technology (wfrank@ \\
mit.edu); Takảaki Taira, University of California, Berkeley \\
(taira@berkeley.edu); Haijiang Zhang, University of Science \\
and Technology of China (zhang11@ustc.edu.cn)
\end{tabular}

\section{A Cross-Correlation Algorthim for Detecting Small} Earthquakes in Frequency Domain

RAMIREZ PINA, C. R. P., Universidad Autónoma del Estado de México, Toluca, Mexico, carlos.ramz.pina@gmail.com; LEON SOTO, G. L. S., Universidad Michoacana de San Nicolás de Hidalgo, Morelia, Mexico, gleon. soto@gmail.com; HERNANDEZ SERVIN, J. H. S., Universidad Autónoma del Estado de México, Toluca, Mexico, xoseahernandez@gmail.com; ESCUDERO AYALA, C. E. A., Universidad de Guadalajara, Puerto Vallarta, Mexico, christian.escudero@cuc.udg.mx

We present a cross correlation algorithm in the frequency domain to detect seismic waveforms. A known seismic event (master event) is correlated with a one-day recording. This longer time series is split into smaller time windows. The master event is shifted along each window and cross correlation is computed for each step. Cross correlation is computed in the frequency domain using the cross correlation theorem under a Cauchy-Schwarz normalization. Possible candidates are selected defining a threshold ( 0.8 in our case) for further analysis. Transforming the selected candidates back to the time domain, we obtain a seismic signal. We link our waveforms to an automatic P-phase picker, location algorithm, double-difference relocation code, and a coda magnitude calculator. We used 293 master events from a previ- 
ous catalog in western Mexico. The dataset analyzed was a temporal Passcal experiment (CODEX) that was in operation from January 2006 to December 2007. It consisted of 22 broadband stations located around the Colima volcanic complex. Only the vertical component was taking into account. We could identify 1003 total events ranging in coda magnitude from 1.2 to $3.8 \mathrm{Mc}$. Our algorithm, as compared to free software codes; e.g. python (Obspy, Numpy, Scipy, matplotlib, pandas), has shown be more time efficient locating small magnitude events (down to $\sim 1.2 \mathrm{Mc}$ ). Our code is written in free software and soon will be publicly available.

\section{Analysis of Repeating Earthquakes Near the Locking Transition of New Zealand's Hikurangi Subduction Zone}

PITA-SLLIM, O. D., Victoria University of Wellington, Wellington, New Zealand, oliv.dayanara@gmail.com; CHAMBERLAIN, C. J., Victoria University of Wellington, Wellington, New Zealand, calum.chamberlain@ vuw.ac.nz; TOWNEND, J., Victoria University of Wellington, Wellington, New Zealand, john.townend@vuw.ac.nz

The Hikurangi subduction zone beneath eastern North Island, New Zealand, exhibits a variety of fault-slip related phenomena. The northern Hikurang margin hosts shallow slow-slip and is weakly coupled to shallow depths on inter-seismic timescales. In contrast, the southern Hikurangi margin is strongly coupled beneath the southern North Island, and only deep slow-slip has been observed. The transition in coupling occurs beneath the township of Porangahau, and is an exemplary focus region for studying how this alongstrike change in locking is accommodated.

To examine slip processes at this key transition zone, we have constructed and analysed a catalogue of repeating earthquakes that occurred over a period of 14 years between 2004 and 2018. To build our catalogue we first clustered GeoNet's extensive earthquake catalogue by distance and correlation using weak constraints to identify potentially repeating events. We then used a stronger cross-correlation threshold of at least 0.95 normalised cross-correlation on three or more stations to identify repeating earthquakes from the initial clusters. This threshold was determined by our group's previous work on the northern Hikurangi margin.

We computed precise absolute locations and focal mechanisms of all 225 families and their constituent earthquakes via a combination of manual phase-picking and cross-correlation pick-correction. This analysis yields 225 families of 532 repeating earthquakes, with some of them containing as many as nine events in the span of $>10$ years. Because repeating earthquakes represent cyclic loading, they can be used to detect temporal and spatial changes of slip-rate at depth and hence monitor how stress is transferred to seismogenic zones. This analysis of repeating earthquakes and their changes in time improves our understanding of how the Hikurangi subduction zone is being loaded at this transition zone.

\section{Clusty, A Versatile Waveform-Based Network Similarity Clustering Toolbox}

NIEMZ, P., GFZ German Research Centre for Geosciences, Potsdam, Germany, pniemz@gfz-potsdam.de; PETERSEN, G. M., GFZ German Research Centre for Geosciences, Potsdam, Germany, gesap@gfz-potsdam.de; CESCA, S., GFZ German Research Centre for Geosciences, Potsdam, Germany, cesca@ gfz-potsdam.de; MOUSLOPOULOU, V., National Observatory of Athens, Institute of Geodynamics, Athens, Greece, vasiliki.mouslopoulou@noa.gr; BOCCHINI, G., Ruhr University of Bochum, Institute of Geology, Mineralogy and Geophysics, Bochum, Germany, gianmaria.bocchini@gmail.com

Clusty is an open-source toolbox for earthquake clustering based on event waveform similarity developed to identify and characterize active faults and fault networks. It is highly versatile with possible applications in complex tectonic regions but also in studies of acoustic emissions from small-scale experiments. The toolbox includes several techniques to compute network-based event similarities based on cross-correlations of waveforms recorded by a network of seismic stations. The density-based clustering allows the identification of events pertaining to a common fault over long segments. The clustering procedure is transparent thanks to several graphical outputs visualizing the homogeneity within each cluster and the differences between distinct clusters. Here, we present results of two case-studies over two different scales:

(1) The aftershock sequence of the Mw 6.92018 Zakynthos (Greece) Earthquake. The western termination of the Hellenic Subduction System is known for its complex tectonics. Our clustering results confirm the activation of multiple faults of various kinematics and complex geometric configurations. Based on our results we can identify the causative fault plane of representative focal mechanisms and assign them to individual active faults.

(2) A decameter-scale injection experiment conducted at Äspö Hard Rock Laboratory, Sweden. Here, we apply the clustering toolbox to acoustic emissions detected during high-pressure water injections into granitic rock to gain insight into the growth of hydraulic fractures.

Even in applications where the mechanisms of single events might be unknown, as in the second case study, the waveform-based clustering allows the identification of event clusters that cannot be discriminated based on locations or origin times alone.

\section{Determination of the Near Surface Shear Wave Velocities in the Central Los Angeles Basin Using Dense Arrays}

IA, Z., Caltech, California, USA, zjia@caltech.edu; CLAYTON, R. W. Caltech, California, USA, clay@gps.caltech.edu

We investigate the shallow shear wave velocity structure of the Los Angeles Basin in southern California, using ambient noise correlations between five dense arrays and 21 broadband stations from the Southern California Seismic Network (SCSN). We observe clear fundamental mode and first overtone Rayleigh waves in the frequency band $0.25-2.0 \mathrm{~Hz}$, and obtain group velocity maps through seismic tomography. We further derive a $3 \mathrm{D}$ shear wave velocity model, covering a large portion of the central LA Basin for the depths shallower than $3 \mathrm{~km}$. We found that the small scale shallow velocity structure heterogeneities are better resolved compared with the SCEC Community velocity models. Our model captures the presence of the Newport-Inglewood fault by a NW-SE trending high velocity belt. Our model provides more accurate constraints on local ground motion predictions with detailed mapping of structural heterogeneities.

\section{New Microearthquake Catalog for the Parkfield Section of the San Andreas Fault, California}

NEVES, M., Georgia Institute of Technology, Georgia, USA, mjneves@gatech. edu; PENG, Z., Georgia Institute of Technology, Georgia, USA, zpeng@gatech. edu; LIN, G., University of Miami, Florida, USA, glin@rsmas.miami.edu

We present an updated earthquake catalog for the Parkfield section of the San Andreas Fault, California, spanning from December 2003 to March 2005. Although Parkfield is one of the best seismically instrumented regions, recent studies have shown that catalogs for the area are incomplete due to missing lower magnitude events, especially after the 2004 M6 Parkfield earthquake. The new catalog was compiled using a matched filter detection technique. We use the waveforms of more than 10000 earthquakes from high-quality relocated catalogs recorded at the High-Resolution Seismic Network (HRSN). Detection was performed filtering data between $2-8 \mathrm{~Hz}$ and using a detection threshold of 12 times the Median Average Deviation to the daily cross-correlation functions. For a more robust detection we also included earthquakes from adjacent regions in the 10000 templates, for example aftershocks from the 2003 M6.5 San Simeon earthquake, and removed these detections from the final catalog. To relocate the detected catalog, we used waveform crosscorrelation location package XCORLOC adding waveforms from other seismic networks in the region for better constraint.

The time span of the new relocated catalog includes local earthquakes such as the 2004 M6 Parkfield and the 2003 M6.5 San Simeon earthquake and the 2004 M9.2 Sumatra earthquake at teleseismic distances. We will use the catalog to investigate and understand spatio-temporal evolutions of aftershocks following the 2004 M6 earthquake and how stress changes imposed from regional and remote earthquakes affect local seismicity. In addition, we plan to use the new catalog to better understand different microearthquake behaviors and seismogenic structures in the locked and creeping sections. Updated results will be presented at the meeting.

\section{Persistent Seismicity and Missing Eruptivity: Analysis and Classification of 2003-2019 Earthquakes Recorded at Gareloi Volcano, Aleutian Islands, Alaska}

HARRIS, K. T., Western Washington University, Washington, USA, harri243@ wwu.edu; CAPLAN-AUERBACH, J., Western Washington University, Washington, USA, caplanj@wwu.edu; POWER, J. A., Alaska Volcano Observatory, U.S. Geological Survey, Alaska, USA, jpower@usgs.gov

Mount Gareloi, one of the westernmost volcanoes in the Aleutian arc, has not erupted since 1989, yet it displays extremely high levels of volcanic seismicity on a daily basis. Hundreds of earthquakes are recorded per day on the island since seismometer installation in 2003. We analyzed and classified seismic data collected from 2003-2019 to explore the geophysical processes causing the consistent seismicity with no subsequent eruptive activity. Analysis of waveforms and their corresponding spectra indicate the vast majority of Gareloi earthquakes are characterized by frequencies between 1 and $4 \mathrm{~Hz}$, which are typical of long period (LP) events. Approximately 5,900 earthquake hypocenters calculated by the Alaska Volcano Observatory (AVO) were relo- 
cated using the algorithm hypoDD. From 2003-2007, hypocenters locate shallowly between 2 and 10 kilometers depth, while seismicity from 2016-2019 was broadly deeper, between 6 and 16 kilometers depth and included significantly more high frequency (HF) events. Although relocated hypocenters have similar spatial distribution to the initial locations, events from 2003-2007 cluster more tightly and vertically beneath the island, whereas events from 2016-2019 are more scattered through the region with no obvious clustering Unfortunately, the seismic network experienced numerous station failures from 2008-2015, resulting in inconsistencies within the AVO catalog. Thus, we cannot accurately determine when the transition to deeper, more scattered hypocenters and the increase in HF events occurred. Cross correlation of waveforms provides evidence of repeating LP earthquakes directly associated with Gareloi from May through July of 2007 and few repeating earthquakes from 2008-2019. Based on these analyses, we attribute the shallow LP events of 2003-2007 to volcanic processes while the shift to deeper hypocentral depths coincides with the increase in HF activity and may reflect a change in the magmatic system at Gareloi.

\section{Seasonal Variations of Seismic Velocity From Air Gun and Ambient Noise Data in the Binchuan, Yunan, China}

LIU, C., Chinese University of Hong Kong, Shenzhen, China, cyliu@cuhkri. org.cn; YANG, H., Chinese University of Hong Kong, Hong Kong, hyang@ cuhk.edu.hk

Since 2011, a large-volume air-gun source has been deployed in Binchuan, Yunnan, China for monitoring fault zone at depth. We use repeated air-gun waveforms in the passband of 2-6 Hz to derive seasonal variations of $\mathrm{dt} / \mathrm{t}$ of $\mathrm{P}$ and $\mathrm{S}$ waves. We also use ambient noise data in the same frequency range to study seasonal variations of $\mathrm{dt} / \mathrm{t}$ of scatter waves. Monitoring $\mathrm{dt} / \mathrm{t}$ of body and scatter waves in the same frequency ranges, we expect to explore the possibility of using air-gun waveforms to reveal seasonal changes of crustal behavior. We deconvolve 28 stations from a reference station near the shooting site to retrieve Green's functions and compute seismic velocity changes through the moving-window-cross-spectra method. We observe that 1) amplitude of body wave generally increases in the summer; 2) seasonal variations of $\mathrm{dt} / \mathrm{t}$ of $\mathrm{P}$ and $\mathrm{S}$ waves correlate with variations of the amplitude of them; and 3) Some $\mathrm{dt} / \mathrm{t}$ show positive correlation with the amplitude while others show negative relationship, which illustrates the importance of local crustal response. However, to specifically understand how the crust responds to external loadings, we need to better understand the excitation behavior of air-gun sources. We will further compute seasonal variations of $\mathrm{dt} / \mathrm{t}$ of scatter wave and compare them with changes of body wave to reveal physical meaning behind it.

\section{Shallow Crustal Shear Velocity and Vp/Vs Across Southern California: Joint Inversion of Short-Period Rayleigh Wave Ellipticity, Phase Velocity and Onset of Teleseismic Receiver Functions}

BERG, E. M., University of Utah, Utah, USA, eliza.m.berg@gmail.com; LIN, F., University of Utah, Utah, USA, fanchi.lin@utah.edu; SCHULTE-PELKUM, V., University of Colorado, Colorado, USA, vera.schulte-pelkum@colorado. edu; ALLAM, A., University of Utah, Utah, USA, amir.allam@utah.edu; QIU, H., Rice University, Texas, USA, hq7@rice.edu

We use 231 stations across Southern California to jointly constrain Vp/Vs and shear velocities in the near-surface through a Bayesian inversion of three datasets with complementary sensitivities. These datasets include the onset of teleseismic receiver functions, short-period ambient-noise derived Rayleigh phase velocities, and ellipticity dispersions. We fit all three datasets through the inclusion of a $\mathrm{Vp} / \mathrm{Vs}$ parameter for the near-surface layer, and find strong correlation between short-period Rayleigh-wave ellipticity and apparent onset delay $(0-2 s)$ of receiver functions. In particular we fit receiver functions with a delayed initial peak due to sedimentary basin reverberations, which have long been considered a nuisance to deeper imaging studies. Our updated Southern California model includes upper crust to near-surface $(<10 \mathrm{~km})$ shear velocities, and near-surface $\mathrm{Vp} / \mathrm{Vs}$ ratios. Our model shows near-surface low shear velocity more in line with geotechnical layer estimates, and generally lower than expected $\mathrm{Vp} / \mathrm{Vs}$ outside the basins suggesting widespread shallow frac- turing and/or groundwater undersaturation. This finding is critical to seismic hazard assessment; local $\mathrm{Vp} / \mathrm{Vs}$ ratio strongly influences the amplitude of Rayleigh waves to a greater extent than the shallow near-surface Vs alone. In addition to self-consistent shallow constraint and regional coverage, the applied Markov Chain Monte Carlo inversion fully quantifies data sensitivity and uncertainty.

\section{Signatures of Seismic Waveguides in Los Angeles From Numerical Simulations and Noise Cross Correlations}

WANG, N., San Diego State University, University of California, San Diego, California, USA, naw021@ucsd.edu; SCHMITT, J., Harvard University Massachusetts, USA, jschmitt@college.harvard.edu; DENOLLE, M., Harvard University, Massachusetts, USA, mdenolle@uw.edu; OLSEN, K. B., San Diego State University, California, USA, kbolsen@sdsu.edu; CLEMENTS, T., Harvard University, Massachusetts, USA, thclements@g.harvard.edu; ERMERT, L., Harvard University, Massachusetts, USA, lermert@g.harvard. edu; CLAYTON, R. W., Caltech, California, USA, clay@gps.caltech.edu

Waveguides are confined geological units capable of channeling and focusing seismic energy over long distances. In the Los Angeles (LA) area, 3D simulations (e.g., TeraShake, ShakeOut) suggest that the presence of such waveguides caused by the connectivity of the sedimentary basins (Los Angeles - San Gabriel - Chino - San Bernardino) strongly increases ground motion predictions for large, northwestward ruptures on the southern San Andreas fault (SAF). However, the efficiency in focusing and increase in ground motions due to the waveguides depend on the accuracy of the basin structure in the velocity models.

In this project, we attempt to validate the presence of several waveguides in the LA region, as indicated by $3 \mathrm{D}$ earthquake simulations, with observed data from earthquakes and ambient noise. Using over 700 temporary (nodal and broadband) and permanent (SCSN) stations as receivers, and 14 station sources located along the SAF as virtual sources, we calculate and compare all 9 components of the correlation and Green's function tensor. We calculate over $\sim 40,000$ correlations. We compare the numerical and empirical surfaceto-surface Green tensors for small earthquakes that are located nearby stations, and for virtual sources located on the SAF. The regions of large peak motions caused by waveguide focusing in the simulations show generally good agreement with increases in the Green tensor amplitudes, supporting the presence of two separate waveguides in greater LA. Analysis of the cross terms and particle motions confirm that $0.1-0.5 \mathrm{~Hz}(2-10 \mathrm{~s})$ surface waves play the most important role in the waveguide focusing.

\section{The Scattering Signal in Ambient Noise Correlation}

LI, Y., Caltech, California, USA, yidali@caltech.edu; CLAYTON, R. W., Caltech, California, USA, clay@gps.caltech.edu

The ambient noise correlation has been a powerful tool to extract seismic signals. Often the correlation function contains a direct wave Green's function and a strong scattered signal due to discontinuities in the medium. The direct wave Green's function contains the travel time information and can therefore be used for tomography. The scattering signal can be used to locate abrupt discontinuities such as steep structural boundaries or faults.

Between 2017 and 2019, several dense arrays were deployed in the San Gabriel basin and San Bernardino Basin. We have correlated both dense array-dense array station pairs and dense array-broadband station pairs. In the correlation function, both direct wave Empirical Green's Function and scattering signal can be observed. We extracted the surface wave dispersion curve from the direct wave Green's Function to construct the velocity model, using Rayleigh and Love waves, with both fundamental mode and first-higher mode. We have initially use group velocities but plan to include phase velocities to improve the resolution. Using the velocity model from direct wave Green's function, we developed an approach to invert for the near field noise source distribution using the scattering signal. The inverted noise source distribution, shows a strong spatial correlation with the fault structure and the basin edges. This technique provides a new method for locating faults, some of which may have no surface expression. 


\section{What Can We Infer About the Earthquake Source Through Analyses of Strong Ground Motion? \\ I: Oral Session · Wednesday · 21 April · 9:45 AM Pacific \\ II: Oral Session · Wednesday · 21 April · 2:00 PM Pacific \\ Session Chairs: Ralph J. Archuleta, University of California, \\ Santa Barbara (ralph.archuleta@ucsb.edu); Joe Fletcher, U.S. Geological Survey (jfletcher@usgs.gov); Greg Beroza, Stanford University (beroza@stanford.edu)}

A Slip Model and Stress Drops From Source Time Functions for a M4.5 Aftershock of the Ridgecrest Earthquake FLETCHER, J. B., U.S. Geological Survey, California, USA, jfletcher@usgs. gov; ERDEM, J. E., U.S. Geological Survey, California, USA, jerdem@usgs. gov; BAKER, L. M., U.S. Geological Survey, California, USA, baker@usgs.gov

We determine a slip model for a M4.5 aftershock from the 2019 Ridgecrest earthquake sequence using source time functions (STFs). To obtain the STFs, we deconvolve a smaller magnitude earthquake from collocated main shock using an iterative least-squares procedure in the time domain with positivity constraints. The STFs are smoothed envelopes of the sub-events required to reproduce the wave form of the main event. We use accelerograms from 13 permanent and temporary accelerometer stations with good azimuthal distribution. We used a M2.7 aftershock as an empirical Green's function that was about $0.3 \mathrm{~km}$ from the composite earthquake. These shocks occurred about one and one half weeks after the mainshocks and allowed us to use data from two deployments of portable recorders. The STFs exhibit directivity to the northwest with STFs narrower to the northwest and broader and more complex to the southeast. In the forward direction, the STFs are mostly symmetrical pulses that are about $0.8 \mathrm{~s}$ long. The STFs are inverted for slip and rupture time with a tomographic algorithm that uses a high-frequency approximation to far-field ray theory for the forward problem. Slip is concentrated in a narrow region from the hypocenter to about $0.7 \mathrm{~km}$ to the northwest. Regions of more diffuse slip circle the peak slip with a diameter of about $3.0 \mathrm{~km}$. Slip accelerates from the hypocenter towards the northwest with fairly high rupture velocities for the first 0.5 second. We calculate static stress drops from the slip distribution by applying Okada's formula that associates stress with slip in a half space. We obtain a peak value of about 40 bars just northwest of the hypocenter, but the static stress drop is quite heterogeneous with an average over the main slip plane of 2 bars.

\section{Characterizing Multi-Subevent Earthquakes Using the Brune Source Model}

LIU, M., University of Michigan, Michigan, USA, meichenl@umich.edu; HUANG, Y., University of Michigan, Michigan, USA, yiheh@umich.edu; RITSEMA, J., University of Michigan, Michigan, USA, jritsema@umich.edu

Brune source model has been widely used in ground motion prediction and source parameter estimation by describing the source process as a single pulse with a characteristic corner frequency. However, one pulse could be oversimplified for moderate to large earthquakes when $80 \%$ of $\mathrm{Mw}>5.5$ earthquakes in the SCARDEC Source Time Functions Database are found to have multiple pulses that represent subevents in the rupture process (Danr et al., 2019).

Here we investigate the performance of Brune source model in characterizing complex earthquake sources. We first decompose source time functions in the SCARDEC database into summations of multiple Brune sources. Through the decomposition we obtain source parameters including the seismic moment, corner frequencies, and onset times of each subevent, such that we are able to compare subevents to the master events. We then select earthquakes identified with 2 subevents and explore the ranges of source parameters. We then build synthetic two-subevent source time functions varing source parameters accordingly. We generate synthetic waveforms of the twosubevent earthquakes and an empirical Green's function using the FrequencyWavenumber (FK) method. We fit the corner frequency of the master event using the spectral ratio method. In both SCARDEC database analysis and the synthetic test, the master event corner frequency is more related to the subevent with a larger seismic moment. We also find that the order of subevents matters, in which case the corner frequency of the master event is systematically higher when the larger subevent occurs first than when the smaller subevent occurs first.
Rupture Complexity of Small and Moderate Earthquakes in the 2019 Ridgecrest Earthquake Sequence and the Effects on Stress Drop Estimation and Ground Motions

WU, Q., Lettis Consultants International, Inc., California, USA, wu@lettisci. com; CHEN, X., University of Oklahoma, Oklahoma, USA, xiaowei.chen@ ou.edu

It is well known that many larger earthquakes have highly complex rupture processes with significant variation in slip and stress drop over the rupture plane. As the quantity and quality of data increase, similar source complexity is being observed for well-recorded smaller earthquakes. In this study, we attempt to show evidence for complex rupture processes in earthquakes of $M$ 2-5 using both time and frequency domain analyses, and investigate how such source complexity depends on structural complexity and affects stress drop estimates and strong ground motions.

We systematically analyze the abundant instrumental seismic data recorded for the 2019 Ridgecrest earthquake sequence, which occurred within zones of complex and distributed fault system within the eastern California shear zone (ECSZ), to explore the source complexity involved in the rupture processes of small to moderate earthquakes $(M \sim 2-5)$. We combine both frequency and time domain analyses based on the empirical Green's function (EGF) technique to investigate the characteristics of source complexity for these earthquakes. In the frequency domain, we apply the multiple spectral ratio method on all potential target events with $M \geq 2$ in the Ridgecrest sequence. We quantify the complexity of the stacked spectral ratios by examining their deviation from the simple omega-square source model. In the time domain, we apply an iterative deconvolution method to retrieve relative source time functions (RSTFs), from which we can quantify possible directivity effects and the existence of multiple subevents. Our results will contribute to a better understanding of fundamental earthquake rupture processes, and the limitations of Brune-type simple source model in estimating source parameters such as stress drop and source dimension and the influence on ground motion predictions.

\section{Stress Drops Estimates of the 2019 Ridgecrest Aftershock Sequence Based on Finite Source Modeling}

MAGANA, I. A., Berkeley Seismological Laboratory, California, USA, josemagana@berkeley.edu; DREGER, D. S., University of California, Berkeley, Berkeley Seismological Laboratory, California, USA, ddreger@berkeley.edu; TAIRA, T., Berkeley Seismological Laboratory, California, USA, taira@ berkeley.edu

The connection between the strength of tectonic faults and the earthquake rupture is central to studies of the physics of earthquakes. Finite-source models of the M6.1 foreshock and M7.0 mainshock (e.g. Kang et al., 2020) report slow rupture velocity suggesting relatively high fracture energy in rupturing an immature and geometrically complex fault. Here we investigate the stress drop of the aftershocks comparing with estimates from finite source models of the foreshock and mainshock. We use an empirical Greens function (EGF) derived moment rate function inversion method (Mori and Hartzell, 1990; Dreger, 1996) to determine the causative rupture plane of aftershocks, the slip distribution, and the stress change (e.g. Ripperger and Mai, 2004). Possible EGF events will be identified through relative event location, crosscorrelation, and recovery of moment rate pulses from the EGF deconvolution. Seismic moment tensor solutions will be reviewed or determined as needed for specific target and EGF events, and both possible nodal planes will be tested in the moment rate inversion (e.g. Mori and Hartzell, 1990). The derived best fitting fault planes and slip distributions will be used to determine the stress change (Ripperger and Mai, 2004). We will explore the rupture area and slip scaling of the sequence and compare with existing scaling relationships and results for different earthquake sequences.

\section{What Can the Data Inform Us About the Earthquake Source? \\ ARCHULETA, R. J., University of California, Santa Barbara, California, USA, ralph.archuleta@ucsb.edu}

It has been 53 years since Aki (1968) published the first paper to infer source parameters of an earthquake (1966 Parkfield) by synthesizing near-source strong motion records from a kinematic simulation. Although methods for analysis were being developed, there were only a few large magnitude earthquakes that had been well recorded on-scale by near-source seismometers and accelerometers in the following two decades (1970-80's). As the instrumentation increased, so have the methods of analysis and the number of papers with inferences about the properties of the source. The most obvious change since Aki's 1968 paper, is the spatial heterogeneity of the kinematic param- 
eters: slip, slip rate, rupture velocity, rise time. In his seminal paper Haskell (1964) had proposed a constant slip function and constant rupture velocity as a starting point. He clearly knew that the parameters spatially varied on the fault (Haskell, 1966). With the development of efficient inversion methods, kinematic models are routinely produced for every significant earthquake. What features are robust? What features are required by the data? How much uncertainty is there for any inferred property at any point on the fault? Such questions have consequences for inferences about the physics of the rupture, e.g., slip weakening distance, breakdown work, rupture velocity, variability. Many outstanding scientists have contributed to our body of knowledge about the earthquake process. I will look at some of the work of Dr. Paul Spudich and his impact. His work covers a broad area and examines the source with different methods to get the most robust result from the data. Spudich recognized that an excellent match between a synthetic and a recorded ground motion time history does not necessarily indicate a well-resolved source description. Spudich was focused on how one can assess the quality of the model and move forward in interpreting the earthquake process.

\section{High-Frequency Rupture Processes of the Mw 8.2 Iquique and Mw 8.3 Illapel, Chile Earthquakes Determined from Strong Motion Recordings}

FRANKEL, A., U.S. Geological Survey, Washington, USA, afrankel@usgs.gov

I determined the locations, extents, and rupture propagation of high-frequency sub-events of the $2014 \mathrm{M}_{\mathrm{w}} 8.2$ Iquique and $2015 \mathrm{M}_{\mathrm{w}} 8.3$ Illapel, Chile earthquakes using strong motion recordings from the National Seismological Center, University of Chile, seismic network. These sub-events radiated most of the seismic energy of these earthquakes at frequencies above $0.3 \mathrm{~Hz}$ and were located down dip of the areas of peak coseismic slip. For the Iquique earthquake, southward rupture propagation is directly observed from moving window cross correlations of waveforms from a dense array of accelerometers. Analysis of the array recordings indicates that the source of radiated high-frequency energy $(-1 \mathrm{~Hz})$ was located down dip of the source of low frequency energy $(-0.1 \mathrm{~Hz})$. The rupture for both frequency bands propagated southward at about the same speed. Large aftershocks that occurred 30-40 s after the Iquique main shock were also identified from the cross correlations of array recordings. I fit envelopes of the high frequency accelerograms $(>=1$ $\mathrm{Hz}$ ) for both Mw 8 earthquakes using a nonlinear inversion to determine the locations and strengths of sources of high-frequency radiation on the rupture zones. Aftershock waveforms were applied as empirical Green's functions when constructing the synthetic envelopes for the inversion. Two distinct subevents were observed in the Illapel earthquake, one just north and down dip of the hypocenter and one at about $50 \mathrm{~km}$ depth, down dip of the hypocenter. Ratios of the Fourier spectra of the mainshock and aftershock indicate that the apparent high-frequency $(f)$ fall-offs of the displacement spectra of the Illapel earthquake vary from $f^{-1}$ to $f^{-2}$ from 0.1 to $1 \mathrm{~Hz}$ and depend on rupture directivity. These observations are important for accurately predicting strong ground motions for future $\mathrm{M}_{\mathrm{w}}-8$ subduction-zone earthquakes and understanding rupture dynamics.

\section{Modelling the Ground-Motion Directivity Effects for Non-Ergodic Scenarios in Central Italy}

COLAVITTI, L., Istituto Nazionale di Geofisica e Vulcanologia, Milano, Italy, leonardo.colavitti@ingv.it; LANZANO, G., Istituto Nazionale di Geofisica e Vulcanologia, Milano, Italy, giovanni.lanzano@ingv.it; SGOBBA, S., Istituto Nazionale di Geofisica e Vulcanologia, Milano, Italy, sara.sgobba@ingv. it; PACOR, F., Istituto Nazionale di Geofisica e Vulcanologia, Milano, Italy, francesca.pacor@ingv.it; GALLOVIČ, F., Charles University, Prague, Czech Republic, gallovic@karel.troja.mff.cuni.cz

We develop a non-ergodic empirical predictive model of the acceleration Fourier ordinates (FAS) in Central Italy to capture the anisotropic distribution of ground motion amplitudes due to fault rupture directivity. We extend the model of Sgobba et al. (2020) proposed for the peak ground acceleration (PGA) and the linear elastic acceleration response spectral ordinates (SA) in the range from 0.5 to $25 \mathrm{~Hz}$ with the $5 \%$ damping.

The dataset used for the model calibration consists of more than 30 '000 high-quality waveforms from about 450 earthquakes in the magnitude range from 3.4 to 6.5 and more than 460 stations within $120 \mathrm{~km}$ epicentral distance. The dataset is related to the events recorded in Central Italy from 2008 to 2018.

With our model, we adjust the median prediction with several corrective terms accounting for the systematic effects related to events, sourceregions, sites and source-to-site paths. We investigate the residuals' azimuthal variation of the corrections for the event, source, site, and path effects. These variations are modelled as source-directivity contributions by the directivity function Cd (Pacor et al., 2016; Wang et al., 2016). We find that the directivity effects do not occur uniformly in the entire investigated frequency band: the events with smaller magnitude $(\mathrm{M}<4.0)$ show directivity amplification at higher frequencies $(>10 \mathrm{~Hz})$, while the stronger earthquakes exhibit more significant effects only at intermediate frequencies.

The azimuthal directions with the greatest increase of the ground motion corresponding, on average, to the strike angles of the main active faults in the Central Apennines. Among all the events detected with a relevant directivity component, about $50 \%$ show increases in seismic motion northwards and the remaining 50\% southwards, suggesting that there is no preferential direction for the rupture propagation in Central Italy. We aim to parameterize the directivity amplification by a function of magnitude and source parameters, and implement it in the predictive ground motion model.

\section{Near-Field Corner Frequency Analysis of Data-Integrated Large-Scale Dynamic Rupture Simulations of the 2019 Ridgecrest and the 1992 Landers Earthquakes}

SCHLIWA, N., Ludwig-Maximilians Universität, Munich, Germany, nico. schliwa@geophysik.uni-muenchen.de; GABRIEL, A., Ludwig-Maximilians Universität, Munich, Germany, gabriel@geophysik.uni-muenchen.de; TAUFIQURRAHMAN, T., Ludwig-Maximilians Universität, Munich, Germany, taufiqurrahman@geophysik.uni-muenchen.de

The rise of Distributed Acoustic Sensing and high-rate GNSS networks highlight the potential of dense ground motion observations in the near-field of large earthquakes. Physics-based spontaneous dynamic rupture simulations can provide high-resolution synthetic waveforms accounting for non-linear source, path and site complexity. We present spectral analysis of $>100,000$ synthetic near-field strong motion waveforms (up to $2 \mathrm{~Hz}$ ). The waveforms are generated in observationally constrained geometrically complex 3-D dynamic rupture simulations of the 2019 Ridgecrest sequence and the 1992 Landers earthquake (Taufiqurrahman et al., 2020; Wollherr et al., 2019), which incorporate 3-D fault geometry, high resolution topography, plastic off-fault deformation, and 3-D velocity models. We find that the spectral corner frequency may serve as a scalar proxy, which, when available with high-spatial resolution in the near-field, contains information about on-fault slip distribution, rupture directivity, fault segmentation, seismic moment, and path effects.

We generate high resolution maps of corner frequencies $\left(f_{c}\right)$ determined by minimizing the misfit between the displacement spectra and the Brune model. For the analyzed dominantly strike-slip events $f_{c}$ of the vertical component reveals rays of elevated corner frequencies radiating from each slipping fault in rupture forward direction. These rays indicate high accumulated slip and trace the curvature of the segmented fault systems as well as path effects such as wavefield deflections at strong velocity contrasts. A shadow zone in backwards direction of the $M_{w} 6.4$ Searles Valley foreshock indicates a unilateral rupture, whereas the ray structure of the $M_{w} 7.1$ event agrees with its bilateral rupture. Our findings highlight the future potential of spectral analysis of spatially dense (low frequency) ground motion observations for inferring earthquake kinematics and understanding earthquake physics directly from near-field data; while synthetic studies are crucial to identify "what to look for" in the vast amount of data generated.

\section{Source Physics Interpretation of Non-Self-Similar Double- Corner Frequency Source Spectral Model JA19_2S}

II, C., University of California, Santa Barbara, California, USA, ji@geol.ucsb. edu; ARCHULETA, R. J., University of California, Santa Barbara, California, USA, ralph.archuleta@ucsb.edu

Source spectral models developed for strong ground motion simulations are phenomenological models that represent the average effect that the source processes have on near fault ground motion. Their parameters are directly regressed from the observations and often do not have clear meaning for the physics of the source process. We investigate the relation between the kinematic double-corner frequency (DCF) source spectral model JA19_2S (Ji and Archuleta, BSSA, 2020)and static fault geometry scaling relations proposed by Leonard (2010). We derive scaling relations for the low and high corner frequency in terms of static stress drop, dynamic stress drop, fault rupture velocity, fault aspect ratio, and relative hypocenter location. We find that the non-self-similar low corner frequency scaling relation of JA19_2S model for $5.3<M<6.9$ earthquakes is well explained using the fault length scaling relation of Leonard's model combined with a constant rupture velocity. Earthquakes following both models have constant average static stress drop and constant average dynamic stress drop. The high frequency source radiation is controlled by seismic moment, static stress drop and dynamic stress drop but strongly modulated by the fault aspect ratio and the hypocenter's relative location. The mean, scaled energy (or apparent stress) decreases with magnitude 
due to the magnitude dependence of the fault aspect ratio. Based on these two models, the commonly quoted average rupture velocity of $70-80 \%$ of shear wave speed implies predominantly unilateral rupture.

\section{What Is the Magnitude in Earthquake Early Warning?}

BALTAY, A., U.S. Geological Survey, California, USA, abaltay@usgs.gov; HANKS, T. C., U.S. Geological Survey, California, USA, thanks@usgs.gov

We explore the link between earthquake stress drop, high-frequency ground motions, and various magnitude estimates, in particular those generated in earthquake early warning (EEW) systems from the first few seconds of the $\mathrm{P}$ wave. Moment magnitude is the zero-frequency measure of an earthquake; any other magnitude is based on higher-frequency ground motions. The difference between moment magnitude and local magnitude, for example, should reflect the relative stress drop of that event with respect to the average stress drop of the region. In source-based EEW algorithms, such as ShakeAlert's EPIC, the first few seconds of the $\mathrm{P}$ wave are integrated to displacement and used in an empirical correlation with the catalog magnitude to generate a rapid magnitude estimate. To issue alerts, the magnitude and location are combined with ground-motion prediction equations (GMPEs) to estimate the extent of a desired threshold of shaking. GMPEs are based on moment magnitude, and high-frequency event-based deviations from the model are attributed to stress drop. EEW magnitudes are often biased compared to the catalog magnitudes, especially in the very early part of the waveform; because they use a short time window of $\mathrm{P}$ wave, the estimated magnitudes will reflect high-frequency motions and may be more similar to local magnitude. We consider a database of California earthquakes for which the ShakeAlert system was operative and correlate the time-dependent EEW magnitudes with catalog moment, local, and body-wave magnitudes. We also estimate high-frequency (i.e., PGA) GMPE event terms for each earthquake, and search the literature for independent estimates of stress drop to determine the extent to which EEW magnitudes are reflecting stress drop. If the error in EEW magnitude actually propagates into a more correct GMPE prediction, this implies that the magnitude bias is actually accounting for any deviations in earthquake stress drop. Thus this "high-frequency" EEW magnitude is a better predictor than moment-magnitude of the high-frequency ground motions for which ShakeAlert aims to warn.

\section{What Can We Infer About the Earthquake Source Through Analyses of Strong Ground Motion? \\ Poster Session · Wednesday · 21 April · 3:45 PM Pacific \\ Session Chairs: Ralph J. Archuleta, University of California, Santa Barbara (ralph.archuleta@ucsb.edu); Joe Fletcher, U.S. Geological Survey (jfletcher@usgs.gov); Greg Beroza, Stanford University (beroza@stanford.edu)}

\section{A Community Stress Drop Validation Study Using the 2019 Ridgecrest Earthquake Dataset}

BALTAY, A., U.S. Geological Survey, California, USA, abaltay@usgs.gov; ABERCROMBIE, R. E., Boston University, Massachusetts, USA, rea@bu.edu TAIRA, T., Berkeley Seimological Laboratory, California, USA, taira@ berkeley.edu

We introduce a community stress drop validation study using the 2019 Ridgecrest earthquake sequence, in which we invite researchers to use a common dataset to estimate earthquake stress drop. Earthquake stress drop is a key parameter in many ground motion, rupture simulation, and source physics problems in earthquake science as in theory it relates the average slip on a fault to rupture area, and in practice it inherently indicates the high-frequency energetics of an earthquake. We seek to understand the physical controls and methodological reasons for similarity or differences in stress drop estimates, so that they can be used more reliably by the earthquake science community. We develop a common dataset consisting of 2 weeks of earthquakes following the 2019 Ridgecrest M6.4 earthquake, including nearly 13,000 earthquakes of M1 and greater, recorded on stations within $100 \mathrm{~km}$; this dataset is available for all to use. We are soliciting stress drop estimates from community participants on any subset of these events, using a variety of methods. We are correlating and comparing these resulting stress drops as they are made available in a meta-analysis, to understand why similarities or differences arise.
We will first examine which earthquakes or methods generate grossly similar or different results. Initial results from a few preliminary datasets show only weak correlation between various methods, so we next consider the details of the methods, assumptions and data selection criteria. As a community study, all are invited to join!

\section{A Mechanism That Can Lead to a Slip Patch With Extremely Large Stress Drop}

NOZU, A., Port and Airport Research Institute, Yokosuka, Japan, nozu@p. mpat.go.jp

During the 2011 Tohoku earthquake $\left(\mathrm{M}_{\mathrm{w}} 9.0\right)$, pulse-like strong ground motions with a time width of approximately $1-2 \mathrm{~s}$ were observed. The most prominent pulse was included in the second wave packet observed in Miyagi prefecture. Nozu (2012) estimated that the pulse was generated at a small region located at $142.574 \mathrm{E}, 38.062 \mathrm{~N}$, at a depth of $28.3 \mathrm{~km}$. A similar location was also suggested by Kurahashi and Irikura (2013). The short time constant associated with the pulse indicates that the pulse was generated, not from an SMGA that spans several tens of kilometers but from an SPGA (Nozu et al., 2012) that spans only several kilometers. Nozu et al. (2012) estimated that a seismic moment of approximately $2.1 \times 10^{19} \mathrm{Nm}$ was released at a region occupying only $10.5 \mathrm{~km}^{2}$. Therefore, it is a slip patch with an extremely large stress drop. If we simply apply the Eshelby's (1957) equation, a stress drop of $1504 \mathrm{MPa}$ is estimated, although it is not reasonable to simply apply the equation because the slip outside the SPGA is nonzero. On the other hand, if we relate the initial slip velocity with the instantaneous stress drop as $\tau=\rho \beta V_{0} / 2$ following Brune's idea, a stress drop of $1026 \mathrm{MPa}$ is estimated. The question is how we can interpret this large stress drop. Because the subduction interface is approximately horizontal and the depth is approximately $30 \mathrm{~km}$, by assuming a density of $3 \times 10^{3} \mathrm{~kg} / \mathrm{m}^{3}$, the effective normal stress acting on the interface can be estimated as $600 \mathrm{MPa}$. Therefore, as long as we assume a static friction coefficient of 0.6 , the shear strength only up to $360 \mathrm{MPa}$ is available. Therefore, even if we assume that the stress is completely released (Hasegawa et al., 2011), the stress drop can be no more than $360 \mathrm{MPa}$. Therefore, I infer that cementation occurred locally at the plate interface before the 2011 event which resulted in apparent static friction coefficient exceeding 1.0. The SPGA may correspond to a region where the cementation occurred.

\section{Directly Inverting Strong-Motion Data for Fault Stress Evolution of the Coseismic Process}

DUAN, B., Texas A\&M University, Texas, USA, bduan@tamu.edu; MENG, Q., Texas A\&M University, Texas, USA, qimeng@tamu.edu; LIU, D., University of Texas, Austin, Texas, USA, dunyu.liu@austin.utexas.edu; CAI, Y., Peking University, Beijing, China, yongen@pku.edu.cn

Kinematic inversion for slip evolution has been the major approach in using strong-motion data to study co-seismic rupture propagation of past earthquakes. Static stress drop may be calculated from final slip distribution with some assumptions. One may also perform kinematic rupture modeling with inverted slip evolution as a boundary condition to obtain fault stress evolution. In this study, we develop a new method to directly inverting strong-motion data for both fault shear and normal stress evolution during the coseismic process, without the need of the middle step of slip inversion. The method is based on an earthquake stress model that is used recently to invert GPS data for static coseismic stress changes (Xie and Cai, 2018) and quasi-static stress evolution between earthquakes (Xie et al, 2019), which show impressive results for the $2011 \mathrm{Mw} 9.0$ Tohoku earthquake. In the earthquake stress model, the deformation field (including strong ground motion) is considered as the result of stress changes on the fault, and thus the model is a dynamic model, compared with the kinematic model of slip inversion. In our method, we use a dynamic finite element code to calculate numerical Green's functions for unit stress changes on the fault patches. The classical least-squares inversion method with a set of constraints is used to perform stress inversion. The checkerboard and synthetic data tests show the method has good resolution and can recover stress changes well with a good station coverage. We apply the method to the $2016 \mathrm{Mw} 5.0$ Cushing earthquake and compare the results with those from a kinematic slip inversion. Although more studies are needed to understand what advantages the stress inversion may have over the slip inversion, the dynamic nature of the stress inversion allows us to build a direct link between strong-motion recordings and coseismic fault stress evolution, which may open new opportunities in using strong motion data to study source physics. 
Inferring Critical Slip-Weakening Distance From Near-Fault Accelerogram of the 2014 Mw 6.2 Ludian Earthquake CHEN, X., The Chinese University of Hong Kong, Hong Kong, xiangchen@ link.cuhk.edu.hk; YANG, H., The Chinese University of Hong Kong, Hong Kong, hyang@cuhk.edu.hk

To better assess potential earthquake hazards and mitigate ground damage requires a better understanding of fault friction and rupture dynamics. Critical slip-weakening distance $\left(D_{c}\right)$ as one of the pivotal friction parameters however is hard to be determined on natural faults. For strike-slip earthquakes, we may directly estimate the $D_{c}$ value (Fukuyama and Mikumo, 2007) from the near-fault ground displacement at the moment of the peak ground velocity $\left(D_{c}\right.$ "). Yet near-fault observations are very few and thus there were only four earthquakes with such $\mathrm{D}_{\mathrm{c}}$ " estimation. In 2014, an Mw 6.2 strike-slip event, the Ludian earthquake, occurred in an unmapped fault in south-western China and caused 617 fatalities and economic loss over 19.8 billion CNY. The recording of a strong motion station (LLT) that is $\sim 0.45 \mathrm{~km}$ from the fault enables us to estimate the $\mathrm{D}_{c}$ " on the seismogenic fault. We first apply baseline adjustment and correction on the seismogram recorded at the accelerometer. Then we recover the ground displacement and obtain the value of $D_{c} " \approx 0.1 \mathrm{~m}$. We also calculate the static stress drop on the seismogenic fault from a kinematic slip model, which shows the largest stress drop of $\sim 18 \mathrm{MPa}$ in the slip asperity. This case extends the lower magnitude boundary of the $\mathrm{D}_{c}$ " values obtained from real faults and opens a window into the friction property of the unmapped fault in the seismically active region, which may provide us a better understanding of the earthquake source and seismic hazard near the Ludian region.

\section{Quantifying the Sensitivity of Microearthquake Slip Inversions to Station Distribution Using a Dense Nodal Array}

PENNINGTON, C.N., U.S. Geological Survey, California, USA, cpennington@ usgs.gov; CHANG, H., Massachusetts Institute of Technology, Massachusetts, USA, hilarych@mit.edu; RUBINSTEIN, J. L., U.S. Geological Survey, California, USA, jrubinstein@usgs.gov; ABERCROMBIE, R. E., Boston University, Massachusetts, USA, rea@bu.edu; NAKATA, N., Massachusetts Institute of Technology, Massachusetts, USA, nnakata@mit.edu; UCHIDE, T., Geological Survey of Japan, Tsukuba, Japan, t.uchide@aist.go.jp; COCHRAN, E. S., U.S. Geological Survey, California, USA, ecochran@usgs.gov

We perform multiple finite fault inversions of two microearthquakes that occurred within the high density LArge-n Seismic Survey in Oklahoma (LASSO) nodal array to investigate the sensitivity of these inversions and their resulting slip distributions to station distribution. The LASSO array's dense distribution of 1825 geophones provides an exceptional level of spatial and azimuthal coverage. We used it to compute more accurate slip inversions than are possible with typical station distributions and, in turn, we explored the sensitivity of slip inversions to station distribution and parameter choices. We analyzed these effects on two well-recorded microearthquakes (M 1.7 and M2.7) using an Empirical Green's Function (EGF) method. These earthquakes have maximum azimuthal gaps of 7 and 100 degrees, respectively, for stations within $8 \mathrm{~km}$ of the earthquakes. Source time function analysis of these events indicates that the M2.7 had multiple periods of moment release during its rupture, while the M1.7 had only one. For each of the events we performed multiple inversions with a randomly sampled selection of stations uniformly selected from different azimuth and distance bins relative to the respective hypocenter of each event. We examined the sensitivity of the final slip distribution to site effects that were left uncorrected by the EGF method such as those that are magnitude or time dependent. We also examined the effects of the complete absence of stations for different azimuth ranges and distance bins in relation to the fault geometry to understand how this lack of data affects the resulting slip distributions. Finally, we performed the analysis using a selection of stations that would be considered representative of the network distributions utilized in traditional finite fault inversion analysis and compared it to the inversion obtained using the dense network.

\section{Seismic Energy Radiated by Earthquakes Near the Rupture Area of the 1887 Mw 7.5 Sonora, Mexico Earthquake CASTRO, R. R., Centro de Investigación Científica y de Educación Superior de Ensenada, Baja California, Ensenada, Mexico, raul@cicese.mx; VILLALOBOS-ESCOBAR, G. P., Universidad Autónoma de Tamaulipas, Tampico, Mexico, gvillalobose@gmail.com}

We found that events located at the southern end of the fault that ruptured in 1887, between the stepovers of two major fault segments (Teras and Otates), have high scaled seismic energy (Es/Mo). In this zone, the fault system changes strike direction from nearly NS to NW-SE and, the tectonic stress may accumulate. It is likely that tectonic stress also accumulated in that zone after the fault ruptured in 1887. The apparent stress is heterogeneous, not showing a clear correlation with the seismic moment or focal depth. We estimated the source parameters of the earthquakes analyzed using a spectral inversion technique from seismograms recorded by the local network RESNES (Red Sismica del Noreste de Sonora), which operated from 2003 to 2011. We calculated the seismic energy by integrating the square velocity source spectrum of 47 earthquakes near the fault segments that rupture during the 3 May 1887 Mw 7.5 Sonora earthquake in the Mexican Basin and Range Province. We estimate an average $\log (E s / M o)=-5.76$ and found that most earthquakes analyzed have low apparent stress, varying between $0.5 \times 10^{-3}$ and $1.85 \mathrm{MPa}$, with an average value of $0.0521 \mathrm{MPa}$. We also found that the near-surface attenuation parameter $K_{0}$ is higher on the northern fault segments of the 1887 rupture. The high $K_{0}$ probably resulted from earthquake-related rock-damage after the fault ruptured.

\section{Validating the Graves-Pitarka Broadband Simulation Method Using a Grid-Search Technique}

GRAVES, R. W., U.S. Geological Survey, California, USA, rwgraves@usgs.gov

The objectives of this work are to demonstrate the ability of the Graves-Pitarka broadband simulation approach in reproducing observed ground motions from past earthquakes and to investigate appropriate ranges of key kinematic rupture parameters for these events. The events analyzed here are the 1989 M6.94 Loma Prieta and 1994 M6.70 Northridge, California earthquakes. For each event, suites of simulations are computed using the Graves and Pitarka (2010) hybrid simulation method and compared with recorded motions using the spectral acceleration goodness-of-fit criteria of Goulet et al (2015). Strong motion stations out to a distance of roughly one fault length are included with the processed ground motion time series obtained from the NGA-West2 database. In addition to spatial variability in slip and fault roughness, each rupture realization samples from distributions of average rupture speed (expressed as fraction of local shear wave velocity, $\left.\mathrm{V}_{\mathrm{r}} / \mathrm{V}_{\mathrm{s}}\right)$ and down-dip fault width $\left(\mathrm{F}_{\text {wid }}\right)$. A total of 121 realizations are generated for each event, consisting of a grid sampling discrete combinations of 11 values of $\mathrm{F}_{\text {wid }}$ and 11 values of $\mathrm{V}_{\mathrm{r}} / \mathrm{V}_{\mathrm{s}}$. Mean values of these parameters are taken from previous studies and the ranges are set at $\pm 15 \%$ for $\mathrm{F}_{\text {wid }}$ and \pm 0.1 for $\mathrm{V}_{\mathrm{r}} / \mathrm{V}_{\mathrm{s}}$. In general, the results are most sensitive to variations in average rupture speed with the lowest misfits occurring for $\mathrm{V}_{\mathrm{r}} / \mathrm{V}_{\mathrm{s}}$ of 0.75 to 0.80 for Loma Prieta and 0.85 to 0.90 for Northridge. Results are less sensitive to variations of fault width with the lowest misfits occurring for $\mathrm{F}_{\text {wid }}$ of 15 to $18 \mathrm{~km}$ for Loma Prieta and 20 to $24 \mathrm{~km}$ for Northridge. Notably, there are cases where different combinations of parameters produce equally good fits to the observations, highlighting the non-uniqueness of this approach. This reinforces the importance of adequately sampling ranges of rupture parameters when performing validations with past earthquakes, as well as when simulating ground motions for future events.

\section{When Seismology Meets Machine Learning, Data Science, HPC, Cloud Computing and Beyond}

I: Oral Session · Monday · 19 April · 9:45 AM Pacific

II: Oral Session · Monday · 19 April · 2:00 PM Pacific

III: Oral Session · Monday 19 April · 5:00 PM Pacific

Session Chairs: Qingkai Kong, Berkeley Seismology Lab, University of California, Berkeley (kongqk@berkeley.edu); S. Mostafa Mousavi, Stanford University (mmousavi@stanford. edu); Jiun-Ting Lin, University of Oregon (jiunting@ uoregon.edu)

\section{Earthquake Phase Association Using a Gaussian Mixture Model}

ZHU, W., Stanford University, California, USA, zhuwq@stanford.edu; MCBREARTY, I. W., Stanford University, California, USA, imcbrear@stanford. edu; MOUSAVI, S., Stanford University, California, USA, smousavi05@gmail. com; ELLSWORTH, W. L., Stanford University, California, USA, wellsworth@ stanford.edu; BEROZA, G. C., Stanford University, California, USA, beroza@ stanford.edu

Earthquake phase association algorithms, which aggregate detected phases from a network of seismometers into individual earthquakes, play an impor- 
tant role in many earthquake monitoring pipelines. Dense seismic networks and improved phase picking methods are producing massive earthquake phase datasets, particularly for earthquake swarms and aftershocks, making phase association a challenging problem. We present an association method (GMMA) by combining the Gaussian mixture model with earthquake origin time, location, and magnitude estimation. We treat earthquake phase association as an unsupervised clustering problem in a probabilistic framework, where each earthquake corresponds to a cluster of phases following the hyperbola of phase travel times and in which we also account for the decay of amplitude with distance. The recorded phases of each cluster scatter around the theoretical travel times and amplitudes determined by the underlying earthquake. We approximately model each cluster of phases using a Gaussian distribution whose mean is at the predicted travel time and amplitude. We use the Gaussian mixture model to calculate the probability that the set of phases are generated by a group of $\mathrm{N}$ earthquakes. The assignment of phases to each earthquake and the underlying latent variables, i.e. earthquake origin time, location, and magnitude, can be determined by the maximum likelihood criterion using the expectation-maximization (EM) algorithm. Our GMMA method does not require common association steps like grid-search, back-projection, or training. The probability framework can flexibly consider multiple phase types, phase pick quality, velocity/acceleration amplitudes, and uncertainties in travel time and amplitude calculations. Preliminary results show the GMMA method can effectively associate phases from a temporally dense earthquake sequence.

\section{HypoSVI: Hypocenter Inversion with Stein Variational Inference and Physics Informed Neural Networks}

DANIEL, J. D., Caltech, Seismological Laboratory, California, USA, jdsmith@caltech.edu; ROSS, Z. E., Caltech, California, USA, zross@caltech. edu; AZIZZADENESHELI, K., Purdue University, Lawson Computer Science Building, Indiana, USA, kamyar@purdue.edu; MUIR, J., Caltech, Seismological Laboratory, California, USA, jmuir@caltech.edu

High resolution earthquake hypocentral locations are of critical importance for understanding the regional context driving seismicity. We introduce a scheme to reliably approximate a hypocenter posterior in a continuous domain that relies on recent advances in deep learning.

Our method relies on a differentiable forward model in the form of a deep neural network, which is trained to solve the Eikonal equation (EikoNet). EikoNet can rapidly determine the travel-time between any source-receiver pair for a non-gridded solution. We demonstrate the robustness of these travel-time solutions are for a series of complex velocity models.

For the inverse problem, we utilize Stein Variational Inference, which is a recent approximate inference procedure that iteratively updates a configuration of particles to approximate a target posterior by minimizing the so-called Stein discrepancy. The gradients of this objective function can be rapidly calculated due to the differentiability of the EikoNet. The particle locations are updated until convergence, after which we utilize clustering techniques and kernel density methods to determine the optimal hypocenter and its uncertainty.

The inversion procedure outlined in this work is validated using a series of synthetic tests to determine the parameter optimisation and the validity for large observational datasets, which can locate earthquakes in 439s per event for 2039 observations. In addition, we apply this technique to a case study of seismicity in the Southern California region for earthquakes from 2019.

\section{Latent Crustal Fluid Injection Transients in Southern California Viewed Through Long-Duration Earthquake} Swarms

ROSS, Z. E., Caltech, California, USA, zross@caltech.edu; COCHRAN, E. S., U.S. Geological Survey, California, USA, ecochran@usgs.gov

Earthquake swarms are often manifestations of aseismic driving processes deep in the crust, such as fluid movement. We examine the spatiotemporal distribution of aseismic processes in Southern California using a 12-year cata$\log$ of swarms derived with deep learning algorithms. In a core portion of the plate boundary region, which is not associated with elevated heat flow, we identify nearly a hundred long-duration swarms ranging from 6 months to 7 years. Many swarms exhibit ultra-slow diffusive patterns with propagating backfronts. Backfronts are indicators of fluid injection into the crust whereby seismicity rates decrease following reduction or cessation of the fluid injection. The chronology of the swarms indicates that these fluid diffusion processes were occurring at all times during 2008-2020. The observations challenge common views about the nature of swarms, which would characterize any one of these sequences as anomalous. The regional prevalence of these sequences may indicate that transient fluid injection, rather than steady fluid movement, play a key role in transporting fluids through the crust.

\section{Machine-Learning-Facilitated Earthquake Detection and Characterization Near the Weiyuan Shale Gas Blocks, Sichuan, China}

ZHOU, P., Chinese University of Hong Kong, Shatin, Hong Kong, pengcheng. zhou@link.cuhk.edu.hk; ELLSWORTH, W. L., Stanford University, California, USA, wellsworth@stanford.edu; YANG, H., Chinese University of Hong Kong, Shatin, Hong Kong, hyang@cuhk.edu.hk; TAN, Y., Chinese University of Hong Kong, Shatin, Hong Kong, yjtan@cuhk.edu.hk; BEROZA, G. C., Stanford University, California, USA, beroza@stanford.edu; SHENG, M., State Key Laboratory of Geodesy and Earth's Dynamics, Innovation Academy for Precision Measurement Science and Technology, Chinese Academy of Sciences, Wuhan, China, shengminhan@apm.ac.cn; CHU, R., State Key Laboratory of Geodesy and Earth's Dynamics, Innovation Academy for Precision Measurement Science and Technology, Chinese Academy of Sciences, Wuhan, China, chur@asch.whigg.ac.cn

Increasing seismicity in shale gas blocks of the Sichuan Basin, China, presents a challenge for rapid analysis and characterization of earthquake sequences, which is critical for seismic hazard assessment and risk mitigation. We analyze the early stages of the Weiyuan, Sichuan, earthquake sequence, which was potentially induced by hydraulic fracking (HF) starting in early 2015, during the 1-year time period from November 2015 to November 2016. The densely clustered small earthquakes were initially detected and located using a dedicated temporary network of 50 stations covering the Weiyuan Shale Gas Blocks and a machine-learning-based phase picker-PhaseNet. Both P- and $\mathrm{S}$-phases are picked and associated for location. Our primary catalog contains more than 70,000 earthquakes, about 60 times as many earthquakes as appear in the catalog of the Chinese Earthquake Network Center (CENC), which only used the sparsely distributed permanent stations. We also measure the local magnitude and achieve a magnitude of completeness of $M_{L} 0$. We calibrate the velocity model and refine locations of earthquakes, with magnitudes $-0.5 \leq \mathrm{M}_{\mathrm{L}} \leq 3.5$. Finally, we located $\sim 43,000$ earthquakes that form several spatially compact clusters with the double-difference relocation algorithm and an improved velocity model. Most clustered earthquakes during this time were spatially correlated with HF wells but not with mapped faults. We found clusters of events, most likely induced by HF, showing migration patterns in the Wei202 and Wei204 blocks. Our results demonstrate the applicability of a machine-learning phase picker to a dense seismic network. The algorithms can be run in real time, facilitating rapid characterization of earthquake sequences as they develop.

\section{Scalable Machine-Learning Driven Model for Declustering Earthquake Catalogs}

ADEN-ANTONIOW, F., Massachusetts Institute of Technology, Massachusetts, USA, faden@mit.edu; FRANK, W. B., Massachusetts Institute of Technology, Massachusetts, USA, wfrank@mit.edu; SEYDOUX, L., ISTerre, Université Grenoble-Alpes, Grenoble, France, leonard.seydoux@univgrenoble-alpes.fr

The rate of background seismicity in active seismic regions is a potential candidate for better accessing the physical state of fault systems and improve the monitoring of large events. However, the occurrence of aftershock sequences prevents a detailed analysis of this background seismicity. Therefore, the declustering i.e. the identification of aftershocks in earthquake catalogs is a crucial problem in seismology. Nowadays, most solutions involve temporal and spatial distances between successive events, such as the NearestNeighbor-Distance algorithm widely used in various contexts. This algorithm assumes that the space-time metric $\eta$ follows a binomial distribution with one peak related to the background seismicity usually modeled by a Weibull function, and another peak representing the aftershocks distribution modeled by a Gaussian function. The correct splitting between these two overlapping peaks is the key for accurate identification of aftershocks. So far, most approaches use a linear splitting based on a threshold, ignoring the overlapping between the two populations, resulting in a misidentification of background earthquakes and aftershock sequences. We propose to revisit this problem with machinelearning classification (supervised) and clustering (unsupervised) algorithms After testing several popular algorithms, we show that a random forest trained from various synthetic catalogs (Epidemic Type Aftershock Sequence) outperforms approaches such as K-means, Gaussian-mixture models, or Support Vector Classification. In the present study, we discuss the different features we selected and their role in aftershock identification success. We discuss our model robustness by investigating different real-case earthquake catalogs from the Hikurangi subduction zone and Southern California. 
Early Warning for Great Earthquakes from Characterization of Crustal Deformation Patterns with Deep Learning

LIN, I., University of Oregon, Oregon, USA, jiunting@uoregon.edu; MELGAR, D., University of Oregon, Oregon, USA, dmelgarm@uoregon.edu; THOMAS, A. M., University of Oregon, Oregon, USA, amthomas@uoregon. edu; SEARCY, J., Research Advanced Computing Services, University of Oregon, Oregon, USA, jsearcy@uoregon.edu

Large earthquakes can be extremely damaging and occur on subduction and intraplate faults worldwide. Current earthquake early warning systems aim to estimate earthquake magnitude by the early metrics of waveforms, relying on empirical scaling relationships of abundant past events. However, both the rarity and complexity of great events limited their ability to characterize great earthquakes, making inaccurate estimation of magnitude and the resulting hazards. Here we propose a model, M-LARGE, that leverages the power of deep learning to characterize crustal deformation patterns of large earthquakes in real time. We generate realistic rupture scenarios and use these to train a model that directly measures earthquake magnitude, centroid location, and rupture dimension from ground displacements. We find that M-LARGE can learn these 6 source parameters even under imperfect situations (e.g. predominant GNSS noise and station outage). For the magnitude estimation, M-LARGE successfully performs reliable estimation on the testing dataset with an accuracy of $99 \%$ for simulated events and for five damaging historical earthquakes in the Chilean Subduction Zone. Unlike existing models which focus on the final source parameters, M-LARGE tracks the evolution of the source process and can make faster and more accurate magnitude and other source parameters estimation, frequently before rupture is complete, significantly outperforming currently operating EEW algorithms.

\section{Identification of Repeating Seismic Events Using Non- Linear Dimensionality Reduction}

BREGMAN, Y., Soreq Nuclear Research Center, Yavne, Israel, yuri@soreq. gov.il; NIV, I., Tel-Aviv University, Tel Aviv, Israel, itayniv10@gmail.com; BEN HORIN, Y., Soreq Nuclear Research Center, Yavne, Israel, yochai@ndc.soreqndc.gov.il; RABIN, N., Tel-Aviv University, Tel Aviv, Israel, netara@tauex.tau. ac.il

In this work, we develop a machine learning based algorithm for automatic identification of repeating seismic events such as aftershocks and mine explosions. Identification of such events will help to improve the quality of automatic bulletins and to lighten the analysts' burden. The algorithm constructs a low-dimensional representation of the examined data by using a variant of a non-linear dimensionality reduction algorithm named diffusion maps.

The proposed methods begin with a pre-processing stage in which a time-frequency representation is extracted from each seismogram while capturing common properties of seismic events and overcoming magnitude differences. Then diffusion maps are used in order to construct a low-dimensional model of the original data. This enables to split the data into one cluster that contains the repeating events and another cluster that holds of the other processed waveforms, which are not related to the examined events of interest.

The algorithm's performance is demonstrated on several seismic data sets that were recorded at International Monitoring System (IMS) stations. In particular, at the IMS station EIL we identify arrivals that were caused by the blasts at the nearby Eshidiya mine in Jordan. Identification and masking of such arrivals should reduce the number of false associations in the automatic bulletins.

\section{Nature of Deep Earthquakes in Pacific Plate From Unsupervised Machine Learning}

MAO, G. L., William Mason High School, Ohio, USA, gilbertmao3266123@ gmail.com; FERRAND, T. P., Institut des Sciences de la Terre d'Orléans, Université d'Orléans / CNRS, Orléans, France, ferrthomas@gmail.com; ZHU, B., Yale University, Connecticut, USA, brian.zhu@yale.edu; XI, Z., Michigan State University, Michigan, USA, xiziyi@msu.edu; CHEN, M., Michigan State University, Michigan, USA, chenmi22@msu.edu

Deep earthquakes, greater than $300 \mathrm{~km}$ in depth, have been observed for decades, but their mechanism remains enigmatic. The leading interpretation is transformational faulting of the metastable olivine wedge (MOW) within the cold subducting slabs that enter the mantle transition zone. At such depths, observations have been limited to large magnitude earthquakes due to detection issues, preventing full understanding of small-scale earthquake nucleation processes. An unsupervised machine learning approach, the K-means algorithm, was used to analyze deep earthquakes in the northwestern Pacific subduction zones using 15 years of the Japan Meteorological Agency catalog, one of the most complete catalogs. The statistical analysis of the seismicity in the Izu-Ogasawara subduction zone reveals a kink at $\mathrm{Mw}$ of $3.8 \pm 0.1$ in addition to the previously reported $\mathrm{Mw}$ of $6.5 \mathrm{kink}$. This new kink is only observed for two unique clusters of deep earthquakes within the Izu-Ogasawara slab. The $\mathrm{b}$ value changes abruptly from $1.35 \pm 0.15$ to $0.7 \pm 0.1$, indicating a fractal dimension change related to the highly hydrated MOW of the slab in the Izu-Ogasawara trench compared to the Kuril and Japan trenches. Our unique observation of $\mathrm{b}$ values with the Mw 3.8 kink supports the existence of the transformational faulting mechanism that triggers a large number of lower magnitude earthquakes within the unstable edge of the MOW with a width less than $1 \mathrm{~km}$. Additionally, intermediate magnitude earthquakes between 3.8 and 6.5 can rupture inward from the unstable edge into the stable MOW with a width of approximately $10 \mathrm{~km}$. Large earthquakes with $\mathrm{Mw}$ greater than 6.5 can rupture outside the MOW, but still within the rigid part of the slab.

\section{Structural Earthquake Damage Warning Use IoT Sensor and Machine Learning \\ DANG, L., Saitama University, Saitama, Japan, dangji@mail.saitama-u.ac.jp}

Rapidity infrastructure damage detection, diagnose and reopen are the foundation of a resilience of urban area under multiple type of disasters. Recent bridge collapse cases implied not only earthquake but also many other human or nature disaster caused damage or collapse to structures are also needed to be warned or fast, real time detect, to prevent secondary damages or car accidents. The main target of the Structural Disaster Warning System is to give an early structural damage warning due to earthquake, Typhoon, flooding, scouring, ship collision, or structural deterioration. The basic sensing system can be constructed by an eco., sustainable and easy to apply way using low cost IoT sensors. Acceleration and displacement measurement using sensor head and Raspberry pi are introduced. Their performance tests by shake table, and real bridge measurements. Bridge damage detection due to earthquake using Artificial Neural Network (ANN) was investigated and verified by using acceleration and associated displacement. The feasibility of this method was verified by large scale shale table tests results.

\section{Transfer Learning: Improving Neural Network for IM Prediction in an Area With Small Number of Training Data} IOZINOVIĆ, D., Istituto Nazionale di Geofisica e Vulcanologia Rome Headquarters, Rome, Italy, dario.jozinovic@ingv.it; LOMAX, A., ALomax Scientific, Mouans-Sartoux, France, alomax@free.fr; ŠTAJDUHAR, I., University of Rijeka, Rijeka, Croatia, istajduh@riteh.hr; MICHELINI, A., Istituto Nazionale di Geofisica e Vulcanologia, Rome, Italy, alberto.michelini@ ingv.it

In a recent study (Jozinović et al, 2020, http://doi.org/10.1093/gji/ggaa233), we showed that Convolutional Neural Networks (CNNs) applied to network seismic traces can be used for rapid prediction of ground motion at distant stations using only the recordings from stations near the epicenter. The predictions are made without any previous knowledge concerning the earthquake location and magnitude. This approach differs significantly from the standard procedure adopted by Earthquake Early Warning Systems (EEWSs) that rely on location and magnitude information. In our previous study, we used 10s, raw, multistation (39 stations) waveforms for the 2016 earthquake sequence in central Italy for $915 \mathrm{M} \geq 3.0$ events (CIT dataset). The CIT dataset has a large number of spatially concentrated earthquakes and a dense network of stations.

In this work, we applied the same CNN model to an area around the VIRGO gravitational waves observatory sited near Pisa, Italy. This large infrastructure can greatly benefit from an EEWS to shut-off the data acquisition in case of significant earthquakes in the vicinity. In our initial application of the technique, we used a dataset consisting of $266 \mathrm{M} \geq 3.0$ earthquakes recorded by 39 stations. We found that the $\mathrm{CNN}$ model trained using this smaller-sized dataset performed worse compared to the results presented in the original study by Jozinović et al. (2020).

To counter the lack of data, we explored the adoption of "transfer learning" (TL) methodologies using two approaches: first, by using a pre-trained model built on the CIT dataset and, next, by using a pre-trained model built on a different (seismological) problem.

We show that the use of TL improves the results in terms of outliers, bias and variability of the residuals between predicted and true PGM values. We also demonstrate that adding knowledge of station positions as an additional layer in the neural network improves the results.

\section{An EPIC Machine Learning Implementation}

CHUNG, A. I., Berkeley Seismological Laboratory, California, USA, aichung@ berkeley.edu; MEIER, M., Swiss Seismological Service, Zürich, Switzerland, 
mmeier@caltech.edu; HENSON, I., Berkeley Seismological Laboratory, California, USA, ihenson@berkeley.edu

Machine learning techniques are rapidly gaining popularity as means to quickly and accurately classify large amounts of data. In the field of seismology, machine learning has been used in a wide range of applications from detecting tiny earthquakes (Ross et al., 2019) to denoising seismic signals (Zhu et al., 2019).

In their recent study, Meier et al. [2019] demonstrated the feasibility of using machine learning to distinguish between earthquake and spurious noisy signals with a high degree of accuracy. Here we apply a modified version of the machine learning model developed in that study to the EPIC realtime earthquake early warning algorithm in order to more accurately classify incoming triggers. EPIC is one of the two algorithms currently running on the ShakeAlert production system. Though recent improvements have reduced the number of false triggers coming into the system, there have still been 7 M4.5+ and nearly $100 \mathrm{M} 3.5+$ false alerts over the past two years (2019-01-01 through 2020-12-31). By applying the machine learning methodology from Meier et al., [2019] we hope to drastically reduce the number of false triggers. Furthermore, with higher confidence in the accuracy of the EPIC triggers, we will be able to explore the possibility of detecting earthquakes with fewer stations (the algorithm currently requires 4 station triggers to create an alert).

We will present both real-time and offline replay results comparing versions of EPIC with and without the machine learning classifier. We will also describe modifications made to the original classifier model to optimize it for real-time use in the ShakeAlert earthquake early warning system.

\section{Data-Driven Accelerogram Synthesis Using Deep Generative Models}

FLOREZ, M. A., Caltech, California, USA, mflorezt@caltech.edu;CAPORALE, M., Caltech, California, USA, mvacaporale@gmail.com; BUABTHONG, P., Caltech, California, USA, pai@caltech.edu; ROSS, Z. E., Caltech, California, USA, zross@caltech.edu; ASIMAKI, D., Caltech, California, USA, domniki@ caltech.edu; MEIER, M., Caltech, California, USA, mmeier@caltech.edu

Robust estimation of ground motions generated by scenario earthquakes is critical for many engineering applications. We leverage recent advances in Generative Adversarial Networks (GANs) to develop a new framework for synthesizing earthquake acceleration time histories. Our approach extends the Wasserstein GAN formulation to allow for the generation of ground-motions conditioned on a set of continuous physical variables. Our model is trained to approximate the intrinsic probability distribution of a massive set of strongmotion recordings from Japan. We show that the trained generator model can synthesize realistic 3-Component accelerograms conditioned on magnitude, distance, and Vs30. Our model captures the expected statistical features of the acceleration spectra and waveform envelopes. The output seismograms display clear P and S-wave arrivals with the appropriate energy content and relative onset timing. The synthesized Peak Ground Acceleration (PGA) estimates are also consistent with observations. We develop a set of metrics that allow us to assess the training process's stability and tune model hyperparameters. We further show that the trained generator network can interpolate to conditions where no earthquake ground motion recordings exist. Our approach allows the on-demand synthesis of accelerograms for engineering purposes.

\section{Nowcasting Earthquakes: Imaging the Earthquake Cycle in California With Machine Learning}

RUNDLE, J. B., University of California, Davis, California, USA, jbrundle@ ucdavis.edu; DONNELLAN, A., Jet Propulsion Laboratory, California, USA, andrea.donnellan@jpl.nasa.gov

We propose a new machine learning-based method to image the time-dependent earthquake cycle. The result is a nowcasting timeseries which may correspond to the process of stress accumulation and release. The timeseries is constructed by using Principal Component Analysis of regional seismicity. We first compute the characteristic spatial patterns for the region at time $t$ using seismicity data for times $t^{\prime} \leq t$ in California. The patterns are found as eigenvectors of the cross-correlation matrix of a collection of seismicity timeseries in a coarse grained regional spatial grid. The eigenvalues of this matrix represent the relative importance of the various eigenpatterns. Using the eigenvectors and eigenvalues, we then compute the weighted correlation timeseries (WCT) of the regional seismicity. This timeseries has the property that the weighted correlation generally decreases prior to major earthquakes in the region, and increases suddenly just after a major earthquake occurs. Comparing our results with those from a previous paper (Rundle and Donnellan, 2020), we find that this method produces a timeseries that resembles the hypothesized regional stress accumulation and release process characterizing the earthquake cycle. We propose that this timeseries can be used as a proxy for judging the relative maturity of the current state of the California region in the recurring cycle of major earthquakes. Using a simple timeseries prediction method based on a random forest classifier, we report mixed results in forecasting future values of the WCT. If an accurate and reliable timeseries prediction method can be developed, it might allow the development of a new regional earthquake forecasting methodology.

\section{Semi-Supervised Surface Wave Tomography Using Wasserstein Cycle-Consistent GANs: Application to Southern California Plate Boundary Region}

CAI, A., Rice University, Texas, USA, ac98@rice.edu; QIU, H., Rice University, Texas, USA, hq7@rice.edu; NIU, F., Rice University, Texas, USA, niu@rice.edu

Current machine learning based shear wave velocity (Vs) inversion using surface wave dispersion measurements utilizes synthetic dispersion curves calculated from existing 3-D velocity models as training datasets. It is shown in the previous studies that the performances of the resulting networks are dependent on the diversity of the training data. We present an improved semi-supervised deep learning algorithm-based method that incorporates both observed and synthetic surface wave dispersion curves in the network training process. The algorithm is termed Wasserstein cycle-consistent generative adversarial networks (Wcycle-GAN), which combines the architecture of cycle-consistent GAN with Wasserstein loss metrics in optimization. Different from conventional supervised deep learning approaches, the GAN architecture also extracts structural information from the observed surface wave dispersion data in the training process that may improve generalization of the resulting network. The cycle-consistent loss addresses soft constraints on the trained neural networks to be reversible and thus reduces the variance of the trained networks. The Wasserstein metric provides weaker topology for convergence and improves spatial continuity of the predicted shear velocity (Vs) models. We demonstrate these improvements by applying the WcycleGAN to 4076 fundamental mode Rayleigh wave phase and group dispersion curves obtained in Southern California (SC). In general, the 3-D Vs model predicted by the best training Wcycle-GAN is consistent with previous surface wave tomography studies of SC in the overlapping area, but with smaller data misfit, yields better spatial smoothing, and provides improved images of structures near faults and in the top $15 \mathrm{~km}$. Our results indicate that the proposed Wcycle-GAN algorithm has strong training stability and generalization abilities.

\section{Slab Morphology at the Source Region of the 2015 Mw 7.9} Bonin Earthquake Imaged by Full Waveform Inversion

CHEN, M., Michigan State University, Michigan, USA, chenmi22@msu.edu; XI, Z., Michigan State University, Michigan, USA, xiziyi@msu.edu; KISER, E., University of Arizona, Arizona, USA, ekiser@arizona.edu; KEHOE, H., University of Arizona, Arizona, USA, hlkehoe@email.arizona.edu

The mechanism of the very deep $2015 \mathrm{Mw} 7.9$ Bonin earthquake (about 680 $\mathrm{km}$ deep) is highly debated, partly due to the controversial slab morphology imaged near the source. We obtain significantly improved slab images near this earthquake source region based on full waveform inversion using a large waveform dataset recorded in East Asia. Profiles of the Vp and Vs models in the trench normal direction indicate a well-defined vertical slab deflected to the west at the bottom of the transition zone which hosts abundant deep-focus earthquakes at depths of $350-550 \mathrm{~km}$ where significant slab necking is also observed. This vertically sinking slab has undergone substantial folding and piling and the more ancient slab segment at the bottom of the pile has penetrated to the top of the lower mantle while bending eastward. The 2015 Bonin earthquake occurred where the slab bends in the lower mantle with noticeable slab necking. Additionally, a prominent slab segment at the bottom of the mantle transition zone is imaged above and to the east of the 2015 Bonin earthquake mainshock, spatially correlated with recently imaged foreshock and aftershock locations and interpreted as a horizontally detached Pacific slab from the south due to the recent trench advance in the region. The spatial relationship between the imaged 3-D slab morphology and the 2015 Bonin earthquake sequences suggests that the significant slab deformation and necking control the distribution of the deep-focus seismicity in this region. 


\section{When Seismology Meets Machine Learning, Data Science, HPC, Cloud Computing and Beyond}

Poster Session · Monday · 19 April · 3:45 PM Pacific

Session Chairs: Qingkai Kong, Berkeley Seismology Lab, University of California, Berkeley (kongqk@berkeley.edu); S. Mostafa Mousavi, Stanford University (mmousavi@stanford. edu); Jiun-Ting Lin, University of Oregon (jiunting@uoregon. edu)

\section{Application of the U-Net Neural Network Architecture to 2D Partially Non-Ergodic Ground Motion Modeling} LILIENKAMP, H., GFZ German Research Centre for Geosciences, Potsdam, Germany, lilienka@gfz-potsdam.de; VON SPECHT, S., Institute of Earth Sciences, Academia Sinica, Taipei, Taiwan, Taipei, Taiwan, specht@ gfz-potsdam.de; WEATHERILL, G., GFZ German Research Centre for Geosciences, Potsdam, Germany, gweather@gfz-potsdam.de; COTTON, F., GFZ German Research Centre for Geosciences, Potsdam, Germany, fcotton@ gfz-potsdam.de; CAIRE, G., Technical University of Berlin, Berlin, Germany, caire@tu-berlin.de

Ground motion models are a key component of probabilistic seismic hazard analysis and have a huge impact on the estimation of economic losses due to earthquakes. While modern parametric models have become extremely complex, their uncertainties are still large due to limited knowledge of earthquake source processes, wave propagation and local site-effects. Increasing amounts of data have recently led to an increasing interest in data-driven models. While traditional methods describe relations between predictive parameters and a target intensity measure (IM), these new methods can also grasp trends from the target IM itself when there is no suitable predictive parameter available. Besides the use of new modeling techniques, also the removal of the ergodic assumption is an innovative trend in the literature. While both aspects are being studied extensively, the benefits of combining the two approaches is not well understood.

In our study we apply the U-Net neural network architecture to the task of partially non-ergodic ground motion prediction. The U-Net processes continuous 2D maps of predictive parameters to predict a continuous 2D map of an IM that is evaluated against sparsely recorded measurements during training. While traditional models are used to make point-wise predictions, our method provides a coherent, spatially consistent simulation of entire ground motion fields. The regression of predictive parameters against the IM, capturing of implicit trends in the data, and spatial interpolation is performed in an easy-to-use single-step procedure. Due to the simple configuration of the training, the suggested method is well suited for comparing the predictive power of input parameters. The estimation of uncertainties and interpretation of interpolated values pose major challenges in our approach. We demonstrate the application of the model to a dataset of spectral acceleration recorded in the Kanto basin, Japan. The final uncertainties are comparable to those of other models.

\section{Damage Building Detection from Crowdsourcing Images Using Transfer Learning}

CHACHRA, G., University of California, Berkeley, California, USA, chachra@ berkeley.edu; KONG, Q., Berkeley Seismological Laboratory, California, USA, kongqk@berkeley.edu; HUANG, J., AT\&T, California, USA, ccjimhuang@ gmail.com; KORLAKUNTA, S., University of California, Berkeley, California, USA, srujay@berkeley.edu; ROBSON, A., University of California, Berkeley, California, USA, a.robson@berkeley.edu; GRANNEN, J., University of California, Berkeley, California, USA, jenngrannen@berkeley.edu; ALLEN, R., Berkeley Seismological Laboratory, California, USA, rallen@berkeley.edu

In this presentation, we used images from public domain, i.e. Twitter, Getty images etc to train a deep learning model to recoganize damaged buildings caused by earthquakes. The goal of building this model is to label damaged buildings from crowdsourcing images fast after an earthquake, and combining with geolocation information, this can be used to verify the damage in a city. We started from VGG19 model, and use transfer learning to fine tune the last block CNN layers. We tested the model both in real time and offline on Twitter, and the model achieves really good performance in terms of precision and recall. In addition, we also try to visualize what the model learns to make the decision via Grad-CAM. We will also discuss some challenges we found, such as night scenes, arial images etc.

\section{Performance Evaluation of Machine Learning Phase} Detection Models on a Megathrust Aftershock Sequence REICHARD-FLYNN, W., Lehigh University, Pennsylvania, USA, wir219@ lehigh.edu; MELTZER, A., Lehigh University, Pennsylvania, USA, ameltzer@ lehigh.edu; AGAR, J., Lehigh University, Pennsylvania, USA, joshua.agar@ lehigh.edu; HOSKINS, M. C., Lehigh University, Pennsylvania, USA, mac716@lehigh.ed; STACHNIK, J., Lehigh University, Pennsylvania, USA, jcstachnik@gmail.com

Many promising machine learning models have emerged for automatic phase detection. However, thorough analysis of their efficacy on datasets which differ from training data is not frequently conducted, making it difficult to select appropriate models or to identify effective structures for future development. Aftershock sequences possess both unique utility in hazard analysis and unique waveform characteristics compared to background seismicity. This research conducts an analysis of three machine learning models - the generalized phase detector (GPD) published by Ross et al. (2018), the earthquake transformer (EqT) published by Mousavi et al. (2020), and a tuned version of EqT - to examine each model's effectiveness on the aftershock sequence of the 2016 Pedernales megathrust event. To assess accuracy, the numbers of true positives, false positives, and missed detections were calculated for both associated events and arrivals within events. In addition to accuracy, the temporal precision of the automatic arrivals in comparison to hand-picked arrivals was assessed. Quantitative and qualitative waveform characteristics were tested for their significance on model performance. EqT returned minimal false positives, while GPD returned approximately two-thirds more true positives than EqT. Tuning the EqT model resulted in increased true detections, but also increased false positives.

\section{Quality Control Seismic Waveforms Using Transfer Learning}

ORTEGA,R., Centro de Investigación Científica y de Educación Superior de Ensenada, La Paz, Mexico, ortegarobe@gmail.com; CARCIUMARU, D., Centro de Investigación Científica y de Educación Superior de Ensenada, La Paz, Mexico, carciumaru@cicese.mx; MALAGNINI, L., National Institute of Geophysics and Volcanology, Rome, Italy, luca.malagnini@ingv.it

Quality control seismic waveforms is a time-consuming task. It requires a detailed analysis to eliminate records with instrumental malfunctioning (e.g. electrical glitches, mass centering or internal problems) or to review and reject waveforms that have multiple events in the same record. The main purpose is to select those waveforms that represent the source, propagation and site effects eliminating records that cause problems in data processing for final interpretation. Here, we present a machine learning approach using artificial neural networks to classify quality waveforms discarding records that are not useful for ground motion studies. We designed the artificial neural network classifying the waveforms depending on their shape. We computed the spectrograms of the different sets. Each spectrogram is resized as images of 300 by 300 pixels. Our four neural network models are: a) CNN using AlexNet architecture, b) VGG16 using the Simonyan and Zisserman, 2015 model, c) Deep residual (He at al. 2016) and d) DenseNet (Huang et al., 2017). Only the first model is trained and the remaining three models were trained using transfer learning. Transfer learning is a technique that takes advantage of a model trained in one domain and is used in another one. This approach has the advantage that a large amount of data can be adapted without many modifications. Contrary to seismic detection, in quality-control seismic waveforms the accuracy depends on an accurate training data set. A good- or bad- quality waveform does not depend on discriminate earthquakes from noise, most of the cases bad quality waveforms are seismic records with recording problems and visual classification is fundamental. We analyzed 20,000 waveforms with $50 \%$ for training, $30 \%$ for validation and $20 \%$ for out-of-sample testing. Finally we compared our results using a multiple regression ground motion analysis to separate source, path and site terms.

\section{The Hidden Induced Seismicity in Oklahoma Revealed by Machine Learning}

MA, X., Los Alamos National Laboratory, New Mexico, USA, xfma@lanl.gov; CHEN, T., Los Alamos National Laboratory, New Mexico, USA, tchen@lanl. gov

A complete earthquake catalog is essential to understanding earthquake nucleation and fault stress. Following the Gutenberg-Richter law, smaller seismic events dominate the earthquake catalog and are invaluable for revealing the fault state. We developed a new machine learning based method to efficiently identify and locate small seismic events in noisy background, which is challenging to achieve otherwise. The models were trained with over 1 million 
samples extracted from regional seismic stations and reach high accuracy. We applied our method to 15- month continuous seismic data in Oklahoma, USA and detected 14 times of earthquakes compared with Oklahoma Geological Survey catalog. The new catalog highlights distinct seismic hotspots, and provides important insights and prospects into induced earthquakes in
Oklahoma, such as the poroelastic effect in the Jones earthquake swarm and foreshock behavior before the M5.7 Prague earthquake. It takes only a few minutes for the models to process one week of continuous data on a personal computer, making them a great candidate for real-time monitoring. 
Aagaard, B. 1340, 1411, 1455 Abbott, R. E. 1357, 1358, 1367

Abdelmeguid, M. 1301, 1391 Abercrombie, R. E. 1354, 1392, 1446, 1447, 1466, 1467

Abers, G. 1310, 1424, 1458

Abolfathian, N. 1222, 1335

Abrahamson, N. 1360, 1362, $1417,1418,1420,1428$, 1452,1453

Abrams, J. R. 1357

Ackerley, N. 1347

Adams, A. 1232, 1296

Adams, J. 1347, 1349, 1421, 1425

Aden-Antoniow, F. 1299, 1438,1468

Aderhold, K. 1386, 1399

Adero, B. 1393

Afanasiev, M. 1356, 1360

Agar, J. 1471

Aguiar Moya, A. C. 1220, 1416

Aguilar Bardales, Z. 1434

Agurto-Detzel, H. 1233, 1435

Ahdi, S. K. 1304, 1361, 1372

Ahern, T. 1320, 1321, 1449

Aikin, K. E. 1400

Ajo-Franklin, J. 1222, 1365, 1367

Akhlaghi, M. M. 1374

Akinci, A. 1413

Al Atik, L. 1428

Albert, S. A. 1378,1379

Alexandru, M. 1441

Alfaro-Diaz, R. A. 1357, 1395

AlHamaydeh, M. 1304

Ali, A. 1429

Allam, A. 1463

Allen, R. 1340, 1341, 1342, 1456,1471

Allen, T. I. 1424, 1434

Allstadt, K. 1432

Almeida, R. 1233

Altekruse, J. M. 1454, 1456, 1457

Alva Hurtado, J. 1434

Alvarado, A. 1435

Alvarado Sosa, R. 1343, 1345

Álvarez-Ruedas, H. R. 1436

Ambruz, N. B. 1402

Amemoutou, A. 1392

Amlani, F. 1301

Ampuero, J. 1353, 1390, 1414,1435

An, Y. 1405

Anderson, J. 1378, 1380, 1381

Anderson, J. G. 1373, 1419

Anderson, K. 1423

Anderson, M. 1344

Anderson, Z. W. 1387

Andrew, J. E. 1333

Angster, S. J. 1222, 1452
Anthony, R. 1319, 1400, 1401, 1459

Antoun, T. H. 1357, 1380, 1444

Aquino-Sándoval, G. C. 1445

Arcas, D. 1302

Archuleta, R. J. 1235, 1464, 1465

Arcos, M. E. 1360, 1363

Ardhuin, F. 1379

Arellano, D. 1375

Arrowsmith, R. 1363

Arrowsmith, S. 1219, 1378, $1379,1380,1381$

Arroyo, D. 1420

Asimaki, D. 1222, 1339, 1414,1470

Aslam, K. 1348

Aslan, Y. 1314

Assink, J. D. 1314, 1378

Assumpção, M. 1400, 1436, 1438,1445

Aster, R. C. 1221

Atkinson, G. M. 1371, 1396

Attanayake, J. 1304

Atwi, Y. 1314

Audet, P. 1299

Auerbach, D. 1401

Averbuch, G. 1227, 1314, 1378,1379

Avery, J. 1344

Azizzadenesheli, K. 1468

Babikoff, J. 1313

Baez, J. 1344

Báez-Sánchez, G. 1217, 1295, 1448

Baig, A. 1393

Bailey, M. 1411

Baird, A. F. 1363

Baise, L. G. 1372, 1374, 1375

Baize, S. 1360, 1361

Baker, B. 1389, 1400

Baker, L. M. 1464

Baker, M. G. 1367

Baker, M. R. 1368

Bal, A. 1413

Baldwin, J. 1362, 1427

Ball, J. S. 1373

Ballard, S. 1355

Baltay, A. 1305, 1340, 1341, $1342,1345,1354,1370$, 1455,1466

Bandyopadhyay, S. 1411

Banerdt, W. B. 1227, 1382, $1383,1384,1385$

Banfield, D. 1382, 1383

Banks, F. D. 1367

Bao, F. 1365, 1422

Bao, H. 1325

Baptie, B. 1425

Baraldi, R. 1302

Barall, M. 1294, 1351

Barbot, S. 1445

Barcheck, G. 1222, 1458

Bargabus, S. 1401

Barlow, N. M. 1459

Barnes, C. R. 1449
Barnhart, W. D. 1388, 1398,

$$
1443
$$

Barno, J. 1328, 1365

Barrientos, S. E. 1214, 1234, $1310,1342,1448$

Bartelt, P. 1330

Bas, E. E. 1339

Bataille, K. 1437

Battaglia, J. 1435

Battiston, R. 1315

Bauer, L. M. 1231

Bauer, R. 1393

Bayless, J. 1452

Bayliss, K. 1326

Bayona, J. A. 1325, 1326

Bazzurro, P. 1396

Bécel, A. 1311

Beck, E. 1313

Beck, S. L. 1233, 1435

Bedran, E. 1314

Beeler, N. 1224

Begnaud, M. L. 1313, 1355

Bekaert, D. 1435

Bellini, J. 1399

Benali, A. 1323

Benavente, R. 1437

Benavidez, A. 1401

Bender, A. M. 1336, 1337, 1454

Ben Horin, Y. 1314, 1469

Ben Mansour, W. 1437

Bennett, S. 1335

Bensi, M. T. 1440

Benson, R. 1382

Bent, A. L. 1433, 1438, 1441

Benz, H. 1305, 1399, 1402

Ben-Zion, Y. 1299, 1300,

1329, 1404, 1411, 1417, 1422, 1430

Berg, E. M. 1378, 1463

Bergen, K. 1214

Bergman, E. 1321, 1388, 1446

Beroza, G. C. 1235, 1339, 1467, 1468

Bertoni, M. 1339

Besser, B. P. 1316

Best, J. S. 1314

Beyranvand, M. 1334

Bhadha, R. 1319

Bhaskaran, A. 1319

Bhat, H. S. 1301

Bhattarai, R. 1375

Biagi, P. F. 1316

Bianchi, M. 1445

Bianco, M. 1461

Biek, R. F. 1387

Bieńkowski, J. 1432

Bierma, R. 1399

Bilek, S. L. 1347

Bindi, D. 1340, 1402, 1419

Biondi, B. 1339

Bird, A. 1349

Bird, E. J. 1380

Bishop, J. W. 1227, 1381

Blanck, H. 1421

Blom, N. 1377

Blom, P. S. 1313, 1314, 1379

Bloszies, C. 1427
Bocchini, G. 1462

Bock, Y. 1303, 1332

Bockholt, B. 1389, 1390

Boehm, C. 1356, 1360, 1366

Boese, C. M. 1393

Boese, M. 1341

Bohnen, B. 1393

Bohnhoff, M. 1332, 1392, 1394

Bohon, W. 1232, 1386

Bold, S. 1348

Bombardier, M. 1461

Bommer, J. J. 1213

Boncio, P. 1360, 1361

Bondár, I. 1321

Bonilla, L. 1372

Bonnieux, S. 1449

Bormann, J. M. 1228, 1388

Bosa, A. R. 1381

Boschelli, J. D. 1299

Böse, M. 1343, 1383, 1385

Bossu, R. 1442

Bostrom, A. 1224

Boudjada, M. 1316, 1317

Boué, P. 1300

Boulton, C. 1446

Bouzid, K. 1375

Bowden, D. 1409

Bowman, D. C. 1379, 1380, 1382

Bowman, S. D. 1386

Boyd, O. S. 1219, 1308, 1342, 1440

Bozdağ, E. 1410, 1429, 1436

Bozorgnia, Y. 1225, 1304, $1360,1409,1452$

Brandenberg, S. J. 1361, 1419,1420

Braun, T. 1330

Braunmiller, J. 1387

Bravo, T. 1382

Bregman, Y. 1469

Brengman, C. 1398

Brenguier, F. 1300

Briggs, R. W. 1231, 1292, $1337,1440,1452,1456$

Brisbourne, A. M. 1363

Brissaud, Q. 1380, 1409

Brodsky, E. E. 1350

Brogan, R. 1378

Brooks, B. A. 1344,1350

Brothers, D. S. 1335, 1337

Brotherson, L. O. 1385, 1403

Brudzinski, M. R. 1432, 1443

Brunsvik, B. R. 1311

Bryan, J. T. 1299,1300

Bryant, A. 1384

Buabthong, P. 1470

Bubeck, A. 1427

Buckreis, T. E. 1419

Bunn, J. J. 1341, 1342, 1344, 1373

Bürgmann, R. 1292, 1318

Burgoa Rosso, B. 1343, 1345

Burns, S. 1376

Busby, R. W. 1399

Butcher, A. C. 1363, 1367

Buttinelli, M. 1413

Cabas, A. 1375

Cabral, J. 1337

Cabrera, L. 1404

Cai, A. 1329, 1470

Cai, Y. 1466

Caire, G. 1471

Çaktı, E. 1305, 1410, 1417, 1427

Callaghan, S. A. 1414, 1417

Camarillo, L. 1344

Cameron, A. 1444

Campman, X. 1300

Campuzano, S. A. 1317 
Chauvin, B. 1362

Chaves, E. J. 1223, 1235, 1343,1345

Chedraoui, R. 1314

Chen, H. 1296

Chen, M. 1226, 1300, 1469, 1470

Chen, R. 1360

Chen, S. 1319

Chen, T. $1296,1357,1395$, 1471

Chen, X. 1390, 1392, 1401, 1409, 1464, 1467

Chen, Y. J. 1449

Cheng, B. 1316

Cheng, F. 1365, 1367

Cheng, Y. 1318

Cheung, K. F. 1293

Chi, B. 1365,1422

Chi, C. 1318

Chiaia, B. 1330

Chiama, K. 1362

Chiang, A. 1355, 1356, 1357, 1360

Chi-Duran, R. 1356

Chiou, B. 1360

Chmiel, M. 1300, 1329

Chong, J. 1332

Choo, J. 1394

Chouinard, L. 1426, 1438

Chow, B. 1376

Chow, W. 1424

Chu, R. 1468

Chu, S. 1355

Chuang, L. Y. 1460

Chung, A. I. 1223, 1340, 1342,1469

Chupik, C. M. 1337

Cianchini, G. 1317

Ciardelli, C. 1436

Cicone, A. 1315

Clahan, K. 1427

Clark, A. 1382

Clark, D. L. 1387

Clark, K. 1336

Clarke, A. 1363

Claycomb, A. 1459

Clayton, B. S. 1454, 1455

Clayton, R. W. 1304, 1306, $1319,1373,1429,1462$, 1463

Clements, T. 1300, 1319, 1463

Cleveland, M. K. 1358, 1359

Clinton, J. 1343, 1345, 1382, $1383,1385,1432$

Cochran, E. S. 1341, 1342, 1344, 1345, 1391, 1392, 1467,1468

Coffin, M. 1377

Colavitti, L. 1370, 1465

Cole, H. 1385

Cole, S. 1364

Collaço, B. 1445

Collett, C. M. 1452, 1456

Colon Rodriguez, B. 1295, 1448

Colquhoun, R. L. 1403

Condon, S. J. 1322

Conley, A. 1355

Contreras-Reyes, E. 1310

Cooke, M. L. 1234, 1332, 1445
Coppersmith, K. J. 1363

Coppersmith, R. 1363

Cordero Nieves, H. 1295, 1448

Cornou, C. 1313, 1314

Cornthwaite, J. 1436, 1437

Cotton, F. 1306, 1325, 1369, $1370,1372,1374,1375$, $1402,1419,1471$

Cox, B. R. 1338, 1371

Cramer, C. H. 1375, 1438, 1439, 1453

Crandall-Bear, A. T. 1388

Crane, S. 1347, 1349

Crawford, B. M. 1358

Crayne, J. 1344

Creasy, N. 1410

Criley, C. 1350

Crowell, B. W. 1217, 1292, 1303, 1305

Cruz-Atienza, V. M. 1461

Cuddus, Y. 1215

Cuellar, A. 1344

Cui, J. 1220, 1316

Cunningham, E. 1353, 1439

Cunow, C. 1364

Curran, J. 1336

Dabaghi, M. 1312

Dahm, R. A. 1421

Dahm, T. 1391, 1421

Dahmen, N. 1382, 1383, 1385

Dalguer, L. 1414

D'Amico, M. 1433

Daneshvaran, S. 1455

Dang, J. 1469

D’Angelo, G. 1315

Daniel, G. 1428

Daniel, J. D. 1468

Daniels, M. 1296

Dannemann Dugick, F. K. $1219,1227,1379$, $1380,1382,1385$

Daout, S. 1396

Daryono, M. 1377

Datta, A. 1340

Daud, N. 1296

Davenport, K. 1309

Davidenko, D. 1315

Davis, E. 1449

Davis, P. 1399, 1401

Dawson, P. B. 1461

Dawson, T. 1360, 1362, 1363

Day, S. M. 1352

de Angelis, S. 1381

Dearborn, D. S. 1449

De Barros, L. 1435

De Carlo, M. 1379

Dee, S. 1389

De Gori, P. 1413

de Groot, R. 1344, 1345

Dehant, V. 1383

DeKoning, M. W. 1298

De Laat, J. I. 1438

Delisle, M. 1361

Delva, M. 1316

Deng, S. 1405, 1407

Denisenko, V. 1317

Denolle, M. 1218, 1235, 1300, 1319, 1352, 1354, 1463

den Ouden, O. F. C. 1378

DePaolis, J. 1336
Deras, K. 1344

Derendyaev, A. 1315

Derosier, B. 1310

De Santis, A. 1317

DeShon, H. 1228, 1374, 1395

Desilva, S. 1429

Dettmer, J. 1364

Dewey, J. 1220

Dhakal, Y. P. 1312

Dianala, J. B. 1351

Dickey, J. T. 1399

Diederichs, A. 1449

Diego, P. 1315

Di Giacomo, D. 1321, 1412

Di Mauro, D. 1317

Dionicio, V. 1436, 1437

Dittmann, S. 1297

Dittmann, T. 1297

Dobson, P. 1365, 1367

Dodds, N. 1446

Dodge, D. 1357

Dokht Dolatabadi Esfahani, R. 1372

Dominguez, L. A. 1461

Donahue, J. 1360

Dong, B. 1365

Donnellan, A. 1303, 1361, 1470

Doody, C. 1356,1360

Doser, D. I. 1368,1421

Dosso, S. 1461

Douilly, R. 1224, 1353

Dowling, D. R. 1352

Downey, N. 1379

Dreger, D. S. 1356,1464

Dreossi, I. 1306, 1308

Dresen, G. 1332, 1393, 1394

Driscoll, N. 1310

Du, Y. 1353

Duan, B. 1228, 1414, 1436, 1466

Dugdale, J. 1313

Duncan, C. 1344

Dunham, A. 1359, 1415

Duputel, Z. 1403, 1435

Dura, T. 1292

Durand, V. 1332

DuRoss, C. B. 1336

Dutta, R. 1388

Duzet, C. J. 1389

Dyaur, N. 1395

Dybing, S. N. 1298, 1385

Eakin, C. 1226, 1377

Earle, P. S. 1328, 1399, 1402

Eaton, D. W. 1393, 1394, 1395,1439

Ebel, J. 1229, 1372, 1405

Eberhart-Phillips, D. 1351

Ebinger, C. 1320

Eble, M. C. 1353

Eckert, E. 1306

Edme, P. 1364, 1366

Edwards, B. 1304, 1387, 1403

Egbert, G. D. 1439

Eguchi, R. T. 1416

Eichelberger, H. 1316, 1317

Eilon, Z. C. 1310, 1311

Ekhtari, N. 1350

Elbanna, A. 1301, 1391

El Hajj, M. 1314

Eliassi, M. 1359

Elliott, A. J. 1389, 1446

Elliott, J. 1318

Elliott, J. L. 1292, 1293, 1451

Ellsworth, W. L. 1320, 1340, $1447,1467,1468$

Elston, H. 1332, 1445

Elwood, K. J. 1231, 1426

Engdahl, E. R. 1321

Engelhart, S. E. 1292

Engler, D. T. 1297, 1456

Enloe, K. 1297

Erdem, J. E. 1464

Ericksen, T. 1344, 1350

Erickson, B. A. 1386

Ermert, L. 1463

Escobar-Wolf, R. 1381

Escudero Ayala, C. E.

$$
\text { A. } 1461
$$

Espinosa-Aranda, J. 1344

Euchner, F. 1382, 1383, 1385

Euler, G. G. 1220, 1314, 1320

Evangelidis, C. 1434

Evans, B. R. 1298

Evans, E. L. 1332, 1451

Evers, L. G. 1314, 1378

Eyre, T. S. 1394, 1439

Ezzedine, S. M. 1313, 1357, 1380, 1444, 1449

Facincani, E. 1445

Fahed, M. 1314

Fairhurst, M. 1371

Faith, J. L. 1421

Famiani, D. 1330

Fan, M. 1317, 1318

Fan, W. 1233, 1352, 1403

Fang, Y. 1376

Farajpour, Z. 1454

Farghal, N. S. 1341

Farrell, J. 1389, 1400, 1423

Fasola, S. 1432

Faulkner, D. R. 1403

Fee, D. 1381

Felicetta, C. 1433

Feliciano Ortega, A. 1448

Feng, G. 1397

Fernando, B. 1385

Ferrand, T. P. 1469

Ferrer, F. 1398, 1401

Ferris, A. N. 1375

Fichtner, A. 1364, 1366, 1409

Field, E. H. 1221, 1327, 1354, $1451,1452,1457$

Fielding, E. J. 1335, 1435, 1444

Figueiredo, P. M. 1337

Filiano, D. L. 1336, 1337

Filippitzis, F. 1373

Fischer, K. M. 1459

Fischer, T. 1393

Fitzenz, D. D. 1221, 1326, 1368

Fleischhut, N. 1347

Fletcher, J. B. 1235, 1464

Florez, M. A. 1470

Font, Y. 1435

Forbriger, T. 1383

Ford, S. R. 1357, 1358, 1359

Foster, J. 1344

Fox, J. 1404

Fox, O. 1297

Franco Marin, L. 1330

Franek, P. 1321

Frank, W. B. 1235, 1299, 
Goldfinger, C. 1346, 1348, 1447

Goldman, M. 1350

Golombek, M. 1382, 1384

Golriz, D. 1303

Gombert, B. 1435

Gómez-Novell, O. 1418

Gong, J. 1310

Gong, W. 1397

Gonzáles Trujillo, C. 1434

Gonzalez, L. 1222

Gonzalez, W. 1217

González, Á. 1329

González, P. J. 1292

González-Ortega, A. J. 1435

Good, A. 1341

Gospe, T. 1372

Gottlieb, M. H. 1296, 1297

Goulet, C. A. 1225, 1354, 1360, 1361, 1362, 1414, 1416, 1417

Graber, L. 1433

Gracía-Mayordomo, J. 1418

Gradon, C. 1300

Graf, W. 1455

Graham, S. E. 1325

Graizer, V. 1427

Grannen, J. 1471

Grant, A. 1347

Grapenthin, R. 1292, 1293

Graves, R. W. 1417, 1455, 1467

Gray, B. T. 1362

Gray, H. J. 1336

Graymer, R. 1351

Green, D. 1381

Green, L. 1446

Greenberg, S. 1393

Gregor, D. 1408

Gregor, N. 1428

Grevemeyer, I. 1310

Grigoli, F. 1366

Grigoratos, I. 1391, 1396

Grimm, C. 1324

Gronewold, A. 1404

Grott, M. 1382

Gruetzner, C. 1321, 1446

Grzan, D. 1303

Gualtieri, L. 1449

Gueguen, P. 1314

Guillemot, C. 1296

Guillier, B. 1314

Gulia, L. 1327

Gulick, S. P. S. 1377

Gunnels, M. 1401

Guo, F. 1336

Guo, H. 1336

Guralp, C. M. 1430

Gurnis, M. 1377

Gurung, G. 1430

Guttorp, P. 1325, 1347

Guven, C. 1442

Guy, M. 1399, 1402

Guy, R. 1373

Haddadi, H. 1232, 1433

Haendel, A. 1370

Haeussler, P. J. 1292, 1336, 1337,1454

Hafner, K. 1399, 1401

Hagos, L. Z. 1433

Hahn, T. 1441

Hainzl, S. 1324, 1325

Halchuk, S. 1421, 1425, 1438
Hale, J. 1443

Hallal, M. M. 1338, 1371

Hamburger, M. W. 1369

Hammond, P. 1355

Hammond, W. C. 1388

Han, X. 1296

Han, Y. 1407, 1408

Hancilar, U. 1427

Haney, M. 1310

Hanks, T. C. 1466

Hanson, K. L. 1360, 1363

Harb, J. 1313, 1314

Hardebeck, J. L. 1294, 1325, 1328

Hardwick, C. L. 1387

Haritashya, U. 1415

Harrichhausen, N. 1335

Harrington, R. M. 1392

Harris, J. 1321, 1412

Harris, K. T. 1462

Harris, R. 1224, 1351, 1352

Harrison, V. 1375

Hartog, R. 1229

Hashash, Y. M. A. 1312

Hassani, B. 1371, 1372

Hatch, J. 1445

Hatch-Ibarra, R. 1388, 1460

Hatem, A. E. 1337, 1389, 1451, 1452, 1456

Hattori, K. 1315

Hauksson, E. 1319

Hawthorne, J. 1403

Hayashi, K. 1376

Hayes, G. P. 1305, 1399

He, B. 1458

He, J. 1228

He, R. $1378,1422,1423$

He, V. 1339

He, X. 1317, 1318

Hearn, E. H. 1451

Heaton, T. 1373

Heesemann, M. 1449

Heggelund, Y. 1367

Heidbach, O. 1419

Heimann, S. 1421

Hello, Y. 1449

Hellweg, M. 1342, 1431

Helprin, O. L. 1334

Hemphill-Haley, E. 1336

Henson, I. 1341, 1342, 1469

Herman, M. W. 1293

Hernandez, F. 1294

Hernandez, S. 1435

Hernandez Servin, J. H. S. 1461

Herran, C. 1344

Herrera, C. 1321

Herring, J. 1424

Herrmann, M. 1324

Herrmann, R. B. 1442

Hesir, G. P. 1421

Hetland, E. A. 1332, 1334

Hibert, C. 1329

Hickman, J. B. 1308

Hicks, S. 1393

Hightower, E. 1377

Hill, P. 1294, 1344, 1450

Hindriks, K. 1300

Hines, T. T. 1332

Hirakawa, E. T. 1411

Hirao, B. W. 1350

Hirshorn, B. 1303

Hirth, G. 1355
Hiscock, A. I. 1369, 1386

Hobbs, T. E. 1226, 1331, 1335,1424

Hodgkinson, K. 1218, 1296, 1297, 1298

Holland, J. 1401

Holt, J. 1387, 1402

Holt, M. M. 1227, 1389, 1400

Hooper, R. 1364

Horálek, J. 1421

Horleston, A. 1383, 1385

Horspool, N. 1426

Horton, S. 1375, 1439

Horton, Jr., J. 1441

Hoshiba, M. 1342

Hoskins, M. C. 1435, 1471

Hotovec-Ellis, A. J. 1461

Hough, S. E. 1230, 1386, 1418,1420

Houlton, H. 1431

Howarth, J. 1446

Howe, B. 1302, 1449

Howe, J. 1335

Howell, A. 1336

Hsu, Y. 1460

Hu, Z. 1415, 1416, 1455

Hua, J. 1459

Huang, J. 1315, 1317, 1471

Huang, M. 1222

Huang, Q. F. 1318, 1407

Huang, X. 1296

Huang, Y. 1302, 1346, 1352, $1371,1404,1417,1443$, 1464

Hubbard, J. 1445

Hubenthal, M. 1431, 1432

Hudnut, K. 1350

Hudson, K. S. 1361, 1372

Hudson, M. B. 1361

Hudson, T. S. 1363

Huerfano, V. A. 1217, 1233, $1234,1294,1402,1444$, 1448

Hughes, A. 1415

Hupe, P. 1314

Hurford, T. A. 1384

Hurst, K. J. 1382, 1383

Huynh, M. 1341

Hwang, L. J. 1320, 1321

Hylland, M. D. 1369, 1387

Ibarrola, G. 1344

Ichinose, G. A. 1357, 1358, 1368,1388

Illian, J. 1326

Imanishi, K. 1334

Infantino, M. 1415

Irving, J. C. E. 1449

Isaacson, M. 1309

Ischuk, A. 1396

Ishii, M. 1320

Iskandar, R. 1313

Isken, M. 1421

Islas, R. 1344

Ito, E. 1320, 1338, 1374

Ito, Y. 1461

Jackson, D. D. 1221, 1230, $1325,1328,1412$

Jaffe, B. 1218

Jaiswal, K. S. 1297, 1432, 1451, 1456

Janiszewski, H. A. 1310, 1458
Jaramillo-Nieves, L. G. 1217,1294

Jarrin, P. 1435

Jenkins, M. R. 1344, 1345

Jeong, C. 1229, 1409, 1410

Jeong, S. 1374

Jeremic, B. 1409

Ji, C. $1322,1375,1465$

Ji, K. 1296, 1371

Ji, Z. 1422, 1423

Jia, Z. 1462

Jiang, C. 1300,1377

Jiang, H. 1405, 1408

Jiang, J. 1332

Jiang, X. 1407

Jiang, Y. 1292

Jimenez-Martinez, V. 1393

Jin, Y. 1395

Jin, Z. 1423

Jo, B. 1430

Jobe, J. A. T. 1222

Johanson, I. 1296

Johnson, A. 1382

Johnson, B. 1396

Johnson, B. N. 1227

Johnson, C. 1329, 1404

Johnson, J. 1344

Johnson, J. B. 1227, 1380, 1381, 1389

Johnson, K. 1351, 1451, 1457

Johnson, K. L. 1424

Johnson, P. 1404

Johnson, W. 1296

Jolivet, R. 1351, 1435

Jones, J. 1296

Jordan, T. H. 1333, 1334, 1354

Journeay, J. M. 1335, 1424

Jousset, P. 1364, 1421

Joyce, J. 1444

Jozinović, D. 1469

Juarez, A. 1333, 1334

Juarez Garfias, I. C. 1446 , 1447

Julian, B. 1384

Kafatos, M. 1315

Kaip, G. 1423

Kaiser, D. 1441

Kakoty, P. 1348

Kalia, A. C. 1314

Kamalov, V. 1365

Kanamori, H. 1215, 1293

Kaneko, Y. 1376, 1412, 1446

Kao, H. 1461

Kapetanidis, V. 1304

Karasozen, E. 1293

Kargel, J. 1415

Karplus, M. 1231, 1421, 1423

Karrenbach, M. 1364

Käser, M. 1324

Kawamura, T. 1383, 1385

Kawase, H. 1320, 1338, 1371, 1374

Kearns, A. 1401

Kedar, S. 1227, 1382, 1384

Keehoon, K. 1359

Kehoe, H. 1470

Kelsey, H. 1348

Kemal, E. 1421

Kemna, K. B. 1392

Kenawy, M. 1414

Kendall, J. 1363

Kero, J. 1380 
Kunkle, T. D. 1314

Kunugi, T. 1312

Kuo, C. 1360,1361

Kværna, T. 1380

Kwak, D. 1374

Kwiatek, G. 1392, 1393, 1394

Kwong, K. B. 1227, 1302, 1303

Kyriakopoulos, C. 1224, 1351, 1353

Labak, P. 1356

Ladinsky, T. C. 1348

Lahiri, S. 1411

Lamb, O. 1330

Lammegger, R. 1316

Landès, M. 1442

Lange, D. 1310

Langenbruch, C. 1326, 1368

Langer, L. 1408

Langet, N. 1393

Langston, C. A. 1356,1440

Lanza, F. 1354, 1366

Lanzano, G. 1232, 1370, 1433,1465

Lapusta, N. 1390

Larmat, C. 1357, 1358

Larochelle, S. 1390

Larose, E. 1215

Latchman, J. L. 1233

Laurentiu, D. 1441

Lavrentiadis, G. 1360, 1452

Lawton, D. C. 1439

Lay, T. 1293

Lazares La Rosa, L. 1434

Lazecky, M. 1318

Lazo, J. 1330

Lebedev, S. 1438

Lecocq, T. 1215

Lee, J. 1409

Lee, R. F. 1305

Lee, S. 1330

Lee, T. A. 1220,1320

Lee, W. 1430

Lee, Y. 1416, 1455

Leeds, A. 1309

Lees, J. M. 1330, 1380

Leetaru, H. 1393

Lefeuve-Mesgouez, G. 1408

Lei, Z. 1358

Lekic, V. 1218, 1439

Lellouch, A. 1225

Lengliné, O. 1403

Leonhardt, M. 1394

Leoni, M. 1336

Leon-Rios, S. 1435

Leon Soto, G. L. S. 1461

Le Pichon, A. 1379, 1380

Leser, U. 1340

Lettis, W. R. 1362

Levander, A. 1436, 1437

Levandowski, W. 1233, 1309,1440

LeVeque, R. J. 1302

Levish, D. 1373

Lewandowski, N. S. 1362

LeWinter, A. L. 1336, 1337

Lewis, R. 1220

Li, B. 1353

Li, C. 1398

Li, D. 1352,1412

Li, J. 1300

Li, K. 1318,1336

Li, L. 1443
Li, X. 1417

Li, Z. 1422, 1457, 1458

Li, Y. 1378,1463

Liang, C. 1435

Liao, M. 1228, 1397

Liberty, L. 1219, 1307, 1331, $1380,1381,1389,1390$

Lieser, K. 1412

Lilienkamp, H. 1471

Lin, F. 1463

Lin, G. $1233,1401,1462$

Lin, J. 1236, 1415, 1469

Lin, R. 1365,1422

Lin, Y. 1306

Lindsay, D. 1318

Lindsey, J. 1294, 1344, 1450

Lipovsky, B. P. 1364

Lipus, M. P. 1364

Lisowski, M. 1296

Listowski, C. 1380

Litchfield, N. 1336

Liu, C. 1394,1463

Liu, C. M. 1302

Liu, D. 1414, 1466

Liu, F. 1394

Liu, J. 1315, 1405

Liu, L. 1439

Liu, M. 1464

Liu, Q. 1377,1458

Liu, T. $1377,1442,1458$

Liu, X. 1330

Liu, Y. 1376

Liu, Z. 1420

Liu-Zeng, J. 1447

Lizarazo, S. C. 1437

Llenos, A. L. 1221, 1294, $1323,1324,1328$

Lockner, D. 1350, 1351

Lognonné, P. 1382, 1383, 1384,1385

Lomax, A. 1393, 1469

Longnecker, P. 1337

Lopez-Venegas, A. 1402, 1444

Lorenz, R. D. 1384

Louie, J. N. 1306, 1308, 1460

Loveless, J. P. 1325, 1332

Loviknes, K. 1375

Lowe-Worthington, L. 1219

Lozos, J. 1233, 1352, 1446

Lu, X. 1318

Lu, Y. 1299

Lucas, M. C. 1418,1420

Lucey, J. 1361

Luco, N. 1231, 1426, 1432, 1455

Luo, B. 1436

Lüth, S. 1364

Luzi, L. 1433

Lv, H. 1365, 1422

Lynett, P. J. 1353

Lynner, C. 1311, 1435

Lyons, J. 1381

Lyzenga, G. 1361

Ma, B. 1310

Ma, K. 1306

Ma, S. 1353, 1414

Ma, W. 1316

Ma, X. 1301, 1395, 1471

Ma, Y. 1296, 1405, 1406, 1407

MacCarthy, J. K. 1220, 1319

Macedo, J. E. 1428
Madugo, C. 1427

Madugo, D. 1360

Maechling, P. J. 1328, 1417

Magana, J. A. 1464

Maghsoudi Mehrani,

$$
\text { Y. } 1318
$$

Magnani, M. 1437

Magnes, W. 1316, 1317

Maguire, R. 1218

Maguire, R. R. 1300

Magura, B. 1344

Mahan, S. A. 1336

Mahanama, A. 1453

Maher, E. L. 1367, 1419

Main, I. 1326

Makdisi, A. J. 1425

Malagnini, L. 1471

Mancini, S. 1327

Manea, E. 1441

Manga, M. 1384, 1392

Mannah, J. 1314

Mao, G. L. 1469

Marchetti, D. 1317, 1318

Marcillo, O. E. 1319

Margerin, L. 1382

Marion, K. P. 1393

Marroquin, G. 1343, 1345

Marsan, D. 1403

Marshall, N. 1446

Marshall, S. T. 1332

Martens, H. R. 1389

Martin, E. 1339, 1364, 1421

Martin, S. S. 1386

Martinez, E. 1294

Martinez-Cruzado, J. A. $1294,1295,1359$, 1448

Martinez-Garzon, P. 1332, 1392, 1394

Marusiak, A. 1384

Marzocchi, W. 1221, 1324

Masana, E. 1418

Mascandola, C. 1433

Mason, D. 1399

Massin, F. 1343, 1345

Matasovic, N. 1370

Materassi, M. 1315

Materna, K. 1318, 1350

Mathurin, J. 1386

Matsushima, S. 1371

Mattioli, G. 1296

Matulka, P. 1458

Matzel, E. 1300, 1307, 1331, $1357,1365,1367$

Maurer, J. 1435

May, A. 1357

Mayeda, K. 1295, 1328, 1387, 1402, 1441

Mazzoni, S. 1360

McArdell, B. 1329

McBeck, J. A. 1411

McBrearty, I. W. 1467

McBride, S. K. 1294, 1344, 1345

McCaffery, E. 1373

McCallen, D. 1414

McCleave, J. 1305

McCormack, D. 1347, 1349

McCreery, C. 1303

McDonald, G. N. 1369, 1386

McDowell, M. 1347

McGuire, J. 1310, 1341, 1408

McKean, A. P. 1386, 1387

McKee, L. 1349

McLaskey, G. C. 1391

McLin, K. 1390

McNamara, D. E. 1324

Meade, B. J. 1325

Mecozzi, A. 1365

Medina, M. 1342

Meier, M. 1223, 1341, 1469, 1470

Meier, T. 1393

Melgar, D. 1214, 1231, 1292, $1298,1302,1303,1304$, $1305,1342,1346,1348$, 1415,1469

Mellors, R. 1357, 1365, 1367, 1399

Melosh, B. 1350

Meltzer, A. 1423, 1435, 1471

Mencin, D. 1218, 1296, 1297, 1298,1319

Mendoza, M. 1353

Meng, H. 1329, 1403

Meng, L. 1407, 1408

Meng, Q. 1436, 1466

Meng, X. 1361, 1414, 1417

Mercerat, D. 1314

Meremonte, M. 1373

Merzlikin, D. 1421

Mesgouez, A. 1408

Mesimeri, M. 1386, 1402, 1443

Meyer, M. 1374

Mia, M. 1391

Miao, W. 1437

Michael, A. 1221, 1294, 1323, 1324,1325

Michailos, K. 1355, 1446

Michalak, M. 1348

Michaut, C. 1384

Michelini, A. 1469

Mikesell, T. D. 1319, 1380, $1381,1389,1390$

Milkereit, C. 1391,1421

Miller, M. S. 1215, 1235, 1377

Miller, P. L. 1449

Milligan, P. 1342

Milliner, C. W. D. 1333, 1360

Milner, K. 1327, 1354, 1414, 1451

Miner, J. 1399

Minson, S. 1340, 1341, 1342, $1344,1345,1435$

Mir, R. R. 1430

Miranda, E. 1295

Miranda Berrocales, V. M. 1295

Mirzaei, N. 1334

Misson, C. 1316

Mitchell, R. 1422

Mizrahi, L. 1322, 1326

Moafi, S. 1314

Moaveni, B. 1374

Moczo, P. 1229, 1356, 1408

Modrak, R. 1359, 1376, 1381

Molina-Hutt, C. 1224,1348

Molnar, S. 1350

Montgomery-Brown, E. 1296

Moore, D. 1350, 1351

Moore, G. L. 1335

Moore, K. 1214 
Nocquet, J. 1435

Noh, H. 1297

Nolet, G. 1429, 1449

Nollet, M. 1426

Noor, S. 1353

Norabuena, E. O. 1223

Nosov, M. A. 1301

Nozu, A. 1466

Nunez Jara, S. 1437

Nurislamova, G. N. 1301

Nurlu, M. 1332

Nurminen, F. 1360, 1361

Nuttall, J. 1309

Nweke, C. C. 1361

Nychka, D. 1411

Nye, T. 1218, 1305

Nykolaishen, L. 1349

Obayashi, M. 1449

O'Connell, D. 1309

O'Donnell, T. 1312

Odum, J. K. 1309

Oglesby, D. D. 1224, 1353

Ogwari, P. O. 1398, 1401

Okal, E. 1320

Okubo, K. 1300

Okubo, P. 1320

Olds, S. 1344

Olsen, K. B. 1413, 1415, 1417, 1461, 1463

Olugboji, T. 1299, 1311

Onur, T. 1321

Onyango, E. A. 1424

Oral, E. 1414

Ordaz, M. G. 1420

Orhand-Mainsant, G. 1385

Orlando, M. 1317

Ormand, C. 1431

O'Rourke, C. 1341, 1342

O’Rourke, W. T. 1298

Ortega, R. 1471

Ortuño, M. 1418

Oskin, M. E. 1333, 1447

O'Sullivan, P. 1337

Oth, A. 1402

Ou, Q. 1220, 1321

Ousborne, M. 1297

Ouzounov, D. 1220, 1315

Paap, B. 1367

Pace, B. 1360, 1361

Pacor, F. 1370, 1465

Pagani, M. 1324, 1424

Page, M. T. 1294, 1323, 1451

Page, W. 1427

Paitz, P. 1225, 1364, 1366

Palmer, S. M. 1372

Pancha, A. 1308

Pankajakshan, R. 1414

Pankow, K. L. 1229, 1307, $1386,1387,1400,1402$, 1443

Panning, M. P. 1227, 1382, 1383,1384

Paolucci, R. 1413

Park, S. 1304

Parker, G. A. 1224, 1341, 1370

Parker, T. $1345,1429,1450$

Parker, T. J. 1401

Parolai, S. 1306, 1308, 1339

Parrot, M. 1317

Parsekian, A. 1431

Parsons, B. 1351, 1396

Parsons, T. 1327
Parvez, I. A. 1430

Pasten-Araya, F. 1435

Pasyanos, M. E. 1313, 1355, 1357

Patel, A. A. 1298

Patel, J. 1377

Patel, S. 1340, 1341, 1456

Patton, H. J. 1358

Patton, J. 1399, 1402

Pauk, B. 1296

Paul, C. 1349

Pechmann, J. C. 1387,1389

Pelyk, N. 1345, 1429, 1450

Pena, R. 1399

Peng, Y. 1376

Peng, Z. 1215, 1229, 1235, $1404,1443,1460,1462$

Pennington, C. N. 1392 , 1447, 1467

Pentti, M. 1394

Peresan, A. 1323

Perez, A. 1412

Pérez-Campos, X. 1214, 1436

Perez Paulino, J. E. 1295

Perlin, M. 1429, 1450

Perrin, C. 1384

Perrone, L. 1317

Persaud, P. 1306

Perton, M. 1339

Peruqui Guidio, B. 1409, 1410

Peruqui Guidio, L. 1409

Petersen, F. 1310

Petersen, G. M. 1391, 1462

Petersen, M. D. 1235, 1324, 1360, 1451, 1455, 1456

Petersson, A. 1414

Petrov, K. 1315

Pezeshk, S. 1375, 1454

Phillips, W. S. 1313, 1357

Pickering, A. 1389

Pienkowska-Cote, M. 1409

Pierce, I. K. D. 1338, 1389, 1396, 1446

Piersanti, M. 1315

Pike, W. T. 1382, 1383, 1385

Pilger, C. 1314

Pilia, S. 1226

Pilz, M. 1226, 1369, 1370, $1374,1375,1402$

Pineda, A. 1381

Pipatprathanporn, S. 1449

Piscini, A. 1317

Pitarka, A. 1230, 1357, 1367, 1413, 1414, 1416

Pita-Sllim, O. D. 1462

Plank, G. 1390

Plasman, M. 1383

Plesch, A. 1333, 1362, 1368

Plourde, A. P. 1311

Podrasky, A. 1367

Podrasky, D. 1367

Poggi, V. 1308

Poitra, K. 1386

Polanco, E. 1233

Poli, P. 1404

Pollinger, A. 1316, 1317

Pollitz, F. F. 1408, 1451

Ponce, D. 1351

Pontrelli, M. A. 1372, 1375

Popescu, A. 1365

Poppeliers, C. 1359
Porter, R. 1386

Portner, D. E. 1310, 1458

Pothan, S. 1341

Potin, B. 1435

Pousse-Beltran, L. 1388

Powell, C. A. 1233, 1438, 1440,1442

Power, J. A. 1310, 1384, 1458, 1462

Powers, P. M. 1231, 1235, 1324, 1451, 1454, 1455, 1456,1457

Pratt, T. L. 1307, 1308, 1441

Prejean, S. G. 1461

Premus, J. 1353

Preston, L. 1358, 1359

Pridmore, C. 1344

Prieto, G. 1385, 1436, 1437

Prothro, L. 1358, 1460

Protti, M. 1223, 1343, 1344, 1345

Prush, V. B. 1233, 1447

Puglia, R. 1433

Pulinets, S. 1315

Pursley, J. 1399

Pyle, M. L. 1357, 1358

Qin, L. 1460

Qiu, H. 1422, 1460, 1463, 1470

Qu, C. 1397

Quigley, M. 1304

Quinones, L. A. 1395

Quitoriano, V. 1340, 1442

Rabin, N. 1469

Racine, R. 1343, 1345

Rademacher, H. 1320, 1431

Ramesh, V. 1428

Ramirez Pina, C. R. P. 1461

Ramos, M. 1346

Rao, A. 1424

Rastin, S. J. 1324

Rathje, E. 1391, 1396

Rawlinson, N. 1377

Rebez, A. 1339

Redwine, J. 1231

Regnier, M. 1435

Reichard-Flynn, W. 1471

Reichenbacher, R. 1375

Reiner, D. 1297

Reinsch, T. 1421

Reis, W. 1294, 1344, 1450

Reiter, D. 1312

Rekoske, J. M. 1349, 1432, 1454

Ren, J. 1336

Ren, Y. 1226, 1371

Renard, F. 1411

Renner, J. 1393

Reyes, C. 1327

Rezaeian, S. 1231, 1235, 1426, 1455

Rhoades, D. A. 1324, 1326, 1328

Rietbrock, A. 1435

Rim, D. 1302

Rinaldi, A. 1366

Ringler, A. 1319, 1400, 1401, 1459

Riquelme, S. 1342, 1448

Ristvet, B. L. 1314

Ritsema, J. 1464

Rivera, A. 1330

Rivera-Cerdas, F. A. 1448

Robert, H. 1384

Robertson, M. 1365, 1367

Robertsson, J. O. A. 1366

Robson, A. 1471

Roca, A. 1381

Rockwell, T. K. 1310, 1337

Rodgers, A. J. 1230, 1356, 1360, 1380, 1409, 1414, 1416

Rodriguez Padilla, A. M. 1233,1333

Rodríguez Tribaldos, V. $1225,1365,1367$

Rogers, S. R. 1442

Roland, E. 1335

Rolandone, F. 1435

Rollins, C. 1226, 1397, 1451

Roman, D. C. 1310, 1458

Roman-Nieves, J. I. 1295 , 1441

Romano, N. F. 1367

Romanowicz, B. 1213

Rong, M. 1376

Rosa, C. M. 1362

Rosado Class, J. 1448

Rosakis, A. J. 1301

Rosas, V. G. 1354

Rosero-Rueda, S. 1402

Rösler, B. 1429

Ross, S. L. 1353

Ross, Z. E. 1319, 1468, 1470

Rosset, P. 1426, 1438

Rotermund, C. 1365

Rotheram, D. 1424

Rouhana, C. 1314

Rouse, J. W. 1379, 1380

Rowe, C. A. 1313, 1347, 1357, 1367

Rowshandel, B. 1452

Rozhnoi, M. 1315

Rubinstein, J. L. 1328, 1447, 1467

Ruhl, C. J. 1388

Ruiz, M. 1435

Ruiz, S. 1435

Rundle, J. B. 1303, 1470

Ruppert, N. A. 1217, 1235, $1293,1429,1457,1458$

Russo, E. 1433

Ryan, K. 1224, 1353

Sabbagh, D. 1317

Sadek, S. 1312

Saengduean, P. 1298

Sager, K. 1366

Saghbini, C. 1314

Sagiya, T. 1437

Sahakian, V. 1218, 1224, $1304,1305,1310$

Saito, T. 1353

Sakarya, B. 1321

Salameh, C. 1314

Salaree, A. 1302, 1346, 1443

Salditch, L. 1323, 1418, 1420

Salerno, J. A. 1375

Salvage, R. O. 1393, 1395

Sampaio de Melo, G. 1450

Samsonov, S. 1435

Sanchez, R. 1342

Sanders, R. 1399

Sangaraju, S. 1413

Sannikova, N. K. 1302

Sanon, C. 1316

Santellanes, S. 1302 
Shao, Z. 1405

Shapley, M. 1348

Share, P. 1422

Shaw, B. E. 1354, 1451, 1454

Shaw, J. H. 1362, 1368

Shcherbakov, R. 1328, 1396

Shea, H. N. 1398

Shearer, P. M. 1403, 1442

Sheffer, M. 1371

Shelly, D. R. 1328, 1402

Shen, A. 1360

Shen, W. 1439, 1457

Shen, X. 1220, 1315, 1316, 1317

Shen, Z. 1451

Sheng, M. 1468

Sheng, Y. 1300

Shen-Tu, B. 1453

Sheridan, M. 1390

Sherrill, E. M. 1369

Sherstobitoff, J. 1425

Shi, H. 1407

Shillington, D. J. 1311

Shin, C. 1304

Shiraishi, H. 1384

Shirley, M. 1393

Shiro, B. 1384, 1399, 1432, 1461

Shirzaei, M. 1224,1392

Shore, M. 1330

Shore, P. 1437

Shuck, B. 1377

Shugar, D. 1415

Shumway, A. M. 1235, 1432, 1451, 1456

Siebert, A. 1364

Siervo, D. 1400

Sievers, C. 1297

Sigloch, K. 1434, 1449

Silva, F. 1417

Simmons, N. 1356, 1360

Simon, J. D. 1449

Simons, F. J. 1449

Simpson, A. 1306

Singh, R. P. 1220

Sirohey, A. 1350

Sita, M. 1385

Sjogreen, B. 1414

Slater, L. 1431

Slaughter, R. 1432

Sleeman, R. 1432

Slivicki, S. J. 1331

Sloan, V. 1232

Small, D. T. 1415

Smerzini, C. 1413, 1415

Smets, P. S. M. 1378

Smith, A. M. 1363

Smith, D. E. 1341

Smith, K. D. 1308, 1388, 1390, 1460

Smrekar, S. E. 1383, 1384

Snelson, C. 1225

Snieder, R. 1298

Soderquist, J. 1399

Soldani, M. 1317

Sollberger, D. 1366

Solovieva, M. 1316

Song, J. 1375, 1405, 1407, 1408

Song, T. 1303

Song, Z. 1365, 1422, 1423

Soto-Cordero, L. 1295, 1435

Spallarossa, D. 1370
Spence, P. 1381

Spencer, B. D. 1323

Spica, Z. 1339

Spies, T. 1441

Spiga, A. 1383

Spritzer, J. 1459

St Clair, J. 1222

Staats, M. 1399

Stachel, M. 1316, 1317

Stachnik, J. 1471

Stahl, T. 1451

Stähler, S. 1382, 1383, 1384, 1385

Staisch, L. M. 1346

Štajduhar, I. 1469

Stammeijer, J. 1300

Stamps, D. 1296

Stead, R. 1313

Steedman, D. 1357

Steel, A. 1347

Steele, L. 1309

Steidl, J. 1433

Stein, S. 1230, 1323, 1346, $1418,1420,1429$

Steinberg, A. 1314

Stephenson, W. J. 1219, 1309

Stewart, J. P. 1312, 1361, $1371,1372,1419,1420$

Stickney, M. C. 1389

Stirling, M. W. 1451

Stock, J. 1310, 1377

Stone, I. 1307

Storchak, D. A. 1321, 1412, 1434

Stork, A. L. 1363

Stott, A. E. 1382

Stovall, S. 1427

Strader, A. 1325

Strauch, W. 1343, 1345

Strauss, J. 1340, 1341, 1456

Stuart, A. 1339

Stump, B. 1374

Styron, R. H. 1335

Su, J. 1396

Suarez, G. 1223, 1344

Suárez Bonilla, F. 1343

Subedi, S. 1215

Sudhaus, H. 1314

Sui, S. 1439

Sukianto, T. 1319

Suleyman, H. 1305

Sumy, D. F. 1344, 1345, 1431

Sun, H. 1318

Sun, J. 1371

Sun, T. 1423

Sung, C. 1417

Suroyo, P. M. T. 1304

Sutherland, R. 1355, 1377

Swanson, E. 1358

Swanson, M. 1386

Sweet, J. 1423

Syal, M. B. 1449

Symons, N. P. 1367

Synolakis, C. 1301

Szymanski, E. D. 1332

Taber, J. 1386, 1431

Taciroglu, E. 1409

Tadeu, E. 1445

Taira, T. $1235,1298,1461$, 1464,1466

Talavera, E. 1343

Talebian, M. 1446

Tamhidi, A. 1409
Tan, Y. 1468

Tang, B. 1361

Tang, H. 1414

Tannous, C. 1314

Tape, C. 1376, 1381, 1458, 1459

Tarabulsi, Y. 1429

Tarchini, G. 1370

Taufiqurrahman, T. 1352, 1465

Team, C. 1448

Templeton, D. 1307, 1365, 1367

Templeton, M. 1386

Ten Brink, U. 1444, 1445

Terra, F. 1342

Terry, R. 1296, 1297

The Earthquake Science Center Equity,

Inclusion and

Diversity Working

Group, 1431

Thelen, W. A. 1461

Thiel, A. 1379, 1398, 1401

Thingbaijam, K. 1451, 1454

Thio, H. 1353

Thomas, A. M. 1224, 1298, $1346,1348,1469$

Thomas, K. 1360

Thomas, M. Y. 1351

Thomas, P. J. 1367

Thomas, W. A. 1440

Thompson, E. M. 1232, $1349,1411,1432,1433$, $1454,1455,1456$

Thompson, S. C. 1360, 1361, $1362,1363,1427$

Thompson Jobe, J. A. 1337

Tian, L. 1405, 1406

Tian, W. 1404

Tian, X. 1231, 1422

Tian, Y. 1384

Tibi, R. 1225, 1359

Tierney, T. E. 1314

Tilmann, F. 1340

Tissandier, R. 1435

Titov, V. V. 1218

Tkalčić, H. 1377

Tobin, H. J. 1337

Toghramadjian, N. 1368

Tohidi, H. 1375

Toney, L. D. 1385

Tong, P. 1377, 1458

Toro, G. 1372

Townend, J. 1213, 1354, 1355, $1376,1446,1447,1459$, 1462

Trabant, C. 1220,1319

Traversa, P. 1417

Trehu, A. M. 1219, 1309, 1310

Tripati, A. 1232

Triplett, L. A. 1314

Trugman, D. 1214

Trugman, D. T. 1355,1460

Tsai, V. 1355

Tsereteli, N. S. 1420

Tuinstra, K. B. 1366

Turner, J. 1309

Turquet, A. L. 1380

Turtle, E. P. 1384

Tuttle, M. P. 1442

Ubertini, P. 1315

Uchide, T. 1334,1467

Ulrich, T. 1352, 1413, 1414

Uribe, A. 1344

Vaca, S. 1435

Valentini, A. 1361

Valentova, L. 1416

Vallee, M. 1435

Vanacore, E. A. 1359, 1402, 1444

Van Arsdale, R. 1375

Van Avendonk, H. 1377

van Boskirk, E. 1296

van der Elst, N. 1294, 1325

van der Lee, S. 1385, 1436

Van Dissen, R. J. 1412, 1451, 1454, 1456

van Driel, M. 1382, 1383, 1385

Vane, C. 1292

Vantassel, J. P. 1338

van Ulden, J. 1424

Varini, E. 1323

Vega, F. 1344

Veitch, S. 1421, 1423

Velazquez, J. 1420

Velazquez, M. 1420

Ventura-Valetin, W. A. 1443

Vera, E. 1310

Verdecchia, A. 1352

Vernon, F. 1300, 1422, 1430

Vidale, J. E. 1322, 1430

Vieceli, R. E. 1358

Vigny, C. 1435

Villa, V. 1306

Villafuerte, C. 1461

Villalobos-Escobar, G. P. 1467

Villegas-Lanza, J. 1435

Visini, F. 1360, 1361

Von Hillebrandt-Andrade, C. 1234,1450

von Specht, S. 1306, 1419, 1471

Vorobiev, O. Y. 1357, 1359, 1380

Wagner, L. 1310, 1439, 1458

Wagoner, J. 1357

Wakin, M. 1298

Wald, D. J. 1297, 1411, 1432, 1442

Waldhauser, F. 1311

Walker, J. 1333

Walker, R. 1321, 1351, 1396, 1446

Wallace, L. 1412, 1451

Walling, M. 1428

Walsh, T. F. 1379

Walter, F. 1329, 1364

Walter, J. 1379, 1398, 1401

Walter, W. R. 1214, 1225, $1320,1328,1357,1358$ $1359,1380,1387,1402$ 1444

Wan, B. 1422

Wang, B. 1378, 1406, 1407, 1416, 1443

Wang, C. 1423

Wang, F. 1453

Wang, J. 1316

Wang, K. 1377, 1449, 1458

Wang, N. 1463

Wang, P. 1361, 1372, 1420

Wang, R. 1228 
Withers, H. 1439

Withers, K. B. 1230, 1414, 1432, 1454, 1455

Withers, M. M. 1439

Witter, R. 1292, 1336, 1337, 1348,1454

Woelfel, I. 1398, 1401

Wolf, L. W. 1442

Wolin, E. 1399, 1400, 1432

Wollin, C. 1364, 1421

Wong, I. 1215

Wong, S. 1331

Wong, W. 1396

Wonik, T. 1393

Wood, T. 1365, 1367

Woodward, R. 1386, 1423

Woolery, E. W. 1453

Worden, C. B. 1411, 1456

Wordsworth, P. 1396

Worthington, L. L. 1424

Wright, M. A. 1380

Wright, T. 1318

Wu, B. 1353

Wu, D. 1340

Wu, K. 1365

Wu, Q. 1464

Wu, S. 1345

Wu, W. 1422, 1423
Wu, Y. 1460

Wu, Z. 1405

Xi, Z. 1469,1470

Xiao, Z. 1292, 1293

Xie, J. 1215

Xie, M. 1405, 1406, 1407

Xu, W. 1390

Xu, X. 1336, 1389

Xue, L. 1404

Xue, S. 1299

Xue, Y. 1404

Yadav, V. 1393

Yamada, R. 1384

Yamazaki, Y. 1293

Yan, L. 1371

Yan, R. 1405

Yang, H. 1375, 1394, 1396, $1416,1463,1467,1468$

Yang, W. 1407

Yang, X. 1300, 1422

Yang, Y. 1377, 1429, 1440, 1458

Yani Quiyuch, R. 1343, 1345

Yao, D. 1404

Yao, S. 1416

Yartsev, V. 1364

Yassminh, R. 1308

Yazdi, M. 1373
Ye, L. 1293

Yeck, W. 1229

Yeck, W. L. 1328, 1399, 1400, 1402

Yeh, T. 1413

Yelton, J. 1331

Yen, M. 1306

Yenihayat, N. 1410, 1417

Yetirmishli, G. 1321

Yin, F. 1416

Yin, J. 1354

Yin, S. 1365

Yong, A. 1223, 1339, 1372

Yoo, S. 1312

Yoo, S. H. 1219

Yoon, C. 1444

Younesi, K. 1361

Young, B. 1215, 1220

Young, C. J. 1355

Youngs, R. 1360, 1363

Youssef Abdel Massih, D. 1314

Yu, E. 1319

Yu, R. 1322

Yu, Z. 1317, 1318

Yuan, H. 1422

Yuan, Z. 1406

Yue, C. 1406
Yule, D. 1411

Yun, S. 1312

Zaicenco, A. G. 1339

Zaino, A. 1297

Zaliapin, I. 1404, 1419

Zandieh, A. 1362, 1427

Zang, A. 1391

Zang, N. 1409

Zang, Y. 1407

Zeiler, C. 1225, 1390, 1460

Zellman, M. 1231, 1440

Zelt, C. A. 1329

Zeng, X. 1231, 1365, 1422, 1423

Zeng, Y. 1451, 1455

Zenhäusern, G. 1382, 1383

Zentner, I. 1417

Zeren, Z. 1220

Zhai, G. 1392

Zhai, Q. 1460

Zhan, Z. 1365,1368

Zhang, G. 1228, 1397, 1398

Zhang, H. 1235, 1307, 1386, 1457

Zhang, S. 1404

Zhang, S. R. 1220

Zhang, W. 1229, 1409

Zhang, X. 1317, 1405, 1407
Zhang, Y. 1229, 1317, 1397, 1404, 1405

Zhang, Z. 1299, 1311, 1329

Zhao, D. 1397, 1398

Zhao, J. 1405, 1406

Zhao, Q. 1376

Zheng, A. 1390

Zheng, Y. 1395

Zhima, Z. 1315, 1316, 1317

Zhong, J. 1405, 1407

Zhou, B. 1316, 1411

Zhou, P. 1396, 1468

Zhou, R. 1305

Zhou, X. 1376

Zhou, Y. 1353

Zhou, Z. 1406, 1461

Zhou, Z. H. 1405

Zhu, B. 1469

Zhu, C. $1226,1369,1374$

Zhu, K. 1317, 1318

Zhu, T. 1218, 1221, 1330

Zhu, W. 1340, 1467

Zhu, Y. 1453

Zi, J. 1394, 1396

Ziebarth, M. J. 1419

Zimmaro, P. 1312, 1372, 1420

Zürn, W. 1383 